

\section{EDITORIAL POLICY}

Papers must be submitted with the understanding that they have not been published elsewhere (except in the form of an abstract or as part of a published lecture, review, or thesis) and are not currently under consideration by another journal published or any other publisher. The submitting (Corresponding) author is responsible for ensuring that the article's publication has been approved by all the other coauthors. It is also the authors' responsibility to ensure that the articles coming from a particular institution are submitted with the approval of the necessary institution. Only an acknowledgment from the editorial office officially establishes the date of receipt. It is a condition for submission of a paper that the authors permit editing of the paper for readability. All enquiries concerning the publication of accepted papers should be addressed to ejournal.assist@tau.edu.gy. 


\section{ABOUT PLAGIARISM}

Plagiarism is the use or close imitation of the language and ideas of another author and representation of them as one's own original work. Duplicate publication, sometimes called self plagiarism, occurs when an author reuses substantial parts of his or her own published work without providing the appropriate references. This can range from getting an identical paper published in multiple journals, where authors add small amounts of new data to a previous paper.

Plagiarism can be said to have clearly occurred when large chunks of text have been cut and pasted. Such manuscripts would not be considered for publication in TIJBMS Journal. But minor plagiarism without dishonest intent is relatively frequent, for example when an author reuses parts of an introduction from an earlier paper. The editors will judge any case of which they become aware (either by their own knowledge of and reading about the literature, or when alerted by referees) on its own merits.

The paper containing the plagiarism will be obviously returned back to the author's for review, but we earnestly request the authors to avoid submitting plagiarized 


\section{DISCLAIMER}

Texila International Journal of Public Health (TIJPH) make every effort to ensure the accuracy of all the information (the "Content") contained in its publications. However, the TIJPH and its agents make no representations or warranties whatsoever as to the accuracy, completeness or suitability for any purpose of the Content and disclaim all such representations and warranties whether express or implied to the maximum extent permitted by law. Any views expressed in this publication are the views of the authors and are not necessarily the views of the Editor's or Texila International Journal of Public Health. 


\section{TABLE OF CONTENT}

1 Assessing Knowledge and Practice of Prevention of Mother to Child

Transmission of HIV Documentation among Health Workers in Oyo State, South West, Nigeria

Michael Olabode Tomori

2 Public Health Aspects of Refugee Health: A Review of the Evidence on Health Status for Refugees Globally

Krishan Puri

3 The Various Misconceptions of Bipolar Disorder in Barbados

Marlo A.R Browne

4 Knowledge of Auxiliary Healthcare Workers on Injection Safety and

Biological Waste Handling in Taraba State, Nigeria

Danung Monday Langche

5 Effective Communication as a Panacea for Gaining Acceptance of Hospital Services by Clients

Onwubiko Iheanyichukwu Samuel

6 Risk Factors of Type 2 Diabetes among Mbororo Population of GuiwaYangamo Village in the East -Cameroon

Judith Maka

7 Review of Maternal Mortality and Near-Miss Events in Kintampo Municipality in the Brong Ahafo Region of Ghana

Gabriel Opoku

8 Factors Associated with Adherence to Sickle Cell Crisis PreventivePractices among Youths of Sickle Cell Clubs in Abeokuta, Ogun State. Nigeria

Nnodimele O. Atulomah

9 Prevalence of undiagnosed diabetes mellitus amongst hypertensive patients attending an outpatient clinic in Harare, Zimbabwe 
Pasipanodya Ian Machingura

10 Evaluation of Pharmaceutical Waste Disposal Practices in Healthcare

Facilities in Lagos State, South West Nigeria

M. Obono

11 Need, Demand and Supply of Health Care in Regards to Growing

Emerging and Reemerging Diseases in Sub-Saharan Africa

\section{R. Medang}

12 Sexual Behaviorsand Pregnancies of in School and out of School

Adolescents in Kavango region, Namibia

Taimi Amakali-Nauiseb

13 Potential risk characteristics of adolescent pregnancy in schools and out of school in Kavango Region, Namibia

Taimi Amakali-Nauiseb

14 Risk Factors for Contracting Malaria in Nyanga District, Zimbabwe: a Case Control Study

Mashizha S

15 Perception of Health Care Workers on Prevention and Treatment of Uncomplicated Malaria in Pregnancy

Vakkai Dominic Esther

16 Barriers to Prompt Malaria Diagnosis and Effective Treatment among Children Under Five Years of Age in Mpika District

D. Silweya

17 Healthcare Waste Management Practices in Jalingo: A Reflection of the State of Healthcare System in Taraba State, Nigeria

Paul Rambe Yunana

18 Knowledge and Practices Regarding Psychosocial Aspects of Palliative Care among Healthcare Workers in Ohangwena Region, Namibia

Hileni Niikondo

19 Passive Smoking and its Effects among Children of a Rural Population in South Tamilnadu, India

Pethuru Devadason

20 Assess knowledge, attitude and practice regarding Cigarette and Other Tobacco Products Act (COTPA) and tobacco related health problems in rural setting of Bihar, India 
Rajendra Kumar Singh

21 A Study Protocol to Assess Accessibility, Utilization, and Compliance on

Adolescent Sexual Reproductive Health Services in South Sudan Context

Katwesige wycliff

22 Factors Influencing the Purchase of Counterfeit Drugs among Consumers in Rural Community of Cross River State, Nigeria

Agada, Peter Okpe

23 Patient Safety Culture of Iganga, Kamuli Mission and Kakira Hospitals of South Eastern Uganda

Balidawa John

24 Relationship between Climate Change and Health of Adult Residents of Ile-Ife, Nigeria

Ganiyu Abiodun Adedeji

25 The Power of Academic Research for Innovation in Practice and Policy: Systemic Review of Literature

Bala Ibn Shehu Uthman

26 Role of Counseling in the Disclosure of HIV Status to Sexual Partners among HIV Positive Women Accessing PMTCT Services in South Nigeria

Adetumi Adetunji Subulade

27 Infant Feeding Challenges Encountered by HIV Positive Mothers in Korogocho Slums, Nairobi, Kenya

Bennadette Mugita Siruri

28 Assessment of Knowledge Attitude Perception and Practice of Health 308 Insurance Scheme among Community Pharmacies in Lagos State

Ukamaka Gladys Okafor

29 Periodical Screening and Health Education at Work: Producing Healthy Workforce

Adegoke Titilayo

30 Knowledge and practice of self-medication among students of School of 328 Nursing in selected schools in Osun State

Abioye, Abigail Adebisi

31 Prevalence, Knowledge and Perception of Domestic Violence among Women Attending Antenatal Care at Baraudikko Specialist Hospital, Kaduna, Nigeria 
Patricial Idoko

32 Ethical Challenges of International Outbreaks-A Case Study of Ebola Virus Disease

Okafor CN

\begin{tabular}{ccc}
\hline 33 & Middle East Respiratory Syndrome Coronavirus (MERS-CoV) & 350 \\
& Geethamma Jolly & \\
\hline 34 & $\begin{array}{l}\text { Review of Prevention of Mother-To-Child Transmission (PMTCT) } \\
\text { program in a Primary Healthcare Centre in Abuja, Nigeria } \\
\text { Orji Ikechukwu Anthony }\end{array}$ & 375 \\
\hline 35 & $\begin{array}{l}\text { Tuberculosis and gender in Nigeria. Sex differences in diagnosis and } \\
\text { treatment outcome of TB and TB HIV infected patients }\end{array}$ & 385 \\
& $\quad$ Ejike Kenneth Nwene & \\
\hline
\end{tabular}

36 The Use of Task Shifting in the Implementation of Prevention of Mother 392 to Child Transmission of HIV (PMTCT) Services in Cameroon; the Option $\mathrm{B}+$ Experience

Nguosi Wam Joel

37 Exploration into the factors affecting the coverage of household latrines in 396 kagera, Tanzania

James Barongo Bashweka

38 Knowledge of Contraceptives and Unmet Needs of Family Planning among Adolescents Aged 15-19 Years

Bernard, Temitayo Ayobami

39 Risk Factors for Teenage Pregnancy and Youth Health Needs in Nkalashane, Swaziland

Busisiwe Prudence Tsabedze

40 Prevalence of HIV in South Sudan

Etiki John Firstday

41 "A new look care of mother at pregnancy \& lactation”: Socio-cultural 453 practices in neglected population in Kapilvastu district of Nepal

Shashi Kumar Lal Karna

42 A study on factors contributing to communities not accessing Anti Retro 469 viral therapy [ARVs] in some rural health facilities in Eastern Province of Zambia 
43 Knowledge, Attitude and Practice Towards Guinea Worm among The

Resident's of Juba County in Central Equatoria State

Sebit Mustafa Sebit Ebead

44 Effect of Regular Baths on the Development of Ring Worm among Primary School Children

Ifezue Uchechi Grace

45 The Effectiveness of Handwashing Health Education Session on Raising

514 School Children's Knowledge and Skills of Proper Handwashing Technique. a Pre test- Post Test Design

Marie Louise Umwangange

46 Clinical and radiographical evaluation of the healing of large periapical lesions using triple antibiotic paste, photo activated disinfection and calcium hydroxide when used as root canal disinfectant

Dexton Antony Johns

47 Prevalence, Knowledge And Perception of Domestic Violence Among Women Attending Antenatal Care At Barau Dikko Specialist Hospital, Kaduna

Patricia Elameyi Idoko

48 Pre-Menstrual Training, Menstrual Hygiene Practices, Attitudes and Disorders among Nigerian Adolescents

Afusat Adesina

49 The Three Delay Model as Framework to Assess the Burden of Maternal Deaths in the Urban District of Kitwe, Zambia

Elvis Chipili

50 Economic Burden of low Back Pain among Quarry Workers Attending Outpatient Physiotherapy Clinic at a Tertiary Health Institution in Ondo State Nigeria

Ebenezer Obi Daniel

51 The Prevalence, Risk Factors and Treatment Methods for Tungiasis among 578 Residents of Musokoto Sub-Location, in Kenya

Ngetich Albert

52 Plasmodium Falciparum and Schistosoma Heamatobium Infections in 597 Pregnant Women Attending Antenatal Clinic in Sekondi-Takoradi Metropolis Western Region Ghana

Verner. N. Orish 
Performance. A case of clinical Medical Rehabilitation students of Obafemi Awolowo University

Ilesanmi Oluwafemi Temitayo

54 Perceived Determinants of Distribution of Counterfeit Drugs in

Community Pharmacies, Calabar Municipality Local Government Area,

Cross River State, Nigeria

Agada, Peter Okpe

55 Knowledge and Practices of Personal hygiene among Senior Secondary

School students of Ambassadors College, Ile- Ife, Nigeria

Ilesanmi Oluwafemi Temitayo

56 Prevalent Leadership Styles and Their Compatibility to the New Ways of

Working in General Hospitals in Nigeria

Maclawrence Kolapo Famuyiwa

57 Prevalence of Hepatitis-B infection among Pregnant Women in a Primary

650 Healthcare Centre in Abuja, Nigeria

Orji Ikechukwu Anthony

58 Retrospective Study of Fatal Dengue Hemorrhagic Fever in Lahore City

660

Samra Ashraf

59 An Assessment of the Psychosocial Effects of Almajiri system on Child's Development in Gwange Ward Maiduguri, Borno State, Nigeria

Emmanuel O. Chukwu

60 Innovative Policies on Air Pollution Control in China - A Case Study of the Relationship between Environmental Changes and Health Conditions in China 


\title{
Assessing Knowledge and Practice of Prevention of Mother to Child Transmission of HIV Documentation among Health Workers in Oyo State, South West, Nigeria
}

\author{
Article by Michael Olabode Tomori \\ Strategic Information Unit, AIDS Prevention Initiative in Nigeria, Old Bodija, \\ Ibadan, Oyo State, Nigeria \\ E-mail:mtomori@yahoo.com
}

\begin{abstract}
Prevention of mother to child transmission of HIV (PMTCT) programme in Nigeria started in July 2002 with the goals of providing effective PMTCT services for women in the reproductive age group in selected health facilities while providing useful information for policy formulation and decision on intervention for comprehensive PMTCT in Nigeria. However, most of the health workers documenting the PMTCT programmes in the health facility lack the required skills and capacity in offering PMTCT services and effecting efficient documentation of programme activities. Information on the knowledge and practice of PMTCT documentation among health workers in Oyo State was obtained through administration of close-ended questionnaires to the respondents in 113 health facilities. The study concluded that most of the health workers have good knowledge of PMTCT documentation with those working in the public facility having better understanding than those in the private facility. In addition, most of the respondents lack proper understanding of PMTCT HIV testing algorithms. However, private facility will benefit tremendously from further training on documentation and serial HIV testing.
\end{abstract}

Keywords: HIV; PMTCT; Nigeria; Knowledge; Practice; Health workers; Public; Private; Facility

\section{Introduction}

In the sub-Saharan African countries human immunodeficiency virus (HIV) and acquired immune deficiency syndrome (AIDS) are the leading causes of morbidity and mortality amongst women and children. Large number of children who are not up to 15 years of age were newly infected by HIV in 2009 and an estimated 42 000-60 000 pregnant women died as result of HIV all over the world. In addition, more than $90 \%$ of the paediatric infections occurred through mother to child transmission. Nigeria is one of the disadvantaged nations that account for the highest estimated numbers of pregnant women living with HIV, while the number of new HIV infections amongst children and HIV-related deaths is virtually zero in rich countries with timely access to timely preventive services (UNAIDS, 2011).

Nigeria with nine percent of the world HIV burden came second after South Africa in term of highest number of people living with HIV globally (FMOH, 2008 \& Unaidsorg, 2016). Women aged between 20 and 29 years are affected by HIV than men as they accounted for $58 \%$ of the national HIV burden ${ }^{3}$ and this has an effect for the transmission of HIV from mothers to children.

Several factors contribute to the high burden of paediatric HIV infection in Nigeria and other sub-Saharan African countries such as high prevalence of HIV infection amongst women of reproductive age, high birth rates and lack of access to effective prevention interventions of mother to child transmission of HIV (De cock et al, 2000).

$30-45 \%$ of exposed infant born to positive pregnant HIV mothers in developing countries are at risk of being infected. However, rates of Mother to Child Transmission (MTCT) of HIV have fallen to as low as $2 \%$ in the developed countries with the use of the Prevention of Mother to Child (PMTCT) services (Dabis, Leroy \& Castebonk, 2000). HIV counselling and 
testing (HCT) is a key component of services provided (Adewole, Oluwole \& Sagay, 2006). PMTCT programme in Nigeria commenced in July 2002 with the goals of providing effective PMTCT services for women in the reproductive age group in selected health facilities and generating information for the formulation of a national policy and implementation guidelines on intervention for comprehensive PMTCT in Nigeria. Several hundred sites are currently providing these services in Nigeria as the country account for $15-30 \%$ of global gap on PMTCT with PMTCT programme coverage limited as only $4.7 \%$ Ante Natal Care (ANC) offer PMTCT services in the country (WHO/UNICEF/UNAIDS, 2011).

Nigeria has developed a national scale up plan towards elimination of mother to child transmission of HIV (2010-2015) and has adopted the Guidelines on option A and B prophylaxis regimens combination of World Health Organization 2010(Coetzee et al, 2005). Although these goals are clearly fitting in their scope, the disparity in the outcomes they actually target reveals a lack of clarity and consensus around how to monitor the influence of PMTCT programmes. Hence, the need for the enhancement of PMTCT documentation in the country is very desirable.

Reliable and accurate public health information is essential towards achieving the United Nations Millennium Development Goals and hence the need for high-quality data has never been greater (Avertorg, 2016).

Most of the health workers documenting the PMTCT programmes in the health facility lack the required skills and capacity in offering PMTCT services and effecting efficient documentation of programme activities.

The study will evaluate the knowledge and practice of PMTCT documentation among health workers in Oyo State, South-West, Nigeria.

\section{Statement of the problem}

Prevention of Mother to Child transmission of HIV is very important in saving the life of exposed infant and reducing the effect of the disease in sub-Saharan Africa and hence documentation of its programme activities are very critical in making informed decision to improve services. Majority of health workers in Nigeria today are often less informed and less knowledgeable about PMTCT services and documentation. This has resulted in poor knowledge and practices of documentation and subsequently poor health information needed to improve delivery of PMTCT services. It is therefore very necessary to correct this knowledge gap that has effect on the quality of data generated on PMTCT services as a result of poor documentation.

\section{Background of study area}

The study location is Oyo State. Oyo state was established alongside Ogun and Ondo states (Olaniyan, 2013) in April 1976 from the defunct Western States of Nigeria. It lies between latitudes $07^{\circ} 46^{\prime} \mathrm{N}$ and longitudes $03^{\circ} 56^{\prime} \mathrm{E}$.

The total population of Oyo State according to the 2006 Nigeria population census is 5, 591, 589 (Amazoncom, 2016). The population was estimated to be 7,066,807 in 2013.

Oyo state falls within the South Western zone of Nigeria and comprised of 33 Local Government Areas (LGAs), which are vastly dispersed. The state shares an international boundary with the Republic of Benin and nationally with Ogun State, Osun State and Kwara State. The largest city in West Africa, Ibadan is the state capital.

The predominant occupation in Oyo State is farming as there are both rainforest and savannah areas in the State. In addition, Oyo State is highly urbanized with varying degree of urbanization in each of the local government areas and it has one of the fastest growing urban populations.

The first University Teaching Hospital in Nigeria at independence in 1960 is the University College Hospital (UCH) Ibadan created in 1957. Presently, there is additional 3 other teaching hospitals in the state. Oyo State currently has 33 Secondary Health Care Facility and 707 Primary Health Care Facility. 
This study is set to evaluate the health workers knowledge and practice of PMTCT services documentation. New findings from the study will be a pointer to how to improve PMTCT services documentation in Nigeria and will help key public health stakeholders in making quality decision needed to improve health in Nigeria.

The broad objective of the study was to determine (assess) the knowledge and practice of PMTCT documentation among health workers.

- To assess the knowledge of health workers about PMTCT services documentation.

- To explore the practices in health workers regarding PMTCT services documentation.

- To come up with recommendations.

\section{Literature review}

There is paucity of literature review on the assessment of knowledge and practices of PMTCT documentation in Nigeria. However, there are few literatures on similar subject. A study on knowledge and practice of prevention of mother to child transmission of HIV among traditional birth attendants (TBAs) in Lagos State Nigeria was conducted by Balogun and Odeyemi in 2010(Balogun \& Odeyemi, 2010). It was concluded that most of the TBAs did not have adequate knowledge and practice of PMTCT illustrating the need for periodic PMTCT training for TBAs. Another study by Owoaje, Omidokun and Ige in 2012on knowledge and perception of prevention of mother to child services amongst pregnant women accessing antenatal clinic in a Primary Health Care centre in Nigeria. It was inferred from the study that women in the survey were very knowledgeable about the methods of PMTCT but had negative perceptions regarding certain aspects of the HCT services (Owoaje, Omidokun \& Ige, 2012).

Monitoring and Evaluation (M\&E) is an essential component of the activities of PMTCT programme because knowledge derived from it can be used to demonstrate to the programme planners and policy makers that the programme efforts had measurable impacts on the expected outcome (Amazoncom, 2016).

Currently few high-prevalence countries have country-level monitoring of PMTCT ongoing globally with few knowledgeable people with the require skills in PMTCT services and documentation. Closing this public health knowledge gap is critical to global success in the fight against mother to child transmission of HIV which can only be achieved through building of international consensus around PMTCT effectiveness monitoring.

\section{Methodology}

\section{Study type}

Observational study (Cross- sectional descriptive study) was used and it involved data collection, or a representative subset, at one specific point in time (Schmidt \& Kohlmann, 2008). This study involved the assessment of the knowledge and practice of Prevention of Mother to Child Transmission of HIV documentation among Health Workers in primary, secondary and tertiary health facilities in Oyo State through administration of a questionnaire.

\section{Study setting}

The study was conductedat 113 Health Facilities in 23 Local Government Areas of Oyo State.

\section{Study population}

The study population was all Health Workers who have been trained on PMTCT documentation in selected PMTCT provider facilities in Oyo State.

\section{Sample size calculation for respondents}

Minimum sample size was determined by using the formula for calculating sample size for estimating the prevalence of a knowledge, disease or health condition in a population.

$$
\mathrm{N}=\left(\mathrm{Z}_{1}-\alpha / \partial\right)^{2} \mathrm{x} \mathrm{p}(1-\mathrm{p})
$$


Texila International Journal of Public Health

Volume 4, Issue 4, Dec 2016

$\mathrm{N}=$ Minimum sample size

$\mathrm{Z}_{1}-\alpha=$ Confidence coefficient $=1.96$

$\partial=$ Width of the interval

$\mathrm{P}=$ Prevalence in a population. "P" is assumed to be $50 \%$ since the prevalence of usage of

PMTCT documentation tools in any previous studies was not known (Mirkuzie, 2008). Thus,

$\mathrm{N}=(1.96 / 0.05)^{2}(0.50 \times 0.50)$

$=384$

With assumption of $10 \%$ refusal rate among the selected respondents, we expect a minimum sample size of 400 for more robust analysis.

Sampling frame: The 33 Local Government Areas in the 3 Senatorial Areas was used as the sampling frame.

Sampling procedure: A multi-stage sampling technique was used for the selection of respondents. The first stage was the selection of Local Government Areas (LGAs) from the three senatorial districts in the state. A random sampling method was used to select 23 Local Government Areas (LGAs) from the thirty- three (33) LGAs in Oyo State. The second stage involved the selection of health facilities from the selected LGAs. 113 Health Facilities were selected by taking into consideration those in Urban and Rural settings and on the different types of program the site is executing. Two to nine facilities was randomly selected in each of the Local Government Area to accommodate the large sample size required for this study. The third stage involved the selection of respondents from the health facilities. Health Care Workers trained on PMTCT documentation in all the selected facilities was identified and administered with questionnaire.

\section{Data collection methods}

A closed ended questionnaire was designed in English through review of literature and was pre-tested among health workers in a hospital that was not part of the selected facilities by me. Trainings on data collection were done for the LACA Managers who were involved in the administration of the questionnaire on health workers in the selected facilities using a facilitated self-administered method. This was done in order to check if the questions were being understood by the respondents.

\section{Data collection and analysis}

After the administration of questionnaires on the respondents, the quantitative data obtained were entered and analysed using SPSS. Univariate and bivariate analysis were carried out as appropriate. Initial analysis was done by generating frequency tables while further analysis was done to explore statistical association between variables. Appropriate bivariate analysis such as chi-square was carried out to assess statistical association depending on the type or nature of the variable. Descriptive statistics was used to describe distribution of individual characteristics.

\section{Ethical considerations}

This study followed the ethical principles guiding the use of human respondents in research. Written informed consent was obtained from the participants. Permission to carry out this study was also sought from Oyo State Ministry of Health Ethical Research Committee.

\section{Results}

\section{Description of the study respondents}

A total of 113 health facilities both private and public health facility in 23 local government areas were involved in the study. Table 2 revealed that Ibadan North 55 (13.7\%) has the highest number of the respondents and Ibadan South East 43 (10.7\%), and the lowest respondents were from Egbeda and Ogbomoso South both with frequency of 3 (.7\%). 
Texila International Journal of Public Health Volume 4, Issue 4, Dec 2016

Table 2. Number of Respondents per Local Government Areas in Oyo State

\begin{tabular}{|c|c|c|}
\hline $\begin{array}{c}\text { Local } \\
\text { Government }\end{array}$ & Frequency & Percent \\
\hline Ona Ara & 41 & 10.2 \\
\hline Oyo East & 10 & 2.5 \\
\hline Oyo West & 5 & 1.2 \\
\hline Afijio & 14 & 3.5 \\
\hline Atiba & 8 & 2.0 \\
\hline Itesiwaju & 16 & 4.0 \\
\hline Ibadan South East & 43 & 10.7 \\
\hline Ibadan North & 55 & 13.7 \\
\hline Ogbomoso North & 34 & 8.5 \\
\hline Saki West & 27 & 6.7 \\
\hline Ibarapa East & 23 & 5.7 \\
\hline Lagelu & 23 & 5.7 \\
\hline Akinyele & 16 & 4.0 \\
\hline Ibarapa South & 17 & 4.2 \\
\hline \multicolumn{3}{|l|}{ West } \\
\hline Ibadan North East & 8 & 2.0 \\
\hline Ibadan North & 19 & 4.7 \\
\hline \multicolumn{3}{|l|}{ West } \\
\hline Ibarapa North & 7 & 1.7 \\
\hline Egbeda & 3 & .7 \\
\hline Ibarapa Central & 11 & 2.7 \\
\hline Surulere & 4 & 1.0 \\
\hline Oluyole & 8 & 2.0 \\
\hline Ido & 6 & 1.5 \\
\hline Ogbomoso South & 3 & .7 \\
\hline Total & 401 & 100.0 \\
\hline
\end{tabular}

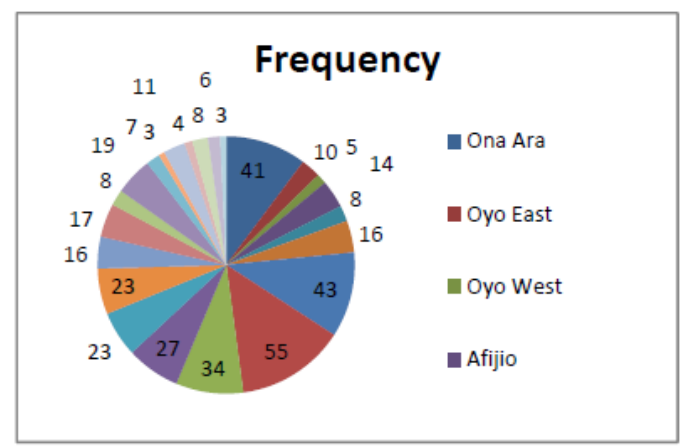

Figure 1. Frequency of Respondents per Local Government Areas

Table 2.1 Social demographic characteristics of the respondents

\begin{tabular}{llrr}
\hline \multicolumn{1}{c}{ Biodata } & \multicolumn{1}{c}{ Items } & Frequency & Percent \\
\hline Type of facility & public facility & 378 & 94.3 \\
& private facility & 23 & 5.7 \\
\hline Age & $\leq 20$ years & 4 & 1.0 \\
& 21-30years & 68 & 17.0 \\
& 31-40years & 141 & 35.2 \\
& 41-50years & 143 & 35.7 \\
& 51-60years & 42 & 10.5
\end{tabular}


Texila International Journal of Public Health

Volume 4, Issue 4, Dec 2016

\begin{tabular}{llrr} 
& 61years and above & 3 & .7 \\
\hline Sex & female & 334 & 83.3 \\
& Male & 67 & 16.7 \\
\hline Religion & Christianity & 310 & 77.3 \\
& Islam & 90 & 22.4 \\
& Traditional & 1 & .2 \\
\hline Ethnicity & Yoruba & 391 & 97.5 \\
& Igbo & 4 & 1.0 \\
& Hausa & 1 & .2 \\
& Edo & 4 & 1.0 \\
Designation in the & Urhobo & 1 & .2 \\
facility & Record Officer & 78 & 19.5 \\
& CHEW & 93 & 23.2 \\
& CHO & 66 & 16.5 \\
& Nurse/Midwife & 112 & 27.9 \\
& health Assistant & 21 & 5.2 \\
& Laboratory Staff & 10 & 2.5 \\
& Doctor & 9 & 2.2 \\
& Public Health & 8 & 2.0 \\
& Officer & & \\
& Pharmacist & 4 & 1.0 \\
\hline & Total & 401 & 100.0 \\
\hline
\end{tabular}

Table 2.1 depicts socio-demographic characteristics of the respondents. A total of $334(83.3 \%)$ of the female and 67(16.7\%) of the male aged between 18 and 64years were interviewed. The results obtained showed that the highest respondents 143 (35.7\%) fell between the age range of 31 and 40 years and lowest age of respondents $3(0.7 \%)$ were 61 years and above. The mean age was 40years $( \pm 8.71)$. Two health facility were also considered in the study, it was observed that the highest 378(94.3\%) of the public facility were visited and data collected while the lowest 23(5.7\%) were the private facility. Christianity 310(77.3\%) was the major religion of the respondents. The tribe with the highest distribution was Yoruba 391(97.5\%) while the lowest is Urhobo 1(0.2\%).

Also most of the respondents were Nurse/Midwife 112(27.9\%), Community Health Extension Workers 93(23.2\%) and Record Officers 78(19.5\%) while the least was pharmacist $4(1 \%)$.

Table 2.2. Information about PMTCT

\begin{tabular}{llrr}
\hline \multicolumn{1}{c}{ Items } & Responses & Frequency & \multicolumn{1}{c}{ Percent } \\
\hline Facility a PMTCT site & No & 26 & 6.5 \\
& Yes & 375 & 93.5 \\
\hline PMTCT testing & opt-in & 133 & 35.47 \\
approach & opt-out & 242 & 64.53 \\
\hline & Total & 375 & 100.0 \\
\hline
\end{tabular}

From the study, highest number of respondents 375(93.5\%) said their facility is a PMTCT center while lowest number of respondents 26(6.5\%) said their facility is not a PMCT center. 242(64.53\%) of the respondents said their facility adopted opt-out approach while 133(35.47\%) adopted opt-in-approach in PMTCT HIV testing in their facilities respectively. 
Table 2.3. Knowledge about PMTCT tools among the respondents

\begin{tabular}{|c|c|c|c|}
\hline Items & Responses & Frequency & Percent \\
\hline \multirow{5}{*}{$\begin{array}{l}\text { Understanding of } \\
\text { PMTCT }\end{array}$} & prevent mum to child transfer & 2 & .5 \\
\hline & $\begin{array}{l}\text { prevention of mother to child } \\
\text { transmission of HIV }\end{array}$ & 383 & 95.5 \\
\hline & Post maternal to child transfer & & \\
\hline & $\begin{array}{l}\text { Prevent mother to children } \\
\text { transfer }\end{array}$ & & \\
\hline & $\begin{array}{l}\text { preventing mother to child } \\
\text { transmission }\end{array}$ & 16 & 4.0 \\
\hline \multirow{2}{*}{$\begin{array}{l}\text { The use of current } \\
\text { general ANC register }\end{array}$} & No & 26 & 6.48 \\
\hline & Yes & 375 & 93.51 \\
\hline \multirow[b]{2}{*}{$\begin{array}{l}\text { The use of current } \\
\text { national standard } \\
\text { separate PMTCT HIV } \\
\text { counseling and testing } \\
\text { register }\end{array}$} & No & 33 & 8.2 \\
\hline & $\begin{array}{l}\text { Yes } \\
\text { this type of register is not in } \\
\text { use at the site }\end{array}$ & 368 & 91.8 \\
\hline The use of current & No & 24 & 6.0 \\
\hline $\begin{array}{l}\text { PMTCT monthly } \\
\text { summary reporting form }\end{array}$ & Yes & 377 & 94.0 \\
\hline \multirow{4}{*}{$\begin{array}{l}\text { The date for the } \\
\text { submission of monthly } \\
\text { report to APIN/SACA }\end{array}$} & 5th to 7th subsequent month & 283 & 70.6 \\
\hline & on the 30th of every month & 46 & 11.5 \\
\hline & on the 1st of new month & 72 & 18.0 \\
\hline & Total & 401 & 100.0 \\
\hline
\end{tabular}

The study showed the respondents comprehensive knowledge of PMTCT tools. Of the respondents, 383(95.5\%) knew the full meaning of PMTCT while the rest gave wrong meaning It was inferred from the study that majority of the respondents knew the meaning of PMTCT. 375(93.51\%) of the respondents claimed that they use current general ANC register, 368(91.8\%) of the respondents responded that they use current national standard separate PMTCT HIV counseling and testing register, 377(94\%) of the respondents said they use current PMTCT monthly summary reporting form. In addition, 283(70.6\%) of the respondents claimed that they do submit monthly report to AIDS Prevention Initiative In Nigeria/State Action Committee on AIDS (APIN/SACA) between 5th to 7th subsequent month, 46(11.5\%) of them said they do submit the report on the 30th of every month whereas $72(18 \%)$ of them claimed that they do submit the report on the $1^{\text {st }}$ (first) of new month.

Table 2.4. Practices of PMTCT Data Documentation

\begin{tabular}{|c|c|c|c|}
\hline Items & Responses & Frequency & $\%$ \\
\hline \multirow{2}{*}{$\begin{array}{l}\text { The request and result form } \\
\text { are the tool used to inform and } \\
\text { seek consent of patients for } \\
\text { testing }\end{array}$} & No & 40 & 10.0 \\
\hline & Yes & 361 & 90.0 \\
\hline \multirow{2}{*}{$\begin{array}{l}\text { Recording the number of } \\
\text { pregnant women who receive } \\
\text { voluntary HIV counseling and } \\
\text { testing for PMTCT }\end{array}$} & No & 26 & 6.48 \\
\hline & Yes & 375 & 93.52 \\
\hline \multirow[t]{3}{*}{ Where information is recorded } & $\begin{array}{l}\text { in the general ANC patient } \\
\text { register }\end{array}$ & 90 & 22.44 \\
\hline & $\begin{array}{l}\text { in the PMTCT counseling } \\
\text { and testing register }\end{array}$ & 277 & 69.1 \\
\hline & Both Registers & 8 & 2.0 \\
\hline
\end{tabular}


Texila International Journal of Public Health

Volume 4, Issue 4, Dec 2016

\begin{tabular}{|c|c|c|c|}
\hline $\begin{array}{l}\text { Pregnant women had known } \\
\text { she is HIV positive upon } \\
\text { presenting at her first ANC } \\
\text { visit is still given an HIV test } \\
\text { for PMTCT }\end{array}$ & $\begin{array}{l}\text { No } \\
\text { Yes }\end{array}$ & $\begin{array}{l}187 \\
214\end{array}$ & $\begin{array}{l}46.6 \\
53.4\end{array}$ \\
\hline $\begin{array}{l}\text { What is recorded in the } \\
\text { pregnant woman's HIV-test } \\
\text { result field in the relevant } \\
\text { register? }\end{array}$ & $\begin{array}{l}\text { Positive } \\
\text { known positive }\end{array}$ & $\begin{array}{r}18 \\
169\end{array}$ & $\begin{array}{r}9.63 \\
90.37\end{array}$ \\
\hline $\begin{array}{l}\text { Is PMTCT HIV testing done at } \\
\text { this site or outside (offsite) } \\
\text { your site }\end{array}$ & $\begin{array}{l}\text { at this site } \\
\text { off-site }\end{array}$ & $\begin{array}{r}362 \\
39\end{array}$ & $\begin{array}{r}90.62 \\
9.73\end{array}$ \\
\hline $\begin{array}{l}\text { Where is off-site PMTCT HIV } \\
\text { testing done? }\end{array}$ & $\begin{array}{l}\text { off-site laboratory } \\
\text { care and treatment center } \\
\text { VCT site }\end{array}$ & $\begin{array}{r}19 \\
5 \\
15\end{array}$ & $\begin{array}{l}48.72 \\
12.82 \\
38.46\end{array}$ \\
\hline $\begin{array}{l}\text { A pregnant women referred to } \\
\text { an off-site location for } \\
\text { PMTCT HIV testing, will do } \\
\text { her HIV testing }\end{array}$ & $\begin{array}{l}\text { always on the same day } \\
\text { sometimes on the same day } \\
\text { rarely on the same day }\end{array}$ & $\begin{array}{r}35 \\
3 \\
1\end{array}$ & $\begin{array}{r}89.74 \\
7.69 \\
2.56\end{array}$ \\
\hline $\begin{array}{l}\text { How the results of off-site } \\
\text { PMTCT HIV testing } \\
\text { physically returned to the } \\
\text { facility }\end{array}$ & $\begin{array}{l}\text { returned by the testing site } \\
\text { returned by the pregnant } \\
\text { woman }\end{array}$ & $\begin{array}{r}33 \\
6\end{array}$ & $\begin{array}{l}84.62 \\
15.38\end{array}$ \\
\hline & Total & 401 & 100.0 \\
\hline
\end{tabular}

From the study 361(90\%) of the respondents claimed that the request and result form are the tools they are using to inform and seek consent of patients for testing while the rest doesn't use inform and consent form. 375(93.52) of the respondents record the number of pregnant women who receive voluntary HIV counseling and testing for PMTCT while 26(6.48\%) don't document. 90(22.44\%) of the respondents recorded the information on those who receive voluntary HIV counseling and testing for PMTCT in the general ANC patient register, 277(69.1\%) of the respondents recorded in the PMTCT counseling and testing register while $8(2 \%)$ of the respondents recorded in both registers.

214(53.4\%) of the respondents claimed that Pregnant women who had known that she is HIV positive upon presenting at her first ANC visit is still given HIV test for PMTCT while 187(46.6\%) of them don't do another HIV test.

Highest number of respondents 169(90.37\%) wrongly recorded known positive in the pregnant woman's HIV-test result field in the relevant register while lowest number of respondents correctly recorded known positive pregnant women in the previously known HIV positive pregnant woman's HIV-test result field in the relevant register.

362(90.27\%) of the respondents said PMTCT HIV testing is done at their site while others are not a PMTCT HIV testing site. 19(48.72\%) of respondents who do offsite testing reported that off-site testing is done at off-site laboratory while $15(38.46 \%)$ of the respondents reported that off-site PMTCT testing is done at the voluntary counseling and testing (VCT) site

Highest number of respondents 35(89.74\%) said that pregnant women who is referred to an off-site location for PMTCT HIV testing will do HIV testing always on the same day while the lowest $1(2.65 \%)$ of the respondents said pregnant women referred to an off-site location for PMTCT HIV testing, will do HIV testing rarely on the same day.

The study also showed that 33(84.62\%) of the respondents claimed that the results of offsite PMTCT HIV testing physically returned to the facility by testing site while $6(15.38 \%)$ of them reported that it would be returned by the pregnant woman. 
Table 2.5. Practices of PMTCT Data Documentation

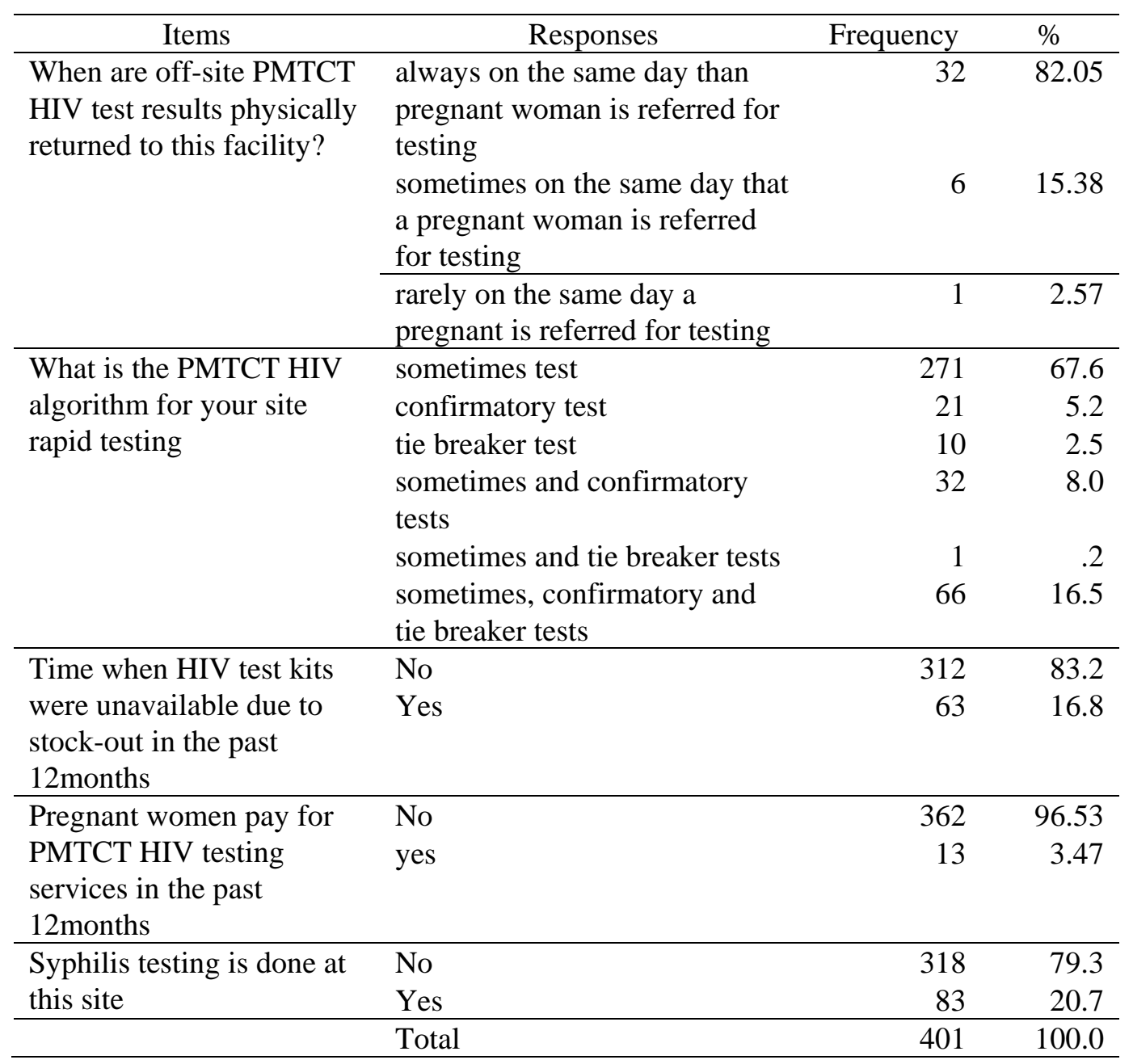

From the study, 32(82.05\%) of the respondents said off-site PMTCT HIV test results are physically returned to their facility always on the same day that pregnant woman is referred for testing whereas $1(2.57 \%)$ of the respondents said off-site PMTCT HIV test results are physically returned to their facility rarely on the same day a pregnant is referred for testing. Also 271(67.6\%) of the respondents said that the PMTCT HIV algorithm for their site rapid testing is screening test while 66(16.5\%) of them said it was screening, confirmatory and tie breaker tests that must be used.

In addition, in the last twelve months at the time of this study 312(83.2\%) of the respondents said there was no stock out of HIV test kits while 63(16.8\%) said there was stock out. It was also observed that highest 362(96.53\%) of respondents said pregnant women don't pay for HIV testing services while lowest $13(3.47 \%)$ of the respondents said that Pregnant women pay for it. Most of the respondents 318(79.3\%) claimed that Syphilis testing is not done at their sites. 
青

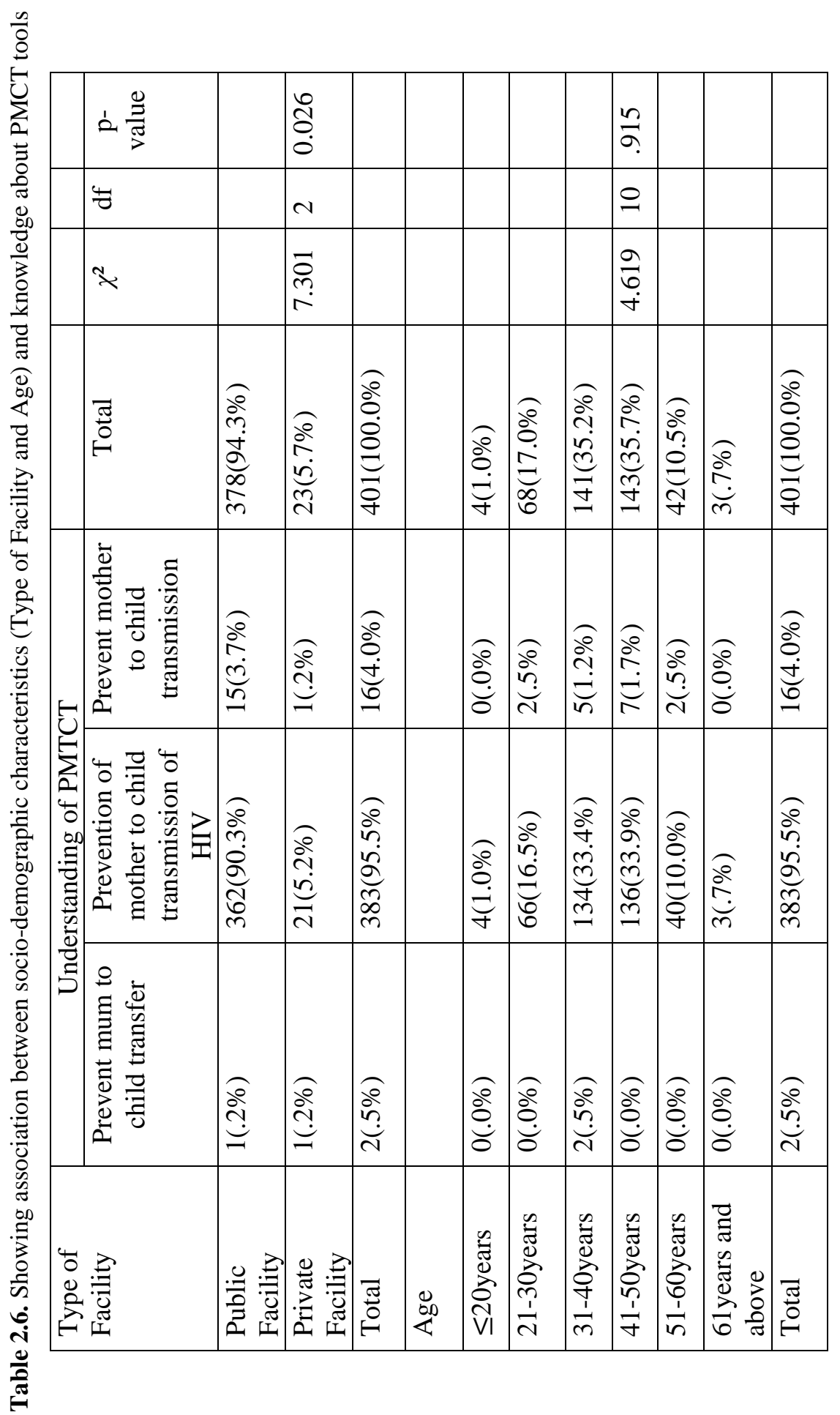


Texila International Journal of Public Health

Volume 4, Issue 4, Dec 2016

The result in table 2.6 showed a significant $(\mathrm{P}<0.05)$ association between the type of facility and knowledge about PMTCT tools. However, there is no significant $(\mathrm{P}>0.05)$ association between the Age and knowledge about PMTCT tools. 
吾

\begin{tabular}{|c|c|c|c|c|c|c|c|c|c|c|c|c|c|}
\hline & i & & $\begin{array}{l}\infty \\
\tilde{\tilde{\vartheta}} \\
\end{array}$ & & & & & & 농. & & & & \\
\hline & $\ddot{\theta}$ & & $\sim$ & & & & & & $\mathscr{\sigma}$ & & & & \\
\hline & $\approx$ & & $\begin{array}{l}\mathscr{O} \\
\infty \\
i \\
i\end{array}$ & & & & & & $\begin{array}{l}\not{8} \\
\mathscr{m} \\
\tilde{m} \\
\end{array}$ & & & & \\
\hline & 点 & 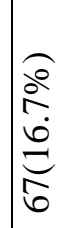 & 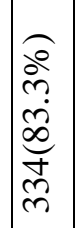 & 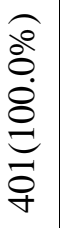 & & 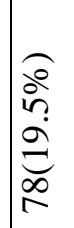 & 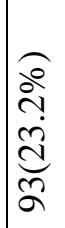 & 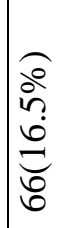 & 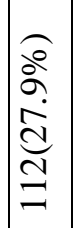 & 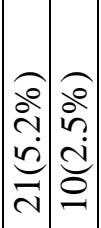 & 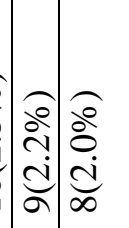 & 吕 & 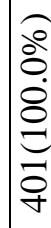 \\
\hline & 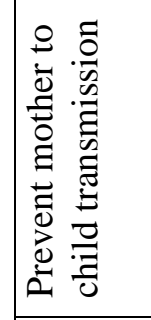 & 검 & 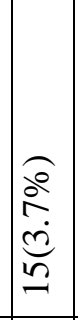 & 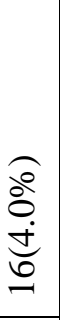 & & & 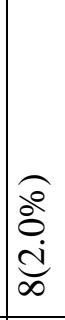 & 高 & ণิ & 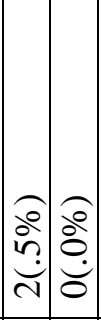 & 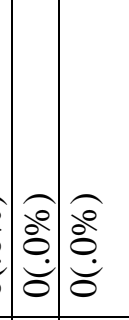 & @̊ & 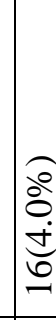 \\
\hline & 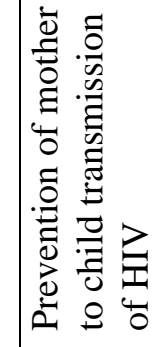 & 六 & $\begin{array}{l}\widehat{o} \\
\dot{0} \\
\tilde{D} \\
\infty \\
\infty \\
\bar{m}\end{array}$ & 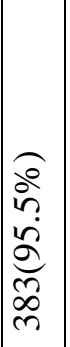 & & $\begin{array}{l}0 \\
8 \\
0 \\
0 \\
0 \\
0 \\
1\end{array}$ & 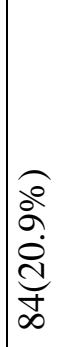 & 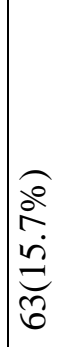 & 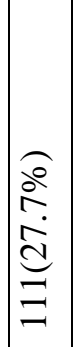 & 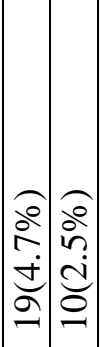 & 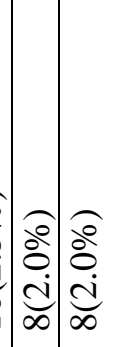 & 命 & o \\
\hline & 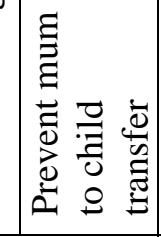 & 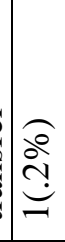 & 离 & 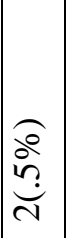 & & ơ & ঐ̊ & ồ & $\begin{array}{l}0 \\
\stackrel{0}{\circ} \\
\dot{\sigma}\end{array}$ & 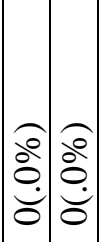 & 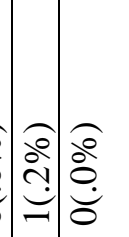 & & 웜 \\
\hline 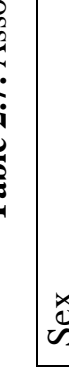 & & $\sum^{\frac{0}{\pi}}$ & 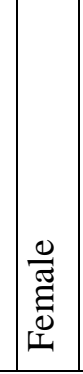 & $\begin{array}{l}\vec{\pi} \\
0 \\
0 \\
\end{array}$ & 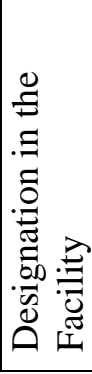 & 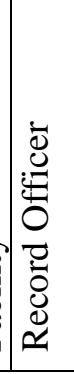 & $\begin{array}{l}3 \\
\mathbf{I} \\
\\
\\
\end{array}$ & 苗 & 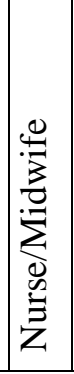 & 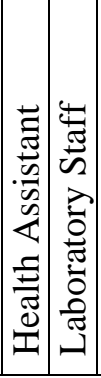 & 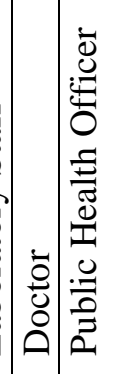 & 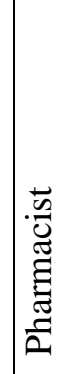 & 퓸 \\
\hline
\end{tabular}


The result in table 2.7 showed that there is no significant $(\mathrm{P}>0.05)$ association between sex and knowledge about PMTCT tools. In addition, there is a significant $(\mathrm{P}>0.05)$ association between designation in the facility and knowledge about PMTCT tools.

Table 2.8. Association between socio-demographic characteristics (Type of facility and Age) and practices of PMTCT data documentation

\begin{tabular}{|c|c|c|c|c|c|c|}
\hline \multirow[t]{2}{*}{$\begin{array}{l}\text { Type of } \\
\text { Facility }\end{array}$} & \multicolumn{2}{|c|}{$\begin{array}{l}\text { Record the number of } \\
\text { pregnant women who } \\
\text { receive voluntary HIV } \\
\text { counseling and testing } \\
\text { for PMTCT }\end{array}$} & \multirow[t]{2}{*}{ Total } & \multirow[t]{2}{*}{$\overline{\chi^{2}}$} & \multirow[t]{2}{*}{$\mathrm{df}$} & \multirow[t]{2}{*}{ p-value } \\
\hline & No & Yes & & & & \\
\hline $\begin{array}{l}\text { Public } \\
\text { Facility }\end{array}$ & $8(2.0 \%)$ & $370(92.3 \%)$ & $378(94.3 \%)$ & & & \\
\hline $\begin{array}{l}\text { Private } \\
\text { Facility }\end{array}$ & $2(.5 \%)$ & $21(5.2 \%)$ & $23(5.7 \%)$ & 3.860 & 1 & .049 \\
\hline Total & $10(2.5 \%)$ & 391(97.5\%) & $401(100 \%)$ & & & \\
\hline \multicolumn{7}{|c|}{ (2) (20) } \\
\hline$\leq 20$ years & $0(.0 \%)$ & $4(1.0 \%)$ & $4(1.0 \%)$ & & & \\
\hline 21-30years & $1(.2 \%)$ & $67(16.7 \%)$ & $68(17.0 \%)$ & & & \\
\hline 31-40years & $5(1.2 \%)$ & 136(33.9\%) & $141(35.2 \%)$ & 1.208 & 5 & .944 \\
\hline 41-50years & $3(.7 \%)$ & $140(34.9 \%)$ & $143(35.7 \%)$ & & & \\
\hline 51-60years & $1(.2 \%)$ & $41(10.2 \%)$ & $42(10.5 \%)$ & & & \\
\hline $\begin{array}{l}\text { 61years and } \\
\text { above }\end{array}$ & $0(.0 \%)$ & $3(.7 \%)$ & $3(.7 \%)$ & & & \\
\hline Total & $10(2.5 \%)$ & 391(97.5\%) & $401(100.0 \%)$ & & & \\
\hline
\end{tabular}

The result in table 2.8 showed significant $(\mathrm{P}<0.05)$ association between the type of facility and practices of PMTCT data of documentation. In addition, there is no significant $(\mathrm{P}>0.05)$ between Age and practices of PMTCT data documentation.

Table 2.9. Association between socio-demographic characteristics (Type of facility and Age) and practices of PMTCT data documentation

\begin{tabular}{|l|l|l|l|l|l|l|}
\hline Sex & \multicolumn{2}{|l|}{$\begin{array}{l}\text { Record the number of } \\
\text { pregnant women who } \\
\text { receive voluntary HIV } \\
\text { counseling and testing } \\
\text { for PMTCT }\end{array}$} & Total & $\chi^{2}$ & df & p-value \\
\cline { 2 - 7 } & No & Yes & & & & \\
\hline Male & $1(.2 \%)$ & $66(16.5 \%)$ & $67(16.7 \%)$ & & & \\
\hline Female & $9(2.2 \%)$ & $325(81.0 \%)$ & $334(83.3 \%)$ & .332 & 1 & .565 \\
\hline Total & $10(2.5 \%)$ & $391(97.5 \%)$ & $401(100.0 \%)$ & & & \\
\hline $\begin{array}{l}\text { Designation in } \\
\text { the Facility }\end{array}$ & & & & & & \\
\hline Record Officer & $3(.7 \%)$ & $75(18.7 \%)$ & $78(19.5 \%)$ & & & \\
\hline CHEW & $2(.5 \%)$ & $91(22.7 \%)$ & $93(23.2 \%)$ & & & \\
\hline CHO & $1(.2 \%)$ & $65(16.2 \%)$ & $66(16.5 \%)$ & & & \\
\hline
\end{tabular}


Texila International Journal of Public Health

Volume 4, Issue 4, Dec 2016

\begin{tabular}{|l|l|l|l|l|l|l|}
\hline Nurse/Midwife & $2(.5 \%)$ & $110(27.4 \%)$ & $112(27.9 \%)$ & & & \\
\hline $\begin{array}{l}\text { Health } \\
\text { Assistant }\end{array}$ & $1(.2 \%)$ & $20(5.0 \%)$ & $21(5.2 \%)$ & 4.878 & 8 & .771 \\
\hline $\begin{array}{l}\text { Laboratory } \\
\text { Staff }\end{array}$ & $0(.0 \%)$ & $10(2.5 \%)$ & $10(2.5 \%)$ & & & \\
\hline Doctor & $1(.2 \%)$ & $8(2.0 \%)$ & $9(2.2 \%)$ & & & \\
\hline $\begin{array}{l}\text { Public Health } \\
\text { Officer }\end{array}$ & $0(.0 \%)$ & $8(2.0 \%)$ & $8(2.0 \%)$ & & & \\
\hline Pharmacist & $0(.0 \%)$ & $4(1.0 \%)$ & $4(1.0 \%)$ & & & \\
\hline Total & $10(2.5 \%)$ & $391(97.5 \%)$ & $401(100.0 \%)$ & & & \\
\hline
\end{tabular}

The result in table 2.9 showed that there is no significant $(\mathrm{P}>0.05)$ association between Sex $\&$ designation in the facility and practices of PMTCT data documentation.

\section{Discussion}

Prevention of mother to child transmission of HIV is critical to saving lives hence there is a need for evidence based data to feed back into program implementation in order to make necessary policy and decision. To achieve this, Record Officers must have up to date information on documentation. This study focused on determining knowledge and practices of PMTCT documentation; assessing the accuracy and completeness of PMTCT data and determining the effect of training on knowledge and documentation of PMTCT.

Most of the respondents were female Christians and mainly Yoruba by tribe with mean age of 40years. The highest contributing facilities were from public facility offering PMTCT services and the designations most common among respondents are Nurse/Midwife and Community Health Extension Workers. This can be justified as most of the facilities selected are PMTCT centres where Nurse/Midwife and Community Health Extension worker is domicile. In addition, many of the respondents adopted opt-out approach in PMTCT HIV testing in their facilities (WHO, 2007). This agreed with the World Health Organization where tests would have to be offered on opt-out basis to increase the provision of HIV testing. With opt-out approach, individuals must specifically decline the HIV test after receiving pretest information if they do not want the test to be performed (WHO, 2007). Nigeria has also adopted the opt-out strategy as part of basic care for antenatal clinic clients, all patients with tuberculosis, sexually transmitted infections and HIV-related diseases (NASCP, 2014). Most of the respondents also have good knowledge of PMTCT tools and are quite aware of the current National tools used for PMTCT services documentation. The study revealed that majority of the respondents submits their monthly report within the stipulated $5^{\text {th }}-7^{\text {th }}$ of subsequent month and therefore complied timeliness of data reporting.

On practices of PMTCT data documentation, most of the respondents carriedout effective documentation using appropriate documentation tools. However, pregnant women with previously known HIV positive status are still re-screened upon presenting at her first Antenatal Care visit. However, majority of the respondents still documented known positive pregnant women in the wrong register. PMTCT HIV testing is always done on the same day by most of the facility while the result of offsite testing is physically returned to the facility by the testing site. This observation is consistent with previous work on new, highly sensitive and specific antibody-based rapid HIV testing, same day results have become possible (WHO, 2007, Jurgens, Cohen \& Beyrer and Swamy, 2007). The respondents are quite aware of PMTCT HIV algorithm for their site rapid testing, but there is limited knowledge on serial testing which is the use of two screening tests employed sequentially to test for HIV antibody and discordant results in the two tests are subjected to further testing (WHO, 2007). Most of the respondents have sound knowledge of logistics management system as there is no stock out of test kits in many of the facilities involved in this study. However, most of the respondents claimed that Syphilis testing is currently not done in their facility. 


\section{Conclusion}

The result of the study showed that most of the respondents have good knowledge of PMTCT documentation, but their level of knowledge is affected by the types of facility and the designation of their health workers. Staff working in public facility has a better understanding of PMTCT documentation than those in private facility. This assertion may be justified by the fact that highly skill personnel are recruited to the facility and they are exposed to more capacity building opportunities. However, private facility will benefit tremendously from further training on documentation. In addition, the study also showsthat respondents have fair knowledge on PMTCT HIV testing but has limited understanding on the types of screening techniques to use. Therefore, seminars and trainings should be regularly organized on serial HIV testing.

\section{Recommendations}

In view of the findings from the study, there is an urgent need to ensure regular validation of PMTCT data collected from all the health facilities. Re-training of all health workers on current monitoring and evaluation tools used in capturing PMTCT data is very necessary in addition to regular monitoring and supervisory visit to all the health facilities. Also simplified data collecting systems or the use of sophisticated electronic data validation systems to provide a reliable data must be encouraged in all the facility. Further research on the knowledge and practice of documentation of HIV counseling and testing and ART treatment and care given to HIV positive patients are recommended as a follow up to the findings of this study. The findings from such a research will help in the generation of useful information that can be used for making judgement by policy makers to improve HIV program services delivery in the state.

\section{References}

[1] Adewole, I, Oluwole, O \& Sagay, A. (2006). Prevention of Mother-to-Child transmission of HIV: The Nigerian PMTCT Programme. AIDS in Nigeria, 1(1), 349-84.

[2] Amazoncom. (2016). Amazoncom. Retrieved 18 July, 2016, from https://www.amazon.com/Encyclopedia-African-American-Heritage-Susa...

[3] Avertorg. (2016). Avertorg. Retrieved 17 July, 2016, from http://www.avert.org/preventingmother-child-transmission-hiv.htm.

[4] Balogun, M \& Odeyemi, K. (2010). Knowledge and practice of prevention of mother-to-child transmission of HIV among traditional birth attendants in Lagos State, Nigeria. Pan Afr Med J, 5(1), 7.

[5] Coetzee D, Hilderbrand K, Boulle A, Draper B, Abdullah F and Goemaere, E. (2005). Effectiveness of the first district-wide programme for the prevention of mother-to-child transmission of HIV in South Africa. Bull World Health Organ, 83(7), 489-94.

[6] Dabis, F, Leroy, V \& Castebonk, E. (2000). Prevention of Mother to Child Transmission of HIV1 in Africa. AIDS, 14(1), 1017-1026.

[7] De cock, K. M., Fowler, M. K., Mercier, E., De Vincenzi, I., Saba, J., Hoff, E., Alnwick, D. J., Rogers, M., and Shaffer, N. (2000). Prevention of mother-to-child HIV transmission in resource-poor countries: translating research into policy and practice. JAMA, 283(1), 1175-1182.

[8] Federal Ministry of Health. (2008). Technical Report on the National HIV/Syphilis Seroprevalence Sentinel Survey among Pregnant Women Attending Antenatal Clinics in Nigeria. NASCP Abuja: Nigeria.

[9] Joint United Nations Programme on HIV/AIDS (UNAIDS). (2011). Countdown Zero. UNAIDS. Geneva.

[10] Jurgens, R, Cohen, J \& Beyrer, C. (2007). Increasing access to HIV testing and counselling while respecting human rights. HIV AIDS Policy Law Rev, 12(2-3), 63-6.

[11] Mirkuzie, A. H. (2008). Utilization of PMTCT services in Awassa town Ethiopia. Center for Internal Health, Faculty of Medicine and Dentistry, University of Bergen, Norway. 
Texila International Journal of Public Health

Volume 4, Issue 4, Dec 2016

[12] National AIDS/STIs Control Programme Federal Ministry of Health. (2014). Integrated National Guidelines for HIV Prevention, Treatment and Care.

[13] Olaniyan, F.A. (2013). Spatial Inequalities in the Provision of Private Health Facilities in Oyo State. Indonesian Journal of Geography, 45(1).

[14] Owoaje, E, Omidokun, A \& Ige, O. (2012). Knowledge and perception of Prevention of Mother to Child services amongst pregnant women accessing antenatal clinic in a Primary Health Care centre in Nigeria. Afr J Prim Health Care Fam Med, 4(1), 32.

[15] Schmidt, C. O \& Kohlmann, T. (2008). When to use the odds ratio or the relative risk? International Journal of Public Health, 53(3), 165-167.

[16] Swamy, M. (2007). UN agencies issue new guidelines for HIV testing. HIV AIDS Policy Law Rev, 12(2-3), 39-40.

[17] Unaids.org. (2016). Unaidsorg. Retrieved17July,2016, from http://data.unaids.org/pub/Report/2010/nigeria_country_progress_report_en.pdf.

[18] World Health Organization. (2007). Guidance on provider-initiated HIV testing and counseling in health facilities.

[19] WHO/UNICEF/UNAIDS. (2011). Calculated from Universal Access Country reported unpublished data. 


\title{
Public Health Aspects of Refugee Health: A Review of the Evidence on Health Status for Refugees Globally
}

\author{
Article by Krishan Puri \\ Master of Public Health, Texila American University, Nepal \\ E-mail: krishnjames77@gmail.com
}

\begin{abstract}
Introduction: Asylum seekers and refugees are identified as those who did not make voluntary choice to leave their origin country and cannot return home safely. Internally displaced persons and refuges are extremely vulnerable to human rights abuses, especially the absence and denial of mental and physical health care. For more than 50years, the fundamental framework of refugee protection has been established and accepted globally. The lack of respect to human rights of refugees and failure to provide adequate humanitarian help such as health care. The Geneva Conventions, the Universal Declarations of Human Rights, Statute of the office of the United nations High Commissioner for Refugees, and the Convention Relating to the Status of Stateless Persons, all establish international standards for private and governments organizations that set guidelines for assimilation and repatriation of refugees that create international standards.

Methods: The study was conducted through a systematic literature review of articles dating between 2001 and 2015 on Embase, PsychInfo, Medline and Cochrane Controlled Trials, UNHCR, IOM and World Health Organization databases. The study decided on the articles to review by reading abstracts to determine inclusion of data about the health status of either the internally displaced person or the refugees. The abstracts were selected randomly and independently. A limited random search of the reference lists of all included studies was also undertaken. And also few English language studies of evaluated primary health care models of care for refugees in developed countries of resettlement were included.

Results: The internally displaced people's and refugees are extremely vulnerable to human rights abuses From the research, it is clear that across the globe, access of primary healthcare amongst the refugees is overwhelmingly shaped by the regulations of the migration process and legal frameworks of individual states and nations. The study discusses that there is a primary need for advanced communication with refugees and coordination of activities between agencies either public or private within and beyond the health care structure. The study seeks to unveil the channels that create the neglect of refugees' right to a chance of survival. The study recommends that improved data are imperative towards supporting inter-sectorial work in addressing health care needs of refugees.
\end{abstract}

Keywords: Refugee health, public health, migration health, healthcare, global

\section{Introduction}

\section{Problem statement}

Globally, migration is a critical public health, political and social challenge. The number of international migrants globally rose by over 77 million between the year 1990 and 2013 . Europe is identified as the leading continent in receiving international migrants (Janmyr, 2014). More specifically, there was an approximate half a million people who sought asylum in Europe in 2013 which according to the United Nations High Commissioner for Refugees (UNHCR) represents a 32\% percent increase since 2012. According to the research, Europe involuntarily creates a safe haven for people on the run. Research shows government and economic stability as one of the main characteristics of refuged paces. Evidently, as the immigration laws constantly tend to have strategic bottlenecks to reduce the influx in refugee camps other aspects fuel the movement. Insecurity in the neighboring areas slows down the 
Texila International Journal of Public Health

Volume 4, Issue 4, Dec 2016

much effort invested in the same. Currently, there is lack of evidence that the global burden of refugees is likely to fall. The ongoing crisis in Aegean and southern Mediterranean nations suggests the exact opposite. The situations in Turkey, Iraq, Syria, and Somalia amongst others indicates that the rates of refugees will keep growing. It is thus important for host nations in collaboration with global agencies to focus on availing equitable access to health promotion and disease prevention and care to the migrants.

By international law and standards, refugees are owed protection including access to health services from their first nation of registration for asylum. However, such rights may not be provided at the asylum determination stage. The internally displaced people and refugees are extremely vulnerable to human rights abuses, particularly the denial of mental and physical healthcare. For over 50 years, the basic framework of protecting refugees has been established and accepted globally. There are however signs indicating that there is little commitment towards providing adequate humanitarian assistance and respect of the human rights of refugees which includes health care. Several protocols and conventions such as the Universal Declaration of Human Rights, the Geneva Conventions, the Convention Relating to the Status of Stateless Persons and the Statute of the Office of the United Nations High Commissioner for Refugees. All these set standards that should be abided to by private and government organizations. This creates the idea that the set regulations and standards on service delivery to such people has few loopholes that leak out the quality and quantity of service and material delivery to aid daily survival needs. This study seeks to collect literature evidence on the global health status, which will indicate the failure or success of the international and state protocols and conventions in the public health front.

\section{Significance and structure of the study}

The public health standards for the refugees are rarely enforced fully. According to a survey on the causes of increased refugee immigration, organization with the mandate to provide and maintain a sanitized environment fail to do the same due to a constant budgetary strain by the radical growth in population of both the local citizens and the refugees in the camps. The systematic literature review seeks to detail the problems that come up in the absence of full implementation as well as serve refugee needs in their interim. To meet that need, the structure will be organized in the following five fronts;

Mental health: Naturally, refugees are prey to climates of violence that have the potential to damage the status of their mental health and this can proceed to cause Post Traumatic Stress Disorder (PTSD). In essence, therefore, the study will collect literature evidence on the issue that while humanitarian aid mainly focuses on the immediate physical needs of refugees such as shelter, food, and clean water, there is a chance that mental health is overlooked.

Children: Juvenile refugees are often in potential threat of hazardous labor conditions, sexual and physical abuse. The practical dimensions on this problem will be addressed.

Women: refugee women are in typical need of basic health care which includes education on reproductive health information or family planning. The paper will analyze the morbidity and mortality of women refugees that will be essential in calling attention to the immediate need for public health intervention.

Africa: Africa offers a special interest due to many wars, natural disasters, and political instability that results to large numbers of internally displaced people and refugees. Additionally, Africa is faced by financial crises making states render them of incapability to address the challenge adequately.

Europe and America: In the last decade, Europe has been receiving high levels of refugees more than any other continent. As a result, the study will shed light on how the public health issue of the immigrants is being handled and thus draw comparisons to Africa.

\section{Study methodology}

The study is a systematic literature review. This review primarily refers to statistics and articles referred to or financed by United Nations (UN) agencies and more specifically the 
International Organization for Migration (IOM) and United Nations High Commissioners for Refugees (UNHCR). This determines the databases to be selected as recommended by the international agencies which will be examined using headings search and keywords. Through this approach, the researcher will be in position to summarize findings in studies where the methods of study are diverse and integrate quantitative data across studies where similar outcome measures have been adopted.

\section{Scholarly papers identification}

The researcher utilized six electronic databases; Cochrane Library (2004- 2015), National Center for Biotechnology (2004- 2015), ScienceDirect (2004- 2015), Web of Science (20042015), ProQuest (2004- 2015) and PubMed (2004- 2015). The years of publication were restricted to the last decade which ensures that the data is current and comparable. Public health measures included the mortality and morbidity rates in amongst the refugees and internally displaced persons. Due to language barrier, the articles were be restricted to English and to the developed and developing countries to allow for comparisons between the nations. Secondary references were then gathered from the primary sources.

\section{Selection criteria}

The study decided on the articles to review by reading abstracts to determine inclusion of data about the health status of either the internally displaced person or the refugees. The abstracts were selected randomly and independently. The information was then coded after extraction. The coding was categorized under the aim of the study, study design, study population typology, demographic characteristics, intervention type, study measure type, summary of the results, main outcomes, strategy adopted in sampling, and the response rate and sample size, and the demographics.

\section{Results}

As the figure below indicates (acquired from the Migration Policy Institute, 2015), the rates of refugees has been growing gradually across all nations but mainly across Europe;

\begin{tabular}{|c|c|c|c|c|c|c|c|c|}
\hline \multicolumn{3}{|c|}{2015} & \multicolumn{3}{|c|}{2014} & \multicolumn{3}{|c|}{2013} \\
\hline Country & Number & Percent & Country & Number & Percent & Country & Number & Percent \\
\hline Burma & 18,386 & 26.3 & Iraq & 19,769 & 28.2 & Iraq & 19,488 & 27.9 \\
\hline Iraq & 12,676 & 18.1 & Burma & 14,598 & 20.9 & Burma & 16,299 & 23.3 \\
\hline Somalia & 8,858 & 12.7 & Somalia & 9,000 & 12.9 & Bhutan & 9,134 & 13.1 \\
\hline Dem. Rep. Congo & 7,876 & 11.3 & Bhutan & 8,434 & 12.1 & Somalia & 7,608 & 10.9 \\
\hline Bhutan & 5,775 & 8.3 & Dem. Rep. Congo & 4,540 & 6.5 & Cuba & 4,205 & 6.0 \\
\hline Iran & 3,109 & 4.4 & Cuba & 4,062 & 5.8 & Iran & 2,578 & 3.7 \\
\hline Syria & 1,682 & 2.4 & Iran & 2,846 & 4.1 & Dem. Rep. Congo & 2,563 & 3.7 \\
\hline Eritrea & 1,596 & 2.3 & Eritrea & 1,488 & 2.1 & Sudan & 2,160 & 3.1 \\
\hline Sudan & 1,578 & 2.3 & Sudan & 1,315 & 1.9 & Eritrea & 1,824 & 2.6 \\
\hline Cuba & 1,527 & 2.2 & Afghanistan & 753 & 1.1 & Ethiopia & 765 & 1.1 \\
\hline $\begin{array}{l}\text { All other countries, } \\
\text { including unknown }\end{array}$ & 6,870 & 9.8 & $\begin{array}{l}\text { All other countries, } \\
\text { including unknown }\end{array}$ & 3,182 & 4.5 & $\begin{array}{l}\text { All other countries, } \\
\text { including unknown }\end{array}$ & 3,302 & 4.7 \\
\hline Total & 69,933 & 100.0 & Total & 69,987 & 100.0 & Total & 69,926 & 100.0 \\
\hline
\end{tabular}

\section{Mental health status}

The prevalence of mental distress is higher among the refugees when compared to the nonrefugees (Bergen, 2004). Asylum seekers seem to portray higher risks than the refugees do. The risk factors associated with poor mental health among the refugees include lack of social support after forced migration, older age, trauma experiences, and being a woman (Kemp \& Rasbridge, 2004). As refugees fled from Syria to Lebanon, the laws put in place by the Lebanon government denied foreigners without passports to work in the country. In such a state, refugees bear more than the plight of separation from family and home. They also live 
Texila International Journal of Public Health

Volume 4, Issue 4, Dec 2016

through fear, despair, false hope from unending negotiations between their country of origin and organizations seeking to get back home. According to psychologists, separation from family or friend and rejection from all ends create a high risk of mental instability. The mind then rests on the support of racism, death threats, human trafficking, and organ theft among some of the basic problems stated out in the statured laws and regulations when it comes to service delivery to the refugees.

Looking into the same, as host governments and other relative organizations go out of their way to provide a healthy environment, many issues arise due to the changing times. Therefore, funds directed towards aid become unutilized due to the unattended and still strains not mentions or catered to in the operational structure. Besides focusing on offering material aid to the women and children in refugee camps such as sanitary items, organization overlook some facts as teaching the women and children how to use these items. On the same, some of the refugees, if not all, seek explanations as to why they are in their current state and to some as orphans in the camps, guidance and counselling should come in. Over the long term, the mental health appears to get worse, which is a result of lack of education, and employment that adds on the stress experienced by the refugees. Problems in the camp appear to be cyclic (Bergen, Heredia, \& Schouler-Ocak, 2014). For the host organizations to handle all issues regarding public health among the refugees, the whole idea requires an approach from a very different angle. When refugees settle in the host countries, governments and the involved organizations should look into the matter by creating a good environment to enable them to get back on their feet and fend for themselves.

\section{Children health status}

In majority of the refugee camps worldwide, children accrue to almost half the population of refugees. This follows the fact that most of the displaced people are in groups of families, large families. Moreover, when these people are in camps, there is little or no birth control knowledge dispatched to them. In order to have sufficient funds to cater for the whole population in the camps, it is crucial to monitor the population growth in the camps against the set budget. Children are the most vulnerable in these camps due to their susceptibility to cold, diseases, and hunger among other problems. It becomes a challenge for aiding organizations to set up a structured flow of material and service aid to reach everyone in these camps. Children in refugee camps are entitled to equal rights and opportunities as ones that are not. As much as allocation of the aid flowing in is with regard to its scarcity, priority becomes an important fact. Children require not only food and shelter, but security is crucial.

Children in these camps are vulnerable to kidnappers, sexual and gender risks, and killers. The structures set up to shelter refugees in host countries neglect some minor issues that mold into bigger problems (Segal \& Elliott, 2012). These camps host people from all lifestyles. Therefore, there comes a high risk of diseases: airborne and sexual. In both cases, children are at a high risk of contraction. Many of these camps lack in quality facilities like screening centers, which are important to distinguish the types and number of diseases to treat and ones to quarantine. Specifically to children, refugee camps lack in regular immunization and maternal care. Research shows that these camps can be in existence up to 30 years and more. This means that refugee camps can see a more than a life's time. The quality of natal and maternal care in these camps being below standard reflects on the standard of living in them. The distribution and monitoring structure in the food sector also neglects nutrition, which is important to both growing children and adults. Having a regular or occasional supply of food id never enough in such cases. This is especially because of the environment that these children live in. Unlike a normal child, one in a refugee camp is open to more risks. According to a research, a child's health status highly depends on the kind of education he or she gets regarding maintaining a healthy lifestyle. A number of camps directs its time, attention and funds on the basic needs in a bid to cater for all. It breaks down to more than basic needs as food and shelter when aiming for better results. 


\section{Women health status}

Refugee camps have a generalized management plan that bundles people up in clusters. This suppresses some of the women needs in the camps. Being the most affected, women, and their children require extra attention and care. Women in refugee camps go through a number of health related problems. Depending on the variation in level of services available, women need maternal care for expectant mothers. This is important because in the end it saves more than a life. It is important for the camp managers to carry out a fully detailed population census. Having a detailed record of everyone in the camp gives a clear path in creating health and sanitation budgets. Expectant women in many camps lack regular clinic checkups to monitor growth progress of their infants. In addition, women in general in many camps especially in Africa, lack a regular supply of sanitary pads. Depending on the number of women and girls in the camp, the reimbursement period and quantity need to work out a balance. Its importance reflects in maintaining healthy standards during distribution of sanitary pads, and disposal. Despite the basic health care, women in refugee camps require education on health issues such as family planning and reproduction care (Gebreiyosus, 2014). Women in refugee camps undergo a lot of trauma and abuse from men in the same camps and locals in the community. It becomes difficult to protect them from such risks and injustices. Women in these camps are the overworked gender. In many camps, the local community takes advantage of the cheap labor from refugees. In the end, women and children work for little or no pay at the mercy of the local community. Subjected to such labor conditions and unknown health hazards just to fend for their families puts both the women and children at risk.

\section{Health status in african refugees and internally displaced persons' camps}

In Africa, the rise in number of refugees is rampant due to the many wars, political instability, and financial crises. This becomes a major problem when the governments in African countries become incapable of funding and controlling the case. Internally displaced people develop diseases due to inadequate or no healthcare facilities, which then spread easily around the country. A record problem is the spread of sexually transmitted diseases (In Furman, In Epps, \& In Lamphear, 2016). Financial struggles in Africa force refugees indulge in sex trafficking to earn a living. Huge numbers result in the same creating a stringed death toll, which includes the locals. When refugees mix up with the locals, it creates a security risk because the refugees will be forced to indulge in any activity for a dime. Such activities may involve dealings in arms, robbery, and drugs. This threatens both local and refugees' health status in the end.

\section{Health status in refugee and asylum seekers in europe and america}

Questions arise when it comes to international law, both for and against the refugees. Despite the risks posed to the host country when tending to refugees, certain issues need to be set clear to ease the approach to aid (Janmyr, 2014). In Europe and America, refugees seek protection and aid with varied motives behind them. A case in the recent years where Europe's economic drop pointing to the increased refugee population in the continent. Most of these refugees come from underdeveloped countries, seeking better standards of living. In turn, health risks come in where lack of jobs due to nationality leads them to settle for anything. These refugees are used as drug mules and prostitutes (Nair, \& Sen, 2007).

\section{Discussion}

The research shows that conditions in refugee camps are not a choice, but the closest option to survival. However, conditions in the camps ought to be better than other options. Refugee management need to focus on more issues not just food and shelter. Structural organization in the refugee camps need to incorporate mental health care to control the fear, despair, and rejection that these people face. These measures need, not only come from the management, but also from the peers among the people in the camps. To do so, scheduled 
Texila International Journal of Public Health

Volume 4, Issue 4, Dec 2016

programs can help create a positive routine to enhance team building and nature care among the refugees themselves.

Additionally, health care centers in the camps need to be readily available and mobile. To reach all needy people in the area, refugee management teams need to organize regular visits in the tents or clusters to offer medical care and health tips to the refugees. This will create a systematic approach to the problem at hand and make the refugees feel less threatened in the environment and more welcome to build the community. The management should have paying labor opportunities for the refugees in the camp to earn a living in a bid to get on their feet again.

Refugee camp management need to offer ample security to the people in the camps. Many times locals blend in as refugees and receive aid in material terms, which they later sell to the refugees, payable in labor terms. This creates a shortage in aid and a conflict in interest. Management teams need to create a barrier around the shelters and have a detailed census database to avoid misallocation of resources in the camps. Security also extends to the refugee community in the camps. The managers ought to protect the women and children from sexual abuse and the community as a whole from violence. Within the camp, there may be a varied number of races. Therefore, the management should separate people within the camp to avoid racial conflicts.

Refugee camps should have disease screening centers to avoid taking in contagious diseases, which puts the whole nation at risk. Camps are easy breading environments for catastrophes. Therefore, local governments in conjunction with the aid groups ought to have camp setups on the go to control influx of refugee population and monitor the same.

\section{Conclusion}

The strategic and systematic literature review has relied heavily on migration policy institute and United Health organizations in determining the appropriate articles to offer quality and timely information. Through the analysis conducted, it is clear that the state of being a refugee and asylum seekers physically and emotionally depreciates a human being. The migrants and refugees experiences a unique and complex health problems which can be met by primary health care services. This study goes further in identifying the specific strategies required to provide accessible and well-coordinated care for refugees. Through the analysis, the dependent of dependent and their parents makes them vulnerable. Women are more prone to vulnerability through their basic health sex needs. While men are minimally affected, they join the statistics that clearly indicate the act of being a refugee is a contributor in causing post-dramatic stress, chronic stress and physical injury. These are negative indicators of the mental health of the people in the communities. Therefore, this study recommends that there should be implementation of new rules and policies be introduced and the previous ones implemented full which is a promise of improved mental health statistics of all individuals. Furthermore, the study concludes by requesting for more and mainly specific researches on the same matter to be cleared and elaborated further.

\section{References}

[1]. Akresh, I. R., \& Frank, R. (2008). Health selection among new immigrants. American Journal of Public Health, 98(1), 2058-2064.

[2]. Bergen, D. D., Heredia, M. A., \& Schouler-Ocak, M. (2014). Suicidal behavior of immigrants and ethnic minorities in Europe.

[3]. Bowers EJ, Cheng I-H: Meeting the primary health care needs of refugees and asylum seekers. Primary Health Care Research and Information Service: Research Roundup. 2010, 16.

[4]. Clark RC, Mytton J. Estimating infectious disease in UK asylum seekers and refugees: a systematic review of prevalence studies. Journal of Public Health 2007 Dec;29(4):420-428 (open access)

[5]. Department of Immigration and Border Protection: Fact sheet 60 - Australia's refugee and humanitarian program. 2010, Canberra: Australian Government, Department of Immigration and 
Border Protection Harris MF, Telfer BL: The health needs of asylum seekers living in the community. Med J Aust. 2001, 175: 589-593.

[6]. Evans, J. (1987). Introduction: migration and health. International Migration Review, 21(3), v-xiv.

[7]. Feldman R: Primary health care for refugees and asylum seekers: a review of the literature and a framework for services. Public Health. 2006, 120

[8]. Furman, R., In Epps, D., \& In Lamphear, G. (2016). Detaining the immigrant other: Global and transnational issues.

[9]. Fazel M., Reed R., Panter-Brick C., Stein A., Mental health of displaced and refugee children resettled in high-income countries: risk and protective factors The Lancet 2011 379(9812):266-282.

[10]. Fazel M, Wheeler J, Danesh J. Prevalence of serious mental disorder in 7000 refugees resettled in western countries: a systematic review. Lancet 2005 Apr 9-15;365(9467):1309-1314

[11]. Filges T., Montgomery E., Kastrup M., Klint Jørgensen A.M. The impact of detention on the health of asylum seekers: A systematic review Campbell Collaboration Library 2015-09-01 Volume 11, number 13.

[12]. Gagnon AJ, Merry L. and Robinson C. (2002). A systematic review of refugee women's reproductive health. Refuge: Canada's Journal on Refugees 2002; 21(1):6-17

[13]. Gebreiyosus, Y. (2014). Women in African Refugee Camps. Hamburg: DiplomicaVerlag.

[14]. Harris MF, Harris E, Roland M: Access to primary health care: three challenges to equity. Aust J Prim Health. 2004, 10 (3): 21-29.

[15]. Hadgkiss EJ, Renzaho AMN. The physical health status, service utilisation and barriers to accessing care for asylum seekers residing in the community: a systematic review of the literature. Australian Health Review 2014 May;38(2):142-159 (open access)

[16]. Hyman, I., \& Jackson, B. (2010). The healthy immigrant effect: a temporary phenomenon. Health Policy Research Bulletin, 17, 17-21.

[17]. Janmyr, M. (2014). Protecting civilians in refugee camps: Unable and unwilling states, UNHCR and international responsibility. Leiden: Martinus Nijhoff Publishers.

[18]. Kemp, C., \& Rasbridge, L. A. (2004). Refugee and immigrant health: A handbook for health professionals. New York: Cambridge University Press.

[19]. Le Feuvre P: How primary care services can incorporate refugee health care. Med ConflSurviv. 2001, 17: 131-136.

[20]. Muggah, E., Dahrouge, S., \& Hogg, W. (2012). Access to primary health care for immigrants: results of a patient survey conducted in 137 primary care practices in Ontario, Canada. BMC Family Practice.

[21]. Nair, P. M., \& Sen, S. (2007). Trafficking in women and children in India. New Delhi: Orient Longman.

[22]. Noymer, A., \& Lee, R. (2013). Immigrant health around the world: evidence from the World Values Survey. Journal of Immigrant \& Minority Health, 15(3), 614-623.

[23]. Norredam M, Nielsen SS, Krasnik A: Migrants' utilization of somatic healthcare services in Europe-a systematic review. The Eur J Public Health. 2009, 20: 555-563.

[24]. Owen A, Grootemaat P, Samsa P, Fildes D, Eager K: A review of the literature and practice on models of care for refugee health. 2009, Cenre for Heatlh Service Development: University of Wollongong

[25]. Ott E., Montgomery P., Interventions to improve the economic self-sufficiency and well-being of resettled refugees: A systematic review. Campbell Collaboration Library 2015-01-02 Volume 11, number 4.

[26]. Pooley J.A., Sims K. Posttraumatic growth amongst refugee populations: A systematic review. Chapter 19 of The Routledge International Handbook of Psychosocial Resilience. 2016.

[27]. Reed R., Fazel M., Jones L., Panter-Brick C., Stein A., Mental health of displaced and refugee children resettled in low and middle-income countries: risk and protective factors The Lancet 2011 379(9812):250-265.

[28]. Segal, U. A., \& Elliott, D. (2012). Refugees worldwide: Vol. 4. Santa Barbara, Calif: Praeger.

[29]. Tyrer R.A., Fazel M. hSchool and community-based interventions for refugee and asylum seeking children: A systematic review Published February 24, 2014. Plos One 9(2), e89359. 
Texila International Journal of Public Health

Volume 4, Issue 4, Dec 2016

[30]. United Nations High Commissioner for Refugees: Asylum levels and trends in industrialized countries, first half, 2012: statistical overview of asylum applications lodged in Europe and selected non-European countries.

[31]. United Nations High Commissioner for Refugee: The 1951 Convention Relating to the Status of the Refugees and Its 1967 Protocol. 2011, Geneva, Switzerland: United Nations High Commissioner for Refugees.

[32]. United Nations High Commissioner for Refugees: Refugee resettlement: an international handbook to guide reception and integration. 2002, Geneva: United Nations High Commissioner for Refugees.

[33]. United Nations High Commissioner for Refugees: Frequently asked questions about resettlement. 2012.

[34]. Victorian Foundation for Survivors of Torture: Towards a health strategy for refugees and asylum seekers in Victoria. 2004, Victoria: Victorian Foundation for Survivors of Torture. 


\title{
The Various Misconceptions of Bipolar Disorder in Barbados
}

\author{
Article by Marlo A.R Browne \\ Master of Public Health, Texila American University, Barbados \\ E-mail: ricobro@hotmail.com
}

\begin{abstract}
Bipolar disorder, also known as manic depressive illness, is a complex, chronic and severe mental health disorder that is characterized by episodes of mania, depression or a combination of both. The study seeks to examine the plethora of current and prevalent misconceptions perceived by members of the general population within the Caribbean country of Barbados. Different research methodologies were employed for the purpose of the study, including the conduction of the survey, which illustrates the general misconceptions, held by the Barbadian public, as well as interviews with local mental health professionals to discredit these misapprehensions. Four hundred people completed the survey. Results indicate that there is a percentage of the population which understood the disease, but which believes that effective knowledge dissemination was the key to the increase of awareness and the reduction of the misconceptions, as well as the fact that females were susceptible to the disorder, especially during the ages of 25-29.
\end{abstract}

Keywords: Bipolar Disorder, Misconceptions, Barbados

\section{Introduction}

Bipolar disorder, also known as manic depressive illness, is a complex, chronic and severe mental health disorder that is characterized by episodes of mania, depression or a combination of both. Craddock and Jones (1999) describe it as a complex genetic disorder where the primary feature is an incorrigible disturbance in mood that fluctuates between periods of euphoria or jubilation, which is termed as mania, to periods of severe depression which usually affects thinking and behavior patterns and may include some psychotic symptoms like delusions and hallucinations. They elaborate further by defining bipolar disorder as an episodic illness, suggesting that full recovery can occur within episodes. Sajatovic(2005) agrees with this view, by defining bipolar disorder as a chronic psychiatric illness, that has distinguishable and recurrent features of mania, hypomania and depression and contributes to the global economic burden of disease, due to the fact that the actual treatment cost of the disease may exceed a total of $\$ 7$ billion. She stresses the importance of bipolar disorder as a global public health concern by providing statistics which indicate its prevalence could lie within the range of 1 and $2 \%$ and that approximately $73 \%$ of patients experience a relapse within the duration of 5 years. Therefore, she cites it as the sixth highest cause of medical disability among the US population, between the ages of 15 and 44 . She also notes that it caused a staggering unemployment rate of $60 \%$ among the patients that were examined. Although the American Health Association sub-classifies bipolar disorder into two recognizable types, which have been conveniently named Bipolar I and Bipolar II disorder respectively, in their book The Diagnostic and Statistical Manual of Mental Disorders (1952), there are in actuality several types, including cyclothymic disorder. Craddock and Jones (1999) define bipolar I disorder, as classified by the DSMIV, as a form of the illness in which the patient experiences extreme manic or mixed episodes. The manic episodes may last for duration of seven days. Sajatovic(2005) implies that persons with this form of the disease are about 3 times as susceptible and 7 more times susceptible to alcohol and drug abuse and dependence respectively, comparable to the general population. She extends her point by expressing the view that patients with bipolar disorder are 26 more times susceptible to panic disorders, as well as 8 more times likely to experience obsessive compulsive disorder. In 
Texila International Journal of Public Health

Volume 4, Issue 4, Dec 2016

contrast, bipolar II disorder is defined as the form of the disease where the patient undergoes more depressive episodes and only milder forms of mania, which are often referred to as hypomania. Gitlin(2006), in his article, states that the depressive episodes in bipolar II patients, greatly outweighed the hypomanic episodes, boasting a ratio of 39:1. In Barbados, research proposes that the average amount of healthy years lost per 100,000, due to bipolar disorder has increased from 1990 by a rate of $2.9 \%$. This research also suggests that the peak age range of those affected by the disorder, falls within the productive years of 25-29 and that women were more susceptible to it, with the amount of healthy years lost estimated to be about 310 per 100,000.

\section{Purpose of study}

The purpose of this research is to effectively evaluate the plethora of current and prevalent misconceptions of bipolar disorder that are perceived by members of the general population within the Caribbean country of Barbados. Through this article, I hope to educate them with the knowledge so that the social stigma that is heavily placed on people who suffer from mental illnesses, including bipolar disorder, is reduced. In Barbados, there has been a certain proclivity to perpetuate the belief that all moody behaviors are associated with bipolar disorder. This is in fact, a blatant myth and can be attributed to the lack of knowledge about the chronic medical condition. This is also due to the person's inherent laziness to access the available information so that they can be able to educate themselves thoroughly about the disease. Ghaemi and Dally (2015) agree with this, by stating that there are people who believe that since mood liability can be an important criterion in the definition of borderline personality, then it can precipitate to bipolar and other personality disorders. They elaborate, through the usage of previous research, conducted by Kraepelin, in the 1900s, to compare mood liability to a fever. They convey this comparison by stating that since a fever is a symptom of pneumonia, but is non-specific, then it is unable to be used in the nosology of pneumonia. Through this approach, the view is imparted that mood liability is like the fever of psychiatry, showing that although it may be prevalent with several conditions, it does not illustrate the true representation of the diseases that may be present. Another common myth that needs to be rectified is that bipolar disorder is an endogenous process (Hlastala et al, 2000). This can also be attributed to the lack of thorough education and research.

\section{Theoretical framework}

\section{Bipolar disorder and age detect ability}

There is a recurrent fallacy among the general population that mental health practitioners are unable to detect and diagnose bipolar disorder until the patient reaches the age of 18 . Sajatovic(2005) disputes this by saying that there was no specific correlation between age and the mental health disorder, but it was noted that the apogee for its onset existed within the range between 15 to 19 years of age. She provides further evidence to debunk this myth through the information obtained from two different sources. The first piece of evidence from a survey conducted by the National Depressive and Manic-Depressive Association (NDMDA) elucidated that approximately 59\% of the present patients with bipolar disorder were said to experience their first symptoms, either through childhood or at the adolescent stage. The second piece of evidence came through another study which suggested that the onset of disease could occur in patients, aged 60 years and older. Some researchers imply that the illness should be treated seriously and should not be mistaken for children going through their normal trials and tribulations. Instead, they believe that children with bipolar disorder are often unable to sleep, as well as performing to their full potential in school. Almeida et al (2002) compares the two sets of patients, and they are of the view that patients who experience the disease during adulthood are strongly associated with organic brain disease, while those who have the early onset are associated with a hereditary origin. Post et al (2010) support this view by stating that onset of the disease was extremely common in children and this eventually led to these patients experiencing a significant increase in the severity and the 
duration with which they encountered manic and depressive episodes in comparison to those patients who developed the disorder during adulthood. They attributed this to the fact that the patients whose onset emerged during childhood, received a lag in their treatment.

\section{Bipolar disorder and quality of life}

There is a popular vantage point that people with bipolar disorder are able to lead normal lives and be contributing members to the society, as long as they receive the proper treatment. However, research has shown that bipolar disorder often contributes to the concept of functional impairment. Bowden (2005) provides evidence of this through the utilization of information from various studies. In one study, conducted by the NDMDA, it was emphasized that the amount of people who had occupational difficulties was an embarrassing 88\%. Another study conducted in the United States, highlighted the social stigma that was associated with bipolar disorder. Through the perception of the danger associated with mental disorders, there was a drastic decline in the amount of paid employment by as much as $40 \%$. A third study involved a follow up period of six months, where it showed that although $80 \%$ of the patients were symptom free or mildly symptomatic, only $43 \%$ of them were fully employed. Of that percentage, all of them were hospitalized for a manic episode. Sajatovic(2005), supports this by saying that in another study, it was discovered that approximately $64 \%$ of the patients observed failed to commit to long-term relationships, while $65 \%$ of the respondents had problems with their children. However, she attributes this to either of two facts, a) That most of the patients go untreated and/or b) There is an occurrence of comorbidity. She contends the view that bipolar patients are unable to lead functional lives by implying that the authors of the study had limited knowledge and that as time passed and more information became available, then it became possible for the impairment of these individuals to decrease. Through that view, it can be proposed that this observation is not entirely untrue.

\section{Violent behaviors associated with bipolar disorder}

Another popular misconception is the perception that everyone who has bipolar disorder is extremely violent. This is in fact, not true. Researchers concur that while people with mental disorders may tend to exhibit bursts of violent behavior, it can be attributed to other factors and not the disorder itself. Vann (2010) agrees with this and cites factors such as substance abuse and emotional stress as contributors to violence. She insinuates that substance abuse is more prevalent in people with mental illnesses and this increases the incidence of episodes, which predisposes to the violent act. She also states that dealing with the loss of a loved one can increase emotional stress, acting as the trigger to a violent outburst in bipolar patients. Sajatovic (2005) also implies that bipolar patients are more susceptible to substance abuse by stating that as much as 41 and $46 \%$ had drug and alcohol abuse and dependence respectively. It can also be implied that the more addicted or dependent an individual is to a particular substance, the more violent he or she may become, if he or she is unable to attain that substance. This also detracts the image that mental illnesses, including bipolar disorder, are associated with violent or dangerous behavior.

\section{Suicide and bipolar disorder}

In contrast to the previous view, people with bipolar disorder are more of a danger to themselves. Vann (2010) supports this claim by saying that although bystanders may fear for their lives when interacting with people who have this condition, the real damage is dealt to the person living with the disease. She elaborates this by suggesting that people with bipolar disorder are 9 times more likely to take their own lives than those of their peers. Sajatovic (2005) provides further evidence of this when she implies that according to one study, the suicide rate associated with bipolar disorder cases was significantly higher than any other axis I psychiatric disorders, boasting an odds ratio of 6.2. Using another study, she proposed that suicidal attempts in bipolar patients were as much as $50 \%$, with $35 \%$ of these attempts 
Texila International Journal of Public Health

Volume 4, Issue 4, Dec 2016

resulting in hospitalization. She concluded her point by showing that the total rate of completed suicide was $20 \%$.

\section{Methodology}

\section{Survey of views that the barbadian public has about bipolar disorder}

A survey design was employed in the study. Employees from four different businesses, as well as pedestrians, were asked to speak about their beliefs, regarding disease etiology, functional impairment, behavioral patterns, as well as any treatment that was associated with the disorder. They were also asked if they believed that people with bipolar disorder were indeed crazy. The employees from businesses included managers, administration, janitors and every possible employee that was present, including those that were physically disabled. All views were documented for the purpose of this article, which amassed to a total of 400 persons.

\section{Interviews with nurses and psychiatrists from the psychiatric hospital}

Several interviews were conducted to debunk the myths that were associated with the mental disorder. The questions that were asked included ones on the prevalence of the disease in the country, age of onset of the disease, violent behaviors associated with the disease, gender most affected by the disease, comparison of it with other Caribbean countries as well as the overall care of all mental health patients that lived within the Psychiatric Hospital. All results were documented, either written or graphically for the purpose of this article.

\section{Presentation of results}

\section{Survey results}

Results from the survey served as an indication that the Barbadian public had contrasting views when it came to the issue of bipolar disorder. Approximately $31 \%$ of the respondents were uncertain about the disease, asking if it exists. Of that percentage, one was bold enough to state that he did not have the time to think about that. Another $15 \%$ of the respondents believe that there is a lack of empirical and statistical evidence to authenticate the validity of the prevalence of the disorder. One respondent even suggested that people with this disease are possessed, citing a verse from the Bible as his reference. The verse, Ephesians 6, verse 12, depicts the view that human beings are in a battle that is not of flesh, but they are fighting against cosmic forces who reign over darkness. Therefore, the respondent is implying that these forces are responsible for the changes in the patients' moods and behavioral patterns. Another respondent was very articulate in his response. He said that he believed that it was a period of emotional change and propounded that there was a comprehensive list of people who held esteemed positions that had the disorder. He continued by saying that there was a switch in moods, going from a period of extreme happiness to a state of depression. Approximately $54 \%$ of the respondents had an indication of the existence of the disease. Half of that percentage cited emotional stress as one of the etiological factors, utilizing the stories of family members who had the disease to speak about functional impairment and behavioral patterns. One of these respondents painted a vivid picture where she described her niece as holding a steady job at the bank, where she interacted vivaciously with her coworkers, but when she left the establishment, she was a different person. She stated that her niece believed that people, with the exception of her workmates were enemies. Another one of these respondents said that one of her family members experienced a bad ending to a relationship, which served as the emotional trigger for the onset of the disorder. She proposed that the major misconception that Barbadians possess was the perception that the afflicted individuals are crazy. However, in actuality, once they receive the appropriate treatment, they can lead fully functional lives. Another female respondent suggested that the awareness of the disease needs to be increased in Barbados because the general population views it as a joke and they fail to understand the severity of the disorder. She emphasizes that a social stigma is still 
associated with the disorder and that the people with the illness needs specialized treatment so that they will be able to live normal lives. Another female respondent corroborated this view and felt empathy for the bipolar patients. She said that it takes a lot of emotional strength to endure that condition and she always admires their determination.

\section{Results from the interviews with the mental health professionals}

All of the mental health professionals indicated that bipolar disorder was a mental disorder in which there are manic and depressive episodes that are coordinated, but occur at sporadic rates. They were very tight-lipped on the conditions with which the patients are treated in the Psychiatric Hospital, saying that they received optimal care. The answers to the other questions, such as the prevalence of the disease, age of onset and comparison with other countries are illustrated below.

Table 1: Bipolar disorder relative to other mental and substance use disorders (Barbados)

\begin{tabular}{|l|l|l|}
\hline Cause of Harm & Daily Rate per 100 000 & Change (1990-2013) \\
\hline Depressive Disorders & 1031 & $5 \%$ \\
\hline Anxiety Disorders & 581.5 & $0 \%$ \\
\hline Schizophrenia & 227.7 & $17 \%$ \\
\hline Bipolar Disorder & 173 & $3 \%$ \\
\hline Drug Use Disorders & 158.8 & $12 \%$ \\
\hline $\begin{array}{l}\text { Other Mental and Substance } \\
\text { Use Disorders }\end{array}$ & 143.4 & $12 \%$ \\
\hline
\end{tabular}

Through this table, it is shown that the three most enervating mental health disorders in Barbados during 2013 were depressive disorders, anxiety disorders and schizophrenia respectively. The major change, related to increased prevalence of the disease was schizophrenia, which boasted an increase of $17 \%$ over the last decade. The number of reported cases of bipolar disorder only increased by 3\% during this period and the mental health professionals theorized that due to this miniature increase of cases, an inverse proportion of awareness of the disease was generated during that period. As a result, Barbadians came up with many misconceptions through ignorance. They also proposed that although various demographic groups are affected differently, the statistics might also vary in relation to age.

Table 2: Bipolar Disorder Impact Relative to Other Locations in the Caribbean

\begin{tabular}{|l|l|l|}
\hline Location & Daily Rate per 100,000 & Change (1990- 2013) \\
\hline Cuba & 176.8 & $5 \%$ \\
\hline Trinidad and Tobago & 173.7 & $17 \%$ \\
\hline Barbados & 173 & $3 \%$ \\
\hline The Bahamas & 171.5 & $13 \%$ \\
\hline Antigua and Barbuda & 164.1 & $3 \%$ \\
\hline Saint Lucia & 164 & $20 \%$ \\
\hline $\begin{array}{l}\text { Saint Vincent and the } \\
\text { Grenadines }\end{array}$ & 162.2 & $19 \%$ \\
\hline
\end{tabular}

From this table, it can be seen that Barbados is the country with the third highest number of cases in the Caribbean, although the overall change in cases over the last decade is minimal. This provides further evidence to support the view that bipolar disorder is a serious mental health condition in Barbados, which is contrary to the general consensus of the average Barbadian.

The medical health professionals also stated that the health burden of the disease was at its pinnacle when both sexes reached the ages of 25-29, but argued that women were more susceptible. They said that the average amount of healthy years lost for women during that age range was about 310 per 100,000, while it was about 258.9 per 100,000 in men. They also 
Texila International Journal of Public Health

Volume 4, Issue 4, Dec 2016

said that the disease was least harmful during the ages of 10-14 in both sexes, with the amount of healthy years lost being 30.2 per 100,000 and 24.4 per 100,000 in females and males respectively. In comparison to the global burden of disease, the average amount of healthy years lost in Barbados were 173 per 100,000, while in the world, it was about 130 per 100,000 .

\section{Discussion}

The statistics provided by the mental health professionals presents verification of the disease, debunking the myth that there is a lack of statistical data. However, I believe that this information should be made more accessible to the general public so that they would not be basking in their ignorance and formulating these bizarre misconceptions. This is supported through the response given by one individual to the survey, where he suggested that the afflicted individuals are possessed. With increased availability and accessibility to this information, the average Barbadian could become more cognizant, which would lead to a drastic decline to the social stigma that prevails in the small Caribbean country. People with mental illnesses are shunned and treated as if they are deranged. Subsequently, they tend to be discriminated against or exploited, either through diminished job opportunities or the failure to maintain effective relationships with significant others. One respondent was quoted as saying that he could not deal with those bipolar individuals, because one minute they are good, then in the next minute, they "freak out".

Shamsaei et al (2013) zone in on the severity of the disorder by proposing that even the individuals that receive the optimal mental health care are still susceptible to relapses and therefore have trouble keeping jobs and establishing effective social relationships with others. They estimate that the overall lifetime prevalence of the disorder, falls within the range of 1 and $2 \%$. They also support the view that Sajatovic held, by implying that bipolar disorder was one of the world's most debilitating conditions and that it can affect anyone, irrespective of nationality, race or socio-economic status. They also suggest that family members of the afflicted individuals, as well as the primary caregivers can experience a similar level of social stigma as the bipolar individual, through association. Their research shows that family members experienced feelings of isolation and shame and that they were often criticized by other family members as well as by the mental health practitioners. This situation is also prevalent in Barbados. I have seen several instances where family members are blatantly humiliated by other people due to the fact that they are related to an individual with a mental disorder. Shamsaei et al (2013) are also of the view that bipolar patients are deprived of the ability to acquire satisfactory housing conditions. Evidence of this is also seen in Barbados. I am aware one incident where one particular person was denied the opportunity to rent an apartment because she had a mental history. The landlord told the prospective tenant that he was unable to rent the apartment to her, because she was crazy and that he does not want any 'loony goon' around his premises.

I could also see the hurt of some of the family members of the patients of bipolar disorder who had participated in the survey. The respondent whose niece worked at the bank talked to me in detail after the survey was completed. She expressed her concern that a good proportion of the Barbadian population are ignorant to mental disorders and she wanted to avoid her niece having any unnecessary confrontation with anyone in the workplace. She informed me that to interact with a bipolar individual was difficult, because you had to carefully monitor the mercurial changes in their behavior, and not just classify them as "mood swings." She also said that she was tired of the perception that Barbadians hold that every individual that experience a sudden change in mood was bipolar. She concurred with the view that I had, in which I believe that only through proper research and understanding of the disorder, can the misconceptions of the disease be obliterated. Ghaemi and Dally (2015), believe that the problem stems from the lack of precision in the definition of bipolar spectrum conceptions. They use previous research to attribute this to the fact that prior definitions involve vague and 
over-inclusive language. They stress that emphasis should be placed on mood temperaments, not mood liability, since this is an important part of the bipolar spectrum.

Another female Barbadian respondent also implied that there was a small percentage of the Barbadian population who realized that mental disorders, including bipolar disorder, can be inherited. She concurred with me that a lot was not known about its etiology. Ghaemi and Dally (2015) describe this as the biopsychosocial errors that are associated with borderline personality, and indirectly bipolar disorder. They propose that the etiology of this disorder is almost completely genetic, with an approximation of about $80 \%$ of the heritability based on previous twin studies and that psychosocial factors rarely contribute to disease etiology, since only about $50 \%$ of all personality traits are genetic in bipolar disorder.

The medical professionals also quashed the delusion that bipolar disorder was only detectable at age 18. From the results, it can be seen that the disorder was detected from as early as 10 years old in both sexes, but it was severely heightened at ages 25-29, with the average amount of healthy years lost being 284.4 per 100,000 in 2013. It can also be suggested that the reason why Barbadians do not consider bipolar disorder to be a significant problem was the fact that there are not a lot of reported cases of it in Barbados, so the information would not be as widespread as depressive disorders. If you refer to table 1 , you would notice that the daily rate of depressive disorders in Barbados was 1031 per 100,000 in 2013, in contrast to bipolar disorder, which was a meager 173, indicating that the ratio of daily cases of depressive disorders to bipolar disorders was almost 6:1. Therefore, there was a lot more information about depression than bipolar disorder, so Barbadians do not consider it to be a serious problem, although, as shown in table 2, Barbados has the third highest prevalence rate of the disease in the Caribbean, as measured in 2013.

\section{Conclusion}

Bipolar disorder is simply not an appellation that was created by scientists. It is a chronic, recurrent and remitting mental illness, in which the manifestational criteria for classifying the disease include separate periods of mania and depression. Mania includes excessive behavior and inflated self-esteem as well as the perception held by the individual that they do not require sleep, whereas depressive episodes include changes in sleep patterns, appetite, low self-worth and suicidal thoughts and plans. Without efficient knowledge dissemination, a variety of misconceptions developed within the country of Barbados. This research article serves as the platform, where several of those fallacies were discredited and the factual information came to light. Again I reiterate that the information needs to be properly distributed, so that the levels of ignorance and social stigmas that accompany mental illnesses can be reduced. For a country that boasts of its population's literacy, the number of misconceptions that occurred were appalling. Through the use of descriptive statistics, it was shown that although it is not as serious as other depressive disorders in Barbados, bipolar disorder is still pretty significant. It is a condition that needs to be treated seriously, so that the afflicted persons can receive the appropriate and timely treatment, in order that they can lead successful lives. From the survey, it is shown that they can live productive lives, but certain aspects of their lives, such as social interaction, still need to be addressed.

\section{Acknowledgement}

I would like to thank Ms. Faye Boyce for her help in compiling the data for this article. I would also like to thank the respondents of the survey, as well as the mental health professionals that participated in the interviews. Without them, this article would not be possible. 
Texila International Journal of Public Health

Volume 4, Issue 4, Dec 2016

\section{References}

[1] Almeida, Oswaldo P and Fenner, Stephen. Bipolar Disorder: Similarities and Differences Between Patients With Illness Onset Before and After 65 Years of Age in International Psychogeriatrics, Volume 14, Issue 3, pp. 311-322 (2002).

[2] American Psychiatry Association. Diagnostic and Statistical Manual of Mental Disorders (1952)

[3] Bowden, Charles L. Bipolar Disorder and Work Loss (2005)

[4] Craddock, Nick and Jones, Ian. Genetics of Bipolar Disorder in J Med Genet, Issue 36, pp. 585-594 (1999)

[5] Ghaemi, S Nassir and Dally, Shannon. The Bipolar Spectrum: Conceptions and Misconceptions (2015)

[6] Gitlin, M. Treatment- resistant Bipolar Disorder in Molecular Psychiatry, Issue 11, pp. 227-240 (2006)

[7] Hlastala, Stephanie A, Frank, Ellen, Kowalski, Jeanne, Sherrill, Joel T, Tu, Xin M, Anderson, Barbara and Kupfer, David J. Stressful Life Events, Bipolar Disorder and the "Kindling Model" in Journal of Abnormal Psychology, Volume 109, Issue 4, pp. 777-786 (2000)

[8] Post, Robert M, Leverich, Gabriele S, Kupka, Ralph W, Keck Jr, Paul E, McElroy, Susan L, Altshuler, Lori L, Frye, Mark A, Luckenbaugh, David A, Rowe, Michael, Grunze, Heinz, Suppes, Trisha and Nolen, William A. Early Onset Bipolar Disorder and Treatment Delay are Risk Factors for Poor Outcome in Adulthood in The Journal of Clinical Psychiatry, Volume 71, Issue 7, pp. 864-872 (2010)

[9] Sajatovic, Martha. Bipolar Disorder: Disease Burden in Am J Manag Care, Volume 11, pp. S80S84 (2005)

[10] Shamsaei, Farshid, Kermanshahi, Sima Mohammed Khan, Vanaki, Zohreh and Holtforth, Martin Grosse. Family Care-giving in Bipolar Disorder: Experiences of Stigma in Iran J Psychiatry, Volume 8, Issue 4, pp.188-194 (2013)

[11] Vann, Madeline. Are People with Bipolar Disorder Dangerous? (2010) 


\title{
Knowledge of Auxiliary Healthcare Workers on Injection Safety and Biological Waste Handling in Taraba State, Nigeria
}

\author{
Article by Danung Monday Langche ${ }^{1}$, Jegede Feyisayo ${ }^{2}$, Usman Abdulrasheed ${ }^{3}$ \\ ${ }^{1}$ Ph.D. in Public Health, Texila American University, Nigeria, ${ }^{2,3}$ Federal Medical \\ Center Jalingo, Taraba State \\ E-mail: 1danungml@gmail.com, ${ }^{2}$ feyitab@yahoo.com, ${ }^{3}$ usmanurasheed@gmail.com
}

\begin{abstract}
Background: Individuals working in healthcare settings occasionally are at risk of infections as a result of exposure to certain diseases causing agents. However, in most developing countries attention on prevention is mainly focused on skilled healthcare workers (HCWs) with "neglect" of auxiliary health workers (AHWs) who may not be knowledgeable on job health hazard and carries high risk of exposure to infectious agents.

Objective: To assess knowledge of auxiliary healthcare workers on injection safety and biological waste handling as well as attitude towards post exposure prophylaxis in the event of any exposure.

Methods: A descriptive cross-sectional study conducted among AHWs on knowledge on injection safety and biological waste handling in June 2016. Participants included ward orderlies (WOs), lab attendants (LAs), compound laborers (CLs), theater attendants (TAs) and laundry personnel (LPs) randomly selected. A semi structured questionnaire administered to consented respondents. Data was presented as descriptive analysis and percentage compared using Chi-square test with significant level 0.05 at 95\% Confidence interval.

Results: A total of 68 auxiliary healthcare workers consisting of male $44.1 \%(n=30)$ and female $55.9 \%(n=38)$ were interviewed. Respondent's mean $\pm(S D)$ age was $31 \pm 5.30$ years and ranged from 27- 55 years. Knowledge on injection safety and biological waste handling among AHWs showed (WOs) 42/68 (61.7\%), (LAs) 5/68 (7.4\%), (CLs) 9/68 (13.2\%), (TAs) 5/68 (7.4\%) and (LWs) 7/68 (10.3\%). A significant difference in knowledge on injection safety and biological waste handling among AHWs was observed. $\left(X^{2}=1.56, d f 4\right.$, critical value 9.488 at $95 \%$ confidence level.

Conclusion: There is low level of knowledge on needle stick injury (NSI), biological waste handling and poor attitude towards PEP among auxiliary healthcare workers in GH Wukari and GH Zing.
\end{abstract}

Keywords: Knowledge, Auxiliary, Biological, Injection, Waste, Safety

\section{Background and introduction}

It is no longer news that individuals working in healthcare settings occasionally falls victim of certain illness as a result of exposure to certain disease causing agents in the cause of their work. As defined by the World Health Organization (WHO - 2015), "occupational health deals with all aspects of health and safety in the workplace and has a strong focus on primary prevention of hazards ${ }^{1}$. In terms of healthcare providers, disorders could occur as a result of work-related exposure to biological, chemical and physical disease causing agents. Exposure could lead to a point where usual physiological mechanisms are affected and with resultant impairment of the personnel's health ${ }^{1}$.

Low cadre Hospital personnel include but not limited to ward orderlies, Laboratory attendants, waste handlers (compound laborers) and laundry workers. These categories of staffs have potentials of being exposed to biological waste via needle-stick injuries with attendant consequences. Well planned hazard control mechanisms and interventions process put in place against generation and release of agents that could be harmful or injurious to 
personnel can prevent fatal outcome. This can protect this cadre of healthcare providers and reduce possible pollution of the environs were such facilities are located. In a study by Susan Q. Wilburn \& Gerry Eijkemans, 2013 - a WHO-ICN Collaboration on Preventing Needle stick Injuries among Healthcare Workers; it was documented that $28 \%$ of injuries often occurred during contact with medical waste bags ${ }^{2}$.

The 2006 World Health Report: "Working Together for Health on human resources" reported on a global shortage of health personnel which had reached crisis level in 57 countries, and called for the support and protection of the health workforce ${ }^{3}$. Importantly, health facilities should have implementable documents on prevention policies in place aimed at addressing immunizations for vaccine-preventable diseases such as HBV, isolation precautions to prevent exposures to infectious agents, management of health care personnel exposure to infected persons such as restrictions for exposed or infected health care personnel and provision of post-exposure prophylaxis. Such document should be read and endorsed by each member of staff or be read and interpreted in a language that personnel that cannot read and write understand. On the basis of documented nosocomial infection, Healthcare Providers are considered to be at substantial risk for acquiring or transmitting hepatitis B, influenza, Ebola, Lassa, HIV among other blood-borne pathogens ${ }^{4}$. Strategies aimed at the prevention and control of work related hazards occurring as a result of exposure could be referred to as occupational hygiene. Occupational hygiene has three main objectives - Ensuring safety and advancement of employee's health; environmental protection and contribution towards a safe and sustainable development. Occupational hygiene plays a key role as one of the best approaches towards protection of healthcare providers from occupational exposure. This is so because even though exposed individual can have the best diagnosis, treatment and cure for an occupational disease, that does not prevent further occurrences unless exposure to the etiological agent is halted. To achieve this, capacity building of personnel especially those in the low cadre on personal hygiene and healthcare waste management is very vital. In a study on epidemiology and management of occupational exposure to blood borne viral infections in resource poor settings: The case for availability of post exposure prophylaxis; $O$. Erhabor et al, 2007 demonstrated a prevalence of 53.9\% among house officers, $23.1 \%$ among resident doctors and $23.1 \%$ among Laboratory Scientists exposure to needle stick injury ${ }^{5}$. In another finding; Amira CO and Awobusuyi JO (2014) in a study on needle-stick injury (NSI) among health care workers in hemodialysis units in Nigeria: A multi-center study reported a prevalence of $24.5 \%$ within the last 12 months and $40.2 \%$ in their entire service career among participants. The report also had it that improper disposal of needles accounted for $30 \%$ of exposure $^{5}$. Interestingly, the forgoing also reported that only $37 \%$ of respondents reported their exposure to their unit head or designated officer in order to get medical advice ${ }^{6}$. This findings show that NSI is common among healthcare providers. Also, the level of understanding among healthcare providers on proper steps to take when exposure occurs seems limited. Importantly, the study population in above were mostly educated individuals (Doctors (37.3\%), Nurses 41.2\%), Technicians (13.7) while auxiliary staff constituted only $(7.8 \%)^{6}$. Needless to say that individuals working in hospital set ups in emerging countries of the world of which my country Nigeria is one, are predominantly at greater risk of infections from blood-borne pathogens due to high prevalence of such etiological agents coupled with limited basic personal protective equipment in such settings and also awareness on proper reporting and care for exposed persons. Soad A. Habiba et al (2012), in a research titled: Knowledge, attitude and behavior of health care workers regarding hepatitis B infection in primary health care, Kuwait, concluded that "Health care workers in primary health care showed high to partial levels of knowledge and attitudes, regarding hepatitis B virus infection and vaccination with important gaps which need to be strengthened especially among nonvaccinated group" ${ }^{7}$. From the foregoing, participants in the study are mostly educated persons ranging from Doctors, Nurses, Laboratory Scientist and technicians. Since such a findings could occur in this group of persons, one could just but imagine what would happen to the group under study - auxiliary healthcare workers. These are mostly lay workers with very 
minimal training if any on how to handle biological waste some of which carries improperly disposed sharps. In most hospital settings GH Wukari and GH Zing inclusive, hospital waste are easily spotted just at the back of the hospital premises. Young boys are at times also easily seen scavenging inside these waste to look for any salable recycle material. Unfortunately, inside those waste one can also see used syringes and needles and all manner of biological waste. In a study on Prevalence and Determinants of Occupational Exposures to Blood and Body Fluids among Health Workers in two Tertiary Hospitals in Nigeria, DimieOgoina et al., (2014) reported a prevalence of 85\% exposure among studied health workers reporting one or more type of exposures in the previous year ${ }^{8}$. Nigeria being one of the most populated developing nation in the world is said to be endemic for certain blood-borne infectious agents mainly hepatitis B virus (HBV), hepatitis C virus (HCV) and $\mathrm{HIV}^{8}$. Additionally, cases of Lassa fever have been reported in some states in Nigeria in January 2016 which includes Bauchi, Kano, Nassarawa, Niger, Rivers, Edo, Lagos, and Taraba ${ }^{9}$. Although there are a few research work within Nigeria that reports high prevalence of occupational exposures to blood and body fluids among health workers (Medubi et al 2006, Erhabor et al 2007; Isara et al 2012; Ansa et al, 2002); there remains dearth of information from research studies in the country that describe occurrence, prevalence and causes of these exposures among various cadres of health workers ${ }^{8}$.

The Centers for Disease Control and Prevention National Institute for Occupational Safety and Health (NIOSH) Alert on Preventing Needle stick Injuries in Health Care Settings recommends that health care setting should analyze needle stick and other sharps-related injuries in workplace to identify hazards and injury trends ${ }^{11}$. Findings from such analysis would provide idea early enough to re-assess or put in place preventive mechanisms.

It is recommended that Hospitals provide targeted interventions to increase awareness of the risks of needle stick injuries and reduce such injuries, A. Ruhi Toraman et al, $2011^{12}$

Undoubtedly, risk level of each exposed health care worker differs according to his/her profession, occupation and unit of work ${ }^{13 .}$ It is on records that health care providers such as nurses, physicians, dentists, orderlies and janitors carry the highest risk of being exposed to blood-borne pathogens ${ }^{13}$.

Although the Taraba State strategic health development plan $(2010 \text { - 2015 })^{14}$ reported that research for health in Taraba is almost non-existent; available documented findings indicate that in Taraba state, at a time HIV/AIDS prevalence rate is slowing down to a manageable level in other states of the federation, the rate is on the rise with a prevalence rate of $10.5 \%$ since 2012 in adults $15-49$ years ${ }^{15}$, the state ranks top in the north east and second highest in the country ${ }^{15}$. This high prevalence of HIV placed the State second to only River State with a prevalence of $15.2 \%{ }^{15}$. This rate is far higher than the National prevalence in same age group $3.5 \%{ }^{15}$. With this high prevalence, the likely risk of contaminated sharps used on patients in health facilities could be said to be high too, thereby posing a great danger to lay workers who may get pricked accidentally. Also, the prevalence of HBV is high in Taraba State (26.37\%) ${ }^{16}$. Again this is higher than the national prevalence of HBV $(13.6 \%)^{18}$. These documented evidences are genuine pointer to the high risk of infection from blood borne pathogens from accidental needle stick injuries and therefore calls for concern to health care workers. The prevalence of HCV in Taraba is $13 \%{ }^{16}$. The prevalence of HCV in Nigeria indicates variation from one region of the country to the other ${ }^{19}$

HCV prevalence range from $4.7-5 \%$ in Ilorin, to $5.3-6.6 \%$ in Enugu, to $11 \%$ in Ibadan, $13 \%$ in Taraba and $20 \%$ in Benin ${ }^{16,18}$. This also presence risk of likely infection be health care workers as a result of needle stick injuries with possibility of developing debilitating or fatal liver disease at some point in their lives and transmitting the infection to others unknowingly. From the 2006 national population census, Taraba has a population of 2,300,736 $1.643^{19}$. With high prevalence of HIV, HBV and HVC as enumerated above, the likely hood of danger from needle stick injuries to healthcare workers cannot be overemphasized. According to the Taraba State strategic health development plan (2010 2015), there is a dearth of quality health care workers in the state with a skewed distribution 
Texila International Journal of Public Health

Volume 4, Issue 4, Dec 2016

in favor of the urban dwellers ${ }^{14}$. This further compounds the problem since the mostly learned personnel ordinarily would likely migrate to the state capital leaving the less educated in facilities far away from the state capital, one could but say that lay workers in these two facilities stand the chance of getting exposed easily if not properly educated. World Health Organization (WHO) reported HBV to be a major cause of liver disease morbidity and mortality worldwide, accounting for over 360 million cases of chronic hepatitis and 620,000 deaths per a year ${ }^{20}$

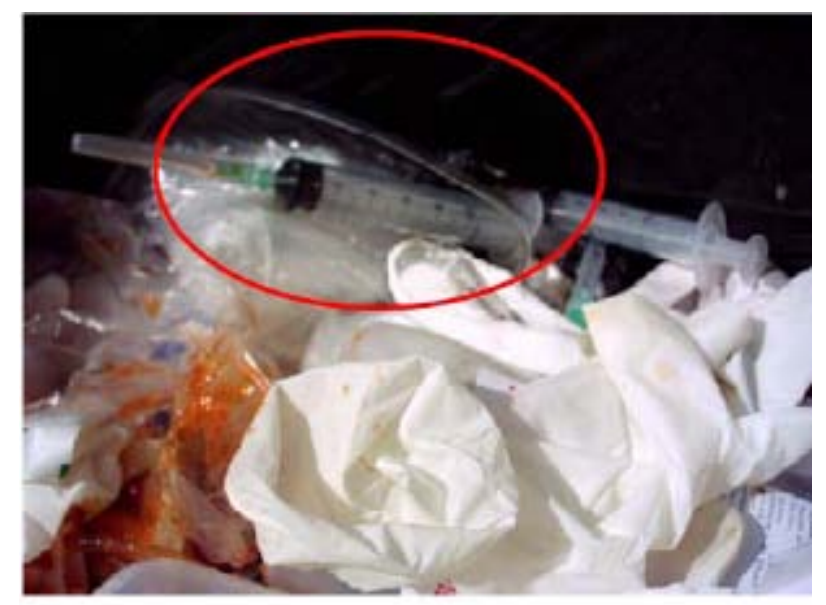

Figure 1. Hospital Biological Waste. No Segregation

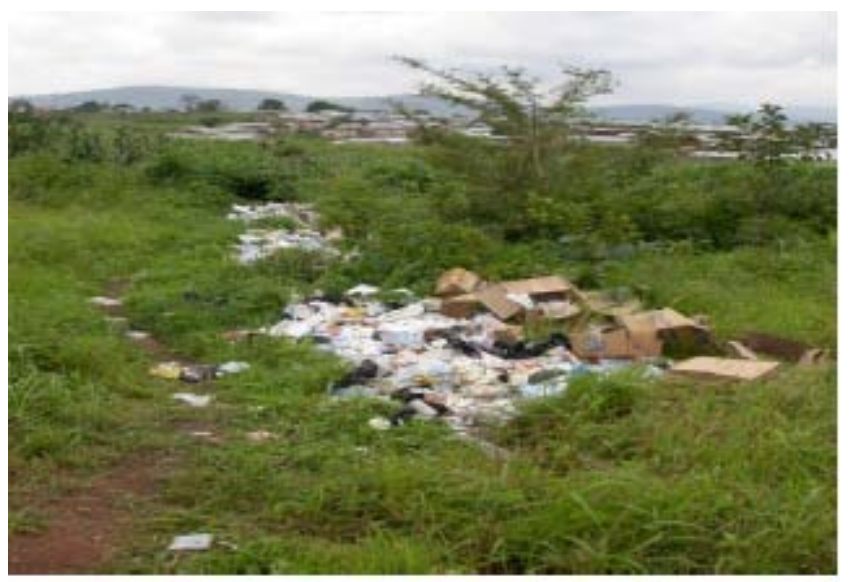

Figure 2. Hospital Waste. Improperly disposed

\section{Statement of the problem}

Although a number of safety measures and procedures have been instituted to halt the likelyhood of occupational health hazard on the safety and increased mortality/morbidity of healthcare providers, nevertheless; it has been documented that more and more healthcare workers suffer occupational hazards from needle stick injury due to exposure from occupational risk in health care setting ${ }^{10}$. Unfortunately, low cadre personnel including cleaners, ward orderly and laboratory attendants who handle hospital waste have minimal formal training on how to handle healthcare waste. Therefore, assessment of knowledge on injection safety and waste handling in this vulnerable group of individuals will provide firsthand information(s) aimed at instituting appropriate training and preventive measures in place.

\section{General objective}

This study aimed at assessing the level of knowledge of auxiliary healthcare providers on injection safety and biological waste handling in General Hospital (GH) Wukari and GH 
Zing, located in southern and northern senatorial districts of Taraba State, North Eastern Nigeria respectively.

\section{Specific objectives}

Description of respondents' socio-demographic status, assessment of frequencies of needle-stick injury among this group of healthcare workers, assess level of awareness on blood borne pathogens such as HBV, HCV, Lassa, HIV determine the awareness and attitude on management of post exposure and assess respondents on immunizations for vaccinepreventable diseases.

\section{Materials and method}

\section{Study sites}

General Hospital Wukari is located in the Southern senatorial district of Taraba state with a distance of about $209 \mathrm{~km}$ away from the state capital Jalingo. GH Wukari, a 250 bed space facility is a secondary health facility established on April, $30^{\text {th }} 1962$. The hospital serves residence from both Benue and Taraba states being located at the border of these two states. The settlement could be said to be the headquarters of the Jukun speaking tribe in Taraba State since that is where the palace of the paramount Jukun chief and chairman Taraba traditional Council, The Akuka is located. Other tribes benefiting from the hospital include the Tivs, Fulanis', and some other minority tribes. Similarly, General Hospital Zing is also a secondary health facility with 100 bed space. The hospital is located in Zing LGA, Northern senatorial district of Taraba state. The distance is about $70 \mathrm{~km}$ away from Jalingo the state capital. Established in 1988, and serves people from Zing and other surrounding LGAs such as Yoro and Mayo Belwa in Adamawa State. The main language spoken is Mumuye. Zing also housed the palace of the paramount ruler of the Mumuye Chiefdom - the Kpanti Zing. Other tribes benefiting from this health facility include the Yandang and Fulanis'.

A descriptive cross-sectional survey conducted among auxiliary health workers comprising of ward orderlies, lab attendants, compound laborers, theater attendants and laundry personnel in the Month of June, 2016. Although these cadres may not be directly involve with patient care as the Doctors, Nurses, Laboratory Scientist and the Pharmacist, they come in contact with hospital generated wastes such as sharps and or soiled patient beddings in their routine work.

\section{Justifications for site selection}

General Hospital Wukari and General Hospital Zing are located at two different axis of Taraba State. Low cadre staff are not privilege to be transferred from one health facility to the other as their counterpart (example Doctors, Nurses, Laboratory Scientists and Pharmacists). Experience on how things are done from one facility to the other would therefore be absent among these groups. With this selection, a fair representation from lay healthcare personnel with relatively different sociocultural background was gotten.

\section{Data collection}

A semi structured interviewer/self-administered questionnaire was used for respondents that could read and write while the research assistant translate and explained the questions in language that respondent understands best for those that could not read and write. The questionnaire was developed using the Monkey Survey to generate the questions and a hard copy printed. Questions were based on CDC Advisory Committee (HICPAC) recommendations and guidelines for Healthcare Infection Control Practices and Environmental Infection Control in Health-Care Facilities ${ }^{21}$, customized to suit the purpose of this study. Demographic data such age, sex, cadre and work station were taken from each respondent. The purpose of the study was explained to each of the respondents and obtained their consent before completion of the questionnaire. The idea of developing my questionnaire in line with this guideline is to be able to obtain the relevant data from 
Texila International Journal of Public Health

Volume 4, Issue 4, Dec 2016

participants that would present a true reflection of the practice on ground by lay health care providers in these two facilities. Questionnaires were filled unanimously by respondents and returned at close of work day. Prior to commencement of the study, the questionnaire were field tested by administering to 15 auxiliary staff of First Referral Hospital MutumBiyu and minor corrections effected.

The study population was made up of a total of 68 persons comprising ward orderlies 42 (GH Wukari 25, GH Zing 17); lab attendants 5 (GH Wukari 3, GH Zing 2); compound laborers 9 (GH Wukari 5, GH Zing 4); theater attendants 5 (GH Wukari 3, GH Zing 2); and laundry personnel 7 (GH Wukari 4, GH Zing 3). Participants were identified with the use of random number. Ethical clearance was sought for and obtained from the Ethics Committee of the two General Hospitals where this work was carried out. Additionally, consent of each of the respondents concern was sought for and obtained before administering the questionnaire. Participants were given option not to answer any question they wish not to.

\section{Limitations}

Our in ability to cover all auxiliary healthcare workers in the two health facilities was a limitation to the study.

\section{Data analysis}

Data generated from the questionnaire were entered into spread sheet (Microsoft Excel software) and later moved to STATA version 13, a statistical software developed by StataCorp LP for analysis. Measures of central tendency (Means, medians, mode), standard deviations, and proportion were determined as applicable. Differences between groups were compared using Chi-square $\left(\chi^{2}\right)$ test. Correlation between percent knowledge and practice score was ascertained by Spearman correlation. Level of statistical significance was set at 95\% $(\mathrm{P} \leq 0.05)$.

\section{Results}

Out of 75 questionnaires sent out, 69 representing 92.0\% response rate were received one of which was removed due to improper filling leaving us with 68 (90.7\%) properly filled questionnaires to work with.

Table 1. Respondents Demographic and service delivery point (n=68)

\begin{tabular}{llllll} 
SDPs & GH Wukari & & GH Zing & \multicolumn{2}{c}{$\begin{array}{l}\text { Total } \\
\text { (\%) }\end{array}$} \\
\hline & Male (\%) & $\begin{array}{l}\text { Female } \\
\text { (\%) }\end{array}$ & Male (\%) & $\begin{array}{l}\text { Female } \\
\text { (\%) }\end{array}$ \\
\cline { 2 - 6 } Ward orderlies & 8 & 21 & 4 & 9 & $42(61.7)$ \\
Lab attendants & 2 & 1 & 0 & 2 & $5(7.4)$ \\
Com. Laborers & 4 & 1 & 3 & 1 & $9(13.2)$ \\
Theater Attendants & 2 & 1 & 2 & 0 & $5(7.4)$ \\
Laundry cleaners & 3 & 1 & 2 & 1 & $7(10.3)$ \\
\hline & $19(27.9)$ & $25(36.7)$ & $11(16.2)$ & $13(19.1)$ & $68(100)$ \\
\cline { 2 - 7 }
\end{tabular}

From the various service delivery points (SDPs) that responded in this survey, ward orderlies constituted the highest percentage (61.7\%), followed by compound laborers (13.2\%). Laundry sections came third with (10.3\%) while laboratory and theater attendants ties the fourth position with $7.4 \%$ each. Out of the total respondents in this survey, 40 representing 58.8 percent were from GH Wukari. While GH Zing constituted 28 representing 41.2 percent. Female folks from GH Wukari were 22(55.5\%) as against their male counterpart 18(45.0\%) out of participants from GH Wukari, while females from GH Zing were 16(57.1\%) as against their male counterpart 12(42.9\%) out of respondents from GH Zing. 
Table 2. Knowledge about blood borne pathogens ( $n=37)$

\begin{tabular}{llllll} 
SDPs & GH Wukari & GH Zing & \multicolumn{1}{l}{$\begin{array}{l}\text { Total } \\
\text { (\%) }\end{array}$} \\
\hline Ward orderlies & Male & Female & Male & Female & \\
Lab attendants & 2 & 11 & 2 & 7 & $23(62.1)$ \\
Com. Laborers & 1 & 1 & 0 & 2 & $5(100.0)$ \\
Theater Attendants & 2 & 0 & 1 & 0 & $2(5.4)$ \\
Laundry cleaners & 1 & 1 & 2 & 0 & $5(100.0)$ \\
\hline Total (\%) & $9(24.3)$ & $13(35.1)$ & $6(16.2)$ & $9(24.3)$ & $37(100)$ \\
\hline
\end{tabular}

From Table 2 above, only slightly over half of the respondents 37 (54.4\%) reported being knowledgeable about blood borne pathogens (HBV and HCV). All respondents from the laboratories and the theater in both facilities reported being aware of HBV, and HCV in addition to HIV which all participants reported to be aware of respectively. Respondents with least knowledge of HBV and HCV were from the compound laborers and the laundry workers (5.4\%) respectively.

Table 3. Have had Needle stick injury in last six months $(\mathrm{n}=32)$

\begin{tabular}{llllll} 
& GH Wukari & \multicolumn{3}{c}{ GH Zing } & \\
\cline { 2 - 5 } & Male & Female & Male & Female & Total (\%) \\
\hline Ward orderlies & 5 & 9 & 2 & 4 & $20(62.5)$ \\
Lab attendants & 1 & 1 & 0 & 2 & $4(12.5)$ \\
Com. Laborers & 2 & 1 & 3 & 0 & $3(9.4)$ \\
Theater Attendants & 1 & 1 & 1 & 0 & $3(9.4)$ \\
Laundry cleaners & 1 & 0 & 1 & 0 & $2(6.3)$ \\
\hline & 10 & 12 & 7 & 6 & $32(100)$ \\
\hline
\end{tabular}

Of the 68 AHCWs who took part in this study, a high proportion 32/68 (47.0\%) reported to have had needle stick injury within the last six months (table 3). Exposure to needle stick injury cuts across all service delivery points.

Level of HBV, HCV Knowledge Vs Route of transmission

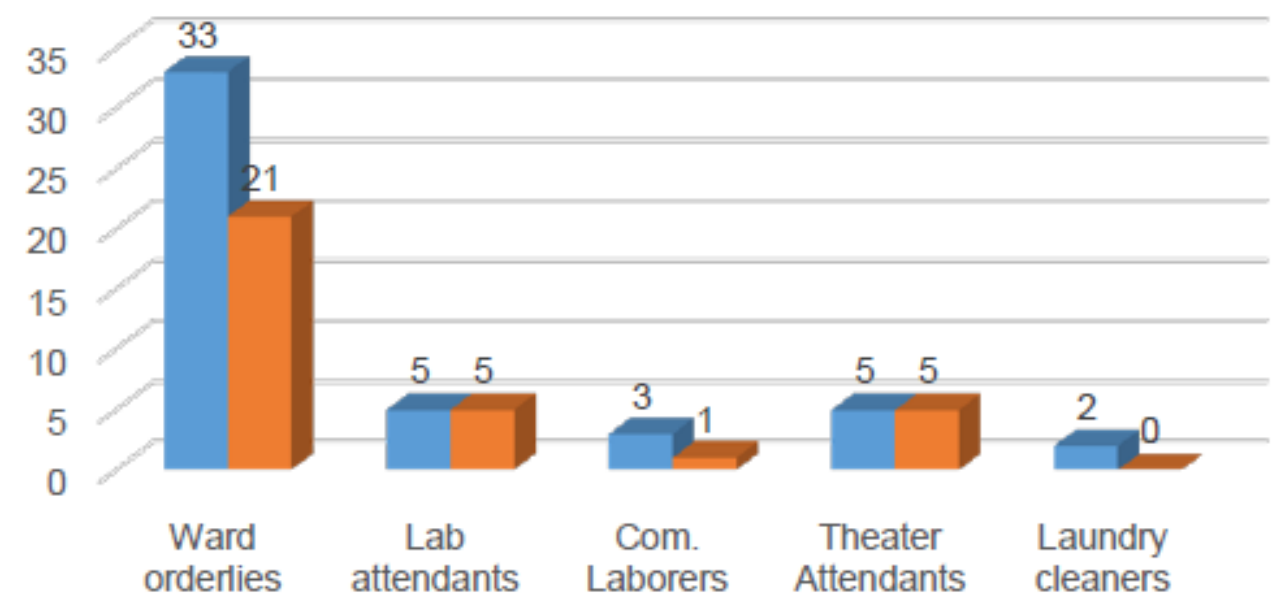

anowledge of HBV $\quad$ Route of Transmission of HBV

Chart 1. Level of HBV Knowledge Vs Route of transmission 
Texila International Journal of Public Health

Volume 4, Issue 4, Dec 2016

On average, the general level of knowledge of the respondents in various service delivery points to HBV and HCV seems very high (chart 1). However; although a high number of ward orderlies (33/42, 78.6\%) are aware of the HBV and HCV, only a half (21/42, 50\%) are aware of the route of transmission. Similarly, only $1 / 3$ of compound laborers who claimed to be aware recorded knowledge of route of transmission while none of the 2 laundry workers who reported awareness of HBV/HCV knows the route of transmission.

\section{Exposed AHCWs Vs Those who accessed PEP}

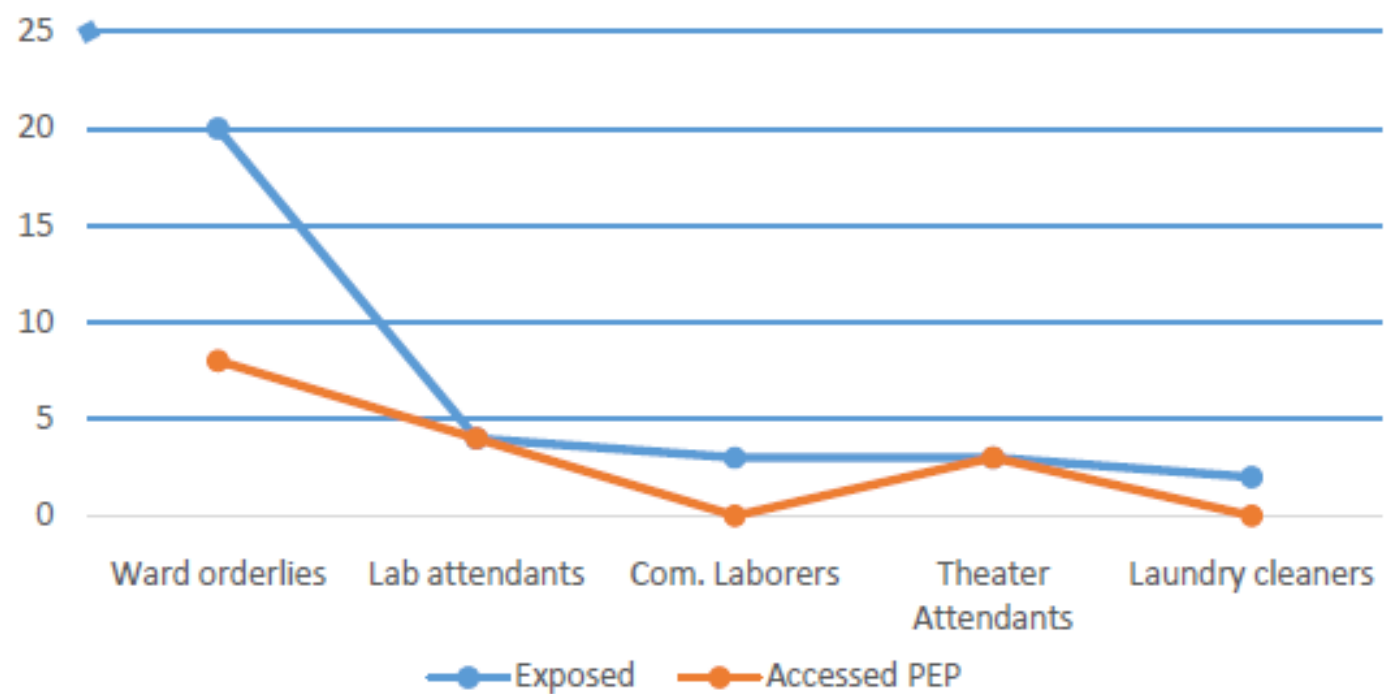

Chart 2: Exposed AHCWs Vs those who accessed PEP

In assessing the level of needle-prick injury accident management (NPIAM) and post exposure prophylaxis (PEP) among respondents (Chart 2), only Theater and Lab attendants seems to be more knowledgeable about PEP as all exposed persons $(5 / 5,5 / 5)$ in that order accessed PEP. Less than half of Ward orderlies 8/20 (40\%) of those who had needle stick injury in the last six months accessed PEP while none of the exposed persons among the compound cleaners and laundry workers accessed PEP.

\section{Usage of gloves and rain boots (PPE)}

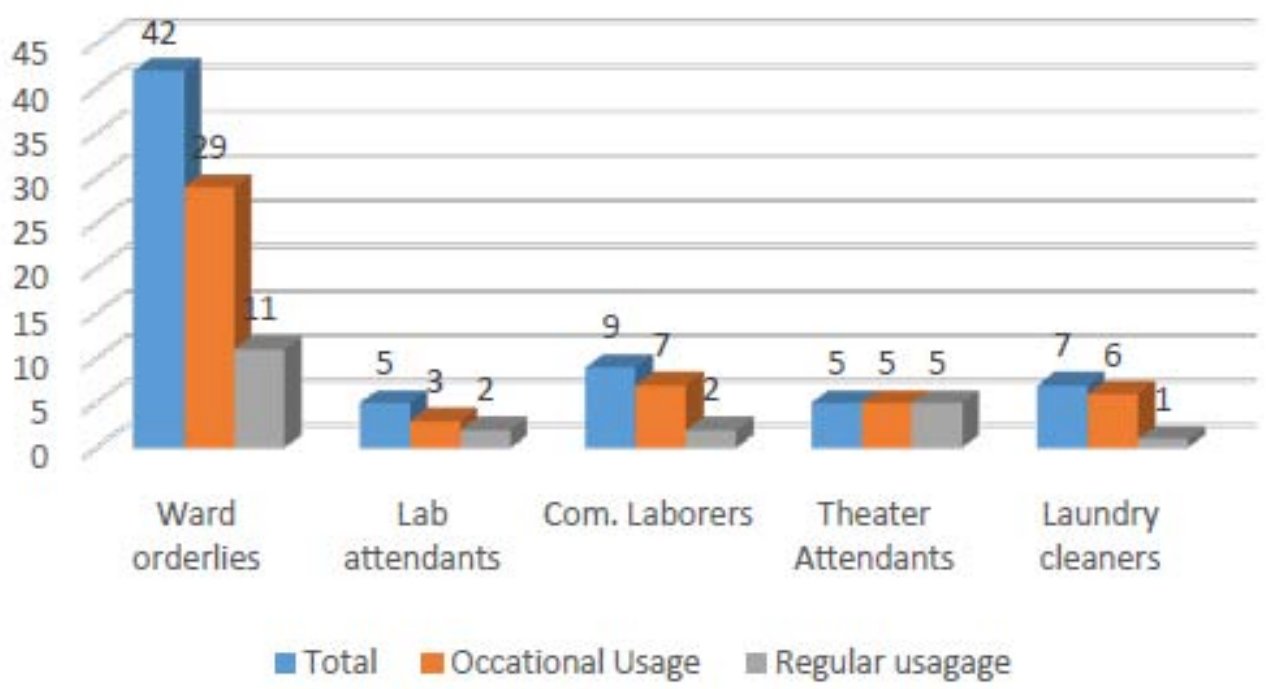

Chart 3. Usage of personal protective equipment (PPE) 
Chart 3 represents participant's usage of PPE. Only theater attendants had total compliance to regular usage of PPE. Out of 42 Ward orderlies who responded, 29 (60.1\%) and $11 / 42(26.2 \%)$ used hand gloves occasionally and regularly respectively, while Laboratory attendants reported $3 / 5(60 \%)$ and $2 / 5(40 \%)$ occasional and regular usage in that order. Compound laborers reported 7/9 (77.8\%) and 22.2\%) occasional and regular usage. Similarly, Laundry workers reported 6/7 (85.7\%) and 1/7 (14.3\%) occasional and regular usage respectively.

\section{Discussion}

Consequent to the potential impact of occupational health hazard on safety, increased mortality and morbidity of health care providers, various precautionary safety measures have been instituted, however healthcare workers are continually exposed to occupational risk factors in health care settings from blood borne pathogens. Biosafety procedures are critical as long as health care delivery is concerned and the service delivery of health workforce is certainly mandatory. Protective strategies aimed at prevention of occupational hazards in the lay workers and adherence to safety strategies is sacrosanct to ensure a safe and healthy worker force in the health industry.

Findings from this study reveals that all the participants seems to be aware of HIV. This is likely so because in both facilities, comprehensive HIV program has been on since 2007. Awareness about HIV is very high in the two facilities under study. However; knowledge of other blood borne disease causing agent including HBV and HCV seems to be low. Only about a half of the participants 37/68 (54.4\%) exhibited good knowledge of other blood borne pathogens (HBV and $\mathrm{HCV}$ ). This findings corroborated the report on Injection safety assessment in Nigeria, 2004 conducted by John Snow Incorporated through funding from USAID which concluded that level of knowledge of health care providers about injection safety was limited ${ }^{23 .}$ Occupational exposure to sharp objects could lead to transmission of infections among healthcare providers. This usually occurs as a result of deficiency in the knowledge of healthcare providers about guidelines on hospital infection control procedures. Interaction with these lay healthcare workers who takes care of the hospital waste revealed knowledge gap on waste segregation and even disposal. This knowledge gap was clearly seen on visitation to some of the dump sites as shown in the portrait. Due to lack of incinerator in the two facilities, wastes are disposed untreated in landfills while burning of wastes in the open within the hospital premises was common in the two hospitals.

Instituting educational activities to healthcare providers, ancillary personnel inclusive aimed at educating them on infection control measures will curb this. However, the gap on knowledge and practice of infection control among healthcare givers has to be established. Of all the 68 AHCWs that took part in this study, 32/68 (47.1\%) reported to have had needled stick injury in the past six months. This might not be unconnected with frequent usage of needle in Nigerian health institutions with improper disposal method in place. This finding agrees with findings on Injection safety assessment in Nigeria, 2004 conducted by John Snow Incorporated through funding from USAID in which it was reported that "a very high burden of injection was found prevailing in Nigeria” ${ }^{\text {,2 }}$. There is no proper disposal of sharp wastes in most health institutions in Nigeria. This can be easily seen behind hospital buildings where they are either dumped in a pit or discarded in openings where young boys could be seen scavenging for re-useable items. Such was the finding in the two facilities under study. Worthy of note is the issue of post exposure prophylaxis. In all, only 15/32 representing $46.9 \%$ of the respondents (about one half) of the individuals who reported to have had needle stick injury in the last six months reported to have accessed post exposure prophylaxis (PEP). This study suggests that personal safety measures by auxiliary healthcare workers in GH Wukari and GH Zing was being handled with laxity due to dearth of knowledge on the consequences of such exposure. This findings corroborate the findings of Oguamanam et al 2014 who reported an alarming finding that despite the fact that about two thirds of respondents knew of post exposure prophylaxis, only a quarter of those who had needle prick 
injury accessed needle prick injury and management of post exposure prophylaxis and concluded that "the level of knowledge was high but poor in Post-Exposure Prophylaxis and Needle-prick injury accident management (NPIAM) protocol and register for post-exposure prophylaxis" ${ }^{23}$. With the exception of theater attendants, the attitude of respondents on usage of personal protective equipment showed a negative perspective. Very low percentages of the AHCWs reported regular usage of hand gloves despite their continuous exposure to biological waste in the course of their work $(26.2 \%, 40 \%, 22.2 \%$ and $14.3 \%)$ of WOs, Las, CL and LW respectively. Rain boots and utility gloves are supposed to be used regularly by the Compound laborers due to their exposure to sharps and other biological waste but was not the case. This may not be unconnected with the level of awareness in this category of health care providers.

Essential medical equipment and commodities for infection prevention and control (IPAC) are supposed to be made available for efficient service delivery by healthcare workers. Personal protective equipment including biosafety gloves, face mask, lab coats, boots and proper waste containers such as sharp boxes, color-coded bins and bin linings are rarely provided or not at all. In situations where such items are provided, HCWs are not willing to use them. Waste not being segregated was readily observed in the two facilities. Neither of the two facilities had incinerator hence waste are dumped outside behind the hospital.

\section{Conclusion}

We conclude that there is low level of knowledge on needle stick injury (NSI), biological waste handling and poor knowledge/attitude towards PEP among auxiliary healthcare providers in GH Wukariand GH Zing.

\section{Recommendations}

The following recommendations are hereby made to ensure health and safety of auxiliary healthcare workers at GH Wukari and GH Zing at their service deliver points:

1. There is need for capacity building and regular knowledge update of low cadre personnel on injection safety and biological hospital waste management. During Continuous Medical Education (CME), sessions could be made for presentations in languages that are easily understood by the lay personnel. This will enshrine good injection safety and hospital waste management among AHCWs.

2. The Hospital management could make provision for and awareness creation on HBV vaccine and make it mandatory for healthcare providers

3. Lay personnel should be educated on detail contacts and steps to be taken for Post Exposure Management.

4. The hospital management should make available commodities such as utility hand gloves, rain boots etc. for cleaners to avoid exposure to biological wastes.

5. Similar research could be carried out in other healthcare facilities of the state to present a wider findings in this important cadre of personnel in Taraba health facilities

\section{References}

[1]. Amira CO, Awobusuyi JO (2014). Needle-stick injury among health care workers in hemodialysis units in Nigeria: a multi-center study. Int J Occup Environ Med 2014; 5:1-8.

[2]. Centers for Disease Control and Prevention: Exposure to Blood: What Healthcare Personnel Need to Know. 2003, Available: http://www.cdc.gov/HAI/pdfs/bbp/Exp_to_Blood.pdf. Accessed June 2016 www.cdc.gov/niosh Accessed $17^{\text {th }}$ July, 2016

[3]. CDC MMWR / November 25, 2011 / Vol. 60 / No. 7

[4]. Dimie Ogoina, Kemebradikumo Pondei, Babatunde Adetunji, George Chima, Christian Isichei, and Sanusi Gidado (2014). Prevalence and Determinants of Occupational Exposures to Blood and Body Fluids Among Health Workers in Two Tertiary Hospitals in Nigeria Afr J Infect Dis. 8(2): 5054. 
[5]. Ejiofor O S, Emechebe G O, Igwe W C, Ifeadike C O, Ubajaka C F. Hepatitis C virus infection in Nigerians. Niger Med J 2010;51:173-6

[6]. https://en.wikipedia.org/wiki/Occupational_safety_and_health Accessed $13^{\text {th }}$ June, 2016

[7]. http://www.tandfonline.com/doi/abs/10.1179/oeh.2004.10.4.451 Accessed $13^{\text {th }}$ June, 2016

[8]. http://www.who.int/occupational_health/topics/hcworkers/en/. Accessed $14^{\text {th }}$ June, 2016

[9]. http://deolaonline.com/factsheets-on-lassa-fever/. Accessed $14^{\text {th }}$ June, 2016

[10]. https://naca.gov.ng/article/hivaids-prevalence-rate Accessed $18^{\text {th }}$ July, 2016

[11]. http://en.wikipedia.org/wiki/List_of_Nigerian_states_by_population Accessed $13^{\text {th }}$ July, 2016

[12]. http://www.cdc.gov/mmwr/preview/mmwrhtml/rr5210a1.htm. Accessed $14^{\text {th }} \mathrm{July}, 2016$

[13]. http://www.who.int/immunization/topics/hepatitis/en/ Accessed 14 $4^{\text {th }}$ July, 2016

[14]. http://nigeria.usembassy.gov/uploads/images/McLyWtfPi8-

VIVCnFmfaLQ/Injection_Safety_Assessment_in_Nigeria.pdf Accessed $15^{\text {th }}$ July, 2016

[15]. Karwowski W, Jang RL, Rodrick D, Peter MQ, Cronin SN. Self-evaluation of biomechanical task demands, work environment and perceived risk of injury by nurses: a field study. Occup Ergon. 2005;5:13-27.

[16]. Musa B, Bussell S, Borodo M M, Samaila A A, Femi O L. Prevalence of hepatitis B virus infection in Nigeria, 2000-2013: A systematic review and meta-analysis. Niger J ClinPract 2015;18:163-72

[17]. O. Erhabor, O.A. Ejele and C.A. Nwauche (2007). Epidemiology and management of occupational exposure to blood borne viral infections in resource poor settings: The case for availability of post exposure prophylaxis. Nigerian Journal of Clinical Practice, June 2007 Vol 10(2): 100-104

[18]. OS Elkanah, AL Okoye, OE Debby-Sambo. Prevalence of Hepatitis-B Surface Antigen among Blood Donors in Jalingo, Taraba State, Nigeria Nigerian Journal of Parasitology Vol 34, No 2 (2013

[19]. OguamanamOkezieEnwere, Kevin ChiekulieDiwe 2014: Knowledge, perception and practice of injection safety and healthcare waste management among teaching hospital staff in south east Nigeria: an intervention study Pan Afr Med J. 2014; 17: 218.

[20]. RuhiToraman, FatmaBattal, Kirstin Ozturk\&BetulAkcin (2011) Sharps Injury Prevention for Hospital Workers, International Journal of Occupational Safety and Ergonomics, 17:4, 455-461, DOI: 10.1080/10803548.2011.11076908

[21]. Soad A. HabibaGhadeer A. Alrashidi, Afaf E.M. Al-otaibi, Ghizayel R. Almutairi, Gamal Makboul and Medhat K. El-Shazl (2012): Knowledge, attitude and behavior of health care workers regarding hepatitis B infection in primary health care, Kuwait. Greener Journal of Medical Sciences Vol. 2 (4), pp. 077-083

[22]. Taraba State strategic health development plan (2010 - 2015) 


\title{
Effective Communication as a Panacea for Gaining Acceptance of Hospital Services by Clients
}

\author{
Article by Onwubiko Iheanyichukwu Samuel \\ Master of Public Health, Texila American University, Nigeria \\ E-mail: sammyblackjeese@yahoo.com
}

\begin{abstract}
Health communication is essential in providing avenue for effective dissemination of health information in order to improve healthcare delivery. Lack of effective communication between healthcare providers and their clients especially in secondary health facilities has impeded the effective and efficient delivery of quality healthcare. The objective of this study is to demonstrate effective communication as a solution for clients to accept quality healthcare services.

A descriptive cross-sectional study of three secondary health facilities in Northern Cross River, Nigeria. Population of 2050 in 3 facilities with sample size (n) of 335 allocated 147, 57, 98 and 33 among the 3 facilities and staff categories respectively. Systematic sampling technique was used and semi-structured self-administered questionnaire for data collection. Data analysis was done using statistical package for social science. Non-parametric statistics was used in the analysis as data was categorical and not normally distributed.

Out of 335 respondents, 278 completed the questionnaire giving a response rate of $83 \%$. Modal Age group is 25-34 (29.5\%) and Modal level of education is tertiary (38.5\%). Majority of clients (53.6\%) concurred to good communication skills (listening skills and allowing feedback from patient) from healthcare providers improved acceptance to healthcare delivery $(P=0.019)$. Majority (45.3\%) who confirmed friendly approach of health workers maintained them as their health providers.

Effective communication is key to acceptance of services rendered to clients by healthcare personnel and also, for clients to have a positive perception of services rendered.
\end{abstract}

Keywords: Communication barriers, communication tools, acceptance, healthcare delivery, healthcare provider, cross river,

\section{Introduction}

The lack of effective communication between healthcare personnel and their clients in the hospital setting impedes the effective and efficient delivery of quality clinical and healthcare services and this negatively affects the successful partnership in the hospital setting, resulting in industrial disputes among staff as well as adverse effects on patients. Health communication thus, is essential as it provides an avenue for effective dissemination of health information in order to improve healthcare delivery. Also, since communication is essential in ensuring adequate provider-client relationship, it is imperative that a strong positive relationship is established between a healthcare team member's communication skills and a patient's capacity to follow through with medical recommendations, self-manage a chronic medical condition, and adopt preventive health behaviors. This study was conducted in the three (3) high volume secondary health facilities (General hospital Ogoja, Catholic Monaya Hospital Ogoja and Sacred heart Catholic Hospital) in the Northern District of Cross River state. The specific objectives of this study include:

- To examine the perception of clients on the quality and suitability of verbal and nonverbal communication strategies employed by healthcare personnel in secondary health facilities.

- To assess the feedback and responses of clients to relevant clerking sessions by healthcare workers in secondary health facilities. 
Texila International Journal of Public Health

Volume 4, Issue 4, Dec 2016

- To identify the various communication barriers and evaluate strategies aimed at preventing and overcoming the barriers to effective communication in the hospital.

- To describe the usefulness of communication tools such as listening skills, media, reference materials used by healthcare personnel in ensuring effective client acceptance and patient management.

\section{Methods}

The study was conducted in three (3) high volume secondary health facilities in Northern District of Cross River State in Nigeria. They are General Hospital Ogoja (GH Ogoja), Catholic Monaya Hospital Ogoja (CMH Ogoja) and Sacred Heart Catholic Hospital Obudu (SHCH Obudu).

The study type is descriptive cross-sectional study in which a thorough description of the concept of effective communication is analyzed as well as the type of responses from respondents. The population that was used for the study encompassed all the clients that access healthcare at GH Ogoja, CMH Ogoja and SHCH, Obudu. The average client attendance at General Hospital Ogoja is 900 clients, while CMH Monaiya has about 600 clients and SHCH Obudu has about 350 clients. The facilities also have combined staff strength of about 200 staff. Hence, giving a total population of 2050 was used. The Sample size used for the study was determined using the Taro Yamane's formula thus;

$\mathrm{n}=$

$$
\frac{\mathrm{N}}{1+\mathrm{N}(\mathrm{e})^{2}}
$$

Where;

$\mathrm{n}=$ Sample size.

$\mathrm{N}=$ Total population size.

$\mathrm{e}=$ level of significance.

The Bourley's1964 population allocation formula was used to determine the sample size per health care facility. The formula is stated as follows;

$$
\mathrm{nh}=\frac{\mathrm{n} \mathrm{x} \mathrm{Nh}}{\mathrm{N}}
$$

Where;

nh=Sample size per health facility.

$\mathrm{Nh}=$ Total number of clients in each health facility.

$\mathrm{N}=$ Total Population size.

$\mathrm{n}=$ Total sample size.

Thus, 147 client responses were considered at GH Ogoja, while 98 and 57 were considered at CMH Monaiya and SHCH Obudu respectively. Also, 33 responses will be obtained from staff of the facility

The Sampling procedure utilized was the systematic sampling technique, a probability sampling procedure.

In this procedure, a respondent was chosen such that the first person is picked at random from the start. After this, every second name was then selected as computed by the formula below;

For GH Ogoja,

$$
\mathrm{K}=\frac{\mathrm{N}^{-}=}{\mathrm{n}} \frac{900=6.1}{147}=6
$$

For CMH Monaiya,

$$
\mathrm{K}=\frac{\mathrm{N}}{\mathrm{n}}=600=6.1=6
$$

For SHCH Obudu, 
For Staff across the facilities,

$$
\mathrm{K}=\frac{\mathrm{N}}{\mathrm{n}}=\frac{350=6.1}{57}=6
$$

$$
\mathrm{K}=\frac{\mathrm{N}}{\mathrm{n}}=\frac{200=6.1}{33}=6
$$

Hence, every $6^{\text {th }}$ client was selected until the sample size of 147, 98, 57 and 33 was obtained at GH Ogoja, CMH Monaiya, SHCH Obuduand staff across the facilities respectively.

The data collection technique utilized for the survey include the use of data collecting instruments such as a semi-structured self-administered questionnaire to collect primary data. The data was analyzed using Statistical Package for Social Science tool. Also, since the research entails an evaluation of the perception of clients on the efficacy of communication with healthcare providers, it is observed that two groups are involved, i.e. the client and the provider, hence, we utilized the principles of Inferential Statistics for the study.

Consequently, non-parametric statistics method is used to analyze data, it assumes that data is categorical and in some cases, it may be continuous but not normally distributed.

\section{Results}

The responses obtained after administration of questionnaires were tabulated and frequency tables and charts generated

Table 1: Age in years

\begin{tabular}{|l|l|c|c|c|c|}
\hline & & Frequency & Percent & $\begin{array}{c}\text { Valid } \\
\text { Percent }\end{array}$ & $\begin{array}{c}\text { Cumulative } \\
\text { Percent }\end{array}$ \\
\hline Valid & $15-24$ & 54 & 19.4 & 19.4 & 19.4 \\
& $25-34$ & 82 & 29.5 & 29.5 & 48.9 \\
$35-44$ & 64 & 23.0 & 23.0 & 71.9 \\
$45-54$ & 37 & 13.3 & 13.3 & 85.3 \\
& $55-64$ & 25 & 9.0 & 9.0 & 94.2 \\
& $65-74$ & 9 & 3.2 & 3.2 & 97.5 \\
& $>75$ & 7 & 2.5 & 2.5 & 100.0 \\
\cline { 2 - 6 } & Total & 278 & 100.0 & 100.0 & \\
\hline
\end{tabular}

Table 2: Level of Education

\begin{tabular}{|l|l|c|c|c|c|}
\hline & & Frequency & Percent & $\begin{array}{c}\text { Valid } \\
\text { Percent }\end{array}$ & $\begin{array}{c}\text { Cumulative } \\
\text { Percent }\end{array}$ \\
\hline Valid & No formal & 56 & 20.1 & 20.1 & 20.1 \\
& Education & & & & \\
& Primary & 41 & 14.7 & 14.7 & 34.9 \\
& Secondary & 74 & 26.6 & 26.6 & 61.5 \\
& Tertiary & 107 & 38.5 & 38.5 & 100.0 \\
& Total & 278 & 100.0 & 100.0 & \\
\hline
\end{tabular}


Texila International Journal of Public Health

Volume 4, Issue 4, Dec 2016

Table 3: Preference of care

\begin{tabular}{|l|l|c|c|c|c|}
\hline & & Frequency & Percent & $\begin{array}{c}\text { Valid } \\
\text { Percent }\end{array}$ & $\begin{array}{c}\text { Cumulative } \\
\text { Percent }\end{array}$ \\
\hline Valid & Strongly & 148 & 53.2 & 53.2 & 53.2 \\
& Agree & 73 & 26.3 & 26.3 & 79.5 \\
& Agree & 8 & 2.9 & 2.9 & 82.4 \\
& Not sure & 5 & 1.8 & 1.8 & 84.2 \\
& Disagree & 44 & 15.8 & 15.8 & 100.0 \\
& Strongly & & & & \\
& disagree & 278 & 100.0 & 100.0 & \\
& Total & & & & \\
\hline
\end{tabular}

Table 4: Non verbal techniques utilized

\begin{tabular}{|l|l|c|c|c|c|}
\hline & & Frequency & Percent & $\begin{array}{c}\text { Valid } \\
\text { Percent }\end{array}$ & $\begin{array}{c}\text { Cumulative } \\
\text { Percent }\end{array}$ \\
\hline Valid & Strongly agree & 149 & 53.6 & 53.6 & 53.6 \\
& Agree & 76 & 27.3 & 27.3 & 80.9 \\
& Not sure & 5 & 1.8 & 1.8 & 82.7 \\
& Disagree & 8 & 2.9 & 2.9 & 85.6 \\
Strongly & 40 & 14.4 & 14.4 & 100.0 \\
& disagree & & & & \\
& Total & 278 & 100.0 & 100.0 & \\
\hline
\end{tabular}

Table 5: Careful listening

\begin{tabular}{|l|l|c|c|c|c|}
\hline & Frequency & Percent & $\begin{array}{c}\text { Valid } \\
\text { Percent }\end{array}$ & $\begin{array}{c}\text { Cumulative } \\
\text { Percent }\end{array}$ \\
\hline Valid & Strongly agree & 116 & 41.7 & 41.7 & 41.7 \\
& Agree & 102 & 36.7 & 36.7 & 78.4 \\
& Not sure & 8 & 2.9 & 2.9 & 81.3 \\
& Disagree & 10 & 3.6 & 3.6 & 84.9 \\
& Strongly & 42 & 15.1 & 15.1 & 100.0 \\
& Disagree & & & & \\
& Total & 278 & 100.0 & 100.0 & \\
\hline
\end{tabular}

Table 6: Friendliness of staff

\begin{tabular}{|l|l|c|c|c|c|}
\hline & & Frequency & Percent & $\begin{array}{c}\text { Valid } \\
\text { Percent }\end{array}$ & $\begin{array}{c}\text { Cumulative } \\
\text { Percent }\end{array}$ \\
\hline Valid & Strongly Agree & 126 & 45.3 & 45.3 & 45.3 \\
& Agree & 102 & 36.7 & 36.7 & 82.0 \\
& Not sure & 26 & 9.4 & 9.4 & 91.4 \\
& Disagree & 15 & 5.4 & 5.4 & 96.8 \\
& Strongly & 9 & 3.2 & 3.2 & 100.0 \\
& Disagree & & & & \\
Total & 278 & 100.0 & 100.0 & \\
\hline
\end{tabular}


Table 7: Clarity of Communication

\begin{tabular}{|l|l|c|c|c|c|}
\hline & & Frequency & Percent & $\begin{array}{c}\text { Valid } \\
\text { Percent }\end{array}$ & $\begin{array}{c}\text { Cumulative } \\
\text { Percent }\end{array}$ \\
\hline Valid & Strongly Agree & 121 & 43.5 & 43.5 & 43.5 \\
& Agree & 113 & 40.6 & 40.6 & 84.2 \\
& Not sure & 19 & 6.8 & 6.8 & 91.0 \\
& Disagree & 15 & 5.4 & 5.4 & 96.4 \\
& Strongly & 10 & 3.6 & 3.6 & 100.0 \\
& Disagree & & & & \\
Total & 278 & 100.0 & 100.0 & \\
\hline
\end{tabular}

Table 8: Verbal communication

\begin{tabular}{|l|l|c|c|c|c|}
\hline & & Frequency & Percent & $\begin{array}{c}\text { Valid } \\
\text { Percent }\end{array}$ & $\begin{array}{c}\text { Cumulative } \\
\text { Percent }\end{array}$ \\
\hline Valid & Strongly Agree & 108 & 38.8 & 38.8 & 38.8 \\
& Agree & 111 & 39.9 & 39.9 & 78.8 \\
& Not sure & 24 & 8.6 & 8.6 & 87.4 \\
Disagree & 20 & 7.2 & 7.2 & 94.6 \\
Strongly & 15 & 5.4 & 5.4 & 100.0 \\
Disagree & & & & \\
Total & 278 & 100.0 & 100.0 & \\
\hline
\end{tabular}

Table 9: Change in communication

\begin{tabular}{|l|l|c|c|c|c|}
\hline & & Frequency & Percent & $\begin{array}{c}\text { Valid } \\
\text { Percent }\end{array}$ & $\begin{array}{c}\text { Cumulative } \\
\text { Percent }\end{array}$ \\
\hline Valid & Strongly agree & 66 & 23.7 & 23.7 & 23.7 \\
& Agree & 76 & 27.3 & 27.3 & 51.1 \\
& Not sure & 44 & 15.8 & 15.8 & 66.9 \\
& Disagree & 30 & 10.8 & 10.8 & 77.7 \\
& Strongly & 62 & 22.3 & 22.3 & 100.0 \\
& disagree & & & & \\
& Total & 278 & 100.0 & 100.0 & \\
\hline
\end{tabular}

Table 10: Quality of Communication

\begin{tabular}{|l|l|c|c|c|c|}
\hline & & Frequency & Percent & $\begin{array}{c}\text { Valid } \\
\text { Percent }\end{array}$ & $\begin{array}{c}\text { Cumulative } \\
\text { Percent }\end{array}$ \\
\hline Valid & Strongly agree & 136 & 48.9 & 48.9 & 48.9 \\
& Agree & 91 & 32.7 & 32.7 & 81.7 \\
& Not sure & 15 & 5.4 & 5.4 & 87.1 \\
& Disagree & 23 & 8.3 & 8.3 & 95.3 \\
& Strongly & 13 & 4.7 & 4.7 & 100.0 \\
& disagree & & & & \\
& Total & 278 & 100.0 & 100.0 & \\
\hline
\end{tabular}


Texila International Journal of Public Health

Volume 4, Issue 4, Dec 2016

Table 11: Change in Health Provider

\begin{tabular}{|l|l|c|c|c|c|}
\hline & & Frequency & Percent & $\begin{array}{c}\text { Valid } \\
\text { Percent }\end{array}$ & $\begin{array}{c}\text { Cumulative } \\
\text { Percent }\end{array}$ \\
\hline Valid & Strongly agree & 70 & 25.2 & 25.2 & 25.2 \\
& Agree & 77 & 27.7 & 27.7 & 52.9 \\
& Not sure & 40 & 14.4 & 14.4 & 67.3 \\
& Disagree & 41 & 14.7 & 14.7 & 82.0 \\
& Strongly & 50 & 18.0 & 18.0 & 100.0 \\
& disagree & & & & \\
& Total & 278 & 100.0 & 100.0 & \\
\hline
\end{tabular}

Table 12: Suitability of communication strategies employed by healthcare personnel to perception by clients

\begin{tabular}{|l|c|c|c|c|c|}
\hline & $\begin{array}{c}\text { Sum of } \\
\text { Squares }\end{array}$ & Df & $\begin{array}{c}\text { Mean } \\
\text { Square }\end{array}$ & F & Sig. \\
\hline $\begin{array}{l}\text { Between } \\
\text { Groups }\end{array}$ & 11.655 & 4 & 2.914 & 1.170 & 0.324 \\
$\begin{array}{l}\text { Within Groups } \\
\text { Total }\end{array}$ & 679.741 & 273 & 2.490 & & \\
\hline
\end{tabular}

Table 13: Feedback/response of clients to client satisfaction

\begin{tabular}{|l|c|c|c|c|c|}
\hline & $\begin{array}{c}\text { Sum of } \\
\text { Squares }\end{array}$ & Df & $\begin{array}{c}\text { Mean } \\
\text { Square }\end{array}$ & F & Sig. \\
\hline Between & 21.541 & 4 & 5.385 & 3.001 & .019 \\
Groups & 488.091 & 272 & 1.794 & & \\
Within Groups & 509.632 & 276 & & & \\
Total & 50.632 & \\
\hline
\end{tabular}

\section{Discussion}

From the study, it was observed that 335 questionnaires were administered and 278 of the administered copies recovered, representing $83 \%$ retrieval rate. It was also observed that the age group with the most respondents belonged to the 25-34 range with $29.5 \%$, while the least responses was gotten from participants above 70 years old (Table 1). The level of education of the respondents are majorly tertiary level $38.5 \%$ (Table 2). $53.2 \%$ of the clients strongly agree that they prefer accessing care in the hospitals (Table 3). It was also observed that respondents agreed to the fact that appropriate utilization of the right verbal and non-verbal communication techniques is key to ensuring effective communication in the facilities, subsequently, improving the quality of services. This was reflected in the responses as $39.9 \%$ of respondents said healthcare personnel utilize verbal means of communication (Table 8), while 53.6\% said non-verbal communication is utilized (Table 4). However, the respondents had different individual perceptions on the services offered, depending on the nature of services they received. Some suggested that the health personnel change their manner of communication and about $25.2 \%$ of respondents stated they would like to change their health care provider (Table 11). Also, a computation of the probability values comparing the various views of respondents on the quality of services indicates a value of 0.324 which is greater than (>) 0.05 (Table 12), indicating that there is no significant difference between the perception of clients and the quality of communication strategies offered by healthcare providers. This proves and subsequently accepts the null hypothesis. Furthermore, analysis of the responses indicate that negative attitude of some healthcare staff towards clients has also led to some deciding to change their providers, some even observed that some healthcare providers they had met in some facilities used negative language during communication, this 
has contributed to the different opinions of clients and has further aided the resolve of some to change healthcare providers (Table 11).

From the results of the study, it was observed that $45.3 \%$ of respondents strongly agreed that the healthcare personnel that attended to them were friendly; this generated a feeling of security in them and probably led to their willingness to open up with respect to providing feedback during care and counseling sessions (Table 13). 41.7\% of the clients also indicated that staff often listen to their complaints with considerable attention (Table 5). It was observed that the reactions of clients to healthcare providers during care sessions are greatly dependent on the degree to which they are satisfied with the quality of communication (Table 10). However, it was seen that although majority of clients strongly agreed to the fact that their feedback determined their rate of satisfaction, this result confers a level of significance as reflected in the $\mathrm{p}$ value of 0.019 , which is $<0.05$ (Table 13).

\section{Conclusion}

From the study, it was observed that effective communication is key to the acceptance of services rendered to clients by healthcare personnel. It is also seen that in order for clients to have a positive perception of services rendered, it is important for the providers to make a general improvement in services rendered. It is also observed that the quality of feedback or responses that clients provide to care providers is largely dependent upon the rate of satisfaction as perceived by the clients. This is seen in the responses of clients who believe that with the right attitude by facility staff in the right environment, clients will be encouraged to provide better feedback. Also, it is observed that there is need for healthcare personnel to occasionally change or improve on the quality of their services such as positive behavioral and attitudinal change, improvement of environment of care, greater assurance and education of clients, reduction in patient waiting time, ensuring audio-visual privacy and a change in methods to suite particular clients.

However, it was observed that there exist some barriers to communication in healthcare facilities which are common to the locality where the study was undertaken. They include

Personality, environmental and system level barriers.

Thus, it is concluded that the key to efficient and effective services in the healthcare facilities is effective communication.

\section{Recommendations}

Some of the recommendations generated from the study include;

- The need for an improvement in the environment of communication, which include structural and functional infrastructure.

- The need for creation of audio-visual privacy when attending to clients.

- There is need to ensure effective turnaround time and reduce patient waiting time.

- There is need to carefully and patiently listen to client's concerns before acting.

- It is essential that patients are given sufficient time and opportunity to provide appropriate feedback and response to ensure objective judgment treatment.

- There is need for continuous on the job training and orientation for healthcare personnel on ethics and client management.

- There is need for healthcare providers to occasionally change their methods of communication to specific clients.

- It is essential that diverse communication strategies be put in place to overcome communication barriers.

- There is need for active service units to be put in place in different facilities to obtain regular feedback on the quality of service delivery in the health facilities.

- There is need to engage only experienced and highly qualified healthcare professionals in the healthcare facilities.

- Consider the utilization of interpreters to overcome language barrier. 
Texila International Journal of Public Health

Volume 4, Issue 4, Dec 2016

- The need for healthcare personnel to apply a proper mix of verbal and non-verbal communication techniques to ensure effective communication.

\section{References}

[1.] Aleshire, B. (2010) Effective communication and leadership at health care Site. Retrieved fromhttp://www.slideshare.net/ksllnc/advancing-effective-communication-cultural-competence-andpatient-and-family-centered-care-a-roadmap.

[2.] Baxamusa, B. N. (2010). Communication barriers in healthcare. Retrieved from http://www.buzzle.com/articles/communication-barriers-in-healthcare.html

[3.] Bertalanffy, L.V. (1968). General System theory.

Retrieved from http://www.panarchy.org/vonbertalanffy/systems.1968

[4.] Brown, B. (2014). What is effective communication? Retrieved from http://www.livestrong.com/article/69309-effective-communication/?

[5.] Bryant, D. (2011). Effective Communication and Leadership at Health Care

Sites. Available fromhttp://healthcarecomm.org/about-us/impact-of-communication-in-healthcare/ institute for healthcare communication.

[6.] Clark, P. A. (2003). Medical practices' sensitivity to patients' needs: Opportunities and practices for improvement. Journal of Ambulatory Care Management, 26(2), 110-12.

[7.] Committee on Bioethics, American Academy of Pediatrics. (2008). Informed consent, parental permission, and assent in pediatric practice. Pediatr Rev; 29: e2-e3

[8.] Communication theories, Retrieved from https://en.wikipedia.org/wiki/Communication_theory

[9.] Donald L. R. (1993). "Listen ability = Oral-based Discourse + Considerateness," in Perspectives on Listening, eds. Andrew D. Wolvin and Carolyn Gwynn Coakley (Norwood, NJ: Alex Publishing Corporation), 269.

[10.] Egan (1986) SOLER, Using non-verbal skills to aid Listening. Retrieved from http://retaileap.co.uk

[11.] Foulger, D. (2004). Models of the Communication Process. Available from

http://www.jackwhitehead.com/teesonphd/004c3.pdf

[12.] Hamilton, S.J., Martin, D.J. (2007) A framework for effective communication skills. Extended version of Nursing Times; 103: 48, 30-31

[13.] Handzo, G. (2012). Good communication in health care is about Listening. Retrieved from http://communicationtheory.org/effective-communication/

[14.] Hanes, T. (2013). What is verbal communication? Retrieved from http://www.livestrong.com/article/150573-what-is-verbal-communication/

[15.] Hanlon, T. (2010). Barriers to effective communication in a hospital

Available from http://www.ehow.com/list_6940461_barriers-effective-communication-hospital.html.

[16.] Harper, D. (2013) "communication". Online Etymology Dictionary.

Retrieved from http://dictionary.reference.com.

[17.] Jain, R. (2008).The Barriers to Effective Communication. Available

From http://www.skillsyouneed.com/ips/barriers-communication.html

[18.] Klapper, J. (1960). The effects of mass communication.

Retrieved from https://books.google.com.ng

[19.] Lasswell, H. (1948). "The structure and function of communication in society." In Lyman Bryson (ed.), The Communication of Ideas. Harper and Row

[20.] Levinson, W., Roter, D., \& Mullooly, J., Dull, V., \& Frankel, R. (1997). Physician-patient communication. The relationship with malpractice claims among primary care physicians and surgeons. JAMA ; 277: 553-9.

[21.] Makaryus, A. N., \& Friedman, E. A. (2005). Patients' understanding of their treatment plans and diagnosis at discharge. Mayo Clinic Proceedings, 80(8), 991-994. pubmed

[22.] Monroe, A. H. (1943). Monroe's principles of speech (military edition). Chicago: Scott, Foresman PN4121.M578. Retrieved from; https://en.wikipedia.org/wiki/Monroe's_motivated_sequence

[23.] National Communication Association (2013) What is communication Retrieved from https://en.wikipedia.org 
[24.] Nelson, L. (2010). Importance of effective communication in healthcare Available from http://www.ehow.com/about_6464377_importance-effective-communication-healthcare.html [25.] Owen H. (2011) Skilled Interpersonal Interaction: Research, Theory, and Practice (London: Routledge), 189-99

[26.] Papa, J. (2009). Effective healthcare communication. Available From http://www.ehow.com/about_5421324_effective-healthcare-communication.html.

[27.] Piette, J. D., Heisler, M., \& Wagner, T. H. (2004). Cost-related medication underuse among chronically ill adults: The treatments people forgo, how often, and who is at risk. American Journal of Public Health, 94(10), 1782-1787.

[28.] Robbins, S., Judge, T., Millett, B., \& Boyle, M. (2011). Organisational behaviour. 6th ed. Pearson, French's Forest, NSW p315-317.

[29.] Robinson, L., Segal, J., Segal, R. (2014). Improving communication skills in business and relationships. Retrieved from http://helpguide.org/mental/effective_communication_skills.htm [30.] Shannon, E. C., \& Weaver, W. (1949). The Mathematical Theory of Communication. Univ of Illinois Press ISBN 0-252-72548-4

[31.] Schattner, A. (2009). The silent dimension: expressing humanism in each medical encounter. Arch Intern Med; 169:1095-99.

[32.] Schwartz, F., Lowe, M., \& Sinclair, L. (2010). Communication in Health Care: Considerations and strategies for successful consumer and team dialogue Hypothesis, 8(1): e7.

[33.] Suresh, K. (2003). Journalism and mass communication. Retrieved from http://en.wikipedia.org/wiki/Communication. P.1-4.

[34.] Thiedke, C. C. (2007). What do we really know about patient satisfaction? Family Practice Management, 33-36. pubmed. Retrieved from http://healthcarecomm.org/about-us/impact-of-communication-in-healthcare/

[35.] Tongue, J., Epps, H., \& Forese, L. (2005). Communication skills for patient- centered care; research-based, easily learned techniques for medical interviews that benefit orthopaedic surgeons and their patients. J Bone Joint Surg Am ; 87:652-8 


\title{
Risk Factors of Type 2 Diabetes among Mbororo Population of Guiwa-Yangamo Village in the East -Cameroon
}

\author{
Article by, ${ }^{1 *}$ Judith Maka, ${ }^{2}$ Félix Assah, ${ }^{3}$ Clarisse Mapa-Tassou, ${ }^{4}$ Clément Kufe, \\ ${ }^{5}$ Akenji Siri and ${ }^{6}$ Jean-Claude Mbanya \\ ${ }^{1 *}$ Health of Population in Transition Research Group District hospital of Biyem- \\ assi, Yaounde, Cameroon, ${ }^{2,3,4}$ Health of Population in Transition Research Group, ${ }^{5}$ \\ District hospital of Biyem-assi, Yaounde, ${ }^{6}$ Health of Population in Transition \\ Research Group Central Hospital of Yaounde Faculty of Medicine and Biomedical \\ Sciences, University of Yaounde \\ E-mail: ${ }^{1 *}$ judithmani70@hotmail.com, ${ }^{2}$ kembeassah@yahoo.com, \\ ${ }^{3}$ mapatassou@yahoo.fr, ${ }^{4}$ kufekle@yahoo.co.uk, ${ }^{5}$ siriakenji@yahoo.com, \\ jcmbanya@hopitcam.net
}

\section{Introduction}

In the world in 2013, Diabetes affected 382 million of people, and 316 million were at risk of developing it. Diabetes was responsible for the dead of 5 million persons aged 20-79, that was $8,4 \%$ of the world's mortality for this age range (1). Type 2 diabetes is the most common type and is the challenge of the 21st century for health (2). Its risk factors like obesity and complications like limbs amputations and others cost much (3). It therefore presents a severe health problem for the population with low socio-economic level and disfavored groups. Described by the WHO, the minority " Autochthones ", " Aborigines » or " Indigenous » people know the abnormal high of prevalence, complications, risk factors, and a high mortality compared to non autochthones of the same age group (4),(5). In 2007, the United Nation Organization launched the declaration of the right of these $5 \%$ of the world's population who experiencing many Burden (6).

In the Sub Sahara Africa, the word « Indigenous » is contested (7),(8) and the scarcity of data on diabetes in this « indigenous « community makes the situation of diabetics complex in the " massai » of Kenya, " pygmies " and Mbororo » of Cameroon, and "San » of South Africa; these could compromise the effectiveness of the health services (9) and the stable development(10).

In Cameroon, the prevalence of diabetes moved from 1, 5\% in 1990, to 6.6\% in 2003. 80\% of patients are still undiagnosed (11). Diabetes is one of the first causes of the mortality amongst patients on hemodialysis (12). As pastoralist, the Mbororo minority group is not well censored (13); they live a " complex " social relationship hence always considered as " strangers " (14). Most of the Mbororo of the East region has lost their " cheptel " due to conflicts, epidemics, climatic changes, and soil degradation. They progressively practice agriculture on borrowed soil (15). Health care is frequently inaccessible. Women, children and the old are suffering in their Camps; they could therefore develop type 2 diabetes. With our actual knowledge, no study has been carried out to determine the prevalence and the magnitude of diabetes among Mbororos. It is then necessary to investigate on their needs and risk of developing diabetes and Blood pressure like others " indigenous " populations in the world.

As to respond to this need, a project was initiated to ameliorate the access to diabetic health care in 5 villages of the Adamaoua and East region, in order to propose strategic health management of " indigenous ». As part of this project, we conducted a study based on the prevalence and risk factors of the type 2 diabetes amongst adults Mbororo in the Guiwa Yangamo village.

To present this experience, we will explore the generalities on topic, followed by the method used and results, at the end, conclusion, recommendations and some perspectives. 
Texila International Journal of Public Health

Volume 4, Issue 4, Dec 2016

\section{Method}

This study is a part of a big research project on « Amelioration of the access to diabetic healthcare in five villages in the East and adamaoua regions ". Entirely financed by the International Federation of Diabetes (IFD), this was conducted in Five villages: GuiwaYangamo, Mandjou II, Sabga, Gom-mana, Madzidou.

\section{Description of site}

Cameroon is a country in the central Africa and its population in 2011 was estimated to 19406100 inhabitants according to the National institute of statistics. It is made of 10 Regions, 58 Divisions, 360 sub-Divisions. Guiwa-Yangamo is situated in the East region, in Ngoura sub-Division. It is situated $80 \mathrm{Km}$ from the town of Bertoua on the national road, going to the Adamaoua region. It belongs to the Bétaré- Oya Health District and in the Tongo-Gandima health area. According to the authorities of the Bétaré-oya Health District, this village had about 2325 inhabitants in 2013, giving an estimated 1000 adults.

\section{Study design}

The complex sampling frame permits us to calculate the quota of participation of each village to the big research project. Our study population was adults aged 20 and above, living in Guiwa-Yangamo village.

During a week in January 2013, we interviewed 682 adults of which were 261 Mbororo, using the standard data collecting tool STEPS of WHO for surveillance and collection on non transmissible diseases. This cross-sectional study had as analysis unit, an adult Mbororo aged 20 and above, having being censored and living in Guiwa -Yangamo village for at least one year.

\section{Description of the method used and data collection}

A manual of investigators made available. These investigators were trained on the data collection. During the visit to each household, the consent of the participant was fist obtained before his/her information was collected. Data collecting tool was based on "STEPswise » approach, which permitted to obtain sociodemographic (Step1), anthropometric (Step 2), et biomedical (Step 3) information. Many variables were therefore taken into consideration : Age, matrimonial status, sex, family history of diabetes, tobacco consumption, alcohol consumption, frequency of fruits or vegetable consumption, excessive consumption of sugar, level of physical activity, high blood Pressure, weight, Height, Body Mass Index, Waist circumference, Hip circumference, (independent variables). The outcome of type 2 diabetes (dependant variable). Diabetes diagnosis is performed through a capillary Fasting Blood Sugar (FBS), using HemocueB-201RT glucometer. Normal Fasting Blood Sugar $<1.10 \mathrm{~g} / \mathrm{l}$ $(6,1 \mathrm{mmol} / \mathrm{l})$. All the participants presenting with FBS between $100 \mathrm{mg} / \mathrm{dl}$ et $125 \mathrm{mg} / \mathrm{dl}$ $(6.1 \mathrm{mmol} / \mathrm{l}$ to $6.9 \mathrm{mmol} / \mathrm{l})$, we carried out provoked hyperglycemia test in order to classify them as pre-diabetic or diabetic.

\section{Pilot study}

A pilot study was carried out on a random sample of 5 households out of the study site in a neighboring village (Mandjou I).

\section{Statistical methods used}

Data collected were registered in software called Epi Data version 3.1.

Using a descriptive analysis, we calculated the mean, Standard deviation for continuous data and the proportion for categorized data.

The analysis of quantitative data was done with the help of software STATA 11.2. The bivaried analysis to show the existing association between each different risk factor and the development of diabetes: Chi 2 test. A logistic regression was done to estimate the risk of developing diabetes. 
All the statistical analysis were adjusted to take into consideration the complex sampling and the existence of the clusters in the households when using

STATA / IC version 11.2. The Odds ratio obtained by the logistic regression was used to estimate the risk. The degree of significance of the p-value was 0,05 .

\section{Ethical Considerations}

An ethical clearance was obtained from the National Ethical Committee of Cameroon, An administrative authorization from the ministry of public health. An authorization from the administrative authorities of the study area was obtained before the data collection.

Participants had to confirm their consent before the interview and received a feedback of the study. We kept all these information's in an area not accessible by anyone who was not part of the study team. Patients were referred to a health facility in the area for a better healthcare management.

\section{Results}

The presentation of our results was done with tables and figures. We recruited a total of 682 adults in Guiwa-Yangamo including 261 Mbororo (38.1\%). Among the Adults Mbororo, 108 (41.4\%) were males and 153 (58.6\%) females. The majority of Mbororos (96.9\%) needed an interpreter during the interview and 31.1\% could express themselves in French.

Table 1: Socio-demographic characteristics of the participants

\begin{tabular}{|l|l|l|l|}
\hline Variable & Males, N (\%) & Females, N (\%) & Total, N (\%) \\
\hline Age range & & & \\
\hline $20-29$ & $24(2.2)$ & $58(37.9)$ & $82(31.4)$ \\
\hline $30-39$ & $30(27.8)$ & $48(31.4)$ & $78(29.9)$ \\
\hline $40-49$ & $19(17.6)$ & $24(17.7)$ & $46(17.6)$ \\
\hline $50-59$ & $25(23.2)$ & $13(8.5)$ & $38(14.6)$ \\
\hline $60+$ & $9(8.3)$ & $6(3.9)$ & $15(5.8)$ \\
\hline Matrimonial status & & & \\
\hline Married(e) & $84(38.4)$ & $135(61.6)$ & $219(85.2)$ \\
\hline Single & $16(88.9)$ & $2(11.1)$ & $18(7.0)$ \\
\hline Divorced(e) & $1(20.0)$ & $4(80.0)$ & $5(1.9)$ \\
\hline widower (widow) & $3(25,0)$ & $9(75.0)$ & $12(4.7)$ \\
\hline others & $0(0.0)$ & $3(100)$ & $3(1.7)$ \\
\hline Profession & & & \\
\hline Pastoralist & $16(100)$ & $0(0.0)$ & $16(6.2)$ \\
\hline Seller & $20(76.9)$ & $6(23.1)$ & $26(10.0)$ \\
\hline Farmer & $30(78.9)$ & $8(21.1)$ & $38(14.6)$ \\
\hline Housewife/pastoralist & $4(80.0)$ & $1(20.0)$ & $5(1.9)$ \\
\hline Miners & $3(100)$ & $0(0.0)$ & $3(1.2)$ \\
\hline Builder & $4(100)$ & $0(0.0)$ & $4(1.5)$ \\
\hline Tailor /Seamstress & $5(71.4)$ & $2(28.6)$ & $7(2.7)$ \\
\hline Technician/ Moto or taxi driver & $8(100)$ & $0(0.0)$ & $8(3.1)$ \\
\hline Traditional Doctor/Native Doctor & $3(100)$ & $0(0.0)$ & $3(1.2)$ \\
\hline Teacher (e) & $1(100)$ & $0(0.0)$ & $1(0.4)$ \\
\hline No profession & $6(50.0)$ & $6(50.0)$ & $12(4.6)$ \\
\hline Not available & $2(28.6)$ & $5(71.4)$ & $7(2.7)$ \\
\hline Housewife & $0(0.0)$ & $127(100)$ & $127(48.8)$ \\
\hline Pupils/student & $2(100)$ & $0(0.0)$ & $2(0.8)$ \\
\hline Coranic Teacher & $1(100)$ & $0(0.0)$ & $1(0.4)$ \\
\hline Level of Education & & & $203(78.7)$ \\
\hline Never & $74(36.5)$ & $129(63.5)$ & \\
\hline & & & \\
\hline
\end{tabular}


Texila International Journal of Public Health

Volume 4, Issue 4, Dec 2016

\begin{tabular}{|l|l|l|l|}
\hline Less than primary & $13(48,2)$ & $14(51.8)$ & $27(10.5)$ \\
\hline Primary & $5(41.7)$ & $7(58.3)$ & $12(4.7)$ \\
\hline Secondary (form1 - 4)) & $5(100)$ & $0(0.0)$ & $5(1.9)$ \\
\hline Secondary (form 5 - upper Sixth) & $0(0.0)$ & $0(0.0)$ & $0(0.0)$ \\
\hline University & $0(0.0)$ & $0(0.0)$ & $0(0.0)$ \\
\hline Doctorate & $0(0.0)$ & $0(0.0)$ & $0(0.0)$ \\
\hline Coranic school & $8(72.7)$ & $3(27.3)$ & $11(4.3)$ \\
\hline Region of origin & & & \\
\hline Centre & $0(0.0)$ & $1(100)$ & $1(0.4)$ \\
\hline South & $0(0.0)$ & $0(0.0)$ & $0(0.0)$ \\
\hline East & $52(40.0)$ & $78(60.0)$ & $130(49.8)$ \\
\hline Littoral & $0(0.0)$ & $0(0.0)$ & $0(0.0)$ \\
\hline South West & $0(0.0)$ & $0(0.0)$ & $0(0.0)$ \\
\hline North West & $0(0.0)$ & $0(0.0)$ & $0(0.0)$ \\
\hline West & $0(0.0)$ & $0(0.0)$ & $0(0.0)$ \\
\hline Adamaoua & $42(47.2)$ & $47(52.8)$ & $89(34.1)$ \\
\hline North & $0(0.0)$ & $1(100)$ & $1(0.4)$ \\
\hline Far North & $1(100)$ & $0(0.0)$ & $1(0.4)$ \\
\hline Strangers & $13(39.3)$ & $26(60.7)$ & $39(14.9)$ \\
\hline
\end{tabular}

The majority of the participants have never been to school (78.7\%). More males (72.73\%) than females (27.27\%) have visited the Muslim Coranic School (figure 1.

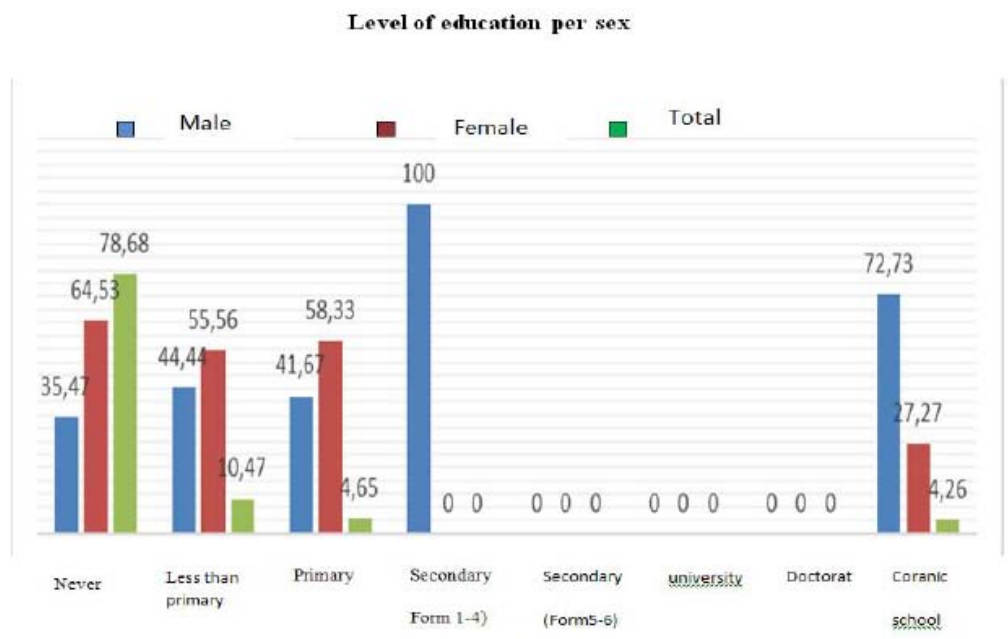

Figure1: Representation of participants according to their educational level and per sex.

More than $95 \%$ of participants have a Body Mass Index (BMI) less than $25 \mathrm{~kg} / \mathrm{m}^{2}$ with almost $50 \%$ of underweight $(\mathrm{BMI}<18 \mathrm{~kg} / \mathrm{m} 2)$. Overweight was noticed more in women $(62.50 \%)$ than in men $(37.50 \%) .91 .67 \%$ of women were obesed (waist circumference $\geq$ $88 \mathrm{~cm}$ ), against $8.33 \%$ of males (waist circumference $\geq 102 \mathrm{~cm}$ ).

In general, we noticed that vegetable consumption was reduced with advancing age; $31.50 \%$ in the age group of $20-29$ years against $5.91 \%$ in the age of 60 and above (figure 2 ). 


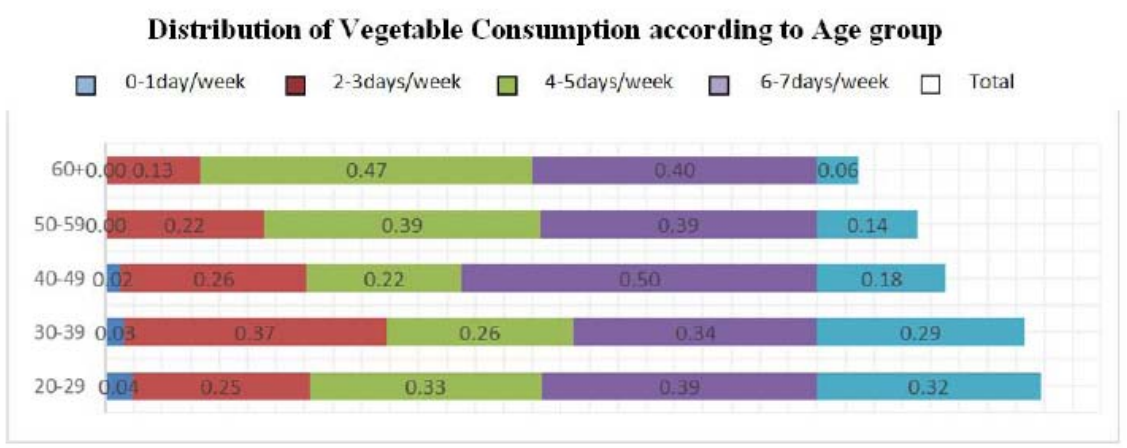

Figure 2: Representation of vegetable consumption according to age.

The prevalence of diabetes was de $2.3 \%$, 3.7\% in men and $1.3 \%$ in women (figure 3 ).

The prevalence of impaired fasting Blood sugar in this population was $21.7 \%, 19.8 \%$ in men and $22.9 \%$ in women (figure 4 ).

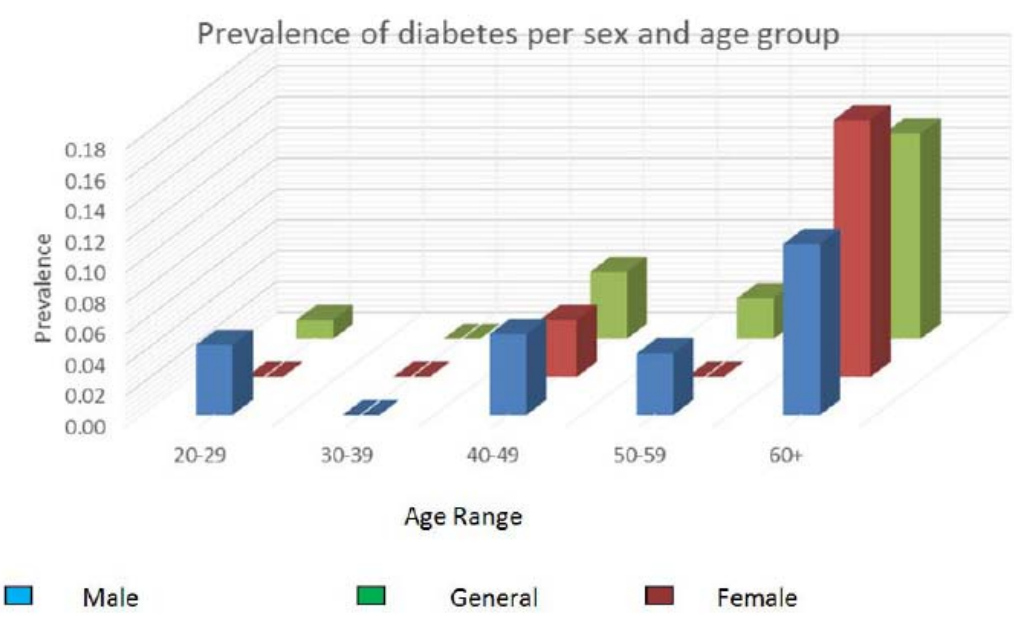

Figure 3: Prevalence of Diabetes per age group

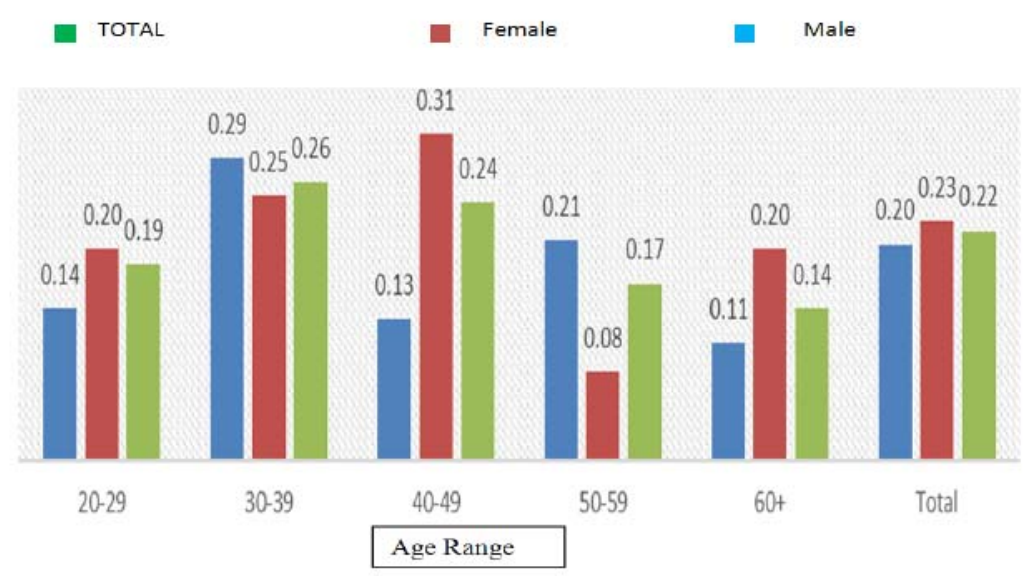

Figure 4: Prevalence of Impaired Fasting Blood Sugar (6,1mmol/l $\geq$ Fasting Blood Sugar $\leq$ $6,9 \mathrm{mmol} / \mathrm{l})$.

Amongst the 6 diabetic cases, 50\% were known diabetic and more than half were on ant diabetic treatment. The Chi 2 test permitted us to describe our diabetic population as follows:

$66.7 \%$ diabetic cases were male and $33.3 \%$ female,

83.3\% amongst them were aged 40 and above, 
Texila International Journal of Public Health

Volume 4, Issue 4, Dec 2016

All the diabetic cases had never been to school,

$50 \%$ were hypertensive,

4 diabetic cases out of the 6 added Sugar to their daily drinks.

\section{Inferential analysis}

A logistic regression was done on each independent variable. The following table summarizes the risk factors and their association with the development of type 2 diabetes in our study population.

Table 2: Risk Factors of Type 2 diabetes amongst Mbororo aged 20 and above

\begin{tabular}{|c|c|c|c|}
\hline \multirow[t]{2}{*}{ Variables } & \multicolumn{3}{|c|}{ Logistic Regression } \\
\hline & OR & CI : $95 \%$ & p-value \\
\hline \multicolumn{4}{|l|}{ Demographics } \\
\hline \multicolumn{4}{|l|}{ Sex $(n=260)$} \\
\hline Male & Ref & & \\
\hline Female & 0.34 & $0.07-1.73$ & 0.152 \\
\hline \multicolumn{4}{|l|}{ Age-Range $(\mathrm{n}=180)$} \\
\hline $20-29$ & Ref & & \\
\hline $30-39$ & 3.64 & $0.320-41.24$ & 0.297 \\
\hline $40-49$ & 2.16 & $0.131-35.52$ & 0.589 \\
\hline $50-59$ & 12.31 & $1.04-145.64$ & 0.046 \\
\hline $60+$ & -- & & \\
\hline \multicolumn{4}{|l|}{$\begin{array}{l}\text { Matrimonial Status } \\
(n=256)\end{array}$} \\
\hline Married & Ref & & \\
\hline Single & 3.14 & $0.18-53.59$ & 0.324 \\
\hline Others & 2.81 & $0.57-13.83$ & 0.145 \\
\hline \multicolumn{4}{|l|}{ BMI (n=254) } \\
\hline Underweight & Ref & & \\
\hline Normal & 0.9 & $0.90-0.91$ & $<0.001$ \\
\hline Overweight & 6.61 & $6.61-6.62$ & $<0.001$ \\
\hline \multicolumn{4}{|l|}{$\begin{array}{l}\text { Waist/Hip circumference } \\
(\mathrm{n}=\mathbf{2 6 0})\end{array}$} \\
\hline$<0.90$ or $<0.85$ & Ref & & \\
\hline$>0.90$ or $>0.85$ & 0.64 & $0.07-5.74$ & 0.608 \\
\hline \multicolumn{4}{|l|}{$\begin{array}{l}\text { Waist Circumference } \\
(\mathbf{n}=246)\end{array}$} \\
\hline$\leq 94$ or $\leq 80 \mathrm{~cm}$ & Ref & & \\
\hline $94>\&<102$ or $80>\&<88 \mathrm{~cm}$ & 2.61 & $0.08-76.05$ & 0.473 \\
\hline$\geq 102$ or $\geq 88 \mathrm{~cm}$ & 4.75 & $0.07-296.48$ & 0.354 \\
\hline \multicolumn{4}{|l|}{ HTA $(n=257)$} \\
\hline Normal & Ref & & \\
\hline Pre- hypertension & 5.84 & $0.57-59.49$ & 0.094 \\
\hline Hypertension & 10.13 & $1.01-96.11$ & 0.047 \\
\hline \multicolumn{4}{|l|}{$\begin{array}{l}\text { Tobacco consumption } \\
(\mathrm{n}=\mathbf{2 5 1})\end{array}$} \\
\hline Never & Ref & & \\
\hline Ex smokers & 5.84 & $0.36-93.94$ & 0.136 \\
\hline \multicolumn{4}{|l|}{$\begin{array}{l}\text { Physical activity at work } \\
(\mathrm{n}=214)\end{array}$} \\
\hline None & Ref & & \\
\hline
\end{tabular}




\begin{tabular}{|l|l|l|l|}
\hline Little & 1.86 & $1.58-2.19$ & 0.004 \\
\hline middle & 0.81 & $0.64-1.02$ & 0.059 \\
\hline $\begin{array}{l}\text { Fruits consumption } \\
\text { (n=150) }\end{array}$ & & & \\
\hline 0day/week & Ref & & \\
\hline 1-2days /week & 0.26 & $0.14-0.49$ & 0.011 \\
\hline $\begin{array}{l}\text { Vegetable consumption } \\
\text { (n=177) }\end{array}$ & & & \\
\hline 0-1day/week & Ref & & \\
\hline 4-5days/week & 1.31 & $1.00-1.71$ & 0.049 \\
\hline $\begin{array}{l}\text { Addition sugar in } \\
\text { tea/coffee (n=257) }\end{array}$ & & & \\
\hline No & Ref & & \\
\hline Yes & 2.71 & $2.11-3.49$ & 0.003 \\
\hline
\end{tabular}

All participants aged between 50 - 59 years were 12.31 times (OR : 12.31 , 95\% CI : $1.04-$ $145.64: \mathrm{P}=0.046)$. More at risk of developing diabetes than those with age between $20-29$ years. Participants who had high blood pressure were ten times more at risk than those who had abnormal blood pressure (OR : 10.13, 95\% CI : $1.06-96.11, \mathrm{p}=0.047)$.

Persons with overweight were 6 times more at risk of developing diabetes than those who were underweight (OR: 6.61: 95\% CI: $6.61-6.62 \mathrm{p}<0.0001)$. Those who added Sugar into their daily drinks (Coffee, Tea etc) were 2 times (OR: 2.71: 95\% CI: $2.11-3.49$; p = 0.003) more at risk of developing diabetes with respect to those who did not add. Those who consumed vegetables 4 to 5 days per week were one time (OR: 1.31; CI: $1.00-1.71, \mathrm{p}=0$. 049) at risk of developing diabetes compared to those who did not at all. All participants practicing physical activities during the day were one time at risk (OR: 1.86; CI: $1.58-2.19$, $\mathrm{p}=0.004)$.

Discussion: This study carried out in a rural area in the East region of Cameroon had as principal objective to determine the prevalence and to describe the risk factors associated with the development of type 2 Diabetes in the adult "' Indigenous " Mbororo population in the Guiwa- Yangamo village. The result showed that diabetes is present in this indigenous population of Cameroun. Its prevalence is 2, 3\% and the impaired glucose tolerance is 21 . $7 \%$. Risk factors like age, high blood pressure, excess sugar in their diet, little physical activity were associated to the development of diabetes in this population.

This prevalence is smaller compared to that obtained in other rural zones in Cameroon probably due to the fact that they are physically more active than in urban zones and most of them have an underweight. This prevalence is relatively identical to the value of 2,6\% found amongst the Touareg rarers of Mali (9). But the distributions is contrary to that which was described in the Touaregs of Mali where fat women were less active than men and had a much more prevalence of diabetes $35 \%$ than $4.2 \%$ in men (9). This is probably linked to the progressive modification of the lifestyle of the Mbororos. This low prevalence which respect to the $12 \%$ reported amongst the "Aborigines'” of Australia (16) makes us to think that there would be a specific protecting factor amongst the Mbororos of Cameroun. Could this not be attributed to their underweight?

Amongst the Mbororos of the East, the prevalence of the impaired Fasting Blood sugar, 54 on 249 (21.7\%), that is $19.8 \%$ in men and $22.9 \%$ in women. This tendency can be explained also that in their Community, the” autochthone” Mbororo have just changed their lifestyle. As concerns pre- diabetes, we noticed that female Mbororos shall, in the nearest future (4 to 5 years) be at a higher risk of developing diabetes if nothing being done. Men are physically more active benefiting from a protector effect than women. This calls for a special attention in this group of population to prevent them from becoming diabetic.

The $50 \%$ of the diabetic cases were not informed of their pathology at the moment of diagnostic, hence the need for the IFD to insist on screening in order to identify patients who 
are not aware of their situation. This value is low compared to that described in the CAMBOD survey in 2008 where about $80 \%$ were not aware of their pathology(11). Is it due to the effect of sensitization or to the reduced sample size of our study?

After reviewing all the analysis we came out with the following risk factors attributed to the development of type 2 diabetes amongst the adult Mbororo in the Guiwa- Yangamo village. In our study population the most representative age group was between 20 and 39 Years and that of the diabetic cases from 40 years. This result is similar to those found in the CAMBOD survey in 2008 (11) which was on a more varied and larger population in Cameroon. This population is made up of mostly youths and the diabetic complications shall be more serious due to the high cost it shall generate. Advanced age especially in the between 50 - 59 years was statistically associated to the outcome of diabetes in the Mbororos. This has been described in a rural population in Bangladesh where the advanced age was attributed to the development of diabetes (17). With the advanced age, we noticed a reduction of physical activity and a probable development of obesity.

In the Mbororo population, overweight had a strong association with the development of diabetes in adults. BMI is therefore the best predicator of obesity (16), contrary to an autochthones population in Ireland with more than 90\% abdominal obesity (18). This result in "Mbororos" is different from which was described in an urban Cameroonian population where obesity was more associated to the development of diabetes (19). Could there be specificity amongst the Mbororos with respect to the rest of the Cameroonians?

Most of the Mbororo were married and kept the family culture. In general, in this zone, local tea or "thaî "is being consumed throughout the day and is being served within the family with a lot of sugar. This consumption or the fact that sugar is being added in the tea showed the level of ignorance of the population and their exposure to diabetes. Future studies shall be necessary to evaluate the perception of this disease and/or sugar in this community. Addition of sugar has been shown to be a risk factor associated to the development of diabetes in Cameroon(19). It has been demonstrated in literature that excess of sugar exposes one to the development of diabetes. This family life is a point showing the responsibility of the man and could be used positively when putting in place education strategies for households in general.

Amongst the Mbororo, 50\% of the diabetic cases had high blood pressure. This prevalence was higher compared to that obtained in European diabetics (17) and African diabetes (19). This value was two times higher than that described among the Touaregs diabetics of Mali (20.44\%). This demonstrated that Mbororos in the nearest future, are exposed to cardiovascular complications linked to this co morbidity (diabetes and high blood pressure) if nothing is done. This could be linked to the excess consumption of salt in vegetables, and to the quality of life style (e.g stress) that this population is experiencing. Low physical activity was associated to the development of diabetes. Amongst the risk factors described in the $6^{\text {th }}$ edition of the IFD Atlas. This factor is described as being associated to the obesity (1). It was noticed amongst the Touaregs of Mali as the first factor responsible in women as compared to men. The African culture obliges the man to be more active physically and the woman to stay backs at home to take care of family. Also fat women were more appreciated (9). This is seen amongst the Mbororos where women are less active than men. This partly explains why women have a higher risk to develop diabetes in the future than men. The Mbororos have as primary activity farming contrary to what we thought of because the community is one known to be made up of cattle rarers. Today they are obliged due to certain circumstances (20) to carry out activities like others.

More than $50 \%$ of our participants oral even those who were diabetic were from the East. This study site did not favor the movements because it was still enclave some year back. This could explain their greater representatives followed by that of Adamaoua which is a region closer to them.

In this forest zone, vegetables are the main source of nutrition. The consumption of vegetables was higher in the age between $40-49$ years; its age of maturity, man is more active and can afford for pleasure. These vegetables are being prepared in different ways and could 
be consumed with much salt and oil. This could explain the association between the consumption of vegetables more than 4 to 5 days with the development of diabetes. Excess consumption of salt could lead to high blood pressure and excess consumption of fatty foods to obesity. All these two factors could favor the development of diabetes.

\section{Advantage of the study}

A censor carried out on the adult population enabled us to have an idea of the population in order to put in place a good data collection strategy. It enabled us to extract Mbororos who were 20 years and above and those who were diabetic as our observations showed to be our participants in survey.

The WHO "STEPS wise" questionnaires with different sections helped us for data collection. It was pretested before using to answer comprehension and feasibility.

Face to face interview was beneficial for translation to the participant, avoided discrimination, ensured minimum confidentiality and above all facilitated meeting with the female participant who were mostly housewives.

The investigators were trained on how to use the tool are they carried out a role play to better understand the tool.

Some specificities of Epi info Software were used to eliminate variables which did not respect the norms to ensure quality and control.

The analysis of our data was done using STATA 11.2 software taking into consideration the complexity of the sampling, the existence of clusters are uncompleted data bases.

The preferential choice of the Glucometer Hemocue B20IRT which gives the best result of blood sugar at an ambient temperature.

\section{Limitation of the study}

It's a transversal study; therefore, it describes the situation of the population only at a given moment. Also it is difficult to generalize this survey without carrying out a more detailed and analytic study and also on a larger sample size. This survey carried out on a psychologically vulnerable population was susceptible to selection and/or information's biases. This population is less exposed or opened out due to their very reserved attitude hence making data collection at times difficult.

\section{Conclusion}

The central objective of this study was attained following the epidemiological profile description of the adult Mbororo of Guiwa -Yangano and the results showed that the sample population studied had a very little knowledge on diabetes. They had a very little or no access to health care and medications. The prevalence of type 2 diabetes in adult Mbororo age 20 and above in Guiwa- Yangamo is $2.3 \%$ and almost 22\% have the risk of developing diabetes if nothing is done. This situation needs the re- enforcement of public health actions in this reserved community but rich in gracing culture. The following three axes seem to be priority: prevention screening and adapted health care provision.

\section{Competing interests}

The authors declared they had no competing interest. The authors declared they benefited from the funds of the IFD.

\section{Author's contributions}

Judith Maka: Conception, design, data collection, data analysis, and drafted the manuscript, Klement Kufe : Conception, design, data analysis and reviewed the manuscript, Félix Assah: Reviewed the manuscript, Akenji Siri: Translated the manuscript, Clarice Mapa Tassou: Reviewed the manuscript, Jean-Claude Mbanya: Conception, design, supervision and reviewed the manuscript. 
Texila International Journal of Public Health

Volume 4, Issue 4, Dec 2016

\section{Acknowledgements}

We thank the participants for taking part in this survey, thereby helping to make advocacy and making health policies backed by local evidence. We also thank the IFD, all the research team members, the staff of the Catholic University of the Central Africa who somehow contributed to the success of this work.

\section{References}

[1.] Aguiree F, Brown A, Cho NH, Dahlquist G, Dodd S, Dunning T, et al. IDF Diabetes Atlas : sixth edition [Internet]. International Diabetes Federation; 2013 [cited 2016 Oct 26]. Available from: http://dro.deakin.edu.au/view/DU:30060687

[2.] American Diabetes Association. Diagnosis and Classification of Diabetes Mellitus. Diabetes Care. 2010 Jan 1;33(Supplement 1):S62-9.

[3.] Almutairi N, Alkharfy KM. Direct medical cost and glycemic control in type 2 diabetic Saudi patients. Appl Health Econ Health Policy. 2013 Dec;11(6):671-5.

[4.] Boutrais J. Les savoirs pastoraux des Mbororo de l'Adamaoua: évolution et rapports au développemment. In: Holtedahl L, Gerrard S, Njeuma MZ, Boutrais J, Le Rôle du Savoir dans le Développement Régional : Conférence Internationale, Tromso (NOR), 1993/09/19-21, editors. Le pouvoir du savoir : de l'Arctique aux Tropiques = The power of knowledge: from the Arctic to the Tropics [Internet]. Paris: Karthala; 1999 [cited 2016 Oct 26]. p. 146-66. (Hommes et Sociétés). Available from: http://www.documentation.ird.fr/hor/fdi:010017690

[5.] Brimblecombe J, Mackerras D, Garnggulkpuy J, Maypilama E, Bundhala L, Dhurrkay R, et al. Leanness and type 2 diabetes in a population of indigenous Australians. Diabetes Res Clin Pract. 2006 Apr;72(1):93-9.

[6.] Bhowmik B, Afsana F, My Diep L, Binte Munir S, Wright E, Mahmood S, et al. Increasing prevalence of type 2 diabetes in a rural bangladeshi population: a population based study for 10 years. Diabetes Metab J. 2013 Feb;37(1):46-53.

[7.] Fouda H, Muna W, Ashutangtang, al. Mortalité chez les Hemodialysés chroniques au Cameroun. University of Yaounde I; 2006.

[8.] Hadley L, Kooijmans M. Pour lee diabete et le developpement. point de Vue 4 nouvelles En Bref 61A. cAmpAgne mondiAle. 58th ed. 2013;8.

[9.] Health of Population in Transition (HoPiT) Research Group. Cameroon Burden of Diabetes (CAMBoD) Baseline survey Report. Yaoundé; 2004.

[10.] International Diabetes Federation, World Diabetes Foundation. Expert Meeting on Indigenous people, Diabetes and development. Copenhagen; 2012 March.

[11.] Jago C. American Diabetes Association - 66th scientific Sessions. Washington DC, USA; 2006.

[12.] Kufe CN, Klipstein-Grobusch K, Leopold F, Assah F, Ngufor G, Mbeh G, et al. Risk factors of impaired fasting glucose and type 2 diabetes in Yaoundé, Cameroon: a cross sectional study. BMC Public Health. 2015 Jan 31;15:59.

[13.] Ministère des Affaires sociales. Annuaire statistique du Cameroun de juin 2012. Yaounde Cameroun; 2012.

[14.] Nakashima D., Galloway Mclean K, Thulstrup H., Ramos Castillo A, Rubis J. Weathering Uncertainty: Traditional knowledge for climate change assessment and adaptation. UN University and UNESCO; 2012.

[15.] Nicolaisen I. Les populations indigènes atteintes de diabète: négligées ou en danger. diabetes voice. 51st ed. 2006;34-6.

[16.] Ohenjo N 'ori, Willis R, Jackson D, Nettleton C, Good K, Mugarura B. Health of Indigenous people in Africa. Lancet Lond Engl. 2006 Jun 10;367(9526):1937-46.

[17.] Pelican M. Mbororo on the move: from pastoral mobility to international travel. J Contemp Afr Stud. 2011 Oct 1;29(4):427-40.

[18.] Pink B, Allbon P. The health and welfare of Australia's Aboriginal and Torres Atrait Islander peoples. Commonwealth of Australia. 2008; 
Texila International Journal of Public Health

Volume 4, Issue 4, Dec 2016

[19.] Scott J, Gavin J, Egan AM, Avalos G, Dennedy MC, Bell M, et al. The prevalence of diabetes, pre-diabetes and the metabolic syndrome in an Irish regional homeless population. QJM Mon J Assoc Physicians. 2013 Jun;106(6):547-53.

[20.] World Health Organization. Health of indigenous peoples. 2007. 


\title{
Review of Maternal Mortality and Near-Miss Events in Kintampo Municipality in the Brong Ahafo Region of Ghana
}

\author{
Article by Gabriel Opoku \\ Ph.D. in Public Health, Texila American University, Ghana \\ E-mail: gabfaraday74@gmail.com
}

\begin{abstract}
Background: Ghana is one of the countries associated with high maternal deaths and near-miss events. This country has adopted the millennium development goals including reducing maternal mortality by three-quarters, and put improvement in maternal health as one of the health sector development programme performance indicators. The purpose of the study was to review maternal mortality and near-miss events in Kintampo Municipality in the Brong Ahafo Region of Ghana in the past 5 years.

Objectives: The measurement of the study were antenatal and postnatal services family planning and abortion practices, delivery care, education and information services, delay in reaching health facility and facility delay

Methods: Study participants were 196. Secondary data was used to collect information at facility level of which 16 health staff took part. In all, 30 maternal deaths and 45 near-misses from 2007 to 2011 were reviewed. Verbal autopsy was used on 180 participants from 5 communities.

Results: 92\% of maternal deaths occurred among young adults. 73\% were in critical condition upon arriving at the hospital. 97\% of the death occurred at the health facility. Attitude of health staff and inadequate maternal health services were significantly associated with maternal deaths. $90 \%$ were not practicing family planning. $48 \%$ of them have practiced unsafe abortion before. Facility delay is significantly associated with maternal death and near-miss events

Conclusion: The results of the study can stimulate a change in clinical practice. The study can be used as a quality improvement tools in facilities.
\end{abstract}

\section{Definition of terms}

Adolescence: According to Eric Erikson's stages of human development, adolescence is from 13 to 19 years.

Community: A group of people who have something in common and act together in their common and collective interest.

Family planning: Family planning includes methods and practices to space births, limit family size and prevent unwanted pregnancies.

Haemorrhage: Haemorrhage is merely another word for bleeding or blood loss. It is a profuse bleeding from ruptured blood vessels.

Live birth: The birth of an infant, after the duration of gestational viability (28 weeks), that exhibits any sign of life, such as respiration, heartbeat, or umbilical pulsation

Maternal mortality: The death of a woman while pregnant or within 42 days of termination of the pregnancy, irrespective of the duration and site of the pregnancy, from any cause related to or aggravated by the pregnancy or its management but not from accidental or incidental causes

Middle adult: According to Erik Erikson's stages of human development, a person in the middle adulthood is from 40 to 64 years.

Multiparous: A mother having two or more children

Near-miss: Any pregnant or recently delivered woman (within six weeks after termination of pregnancy or childbirth) who experienced complications that immediately threatened her survival but did not lead to her death. 
Texila International Journal of Public Health

Volume 4, Issue 4, Dec 2016

Nulliparous: A woman who has never given birth.

Obstructed labour: The term implies failure of progress of labour due to mechanical obstruction despite strong uterine contractions.

Primiparous: A woman who has given birth only once or a woman who has borne but one child

Puerperium: The period immediately after childbirth when the womb is returning to its normal size, lasting approximately six weeks

Skilled birth attendants: Providers with midwifery and obstetric skills, thus excluding trained birth attendants.

Stillbirth: Stillbirth is the birth after 28 weeks of pregnancy which shows no signs of life. It can happen before the baby is born, during the pregnancy or during labour.

Sepsis: It is a severe illness caused by overwhelming infection of the bloodstream by toxin-producing bacteria. Microorganisms invading the body cause infections.

Young adult: A young adult, according to Erik Erikson's stages of human development, is generally a person in the age range of 20 to 40 .

\section{Introduction}

A maternal death is defined as "the death of a woman while pregnant or within 42 days of termination of pregnancy, irrespective of the duration and site of the pregnancy, from any cause related to or aggravated by the pregnancy or its management but not from accidental causes.

(WHO 1993)

Maternal near-miss event is defined as any pregnant or recently delivered woman (within six weeks after termination of pregnancy or childbirth) who experiences complication that immediately threatened her survival but did not lead to her death because of a decisive and timely intervention. Such a woman arrives at the hospital or clinic in a critical condition or developed a critical complication after admission (WHO, 2004; Fillippi et al., 2005.)

According to the last international estimates published in 2012, 287,000 maternal deaths occur annually worldwide, which represents a 47\% decline from levels in 1990. However, $99 \%$ of these still occur in developing countries, with $85 \%$ occurring in sub- Saharan Africa and South Asia. Among developing regions, sub-Saharan Africa has the highest Maternal Mortality Ratio (MMR), with 500 maternal deaths per 100,000 live births (in comparison to a global MMR of 210).

In addition, for every woman who dies, approximately 20 more experience infection, injuries or disability.

Perinatal mortality tends to follow the same geographical pattern as maternal mortality. Every year there are 3.3 million stillbirths and over 4 million newborns die during the first 28 days of life, of which 3 million die in the first 7 days (3-4). In developing countries, about one third of these deaths are related to perinatal complications responsible for birth asphyxia.

The main causes of maternal mortality are known, and more than $80 \%$ of maternal deaths could be prevented or avoided through actions that are proven to be effective and affordable, even in the poorest countries in the world.

The international health community has repeatedly called for action to reduce the large number of preventable deaths and complications from childbearing and governments have formally committed themselves to act in order to achieve this.

Skilled attendance at delivery is advocated as the single most effective intervention for preventing maternal deaths, and the proportion of births attended by skilled health personnel is one of the indicators for the fifth Millennium Development Goal. Access to skilled delivery care is also crucial to prevent stillbirths and to improve newborn survival.

It is critical that women with serious complications receive care from a skilled birth attendant in an appropriate environment. This entails ensuring that appropriate drugs, equipment and infrastructure are available. "Hospital births alone are not enough to save 
mothers' lives; high maternal mortality rates have occurred in hospitals where the quality of care is poor".

"The quality of care provided to the women is a key determinant in maternal outcome and that simple changes in practice can save many lives".

To improve quality of care, the WHO has developed and made available norms, tools, clinical standards and guidelines. These are aimed at ensuring that standardised guidance is available for the treatment and prevention of the major obstetric complications, which are responsible for the vast majority of deaths and disabilities.

However, having guidelines and evidence-based clinical standards in place may not be sufficient, and action is also needed to promote adherence to recommendations. Medical audits may help to maintain or increase adherence to clinical standards and improve quality of care. The Maternal Death Review (MDR) is a type of medical audit. It is "a qualitative, indepth investigation of the causes of and circumstances surrounding maternal deaths occurring at health facilities".

"Avoiding maternal deaths is possible, even in resource-poor countries, but it requires the right kind of information on which to base programmes. Knowing the level of maternal mortality is not enough; we need to understand the underlying factors that led to the deaths. Each maternal death has a story to tell and can provide indications on practical ways of addressing the problem. A commitment to act upon the findings of these reviews is a key prerequisite for success".

Avoiding maternal deaths is possible, even in resource-poor countries, but it requires the right kind of information on which to base programmes. Knowing the level of maternal mortality is not enough; we need to understand the underlying factors that led to the deaths. Each maternal death has a story to tell and can provide indications on practical ways of addressing the problem. A commitment to act upon the findings of these reviews is a key prerequisite for success

\section{Problem statement}

In Ghana, for the past 10 years of Millennium Development Goals implementation, challenges of inequalities, geographical disparities and sustaining the progress still remain. Last year marked Millennium Development Goals implementation deadline, Ghana still lack behind its efforts towards the achievement of all the Millennium Development Goals especially those lagging behind such as Millennium Development Goal 4 (Child Health), 5 (Maternal Health), and 7 (Environmental).

Maternal mortality rate as captured by both survey and institutional data has shown an improvement over the past 20 years. However, the pace has been slow. Between 1990 and 2005, maternal mortality ratios reduced from 740 per 100,000 live births to 503 per 100,000 live births; and then to 451 deaths per 100,000 live births in 2008. This trend is also supported by institutional data which suggest that maternal deaths per 100,000 live births has declined from $224 / 100,000$ in 2007 to 201/100,000 in 2008, after an increase from 187/100,000 in 2004 to $197 / 100,000$ in 2006. If the current trends continue, maternal mortality will be reduced to only 340 per 100,000 in 2015 instead of the Millennium Development Goal target of 185 per 100,000 by 2015 . There are disparities in maternal mortality ratio (institutional) across the 10 regions in Ghana from 1992-2008. Maternal mortality ratio has decreased by up to, 195.2 per 100,000 in Central and Upper East region; 141 per 100,000 in Northern and Western Regions; 120.1 per 100,000 in Volta and Eastern Region; and 59.7 per 100,000 in Upper West, Brong Ahafo and Ashanti Regions. The only region where maternal mortality rate has worsened is Greater Accra (by 87.6 per 100,000). Unless extreme efforts are made by all stakeholders, Ghana is unlikely to meet the Millennium Development Goal target.

Policy measures for improving health services in general and maternal care in particular, are enshrined in the national development policy frameworks including the GPRS I, GPRS II and draft Medium-Term National Development policy Framework 2010-2013 as well as specific Health sector policies. Furthermore, Ghana has numerous initiatives in place to 
address the issue of maternal mortality but the results have not led to desirable improvement in Millennium Development Goal target.

5. Specific initiatives put in place to address the high levels of maternal deaths include the Safe Motherhood Initiative, Ghana Vitamin A Supplementation Trial (VAST), Survival Programme, Prevention of Maternal Mortality Programme (PMMP), Making Pregnancy Safer Initiative, Prevention and Management of Safe Abortion Programme, Intermittent Preventive Treatment (IPT) of Malaria, Maternal and Neonatal Health Programme, Roll Back Malaria programme, and the free Antenatal Care.

In spite of the efforts made to reduce maternal mortality, it remains high in Ghana, and the Brong Ahafo region is of no exception. In 2007 Brong Ahafo region recorded 88 maternal deaths. However, in 2008, maternal deaths in Brong Ahafo region reduced from 88 to 81 . In 2009, maternal deaths in the Brong Ahafo Region increased from 81 (in 2008) to 94, according to the opening report of the 2009 annual review meeting of the Regional Health Directorate at Fiapre near Sunyani on February 18, 2010. Again the Regional Health Directorate of the Ghana Health Service recorded 76 cases of maternal deaths in 2011 as against 66 cases the previous year. Looking at these statistics from 2007 to 2011, Brong Ahafo region alone has experienced 405 maternal deaths of which Kintampo alone experienced 30. In 2007, Kintampo municipality experienced 2 maternal deaths, and in 2008 the figure increased to 8. Maternal mortality was 6 in 2009. In 2010 the municipality experienced 10 maternal deaths out of the total of 66 of the entire region. In 2011, Kintampo municipality recorded 4 maternal deaths.

The increase in maternal death and near-miss in the region substantiate to the need for this research to be done to find out the factors contributing to maternal mortality and morbidity in Brong Ahafo region using the Kintampo Municipality as a case study.

\section{Rationale for the study}

Ghana, like other developing countries has a high maternal mortality ratio. Despite heightened efforts to reduce maternal deaths over the last decade, the country has lagged behind in achieving agreed targets as stated under Millennium Development Goal 5. It is unacceptable for 451 women out of every 100,000 babies born alive to die through pregnancy related complications in Ghana. Complications of pregnancy and child birth are usually not predictable but prevention of the fatality is possible when there is early recognition and effective management of the situation. Whenever we complain about children on the streets and other attendant problems, the problem can partly be traced to the nonavailability of a mother to support the family.

While we talk about reducing maternal deaths as Goal 5, it invariably links up with Goal 4 which is reducing Child Mortality and Goal One in eradicating extreme poverty and hunger. The effort to encourage women to visit their health facilities during pregnancy must be compliment by positive attitude from health workers. This is the only way to motivate the mothers to continue to show up at the facilities. Every life is important and it pays for all not to see the figures as just mere statistics. They can relate to anybody from government officials through health workers to the person on the street. A woman should not die when giving life.

This study seeks to identify the major factors contributing to high maternal mortality in Kintampo North Municipality. Recommendations were based on the findings. This will help the municipal, government and other non-governmental organizations to adopt appropriate measures to bring the tragedy of maternal mortality in the municipality under control. The study will also serve as a reference material for policy makers and other stakeholders.

\section{Objectives of the study}

\section{Main objective}

The main objective is to study maternal deaths and near-miss events at the community and facility levels of Kintampo municipality of the Brong Ahafo region to explore the causes and circumstances surrounding maternal mortality and near-miss events. 


\section{Specific objectives}

1. To determine factors that influence utilization of antenatal care services.

2. To determine factors that influence utilization of family planning.

3. To ascertain factors that influence women to opt for abortion.

4. To determine how delivery care influences maternal deaths.

5. To determine factors that influence postnatal care services.

6. To determine how education and information services influence maternal health.

7. To determine how delay in reaching health facility influences maternal mortality and severe morbidity.

\section{Methodology}

\section{Study type}

A non-experimental, descriptive design utilizing maternal death and near-miss events was used for data collection to determine factors contributing to maternal mortality and near-miss event in Kintampo North Municipality in the Brong Ahafo region of Ghana.

\section{Study area}

The study area comprised all the sub-districts in Kintampo North Municipality.

\section{Target population}

Interviews were conducted with women who suffered a severe morbidity or near-miss events, family members of women who died or presented with a severe morbidity, community members and health workers involved in the care of the women. Focus group discussion was also done in four sub-districts that experienced high rate of maternal mortality and near-miss events from 2007 to 2011.

\section{Data collection techniques and tools}

Data was collected on all maternal deaths and near-miss events which meet the purpose of the study. Secondary data was used to collect information on maternal mortality and nearmiss events. The tools included sections for gathering demographic data as well as information from chart reviews. Health personnel were interviewed based upon the facility secondary data. In all, from 2007 to 2011, Kintampo municipality experienced 30 maternal deaths and 45 near-miss events. (Municipal Health Information Department)

In addition, to facilitate a better understanding of the circumstances surrounding the death or near-miss events, secondary data was used to collect information at facility level of which 16 health staff took part. In all, 30 maternal deaths and 45 near-missed from 2007 to 2011 were reviewed.

Verbal autopsy was used on 180 participants from 5 communities.

Interviews were conducted using open and close ended questions were conducted among women who suffered severe morbidity or near-miss event and family members of women who died or presented with a severe morbidity.

The sub-districts selected were New Longoro, Kawoumpe, Dawadawa, Portor, and Kintampo.

Interviews were conducted in the participant's choice of language with responses immediately recorded onto the tool in English language. Prior to data collection, the purpose of the study was explained to participants. Confidentiality was assured and verbal informed consent was obtained. Participants were informed they could decline to answer any questions or end the interview at any time. 
Texila International Journal of Public Health

Volume 4, Issue 4, Dec 2016

\section{Sampling techniques and sample size}

\section{Sample size}

A total of 196 respondents was estimated and used for the study. This was based on the maternal mortality and morbidity prevalence rate of $15 \%$ in the municipality. (MHMT, 2010)

$\mathrm{n}=\mathrm{z}^{2}(\mathrm{pq}) / \mathrm{d}^{2}$ (Wayne 2006) Where

$\mathrm{n}=$ sample size

$\mathrm{z}=$ Reliability Coefficient with 95\% confidence interval

$\mathrm{p}=$ Population variance available from previous data, where $\mathrm{q}=1-\mathrm{p}$

$\mathrm{d}=$ the desired or the required size of standard error allowed. If the value of $\mathrm{p}$ is 0.15 and the desired standard error chosen to be 0.05 with reliability coefficient of $95 \%$ certainty $(\mathrm{z}=$ 1.96).

$$
\begin{aligned}
& \text { Then, } \mathrm{n}=\frac{\left[(1.96)^{2}\left(0.15^{*} 0.85\right)\right]}{(0.05)^{2}} \\
& \mathrm{n}=\mathbf{1 9 5 . 9} \approx \mathbf{1 9 6}
\end{aligned}
$$

\section{Sampling technique}

Kintampo North municipality consists of seven sub-districts. Secondary data from each sub-district health facility was used to collect information on all maternal deaths and nearmiss events and circumstances that led to the death or near-miss events. After having information on maternal mortality cases and near-miss events from 2007 to 2011 in each health facility in the sub-district, health workers involved in the care of the women were purposively selected and interviewed. This was done to validate and confirm secondary data collected from each facility.

Also all information on near-miss events, recorded at each health facility in the subdistricts was obtained.

Verbal autopsy was also used in the study to know the perception of the community members on the causes of maternal mortality and near-miss events in the community. This was based on the prevalence rate of maternal mortality and near-miss events in the subdistricts. The sub-districts selected were New Longoro, Kawoumpe, Dawadawa, Portor and Kintampo.

\section{Data analyses}

Data was analysed to identify factors contributing to maternal morbidity and mortality. Secondary data for both quantitative and qualitative were collected at the facility and community level. Quantitative data was transcribed into an excel spreadsheet for analysis. Quantitative data was analyzed within the framework of the objectives of the study.

\section{Limitation}

Limitations to the study were that, data was collected in only one of 22 districts in the region. There might be also selection bias, recall bias and information bias. These were addressed by cross-checking respondent's responses with other close relative for better accuracy. Order than that, this might have affected the general representation of the results.

\section{Results}

\section{Introduction}

This chapter details the findings of the 196 respondents interviewed. In all, 30 maternal deaths and 45 were near-miss events which occurred from 2007 to 2011 were analyzed and reviewed at the selected facilities. Verbal autopsy was also used on 121 respondents.

The presentation of the results is based on the objectives of the study. 


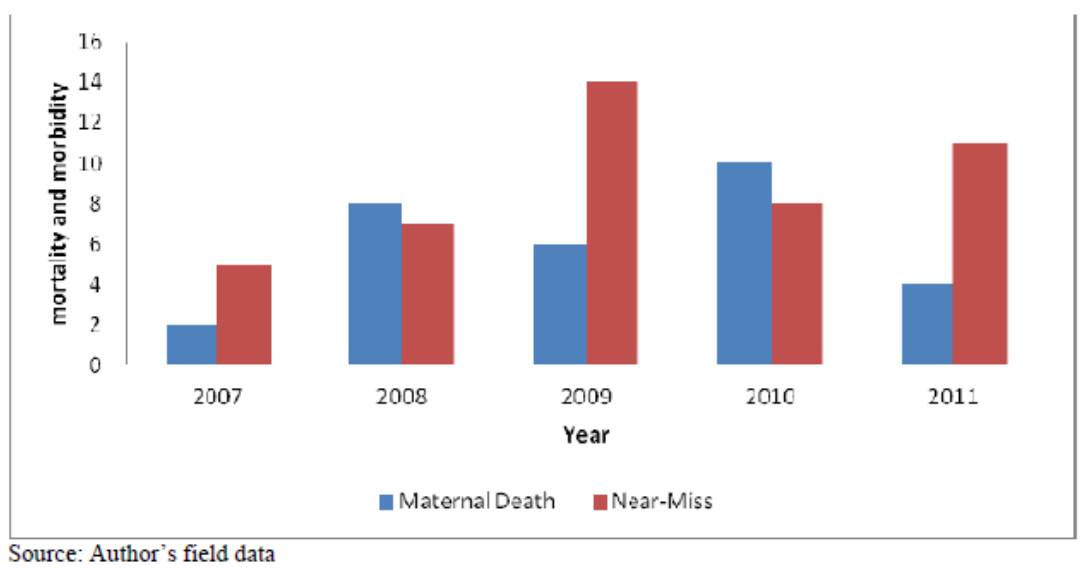

Figure 1: Distribution of Maternal Mortality and Near-Miss Events per Year.

Figure 1 above indicates that from 2007 to 2011, Kintampo North Municipality experienced 30 maternal deaths and 45 near-miss events. Out of the total deaths and nearmiss events, there were six (6) deaths and fourteen (14) near-miss events that constitute $20.0 \%$ and $31.0 \%$ in 2009. In 2010, maternal mortality increased from 6 to 10 and maternal morbidity reduced from 14 to 8 respectively and constitutes $33.3 \%$ and $17.8 \%$. In 2011, there were 4 (13.3\%) deaths and $11(24.0 \%)$ near-miss events.

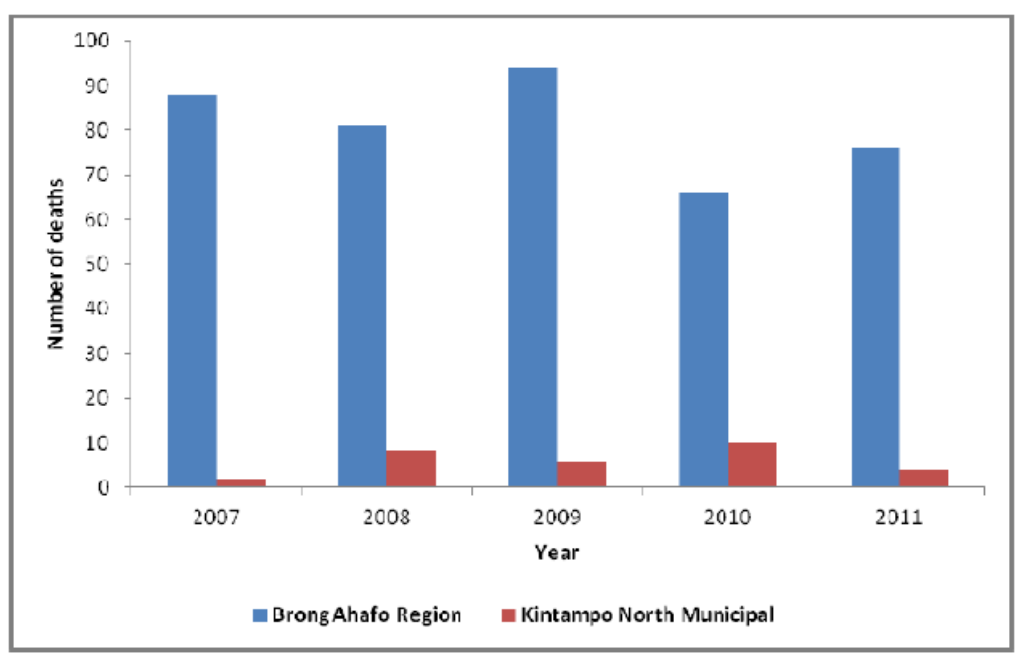

Figure 2: Maternal Mortality figures in Brong Ahafo Region as against Kintampo North Municipal; (2007-2011).

Looking at figure 2; from 2007 to 2011, Brong Ahafo Region experienced four hundred and five (405) maternal deaths for the entire 22 districts of which Kintampo North Municipality alone experienced thirty (30) maternal deaths which constitutes $7.4 \%$.

The graph above indicates that in 2009 there were 94 maternal deaths in Brong Ahafo region and out of it; Kintampo North experienced 6 deaths constituting 6.3\% in the region. In 2010 and 2011 there were 66 and 76 maternal deaths in the region of which Kintampo obtained 10 and 4 respectively constituting $15.2 \%$ and $5.3 \%$.

Table 1: Demographic Characteristic of Study Population Stratified by Maternal Mortality and Near-Miss

\begin{tabular}{|l|l|l|l|}
\hline Parameter & $\begin{array}{l}\text { Total Population } \\
n=75(\%)\end{array}$ & $\begin{array}{l}\text { Maternal Deaths } \\
n=30(\%)\end{array}$ & $\begin{array}{l}\text { Near-Miss } \\
n=45(\%)\end{array}$ \\
\hline Marital Status & & & \\
\hline Single & $17(22.67)$ & $7(41.17)$ & $10(58.82)$ \\
\hline
\end{tabular}


Texila International Journal of Public Health

Volume 4, Issue 4, Dec 2016

\begin{tabular}{|l|l|l|l|}
\hline Married & $58(77.33)$ & $23(39.65)$ & $35(60.34)$ \\
\hline Religion & & & \\
\hline Christianity & $46(61.33)$ & $16(34.78)$ & $30(65.22)$ \\
\hline Islam & $24(32.00)$ & $10(41.67)$ & $14(58.33)$ \\
\hline Traditional & $5(6.67)$ & $4(80.00)$ & $1(20.00)$ \\
\hline Educational Status & & \multicolumn{2}{|l|}{} \\
\hline No Education & $37(49.33)$ & $18(48.65)$ & $19(51.35)$ \\
\hline Basic & $32(42.67)$ & $11(34.38)$ & $21(65.62)$ \\
\hline Secondary & $6(8.00)$ & $1(16.67)$ & $5(83.33)$ \\
\hline Occupational Status & & & \\
\hline Unemployed & $8(10.67)$ & $1(12.50)$ & $7(87.50)$ \\
\hline Farmer & $30(40.00)$ & $11(36.67)$ & $19(63.33)$ \\
\hline Trader & $24(32.00)$ & $5(20.83)$ & $19(79.17)$ \\
\hline Other & $13(17.33)$ & $13(100)$ & $0(0.00)$ \\
\hline Parity & & & \\
\hline Nulliparous & $14(18.67)$ & $8(57.14)$ & $6(42.86)$ \\
\hline Primiparous & $17(22.67)$ & $10(58.82)$ & $7(41.18)$ \\
\hline Multiparous & $44(58.66)$ & $12(27.27)$ & $32(72.73)$ \\
\hline Psychosocial Dev't & & & \\
\hline Adolescence & $5(6.67)$ & $2(40.00)$ & $3(60.00)$ \\
\hline Young Adult & $69(92.00)$ & $28(40.58)$ & $41(59.42)$ \\
\hline Middle Adult & $1(1.33)$ & $0(0.00)$ & $1(100)$ \\
\hline Average age & 27.52 & 25.27 & 29.02 \\
\hline
\end{tabular}

Data is presented as figure with percentages in parenthesis, and averages. N- Number, \%percentage, Dev't- development.

Table 1 indicates that the average age of women who experienced maternal mortality and women with a near-miss event was approximately 28 years with the greatest number between 20 and 30 years, of which 17 of them were single and 58, were married constituting $22.7 \%$ and $77.3 \%$ respectively. The computed chi-square statistic has a value of 22.413 and the significance value is 0.00 . Since this value is less than the alpha level, we can reject the hypothesis of independence at the 0.05 level. Thus, marital status has influence on maternal mortality and morbidity.

Also looking at Table 1 above, majority, 46 were Christian, 24 Islam, and only 5 were traditionalists, constituting $61.3 \%, 32.0 \%$, and $6.7 \%$ respectively. The computed chi-square has a value of 33.680 and the significance level is 0.00 . Since this value is less than the alpha level, we can reject the hypothesis of independence at the level 0.05 . Thus religion and maternal mortality and morbidity are in fact related.

Out of 75 women who experienced maternal mortality and near-miss events, majority $37(49.3 \%)$ had no education, 32(42.8\%) had basic education, and only $6(8.0 \%)$ had up to secondary education respectively. The obtained chi-square statistic is 22.160 and significance value is 0.00 . Since this value is less than the alpha level, we can reject the hypothesis of independence at the 0.05 . Thus the level of education and maternal mortality and morbidity are in fact related.

Table 1 above further shows that out of the 75 women who experienced maternal mortality and morbidity, $8(10.7 \%)$ were unemployed, 30(40.0\%) were farmers, $24(32.0 \%)$ were traders, and $13(17.3 \%)$ were hair-dressers respectively. There was no civil servant. The computed chisquare statistic has a value of 16.147 and its significance value is 0.001 . Since this value is less than the alpha level of 0.05 , we can conclude that occupation and maternal mortality and morbidity are not independent; rather the two variables are related. 
Table 1 indicates further that, 14(18.7\%) women had no children, 17(22.7\%) were having 1 child each, and 44(58.6\%) were having 2 or more children each. The computed chi-square statistic has a value of 21.840 and significance value 0.00 . Since significance value is so low that it is displayed as 0.00 , the two variables are indeed related. Thus the number of children of a woman actually influences maternal mortality and near-miss.

Table 2: Respondent Health Seeking Behaviour and Priority Rating of Factors that Contribute to Maternal Death and Near-Miss Events

\begin{tabular}{|l|l|l|l|}
\hline Parameter & $\begin{array}{l}\text { Total } \\
(\mathbf{n}=75)\end{array}$ & $\begin{array}{l}\text { Maternal Deaths } \\
(\mathbf{n}=30)\end{array}$ & $\begin{array}{l}\text { Near-Miss } \\
(\mathbf{n}=\mathbf{4 5})\end{array}$ \\
\hline \multicolumn{2}{|l|}{ Health Seeking Behaviour } & \\
\hline Excellent & $28(37.33)$ & $13(46.43)$ & $15(53.57)$ \\
\hline Good & $22(29.33)$ & $7(31.82)$ & $15(68.18)$ \\
\hline Poor & $25(33.34)$ & $10(40.00)$ & $15(60.00)$ \\
\hline Priority Factor Rating & $28(37.33)$ & $11(39.29)$ & $17(60.71)$ \\
\hline USA & $22(28.00)$ & $8(38.14)$ & $114(61.91)$ \\
\hline NAAC & $14(18.67)$ & $3(21.43)$ & $11(78.57)$ \\
\hline DRH & $5(8.00)$ & $2(33.33)$ & $3(66.67)$ \\
\hline IDC & $2(2.67)$ & $2(100)$ & $0(0.00)$ \\
\hline IEDU & $2(2.67)$ & $2(100)$ & $0(0.00)$ \\
\hline NPCS & $2(2.67)$ & $2(100)$ & $0(0.00)$ \\
\hline TMB & & & \\
\hline
\end{tabular}

Data is presented as figures with percentages in parenthesis, N-number, \%-percentages, USA-unsafe abortion, NAAC-not attending antenatal care, DRH-delay in reaching health facility, IDC-inadequate delivery care, IEDU-inadequate education and information services, NPCS- not attending for postnatal care services, TMB-too many births.

Of the 75 respondents who were interviewed on contributory factors to maternal mortality and near-miss events, 28(37.3\%) attributed it to unsafe abortion, and 22(28.0\%) said not going for ANC services. Delay in reaching health facility also constituted 14(18.7\%). The rest attributed it to inadequate delivery care 5(8.0\%), inadequate education and information services 2(2.7 \%), not going for postnatal care services 2(2.7\%), and 2(2.7\%) said too many births. 

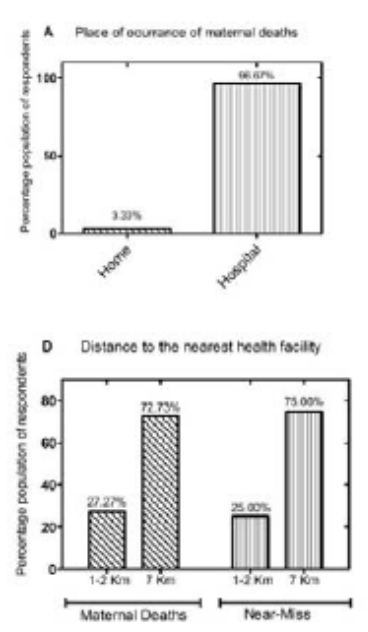
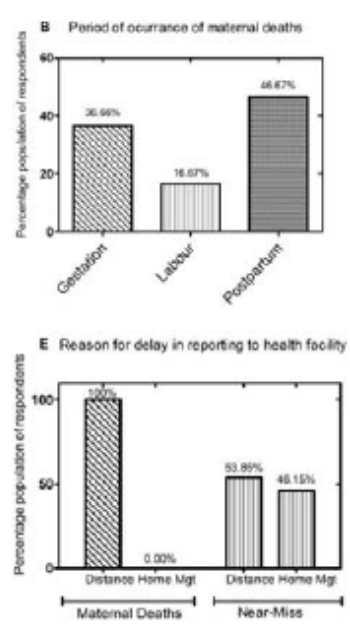
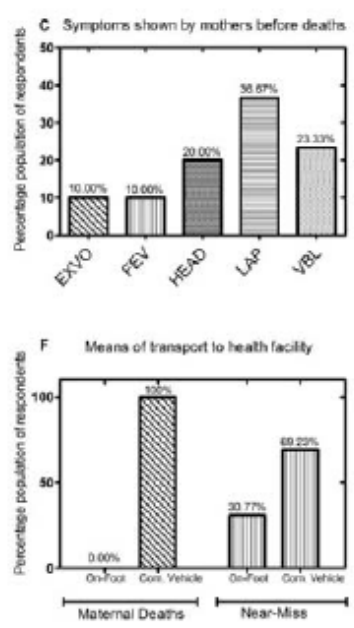

Figure 3: graph (A) shows place of occurrence of maternal deaths, (B) gestational period of occurrence of maternal deaths, (C) symptoms shown by mothers before death, (D) distance to the nearest health facility, (E) reason for delay in reaching health facility, and (F) means of transport.

Figure 3, graph (A) above indicates that out of 30 maternal deaths, only $1(3.3 \%)$ death occurred at home, and the rest 29(96. 7\%) constituting the majority occurred in hospital. Figure 3 graph B; shows that majority of the deaths 14(46.6\%) occurred immediately after delivery, 11(36.7\%) during pregnancy, and 5(16.7\%) during labour. Figure 3 graph C; indicates the symptoms shown by mothers before death. Lower abdominal pains (36.7\%), vaginal bleeding (23.3\%), headache (20.0\%), fever (10.0\%), and excessive vomiting (10.0\%). Figure 3 graph D; shows that the for majority constituting $(72.7 \%)$ of women who experienced maternal death, the distance to the nearest health facility was $7 \mathrm{~km}$ and only (27.3\%) was $1-2 \mathrm{~km}$. For women who experienced maternal morbidity, (75.0\%) distance to the nearest health facility was $7 \mathrm{~km}$ and only $(25.0 \%)$ was $1-2 \mathrm{~km}$. Figure 3 graph E; indicates that; for the maternal deaths, all the women who were delayed in reaching the health facility attributed the delay to distance to the nearest health facility was too far. For maternal morbidity, the majority (53.8\%) attributed the delay to distance; whiles (46.2\%) attributed it to delay at home. Figure 3, graph F shows that, for the maternal deaths, means of transport to health facility was by commercial vehicle whiles women who experienced near-miss, majority (69.3\%) means of transport to facility was by commercial vehicle and only (30.7\%) walked to the facility.

\section{Discussion}

\section{Introduction}

This section of the study discusses the findings of the study. The implications of the findings to the health of the community and mostly, pregnant women are inferred. In addition, it provides other observation of maternal mortality and near-miss events that have been established in related work and also related to the observations made in this study. It arrangement is based on the objectives of the study.

\section{Maternal Mortality and Near-Miss events trend in Kintampo North Municipality compared to that of the Brong Ahafo Region.}

In 2007 to 2011, Kintampo North experienced 30 maternal deaths and 45 near-miss events. In 2007, maternal death was 2 and near-miss events 5. In 2008, maternal death was 8 and near-miss was 7. In 2009 maternal death was reduced from 8 to 6 deaths whiles near-miss was increased from 7 to 14 in the same year. Again in 2010, maternal death increased from 6 to 10 whiles near-miss reduced from 14 to 8 . In 2011, maternal mortality was reduced from 
10 to 4 whiles near-miss increased from 8 to 11. In the same year period, (2007 to 2011) the Brong Ahafo Region experienced 405 maternal deaths. In 2007, the region experienced 88 maternal deaths. In 2008, maternal deaths in the region assuaged from 88 to 81 whiles in 2009 it increased from 81 to 94. In 2010, maternal deaths in the region abated from 94 to 66 deaths. However, in 2011, maternal death increased from 66 to 76.

This unfortunate trend has implications on improving the lives of women in the region and more importantly achieving the MDG goal number five (Hertcht, 2006). On the later, if the trend continues it is obvious that reducing mortality ratio by $75 \%$ by the year 2015 would be a mirage. There is therefore the need to critically examine the impact of current interventions aimed at achieving this objective such that, at least, a reasonable achievement could be made towards the target within the few years left towards 2015.

It was observed that, almost half of the deaths 14 (46.6\%) occurred after delivery, 11(36.7\%) during pregnancy, and only 5(16.7\%) during labour. Most of the deaths, $96.7 \%$ occurred in health facility and only 3.3\% occurred at home. Most symptoms associated with the deaths were severe labour pains $36.67 \%$, and vaginal bleeding was $23.33 \%$

\section{Association between Socio Demographic Characteristic of Respondents and Maternal Death and Morbidity}

Age has been noted to be a significant factor in the incidence of maternal death and morbidity (Christian, 2009). Indeed most of the maternal deaths and morbidity occurred among relatively younger women. The study found out that $5(6.67 \%)$ of the women who experienced maternal mortality and morbidity were adolescence, 69(92.00\%) were young adult and only $1(1.33 \%)$ was middle adult. Prolonged labour or obstructed labour occurs where malnutrition is greater and where girls marrying at a young age are expected to prove their fertility. (The consequences of maternal morbidity and mortality, national research council, 2000). The young women form critical part of the productive sector of the economy of the municipality. They could have dispensed their energy in farming, education, and among other occupation to the benefit of the people and the municipality. The death of these young women therefore could affect the development of the area. The essence of young people forming the critical manpower for every community cannot be underestimated. It is therefore worrying that despite this recognition, the communities are still not up to the task of protecting their own from avoiding deaths such as maternal deaths. The life of these young and productive women could be saved through family and community support and the use of the community structured health services including CHIPS were used.

It is perceived that married couples would care for each other by providing social and financial support for each other in times of meeting health needs of one another. Pregnant women who might have been sick or required urgent attention during labour may have received enough assistance and care from the spouse so as to prevent death. Unlike the unmarried women who are pregnant, there should be some concern and response to ill health in times of pregnancy among married women. However, it is worth noting that maternal deaths and near-miss were higher in married women than single women. Maternal deaths and morbidity among married women was 58(77.3\%) as compared to single women $17(22.7 \%)$ respectively. This may be due to the fact that the majority of the women's husbands were unemployed. The occupation of the women husbands is a significant predictor of maternal deaths. The unemployed partner may not have the requisite resources to support the pregnant wife to go through regular ANC, labour and delivery.

It is evident from this study that the educational level of the women had strong relationship with maternal mortality and morbidity. In fact, out of 75 women who experienced maternal mortality and morbidity from 2007 to 2011, 37(49.3\%) had no basic education, 32(42.8\%) had basic education, and only $6(8.0 \%)$ had education up to 2 nd circle. The computed chisquare statistic is 22.160 and significance value is 0.00 . Therefore the study found that the level of education and maternal death are not independent. 
The occupation of the women was also a significant predictor of maternal deaths and nearmiss event. The study found out that $8(10.7 \%)$ of the women were unemployed, 30(40.0\%) were in small scale farming, 24(32.0\%) were petty traders, and 13(17.3\%) were in apprentice in seamstress and hairdressing. In fact there was no death and near-miss among civil/public servant. It is presumed that the pregnant women who were employed were more capable, concerned and responsible for themselves either than relying on their husbands as compared to those unemployed. The obtained chi-square statistic has a value of 16.147 and its significance value is 0.001 . Since this value is less than the alpha level of 0.05 , the study concluded that, occupation and maternal mortality and morbidity are in fact related.

The parity of the women had significant influence on maternal death and near-miss (Christian, 2009). The trend analysis showed that women who were nulliparous 14(18.7\%) were less likely to experience maternal mortality and morbidity as compared to primiparous, 17(22.7\%), and those who were multiparous, 44(58.665\%) are more likely to experience maternal mortality and morbidity. The computed chi-square has a value of 21.840 and significance value 0.00 . It is well documented that increased risk of maternal death and morbidity has a relationship with parity. Indeed, the Ghana health service identifies women with parity five and above as high risk groups requiring tertiary services attention due to the possibility of developing of complications.

\section{Health Seeking Behaviour of Mothers who Experienced Maternal Mortality and Near-Miss Events}

Attending ANC is one of the key indicators for measuring pregnancy outcomes (Galadance et.al, 2007). Ghana health service promotes the use of ANC services as a means of preventing avoidable maternal deaths. Antenatal care is one of the most important ways of reducing maternal mortality and morbidity (2007 maternal health survey). The question is; how many women are taking advantage of it? This is intended through the intensive education in the community on the need to use ANC services coupled with providing services to the door steps of the women in the form of CHPS. It is enshrined in the ANC policy of the GHS that women who access the services among several services are examined thoroughly for possible complications of pregnancy and are advised or treated appropriately. The problem is that some of these complications cannot be predicted and worst of all cannot be prevented. Yet early identification in a facility can help for it to be managed to avoid needless death (Save the Children, 2000). Unfortunately majority of the women who died as a result of pregnancy or its related complications did not use ANC services. This was also observed in many studies (Onah et.al. 2006; Galadance et al 2007). Indeed those (70.7\%) who used the services fell below the national average of about $90 \%$ (GHS, 2007).

It is not only important to attend ANC but to also be regular. It is expected that every pregnant woman in Ghana should attend ANC at least four times. Regular attendance to ANC would ensure that indicators for complications and necessary delivery plans such as caesarean section are quickly noted and planned ahead of time. It was observed in the study that (81.1\%) attended ANC twice or more. However, only 1(0.02\%) attended ANC four times. Gestational period at first ANC; three months or less was $62.3 \%$. It was observed in the study that majority (99.98\%) of the maternal deaths and morbidity was noted to have not attended ANC four times or more. The question is what could have accounted for this? During interview, majority (67.3\%) said ANC services are discouraged as a result of attitude of health staff during ANC services and only (32.7\%) pivoted it to inadequate maternal health services during ANC. Also during focus group discussion among community members, majority (53.3\%) said attitude of health staff and financial constraints. The studies found out that, the health seeking behaviour of the women are not encouraging and this could have accounted for this high incidence of maternal deaths and near-miss events. 


\section{Delivery Care, Necessary Emergency Obstetric Care facility and Equipment and Utilization of Postnatal Care Services}

Postnatal period is the medical term for the period following childbirth during which the body tissues, in particular the genital and pelvic organs, return to the condition in which they were in pre-pregnancy. This post delivery period of change continues about six weeks (42 days) from delivery. Postnatal care is the care given to both mother and the baby during this period. The first 24 hours after birth is a critical stage of the postpartum period. Occasionally, this is the time most life threatening complications of delivery manifest. Ideally, a new mother should visit a health facility for her first postpartum, or be visited by a health worker at home, within 7 to 10 days after the delivery. This is especially true if she delivered at home. This visit is important to make sure that the woman and the baby are recovering from the labour and delivery.

Serious complications can still occur after the woman has given birth and as such activities carried out during PNC include management of the normal puerperium, identification and management of complications, micronutrient supplementation, immunization of mother and baby, voluntary counselling and testing and STI prevention, family planning counselling and services. (Dr. Arkutu, 1995)

The study found out that $48(64.0 \%)$ of the women were able to carry their pregnancy to gestational term, majority 36(75.0\%) delivered at health facility and the rest 12(25.0\%) delivered at home. The study observed that of the women who delivered at home, 10(88.3) experienced complications during labour and 4 died. According to State of the World's Mothers 2000, Save the Children; and Reproductive Health Interventions, although Sri Lanka has a low per capita income, over 94 percent of it births occurred in hospitals causing its MMR to decline thus, 30 deaths per 100,000 live births in 1999.

Those who delivered at health facility $11(30.6 \%)$ of them experienced complications during labour and 1 of them died. The complications were haemorrhage (33.3\%), and severe anaemia (31.0\%) followed by sepsis (27.7\%) and eclampsia (9.0\%). Furthermore, it was noticed that, only 4(33.3) of women who delivered at home had live births whiles live births for women who delivered at health facility was almost $64 \%$.

It was also observed in the study that 37 mothers who experienced complications after delivery, 6(16.2\%) had their PNC less than three days after delivery, 11(29.7\%) three days and above, and 20(54.1\%) had no PNC. Of the women who did not have any PNC, 14(70.0\%) of them died. During focus group discussions among community members, almost 75.0 percent of the respondents said some women do not use health facility during delivery because of unfriendly attitude of health staff and financial constraint. Almost 76 percent said they are assisted by Traditional Birth Attendants of which 60 percent of them are trained.

Of the women who did not attend PNC after delivery, 6(30.0\%) attributed their absenteeism to the attitude of health staff, 11(55.0\%) not having money for the services, 5(25.5\%) inadequate maternal health services. According to (MOH 2008), the available data showed that over $40 \%$ of women did not use health facility during delivery and after delivery because some of them thought it was unnecessary to do so. The causes of the complications were severe bleeding (46.0\%), prolonged labour (32.4\%), and sepsis (21.6\%)

World Health Organisation report (2007) indicated that most maternal deaths occur during labour, delivery, or the first 24 hours after delivery, and most complications as mentioned earlier cannot be prevented or predicted. This study found out that most of the deaths occurred during labour 11(36.7\%), and after delivery (46.7\%).

Skilled care during pregnancy, childbirth, and the immediate postpartum period, by health care professionals with appropriate skills has been recognised as the key intervention to reduce maternal mortality. Skilled birth attendants include midwives and other health professionals with midwifery skills. The study reviewed that majority 52(69.3\%) of women who experienced maternal deaths and morbidity received care from auxiliary midwives and TBA's. Sri Lanka's nationwide healthcare system expansion and improved midwifery skills 
Texila International Journal of Public Health

Volume 4, Issue 4, Dec 2016

contributed to a dramatic decline in the MMR, (The Consequences of Maternal Morbidity and Maternal Mortality, National Research Council, 2000)

Report of the Ghana Statistical Service (2005, 2008), Ministry of Health (2006) indicated that delivery that were assisted by a health professional recorded a slow progress, increasing from $40 \%$ in 1988 to 59\% in 2008. In the Northern region, 1 in 4 compared to 4 in 5 children in Greater Accra region, is likely to be delivered in a health facility. Professional assistance at birth for women in urban areas was found to be twice more likely to occur than those in the rural areas (MOH, 2008). The available data showed that over $40 \%$ of women did not deliver in a health facility because some of them thought it was unnecessary to do so. (MOH, 2008). According to MOH, 2010 Programme of Work, skilled delivery was a key in the maternal health care. Labour and delivery are the shortest and most critical periods in the childbirth continuum. It stated that "most maternal deaths occur from complications during delivery." Even with the best possible antenatal care, any delivery can become complicated. Therefore, skilled assistance is required to ensure safe delivery care.

The GHS road map for accelerating the attainment of the MDGs related maternal and neonatal health in Ghana 2007-2011 indicated that there have been several attempts to widen coverage of skilled delivery service and improve service utilization. These include introduction of free delivery, NHIS, community education to improve demand, posting of midwives to health centres and CHPS compounds, lifesaving skills training. A mix of strategies exists to improve the quality of skilled delivery care, including maternal deaths audit and maternal death notification.

However, skilled delivery rate has remained low at 59\% (GDHS 2008) annually compared to antenatal registrant rate of above $90 \%$. The challenges explained the low rates of skilled delivery among others are the provider attitude, socio- cultural challenges and inadequate midwives.

It must, however, be noted that for skilled birth attendants to effectively perform, they need the necessary emergency obstetric care facilities and equipment in order to prevent the senseless deaths of our mothers and sometimes their children which had continued over the years. It was observed in the study that, majority (69.3\%) of women who experienced maternal deaths and morbidity were not cared by facility with necessary emergency obstetric care and equipment. It was observed in the study that most of these women were normally referred to Kintampo government hospital which majority (61.5\%) said the distance to the facility is between 6-15 miles, and the means of transport to the referral facility was clients' own means through the use of commercial transport which sometimes it was difficult to come by.

\section{Delay in Reaching Health facility and Delay at facility}

The first delay is the decision to seek care by the woman and/or family. This level of delay is one of the most complexes as it involves many layers of socio-cultural factors such as educational level, women's status, cultural beliefs and perception in illness severity. All of these elements play a role when a woman and her family and birth attendant (if present) decide to seek skilled care. The study observed that of the women who experienced maternal mortality and morbidity most of them (72.7\%) and (70.0\%) distance to the nearest health facility was $7 \mathrm{~km}$ and above. For maternal mortality cases, (73.3\%) were delayed in reaching health facility and the reason was distance to the nearest health facility was too far. Various modes of transportation were used including walking, taxis and market trucks. Eighteen women with near-miss and nine women who died at the facility experienced some delay in transfer to a health facility including difficulty in finding money for transportation, living in remote villages with no transportation available and seeking assistance during the night when people did not want to travel on unsafe roads.

One woman stated, "it took almost 2 hours to get to reach the hospital because the driver refused to bring me, so we have to look for extra money to pay another driver to take me to the hospital. 
The family of one woman who died in the community recounted difficulty in finding transportation. This woman died while the family members searched for a way to transport the woman to the hospital.

Indeed majority, (96.7\%) of the deaths occurred in health facility. The majority of women experiencing maternal mortality and near-miss event (74.0\%) were in critical condition upon arrival at the hospital suggesting that important delays were encountered in reaching the facility. Nearly half $(49.0 \%)$ were referred from another facility, usually a rural clinic or facility without necessary emergency obstetric equipment. Of the mothers who were nearmiss, $28.9 \%$ delayed in reaching health facility and the reasons were distance $(53.8 \%)$ and home management (46.2\%). A delay in the recognition of obstetric complications among women, family members and community members including traditional midwives was the most common in the data when examining for each delay. A total of 35 with maternal mortality and near-miss events (74.3\%) experienced this delay. In addition, a delay in the decision to seek care was reported in connection with eight women who died at the facility and one woman who died in the community. Other factors contributing to the delay included keeping a problem hidden from others and trying self-treatment or traditional remedies before seeking care. Women were often referred to multiple levels of providers before seeking care at the tertiary care level. One participant said the following: "I was in labour at home for very long hours, about 7 hours, when I started feeling very weak and unable to push my baby. That was the time I told my Auntie that they should take me to hospital. I was given country herbs to drink. My stomach was rubbed with chalk. I was very restless and my stomach became very tense and tender." Her family waited to seek help from a trained provider until the situation worsened despite the woman's desire to find help sooner.

The most common causes of mortality and severe morbidity were haemorrhage (45\%) and severe anaemia (24\%) followed by sepsis (17\%) and eclampsia (14\%). Distance from a health centre, quality of care expected at the health centre and ability to pay for services also can affect the decision to seek care (Thaddeus and Maine, 1994).

Reaching an adequate health facility is the second delay in the three delay model. Access to health facilities, adequate infrastructure for transportation and distribution of appropriate health facilities are all logistical factors in causing a delay for a woman and her family (Thaddeus and Maine, 1994).

Mothers who were not delayed in reaching health facility, 5(12.5\%) experienced complications as a result of facility delay. After delivery, 3(60.0\%) experienced excessive bleeding and there was no blood in facility blood bank and they became weak leading to unconsciousness. Forty percent (40.0\%) experienced excessive bleeding because at the time they reached the facility, there were no adequately trained staffs present. According to Thaddeus and Maine, (1994) once a woman arrives at the facility, she may not receive the care she needs. Staff may not be present or adequately trained and supplies may not be available and this goes a long way to worsen their health status.

\section{Education and Information Services during Pregnancy, Delivery and after Delivery}

Education and information services comprise community education about safe motherhood, education about pregnancy danger signs and complications, and reproductive health and family planning information and services for adolescents and adults. The study found out that almost $72.0 \%$ of mothers who experienced maternal mortality and near-miss events did not receive adequate care during pregnancy, delivery and after delivery. The director of Noguchi Memorial Institute for Medical Research, Prof Ofori-Adjei, speaking at the launching of the Initiative for Maternal Mortality Programme Assessment (IMMPACT) in Accra on Wednesday, $6^{\text {th }}$ of February, 2003, attributed the high maternal deaths to lack of information in designing effective interventions to save the lives of many women. He observed that, despite efforts at reducing maternal deaths in the country, following the 
Texila International Journal of Public Health

Volume 4, Issue 4, Dec 2016

coming into force of the safe motherhood initiative in 1987, data assessment on maternal deaths still remains unacceptably high.

According to Ghana MAF Action Plan (CAP) (August 2010), behaviour change communication is another key initiative to create awareness about pregnancy risk factors, danger signs and increased demand and utilization of antenatal services, skilled personnel, emergency obstetric care and postnatal care. The programme uses the media to inform, educate and communicate messages for adoption of desired behaviours; printing of posters, leaflets, fliers; advocacy; use of traditional leaders/religious leaders and groups etc. Recently, with support from UNICEF, the Health Promotion Department of Ghana Health Services has developed a common framework for behavioural change termed "Communication for Development" (C4D).

\section{Family Planning and Abortion Practices}

According to Ghana MAF Action Plan (CAP) (August 2010), effective family planning is one of the high impact interventions that reduce the risk of maternal deaths from pregnancy related complications and unsafe abortion. But as indicated, family planning acceptor rate remained low (21.2-25.4\%) of women in their reproductive age between year 2001 and 2007. It was observed in the study that almost (90.0\%) of women who experienced maternal mortality and morbidity were not practicing family planning.

It was articulated in the study that, side effects were the main reason that prevent them from family planning utilization. The majority, 63 percent said the practice delays pregnancy in later life, 34 percent said the practice leads to infertility, only 3 percent said they sleep a lot due to the practice. Since the implementation of the "repositioning of FP" to improve comprehensive FP coverage, fear of side effects bottlenecks among many others, that slow down the achievement of set targets still persist. (Demographic and Health Survey, 2008)

It was found in the study that women who were not practicing family planning, almost (60.0\%) of their pregnancies were unplanned. Family planning prevents unwanted pregnancy and reduces the risk of maternal deaths from pregnancy related complications and unsafe abortion, (Demographic and Health Survey, 2008). During focus group discussion, majority 94 percent said the number of children each woman has is five and above, and 100.0 percent said they do not practice family planning because of its side effects. Majority, almost $49 \%$ said the practice delays pregnancy in later life. One in four maternal deaths could be prevented by family planning. Access to family planning has a great impact on maternal mortality. (Save the child). An estimated 150 million women in developing countries want to delay or stop childbearing, but are not using family planning. (Save the child). Almost (48.0\%) of women who were not practicing family planning had unsafe abortion.

According to WHO 2007 report, preventing unplanned pregnancies could reduce unsafe abortions and maternal deaths, especially among young women by about 30 per cent.

It was articulated in the study by almost 58 percent that the reason for having an abortion was to space childbearing and 42 percent said they were not financially viable to take care of the pregnancy and the baby as well. Majority, almost 74 percent partners were in favour of abortion. Majority, almost 79 percent practiced unsafe abortion. Their pregnancies were terminated by either buying drugs from a pharmacy or chemical stores. During the focus group discussion, it was revealed that: when partner denies pregnancy 39 percent, financial constraints 34 percent, and to space childbearing 27 percent were the main reasons for abortion practices.

Thirty per cent of maternal deaths recorded in Accra in 2001 were said to be caused by unsafe abortion. Abortion is legal in Ghana, but many of the women go for backstreet abortions due to poverty. (World Health Statistics, 2010). In an interview under which abortion is legal, almost 74 percent said when the life of the mother is in danger and 26 percent said risk to physical health of mother. Majority, 68 percent said they were counselled by health professional following abortion. 


\section{Conclusion and Recommendations}

\section{Conclusion}

\section{Socio-Demographic Characteristics in Relation to Maternal Mortality and Near-Miss Events in the District.}

- Most of the maternal deaths and morbidity occurred among young adults within the ages of (20-30) with mean age 27 years.

- The risk of maternal death as well as morbidity is less among unmarried women than married women.

- Women who are not educated stand the risk of maternal death than those who are educated.

- Pregnant women who are unemployed are more likely to die than their counterparts who are employed

- Women with more parity are at risk of experiencing maternal deaths and morbidity

- More women die during delivery and after delivery in the district.

Health Seeking Behavior among Mothers who Experienced Maternal Mortality and Morbidity

- Majority of pregnant women in Kintampo north district use ANC services

- Majority use ANC services less than four times as required

- Majority complained about unfriendly attitude of health staff during ANC and that discouraged them from utilizing the ANC services.

- Many of the pregnant women in the district develop complications

- The complications arise because of delay in reaching health facility

- They only seek health care when the women have advanced in the development of complication.

Delay in Reaching Health Facility by Women who experienced maternal Mortality and Near-Miss Events

- More maternal deaths occurred in the health facility in the district than at home

- On the basis of results of this study, it is evident that women and family members prolonged the decision to seek professional care from the hospital or community based clinic and that many women arrived at the hospital in very poor condition

- Majority of the women distance to the nearest health facility was $7 \mathrm{~km}$ and above

- The contributory factors to the delay were distance to the nearest health facility and home management

- Various modes of transportation were used including walking, taxis and market trucks.

- Most of them who delayed in reaching health facility suffered complications.

- Among complications experienced were excessive bleeding, and severe anaemia, eclampsia, and sepsis.

\section{Delivery and Postnatal Care Services, and Education and Information Services}

- Most of the women delivered in the health facility

- Most of the women who delivered in the health facility were assisted by auxiliary midwives.

- Women who did not deliver in the health facility were assisted by TBAs, at home of which majority of them are trained.

- Majority of women who did not deliver at health facility attributed their failure to do so to unfriendly attitude of health staff

- Women who delivered at home have risk of dying as compared to those who delivered at health facility 
Texila International Journal of Public Health

Volume 4, Issue 4, Dec 2016

- Risk of experiencing stillbirth in women who delivered at home is higher than those who delivered in health facility

- Most of the mothers did not utilise PNC services

- Attitude of health staff and financial constraint were the contributory factors that discouraged the use of PNC services

- Most of the facilities do not have necessary emergency obstetric equipment for maternal health services.

- If needed, clients are stabilised before referring to Kintampo north government hospital.

- Majority of the women did not have adequate monitoring during pregnancy, delivery, and after delivery

- Most health facilities do not have blood banks, and even a few of them that have, always experience shortage.

- Majority of women who experienced maternal mortality and morbidity did not receive much education and information services during pregnancy, delivery and after delivery.

\section{Family Planning and Abortion Practices}

- Most of the women who experienced maternal mortality and near-miss events were not practicing family planning.

- Most of the women who were not practicing family planning have more children compare to those who are practicing

- The reason for not practicing family planning was its side effects

- Among the side effects mentioned were, it leads to infertility, it delays pregnancy in later life and it leads to too much sleep.

- Majority of women who did not practice family planning experienced unplanned pregnancy.

- Most of them who experienced unplanned pregnancy aborted the pregnancy

- Majority of the abortion practices were unsafe

- Most of the women who had unsafe abortion either bought drugs from chemical or pharmacy shops

- Most of the women died as the result of unsafe abortion

- Few who were near-miss experienced severe complication like excessive bleeding or damaged to the womb

- Reasons for having an abortion were financial constraints, wanted to space childbearing or when partner denies pregnancy

- Most of their partners were in favour of abortion practices

- Those who were near-miss were counselled by health professional following abortion

\section{Recommendation}

Health seeking behaviour

1. Health education should be intensified by health workers on the importance of early ANC and PNC services

2. Women and women groups should come together and identify the real needs as far as seeking maternal care is concerned.

3. In groups, women in the district should advocate for freedom from male dominance that affects the life and health and most importantly the rate of death.

4. Mothers in-law should assist their daughters in-law to seek prompt medical care whenever they are pregnant

5. Pregnant women in the district should take action to seek for ANC and PNC services when pregnant and after delivery and continue with it to term 
6. Women and women groups should also advocate for equity in terms of access to education and employment by women since it is a protective measure against the incidence of maternal deaths

7. Health staff should change their unfriendly attitudes towards clients during ANC and PNC visits and adopt friendly attitude that will bring conducive atmosphere to encourage ANC and PNC utilisation services among women

8. Educating family and community members as well as traditional birth attendants on issues concerning maternal death can be instrumental in encouraging a family to seek early care when complications arise.

9. Community based interventions such as educating traditional midwives, families and women in early problem recognition and prompt referral can help save lives

10. Policy makers and providers must re-examine current approaches to improve reproductive health, addressing the contextual factors and community based issues. Uncovering and unveiling the barriers to seeking care embedded in the context of this study could be a beginning step to address reducing maternal morbidity and mortality.

11. District health administration in collaboration with district assembly can have free transit accommodation nearer to health facility for pregnant women who are in the remote areas whose pregnancies are few weeks or months to gestational term. If this is done, it will avoid unnecessary delay

\section{Maternal Health Care Services during Pregnancy, Delivery and after Delivery}

1. There should be proper medical attention and hygienic conditions during delivery. This will reduce the risk of complications and infections. There should be attention to clean delivery and testing for and management of STDs during pregnancy to prevent sepsis

2. It is necessary to increase the births in medical facilities with trained attendants. Training skilled attendants who are able to prevent, detect and manage obstetric complications as well as provide equipment, drugs and other supplies is the single most important factor in preventing maternal deaths. Primary convulsion, or eclampsia, can be prevented with monitoring during pregnancy and simple drug treatment, and severe bleeding can be prevented by the prompt administration of drugs to stop the bleeding and by the massage of the uterus.

3. Blood must be available at all times in the blood bank. There is a need to strengthen blood replacement at the bank. Embarking on blood donation campaign by quality assurance team. Request for blood donation for health facilities.

4. Follow-up care encompasses care for complications and emergencies, and postpartum care

\section{Family Planning, Education and Information Services}

1. Education and information services comprise community education about safe motherhood, education about pregnancy danger signs and complications, and reproductive health and family planning information and services for adolescents and adults.

2. Access to low-cost, good quality contraceptives to prevent unwanted pregnancies and increase women's age at first childbirth can prevent prolonged labour

3. Unsafe abortion can be prevented with access to family planning information and services, care for abortion-related complications and, where legal, safe abortion services.

4. Municipal Health Management Team should assist in the development of programmes and policies that reduce unsafe abortion and improve access to safe abortion and high quality post abortion care. 
Texila International Journal of Public Health

Volume 4, Issue 4, Dec 2016

\section{Acknowledgement}

It is a great pleasure to record my thanks to the several people who have made the task of producing this work easy. Help on the contents of the study has come from several sources, but I would particularly like to mention my supervisor, K.A Danso, a former Dean of School of Medical Sciences, Kwame Nkrumah University of Science and Technology, Kumasi, who is also a Professor of Obstetrics and Gynaecology, and a Consultant Obstetrician/Gynaecologist at Komfo Anokye Teaching Hospital, Kumasi. A special debt of gratitude is owed to him.

I wish also to record the enormous encouragement from the lecturers and administrative staff of the Department of Community Health at the Kwame Nkrumah University of Science and Technology for the knowledge and experience that they have imparted to me.

Mr. Saka Allotey, Deputy Chief Health Tutor, College of Health Kintampo, deserves special mention. He reviewed the manuscript and offered valuable suggestions. I also like to express my appreciation to the staff of the District Health Directorate of Kintampo North, especially the Acting Municipal Director of Ghana Health Services, Madam Alice Vorleto, and Mr. Simon Owusu, Senior Disease Control Officer for their immense contribution towards the study.

To my colleagues (2011/2012) academic year group at the Department of Community Health, I say thank you for the friendship, support and the sharing of ideas throughout the period that we have known each other especially Margareta Odame Antwi, Ofori Amoah Robert, and Daniel Ashiaw Afoakwah; may God richly bless you all.

\section{References}

[1] Arkutu, (1995). Activities carried out during PNC include management of the normal puerperium, identification and management of complications, micronutrient supplementation, immunization of baby, counselling and testing and STI prevention, family planning counselling and services.

[2] Brong Ahafo Region Annual Performance Meeting Report (2011) on 21st February, 2012, Sunyani

[3] British Medical Journal report, (2003)

[4] Christian, P. (2009). Prenatal Origins of undernutrtion. Nestle Nutr Workshop Ser Pediatr Program 63: 59; 74 - 77.

[5] Family Planning Acceptor Rate by Region, (2007-2009)

[6] Galadance H.S., Ejembi, C.L. Iliyasu, Z., Alagh, B. and Umar, U.S., (2007). Maternal health in Northern Nigeria: a far cry from ideal. BJOG 114 (40: 448 - 552

[7] Ghana Health Service (2007) Indicators in measuring ANC and Influence of Delivery Care on Maternal Health

[8] GDHS (2008)

[9] GHS road map for accelerating the attainment of the MDGs related maternal and neonatal health in Ghana (2007-2011)

[10] Ghana Demography and Health Survey, (2008)

[11] Ghana MDG Acceleration Framework Action Plan (CAP) (August 2010)

[12] Ghana Maternal Health Survey (2007)

[13] Ghana Statistical Services, (2003). Ghana Demographic and Health Survey Report

[14] Ghana Statistical Service $(2005,2008)$ Report

[15] Ghana Statistical Service (2005, 2008), Ministry of Health (2006) quality of care during delivery

[16] Health Information Department, Kintampo Municipal Directorate

[17] Hecht, R., Alban, A., Taylor, K., Post, S., Andersen, N.B., Swarz, R. (2006). The Millennium Development Goals. PLoS Med. 3(11): e455

[18] Initiative for Maternal Mortality Programme Assessment (IMMPACT) in Accra on Wednesday, 6th of February, (2003)

[19] Maternal and Neonatal Health in Ghana (2007-2011)

[20] Ministry of Health (2006) Annual Report 
[21] Ministry of Health (2008) Annual Report

[22] Ministry of Health (2010) Programme of Work

[23] National Research Council, (2000) Consequences of maternal mortality and morbidity

[24] Onah, H.E., Ikeako, L.C., Iloabachie, G.C. (2006). Factors associated with the use of maternity services in Enugu, southeastern Nigeria. Soc Sci Med. 63 (7): 1870 - 78

[25] Thaddeus and Maine, (1994), distance from a health centre, quality of care expected at the health centre and ability to pay for services also can affect the decision to seek care

[26] United Nations, (2009) Millennium Development Goal five Annual Report

[27] World Health Assembly Report, May (2004)

[28] World Health Organisation (1993) Report

[29] World Health Organisation, (2004); Fillippi et al., (2005) Definition of Maternal near-miss events

[30] World Health Organisation (2004), Maternal Mortality Rates

[31] World Health Organisation (2007), Annual Report

[32] World Health Organisation, (2008) Annual Report. Geneva.

[33] World Health Statistics, (2010) Report 


\title{
Factors Associated with Adherence to Sickle Cell Crisis Preventive-Practices among Youths of Sickle Cell Clubs in Abeokuta, Ogun State, Nigeria
}

\author{
Article by ${ }^{1}$ Nnodimele O. Atulomah \& ${ }^{2}$ Elizabeth O. Oyeneye \\ ${ }^{1,2}$ Department of Public Health, Babcock university, Ilishan, Nigeria \\ E-mail: ${ }^{1}$ atulomahn@babcock.edu.ng, ${ }^{2}$ foyeneye@yahoo.co.uk
}

\begin{abstract}
Adherence to sickle cell crisis preventive-practices is a major problem in at-risk population. Evidenced-based studies on factors associated with adherence to crisis prevention are few. This study sought to explore how the Information-Motivation-Behavioural Skill (IMB) model can provide understanding of underlying factors associated with adherence to crisis-preventive-practices behaviour among youths with sickle cell disease in Abeokuta, Nigeria.

This cross-sectional descriptive study employed a validated 43-item questionnaire to collect information from 84 participants who consented about crisis-risk prevention. Variables in the study were information, motivation, self-efficacy and adherence behaviour and measured on a 10-, 36-, 15- and 21- point scale respectively. Correlation and regression analysis was used to test for association, significance and prediction of best pathway to adherence with a cut-off at $p \leq 0.05$ level of significance.

The Mean Age of the participants was 20.07(0.69) \pm 6.28 with $40.5 \%$ males and $59.5 \%$ females. Majority were Yoruba and single with minimum of secondary school education. The sample mean scores reported for knowledge about crisis-prevention in sickle cell disease was $7.93 \pm 1.22$, motivation was $30.07 \pm 4.67$ and self-efficacy skills were $11.88 \pm 2.88$. The Adherence behaviour mean score was $11.23 \pm 3.30$ giving a behaviour prevalence rate of 53.5\%. Motivation was significantly associated with self-efficacy skills and adherence behaviour, while information was not significantly associated with either. Self-efficacy skills were significantly correlated with adherence behaviour. Path-analysis showed that the combined motivation and self-efficacy adherence behaviour $(r 2=0.34)$.

Findings showed that an informed and motivated sickle cell youth with good self-efficacy skills will adhere better to the crisis prevention-practices. The study recommends that counselling that provides information should be motivational to build self-efficacy that promotes crisis-prevention behaviour.
\end{abstract}

Keywords: Sickle cell crisis, preventive-practices, Information, Motivation, Adherence behaviour, Self-efficacy skill.

\section{Introduction}

Individuals with sickle cell disease are seriously challenged, particularly when they have to cope with repeated occurrence of associated crisis which in most cases is life threatening. Sickle cell disease crisis is a clinical emergency that require prompt attention. Invariably, this event is triggered by a number of factors that are preventable. Adherence to sickle cell disease crisis prevention-practices has been a challenge in the prevention of crisis and management of sickle cell disease. Generally, sickle cell disease is characterised by multiple morbidity and low quality of life as a result of the frequency of sickle cell crisis. Despite the increased life expectancy recorded in recent times due to medical advancement in the management of sickle cell disease, the morbidity profiles and health outcomes is still poor. However, many factors militate against adherence to preventive-practices and there is need to investigate these factors so that health care provider can develop a better workable strategy and intervention for prevention and management of sickle cell disease and crisis. 
Sickle cell disease is a genetic abnormality involving red blood cells and haemoglobin. It is estimated that 300,000 children are born with sickle cell disease every year globally (1). This directly translates to an estimated yearly global deaths of about 29,000 deaths. (2) It is found in many parts of the world, and most prevalent in sub-saharan Africa, India, Saudi Arabia and Mediterranean countries. In the Nigerian population, it is estimated that $25 \%$ of the population has the sickle cell trait AS-genotype and $2 \%$ are born annually with sickle cell disease SS-genotype with an estimated 150,000 children born every year in Nigeria with the disease(3).

Sickle cell disease is characterized by repeated and unpredictable painful episodes (crisis) capable of disabling its victims. Sickle Cell Crisis is a medical emergency. Signs and symptoms of sickle cell crisis can be mild or severe, can get worse over time and may change each time there is a crisis. Sickle cell crisis is characterized by pains in various parts of the body such as the back, stomach, chest, or bones, anaemia signs (headaches, and trouble breathing) pale skin colour change; Priapism (men's severe painful penile erection in the absence of sexual desire stimulation); Acute chest syndrome, chest pain and trouble breathing; Spleenicse questrian crisis characterised by feeling of weakness, shortness of breath with swollen abdomen and pain. Most crises last between five and seven days. Sickle cell crisis triggers could be unknown and varied for individual. Sickle cell crisis could be triggered by dehydration, microorganism infections of the host, inadequate supply of oxygen to the blood, low temperature, any form of stress, anger, frustration and depression. Treatment for sickle cell crisis includes coping with pain and other signs and symptoms, reducing pain during a crisis, prevention of a crisis from growing to become life-threatening and prevention of another crisis.

Sickle cell crisis can last between five and seven days and predisposing causes may be unknown. Many things could cause sickle cell crisis and it varies for individual. Sickle cell crisis may be triggered by dehydration, infections, hypoxia, cold temperature, surgery and emotional stress. Sickle cell crisis is the most complained and cause of hospital admission, however the crisis can be prevented most of the times by some preventive-practices which can reduce frequency of sickle cell crisis and improve quality of life.

Sickle cell disease can be managed by high fluid intake, healthy diet, folic acid supplementation, pain medication, vaccination and antibiotics for the prevention and treatment of infections, and other therapeutic measures (5). The recurrent pain and complications caused by the disease can affect the patient's quality of life and development. In order to prevent frequent sickle cell crisis, people living with sickle cell disease should rest during a sickle cell crisis, regular exercise, avoidance of sudden change of air pressure or lack of oxygen, avoidance of smoking and extremities of weather. The crisis prevention-practices is summarised into the following 4 components for the purpose of this study:

1. Routine medications and first aid,

2. Appropriate Diet \& rest,

3. Hazard \& infection control,

4. Keeping of routine medical check -up appointment

The Information, Motivation and Behavioural skill (IMB) model specifies that motivation acts as a catalyst to enhance health related behaviours and determines whether even wellinformed individuals will be inclined to undertake health promotion actions. Patients who is well-informed and well-motivated, but lacks critical behavioural skills, may be less likely to achieve or sustain high levels of adherence (6). The Fisher conceptual framework suggests that individuals, who are knowledgeable about HIV transmission and prevention, are motivated to prevent infection, and perceive themselves as capable of enacting preventive behaviours will act to reduce their HIV risk (7). The IMB model has been used with other youth populations. Youth with optimal knowledge about sickle cell disease and who receives maximum social support may likely be motivated to adhere to preventive-practices that may lead to improved quality of life (8). Despite the advancements in management of the disease, the global burden and morbidity is still on the rise, hence the need to look at factors 
associated with secondary preventive-practices and quality of life using an evidenced based theoretical model.

This study was undertaken to explore how IMB model theory and concept can provide understanding of factors such as information, motivational and self-efficacy is associated with adherence to preventive-practices behaviour in sickle cell crisis among youth with sickle cell disease. To my knowledge no study in Nigeria has explored the factors associated with sickle cell crisis preventive -practices among the youth using the IMB model construct. The sickle cell prevalence and burden in Nigeria is increasing (5). Preventive-practices can reduce frequency of crisis and improve quality of life, but there appears to be more to survival, coping and improved quality of life in sickle cell disease. Gaining a better understanding of the factors that influence adherence in any population of sickle cell may provide valuable information for theory and intervention. However, better understanding of adherence to preventive-practices in sickle cell disease is particularly critical for sickle cell patients in Abeokuta, Ogun state and Nigeria.

\section{Methods}

The study is a cross-sectional descriptive study carried out in Abeokuta, Ogun state located in the tropical rainforest of South-western Nigeria. A 43-itemquestionnaire which was based on IMB model conceptual domains of information, motivation, self-efficacy and behavioural skill was pilot tested with youths from sickle cell club of Ijebuland, Ogun state. Participants were drawn from a convenience sample of 84 youths aged 13years to 36years from the two sickle cell clubs in Abeokuta (Aglow sickle cell club and Hope Alive sickle cell club) with population of 800.Informed consent was sought from all who accepted to participate. The validated questionnaire was administered to consented 84 participants to evaluate crisis risk prevention information, motivation, self-efficacy and adherence behaviour with respect to sickle cell crisis prevention-practices measured on a 10-, 36-, 15- and 21- point scale respectively. The research was approved by ethical committee of Babcock University Ilisan, Ogun State, Nigeria.

The data collected were examined for completeness, coded manually and entered into a pass worded computer for analysis using the computer-assisted software Statistical Package for Social Sciences (SPSS) version 14 to conduct all statistical analysis. Descriptive statistics such as frequency distributions, means, standard error of mean (SEM) and standard deviation (SD) were used to evaluate levels of health information, motivation, self-efficacy and adherence behaviour. Regression analysis was conducted to validate the association between motivation, self-efficacy and adherence behaviour. Furthermore, path-analysis was conducted for the variables in the study to determine variables that most predict the adherence behaviour. The level of significance was set at $\mathrm{P}=0.05$ forallstatisticalprocedures.

\section{Results}

The demographic characteristics of the respondents are presented in table 1. The Mean age of the respondents is 20.07 (SEM $=0.69$ ) \pm 6.28 , while minimum age is 13years and maximum age is 36years. The sample consisted of 84 youths with sickle cell disease of $40.5 \%$ male and $59.5 \%$ female. The majority are Yoruba (91.7\%) and single (89\%) with minimum of secondary school education (51.2\%). Up to $67.9 \%$ are students and $66.7 \%$ are Christians (table 1). The Study sample $\mathrm{N}=84$

The Mean Response Score of Sickle Cell Disease Risk-preventive Information, Motivation, Self - efficacy, knowledge and past Adherence Behaviour of the Respondents is presented in table 2

The mean information score $(7.93 \pm 1.22)$ is high. The mean score of computed motivation responses out of the 36-point scale measure of the respondents is mean \pm SD $(30.07 \pm 4.67)$. The sample can be said to be well motivated about the preventive-practices of sickle cell disease crisis. The mean score of computed self-efficacy skills responses out of the 15-point scale measure of the respondents is mean \pm SD (11.88 \pm 2.88$)$. The extent of self-efficacy 
Texila International Journal of Public Health

Volume 4, Issue 4, Dec 2016

estimated as the ratio between the correctly answered questions and the total asked questions $(11.88 / 15 \times 100 \%)=79.2 \%$. The respondents can be said to have good self-efficacy skills about preventive-practices of sickle cell disease crisis. The mean score of computed Adherence behaviour responses out of the 21-point scale measure of the respondents is mean \pm SD $(11.23 \pm 3.30)$. The extent of adherence behaviour is estimated as the ratio between the correctly answered questions and the total asked questions $(11.23 / 21 \times 100 \%)=53.5 \%$. The respondents have about average adherence behaviour of preventive-practices of sickle cell disease crisis.

Table 1: Demographic Characteristics of the Respondents

\begin{tabular}{|c|c|c|}
\hline Variable & \multicolumn{2}{|l|}{ Responses } \\
\hline \multirow{4}{*}{$\begin{array}{l}\text { Gender } \\
\text { Male } \\
\text { Female } \\
\text { Fthnic }\end{array}$} & Frequency & Per cent \% \\
\hline & 34 & 40.5 \\
\hline & 50 & 59.5 \\
\hline & \\
\hline & 77 & 91.7 \\
\hline Igbo & 5 & 6.0 \\
\hline Others & 2 & 2.4 \\
\hline \\
\hline \multirow{4}{*}{$\begin{array}{l}\text { Single } \\
\text { Married } \\
\text { Widowed } \\
\text { Educational status } \\
\text { nrimary }\end{array}$} & 75 & 89.3 \\
\hline & 8 & 9.5 \\
\hline & 1 & 1.2 \\
\hline & & \\
\hline \multirow{2}{*}{$\begin{array}{l}\text { primary } \\
\text { secondary }\end{array}$} & 9 & 10.7 \\
\hline & 43 & 51.2 \\
\hline \multirow{2}{*}{$\begin{array}{l}\text { tertiary } \\
\text { postgraduate }\end{array}$} & 25 & 29.8 \\
\hline \multirow{2}{*}{\multicolumn{3}{|c|}{ Occupation }} \\
\hline & & \\
\hline \multirow{2}{*}{$\begin{array}{l}\text { employed } \\
\text { Unemployed }\end{array}$} & 57 & 67.9 \\
\hline & 10 & 11.9 \\
\hline \multirow{2}{*}{$\begin{array}{l}\text { Self-employed } \\
\text { Religion }\end{array}$} & 7 & 8.3 \\
\hline & 10 & 11.9 \\
\hline \multirow{4}{*}{$\begin{array}{l}\text { Christianity } \\
\text { Islam } \\
\text { Traditionalist }\end{array}$} & & \\
\hline & 56 & 66.7 \\
\hline & 28 & 33.3 \\
\hline & 0 & 0.0 \\
\hline
\end{tabular}

Table 2: The Mean Response Score of Sickle Cell Disease Risk-preventive Information, Motivation, Self -efficacy, knowledge and past Adherence Behaviour of the Respondents

\begin{tabular}{|c|c|c|c|}
\hline \multirow{2}{*}{ Variables: } & \multicolumn{3}{|l|}{\begin{tabular}{|l|} 
Responses \\
\end{tabular}} \\
\hline & $\begin{array}{l}\text { Maximum } \\
\text { Score }\end{array}$ & $\begin{array}{l}\text { Mean } \\
\text { Score }(\ddot{\mathbf{X}})\end{array}$ & \begin{tabular}{|l|} 
Standard \\
Deviation(SD)
\end{tabular} \\
\hline $\begin{array}{l}\text { Computation of Sickle cell disease Risk- } \\
\text { Prevention Information on a } 10 \text {-point scale }\end{array}$ & 10.00 & 7.93 & 1.22 \\
\hline $\begin{array}{l}\text { Computation of Sickle cell disease Crisis } \\
\text { Preventive-Practices Motivation on a } 36 \text { point } \\
\text { scale }\end{array}$ & 36.00 & 30.07 & 4.67 \\
\hline $\begin{array}{l}\text { Computation of Sickle cell disease Crisis } \\
\text { Preventive-Practices Self-Efficacy on a 15- }\end{array}$ & 15.00 & 11.88 & 2.88 \\
\hline
\end{tabular}




\begin{tabular}{|l|l|l|l|}
\hline point scale & & & \\
\hline $\begin{array}{l}\text { Computation of Sickle cell disease Crisis } \\
\text { Preventive-Practices past Adherence } \\
\text { Behaviour on a 21- point scale }\end{array}$ & 21.00 & 11.23 & 3.30 \\
\hline
\end{tabular}

The frequency distribution of correct responses on Sickle Cell Disease Risk-Prevention Information is as shown in table 3. The highest mean correct score (97.5\%) was recorded on information on healthy diet with plenty of water and rest as prevention of crisis, while the lowest score (44.0\%) was recorded on information about the cure of sickle cell disease. About $65.5 \%$ responded that adhering to the preventive-practices of sickle cell crisis all the time is necessary to prevent sickle cell crisis.

Table 3: Frequency Distribution of Respondents with Correct Responses on Sickle Cell Disease RiskPrevention Information.

\begin{tabular}{|l|l|l|}
\hline Variable: Sickle cell disease Risk-Prevention Information on & Responses \\
\cline { 2 - 3 } a 10-point scale & Frequency & Per cent \% \\
\hline $\begin{array}{l}\text { 1. Sickle cell disease is a generic abnormality involving red } \\
\text { blood cells. }\end{array}$ & 74 & 88.1 \\
\hline $\begin{array}{l}\text { 2. Prompt report of sickle cell crisis in the hospital within } \\
\text { 24hours can prevent complication and death. }\end{array}$ & 77 & 91.7 \\
\hline $\begin{array}{l}\text { 3. Sickle cell crisis can be prevented by some routine } \\
\text { preventive practices. }\end{array}$ & 78 & 92.9 \\
\hline $\begin{array}{l}\text { 4. Sickle cell crisis cannot be prevented by routine medications } \\
\text { (Folic acid, e.t.c) and first aid? }\end{array}$ & 53 & 63.1 \\
\hline $\begin{array}{l}\text { 5. Sickle cell crisis can be prevented by healthy diet with } \\
\text { plenty of water, and rest. }\end{array}$ & 82 & 97.5 \\
\hline $\begin{array}{l}\text { 6. Sickle cell disease is transmitted through kissing, coughing } \\
\text { and blood transfusion. }\end{array}$ & 72 & 85.7 \\
\hline 7. Sickle cell disease can be cured & 37 & 44.0 \\
\hline $\begin{array}{l}\text { 8. Adhering to the preventive-practices of sickle cell crisis all } \\
\text { the time is not necessary to prevent sickle cell crisis. }\end{array}$ & 55 & 65.5 \\
\hline $\begin{array}{l}\text { 9. Keeping regular medical check-up appointment can prevent } \\
\text { sickle cell crisis. }\end{array}$ & 76 & 90.5 \\
\hline $\begin{array}{l}\text { 10. Control of Hazard and infections can prevent sickle cell } \\
\text { crisis }\end{array}$ & 62 & 73.8 \\
\hline
\end{tabular}

Correlation is significant at the 0.05 level for Motivation and Adherence Behaviour. Correlation is significant at the 0.01 level for motivation and self-efficacy. However, correlation is not significant for other variable path to adherence and self-efficacy, such as Information and Motivation with adherence behaviour, Information and Self-efficacy, Information and Motivation with adherence behaviour, Self-Efficacy and Adherence Behaviour, Information and Adherence Behaviour (Table 4) 
Texila International Journal of Public Health

Volume 4, Issue 4, Dec 2016

Table 4: Summary of the Correlation Analysis of Variables measured in Sickle Cell Crisis PreventivePractices.

\begin{tabular}{|l|l|l|l|l|}
\hline $\mathbf{S} / \mathbf{N}$ & Variables & $\begin{array}{l}\text { Pearson } \\
\text { correlation } \\
\text { coefficient (r) }\end{array}$ & $\begin{array}{l}\text { P- } \\
\text { value }\end{array}$ & Remarks \\
\hline $\mathbf{1}$ & $\begin{array}{l}\text { Information and } \\
\text { Motivation with } \\
\text { adherence behaviour }\end{array}$ & $0.066(\mathrm{r} 1)$ & 0.274 & $\begin{array}{l}\text { Correlation is not } \\
\text { significant }\end{array}$ \\
\hline $\mathbf{2}$ & $\begin{array}{l}\text { Information And Self } \\
\text { Efficacy }\end{array}$ & $-0.002(\mathrm{r} 2)$ & 0.491 & $\begin{array}{l}\text { Correlation is not } \\
\text { significant }\end{array}$ \\
\hline $\mathbf{3}$ & $\begin{array}{l}\text { Motivation and Self } \\
\text { Efficacy }\end{array}$ & $\mathbf{0 . 5 7 9}$ (r3) & $\mathbf{0 . 0 0 0 1}$ & $\begin{array}{l}\text { Correlation is } \\
\text { significant at the 0.01 } \\
\text { level (1-tailed). }\end{array}$ \\
\hline $\mathbf{4}$ & $\begin{array}{l}\text { Self-Efficacy and } \\
\text { Adherence Behaviour }\end{array}$ & 0.003 (r4) & 0.489 & $\begin{array}{l}\text { Correlation is not } \\
\text { significant }\end{array}$ \\
\hline 5 & $\begin{array}{l}\text { Information and } \\
\text { Adherence Behaviour }\end{array}$ & 0.003 (r5) & 0.490 & $\begin{array}{l}\text { Correlation is not } \\
\text { significant }\end{array}$ \\
\hline 6 & $\begin{array}{l}\text { Motivation and } \\
\text { Adherence Behaviour }\end{array}$ & $\mathbf{0 . 1 9 8 ( r 6 )}$ & $\mathbf{0 . 0 3 5}$ & $\begin{array}{l}\text { Correlation is } \\
\text { significant at the 0.05 } \\
\text { level (1-tailed). }\end{array}$ \\
\hline
\end{tabular}

In order to determine the extent to which the IMB model constructs predicts adherence behaviour, significantly associated variables from table 4 (motivation, self-efficacy skills and adherence behaviour) were subjected to regression analysis. The respondent's score of information about the sickle cell crisis preventive-practices is not significantly correlated with adherence behaviour. ( $\mathrm{r} 5=0.003, \mathrm{p}=0.490$ ). The model indicated that self-efficacy skills $(\beta=$ $0.582, \mathrm{P}<0.001)$ and motivation $(\beta=0.199 ., \mathrm{P}<0.001)$ were both predictors of adherence to crisis preventive-practices. Information was not significantly correlated to adherence behaviour $(\beta=-0.10, \mathrm{P}>0.05)$ and behavioural skills $(\beta=-0.041, \mathrm{P}>0.05)$. Findings of this study indicated that self-efficacy skills were predicted by motivation of the respondents and not information. Regression Analysis R2 Value (0.337) indicates that the self-efficacy is predicted by about 33.7\% (0.337 x100\%) of motivation (Table 5).

Table 5: Regression Value for Dependent Variable: Self Efficacy and Independent variables (Motivation and Information) with respect to sickle cell crisis preventive-practices for Respondents

\begin{tabular}{|l|l|l|l|l|}
\hline & \multicolumn{4}{|c|}{ Dependent variable: Self-efficacy skills } \\
\hline Independent variables & R value & $\mathbf{R}^{2}$ value & B value & Beta value \\
\hline Motivation & 0.580 & 0.337 & 0.358 & 0.582 \\
\hline Information & & & -0.097 & -0.041 \\
\hline
\end{tabular}

Motivation predicted adherence behaviour $(\beta=0.199, \mathrm{P}<0.001)$ to sickle cell crisis preventive-practices. Regression Analysis $\mathrm{R}^{2}$ Value (0.039) indicates that the adherence behaviour is predicted by about $3.9 \%(0.039 \times 100 \%=3.9 \%)$ of motivation (Table 6.)

Table 6: Regression Analysis of Information and Motivation with Adherence Behaviour of sickle cell disease crisis preventive-practices for respondents

\begin{tabular}{|l|l|l|l|l|}
\hline & \multicolumn{4}{|l|}{ Dependent Variable: Adherence Behaviour } \\
\hline Independent variables & R value & $\mathbf{R}^{2}$ value & B value & Beta value \\
\hline Motivation & 0.198 & 0.039 & 0.203 & 0.199 \\
\hline Information & & & -0.41 & -0.10 \\
\hline
\end{tabular}




\section{Conceptual Model and Path Analysis}

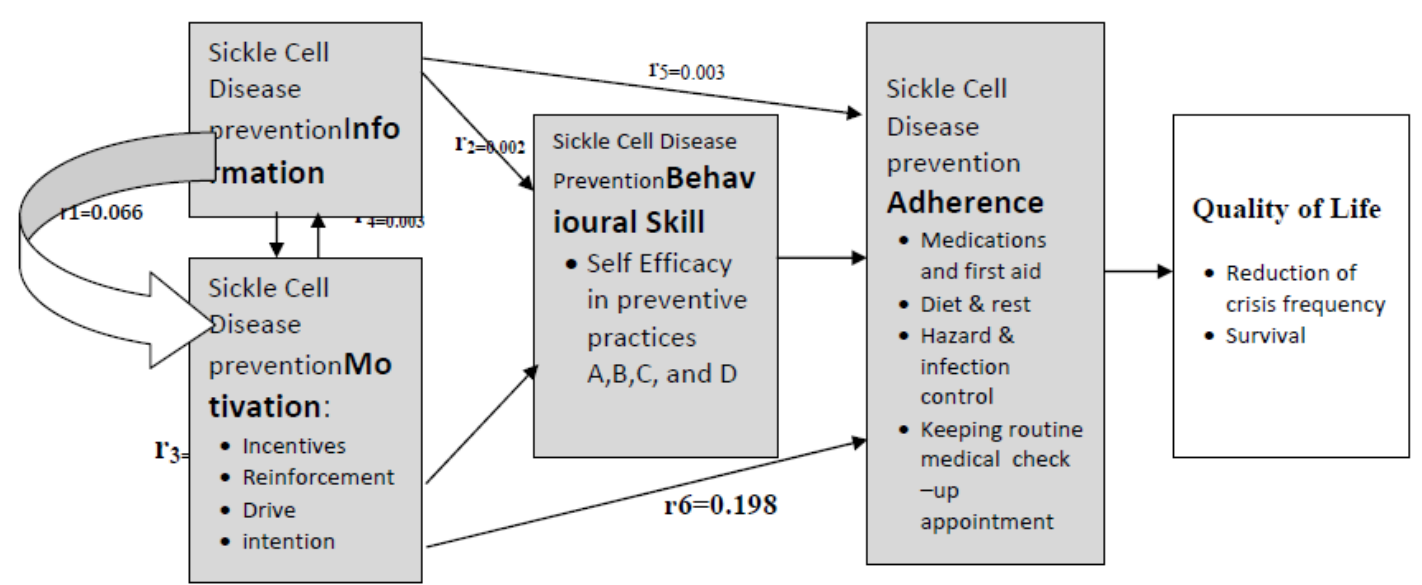

Figure 1: Path Analysis Regression for Factors Associated with Adherence to Sickle Cell Disease Crisis Preventive-Practices among Sickle Cell Disease Youth Based on the Information- MotivationBehavioral Skills (IMB) Model

Adherence behaviour is mostly predicted by motivation, which in turn was highly predicted by self-efficacy skills, the contribution of information to the adherence behaviour is very small from both path through self-efficacy and direct path to adherence from information. The resultant effect from information and motivation is also low; this suggests that motivation is the stronger predictor of self-efficacy which is responsible for the adherence behaviour. In practice a better motivated sickle cell youth will adhere better to the sickle cell disease crisis preventive-practices. This result is consistent with the report by Michele et al (2013), Zhu et al (2013) \& Jungling, et al, (2013) (9, 10,11). In essence study result has provided validity for the theoretical and conceptual framework that guided this study. (Figure 1)

\section{Discussion}

Despite the advances in the management of sickle cell disease, the global burden and morbidity is still unacceptably high. Sickle cell crisis is a preventable cause of hospital admission, morbidity and mortality. Adherence to crisis preventive-practices is a major problem in at risk population and evidenced based studies on factors associated with adherence to crisis prevention are few. The objective of this study therefore was to explore the dynamics involved in the use of the IMB model to provide predictors of adherence to crisis prevention-practices that could improve quality of life of at risk population. The study assessed the nature of associations between variables in the conceptual framework construct and ultimately determined the path-analysis that best predicted which path between information, self-efficacy skills and motivation provides better adherence to sickle cell crisis preventive-practices.

Information is an important resource that provides opportunity to make decisions about best options to choose to achieve set objectives. It is however important to note that basic knowledge and awareness about a medical condition that might include how the disease develops, its expected course and effective plans for its management are usually acquired through information dissemination. Motivation involves the dynamics of how various reinforces such as perceived social support from significant others may arouse desires in a person and drives the individual to behave in a particular way, for this study, adherence to crisis-prevention behaviour. Furthermore, how Behavioural skills construct accounts for the nature and level of confidence in the patient to perform the required adherence behaviour with the behavioural tools, social support and other self-regulation strategies or self-efficacy. The 
relationship between the information and motivation constructs is weak. However, in the IMB model, both information and motivation increase the chances of adherence behaviour.

The educational status of the study sample coupled with their experience of the disease and participation in the sickle cell club might have influenced their high level of information, yet, this does not necessarily translate to a correlation in crisis - prevention behaviour as the data from this study demonstrated. Since belief in the health behaviour can lead to behavioural change. The acquisition of knowledge about a disease is important in behaviour adaptation; especially if it is paired with believe that one's behaviour will have positive impact on health. (16). A person can only attempt to change his former behaviour if he believes in the new behaviour and then perceive that he can behave in the new prescribed behaviour. However, the result was not consistent with studies that reported that sickle cell patients mostly lack knowledge about their disease. The literature reported little, moderate and poor understanding or knowledge about sickle cell disease among sickle cell patients (17, 18 and 19). They recommended the need to educate the sickle cell patients about their illness. The finding of this study is inconsistent with this report, but it could also be assumed that the recommendation over the years was followed and the impact is our observation in the sickle cell patients in Abeokuta, Nigeria. The observed high score of information could also be the impact of the internet, school, sickle cell clubs and hospital education of the community, the students, the members of the club and the patients over the years. The awareness campaign is on and will yield better outcome if the effort remains consistent. This report is inconsistent with the report of Jaffer et al (3) where the sickle cell patients were moderately knowledgeable about the sickle cell crisis preventive measures (Mean of Knowledge score = $55 \%$ ). The respondent's knowledge (about the preventive measures) was found to be moderately and positively correlated $(r=0.57, r 2=0.32, p=0.000)$ with their attitudes toward crisis prevention. However, this study finding is consistent with the report of finding of Zhu et $\mathrm{al}(10)$ where the IMB model indicated that information was not significantly related to intention to smoke $(\beta=-0.001, \mathrm{P}>0.05)$ and behavioural skills $(\beta=0.002, \mathrm{P}>0.05)(10)$. Also the result is consistent with the report by Michele et al $(2013)$ \& Gao et al, $(2013)(9,11)$.

Adherence behaviour is mostly predicted by motivation, which in turn was highly predicted by self-efficacy skills, the contribution of information to the crisis - preventive behaviour is very small from both path through self-efficacy and direct path to adherence from information. The resultant effect from information and motivation is also low; this suggests that motivation is the stronger predictor of self-efficacy which is responsible for the adherence behaviour. This result is consistent with the report by Michele et al (2013), Zhu et al (2013) \& Jungling et al, (2013) (9, 10,11). In essence the study result has provided validity for the theoretical and conceptual framework (IMB model) that guided this study. (Figure 1). In practice a better motivated sickle cell youth will adhere better to the sickle cell disease crisis preventive-practices.

Motivation is positively correlated with self-efficacy for the respondents at 0.01 level $\left(\mathrm{r}=0.579, \mathrm{p}=0.0001, \mathrm{R}^{2}=0.337\right)$. Also motivation is significantly correlated with adherence behaviour at the 0.05 level $\left(r=0.198, p=0.035 \mathrm{R}^{2}=0.039\right)$. This study finding is consistent with the report of finding of Zhu et al where the model indicated that behavioural skills $(\beta=$ $0.670, \mathrm{P}<0.001)$ and motivation $(\beta=0.095, \mathrm{P}<0.001)$ were both predictors of intention to smoke. Furthermore, the model showed that motivation and behavioural skills were strongly related $(\beta=0.570, \mathrm{P}<0.001)$. Motivation was predicted by media exposure $(\beta=0.356, \mathrm{P}<$ $0.001)$, perceived smoking environmental $(\beta=0.409, \mathrm{P}<0.001)$, and normative expectations $(\beta=0.612, \mathrm{P}<0.001)(10)$.

The Information, Motivation and Behavioural skill model however asserts that to the extent that one is well-informed and well-motivated, he or she will acquire behavioural skills and apply these skills to the challenge of adherence to therapy. This finding may reflect youths' cumulative exposure to crisis prevention messages in the sickle cell clubs. The result is consistent with report of studies based on the extended IMB model for HIV studies where 
prevention information and motivation predicted behaviour and perceived self-efficacy skills. (6, 7 and 8$)$.

The extent of self-efficacy estimated as the ratio between the correctly answered questions and the total asked questions $(11.88 / 15 \times 100 \%=79.2 \%)$ is high. Motivation is positively correlated with self-efficacy for the respondents at 0.01 level $\left(r=0.579, p=0.0001, R^{2}=0.337\right)$. Since self-efficacy is acquired over time with practices, as the saying goes "practice makes perfect". Self-efficacy levels can enhance or impede the motivation to act. Individuals with high self-efficacy choose to perform more challenging tasks. They set themselves higher goals and stick to them (20). Actions are pre shaped in thought. Once an action has been taken, high self-efficacious persons invest more effort and persist longer than those with low self-efficacy. A sense of competence can be acquired by mastery experience, vicarious experience, verbal persuasion, or physiological feedback (21). Motivation is positively correlated with self-efficacy for the respondents at 0.01 level ( $r=0.579, \mathrm{p}=0.0001, \mathrm{R}^{2}=0.337$ ). The correlation between information and self-efficacy with respect to sickle cell disease preventive-practices is negative and not significant.

Despite the respondent's high level of information, motivation and self-efficacy, their crisis- prevention behaviour mean score is barely above average (percentage of the mean score to the total obtainable scores for adherence behaviour i.e. 11.22 / 21 x $100=53.42 \%$ ). This is suggestive of the fact that there are other factors and variance apart from information and motivation that are responsible for adherence behaviour. This result is consistent with the report by Fisher on "Adapting the Information-Motivation-Behavioural Skills Model: Predicting HIV-Related Sexual Risk among Sexual Minority Youth" where the results indicated that model variables accounted for $35 \%$ of the variance in primary sexual risk behaviours. The remaining factors are responsible for $66.3 \%$ of adherence behaviour (22). These other factors could be explored by another study.

The regression analysis indicates that motivation of the respondents predicted greater selfefficacy skills $\left(\mathrm{R}^{2}=0.337\right)$ than adherence behaviour $\left(\mathrm{R}^{2}=0.039\right)$ to sickle cell crisis prevention behaviour in the respondents. The IMB model demonstrates that information is a prerequisite for changing behaviour, but in itself is insufficient to achieve this change. Motivation and behavioural skills are critical determinants and are independent of behaviour change. This suggests that it may be particularly important to tailor sickle cell crisis risk prevention messages for youth around motivation in other to encourage them to develop selfefficacy skills needed to adhere to crisis preventive-practices. The linear regression model fit for this study is validated. Motivation of sickle cell youth is directly proportional to adherence behaviour with a positive intercept on the Adherence axis. Hence, an increase in adherence can be achieved with a proportionate increase in motivation achieved through self -efficacy skills.

Sickle cell crisis preventive - practices behaviour was mostly predicted by motivation, which in turn was highly predicted by self-efficacy skills. In essence the study result has provided validity for the theoretical and conceptual framework that guided this study for the sickle cell youth population.

Despite the social and medical information interventions, sickle cell crisis among youth is not abating. For this reason, research testing adapted models for this population, such as the present study, are urgently needed. These findings enhance our understanding of the sickle cell disease crisis risk prevention behaviours of sickle cell youth and provide a theoretical foundation for the development of preventive interventions tailored for this population. Effective prevention programs must therefore address the unique motivational factors that affect sickle cell crisis risk prevention. The IMB model used in this study offers insight into factors associated with adherence to sickle cell disease crisis preventive-practices for youth. Knowledge gained from this investigation is a first step toward developing innovative and culturally relevant interventions for an underserved youth population at high risk for sickle cell disease crisis in Abeokuta and by extension to all sickle cell youth globally. 
Texila International Journal of Public Health

Volume 4, Issue 4, Dec 2016

\section{Recommendations}

The sickle cell disease crisis consequences can be prevented if the sickle cell patients adhere to sickle cell disease crisis preventive-practices, take the responsibility of self-efficacy skills about crisis prevention and regular medical check-up, get involved in social activities designed for motivating sickle cell patients, be an active member of sickle cell club where support and motivation could be obtained to reduce the incidence of sickle cell disease crisis.

Similar research is recommended in other sickle cell clubs in other state in Nigeria to validate the Information, Motivation and Behavioural skill (IMB) model among the sickle cell population, in order to develop appropriate intervention to prevent sickle cell crisis. Stakeholders (Government, Nongovernmental organization, religious associations and institution, fathers, mothers, health workers, friends, schools, media and sickle cell clubs) should be involved and sponsor research to explore other factors that could predict adherence to crisis preventive-practices among sickle cell population and support same in any way they can in order to reduce mortality due to sickle cell disease crisis and complication.

\section{Limitation of the study}

These study findings should be considered in light of the following limitations. First, the convenience sample of 84 sickle cell youths recruited from the sickle clubs in Abeokuta limits the generalizability of findings to all young sickle cell youths, particularly those who are not involved with such clubs. Thus, study findings may be used to inform future sickle cell crisis preventive-practices interventions for sickle cell youth in other sickle cell clubs in other states in Nigeria and other African countries. Second, although the term predict is used in reference to path analysis, causality cannot be determined by non-experimental designs such as the one used in this study. Third, reliance on youth's self-reports may threaten data reliability and validity. However, strategies such as emphasizing confidentiality, and reminding respondents that their answers would be used to improve programs for sickle cell crisis prevention in youth were employed to facilitate accurate self-reports of respondents' behaviours. Finally, the IMB model tested in this study focuses on individual-level factors influencing sickle cell disease crisis prevention risk. It is likely that other factors are associated with adherence to crisis preventive-practices in the youth.

\section{The Contributions of this Study}

This study is significant because the findings would provide clear understanding regarding the dynamics involved with adherence to sickle cell crisis preventive-practices among this population. The finding also have policy implications: The Government, sickle cell patients and their parents, Non-Governmental Organisations (NGO's), and other stakeholders may also make use of the report of the study as need assessment to plan appropriate health promotion and education intervention. Furthermore, recommendations from the study would be useful in strengthening health Education counselling for these at - risk group. Finally, results of hypotheses regarding path analysis through which adherence is best achieved will provide validity of the theoretical framework that guided the study.

\section{Conclusions}

The IMB model indicated that behavioural skills (self-efficacy) $(\beta=0.582, \mathrm{P}<0.001)$ and motivation $(\beta=0.199$., $\mathrm{P}<0.001)$ were both predictors of adherence to crisis preventivepractices. Information was not significantly correlated to adherence behaviour $(\beta=-0.10$, $\mathrm{P}>0.05)$ and behavioural skills $(\beta=-0.041, \mathrm{P}>0.05)$. Self-efficacy skills and motivation of the respondents predicted greater adherence to sickle cell crisis preventive-practices in the respondents. The study is consistent with IMB model. Sickle cell crisis risk prevention messages for youth should be tailored around motivation to develop self-efficacy skills to adhere to sickle cell crisis preventive-practices. Despite its limitations, this study added to knowledge and validated the IMB model on sickle cell disease crisis prevention information, 
preventive-practices motivation and self-efficacy as predictive factors for adherence behaviour to crisis preventive-practices among sickle cell population.

This research is a step toward developing a culturally specific IMB model of sickle cell disease crisis risk prevention, and findings have implications for policy, research and practice. Although the study results identify specific factors that may be important targets for sickle cell disease crisis preventive interventions with the youth, cross-sectional methods are limited in their assessment of developmental processes and trajectories. Longitudinal studies and mixed method approaches would provide opportunities to assess these important developmental processes and experiences more precisely and investigate the complex developmental trajectories of these youth more fully. Because subgroup analysis was not possible in this study, future research is needed to explore the predictive power of the IMB model with specific racial/ethnic groups of Nigerian's youth. Youth programs at sickle cell clubs should develop motivation related programs that include content on incentives, social support, reinforcements, drive and intention. Knowledge gained from this investigation is a first step toward developing innovative and culturally relevant interventions for an underserved youth population at high risk for sickle cell disease crisis in Abeokuta and by extension to all sickle cell youth globally.

\section{References}

[1] Al - Nasir F, Niazi G (1997). Sickle cell disease: patients' Awareness and management. Journal of Saudi Medicine. 18(1): $63-65$

[2] Butler, Dennis, J, Beltran, Lou, R. (1993) Functions of an adult sickle cell group: Education, task orientation, and support. Health and Social Work, 18(1): 49 - 56

[3] Bandura Albert, (1977) Self efficacy: Toward a unifying theory of Behavioural change: Psychological Review vol 84, no 2,191-215

[4] Babwah F, Baksh S, Blake L, Cupid-Thuesday J, Hosein I, Sookhai A, Poon-King C, Hutchinson $\mathrm{G}$ (2006). The role of gender in compliance and attendance at an outpatient clinic for type 2 diabetes mellitus in Trinidad. Rev Panam Publication, 19(2); 79-84

[5] Fisher Colleen M. (2011): Adapting the Information-Motivation-Behavioral Skills Model: Predicting HIV-Related Sexual Risk among Sexual Minority Youth Health Education \& Behavior, published online 21 June 2011.

[6] Fisher WA, Fisher JD, Harman J (2003), The Information-Motivation-Behavioral skills model as a general model of health behavior change: Theoretical approaches to individual-level change. In: Suls J, Wallston K, editors. Social psychological foundations of health. Blackwell Publishers; London:127153.

[7] Fisher, Jeffrey D.; Fisher, William A.; Bryan, Angela D.; and Misovich, Stephen J., J (2002) "Information-Motivation-Behavioral Skills Model-Based HIV Risk Behaviour Change Intervention for Inner-City High School Youth" Health Psychology;2002;21 (2); 177-86.

[8] Fisher JD, Fisher WA. (1992) Changing AIDS-Risk Behavior. Psychological Bullettin, 111(3):455-74.

[9] Gil, KM, Abrams MR, Phillips G, Keefe FJ (1989). Sickle cell disease pain: Relation of coping strategies to adjustment. Journal of Consultant Clinical Psychology 57: 725 - 731

[10] Jaffer DE, Amrallah FK, Ali KM, Mohammed NA, Hasan RA and Humood ZM (2009) Adult Sickle cell disease patients' knowledge and attitude toward the preventive measures of sickle cell disease crisis. International Journal of Nursing and midwifery 1(2), 010-018. Journal of Intravenous Nursing, 21(1), 27-39

[11] Jungling Gao, Jingli Wang, Yaocheng Zhu and Jinming Yu, (2013): Validation of an Information-Motivation-Behavioural skills model of self-care among Chinese adults with type 2 diabetes. Biomed Central Public Health 13:100

[12] Lozano, (2010) Haematological parameters among sickle cell anaemia

[13] Locke E. A \& Latham, G.P (1990). A theory of goal setting and task performance Upper Saddle River, NJ: Prentice Hall. 
Texila International Journal of Public Health

Volume 4, Issue 4, Dec 2016

[14] Michele L.Ybarra, Josephine Korchmaros, Julius Kiwanuka, David R. Bangsberg and Sheana Bull (2013)Examining the applicability of the IMB model in predicting condom use among sexually active secondary school students in Mbarara, Uganda. AIDS Behaviour 17(3)1116-1128

[15] Mentzer, W. C., Heller, S., Pearle, P. R., Hackney, E., \&Vichinsky, E. (1994). Availability of related donors for bone marrow transplantation in sickle cell anemia. American Journal of Pediatric Hematology/Oncology, 16(1), 27-29.

[16] Ogamdi S (1994). African American Students' awareness of sickle cell disease. J.A m. Coll. Health 42 (5):234-236

[17] Okpala, Thomas, Westerdale, Jegede, Raj, Daley, Costello-Binger, Mullen, Rochester- Peart, Helps, Tulloch, Akpala, Dick, Bewley, Davies, and Abbs, 2002

[18] Simon, K., Lobo, M. L., \& Jackson, S. (1999). Current knowledge in the management of children and adolescents with sickle cell disease. Part 1: Physiology issues. Journal of Pediatric Nursing, 14(5), 281-295.

[19] World Health Organization, 2006

[20] World Health Organization, 2012

[21] Walters, M. C. (1999). Bone marrow transplantation for sickle cell disease: Where do we go from here? Journal of Pediatric Hematology/Oncology 2(6),

[22] Zhu, C., Cai Y., Ma, J., Li, N., Zhu, J., He, Y., Redmon, P., and Qiao, Y. (2013) Predictors of Intention to Smoke among Junior High School Students in Shanghai, China: An Empirical Test of the Information-Motivation-Behavioral Skills (IMB) Model. PLoS ONE, 8(11). 


\title{
Prevalence of Undiagnosed Diabetes Mellitus amongst Hypertensive Patients Attending an Outpatient Clinic in Harare, Zimbabwe
}

\author{
Article by Pasipanodya Ian Machingura, Rosinah Murambiwah \\ Ph.D. in Public Health, Texila American University, Zimbabwe \\ E-mail: imachingura@yahoo.co.uk
}

\begin{abstract}
Diabetes mellitus is amongst the largest health emergencies of the $21^{\text {st }}$ century. However studies have reported that a substantial proportion of people with diabetes mellitus had not previously been diagnosed. On the other hand hypertension prevalence has been reported to be on the increase. Hypertension has also been associated with the development of diabetes mellitus. The study sought to determine the prevalence of undiagnosed diabetes mellitus in hypertensive patients attending an outpatient clinic in Harare, Zimbabwe.

A cross sectional study was conducted at Parirenyatwa Group of Hospitals Outpatient Clinic. All hypertensive patients attending the outpatient during the study period were given the information about the study. All hypertensive patients who were previously not diagnosed of diabetes mellitus who consented to participate in the study were consecutively enrolled. A questionnaire was administered and blood samples were collected for Glycosylated hemoglobin analysis. Glycosylated hemoglobin was analysed using a Mindray BS800 Chemistry Analyser.

One hundred and four hypertensive patients were enrolled into the study whose mean age was 60.91( \pm standard deviation of 14.06) years. Patients with duration of hypertension greater than 10 years constituted 34\% (35) of the study population. The prevalence of undiagnosed diabetes mellitus was $22.1 \%$ (23). Among the previously undiagnosed diabetic patients $56.5 \%$ (13) were females and $43.5 \%$ (10) males.

The prevalence of undiagnosed diabetes mellitus was found to be 22, 1\% among hypertensive patients which is higher than that reported in Kenya but lower than that reported in Uganda. Diabetes mellitus can be highly prevalent in hypertensive patients thus there is need for constant monitoring for the development of diabetes mellitus and further research using a national representative sample.
\end{abstract}

Keywords: Diabetes mellitus, pre-diabetes, glycosylated haemoglobin

\section{Introduction}

Diabetes mellitus is the amongst the largest health emergencies of the $21^{\text {st }}$ century causing life changing complications. Africa is reported to have the largest proportion of undiagnosed diabetes mellitus, it is estimated over two thirds of the people with diabetes mellitus are unaware of it(1). Diabetes mellitus and hypertension coexist in patients. The prevalence of hypertension is reported to be 1.5 to 2.0 times more in diabetes mellitus patients compared to non-diabetics whilst approximately a third of hypertension patients would develop diabetes mellitus. The coexistence of the two results in an increased risk and can accelerate vascular complications (2).

There is a complex cause effect relationship between hypertension and diabetes mellitus which is hypothesised. The new onset diabetes mellitus in hypertensive patients could be caused by treatment with antihypertensive drugs such as diuretics and beta blockers (3). Both diabetes mellitus and hypertension are manageable health conditions which can be controlled through use of medicines, exercise and diet. The detection of progenitors namely pre-diabetes and prehypertension by surveillance enables the early intervention and result in delay in the disease progression (2). The World Health Organisation does recommend cardiovascular risk 
Texila International Journal of Public Health

Volume 4, Issue 4, Dec 2016

assessment which does include glucose testing amongst patients presenting with hypertension (4). A third of all people with diabetes mellitus are reported that they may be undiagnosed and above $60 \%$ of the newly diagnosed diabetes mellitus patients are unaware of their condition until they develop complications (5).

There is paucity of documented data on prevalence of undiagnosed diabetes mellitus in high risk groups such as hypertensive patients in a clinical setting in Zimbabwe. Thus the study sought to determine the prevalence of undiagnosed diabetes mellitus in hypertensive patients attending an outpatient clinic in Harare, Zimbabwe.

\section{Methods}

\section{Ethical considerations}

The study was approved by the Joint Research Ethics Committee of the Parirenyatwa Group of Hospitals and University of Zimbabwe College of Health Sciences (JREC 342/15) and informed consent was obtained for all the study participants included in the study.

\section{Study design and study sites}

A cross-sectional study was carried out on hypertensive patients attending Parirenyatwa Group of Hospitals Outpatient Clinic, Harare, Zimbabwe in the period 08 February 2016 to 21 March 2016.ParirenyatwaGroup of Hospitals is at tertiary teaching hospital located in the capital city of Zimbabwe Harare.

\section{Study subjects}

All adult hypertensive patients (18 years and above) attending Parirenyatwa Group of Hospitals Outpatient Clinic were given information on study. All hypertensive patients who were not diagnosed of diabetes mellitus before who consented to participate in the study were consecutively enrolled.

\section{Data collection}

A questionnaire was administered on all adult hypertensive patients who consented to participate in study. A blood sample was collected into an ethylenediaminetetra acetic acid (EDTA) tube for glycosylated haemoglobin analysis(HbA1c) using vacuitaner method of blood collection.

\section{Sample analysis}

The samples collected in EDTA tubes were stored at 2 to 8 degrees Celsius and analysed for HbA1c within a week. The samples were thawed to room temperature and glycosyslated haemoglobin analysis was carried outon a Mindray BS 800 Chemistry Analyser(Mindray, Shenzhen, China). The assay kits, calibrators and standards were supplied by the manufacturer. The analyser was calibrated and then controls were assayed before the samples were analysed following manufacturers' recommendations.

\section{Data analysis}

Statistical Package for the Social Sciences version 8 data analysis package was used to analyse the data. Normally distributed data was analysed using mean and standard deviation. Normally distributed data was compared using the student $t$ test.

\section{Definitions}

The following case definitions were used:

- $\quad$ Non-diabetes, HbA1c $<6.0 \%(6)(7)$

- $\quad$ Pre-diabetes, HbA1c between $6.0 \%$ and $6.4 \%(6)(7)$

- $\quad$ Diabetes mellitus, HbA1c $\geq 6.5 \%$ (6)(7) 


\section{Results}

One hundred and four hypertensive patients were recruited into the study of whom $64.4 \%$ (67) were female. The mean age of study participants was $60.91( \pm$ standard deviation of 14.06) years. $76.0 \%$ (79) of participants were on enalapril and $24.0 \%$ (25) were on atenolol antihypertensive drugs. The mean $\mathrm{HbA1c}$ was $5.8 \%$. There was no significant difference in mean HbAIc levels of females (5.7\%) and male (5.9\%) participants, (p value $=0.335$ ).

Patients with the duration of hypertension greater than 10 years constituted $34 \%$ (35) of the study population and $81 \%$ (84) of participants had no family history of diabetes mellitus. Eighty six percent (89) of the study participants reported that they do not undertake regular exercise.

Table 1: To show the classification of study participants according to diabetes mellitus status

\begin{tabular}{|l|l|l|}
\hline Category & $\begin{array}{l}\text { Number of } \\
\text { patients }\end{array}$ & Percentage (\%) \\
\hline Non-Diabetes & 54 & 51.9 \\
\hline Pre-diabetes & 27 & 26.0 \\
\hline Diabetes mellitus & 23 & 22.1 \\
\hline Total & 104 & 100 \\
\hline
\end{tabular}

Table 1 shows the prevalence of undiagnosed diabetes mellitus was 22.1\% (23). Among diabetic hypertensive participants were $56.5 \%$ (13) females and $43.5 \%$ (10) males. Prediabetes constituted 26\% (27) of participants with 66.7\% (18) being females and 33.3\% (9) were males. $51.9 \%$ (54) of study participants were non-diabetic and of these $66.7 \%$ (36) were females while $33.3 \%$ (18) were males.

\section{Discussion}

The coexistence of hypertension and diabetes mellitus does increase the risk of end organ damage, the incidences of cardiovascular disease and mortality. Whilst pre-diabetes is an independent risk factor for incident cardiovascular disease and mortality(8). Pre-diabetes is an intermittent stage of overt diabetes where blood glucose is higher than normal value but not high enough to meet diagnostic criteria of diabetes mellitus. The majority of diabetes mellitus patients are reported to go through a pre-diabetes phase for several years in which an opportunity exist to identify them and commence timely prevention. Studies have reported that the use of HbA1c is a highly standardised convenient test which exhibits low intraindividual variation which can be obtained at any time requiring no patient preparation and a sample is relatively stable at room temperature after collection. A strong correlation exists between average plasma glucose and HbA1c (5) which we used in this current study.

In this current study the prevalence of pre-diabetes mellitus was $26.0 \%$ whilst that of diabetes mellitus was 22.1\%. A study at a district hospital in Kiambu Kenya [2014] reported prevalence of pre-diabetes of $18 \%$ and $14 \%$ newly diagnosed diabetes mellitus(5). In as study at Mulago hospital in Uganda [2005-2006] prevalence of pre-diabetes mellitus was 50\% and newly diagnosed diabetes mellitus was $24 \%$ (9).A study at a tertiary hospital in Imo state of Nigeria [2011] reported a prevalence of pre-diabetes of 33.1\% amongst adult Nigerians with essential hypertension (10).

In Germany amongst hypertensive patients they reported prevalence of pre-diabetes of $39 \%$ and diabetes mellitus of $12 \%$ (11). Lower prevalence of pre-diabetes and diabetes mellitus are expected in developed countries due to their better glucose testing programmes. Whilst on the contrary higher rates of pre-diabetes and diabetes in developing countries are due to lack of rigorous screening which leaves many patients undiagnosed (9). 
Texila International Journal of Public Health

Volume 4, Issue 4, Dec 2016

Above three quarters of the patients were on enalapril an angiotensin converting enzyme inhibitor which is amongst the second line antihypertensive agents in Zimbabwe whilst the rest were on atenolol a beta blocker which is amongst the first line antihypertensive agents in Zimbabwe (12). Beta blockers have been associated with new onset diabetes amongst hypertension patients (3).

Eighty nine percent of patients reported that they do not undertake regular exercise which however has been reported that if it is combined with dietary intervention decrease incidence of type 2 diabetes mellitus in high risk group(13).

We recommend regular screening of diabetes mellitus amongst the hypertensive patients to diagnose pre-diabetes mellitus and prevent the development of diabetes mellitus which is associated with morbidity and mortality.

\section{Conclusion}

The prevalence of undiagnosed diabetes mellitus was found to be 22, $1 \%$ among hypertensive patients which is higher than that reported in Kenya but lower than that reported in Uganda. Diabetes mellitus can be highly prevalent in hypertensive patients thus there is need for constant monitoring for the development of diabetes mellitus and further research using a national representative sample.

\section{References}

[1] Bruno RM, Taddei S. New-onset diabetes in hypertensive patients and mortality: timing is everything. Eur Heart J. 2016 Mar 21;37(12):975-7.

[2] International Diabetes Federation. International Diabetes Federation Diabetes Atlas Seventh Edition [Internet]. 2015 [cited 2016 Jul 20]. Available from: www.diabetesatlas.org

[3] Iloh GUP. Risk Factors of Pre-Diabetes among Adult Nigerians with Essential Hypertension in a Resource-Constrained Setting of a Primary Care Clinic in Eastern Nigeria. Am J Health Res. 2013;1(3):56.

[4] Joshi SR, Saboo B, Vadivale M, Dani SI, Mithal A, Kaul U, et al. Prevalence of Diagnosed and Undiagnosed Diabetes and Hypertension in India—Results from the Screening India's Twin Epidemic (SITE) Study. Diabetes Technol Ther. 2012 Jan;14(1):8-15.

[5] Korhonen P, Aarnio P, Saaresranta T, Jaatinen P, Kantola I. Glucose Homeostasis in Hypertensive Subjects. Hypertension. 2008 Apr 1;51(4):945-9.

[6] Lüders S, Hammersen F, Kulschewski A, Venneklaas U, Züchner C, Gansz A, et al. Diagnosis of impaired glucose tolerance in hypertensive patients in daily clinical practice. Int $\mathrm{J}$ Clin Pract. 2005;59(6):632-8.

[7] Ministry of Health and Child Welfare Republic of Zimbabwe. 6th Essential Medicines list and standard treatment guidelines for Zimbabwe. 2011.

[8] Mutebi E, Nakwagala FN, Nambuya A, Otim M. Undiagnosed diabetes mellitus and impaired glucose tolerance among hypertensive patients in Mulago Hospital, Kampala, Uganda. Afr J Diabetes Med [Internet]. 2012 [cited 2016 Oct 28];20. Available from: http://www.africanjournalofdiabetesmedicine.com/articles/May_2012/AJDM\%20MAY\%20PP\%202023.pdf

[9] Meme N, Amwayi S, Nganga Z, Buregyeya E. Prevalence of undiagnosed diabetes and prediabetes among hypertensive patients attending Kiambu district Hospital, Kenya: a cross-sectional study. Pan Afr Med J [Internet]. 2015 [cited 2016 Oct 28];22. Available from: http://www.panafricanmed-journal.com/content/article/22/286/full/

[10] Organisation mondiale de la santé. Global status report on noncommunicable diseases 2014: attaining the nine global noncommunicable diseases targets; a shared responsibility. Geneva: World Health Organization; 2014.

[11] Organization WH, others. Use of glycated haemoglobin (HbA1c) in diagnosis of diabetes mellitus: abbreviated report of a WHO consultation. 2011 [cited 2016 Oct 28]; Available from: http://apps.who.int/iris/handle/10665/70523 
[12] Orozco LJ, Buchleitner AM, Gimenez-Perez G, Roqué i Figuls M, Richter B, Mauricio D. Exercise or exercise and diet for preventing type 2 diabetes mellitus. In: The Cochrane Collaboration, editor. Cochrane Database of Systematic Reviews [Internet]. Chichester, UK: John Wiley \& Sons, Ltd; 2008 [cited 2016 Oct 28]. Available from: http://doi.wiley.com/10.1002/14651858.CD003054.pub3

[13] The International Expert Committee. International Expert Committee Report on the Role of the A1C Assay in the Diagnosis of Diabetes. Diabetes Care. 2009 Jul 1;32(7):1327-34. 


\title{
Evaluation of Pharmaceutical Waste Disposal Practices in Healthcare Facilities in Lagos State, South West Nigeria
}

\author{
Article by Margaret Okama Obono \\ Master of Public Health, Texila American University, Nigeria \\ E-mail:okamaobono@gmail.com
}

\begin{abstract}
The objective of this study is to find out how unused, expired, damaged and unwanted medicines are handled and disposed of in health facilities in Lagos State, South West Nigeria. An average hospital stocks between 2000 to 4000 drug items for use by patients at any point in time. Hospitals and households have been identified as the largest source of Pharmaceutical waste going into the sewer system.

A large quantity of Pharmaceutical Waste generated in hospitals include regulated hazardous and non-regulated hazardous Pharmaceutical waste and a significant amount of these have been found in underground water and drinking water.

195 health facilities made up of 5 tertiary teaching/specialist hospitals, 25 secondary healthcare facilities and 165 primary healthcare centres were evaluated using structured questionnaires to collect data. Data were analyzed using SPSS version 20.

Results show that $85 \%$ of disposal of pharmaceutical waste was done by open burning, a method that causes air pollution. There was no significant association between category of Health Facility and method of disposal of pharmaceutical waste. Less than 10\% of Health Facilities had Pharmaceutical Waste Disposal(PWD) programmes in place.15\% of respondents see the need for designated drug take - back centres and will consider establishing one. The need for additional training on PWD was identified.
\end{abstract}

Keywords

1. PHARMACEUTICAL WASTE:- Solid, liquid or gas waste from Pharmaceutical products that can pose a substantial hazard to human/animal health and the environment when not properly managed (40 CFR part 261).

2. HAZARDOUS WASTE:- Wastes with properties that make the product dangerous or potentially harmful to human health or the environment.

3. HAZARDOUS WASTE LANDFILL:- A disposal facility where hazardous waste is placed in a land treatment facility, a surface impoundment, an underground injection well, a salt dome formation, a salt bed formation, an underground mine, a cave or a corrective action management unit (40 CFR 260.10)

4. DRUG TAKE -BACK EVENTS: - Any programme or series of programmes organized by the Drug Enforcement Administration (DEA).Drug takes back initiative on which the public can return unwanted, unused or expired drugs.

5. LISTED HAZARDOUS WASTES:- Materials specifically listed by regulatory authorities as waste from non-specific sources, specific sources or discarded chemical product.

6. OTC MEDICINES:- Over -the- counter drugs that can be sold directly to a client without a prescription from a healthcare professional.

\section{Introduction}

Pharmaceuticals include but are not limited to prescription medicines and over-the-counter (OTC) remedies, veterinary medicines, nutritional supplements, herbal medicines, various alcoholic and non-alcoholic beverages and drugs of abuse that are used for non-medical purposes. Any unused, expired, damaged, deteriorated drug or product as listed above becomes Pharmaceutical Waste. 
Texila International Journal of Public Health

Volume 4, Issue 4, Dec 2016

Pharmaceutical Waste can be put into the following groups:-

- Hazardous Wastes e.g. Carcinogenic or Mutagenic agents.

- Non - hazardous Wastes e.g. non-carcinogenic, they constitute the largest group of Pharmaceutical Waste.

- Not pharmaceutically active waste e.g. dietary supplements, intravenous fluids.

- Flammable, irritant, harmful, oxidizing or Eco-toxic medicines e.g. disinfectants.

An average hospital pharmacy stocks between 2000 and 4000 different pharmaceuticals products for use of patients. This number of pharmaceuticals is continuously on the increase due to research and development of new drugs annually and these results in a corresponding increase in pharmaceutical waste. Hospitals and households have been identified as the largest source of Pharmaceutical Waste going into the sewer system. Hospital and healthcare facilities may fall into one of these two groups in generation of Pharmaceutical Waste.

1. Large Quantity Generators(LQGs):- Facilities that generate greater than or equal to $1000 \mathrm{~kg}$ of hazardous Waste per calendar month or greater than $1 \mathrm{~kg}$ of acute hazardous waste per calendar month.

2. Small Quantity Generators (SQGs) :- Facilities that generate between $100 \mathrm{~kg}$ and $1000 \mathrm{~kg}$ of hazardous waste per calendar month and accumulate less than $6,000 \mathrm{~kg}$ of hazardous Waste at any time or generate $1 \mathrm{~kg}$ or less of acutely hazardous waste per calendar month.

The Pharmaceutical Waste generated in most cases is burnt, buried or poured down the drain.

Disposal methods that have been utilized for unwanted pharmaceuticals are:

- Return to donor or manufacturer

- Dispose through landfill

- Waste immobilization: encapsulation or inertization

- Through server system

- Burning in open containers

- Medium temperature incineration

- Novel high temperature incineration

- Chemical decomposition

Improper disposal of Pharmaceuticals may have the following consequences:-

- Contamination of underground water.

- Contamination of drinking water

- Lead to accidental ingestion by children or pets

- Lead to unintended use and misuse of medicines

- Expired medicines may be diverted and rebelled for sale

- May cause damage to aquatic life

- Some pharmaceuticals kill bacteria necessary for treatment of sewage.

- Disposal of pharmaceuticals by burning may cause a release of toxic pollutants into the air.

- There may be development of antibiotic resistance due to ingestion from animals that have been continuously exposed to antibiotic waste in the environment.

It is dangerous to allow unqualified persons to handle the Pharmaceutical Waste. Pharmaceutical Waste Management is especially challenging given the complexity of the regulations that govern its activities and the multiple regulatory agencies that oversee Waste Management.

In the United States, Pharmaceutical Waste Management is regulated by agencies such as:-

- Environmental Protection Agency (EPA)

- Department of Transportation (DOT)

- Drug Enforcement Administration(DEA)

- Occupational Safety and Health Administration (OSHA)

- Pharmacy Board 
In the United States treatment, storage and disposal of hazardous waste are regulated under the "Resource Conservation and Recovery Act" (RCRA) in 40 CFR 261 where they are divided into 2 major categories. ${ }^{3}$

1. Characteristic Waste:- According to the characteristic exhibited by the chemicals like: ignitability, reactivity, corrosivity\& toxicity.

2. Listed Hazardous Wastes are materials specifically listed by regulatory authorities as hazardous wastes which are from non-specific sources, specific sources or discarded chemical products.

Hazardous waste can be in different physical states:- gaseous, liquid or solid. They cannot be disposed of like any other waste from households. Their disposal is complex and expensive.

\section{Disposal of Hazardous Waste}

- Disposal in landfills: Some disposed hazardous waste in landfills eventually enter to the natural hydrologis system. Thus many landfills now require counter measures against ground water contamination. Barriers are installed along the foundation of the landfills to absorb these chemicals. Currently hazardous waste must be stabilized and solidified and must undergo treatment before disposal. Flammable materials can be recycled into industrial fuel.

- Cement Based Solidification and Stabilization is a method used to treat range of hazardous waste by improving physical characteristics and decreasing the toxicity and transmission of contaminants. The process converts sludge into cement and pharmaceutical hazard adjustment agents added (phosphates or sulfur) to reduce settling time, increase the compressive strength or reduce the leach ability of contaminants.

- Incineration, destruction and waste to energy. Incinerating at high temperature is a method of disposal of hazardous waste. Current technology has developed more efficient incinerators that control the emission of toxic gases. Different incinerators are used depending on the characteristics of the waste. Today incineration treatment is also used to generate energy from the gases released in the process.

- Pyrolysis:-Some hazardous waste like concentrated organic waste, pesticides, organic pollutants can be eliminated using pyrolysis in ultra high temperature electrical arc, in inert conditions to avoid combustion.

\section{Objectives of Study}

1. To assess the method of Pharmaceutical Waste disposal in healthcare facilities in Lagos State.

2. To determine the association between the methods of pharmaceutical waste disposal and the categories of healthcare facility.

3. To find out if Pharmacists working in these health facilities have received additional training on Pharmaceutical Waste Disposal.

4. To know if there are Pharmaceutical Waste Management programs in these healthcare facilities.

5. To know if there are designated centres for recall/take-back of expired and unused drugs in these health facilities.

\section{Method of Study}

Study Design:- This is a cross sectional descriptive survey that was done using structured questionnaire to collect data from various healthcare facilities in Lagos State.

Study Location and Population:- Lagos State is located in the Southwestern geopolitical zone of Nigeria. It is the smallest of the 36 states of Nigeria and has an area of $3577 \mathrm{~km} 2$ and a population of 17,552,940 as at 2012 census. It however contains the largest urban city and is claimed to be the economic nerve centre at the country. 
There are 6 tertiary/specialist hospital, 26 secondary hospitals and 288 primary healthcare centres that are run by the government of Lagos State to serve the population. Most of these primary health centres are located in the rural areas and high density populated area.

Sample size determination: The sample size of the number of health facilities to collect data from was calculated using the formula:-

$\mathrm{n}_{\mathrm{o}}=\mathrm{z}^{2} \mathrm{pq} / \mathrm{e}^{2}$

Where:-

$$
\begin{array}{lll}
\mathrm{n}_{\mathrm{o}} & = & \text { sample size } \\
\mathrm{Z} & = & \text { confidence level taken as } 1.96 \\
\mathrm{P} & = & \text { variability taken as } 0.5 \\
\mathrm{q} & = & 1-\mathrm{p} \\
\mathrm{e} & = & \text { desired level of precision taken as } \pm 5 \%
\end{array}
$$

Then the minimum required sample size $\mathrm{n}$, by the finite population correction for proportions

$$
\mathrm{n}=\mathrm{n}_{\mathrm{o}} / 1+\mathrm{n}_{\mathrm{o}}-1 / \mathrm{N}
$$

Where $\mathrm{N}=$ population of healthcare facilities $(\mathrm{HC})$

\section{Calculated sample size}

\begin{tabular}{|l|l|l|}
\hline Types of HF & Number of HF Lagos State & Minimum required sample size \\
\hline Tertiary hospitals & 6 & 5 \\
\hline Secondary HF & 26 & 25 \\
\hline $\begin{array}{l}\text { Primary healthcare } \\
\text { centers }\end{array}$ & 288 & 165 \\
\hline & & 195 total \\
\hline
\end{tabular}

\section{Research Instrument for Data Collection}

The study utilized structured questionnaires consisting of both closed and open ended questions. It was made up of two sections. The first section was to identify the category of health facility and give the demographics of the Drug Manager or in each of these health facilities. It also sort to assess the type of additional training acquired on Pharmaceutical Waste Management.

The second section had questions to assess the actual practice of disposal of pharmaceutical waste to determine availability of drug take-back centres and pharmaceutical waste management programs in each of these facilities.

The responses from the retrieved questionnaires were examined and a coding scheme prepared to facilitate analysis of data. Data entry, cleaning and analysis was done using the statistical package for social sciences (SPSS.20).

Descriptive Statistics, frequencies and percentages, as well as inferential statistics were generated.

Limitation of the Study:- This study was carried out in Lagos and may not be a reflection of pharmaceutical waste disposal in other parts of the country. It also did not assess the health impact of improper waste disposal.

\section{Results}

A total of 195 questionnaires were distributed to the government owned health facilities in Lagos State. All the questionnaires to the tertiary HF and secondary HF were retrieved. Due to the short period used for the study and large spread of the primary HF only 105 of the questionnaires were retrieved.

The percentage of response was $69.2 \%$. Some of the questionnaires were not properly filled and so could not be utilized.

Distribution of Health Facilities showed a $77.8 \%$ of respondents from primary HF, $18.5 \%$ from secondary health facilities and $3.7 \%$ of respondents from tertiary health facilities. (Figure 1) 
Demographic Characteristics:- Results showed a 1.3 ratio of male (27\%) to female (73\%) respondents. (Figure 2) Majority of respondents are of middle age between 31 -50 years (70\%). (Figure 3)

The designations/rank of Pharmacists in charge of drug management in these health facilities showed that almost $40 \%$ of respondents are in the directorate cadre (Administrative cadre) and all of these officers are managers of either the tertiary or secondary health facility. None of the primary health facilities were headed by a Director of Pharmacy. On qualification, results showed that all the respondents either had a first degree or postgraduate qualification in Pharmacy.

In the area of number of years of experience, $25 \%$ of respondents had between 5-9 years of experience, $26.8 \%$ had between 10-14years of experience in practice, 25\% had 15-19 years and $22.3 \%$ had more than 20 years of professional experience. (Figure 4) Only $11 \%$ of all these respondents agreed to having had any form of additional training on Pharmaceutical Waste disposal/management. (Figure 5)

\section{Pharmaceutical Waste Disposal Practice}

Results show that in about $85 \%$ of the health facilities collation and disposal of pharmaceutical waste was done once in 6 months or one year. Disposal was by burning. (Table 3)

Donated drugs or drugs used for research or programs were returned to the donors on expiry to reduce the value of expired pharmaceuticals in the facilities at any point in time.

Only the few tertiary health facilities had stock of expired hazardous pharmaceuticals (4\%) (Figure 6).

Only $8 \%$ of the respondents agreed to having a pharmaceutical waste disposal programs in their health facilities (Figure 8). No health facility currently has an established drug take back program/centre, (Figure 7) but 15\% of respondents agree that recall of expired/unwanted drugs is necessary and they will consider the establishment of a centre.

Association between method of disposal of pharmaceutical waste and grade/category of health facility.

Results show that the common method of disposal which is burning was practiced by all categories of healthcare facilities(Figure 9). Therefore there was no significant association between the category of HF and disposal method.

\section{Discussion}

The increasing number of both hazardous and non-hazardous drugs in circulation and the consequent increase in amount of expired, damaged and unwanted pharmaceutical wastes are disposed of.

Expired and unused drugs in households as well as those generated in health facilities pose a serious danger to humans and the environment if not properly disposed of.

This study revealed that both hazardous and non-hazardous drugs are utilized in the three categories of health facilities and Pharmaceutical Waste generated includes both hazardous (4\%) and non-hazardous (96\%) waste. There is need to ensure that Pharmaceutical Waste are disposed of properly to avoid the numerous consequences of inappropriate disposal.

The study revealed that very senior professionals with several years in practice are responsible for drug management in all the facilities studied. This however did not confer expert knowledge of pharmaceutical waste disposal. Healthcare professional : doctors, pharmacists, nurses etc do not receive the training on hazardous waste management during their training so they need additional training on pharmaceutical waste management practice. Safety and Environmental Services Managers who receive training in Waste Management may not be familiar with the active ingredients of these pharmaceutical products and the level of toxicity so may not be able to treat them appropriately.

On the actual practice of disposal, 85\% of the Pharmaceutical Waste was disposed by burning and burying. Studies have shown that expired drugs buried or put in landfills 
eventually leach into ground water and drinking water. The drugs burnt in open air cause a release of pollutants into the atmosphere posing a health hazard. Proper disposal of Pharmaceutical Waste may be expensive because of the numerous regulatory agencies controlling these processes, but there are currently numerous methods of proper disposal of Pharmaceutical Waste.

The study revealed that very few health facilities (8\%) have documented pharmaceutical waste management programs in place. This should be given priority and the regulatory agencies should enforce its implementation considering the dangers of inappropriate disposal of Pharmaceutical Waste.

A Large amount of expired and unwanted Pharmaceuticals are in households with people who have recovered or whose prescriptions were changed and they do not need those drugs. There is virtually no drug take-back centres designated in the Pharmacies of healthcare facilities as revealed by this study. Establishment of these centers will reduce the practice of pouring drugs down the drain or putting them into the trash can. There is need to encourage patients to return their unwanted medicines to designated centers for proper disposal.

There was no association established between the category of health facility and the method of pharmaceutical waste disposal. The primary HF in rural areas and tertiary HF in the urban area all dispose of by burning or burying. The study did not identity any association between the educational qualification or number of years of professional experience and the methods of Pharmaceutical Waste disposal.

\section{Conclusion}

The disposal of Pharmaceutical Waste especially hazardous Pharmaceutical Waste is a complex procedure that requires specific training of healthcare professional to carry out. Most healthcare professionals currently managing medicines in Lagos State healthcare facilities do not have adequate training to handle the appropriate disposal of pharmaceutical waste.

There is need to put in place a plan to give/organize additional periodic training for Drug managers in all health facilities in Lagos State.

This study revealed that most of the Pharmaceutical Waste being generated by healthcare facilities in Lagos State is currently not being properly disposed of and may pose a health hazard in future. There was no association identified between the category of healthcare facility (tertiary, secondary or primary) and the method of disposal of pharmaceutical waste. All the health facilities used the same method of disposal.

There is standardized documented Pharmaceutical Waste management program in existence and there is need to put one in place.

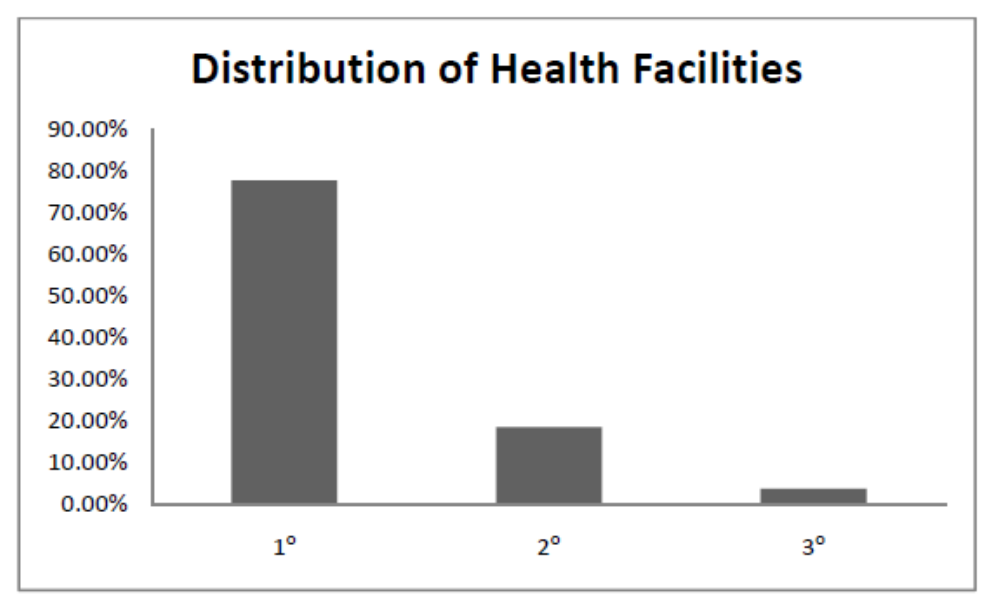

Figure 1 
TABLE 1

\begin{tabular}{|c|c|}
\hline \multicolumn{2}{|c|}{ DESIGNATION OF RESPONDENTS } \\
\hline Pharmacists cadre & $61.30 \%$ \\
\hline Director Cadre & $38.70 \%$ \\
\hline
\end{tabular}

Gender of

Respondents Gender of Respondents

$0 \%$

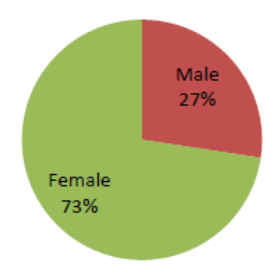

FIGURE 2

TABLE 2

\begin{tabular}{|c|c|}
\hline \multicolumn{2}{|c|}{ Highest Professional Qualification } \\
\hline BPharm & $46.50 \%$ \\
\hline 2nd Degree & $53.50 \%$ \\
\hline PhD & $0 \%$ \\
\hline
\end{tabular}

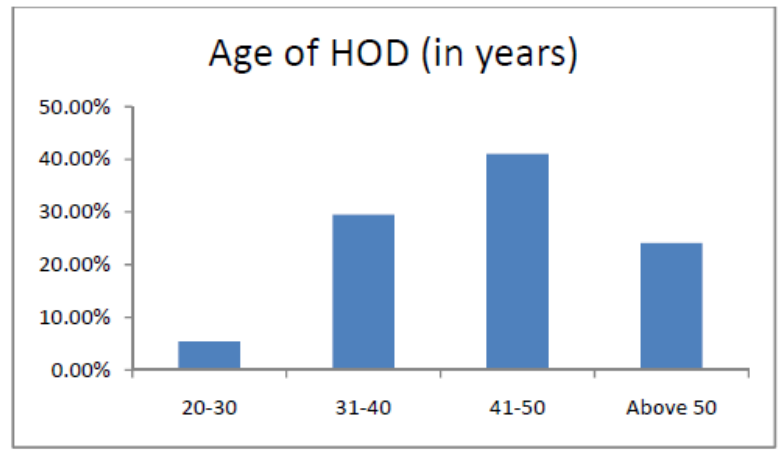

FIGURE 3

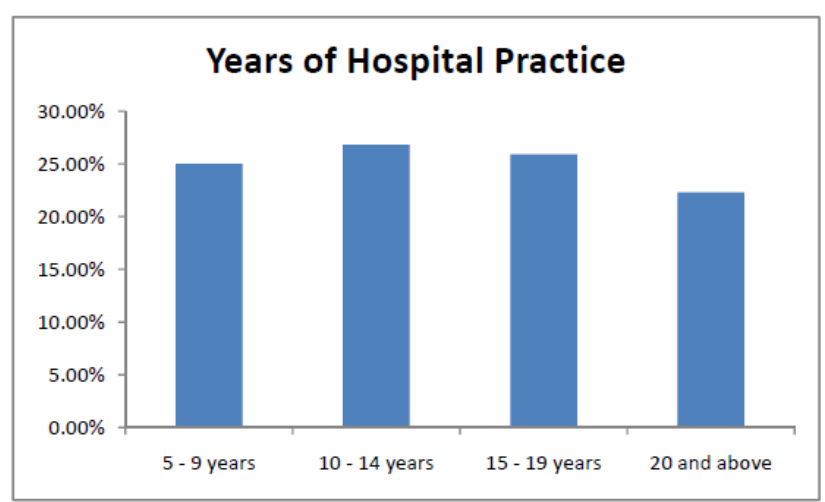

FIGURE 4 
Texila International Journal of Public Health Volume 4, Issue 4, Dec 2016

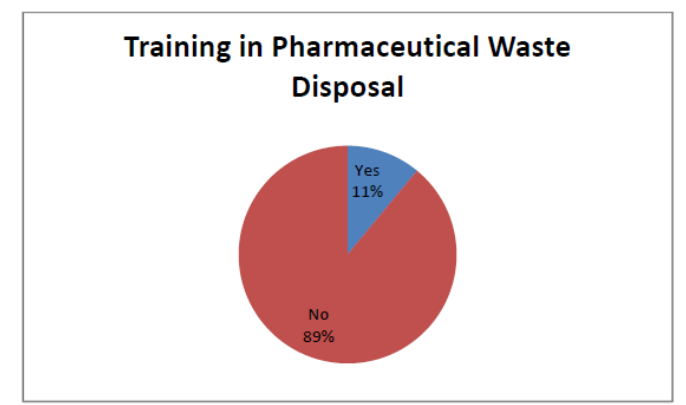

FIGURE 5

TABLE 3

\begin{tabular}{|c|c|}
\hline \multicolumn{2}{|c|}{ Frequency of Drug Disposal } \\
\hline Never & $6.45 \%$ \\
\hline Under a month & $3.60 \%$ \\
\hline 1 - 3 months & $4.50 \%$ \\
\hline 4 - 6 months & $40.00 \%$ \\
\hline 6 months to 1 year & $45.50 \%$ \\
\hline
\end{tabular}

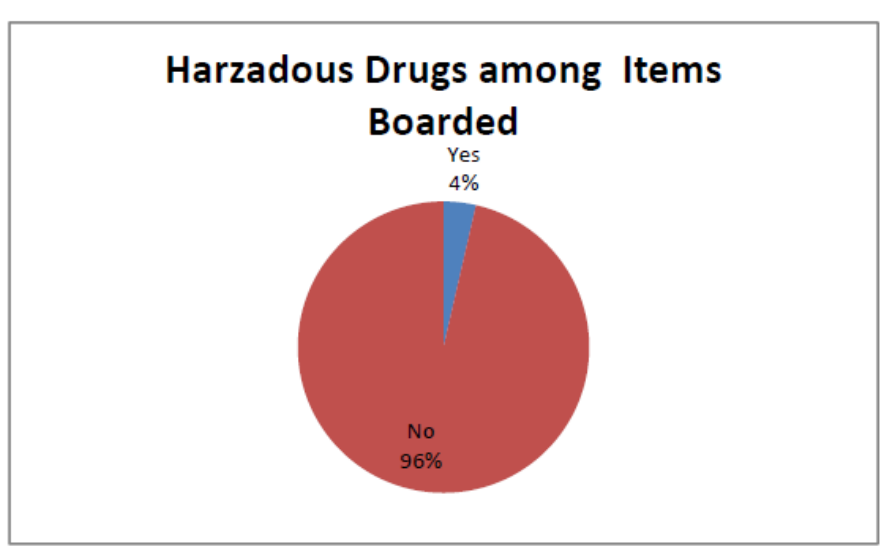

FIGURE 6

TABLE 4

\begin{tabular}{|c|c|}
\hline \multicolumn{2}{|c|}{ Method of Disposal } \\
\hline Burn & $85.50 \%$ \\
\hline Bury & $2.70 \%$ \\
\hline Incinerate & $1.80 \%$ \\
\hline Pour down the drain & $2.70 \%$ \\
\hline Put into trash & $0 \%$ \\
\hline Send to landfill & $4.60 \%$ \\
\hline Others & $2.70 \%$ \\
\hline
\end{tabular}




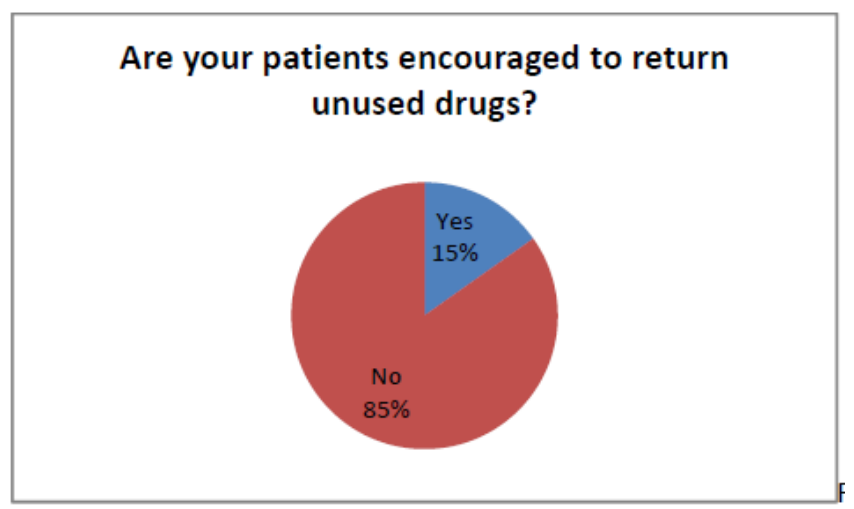

FIGURE 7

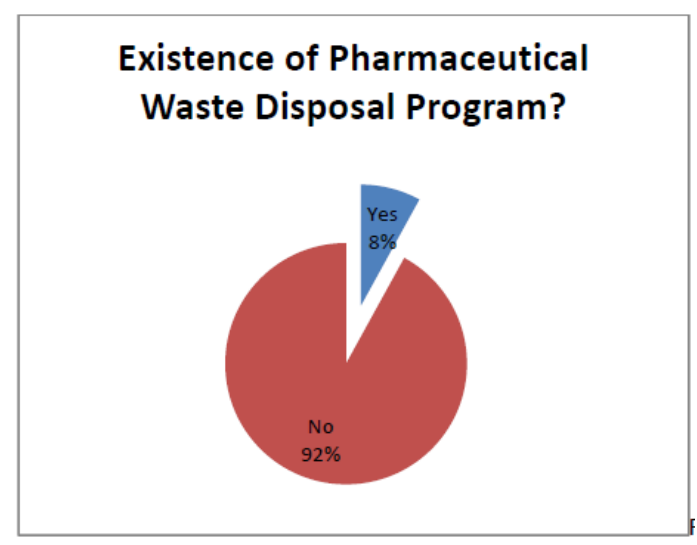

FIGURE 8

Method of Pharmaceutical Waste Disposal within Healthcare Facilities

TABLE 5

\begin{tabular}{|c|c|c|c|}
\hline & $1^{0} \mathrm{HCF}$ & $2^{\circ} \mathrm{HCF}$ & $3^{\circ} \mathrm{HCF}$ \\
\hline Burn & $82.60 \%$ & $81.50 \%$ & $20.00 \%$ \\
\hline Bury & $0 \%$ & $4 \%$ & $40 \%$ \\
\hline Incinerate & $0 \%$ & $0 \%$ & $20 \%$ \\
\hline Pour down drain & $0 \%$ & $11 \%$ & $0 \%$ \\
\hline Trash In bin & $0 \%$ & $0 \%$ & $0 \%$ \\
\hline Send to Landfill & $5.80 \%$ & $0.00 \%$ & $0.00 \%$ \\
\hline Others & $11.60 \%$ & $3.70 \%$ & $20.00 \%$ \\
\hline
\end{tabular}

FIGURE 9

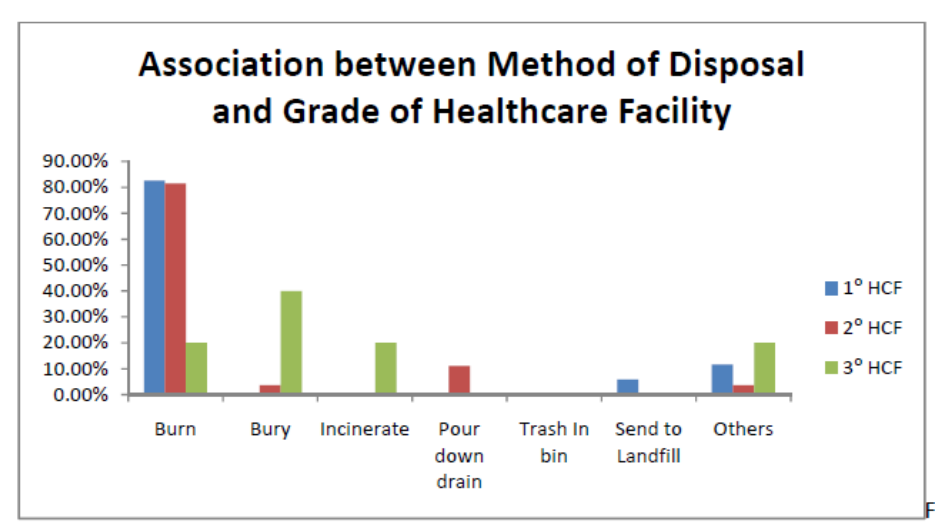


Texila International Journal of Public Health

Volume 4, Issue 4, Dec 2016

\section{References}

[1] 40 CFR 261

[2] Barbalace, Roberta Crowell (2003 - 08-01). The History of Waste” Environmental

Chemistry.com. Retrieved 2013 -12-09

[3] Chaudhary R, Rachana M.,2006. "Factors affecting hazardous waste solidification/stabilization”. A review in Journal of Hazardous Materials B137pp.267-276

[4] Encyclopedia Britannica

[5] Guidelines for the safe Disposal of unwanted Pharmaceuticals in and after Emergencies

[6] Glossary of Environment Statistics: Series F. No.67/Department for Economic and Social Information and Policy Analysis, United Nations. New York: UN 1997

[7] Hazardous Waste Landfills

[8] Land Disposal Restrictions for Hazardous Waste

[9] RESEM Waste Tyre Pyrolysis Plant in USA, retrieved 2011-10-24

[10] "Resource conservation and Recovery Act" US EPA

[11]The US. EPA's Hazardous Waste Cleanup Information System.

[12] United Nations Environmental Programme (2013) “Guidelines for National Waste Management Strategies Moving from Challenges to Opportunities”. ISBN 978-92-807-3333-4.

[13] Waste Management (2013). "Editorial Board/Aims \& Scopes”. Waste Management

34:IFC.doi:10.1016/so956-053x (14) 00026 - 9.

[14] www.who.int/water-sanitation-health/medicalwaste/unwantpharm.pdf

[15] www.usecology.com/services/field-services/pharmaceutical-waste-management.aspx 


\title{
Need, Demand and Supply of Health Care in Regards to Growing Emerging and Reemerging Diseases in Sub-Saharan Africa
}

\author{
Article by Medang Raphael \\ Ph.D. in Public Health, Texila American University, Cameroon \\ E-mail: rmedang@metabiota.com
}

\section{Introduction}

Need in relation to health care, has generally been defined as the amount of medical care that medical experts believe a person should have to remain or become as healthy as possible, based on a current medical knowledge. This is also true for the individual and for the entire community. Thus, if a problem, a barrier or difficulty continues to exist on the path to accession to a higher level of health, the need exists. In "The definition and identification of need for health care ${ }^{1}$," Acheson stated that there exist four phenomena underlying health needs including: - the risk of pain and illness (in the sense of discomfort, or "malaise") - the risk of sickness - the inadequacy and deficiency - the mortality risk. Finally, although certain health needs are expressed, they do not correspond to real needs. This would provide different areas related to health interventions, including:

- The ideal zone (a need corresponds to an expressed demand and adequate health action);

- The area of non-use (a health action not corresponding to any demand);

- Non-use of family planning services in both high population growth areas but also high poverty

- The waste area (a health action corresponding to a demand but with no corresponding need);

- The prescription of laboratory tests and other unnecessary medical procedures in response to public solicitation, especially persons holding health insurance

- The discontent area (a demand triggered by a real need, but to which no health action is taken);

- The recurrence of malaria cases in one region, and the desire by local residents, to have currently non-existent measures, to be taken by health and government authorities, on the environmental and sanitation plan.

The following figure describes the triad related to health care needs, demands and responses

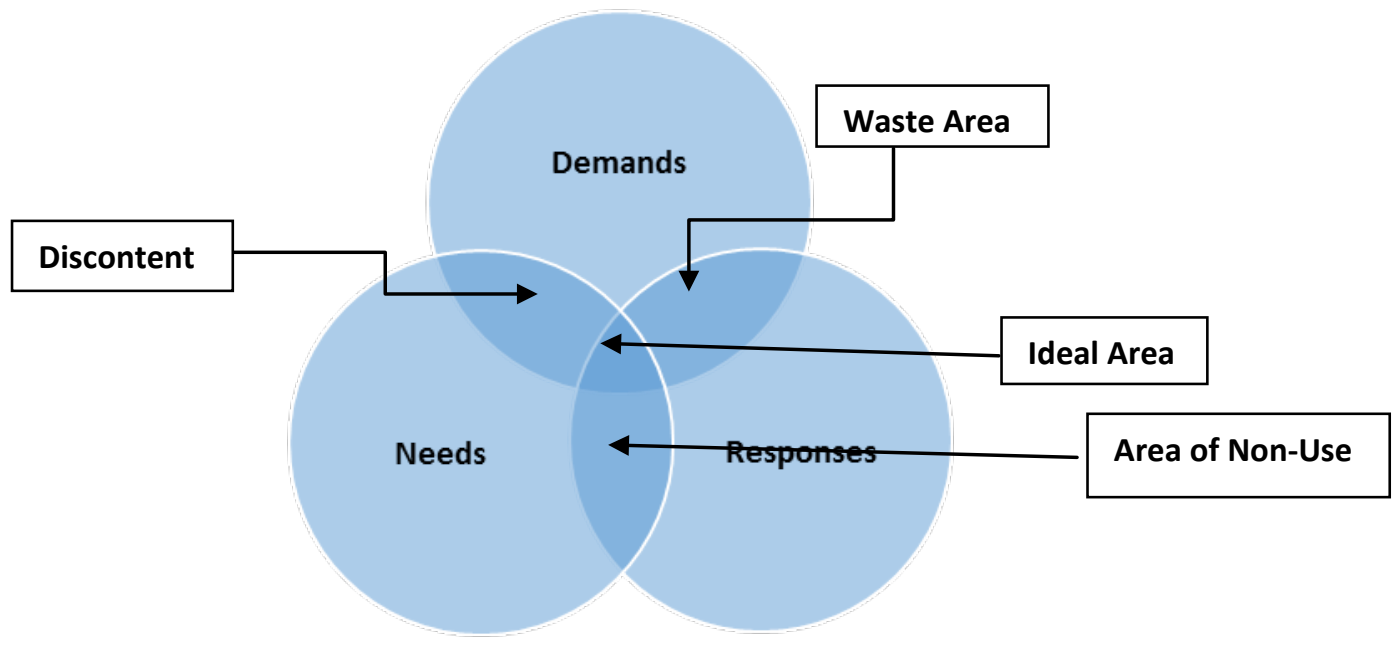

Graph 1. The Triad of Public Health

\footnotetext{
${ }^{1}$ Acheson, 1978
} 
As we can see, needs, demands, and responses (that can also be identified as health supply) are then interconnected. This means that there is a real need for health systems to be able to adapt and to react positively to new, emerging and reemerging situations in relation to the health of populations. This is especially true in low-income countries such as those in Sub-Saharan Africa.

These emerging infections (Els) are most of the time defined as "infections that have newly appeared in a population or have existed previously but is rapidly increasing in incidence or geographical range.” This means that the most important point here is the increase in incidence, that is to say the new cases of new infections within a population. These infections are usually caused by newly identified agents, such as HIV or the Ebola Virus. Factors that contribute to the emergence of these diseases are numerous and can be listed as follow: - inadequate control in water supply, international travel; increased use of child-care facilities - interruption of immunization programs due to political changes - drug resistance; favorable conditions for mosquito vector - refusal to vaccinate based on fears that the vaccine is not safe; other possible factors; decreased vaccine efficacy or waning immunity among vaccinated adults - breakdown in public health measures; changes in land use; travel; - dam construction - ecological changes - insecticide resistance - poverty and social inequality - war and famine - etc. This increase in disease incidence, will obviously lead to the increase in demand for health services.

In a context of scarcity of financial resources, populations will face an increase in terms of varieties and number of infections they will face, but also a health system in which they are the main donors. As a matter of fact, talking of health financing in Sub-Saharan Countries, there's a common concept which states that health insurance helps reduce out-of-pocket costs. Unfortunately, out-of-pocket continues to be the main pillar of the health system funding sources in some countries, such as Cameroon, a central African country. In Cameroon Economic Update, a twice-yearly World Bank publication designed to promote dialogue on various aspects of the country's outlook, the sixth issue was devoted to the subject of health. According to the publication, even though Cameroon's proportion of doctors (1.9 per 1,000 inhabitants) is twice the minimum recommended by the World Health Organization, the country's health statistics are paradoxically behind the curve. Life expectancy for Cameroonians has decreased by about two years since 1990, while it has increased by an average of five years in the rest of sub-Saharan Africa. Worldwide, Cameroon is also among the countries where the mortality rate for children under five years of age (122 deaths per 1,000 live births) has decreased the least. To this end and according to a report issued by the World Bank in 2013, Cameroon (a country with over 20 million inhabitants), "spends more money on health than any other sub-Saharan country (except South Africa): US\$61 per capita, as opposed to US\$51 on average. It is Cameroonians themselves, however, who shoulder the majority of this financial burden. "Out of those \$61, the State finances only \$17; and out of that sum, \$8 comes from international donors," notes Raju Jan Singh, the World Bank lead economist for Central Africa and the main author of the report. "This means there is a strong correlation between health statistics and revenue statistics," he adds, "with well-off households and wealthy regions having better access to health services." This means obviously that, there exist problems related not only to affordability and access to health care, but also in a more general way, those of equity. The health system is heavily based on the out of pocked financing system by individuals and households. And as such, only those who are able to pay will be able to obtain health care, particularly health care of good quality. However, mechanisms such as those of health or social insurance coverage are very uncommon here. Only a few people exercising in the formal sector are eligible for health insurance mechanisms or some other social insurance. According to the results of the Second Survey of Employment and the Informal Sector in Cameroon (EESI 2) 2010, "the main problem of the labor market in Cameroon is not unemployment but underemployment. Nearly three out of four workers are underemployed, underemployment, which is mainly due to low pay, since $70.3 \%$ of workers earn less than the legal monthly minimum wage which is 28,500 CFA francs. That's as many people that are practically excluded from the formal and 
modern system of health care. Their only recourse then remains in the so-called traditional medicine or self-medication.

The issues related to access to services are not only financial, but also geographic. In this regard, the report of the World Bank emphasizes in particular that "The geographic disparities are striking: $40 \%$ of the country's doctors practice in the Centre region (which includes Yaoundé, the capital), where only $18 \%$ of the population lives. On the other hand, the Far North region, which also holds $18 \%$ of the population, employs only $8 \%$ of Cameroon's doctors. It can be seen that the main consequence of the health system as currently implemented and as it currently operates in Cameroon, is that of exclusion. "Some form of exclusion appears in respect to the poorest social strata, especially the rural population, those exercising in the informal sector in both urban and rural areas, and people under the general underemployment sectors.

Two major challenges thus emerge here, not only in relation to the population, but also in relation to the public health system. The first challenge is related to the ability of people to seek services, seek and obtain health services as regard to their health needs in a context of emerging infections. The second challenge is related to the capacity of the health system to adequately respond to the needs of its population, still in the context of emerging and reemerging diseases, knowing also that we are in a context where the most economically disadvantaged are the most vulnerable to disease and other illnesses.

Based on all the above, our focus in terms of research questions were the following; "What are the current trends concerning health care, public surveillance and research activities related to emerging and reemerging diseases?” - What are the procedures, the practices and state of situation as regards to needs and demand of health care concerning emerging and reemerging diseases? - What are some research activities, as well as public surveillance activities currently undertaken in regards to emerging and reemerging diseases? By answering these questions, we might be able not only to put together a number of data, knowledge and practices related to emerging and reemerging diseases, but also the way in which these scourges are taken care of and brought under control by health systems around the world.

The general objective was to determine from the literature, the state of the art concerning needs and demand of health care, public health surveillance and fundamental research activities related to emerging and reemerging diseases. On this basis, the specific objectives were to: -Describe overall knowledge on emerging and reemerging diseases. - Describe state of needs and demand of health care as regards to emerging and reemerging diseases - Describe some of the procedures involved in scientific research as well as public health surveillance of emerging and reemerging diseases.

\section{Methodology}

We carried out a historical literature review of published and grey literature on various aspects of emerging and reemerging diseases, including needs, demands and responses. It was indeed a literature review from 1995 to 2015, that is to say publication spanning over 20 years. Thirty-seven scientific and published articles, key documents and reviews were consulted through PubMed, Medline and Google Scholar, to screen relevant information on emerging and reemerging infections, as well as needs, demands and provision of services related to this. Out of these, a total number of 21 were eligible for this review. The chosen articles and publications were selected and identified using terms such as emerging diseases in Africa, reemerging diseases in Africa, demand for health care, and provision of health care. Only articles, reports, key documents and reviews published in English from 1995 to 2015 were selected (except the key document related to the definition and identification of need for health care). However, we did not assess the methods or reliability of the various estimates or data presented here, but tried to collect as much information as possible in order to have a comprehensive review of the situation with regards to emerging and reemerging diseases, needs and demands for services, as well as provision of health care. 
Texila International Journal of Public Health

Volume 4, Issue 4, Dec 2016

\section{Results}

As some authors have already reported, several factors may be at the origin of emerging and reemerging diseases in the World, and more particularly in Sub-Saharan Africa. In a publication entitled "Factors in the Emergence of Infectious Diseases"," "Emerging" infectious diseases were defined as infections that have newly appeared in a population or have existed but are rapidly increasing in incidence or geographic range. Ecological changes, including those due to agricultural (see Table 1) or economic development, are among the most frequently identified factors in emergence. They are especially frequent as factors in outbreaks of previously unrecognized diseases with high case-fatality rates, which often turn out to be zoonotic introductions. Ecological factors usually precipitate emergence by placing people in contact with a natural reservoir or host for an infection hitherto unfamiliar but usually already present (often a zoonotic or arthropod-borne infection), either by increasing proximity or, often, also by changing conditions so as to favor an increased population of the microbe or its natural host.

\footnotetext{
${ }^{2}$ Morse, 1995
} 


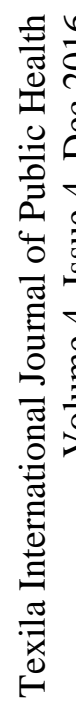

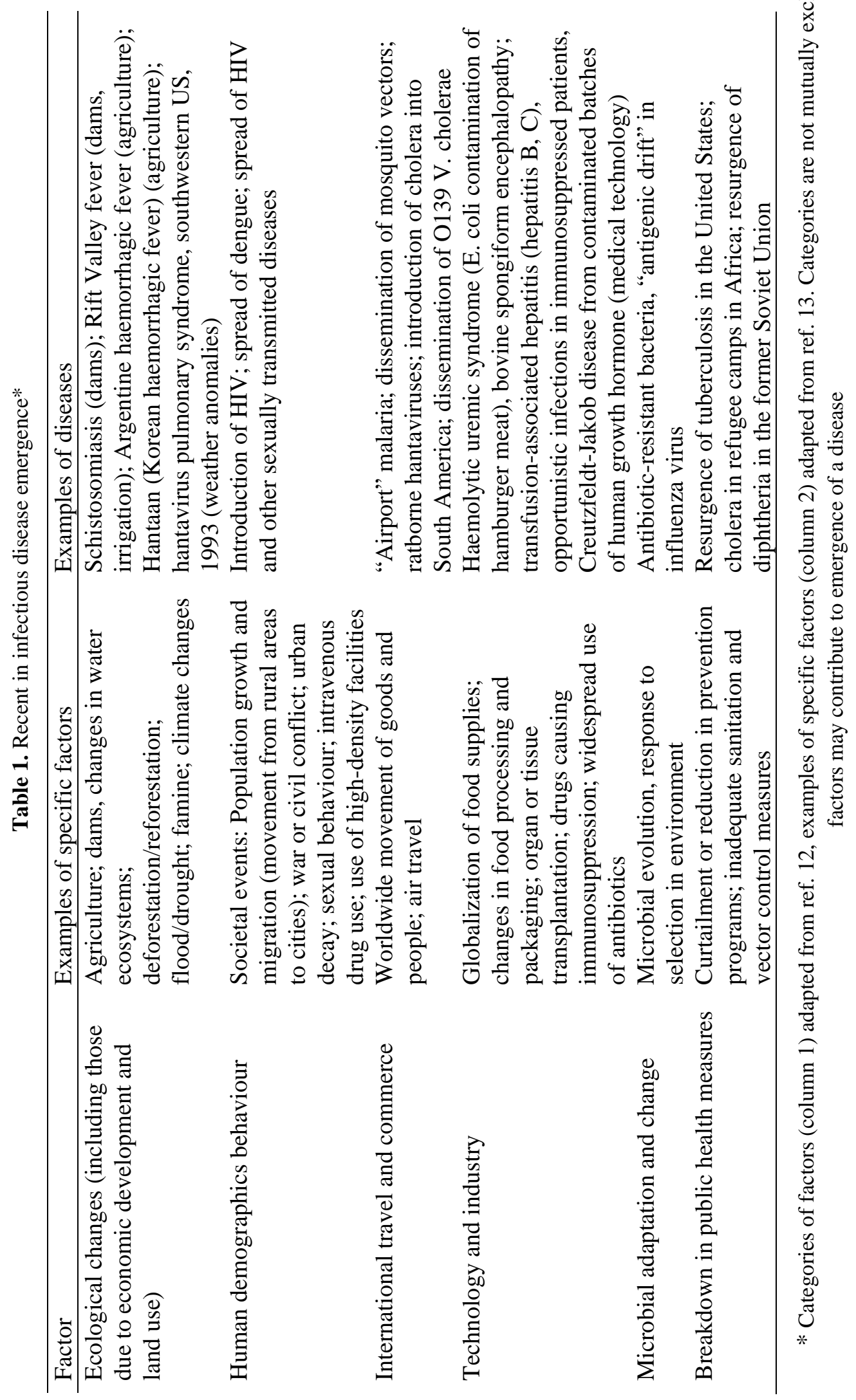


As demonstrated by influenza epidemics, under suitable circumstances, a new infection first appearing anywhere in the world could traverse entire continents within days or weeks. Recent examples of emerging diseases in various parts of the world include HIV/AIDS; classic cholera in South America and Africa; cholera due to Vibrio cholerae O139; Rift Valley fever; hantavirus pulmonary syndrome; Lyme disease; and haemolytic uremic syndrome, a foodborne infection caused by certain strains of Escherichia coli (in the United States, serotype O157:H7). Although these occurrences may appear inexplicable, rarely if ever do emerging infections appear without reason. Some of the specific emerging and re-emerging diseases were identified and classified as follow:

- Viral: Argentine, Bolivian haemorrhagic fever - Bovine spongiform encephalopathy (cattle) Changes in agriculture favouring rodent host - Dengue haemorrhagic fever - Ebola - Hepatitis B, C - HIV - HTLV - Influenza (pandemic) - Lassa fever - Rift Valley fever - Yellow fever

- Bacterial: Brazilian purpuric fever (Haemophilus influenzae, biotype aegyptius) - Cholera Helicobacter pylori - Haemolytic uremic syndrome (E. coli O157:H7) - Legionella (Legionnaires' disease) - Lyme borreliosis (Borrelia burgdorferi) - Streptococcus, group A Toxic shock syndrome (Staphylococcus aureus)

- Parasitic: Cryptosporidium, other waterborne pathogens - Malaria (in "new" areas) Schistosomiasis and other helminthiasis.

In terms of prevalence, geographic distribution and disease burden, as well as types of diseases, the diseases labelled as neglected account among the most emerging ones. In fact, according to the result of a study entitled "Neglected Tropical Diseases in Sub-Saharan Africa: Review of Their Prevalence, Distribution, and Disease Burden" ${ }^{3}$, many neglected tropical diseases (NTDs) also appear to be emerging diseases. According to the authors, "the neglected tropical diseases (NTDs) are the most common conditions affecting the poorest 500 million people living in sub-Saharan Africa (SSA), and together produce a burden of disease that may be equivalent to up to one-half of SSA's malaria disease burden and more than double that caused by tuberculosis.” Today, the world's greatest concentration of poverty occurs in sub-Saharan Africa (SSA). According to a recent World Bank analysis, $51 \%$ of the population of SSA lives on less than US\$1.25 per day, and $73 \%$ of the population lives on less than US\$2 per day (see Table 2).

Table 2. Poverty in Sub-Saharan Africa.

\begin{tabular}{ll}
\hline Percentage of SSA population living on less than US\$1.25 per day & $51 \%$ \\
Total SSA population living on less than \$1.25 per day & 390.6 million \\
Percentage of world's population living on less than US\$1.25 per day in SSA $28 \%$ \\
Percentage of SSA population living on less than US\$2 per day & $73 \%$ \\
Total SSA population living on less than $\$ 2$ per day & 556.7 million \\
Percentage of world's population living on less than US\$2 per day in SSA & $22 \%$ \\
\hline
\end{tabular}

From http://www-wds.worldbank.org.

Still according to the above-mentioned article, specific information on the prevalence, distribution, and disease burden resulting from the NTDs in SSA are as follow:

- Helminth infections, especially the soil-transmitted helminth (STH) infections, schistosomiasis, and the filarial infections and onchocerciasis, are the most common NTDs in SSA, followed by trachoma and other bacterial infections.

- Human African trypanosomiasis (HAT) and leishmaniasis are the most common serious protozoan infections, especially in areas of conflict where these diseases emerge in the setting of inadequate housing and forced migrations.

\footnotetext{
${ }^{3}$ Hotez \& Kamath, 2009
} 
- However, there are more than a dozen important NTDs, including the protozoan infections, amoebiasis and toxoplasmosis; bacterial infections such as Salmonella infections (both typhoid fever and non-typhoidal salmonellosis), the tick-borne zoonoses, and yaws; and viral infections such as Rift Valley fever, for which there is insufficient information available in order to estimate their prevalence in SSA.

Considering in particular STH and schistosomiasis, the authors pointed out the following that since the global prevalence of STH infections was first estimated by Stoll over 60 years ago, the overall prevalence of the STH infections is believed to have remained relatively constant in SSA, whereas it has diminished elsewhere in the developing world. Today, between one-quarter and one-third of SSA's population is affected by one or more STH infections, with children, especially school-aged children, disproportionately affected. Of the estimated 181 million school-aged children in SSA, almost one-half (89 million) are infected with hookworm, ascariasis, trichuriasis, or some combination of these STH infections. Hookworm infection ("hookworm"). Hookworm is the most common STH infection and the most common NTD in SSA. It is also one of the most important in terms of disease burden, accounting for up to one-third of the total burden from NTDs in SSA (see Table 3). Based on previous estimates derived in 2002. it is estimated that 198 million people in SSA are infected with hookworm (29\% of the region's population), including 40-50 million school-aged children. Approximately one-third of the world's hookworm today occurs in SSA, with the greatest number of cases occurring in Nigeria (38 million) and the Democratic Republic of Congo (DRC, 31 million), followed by Angola, Ethiopia, and Ivory Coast (10-11 million)). Hookworm is the most widely distributed NTD in SSA and it is pervasive throughout the region (including both rural and urban areas) except in some parts of extreme southern Africa. Two areas are particularly notable for their high hookworm prevalence and intensity compared to other helminth infections, namely coastal regions, and areas of extremely high temperatures (where land surface temperatures exceed $37-40^{\circ} \mathrm{C}$ ), including those near the Sahel such as Cameroon, Chad, and Mali. For instance, it is estimated that approximately $90 \%$ of the 50 million school-aged children with hookworm are at risk for coincident co-infection with falciparum malaria. of the world's 207 million estimated cases of schistosomiasis, 93\% occur in SSA (192 million), with the largest number in Nigeria (29 million) followed by the United Republic of Tanzania (19 million), DRC and Ghana (15 million each). Approximately 76\% of the population in SSA lives near rivers, lakes, and other water bodies contaminated with snail intermediate hosts. Those living near dam reservoirs are at particular risk, and SSA has several examples where the infection has emerged or where there has been a dramatic rise in the prevalence of schistosomiasis as a result of irrigation project construction. Climate change and global warming may also be factors. The highest prevalence and intensities of human schistosomiasis occur in schoolaged children, adolescents, and young adults who also suffer from the highest morbidity and mortality. There are two major forms of schistosomiasis found in SSA. Approximately two-thirds of the schistosomiasis cases are due to infection caused by Schistosoma haematobium, which represents an important cause of severe urinary tract disease. In 2000, van der Werf et al. estimated that 70 million and 32 million individuals out of 682 million people in SSA had experienced hematuria and dysuria, respectively, within the last two weeks. S. haematobium produces bladder wall pathology in approximately 18 million people in SSA, and 10 million people suffer from hydronephrosis. Renal failure accounts for a large percentage of the estimated 150,000 deaths from urinary tract schistosomiasis in SSA, and there is also a significant association between major bladder wall pathology and squamous cell carcinoma. A significant percentage of women and men with urinary schistosomiasis acquire genital ulcers and other lesions. In the former, urogenital schistosomiasis is a significant cause of poor reproductive health, including sexual dysfunction and infertility. Genital schistosomiasis also promotes the horizontal transmission of HIV/AIDS in SSA. Intestinal schistosomiasis from $S$. mansoni causes most of the remaining cases in SSA. An estimated 4.4 million people with $S$. mansoni have bloody diarrhea and bowel ulceration, and 8.5 million develop hepatomegaly and/or associated periportal liver fibrosis, portal hypertension, and hematemesis from 
S. mansoni infection, with approximately 130,000 deaths. S. intercalatum causes a second form of intestinal schistosomiasis, but with a restricted distribution in West and Central Africa. The current disease burden calculations for schistosomiasis range between 1.7 and 4.5 million DALYs lost annually (1.6 and 4.2 million DALYs in SSA), but these current estimates do not fully consider the general morbidities outlined above.

Table 3. Disease Burden (DALYs) in SSA Resulting from the NTDs.

$\begin{array}{llll} & \text { Estimated Global } & \text { Estimated \% } & \\ \text { Disease } & \text { Disease Burden in } & \begin{array}{l}\text { Disease Burden in } \\ \text { DALYs }\end{array} & \begin{array}{l}\text { SSA } \\ \text { Bstimated SSA Disease }\end{array} \\ \text { Hookworm } & 1.5-22.1 \text { million } & 34 \% & \\ \text { Schistosomiasis } & 1.7-4.5 \text { million } & 93 \% & 0.5-7.5 \text { million } \\ \text { Ascariasis } & 1.8-10.5 \text { million } & 21 \% & 1.6-4.2 \text { million } \\ \text { Lymphatic filariasis } & 5.8 \text { million } & 35 \% & 0.4-2.2 \text { million } \\ \text { Trichuriasis } & 1.8-6.4 \text { million } & 27 \% & 2.0 \text { million } \\ \text { Human African } & 1.5 \text { million } & 100 \% & 0.5-1.7 \text { million } \\ \text { trypanosomiasis } & & 52 \% & 1.5 \text { million } \\ \text { Trachoma } & 2.3 \text { million } & 99 \% & 1.2 \text { million } \\ \text { Onchocerciasis } & 0.5 \text { million } & 18 \% & 0.5 \text { million } \\ \text { Leishmaniasis } & 2.1 \text { million } & 14 \% & 0.4 \text { million } \\ \text { Leprosy } & 0.2 \text { million } & <1 \% & 0.02 \text { million } \\ \text { Dengue } & 0.6 \text { million } & 15 \%-37 \% & 0.005 \text { million } \\ \text { Total NTDs } & \leq 56.6 \text { million } & & 8.6 \text { million-21.2 million }\end{array}$

DALY estimates for STH infections and schistosomiasis were obtained by adjusting a wide range of available global estimates according to the percentage of the total number of cases that occur in SSA, while for the other NTDs the disease burdens were quoted directly from WHO estimates.

Apart from NTDs, other groups of emerging diseases are also of utmost importance in SSA. These diseases include for instance, Non Communicable Diseases (NCDs). A study was carried out in Mozambique in relation to NCDs, entitled: "Non-communicable diseases in Mozambique: risk factors, burden, response and outcomes to date." Mozambique was described in that study as one of the poorest countries in the world being ranked 184 out of 187 on the Human Development Index. Gross Domestic Product (GDP) per capita was International US\$ 1,000 and GDP (real growth) in 2010 was 7\%. In parallel to this economic development the rate of urbanization was estimated to be $4 \%$ with $31 \%$ of the total population living in urban areas in 2011. In comparison to other countries in Southern Africa Mozambique is currently one of the least urbanized countries. However, by 2025 it is estimated that it will be the fourth most urbanized. The four main NCDs, cardiovascular disease (CVD), cancer, diabetes and chronic obstructive pulmonary disease (COPD) share four common risk factors, tobacco use, the harmful use of alcohol, poor diet and lack of physical activity.

In "The emerging epidemic of obesity in developing countries", the authors stated that the pandemic is growing at such a pace that prevalence statistics become rapidly outdated. Detailed data on obesity from two nationwide surveys were available for Gambia, a small West African country on the southern edge of the Sahara that is typical of many nations in sub-Saharan Africa with respect to the epidemic. Gambia is in the early phases of the demographic and nutritional transitions described by Popkin. Like many such countries urbanization is increasing rapidly with a constant passage of

\footnotetext{
${ }^{4}$ Silva-Matos \& Beran, 2012

${ }^{5}$ Prentice, 2006
} 
young people from the rural areas to seek education and work in urban areas. In 1995, a representative survey was conducted on 6048 rural and urban adults (>15 years) from 73 communities using multistage stratified cluster sampling based on the 1993 national census. A second survey with similar results was conducted on 5373 adults in 1996-97. In the later survey the overall obesity rate was recorded as just $4 \%$ but this concealed major variations. In the rural population, obesity was essentially undetectable in men $(<0.2 \%$ prevalence) and only detectable in women $>35$ years at a prevalence of $<3 \%$. Among urban men the obesity rate was $<2 \%$ but amongst women it was much higher.

Still concerning non-communicable diseases, and in a study whose topic was "Noncommunicable diseases in sub-Saharan Africa: where do they feature in the health research agenda? ${ }^{6}$, it was mentioned that non-communicable diseases were not a high priority area for health research and development in the SSA countries. The estimates in the 1990 Global Burden of Disease study suggested that non-communicable diseases accounted for only $14 \%$ of the total burden in subSaharan Africa, and for just under a third in adults aged 15-59 years. Nonetheless, in absolute terms the estimates also suggested that the probability of death from non-communicable diseases was higher in sub-Saharan Africa than in Established Market Economies. Because of the lack of reliable mortality and morbidity data from SSA, these estimates were heavily based on assumptions and extrapolations. In at least three areas of the United Republic of Tanzania, one of Africa's poorest countries, the probabilities of death from non-communicable diseases were indeed higher than in Established Market Economies. Additionally, among adults, the age-specific death rates from non-communicable diseases were substantially higher in all age groups (i.e. 15-29 years, 30-44 years, and 45-59 years) in these three areas of the country than in the Established Market Economies. On the other hand, noncommunicable diseases account for $15-25 \%$ of all adult deaths (i.e. in persons aged 15-59 years) in the Tanzanian areas covered by the demographic surveillance system, a much smaller proportion than the $67 \%$ (men) to $80 \%$ (women) in the Established Market Economies.

Other emerging diseases or epidemics in SSA, such as the one related to Diabetic retinopathy (DR), were studied by other groups or researchers. This was the case with the study on "Diabetic retinopathy in sub-Saharan Africa: meeting the challenges of an emerging epidemic." A study in which the authors stated that diabetes causes visual impairment (VI) through early-onset cataract and diabetic retinopathy (DR), a progressive disease of the retinal microvasculature. Cataract and DR are the second and sixth leading causes of global VI, respectively. In a recent population-based survey $(\mathrm{n}=4,414)$ in Nakuru, Kenya, identified a prevalence of 'any DR' of 35.9\% (95\% CI: 29.7, 42.6) and of 'severe non proliferative DR or PDR' of 13.9\% (95\% CI: 10.0, 18.8) in 277 people with diabetes [Bastawrous, personal communication]. Clinic-based studies report a wide range of prevalence, often with higher levels of sight-threatening disease, but these are subject to bias. The proportion of any visual impairment (VI) in African populations due to DR is largely unknown. A recent populationbased study from Cape Town, South Africa, of visual loss using WHO methods, identified DR as the cause of $8 \%$ of blindness and $11 \%$ of severe visual loss in persons' $\geq 50$ years.

Concerning emergence of HIV as well as reemergence of tuberculosis, the "Tuberculosis case fatality rates in high HIV prevalence populations in sub-Saharan Africa" ${ }^{8}$ study was carried out in some SSA countries. The study was aiming at analysing the extent of the increased tuberculosis case fatality rate (CFR) in high HIV prevalence populations in sub-Saharan Africa, the reasons for this increase and the causes of death, in order to identify possible ways of tackling this problem. The CFR in HIV-positive and HIV-negative patients with sputum smear-positive pulmonary tuberculosis were respectively $6.1 \%$ and $0.4 \%$ in Cote d'Ivoire, $18 \%$ and $10 \%$ in Zomba, Malawi, $29 \%$ and $8 \%$ in Ntcheu, Malawi, 14\% and 0.5\% in Johannesburg, South Africa, and 13\% and 0\% in Zaire. The lowest tuberculosis CFR in HIV-positive patients was reported in Ivory Coast and should be interpreted

\footnotetext{
${ }^{6}$ Unwin et al, 2001

${ }^{7}$ Burgess, Msukwa, \& Beare, 2013

${ }^{8}$ Mukadi, Maher, \& Harries, s. d.
} 
cautiously given that one-third of the HIV-positive patients were lost to follow-up. A study in Malawi in patients with sputum smear- negative pulmonary tuberculosis reported a higher CFR in HIVpositive (59\%) than in HIV-negative (26\%) individuals. For comparison, the corresponding CFRs in sputum smear-positive patients were 18\% in HIV-positive and 10\% in HIV-negative patients.

Keeping talking about HIV, a review that was intended to provide some key examples of emerging HIV and AIDS pharmacotherapy issues, challenges, and priorities within resource-limited subSaharan African countries, and highlight how they contrast with those of the developed world, was carried out. The topic of the study was: "HIV Pharmacotherapy Issues, Challenges, and Priorities in sub-Saharan African Countries." In terms of challenges to resource provision for supporting HIV and AIDS pharmacotherapy, it was revealed concerning drug financing that the Gross National Products (GNPs) per capita in most sub-Saharan African countries was low (see Table 4). Therefore, until recently, antiretroviral drugs have been beyond the economic reach of most. Owing to economic hindrances, most of these countries have used a variety of strategies to address the issue of equitable access to antiretrovirals. Such strategies include adopting the World Trade Organization's Trade Related Intellectual Properties (WTO- TRIP) safeguards into national legislation, actively encouraging generic competition, seeking differential pricing of drugs from international suppliers, creating high volume and demand through regional procurement, and encouraging local production through licensing and technology transfer. Approximately 90\% of newly infected children in 2006 lived in SSA countries, where the major route of infection is through mother-to-child transmission. As a result of the limited accessibility to antiretroviral therapy, the emphasis in SSA countries is still largely on the prevention of HIV transmission. The HIV and AIDS epidemic has highlighted the weakness of health care systems in resource-limited SSA countries in terms of referral systems, human resources, and laboratory capacity, as well as drug procurement and supply chains. Lack of capacity in the educational system has led to an overall shortage of qualified health personnel including pharmacists and pharmacy staff.

T able 4. Pharmacy Infrastructure in 5 African Countries in 1999

\begin{tabular}{|c|c|c|c|c|c|}
\hline & Botswana & Malawi & Swaziland & Zambia & Zimbabw \\
\hline Total population (million) & 1.5 & 11.0 & 0.9 & 10.2 & 12.4 \\
\hline GNP per capita (\$US) & 6872 & 586 & 3987 & 756 & 2876 \\
\hline $\begin{array}{l}\text { Number of pharmaceutical } \\
\text { manufacturers/wholesalers }\end{array}$ & 3 & 3 & 0 & 5 & 22 \\
\hline Number of registered drug products & 340 & 1500 & No DRA & 1200 & 1700 \\
\hline Number of registered pharmacists & 160 & 60 & 33 & 100 & 530 \\
\hline $\begin{array}{l}\text { Number of registered pharmacy } \\
\text { outlets }\end{array}$ & 63 & 16 & 13 & 78 & 240 \\
\hline
\end{tabular}

Adapted from World Health Organization study of drug regulatory authorities, 1999. GNP indicates gross national product; DRA, drug regulatory authority

From July to January 2013, MHRL conducted first-tier lateral flow immunoassay (LFI) tests of blood samples from all 932 outpatientes 5 years of age who had been clinically examined at the hospital, were found to have febrile illness, and consented to having blood drawn for laboratory

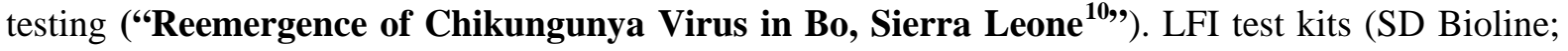

\footnotetext{
${ }^{9}$ (Maponga, Ma, Slish, \& Morse, 2007)

${ }^{10}$ Ansumana et al., 2013
} 
Standard Diagnostics, Inc., Seoul, South Korea) were used for diagnosis of IgM against CHIKV; IgG and IgM against dengue virus and hepatitis A virus; hepatitis B virus surface antigen, hepatitis C virus, HIV-1/2, and antibodies against these viruses; and IgG and IgM against Leptospira spp., Salmonella enterica Serovar typhi, and syphilis. Most patients reported that they had sought medical care within several days after the onset of their febrile illnesses. Levels of IgM against CHIKV are usually detectable by immunochromatographic methods within a few days after infection and persist for $\approx 3-4$ months. The LFI test kits for CHIKV were reported by the manufacturer to have a sensitivity of $97.1 \%$ and a specificity of $91.1 \%$ compared with those of ELISA. An independent evaluation found a sensitivity of $50.8 \%$ and a specificity of $89.2 \%$ for the kits; sensitivity ranged from $40.9 \%, 1-5$ days after onset of illness to $65.4 \%, 16-20$ days after onset. Specificity decreases after the first week. More than half of the cases tested during the first week of the surveillance program were positive by LFI for CHIKV. Thus, we notified the Sierra Leone Ministry of Health and Sanitation of a possible CHIKV outbreak. By January 10, 2013, 400 (42.9\%) of 932 febrile patients were positive by LFI for CHIKV. Ages of the 400 CHIKV IgM-positive patients ranged from 6 years to 85 years; 172 (43.0\%) were male patients. Of these 400 patients, $220(55.0 \%)$ reported arthralgia, 189 (47.3\%) chills, and 156 (39.0\%) headaches. Co-infections were common; 92 (23.0\%.) were co-infected with malaria, 37 (9.3\%) with HIV, 33 (8.3\%) with hepatitis B virus, and smaller numbers with hepatitis A, hepatitis C, tuberculosis, typhoid, and syphilis. Four CHIKV-positive samples were also positive for dengue.

A study to better understand the implications of the presence of body lice in some individuals, was carried in six countries ("Body lice as tools for diagnosis and surveillance of reemerging

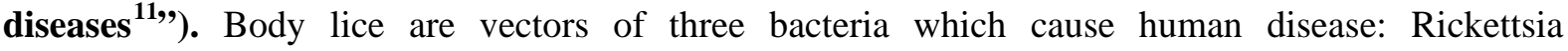
prowazekii, the agent of epidemic typhus; Bartonella quintana, the agent of trench fever; and Borrelia recurrentis, the agent of relapsing fever. A recrudescence of body lice is being observed as the numbers of individuals living under social conditions which predispose individuals to infestation have increased. Because this phenomenon may lead to the reemergence of infections transmitted by body lice, we aimed to assess the occurrence and prevalence of the three agents described above in more than 600 body lice collected from infested individuals in the African countries of Congo, Zimbabwe, and Burundi, in France, in Russia, and in Peru. The presence of the three bacteria in each louse was determined by specific PCR amplification, and the identities of the organisms detected were confirmed by determination of the nucleotide base sequences of the amplification products. Using this approach, we were able to confirm the presence of R. prowazekii in lice collected from refugees in Burundi, among whom typhus was epidemic, and the presence of B. quintana in lice collected from all locations except the Congo. B. recurrentis was never found. Molecular approaches are convenient tools for the detection and identification of bacterial DNA in body lice and for the epidemiological study of louse-borne bacteria from countries where no medical and biological laboratory facilities are available. The sensitivities of the PCR assays with the primers CS-877 and CS-1273, CSBAR-218 and CSBAR-698, and Bf1 and Br1 were estimated to be from 1 to 10 copies of the gene (DNA). For the detection of $B$. quintana, PCR amplification was performed with the primers CSBAR-218 and CSBAR-698, and the positivity was confirmed with the primers QHVE1 and QHVE3. For the detection of $R$. prowazekii, PCR amplification was performed with the primers CS-877 and CS-1273, and the positivity was confirmed with the primers 120-M59 and 120-797.

In addition to the high propensity of these infections, the populations in SSA as we have already said, also suffer significant problems of poverty and Inequality of access to care. This was demonstrated in the study entitled: "Poverty, inequality and health: the challenge of the double burden of disease in a non-profit hospital in rural Ethiopia. ${ }^{12}$ ” This study was aimed at describing disease patterns in a rural zone of Oromiya region, Ethiopia through a retrospective analysis of discharge records for 22,377 inpatients of St. Luke Hospital, Wolisso, Ethiopia in the 2005-2007 period. The leading cause of admission was childbirth, followed by injuries, malaria and pneumonia.

\footnotetext{
${ }^{11}$ Roux \& Raoult, 1999

${ }^{12}$ Accorsi et al., 2009
} 
Injuries were the leading cause of in-hospital deaths, followed by pneumonia, malaria, cardiovascular disease and AIDS. Vulnerable groups (infants, children and women) accounted for $73.3 \%$ of admissions. Most of the disease burden resulted from infectious diseases, the occurrence of which could be dramatically reduced by cost-effective preventive and curative interventions. Furthermore, a double burden of disease is already emerging at the early stage of the epidemiological transition, with a mix of persistent, emerging and re-emerging infectious diseases and increasing prevalence of chronic conditions and injuries. This will lead to fundamental changes in the volume and composition of demand for healthcare, with a more complex case mix and costlier service utilization patterns. The challenge is to address the double burden of disease, while focusing on poverty-related conditions and targeting vulnerable groups. Monitoring disease and service utilization patterns through routine hospital information systems can provide sustainable, low-cost support for evidence-based health practice.

The data and information provided by all the above mentioned studies, demonstrate widely that there exists a high degree of needs, but also demands, in regards to emerging and reemerging diseases in SSA, even if tremendous efforts have been made. We can indeed observe on the basis of epidemiological data and the above information that, the pressure due to these so-called emerging diseases both on populations and communities, as well as on the public health systems, is huge. Pressure which of course led to the different health systems, researchers and other stakeholders to become more involved in the search for solutions.

However, the search for appropriate solutions should nevertheless be accompanied by respect for universal and well recognized ethical standards. It is in that line that a study on ethical issues related to compulsory and voluntary screening was carried out in Kenya. The study whose subject was "Ethical issues evolving from patients' perspectives on compulsory screening for syphilis and voluntary screening for cervical cancer in Kenya ${ }^{13}$, revealed that real ethical challenges exist in the voluntary and compulsory screening approaches. Also, participants were more concerned about the benefits of the procedure and whether their dignity is respected than the compulsoriness of screening per se. The implication is for the policy makers to clarify in the guidelines how to manage ethical challenges, while at the operational level, providers need to be judicious to minimize potential harm to participants and families when screening for disease in women.

Still in Kenya, a study documented opportunities and challenges encountered in managing cervical cancer from the health care workers' perspectives. Kenya, like other developing countries is low in resource setting and is facing a number of challenges in the management of cervical cancer. A qualitative study ("An exploration of opportunities and challenges facing cervical cancer

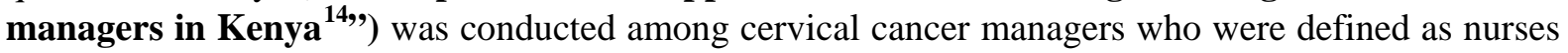
and doctors involved in operational level management of cervical cancer. Four themes were identified. Patient related challenges included a large number of patients, in the late stage of the disease, low levels of knowledge on cancer of the cervix, low levels of screening and a poor attitude towards screening procedures. Individual health care providers identified a lack of specialized training, difficulty in disclosure of diagnosis to patients, a poor attitude towards cervical cancer screening procedures and a poor attitude towards cervical cancer patients. Health facilities were lacking in infrastructure and medical supplies. Some managers felt ill-equipped in technological skills while the majority lacked access to the internet. Mobile phones were identified as having great potential for improving the management of cervical cancer in Kenya.

In the meanwhile, a group of researchers in Ghana worked on Buruli ulcer, which is considered a re-emerging disease in West Africa where it has suffered neglect over the years, though children below the age of 16 years are the worst affected in most endemic regions. "Enhancing Buruli ulcer control in Ghana through social interventions: a case study from the Obom sub-district ${ }^{15 \text { ” }}$ was

\footnotetext{
${ }^{13}$ Omondi Aduda \& Mkhize, 2014

${ }^{14}$ Kivuti-Bitok, Pokhariyal, Abdul, \& McDonnell, 2013

${ }^{15}$ Ahorlu, Koka, Yeboah-Manu, Lamptey, \& Ampadu, 2013
} 
the title of their study. According to them and due to delayed health seeking, the disease leads to disabilities resulting from amputation and loss of vital organs like the eye, leading to school dropout and other social and economic consequences for the affected family. The mode of transmission of Buruli ulcer is not known and there is no effective preventive vaccine for Buruli ulcer. Thus the only effective control tool is early case detection and treatment to reduce morbidity and associated disabilities that occur as a result of delayed treatment. It is therefore essential to implement interventions that remove impediments that limit early case detection; access to early effective treatment and this paper reports on such effort where the feasibility of social interventions to enhance Buruli ulcer control was assessed. At full implementation, treatment default and dropout reduced significantly from $58.8 \%$ and $52.9 \%$ at baseline to $1.5 \%$ and $1.5 \%$ respectively. The number of early case detection went up significantly.

In the same perspective but considering now the field of medical laboratory analyzes, considerable resources have been invested in recent years to improve laboratory systems in resource-limited settings. A study in which published reports were reviewed, major donor organizations were interviewed, and case studies of laboratory systems were conducted in 3 countries to assess how countries and donors have worked together to improve laboratory services was carried out. While infrastructure and the provision of services have seen improvement, important opportunities remain for further advancement. Implementation of national laboratory plans is inconsistent, human resources are limited, and quality laboratory services rarely extend to lower tier laboratories (eg, health clinics, district hospitals). Coordination within, between, and among governments and donor organizations is also frequently problematic. Laboratory standardization and quality control are improving but remain challenging, making accreditation a difficult goal. Host country governments and their external funding partners should coordinate their efforts effectively around a host country's own national laboratory plan to advance sustainable capacity development throughout a country's laboratory system. (Strengthening Laboratory Systems in Resource-Limited Settings ${ }^{16}$ )

Apart from the human resources issues, infrastructure or technology, Sub-Saharan Africa also faces enormous difficulties in terms of health-related information. This applies both with regard to the information towards the population and to the information directed to the service providers. And this is what was highlighted in a study that was carried out in South Africa and Uganda: "Meeting information needs of patients with incurable progressive disease and their families in South Africa and Uganda: multicentre qualitative stud ${ }^{17}$ " Five themes emerged from the data. (1) Information sources: a lack of information from general healthcare providers meant that patients and caregivers had to draw on alternative sources of information. (2) Information needs: patients and caregivers reported needing more information in the key areas of the causes and progression of the disease, its symptoms and treatment, and financial/social support. (3) Impact of unmet needs: poor provision of information had a detrimental effect on patients' and caregivers' ability to cope. (4) Communication: negative experiences of communication with general healthcare staff were reported (misinformation, secrecy, insensitivity). (5) Barriers to effective provision of information: barriers related to symptoms, culture, time constraints in hospital, and paternalism in general health care.

Yet all is not negative, not everything is reduced to failures and malfunctions. Many advances have been made all the same, even if people do not talk enough about them. In fact, a number of researches have been carried out, to enhance and reinforce practices in these domains. It is in this perspective that a group of researchers worked on the theme called "Health sector demand-side financial incentives in low- and middle-income countries: a systematic review on demand- and supply-side effects. ${ }^{18}$ " According to the authors, Demand-side financial incentive (DSF) is an emerging strategy to improve health seeking behavior and health status in many low- and middleincome countries. This narrative synthesis assessed the demand- and supply-side effects of DSF.

\footnotetext{
${ }^{16}$ Olmsted et al., 2010

${ }^{17}$ Selman et al., 2009

${ }^{18}$ Gopalan, Mutasa, Friedman, \& Das, 2014
} 
Forty-one electronic data bases were searched to screen relevant experimental and quasi-experimental study designs. Out of the 64 selected papers, 28 were eligible for this review and they described 19 DSF initiatives across Asia, Africa and Latin America. There were three categories of initiatives, namely long-run multi-sectoral programs or LMPs (governmental); long-run health-exclusive programs (governmental); and short-run health-exclusive initiatives (both governmental and nongovernmental). Irrespective of the nature of incentives and initiatives, all DSF programs could achieve their expected behavioral outcomes on healthcare seeking and utilization substantially. However, there existed a few negative and perverse outcomes on health seeking behavior and DSF's impact on continuous health seeking choices (e.g. bed net use and routine adult health check-ups) was mixed. Their effects on maternal health status, diarrhea, malaria and out-of-pocket expenditure were underexplored; while chronic non-communicable diseases were not directly covered by any DSF programs. DSF could reduce HIV prevalence and child deaths, and enhance nutritional and growth status of children. The direction and magnitude of their effects on health status was elastic to the evaluation design employed. On health system benefits, despite prioritizing on vulnerable groups, DSF's substantial effect on the poorest of the poor was mixed compared to that on the relatively richer groups. Though DSF initiatives intended to improve service delivery status, many could not optimally do so, especially to meet the additionally generated demand for care. Causal pathways of DSF's effects should be explored in-depth for mid-course corrections and cross-country learning on their design, implementation and evaluation. More policy-specific analyses on LMPs are needed to assess how 'multisectoral' approaches can be cost-effective and sustainable in the long run compared to 'health exclusive' incentives.

Training/capacity building of human resources thus appears as one of the main challenges. It is true that the one of infrastructure and technology is equally garish. Reason why Nigeria for instance, has opted for the training of service providers and more particularly of field epidemiologists. The program was presented in a paper ("Training and Service in Public Health, Nigeria Field Epidemiology and Laboratory Training, 2008 - 2014 ${ }^{19}$ ") in which strategies and results were described. According to the authors, the health workforce is one of the key building blocks for strengthening health systems. There is an alarming shortage of curative and preventive health care workers in developing countries many of which are in Africa. Africa resultantly records appalling health indices as a consequence of endemic and emerging health issues that are exacerbated by a lack of a public health workforce. In low-income countries, efforts to build public health surveillance and response systems have stalled, due in part, to the lack of epidemiologists and well-trained laboratorians. The Nigeria Field Epidemiology and Laboratory Training Program (NFELTP) was established in October 2008 as an in-service training program in field epidemiology, veterinary epidemiology and public health laboratory epidemiology and management. The first cohort of NFELTP residents began their training on October 20, 2008 and completed their training in December, 2010. The program was scaled up in 2011 and admitted 39 residents in its third cohort. The program has admitted residents in six annual cohorts since its inception, admitting a total of 207 residents as of 2014 covering all the States. In addition, the program has trained 595 health care workers in short courses. Since its inception, the program has responded to 133 suspected outbreaks ranging from environmental related outbreaks, vaccine preventable diseases, water and food borne diseases, zoonoses, (including suspected viral hemorrhagic fevers) as well as neglected tropical diseases. The program has been involved in polio eradication efforts through its National Stop Transmission of Polio (NSTOP). The commencement of NFELTP was a novel approach to building sustainable epidemiological capacity to strengthen public health systems especially surveillance and response systems in Nigeria.

Countries in SSA regions, although late in the matter, have nevertheless taken some positive steps in terms of new medical technologies. Thus to illustrate this, and in a study conducted in Cameroon entitled "Local innovation for improving primary care cardiology in resource-limited African

\footnotetext{
${ }^{19}$ Nguku et al, 2014
} 
settings: an insight on the Cardio Pad project in Cameroon ${ }^{20 "}$, it was said that to overcome the current health workforce shortage in African countries, some strategies such as the task shifting and telehealth have been suggested as means for rapidly increasing access to prevention and curative services for emerging cardiovascular diseases (CVD) and NCDs. In addition, cardiovascular disease (CVD) is an emerging threat to the health of populations in Africa. With the inadequate health infrastructures, understaffed and underfunded health systems, African countries are ill-prepared to cope with the increasing demand of care for CVD, particularly for populations in remote and underserved rural areas, where $60 \%$ of the population currently reside. Task shifting and telehealth have been suggested as strategies to overcome the current health workforce shortage in African countries, and to increase access to prevention and curative services for emerging CVD. However, strategies for promoting their incorporation into the existing health systems, have yet to be developed. The Cardio Pad initiative (originating from Cameroon) seeks to provide appropriate solutions to improve the application of telemedicine for CVD prevention and control in remote African settings. The Cardio Pad is a telecardiology device which provides a number of advantages in terms of cost, ease of use, autonomy and reduced technology requirements. It is a fully touch screen medical device which enables cardiac tests such as electrocardiograms (ECG) to be performed in remote underserved areas (rural areas for instance), while the test results are transferred wirelessly via mobile phone connection, to specialist physicians who can interpret them and provide assistance with case management.

Discussion: Without any willingness of stigmatization, two countries appear on the basis of most data described above, to have the largest number of emerging diseases, in particular as part of NTD cases and possibly disease burden. Nigeria is estimated to have the highest prevalence of helminth infections such as hookworm, schistosomiasis, ascariasis, trichuriasis, and LF in SSA, as well as the second highest registered prevalence of leprosy. In addition, arboviral and other zoonotic infections are common in Nigeria, including yellow fever, rabies, and toxoplasmosis, while Buruli ulcer is found in the southern and southeastern areas of the country. Similarly, DRC exhibits the highest prevalence of HAT and leprosy in SSA, as well as the second highest prevalence of hookworm infection and trichuriasis (and possibly LF), and the third highest prevalence of schistosomiasis and ascariasis. Together, Nigeria and DRC account for approximately one-third of the helminth infections and leprosy in SSA, as well as up to one-fifth of the cases of HAT. It should otherwise be pointed out that these countries are the most populated and the one with the highest size respectively, in SSA. A targeted approach for these two countries could make a substantial impact on Africa's overall NTD disease burden. In "Defining an emerging disease ${ }^{21}$ " the authors underlined that the definition of emerging disease is not straightforward, as there are several different types of disease emergence. For example, there can be a 'real' emergence of a brand new disease, such as the emergence of bovine spongiform encephalopathy in the 1980s, or a geographic emergence in an area not previously affected, such as the emergence of bluetongue in northern Europe in 2006. In addition, disease can emerge in species formerly not considered affected, e.g. the emergence of bovine tuberculosis in wildlife species since 2000 in France. There can also be an unexpected increase of disease incidence in a known area and a known species, or there may simply be an increase in our knowledge or awareness of a particular disease. What all these emerging diseases have in common is that human activity frequently has a role to play in their emergence... They further continued by saying that globalisation and population growth will continue to affect the epidemiology of diseases in years to come and ecosystems will continue to evolve.

In most of the papers reviewed, main issues raised were on one hand related to the pressure put on the facility by patients and caretakers of these patients, and on the other hand, the global matter of information.

\footnotetext{
${ }^{20}$ Noubiap, Jingi, \& Kengne, 2014

${ }^{21}$ Moutou \& Pastoret, 2015
} 
Concerning pressure put on health facilities and the health system, it was for instance demonstrated during the study on Buruli Ulcer ("Enhancing Buruli ulcer control in Ghana through social

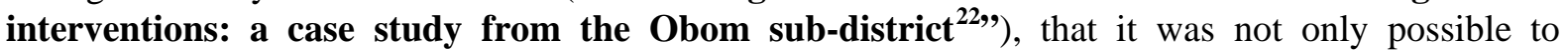
increase Buruli Ulcer early case detection and diagnosis but also to effectively treat patients on outpatient basis at health centers to significantly reduce in-patient pressure on the health facilities in terms of space for admission. Hospital admission do not only put pressure on the health facility but also on the family caretakers who have to stay on 'admission' with the patients for as long as it takes to get the patient discharged from the hospital. In this study, caretakers were not even accompanying patients to the health center and this made it possible for them to go about their normal daily life while patients received effective treatment from the health center. In the study related to "Meeting information needs of patients with incurable progressive disease and their families in South Africa and Uganda: multicentre qualitative study ${ }^{23}$, , it was the first time in Africa that a study tried to understand experiences of communication and information sharing among patients with incurable progressive disease and their informal caregivers and to identify their unmet needs. Most patients and caregivers lacked information and had unanswered questions about their conditions. This situation seemed to exist in spite of them drawing on a wide range of sources for information. Patients and caregivers often considered general medical services to be inadequate at providing accessible information that met their needs... Poor knowledge and provision of information adversely affected patients' and caregivers' ability to cope with their situation, directly affecting caregivers' ability to care for patients, as well as patients' ability to care for themselves and plan for the future. For both groups, not having the information they needed was related to anxiety about the disease and the future.

Despite these many failures, progress has been made all the same, not only in the field of financing, with demand-side financial incentives ("Health sector demand-side financial incentives in lowand middle-income countries: a systematic review on demand- and supply-side effects ${ }^{24}$.”) but also in the field of training of epidemiologists, to reinforce public surveillance ("Training and Service in Public Health, Nigeria Field Epidemiology and Laboratory Training, $2008-2014$ "). In a final note, Technological innovations in medical domains, are nevertheless to be credited to researchers and scientists from the SSA region. We would particularly mention the case of the Cardio Pad, which was developed by a young Cameroonian, to rapidly increase access to prevention and curative services for emerging cardiovascular diseases (CVD) and NCDs.

Conclusion: Emerging and reemerging infections or diseases, really represent a major public health issue in SSA, but also a major economic problem, through the disease burden that they represent. This review has enabled us to get an idea of the magnitude of the problem, epidemiologically and as regard to the disease burden in terms of Disability Adjusted Life Year (DALY). In fact, populations in the SSA region are constantly plagued by threats and epidemics such as malaria, HIV, Ebola, chikungunya, the schistosomiasis, helminths and other non-communicable diseases. These different diseases and infections that endanger the lives of these populations are most often the result of human action in the field of agriculture, dam construction, ecological changes, and so one and so forth. As such it can be also by human action that these scourges can be eradicated. Challenges exist in terms of the resurgence of these diseases, as well as their magnitude, as regards to epidemiological data, burden, and capacity of health systems to meet the needs and demands of the populations, but also ability of each other to adapt to these new situations.

Fortunately, several initiatives are underway or have been taken to resolve some of these situations. This was particularly the case in terms of building human resource capacity, better financing of demand, but also in terms of technological innovation.

\footnotetext{
${ }^{22}$ Ahorlu et al. 2013

${ }^{23}$ Selman et al, 2009

${ }^{24}$ Gopalan et al, 2014

${ }^{25}$ Nguku et al, 2014
} 


\section{References}

[1]. Accorsi, S., Kedir, N., Farese, P., Dhaba, S., Racalbuto, V., Seifu, A., \& Manenti, F. (2009a). Poverty, inequality and health: the challenge of the double burden of disease in a non-profit hospital in rural Ethiopia. Transactions of the Royal Society of Tropical Medicine and Hygiene, 103(5), 461-468. https://doi.org/10.1016/j.trstmh.2008.11.027

[2]. Acheson, R. M. (1978). The definition and identification of need for health care. Journal of Epidemiology and Community Health, 32(1), 10-15.

[3]. Ahorlu, C. K., Koka, E., Yeboah-Manu, D., Lamptey, I., \& Ampadu, E. (2013). Enhancing Buruli ulcer control in Ghana through social interventions: a case study from the Obom sub-district. BMC Public Health, 13, 59. https://doi.org/10.1186/1471-2458-13-59

[4]. Ansumana, R., Jacobsen, K. H., Leski, T. A., Covington, A. L., Bangura, U., Hodges, M. H., ... Stenger, D. A. (2013). Reemergence of chikungunya virus in Bo, Sierra Leone. Emerging Infectious Diseases, 19(7), 1108-1110. https://doi.org/10.3201/eid1907.121563

[5]. Burgess, P. I., Msukwa, G., \& Beare, N. A. V. (2013). Diabetic retinopathy in sub-Saharan Africa: meeting the challenges of an emerging epidemic. BMC Medicine, 11, 157. https://doi.org/10.1186/1741-7015-11-157

[6]. Gopalan, S. S., Mutasa, R., Friedman, J., \& Das, A. (2014). Health sector demand-side financial incentives in low- and middle-income countries: a systematic review on demand- and supply-side effects. Social Science \& Medicine (1982), 100, 72-83. https://doi.org/10.1016/j.socscimed.2013.10.030

[7]. Hotez, P. J., \& Kamath, A. (2009). Neglected Tropical Diseases in Sub-Saharan Africa: Review of Their Prevalence, Distribution, and Disease Burden. PLOS Negl Trop Dis, 3(8), e412. https://doi.org/10.1371/journal.pntd.0000412

[8]. Kivuti-Bitok, L. W., Pokhariyal, G. P., Abdul, R., \& McDonnell, G. (2013). An exploration of opportunities and challenges facing cervical cancer managers in Kenya. BMC Research Notes, 6, 136. https://doi.org/10.1186/1756-0500-6-136

[9]. Maponga, C. C., Ma, Q., Slish, J. C., \& Morse, G. D. (2007). HIV pharmacotherapy issues, challenges, and priorities in sub-Saharan African countries. Topics in HIV Medicine: A Publication of the International AIDS Society, USA, 15(3), 104-110.

[10]. Morse, S. S. (1995). Factors in the emergence of infectious diseases. Emerging Infectious Diseases, 1(1), 7-15.

[11]. Moutou, F., \& Pastoret, P.-P. (2015). Defining an emerging disease. Revue Scientifique Et Technique (International Office of Epizootics), 34(1), 41-52.

[12]. Mukadi, Y. D., Maher, D., \& Harries, A. (s. d.). Tuberculosis case fatality rates in high HIV prevalence popu...: $\quad$ AIDS. Consulté 25 septembre 2016, à l'adresse http://journals.lww.com/aidsonline/Fulltext/2001/01260/Tuberculosis_case_fatality_rates_in_high_HIV.2.aspx [13]. Nguku, P., Oyemakinde, A., Sabitu, K., Olayinka, A., Ajayi, I., Fawole, O., ... Nasidi, A. (2014). Training and service in public health, Nigeria Field Epidemiology and Laboratory Training, 2008 - 2014. The Pan African Medical Journal, 18 Suppl 1, 2. https://doi.org/10.11694/pamj.supp.2014.18.1.4930

[14]. Noubiap, J. J. N., Jingi, A. M., \& Kengne, A. P. (2014). Local innovation for improving primary care cardiology in resource-limited African settings: an insight on the Cardio Pad(®) project in Cameroon. Cardiovascular Diagnosis and Therapy, 4(5), 397-400. https://doi.org/10.3978/j.issn.2223-3652.2014.10.01

[15]. Olmsted, S. S., Moore, M., Meili, R. C., Duber, H. C., Wasserman, J., Sama, P., ... Hilborne, L. H. (2010). Strengthening laboratory systems in resource-limited settings. American Journal of Clinical Pathology, 134(3), 374-380. https://doi.org/10.1309/AJCPDQOSB7QR5GLR

[16]. Omondi Aduda, D. S., \& Mkhize, N. (2014). Ethical issues evolving from patients' perspectives on compulsory screening for syphilis and voluntary screening for cervical cancer in Kenya. BMC Medical Ethics, 15, 27. https://doi.org/10.1186/1472-6939-15-27

[17]. Prentice, A. M. (2006). The emerging epidemic of obesity in developing countries. International Journal of Epidemiology, 35(1), 93-99. https://doi.org/10.1093/ije/dyi272

[18]. Roux, V., \& Raoult, D. (1999). Body lice as tools for diagnosis and surveillance of reemerging diseases. Journal of Clinical Microbiology, 37(3), 596-599. 
Texila International Journal of Public Health

Volume 4, Issue 4, Dec 2016

[19]. Selman, L., Higginson, I. J., Agupio, G., Dinat, N., Downing, J., Gwyther, L., ... Harding, R. (2009). Meeting information needs of patients with incurable progressive disease and their families in South Africa and Uganda: multicentre qualitative study. BMJ (Clinical Research Ed.), 338, b1326.

[20]. Silva-Matos, C., \& Beran, D. (2012). Non-communicable diseases in Mozambique: risk factors, burden, response and outcomes to date. Globalization and Health, 8, 37. https://doi.org/10.1186/1744-8603-8-37

[21]. Unwin, N., Setel, P., Rashid, S., Mugusi, F., Mbanya, J.-C., Kitange, H., ... Alberti, K. G. M. M. (2001). Noncommunicable diseases in sub-Saharan Africa: where do they feature in the health research agenda? Bulletin of the World Health Organization, 79(10), 947-953. https://doi.org/10.1590/S0042-96862001001000008 


\title{
Sexual Behaviors and Pregnancies of in School and out of School Adolescents in Kavango region, Namibia
}

\author{
Article by Taimi Amakali-Nauiseb ${ }^{1}$, Honore K.Mitonga ${ }^{2}$ \\ ${ }^{1}$ University of Namibia University of Namibia \\ E-mail: tnauiseb@unam.na
}

\begin{abstract}
The objective of this study is to determine the sexual patterns among their school and out of school adolescents in Kavango region, Namibia and identify the association between the socio-demographic characteristics of the adolescents and their sexual behaviors.

A cross-sectional analytical study was conducted using mixed methods - quantitative and qualitative approaches among 350 school learners (grade 6 to grade 12) and 150 school dropout adolescents (aged 12 to 18 years). The stratified random sampling techniques were used in the selections of the circuit and the schools. Structured questionnaires were used in face-to-face interviews, and in depth interviews were conducted among the key informants (teachers). The following variables include the demographics (age, grade, parent marital status, and school drop-out status), sexual behavior (age at first sexual intercourse, number of sexual partners, abortion, and age at abortion), economic (employment, financial support).

Descriptive statistics was used to summarise the above-mentioned variables. Crosstabulations of demographic, sexual and economic variables were used to describe the relative frequencies.

The associations between different categorical variables were assessed using Chi-square test whilst the identification of different determining factors was analyzed with the epidemiological methods using odds ratios and/or estimated relative risks. The means, standard deviation and $95 \%$ confidence interval were computed. The differences between different variables or factors were considered to be statistically significant for p-values less than 0.05 .

The study found that early sexual debut, first sexual intercourse, number of sexual partners, relationship with sexual partners older than 5 years and dropping out of schoolwere associated with adolescent pregnancy in Kavango region.
\end{abstract}

Keywords: Adolescence, Adolescents, Reproductive health, Sexual behaviors, Sex education.

\section{Introduction}

Teenage pregnancies give an impression of being unwanted because they are never planned. According to (USAID, 2011) 91\% of teenage pregnancies in the Kavango region in Namibia were unwanted. The unplanned and unwanted pregnancies among teenage girls are often terminated by unsafe abortions which may have a long term negative effect on their social and emotional being. The Demographic Health Survey as reported in Ministry of health \& social service, (MOHSS) 2013 and USAID 2011study revealed that the teenage pregnancy rate in the Kavango Region was double the national average, standing at $34 \%$ among the 15 19 year old. The national average teenage pregnancy rate was $15 \%$ and $15.4 \%$ respectively; and three times the rates in some of the neighboring regions, such as Ohangwena, Omusati, and Oshana.

In Namibia, 2015the prevalence of adolescent pregnancy was 31.3\%; and as stated by Lillian P; Mumbango T, 2015, adolescent pregnancy was influenced by generation, region, highest educational level, socio-economic status and cultural factors. Therefore, intervention programs and policy initiatives should focus on youth, regions, everyone regardless of the socio-economic or culture. 
Although different regions of Namibia are affected, Kavango region in Northern Namibia is mostly affected by the problem of teenage pregnancy. According to a USAID report(USAID, 2011), the region has the highest rate of 34\% teenage pregnancy among 15 to 19 year olds.

With the commemoration of the World Population Day, the United Nations Population Fund (UNFPA,2013), released these statistics, which is celebrated on the 11 July every year. This year the theme was "Investing in Teenage Girls "When the statistics were compiled, there were 245431 adolescent girls population in Namibia aged between 15 and 19. 46000 adolescent fell pregnant, $66 \%$ of the population between 15 and 19, 39\% below the age of 15 .

As previously stated, the pregnancy rates are high in some regions, with $20 \%$ of teenagers in some rural areas becoming mothers earlier than their counterparts in urban areas. One of the reasons being is that rural teenage girls only have primary-level education, while girls in urban areas are better educated. Apart from the academic factor, the report also said some girls do not know how to avoid falling pregnant, while others feel shy or are ashamed to access contraceptives (Nomhle Kangootui, 2016; UNFPA, 2013).

The USAID report (USAID, 2011) on teenage pregnancy in Kavango region indicates that lack of access to family planning as a result of the traditional orientation of family planning in favor of older and married women by health care providers is partly responsible for teenage pregnancy in the region. Furthermore, the report indicated that while $98 \%$ of young people in Kavangowere informed about contraceptives, but only $8.7 \%$ of them use it. Condom use in the Kavango Region was very low at $36 \%$.

This article was extracted from the authors study "a model for reproductive health and pregnancy preventing strategies among adolescents in schools in Kavango region, Namibia" and thus cover the results related to the study to determine the sexual patterns among the in school and out of school adolescents in Kavango region, Namibia and identify the association between the socio-demographic characteristics of the adolescents and their sexual behaviors.

\section{Objectives}

The objective of this study is to determine the sexual patterns among the in school and out of school adolescents in Kavango region, Namibia and identify the association between the socio-demographic characteristics of the adolescents and their sexual behaviors.

Limitation of the study

The study focused only on public schools in Kavango region. Therefore, the outcomes of the study can only be recommended developing a model for adolescents within the public schools in Kavango regions. Consequently, the findings of the study need to be adjusted to the rest of the other schools in other regions in the country in order to be generalized. So, yes generalization of findings to the whole Namibian country will be applicable and will be done. Generalization of the study to Africa, the answer will be no because the model need to be adapted according to the countries culture and needs which need to be country specific. The model needs to be benchmark and due to constraints in time and resources implementation and evaluation of the model will not be completed now at the specific point in time.

\section{Delimitation of the study}

The study was carried out solely in Kavango region and not in any other regions of the country. The model needs to be benchmark and due to constraints in time and resources implementation and evaluation of the model will not be completed now at the specific point in time. 


\section{Methods}

\section{Study design}

A cross-sectional analytical study was conducted using mixed methods - quantitative and qualitative approaches among 350 school learners (grade 6 to grade 12) and 150 school dropout adolescents (aged 12 to 18 years). The stratified random sampling techniques were used in the selections of the circuit and the schools. Structured questionnaires were used in face-to-face interviews, and in depth interviews were conducted among the key informants (teachers). The following variables include the demographics (age, grade, parent marital status, and school drop-out status), sexual behavior (age at first sexual intercourse, number of sexual partners, abortion, and age at abortion), economic (employment, financial support).

\section{Study population}

The study population groups were in threefold, the school learners in primary or secondary school, the teachers at different schools and the adolescent's in the community who had dropped out of school.

\section{Target population}

The first target population were the school learners falling within the age group of between 12- 19 years, in public primary and as well secondary schools in Kavango region. The second target population were teachers at different schools teaching Life Science, Life Skills, Biology or Natural Science. The third target populations were the adolescent's in the communities who had dropped out and or never went to school and falls within the age group of between 12- 19 years.

\section{Sample size}

A sample size of 500 adolescents was determined using Epiinfo version 7 considering at least $95 \%$ significance level.

Data collection: preparing the field,

For both the schools and the community: Prior telephonic arrangements were done with the school principals and councilors regarding the purposes of the visit, date and time for the visits to Kavango Region and to the specific schools.

\section{Data collection procedure at schools}

The researcher (Mrs. T.Nauiseb) reported at the principal's office whereby the researcher submitted all written proof of letters for permission as obtained from the different institutions.

The principal accompanied the researcher to the Laboratory classroom or Life Skills class where the data collection took place. At some schools, the teacher responsible for Life Science, Life Skills, Natural Science or Biology accompanied the researcher to the Laboratory classroom or to the Life Skills class where the data collection took place. At some instances the learners waited at the mentioned classrooms and at other schools learners were called for the data collection once the researcher turned up.

The researcher was provided in advance with the class list of the specific grades, and carried out simple random selection. At the Primary schools: all learners from the different grades 6-7 came to the one central classroom, which was the Life Skills class's room. At the Secondary schools: all learners from the different grades 8-12 came to the one central classroom, which was the Life Skills, Biology or the laboratory classroom.

After explaining the aims of the study and obtaining permission from the learners, the researcher distributed the questionnaires to each learner. The questionnaires were in English and consisted out of open ended close questions. The researcher utilized questionnaires with the learners to understand their take on the curriculum provided at schools. Questionnaires on the learners were used to collect data and an individual in-depth face-to-face interview was carried out with the teachers offering at school the abovementioned subjects. The teacher's indepth interview pointed out their challenges, experiences and shortcomings with the 
Texila International Journal of Public Health

Volume 4, Issue 4, Dec 2016

implementation of the curriculum. The data collected by the main researcher focused on reproductive issues, whether it is included and discussed comprehensively or partly in the abovementioned subjects.

The questionnaire's consisted out of five subsections which were as follows: demographic data; sexual and reproductive health characteristics potential risk factors, family planning and social background.

\section{Data collection procedure in the community}

The constituencies were visited on different days. The researcher (Mrs. T.Nauiseb) reported at the constituencies' office and the representative of the councilor was waiting as prior arranged.

\section{Conducting interviews}

After explaining the aims of the study and obtaining permission from the adolescents the researcher distributed the questionnaires to each learner. The researcher distributed the questionnaire to the learners and they responded to the questionnaires accordingly, the researcher was present for any possible questions or clarity. The learners took approximately 30-45 minutes to respond to the questionnaires.

\section{Data analysis}

Data were entered and analyzed using SPSS software version 23 was used in data analyses. Descriptive statistics was used to summarize the above-mentioned variables. Crosstabulations of demographic, sexual and economic variables were used to describe the relative frequencies. The associations between different categorical variables were assessed using Chi-square test whilst the identification of different determining factors was analyzed with the epidemiological methods using odds ratios and/or estimated relative risks. The means, standard deviation and $95 \%$ confidence interval were computed. The differences between different variables or factors were considered to be statistically significant for $\mathrm{p}$-values less than 0.05 .

\section{Results}

Table 1 provides the following: The mean age of respondents was 16 years, with a standard error of 0.107 and a standard deviation of 2.384 .

Age of first sexual intercourse was 15 years, with a standard error of 0.135 and a standard deviation of 2.086 .

Number of sexual partners in the past 12 months in total 224 out of 500 where having more than 1 sexual partner with a mean of1.83, with a standard error of 0.073 with a standard deviation of 1.099 .

The mean age at abortion was 16 years, which shows an association statistically significant ( $p$-value $=0.023<0.05$ ) between the ages of respondents.

$0.2 \%$ of adolescents who did perform abortion are age $12-15$ years; $2.4 \%$ of adolescents who did perform abortion are age 16-19 years.2.6\% of adolescent perform abortion which indicated that this is a public health concern and is statistically significant with a p-value of 0.023(Table 2).

In table 3, abortion with $95 \%$ confidence interval (CI) odd ratios (OR) varying between 0.017 to 1.019 for all age categories and the researcher found that the respondents aged 12 to 15 years perform abortion 0.198 times with $95 \%$ CI OR varying between 0.030 to 1.307; also the adolescents aged between 16 to 19 years perform 1.5 times abortion with a $95 \%$ CI OR varying between 1.270 to 1.792 . The results show that the adolescent have a minimum risk of performing abortion 0.017 times and a maximum risk of performing abortion of 1.019 times. These results are different from the specific ages 'categories.

Table 3, presented information association between grade, financial support and working and are statistically significant with a value $=0.021$. Financial support with $95 \%$ CI OR 
varying between 0.619 to 1.679 for married parents who are working and the researcher found that the adolescents are having 1.019 times chance of receiving financial support.

For those married parents not working the adolescents had 0.998 times chances of receiving pocket money with $95 \%$ CI OR varying between 0.938 to 1.061 . The adolescents has a minimum chance 0.998 of receiving pocket money and a maximum chance of 1.019 times of receiving pocket money.

Pocket money with $95 \%$ CI OR for those working varying between 0.619 to 1.679 for married parents and the researcher found that the adolescents are 1.019 times chance of receiving pocket money. For those not working had 0.998 times chances of receiving pocket money with $95 \%$ confidence interval odd ratios varying between 0.938 to 1.061 . The adolescents has a minimum chance 0.998 of receiving pocket money and a maximum chance of 1.019 times of receiving pocket money (Table 3).

The social characteristics, was found having an association statistically significant between sex education and the grades of the participants ( $p$-value $=0.017<0.05$ ). Similarly, the risky behavior and the age were statistically significant ( $\mathrm{p}-$ value $=0.015<0.05)($ Table 4$)$.

Table 3 provide the adolescents study status who became pregnant with $95 \%$ CI OR varying between 0.786 to 2.415 ; the researcher found that those who became pregnant are 1.378times at risk of dropping out of school and those who didn't became pregnant are 0.942 times at risk of dropping out, with $95 \%$ CI OR varying between 0.856 to 1.036 .

The above results show that the adolescent who became pregnant have a minimum risk of dropping out of school 0.942 times and a maximum risk of dropping out of school 1.378 times.

\section{Discussion}

Adolescent pregnancy prevention research and programs predominantly focus on factors controlled by the adolescent girl. However, the most important factors linked to early pregnancy in this study are,age of sexual debut, number of sexual partners and the mean age of abortion, low family planning utilization, relationship with sexual partners older than 5 years and dropping out of school

The USAID reported that ignorance among the adolescent girls is also to blame for teenage pregnancy. The report indicates that while $98 \%$ of young people were informed about contraceptives, but only $8.7 \%$ of them use it. This claim is also substantiated by UNICEF's report, which indicates that adolescent girls in Namibia have low level of contraceptive use and, only above $61 \%$ of condom use(The United Nations Children's Fund (UNICEF), 2012).

Teenage pregnancy appears unwanted because it is unplanned. This is substantiated by the study on teenage pregnancy by the USAID (USAID, 2011)in Namibia the findings of which has proven that $91 \%$ of pregnancies among teenagers in Kavango region of Namibia were unwanted. Unplanned teenage pregnancy is often terminated by abortion, a negative experience that may have a lifelong emotional and social impact on her.

Teenagers in some rural areas becoming mothers earlier than their counterparts in urban areas. One of the reasons being is that rural teenage girls only have primary-level education, while girls in urban areas are better educated. Apart from the academic factor, the report also said some girls do not know how to avoid falling pregnant, while others feel shy or are ashamed to access contraceptives (Nomhle Kangootui, 2016; UNFPA, 2013).

Adolescent pregnancy was considered a private matter that only involved the pregnant adolescent and the immediate family members. This issue has now however become a public concern. An increasing awareness of social and economic consequences of adolescent pregnancy has led to a consensus among researchers and policy makers and the general public at large that adolescent pregnancy and childbearing is a serious social problem. It is linked to concerns such as the spread of HIV/ AIDS, non-marital births, sexual abuse and neglect, abortions, infant and maternal mortality, high rate of unemployment, school failure and dropouts, and loss of self-esteem and limited future career opportunities (Lillian P; Mumbango T, 2015). 
About 16 million girls aged 15 to 19 years and two million girls under the age of 15 give birth every year. Worldwide, one in five girls have given birth by the age of 18 . In the poorest regions of the world, this figure rises to over one in three girls, almost all adolescent births about $95 \%$ occur in low- and middle-income countries. Within countries, adolescent births are more likely to occur among poor, less educated and rural populations (WHO, 2014).

As indicated in the study by (Omar, K., Hasim, S., Muhammad, N. A., Jaffar, A., Hashim, S. M., \& Siraj, 2010), there were significant associations between adolescent pregnancy and low education level, low socioeconomic status, being raised by a single parent, not engaging in extracurricularschool activities, engaging in unsupervised activities with peers after school, and substance abuse being anemic, being unsure of the expected delivery date (Omar, K., Hasim, S., Muhammad, N. A., Jaffar, A., Hashim, S. M., \& Siraj, 2010).

\section{Conclusion}

The study found that early sexual debut, first sexual intercourse, number of sexual partners, relationship with sexual partners older than 5 years and dropping out of school were associated with adolescent pregnancy in Kavango region.

\section{Figures and tables}




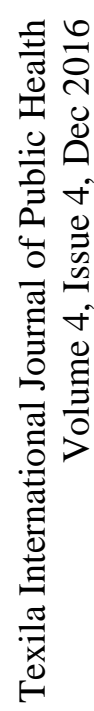

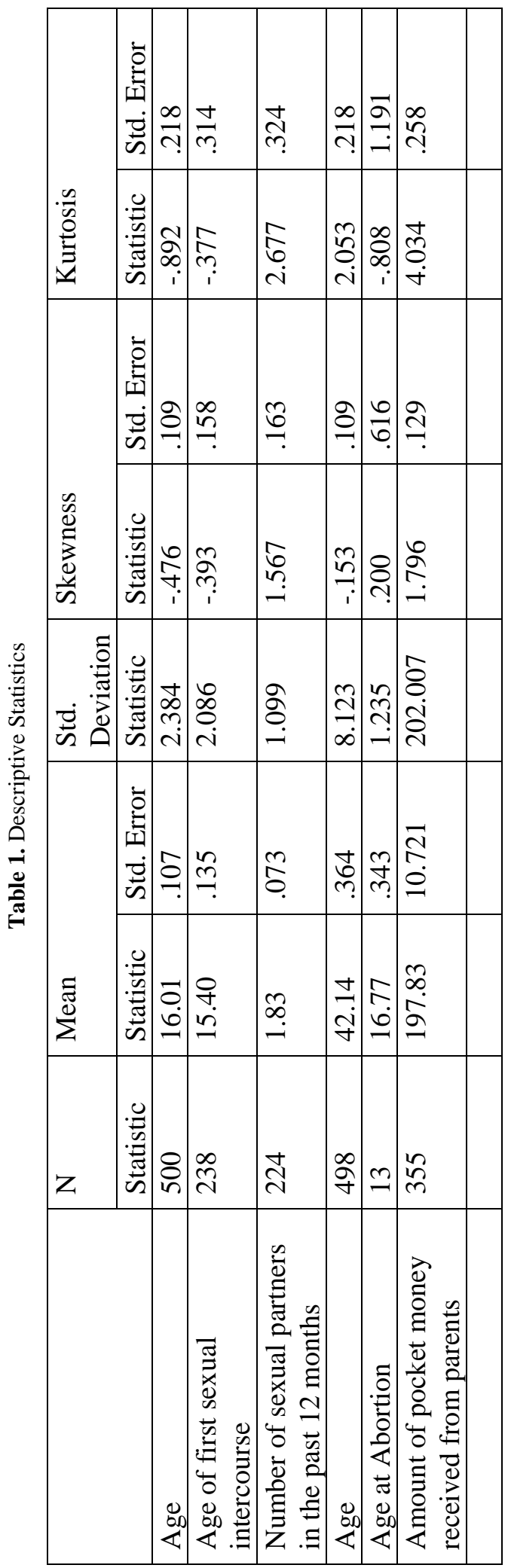


Texila International Journal of Public Health

Volume 4, Issue 4, Dec 2016

Table 2. Demographic Characteristics-Association between abortion and age-category

\begin{tabular}{|c|c|c|c|c|c|c|}
\hline & \multicolumn{2}{|c|}{ Age-Category } & \multirow[t]{2}{*}{ Total } & \\
\hline & & & $12-15$ & $16-19$ & & P-value \\
\hline \multirow[t]{4}{*}{ Abortion } & Yes & Count & 1 & 12 & 13 & \multirow{6}{*}{0.023} \\
\hline & & $\begin{array}{l}\text { \% of } \\
\text { Total }\end{array}$ & $0.2 \%$ & $2.4 \%$ & $2.6 \%$ & \\
\hline & No & Count & 189 & 298 & 487 & \\
\hline & & $\begin{array}{l}\text { \% of } \\
\text { Total }\end{array}$ & $37.8 \%$ & $59.6 \%$ & $97.4 \%$ & \\
\hline \multirow{2}{*}{\multicolumn{2}{|c|}{ Total }} & Count & 190 & 310 & 500 & \\
\hline & & $\begin{array}{l}\text { \% of } \\
\text { Total }\end{array}$ & $38.0 \%$ & $62.0 \%$ & $100.0 \%$ & \\
\hline
\end{tabular}

* P-value statistically significant at the level of significant 0.05

Table 3. Risk Estimate

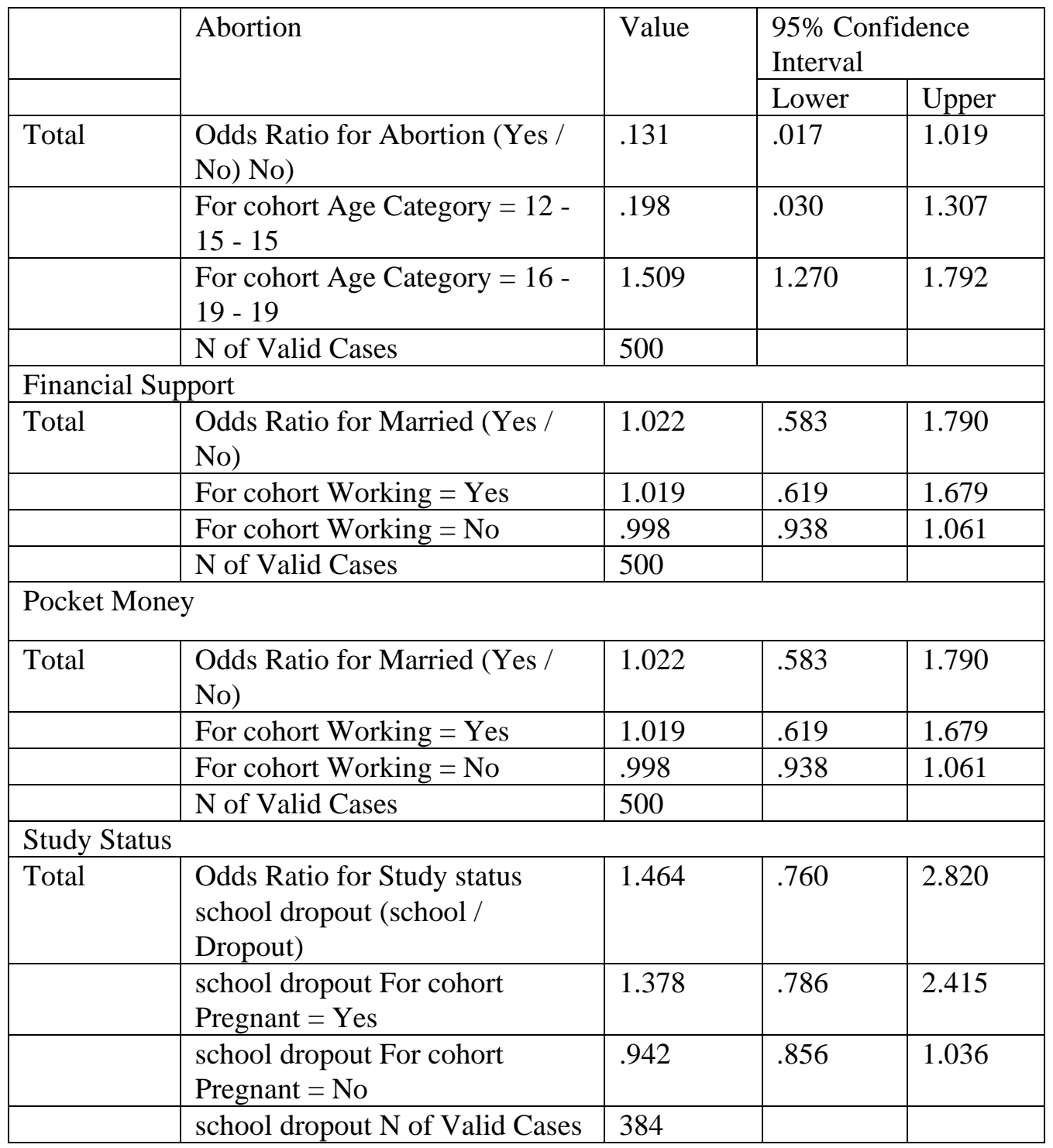


Texila International Journal of Public Health Volume 4, Issue 4, Dec 2016

Table 4. Social characteristics -Association between sex education and grades

\begin{tabular}{|c|c|c|c|c|c|c|}
\hline & \multicolumn{3}{|c|}{ Sex education } & \multirow[t]{2}{*}{ Total } & \multirow[t]{2}{*}{ P-value } \\
\hline & & \multirow{2}{*}{$\begin{array}{l}\text { Yes } \\
26 \\
\end{array}$} & \multirow{2}{*}{$\begin{aligned} \text { No } \\
14 \\
\end{aligned}$} & \multirow{2}{*}{$\begin{array}{r}\begin{array}{l}\text { Not } \\
\text { sure }\end{array} \\
12 \\
\end{array}$} & & \\
\hline \multirow{7}{*}{$\begin{array}{l}\text { Grad } \\
\text { es }\end{array}$} & Grade 6 & & & & 52 & \multirow{8}{*}{0.017} \\
\hline & Grade 7 & 37 & 12 & 10 & 59 & \\
\hline & Grade 8 & 56 & 8 & 4 & 68 & \\
\hline & Grade 9 & 48 & 11 & 2 & 61 & \\
\hline & $\begin{array}{l}\text { Grade } \\
10 \\
\end{array}$ & 40 & 20 & 1 & 61 & \\
\hline & $\begin{array}{l}\text { Grade } \\
11 \\
\end{array}$ & 58 & 32 & 3 & 93 & \\
\hline & $\begin{array}{l}\text { Grade } \\
12\end{array}$ & 80 & 23 & 3 & 106 & \\
\hline \multicolumn{2}{|c|}{ Total } & 345 & 120 & 35 & 500 & \\
\hline \multicolumn{5}{|c|}{ Risky Behavior } & & \multirow{10}{*}{0.015} \\
\hline \multirow[t]{8}{*}{ Age } & 12 & 24 & 15 & 11 & 50 & \\
\hline & 13 & 29 & 25 & 6 & 60 & \\
\hline & 14 & 32 & 7 & 2 & 41 & \\
\hline & 15 & 40 & 8 & 5 & 53 & \\
\hline & 16 & 50 & 14 & 7 & 71 & \\
\hline & 17 & 41 & 16 & 0 & 57 & \\
\hline & 18 & 71 & 19 & 9 & 99 & \\
\hline & 19 & 64 & 14 & 5 & 83 & \\
\hline \multicolumn{2}{|c|}{ Total } & 349 & 113 & 38 & 500 & \\
\hline
\end{tabular}

* P-value statistically significant at the level of significant 0.05

Table 5. Sexual and reproductive health characteristics -Association between sexual partner in 12months, partner older and partner HIV status

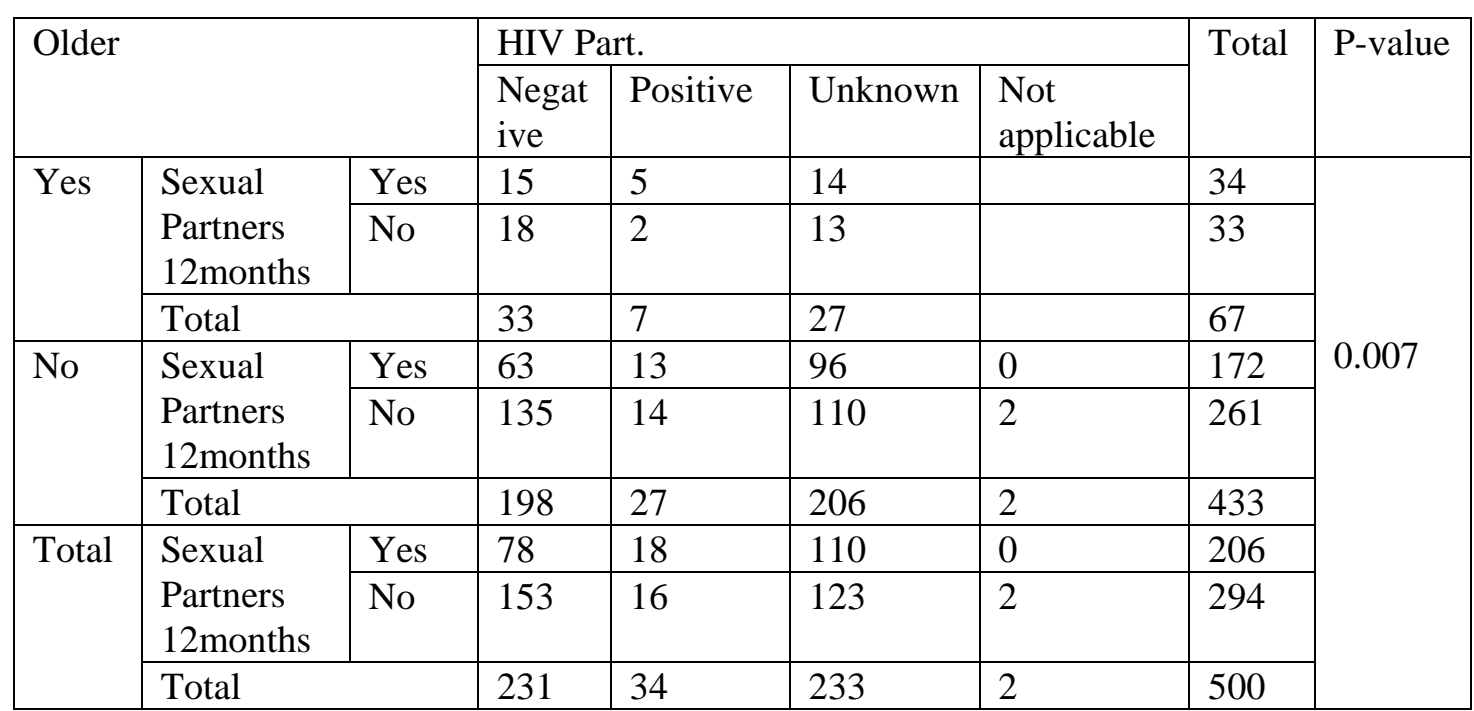

* P-value statistically significant at the level of significant 0.05 
Texila International Journal of Public Health

Volume 4, Issue 4, Dec 2016

\section{References}

[1]. Lillian P; Mumbango T. (2015). Statistical Modeling of Adolescent Pregnancy in Namibia. J Nurs Care, 4, 262. doi:10.4172/2167-1168.1000262

[2]. Ministry of Health \& Social Services (MoHSS). (2013). Namibia Demographic Health Survey 2013.

[3]. Nomhle Kangootui. (2016). Pregnancy statistics in Namibia. Namibian Newspaper, p. 14 July 2016.

[4]. Omar, K., Hasim, S., Muhammad, N. A., Jaffar, A., Hashim, S. M., \& Siraj, H. H. (2010). Adolescent Pregnancy Outcomes and Risk factors in Malaysia. International Federation of Gynecology and Obstetrics, 111(3), 220-223. doi:http://doi.org/10.1016/j.ijgo.2010.06.023

[5]. The United Nations Children's Fund (UNICEF). (2012). Progress for Children: A Report Card on Adolescents.

[6]. UNFPA. (2013). World Population Day the United Nations Population Fund.

[7]. USAID. (2011). Teenage Pregnancy in Kavango Region. Contributing Factors and Program Recommendations.

[8]. WHO. (2014). Adolescent Pregnancy Fact Sheet. Geneva, Switzerland. 


\title{
Potential Risk Characteristics of Adolescent Pregnancy in Schools and out of school in Kavango Region, Namibia
}

\author{
Article by Taimi Amakali-Nauiseb ${ }^{1}$, Honore K.Mitonga ${ }^{2}$ \\ ${ }^{1,2}$ University of Namibia University of Namibia \\ E-mail: ${ }^{1}$ tnauiseb@unam.na
}

\begin{abstract}
The objective is this study is to determine the potential risk characteristics among the in-school and out of school adolescents in Kavango region, Namibia.

A cross-sectional analytical study was conducted using mixed methods - quantitative and qualitative approaches among 350 school learners (grade 6 to grade 12) and 150 school drop-out adolescents (aged 12 to 19 years). The stratified random sampling techniques were used in the selections of the circuit and the schools. Structured questionnaires were used in face-to-face interviews, and in depth interviews were conducted among the key informants (teachers).

The following variables include the potential risk characteristics alcohol used, drug used, marijuana used, more than one sexual partner in past 12 months, partner older than 5 years, orphan, abortion, sex regularly, mothers education, contraceptive used, current pregnancy and outcome of birth.

Descriptive statistics was used to summarise the above mentioned variables. Cross-tabulations of demographic, sexual and economic variables were used to describe the relative frequencies.

The associations between different categorical variables were assessed using Chi-square test whilst the identification of different determining factors was analyzed with the epidemiological methods using odds ratios and/or estimated relative risks. The means, standard deviation and $95 \%$ confidence interval were computed. The differences between different variables or factors were considered to be statistically significant for p-values less than 0.05 .
\end{abstract}

Keywords: Adolescence, Adolescents Contraceptives, First intercourse, Sexual health, Sexual partner.

\section{Introduction}

The article covers the results related the potential risk characteristics among the in-school and out of school adolescents in Kavango region, Namibia.

This article was extracted from the authors study "a model for reproductive health and pregnancy preventing strategies among adolescents in schools in Kavango region, Namibia. With the commemoration of the World Population Day the United Nations Population Fund (UNFPA) released these statistics in, celebrated on the 11 July every year. This year the theme was "Investing in Teenage Girls "When the statistics were compiled, there were 245431 adolescent girls population in Namibia aged between 15 and 19. 46000 adolescent fell pregnant, $66 \%$ of the population under the age, $39 \%$ below the age of 15 . The figures are higher in some regions, with $20 \%$ of teenagers in some rural areas becoming mothers earlier than their counterparts in urban areas. One of the reasons being is that rural teenage girls only have primary-level education, while girls in urban areas are better educated. Apart from the academic factor, the report also said some girls do not know how to avoid falling pregnant, while others feel shy or are ashamed to access contraceptives (Namibian newspaper, 14 July 2016), (UNFPA, 2013).

Adolescent pregnancy is an increasing problem in Namibia. Adolescent pregnancies are associated with a higher risk of complications during pregnancy and childbirth because the girls are physically and emotionally immature. Although many children become sexually active between 15 and 18 years, they do not have access to correct and relevant information on sexual matters. Pregnancy before the 
age of 18 years, and especially before the age of 16 years, carries a considerable risk to the health of the mother. Adolescent pregnancy increases the risk of ectopic pregnancy, pre-eclampsia, eclampsia, premature rupture of membranes, preterm labor, and cesarean among mothers up to 16 years of age (Omar et al., 2010).

Although different regions of Namibia are affected, Kavango region in Northern Namibia is mostly affected by the problem of teenage pregnancy. According to a USAID (2011) report, the region has the highest rate of 34\% teenage pregnancy among 15 to 19 year olds.

In Namibia, Mufune (2003) showed that taboos and social sanctions against prohibited social behavior have changed markedly; thereby loosening community control over sexuality and sexual behaviors that may predispose to HIV/AIDS related risk(Lillian \& Mumbango 2015).

\section{Objectives}

The objective is this study is to determine the potential risk characteristics among the in-school and out of school adolescents in Kavango region, Namibia.

Limitation of the study

The study focused only on public schools in Kavango region. Therefore, the outcomes of the study can only be recommended developing a model for adolescents within the public schools in Kavango regions. Consequently, the findings of the study need to be adjusted to the rest of the other schools in other regions in the country in order to be generalized. So, yes generalization of findings to the whole Namibian country will be applicable and will be done. Generalization of the study to Africa, the answer will be no because the model need to be adapted according to the countries culture and needs which need to be country specific. The model needs to be benchmark and due to constraints in time and resources implementation and evaluation of the model will not be completed now at the specific point in time.

\section{Delimitation of the study}

The study was carried out solely in Kavango region and not in any other regions of the country. The model needs to be benchmark and due to constraints in time and resources implementation and evaluation of the model will not be completed now at the specific point in time.

\section{Methods}

\section{Study design}

A cross-sectional analytical study was conducted using mixed methods - quantitative and qualitative approaches among 350 school learners (grade 6 to grade 12) and 150 school drop-out adolescents (aged 12 to 19 years). The stratified random sampling techniques were used in the selections of the circuit and the schools. Structured questionnaires were used in face-to-face interviews, and in depth interviews were conducted among the key informants (teachers). The following variables were included the potential risk characteristics alcohol used, drug used, marijuana used, more than one sexual partner in past 12 months, partner older than 5 years, orphan, abortion, sex regularly.

\section{Study population}

The study population groups were in three fold, the school learners in primary or secondary school, the teachers at different schools and the adolescent's in the community who had dropped out of school.

\section{Target population}

The first target population were the school learners falling within the age group of between 12- 19 years, in public primary and as well secondary schools in Kavango region. The second target population were teachers at different schools teaching Life Science, Life Skills, Biology or Natural 
Science. The third target populations were the adolescent's in the communities who had dropped out and or never went to school and falls within the age group of between 12- 19 years.

\section{Sample size}

A sample size of 500 adolescents was determined using Epiinfo version 7 considering at least 95\% significance level.

\section{Data collection: preparing the field}

For both the schools and the community: Prior telephonic arrangements were done with the school principals and councilors regarding the purposes of the visit, date and time for the visits to Kavango Region and to the specific schools.

Data collection procedure at schools

The researcher reported at the principal office whereby the researcher submitted all written proof of letters for permission as obtained from the different institutions. The principal accompanied the researcher to the Laboratory classroom or Life Skills class where the data collection took place. At some schools, the teacher responsible for Life Science, Life Skills, Natural Science or Biology accompanied the researcher to the Laboratory classroom or to the Life Skills class where the data collection took place. At some instances the learners waited at the mentioned classrooms and at other schools learners were called for the data collection once the researcher turned up.

The researcher was provided in-advance with the class-list of the specific grades, and carried out simple random selection. At the Primary schools: all learners from the different grades 6-7 came to the one central classroom, which was the Life Skills class's room. At the Secondary schools: all learners from the different grades 8-12 came to the one central classroom, which was the Life Skills, Biology or the laboratory classroom. After explaining the aims of the study and obtaining permission from the learners, the researcher distributed the questionnaires to each learner. The questionnaires were in English and consisted out of open ended close questions. The researcher utilized questionnaires with the learners to understand their take on the curriculum provided at schools. Questionnaires on the learners were used to collect data and an individual in-depth face-to-face interview was carried out with the teachers offering at school the abovementioned subjects. The teacher's in-depth interview pointed out their challenges, experiences and shortcomings with the implementation of the curriculum. The data collected by the main researcher focused on reproductive issues, whether it is included and discussed comprehensively or partly in the abovementioned subjects. The questionnaire's consisted out of five subsections which were as follows: demographic data; sexual and reproductive health characteristics, potential risk characteristics, family planning and social background.

\section{Data collection procedure in the community}

The constituencies were visited on different days. The researcher reported at the constituencies' office and the representative of the councilor was waiting as prior arranged.

\section{Conducting interviews}

After explaining the aims of the study and obtaining permission from the adolescents the researcher distributed the questionnaires to each learner. The researcher distributed the questionnaire to the learners and they responded to the questionnaires accordingly, the researcher was present for any possible questions or clarity. The learners took approximately 30-45 minutes to respond to the questionnaires.

\section{Data analysis}

Data were entered and analyzed using SPSS software version 23 was used in data analyses. Descriptive statistics was used to summarize the above mentioned variables. Cross-tabulations of demographic, sexual and economic variables were used to describe the relative frequencies. 
The associations between different categorical variables were assessed using Chi-square test whilst the identification of different determining factors was analyzed with the epidemiological methods using odds ratios and/or estimated relative risks. The means, standard deviation and $95 \%$ confidence interval were computed. The differences between different variables or factors were considered to be statistically significant for p-values less than 0.05 .

\section{Results}

In table 1, 1.6\% of adolescents who did perform abortion are orphaned; $1.0 \%$ of adolescents who did not perform abortion are not orphaned.2.6\% of adolescent perform abortion which indicated that this is a public health concern and is statistically significant with a p-value of 0.004 .

As illustrated in table 2, the orphans with $95 \%$ confidence interval odd ratios varying between 1.457 to 3.720; the researcher found that the orphans are 2.360times at risk of performing abortion and those who are not orphans are 0.520 times at risk of performing abortion, with $95 \%$ confidence interval odd ratios varying between 0.261 to 1.037 . This results show that the orphaned adolescent have a minimum risk of performing abortion 0.052 times and a maximum risk of performing abortion of 2.360 times.

As pointed out in table 2,0.2\% of adolescents who did perform abortion are smoking marijuana; 2.4 $\%$ of adolescents who did not perform abortion are not are smoking marijuana. $2.6 \%$ of adolescent perform abortion, which indicated that this is a public health concern.

The adolescents who smoke marijuana with $95 \%$ confidence interval odd ratios varying between 0.356 to 17.516; the researcher found that those who smoke marijuana 2.497 times at risk of performing abortion and those who do not who smoke marijuana are 0.952 times at risk of performing abortion, with $95 \%$ confidence interval odd ratios varying between 0.813 to 1.115 . The results show that the adolescent who smoke marijuana have a minimum risk of performing abortion 0.952 times and a maximum risk of performing abortion of 2.497 times (table 2).

$0.6 \%$ of adolescents who performed abortion are using drugs; $2.0 \%$ of adolescents who did not perform abortion are not are using drugs. 2.6\% of adolescent perform abortion, which indicated that this is a public health concern and is statistically significant with a p-value of 0.000 (table 2).

In table 2, the adolescents who used drugs with $95 \%$ confidence interval odd ratios varying between 3.499 to 36.092; the researcher found that those who used drugs are 11.238 times at risk of performing abortion and those who do not who are using drugs are 0.785 times at risk of performing abortion, with $95 \%$ confidence interval odd ratios varying between 0.583 to 1.058 . The results show that the adolescent who are used drugs have a minimum risk of performing abortion 0.785 times and a maximum risk of performing abortion of 11.238 times.

Table4, an association exist between gender of participants, had sex regularly, alcohol, and circumstances used are statistically highly significant ( $\mathrm{p}-$ value $=0.001<0.05 ; \mathrm{p}-$ value $=0.002<0.05$; $\mathrm{p}$-value $=0.001<0.05 ; \mathrm{p}$-value $=0.031<0.05$ )

Table 4, the association between gender of participants, mother's education, partner older than 5years and contraceptives is statistically significant $(\mathrm{p}-$ value $=0.042<0.05 ; \mathrm{p}-$ value $=0.031<0.05 ; \mathrm{p}$ -value $=0.030<0.05)$.

Table 5, a highly statistically significant exists between gender of participants, more than one sexual partner in past 12 months and outcome of birth is $(\mathrm{p}$-value $=0.003<0.05$; $\mathrm{p}$-value $=$ $0.001<0.05)$.

\section{Discussion}

Adolescent pregnancy was considered a private matter that only involved the pregnant adolescent and the immediate family members. This issue has now however become a public concern. It is linked to concerns such as the spread of HIV/ AIDS, non-marital births, sexual abuse and neglect, abortions, infant and maternal mortality, high rate of unemployment, school failure and drop-outs, and loss of self-esteem and limited future career opportunities (Lillian \& Mumbango, 2015). 
The study by Liang, (2013) mentioned that the young adolescents, who are first time mothers, face significant risks during pregnancy, including obstetric fistula and maternal death. Due to the fact that they start childbearing early; a married girl will likely have more children and at shorter intervals during her lifetime. The abovementioned factors; a young age, multiple children and a short interval between births, are all linked or related to a higher risk of death and disability due to pregnancy or childbirth.

The pregnant teenagers were significantly more likely to have experienced forced sexual initiation and were beaten more often. The findings further indicated that both forced sexual initiation and unwillingness to confront an unfaithful partner were strongly associated with the pregnancy.

Furthermore, the USAID (2011) report indicates that while 98\% of young people were informed about contraceptives, only $8.7 \%$ of them use it which is describes as ignorance from the side of the adolescent girls. This claim is also substantiated by UNICEF's report, which indicates that adolescent girls in Namibia have low level of contraceptive use and, only above $61 \%$ of condom use(2012).

Lillian \& Mumbango (2015) pointed out that, attitudes, multiple sexual partners as well as other factors were linked to risk factors for adolescent pregnancy. Chinsembu et al (2008) conquered with the fact that the term that adolescent sexuality is an important public health issue, as it affects risks to contract HIV and other sexually transmitted infections. Sexual prevalence for school-going male in 2004 was $44 \%$ while for females it was $24.8 \%$ in Namibia. In the study parental supervision was negatively associated with sexual intercourse.

According to Mmari and Blum in (2009) they concur that the most important pregnancy risk factors are education and schooling; knowledge and attitudes related to condom and contraception; perceived sexual behavior of friends; partner approval and support for using condoms and contraceptives.

The study by Liang, (2013). mentioned that the young adolescents, who are first time mothers, face significant risks during pregnancy, including obstetric fistula and maternal death. Due to the fact that they start childbearing early; a married girl will likely have more children and at shorter intervals during her lifetime. The abovementioned factors; a young age, multiple children and a short interval between births, are all linked or related to a higher risk of death and disability due to pregnancy or childbirth. Adolescent pregnancy exposes young girls to the risk of HIV and sexually transmitted infections. Girls in a marriage or union often have older, more sexually experienced husbands or partners, lack the power to negotiate safer sex and have little access to family planning information.

The study by the Department of Reproductive Health and Research of the World Health Organization (2011) elaborated that the main immediate consequences of an unwanted pregnancy are: induced abortion, lack of prenatal care, personal and family disruption, adoption and abandonment.

In the study by the National Statistical Office United Nations Children's Fund (2008), it was clearly pointed out that promoting safer sexual behavior is critical for reducing HIV prevalence. The promotion and the use of condoms during sexual intercourse, specifically with non-regular partners, are especially important for reducing the spread of HIV. In most countries, over half of new HIV infections occur amongst young people aged 15-24 years, indicating that influencing the behavior of this age group is key to reducing new infections.

Study by Thornberry et al (2015), suggested that involvement in delinquency, drug use, and sexual behavior at an early age affects the adolescent risk behaviors which will have short- and long-term consequences that disrupt the orderly flow of later development, including impacts on patterns of partner relationships. The abovementioned view was supported by Olumide, et al (2014) indicating that adolescent substance use is still a major issue among adolescents around the world, with numerous consequences underscoring the need for continued research and interventions.

\section{Conclusion}

The study found that factors such as, the circumstances of first sexual intercourse; the gift after first intercourse, having more than one sexual partner in past 12 months, alcohol used and partners older than 5 years, were associated with adolescent pregnancy in Kavango region, Namibia. 
Texila International Journal of Public Health

Volume 4, Issue 4, Dec 2016

\section{Figures and tables}

Table 1. Potential risk characteristics -Association between abortion and orphan

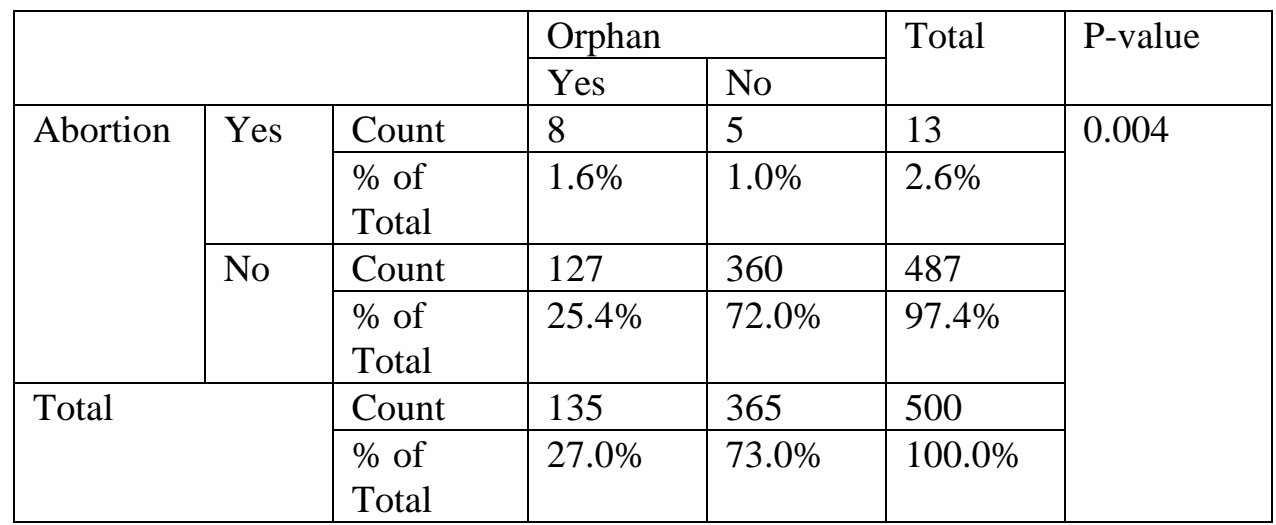

* P-value statistically significant at the level of significant 0.05

Table 2. Risk Estimate

\begin{tabular}{|l|l|l|l|}
\hline \multirow{2}{*}{} & \multirow{2}{*}{ Value } & \multicolumn{2}{|c|}{$\begin{array}{c}\text { 95\% Confidence } \\
\text { Interval }\end{array}$} \\
\cline { 3 - 4 } & & Lower & Upper \\
\hline $\begin{array}{l}\text { Odds Ratio for Abortion } \\
\text { (Yes / No) }\end{array}$ & 4.535 & 1.457 & 14.118 \\
\hline For cohort Orphan= Yes & 2.360 & 1.497 & 3.720 \\
\hline For cohort Orphan= No & .520 & .261 & 1.037 \\
\hline N of Valid Cases & 500 & & 21.494 \\
\hline $\begin{array}{l}\text { Odds Ratio for Abortion } \\
\text { (Yes / No) }\end{array}$ & 2.622 & .320 & 17.516 \\
\hline $\begin{array}{l}\text { For cohort Marijuana }= \\
\text { Yes }\end{array}$ & 2.497 & .356 & 1.115 \\
\hline $\begin{array}{l}\text { For cohort Marijuana }= \\
\text { No }\end{array}$ & .952 & .813 & 60.047 \\
\hline N of Valid Cases & 500 & 3.410 & 36.092 \\
\hline $\begin{array}{l}\text { Odds Ratio for Abortion } \\
\text { (Yes / No) }\end{array}$ & 14.310 & 3.499 & \\
\hline For cohort Drug = Yes & 11.238 & 385 & \\
\hline For cohort Drug = No & .785 & .583 & 1.058 \\
\hline N of Valid Cases & 500 & & \\
\hline
\end{tabular}


Table 3. Potential risk characteristics-Association between abortion, marijuana and partner 5years older

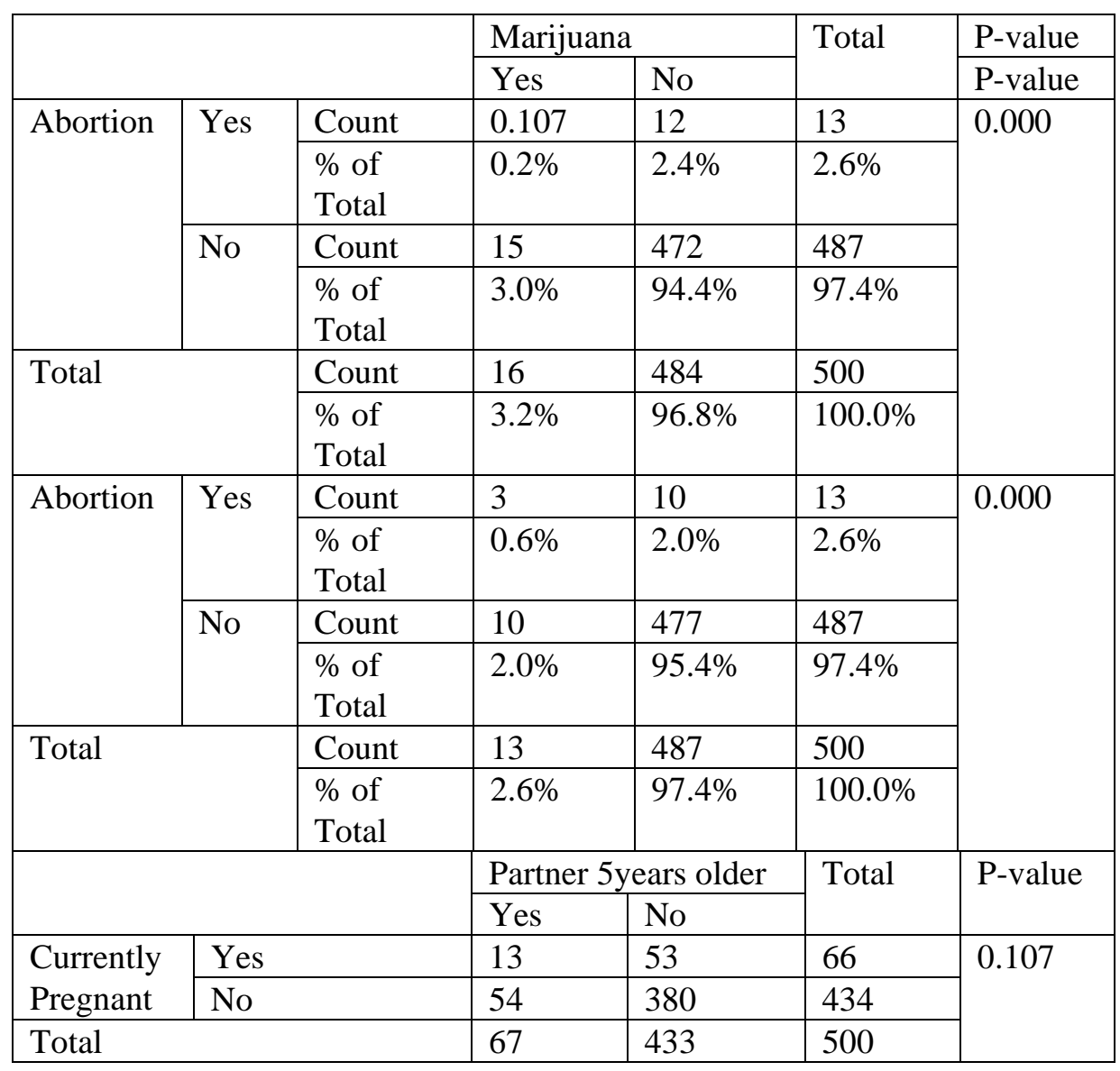

* P-value statistically significant at the level of significant 0.05

Table 4. Potential risk characteristics -Association between gender of participants, had sex regularly, alcohol used, partner 5years older and sexual partner in past 12 months.

\begin{tabular}{|c|c|c|c|c|c|c|}
\hline & \multicolumn{2}{|c|}{$\begin{array}{l}\text { Gender } \\
\text { participants }\end{array}$} & \multirow[t]{2}{*}{ Total } & \multirow[t]{2}{*}{$\begin{array}{l}\mathrm{P} \text { - } \\
\text { value }\end{array}$} \\
\hline & & & Male & Female & & \\
\hline \multirow{10}{*}{$\begin{array}{l}\text { Sex } \\
\text { regularly }\end{array}$} & \multirow[t]{4}{*}{ Yes } & Count & 53 & 33 & 86 & \multirow[t]{10}{*}{0.001} \\
\hline & & \% within Sex regularly. & $61.6 \%$ & $38.4 \%$ & $\begin{array}{l}100.0 \\
\%\end{array}$ & \\
\hline & & 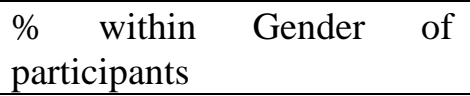 & $24.0 \%$ & $11.8 \%$ & $17.2 \%$ & \\
\hline & & $\%$ of Total & $10.6 \%$ & $6.6 \%$ & $17.2 \%$ & \\
\hline & \multirow[t]{4}{*}{ No } & Count & 107 & 175 & 282 & \\
\hline & & \% within Sex regularly. & $37.9 \%$ & $62.1 \%$ & $\begin{array}{l}100.0 \\
\%\end{array}$ & \\
\hline & & 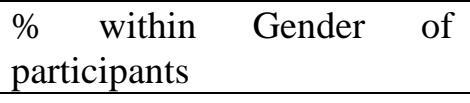 & $48.4 \%$ & $62.7 \%$ & $56.4 \%$ & \\
\hline & & $\%$ of Total & $21.4 \%$ & $35.0 \%$ & $56.4 \%$ & \\
\hline & \multirow[t]{2}{*}{ Not applicable } & Count & 56 & 70 & 126 & \\
\hline & & \% within Sex regularly. & $44.4 \%$ & $55.6 \%$ & $\begin{array}{l}100.0 \\
\%\end{array}$ & \\
\hline
\end{tabular}


Texila International Journal of Public Health

Volume 4, Issue 4, Dec 2016

\begin{tabular}{|c|c|c|c|c|c|c|}
\hline & & 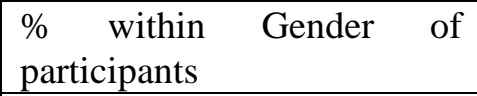 & $25.3 \%$ & $25.1 \%$ & $25.2 \%$ & \\
\hline & & \% of Total & $11.2 \%$ & $14.0 \%$ & $25.2 \%$ & \\
\hline & \multirow[t]{4}{*}{\begin{tabular}{|l} 
Not counted \\
\end{tabular}} & Count & 3 & 0 & 3 & \\
\hline & & \% within Sex regularly. & $\begin{array}{l}100.0 \\
\%\end{array}$ & $0.0 \%$ & $\begin{array}{l}100.0 \\
\%\end{array}$ & \\
\hline & & 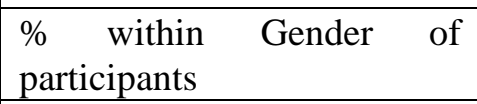 & $1.4 \%$ & $0.0 \%$ & $0.6 \%$ & \\
\hline & & $\%$ of Total & $0.6 \%$ & $0.0 \%$ & $0.6 \%$ & \\
\hline & \multirow[t]{4}{*}{ Not counted } & Count & 2 & 1 & 3 & \\
\hline & & \% within Sex regularly. & $66.7 \%$ & $33.3 \%$ & $\begin{array}{l}100.0 \\
\%\end{array}$ & \\
\hline & & 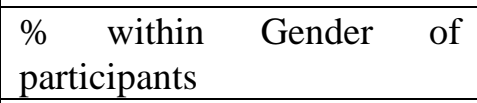 & $0.9 \%$ & $0.4 \%$ & $0.6 \%$ & \\
\hline & & \% of Total & $0.4 \%$ & $0.2 \%$ & $0.6 \%$ & \\
\hline \multirow{4}{*}{\multicolumn{2}{|c|}{ Total }} & Count & 221 & 279 & 500 & \\
\hline & & \% within Sex regularly. & $44.2 \%$ & $55.8 \%$ & $\begin{array}{l}100.0 \\
\%\end{array}$ & \\
\hline & & 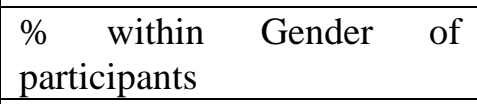 & $\begin{array}{l}100.0 \\
\%\end{array}$ & $100.0 \%$ & $\begin{array}{l}100.0 \\
\%\end{array}$ & \\
\hline & & $\%$ of Total & $44.2 \%$ & $55.8 \%$ & $\begin{array}{l}100.0 \\
\%\end{array}$ & \\
\hline \multirow{8}{*}{$\begin{array}{l}\text { Alcoho } \\
\text { l }\end{array}$} & \multirow[t]{4}{*}{ Yes } & Count & 33 & 16 & 49 & \multirow[t]{12}{*}{0.001} \\
\hline & & \% within Alcohol & $67.3 \%$ & $32.7 \%$ & $\begin{array}{l}100.0 \\
\%\end{array}$ & \\
\hline & & 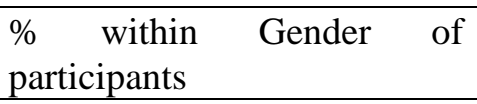 & $14.9 \%$ & $5.7 \%$ & $9.8 \%$ & \\
\hline & & $\%$ of Total & $6.6 \%$ & $3.2 \%$ & $9.8 \%$ & \\
\hline & \multirow[t]{4}{*}{ No } & Count & 188 & 263 & 451 & \\
\hline & & \% within Alcohol & $41.7 \%$ & $58.3 \%$ & $\begin{array}{l}100.0 \\
\%\end{array}$ & \\
\hline & & 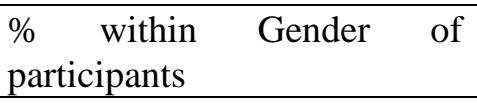 & $85.1 \%$ & $94.3 \%$ & $90.2 \%$ & \\
\hline & & $\%$ of Total & $37.6 \%$ & $52.6 \%$ & $90.2 \%$ & \\
\hline \multirow{4}{*}{\multicolumn{2}{|c|}{ Total }} & Count & 221 & 279 & 500 & \\
\hline & & \% within Alcohol & $44.2 \%$ & $55.8 \%$ & $\begin{array}{l}100.0 \\
\%\end{array}$ & \\
\hline & & 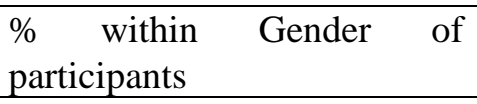 & $\begin{array}{l}100.0 \\
\%\end{array}$ & $100.0 \%$ & $\begin{array}{l}100.0 \\
\%\end{array}$ & \\
\hline & & $\%$ of Total & $44.2 \%$ & $55.8 \%$ & $\begin{array}{l}100.0 \\
\%\end{array}$ & \\
\hline \multirow{6}{*}{$\begin{array}{l}\text { Partn } \\
\text { er } 5 \\
\text { years } \\
\text { older }\end{array}$} & \multirow[t]{4}{*}{ Yes } & Count & 21 & 45 & 66 & \multirow[t]{6}{*}{0.031} \\
\hline & & \% within Older & $31.8 \%$ & $68.2 \%$ & $\begin{array}{l}100.0 \\
\%\end{array}$ & \\
\hline & & 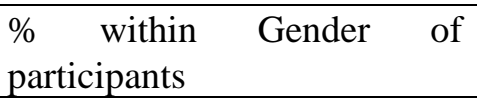 & $9.6 \%$ & $16.2 \%$ & $13.3 \%$ & \\
\hline & & $\%$ of Total & $4.2 \%$ & $9.1 \%$ & $13.3 \%$ & \\
\hline & \multirow[t]{2}{*}{ No } & Count & 198 & 233 & 431 & \\
\hline & & \% within Older & $45.9 \%$ & $54.1 \%$ & 100.0 & \\
\hline
\end{tabular}




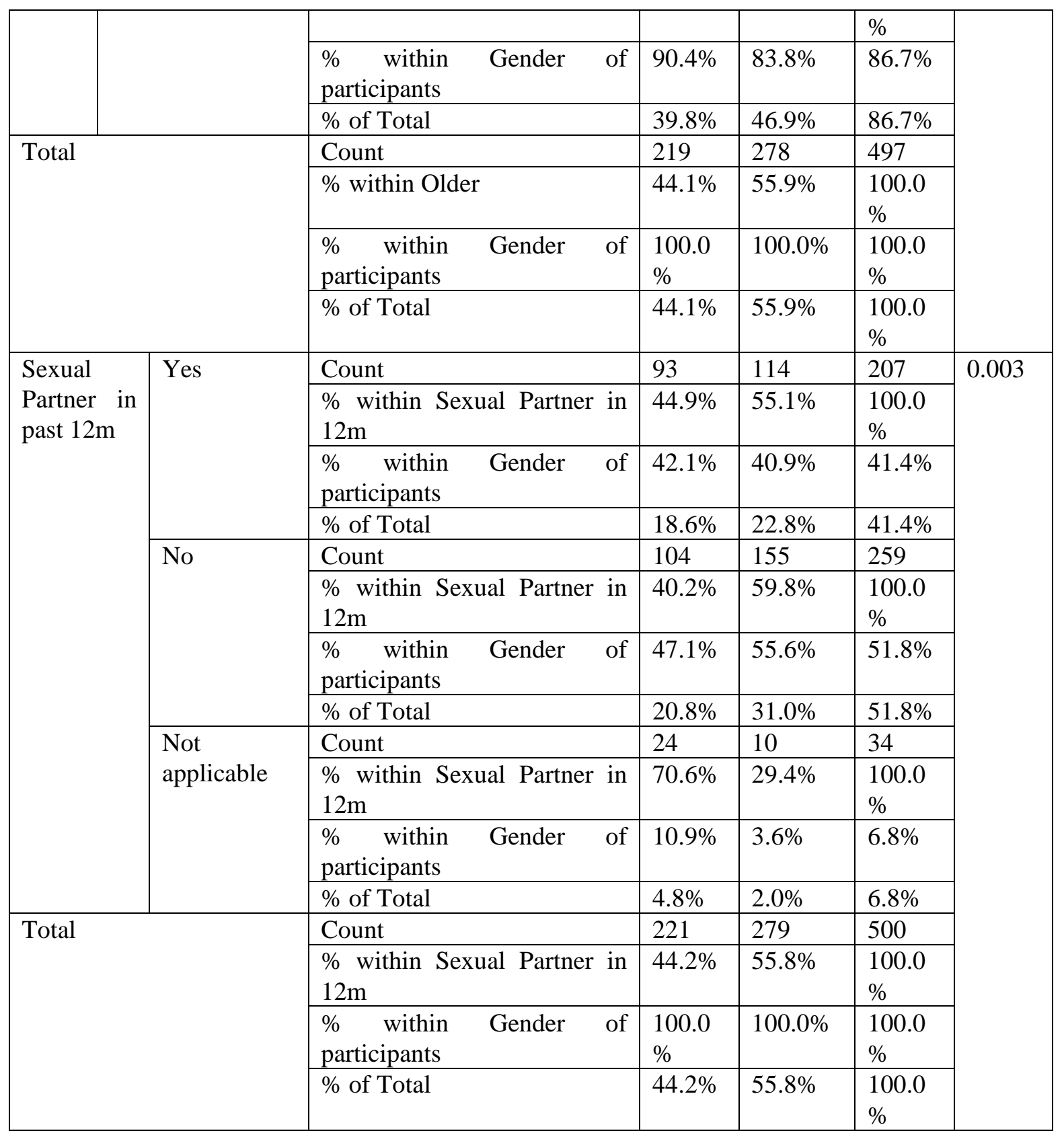

* P-value statistically significant at the level of significant 0.05

\section{References}

[1]. Chisembu K.C., Siziya.S. Muula. A.S. (2008). Prevalence and Social Correlates of Sexual Intercourse among School going Adolescents in Namibia.

[2]. Department of Reproductive Health and Research World Health Organization. (2011). Adolescent Pregnancy. Avenue Appia 20, CH-1211 Geneva 27, Switzerland E-mail: reproductivehealth@who.int.

[3]. Liang, E.L.M. (2013). Adolescent Pregnancy: A Review of the Evidence. UNFPA New York, 2013

[4]. Lillian P, Mumbango T (2015) Statistical Modeling of Adolescent Pregnancy in Namibia. J Nurs Care 4: 262. doi: Volume 4 • Issue $4 \cdot 10.4172 / 2167-1168.1000262$.

[5]. Mufune. P. (2003). Changing Patterns of sexuality in Northern Namibia: Implication a for the transmission of HIV/AIDS.

[6]. Minesota Department of Health. (2010). Adolescent Pregnancy Prevention Interventions. Website:http://www.advocatesforyouth.org/storage/advfy/documents/sspregnancies.pdf. 
[7]. Mmari, K. \& Blum, R.W. (2009). Risk and Protective Factors that Affects Adolescents Reproductive health in Developing Countries: A structured Literature review. Global Public Health.

[8]. Nomhle Kangootui. Namibian Newspaper, 14 July 2016. Pregnancy statistics in Namibia. Windhoek.

[9]. National Statistical Office United Nations Children’s Fund. (2008). Teenage Pregnancy and Motherhood. Malawi.

[10]. Olumide, A. O., Robinson, A. C., Levy, P. A., Mashimbye, L., Brahmbhatt, H., Lian, Q., Blum, R. W. (2014). Predictors of Substance use among Vulnerable Adolescents in five cities: findings from the well being of Adolescents in Vulnerable Environments Study. The Journal of Adolescent Health : Official Publication of the Society for Adolescent Medicine, 55(6 Suppl), S39-47. http://doi.org/10.1016/j.jadohealth.2014.08.024.

[11]. Omar, K., Hasim, S., Muhammad, N. A., Jaffar, A., Hashim, S. M., \& Siraj, H. H. (2010). Adolescent Pregnancy Outcomes and Risk factors in Malaysia. http://doi.org/10.1016/j.ijgo.2010.06.023

[12]. Thornberry, T. P., Krohn, M. D., Augustyn, M. B., Buchanan, M., \& Greenman, S. J. (2015). The impact of Adolescent risk behavior on Partner Relationships. Advances in Life Course Research. http://doi.org/10.1016/j.alcr.2015.04.002

[13]. UNICEF. (2012). Progress for Children: A Report Card on Adolescents, No 10, April 2012.

[14]. UNFPA(2013). World Population Day the United Nations Population Fund.

[15]. USAID (2011). Teenage Pregnancy in Kavango Region. Contributing Factors and. Program Recommendations.

[16]. WHO (2014). Adolescent Pregnancy Fact Sheet, Department of Reproductive Health and Research, Geneva, Switzerland. 


\title{
Risk Factors for Contracting Malaria in Nvanga District, Zimbabwe: a Case Control Study
}

\author{
Article by Mashizha $\mathrm{S}^{1}$, Gombe $\mathrm{N} \mathrm{T}^{2}$, Gunda $\mathrm{T}^{3}$ \\ ${ }^{2}$ Ph.D. in Public Health, Texila America University, International Organisation for \\ Migration, Zimbabwe \\ E-mail: ${ }^{2}$ tgombe@Gmail.com
}

\begin{abstract}
Introduction: A review of Nyanga District malaria weekly surveillance data showed that malaria cases had surpassed the thresholds from week 4 confirming that an outbreak was underway. We investigated the outbreak to determine risk factors associated with contracting malaria.

Methods: A 1:1 Unmatched Case control study was carried out in Nyanga district. Interviewer administered questionnaires and WHO adapted Integrated Disease Surveillance and Response (IDSR) checklists were used to collect information on risk factors and on outbreak response. Data were analysed using Epi-Info 7 statistical software.

Results: Eighty three cases and 83 controls were enrolled into the study. Most (76\%) of the under 5 year cases came from villages across the border in Mozambique. Presence of stagnant water bodies near home [OR=11.06; 95\%CI $(2.32 ; 52.68)]$ was associated with contracting malaria. Consistently sleeping under a net [OR=0.13; 95\% CI (0.03; 0.59)] Use of mosquito repellents $[O R=0.16 ; 95 \%$ CI $(0.04 ; 0.58)]$ and having received health education on malaria in the past year $[O R=0.19 ; 95 \%$ CI $(0.07 ; 0.52)]$ were protective against contracting malaria.

Conclusion: The district was not prepared for the outbreak and the outbreak mainly affected children under five years from Mozambique. The risk factor for contracting malaria during the outbreak was presence of stagnant water bodies near homes which facilitated breeding of the vector. Consistently sleeping under a mosquito net, use of mosquito repellents and reported history of receiving health education on malaria in the past year were protective. As a result of this study health education was given to the community.
\end{abstract}

Keywords: Thresholds, Malaria, Case Control, Risk Factors

\section{Introduction}

Malaria is a disease caused by infection of the red blood cells with the protozoan parasites Plasmodium. There are four Plasmodium species that infect humans: P. falciparum, P. vivax, $P$. ovale and $P$. malariae. $P$. falciparum is the most virulent of the plasmodia and is responsible for majority of infections in Africa. The disease is transmitted through a bite from an infected female anopheles mosquito ${ }^{1}$.

Malaria can present as uncomplicated or complicated malaria. Uncomplicated malaria usually presents with fever, chills, general body weakness, headache and joint pains and at times abdominal pains and diarrhoea. Complicated malaria presents with any signs and symptoms of uncomplicated disease plus any of the danger signs which includes convulsions, coma, severe pallor, jaundice, inability to drink and passing dark or little urine. Complicated malaria is an emergency and is associated with high morbidity and mortality ${ }^{2}$. Malaria diagnosis is made through malaria parasite slide (MPs) and the Rapid Diagnostic Test (RDTs). In Zimbabwe, uncomplicated malaria is treated with Coartemether, Quinine and Doxycycline or Clindamycin while complicated with parenteral Quinine. ${ }^{2}$

Malaria is both preventable and curable, and mosquito bites can be averted. The disease can be eliminated, but resurgence is always a possible threat. Malaria control intervention 
strategies are case management, vector control, surveillance and research, social mobilization and advocacy and emergency preparedness and response.

Vector control methods used are use of insecticide treated nets (ITN), indoor residual spraying (IRS), environmental management and larviciding ${ }^{3}$.

Globally, 300-500 million malaria cases are recorded annually, and 90\% of these occur in Sub Saharan Africa. Between 1.1-2.7 million people die annually from malaria, and more than one million are children under five years. ${ }^{4}$

In 2010, the World Health Organisation (WHO) estimates that there were 3.3 billion people at risk of malaria and 216 million cases were reported; of these $81 \%$ were in Sub Saharan Africa ${ }^{5}$. Of the estimated 655,000 people who died of malaria, 91\% were in SubSaharan Africa and $86 \%$ children under 5 years ${ }^{5}$.

Most people at risk of malaria in Africa live in areas where transmission is intense and continuous. They develop some degree of immunity to the disease with age and children under 5 years and pregnant women are most at risk ${ }^{4}$. A smaller proportion of people live in areas of seasonal and unstable transmission. They have lower levels of immunity and hence all age groups are vulnerable to seasonal transmission and epidemics ${ }^{4}$.

In Zimbabwe malaria is a public health concern. More than half of the population resides in malaria transmission risk areas. Out of the 56 districts, malaria transmission occurs in $42^{6}$. This stratification was done in 2002 based on the national parasite prevalence survey, health management information system data, entomological data and expert opinion. ${ }^{6}$

Zimbabwe is divided into three strata. Free malaria transmission areas, where there is no local transmission, unstable malaria transmission areas were transmission is seasonal and low. These areas are prone to epidemics because the population does not have some degree of immunity to malaria and all age groups are at risk. Stable transmission areas are highly endemic and the local people develop some degree of immunity. Children under 5 years, pregnant women are most affected and are at risk of developing complicated malaria. ${ }^{6}$

Nyanga is one of the seven districts in Manical and Province. It borders with Mutoko District to the north, Mutasa District to the south and Mozambique to the east. It is characterised by moderate transmission of malaria which is seasonal. Most of the malaria cases are seen at Rural Health Centres (RHC) centres. Complicated cases are referred to the three hospitals in the district.

The malaria control measures being implemented in Nyanga include vector control through indoor residual spraying (IRS) and distribution of long lasting insecticide treated nets (LLITNs), intermittent preventive therapy (IPT) in pregnant women and case management. The district also distributes anti-malaria drugs and malaria tests kits (RDT) to community based health workers who include Village Health Workers (VHW) and ACT Holders. In addition, there is continuing health education to the community about malaria related issues.

Chatindo clinic is situated $80 \mathrm{~km}$ from Nyanga district hospital. The estimated clinic catchment population is 5750. It is situated in ward 11. The clinic's attachment area includes wards 11 and part of ward 10 . The clinic is situated within a walking distance from the international border with Mozambique, so people who live along the border on the Mozambican side use this health facility. The referral center for the clinic is Regina Coeli Mission Hospital.

A review of the Nyanga District Malaria Weekly Disease Surveillance System (WDSS) data revealed that malaria cases at Chatindo clinic had surpassed the thresholds from week 4. For weeks four to six the clinic recorded 88; 114 and 108 cases of malaria against thresholds of 81; 52 and 96 respectively (Figure 1). The district Rapid Response Team went to investigate on the $2^{\text {nd }}$ of February 2013 and confirmed an outbreak. We investigated the outbreak to determine risk factors associated with contracting the disease. 
Texila International Journal of Public Health

Volume 4, Issue 4, Dec 2016

\section{Materials and Methods}

An unmatched 1:1case-control study was carried out at Chatindo Rural Health Centre and its catchment area among residents of Chatindo ward and those residing in the clinic's catchment area. A case was defined as a person residing in Chatindo or the clinic's catchment area, who presented to Chatindo clinic with sudden onset of intermittent fever with shivering, sweating, headache, joint and muscle pains, nausea and vomiting, chills and body weakness and would have been diagnosed of malaria using rapid diagnostic test (RDT) during the period 20 January 2013 to 24 February 2013 and a control as a person residing in Chatindo or the clinic's catchment area who was attended at the clinic during the period 20 January 2013 to 24 February 2013 and tested negative for Malaria using malaria rapid diagnostic test.

A sample size of 166 respondents comprising 83 cases and 83 controls was calculated using Epi Info 7 with the following assumptions, 36.4\% exposure in controls and 59.15\% exposure in cases that stay in a house that was not sprayed, Odds Ratio of 2.53 (Maenzanise et al 2004), 95\% confidence and $80 \%$ power.

Cases were selected from the clinic register. A list containing all malaria cases seen at Chatindo clinic from 20 January 2013 to 24 February 2013 was prepared and used as a sampling frame. Individual cases were selected randomly from the sampling frame using random number tables until 83 cases were selected. Controls were also selected from the same register. A list of people who were attended at the clinic from 20 January 2013 to 24 February 2013 who did not develop malaria and tested negative for malaria using RDT was prepared and used as a sampling frame. Individual controls were selected randomly using random number tables until 83 controls were selected. Controls that were selected from the T12 register that came from Mozambique were called to the clinic for interviews using village health workers and those that resided in Zimbabwe were followed to their homes.

Permission to conduct the study was sought from the Provincial Medical Director (PMD) Manicaland Province, the District Medical Officer Nyanga and the Health Studies Office. Informed written consent was obtained from all participants. Participants' right to participate was respected. All information was kept confidential and completed questionnaires were kept under lock and key and permission to take pictures was sought and obtained from individual participants.

Interviewer administered questionnaires were used to collect data on demographic characteristics, risk factors, details of illness and treatment given. The questionnaire was also used to assess knowledge, attitudes and practises of cases and controls towards malaria prevention. Data on practices which included personal protection methods, use of mosquito repellents, presence, condition and use of insecticide treated mosquito nets were also collected. Medical records were reviewed to verify data on the treatments given and an Integrated Disease Surveillance and Response (IDSR) adapted check list was used to assess preparedness of district health team in malaria outbreak.

Pre testing of the study was done one week before carrying out the study at Nyamaropa clinic which is situated $10 \mathrm{~km}$ from Chatindo clinic. Data collection tools were assessed for the quality of answers to the questions, the time needed to administer the questionnaire, the willingness of respondents to answer questions and appropriateness of the answers and adjustments were made accordingly.

Epi Info statistical software was used to analyse data. We performed chi-square test for association; calculate odds ratios and their confidence intervals as well as p-values. Stratified analysis was carried out to check and control for confounders and assess for effect modification. Multivariate analysis (logistic) regression was used to identify independent risk factors for contracting malaria and to control for confounding variables

\section{Results}

Eighty three cases and 83 controls were enrolled into the study. The outbreak started in week in week 4 of 2013 when the clinic recorded 108 malaria cases against a threshold of 88 
and was only detected in week 5 by the District Health Information Officer when he calculated the thresholds for the Clinic. It was declared over in week 10 (figure1).

Socio- demographic characteristics of Cases and Controls were comparable, there was no statistical significant difference between cases and controls on variables age group, sex, Occupation, place of residence and level of education (Table 1).

Knowledge of controls on malaria was better than of cases. There were statistical significant differences on knowledge among cases and controls on malaria prevention practices.

Socio demographic characteristics associated with contracting Malaria in Chatindo were age less than five years OR 3.24 (0.84-12.44), place of residence in Mozambique OR $1.27(0.58-2.78)$ and male sex OR $1.37(0.72-2.59$ though not statistically significant however reported history of receiving health education on Malaria in the past year OR $0.15(0.07-0.30)$ was significantly protective against contracting Malaria

Personal and environmental factors associated with contracting malaria in Chatindo were potential stagnant water body around home OR 5.9(2.50-13.80), presence of tall grass and bushes around home OR 2.63(0.89-7.86), irrigating during the evening OR 2.12(1.07-4.21), sitting outside the house at night OR 2.20(1.15-4.20) and wearing short sleeved clothes during the night OR 5.7(2.25-13.47) were significantly associated with contracting Malaria. However reported sleeping under a mosquito net OR 0.31(0.16-0.63), reported consistently sleeping under a mosquito net OR 0.16(0.04-0.56), staying in a house that was sprayed in the last IRS season OR $0.46(0.21-0.97)$ and use of mosquito repellents $0.17(0.07-0.40)$ was protective

On logistic regression, presence of stagnant water bodies near the homestead OR 11.06(2.32-52.68), consistently sleeping under a mosquito net OR 0.13(0.03-0.59), use of mosquito repellents OR 0.16(0.04-0.58) and having received health education in the past year OR $0.19(0.07-0.52)$ were factors independently associated with contracting malaria in this study (Table 2).

The common presentation signs and symptoms were headache (73.5\%) followed by fever (49.4\%) general body weakness (45.8\%), shivering (25.3\%), muscle and joint paints (22.9\%) and nausea and vomiting (13.3\%) the least was diarrhea(1.2\%) (Figure 2). All cases were diagnosed using RDT and were managed on Coartemether as per national malaria treatment guidelines. There were no reported complications or fatalities among cases interviewed.

Regarding Malaria outbreak preparedness, health workers had not been trained in IDSR, there were no IDSR guidelines at the clinic, malaria thresholds were not in place, and EPR plans were not in place before, during and after the outbreak. Malaria thresholds were not in place they were only calculated at the district and send to the clinic on 30 January 2013. The IRS coverage (76\%) was below the program target of $85 \%$.

\section{Discussion}

In this study majority of the cases came were imported. Children under five years are at increased risk of contracting malaria because their immune system is still developing ${ }^{4}$. So in a community like Mozambican villages were malaria vector control interventions (IRS and Mosquito net distribution) are non-existent, children under five years are at more risk of contracting malaria than the general population. This could explain the high proportion of cases in the less than five years age group coming from Mozambique. Malaria vector control interventions like IRS and Net distribution which were done in Chatindo in November 2012 and August 2010 respectively were not done on the Mozambican side despite the close proximity of these communities.

Mosquito net usage and staying in a house that was sprayed in the last IRS season were significantly protective against contracting malaria. This could explain the high proportion of cases from Mozambique. These finding are consistent with findings by Mpofu et al in 2006 identified consistently sleeping under a net and staying in a house that was sprayed (IRS) as significantly protective against contracting malaria. ${ }^{8}$ 
From the villages in Zimbabwe, the majority of the cases came from the Irrigation areas A and B, and it mainly affected the economic active age group 15 years and above. This age group is involved in the farming activities in the irrigation area and in some instances people knock off from the fields after dawn and irrigate during the night. Evening outdoor activities like irrigating in the evening or during the night were found in the study as a significant risk factor for contracting malaria in Chatindo. This could explain the higher proportion of cases in the age group 15 and above contracting malaria in the irrigation areas. Dhege and others in 2012 also found irrigation/watering at night as a significant risk factor for contracting malaria $^{10}$.

Controls were more knowledgeable on malaria prevention practices than cases. Having received health education on malaria in the past year was protective against contracting malaria in this study. Health education can result in malaria prevention practices like consistent use of a net and uptake of IRS which have been found to be protective in this study and eliminating potential breeding sites by filling of stagnant water bodies and potholes near home and cutting tall grass and bushes around home which were significant risk factor for contracting malaria in this study. Provision of health education on malaria can result in increased awareness on malaria prevention practices, of which when done will result in reduced risk of contracting the disease.

Presence of stagnant water bodies near home was significantly associated with contracting malaria in the study. This is similar to finding by Marape and others in 2008 who also found stagnant water bodies near home as risk factors for contracting malaria. ${ }^{7}$

Rains also promote the growth of bushes and grass around homes which also provides resting places for adult mosquitoes as well as breeding places. Thick vegetation, tall grass and bushes around the home were also identified as a risk factor for contracting malaria in Chatindo. This is consistent with findings by Chikwanha and others in 2010 in Mazowe malaria outbreak investigation that identified presence of tall grass and thick vegetation around home as a significant risk factor for contracting malaria. ${ }^{9}$

Under 5 year age group was associated with contracting Malaria, so malaria prevention interventions like mosquito net distribution should target under five years old children.

Chatindo clinic was not prepared for the malaria outbreak. Heath workers were not trained in IDSR, there were no IDSR guidelines at the clinic, malaria thresholds were not in place, and Epidemic Preparedness and Response (EPR) plans were not in place before, during, and after the outbreak. Malaria thresholds were not in place they were only calculated at the district and send to the clinic on 30 January 2013 after the outbreak had started. This shows lack of supervision by the DHE which is supposed to make sure that EPR plans and epidemic thresholds are in place at all clinics. This will prevent late detection of the outbreaks which can result in morbidity and mortality that could be prevented by early detection and prompt appropriate interventions.

Although IRS was carried out in Chatindo, the coverage was low (76\%) for public health impact, for a public health intervention to achieve desirable outcome the coverage should be at least above $85 \%$. This was due to refusals and locked rooms. Some of the reasons were that people were busy in the fields and the chemical was not effective because it was not killing the cockroaches.

There are no structures for inter district collaboration between Nyanga district and Mozambique, This makes it difficult to coordinate vector control interventions between Nyanga district and Mozambique. In order to harmonize malaria control interventions structures for collaboration should be put in place first.

\section{Conclusion}

Chatindo Clinic was not prepared for the outbreak and the risk factor for contracting malaria during the outbreak in Chatindo was presence of stagnant water bodies near homes. However, consistently sleeping under a mosquito net, use of mosquito repellents and reported history of receiving health education on malaria in the past year were protective. 
Texila International Journal of Public Health

Volume 4, Issue 4, Dec 2016

\section{Recommendations}

In view of the findings, sstructures for collaboration between Nyanga District and Mozambique should be put in place to enable harmonisation of malaria vector control intervention such as IRS and ITNs in the two districts. All clinics should have malaria epidemic thresholds in place to improve outbreak preparedness and the District Medical Officer should arrange for IDSR trainings and ensure that emergency preparedness and response plans are in place at all clinics so as to detect outbreaks early.

\section{References}

[1] Chikwanha TM, Chinhengo TP, Hanyana N : Malaria Outbreak Investigation Mazowe District Mashonaland Central Province, Zimbabwe 2010 (Unpublished)

[2] Centre for Disease Control and Prevention. Malaria accessed from www.cdc.gov/malaria/about/facts.html on 14/02/13

[3] Dhege C, Zizhou S T, Muyengwa P. Malaria Outbreak investigation in Mudzi District 2012.(unpublished)

[4] Ministry of Health and Child Welfare, Zimbabwe: Preliminary Malaria Stratification Report, 2002 accessed from www.rbm.who.int/countryaction/.../naZimbabwe.pdf on 14/02/13

[5] Marape G, Mpeta ET, Ndlovu N: Factors associated with contracting malaria at Mbembeswana, 10 March to 25 April 2008, Zimbabwe (Unpublished)

[6] Mpofu M, Nkomo B.M.M, Kulkarni R, Mabaera B: Malaria Outbreak in Tsholotsho District in Matabeleland North Province, Zimbabwe, 2006 (Unpublished)

[7] Ministry of Health and Child Welfare Zimbabwe: World Health Organisation, United Nations Development Programme and the Global Fund. Guidelines for Management of Malaria in Zimbabwe, Revised December 2009.

[8] Ministry of Health and Child Welfare, World Health Organisation, united nations Development Programme and the Global Fund. Guidelines for management of malaria in Zimbabwe, revised December 2009.

[9] Maenzanise S R, Kusangaya O, Chirenda J, Tshimanga M : Malaria Outbreak Investigation In Msampakaruma, Kariba District, 2004 (Unpublished)

[10] Rasheed S. et al (2000), Economic impact of febrile morbidity and use of permethrinimpregnated bed nets in a malarious area II, Determinants of febrile illness and the cost of their treatment and malaria prevention,. AMJ Trop. Med Hyg. 62: 181-6

[11] WHO: Guidelines for treatment of malaria, Second edition, WHO Library Cataloguing in Publication Data, 2010.

[12] WHO: A commitment to supporting national programs for greater coverage of Malaria control interventions, Annual Report 2006, World Health Organization, 2006

[13] WHO: Malaria Case Management Operational Manual, World Health Organization, Geneva, 2009

[14] World Health Organization :World Malaria Report, 2011, Geneva, 2011

[15] World Health Organization, Global Malaria Action Plan, Roll Back Malaria Partnership, World Health Organization, Geneva, 2008 accessed from http://rbm.who.int/gmap/2-3.html on 14/01/13 
Texila International Journal of Public Health

Volume 4, Issue 4, Dec 2016

\section{Tables and figures}

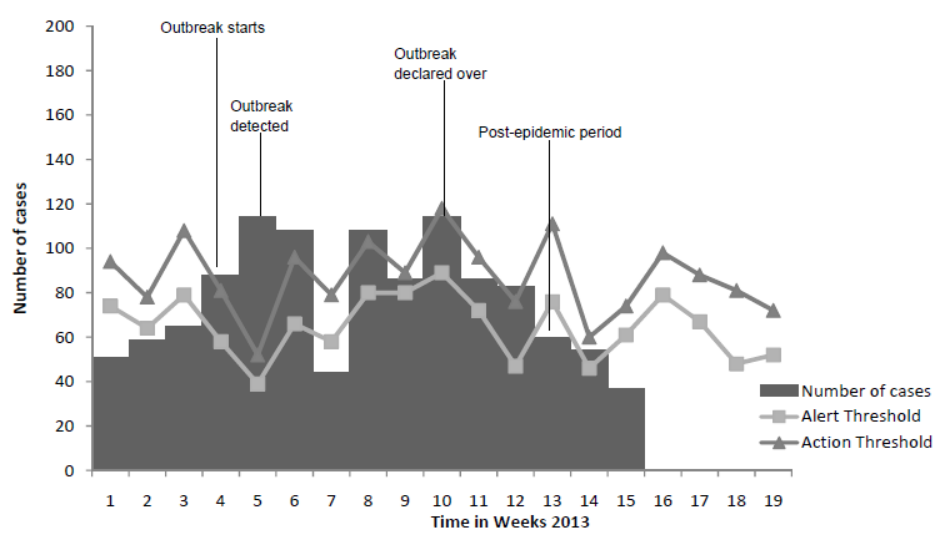

Figure 1:Distribution of Malaria Cases against the Thresholds in Chatindo 2013

Table 1: Demographic Characteristics of Cases and Controls in Chatindo Malaria Outbreak Investigation in 2013

\begin{tabular}{|c|c|c|c|c|}
\hline Variable & Category & $\begin{array}{c}\text { Cases } \\
n=83(\%)\end{array}$ & $\begin{array}{c}\text { Controls } \\
n=83(\%)\end{array}$ & P-value \\
\hline \multirow[t]{2}{*}{ Sex } & Male & $32(39.8)$ & $27(32.5)$ & 0.33 \\
\hline & Female & $50(60.2)$ & $54(67.5)$ & \\
\hline \multirow[t]{3}{*}{ Educational level } & None & $15(18.1)$ & 11(13.3) & 0.51 \\
\hline & Primary & $36(43.4)$ & $43(51.8)$ & \\
\hline & Secondary & $32(38.5)$ & $29(34.9)$ & \\
\hline \multirow[t]{4}{*}{ Religion } & Apostolic & $24(28.9)$ & $32(38.6)$ & 0.02 \\
\hline & Pentecostal & $31(37.3)$ & $22(26.5)$ & \\
\hline & Orthodox & $14(16.9)$ & $24(28.9)$ & \\
\hline & None & $14(16.9)$ & $5(6.0)$ & \\
\hline \multirow[t]{2}{*}{ Occupation } & Formal & $7(8.4)$ & $9(10.8)$ & 0.50 \\
\hline & Informal & $76(91.6)$ & $74(89.2)$ & \\
\hline \multirow[t]{5}{*}{ Age group } & $<5 y e a r s$ & $9(10.8)$ & $3(3.6)$ & 0.13 \\
\hline & $5-14$ yrs & $27(32.5)$ & $19(22.9)$ & \\
\hline & $15-24 y r s$ & $17(20.5)$ & $17(20.5)$ & \\
\hline & $25-49$ yrs & $21(25.3)$ & $32(38.6)$ & \\
\hline & $50+$ yrs & $9(10.8)$ & $12(14.5)$ & \\
\hline \multirow{4}{*}{ Place of Residence } & Irrigation A & 24(28.9) & 33(39.80 & 0.06 \\
\hline & Irrigation B & $25(30.1)$ & $30(36.10$ & \\
\hline & Mozambique & $17(20.5)$ & $6(7.2)$ & \\
\hline & Nyadowa & $17(20.5)$ & $14(16.9)$ & \\
\hline
\end{tabular}

Table 2: Factors independently associated with Contracting Malaria in Chatindo, 2013

\begin{tabular}{llll}
\hline \multicolumn{1}{c}{ Factor } & $\begin{array}{c}\text { Crude Odds Ratio } \\
\text { (95\%CI) }\end{array}$ & $\begin{array}{c}\text { Adjusted Odds Ratio } \\
\text { (95\%CI) }\end{array}$ & P-value \\
\hline $\begin{array}{l}\text { Presence of stagnant water } \\
\text { bodies near homestead }\end{array}$ & $5.9(2.50-13.80)$ & $\mathbf{1 1 . 0 6}(2.32-52.68)$ & 0.003 \\
$\begin{array}{l}\text { Reported consistently sleeping } \\
\text { under a mosquito net }\end{array}$ & $0.16(0.04-0.56)$ & $\mathbf{0 . 1 3}(0.03-0.59)$ & 0.008 \\
$\begin{array}{l}\text { Use of mosquito repellents } \\
\begin{array}{l}\text { Receiving health education on } \\
\text { malaria in the past year }\end{array}\end{array}$ & $0.17(0.07-0.40)$ & $\mathbf{0 . 1 6}(0.04-0.58)$ & 0.005 \\
\hline
\end{tabular}


Texila International Journal of Public Health

Volume 4, Issue 4, Dec 2016

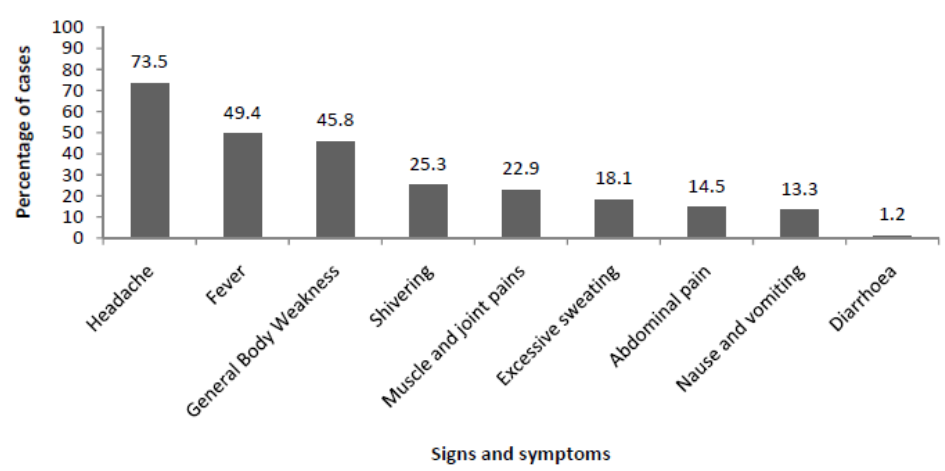

Figure 2: Presenting Signs and Symptoms for Malaria Cases in Chatindo 2013

Table 3: Treatment Given to Malaria Cases at Chatindo Clinic, Nyanga during the Outbreak in 2013

\begin{tabular}{lll}
\hline \multicolumn{1}{c}{ Treatment given } & $\mathbf{n = 8 3}(\mathbf{\% )}$ \\
\hline Coartemether & $83(100)$ & \\
Cases attended by nurses & $67(80.7)$ & \\
Cases attended by nurse aides & $16(19.3)$ \\
Paracetamol & $69(83.1)$ \\
Intravenous quinine & 0 \\
Intravenous fluids & 0 \\
Complications & 0 \\
Case fatality & 0 & \\
\hline
\end{tabular}

Table 4: Nyanga District Outbreak Response, 2013

\begin{tabular}{llll}
\hline \multicolumn{1}{c}{ Indicator } & Target & $\begin{array}{c}\text { Achieved } \\
\text { timeliness }\end{array}$ & \multicolumn{1}{c}{ Comments } \\
\hline $\begin{array}{l}\text { Outbreak identification and } \\
\text { reporting to district level }\end{array}$ & within 24hrs & Nil & $\begin{array}{l}\text { Outbreak was detected by } \\
\text { the DHE 48hrs later } \\
\text { (Delayed) }\end{array}$ \\
$\begin{array}{l}\text { District notification and field } \\
\text { investigation }\end{array}$ & within 48hrs & $72 \mathrm{hrs}$ & $\begin{array}{l}\text { DHE visited healthcare } \\
\text { centres to verify outbreak } \\
\text { (delayed) } \\
\text { Poor response }\end{array}$ \\
$\begin{array}{l}\text { District level concrete } \\
\text { response by district }\end{array}$ & within 48hrs & 96 hours & Achieved \\
$\begin{array}{l}\text { Start of outbreak and } \\
\text { submission of outbreak } \\
\text { report to higher levels }\end{array}$ & within 2weeks & 10 days & \\
\hline
\end{tabular}




\title{
Perception of Health Care Workers on Prevention and Treatment of Uncomplicated Malaria in Pregnancy
}

\author{
Article by Vakkai Dominic Esther \\ Master of Public Health, Texila American University, Nigeria \\ E-mail:vakkai8@gmail.com
}

\begin{abstract}
Introduction: Malaria is the commonest endemic disease, and the most vulnerable group of persons affected by malaria is the pregnant women. This has posed serious public health challenge in Nigeria; it is with these considerations that the Nigerian Government in the past few years has renewed efforts towards controlling malaria. Several interventions have been introduced amongst which were the introductions of Artemisinin-based combination therapies (ACTs) and massive distribution of long lasting insecticidal nets. Statistic has shown that 8 million women are pregnant every year in Nigeria and about 545 women out of every 100,000 die as a result of pregnancy-related complications.

Objectives: This study was done to ascertain the Diagnosis and treatment characteristics of malaria in pregnant women and assessed the training, work experience, knowledge, and perception of health workers regarding malaria in pregnancy, in North Western Nigeria.

Method: Arandom sampling method was carried out across 10 local governments and 15 health facilities in North Western Nigeria. Two participants from each facility gave a total of 300 health care workers recruited into this study.

Results: $91 \%$ of the participant believe that RDT /microscopy is the appropriate test for malaria; $38 \%$ of them agree that the test miss malaria cases while 14\% believe that treatment should be given to a client that test Negative to either of the test. 37\% of the participant prescribed Quinine, while $48 \%$ of the participant will prefer ACT and the least $2 \%$ will still go for Chloroquine.

Conclusion: This study exposed the under-diagnosis as well as miss treatment of malaria in pregnancy and the need for training and retraining of health care workers as well as establishing the malaria diagnosis quality assurance program to ensure the accuracy of malaria microscopy and RDT results at all levels.
\end{abstract}

\section{Acronyms meaning}

$\begin{array}{ll}\text { ACT } & \text { Artemisinin-based Combination Therapy } \\ \text { ANC } & \text { Antenatal Care / Clinic } \\ \text { CHEW } & \text { Community Health Extension Worker } \\ \text { JCHEW } & \text { Junior Community Health Extension Worker } \\ \text { CHO } & \text { Community Health Officer } \\ \text { DOT } & \text { Directly Observed Therapy / Treatment } \\ \text { HIV } & \text { Human Immunodeficiency Virus } \\ \text { IPT } & \text { Intermittent Preventive Treatment } \\ \text { LLIN } & \text { Long Lasting Insecticidal Net } \\ \text { mRDT } & \text { Malaria Rapid Diagnostic Test } \\ \text { SP } & \text { Sulphadoxine -Pyrimethamine } \\ \text { EPI } & \text { Expanded Programme on immunization }\end{array}$


Texila International Journal of Public Health

Volume 4, Issue 4, Dec 2016

\section{Introduction}

\section{Burden of Malaria}

Malaria is highly endemic in Nigeria and poses a major health challenge with attendant risk of morbidity and mortality contributing to loss of productivity and economic development 4. In 2004, the Federal Government of Nigeria adopted prevention of Malaria in Pregnancy intervention as a component of Focused Antenatal Care with a view to drastically reduce the burden of malaria in the country. Though the provision of malaria preventive services has been free in all public facilities, across the country, the utilization has remained low due to the consistently low antenatal attendance, especially in some states in northern Nigeria where ANC attendance is still less than $30 \%$ (NDHS, 2013). The 2008 NDHS showed an average of $43.7 \%$ and $76.9 \%$ ANC attendance by rural and urban dwellers respectively. This improved slightly to $46.5 \%$ and $86.0 \%$ in 2013 . This makes the administration of the intervention difficult in higher prevalence rural areas as it is primarily facility based at present and requires supervision by skilled health care providers. However, new strategies are being developed to involve the communities in the intervention(5)

\section{Problems associated with malaria in pregnancy}

Pregnancy increases the frequency and severity of most infectious diseases but its effect on malaria seems worse (3). Several theories have been put forward to explain this increased risk including changes to the cellular immune responses that otherwise should offer protection, and increased attractiveness of the pregnant woman to mosquitoes. The former is believed to result from the increased level of circulating maternal steroids in pregnancy (20). This was the subject of the extensive research by Bouyou-Akotet et al in which they surmised that a sustained increase in cortisol level underlies the increased susceptibility of pregnant women to malaria (1) Lindsay et al found that pregnant women attracted twice the number of anopheles' mosquito compared to their non-pregnant counterparts.

The National Malaria Control Program (NMCP) in Nigeria has been in the forefront of managing malaria and is the permanent policy for prevention, and control of the disease in the country. The control rationale focuses on prompt access to the parasitological diagnosis and the provision of the appropriate treatment. Considering the recommended treatment for uncomplicated malaria infection in pregnancyas part of efforts aimed at eliminating cases of Malaria attack in the country by half and deepening the understanding of modern malaria treatment methods the Federal Ministry of Health has announced a name change for its anti-malaria programme from a control program, to Nigerian Malaria Elimination Programme (NMEP).

There have been collaborative efforts, spearheaded by the World Health Organization (WHO) and including governments and allied agencies to tackle the problem of malaria in pregnancy. The leading efforts have been: to increase the use of Long Lasting Insecticide Net (treated mosquito nets). Intermittent preventive treatment of malaria [IPT]; testing all pregnant women presenting with fever using RDT or Microscopy, and adequate case treatment of acute malaria attacks in pregnancy. The need to confirm malaria before treatment and enforcement of completion of therapy once started.

\section{Consequences of malaria in pregnancy}

Malaria in pregnancy is associated with increased risks of maternal anemia, spontaneous abortion, low birth weight, premature delivery, congenital infection, and neonatal and/or maternal death (13). Malaria can occur in pregnancy even when the woman does not have malaria symptoms, in hightransmission settings, where levels of acquired immunity tend to be high, P. falciparum infection is usually asymptomatic in pregnancy. Yet, parasites may be present in the placenta and contribute to maternal anaemia even in the absence of documented peripheral parasitism(29) The symptoms and complications of malaria in pregnancy vary according to malaria transmission intensity in the given geographical area, and the individual's level of acquired immunity. Malaria infection during pregnancy poses substantial risk to the mother, her foetus, and the neonate. The prevalence of 
parasitaemia appears greatest in the second trimester, and susceptibility to clinical malaria may persist in to the early postpartum period. Due to the endemicity and high transmission rate of malaria in Nigeria, pregnant women have acquired partial being resident in stable malaria area and are susceptible to sub infections, which may result in adverse effects to both mother and child It significantly contributes to anaemia in pregnancy, increases the occurrence of low birth weights and is associated with preterm deliveries, still births and perinatal mortality. Preventing severe anaemia caused by malaria will lead to fewer pregnant women requiring blood transfusion thereby reducing the risk of transfusion-related infections especially HIV and Hepatitis B. The adequate control of malaria in pregnancy should lead to a better outcome of pregnancy, improve survival of mothers and reduce perinatal mortality. Adverse consequences of malaria during pregnancy of stable transmission (31). Malaria in pregnancy has adverse consequences both to the mother and the foetus

All pregnant women should receive at least 3 doses of Sulphadoxine-Pyrimethamine (SP) as Intermittent Preventive Treatment (IPT) except where contraindicated. All pregnant women should sleep under Long Lasting Insecticide Nets (LLINs). This preventive measure against malaria should be encouraged. Pregnant women with symptoms of malaria should be promptly diagnosed and treated(5).

\section{Method}

\section{Study site}

This study was conducted in 10 local government and 15 health facilities per LGA. Each Facility had 2 participants from the rural health districts selected by random sampling, in north central of Nigeria in September 2016. A well-established collaboration exists between the researcher, the State Ministry of Health and the health unit of the Local Government (LG). At the time of commencing this study, these groups of participant were given training on MIP. Each of this health centers offers ANC for pregnant mothers and are manned by experienced community extension workers.

\section{Sites Selection}

A site is referred to a health facility giving Anti-natal services to pregnant mothers. This can be a general hospital, maternity hospital, primary health care center, comprehensive health center, specialist or teaching hospital. The selections of these sites were based on the following criteria;

- The health facility offers anti-natal care to pregnant women,

- The client inflow for the month is above 100 ,

- It is supported by any of the malaria partners in the state.

- Availability of qualified staff and willingness of the personnel to be part of the survey.

\section{Survey design and sample size}

A cross sectional descriptive study is conducted in Kano state. Random sampling method was carried out across 10 local governments and 15 health facilities in North Western Nigeria. Two participants from each facility gave a total of 300 health care workers recruited into this study

\section{Data collection}

A well designed self-administered questionnaire was passed to selected participant who are all community extension workers, as well as health workers who attend to pregnant women at ANC. Their consent was obtained before they were given the questionnaire by the research assistant and the researcher. This questionnaire explored respondent knowledge on diagnosis on malaria in pregnancy, it treatment as well as current preventive measures practice and approved by the national guidelines. The questionnaire was pretested and validated before the commencement of the study. 


\section{Result}

\section{Frequency table}

\section{Survey Participants}

A total of 300 respondents aged 20-60 years of age were involved in the research more than half $52.7 \%$ are Male while $47.3 \%$ of them are female.

\section{General characteristics of respondent}

\section{Age distribution}

In almost of the participants 39.7\% are of the age group 30-39 years while age group 40-49 and 2029 years constitute $29.6 \%$ and $24.9 \%$ respectively. The least percentage of $1.7 \%$, represent the age group 60years and above.

\section{Occupation}

$58.7 \%$ of the respondents are trained community health extension workers while Health Tech and Nurses constitute $33.3 \%$ and $1.0 \%$ respectively. Only 3.3\% of the respondents represent other profession.

\section{Educational status}

It was observed that most of the Participant $60.5 \%$ have obtain a certificate course while $35.7 \%$ and $1.3 \%$ have Diploma and BSC respectively which represent the highest qualification for this group. $1.7 \%$ of them have the least qualification.

\section{Work experience}

$25 \%$ of the respondents have had 1-2 years of work experience which is the minimum work experience while $21 \%$ has $6-10$ years' work experience. $18.7 \%, 18.3 \%$ are people with $16 y e a r s$ above and 3-5 years working experience

\section{Figures and tables}

\section{Biodata/work experience}

\begin{tabular}{|l|l|l|l|l|}
\hline $\mathrm{N}=300$ & Frequency & percent & $\begin{array}{l}\text { Valid } \\
\text { Percent }\end{array}$ & $\begin{array}{l}\text { Cumulative } \\
\text { Percent }\end{array}$ \\
\hline Gender & & & & \\
\hline Male & 158 & 52.7 & 52.7 & 52.7 \\
\hline Female & 142 & 47.3 & 47.3 & 100.0 \\
\hline Total & 300 & 100.0 & 100.0 & \\
\hline Age & & & & \\
\hline $20-29$ & 74 & 24.7 & 24.9 & 24.9 \\
\hline $30-39$ & 118 & 39.3 & 39.7 & 64.6 \\
\hline $40-49$ & 88 & 29.3 & 29.6 & 94.3 \\
\hline $50-59$ & 12 & 4.0 & 4.0 & 98.3 \\
\hline 60 above & 5 & 1.7 & 1.7 & 100.0 \\
\hline Total & 297 & 99.0 & 100.0 & \\
\hline $\begin{array}{l}\text { Missing } \\
\text { System }\end{array}$ & 3 & 1.0 & & \\
\hline Occupation & & & & \\
\hline Nurse & 3 & 1.0 & 1.0 & 1.0 \\
\hline Health Tech & 100 & 33.3 & 34.6 & 35.6 \\
\hline CHEW & 176 & 58.7 & 60.9 & 96.5 \\
\hline
\end{tabular}




\begin{tabular}{|l|l|l|l|l|}
\hline Others & 10 & 3.3 & 3.5 & 100.0 \\
\hline Total & 289 & 96.3 & 100.0 & \\
\hline $\begin{array}{l}\text { Missing } \\
\text { System }\end{array}$ & 11 & 3.7 & & \\
\hline $\begin{array}{l}\text { Educational } \\
\text { Status }\end{array}$ & & & & \\
\hline SSCE & 5 & 1.7 & 1.7 & 1.7 \\
\hline Diploma & 106 & 35.3 & 35.7 & 37.4 \\
\hline Certificate & 182 & 60.7 & 61.3 & 98.7 \\
\hline Bsc & 4 & 1.3 & 1.3 & 100.0 \\
\hline Total & 297 & 99.0 & 100.0 & \\
\hline System & 3 & 1.0 & & \\
\hline $\begin{array}{l}\text { Work } \\
\text { Experience }\end{array}$ & & & & \\
\hline $1-2$ & 76 & 25.3 & 26.3 & 26.3 \\
\hline-5 & 55 & 18.3 & 19.0 & 45.3 \\
\hline $6-10$ & 63 & 21.0 & 21.8 & 67.1 \\
\hline $11-15$ & 39 & 13.0 & 13.5 & 80.6 \\
\hline 16 above & 56 & 18.7 & 19.4 & 100.0 \\
\hline Total & 289 & 96.3 & 100.0 & \\
\hline System & 11 & 3.7 & & \\
\hline
\end{tabular}

\section{Diagnosing malaria in pregnancy}

In the diagnosis of malaria during pregnancy, about $50 \%$ of the respondents agree that patient who reacted positively to mRDT has malaria, $42 \%$ strongly agreed with $3.3 \%$ neutral, while $2.7 \%$ and $0.7 \%$ strongly disagree and disagree respectively.

On the perception that patients who react negative to mRDT have no malaria, $46.7 \%$ agree, $19.7 \%$ strongly agree, while $13.7 \%$ disagreed, and 5\% strongly disagree while $14 \%$ remained neutral.

$39 \%$ of respondents agree that mRDTs usually miss malaria cases, $5.7 \%$ strongly agree, while $35.3 \%$ and $7.3 \%$ disagreed and strongly disagreed respectively however 5\% are neutral.

$39 \%$ of respondents agree that negative mRDT result does not exclude malaria, $11 \%$ strongly agreed while $26.7 \%$ disagreed and $5.7 \%$ strongly disagreed that negative mRDT result does not exclude malaria.

On the confidence level of mRDT results, 53.3\% agreed and 30.7\% strongly agreed while $9.3 \%$ have no confidence in mRDT result with only $2.7 \%$ remained neutral

\begin{tabular}{|l|l|l|l|l|}
\hline N=300 & Frequency & Percent & Valid Percent & $\begin{array}{l}\text { Cumulative } \\
\text { Percent }\end{array}$ \\
\hline $\begin{array}{l}\text { Patients with +ve mRDT } \\
\text { has malaria }\end{array}$ & & & & \\
\hline Strong Disagree & 8 & 2.7 & 2.7 & 2.7 \\
\hline Disagree & 2 & .7 & .7 & 3.4 \\
\hline Neutral & 10 & 3.3 & 3.4 & 6.8 \\
\hline Agree & 150 & 50.0 & 50.7 & 57.4 \\
\hline Strong Agree & 126 & 42.0 & 42.6 & 100.0 \\
\hline Total & 296 & 98.7 & 100.0 & \\
\hline System & 4 & 1.3 & & \\
\hline $\begin{array}{l}\text { Patients with -ve mRDT } \\
\text { have no malaria }\end{array}$ & & & & 5.1 \\
\hline Strong disagree & 15 & 5.0 & 5.1 & \\
\hline
\end{tabular}


Texila International Journal of Public Health

Volume 4, Issue 4, Dec 2016

\begin{tabular}{|c|c|c|c|c|}
\hline Disagree & 41 & 13.7 & 13.8 & 18.9 \\
\hline Neutral & 42 & 14.0 & 14.1 & 33.0 \\
\hline Agree & 140 & 46.7 & 47.1 & 80.1 \\
\hline strong agree & 59 & 19.7 & 19.9 & 100.0 \\
\hline \multicolumn{5}{|c|}{$\begin{array}{l}\text { mRDTs Usually } \\
\text { malaria cases }\end{array}$} \\
\hline Strong Disagree & 22 & 7.3 & 7.9 & 7.9 \\
\hline Disagree & 106 & 35.3 & 38.3 & 46.2 \\
\hline Neutral & 15 & 5.0 & 5.4 & 51.6 \\
\hline Agree & 117 & 39.0 & 42.2 & 93.9 \\
\hline strong agree & 17 & 5.7 & 6.1 & 100.0 \\
\hline Total & 277 & 92.3 & 100.0 & \\
\hline System & 23 & 7.7 & & \\
\hline \multicolumn{5}{|c|}{$\begin{array}{l}\begin{array}{l}\text { Negative mRDT results } \\
\text { doesn't exclude malaria }\end{array} \\
\end{array}$} \\
\hline Strong Disagree & 17 & 5.7 & 6.1 & 6.1 \\
\hline Disagree & 80 & 26.7 & 28.8 & 34.9 \\
\hline Neutral & 30 & 10.0 & 10.8 & 45.7 \\
\hline Agree & 117 & 39.0 & 42.1 & 87.8 \\
\hline Strong Agree & 34 & 11.3 & 12.2 & 100.0 \\
\hline Total & 278 & 92.7 & 100.0 & \\
\hline System & 22 & 7.3 & & \\
\hline \multicolumn{5}{|c|}{$\begin{array}{l}\text { I have confidence in } \\
\text { mRDT results }\end{array}$} \\
\hline Strong Disagree & 2 & .7 & .7 & .7 \\
\hline Disagree & 28 & 9.3 & 9.6 & 10.3 \\
\hline Neutral & 8 & 2.7 & 2.7 & 13.1 \\
\hline Agree & 160 & 53.3 & 55.0 & 68.0 \\
\hline Strong agree & 92 & 30.7 & 31.6 & 99.7 \\
\hline 6 & 1 & .3 & .3 & 100.0 \\
\hline System & 9 & 3.0 & & \\
\hline
\end{tabular}

\section{Treatment of positive malaria cases}

The table below shows the perception of health workers on the treatment regimen for malaria by health workers. 146 out of 290 respondents agree that anti-mal drugs are justified for malaria cases, 109 respondents strongly agree on the justification for administration of anti-mal drugs in malaria cases. 25 respondents disagreed on the justification for anti-mal drugs in malaria cases.

About 129 respondents disagree that febrile patients should be treated with ACT without RDTs, 60 disagree strongly on treatment of febrile patients with ACT without RDT, while 62 persons agree on treatment irrespective of RDT.

On another vane, $43 \%$ disagree that they will take anti-mal drugs if they feel feverish without doing an mRDT, and $20 \%$ strongly disagree; on the hand, $20.7 \%$ agree to taking antimal-mal medication if they feel feverish without having a test done. 


\begin{tabular}{|l|l|l|l|l|}
\hline & Frequency & Percent & Valid Percent & $\begin{array}{l}\text { Cumulative } \\
\text { Percent }\end{array}$ \\
\hline $\begin{array}{l}\text { Anti-mal drugs are } \\
\text { justified for +ve } \\
\text { Malaria cases }\end{array}$ & N-300 & & & \\
\hline Strong disagree & 5 & & & \\
\hline Disagree & 25 & 1.7 & 1.7 & 1.7 \\
\hline Neutral & 5 & 1.7 & 8.6 & 10.3 \\
\hline Agree & 146 & 48.7 & 1.7 & 12.1 \\
\hline strong agree & 109 & 36.3 & 30.3 & 62.4 \\
\hline Total & 290 & 96.7 & 100.0 & 100.0 \\
\hline System & 10 & 3.3 & & \\
\hline $\begin{array}{l}\text { Febrile patients } \\
\text { should be treated } \\
\text { with ACT even } \\
\text { without RDT or } \\
\text { micro }\end{array}$ & & & & \\
\hline Strong disagree & 60 & 20.0 & 20.8 & \\
\hline Disagree & 129 & 43.0 & 44.8 & 65.6 \\
\hline Neutral & 8 & 2.7 & 2.8 & 68.4 \\
\hline Agree & 62 & 20.7 & 21.5 & 89.9 \\
\hline Strong agree & 29 & 9.7 & 10.1 & 100.0 \\
\hline System & 12 & 4.0 & & \\
\hline $\begin{array}{l}\text { If I have fever, I'll } \\
\text { take anti-mal } \\
\text { without mRDT }\end{array}$ & & & & \\
\hline Strong disagree & 60 & 20.0 & 20.8 & \\
\hline Disagree & 129 & 43.0 & 44.8 & 65.6 \\
\hline Neutral & 8 & 2.7 & 2.8 & \\
\hline Agree & 29 & 20.7 & 21.5 & \\
\hline Strong agree & 9.7 & 10.1 & 100.0 \\
\hline Total & 12 & 96.0 & 100.0 & \\
\hline System & & & & \\
\hline
\end{tabular}

\section{Treatment of choice according to national guide line}

The table below shows the treatment options for malaria according to the National guidelines. About $46.3 \%$ agree that ACT should be the choice drug, 31.3\% prefer Quinine, and $14 \%$ prefer Fansidar while 2.7\% prefer Chloroquine. 


\begin{tabular}{|ll|l|l|l|l|}
\hline $\mathrm{N}=300$ & & & & & Cumulative \\
& & Frequency & Percent & Valid Percent & Percent \\
\hline Valid & Quinine & 94 & 31.3 & 32.0 & 32.0 \\
& ACT & 139 & 46.3 & 47.3 & 79.3 \\
& Chloroquine & 8 & 2.7 & 2.7 & 82.0 \\
& Fansidar & 42 & 14.0 & 14.3 & 96.3 \\
& Strong agree & 11 & 3.7 & 3.7 & 100.0 \\
Missing & System & 6 & 2.0 & & \\
\hline
\end{tabular}

\section{Preventive measures}

The table below shows the preventive measure taken to prevent malaria and results showed that 53\% respondents prefer LLIN (Long Lasting Insecticidal Net), 25.7\% prefer anti-malaria drugs are better for prevention, $14.7 \%$ believe clean environment is a better while 2.7 believe IPT/Fansidar and nutritious diet are better preventive measures.

\begin{tabular}{|c|c|c|c|c|c|}
\hline & & Frequency & Percent & Valid Percent & $\begin{array}{l}\text { Cumulativ } \\
\text { e Percent }\end{array}$ \\
\hline \multirow[t]{6}{*}{ Valid } & Anti-malaria & 77 & 25.7 & 26.0 & 26.0 \\
\hline & LLIN & 159 & 53.0 & 53.7 & 79.7 \\
\hline & IPT/Fansidar & 8 & 2.7 & 2.7 & 82.4 \\
\hline & $\begin{array}{l}\text { Clean } \\
\text { Environment }\end{array}$ & 44 & 14.7 & 14.9 & 97.3 \\
\hline & Nutritious Diet & 8 & 2.7 & 2.7 & 100.0 \\
\hline & Total & 296 & 98.7 & 100.0 & \\
\hline Missing & System & 4 & 1.3 & & \\
\hline Total & & 300 & 100.0 & & \\
\hline
\end{tabular}

\section{Discussion}

Malaria epidemic has posed serious public health issue in Nigeria. It is one of the leading causes of morbidity and mortality and accounts for more than 50\% of all cases seen in the hospitals (4). Pregnant women are particularly vulnerable to malaria as pregnancy reduces a woman's immunity to malaria, increasing her risk of illness, severe anemia, and death, while the risk of spontaneous abortion, stillbirth, premature delivery, and low birth weight increases for the fetus (24).

In this study, health workers were interviewed to know their perception on the prevention and treatment of uncomplicated malaria in pregnant women in Nigeria. Their perception on the diagnosis of malaria, showed that positive reaction to mRDT, is an indication for the presence of malaria parasite. They also agree that mRDTs can miss malaria and and if the result of mRDT is negative it does not exclude malaria. For RDT to be a useful diagnostic, it must achieve greater than 95\% sensitivity (30). Today, most RDTs have achieved this goal for $P$. falciparum, but not for non- $P$. falciparum (27). RDTs can be useful in screening febrile returnees from endemic areas in developed countries (16). In developing countries, RDTs make obsolete the sole dependence on clinical diagnosis for malaria in remote areas, where good microscopy has failed or never reached. RDTs are also recommended in situations exceeding microscopy capability, such as in an outbreak or in occupationally exposed groups (31). As RDTs improve, including in sensitivity for P. vivax and in ability to measure parasitemia levels, at least semi-quantitatively, the scope of RDT applications will expand. Current RDTs are not intended to replace microscopy ( ). RDT has been indicated to be useful in the diagnosis of malaria in pregnant women due to placental sequestration of parasites and 
thus reducing the sensitivity of microscopy (12). The ability to detect placental infection by antigen detection when microscopy does not identify parasitaemia could have a significant impact on material and fetal health care (17)

There was high acceptance of the use of antimalarial drugs for cases with malaria. They however disagree with the administration of ACT drugs to febrile patients without conducting an RDT. The general perception and practice of the health workers is that an RDT should be done before considering the choice of drugs for the treatment. Nigerian government in 2005, adopted its first line drug to the arthemisinin based combination therapy (ACT) and recommended that all fevers be treated presumptively with ACTs where confirmation cannot be made (4). This was also in line with WHO recommendation for endemic countries where the availability and use of laboratories are limited. The respondents' choice is however in line with the current WHO treatment guideline for countries on malaria diagnosis and treatment (28). This guideline places emphasis on testing for malaria with RDTs or microscopy before treating while reaffirming the use of ACTs. In Africa, reports of RDT use have been relatively recent 2011 in Malawi (10) and 2012 in Nigeria (21), compared to in Asia 2007 in Cambodia (Population Services International Research and Metrics, 2007), and only a fraction of providers reported using RDTs (range 22\%-34\%) (Population Services International Research and Metrics, 2007; Onwujekwe et al., 2012; 10).

The health workers preferred ACT as a choice drug for the treatment of malaria, followed by Quinine then Fansidar. The national antimalarial treatment guidelines have stipulated the use of quinine for treatment of uncomplicated malaria in the first trimester and an ACT in the second and third trimesters (10) (11).(15). It has been reported that health care providers in public hospitals adhered to the national policy of prescribing ACTs in the second and third trimester than private hospitals (21). Private hospitals predominantly prescribed SP (70\%) (21). More public than private sector providers prescribed quinine in the first trimester (35\% versus 15\%); private sector providers predominantly prescribed SP (65\%). Okonta found that whilst $56 \%$ of doctors had prescribed quinine during the first trimester, the fear of quinine causing miscarriage was a significant consideration, with all but one physician prescribing quinine at lower than the recommended dose, and showing a preference for CQ (18). Similarly, Okoro and Nwambu found very low prescription of quinine in the first trimester (2.5\%), and ACTs constituted $51 \%$ and $29 \%$ of antimalarial drugs prescribed in the second and third trimesters, respectively (19).

The highest percentage of respondent believes that the best way to prevent malaria is in the use of long lasting insecticidal nets (LLIN) while others suggest the use of anti-malaria drugs. The LLIN has reduced the need for treatment and the pressure on health services, which is particularly important in view of the increase in drug resistant falciparum malaria parasites. It has been reported in Lagos, Nigeria that since 2000 more than One Million Insecticide Treated Nets have been distributed in the State to mothers of children under the age of 5 years either during integrated programs with immunization campaigns or during stand-alone campaigns in some local government areas of the state. It is often considered that one of the main drawbacks of LLINs is the low re-treatment rate; however, with the newly developed long lasting insecticidal nets (LLINs), the issue of net retreatment may be resolved as long as the price is not prohibitively increased by the specific treatment.

\section{Conclusion}

The United States also supports the Nigerian people by training medical personnel and community health workers to care for people with malaria. This past year alone, PMI (President's Malaria Initiative) supported training for nearly 7,000 health workers around the world in malaria case management. PMI also provides the test kits and medicines to help those patients who come to them. In just the past year in Nigeria, PMI procured 19 million anti-malarial treatments and more than 6 million rapid diagnostic tests kits. It is in view of these that, there is a need for all the stake holders in the country to maintain the present momentum of interventions as well as rapidly scale up of these interventions in order to sustain the declining trend of Malaria prevalence in pregnant women through 
Texila International Journal of Public Health

Volume 4, Issue 4, Dec 2016

the improved knowledge of the Health care provider who is provided necessary trainings.

\section{References}

[1]. Bouyou-Akotet M. K., Adegnika A. A., Agnandji S. T., Ngou-Milama E., Kombila M., Kremsner P. G. (2005). Cortisol and susceptibility to malaria during pregnancy. Microbes and Infection. 1217-23.

[2]. Chukwuma Muanya. (2013). National Malaria Elimination Programme, FCA, Total renew commitment towards disease eradication.

[3]. Desai M., Kuile F., Nosten F., McGready R., Asamoa K., Brabin B., Newman R. (2007). Epidemeology and burden of malaria in pregnancy. Lancet of infectious diseases.93-104 Okpere E. E. Malaria in pregnancy. In Okpere E (Ed): Clinical Obstetrics. Uniben Press. 2004:56-63.

[4]. Federal Ministry of Health (FMOH). National Antimalarial Treatment Policy. FMOH, National malaria and Vector Control Division, Abuja, Nigeria 2005.

[5]. Federal Ministry of Health Nigeria (2015). National Malaria Elimination Programme,

[6]. Federal Ministry of health, (2015). National guidelines and strategies for malaria prevention and control during pregnancy, second edition

[7]. James F. Entwistle. (2016). Ending Malaria in Nigeria for good.

[8]. Jelinek T, Grobusch MP, Harms G, 2001. Evaluation of a dip-stick test for the rapid diagnosis of imported malaria among patients presenting within the network TropNetEurop. Scand J Infect Dis 33: 752-754.

[9]. Kalilani-Phiri LV, Lungu D, Coghlan R (2011) Knowledge and malaria treatment practices using artemisinin combination therapy (ACT) in Malawi: survey of health professionals. Malar J 10: 279. doi: 10.1186/1475-2875-10-279

[10]. Kalilani-Phiri, L.V. Lungu, D. Coghlan R. (2011) Knowledge and malaria treatment practices using artemisinin combination therapy (ACT) in Malawi: survey of health professionals. Malaria Journal, 10 p. 279

[11]. Kwansa-Bentum B, Ayi I, Suzuki T, Otchere J, Kumagai T, et al. (2011) Administrative practices of health professionals and use of artesunate-amodiaquine by community members for treating uncomplicated malaria in southern Ghana: implications for artemisinin-based combination therapy deployment. Trop Med Int Health 16: $1215-1224$.

[12]. Leke, R.F.G., R.R. Djokam, R. Mbu, R.J. Leke and J. Fogako et al., 1999. Detection of the Plasmodium falciparum antigen histidine-rich protein 2 in blood of pregnant women: Implications for diagnosing placental malaria. J. Clin. Microbiol., 37: 2992-2996.

[13]. Luz, T.C.B., Suárez-Mutis, M.C., Miranda, E.S., Moritz, A.F., Freitas, L.F., Brasil, J.C., Osorio-de-Castro, C.G. (2013). Uncomplicated malaria among pregnant women in the Brazilian Amazon: Local barriers to prompt and effective case management. Acta Tropica, Volume 125, Issue 2, February 2013, Pages 137-142

[14]. Malaria situation analysis document. Abuja, Nigeria: Federal Ministry of Health; 2000. Federal Ministry of Health; pp. 14-26.

[15]. Manirakiza A, Soula G, Laganier R, Klement E, Djalle D, et al. (2011) Pattern of the antimalarials prescription during pregnancy in Bangui, Central African Republic. Malar Res Treat 2011: 414510

[16]. Marx A, Pewsner D, Egger M, Nuesch R, Bucher HC, Genton B, Hatz C, Juni P, 2005. Meta-analysis: accuracy of rapid tests for malaria in travelers returning from endemic areas. Ann Intern Med 142: 836-846.

[17]. Murray, C.K., R.A. Gasser Jr., A.J. Magill and R.S. Miller, 2008. Update on rapid diagnostic testing for malaria. Clin. Microbiol. Rev., 21: 97-110.

[18]. Okonta PI (2011) How many physicians prescribe quinine for the treatment of malaria in the first trimester of pregnancy? Ebonyi Med J 10: 105-111.

[19]. Okoro RN, Nwambu JO (2012) Evaluation of physicians' prescribing patterns of antimalarial drugs during pregnancy at the obstetrics and gynaecology department of a teaching hospital in Maduguri, Borno State, Nigeria. Int J Pharm Biomed Sci 3: 39-46.

[20]. Okpere, E.E., Enabudoso, E.J. Osemwenkha, A.P. (2010). Malaria in Pregnancy. Department of Obstetrics and Gynaecology, University of Benin Teaching Hospital, Benin City, Edo State, Nigeria Med J 51:109-13. 
[21]. Onwujekwe OC, Soremekun RO, Uzochukwu B, Shu E, Onwujekwe O (2012) Patterns of case management and chemoprevention for malaria-in-pregnancy by public and private sector health providers in Enugu state, Nigeria. BMC Res Notes 5: 211. doi: 10.1186/1756-0500-5-211

[22]. Population Services International Research and Metrics (2007) Cambodia 2007: TRaC study exploring the determinants of malaria health care provision among private providers in malaria endemic areas-first round. Washington (District of Columbia): Population Services International.

[23]. Rogerson S. J., Hviid L., Duffy P., Leke R. (2007). Taylor D. Malaria in pregnancy: pathogenesis and immunity. Lancet infectious diseases. 105- 17.

[24]. Steketee RW, Nahlen BL, Parise ME, Menendez C. The burden of malaria in pregnancy in malaria endemic areas. Am J Trop Med Hyg. 2001;64:28-35.

[25]. Strategic Plan for Rolling Back Malaria in Nigeria 2001-2005. Abuja, Nigeria: Federal Ministry of Health; 2001. Federal Ministry of Health; pp. 9-11.

[26]. Uzochukwu, B.S.C. Ezeoke, O.P Ukaegbu, U.E., Onwujekwe O.E., Sibeudu, F.T. (2010). Malaria treatment services in Nigeria: a review. Nigerian Medical Journal. 51(3) : 114-119

[27]. Wongsrichanalai, C., Barcus, Muth, S., Sutamihardja, A and Wernsdorfer W.H. (2007). A Review of Malaria Diagnostic Tools: Microscopy and Rapid Diagnostic Test (RDT). Am J Trop Med Hyg. 77 (6): 119-127 [28]. World Health Organisation. Roll Back Malaria Factsheet No.94. Geneva. [Last cited on 2011 June 06]. Available from: http://www.who.int/mediacentre/factsheets/fs094en.

[29]. World Health Organization (2015). Malaria In pregnancy Guidelines for the treatment of malaria, third edition.

[30]. World Health Organization, 2000. Malaria Diagnosis New Perspectives. Report of a Joint WHO/USAID Informal Consultation, October 25-27, 2000. Geneva: WHO.

[31]. World Health Organization, 2004. The use of malaria diagnostic tests. Manila: WHO Regional Office for the Western Pacific (WPRO). WHO. 


\title{
Barriers to Prompt Malaria Diagnosis and Effective Treatment among Children Under Five Years of Age in Mpika District
}

\author{
Article by David Silweya \\ Ph.D. in Public Health, Texila American University, Zambia \\ E-mail: silweyadavid@yahoo.com
}

\begin{abstract}
Background: Prompt malaria diagnosis and effective treatment, is a key malaria control strategy which reduces morbidity and mortality in many settings. However, in Zambia studies show that, only 19\% caretaker of children under five years of age accessed prompt and effective treatment in 2010 at health facilities. The factors contributing to this problem are not well understood in Zambia. The objective of this study is to determine barriers to prompt diagnosis and effective malaria treatment among children under the age of five years in Mpika district.

Methods: An analytical cross section study was conducted in Mpika district of Zambia using both the quantitative and qualitative methods with sample size was 380 caregivers and 8 Focused Group Discussions (FGDs) respectively.

Results: The study found that only $13.9 \%$ of children diagnosed with malaria received prompt malaria treatment. The following variables were found to significantly predict uptake of prompt malaria treatment; distance of less than five kilometers to the health facility (Adjusted OR 2.45 95\%CI: $1.22-5.11 \mathrm{P}=0.012$, adequate household income (AOR 2.27 95\%CI: $1.18-4.39 \mathrm{P}=0.014$ ), first action being; taking the child to the health facility (AOR 2.45 95\%CI: $1.26-4.76 P=0.008$ and having health education (IEC) done in the community (AOR 2.14 95\%CI: $1.10-4.13 P=0.024$ ). Non availability of antimalarial drugs at health facilities and self-treatments with antipyretics or herbal medication were reported in FGDs to be associated with delays in seeking appropriate malaria treatment.

Conclusion: The findings of this study highlight the barrier that exits in accessing prompt malaria treatment in a rural setting of Zambia. It underscores the need to formulate and implement interventions aimed at fostering appropriate health seeking behaviors in caretakers of under five children through community health education and addressing socioeconomic barriers that exits in rural setting.
\end{abstract}

\section{Background}

Malaria remains a major public health problem and continues to contribute significantly to infant mortality and morbidity in Africa, despite being a treatable and preventable condition (Masiye and Rehnberg, 2005). Annually, approximately 300-500 million cases and over 1 million deaths are recorded globally in children below the age of five years. Majority of these malaria infections, occur in the sub-Saharan regions were the most complicated forms of the infection are prevalent (Teklehaimanot and Bosman, 1999; Tarimo and Mismanage, 1998). Studies done in Zambia show that, close to 40 percent of infant mortality rate, 20 percent of maternal mortality rate and 45 percent of hospital admissions and outpatient department visits, can be attributed to malaria (Tuba, 2010 and MoH, 2010).

Although fever is a common presentation among childhood illnesses, malaria still accounts for the vast majority of these febrile illnesses (Tarimo et al., 2000). Prompt malaria diagnosis in all childhood febrile illnesses and appropriate treatment is critical in reducing childhood related morbidity and mortality (WHO, 2005 and Schellenberg et al., 2003). The majority of children with fever receive their initial treatment at home and outside the formal health care system (William and Jones, 2004). The Zambia Malaria Indicator Survey (ZMIS) for 2010 showed that, of the 34 percent children who had a febrile episode, only 19 percent received prompt malaria treatment. Children under the age of five years are the hardest hit by malaria 
infection because they lack the acquired immunity towards the infection. Thus, delay in seeking prompt treatment could cause the infection to progress from mild to severe forms and ultimately death within the first 24 hours of onset of symptoms (Baume, 2002).

Caregivers choice of were to seek prompt malaria treatment, is influenced by accessibility to health care, severity of presumed malaria infection and caregivers level of education (Schellenberg et al., 2003; Miguel et al., 1998 and Muller et al., 2003). In addition, other factors have been mentioned to have had a direct bearing on the treatment seeking behaviors of the caregivers namely, the cultural beliefs about the cause, treatment or prevention of malaria, drug stock outs at the health facilities and use of fever relief methods at home such as antipyretics or herbal medications (Schellenberg et al., 2003).

\section{Methods}

\section{Study area and period}

This analytical cross sectional study took place from $4^{\text {th }}$ March 2013 to $14^{\text {th }}$ March 2013 in 8 rural health centers: Mpika Urban, Chilonga Hospital affiliated center, Chalabesa, Kabinga, Kasenga, ZNS and Chibansa in Mpika district. Mpika district has a population of 261,425 with a population growth of 3.8 percent (CSO, 2010). The local economy is based on agriculture, thus most households earn a living through subsistence farming. This region was chosen for the study because of its high malaria endemicity especially during the rainy season. Malaria incidence in the district increased from 185.6/1000 to 441.7/1000 population and malaria related mortality in children under 5 years of age also increased from 48/1000 to 90/1000 from 2008 to 2010, respectively (2010 Mpika DHMT Action plan report).

\section{Study population}

The study populations were caregivers with children under five years of age diagnosed with malaria, attending the selected rural health centers.

\section{Sample size and sampling procedures}

The sample size calculation was based on assumption that the proportion of under-five children who received prompt malaria treatment was 34 percent (Zambia national malaria indictor survey, 2010). The statistical significance level of 5 percent was used with coefficient set at 1.96. Using the formulae and taking into account a non response of $10 \%$, the final sample size of 380 participants was obtained.

Multiple data collection techniques were employed to ensure validity and reliability of the results namely caregivers structured interviews $(n=380)$ and focused group discussions $(n=$ 8). For the structured interviews, a multi-stage sampling was used. The first stage was sampling of health centers. The health centers were identified through probability proportion to size sampling, from a sampling frame of all the 25 rural health centers (RHCs) in Mpika district. The second stage involved sampling of the caregivers attending the health centers with their under five children diagnosed with malaria. Study participants meeting the inclusion criteria at the selected health centers were identified through simple random sampling and were recruited daily for exit interviews until the desired sample size was achieved for that particular health center. The number of caregivers to be sampled at each rural health center was determined by the catchment population of that particular health facility proportional to the total cumulative catchment population of all the eight chosen rural health centers.

Purposive sampling was used to select participants for Focus Group Discussions (FGDs). For each facility, the venue was chosen were the FGD was conducted upon completion of the individual survey interviews. A total of eight FGDs were conducted with groups composed of $8-10$ caregivers at each health facility. 


\section{Data Analysis}

Quantitative data were double entered in an EPI DATA computer software package. Then it was checked for errors and cleaned by checking for information from questionnaires before being transferred to STATA (Version 11) for analysis. The data analysis types used were descriptive and analytical analysis. In descriptive analysis, frequency counts, graphical illustrations and cross tabulations were derived. Logistic regression analysis was used for analytical analysis. First, univariate logistic regression analyses of each independent variable with the dependent variable were performed initially. Secondly, from the univariate analysis, variables that were found to be statistically significant were then entered in the multivariate logistic regression analysis using stepwise forward and backward methods to control the effect of confounders. Adjusted odds ratios, p values and confidence intervals were computed from the best model were used to interpret the study findings. In this study, the statistical significance level of 5 percent (i.e. p value $\leq 0.05$ ) was used. The variables found not to be statistically significant in the univariate analysis were excluded in the multiple regression analysis. Textual data that was derived from Focus Group Discussions was analyzed using qualitative content analysis. The recorded data was first transcribe and followed up by cross checking of recorded data with transcripts. Then textual notes were read and reread in order to gain an understanding of their content. This was followed by classification of questions, numerical coding of themes and categorizing of themes according to the most frequent used themes from different FGDs done at the other health facilities. The qualitative data provided a much deeper insight with regard to the barriers associated with prompt malaria treatment in the district.

\section{Ethical Consideration}

Ethical approval was obtained from the University of Zambia Biomedical Research Ethics Review Committee (Ref: 008-02-13). Mpika District Community Health Office gave permission for the study to be conducted in the district. Informed consent was sought from the participants for their participation in the FGDs and in the in the semi and structured interviews. Participant's confidentiality and anonymity were preserved. Moreover, Participants were informed that they were free to withdraw from the study at any time without any repercussions.

\section{Results}

\section{Socio -demographic characteristics of participants}

A total of 380 caregivers were interviewed. The majority of study children were males aged between $13-24$ months 110/380 (29.0 percent) and their primary caregivers were mostly mothers 293/380 (77.1 percent), aged between 25-34 years 154/380 (44 percent). The majority of the caregivers only went as far as primary level education (65.3 percent) while 12.1 percent had no formal education. Similarly, 234/380 (61.6 percent) of heads of household had attained primary education while 7.9 percent had no formal education. Most of the heads of households were earning their living through subsistence farming 313/380 (82.4 percent) whose household income was inadequate 268/380 (70.5 percent) (Table1).

Table 1: Socio-demographic characteristics of participants

\begin{tabular}{ll}
\hline Age of children with malaria & Percentage \% (n/N) \\
\hline $0-12$ months & $20.5 \%(78 / 380)$ \\
$13-24$ months & $29.0 \%(110 / 380)$ \\
25-36 months & $19.7 \%(75 / 380)$ \\
$37-48$ months & $11.8 \%(45 / 380)$ \\
49-59 months & $19.0 \%(72 / 380)$ \\
\hline
\end{tabular}

Gender of the children

Male

$52.4 \%(119 / 380)$ 
Age of caregiver

15-24 years

$30.8 \%(117 / 380)$

25-34 years

$40.5 \%(154 / 380)$

$35-44$ years

$21.8 \%(83 / 380)$

$>45$ years

$6.40 \%(26 / 380)$

\begin{tabular}{ll}
\hline Relationship of caregiver to the child & \\
Mother & $77.1 \%(293 / 380)$ \\
Father & $17.1 \%(65 / 380)$ \\
Grandmother & $5.0 \%(19 / 380)$ \\
Others & $0.80 \%(3 / 380)$ \\
\hline Education level of caregiver & \\
No School & $12.1 \%(46 / 380)$ \\
Primary & $65.3 \%(248 / 380)$ \\
Secondary & $21.8 \%(83 / 380)$ \\
College & $0.80 \%(3 / 380)$ \\
\hline Education level of head of household & \\
No school & $7.90 \%(30 / 380)$ \\
Primary & $61.6 \%(234 / 380)$ \\
Secondary & $27.6 \%(105 / 380)$ \\
College & $2.90 \%(11 / 380)$ \\
\hline Occupation of head of household & \\
Employed & $9.40 \%(36 / 380)$ \\
Business & $8.20 \%(31 / 380)$ \\
Farmer & $82.4 \%(313 / 380)$ \\
\hline House hold income & \\
Adequate & $29.5 \%(112 / 380)$ \\
Not adequate & $70.5 \%(268 / 380)$ \\
\hline
\end{tabular}

\section{The proportion of children that received prompt malaria treatment}

As low as 53/380 (13.9 percent) children diagnosed with malaria received prompt malaria treatment, while 86.1 percent (327/380) were treated after 24 hours or more of onset of malaria symptoms. The common reason cited for delayed treatment is the long distances required to travel to reach the health facilities, compounded with luck of financial resources (19.3 percent). With regard to malaria knowledge and treatment, 64.5 percent (245/380) mentioned fever as a sign they first saw in their child to suspect malaria illness. The other symptoms mentioned include convulsions (12.1percent), poor appetite (10 percent), and vomiting (9.8 percent). The commonest antimalarial drug prescribed to these children was Lufamenthrine Artemether (Coartem) (91.5 percent). However, the practice of self medication with antipyretics among caregivers was common 36.0 percent (137/380) (Table 2).

Table 2: Characteristics of participants with prompt or delayed malaria treatment.

\begin{tabular}{ll}
\hline Promptness of treating malaria & Percentages \\
\hline Children treated within 24 hours of onset of symptoms & $13.9 \%(53 / 380)$ \\
Children treated after 24 hours of onset of symptoms & $86.1 \%(327 / 380)$ \\
\hline Reasons for delay of treatment & \\
Didn't think of seeking care & $14.4 \%(47 / 327)$ \\
No one to take child to health facility & $6.7 \%(22 / 327)$ \\
No money & $19.3 \%(63 / 327)$ \\
Long distance to health facility & $31.2 \%(102 / 327)$ \\
Child feel sick at night & $28.4 \%(93 / 327)$ \\
\hline
\end{tabular}

Malaria symptoms the child presented with 
Convulsions

Fever

Poor appetite

Vomiting

Shivering

Diarrhea

Initial treatment given to child at home

Antipyretic

Antimalarial

Antibiotic

Herbal medication

Sponging

No treatment given
$12.1 \%(46 / 380)$

$64.5 \%(245 / 380)$

$10.0 \%(38 / 380)$

$9.80 \%(37 / 380)$

$1.80 \%(7 / 380)$

$1.80 \%(7 / 380)$

$36.0 \%(137 / 380)$

$2.40 \%(9 / 380)$

$1.10 \%(4 / 380)$

$0.50 \%(2 / 380)$

$5.0 \%(19 / 380)$

$55.0 \%(209 / 380)$

The statistical analysis was performed using univariate and multivariate logistic regression. The Unvariate analysis found the following factors to be significantly associated with increasing the odds of the child receiving prompt malaria treatment: distance of less than five kilometer to the health facility [odds ratio (OR) 2.60, 95\% CI: $1.35-0.73, \mathrm{P}=0.00$ ], adequate household income (OR 2.67 95\% CI: $1.47-4.88$, P $=0.00$ ), head of household being employed (OR 2.40 95\% CI: $1.06-5.44, \mathrm{P}=0.04$ ), caregiver knowledgeable on malaria transmission (OR 2.76 95\% CI: $1.37-5.57, \mathrm{P}=0.01$ ), sponging the child (OR 4.80 95\% CI: $1.54-14.94, \mathrm{P}=0.007$ ), taking the child to the health facility as the first action (OR $3.4795 \%$ CI: $1.64-7.36, \mathrm{P}=0.001$ ) and having health education IEC done in the community (OR 2.32 95\% CI: $1.28-4.23, \mathrm{P}=0.006$ ) Table 3.

Table 3: Univariate logistic regression analysis of predictors of prompt malaria treatment in under 5 children in Mpika district.

\begin{tabular}{|c|c|c|c|}
\hline Risk factor & Proportion & $\begin{array}{l}\text { Odds ratio (Confidence } \\
\text { Interval) }\end{array}$ & P value $^{1}$ \\
\hline \multicolumn{4}{|c|}{ Initial malaria treatment } \\
\hline Antipyretic & $36 \%(137 / 380)$ & $0.50(0.25-0.99)$ & 0.05 \\
\hline Other treatments & $64 \%(243 / 380)$ & 1.00 & \\
\hline \multicolumn{4}{|c|}{ Malaria symptoms child had } \\
\hline Fever & $65 \%(245 / 380)$ & $0.25(0.11-0.53)$ & 0.00 \\
\hline Poor appetite & $10 \%(38 / 380)$ & $0.27(0.08-0.93)$ & 0.03 \\
\hline Vomiting & $9.8 \%(37 / 380)$ & $0.63(0.23-1.72)$ & 0.37 \\
\hline Diarrhea & $1.8 \%(7 / 380)$ & $0.48(0.04-3.47)$ & 0.39 \\
\hline \multicolumn{4}{|c|}{ Distance to health facility } \\
\hline$<5$ kilometers & $18 \%(70 / 380)$ & $2.60(1.35-4.99)$ & 0.00 \\
\hline$>5$ kilometers & $82 \%(310 / 380)$ & 1.00 & \\
\hline \multicolumn{4}{|l|}{ Household income } \\
\hline adequate & $29 \%(112 / 380)$ & $2.67(1.47-4.88)$ & 0.00 \\
\hline Not adequate & $71 \%(268 / 380)$ & 1.00 & \\
\hline \multicolumn{4}{|l|}{$\begin{array}{l}\text { Occupation of head of } \\
\text { household }\end{array}$} \\
\hline Employed & $9 \%(36 / 380)$ & $2.40(1.06-5.44)$ & 0.04 \\
\hline Self employed & $91 \%(344 / 380)$ & 1.00 & \\
\hline \multicolumn{4}{|l|}{ Gender of children } \\
\hline Male & $52 \%(199 / 380)$ & $1.23(0.68-2.23)$ & 0.49 \\
\hline Female & $48 \%(181 / 380)$ & 1.00 & \\
\hline \multicolumn{4}{|c|}{ Education level of caregiver } \\
\hline Basic education & $88 \%(334 / 380)$ & $0.85(0.35-2.01)$ & 0.70 \\
\hline Never attended school & $12 \%(46 / 380)$ & 1.00 & \\
\hline
\end{tabular}




\author{
transmission \\ Yes $\quad 60 \%(227 / 380)$ \\ No \\ $40 \%(153 / 380)$ \\ $2.76(1.37-5.57)$ \\ 0.01 \\ Knowledge on type of \\ malaria drugs \\ Yes \\ No \\ $99 \%(377 / 380)$ \\ $0.07(0.01-0.84)$ \\ 0.04 \\ Source of malaria drugs \\ $1 \%(3 / 380)$ \\ 1.00 \\ Health center \\ $80 \%(367 / 380)$ \\ $0.33(0.09-1.11)$ \\ 0.08 \\ Local shops \\ $10 \%(13 / 380)$ \\ 1.00 \\ Presence of physical barriers \\ Yes \\ $79 \%(302 / 380)$ \\ $0.51(0.26-0.98)$ \\ 0.04 \\ No
${ }^{1}$ Tested by Univariate analysis \\ ${ }^{1} \mathrm{P}<0.05$ was considered statically significant
}

However, initial antipyretic treatment given to the children at home (OR 0.50 95\% CI 0.25 $-0.99 \mathrm{P}=0.05$ ), children who presented with fever (OR $0.2595 \% \mathrm{CI}: 0.11-0.53 \mathrm{P}=0.00$ ), children who had poor appetite (OR $0.2795 \% \mathrm{CI}$ : $0.08-0.93 \mathrm{P}=0.03$ ) and presence of physical barriers to the health facility (OR $0.5195 \%$ CI: $0.26-0.98 \mathrm{P}=0.04$ ), were found to decrease the likelihood of under five children receiving prompt malaria treatment. The analysis showed the absence of association between prompt malaria treatment and gender of the child (OR 1.23 95\% CI: $0.68-3.23 \mathrm{P}=0.49$ ), education level of caregiver (OR $0.8595 \%$ CI: $0.35-2.01 \mathrm{P}=0.70$ ) and source of antimalarial (OR 0.33 95\% CI: $0.08-1.11 \mathrm{P}=0.08$ ).

When all significant variables were entered in a multivariate analysis with stepwise elimination (Table 4), the following variables were found to significantly predict uptake of prompt malaria treatment among children under five years of age: distance of less than five kilometers to the health facility (Adjusted OR 2.45 95\%CI: $1.22-5.11 \mathrm{P}=0.012$ ). This shows that caregivers who stay less than $5 \mathrm{~km}$ from the health facility were 2.5 times more likely to have prompt malaria treatment for their children than those staying more than $5 \mathrm{~km}$ from the facility. Household income (OR 2.27 95\% CI: $1.18-4.39$ P = 0.014), caregivers whose income was said to be adequate were 2.3 times more likely to seek prompt malaria treatment, than those whose income was said to be inadequate. Furthermore, knowledge on malaria transmission (Adjusted OR $2.0495 \%$ CI: $0.97-4.28 \mathrm{P}=0.049$ ), this shows that caregivers who were knowledgeable about malaria transmission were 2 times more likely to seek prompt malaria treatment. The analysis also showed that taking the child to health facility as the first action (Adjusted OR 2.45 95\% CI: $1.26-4.76 \mathrm{P}=0.008$ had the percent change in odds for SD (standard deviation) of 47.7). This means that taking the child to the facility as the first action 1 standard deviation more, increases the odds of prompt malaria treatment by $48 \%$. Also fever as the symptom (Adjusted OR $0.3695 \%$ CI $0.19-0.69 \mathrm{P}=$ 0.36 had a percentage change in odds for SD of -38.8). This means that having fever as a symptom of malaria 1 standard deviation more decrease the odds of prompt malaria treatment by 39\%. Having health education IEC done in the community (Adjusted OR 2.14 95\% CI $1.10-4.13 \mathrm{P}=0.024$ ), increases the likelihood of prompt malaria treatment. The following variables were not significantly associated with prompt malaria treatment in under five children: initial malaria treatment with antipyretics (Adjusted OR 0.58 95\% CI: $0.28-1.19$ P $=0.138$ ), occupation of the head of household (Adjusted OR $1.3195 \%$ CI: $0.52-3.30 \mathrm{P}=$ 0.060) and caregiver's knowledge on malaria transmission (Adjusted OR 2.04 95\% CI 0.97 $4.28 \mathrm{P}=0.05$ ). This means that, caregivers who gave their children antipyretics as initial home treatment were 0.58 more likely to seek malaria treatment late, than caregivers who gave other treatments. 
Table 4: Multivariate logistic regression analysis of predictors of prompt malaria treatment in under 5 children in Mpika district.

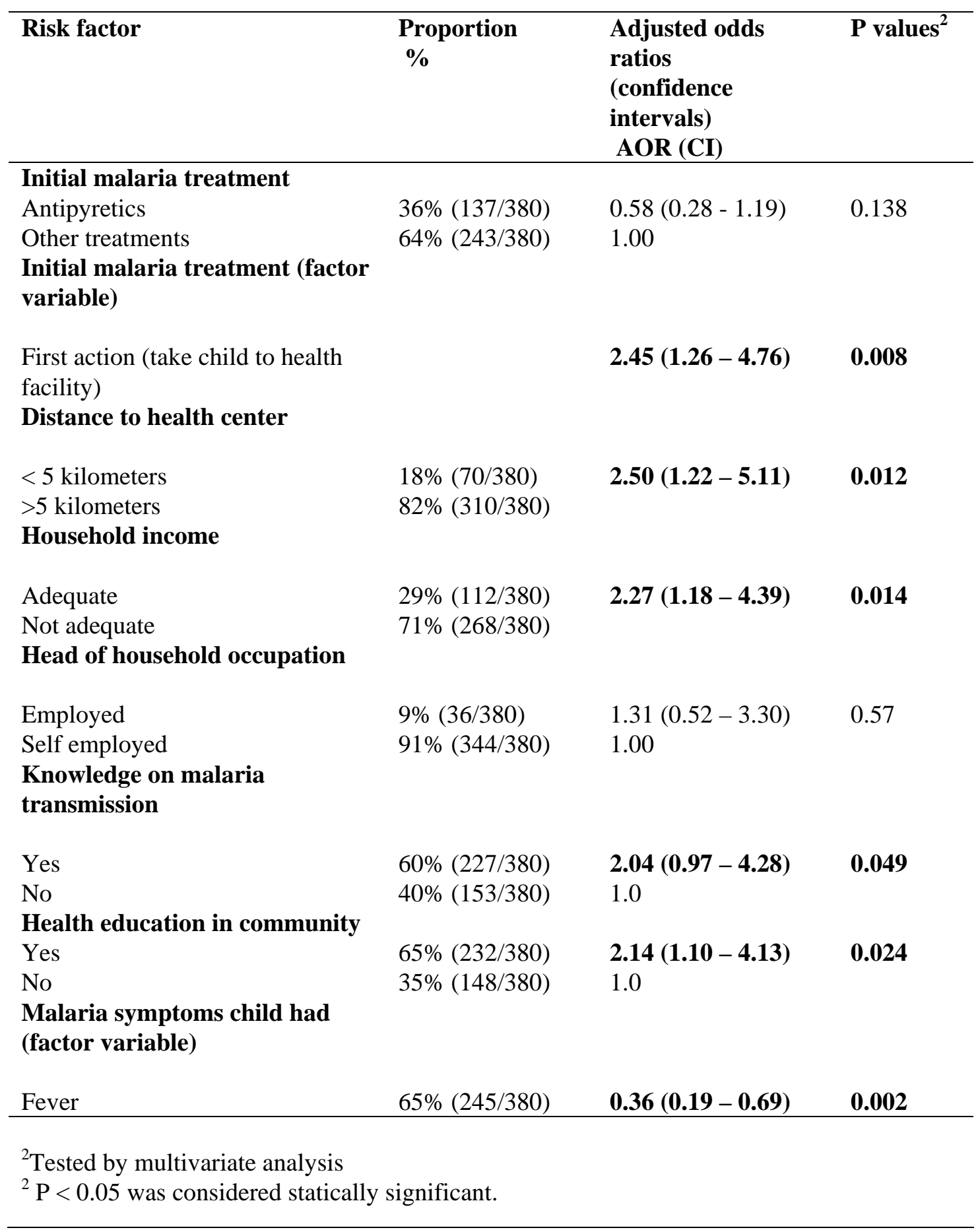

Qualitative data from FGDs highlighted the following barriers to prompt malaria treatment.

\section{Distance and transport to the health facility}

Availability of transport and physical location of the health facility has a bearing on prompt access of health services by the users. Statistical analysis revealed that children of caregivers staying more than $5 \mathrm{~km}$ from the health facility were associated with delayed malaria treatment, equally during FGDs, long distances that caregivers needed to travel either by foot or cycling to reach the health facility was a prominent theme that emerged. This was compounded by presence of physical barriers such as passing through thick forests, traversing mountains which are common physical barriers in Mpika district: 
"The problem is that we stay very far from the health center, for instance I stay in Itongo area which is very far, so if we suspect the child has malaria, we wait until the next day to see if the child will improve" (FDG, female caregiver)

\section{Perceived severity of fever}

Although malaria was recognized as a major problem in all the FGDs and fever was also positively associated as the main symptom of malaria. Caregivers however, classified fever as mild and severe body hotness. Sick children with mild body hotness were not taken to the health facility, not until their fever become severe body hotness:

"Most of the time when we see that the child has developed vomiting, shivering and mild fever, we wait for the child to develop severe body hotness also before we take the child to the health facility. Most of the time when we take such a child with mild fever, they get his blood and test, they tell us that the child has no malaria, and thus we are sent back home on some other medication. If we take the child with high fever, they always find the malaria parasite, so that's the reason we wait at home for the child to develop high fever" (FGD, male caregiver).

\section{Initial treatment of suspected malaria}

In malaria endemic areas, the use antipyretics drug to treat fever episodes is a common practice which negatively impact on prompt access to appropriate malaria treatment. In the study the common initial home treatment for suspected malaria illness, that emerged from the FGDs was the use of antipyretics such as paracetamol, which were mostly left over medication from the previous illness or procured from the local shops "tutembas". However, use of antipyretics was cited as the cause of delay in accessing care for the sick child, since the fever would normally subside after taking paracetamol, thus the caregiver could interpret this as an improvement in the child's condition:

"what causes us not to bring the child the same day they develop fever is that we give the child panadol, the fever goes, so when we wake the following day the child feels much better, so we don't bring the child to the health center" (FGD, female caregiver)

\section{Non availability of antimalarial drugs.}

The availability of drugs at a health facility is an important factor affecting access to malaria treatment. A persistent stock out of antimalarial drugs at the health centers is another barrier that emerged from the FGDs and interviews with rural health center staffs. The reasons attributed to the drug stock outs was mainly erratic RHC essential medicine and supplies of kits from the District health office and huge malaria burden in the catchment populations.

"When we take our sick children at the health center, sometimes the health workers there tell us they don't have medicine to treat malaria, they refer us to either Mpika district hospital or Chilonga general hospital were such medicine are readily available, so we have to go back to the village to prepare ourselves to go to these hospitals which are very far way" (FGD, female caregiver)

"What happens is that when the community hears that the medicine kit has arrived at the health center, they all come in numbers such that within a week, the health center runs out of all the antimalarial, and RDT test kits." (FGD, male caregiver)

\section{Use of herbal medication}

The use of herbal medicine is imbedded in the cultural belief that herbs are effective in treating febrile convulsions (Iloeje, 1989). The FGDs revealed that, some caregivers were able to link febrile convulsions to malaria, and these mentioned that when their child with fever starts convulsing they rush the child to the health center to get treatment. However, other caregiver could not link febrile convulsions to malaria, thus associated convulsions to epilepsy. The initial treatment for febrile convulsion was giving the child tradition medicine 
mostly from advice from their parents or in laws. When the condition of the child worsened, that's the time the child is taken to the health center.

"Some of our parents or in- laws tell us to use herbal medication especially if the child is convulsing (umusanfu)" (FGD, female caregiver).

"Herbal medication was given to my child when he started fitting, but there was no improvement, until I just decided to bring the child to the hospital, that's when the child got better" (FGD, female caregiver).

\section{Discussion}

This study explored the barriers to prompt and effective malaria treatment in children aged below 5 years, in Mpika district. A wide range of interconnected factors at both household and health system level are said to influence access to early and efficacious malaria treatment in children under five years of age (Hetzel et al, 2007). The study identified the following factors to having an impact on prompt and effective malaria treatment: distances to health facilities, household income, knowledge on malaria symptoms, its transmission and treatment, community health education on malaria, availability of antimalarials at the health facilities and staffing levels at health facilities.

This study found that a low proportion of children diagnosed with malaria received prompt and effective malaria treatment in the rural district of Mpika. A similar finding was obtained from a study done in rural Blantyre- Malawi (Hetzel et al., 2008). Clearly prompt malaria treatment still remains a challenge in most rural settings, despite it being a cornerstone in prevention of malaria complications in children (Baume, 2002). The prompt use of an effective malaria treatment was equally low among study participants. Most children with malaria were initially treated with an antipyretic such as paracetamol, before being brought to the health facility. This finding is also consistent with a study done in Tanzania which indicated that as high as $78 \%$ of children received an antipyretic as first action at home prior to being taken to the health facility (Hetzel et al., 2008). Self-treatment is the most common initial treatment in childhood malaria, especially in rural areas of Africa, where three quarters of malaria cases occur ((Hetzel et al., 2008). Although antipyretics are widely used as a treatment options for childhood fevers, these are not biomedical recommended treatment for malaria. Self-treatment of malaria is a recipe for disaster as most such children are at risk of developing complicated malaria, which if not managed accordingly, is associated with a high case fatality.

The study also found that caretakers living within 5 kilometer radius of the health facilities were more likely to access prompt malaria treatment for their children. This finding is in support of the study done in Uganda which highlighted that, caretakers who traveled greater than $5 \mathrm{~km}$ to the health facilities were more likely to have delayed malaria treatment than those that travelled less than 5 kilometers to the health facilities (Rutebemberwa et al., 2009). Long distance has been pointed out by many studies as a common barrier to formal health care in rural settings (Baume, 2000). From FGDs, it was clear that long distance more often than not, make caretakers adopted a wait and see approach (Chibwana et al., 2009). Moreover, some of the strategies being advocated to combat the problem of long distance include: the use of volunteers called Community Health Workers (CHW) trained to conduct Home based management of malaria (HMM). The current HMM involves the CHW making a confirmed malaria diagnosis with Rapid diagnostic testing (RDT) then providing an appropriate antimalarial to malaria children within the community (WHO, 2005). The use of CHWs is widely practiced in many countries in Africa and some parts of Asia (WHO, 2005). Evidence that they are effective is broadly encouraging, where adequate training, supply of drugs and supervision can be maintained, but this is not a light undertaking. The study also highlighted that only a quarter of caretakers were fathers and over three quarters were mothers. Studies have shown that male involvement in the management of child illness improves access to formal health care (Halwindi et al., 2013). This can be attributed to the fact that more often than not, fathers play a pivotal role of regulating women/child access to 
prompt malaria treatment through control of home income, women mobility and health care decision (Halwindi et al., 2013).

The cost of seeking health care has often been mentioned as a major hurdle to malaria treatment in the sub-Saharan Africa (Chuma J, Okungu V, and Molyneux C, 2010). Inadequate household income was cited as one of the barriers to prompt malaria treatment in the study. This finding is consistent with the fact that household income has a bearing on access to health care services availalable to the caretaker, as those with adequate income are able to access the health facilities easily as opposed to self-medication. Mpika district is mostly rural, as such most study participants are peasant farmers with seasonal household income, this coupled with transport costs and other opportunity costs of taking children to the health facilities instead of farming, all interact to make access to effective malaria treatment more difficulty for poor households. This challenge can be addressed by implementing favorable economic policies for local peasant farmers in the district. At present, the local farmers are faced with a lot of challenges such as poor farming methods and lack of favorable markets for their farm produce. Therefore, any policy aimed at improving the livelihood of these farmers will need to be structured around such important issues. The potential spin off of such an undertaking will not only improve health service accessibility but also improve their standard of living, thus significantly reducing vulnerability to illnesses of their children.

The majority of caretakers in the study were knowledgeable on the cause, transmission, symptoms and treatment of malaria. Furthermore, caregivers who were more knowledgeable about malaria were more likely to seek prompt malaria treatment for their under 5 children than those that were not knowledgeable. However, other studies done in Africa showed that knowledge of caretakers on malaria transmission does not always translate into prompt malaria treatment in under 5 children, though such knowledge only tend to improve personal protective behaviors such as use of insecticide treated bed nets (Ahorlu, 2006 and Rutebemberwa, 2009). It is clear that, for strategies aimed at increasing caretaker's knowledge on malaria to have any meaningful impact in fostering better treatment seeking behaviors, other external factors that influence it need to be put into context.

The study demonstrated that community health education on malaria increased the likelihood of prompt malaria treatment among under five children. However, during FGDs, caretakers revealed that most of the health education sessions on malaria were conduct at the health facility by health staffs when caretakers took their children for routine under five immunization days, as opposed to being conducted in the community. There is need to broaden the target population for the health education sessions to include caretakers to do not come to health facilities. To tackle this challenge, need to increase awareness through health campaigns in the community and schools through audio-visual means such drama. Although the extent to which such social mobilization campaigns influence change in health seeking behaviors has not been exhaustively investigated, studies that have examined this issue do not consistently show a correlation between care seeking and malaria related knowledge.

The survey of health facilities revealed that most rural health centers in the district were poorly manned and experienced frequent antimalarial drug stock outs. This lead to the available limited staff being overburdened by huge patient turn over. The antimalarial stock out resulted in patients being referred to the two hospitals further away to access malaria treatment, a similar finding in a study done in Malawi (Becher et al, 2011).

In Zambia the first line malaria treatment is the use of Artemisinin-based combination treatment (ACT), which can only be obtained at the health facility with regard to most rural settings. It's worth noting that the health centers are supplied with few antimalarial in the drug kit which they received monthly from the district hospital thus resulting in non availability of medicines at the health centers. Therefore, it is important that national malaria strategies increase the allocation of ACTs in the drug kits to improve essential medicine commodity security at facility level, thus improving prompt access to effective anti-malarial treatment. The staff attrition was found to be high in the district, thus more trained health care 
provider are needed if the vision of quality health care provision is to be realized in the district.

The study had some limitations. First, the study was conducted in selected rural health centers in Mpika District and the extent to which findings can be generalized to the entire District and other settings is assumed. Second, the study participants were caregivers with sick children under five years of age, accessing care at the health facility; however those caregivers with malaria children but who did not come to the health facilities could not be interviewed introducing a form of bias. Despite these limitations, the finding from this study brings to the fore some of the factors that influence prompt malaria treatment in a rural setting and provide a platform on which future malaria control strategies can be formulated. However, there is need for further research using other methodologies to explore in depth these factors that promote or negatively impact on prompt and effective malaria, in order to have a much deeper perception of not only structural but also the cultural and socio factors at play.

\section{Conclusion}

The results from this study suggest that a low proportion of caretakers of children under five years of age with malaria are seeking care promptly at health facilities in rural settings. Barriers to access of prompt health care include longer distances of travel to health facilities, inadequate household income, shortage of antimalarial at facilities encourages caregivers to the practice of self-medication with other non-biomedically approved malaria treatments such as antipyretics or herbal medication, resulting in delayed malaria treatment. Factors that negatively impact on access to prompt malaria treatment are so complex such that even in a country, they differ from one locality to the other. Therefore there is need to look at the local context in coming up with solutions. Finally, there is an urgent need to direct additional resources towards addressing some of the barriers identified in the study, to reduce the morbidity and mortality associated with malaria among the under five children in the rural setting in order for the country to attain Sustainable Development Goals of reducing malaria infections and infant mortality rates in Zambia by 2030.

\section{Acknowledgements}

The author thanks Mpika District Medical Community Health Office, for allowing the study to be conducted in the district. The health center staffs and caregiver of under five children for providing much needed information. I also thank my family and friends for support and encouragements during the study. The author declares that there are no competing interests.

\section{References}

[1] Ahorlu C K, Koram K A, Ahorlu C, De Savigny D \& Weiss M G (2006) Socio-cultural determinants of treatment delay for childhood malaria in southern Ghana. Tropical Medicine and International Health 11, 1022-1031.

[2] Becher H, Muller O, Jahn A, Gbangou A, Kynast-Wolf G \& Kouyate B (2004) Risk factors of infant and child mortality in rural Burkina Faso. Bulletin of the World Health Organization 82, 265273.

[3] Baume, C. (2002). A Guide to research on care-seeking for childhood malaria. Arlington, Virginia: Sara, Basics ii. 46(30): 256-59.

[4] Central statistical office Zambia (CSO, 2010).

[5] Chibwana AI, Mathanga DP, Chinkhumba J, Campbell CH (2009) Socio-cultural predictors of health-seeking behaviour for febrile under-five children in Mwanza-Neno district, Malawi. Malaria Journal 8: 219.

[6] Chuma J, Okungu V, Molyneux C. (2010) Barriers to prompt and effective malaria treatment among the poorest population in Kenya. Malar J 9: 144. 
[7] Halwindi, H, S. Siziya, P. Magnussen, and A. Olsen (2013). Factors Perceived by Caretakers as Barriers to Health Care for Under-Five Children in Mazabuka District, Zambia. ISRN Tropical Medicine. 10.1155

[8] Hetzel M, Iteba N, Makemba A, Mshana C, Lengeler C, et al. (2007) Understanding and improving access to prompt and effective malaria treatment and care in rural Tanzania: The ACCESS Programme. Malar J 6: 83.

[9] Hetzel M W, Obrist B, Lengeler C, Msechu J J, Nathan R, et al. (2008) Obstacles to prompt and effective malaria treatment lead to low community-coverage in two rural districts of Tanzania. $B M C$

Public Health. 8: 317. [PMC free article] [PubMed

[10] McCombie SC. (2002) Self-treatment for malaria: the evidence and methodological issues. Health Policy Plan.17:333-344. doi: 10.1093/heapol/17.4.333. [PubMed]

[11] Miguel, C.A., Manderson, L., \& Lansang, M.A. (1998). Patterns of treatment for malaria in Tayabas, the Philippines; implications for control. Trop Med Int Health. 3:413-421

[12] Ministry of Health (MoH). Actions for Scale-up for Impact on Malaria in Zambia. National malaria strategic plan 2006 - 2010.

[13] Muller O, Traore C, Becher H, Kouyate B. (2003) Malaria morbidity, treatment seeking behaviour, and mortality in a cohort of young children in rural Burkina Faso. Trop Med lnt Health. 8(4):290-296. PubMed Abstract

[14] Rutebemberwa E, Kallander K, Tomson G, Peterson S \& Pariyo G (2009) Determinants of delay in care-seeking for febrile children in eastern Uganda. Tropical Medicine and International Health 14, 472-479.

[15] Schellenberg J. R. M. A., Victora C. G., Mushi A., De Savigny D., Schellenberg D., Mshinda H., Bryce J. (2003) Inequities among the Very Poor: Health Care Children in Rural Southern Tanzania. Lancet. 361:561-66. [PubMed]

[16] Tarimo D S, Lwihula G K, Minjas J N, Bygbjerg I C. (2000) Mother's perceptions and knowledge on childhood malaria in the holoendemic Kibaha district, Tanzania: implications for malaria control and the IMCI strategy. Trop Med Int Health. 5:179-84.

[17] Tarimo, D. S., Urassa, D. P., Msamanga, G. I. (1998). Caretakers' perceptions of clinical manifestations of childhood malaria in holo-endemic rural communities in Tanzania. East African Medical Journal. 5(3), 93-96.

[18] Teklehaimanot A, Bosman A. (1999) Opportunities, problems and prospects for malaria control in sub-Saharan Africa. Parassitologia. 41:335-338. [PubMed]

[19] Tuba M, Sandoy I F, Bloch P, Byskov J. (2010) Fairness and legitimacy of decisions during delivery of malaria services and ITN interventions in Zambia. Malaria J. 9:309. doi: 10.1186/14752875-9-309.

[20] Mpika DHMT Action Plan 2010.

[21] Masiye, F. \& Rehnberg, C. (2005). The economic value of an improved malaria treatment programme in Zambia: results from a contingent valuation survey. Malaria Journal. 4:60

[22] Ministry of health bulletin (MoH 2010).

[23] Williams HA, Jones CO. (2004) A critical review of behavioral issues related to malaria control in sub-Saharan Africa: what contributions have social scientists made? Soc Sci Med. 59:501-23. PubMed Abstract | Publisher Full Text

[24] WHO/UNICEF: The Africa Malaria Report 2003. World Health Organization/UNICEF, Geneva; 2003.

[25] WHO: The Roll Back Malaria strategy for improving access to treatment through home management of malaria. Geneva, World Health Organization (WHO/HTM/MAL/2005.1101); 2005.

[26] Zambia malaria indicator survey, (ZMIS 2010) 


\title{
Healthcare Waste Management Practices in Jalingo: A Reflection of the State of Healthcare System in Taraba State, Nigeria
}

\author{
Article by Paul Rambe Yunana \\ Ph.D. in Public Health, Texila American University, Nigeria \\ E-mail: pyunana@gmail.com
}

\begin{abstract}
A strong healthcare system is known by efficiency in service delivery through its individual components. The poor quality service delivery by any of these components is a reflection of the degree of its weakness. To achieve a strong health system that will provide efficient and effective health services, there must be a deliberate effort towards strengthening the system and continuous improvement of quality of services in each component at all levels. Previous studies in some hospitals in central and southern parts of Nigeria revealed poor knowledge and waste management practices. The study was undertaken to assess healthcare waste handling practices in some selected hospitals in Jalingo Taraba state and appraise how the poor health system is reflected in this area of service delivery. The assessment was conducted by extensive review of literature on Nigerian health system as relates to healthcare waste management practices; and by direct observation of waste handling practices in those hospitals, compared to standard practices of healthcare waste management. The results revealed that the healthcare waste management in those health facilities is far below WHO standards. This is attributable to the weak and poor healthcare system in the state and the country. Having an implementable hospital waste management plan, training healthcare workers of all cadres on proper waste management and regular supervision by health facility management were recommended as measures to improve healthcare waste management in the state, which is also a way of health system strengthening through this aspect of service delivery.
\end{abstract}

Keywords: Healthcare, Inefficiency, Waste Management, Quality Service, System Strengthening.

\section{Introduction}

A health system or healthcare system refers to the organization of people, institutions, material and human resources put together to provide health services to meet the health needs of a specific population (Abdulraheem, Olapipo, Amodu, 2012; World Bank, 2007). A good health system according WHO $(2007,2014)$ delivers quality services to all people, when and where they need them. It requires a robust financing mechanism (Timothy, Irinoye, Yunusa, Dalhatu, Ahmed, Suberu, 2014), a well-trained and adequately motivated workforce; reliable information for policy making; with facilities and logistic system that are well maintained in order to deliver quality health services (WHO, 2015). Many past studies on Nigerian's healthcare system described it as weak and poor, faced with many problems (Ademiluyi et.al. 2009; NSHDP, 2009-2015; IOM, 2014). These challenges and problems have over the years stalled its development and growth. Olakunle (2012) noted that Nigeria Health system, Taraba state inclusive, is far from providing efficient health services due to many problems bedeviling it. The scanty literatures on Taraba state healthcare system also revealed a more pathetic healthcare service delivery situation (Who 2015). The major challenges and problems can be attributed to poor leadership and coordination, inadequate human resources for health, inadequate supplies of medical products and technologies, poor health information management (weak Monitoring and evaluation system for health) and weak health insurance system (WHO, 2009, 2012). 
Texila International Journal of Public Health

Volume 4, Issue 4, Dec 2016

This weak system is reflected in all components of health services, as seen in the healthcare waste management and disposal in the hospitals in the state. The minimum standard approaches required for handling healthcare wastes are: a written plan for waste treatment with clearly defined roles and responsibilities, knowledge and self-awareness about healthcare waste, segregation and safe collection, temporary storage and transportation, choice of appropriate treatment option before final disposal and sustainable ways of safe treatment plan in line with existing policies (WHO, 2005; 2014, PATH, 2009). The Plan outlines how waste will be treated and how many times in a specified period with clearly defined responsibilities of healthcare staff that will handle waste treatment. The plan must be in line with the health facility and existing national policies on waste treatment.

Knowledge and self-awareness of healthcare waste risks: In addition to universal safety precaution observed in health care facilities, all staff must know the risk involved in handling all categories of hospital waste and must have adequate knowledge of safe ways to handle waste. This is enhanced by training and regular continuous medical education.

Waste segregation: Waste in health facilities is handled by segregating it according to WHO guidelines and classification of healthcare waste. It is separated in to: infectious sharps, non-sharp infectious waste, and non-infectious wastes. This segregation is done at point of waste generation where they are collected in dedicated color-coded containers, while sharps are collected in puncture proof containers e.g. biosafety boxes with cover and biohazard symbol (WHO, 2012).

Waste treatment options: Depending on the category of waste, the option of treatment is chosen. Some waste are incinerated before their by product is finally disposed in landfills. Some waste may not be good for incineration because of their impact on the environment, as such they are buried in a deep pit as means of final disposal (WHO, 2014, 2015; Abah \& Ohimain, 2011).

It is a matter of concern to state that observations made by the authors whose works were reviewed on the status of Nigerian healthcare system, particularly healthcare waste management revealed poor waste management practices across all level of healthcare delivery system. This is undoubtedly attributable to the weak health system. This regrettable situation exposes healthcare workers, the patients including patient relations and the immediate environment of the health facilities, where those wastes are generated, to risk of infection and other hazardous effect of such waste. Most of the interventions geared towards strengthening Nigerian's health system have been largely donor funded (Uneke, Ezeoha, Ndukwe, Oyibo \& Onwe, 2010) and do not most of the times focus on waste management but on other areas, such as infrastructural upgrade, improving maternal and child health care, laboratory services and so forth (Uneke et al. 2010).

Previous studies in some hospitals in central and southern parts of Nigeria revealed poor waste management practices (Babalola, 2008; Cooker, 2009; Awodele, Adewoye \& Oparah, 2016; Toyobo, Baba, Oyeniyi, 2012), and scanty information on hospital waste management in Taraba State. The efforts and interventions launched by the government at different times in the past did not directly target proper waste management. Most of the interventions remained at the policy level and implementation of those policies were not actively pursued (Uneke et al. 2010). It is pertinent that the country's efforts at national and state levels have not given the needed attention to improving waste management in the healthcare system (Olakunle, 2012). It is in this light that this study was carried out, to appraise and present the extent of poor management of hospital waste, due to decay in the health system; and its attendant risks to policy makers and health care implementers for possible action.

The framework used to guide this study is the WHO framework of Health system strengthening. It looks at the health system issues according to their individual building blocks. Recommendation for improving the system is best approached through these individual elements.

The WHO Health Systems Framework 


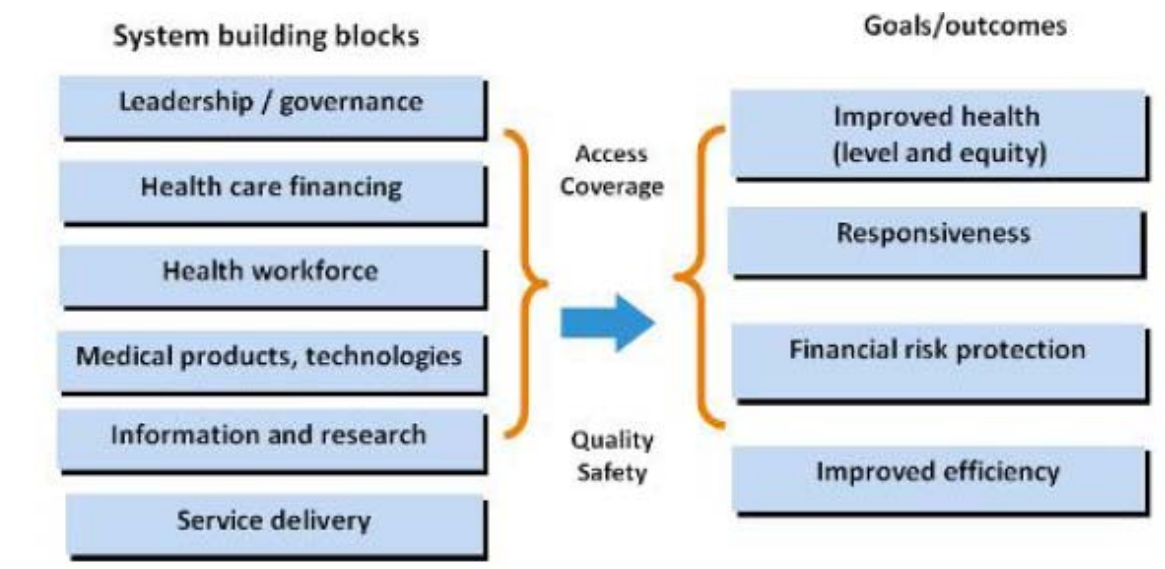

Source: WHO Health Services

Department.http://www.wpro.who.int/health_services/health_systems_framework/en/

The aim of the study was to present the outcome of weak healthcare system in Nigeria, hitherto described by many researchers as failed health system as reflected in poor hospital waste management in Taraba state and recommend ways for improvement.

The specific objectives of the study were:

1. Review relevant literatures to get grasp of the extend of the problems of Nigeria Healthcare system

2. Conduct a visit to selected health facilities to observe and appraise their waste management and disposal practices and relate them to the current state of the healthcare system of the state.

3. Recommend ways for strengthening healthcare systems through improved waste handling and disposal practices in the Taraba State and Nigeria at large.

\section{Methods}

The study was carried in Jalingo the capital of Taraba State. It is located in the north eastern part of Nigeria. The study was conducted between September and October, 2015. It adopted a cross sectional descriptive study design. The method employed was an extensive review of relevant literature on Nigeria's health system and healthcare /hospital waste management practices supplemented by physical observation of how hospital waste are managed and disposed in seven selected hospitals in Jalingo town. The content and ideas were synthesized and related to the practices of waste management observed in those hospitals. This was used to write a research supported article with recommendations to policy makers and healthcare services implementers to adapt in order to improve the healthcare system and thus healthcare waste management and disposal system.

Seven health facilities comprising of a Federal Medical Centre, a State specialist Hospital, 3 primary health healthcare centers, a faith based clinic and one private health facility all located in Jalingo, the capital town of Taraba state were purposively selected for their being popular facilities patronized by patients for observation on waste management practices.

For ethical consideration, permission was sought from the management of the health facilities visited in order to obtain a documented consent for the researcher to interact with the staff handling hospital waste.

Results

Summary of factors responsible for weak healthcare system in Nigeria Health system elements Weaknesses (building blocks)

Leadership /Governance Poor leadership and coordination: This is attributed to frequent changes in leadership, corruption and non-implementation of policies, guidelines and protocols. 
Texila International Journal of Public Health

Volume 4, Issue 4, Dec 2016

Financing

Inadequate and inappropriate financial allocation to the health sector at the three tiers of government- national, state and local government. Where there are meagre funds allocated to health sector, they are usually hardly released for the purpose.

Health workforce

Inadequate human resources for health, poorly motivated workforce, and frequent strike action by workers affect healthcare services delivery.

Information and research Poor record keeping, hospital records handled by untrained personnel. Improper storage of service data. Poor data management by health facilities.

Medical products, technologies

Obsolete equipment, poor maintenance practices for broken down equipment, frequent stock outs of essential medicines and commodities. Poor logistic management system.

Service delivery $\quad$ Decayed infrastructures, poor provision of quality health services. Poor attitude to work by health care workers. Overcrowded hospital wards. None adherence to professional and medical ethics.

\section{Summary of common waste management practices}

1. Most staff handling waste has not been trained on waste management. One Health facility outsourced it waste management to a company whose staff are also not trained.

2. Only two health facility practiced waste segregation, using coded bin most without bin lining. The rest of the facilities mixed their waste in one common bin before they are taken to the dump site.

3. Only two facility had incinerator for waste management. Two PHCs burn their waste in an open place within the hospital premises.

4. All the facilities have sites for dumping mixed waste within the hospital premises before they are conveyed to Landfills untreated.

\section{Discussions}

The effect of poor or weak health care system to the various units of healthcare service delivery are many. This study illustrates one of them. It shows how this affects healthcare waste management practices. Even at facility level, leadership is observed to be a problem. Weak leadership results in poor coordination and management of resources at all levels of health service delivery. At health facility level this does not only result in poor management of resources but also in poor supportive supervision of subordinate staff and in inadequate mentoring of staff by the management team or supervisors. Staffare left unsupervised and so they do what they feel right even when not in line with standard practices and waste management policy. Some of them do not have the adequate knowledge of proper waste handling and disposal. It is the responsibility of the leadership to provide needed training for all staff, so that they can perform their jobs effectively.

Finance: Funding has been identified as one of the major problems of the health sector. Inadequate and inappropriate financing affects every area of service delivery. From procurement of equipment, commodities and training to the payment of salary of staff rests on available funding for the health facility (Onisanwa, 2013; Timothy et.al. 2014; Uneke et.al, 2010). During interaction with the staff in the facilities visited, the common reason given for poor waste management by most of the staff asked, was poor financing. When the funding is adequate and prudently utilized, the management will procure materials for waste management while more staff will be employed in the facility and distributed fairly to all units. There will thus be adequate staffing for handling and disposing waste in line with the 
waste management plan of the health facility. There is therefore need for prioritizing the funding of health facilities by their owners if they must deliver the quality services expected of them. It is a common practice in Nigeria for government and Health facility owners to make annual budgets for health services but later fail in release of the funds appropriated for the services (Welcome, 2011). Appropriate allocation of funds should be followed by timely release to achieve the purpose for which the funds were budgeted.

Health workforce: The dearth of human resources for health is not only in Nigeria. It is reported almost in every developing country (Olaleye, 2014; Itam \& Adindu, 2012). The most important thing is what each country does to address them. The inadequate human resources coupled with lack of adequate training for the available staff is also responsible for the failure of many staff to perform their assigned duties rightly. In some of the facilities visited, the staff saddled with responsibility for waste management were grossly inadequate in number and training, while many skilled healthcare workers at various units do not see waste handling as part of their duty but for the very few persons designated for it.

Medical products/technologies. In an ideal healthcare facility, essential medical equipment and commodities are made available for efficient service delivery. In a country with weak health system most of these equipment are either obsolete or unavailable. Infection prevention and control (IPAC) consumables such as bio safety boxes, colour-coded bins and bin linings, gloves, face masks, boots and the like are infrequently supplied or not supplied at all. None segregation of waste in four out of seven health facilities visited were mainly due to lack of supply of the coded bins and bin linings in those facilities. Incinerators were not also sighted in four hospitals some of which are the major public health facilities in the state.

Information and research. A good practice of collecting, collating and managing hospital service data serves as the most important source (s) of information for planning, research and, decision making (IOM, 2014, Welcome, 2011). In a weak healthcare system, quality data and its efficient management for use are not a regular practice. If service data are not regularly analysed and used for planning, the hospital will not know the number of patients it serves at any point in time. It will be difficult to plan for how to effectively manage the waste that will be generated during services provided to patients at various units in the hospital. If the hospital does not know the average number of surgical operations it carries out every week, it may not plan well for how to appropriately handle and properly dispose the waste generated at the operating theatre. Hence the need for capturing service data and using it appropriately. Service data can also be secondary sources of information for research.

Service delivery: For efficient healthcare service delivery, the other five elements of health system strengthening (WHO, 2014) must be in place. Good service delivery depends on wellmotivated work force, good coordination by the leadership, appropriate funding which translates to adequate and equitable provision of material resources and efficient information management system (IOM, Adindu, \& Asuquo, 2013). This study revealed poor hospital waste handling and disposal practices in Jalingo. It is an example of poor service delivery attributed to issues that are directly related to a weak health care delivery system.

In the seven Hospitals visited, only 2 had written waste treatment plan. The two are both public health facilities, one owned by the federal government while the other by the state government. A good practice observed in all the hospitals was the use of bio safety boxes for sharps (majorly needles). These biosafety boxes are usually dumped alongside other waste at the dump sites. Segregation of waste using color-coded waste bins was observed in only one facility, while others do not pay attention to separating waste according to standard practices. Further interaction with staff who manage the waste, revealed inadequate knowledge on waste segregation. The lack of incinerator in most of the facilities visited including the two major public facilities suggest that the health facilities prefer conveying waste without treating them to the landfills. Some of them burn their waste in the open within the hospital premises. In the two facilities that had incinerator, wastes were also sighted at some hidden corners within the premises of the hospitals. In all the health facilities visited, waste were sighted within the premises either in a big ditch or open space or a container where they are usually carried and 
conveyed to the landfills. The danger to human life by this is also increasing. The waste handling and disposal in health facilities within Jalingo is similar to the one reported by earlier studies in Nigeria.

Poor waste handling poses great danger to healthcare workers, patients, the environment and immediate community where the hospital is located. When rain falls, it washes some of the wastes to the rivers and streams thereby polluting and contaminating water sources. Those that are burn within the hospital premises pollute the air with dangerous fumes. The danger of these practices is transmission of infection and pollution of the environment. This is of public health importance and attention must be given to it..

\section{Recommendations}

In order to improve the waste management and disposal system in Taraba state and in Nigeria, attention must be paid to the entire health system as a long term measure, while the short term measures should be the deliberate actions taken to improve the waste management practices so as to prevent its danger to the health workers, patients and the community.

\section{On health system}

1. Strong leadership and governance is required to strengthen coordination of healthcare services at all levels in the country. Relevant policy documents and guidelines exits, but they are not being implemented. Government at all levels (federal, state and local government) should enforce the implementation of the policy on Health and the National Health bill recently signed by the President of Nigeria.

2. Governments and other health facility owners should increase financial allocation for health sector and health facilities and back it with timely release of such funds in order to meet financial needs of the sector.

3. Public health intervention programs focusing on health system strengthening and continuous quality improvement at health facility should be pursued by Government and supported by donor agencies to strengthened health system in Nigeria at all levels of healthcare delivery.

4. More skilled health workers should be engaged to fill in the large human resource gap in the sector. Both public and private health institutions should be encouraged to implement the task shifting policy to address human resources for health issues in their respective intuitions. There should be training and re-training of health workers by its employers and strict enforcement of ethical and professional practices.

5. Government should make the national health insurance scheme viable by reorganizing it, and reposition it to provide equitable and affordable health services to all citizens in the country.

\section{On healthcare waste management}

1. All health facilities and their management should be sensitized to understand the risk in poor handling of hospital waste and measures to take in order to improve the this aspect. This is a primary responsibility of department of public health at the federal ministry of health.

2. Government and stakeholders in health should ensure all health facilities have clear written down implementable plan for waste management and should enforce the implementation of such plans.

3. All health facility staff should be trained on waste management and such should be included in the facility regular continuous medical education. Those whose schedule is handling waste should be provided with the appropriate protective clothing to minimize transmission of infection during handling.

4. Hospital management should always make available in the hospital infection prevention and control materials like the color coded waste bins, safety boxes, built 
incinerator and form a committee for waste management that will ensure adherence to standard practices.

5. Health facility management should ensure regular supportive supervision of their staff during work especially those responsible for waste handling and disposal.

6. The State Government should standardized the minimum requirements for hospital waste management and include it in the registration criteria for private hospitals.

7. Periodic studies should be conducted on waste management practices to assess improvement, identify and fill in the gaps for continuous quality improvement.

\section{Conclusion}

There is no doubt in the saying that Nigeria health system is weak and grappling with many problems. These problems have affected many if not all areas of health services delivery in the country including waste management system in health care facilities. There is hope of reviving and strengthening the system such that, all services that were affected will gradually improve for the benefit of all citizens. These will translate to improvement in all areas including the healthcare waste management system. These can be achieved if bold steps are taken to immediately implement the recommendations actions put forth for the improvement of the healthcare and waste management systems. Periodic assessment and research in this sector will also help in monitoring the improvement in health system and waste management practices.

\section{Tables and figures}




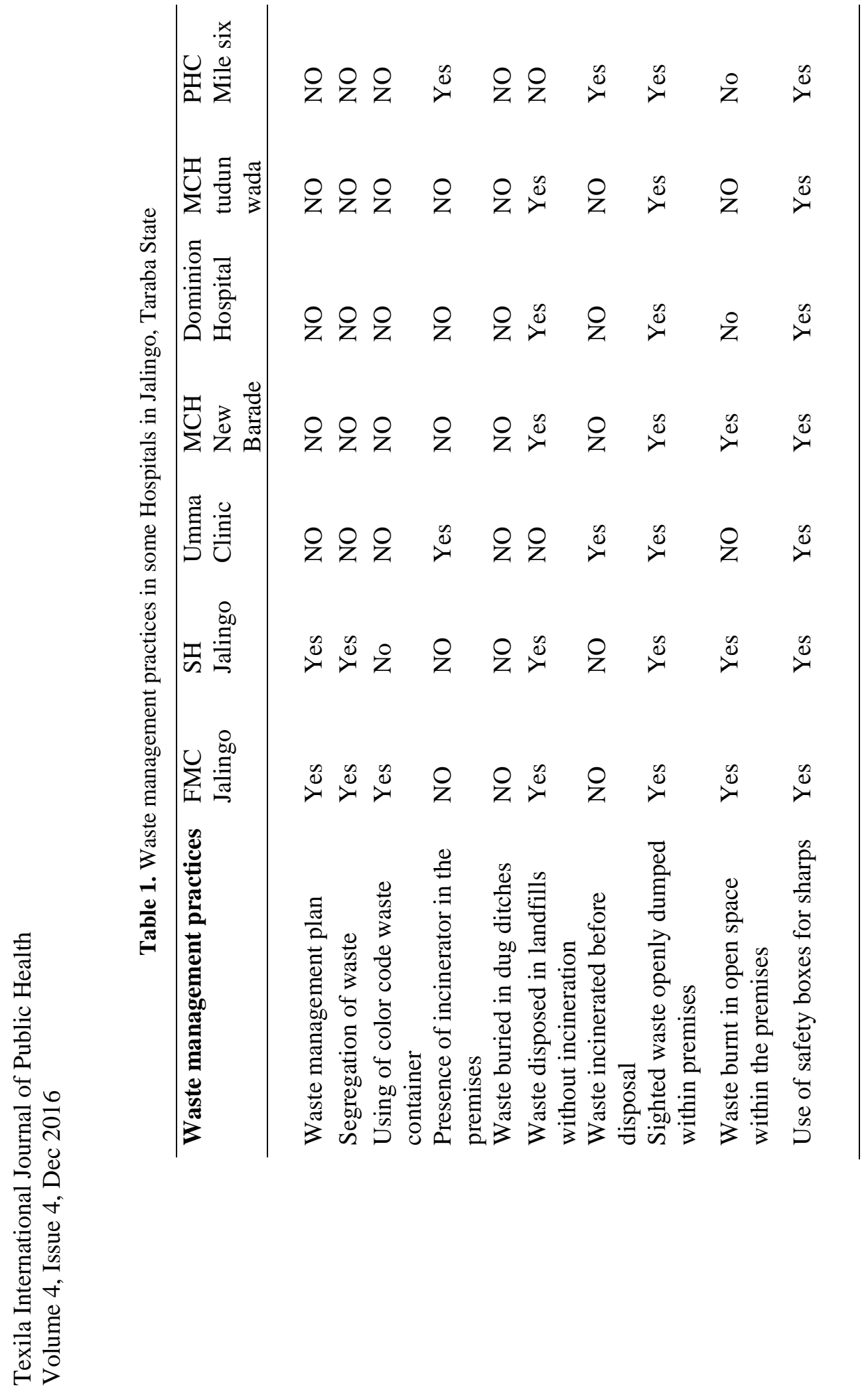


Table 2.

\begin{tabular}{lll}
\hline Waste management practices & $\begin{array}{l}\text { No of facilities } \\
\text { visited engaged in } \\
\text { the practice }\end{array}$ & $\begin{array}{l}\text { \% of facilities } \\
\text { visited }\end{array}$ \\
\hline
\end{tabular}

Waste management plan

Segregation of waste

Using of color code waste container

Presence of incinerator in the premises

Waste buried in dug ditches

Waste disposed in landfills without

0

5 incineration

Waste incinerated before disposal

Sighted waste openly dumped within premises

Waste burnt in open space within the premises

Use of safety boxes for sharps 1

1

14.3

100

3

42.9

7

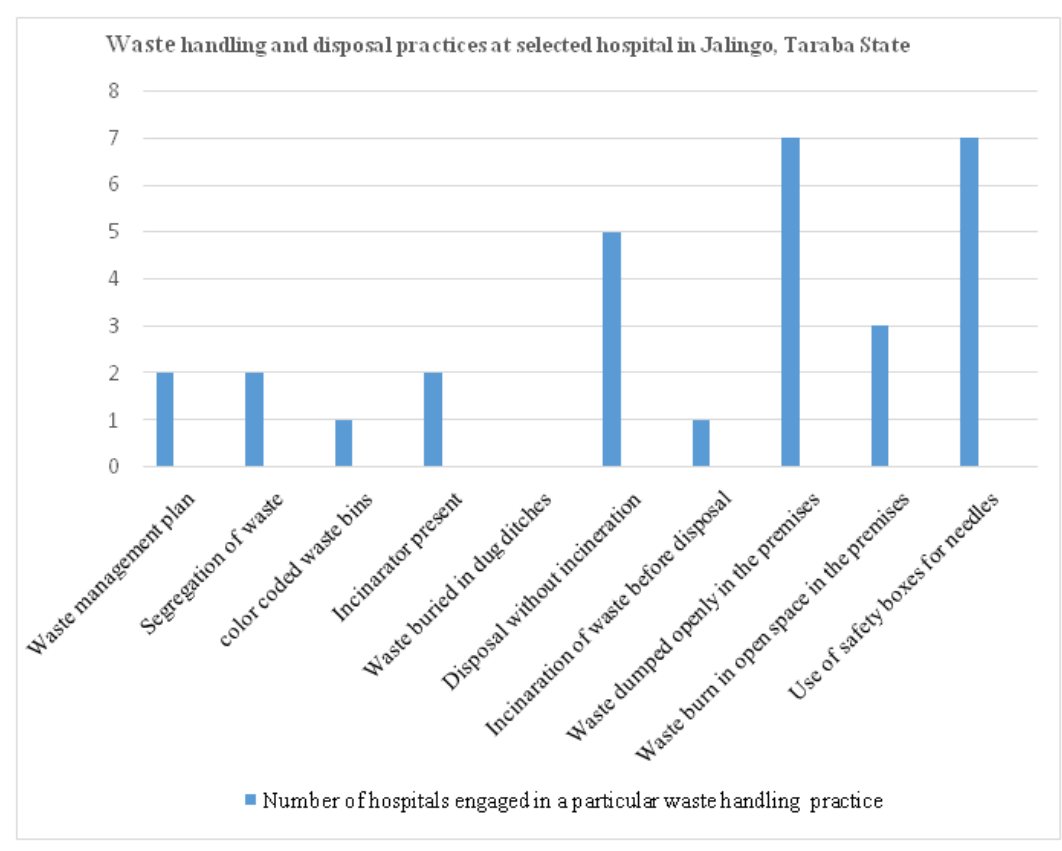

Fig.1.1

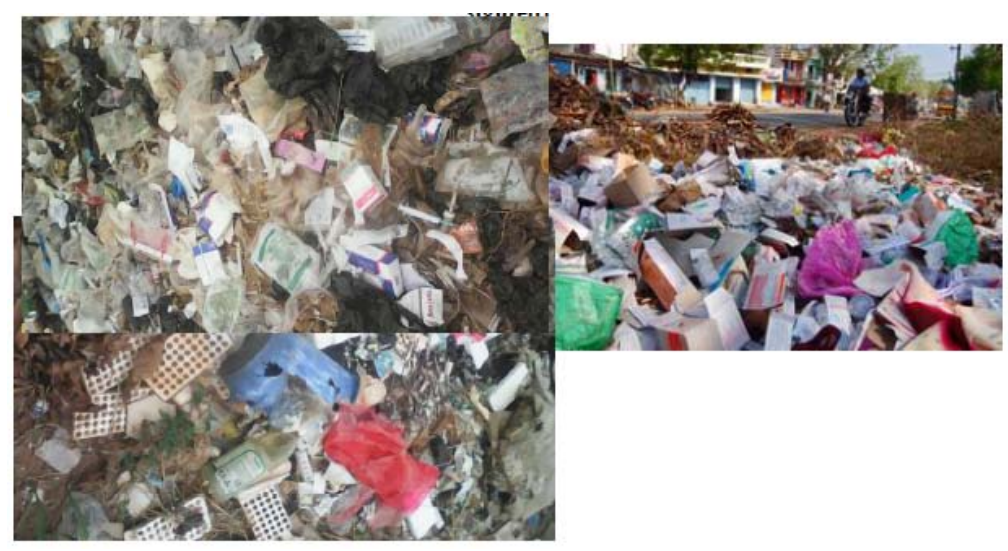


Texila International Journal of Public Health

Volume 4, Issue 4, Dec 2016

Fig 1.2 Pictorials (Pictures of improper hospital waste dumping sighted)

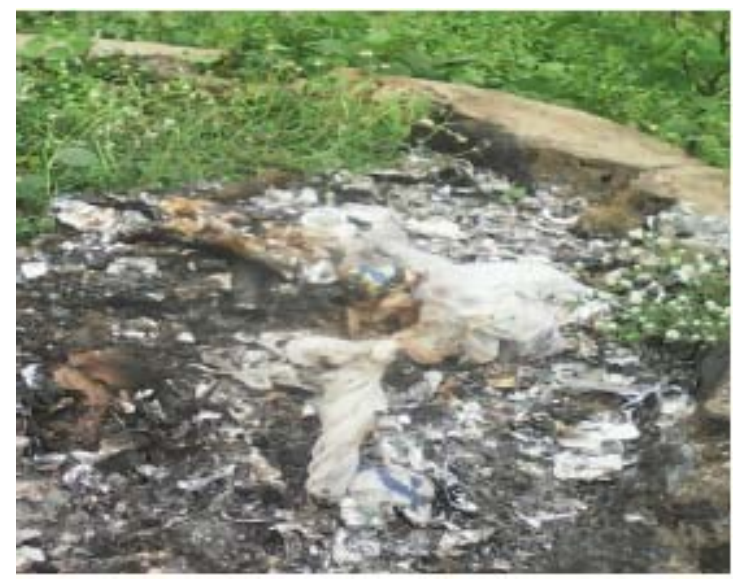

Waste at dump sites before conveying to landfills

Waste burn in open space within facility premises

\section{References}

[1] Abah SO, Ohimain EI (2010). Assessment of Dumpsite Rehabilitation Potential using the Integrated Risk Based Approach: A case study. Online at http://www.academicjournals.org/jphe. Accessed October 9, 2015.

[2] Abah, S. O., Ohimain, E. I (2011). Healthcare waste management in Nigeria: A case study. Journal of Public Health and Epidemiology Vol. 3(3), pp. 99-110, March 2011. Available online at http://www.academicjournals.org/jphe ISSN 2141-2316 (C2011 Academic Journals. Accessed October 19, 2015.

[3] Abdulraheem I. S., Olapipo A. R. Amodu M. O. (2012). Primary health care services in Nigeria: Critical issues and strategies for enhancing the use by the rural communities. Journal of Public Health \& Epidemiology Vol. 4(1), pp. 5-13, January 2012. Available online at http://www.academicjournals.org/JPHE DOI: 10.5897/JPHE11.133 ISSN 2141-2316.

[4] Adegbita M. A, Nwafor S. O, Afon A, Abegunde A. A, Bamise C. T (2010). Assessment of dental waste management in a Nigerian tertiary hospital. Waste. manag. Res., 28: 769-777.

[5] Ademiluyi, I.A., Aluko-Arowolo, S.O. (2009) Infrastructural distribution of healthcare services in Nigeria: An overview, Paper review. Journal of Geography and regional planning vol. 2(5) pp. 104110, May 2009. Available online http://www.academicjournals.org/article/article1379432402_Ademiluyi\%20and\%20AlukoArowolo.pdf. Accessed October 19, 2015.

[6] Adindu, A \& Asuquo, A. (2013). Training human resources for the $21^{\text {st }}$ Century Nigerian Health Sector. Global Journal of Human Resource Management Vol. 1, Issue 3, pp.1-11, September 2013 Published By European Centre for Research Training and Development UK. http://www.eajournals.org/wp-content/uploads/

[7] Awodele, O., Adewoye, A. A., \& Oparah, A. C. (2016). Assessment of medical waste management in seven hospitals in Lagos, Nigeria. BMC Public Health, 16, 269. http://doi.org/10.1186/s12889-016-2916-1

[8] Babatola, J.O (2008). A Study of Hospital Waste Generation and. Management Practice in Akure, Nigeria. www.ajol.info/index.php/afrrev/article/viewFile/41074/8499

[9] Coker (2009). Medical waste management in Ibadan, Nigeria: Obstacles and Prospects. February 2009. Waste Manag., 29(2): 804- 811.

[10] International Organization for Migration - IOM (2014). Needs Assessment of the Nigerian Health Sector. Available at https:/nigeria.iom.int/sites/default/files/newsletter/

[11] Itam, H. I and Adindu, A (2012). Health Security in Africa and Quality of Health Services. Developing Countries Studies, vol.2, 11, 43 -50. 
[12] National strategic health development plan (NSHDP) 2009-2015

http://www.internationalhealthpartnership.net/fileadmin/uploads/ihp/Documents/Country_Pages/Nigeri a/Nigeria\%20National\%20Strategic\%20Health\%20Development\%20Plan\%20Framework\%2020092015.pdf

[13] Olakunle, B. O (2012). Public Healthcare financing in Nigeria: Which way forward? An article review. Annals of Nigerian Medicine / Jan-Jun 2012 / Vol 6 | Issue 1. Downloaded free from http://www.anmjournal.com, October 18, 2015, IP: 105.112.20.120

[14] Olaleye, F.(2014). Human resource management in health care delivery systems: Challenges, trends and strategies. Healthcare and Leadership series, Pharma news. Available at http://www.pharmanewsonline.com/human-resource-management

[15] Onisanwa, I.D. (2013). The Impact of Health on Economic Growth in Nigeria. Journal of Economics and Sustainable Development www.iiste.org ISSN 2222-1700 (Paper) ISSN 2222-2855 (Online) Vol.5, No.19, $2014 . \quad$ Available at http://www.iiste.org/Journals/index.php/JEDS/article/viewFile/16114/16445

[16] PATH (2009). Achieving effective sharps waste management in GAVI host countries. A proposed approach with estimates of cost 2006 Available at http://www.Path.org/files/TS_ach_eff_swm.pdf.

[17] Timothy, G., Irinoye, O., Yunusa, U., Dalhatu A., Ahmed, S. Suberu, A. (2014). Balancing Demand, Quality and Efficiency in Nigerian Health care Delivery system. European Journal of Business and Management ISSN 2222-1905 (Paper) ISSN 2222-2839 (Online)

[18] Toyobo A.E., Baba A.O, Oyeniyi A.B. (2012) Appraisal of university teaching hospital medical waste management in Nigeria: Case Studies of University College Hospital (UCH) Ibadan and Obafemi Awolowo University Teaching Hospital (OAUTH) Ile-Ife, Nigeria. Vol.6, No.23, 2014. Retrieved October 18, 2015 from: www.iiste.org

[19] Uneke, C. J., Ezeoha, A. E., Ndukwe, C. D., Oyibo, P. G., \& Onwe, F. (2010). Development of Health Policy and Systems Research in Nigeria: Lessons for Developing Countries' Evidence-Based Health Policy Making Process and Practice. Healthcare Policy,6(1), e109-e126. https://www.ncbi.nlm.nih.gov/pmc/articles/PMC2929895/

[20] Welcome, M. O. (2011). The Nigerian health care system: Need for integrating adequate medical intelligence and surveillance systems. Journal of Pharmacy \& Bioallied Sciences, 3(4), 470-478. http://doi.org/10.4103/0975-7406.90100. Accessed October 19, 2015 from http://www.ncbi.nlm.nih.gov/pmc/articles/PMC3249694/

[21] WHO (1999). Safe management of wastes from health-care activities, edited by A. Prüss, E. Giroult and P. Rushbrook. Geneva, WHO, 1999, 228 pages. Available at: http://www.who.int/water_sanitation_health/Environmental_sanit/MHCWHanbook.htm

[22] WHO (2012). Ten facts on Universal health coverage. Features: fact files May 2012. Available at http://www.who.int/features/factfiles/universal_health_coverage/en/

[23] WHO (2014) Safe management of wastes from health-care activities / edited by Y. Chartier et al. - 2nd ed. http://www.healthcare-waste.org/fileadmin/user_upload/resources/Safe-Management-ofWastes-from-Health-Care-Activities-2.pd

[24] WHO (2015). Health systems: Tracking Universal health coverage. Accessed October 15, 205 from: http://www.who.int/healthsystems/en/

[25] WHO (2007). Towards better leadership and management in health. Report on International consultation on strengthening leadership and management in low income countries, February 2007. pp

2-13.http://www.who.int/management/working_paper_10_en_opt.pdf?ua=1

[26] WHO (2005). Management of Solid Health-Care Waste at Primary Health-Care Centres: A Decision-Making Guide. World Health Organization, Geneva, 2005, 57 pages. ISBN 9241592745.

Available at: http://www.who.int/water_sanitation_health/medicalwaste/decisionmguide_rev_oct06.pdf Accessed October 20, 2015.

[27] World Bank (2007). Healthy Development: The World Bank Strategy for HNP Results Annex L-April 24, 2007. Available at.

http://siteresources.worldbank.org/HEALTHNUTRITIONANDPOPULATION/Resources/2816271154048816360/AnnexLHNPStrategyWhatisaHealthSystem/ 


\title{
Knowledge and Practices Regarding Psychosocial Aspects of Palliative Care among Healthcare Workers in Ohangwena Region, Namibia
}

\author{
Article by Hileni Niikondo ${ }^{1}$, Kabwebwe H. Mitonga ${ }^{2}$ \\ ${ }^{1}$ MPH, Public Health, Texila American University \\ ${ }^{2}$ PHD, Public Health, University of Namibia \\ E-mail: hniikondo@unam.na
}

\begin{abstract}
In Namibia, palliative care service is necessitated by the situation of progressive life limiting illnesses, which demand access to psychosocially appropriate holistic palliative care. Little is known about the knowledge and practice of healthcare workers on the psychosocial aspects of holistic palliative care.

This study was conducted to critically analyze the knowledge and practice of healthcare workers on psychosocial aspects of holistic palliative care and identify their training needs.

A cross-sectional analytical study was conducted in the public health facilities in Ohangwena region, amongst the randomly selected sample of 56 healthcare workers. Structured questionnaires were self administered to capture the respondent's knowledge and skills.

Respondents mean age was $36.2 \pm 9.81$.Male respondents were 20 (35.71\%) while female were 36 (64.29\%). Of the 56 healthcare workers who participated in the study, 2 (3.6\%) were medical practitioners, 44 (78.6\%) nurses, 1 (1.8\%) physiotherapists, 3 (5.4\%) social workers and 6 (10.7\%) pharmacists. Mean years of professional experience was 9.43 \pm 9.62. Most healthcare workers 39 (69.6\%) indicated not received any training on holistic palliative care.

Knowledge of correct classification for morphine was associated with access to internet $(p<0.05)$. There was a significant association between those confronted by palliative care situation and knowledge of morphine $(p<0.05)$. Knowledge of pain intensity among children was significantly associated with access to internet $(p=0.01)$. Healthcare workers lack knowledge in the psychosocial aspects of holistic palliative care which can implicate the quality of care to patients. This study suggested training of healthcare workers as well as internet access.
\end{abstract}

Keywords: Palliative care, healthcare workers, knowledge, psychosocial care, pain, training

\section{Introduction}

Palliative care and psychosocial palliative care in particular is necessitated by the increased prevalence of life limiting conditions. Namibia has high rate of HIV/AIDS infection of $13.3 \%$ among adults, that is contributing to the high demand of appropriate palliative care, which is part of human rights to healthcare (HPV Information Centre, 2014).In the same vein, Namibia has prevalence of cancer of different body systems which necessitate the need for palliative care. These include cancer of the cervix, cancer of the rectum, cancer of prostate gland and other organs. Patients with cancer endure many difficulties which include experiences of pain and psychological symptoms such as depression, social isolation and spiritual distress especially in the advanced stages of the disease (African Palliative Care Association, 2013). In addition, African Palliative Care Association (2013) also indicated that, family members of those afflicted by cancer also suffer emotional and financial burden related to the demand for care.

As the prevalence of life limiting illnesses increases, the clients' ability to self care diminishes, and more demand is put on healthcare workers as well as on the caregivers.

Therefore, training of healthcare workers in palliative care is necessary for them to have the appropriate knowledge, skills and competencies and to translate these experiences into practices. 
Moreover, training is required for the purpose of changing attitudes, beliefs and values, thus making the palliative care healthcare workers able to perform their duties effectively and ethically (APC, 2014).

Due to the increased need to provide palliative care services, the Ministry of Health and Social Services (MOHSS) of Namibia, complied with the demand of international request by drafting the palliative care policy. The policy indicated that healthcare workers who provide palliative care should be trained to obtain the knowledge and competence into the area of palliative care as per guidelines (Ministry of Health and Social Services, 2013), (African Palliative Care Association, 2011). Equally of important is that, the drafted policy on palliative care stipulated the need for the coordinator to be responsible for the overall implementation to ensure success (Ministry of Health and Social Services, 2013).

In that regards, few healthcare professionals who are mostly expected to be in close proximity to patients in need of care were trained in palliative care. The training covered areas that are important in the provision of palliative care and include: communication in palliative care; death awareness; breaking the bad news; nutrition and hydration in end of life care; self awareness and burnt out; the dying process and support to family and patient; grieve and bereavement; dealing with common reaction to loss and fear; sexuality and gender issues in palliative care; ethical issues in palliative care; spiritual and cultural issues among others (Ministry of Health and Social Services, 2013),(African Palliative Care Association, 2011), (Chipare, 2015). Similarly, it is the duty of trained palliative care healthcare workers to act as focal people, and providers of psychosocial and spiritual care in a palliative care team. It was also noted by Morrison et al. (2011), that in the absence of palliative care services patients may spend much time in hospitalization and that led to burden of diseases and overspending of public resources.

The proper functioning of palliative care unit should ensure training of healthcare workers in holistic palliative care components which are physical; spiritual, emotional and social needs, basic healthcare, general hygiene and symptom management. However, Davidson et al. (2007) reported a similar situation that, patients with life limiting conditions continue to endure many difficulties related to psychosocial and spiritual needs which affect their health and healing.

Therefore, as a result of declined practice of palliative care service in Namibia, it is anticipated that the patients in need of palliative care may not receive the necessary care in areas of end of life care, particularly care regarding communication in palliative care and breaking the bad news; as demanded by the life limiting illnesses. Similarly, healthcare workers are unaware of the need of palliative care service as there is often no consistent referral process or criteria (African Palliative Care Association, 2009).

As a result of declined palliative care services it is expected that burden of disease in the healthcare sectors, increased morbidity and mortality among patients, may continue to affect patients in life limiting conditions. In the same vein, it is anticipated that workload, burn out and stress among healthcare workers may occur, that result into poor work performance.

There is no available evidence that could describe the rationale for the declined practice of holistic palliative care in the Namibian public health services. It is therefore not known if the declined palliative care service is associated with the competence of healthcare workers on the psychosocial, spiritual aspects of palliative care. Hence, the study aimed to critically analyze the knowledge and practice of healthcare workers, on psychosocial aspects of palliative care service in the public health facilities in Ohangwena region and to identify the training needs.

The aim of the study was to critically analyze the knowledge and practice of healthcare workers on psychosocial aspects of palliative care and identify the training needs.

The findings from the study will inform policy makers, providers and implementers of palliative care services on the current state of psychosocial aspects of palliative care. Furthermore, this study contributed to the main study on the development of the conceptual framework of palliative care services in the Namibian public health services. 
The study was delimited to Ohangwena region where there is high profile of HIV patients and ART defaulter rate. Challenges with patients follow up was reported due to cross border activities with Angola (Ministry of Gender Equality and Child Welfare, 2009).Due to the limited resources such as time and financial constraints, the study was only conducted in Ohangwena region and that limit the generalization of the findings.

Knowledge score could not be computed to measure the degree of competences and to calculate the effect measure (odds ratio) in order to identify causality.

The study included healthcare workers who have been employment for the duration of 30 days and who were allocated at the following departments: Medical/surgical units, children's wards, outpatient/ causality departments, oncology units, tuberculosis units, HIV/AIDS clinics, primary health care outreach program, pharmacies, orthopedics units and social work departments.

The following units were excluded; maternity wards, mental health units, theatre, dental departments, intensive care units (ICU) and departments that were not in direct contact with patients.

\section{Methods}

A cross-sectional analytical study was conducted in the public health facilities in Ohangwena region.

\section{Study population}

The study population was healthcare workers at public healthcare facilities. The target population was healthcare workers that were providing care to patients with life limiting conditions at the eligible units. The population size of healthcare workers was 77 which consisted of medical practioners, nurses, physiotherapists, social workers and pharmacists.

\section{Sampling method}

The sample frames were obtained from the administrators of each respective hospital. A stratified sampling method was used to select participants for each professional category. The sample size was calculated by entering values into the following required criteria in Epi Info StatCalc in order to obtain a desired sample size. The following criteria were used: population size of 77 , expected frequency of $50 \%$, confidence limit of $5 \%$ and confidence level of $95 \%$. A sample size of 65 was obtained however only 56 healthcare workers completed the questionnaires.

\section{Data collection and tools}

A structured questionnaire with closed ended questions containing psychosocial knowledge and practice-based variables was designed for healthcare workers and it was developed in English which is an official language used in the Namibian public health system.

Variables in the measuring tools constituted of socio-demographics status of healthcare workers as well as indicators related to knowledge and practices regarding psychosocial aspects of holistic palliative care.

Validity control measures were assured by consulting experienced researchers at the University of Namibia, and the academic advisors at Texila American University, who offered guidance.

In this study, accurate representation of the total population under study, was identified and scientific sampling methods used to determine reliability as stipulated by Golafshani (2003). The research instrument was validated with experts in the field and through pilot testing in Oshana region, which did not form part of the selected regions. Piloting was done to ensure consistency and to remove duplications as well as spelling mistakes.

\section{Field work}

Questionnaire for healthcare workers was handed over at Ohangwena health region at selected health facilities namely, Eenhana, Okongo and Engela hospital respectively. The selected sites were 
substantiated by regional profiles of most patients who were in need of palliative care and the challenges experienced with anti-retroviral treatment (ART) defaulters.

Self administered questionnaires were handed over by the researcher to participants and were collected after two days. Giving two days was done to ensure that participants understood all questions in order to reduce omissions and also to facilitate response rate. Data was collected during the period of one month after approval to conduct the study.

\section{Data analysis}

Quantitative data was analyzed using SPSS version 24 software. Data was entered into computer to create electronic data base and was cleaned for completeness and accuracy. The descriptive statistics was used to summarize the data. The data was then presented as tables, graphs and charts.

Inferential statistic for categorical variables was done with Pearson Chi-square test to calculate associations. A p-value of less than 0.05 for all analysis was considered statistically significant to reject a null hypothesis.

\section{Ethical issues}

Approval to conduct the study was granted by the research committee of Texila American University. Permission was obtained from the permanent secretary of the Ministry of Health and Social Services (MOHSS) of Namibia, as well as from Ohangwena regional health director. Participants were provided with all necessary information before they decide to sign the consent voluntarily. Participants were advised not to write their names or any form of identity on the form to ensure anonymity. All information was kept safe in a computer which was locked with a password to ensure confidentiality. Participants were informed that they had the right to withdraw at any time with no fear of being victimized.

\section{Results}

A total of 56 participants took part in the study. The mean age of respondents was $36.2 \pm 9.81$. Respondents consisted of 20 (35.7\%) males and 36 (64.3\%) females. Their marital status varied from single 27 (48.2\%), married $26(46.4 \%)$ and widow 3(5.4\%). Among the fifty-six respondents, 2 (3.6\%) were medical officers, 44(77.6\%) nurses, 1 (1.8\%) physiotherapist, 3(5.4\%) social workers and $6(10.7 \%)$ pharmacists.

Table 1. Representing the highest qualification of respondents

\begin{tabular}{|l|l|l|}
\hline Variables: & Frequencies $(\mathrm{n}=56)$ & Percentages (\%) \\
\hline Certificate & 24 & $42.9 \%$ \\
\hline Basic diploma & 9 & $16.1 \%$ \\
\hline Basic degree & 19 & $33.9 \%$ \\
\hline Post graduate diploma & 3 & $5.4 \%$ \\
\hline PhD (doctorate degree) & 1 & $1.8 \%$ \\
\hline
\end{tabular}

From table one above, the highest percentages (42, 9\%) were those with certificates followed by $33.9 \%$ of basic degree holders, while the least (1.8\%) was PhD holders.

The professional rank of the respondents range from pharmacist assistants 4 (7.1\%), senior pharmacist assistants 1 (1.8\%), pharmacist, 1 (1.8\%), social workers 3(5.4\%), principal physiotherapist 1 (1.8\%), medical officers 2 (3.6\%), enrolled nurses 18 (32.1\%), registered nurses $21(37.5 \%)$ and senior registered nurses $5(8.9 \%)$.The respondents mean years of professional experience was $9 \pm 9$.63.The minimum years of professional experiences was 1 year and the maximum was 40 years. Twenty respondents (35.7\%) indicated being involved in leadership while 36 (64.3\%) specified not involved in leadership at the healthcare facility.

Among the respondents, 9 (16.1\%) were studying while 47 (83.9\%) were not studying during the time of data collection. Regarding access to computer, one participant (1.8\%) did not respond, 37 
(66.1\%) had access to computer, while 18(32.1\%) had no access to computer. Two participants (3.6\%) did not respond on the question if they had access to internet, while 39(69.6\%) had access to internet and 15 (26.8\%) did not have access to internet. Two participants (3.6\%) did not respond on the question if they had access to E- library, while 4 (7.1\%) had access to e-library and 50 (89.3\%) did not have access to e-library. Two participants (3.6\%) did not respond on the question if they had access to physical library, while 6(10.7\%) had access to physical library, 48(85.7\%) did not have access to physical library.

With regard to the awareness and practice of palliative care, 38 (67.9\%) indicated being confronted by palliative care situation at work, 18 (32.1\%) reported not confronted by palliative care situation at work. The respondents, 13 (23.2\%) had relative receiving palliative care, 43(76.8\% had no relative who is receiving palliative care. Eight respondents (14.3\%) had focal person for palliative care available at work place while $48(85.7 \%)$ had no focal person for palliative care at work. Out of 56 who participated in the study, 10 (17.9\%) were placed in a palliative care service before, while most 46 (82.1\%) expressed no previous palliative care placement.

From figure one, the highest percentages (47\%) of respondents indicated not allocated to any palliative care team.

\section{Palliative care teams}

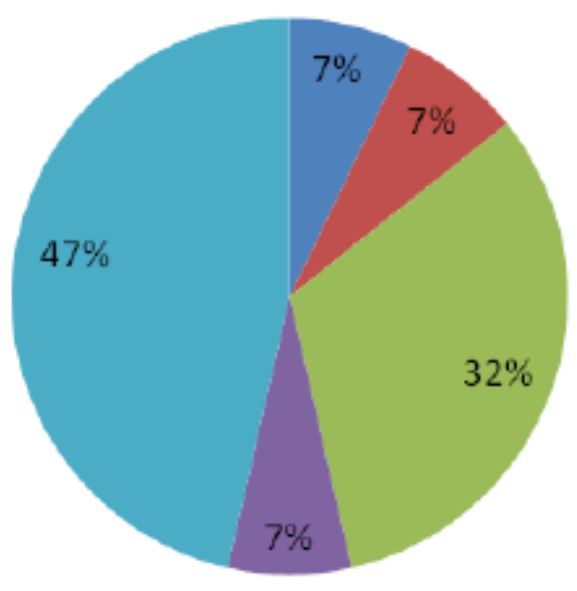

Palliative care units

Hospital support

Outpatient department or

clinic

Psychosocial supports

Had no palliative care

team

Figure1: Pie chart representing the palliative care team of placement of 56 respondents.

The training of holistic palliative care was attended by 17 (30.4\%) while 39 (69.6\%) specified not trained. Those who responded on the type of training acquired, 2 (3.6\%) had a formal palliative care diploma, 6 (10.7\%) formal degree, 4 (7.1\%) short certificate, 4 (7.1\%) in-service training, while 36 (64.3\%) reported no formal palliative care training. Regarding the duration of palliative care training, $9(16.1 \%)$ had days of palliative care training, 3 (5.4\%) were trained in weeks, 3 (5.4\%) were trained in months, 5 (8.9\%) were trained in years and 36 (64.3\%) had no training. Few 17 (30.4\%) took part in palliative care research compared to most, 39 (69.6\%) who did not take part in research.

With regard to the knowledge and practice of the psychosocial, aspects of palliative care, 17(30.4\%) respondents incorrectly indicated that death and dying should not be discussed with patients while 39(69.6\%) respondents correctly agreed that death and dying should be discussed with patients and family. However, there was a significant association between marital status and if death and dying should be discussed with patients $(\mathrm{p}=0.04)$. Among the 27 single respondents, $5(29.5 \%)$ respondents inappropriately indicated not discussing death and dying while 22 (56.4\%) correctly indicated discussing death and dying as the method of spiritual palliative care. Among the 26 married 
respondents 12 (70.6\%) incorrectly indicated not discussing death with patients while 14 (53.8\%) agreed that death should be discussed with patients.

On the knowledge of practice active listening and nonjudgmental attitude when providing psychosocial palliative care, among the 27 single respondents $26(52 \%)$ indicated correctly to the practice of active listening as a good method of providing psychosocial palliative care, while 1(16.7 \%) did not think is important to listen to patients without judgment. Among the 26 married respondents 23(46.0\%) indicated that is important to listen to patient without judgment while $3(50.0 \%)$ felt is less important to listen without judgments. Among the 3 widows, $1(2.0 \%)$ indicated that the practice of active listening and nonjudgmental attitude is needed while 2(33.3\%) did not feel that the practice of active listening and nonjudgmental attitude is worth. However, there was a statistical significant association between the knowledge of active listening attitudes and marital status $(\mathrm{P}=0.04)$, with appropriate knowledge among the widows (33.3\%).

With regard to if visitation by spiritual leaders, mentors and pastors should be discouraged, 48(92.3\%) respondents pointed out that visitation by spiritual leaders should not be discouraged, but on the other hand a significant difference existed between discouraging spiritual leaders to visit their clients based on access to E-library $(\mathrm{P}=0.00)$.

On the knowledge of common barriers to breaking the bad news to patients and families in palliative care, there was no significant association identified based on if respondents felt responsible for maintaining the patient's hope ( $>>0.05$ ). On the contrary, among the 56 respondents, $42(75.0 \%)$ wrongly indicated that cure is the goal of palliative care, compared to $14(25.0 \%)$ who indicated that the goal of palliative care is not to cure. In the same way, a significant association between the goal of palliative care and access to internet was specified $(\mathrm{P}=0.04)$ with most $31(73.8 \%)$ of those who had access to internet, incorrectly specified that cure is the goal of palliative care.

The majority $55(98.2 \%)$ pointed out that the family need to be included in decisions relating to patient care, while $1(1.8 \%)$ felt that the family should not take part in patient care decisions. Thirty three, (58.9\%) responded that photos and personal belongings should not be discouraged when providing palliative care. A significant association between if the use of photos and personal belongings should be discouraged when providing palliative care, was discovered based on marital status ( $\mathrm{P}=0.001)$ with half, $(50 \%)$ of the married respondents stated that the use of photos and personal belongings should be discouraged among palliative care patients.

To the question if it is proper to always consider personal own values before the values of patients, the respondents, 16 (28.6\%) incorrectly indicated considering own value compared to 40 (71.4\%) who stated considering the values of patients before their own values. In opposition, a statistical significant association between considering personal own values before the values of patients do exist based on if the respondent participated in palliative care research $(\mathrm{P}=0.02)$.

Regarding the knowledge if it is proper to refer patients to appropriate persons, who can facilitate the practice of specific customs, 50 (89.3\%) of the respondents correctly felt it is proper to refer patients while $6(0.7 \%)$ indicated that it is not proper to refer patients.

In view of, if time and privacy constraints were reasons for not discussing sexuality with patients, out of the 56 respondents, 42 (75.0\%) experienced challenges, while 14 (25.0\%) did not experience challenges. However, respondents' attitudes on sexuality significantly varied based on access to Elibrary, with most $40(80.0 \%)$ of those without access to E-library experiencing challenges ( $\mathrm{p} \leq 0.05)$.

On the question to define palliative care for children, 51 (91.1\%) respondents correctly defined palliative care as the active total care of the child's body, mind and spirit, while 5 (8.9\%) did not define palliative care as total care. Conversely, a significant association was established based on being confronted with palliative care at the work place $(\mathrm{P}=0.016)$. On the other hand, $10(17.9 \%)$ respondents correctly indicated that palliative care treatment should continue throughout child treatment, 46 (82.1\%) stated that, palliative care treatment should discontinue. A significant association between if treatment should discontinue was indicated based on palliative care team. 
Respondents who belonged to hospital support team indicated high percentage $75.0 \%$ of discontinuing palliative care when the child receive treatment $(\mathrm{P}=0.031)$.

Among the participants, 45 (80.4\%) indicated that they assess the child's pain according to what the child says while, 18 (32.1\%) indicated that clinical sign is the only method to assess pain in children. A significant associations between assessing child's pain and respondent's research participation was found $(\mathrm{P}=0.036)$.

Out of 56 respondents, $8(14.3 \%)$ incorrectly categorized codeine phosphate into step one analgesics, while 48 (85.7) correctly placed codeine into steps 2 analgesics. On the contrary, 35 (62.5\%) respondents incorrectly classified morphine, while 21 (37.5\%) correctly classified morphine into step 3 analgesics. Knowledge of morphine classification significantly varied based on the duration of palliative care training $(\mathrm{P}=0.001)$, with $71.4 \%$ of those not trained in palliative care misclassified morphine.

Among the respondents, 47(83.9\%) used a referral form while 9 (16.1\%) stated not using the referral form. However, association between the use of referral form and participants' highest qualification was significant $(\mathrm{P}=0.007)$.

\section{Discussion}

A total of 56 healthcare workers participated in the study that consisted of medical officers, nurses, physiotherapists, social workers and pharmacists. The mean age of healthcare workers was 36.土 9.81). Meanwhile, previous study by Selman, Young, Vermandere, Stirling, \& Leget, (2014), among palliative care physicians, nurses and chaplains, reported a mean age of $48.5 \pm 10.7$, an age older than the age of participants in this study. Younger age as reported in this study could have an implications related to the impact of experience on healthcare worker's knowledge on palliative care. Knowledge implications could influence the quality of psychosocial palliative care provided to patients with life limiting illness. In this study, female participants were more than males while more male participants (64\%) than females were reported for the study on international survey of palliative care researchers and clinicians. The findings are different from the study conducted by Selman et al., (2014). Participant's responses also varied according to their marital status of being either single, married, or widow. The majority (67.9\%) reported being confronted with palliative care situation in the work place even though most (69.6\%) specified not trained in palliative care. The fact that they encounter palliative care situations without proper training, may affect the quality of holistic palliative care provision. Similarly, Selman et al. (2014) also noted that, cancer patients' spiritual needs were not assessed well by the healthcare team as a result of inadequate knowledge and skills on psychosocial palliative care among the healthcare workers. The respondents mean years of professional experience was 9 years which is a sufficient period to gain skills. The findings is congruent with the study by Bronheim, Can, \& Anthony (2015), who stipulated that healthcare worker's experience influenced their commitment to provide quality services and supports of patients.

Although the majority of respondents indicated being confronted by palliative care situations, only few had their relatives that received palliative care. This means, healthcare workers experienced palliative care situations more at work than at home. Lack of the focal person for palliative care in the healthcare facility as sighted by most respondents, may result into poor supervision and support which will eventually affect the provision of psychosocial palliative care to the patients. In the same vein, it was stipulated by Andershed et al. (2007) that, palliative care activities require more managerial and leadership training and support for palliative healthcare workers.

In this study, it was noted that the placement of healthcare workers in palliative care team was not supportive of psychosocial palliative needs of patients. The absence of palliative care placement could prevent healthcare workers from gaining experiences and skills to assist patients in need of palliative care and that could also affect the quality of care. It was also stipulated in (Global Partners in Care, 2014) that, clinical placements were regarded as appropriate for both healthcare workers at the time of 
training, in order to gain experience with palliative care practice. The gained experience could be adapted in their own practices in future to ensure proper continuity of patients care.

The training of holistic palliative care was attended by few in relation to the majority. Those who responded on the type of training acquired, few had formal palliative care training. Training increase the ability of the practioners to build resilience to stress and burnt out. Similarly and as emphasized by Back, Steinhauser, Kamal, \& Jackson (2016), lack of training can expose healthcare professionals to burnout and psychological exhaustion that will hamper their ability to support patients. The majority did not take part in palliative care research and that may lead to the failure to account for expenditures and outcome in the absence of monitoring and evaluation of their activities. A study by Morrison et al.(2011), emphasized the need for palliative care studies for economic and policy formulation purposes.

Regarding if death and dying should be discussed with patients and family during palliative care, single and married persons equally indicated discussing death and dying as the method of spiritual palliative care with patients, which is the correct method. There was a significant association between marital status and knowledge of discussing death $(\mathrm{p}=0.04)$. Similarly, there was a statistical significant association between active listening attitudes of participants and marital status. $(\mathrm{P}=0.04)$. Participants had no equal knowledge of spiritual care with respect to their marital status.

Meanwhile, a significant difference of knowledge also existed between discouraging spiritual leaders to visit their clients based on access to E-library and to physical library $(\mathrm{P}=0.00)$ and $(\mathrm{P}=0.030)$ respectively. This means that participants had no equal chance of knowledge on this matter based on library access.

Lack of proper information on spiritual palliative care could affect the way a service is rendered to patients facing end of life. Another study on the experience of patients about the fear of death indicated that lack of information on their prognosis led to fear of dying. It is therefore imperative that healthcare workers discuss death with patients and family to prepare them for end of life expectations (Gardiner et al., 2009).

Healthcare professionals need to be mindful when breaking bad news to patients who are faced with challenges of illness prognosis in order to maintain hope. Moreover, it was suggested by Olsman, Leget, Onwuteaka-Philipsen, \& Willems (2014), that healthcare professionals should be realistic by combining hope with the truth, in order to help patients to cope with hopeless situations.

Conversely, there was a significant association between the knowledge on the goal of palliative care and access to internet $(\mathrm{P}=0.04)$. Most of those who had access to internet incorrectly specified that cure is the goal of palliative care

It is crucial that the goal of palliative care be known equally among healthcare workers and to be mindful when accessing information from the internet in order to avoid misconceptions.

The majority of the respondents knew that the family need to be included in decisions related to patient care. On the contrary, half of the married respondents stated that photos and personal belongings should be discouraged among palliative care patients, which is a bad practice.

Allowing patients and family to use memories of their loved ones may enhance hope that could be easily destroyed by disclosure of the truth. Another study by Olsman et al. (2014) noted that disclosure of medical information or use of the word 'palliative care' wipe out hope.

On the knowledge, if it is proper to always consider personal own values before the values of patients. Few respondents, incorrectly indicated considering own value. Respondent's knowledge differs across holistic palliative care training and research participation. The response of the respondents could be worrisome if they consider their own values in expense of patient values. It was suggested by Tan, Seah, Chua, Lim, \& Phua (2014), that patients need to establish their own values even if their wishes differ with their family members on treatment expectations.

The practice of referring patients to appropriate person who can facilitate the practice of specific norms was correctly indicated by the majority. However, there was a statistically significant 
association based on access to computer. It is essential that healthcare workers should respect the diversity of culture and work in harmony with patients and family in order to facilitate wellbeing.

Most of the respondents stated that, time and privacy constraints prevent them from discussing sexuality with patients. Those with limited access to E-library felt limited to discuss sexuality with patients. However sexuality and gender issues were observed as part of palliative care training for healthcare workers (African Palliative Care Association, 2012). Failure to discuss sexuality issues may expose patients to anxiety and that may affect their recovery.

When asked to define palliative care for children, majority correctly defined palliative care as the active total care of the child's body, mind and spirit.

On the contrary, the majority of respondents who belonged to hospital support team incorrectly indicated that palliative care treatment should discontinue when the child receive treatment on life limiting illness. Hospital support team could not define palliative care for children.

In the absence of proper definition for pediatric palliative care, holistic palliative care will not be possible from the time of diagnose throughout treatment and that may affect the prognosis of a child suffering from life limiting illness. A study by Morgan (2009), noted that pediatric palliative care should begin at the time of diagnosis if death is clearly expected, so that the child and parents are prepared for the outcome of illness.

Most participants indicated the correct practice of assessing the child's pain according to what child says, however, a significant associations of their practice was identified based on respondents 's research participation. This means that, the distribution of knowledge regarding assessing pain in children was not equal among the respondents. Another study by Bronheim et al.(2015), also noticed that lack of palliative care service for children affects children's recovery.

Knowledge on how to classify morphine significantly varied based on the duration of palliative care training $(\mathrm{P}=0.001)$, with most of those indicated not trained in palliative care misclassified morphine. However it was suggested in Malawi, that a hospital must have full-time, designated palliative care services and trained staff; registered palliative care patients; a regular supply of drugs, including morphine (Global Partners in Care, 2014).

With regard to the referral system, the majority indicated used a referral form, however, association between the use of referral form and participants' highest qualification was significant $(\mathrm{P}=0.007)$. It is therefore imperative if healthcare workers had equal exposure to the coordinated network system. The presence of proper referral network with functioning referral tools such as referral forms will enhance continuous follow up. It was also stated in The United Republic of Tanzania (2005), that the referral form should contain all the relevant information, including diagnosis and instructions on the current management and treatment in order to provide continuum of care at various levels.

\section{Conclusion}

This study concludes that there is inadequate knowledge and practice regarding psychosocial aspects of palliative care among healthcare workers in Ohangwena region. Lack of knowledge was based on lack of palliative care training among healthcare workers. Secondly, inadequate placement in palliative care team as well as limited exposure to internet also contributed to unequal knowledge distribution among healthcare workers.

\section{Recommendations}

This study recommends the following aspects as indicated by the findings in the study:

Organize workshops and seminars to train healthcare workers on the essential aspects of holistic palliative care especially on spiritual care, sexuality and gender issues, as well as cultural issues in palliative care.

Develop a standardized curriculum to educate healthcare workers about children's pain assessment and management as well as the use of opioids drugs, especially morphine.

Palliative care training should consider difference in age, as well as marital status to cater for variability. 
Facilitate the provision of internet and E- library to facilitate knowledge distribution of psychosocial aspects of palliative care among various healthcare professionals.

Appoint focal persons at district level to coordinate palliative care teams especially for the hospital palliative care services.

Establish a proper referral network with functioning referral tools such as referral forms, to ensure continuity of care.

\section{Acknowledgements}

The authors declare that no funds received for this study and no conflict of interest.

\section{References}

[1]. African Palliative Care Association. (2009). Palliative care situational analysis report. Ministry of Health and Social Services. Windhoek.

[2]. African Palliative Care Association. (2011). African palliative care association standards for providing quality palliative care across Africa. Retrieved from www.africanpalliativecare.org

[3]. African Palliative Care Association. (2012). Palliative care core curriculum. Uganda. Retrieved from www.africanpalliativecare.org

[4]. African Palliative Care Association. (2013). Palliative care for women living with HIV and cervical cancer. Kampala, Uganda. Retrieved from www.africanpalliativecare.org

[5]. Andershed, B., Sims, M. T., Authors, F., Davison, G., Davidson, J. E., Powers, K., ... Fish, A. (2007). Palliative care teams and organisational capability. Palliative Medicine, 24(1), 60-67. http://doi.org/10.1108/13527590210433357.

[6]. APC. (2014). Effective methods of teaching palliative care. A guide for educators and trainers in Africa. Kampala, Uganda. Retrieved from www.africanpalliativecare.org

[7]. Back, A. L., Steinhauser, K. E., Kamal, A. H., \& Jackson, V. A. (2016). Building resilience for palliative care clinicians: An approach to burnout prevention based on individual skills and workplace factors. Journal of Pain and Symptom Management. http://doi.org/10.1016/j.jpainsymman.2016.02.002.

[8]. Bronheim, S. M., Can, E., \& Anthony, B. J. (2015). Improving care coordination for African American and Hispanic children with special healthcare needs. Journal of Children's Services, 10(1), 45-56. http://doi.org/10.1108/JCS-04-2014-0023.

[9]. Chipare, M. (2015). A health education programme to enhance knowledge and communication skills of health care workers serving people living with HIV/AIDS on HAART in Namibia. University of Namibia. Retrieved from www.unam.na

[10]. Davidson, J. E., Powers, K., Hedayat, K. M., Tieszen, M., Kon, A. a, Shepard, E., ... Armstrong, D. (2007). Clinical practice guidelines for support of the family in the patient-centered intensive care unit: American College of Critical Care Medicine Task Force 2004-2005. Critical Care Medicine, 35(2), 605-622. http://doi.org/10.1097/01.CCM.0000254067.14607.EB.

[11]. Gardiner, C., Gott, M., Small, N., Payne, S., Seamark, D., Barnes, S., ... Ruse, C. (2009). Living with advanced chronic obstructive pulmonary disease: patients concerns regarding death and dying. Palliative Medicine, 23(8), 691-697. http://doi.org/10.1177/0269216309107003.

[12]. Global Partners in Care. (2014). For clinical placement in hospice and palliative care in Africa. Alexandria. Retrieved from www.globalpartnersincare.org

[13]. Golafshani, N. (2003). Understanding reliability and validity in qualitative research. The Qualitative Report, 8(4), 597-607. http://doi.org/10.3367/UFNr.0180.201012c.1305.

[14]. HPV Information Centre. (2014). Human papillomavirus and related cancers, Fact Sheet. Retrieved from www.hpvcentre.net

[15]. Ministry of Gender Equality and Child Welfare. (2009). Strengthening commitment and leadership of government to expand HIV and AIDS response, gender issues and women's empowerment. Journal of Petroleum Science and Engineering, 67(3-4), 179. http://doi.org/10.1016/S0920-4105(09)00154-5.

[16]. Ministry of Health and Social Services. (2013). Palliative care training report. Directorate of Ohangwena region. Windhoek. 
[17]. Morgan, D. (2009). Caring for dying children: Assessing the needs of the pediatric palliative care nurse. Pediatric Nursing, 35(2), 86-90.

[18]. Morrison, R. S., Dietrich, J., Ladwig, S., Quill, T., Sacco, J., Tangeman, J., \& Meier, D. E. (2011). The care span: Palliative care consultation teams cut hospital costs for medicaid beneficiaries. Health Affairs, 30(3), 454-463. http://doi.org/10.1377/hlthaff.2010.0929.

[19]. Olsman, E., Leget, C., Onwuteaka-Philipsen, B., \& Willems, D. (2014). Should palliative care patients’ hope be truthful, helpful or valuable? An interpretative synthesis of literature describing healthcare professionals' perspectives on hope of palliative care patients. Palliative Medicine, 28(1), 59-70. http://doi.org/10.1177/0269216313482172.

[20]. Selman, L., Young, T., Vermandere, M., Stirling, I., \& Leget, C. (2014). Research priorities in spiritual care: An international survey of palliative care researchers and clinicians. Journal of Pain and Symptom Management, 48(4), 518-531. http://doi.org/10.1016/j.jpainsymman.2013.10.020.

[21]. Tan, A., Seah, A., Chua, G., Lim, T. K., \& Phua, J. (2014). Impact of a palliative care initiative on endof-life care in the general wards: a before-and-after study. Palliative Medicine, 28(1), $34-41$. http://doi.org/10.1177/0269216313484379.

[22]. The United Republic of Tanzania. (2005). Guidelines for home based care services. Ministry of Health. Dar es Salaam. 


\title{
Passive Smoking and its Effects among Children of a Rural Population in South Tamilnadu, India
}

\author{
Article by Pethuru Devadason ${ }^{1}$, Arya Rajendran ${ }^{2}$, Akhila Vinod ${ }^{3}$, Annu Ann \\ Zachariah $^{4}$, Anoop S. ${ }^{5}$, Aarthy T. 6 , Annie Rexalin Pradeepa T. ${ }^{7}$, Akhila PM ${ }^{8}$ \\ ${ }^{1}$ Professor, Department of Community Medicine, Sree Mookambika Institute of \\ Medical Sciences, Kulasekharam, Kanyakumari Dist., Tamilnadu, India \\ ${ }^{2}$ Junior Consultant(OG), Samad IVF Hospitals, Attingal, Trivandrum, Kerala, India \\ ${ }^{3}$ Third year Resident, Physiology, JJM Medical College, Davangare, Karnataka, \\ India \\ ${ }^{4}$ Third year Resident, Pathology, Mahatma Gandhi Medical College \& Research \\ Institute, Pondicherry, India \\ ${ }^{5}$ Third Year Resident, Orthopedics, Yenepoya Medical College, Mangalore, \\ Karnataka, India \\ ${ }^{6}$ RBSK Medical Officer, Govt. PHC Samayanallur, Madurai, Tamilnadu, India. \\ ${ }^{7,8}$ Sree Mookambika Institute of Medical Sciences, Kulasekharam, Kanyakumari Dist., \\ Tamilnadu, India \\ E-mail: ${ }^{1}$ drpethuru@rediffmail.com, ${ }^{2}$ aryarajendran@gmail.com, \\ 3akhila_vinod@rediffmail.com, ${ }^{4}$ annu.zac@gmail.com, ${ }^{5}$ anoopsuresh88@gmail.com, \\ 6aarthysivaraman01@gmail.com, anniethomas.jes@gmail.com, \\ 8pmakhila@gmail.com
}

\begin{abstract}
Tobacco kills nearly 6 million people each year. Passive smoking is a major hazard to the health of millions of children worldwide. Globally, an estimated $40 \%$ of children are reported to be exposed to passive smoke. Adverse effects of smoking in rural population are well studied in any parts the world. But the impact of passive smoking on the children is not widely studied.

Objectives: This study was carried out with the following two objectives: 1) To determine the prevalence of passive smoking among children in a rural population in South India and 2) To find out the effects of passive smoking on children in the study population.

Methodology: This is a community based cross sectional study. It was carried out in Marappadi village in Kulasekharam Panchayat, Kanyakumari District, Tamilnadu in October 2014. 150 children under 15 years in the village were approached at their houses, with questionnaire for socio demographic details and passive smoking history. Apart from this the history of Low birth weight, Growth retardation, and number of URTIs, LRTIs, Ear Infections, Allergy and Asthma episodes were elicited. Data collected was entered in Excel spreadsheet and Analysis was done using SPSS version 16.

Results: There were 150 under 15 children in the study which were collected from 96 households. They were 82 (54.7\%) males and 68 (45.3\%) females. Passive smoking was present in 32 (21.3\%) children. Overcrowding was present in 61 (40.7\%) children's houses. 64 (42.7\%) children didn't have adequate ventilation. Smoke from kitchen was present in 126 (84.0\%) houses. 40 (26.7\%) of the households were having anti mosquito usage in their house. The number of URTIs was significantly more with children having history of passive smoking as denoted by significant p-value is 0.002. Asthma was present in 20 (13.3\%) of children; ear infection was there in 6 (4.0\%) children and Allergy was present in 18 (12.0\%) children at the time of study. They were more with children having history of passive smoking by looking at the simple percentages. But they were not statistically significant ( $p-v a l u e>$ 0.05).

Conclusion: 1) The prevalence of Passive Smoking in the study population is 21.3\%. 2) Environmental risk factors like Overcrowding, Lack of adequate ventilation, Smoke from
\end{abstract}


Texila International Journal of Public Health

Volume 4, Issue 4, Dec 2016

kitchen and Anti Mosquito smoke are significantly more associated with children having Passive Smoking. 3) Upper Respiratory Infections are more significantly associated with those who have history of Passive Smoking.

Keywords: Passive Smoking, Rural Population, Smoking among Children, Smoking complications, Rural India.

\section{Introduction}

Tobacco kills nearly 6 million people each year. More than five million of those deaths are the result of direct tobacco use while more than 600000 are the result of non-smokers being exposed to second-hand smoke. Unless urgent action is taken, the annual death toll could rise to more than eight million by 2030 . Nearly $80 \%$ of the world's one billion smokers live in low- and middle-income countries.

Passive smoking refers to breathing tobacco smoke that is breathed out by a smoker or comes from the end of a burning cigarette ${ }^{1}$. Breathing in other people's tobacco smoke is known as passive, involuntary or secondhand smoking (SHS). It may also be called environmental tobacco smoke exposure ${ }^{2}$. Secondhand smoke (SHS) is inhalation of other people's tobacco smoke. SHS is also commonly known as 'passive smoking', 'environmental tobacco smoke' and 'involuntary smoking'. Inhaling SHS is an unavoidable consequence of being in a smoke-filled environment.

Globally, an estimated $40 \%$ of children are reported to be exposed to SHS. In the UK around 2 million children are estimated to be regularly exposed to SHS in the home. The home is now the main source of exposure to SHS for children (9). These disorders generate over 300,000 UK GP consultations and about 9,500 hospital admissions every year, costing the NHS about $£ 23.3$ million. Passive smoking is a major hazard to the health of millions of children worldwide. Children from socio-economically disadvantaged backgrounds are generally more heavily exposed to $\mathrm{SHS}^{3}$. Almost half of children regularly breathe air polluted by tobacco smoke in public places. Over $40 \%$ of children have at least one smoking parent. In 2004, children accounted for $28 \%$ of the deaths attributable to second-hand smoke.

Prevalence of passive smoking is much higher in the developing countries esp. SEAR than in developed nation. The burden of ARI, other infectious diseases, growth failure and impaired school performance are also correspondingly higher. Passive smoking may also have a role in contributing to this health disparity, in addition to various other factors.

\section{Effects of passive smoking on children}

Children are at higher risk of damage from passive smoking than adults because of their smaller bodies, higher breathing rates and less developed respiratory and immune systems. They are most likely to be exposed to cigarette smoke in the home or car, but exposure also occurs in such places as shopping centres, other people's homes and social meeting places ${ }^{1}$.

SHS in the home is a major source of exposure because children spend most of their time at home and indoors. Unlike adults who can choose whether or not to be in a smoky environment, children have little choice or control over their SHS exposure. They are far less likely to be able to leave a smoke-filled room if they want to: babies cannot ask, some children may not feel confident about raising the subject, and others may not be allowed to leave even if they do ask ${ }^{2}$.

A review of 79 studies reported that exposure to pre or post-natal SHS was associated with between $30-70 \%$ increased risk of incidents of wheeze, and 21- 85\% increase risk in asthma in children ${ }^{4}$. Lower respiratory tract infections affect the airways and lungs, and include flu, bronchitis and pneumonia. A review of 60 research studies found that SHS exposure in the home increased young infants' risks of developing lower respiratory tract infections by $20 \%$ to $50 \%{ }^{5}$.

A systematic review and meta-analysis on parental and household smoking and the increased risk of bronchitis, bronchiolitis and other lower respiratory infections in infancy which identified 60 studies suitable for inclusion in the meta-analysis. Smoking by either 
parent or other household members significantly increased the risk of LRI; odds ratios (OR) were 1.22 (95\% CI 1.10 to 1.35) for paternal smoking, 1.62 (95\% CI 1.38 to 1.89) if both parents smoked, and 1.54 (95\% CI 1.40 to 1.69) for any household member smoking. Prenatal maternal smoking (OR 1.24, 95\% CI 1.11 to 1.38) had a weaker effect than post-natal smoking (OR 1.58, 95\% CI 1.45 to 1.73). The strongest effect was on bronchiolitis, where the risk of any household smoking was increased by an OR of 2.51 (95\% CI 1.96 to 3.21) $)^{5}$.

Environmental tobacco smoke is an important respiratory tract irritant in young children. To identify factors associated with respiratory disease and determine the main source of smoking exposure in the household, a cross-sectional study of 2,037 children who were immunized in primary health care clinics was conducted (in a sample of 10 out of 38 clinics with 200 children each). Parents answered a questionnaire about children's birth, passive smoking, former and current respiratory morbidity, socio-demographic characteristics, and living conditions. Analysis was based on hierarchical logistic regression. Prevalence of respiratory symptoms was $59.9 \%$ for children who live with smokers. Asthma and bronchitis showed the strongest association with smoking (OR $=1.58$; 95\%CI: 1.18-2.11) ${ }^{6}$.

Considerable evidence supports an association between parental smoking and an increased risk of child health problems. Indeed, in a one-year period, children of parents who smoked inhaled the same amount of nicotine as if they had smoked $60-150$ cigarettes $^{1}$.

Some of the specific effects of passive smoking on children include:

- Sudden infant death syndrome (SIDS)

- Croup, bronchitis, pneumonia and ear infections

- Increased likelihood of childhood asthma

- Learning difficulties

- Behavioural problems

- Heart disease

- Meningococcal disease

In addition, children of smokers are four times more likely to become smokers themselves ${ }^{1}$.

In a study to the impact of exposure to cigarette smoke on blood pressure of elementary school children in Kermanshah, Iran indicates that systolic and diastolic blood pressures are higher in those elementary school children exposed to cigarette smoke compared to those who are not ${ }^{7}$.

Parental smoking affects children and neonates, and is associated with low birth weight, sudden infant death, asthma, bronchitis, pneumonia, otitis media, increased risk of contracting tuberculosis on exposure, Crohn's disease, learning disorders, development retardation and dental caries ${ }^{8}$.

Chronic exposure to cigarette smoke is harmful to ocular tissues through ischemic or oxidative mechanisms. A study by Amany Abdel-Fattah El-Shazly et al in Egypt shows that passive smoking represents a significant risk factor of dry eye in children comparable to that shown with active adult smoking ${ }^{9}$.

Passive smoking may be implicated in the development of cardiovascular disease (CVD) in children because of their partially developed physiological systems. A Systematic Review on passive smoking and the development of Cardiovascular Disease in Children which identified a total of 42 relevant articles (30 reviews and 12 observational) revealed that passive smoking may be implicated in deteriorating cardiovascular status in children in terms of unfavorable high-density lipoprotein levels and deteriorated vascular function ${ }^{10}$.

A large study performed on 9090 adolescent school children demonstrated environmental tobacco smoke (ETS) exposure to be associated with an increased risk of asthma. The odds ratio for being asthmatic in ETS-exposed as compared to ETS-unexposed children was 1.78 (95\% CI: 1.33-2.31) ${ }^{11}$. Another study demonstrated exposure to ETS was a significant trigger for acute exacerbation of asthma. Several adverse pulmonary effects of passive smoking, similar to those described from the western and developed countries, have been described from India ${ }^{12}$. 
Texila International Journal of Public Health

Volume 4, Issue 4, Dec 2016

\section{Passive smoking effects are of two types}

- Negative health outcomes for children: There is considerable evidence to suggest an association between parental smoking and an increased risk of health problems in children, including Sudden Infant Death Syndrome, croup, bronchitis, pneumonia, ear infections, asthma, learning difficulties, behavioural problems and heart disease.

- Smoking uptake later in life: In a one-year period, children of parents who smoke inhale the same amount of nicotine as if they had smoked 60-150 cigarettes. Children of smokers are four times more likely to end up being smokers themselves, due to nicotine inhalation in childhood ${ }^{1}$.

Additionally the impact of passive smoking on children is affected by the following three factors:

- Amount of exposure: Smoking in a car can be 23 times more toxic than in a house because it is a small, enclosed space.

- Whether smoking occurs outside or inside of house: Exclusive smoking outside with the door closed results in lower nicotine exposure levels for children (although higher than that for children from homes where no smoking occurred) than when smoking occurs anywhere indoors, including indoors near either a kitchen fan or an open door.

- Proximity to a smoking area: Well ventilated non-smoking areas still contain at least half the amount of smoke found in adjacent smoking areas.

Passive smoking may increase the risk of infection and disease in adults and children exposed to Tuberculosis. In a study at Medan among children who had household contact with a TB patient, those who exposed to passive smoke are more likely to have $\mathrm{M}$. tuberculosis infection compared to those who not exposed to passive smoke ${ }^{13}$.

\section{Preventing the effects on children}

There is a significant public policy agenda to reduce cigarette smoking with regulation in place to prevent adult exposure to smoke in the workplace. However, it is important to recognize that for children, the home is the equivalent of the workplace, and children remain vulnerable to the effects of passive smoking.

Parents are concerned about the effects of passive smoking on their children and are likely to be willing to make changes to improve children's health. Indeed, research has shown that three of every four adults who smoke would like to give up if they could, and more than half of the rest think about it ${ }^{1}$.

Furthermore, a survey conducted by the Cancer Council of New South Wales of households where at least one parent smoked found that:

- 86 per cent of respondents agreed with the statement 'because children don't have a choice, it's up to adults to think about whether there is tobacco smoke around the children'.

- 24.7 per cent believed that minimising exposure to tobacco smoke was likely to make the biggest difference to children's health (in comparison with a list of other factors).

The strategies that follow focus particularly on the smoking behaviours of parents around children. Most smoking intervention strategies have been focused on adults with far fewer particularly focused on parent specific interventions. Some intervention strategies to reduce passive smoking in children have been trialed and include:

- Intensive counselling

- Non-intensive counselling

- School-based programs.

The following key messages can also be reinforced with parents ${ }^{1}$ :

- Smoking in another room or by an open window is not enough to avoid exposure to environmental tobacco smoke (it's like urinating in a swimming pool!).

- An increasing number of smokers are making their homes and cars smoke-free in order to protect their children from the effects of environmental tobacco smoke.

- Parents who insist on a household free of smoke should be positively encouraged. 
Jyoti Sanghvi et al studied the effectiveness of discontinuation of passive smoking on lung function of children by Peak Expiratory Flow Rate (PEFR) in Indoor, India. There was a significant improvement seen in PEFRs after the discontinuation of passive smoking in 3 months interval. Alterations of the smoking behavior of family member's results in improved PEFR of their children ${ }^{14}$.

Parents can help protect their children from secondhand smoke by taking the following actions ${ }^{15}$ :

- Do not allow anyone to smoke anywhere in or near your home.

- Do not allow anyone to smoke in your car, even with the window down.

- Make sure your children's day care centers and schools are tobacco-free.

- If your state still allows smoking in public areas, look for restaurants and other places that do not allow smoking. "No-smoking sections" do not protect you and your family from secondhand smoke.

Adverse effects of smoking in rural population are well studied in any parts the world. But the impact of passive smoking on the children is not widely studied. Also these kinds of studies have been done rarely in India. That is the reason for considering this study in this rural population.

\section{Objectives}

This study was carried out with the following two objectives:

1) To determine the prevalence of passive smoking among children in a rural population in South India.

2) To find out the effects of passive smoking on children in the study population.

\section{Materials and methods}

Study Design: This is a community based cross sectional study.

Study Area: This study was carried out in Marappadi village in Kulasekharam Panchayat, Kanyakumari District, Tamilnadu.

Study Period: This study was carried out in October 2014. The data collection was done every Saturdays when children will be available for interview.

Study Population: All eligible children under 15 years in the village according to the following Inclusion and Exclusion criteria were considered as study population.

- Inclusion Criteria:

1) Children residing in Marappadi village, the service area of Rural Health Centre of SMIMS.

2) Age between 1-15 years of both genders.

- Exclusion Criteria:

1) Children who were absent on the day of survey.

2) Children / whose parents were not willing to participate in the study.

Sample size: 150 children residing within the service area were considered as sample size. This sample size (n) was calculated based on the prevalence of passive smoking $\mathrm{p}=$ is $40 \%$. Using the formula $\mathrm{N}=4 \mathrm{pq} / \mathrm{d} 2$ where $\mathrm{q}=100-\mathrm{p}$; $\mathrm{d}=20 \%$ of $\mathrm{p}$, sample size was considered as 150.

The study protocol was approved by the faculty of the Department of Community Medicine, SMIMS. A structured questionnaire was applied to get the socio demographic details of the children after getting informed consent from their parent(s) / guardians.

Children were approached at their houses, starting from the health centre, travelling to all 4 directions with 4 teams of volunteers, each house one by one till we get the required 150 samples based on the inclusion and exclusion criteria.

A child having either a parent or any other household member with smoking habit was considered as having passive smoking. Apart from the socio demographic details and passive smoking history, the history of Low birth weight, Growth retardation, and number of URTIs, LRTIs, Ear Infections, Allergy and Asthma episodes were elicited. Height and weight of the 
Texila International Journal of Public Health

Volume 4, Issue 4, Dec 2016

children were measured by stadiometer and bathroom weighing scale respectively. Children under 1 year were excluded from the study. Data collected was entered in Excel spreadsheet and Analysis was done using SPSS version 16.

\section{Results}

There were 150 under 15 children in the study which were collected from 96 houses. They were 82 (54.7\%) males and 68 (45.3\%) females. 31 (20.7\%) were in the 1-5 years group; 71 (47.3\%) were in the 6-10 years group and another 48 (32.0\%) were in the 11-15 years age group.

Altogether passive smoking was present in 32 (21.3\%) children. Overcrowding was present in 61 (40.7\%) children's houses. 64 (42.7\%) children didn't have adequate ventilation. Smoke from kitchen was present in 126 (84.0\%) houses. 40 (26.7\%) of the households were having anti mosquito usage in their house. Regarding present complications mean episode of Upper Respiratory Tract Infections (URTIs) per child in one year was 4.9 and mean episode of Lower Respiratory Tract Infections (LRTIs) per child in one year time was 0.2. Asthma was present in 20 (13.3\%) of children; ear infection was there in 6 (4.0\%) children and Allergy was present in 18 (12.0\%) children at the time of study.

The following tables show the distribution of above particulars distributed between the group of children having passive smoking and children not having passive smoking. Appropriate statistical tests show the relationship between the parameters and passive smoking.

Table1. Distribution of Socio Demographic factors and Passive Smoking

\begin{tabular}{|l|l|l|l|l|}
\hline \multirow{2}{*}{ Factor } & \multirow{2}{*}{ Category } & \multicolumn{2}{|c|}{ Passive Smoking } & \multirow{2}{*}{ Total (N=150) } \\
\cline { 3 - 4 } & & Yes (N=32) & No (N=118) & \\
\hline \multirow{3}{*}{$\begin{array}{l}\text { Age } \\
\text { Group }\end{array}$} & $0-5$ Years & $5(15.6 \%)$ & $26(22.0 \%)$ & \multirow{2}{*}{$31(20.7 \%)$} \\
\cline { 2 - 4 } & 6-10 Years & $15(46.8 \%)$ & $56(47.5 \%)$ & $71(47.3 \%)$ \\
\cline { 2 - 5 } & $11-15$ Years & $12(37.6 \%)$ & $36(30.5 \%)$ & $48(32.0 \%)$ \\
\hline \multirow{2}{*}{ Gender } & Male & $12(37.5 \%)$ & $70(59.3 \%)$ & $82(54.7 \%)$ \\
\cline { 2 - 5 } & Female & $20(62.5 \%)$ & $48(40.7 \%)$ & $68(45.3 \%)$ \\
\hline \multirow{3}{*}{ Religion } & Hindu & $15(46.9 \%)$ & $65(55.1 \%)$ & $80(53.3 \%)$ \\
\cline { 2 - 5 } & Christian & $15(46.9 \%)$ & $51(43.2 \%)$ & $63(42.0 \%)$ \\
\cline { 2 - 5 } & Muslim & $2(6.2 \%)$ & $2(01.7 \%)$ & $7(04.7 \%)$ \\
\hline
\end{tabular}

The above table shows the distribution of socio demographic factors between passive smoking. It is almost equally distributed between the groups.

Table2. Passive Smoking and Household Environmental Risk Factors

\begin{tabular}{|c|c|c|c|c|c|c|}
\hline \multirow{2}{*}{\multicolumn{2}{|c|}{$\begin{array}{c}\text { Household Environmental } \\
\text { Risk Factors }\end{array}$}} & \multicolumn{2}{|c|}{ Passive Smoking } & \multirow{2}{*}{$\begin{array}{c}\text { Chi' }^{2} \\
\text { Value }\end{array}$} & \multirow{2}{*}{ DF } & \multirow{2}{*}{ p - Value } \\
\hline & & Yes $(\mathrm{N}=32)$ & No $(N=118)$ & & & \\
\hline \multirow{2}{*}{ Overcrowding } & Yes (61) & $26(42.6 \%)$ & 35 (57.4\%) & \multirow{2}{*}{20.008} & \multirow{2}{*}{1} & \multirow{2}{*}{$0.0001 *$} \\
\hline & No (89) & $6(6.7 \%)$ & $83(93.7 \%)$ & & & \\
\hline \multirow{2}{*}{$\begin{array}{l}\text { Adequate } \\
\text { Ventilation }\end{array}$} & Yes (86) & $5(5.8 \%)$ & 81 (94.2\%) & \multirow{2}{*}{17.993} & \multirow[t]{2}{*}{1} & \multirow{2}{*}{$0.0001^{*}$} \\
\hline & No (64) & $27(42.2 \%)$ & $37(57.8 \%)$ & & & \\
\hline \multirow{2}{*}{$\begin{array}{l}\text { Smoke from } \\
\text { Kitchen }\end{array}$} & Yes (126) & $31(24.6 \%)$ & $95(75.4 \%)$ & \multirow{2}{*}{4.762} & & \multirow{2}{*}{$0.021 \infty$} \\
\hline & No (24) & $1(4.2 \%)$ & $23(95.8 \%)$ & & & \\
\hline \multirow{2}{*}{$\begin{array}{l}\text { Anti Mosquito } \\
\text { Smoke }\end{array}$} & Yes (40) & $4(10.0 \%)$ & $36(90.0 \%)$ & \multirow{2}{*}{3.666} & \multirow{2}{*}{1} & \multirow{2}{*}{$0.045 \infty$} \\
\hline & No (110) & 28 (25.4\%) & $82(74.6 \%)$ & & & \\
\hline
\end{tabular}

*Statistically significant at $1 \%$; $\infty$ Statistically significant at $5 \%$. 
The above table shows that Household environmental associated risk factors are significantly more associated passive smoking as denoted by the significant $\mathrm{p}$ - values.

Table 3. Passive Smoking and Morbidity - t- Test

\begin{tabular}{|l|l|l|l|l|}
\hline \multirow{2}{*}{ Parameters } & \multicolumn{2}{|c|}{ Passive Smoking } & \multicolumn{1}{c|}{$\begin{array}{c}\mathbf{p}- \\
\text { Value }\end{array}$} & Value \\
\cline { 2 - 3 } & \multicolumn{1}{|c|}{ Yes (N=32) } & No (N=118) & 0.149 \\
\hline Height in Cm (Mean \pm SD) & $131.75 \pm 18.98$ & $123.35 \pm 29.98$ & 2.117 & 0.245 \\
\hline Weight in Kg (Mean \pm SD) & $29.15 \pm 12.54$ & $25.25 \pm 13.51$ & 1.369 & 0.245 \\
\hline $\begin{array}{l}\text { Number of URTIs in a year } \\
\text { (Mean } \pm \text { SD) }\end{array}$ & $7.10 \pm 7.04$ & $4.36 \pm 1.74$ & 9.939 & $0.002^{*}$ \\
\hline $\begin{array}{l}\text { Number of LRTIs in a year } \\
\text { (Mean } \pm \text { SD) }\end{array}$ & $0.15 \pm 0.37$ & $0.18 \pm 0.71$ & 0.023 & 0.879 \\
\hline
\end{tabular}

*Statistically significant at $1 \%$

The above table shows that number of URTIs was significantly more with children having history of passive smoking as denoted by significant p- value less than 0.05 .

Table 4. Passive Smoking and Morbidity - Chi2 - Test

\begin{tabular}{|c|c|c|c|c|c|c|}
\hline \multicolumn{2}{|c|}{ Morbidity Conditions } & \multicolumn{2}{|c|}{ Passive Smoking } & \multirow{2}{*}{$\begin{array}{c}\text { Chi }^{2} \\
\text { Value }\end{array}$} & \multirow{2}{*}{ DF } & \multirow{2}{*}{$\begin{array}{c}\mathbf{p}- \\
\text { Value }\end{array}$} \\
\hline & & Yes $(\mathrm{N}=\mathbf{2 0})$ & No $(\mathrm{N}=80)$ & & & \\
\hline \multirow{2}{*}{ Asthma } & Yes (20) & $5(25.0 \%)$ & 15 (75.0\%) & \multirow{2}{*}{0.088} & \multirow{2}{*}{1} & \multirow{2}{*}{0.766} \\
\hline & No (130) & 27 (20.8\%) & 103(79.2\%) & & & \\
\hline \multirow{2}{*}{ Ear Infection } & Yes (6) & $2(33.3 \%)$ & $4(66.7 \%)$ & \multirow{2}{*}{0.065} & \multirow{2}{*}{1} & \multirow{2}{*}{0.799} \\
\hline & No (144) & $30(20.8 \%)$ & 114(79.2\%) & & & \\
\hline \multirow{2}{*}{ Allergy } & Yes (18) & $4(22.2 \%)$ & $14(77.8 \%)$ & \multirow{2}{*}{0.088} & \multirow{2}{*}{1} & \multirow{2}{*}{0.766} \\
\hline & No (132) & $28(21.2 \%)$ & 104(78.8\%) & & & \\
\hline
\end{tabular}

From the above table, it is observed that morbidity conditions were more with children having history of passive smoking by looking at the simple percentages. But they are not statistically significant as denoted by $\mathrm{p}$ - values more than 0.05 .

\section{Discussion}

This community based cross sectional study was carried out in a rural population in southern part of Tamilnadu, India. More than five million of those deaths are the result of direct tobacco use while more than 600000 are the result of non-smokers being exposed to second-hand smoke or otherwise called passive smoking. The prevalence of passive smoking in the present study is only $21.3 \%$. This is less compared to the global estimate of $40 \%$. The reason for this is already the prevalence of smoking itself is less as compared other parts of India due to many factors especially the literacy ${ }^{16}$.

The household environmental associated risk factors are significantly more associated passive smoking as denoted by the significant $\mathrm{p}$ - values from the table 2 . This shows that the passive smoking is adding fuel to the fire of already existing household environmental risk factors which are detrimental to children's health. 
Texila International Journal of Public Health

Volume 4, Issue 4, Dec 2016

From the table 3, the number of URTIs was significantly more with children having history of passive smoking as denoted by significant p- value less than 0.05 . This is consistent with the observations from other studies. A systematic review and meta-analysis on parental and household smoking and the increased risk of bronchitis, bronchiolitis and other lower respiratory infections in infancy which identified 60 studies suitable for inclusion in the metaanalysis. Smoking by either parent or other household members significantly increased the risk of LRI; odds ratios (OR) were 1.22 (95\% CI 1.10 to 1.35) for paternal smoking, 1.62 (95\% CI 1.38 to 1.89) if both parents smoked, and 1.54 (95\% CI 1.40 to 1.69) for any household member smoking 5 .

From table 4 it is observed that morbidity conditions were more with children having history of passive smoking by looking at the simple percentages. But they are not statistically significant as denoted by $\mathrm{p}-$ values more than 0.05 . A review of 79 studies reported that exposure to pre or post-natal SHS was associated with between $30-70 \%$ increased risk of incidents of wheeze, and 21- 85\% increase risk in asthma in children ${ }^{4}$.

A large study performed on 9090 adolescent school children demonstrated environmental tobacco smoke (ETS) exposure to be associated with an increased risk of asthma. The odds ratio for being asthmatic in ETS-exposed as compared to ETS-unexposed children was 1.78 (95\% CI: 1.33-2.31) [b]. Another study demonstrated exposure to ETS was a significant trigger for acute exacerbation of asthma. Several adverse pulmonary effects of passive smoking, similar to those described from the western and developed countries, have been described from India ${ }^{12}$. The reason for not showing any significant $p$ values in the present study may due to the lesser sample size.

\section{Conclusion}

1) The prevalence of Passive Smoking in the study population is $21.3 \%$.

2) Environmental risk factors like Overcrowding, Lack of adequate ventilation, Smoke from kitchen and Anti Mosquito smoke are significantly more associated with children having Passive Smoking.

3) Upper Respiratory Infections are more significantly associated with those who have history of Passive Smoking.

\section{Significance / recommendations}

1) Morbidity conditions are more with those who have the history of Passive Smoking. So the concerned children to be motivated to avoid passive smoking and their parents also to be motivated to stop smoking especially inside house and while their children are around.

2) Children usually who have the history of passive smoking are already having other environmental risk factors like Environmental risk for like Overcrowding, Lack of adequate ventilation, Smoke from kitchen and Anti Mosquito smoke. They should be specifically motivated to avoid these factors as much as possible.

\section{Limitations}

1) Though it is a community based cross sectional study, the sample were not randomly selected from throughout the village; instead they were selected from the nearby houses from the health centre by convenient sampling.

2) Sample size should have been more to generalize the observation as the prevalence of passive smoking here in the study area is only $20 \%$ as compared to $40 \%$ as proposed from the literature review.

\section{Acknowledgments}

We thank Dr. Usha Devi Karunakaran, the Professor and Head, Department of Community Medicine, SMIMS, for her guidance and support. We also would like to the management of SMIMS for permitting to do the study in their field practice area. 


\section{References}

[1.] ASH Research Report - March 2014:Secondhand Smoke: the impact on children. Available for download from: http://www.ash.org.uk/files/documents/ASH_596.pdf

[2.] Abolhassan Seyedzadeh, Forough Hashemi, Akram Soleimani. Relationship between Blood Pressure and Passive Smoking in Elementary School Children. Iranian Journal of Pediatrics, Volume 22(Number 3), September 2012, Pages: 351-356.

[3.] Amany Abdel-Fattah El-Shazly, Walid Mohamed Abd El Raouf El-Zawahry, Ahmad Mohamed Hamdy, Manal Basyouni Ahmed. Passive Smoking as a Risk Factor of Dry Eye in Children. Journal of Ophthalmology Volume 2012, Article ID 130159, 5 pages. doi:10.1155/2012/130159.

[4.] Burke H, Leonardi-Bee J, Hashim A, Pine-Abata H, Chen Y, Cook DG, et al. Prenatal and Passive Smoke Exposure and Incidence of Asthma and Wheeze: Systematic Review and Meta analysis. Pediatrics. 2012;129(4):735-44.

[5.] Centre for Community Child Health 2006. Preventing Passive Smoking Effects On Children Practice. Available for download from: http://www.rch.org.au/uploadedFiles/Main/ Content/ccch/PR_Smoke_Effects_S2.pdf.

[6.] D Gupta, AN Aggarwal, SK Jindal. Pulmonary effects of passive smoking: the Indian experience. Tobacco Induced Diseases 2002, 1:129-136 doi:10.1186/1617-9625-1-2-129.

[7.] Giorgos S. Metsios, Andreas D. Flouris, Manuela Angioi, Yiannis Koutedakis1. Passive Smoking and the Development of Cardiovascular Disease in Children: A Systematic Review. Cardiology Research and Practice. Volume 2011, Article ID 587650, 6 pages. doi:10.4061/2011/587650.

[8.] Gupta D, Aggarwal AN, Kumar R, Jindal SK. Prevalence of Bronchial asthma and association with environmental tobacco smoke exposure in adolescent school children in Chandigarh, North India. Journal of Asthma 2001, 38:501-507.

[9.] Jyoti Sanghvi, Ravindra Kumar, Mithun Somani. Effectiveness of Discontinuation of Passive Smoking on Lung Function of Children by Peak Expiratory Flow Rate (PEFR). Int. J. Bioassays, 2013, 02 (11), 1457-1461.

[10.] Laura L Jones, Ahmed Hashim, Tricia McKeever, Derek G Cook, John Britton, Jo Leonardi-Bee. Parental and household smoking and the increased risk of bronchitis, bronchiolitis and other lower respiratory infections in infancy: systematic review and meta-analysis. Respiratory Research 2011 12:5.

[11.] Novaily Zuliartha, Ridwan M. Daulay, Melda Deliana, Wisman Dalimunthe, Rini Savitri Daulay. Association between passive smoking and Mycobacterium tuberculosis infection in children with household TB contact. Paediatr Indones, Vol. 55, No. 1, January 2015. Pages 29-34.

[12.] Royal College of Physicians. Passive smoking and children. A report of the Tobacco Advisory Group of the Royal College of Physicians. London: Royal College of Physicians; 2010.

[13.] Regina M. V. Gonçalves-Silva, Joaquim G. Valente, Márcia G. F. Lemos-Santos, Rosely Sichieri. Household smoking and respiratory disease in under-five children. Cad. Saúde Pública [online]. 2006, vol.22, n.3, pp. 579-586.

[14.] The Global Adult Tobacco Survey (GATS) India, 2009-2010. Ministry of Health and Family Welfare 2010, Government of India, New Delhi. Available for download at: http://mohfw.nic.in/WriteReadData/1892s/1455618937GATS\%20India.pdf [15.] U.S. Department of Health and Human Services. Let's Make the Next Generation Tobacco-Free: Your Guide to the 50th Anniversary Surgeon General's Report on Smoking and Health. Available for download at: http://www.surgeongeneral.gov/library/reports/50-years-of-progress/consumer-guide.pdf [16.] Vork K, Broadwin R, Blaisdell R. Developing asthma in childhood from exposure to secondhand tobacco smoke. Health Perspect. 2007;115(10):1394-400. 


\title{
Assess Knowledge, Attitude and Practice Regarding Cigarette and Other Tobacco Products Act (COTPA) and Tobacco Related Health Problems in Rural Setting of Bihar, India
}

\author{
Article by Rajendra Kumar Singh \\ $M B B S, B$. N. Mandal University, India \\ Master of Public Health (MPH), Texila American University, India \\ E-mail: singh.rajendra2727@gmail.com
}

\begin{abstract}
Tobacco addiction is most widespread addiction and it is the most important cause of death in the world. A cross sectional community based study was conducted in Buxar district of Bihar to assess knowledge, attitude and practice regarding Cigarette and Other Tobacco Products Act (COTPA) and tobacco related health problems in rural setting of Bihar, India. Data regarding awareness about tobacco control law in India, tobacco related health problems, attitude regarding tobacco control law and information on tobacco use were collected by interview method using a questionnaire.

The study shows that awareness of COTPA is low, although knowledge and perception about certain components of the COTPA is relatively higher. Attitude and beliefs of participants regarding COTPA showed that at least half of the participants agreeing that provisions were successful in curbing the consumption of tobacco. The mean scores for knowledge, attitude and practice section did not show any statistically significant difference between tobacco users and non-tobacco users after adjusting for sex, age group, occupation. The data shows significant difference in mean score of attitude section between tobacco users and non-users after adjusting for the education status of the individual, no such difference in seen in knowledge and practice totals.

The survey has pinpointed clear areas where a huge gap in knowledge exists; which could be fixed by effective public private partnership. The availability of adequate knowledge and information will lead to change in the attitude regarding consumption of tobacco products in rural India.

A cross Sectional Study in rural population for knowledge, Attitude and Practice of Cigarettes and Other Tobacco Products Act among population of Simri village of Simri Block in Buxar district of Bihar in India.
\end{abstract}

\section{Introduction}

Tobacco contributes to 5 million deaths per year globally. According to World Health Organization (WHO), tobacco kills more people annually than AIDS, alcohol, other addictions (drugs) and accidents put together and this figure is expected to rise to 10 million tobacco deaths annually by 2025. Five hundred million die prematurely due to tobacco use; most of these are children and young adults of today. One-fifth of all worldwide deaths attributed to tobacco occur in India; more than 8,00,000 people die and 12 million people fall ill due to tobacco use each year(1). Tobacco addiction is the most widespread addiction in the world. There are nearly 1.3 billion smokers in the world, $80 \%$ of them are in the developing countries. India has more than 300 million smokers. Tobacco use is the leading cause of death in the world (2). Tobacco is the only legally available consumer product which kills people when it is used entirely as intended (3).

In India, beedi smoking is the most popular form of tobacco smoking (54\%); cigarette smoking is the second most popular form of tobacco smoking (16\%); while tobacco chewing accounts for $30 \%$ of the total consumption(2). Pan with tobacco is the major chewing form of tobacco. Dry tobacco, areca nut preparations such as pan masala, gutkha and khaini are also 
Texila International Journal of Public Health

Volume 4, Issue 4, Dec 2016

popular and highly addictive. Knowledge attitude and practices regarding the cigarettes and other tobacco products act (COTPA) in Simri village of Simri Block in Buxar District of Biharin India. Awareness about hazardous health effects of tobacco has increased over time owing to widespread campaigns in media, but its role alone towards attainment of tobacco free India remains questionable.

Although, the tobacco industry claims it creates jobs and generates revenues that enhance local and national economies, the industry's overriding contribution to any country is suffering, disease, death - and economic losses. Tobacco use currently costs the world hundreds of billions of dollars each year (4). Several negotiations later, the World Health Assembly in May 2003 finally adopted the Framework Convention on Tobacco Control (FCTC), which has provisions for members to have comprehensive legislation to curb the tobacco epidemic. India was one of the first few countries that ratified the FCTC (5). The Government of India formulated "The Cigarettes and Other Tobacco Products (Prohibition of Advertisement and Regulation of Trade and Commerce, Production, Supply, and Distribution) Act (COTPA)" on May 18, 2003. In 2004, the rules regarding COTPA provisions were notified. As per the act, smoking is prohibited in all public places; ban is placed on advertisements of tobacco products, and prohibition of sale of tobacco products to minors and within 100 yards of educational institutions (6). The implementation of this law remained largely ineffective in the initial years. The Government of India reviewed the situation and revised the law, with effect from 2nd October 2008, making additional provisions to improve the implementation of smoke free law (7). Not many studies have been done on awareness and attitudes of the general public regarding Cigarettes and Other Tobacco Products Act (COTPA). For effective implementation of Tobacco control knowledge regarding the awareness, attitudes and practices of the population towards tobacco control is necessary. Hence the present study was undertaken among adults in Simri Block of Buxar District of Bihar with an aim to find the awareness, attitudes and practices regarding Cigarettes and Other Tobacco Products Act (COTPA).

\section{Aims and objective}

The study is planned in one rural setting to know the gap in knowledge, awareness and practice related to COTPA and also to access any change in trends of its (Tobacco) consumption

\section{Material and methods}

\section{Study design}

The present study is a cross-sectional community based survey, will be carried out in Simri Block of Buxar District of Bihar. The study will be carried out in the year 2016. The study will be included Male adults 18 years and above, who were voluntarily willing to participate. Written informed consent will be obtained long with the interview from all the participants. Female are not participate in study due to less (Only 3\%) Females' smokers in India according to WHO report.

\section{Sample size and study area}

Calculation of sample size was done to ensure the minimum number of Persons needed to be a representative sample for the whole population of Simri Village of Simri block in buxar District ofBihar in India. The sample size was determined using Formula implemented in cross sectional study on NCBI website (8). Total population size of Simri village is 9756 peoples, analyze sample size Keeping an confidence level 95\% and Margin of error 5\%, the calculated sample size is 323 persons. But we considered sample size for study is 350 .

Formula:

Sample Size $=\frac{Z^{2} \frac{1-\alpha / 2 p(1-p)}{d^{2}}}{d^{2}}$

Where, 
$\mathrm{Z}_{1-\alpha / 2}^{2}=$ Is standard normal Variate (at $5 \%$ type 1 error $(\mathrm{p}<0.05)$ it is 1 . As in majority of studies $\mathrm{P}$ values are considered significant below 0.05 hence 1.96 is used in formula.

$\mathrm{P}=$ Expected proportion in population based on smoking percentage given by WHO

(smoking in India is $30 \%=0.30$ )

$\mathrm{d}=$ Absolute error of precision (5\%)

Sample Size $=\frac{(1.96)^{2} \times 0.30(1-0.30)}{5}=322.69(323)$

\section{Demography of simri}

Simriis a large village located in Simri Block of Buxar district. The Simri village has population of 9756 of as per Population Census 2011. Simri Block has higher literacy rate compared to Bihar. In 2011, literacy rate of Simri Block was $73.28 \%$ compared to $61.80 \%$ of Bihar.

Table showing rural areas

\begin{tabular}{|l|l|l|l|l|}
\hline $\begin{array}{c}\text { Name of District / Sub- } \\
\text { division }\end{array}$ & $\begin{array}{c}\text { Name of } \\
\text { Blocks }\end{array}$ & $\begin{array}{c}\text { Name of Village } \\
\text { Population }\end{array}$ & Population & $\begin{array}{c}\text { Sample } \\
\text { size }\end{array}$ \\
\hline Buxar / Dumraon & Simri & Simri & 9756 & 350 \\
\hline
\end{tabular}

\section{Data collection}

The data was collected using a structured schedule by interviewing the study participants in the local language. Information on socio-demographic variables, educational status, occupation and monthly incomes will also obtain. Data on awareness about any tobacco control law in India, tobacco related health problems, perceptions about secondhand smoke, attitude towards the tobacco control law and information about use of tobacco will collect. The schedule includes Seven questions to assess the awareness/knowledge level of adults regarding COTPA, which will be two choices i.e., Yes or No. Five questions to assess attitude towards the COTPA, which will be two choices i.e. P(positive) or N(negative) and Five questions to assess practice towards the COTPA, which will be two choices i.e., Yes or No. The choices will be given a score from 1 and 5 .

For every Yes or Positive response, a score of one will be allotted and responses other than mentioned earlier will score Zero. Thus, a maximum score of 7 can be achieved in knowledge part, 5 in attitude and 5 in practice.

\section{Data analysis}

Statistical analysis was done using SPSS version 11.0, after entering the data in Microsoft Office Excel, 2007. Proportions, percentages and Odds ratio will be calculated for relevant variables. A p value of $<0.05$ will be consider statistically significant.

\section{Result:}

Awareness about COTPA among general population in a rural setting is good enough and people have positive attitude about COTPA and they feel that it will reduce burden of Tobacco user. The real problem is in its implementation by the lawmakers and general administration. As a result being quite felt presence of messages of tobacco and its health hazards, COTPA is not getting proportionate success.

Political commitment and legislative support is very much needed to reduce bad effects of tobacco and its products over general population.

There must be monthly progress tracking of COTPA at district and sub district level and responsibility to be fixed with timeline.

It must be reviewed at every level as an important indicator of effectiveness of public health program.

There are many local processing units of tobacco which sells tobacco in form of Kahiani and Bidi, without any warning label must be taken care by law enforcing agencies for labeling the products with warnings as pr norms. 
Texila International Journal of Public Health

Volume 4, Issue 4, Dec 2016

Further research is needed to know effectiveness of COTPA in Urban setting.

\section{Discussion}

We were able to successfully conduct the survey with the target sample size of 350 participants in Simri Village of Simri block in Buxar District of Bihar. Out of the 350 participants interviewed 336 (96\%) were male and 14 (4\%) were female. The majority of participants who volunteered for the survey were between ages 18-29 (46.3\%) and the least number of participants were between ages 50-59 (3.1\%). The data shows that 321 (91.7\%) participants had attained at least high school education and only 29 (8.3\%) participants had an educational level lower than High school. The occupation of participants in the survey was as follows: 53 (15.1\%) participants were unemployed at the time of the interview, 7 (2\%) worked as laborer or Peon, 62 (17.7\%) participants worked as Shopkeeper/Businessman, 97 (27.7\%) participants worked as government officials or teacher and 131 (37.4\%) participants worked as farmer. There were 298 (85.1\%) participants who used one or the other form of tobacco products and 52 (14.9\%) participants did not use any tobacco products.

We are glad to point out that all 17 questions in the 350 surveys conducted were answered by the participants. Table _ shows the response for each survey question. Looking at the response to the Knowledge of COTPA section of the survey, we see that 121 (34.6\%) of participants knew about the act, 131 (37.4\%) participants knew about the penalty for violation of the act, 258 (73.7\%) participants knew that sale of tobacco products near educational institution was banned, 205 (58.6\%) participants knew that sale of tobacco products to minors was banned, only 114 (32.6\%) participants had seen any warning on tobacco products, 188 (53.7\%) participants were aware of tobacco consumption related health problems and only 117 (33.4\%) participants were aware of harmful effects of second hand smoke. The response from the section about the attitude against COTPA shows that 180 (51.4\%) participants felt that COTPA will be successful in reducing tobacco use, 175 (50\%) participants felt that the ban of sale of tobacco products to minor will be effective in controlling tobacco use, 162 (46.3\%) participants felt that the ban on tobacco sale near educational institution will have impact on controlling tobacco use among minors, 172 (49.1\%) participants felt that the health warnings on tobacco products will have positive impact on controlling the consumption and 184 (52.6\%) participants felt that objection against use of the tobacco products in public places would reduce the consumption of tobacco. The response from the section on Practice of COTPA shows that only 92 (26.3\%) participants had seen a poster/billboard regarding COTPA, 229 (65.4\%) participants had heard of fine being imposed for smoking in public places, 197 (56.3\%) participants knew about the fine amount, 183 (52.3\%) participants had seen an advertisement about COTPA in print or electronic media and 303 (86.6\%) participants had seen warnings signs regarding sale of tobacco products to minors at selling points. Further subgroup analysis was performed for each question of the questionnaire to detect any difference in response, but no significant difference in response to the questionnaire was observed during this analysis.

The scoring method and maximum and minimum score for all three sections of the questionnaire have already been discussed in the data collection section. The mean score for was calculated for all the three sections based on response from the participants. Table 3 shows the mean and standard deviation of the total score for each section. The table 3 also shows the mean and standard deviation amongst tobacco user and nontobacco users for the three sections of the questionnaire. The comparison of mean total scores of the knowledge, attitude and practice sections amongst tobacco users and nontobacco users shows no statistically significant difference ( $>0.05)$. The mean scores for knowledge, attitude and practice section did not show any statistically significant difference between tobacco users and non-tobacco users after adjusting for sex, age group, occupation. The data shows significant difference in mean score of attitude 
section between tobacco users and non-users after adjusting for the education status of the individual, no such difference in seen in knowledge and practice totals.

\section{Conclusion}

The data shows that the awareness of COTPA is low amongst the residents of Simri Village, although knowledge and perception about certain components of the COTPA is relatively higher. It was surprising to know that only $32.6 \%$ participants had seen any warning signs on tobacco products. This could be linked to local products not displaying the required warning signs. This is an area of great concern that needs to be addressed. The survey shows that attitude and beliefs of participants regarding COTPA showed a positive outlook with at least half of the participants agreeing that provisions under COTPA were successful in curbing the consumption of tobacco. The section on practice of COTPA showed us that the information was reaching participants by some or the other medium. The display of information about COTPA in public places could be increased which could lead to greater awareness and could effectively reduce the consumption of tobacco products in public places. A large number of participants have seen the warning signs at the selling point which could be very effective in reducing the consumption of tobacco amongst the minors.

The survey gives us a glimmer of hope regarding effectiveness of COTPA in curbing tobacco consumption in rural India. The survey has provided us with a great deal of valuable information regarding gaps in implementation of COTPA in rural area like Simri village of Simri block in Buxar district of Bihar. The survey has pinpointed clear areas where a huge gap in knowledge exists; this could be fixed by effective public and private partnership. The increase in knowledge about COTPA and tobacco related health problems could greatly improve the chances of reducing tobacco consumption in rural India. The availability of adequate knowledge and information will lead to change in the attitude regarding consumption of tobacco products in rural India. The government in currently investing a large amount of resources in tobacco control efforts but the reach of such efforts to most vulnerable sections of society i.e. rural India is questionable based on the results of the survey. There are numerous platforms in rural India that could be utilized to convey the message in a very effective way and the government and numerous organizations need to utilize these platforms to targets the population of rural India. I would like to repeat the survey in future in an urban region of Bihar to compare and contrast the findings with the current survey.

I would like to point out a few limitations of the survey that need to be noted before inferring the data presented. The survey was conducted in a single village of Bihar and although best efforts were made to get a random sample of participants for the survey there were few constraints which made it difficult. A large proportion of participants were tobacco user and so some bias might be introduced as consumers of tobacco are more prone to recall certain information as compared to non-users. The other important point that needs to be considered is the literacy rate in Simri block of Bihar, which is higher than the state average. This could lead to positive scores in all the section of survey and great care needs to be taken before utilizing the survey data for program planning in other regions. Even though the above mentioned limitations prevent generalizability of the survey data, we do get a great picture of current status of knowledge, attitude and practice regarding COTPA and tobacco consumption in rural India. The survey needs to be further administered in various rural areas across India to get high quality data to identify areas of gap and need. 
Texila International Journal of Public Health

Volume 4, Issue 4, Dec 2016

Tables

Table 1. Demographic information of Study Participants:

\begin{tabular}{|c|c|c|c|c|c|c|}
\hline & \multicolumn{2}{|c|}{ Tobacco User } & \multicolumn{2}{|c|}{$\begin{array}{c}\text { Non Tobacco } \\
\text { User }\end{array}$} & \multicolumn{2}{|c|}{ Total } \\
\hline & $\mathbf{N}$ & $\%$ & $\mathbf{N}$ & $\%$ & $\mathbf{N}$ & $\%$ \\
\hline \multicolumn{7}{|l|}{ Sex } \\
\hline Male & 286 & $85.1 \%$ & 50 & $14.9 \%$ & 336 & $96.0 \%$ \\
\hline Female & 12 & $85.7 \%$ & 2 & $14.3 \%$ & 14 & $4.0 \%$ \\
\hline \multicolumn{7}{|l|}{ Age Group } \\
\hline $18-29$ & 139 & $85.8 \%$ & 23 & $14.2 \%$ & 162 & $46.3 \%$ \\
\hline 30-39 & 82 & $82.8 \%$ & 17 & $17.2 \%$ & 99 & $28.3 \%$ \\
\hline 40-49 & 68 & $87.2 \%$ & 10 & $12.8 \%$ & 78 & $22.3 \%$ \\
\hline 50-59 & 9 & $81.8 \%$ & 2 & $18.2 \%$ & 11 & $3.1 \%$ \\
\hline \multicolumn{7}{|l|}{ Educational Status } \\
\hline Lower Primary & 7 & $77.8 \%$ & 2 & $22.2 \%$ & 9 & $2.6 \%$ \\
\hline Higher Primary & 18 & $90.0 \%$ & 2 & $10.0 \%$ & 20 & $5.7 \%$ \\
\hline High School & 196 & $84.1 \%$ & 37 & $15.9 \%$ & 233 & $66.6 \%$ \\
\hline College & 62 & $88.6 \%$ & 8 & $11.4 \%$ & 70 & $20.0 \%$ \\
\hline Degree and above & 15 & $83.3 \%$ & 3 & $16.7 \%$ & 18 & $5.1 \%$ \\
\hline \multicolumn{7}{|l|}{ Occupation } \\
\hline Un Employed & 47 & $88.7 \%$ & 6 & $11.3 \%$ & 53 & $15.1 \%$ \\
\hline Labour/Peon & 7 & $100.0 \%$ & 0 & $0.0 \%$ & 7 & $2.0 \%$ \\
\hline Shopkeeper/Businessman & 52 & $83.9 \%$ & 10 & $16.1 \%$ & 62 & $17.7 \%$ \\
\hline $\begin{array}{l}\text { Government } \\
\text { Officials/Teacher }\end{array}$ & 78 & $80.4 \%$ & 19 & $19.6 \%$ & 97 & $27.7 \%$ \\
\hline Farmer & 114 & $87.0 \%$ & 17 & $13.0 \%$ & 131 & $37.4 \%$ \\
\hline N (Total) & 298 & $85.1 \%$ & 52 & $14.9 \%$ & 350 & $100.0 \%$ \\
\hline
\end{tabular}

Table 2. Response to Knowledge, attitude and practice sections of questionnaire by Participants:

\begin{tabular}{|l|c|c|c|c|}
\hline \multicolumn{1}{|c|}{ Response } & \multicolumn{2}{c|}{ Yes/Positive } & \multicolumn{2}{c|}{ No/Negative } \\
\cline { 2 - 5 } & $\mathbf{N}$ & $\mathbf{\%}$ & $\mathbf{N}$ & $\mathbf{\%}$ \\
\hline \multicolumn{1}{|c|}{ Knowledge of COTPA } & & & & \\
\hline $\begin{array}{l}\text { Do you know about any Act/Legislation } \\
\text { regarding tobacco products (COTPA)? (YES / } \\
\text { NO) }\end{array}$ & 121 & $34.6 \%$ & 229 & $65.4 \%$ \\
\hline $\begin{array}{l}\text { Do you know about penalty for violation of } \\
\text { Act? (YES / NO) }\end{array}$ & 131 & $37.4 \%$ & 219 & $62.6 \%$ \\
\hline $\begin{array}{l}\text { Do you know that there is ban on selling } \\
\text { tobacco products near educational institutes? } \\
\text { YES / NO }\end{array}$ & 258 & $73.7 \%$ & 92 & $26.3 \%$ \\
\hline $\begin{array}{l}\text { Do you know that there is ban on sale of } \\
\text { tobacco products to minors? (YES / NO) }\end{array}$ & 205 & $58.6 \%$ & 145 & $41.4 \%$ \\
\hline
\end{tabular}


Texila International Journal of Public Health

Volume 4, Issue 4, Dec 2016

\begin{tabular}{|c|c|c|c|c|}
\hline $\begin{array}{l}\text { Have you seen any warnings on tobacco } \\
\text { products (YES / NO) }\end{array}$ & 114 & $32.6 \%$ & 236 & $67.4 \%$ \\
\hline $\begin{array}{l}\text { Are you aware about any tobacco related } \\
\text { health problems (like-Cancer, Respiratory } \\
\text { disease, Heart disease, Tuberculosis, } \\
\text { Hypertension, All of the above) (YES / NO) }\end{array}$ & 188 & $53.7 \%$ & 162 & $46.3 \%$ \\
\hline $\begin{array}{l}\text { Are you aware about harmful effects of } \\
\text { second hand smoke (YES / NO) }\end{array}$ & 117 & $33.4 \%$ & 233 & $66.6 \%$ \\
\hline \multicolumn{5}{|l|}{ Attitude against COTPA } \\
\hline $\begin{array}{l}\text { Do you think COTPA will be successful in } \\
\text { banning tobacco use? (P / N) }\end{array}$ & 180 & $51.4 \%$ & 170 & $48.6 \%$ \\
\hline $\begin{array}{l}\text { Do you think that ban on selling tobacco } \\
\text { products to minors will be effective in } \\
\text { controlling tobacco use? }(\mathrm{P} / \mathrm{N})\end{array}$ & 175 & $50.0 \%$ & 175 & $50.0 \%$ \\
\hline $\begin{array}{l}\text { Is banning tobacco sell near educational } \\
\text { premises will have impact on controlling } \\
\text { tobacco use among minors? }(\mathrm{P} / \mathrm{N})\end{array}$ & 162 & $46.3 \%$ & 188 & $53.7 \%$ \\
\hline $\begin{array}{l}\text { Do you think that health warnings on tobacco } \\
\text { products will have any impact? }(\mathrm{P} / \mathrm{N})\end{array}$ & 172 & $49.1 \%$ & 178 & $50.9 \%$ \\
\hline $\begin{array}{l}\text { Do you think objecting other person will } \\
\text { reduce tobacco use in public places? (P / N) }\end{array}$ & 184 & $52.6 \%$ & 166 & $47.4 \%$ \\
\hline \multicolumn{5}{|l|}{ Practice of COTPA } \\
\hline $\begin{array}{l}\text { Have you seen any poster/billboard regarding } \\
\text { COTPA in public places? (Yes/No) }\end{array}$ & 92 & $26.3 \%$ & 258 & $73.7 \%$ \\
\hline $\begin{array}{l}\text { Have you heard of fine being imposed on any } \\
\text { smoker by govt. agencies for using tobacco in } \\
\text { public places? (Yes/No) }\end{array}$ & 229 & $65.4 \%$ & 121 & $34.6 \%$ \\
\hline $\begin{array}{l}\text { Do you know regarding penalty or fine amount } \\
\text { by any mode? (Yes/No) }\end{array}$ & 197 & $56.3 \%$ & 153 & $43.7 \%$ \\
\hline $\begin{array}{l}\text { Have you seen any advertisement in print and } \\
\text { electronic media regarding COTPA? (Yes/No) }\end{array}$ & 183 & $52.3 \%$ & 167 & $47.7 \%$ \\
\hline $\begin{array}{l}\text { Have you ever seen any signage regarding } \\
\text { warnings of Tobacco use among minors at } \\
\text { selling points ?(Yes/No) }\end{array}$ & 303 & $86.6 \%$ & 47 & $13.4 \%$ \\
\hline
\end{tabular}




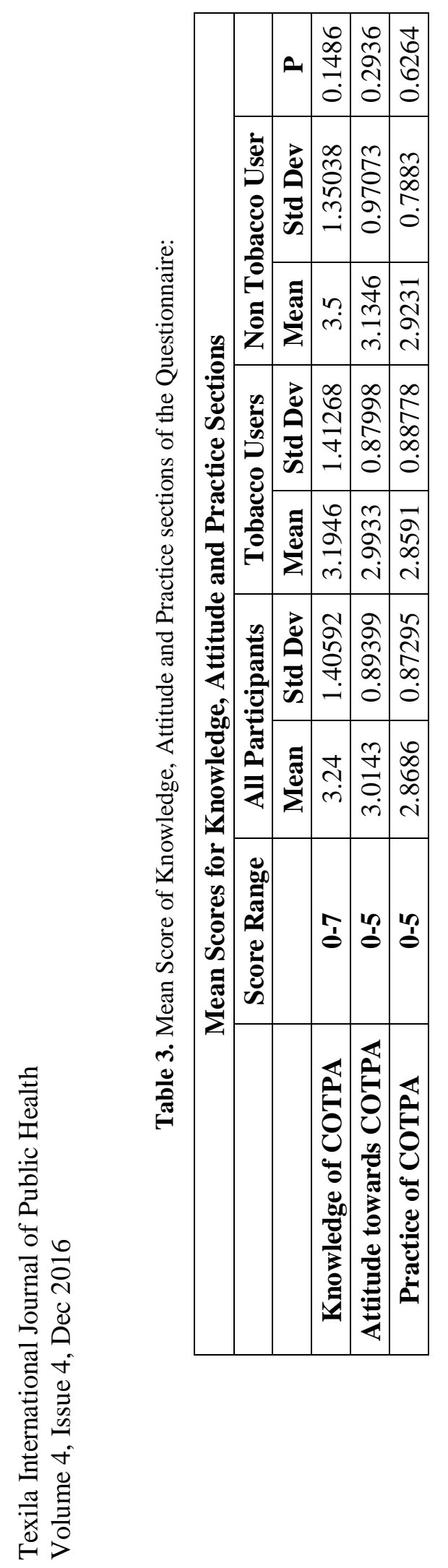




\section{References}

[1] Guindon GE et al. The cost attributable to tobacco use: a critical review of the literature. Geneva, World Health Organization, 2006.

[2] https://www.rit.edu/research/hsro/informed_consent_document_sample_tips

[3] Mackay, Judith / Eriksen, Michael (2002): The Tobacco Atlas. Geneva, The World Health Organization (WHO).

[4] Resource centre for tobacco free India; an initiative of Voluntary Health Association of India,[cited2013Sep1]Available

[5] Tobacco control foundation of India, Tobacco facts, [cited 2013 Sep 1] available from http://tobaccoindia.org/Tobacco-Facts.html

[6] The Cigarettes and Other Tobacco Products (Prohibition of Advertisement and Regulation of Trade and Commerce, Production, Supply, and Distribution) Act, 2003. New Delhi, India: Government of India;2003.

[7] The Cigarettes and Other Tobacco Products (Prohibition of Advertisement and Regulation of Trade and Commerce, Production, Supply, and Distribution) Act, Amendment Bill, 2007. New Delhi, India: Government of India;2007.

[8] Walton J, Barondess JA, Lock S. The Oxford Medical Companion. 1st ed. USA: Oxford University Press: 1994.

[9] WHO Framework Convention on Tobacco Control, WHO, Geneva, Switzerland. [cited2013Sep1]available from http://www.who.int/tobacco/framework/WHO_FCT C_english.pdf 


\title{
A Study Protocol to Assess Accessibility, Utilization, and Compliance on Adolescent Sexual Reproductive Health Services in South Sudan Context
}

\author{
Article by Katwesige wycliff \\ Masters of Public Health, Texila American University, Uganda \\ E-mail: katnagaish@yahoo.com
}

\begin{abstract}
Introduction: Provision of Sexual reproductive health (SRH) to people living in complex humanitarian emergencies is quite challenging. According to World Health Organization (WHO), addressing the health needs of adolescents living in crisis and fragile settings is a fundamental step on the pathway to both sustain the gains of the millennium development goals and achieve the new 2030 sustainable development goals. South Sudan's humanitarian situation remains fragile, precarious, complex and uncertain. The capacity of the nation to respond to the health of its people is crumbled. More than 4.9 million People are in dire need of humanitarian assistance, maternal mortality rate is $789,33 \%$ of the population is youth under 24years. There remain uncertainties as to whether the humanitarian response efforts are taking account of adolescent needs. This project will assess the accessibility, utilization and compliance of adolescents (aged 10-19 years) to health services provision within WHO set standards from selected camps in South Sudan. The study results shall inform advocacy and programming of SRH services by humanitarian partners.

Methodology: The search criteria will include; Cochrane libraries, PubMed, and others. Literature will be organized and referenced by research software like Mendeley. A cross-sectional study using qualitative and quantitative approaches will be conducted. Results will be analyzed using WHO recommended expand-net framework.

Ethics: Participation in an assessment will be voluntary. Parental consent for minors will be obtained before participating in the study. Approval from South Sudan Ministry of Health ethical committee shall be sought.1951 conventions of rights of refugees will be respected.

Foot note: The cross-section, Complex. Humanitarian, Adolescent, sexual Reproductive Health, Refugees, South Sudan

\section{Rationale and background information}

According to World Health Organization (WHO), Sexual health refers to as a state of physical, mental emotional and social well-being as related to sexuality, and not merely the absence of disease, or infirmity" (WHO 2000). Although the Global strategy for women and adolescents calls for "integrated solutions" based on dignity, respect, quality, integrated Healthcare ${ }^{1}$.The response in South Sudan seem more fragmented with different agencies providing what they feel they can best offer. As Sexual health requires a more careful approach to both sexuality and sexual relationships, as well as the possibility of experiencing pleasurable and safe sex, without coercion, discrimination, and violence, This study identifies four categories of Adolescent Sexual reproductive Health (ASRH) services intervention that exist, Thus (1) facility-based, (2) out-of-facility based, (3)programs that reach marginalized or vulnerable populations, (4) interventions to generate demand and/or community acceptance ${ }^{2}$. In September 2015 was globally marked as a year of defining moments for children and adolescents as well as the end point for United Nations Millennium Development Goals (MDG) and the adoption of recent Sustainable Development Goals (SDG) meant to transform the world in next $15 y$ years ${ }^{3}$. It also included the $20^{\text {th }}$ anniversary to celebrate action plans developed at the International Conference on Population and Development (ICPD) which defined SRH services and explicitly declared SRH as a fundamental human right, including for adolescent ${ }^{2}$. The current strategy is based on lessons learned and recent evidence and
\end{abstract}


Texila International Journal of Public Health

Volume 4, Issue 4, Dec 2016

is focused on critical groups within a given population such as women, adolescents and children living in fragile and conflict settings. In 1994 UN conference, the "Women's Commission for Refugee Women and Children" also reported major gaps in the provision of SRH services to refugees and others affected by crises(United Nations \& Conference, 2014). As Adolescence is typically characterized by a desire for information, and experimentation, the need to support adolescents in Complex setting like South Sudan is indeed dire ${ }^{5}$. Since adolescents contribute to one-fifth of the world's population(WHO, 2009), and also associated with high risk of pregnancy-related mortality compared to older women, such risks are indeed higher for adolescents in crisis settings ${ }^{7}$.Since $85 \%$ of adolescents are said to live in low-resource settings, current evidence approves that adolescent SRH is currently an area in need of research ${ }^{8}$. The $21^{\text {st }}$ century has faced challenges such as conflicts and wars especially in the developing world, which has led to a considerable number of people have either been internally displaced (IDPs) or found themselves seeking asylum (Refugees). Thus, adolescents have found themselves at the center of complex/conflict situations. Recently, the environment in south Sudan is now referred to as a "complex emergency" by Aid workers ${ }^{9}$. Before the December 2013 conflict, it was referred to as a "period of transition and recovery". The term complex has been adopted in this project to reflect on the complexity of the situation in which South Sudanese adolescents live as characterized by volatile States and others of relative stability.

According to WHO global report on world's adolescents, a standard driven approach for improving the quality of health care services among adolescents is highly recommended. The world's health body has therefore set global operational standards for quality health care for adolescents in order for them to find it easier to obtain the health care services they need (WHO 2015). Recently, at a September 2015 UN general assembly, an ambitious 15 year plan to pave a road map for improving lives of people throughout the world was adopted. This plan referred to as Sustainable Development Goals (SDG) consists of 17 goals and 189 targets calling for urgent attention to enhancing the availability and accessibility of sexual and reproductive health interventions required for the dignity and health of adolescents and children in those in emergency settings" ${ }^{\prime 10}$.

Of recent, the South Sudan political situation remains fragile following over 2years of hostilities including the most recent fallout between government and Rebel forces. Efforts to address long-term resilience and support national capacity for the delivery of basic health services were shelved. The grim, fragile, precarious, complex and uncertain humanitarian outlook is indeed troubling to the provision of adolescent health services. A humanitarian crisis is herein referred to as an "exceptional and a generalized threat to human life, health or subsistence". Although the perspectives for humanitarian disasters for children and adolescents from global view to save lives can be easily understood, the previous approach by the global community including WHO, World Bank, with other specific initiatives dedicated to adolescent health failed to address these complex issues ${ }^{11}$.

Meanwhile, as more South Sudanese seek refuge in neighboring countries like Uganda, an influx of refugees, above 350,000 was projected to arrive in South Sudan by the year 2013 (UN OCHA 2012). According to Amnesty International on July 6, 2014,over 10,000 deaths and 2 million people were displaced following the conflict ${ }^{12}$. By 2014 South Sudan was hosting over 250,000 refugees from Ethiopia, Central African Republic (CAR), Democratic republic of Congo (DRC) and Sudan. At the same time more than 1.4 million, South Sudanese were displaced internally following these hostilities and worsened by June 2016 clashes. Basing on this context, United Nations High Commissioner for Refugees (UNHCR) strategic mission for South Sudan in 2015 was to improve refugee status in settlements by enhancing the provision of health, and other services (UNHCR, 2015). Recently, the Common Humanitarian Fund (CHF) took responsibility in leading humanitarian efforts while enhancing its coordination in order to mobilize resources for the broader response and boost the visibility of the CHF both in the country and internationally ${ }^{13}$. More research is needed to determine the best linguistically and culturally acceptable means to deliver sexually and reproductive health services to vulnerable and marginalized populations. This study will answer questions aboutwhether SRH needs of adolescents living in such complex setting are accessible, utilized and meet the WHO set standards. 


\section{Problem statement and justification}

Frequent violence and conflicts in Africa are shown to have negative impacts on its society for instance current situation in South Sudan, previous conflicts in the Democratic republic of Congo, Uganda, and Rwanda which has experienced brutal civil wars in last 30years. Based on this context, following the 2013 Juba hostilities, refugees living in South Sudan continue to face serious and life-threatening protection issues, humanitarian workers were also killed on the mission (UNOCHA 2015). This situation, coupled with the total erosion of law and order in the refugee and IDP camps, manyyouths especially adolescents remain vulnerable to the complex environments impacting negatively on their health. The UNHCR mission in South Sudan is mandated to ensure refugees are protected and helped in such context $^{14}$.

According to report by United Nations Population Fund (UNFPA) on South Sudan, nearly 4.9 million people are in dire need of humanitarian assistance, I.5 million are internally Displaced and live in IDP camps, Around 2.8 million people were targeted for reproductive health services, the contraceptive prevalence rate stands at 3, proportion of its youth aged 10-24years accounts to nearly 33\% with Maternal mortality ratio of 789 (OCHA 2014). According to UNOCHA 2016, the population in need is estimated at 6.1 million out of which 4.7 million are in need of Health services and 2.7 million are only targeted by the

humanitarian response ${ }^{16}$.WHO is currently concerned with increasing sexual violence and limited coverage of skilled delivery care in many areas increasing the risks of maternal morbidity and mortality. More research to establish efficient means of delivering services to reach marginalized or vulnerable adolescents like refugees is still demanding ${ }^{2}$.

Recent study from Ajoung Thok a refugee camp in South Sudan revealed quite a large number of unmet adolescent SRH needs in terms of coordination, assessment and monitoring including major gaps on facility based ASRH services, community-based ASRH Services and communication (Africa Humanitarian Agency AHA, 2015). The study further emphasized strong rooted cultural beliefs that affect the delivery of ASRH services in the camp. Unwanted teenage pregnancies were spelled out as a major issue among adolescent girls in this settlement. But this study did not account for the views of teenage mothers partly due to the social and cultural context of people living in the camp. The findings were limited to one settlement hence situation may not be similar to other camps and their generalization is difficult. Furthermore, the study analysis did not fully conform to WHO recommended standard frameworks. In addition, related studies were conducted by the Inter-Agency Working Group (IAWG) for three countries (including south Sudan) to assess Reproductive Health services in Humanitarian settings, also revealed gaps ranging from limited knowledge and skills among service providers to cultural barriers in accessing Reproductive Health (RH) services among beneficiaries. This study also faced limitations ranging from security barriers to a lack of conformity with data analysis protocols recommended by WHO frameworks and limitations on its impact of driving policy change in South Sudan as well. Likewise, After long periods of planning to address ASRH, it's now evident that strengthening access and quality of health services does not alone improve health outcomes ${ }^{17}$. Hence, the call for Cutting-edge research on a measure of equity, accountability, and key determinants of SRH as well as informing UN agencies, with specific analyses and technical inputs has gained shape ${ }^{18}$.

In an attempt to generate demand for scaling up and increasing utilization of health services in context to basic primary health care for adolescents, as well as ensuring public health responsibility to help them protect their health and building on the Ajuong Thok research findings with its recommendations, this study will further assess whether adolescent health services entire South Sudan camp context meet set standards and are well accessed and utilized. The need for humanitarian agencies in the country to focus material and financial support to women, children, and adolescents in such conflict setting are highly demanding ${ }^{11}$. This study is justified by dire need of scaling up and improving the quality of assistance provided to vulnerable persons living humanitarian crisis and other complex settings and will synthesize practically sound evidence base to inform and update advocacy, policy change, and programming of ASRH services ${ }^{8}$ 
Texila International Journal of Public Health

Volume 4, Issue 4, Dec 2016

\section{Study goals and objectives}

\section{Goal}

To assess the factors affecting access, utilization as well as compliance with adolescent sexual reproductive health (ASRH) services provision in accordance to WHO set standards in selected complex humanitarian settings within South Sudan

\section{Research objective}

1. To establish the factors that affect access to ASRH services in a selected complex humanitarian setting within South Sudan

2. To examine the level of utilization of ASRH services in such setting within South Sudan

3. To assess compliance levels in the provision ASRH services in a similar setting within South Sudan to the current WHO set standards.

\section{Research questions}

1. What are the factors that affect access to ASRH services in selected complex humanitarian settings within South Sudan?

2. What could be utilization level of such ASRH services the same setting within South Sudan?

3. Are these ASRH services in a selected setting within South Sudan compliant with WHO set standards?

\section{Hypothesis}

Research on adolescent sexual reproductive health in complex/conflict humanitarian is currently limited ${ }^{2}$. This study will be based on the hypothesis that Identification of special beliefs which predict sexual risk and protective behaviors could lead to the design of linguistically specific interventions. Adolescents living in South Sudan environment are most likely to experience factors that limit their access to, low utilization of ASRHS and provisions of such services are likely to be below WHO set standards. 


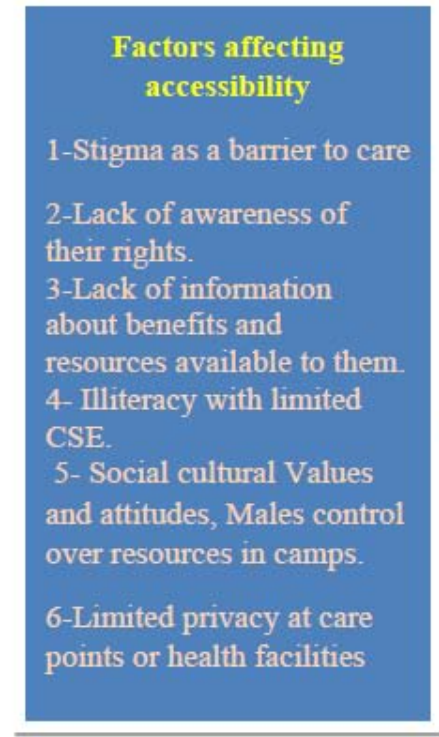

\section{WHO set standards \\ Standard 1.Adolescent Health} Literacy.

Standard 2.Community Support

Standard 3.Appropriate package of services

Standard 4.Providers competencies

Standard 5.Facility characteristics

Standard 6.Equity and non-

discrimination

Standard 7.Data and quality

improvement

Standard 8.Adolescents' participation.
The level of utilization in refugee and IDP camps.

1-Limimited use of package for adolescent care services (counseling treatment, Comprehensive sexual education, and others)

2-Limited Knowledge on adolescent health services in their setting

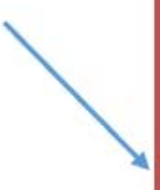

Adolescent Sexual Reproductive (SRH) services

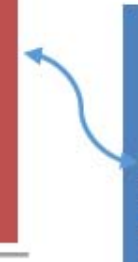

\section{le}

2-Loss of place or home or

places of belonging.

3 - Loss of family, friends

and significant adult role

Models.

4-Loss of order, routines

and meaningful activities,

and the onset of a time of

waste and, emptiness;

5-Loss of health or capacity

through injury, illness and

poor, and

6-Loss of trust in response

to personal or witnessed

experiences of harm or

abuse and sexual

exploitation

Fig 1. Conceptual framework

\section{The Research methodology}

\section{Settings for this study}

\section{Area of Study}

The study will be conducted amongst refugees and internally displaced persons living in camps in South Sudan. This will involve, South Sudanese in IDPs, and the refugees living in Settlement camps. The refugees have origins from Sudan, Democratic Republic of Congo (DRC) and Ethiopia. The refugee's population in South Sudan is 300,000 and IDPs 1.3million(UNOCHA 2016).The camps to be surveyed will undergo a random selection from among the 12 refugee settlement camps within South Sudan and at least 3 UN managed Internally Displaced Person camps (IDPs). 
Texila International Journal of Public Health

Volume 4, Issue 4, Dec 2016

\section{Our study population}

The participants in this study will be composed of both in and out of school adolescents aged (10-19 years). Our focus of the investigation will include; adolescents themselves, the Ministry of Health(MOH) staffs, None Governmental Organizations staff in Country response clusters, parents of these adolescents and their guardians, their teachers and religious as well as cultural leaders among others. Inclusive will be both genders supporting or living in either refugee camps. The study will adhere to rights of vulnerable populations in line with 1951 Universal Declaration of Human Rights and especially Articles 6 and 14, in particular, concerning the rights of refugees ${ }^{19}$.

\section{Study design}

We shall investigate the factors that affect access, utilization levels and compliance to ASRH services in the selected IDP and refugees camps. This will be entirely a cross-sectional study applying both quantitative and qualitative methods approaches to allow triangulation. The quantitative methodology will include face to face interviews and assessment of the existing Health information system (HIS) data. On the other hand, thequalitative methodology will involve Focused group discussions (FGD) as well as Key Informants (KIs). The study will be conducted in early 2017, upon receiving funds for this project.

\section{Population to be studied}

The study will involve both adolescents, teachers as well as health staff from refugee's schools and health units the Camps. Consent shall be sought for minors who will participate in this study from their parents and guardians. Study participation by all respondents shall be maintained on voluntary basis and in line with conventions relating to status of refugees ${ }^{20}$

\section{Inclusion and exclusion criteria}

\section{Inclusion}

All adolescents aged 10-19 years and any technical staff like teachers or health workers within the refugee and IDP camps.

\section{Exclusion}

All technical staff like teachers within the refugees or IDP camps who refuse to participate or decide to withdraw from the study and those adolescents who decline to participate in interviews will be excluded.

\section{Search criteria}

Inclusion criterion; We intend to search publications and written articles on adolescent living in crisis and other humanitarian setting and those on reproductive health services in refugee and IDP camps, the effect of wars and conflicts, WHO Library, World Bank report, with publication ranges between 2005 and 2015.

Exclusion criterion: All the non-English publications or publications before 2005 will not be included in our search.

\section{Sample size determination}

We shall use census for a small population less than 200 for example as a technique to establish the sample size and the number of technical staff will be interviewed to eliminate errors of sampling and provision of data to all the individuals in the study group. Sample size will be the entire adolescent's population (Glenn, 1992). To predict non-response or badly filled, damaged questionnaires we shall add $10 \%$. 


\section{Sample selection procedure}

We shall conduct a multi-stage, KI purposeful and random sampling. The community respondents will be sampled as follows: A list of all the names of individuals in the 12 camps of Refugees and 3 IDP camps will be populated. Every camp name will be written on a separate piece of paper, folded to ensure that all camps have the same chance of being selected as well. The PI shall then randomly pick 4 papers with no replacements. This will generate a total of four camps to be included in the study with each camp having an equal opportunity of being selected. Hence, the 4 Camps will be a representative for South Sudan Refugees and IDP Settlements.

\section{Data collection}

\section{Primary data collection}

\section{Quantitative data collection}

Semi- structured questionnaire will be administered by PI and trained research assistants (RAs) to the heads of households and adolescents.

\section{Qualitative data collection}

Key informants (KI) selected purposively will be interviewed using a question guide. They will include the following: Ministry of Health, Ministry of Education, Directors, Refugee Commissions, UNHCR staffs, NGOs partners at the camps, WHO staff and UNFPA staff.

\section{Secondary data}

This will involve a summary of existing data, previous research reports, books, journals, government and partner NGO statistics and online databases.

\section{Recruitment of study subjects}

The study team will work in close consultation with community leadership (formal and informal) to plan, identify and recruit potential participants for each site. The strategies to recruit members will thereafter be determined by the type and number of data collection activities above. These will be very flexible and modifiable. In case newer topics, research questions, or subpopulations emerge related to the study or initial strategies do not result in the desired number of recruits, or if certain data collection activities of populations do not prove useful in answering the research questions, the criteria for selection will change. The research team shall respect and be responsive to the guidance and advice of local expertise and local leadership (camp and Payam leaderships).

\section{Training interviewers}

The fist training will consist of 2 days classroom based exercises. Didactic teaching kept to a minimum and shall be focused on description methodology its rationale. We shall spend more time on trainees to practice the methods on each other as well providing feedback to the group. Addition observation and systematic data collection methods training will be provided in the field sites just prior to their use.

\section{The management of data and statistical analysis}

\section{Study selection}

For secondary data analysis, three authors (Principal Investigator and 2 research consultants) will independently examine titles and abstracts of selected studies to eliminate none relevant studies. For those studies that meet our inclusion criteria, full texts will be retrieved and two reviewers will assess their final eligibility against the inclusion criteria. As studies in this field for the case of South Sudan and other humanitarian settings, 4 studies will be included in this study. 
Texila International Journal of Public Health

Volume 4, Issue 4, Dec 2016

\section{Management of data}

We shall install, special research software such as Mendeley or Zotero on laptops during collection of secondary data. Articles that will be found eligible for our study will be downloaded and inputted accordingly, author will then independently extract the following details;

1) Title, authors, status of publication, journals, founders and date of publications.

2) Categorization of crisis whether disaster or conflict and the type of crisis whether armed conflict, droughts, landslides, tsunami, and cyclone, hurricanes floods, earthquakes, volcanoes and others

3) How was the nature of onset slow or rapid, stage reported, active or recovery setting and location urban or rural?

We shall dispense semi-structured questionnaires, digital audio tape recordings, emails during primary data collections to field partners and shall observe events as well. Collected data will be discussed and summarized in line with key study areas limited to 3-5 issues as explained during the training workshop. We shall integrate the findings from this background to correlate findings from the field and provide a broader context. Reports will be sent to principal investigator who will provide feedback. The specific choice of people to be interviewed will depend on the camp location. The interviewees might include, policy-makers and program managers, service providers in humanitarian settings, camp managers and health workers including CHWs, as well.

Pre-test of the instruments used will be conducted familiarize team members with the different instruments through an interactive process of developing them included in role-plays and re-testing them before the fieldwork begins. This will enrich team experience with qualitative interview techniques during the training sessions.

Dr. Wamala Joseph is a co-investigator in this study. He works with WHO epidemiology department in South Sudan, he contributed to the design of this study and will lend support to work out the sample size and data analysis sections of the study. He will create a study database, perform data validity checking's concurrent data analysis as well. The standard frameworks and tools like WHO expand net frameworks will be deployed in during analysis.

Variations in the findings from various camp settings due to other factors are expected. If further studies for review are identified, further investigations shall be conducted based on its heterogeneity within groupings here below;

- Place of care such as facility-based versus non-facility or community services)

- The status of displacement for example IDPs versus refugees and the surrounding host communities)

- The type of providers likes skilled versus unskilled providers.

- The current type of service delivery like stationary versus mobile clinics

\section{Expected study outcomes}

\section{Expected primary outcomes}

- The evidence of access and level of coverage of ASRH services in the camps such as the coverage of school health programs, school dropout rates by gender, STIs prevalences among adolescents. Barriers to service access like health worker attitudes.

- The current utilization of overall health services by youth like antenatal (ANC) and family Planning (FP) attendances by adolescents as well as Sexual gender-based violence (SGBV) in the camps.

- Update knowledge in the existing level of standards in services provided to adolescents.

\section{Secondary outcomes}

- Improvement in the quality services provided to adolescents in the camps evidenced by humanitarian agencies adhering to WHO recommended practices guidelines and approaches.

- Improvements in quality of statistics for informing adolescent health programming in Humanitarian emergency settings in Sub-Saharan Africa. 
- Enhanced refugees and IDP protection services reduction in SGBV prevalence rates in the camps as a result of ASRH services scaled up.

\section{Dissemination of results and publication policy}

The principal investigator (PI) will take lead in the publication of the research findings. All pertinent contributors to this research project will be included in the publication as well as major funders.

\section{Ethics and dissemination}

Those selected to participate in this study will do so on entirely voluntary basis and such participants will be allowed to respond freely to the questions. Interviews will be conducted outside school operating hours and in the absentia of their parents and teachers from the room of interview. Questions will not include confidential information to interviewees. There will likely be no ethical committee to review and authorize this study relative to the current security situation and capacity toground. However, prior to the commencement of this study, an interagency committee including members from UNCHR, ACROSS, WHO, and other relevant partners will be established to advise on the study justification and methodology that will respect refugee and other vulnerable population rights. The findings from this study will be published as per the decision of funders.

\section{Project duration}

The study will last a period of 8 to 10 months depending on circumstances in the field including security and access issues on the ground.

\section{Project timelines and limitations}

Due to the current security situation in South Sudan, there is the likelihood of study being affected by security risks in the field. Communication infrastructure is very limited hence road transport in some areas like the Yei, Bor will not be feasible. Hence additional expenses in booking flights for investigators will be incurred.

\section{Ethical considerations}

The principal investigator is updated professional research ethics. He will ensure that the study avoids plagiarisms and violations of refugees and especially vulnerable group rights and conventions and shall, therefore, abide by all the core ethical principles such asbeneficence, justice and exhibit respect for the rights of the vulnerable and refugee rights as stipulated in Geneva conventions of human rights. The study shall be subjected to full ethical review by local ethical review committee for authorization and monitoring. Authority to conduct the study in the settlement camps will be sought from the United Nations High commissioner for Refugees (UNHCR) which shall evaluate direct benefits of this study for the individual refugees and internally displaced persons who will participate in study as well as expected benefits for the host communities in South Sudan in which the study will take place including overall potential benefits to science and the world at large.

\section{Other expected support for the project}

WHO, World Bank, USAID will be sought for funding support?

\section{Collaboration with scientists or other research institutions}

This study will be conducted fully in collaboration with another scientist from various universities in East African mainly Uganda and abroad mainly, Geneva Foundation for medical education and research and Texila American University Public health Department. 
Texila International Journal of Public Health

Volume 4, Issue 4, Dec 2016

\section{Financing, Implementation, and management}

Funds will be wired to Across an international Christian Non-Governmental Organization (INGO) which has operated in South Sudan since the 1970s. Across is currently partnering with UNHCR and manages 2 refugee camps in Central Equatorial State within South Sudan.

\section{Declaration conflict of interest}

The Author works as an expatriate staff for Across, therefore, there is the likelihood of a conflict of interest.

Jennifer Swann_Prof. Lehigh University, Dr. Wanyama_UNFPA, Dr. Petros Gebrewold_UNHCR, Dr. Wamala_WHO, Dr. Allan_WHO, Dr. Brenda Rwanda University of Science, Dr. Albert_IRC, Dr. Abate UNHCR, Sebit Mustafa_UNHCR, Oliot_Cavendish University Uganda. And lastly my course supervisor Suma Menon Faculty Member.

\section{References}

[1]. Kinney M V, Boldosser-Boesch A, McCallon B. Quality, equity, and dignity for women and babies. Lancet. 2016;6736(16):16-17. doi:10.1016/S0140-6736(16)31525-2.

[2]. Denno DM, Hoopes AJ, Chandra-Mouli V. Effective Strategies to Provide Adolescent Sexual and Reproductive Health Services and to Increase Demand and Community Support. J Adolesc Heal. 2015;56(1):S22-S41. doi:10.1016/j.jadohealth.2014.09.012.

[3]. Bill F, Foundation MG. Measuring the health-related Sustainable Development Goals in 188 countries: a baseline analysis from the Global Burden of Disease Study 2015. Lancet. 2016:1813-1850. doi:10.1016/S01406736(16)31467-2.Accessed on 23/09/2016

[4]. United Nations, Conference I. A /69/62. 2014;22369(February):1-286.

[5]. Laski L, Wong S. Addressing diversity in adolescent sexual and reproductive health services. Int J Gynaecol Obstet. 2010;110 Suppl:S10-S12. doi:10.1016/j.ijgo.2010.04.011.

[6]. Who. Quality Assessment Guidebook-A guide to assessing health services for adolescent clients. Circuit World. 2009;5(1):14-14. doi:10.1108/eb043585.

[7]. Nove A, Matthews Z, Neal S, Camacho AV. Maternal mortality in adolescents compared with women of other ages : evidence from 144 countries. 1990:155-164. doi:10.1016/S2214-109X(13)70179-7.

[8]. Hindin MJ. "Setting research priorities for adolescent sexual and reproductive” - Google Search. 2015:1-14. http://www.google.com/search?hl=en\&client=safari\&tbo=d\&rls=en\&q=\%22Setting+research+priorities+for+adoles cent + sexual+and+reproductive\%22\&oq $=\% 22$ Setting+research+priorities+for+adolescent+sexual+and+reproductive \%22\&gs_l=serp.3...4523.11357.0.11566.3.3.0.0.0.0.52.12.

[9]. Mowjee T. HPG Background Paper. Development. 2004;44(0):0-29.

[10]. Galati AJ. HIGHLIGHTS Guttmacher Policy Review. Guttmacher Policy Rev. 2015;18(4):77-84.

[11]. Horton R. Offline: The future for women's and children's health. Lancet. 2016;387(10032):1982. doi:10.1016/S0140-6736(16)30306-3.

[12]. Lancet T. No peace of mind in South Sudan. Lancet (London, England). 2016;388(10041):212. doi:10.1016/S0140-6736(16)31076-5.

[13]. CHF. Common Humanatarian Fund. S.Ignals. 2005.

[14]. Spiegel P, Golub G. Refugees and health: Lessons from World War 1. Lancet. 2014;384(9955):1644-1646. doi:10.1016/S0140-6736(14)61896-1.

[15]. Office for CHF. Overall Humanitarian Needs in South Sudan. 2014.

[16]. Response Plan. humanitarian Response;South Sudan (December 2016).

[17]. Svanemyr J, Amin A, Robles OJ, Greene ME. Creating an enabling environment for adolescent sexual and reproductive health: A framework and promising approaches. J Adolesc Heal. 2015;56(1):S7-S14. doi:10.1016/j.jadohealth.2014.09.011.

[18]. Victora C, Requejo J, Boerma T, et al. Countdown to 2030 for reproductive, maternal, newborn, child, and adolescent health and nutrition. Lancet Glob Heal. 2016;(16):2015-2016. doi:10.1016/S2214-109X(16)30204-2. 
Texila International Journal of Public Health Volume 4, Issue 4, Dec 2016

[19]. Paul Weis. The 1951 Refugee Convention: The Travaux préparatoires analysed with a Commentary. UN High Comm Refug. 1990:1-272.

[20]. Weis P. The Convention Relating to the Status of Stateless Persons. Int Comp Law Q. 1961;10(2):255-264. doi:10.1093/iclqaj/10.2.255 


\title{
Factors Influencing the Purchase of Counterfeit Drugs among Consumers in Rural Community of Cross River State, Nigeria
}

\author{
Article by Agada Peter Okpe ${ }^{1}$, Okareh Oladapo Okareh ${ }^{2}$, Ugobo Emmanuel Eteng ${ }^{3}$ \\ ${ }^{1}$ Senior Pharmacy Specialist, Howard University PACE Center (HU PACE), Strengthening \\ Integrated Delivery of HIV/AIDS Services (SIDHAS) project, Cross River State Office, \\ Calabar, Cross River State, Nigeria \\ ${ }^{2}$ Senoir Lecturer, Dept. of EHS, Faculty of Public Health, College of Medicine, University of \\ Ibadan, Ibadan, Nigeria \\ ${ }^{3}$ Howard University PACE Center (HU PACE), Strengthening Integrated Delivery of \\ HIV/AIDS Services (SIDHAS) project, Cross River State Office, Calabar, Cross River State, \\ Nigeria

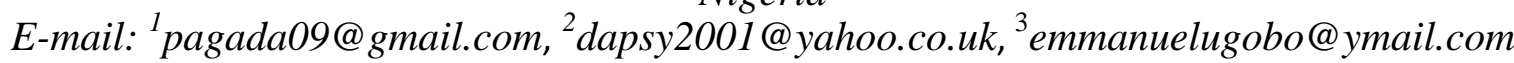

\begin{abstract}
Background: The purchase of counterfeit drugs by consumers is a serious public health problem and there are no sufficient researches dedicated to understanding the problem of drug counterfeiting from the consumers' perspective.

Aim: The aim of this study to assess factors influencing the purchase of counterfeit drugs among consumers in rural community using the concept of planned behavior (TPB) as a guide.

Methodology: This study is a cross-sectional descriptive research, using pretested questionnaire for data collection to ensure validity and reliability of instrument. A sample size of 236 was used for this study. Data was analyzed using SPSS version 20.0.

Results: The respondents mean age is 30.51years $(S D=11.46)$. Findings from this study showed that 139(58.9\%) of the respondents were males while 97(41.1\%) were females. Majority of the respondents 56(23.7\%) reported the cost of the drug as frequently used means of identification of counterfeit drugs in the community. Respondents perceived associated risk of counterfeit drugs includes: unexpected side effects 33(14\%), allergic reactions 38(16.1\%), worsening of their medical condition 48(20.3\%), death 46(19.5\%) and overdose 19(8.1\%). Findings from this study also showed a correlation between behavioural intention and attitude $(R=0.64)$. Subjective norms were associated with behavioural intention $(R=0.65)$ but was not significant at 0.005 . There was also an observed significant relationship between behavioural intentions and motivation $(R=0.52)$.

Conclusion: Drug consumers mainly use cost of drugs as a means of identification of counterfeit drugs. Consumers behavior, intention and attitude towards counterfeit drugs are correlated.
\end{abstract}

Keywords: counterfeit drugs, consumers perspectives, planned behavior.

\section{Introduction}

The availability of counterfeit drugs in the market presents a serious public health problem, particularly in developing countries such as Nigeria, and may have a significant impact on the national disease and economic burden. In 2002, the World Health Organization reported that 70 percent of drugs in Nigeria were fake or substandard; the National Agency for Food and Drug Administration and Control (NAFDAC) estimated that 41 percent of drugs alone were counterfeit $(1,2)$. Estimate suggests that $10 \%$ of prescription drugs sold worldwide are counterfeits, fake or contaminated, and in parts of Africa and Asia, the figures exceed 50\%(3)

Counterfeit medicines are widespread and represent a threat to public health which can lead to healthcare failures, such as resistance to antibiotics and the spread of disease within a community, as well as loss of life. Research has also shown that poor-quality medicines can reach the market through 
deliberate fraudulent practices by those that want to get rich overnight. There is low awareness of the problem of counterfeit medicine; a problem that could lead to public-health crisis (4). Knowledge, attitude and practice regarding counterfeit drugs are often undermine and given less concern in the area of research.

Measuring the magnitude of the phenomenon of counterfeit drugs turns out to be extremely complicated, particularly due to various reasons that have to do with the disposable means to detect the trafficking routes, the number and the identity of those involved in the production and distribution processes, and the difficulty in systematizing and coordinating the information from the various stakeholders in charge of keeping, collecting and analyzing data (4).

Available statistics have tried to propose figures on the exact percentage of counterfeit medicines within the worldwide pharmaceutical market. Their estimations reflect both the magnitude and the volatility of the problem: percentages of counterfeit medicines in different national pharmaceutical markets vary from as 1 percent to as high as 50 percent. In general, higher percentages refer to less developed countries and economies in transition whereas lower percentages refer to the developed countries. Therefore, it is essential to take into account geographical, economic, legal and social criteria in order to interpret these percentages (3).

Research has shown that counterfeit medicines is less spread in more developed countries due to a combination of enhanced legislation, stronger institutions and a more efficient regulatory control. According to the WHO, developed countries such USA, Australia, Canada, Japan, New Zealand and those within the European Union (EU) have a very low proportion of counterfeit medicines no more than one per cent of market value(5).

However, the fact that a considerable amount of counterfeit drugs cases are declared on an annual basis by developed countries proves that this problem still affects both developed and developing countries.

Nevertheless, the situation is more dramatic in less developed countries due to fragile economies, widespread poverty, lack of regulation, difficulties in controlling the system, as well as the difficulties in furthering and enforcing strong legislative measures. WHO has estimate shows that counterfeit medicines would represent approximately ten percent of the entire amount of medicines worldwide (5). Pfizer estimates that counterfeit Viagra alone causes a loss of 2 billion USD in sales. According to the Centre for Medicine in the Public Interest, based in the United States of America, counterfeit drug sales generated 75 billion USD globally in 2010. However, and according to other estimates, these rates increased to 20 per cent as there is a growing problem of drugs that look alike in most market. The situation seems to be even worse in some African countries.

There are no sufficient researches dedicated to understanding the problem of drug counterfeiting in developing countries including Nigeria especially from the consumers' perspective. There have been various published works on exploring, measuring or combating drug counterfeiting using various research design and making recommendations, while those efforts may, succeed in measuring or describing the prevalence of counterfeit drugs in developing countries, these studies fail to consider the factors contributing to the prevalence of these drugs from the consumer's perspective. Therefore, this study seeks to assess factors influencing the purchase of counterfeit drugs among consumers in rural community using the theory of planned behavior as the theoretical framework underpinning the research.

\section{Theoretical framework}

In other to understand why drug consumers engage in counterfeit drug purchase, Ajzen's (6) theoretical framework on planned behavior (TPB) was adopted and applied in this study.

According to TPB, behavioural actions can be predicted from an individual's intention and plan to carry out such behaviour under study. Ajzen proposes three categories of significant beliefs which include the behavioural beliefs, that is often expected to affect attitudes, the normative beliefs, that form the basic part of subjective norms and that of the control beliefs which offer the foundation for 
perceptions of behaviour control. The TPB advocates that the above mentioned beliefs will lead to the intent of an individual to act in a specific manner, although, the significance of the beliefs differs. Based on the findings from the TPB, it has been observed that the stronger the individual beliefs concerning the attitude, subjective norms and the perceived behaviour control, the more the prospect that such person will act in a specific or defined manner (7).

Intention represents the readiness and determination to carry out the behavior, and of the confidence, ability, and availability of indispensable opportunities and resources while behaviour is regarded as the function of intent to execute the behaviour (6). Therefore, the stronger the intention to execute an act or perceived behaviour control over the act, the higher the likelihood of performing a behaviour. According to Ajzen (1991) (6) variables such attitude, subjective norm, and perceived behavioural control are the constructive predictors of intention. Attitude in this context refers to an individual's emotional and evaluative deliberations about a behavior (8).

Emotive deliberation in this context reflects the extent to which an individual loves or disgusts a behavior. Evaluative deliberations can also be defined as a reflection of an individual's perception towards a behavior in relation to its benefits or harm. Based on the current study, it can be hypothetically said that the stronger the individual's attitude towards purchasing counterfeit drugs, the stronger the expectation for engagement into purchasing drugs (6)

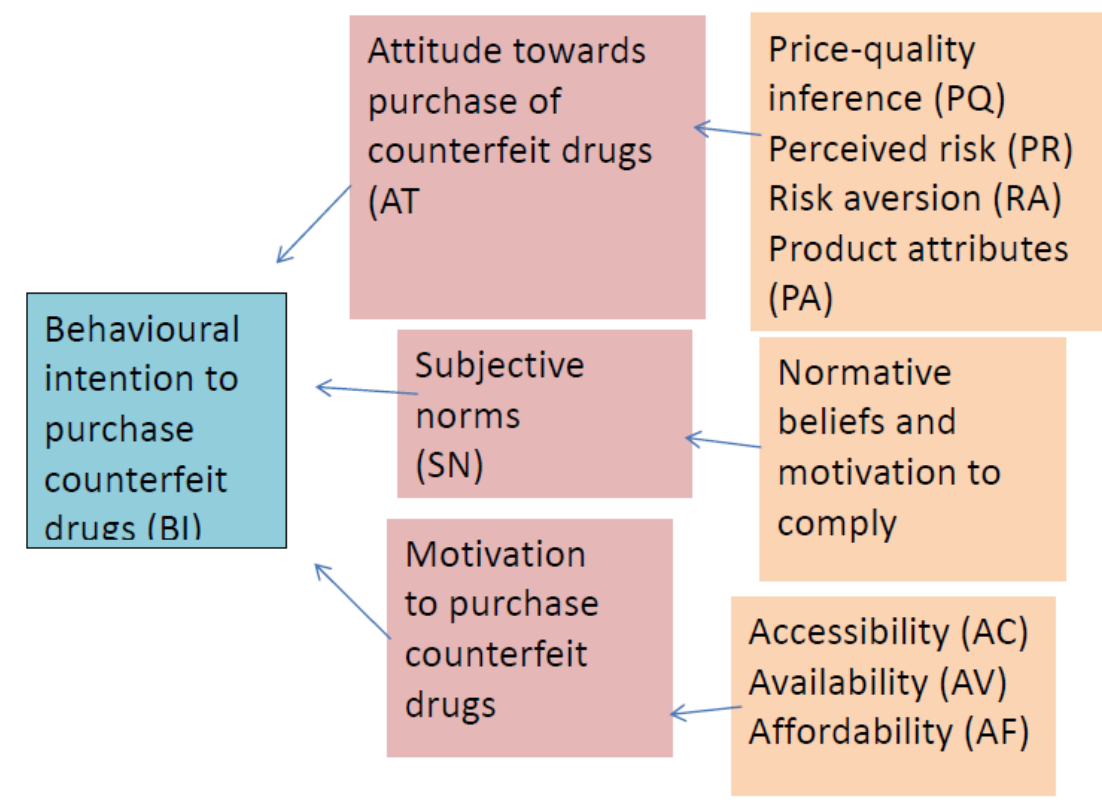

Conceptual framework explaining the theory of planned behavior with respect to the purchase of counterfeit drugs, adopted from Abubakr et al (2012)

\section{Methodology}

\section{Study location}

The study was conducted in Bekwarra Local Government Area. Bekwara is one of the 18 Local Government Areas in Cross River State, Nigeria with a population of 105,822 people existing in an area of $306 \mathrm{~km} 2$ (9). This local authority area is of historical significance to the Nigerian nation. It was in one of its towns, Gakem, that the first shot of the Nigerian Civil war (1967-1970) was fired (10). That war started the disintegration of values in Nigeria, spawning violence, hardships, poverty, hunger, drug abuse, family dysfunction and prostitution, which still rear their ugly heads today (11). Bekwarra indigenes are conservative traditional people with strict customs and values. 
Bekwarra Local Government Area is in the Northern Senatorial District of Cross River State. There are ten political wards in the local government as follows: Abuochiche, Afrike Ochagbe, Afrike Okpeche, Benten, Gakem, Abi-Aragin, Nyanya, Otukpuru, Otukpuru, Ugboro, Ukpah.

Bekwarra Local Government Area has it headquarters at Abuochiche. It is bounded in the north by Benue State, South by Ogoja Local Government Area, East by Obudu Local Government Area and West by Yala Government Area.

The major population groups of the local government area are Ujia, Unwapu, Unwagba Oli West, Oti East, Eya Aba, Beten, Uduo, Eya Adie, Ika-Ichia, Udomu, Atibulum, Afrike, Okpeche, Ikachor and Ochagbe. The major economic activities in the area include agriculture, cattle/goat and poultry rearing, petty trading et cetera. Majority of the indigenes are farmers whose produce and sold within and outside the state. The major traditional festival is the new yam festival held during the first week of September yearly and traditional market days are as includes Udama, Ugbada, Uchagu, Ugidi, Achanya (10)

\section{Study design}

This study is a community based cross-sectional descriptive study that employed the use of questionnaire to elicit information from respondents. The choice of the research design is because of it flexibility and adaptability to change. This design also requires strong focus and concern to create observational skills, capable of getting precise and accurate data and to be competent to interpret different situation effectively.

\section{Data collection tools}

A structure questionnaire was designed using the theory of planned behavior as a guide. The questionnaire contained information on the demographic characteristics of respondents, respondents perceived associated risk of counterfeit drugs, signs that are used to identify whether medication is counterfeit, questions that measured respondents' attitudes towards counterfeit drugs; subjective norm; factors that may motivate their purchase intention; and consumers purchase intention.

Five-point Likert scales were employed in questions that measured respondents' attitudes towards counterfeit drugs; subjective norm; factors that may motivate their purchase intention; and consumers purchase intention; with one representing 'strongly disagree' and five representing' strongly agree'.

\section{Sampling procedures}

Multi-stage sampling technique was employed in the selected of respondents as follows:

Stage I: collection of the list of all registered PMVs from the state ministry of health as sampling frame. This stage also included, mapping, enumeration of patent medicine vendor (PMVs) outlets.

Stage II: Simple random sampling technique was used to select 4 out of the 11 health patent medicine vendors (PMVs) distribution outlet in Bekwara Local government area. Using a list of all the PMVs, each was given a number (1-11), these numbers was written on a piece of paper which was folded, all the 11 papers were put in a container and vigorously shaken then 6 papers were picked from the container and the numbers recorded. PMVs with those numbers were then included in the study.

Stage 2: In each selected PMVs, systematic sampling technique was used to select drug end users (consumers), That is, research assistant was attached to each of the selected community PMVs to interview customers that check in to purchases drug. In order to avoid selection bias, the research assistant selected the first buyer and skip the second buyer, this continued systematically until the required sample size was achieved. Respondents that decline consent to be involved in the research was not included in the study.

\section{Data collection}

Four research assistants (2 males and 2 females) who are fluent in the local language and English will be recruited for data collection and were trained on field exercise and how to handle ethical 
issues. Those field assistant presented themselves as research assistant and follow the research protocol for obtaining data from respondents. Data were collected through one-on-one interview with consumers.

\section{Method of analysis data analysis}

The collected data was entered in excel environment and screened to fulfill the requirement for running analysis and then exported to statistical package for social science (SPSS) version 22.0 for analysis. Descriptive analysis was computed for the demographics to have a thorough description of the demographic characteristics of the respondents. Finally, the inferential statistics were carried out to reach conclusions on the findings to either reject or fail to reject the hypothesis of the research. Level of significance for this study stands at 0.05 .

\section{Test for reliability and validity of instrument}

To ensure the validity and reliability of the constructs, a pilot study was conducted using a different population with similar characteristics with that of the study population. At the end of the pilot study, collected data were entered into SPSS version 20.0 and analyzed. The Cronbach coefficient Alpha was computed to measure the internal consistency of the instrument (12). Cronbach Alpha refers to a reliability coefficient that specifies the degree to which items are correlated positively to one another, the nearer the Cronbach alpha to 1 , the better the internal consistency (13). The entire Cronbach Alpha coefficient for this study is above 0.70 thus, indicating a good internal consistency for the variables under study (Table 6.0).

\section{Ethical consideration}

Permission was granted from Cross River State Health research ethics committee to carry out the research in the state. During field work, information sheets about the study in Bekwara were given out to the respondents, explaining why the research was carried out, by whom, and what it would involve. Participants were allowed to withdraw from interview at any time he or she want.

Confidentiality of all study participants was assured. Everybody was informed that no names or direct identification made to the questionnaire except numerical identification number was used for follow up. Before interview, study respondents were requested to participate voluntarily. Respondents were also told of the benefits they will derive from participating in the study.

\section{Results}

\section{Socio-demographic characteristics}

A total of 250 questionnaires were distributed and 236 questionnaires were filled and returned, resulting to a response rate of $94.4 \%$. The mean age for the collected samples was $30.51(\mathrm{SD}=11.46)$.

Findings from this study shows that 139(58.9\%) of the respondents were males, while $97(41.1 \%)$ were females. Majority of the respondents $127(53.8 \%)$ were single, 99(41.9\%) were married while 10(4.2\%). Findings from this study also shows that a higher percentage of the respondents (97\%) were Christians, 3(1.3\%) were Muslims, 3(1.3\%) practice African traditional religion and only $1(0.4 \%)$ of the respondents practice other religion not mentioned. Majority of the respondents 135(57.2) had secondary school education, 51(21.6\%) had university education, 33(14\%) had primary education while 17(7.2\%) had no formal education (table 1.0).

\section{Means of identification of counterfeit drugs by consumers}

Respondents reported the following frequently used means of identification of counterfeit drugs: a strange smell; 36(15\%), a strange taste or colour; 30(12.7\%), drug breaking apart very easily or be cracked or chipped; 22(9.3\%), labels that have directions that seem incorrect including NAFDAC number and manufacturers address; 32(13.6\%), cost very little, especially compared with the normal price of that particular drug;56(23.7\%) (Table 2.0) 


\section{Perceived associated risk of counterfeit drugs by consumers}

Findings from this study shows that respondents perceived the following as associated risk of counterfeit drugs: unexpected side effects 33(14\%), allergic reactions 38(16.1\%), worsening of their medical Condition 48(20.3\%), death 46(19.5\%) and overdose 19(8.1\%). Respondents sources of information on the perceived risk of counterfeit drugs shows that majority of the respondents, 102(43.2\%) got it from health professionals 54(22.9\%) from Government, 36(15.3\%) from nongovernmental organization, $16(6.8 \%)$ got it from manufacturers, while $28(11.9 \%)$ got it from other sources not mentioned (Table 3.0)

\section{Predicting behavioural intention to purchase counterfeit drugs}

Findings from this study showed a correlation between study variables. Behavioural intention was correlated with attitude $(\mathrm{R}=0.64)$. Subjective norms were associated with behavioural intention $(\mathrm{R}=0.65)$ but was not significant at 0.005 . There was also an observed significant relationship between behavioural intentions and motivation $(\mathrm{R}=0.52)$ (table 7.0)

\section{Confirmatory factor analysis}

One of the requirement to carry out factor analysis is for the data to pass Kaiser-Meyer-Olkin KMO and Bartlett's test, the bench mark usually 0.6 and above $(12,13)$. This study met the criteria with a KMO score above 0.62 and a significant Bartlett's Test, which indicate that factor analysis can be carried out in the collected data (table 5.0)

Table1.0 Socio-demographic characteristics

\begin{tabular}{|c|c|c|}
\hline Variable & Frequency & Percent \\
\hline \multicolumn{3}{|l|}{ Sex } \\
\hline Male & 139 & 58.9 \\
\hline Female & 97 & 41.1 \\
\hline Total & 226 & 100.0 \\
\hline \multicolumn{3}{|l|}{ Marital status } \\
\hline Single & 127 & 53.8 \\
\hline Married & 99 & 41.9 \\
\hline Divorced & 10 & 4.2 \\
\hline Total & 236 & 100.0 \\
\hline \multicolumn{3}{|l|}{ Religion } \\
\hline Christian & 232 & 97.1 \\
\hline Muslim & 3 & 1.3 \\
\hline $\begin{array}{l}\text { Traditional African } \\
\text { Religion }\end{array}$ & 3 & 1.3 \\
\hline Others & 1 & .4 \\
\hline Total & 236 & 100 \\
\hline \multicolumn{3}{|l|}{ Level of education } \\
\hline University & 51 & 21.6 \\
\hline Secondary School & 135 & 57.2 \\
\hline Primary school & 33 & 14.0 \\
\hline $\begin{array}{ll}\text { No } & \text { formal } \\
\text { education } & \\
\end{array}$ & 17 & 7.2 \\
\hline Total & 236 & 100 \\
\hline
\end{tabular}




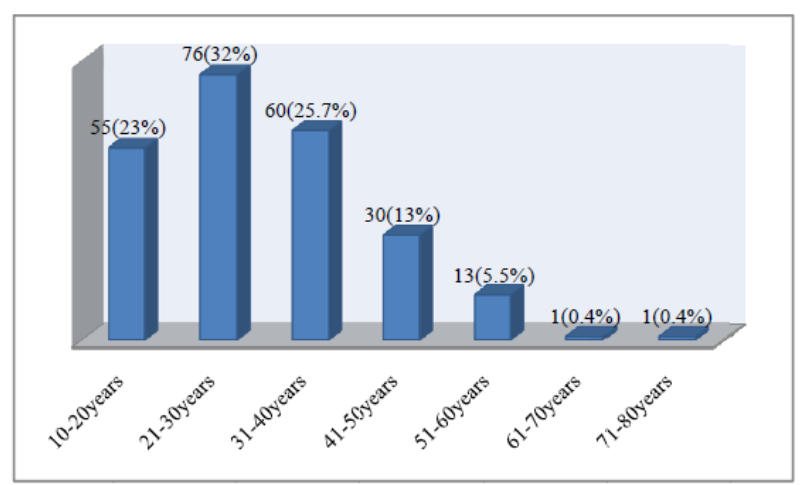

Fig 1.0 Age distribution of respondents

Table 2.0 Means of identification of counterfeit drugs by consumers

\begin{tabular}{|l|c|c|c|c|c|c|}
\hline \multicolumn{1}{|c|}{ Variable } & $\begin{array}{c}\text { Never } \\
\text { used }\end{array}$ & $\begin{array}{c}\text { Rarely } \\
\text { used }\end{array}$ & $\begin{array}{c}\text { Occasionally } \\
\text { used }\end{array}$ & $\begin{array}{c}\text { Frequently } \\
\text { used }\end{array}$ & $\begin{array}{c}\text { Most } \\
\text { frequently } \\
\text { used }\end{array}$ & Total \\
\hline A strange smell & $\mathbf{1 1 9}$ & $\mathbf{2 8}$ & $\mathbf{4 6}$ & $\mathbf{3 6}$ & $\mathbf{7}$ & 236 \\
\hline A strange taste or colour & $\mathbf{1 0 4}$ & 37 & 58 & 30 & 7 & 236 \\
\hline $\begin{array}{l}\text { Drug breaking apart } \\
\text { very easily or be cracked } \\
\text { or chipped }\end{array}$ & $\mathbf{9 5}$ & 34 & 69 & 22 & 16 & 236 \\
\hline $\begin{array}{l}\text { Labels that have } \\
\text { directions that seem } \\
\begin{array}{l}\text { Incorrect including } \\
\text { NAFDAC number and } \\
\text { manufacturers address }\end{array}\end{array}$ & $\mathbf{1 0 8}$ & 27 & 42 & 32 & 27 & 236 \\
\hline $\begin{array}{l}\text { Cost very little, } \\
\text { Especially compared } \\
\text { with the normal price of } \\
\text { that particular drug }\end{array}$ & $\mathbf{6 7}$ & $\mathbf{3 0}$ & $\mathbf{6 7}$ & $\mathbf{5 6}$ & $\mathbf{1 6}$ & $\mathbf{2 3 6}$ \\
\hline
\end{tabular}

Table 3.0 Perceived associated risk of counterfeit drugs

\begin{tabular}{|l|c|c|}
\hline \multicolumn{1}{|c|}{ Variable } & Frequency & Percentage \\
\hline Unexpected side effects & 33 & 14.0 \\
\hline Allergic reactions & 38 & 16.1 \\
\hline $\begin{array}{l}\text { Worsening of their medical } \\
\text { Condition }\end{array}$ & 48 & 20.3 \\
\hline Death & 46 & 19.5 \\
\hline Overdose & 19 & 8.1 \\
\hline Vomiting & 11 & 4.7 \\
\hline General illness & 19 & 8.1 \\
\hline I don't know & 22 & 9.3 \\
\hline Total & 236 & 100.0 \\
\hline
\end{tabular}




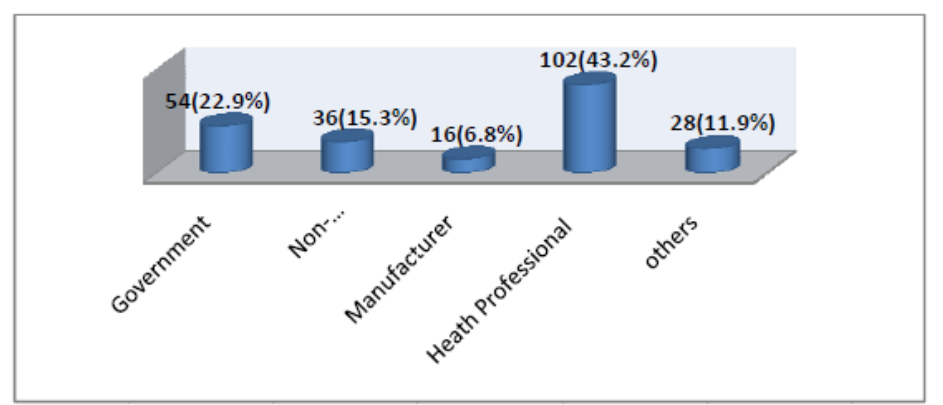

Fig 2.0 Sources of information on the associated risk of counterfeit drugs

Table 4.0 Component loadings for measurement model

\begin{tabular}{|c|c|}
\hline Variable & Loadings... \\
\hline \multicolumn{2}{|l|}{ Perceived product attributes (PA) } \\
\hline $\begin{array}{l}\text { Authentic drugs are often of better quality than non-authentic } \\
\text { drugs }\end{array}$ & 0.225 \\
\hline Non-authentic drugs are just as good as authentic drugs & -0.135 \\
\hline Purchasing non-authentic drugs is worthless & 0.646 \\
\hline Non-authentic drugs are not worth buying & 0.617 \\
\hline Authentic drugs perform much better than non-authentic & 0.403 \\
\hline Authentic drugs are more reliable than non-authentic & 0.188 \\
\hline Authentic drugs are worth the money they cost & 0.350 \\
\hline $\begin{array}{l}\text { Overall, my cognitive belief regarding the attributes of non- } \\
\text { authentic drugs is negative }\end{array}$ & 0.552 \\
\hline \multicolumn{2}{|l|}{ Perceived risks (PR) } \\
\hline The risk that I take when I buy a non-authentic drug is high & 0.584 \\
\hline $\begin{array}{l}\text { There is high probability that the non-authentic drug doesn't } \\
\text { work }\end{array}$ & 0.492 \\
\hline Spending money on non-authentic drugs might be a bad decision & 0.656 \\
\hline Generally speaking, non-authentic drugs can be very dangerous & 0.456 \\
\hline Purchasing non authentic drugs is quite risky & 0.466 \\
\hline \multicolumn{2}{|l|}{ Risk aversion (RA) } \\
\hline When I buy something, I prefer not taking risks & 0.154 \\
\hline I like to be sure the product is good one before buying it & 0.341 \\
\hline I don't like to feel uncertainty when I buy something & 0.292 \\
\hline I always avoid risky things & 0.194 \\
\hline \multicolumn{2}{|l|}{ Price-quality inference (PQ) } \\
\hline $\begin{array}{l}\text { Generally speaking, the higher the price of a drug, the higher the } \\
\text { quality }\end{array}$ & 0.151 \\
\hline You have always to pay a bit more for the best & 0.408 \\
\hline The price of a drug is a good indicator of its quality & 0.254 \\
\hline $\begin{array}{l}\text { The price premium of authentic drugs compare to non-authentic } \\
\text { is mostly justified }\end{array}$ & 0.297 \\
\hline \multicolumn{2}{|l|}{ Awareness of societal consequences (ASC) } \\
\hline $\begin{array}{l}\text { Purchasing non-authentic drugs harms the economy of my } \\
\text { country through loss of taxation revenue }\end{array}$ & 0.245 \\
\hline $\begin{array}{l}\text { Purchasing non-authentic drugs undermines the national health- } \\
\text { care system of my country }\end{array}$ & 0.201 \\
\hline Purchasing non-authentic drugs discourages manufacturers of & 0.341 \\
\hline
\end{tabular}




\begin{tabular}{|c|c|}
\hline $\begin{array}{l}\text { legitimate drugs from investment in research and development } \\
\text { and hence slows the development of new effective drugs }\end{array}$ & \\
\hline \multicolumn{2}{|l|}{ Subjective norm (SN) } \\
\hline $\begin{array}{l}\text { My relatives and friends approve my decision to buy non- } \\
\text { authentic drugs }\end{array}$ & -0.409 \\
\hline $\begin{array}{l}\text { My relative and friends think that I should buy non-authentic } \\
\text { drugs }\end{array}$ & -0.480 \\
\hline \multicolumn{2}{|l|}{ Affordability (AF) } \\
\hline $\begin{array}{l}\text { Generally speaking, one of the reasons for buying non-authentic } \\
\text { drugs is that the prices of authentic drugs are unaffordable }\end{array}$ & 0.002 \\
\hline $\begin{array}{l}\text { Generally speaking, one of the reasons for buying non-authentic } \\
\text { drugs is that it has affordable prices }\end{array}$ & 0.304 \\
\hline $\begin{array}{l}\text { One of the reasons for buying non-authentic drugs is that I would } \\
\text { not be ready to pay the price of the authentic drugs although I } \\
\text { prefer them }\end{array}$ & 0.611 \\
\hline $\begin{array}{l}\text { Generally speaking, one of the reasons for buying non-authentic } \\
\text { drugs is that the authentic drugs are not always available }\end{array}$ & 0.606 \\
\hline $\begin{array}{l}\text { Unaffordable prices of authentic drugs may cause me to buy } \\
\text { non-authentic drugs }\end{array}$ & 0.646 \\
\hline \multicolumn{2}{|l|}{ Availability (AV) } \\
\hline $\begin{array}{l}\text { Generally speaking, one of the reasons for buying non-authentic } \\
\text { drugs is that the authentic are not always available }\end{array}$ & 0.477 \\
\hline $\begin{array}{l}\text { Non-availability of authentic drugs may cause me to buy non- } \\
\text { authentic drugs }\end{array}$ & 0.613 \\
\hline \multicolumn{2}{|l|}{ Accessibility (AC) } \\
\hline $\begin{array}{l}\text { Generally speaking, one of the reasons for buying non-authentic } \\
\text { drugs is that the authentic drugs are not always accessible }\end{array}$ & 0.622 \\
\hline $\begin{array}{l}\text { For me, purchasing a non-authentic drug would not be an option } \\
\text { even if the authentic }\end{array}$ & 0.449 \\
\hline $\begin{array}{l}\text { Non-accessibility of authentic drugs may cause me to buy non- } \\
\text { authentic }\end{array}$ & 0.607 \\
\hline \multicolumn{2}{|l|}{ Behavioural intention (BI) } \\
\hline It is likely that I may buy a non-authentic drug in the future & 0.532 \\
\hline $\begin{array}{l}\text { Still there is a chance that I say favorable things about non- } \\
\text { authentic drugs }\end{array}$ & 0.499 \\
\hline
\end{tabular}

Table 5.0 KMO and Bartlett's Test

\begin{tabular}{|c|c|c|}
\hline \multicolumn{3}{|c|}{ KMO and Bartlett's Test } \\
\hline $\begin{array}{c}\text { Kaiser-Meyer-Olkin Measure of } \\
\text { Sampling Adequacy. }\end{array}$ & .621 \\
\hline $\begin{array}{c}\text { Bartlett's Test of } \\
\text { Sphericity }\end{array}$ & $\begin{array}{c}\text { Approx. Chi- } \\
\text { Square }\end{array}$ & 2053.043 \\
\cline { 2 - 3 } & Df & 666 \\
\cline { 2 - 3 } & Sig. & .000 \\
\hline
\end{tabular}


Table 6.0 Composite reliability

\begin{tabular}{|l|c|}
\hline \multicolumn{1}{|c|}{ Variables } & Cronbach coefficient Alpha \\
\hline Perceived product attributes (PA) & 0.92 \\
\hline Perceived risks (PR) & 0.74 \\
\hline Risk aversion (RA) & 0.93 \\
\hline Price-quality inference (PQ) & 0.81 \\
\hline Awareness of societal consequences (ASC) & 0.77 \\
\hline Subjective norm (SN) & 0.71 \\
\hline Affordability (AF) & 0.90 \\
\hline Availability (AV) & 0.83 \\
\hline Accessibility (AC) & 0.91 \\
\hline Behavioural intention (BI) & 0.90 \\
\hline
\end{tabular}

Table 7.0 Relationship between Behavioural intention and Attitude, subjective norms and motivation

\begin{tabular}{|c|c|c|}
\hline & \multicolumn{2}{|c|}{ BI } \\
\hline & Pearsons ${ }^{\circledR}$ & Sig \\
\hline Attitude (ATT) & $0.64 *$ & 0.133 \\
\hline Subjective norms (SN) & 0.65 & 0.001 \\
\hline Motivation (MT) & $0.52^{*}$ & 0.197 \\
\hline
\end{tabular}

*correlation significant at 0.05

\section{Discussions}

Despite available strategies to control or combat the influx of counterfeit drugs in Nigeria, there is still high proliferation of counterfeit drugs in the Nigeria market (14). Most counterfeit drugs look like genuine version of drug which makes it difficult for consumers to distinguish counterfeit drugs from the original ones.

Findings from this study shows that respondents identify counterfeit based on strange smell; $36(15 \%)$, strange taste or colour; 30(12.7\%), drug breaking apart very easily or be cracked or chipped; 22(9.3\%), Labels that have directions that seem incorrect including NAFDAC number and manufacturers address; 32(13.6\%), Cost very little especially compared with the normal price of that particular drug; 56(23.7\%). This is contrary to the findings of Odili, Osemwenkha, Eke and Okeri Henry (2006) (19)

Respondent's ability to identify counterfeit drugs qualitatively based on packaging, labelling, and appearance/colour are an important step towards creating suspicion and discouraging the illicit trade in counterfeit drugs for malaria and other conditions (14)

Unfortunately, one of the major means to confirm whether a drug is counterfeit is by performing a chemical analysis in a laboratory which is quite expensive but however, physical checks such as the colour of the drugs, the odour/taste of, expiry dates and batch numbers on the box not matching those of the drugs inside, and patient's information leaflets being in the wrong language or out of date may indicate whether a drug/product is counterfeited (14).

The level of awareness of respondents on these signs is important towards suspicion of counterfeit drugs and avoidance of buying such drugs consequently reducing the market and profit of these counterfeit drugs (19).

Another aim of this study was to assess those factors that influence consumers to purchase counterfeit drugs using the theory of planned behavior framework as a guide.

Several researchers have been carried out using the theory of planned behavior to predict intention to perform a defined or various kinds of behaviour including health related behaviours. Findings from this study have shown that the theory of the planned behavior model can be used to explained human behavioural including intensions to carry out various kinds of behaviours including intention to 
purchase counterfeit drugs. Variables such as Attitude, societal norms and motivation were significant predictors of intention to purchase counterfeit drugs.

The present study showed a positive correlation between Attitude of respondents and behavioural intention, Attitude was found to be a major predictor of behavioural intention which was similar to a study carried out by Bisonette and Contento (2001) (15). Also a study carried out by Abubakar et. al (2012) indicated a strong relationship between behavioral attitude and behavioural intention in a (16).

Findings from this study shows a correlation between subjective norms and the intention of respondents to purchase counterfeit drugs but the relation was not significant at $0.005 \mathrm{p}$-value although people tend to be guided by personal norms rather than subjective norms in most situations as the former are more outstanding than the latter (17), this is consistent with other research that has suggested subjective norm to be the weakest predictor of intention in the theory of planned behavior, this study found subjective norms not to be a significant predictor of intention.

The above findings also contradict findings from a study carried out by Mullan and Wong (2009) (18), which reported social normative influences than attitudes. Thus, the decision to purchase counterfeit drugs was mainly determined by what they perceived rather than by the influence of other people or the resources or opportunities they perceived the operation to possess.

\section{Limitations of the study}

Limitations of a study are meant to guide future research. This study had the following limitations which should be addressed in future research. One of its limitations is that of limited sample to test hypothesis. Therefore, there is need to carry out further research in the study area using a larger sample size. Another limitation of this study is that of selection bias as most drug consumers may likely not be selected if they happen not to buy drugs the day questionnaire was collected as research assistants were attached only PMVs outlets. The TPB is a very useful model which can be applied in other settings other than the study area

\section{Conclusion/recommendation}

The involvement of consumers in the community in the fight against counterfeit drugs is often neglected. Drug consumers mainly use cost of drugs as a means of identification of counterfeit drugs. Consumers behavior, intention and attitude towards counterfeit drugs are correlated. The present study establishes a need to empower consumers in the community through awareness and educational interventions to enable them identify counterfeit in the community and report to the appropriate authority.

\section{References}

[1] Akunyili, D.N., 2007. Couterfeiting medicines: A serious crime against humanity. Proceedings of the Directora General of the National Agency for Food and Drug Administration and Control (Nafdac), April 10, 2007, Nigeria to the European Parliament in Brussels, pp: 1-7.

[2] Ajzen I. (1991). The Theory of planned behavior. Organizational Behavior and Human Decision Processes.;50:179-211

[3] Akpan N.U. (1972). The struggle for secession, 1966-70: Personal Account of the Nigerian Civil War. ISBN-10: 0714629499. Frank Cass Publishers, London.

[4] Ajayi J.O. (2003). The HIV/AIDS Epidemic in Nigeria: Some Ethical Considerations. ISBN 88- 7652955-1. Gregorian University Press, Rome Italy

[5] Abubakr A. Alfadl, Mohamed Izham M. Ibrahim and Mohamed A. Hassali (2012). Consumer behaviour towards counterfeit drugs in adeveloping country. Journal of pharmaceutical health service.

DOI 10.1111/j.1759-8893.2012.00095.x ISSN 1759-8885

https://www.researchgate.net/publication/259648430

[6] Bisonette, M. M. \& Contento, I. R. (2001). Adolescents' perspectives and food choice behaviours in terms of the environmental impacts of food production practices: application of a psychosocial mode. Journal of Nutrition Education, 33(2), 72-82. 
[7] Charles Clift (2010). Combating counterfeit, falsified and substandard medicines: defining the way forward? centre on global health security, ghbp 2010/01

[8] Engle, R.L., Dimitriadi, N., Gavidia, J.V., Schlaegel, C., Delanoe, S., Alvarado, I., He, X., Buame, S. and Wolff, B. (2010). "Entrepreneurial intent: a twelve-country evaluation of Ajzen's model of planned behavior”, International Journal of Entrepreneurial Behavior \& Research, Vol. 16 (1), pp. 35-57. Emerald Group Publishing Limited. 1355-2554 DOI 10.1108/13552551011020063.

[9] Liñán, F., and Chen, Y. (2009). Development and cross-cultural application of a specific instrument to measure entrepreneurial intentions. Entrepreneurship Theory \& Practice, 5, 593-617.

[10] Mhando Linus, Jande Mary, Anthony Liwa, Mwita Stanley, \& Marwa Karol (2016). Public Awareness and Identification of Counterfeit Drugs in Tanzania: A View on Antimalarial Drugs.

[11] Mullan, B.A. \& Wong, C.L. (2009). Hygienic food handling behaviors. An application of the Theory of Planned Behaviour. Appetite, 52, 757-761.

[12] National Bureau of Statistics (2006). Federal republic of Nigeria 2006 population census. www.nigerianstat.gov.ng/

[13] Newton PN, Lee SJ, Goodman C, Fernández FM, Yeung S, Phanouvong S, Kaur H, Amin A, Whitty C, Kokwao G, Lindegardh N, Lukulay P, White L, Day N, Green M, White N (2009) Guidelines for field surveys of the quality of medicines: a proposal. PLoS Med 6

[14] Odili, Valentine U., Osemwenkha Sylvia, Eke Esther U. and Okeri Henry A (2006). Identification of Counterfeit Drugs by Community Pharmacists in Lagos State. Tropical Journal of Pharmaceutical Research, 5(1), pp. 545-550

[15] Thogersen, J. (2009). The motivational roots of norms for environmentally responsible behavior. Basic and Applied Social Psychology, 31, 348-362. http://www.textcheck.com/certificate/FKgpLo

[16] Sandhu, M. S., Sidique, F. S., and Riaz, S. (2011). Entrepreneurship barriers and entrepreneurial inclination among Malaysian postgraduate students. International Journal of Entrepreneurial Behaviour \& Research Vol. 17 No. 4, 2011 pp. 428-449 Emerald Group Publishing Limited 1355-2554

[17] Sekaran, U. (2003). Research Methods for Business: A Skill-Building Approach. John Wiley \& Sons, New York, NY.

[18] World Health Organization. Substandard and counterfeit medicines. Fact sheet No. 275, 2012. Available at http://www.who.int/mediacentre/factsheets/2012/fs275/en/ (last accessed 14, September 2016).

[19] Yankus W (2006). Counterfeit Drugs: Coming to a Pharmacy Near You. American Council on Science and Health. Available: www.acsh.org/publications/pubID.1379/pub_detail.asp 


\title{
Patient Safety Culture of Iganga, Kamuli Mission and Kakira Hospitals of South Eastern Uganda
}

\author{
Article by Balidawa John \\ District Health office Jinja District Local Government, Uganda \\ E-mail: balidawajohn@gmail.com
}

\begin{abstract}
Background: Health care is one of the most important services that every one desires to be of high quality and safety, but in real practice, this is not always the case. In the event of seeking health care, many patients are harmed and some get serious disabilities or even death. System failures and blame for errors committed are the ones that mostly promote occurrence of medical errors hence resulting into unsafe healthcare. Blame prevents health care providers from reporting errors for future prevention of re occurrence.

Patient safety, which is a component of quality healthcare, is defined as the absence of avoidable harm to patients during the process of health care, (Carmen A. n.d.). To achieve 100\% absence of avoidable harm to patients is hard to realise as 'to err is human' but efforts to avoid harm are of great importance. In developed countries, thousands of patients are reported to suffer serious harm and death in the event of receiving health care services. In 1999, Institute of Medicine in the USA estimated 44,000 to 98,000 preventable deaths annually due to medical errors in USA hospitals, (IOM 1999). In Uganda`s healthcare system, many patients are harmed and many even die during the event of seeking for healthcare but due to poor reporting systems there is limited information on the magnitude of preventable harmful medical errors.

The study to determine patient safety culture of Iganga, Kakira and Kamuli Mission in south eastern Uganda, had five objectives of; assessing the knowledge of health workers on patient safety, the role of the hospital management in promotion of patient safety culture, determine patient safety culture practices, point prevalence of common inpatient safety incidents, and causal pathways.

Methodology: The study was an observational, descriptive and cross-sectional survey. A sample of 144 health workers were interviewed using a questionnaire, three focus group discussions with hospital managers were conducted, and 169 inpatient records were reviewed. Data was entered in SPSS 16. 0 software then into Excel for further analysis and later presented in graphs.

Results: The study revealed that the knowledge of health workers on patient safety in the study hospitals was just above average at 55.8\%. Under and over dosing of patients, dispensing of wrong drugs and poor infection control being the most common medical errors known, where as Uganda clinical guideline was found to be the most known guideline for patient safety. The study also showed that, the majority of health workers would not report errors due to ignorance and fear of blame. The study showed existence of team work and channels for communication of patient safety issues between management and staff. However, management role in promotion of patient safety is still demanding as there was limited availability of policies and guidelines, lack of patient safety incident record books and patient safety committees. There existed fairly good patient safety practices as communication, hand washing, dispensing and team work were all above average. However it was found out that poor reporting, fear of blame, under staffing and inadequate waste disposal practices did exist. Incidents of failure to monitor vital signs and delayed investigations were more prevalent in over $70 \%$ of all records studied. The majority of the surgical operations were done without pre-operative investigations and had inadequate post operative notes increasing the chances of harm to surgical patients. Causal pathways for medical incidents were mainly lack of guidelines and policies, poor monitoring of adherence to guidelines, limited skills and training of staff, understaffing, heavy
\end{abstract}


workloads, lack of logistics and faultiness of equipments and lack of reporting procedures for patient safety.

Conclusion: In conclusion, the level of knowledge on patient safety culture is just average as awareness is still limited. There is a significant lack and limited availability of policies and guidelines, incident record books and committees that promote patient safety. The bad practices of fear to report incidents, under-staffing and fear of blame for errors committed need improvement. Failure to monitor vital signs, difficulty to access high skilled staff especially the medical officers and inadequate post operative notes also need serious attention as they are part of the causal pathways for patient safety incidents in the study hospitals. Provision of policies and guidelines, training of health worker, management leadership and effective communication and monitoring of patient safety in the study hospitals are highly recommended.

\section{Introduction}

Patient safety is one of the dimensions of quality of care and it is defined as the absence of avoidable harm to patients during the process of health care (Carmen, n.d.). The international classification for patient safety defines patient safety as "The reduction of risk of unnecessary harm associated with health care to an acceptable minimum" (WHO, 2009a p133).

The Department of Health Expert Group in June 2000 estimated that over 850,000 incidents used to harm hospitalized patients in the United Kingdom alone each year, (Department of Health Expert Group, 2000). In 2004, the Canadian Adverse Events Study found that adverse events occurred in more than 7\% of hospital admissions, (Ross B et al, 2004). Such reports have led the World Health Organization to estimate that one in ten persons receiving health care suffer a preventable harm (WHO, n.d.a).

Patient safety involves all aspects related to provision of harmless healthcare to patients such as avoidance of medical errors, incident reporting, adherence to standard guidelines, policies and procedures for patient safety, adequate training of staff, effective communication structures, and patient safety monitoring and evaluation.

Quality assurance in the health sector in Uganda started recently in 1994 as the quality assurance program, which was created to support health service delivery in a decentralized system. The Uganda Ministry of Health supported the Yellow Star Program as a major quality management intervention, which focused on minimum service standards for a range of Primary Health Care services. However, there is a relatively little experience in measuring patient safety culture and improvement in the Ugandan healthcare system.

\section{Justification}

World Health Organization estimates that one in ten hospitalized patients are harmed in the process of provision of healthcare. Uganda's hospitals are not exceptional given the standard of her healthcare system. Organization systems that promote patient safety have improved over years in the developed world, but patient safety measures have remained poor in the developing countries, including Uganda. It is hard to give concrete figures to what extent poor patient safety has affected patients in developing countries simply because of limited documented data and information accessed. However, in Europe, a number of studies carried out confirmed that patient safety was the major concern for that region by 2007, according to the European Union Patient Safety Working Group (EU-PSWG, 2007).

There is limited information on the level of health workers ' knowledge on patient safety, the role manager's play in the promotion of patient safety, patient safety practices, and the prevalence of inpatient safety incidents and their causal pathways in the study hospitals of Kakira, Iganga, and Kamuli Mission. Without this information, patient safety improvement would be hard to be realised and many patients would continue suffering harm and deaths in the process of seeking health care.

The study was meant to build on the knowledge of the researcher, the health workers, Ministry of Health and other stake holders on the level of patient safety in general hospitals so has to seek improvement. This information if used by the hospital managers and health workers will help the 
studied hospitals to plan and improve on their patient safety practices. The Ministry of Health can now benefit from the research findings, if used, by understanding the patient safety culture in the public and private general hospitals of eastern Uganda, to influence policy and guidelines on patient safety. Other stake holders like WHO can also have additional understanding of patient culture in the Ugandan hospitals.

\section{Background of the study area}

The study established the patent safety culture in general hospitals of Iganga, Kakira and Kamuli mission, that were conveniently selected. Iganga Hospital is a public general hospital, Kakira Hospital is a Private For Profit and Kamuli Mission Hospital is a Private Not For Profit hospital.

Study Goal:

To assess the patient safety culture of public and private general hospitals of south eastern Uganda to generate information that if used can contribute to patient safety improvement in Uganda.

\section{Objectives of the study}

To assess the knowledge of health workers on patient safety in the study hospitals.

To assess the role of the hospital management in promotion of patient safety culture in the study hospitals.

To assess the patient safety culture practices in the study hospitals.

To determine the point prevalence of common inpatient safety incidents in the study hospitals

To determine the causal pathways for the common inpatient safety incidents in the study hospitals.

\section{Study type, population, unit and sample size}

The study was an observational, descriptive and cross sectional survey, both qualitative and quantitative in nature. The study population was three general hospitals of South Eastern Uganda of Iganga, Kamuli mission and Kakira. The study units were the health workers in the different departmental units of a hospital and inpatients records. The sample size of the health workers was 143 determined by use of the hyper geometric method for a known population. A census of inpatient records for patients admitted at least 24 hours to the time of survey was conducted to determine the prevalence of patient safety incidents.

\section{Data analysis and presentation methods}

Data was collected, collated and entered into SPSS 16.0 software to get tables of frequencies and percentages. Data was transferred into excel for further calculations and lastly to word from where narrative interpretations were made.

\section{Ethical considerations}

Consent was by respondents signing the questionnaire before completing it. The participants/respondents were also reassured of confidentiality to the information that was obtained from them.

\section{Results and analysis}

\section{Socio-demographic characteristics of respondents}

The percentage of health workers trained in patient safety was that; Iganga hospital had 54.5\% $(\mathrm{n}=44)$, Kamuli mission had 52.4\% $(\mathrm{n}=42)$ and Kakira hospitals had 62.7\% $(\mathrm{n}=51)$.

\section{Distribution of inpatient files reviewed for patient safety incidents per ward. $(n=169)$}

Iganga hospital had the highest number of files studied of 58.6\%, followed by Kamuli Mission with $25.4 \%$ and lastly Kakira hospitals with $16 \%$. This was because Iganga hospital has more workload of patients than Kamuli and Kakira. The more, the patients that are handled, the more the pressure build 
up on the hospital resources and hence the likely hood of occurrence of medical mistakes. However the staffing levels of Iganga also observed to be higher than for other hospitals. All the wards were represented by the inpatient files at the time of survey with children`s ward having more files reviewed than other wards. This means that more children get admitted than adults in the study hospitals except for Kakira hospital that had more of males admitted due to traumas, given the nature of work of working in a factory.

\section{Knowledge of health workers and hospital managers on patient safety}

Health workers able to explain what patient safety is; $32.8 \%$ of health workers interviewed explained well what patient safety is, with Kamuli mission hospital having slightly a higher percentage of $35.1 \%$, than Kakira and Iganga hospitals with $34.8 \%$, and $28.2 \%$ respectively. Kakira hospital that had the highest percentage $(32.8 \%)$ of staff trained in patient safety than the other hospital, on the other hand had a few health workers aware of what patient safety is all about.

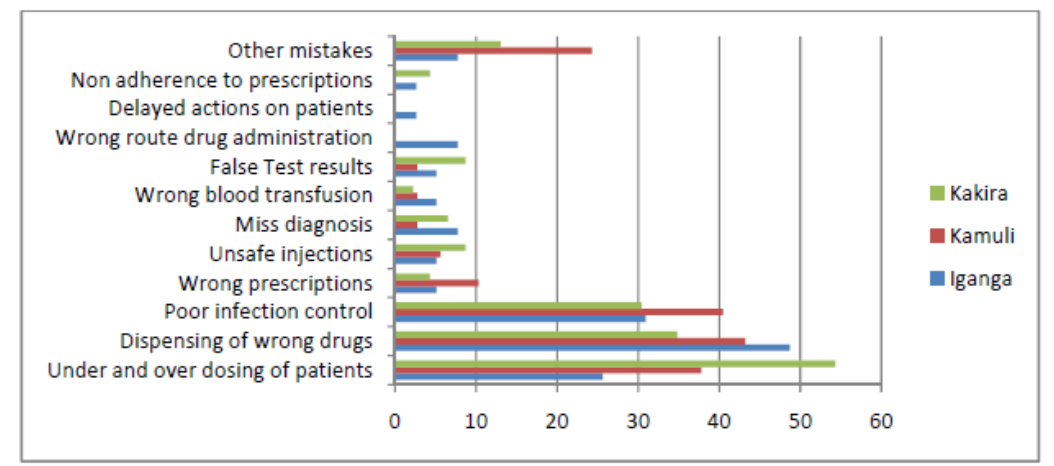

Figure 1. Common medical mistakes known by health workers in percentages. $n=122$

It was noted that $76 \%$ of the respondents from all the study hospitals could mentioned at least two common medical errors known to them. Under/over dosing of patients, dispensing of wrong drugs and poor infection control were the most known medical errors in all the study hospitals as noted in figure 1.

\section{Measures in place for prevention of medical errors reported. $(n=122)$}

Generally, only 55.3\% of the respondents could mention at least two measures in place to prevent medical errors, and a big number of health workers were not aware of the measures in place.

Iganga hospital had the highest percentage (68\%) of respondents mentioning at least two measures in place for prevention of medical errors, followed by Kamuli (52.7\%) and lastly Kakira (46.7\%). Iganga hospital with the least number of staff who could explain well what patient safety is all about, had the highest percentage of staff mentioning at least two measures for prevention of medical errors.

Good patient care practices and observation of infection control were the most reported measures used to prevent medical errors in the study hospitals. Use of CMEs to prevent medical error was reported by less than $20 \%$ of the respondents, yet the researcher thought that it could be mentioned by more staff.

Use of diagnostic service, training and use of skilled staff were least mentioned as measures used to ensure patient safety in the study hospitals. This means that health workers in the study hospitals are not aware that these are measures that also contribute to promotion of good patient safety in health care, so the need for sensitization of staff on these measures. 


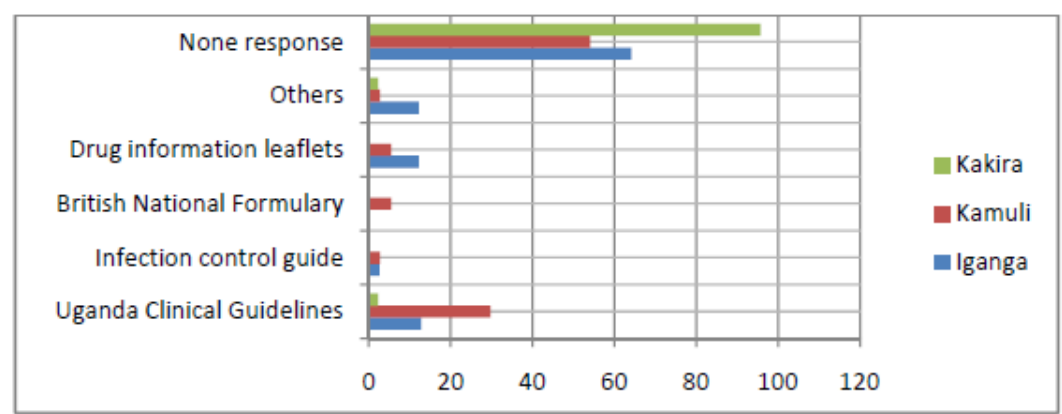

Figure 2. Known policies, documents or guidelines used to ensure patient safety in percentages. $\mathrm{n}=122$

Generally, there were few respondents who could mention at least two policies or guidelines used to promote patient safety. Only 18\%, $23 \%$ and $2 \%$ of Iganga, Kamuli and Kakira hospital health workers respectively would mention at least two policies used. Uganda clinical guideline was the most known document used, compared to infection control guidelines, British National Formulary and drug information leaflets. Kamuli hospital that had more than two copies of the Uganda clinical guidelines in use at the time of survey and more health workers were aware of the policies and guidelines used for patient safety. Kakira hospital that had none of the studied policies/guidelines had the least percentage (2\%) of her health workers aware of such documents. This means that at Kakira hospital there is limited use of policies and guidelines that promote patient safety.

Report practices for medical errors; It was observed that $57.8 \%$ of health workers would report all medical errors committed at the study hospitals. In Iganga hospital, $60.9 \%$ of its health workers would report all medical errors committed as compared to $54.7 \%$ and $58 \%$ of Kamuli and Kakira respectively. This means that a big percentage of errors committed in the study hospitals would go unreported. It is also noted that medical errors with severe harm would be reported more than the ones with no or less severe harm. This can be attributed to the fact that errors with severe harm require involving other high level skilled staff to manage.

\section{Reasons for reporting medical errors}

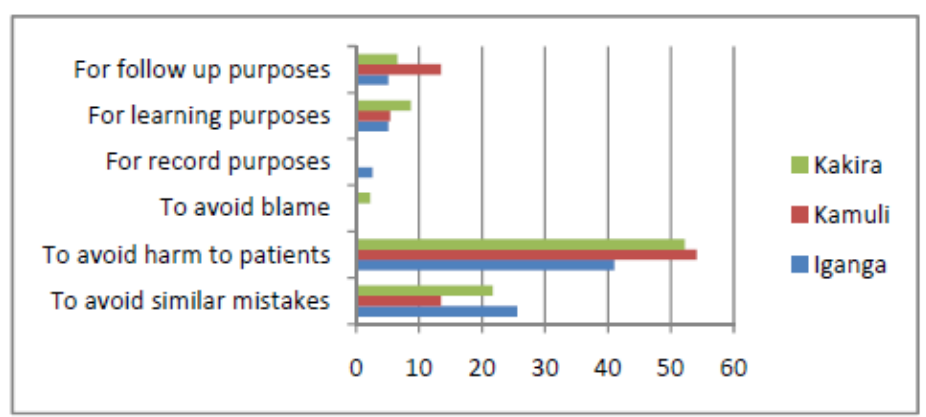

Figure 3 Percentages of reasons for reporting medical errors. $n=122$

More than a half of the respondents ( $\mathrm{n}=122$ ) would report errors to avoid harm to patients and less than $25 \%$ of respondents would report to avoid similar incidents in future. $79.4 \%(n=44), 86.5 \%$ $(n=42)$ and $91 \%(n=51)$ of respondents of Iganga, Kamuli and Kakira hospitals respectively gave at least a correct reason as to why they would report errors. The rest would not report medical errors because of not knowing the importance of reporting and fear of blame.

Conclusively, the level of knowledge on patient safety at the study hospitals was just above average as Iganga hospital scored 55.3\% ( $\mathrm{n}=44)$, Kamuli mission and Kakira hospitals scored 57.8\% $(\mathrm{n}=42)$ and $54.1 \%(\mathrm{~N}=55)$ respectively. 


\section{Managers' role in promotion of patient safety culture}

The manager`s role in promotion of patient safety was studied using six indicators as described in narrative form here under. It was assessed using both observational tools and likert scale grading of the level of agreement to the statements in the questionnaire.

\section{Availability of documents/policies/guidelines that promote patient safety culture}

The study observed that Iganga and Kamuli hospitals had at least a copy of the Uganda clinical guidelines 2010. The fact that only one copy of the Uganda clinical guidelines was available at OPD of Iganga hospital at the time of survey, it means that accessibility to this copy by the rest of the clinicians in their common consultation room was limited. It is only Kamuli Mission hospital that had an Injection Safety Policy in place so it can be taken to have better injection safety practices than Iganga and Kakira hospitals.

Kamuli and Kakira hospitals had patient vital observation charts to promote observation of patient vital signs; whereas Iganga uses un formatted exercise books for recording such information. It was noted that despite the availability of these charts, they were not being used by Kakira hospital and to some extent they were being used by Kamuli Mission hospital. The use of these charts to monitor vital signs in Kamuli Mission hospital was attributed to the practice of the hospital and availability of student nurses and midwives. It was surprising that despite the availability of student nurses from Busoga University at Iganga hospital, there was no patient observation charts for students to practice from. This may result in Busoga university producing nursed with limited skills in observation of vital signs. The limited use of the observation charts in Kamuli Mission hospital was due to break down of equipments used to monitor such signs. Kakira hospital management had not enforced the use of the available patient observation charts as health workers were not interested in completing them.

All the hospitals lacked a used parto-graph, and this means that women who had their labour and delivery in the study hospitals were not being monitored as recommended by the Uganda Ministry of Health. This practice could be resulting into avoidable maternal and infant deaths at these study hospitals. At all the study hospital pharmacies, there was no patient information charts on medicines displayed. This means that patient at the study hospitals cannot easily identify possible problems that they could face in the process of medication and may use drugs irrationally. It was a new term at the study hospitals when I asked about WHO Safe Surgery Saves Lives check-list to check if it was available. All the theatre in charges acknowledged not having heard of such a document in their life time of practice. This means that the chances of misidentification of patients for surgery are high in the study hospitals, so a wrong patient or site could get operated. It can be concluded that the study hospitals are to some extent unsafe for surgical patients.

Lastly, none of the hospitals had a patient incident record book to track occurrence of incidents in the hospital. This means that there is limited means of monitoring patient safety incidents and learning from them.

\section{Monitoring staff adherence to policies and guidelines by management}

The hospital managers of the study hospitals reported monitoring adherence to patient safety guidelines through, support supervision, conduction of patient satisfaction surveys and meetings. However these means of monitoring were not verified to determine to what extent they are used by the hospital management. None of the hospitals reported training and building skills of staff in use of the policies and guidelines.

\section{Communication of patient safety issues in the hospital}

It was reported that communication in the hospital on patient safety was mainly through continuing medical education, internal memos, leaflets, meetings, and supervision. This was not also verified to determine to what extent managers communicated to staff about patient safety. Communication of staff to management was reported to be through direct reporting to senior staff, meetings, suggestion 
box, supervisors and during supervisions. None of the study hospitals uses a patient safety incident record book or a patient safety committee because the two channels of communication were not in place in the study hospitals.

Blame free culture by hospital managers; Management blame for error committed prevents reporting of errors and hence learning from errors is affected. All the managers reported that they support their staff to report errors. None of the managers reported blaming a staff and taking a disciplinary action against such a staff for reporting an incident. All hospital managers reported that they apply their own rules and procedures when an incident is reported instead of reporting to other authorities that could punish for the incident.

Availability of patient safety monitoring team or process; Monitoring patient safety improvement is another indicator for commitment to promotion of a good patient safety culture by management. Management mostly reported continuing medical education and internal supervision on patient safety as the commonly used methods for monitoring patient safety in the study hospitals. None of the managers reported having a patient safety committee or a patient safety incident record book in place. Lack of these two measures promotes a poor learning culture from mistakes committed and management may not realise to what extent they could be contributing to unsafe health care in their hospitals.

Health worker's responses on team building by management of the hospital; The study hospitals had good team building practices, however, their supervisors encourage working faster due to work pressure increasing the chances of medical errors.

\section{Patient safety practices practiced in the study hospitals}

Learning from reporting and team working: The study hospital managers reported learning from incidents reported although there was no incident record book in place to verify this practice. The study further noted that the staff of the study hospitals work as a team, they support one another and this reduces on the chances of mistakes that could be committed if there is no team work.

The practice of reporting incidents; The study revealed that the study hospital staff fear being blamed for errors committed although managers reported supporting staff to report errors. The fact that Kamuli and Kakira hospitals are private, with different employment terms from the government hospitals like Iganga, it was surprising that the difference in the practice of reporting errors is small.

Staffing and working conditions; In all hospitals, staffing and working conditions scored below 13 out of 20. Kakira reported having better staffing and working conditions with a score of 12.6, than Iganga with 9.3 and Kamuli with 8.5. This can be attributed to the number of patients managed at each of the hospitals, as Kakira had the lowest number of inpatients (27), compared to Iganga (99) and Kamuli (43) at the time of survey. Limited staffing in a hospital increases the pressure due workload to the few staff. This can lead to stress, de-motivation and limited use of required resources as the aim is to work and finish up all the patients.

Perception of staff on patient safety; All hospitals scored slightly above 12 out of 20 on perception of staff on patient safety, with Kakira hospital having staff with a good perception, than Kamuli and Iganga hospital respectively.

Hand washing practices; Iganga hospital scored slightly just above 9 out of 20 on hand washing practices. This means that the hand washing practices at this hospital need attention. Kamuli and Kakira hospital scored above average. Kakira hospital had better hand washing practices than the other hospitals and this could be contributed to availability of good hand washing facilities. Poor hand washing practices promote cross infections in the hospital and patients end up with health care acquired infections that can increase on bed occupancy period and hospital costs.

Waste Disposal Practices; On dispose of sharps, all the study hospitals scored above 82\%. It was observed that Kamuli hospital had all the required waste management bins, were as Iganga and Kakira hospitals had none. This means that spread of infections from medical waste was limited at Kamuli hospital, compared to Iganga and Kakira hospital. 
Infection Control; Availability of each of the buckets for JIK, soapy water and plain water was noted to be good at Kakira and Iganga and poor at Kamuli Mission hospitals. This can mean that, although Kamuli hospital minimises spread of infections through good waste disposal, it also spreads other blood born infections from patient to patient and also from patient to health worker.

Dispensing Practices; Observation of dispensing time was averagely between 31-60 seconds per patient in each of the hospitals, yet the good dispensing time would be at least more than 60 second per patient. This means that patients are given limited information about the medicines they are given, a practice that increases chances of irrational use of drugs which is a medical error.

\section{Prevalence of medical incidents}

The point prevalence of inpatient safety incidents based on the patient records was found to be $88.7 \%$. This means that almost all the inpatients in the study hospitals at the time of study were at a high risk of suffering from harm due to health care.

Point prevalence of inpatient safety incidents based on patient records $N=169$

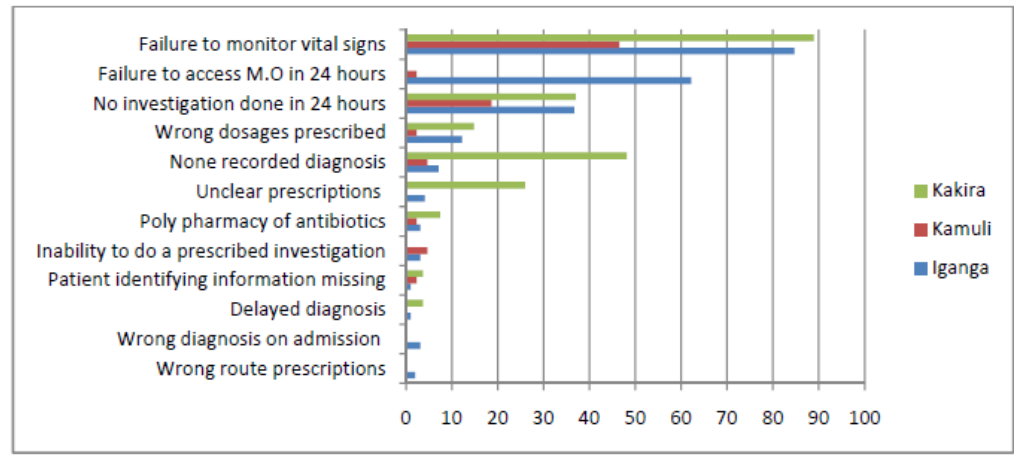

Figure 4. Showing prevalence of patient safety incidents in percentages

The commonly identified incidents were; failure to monitor vital signs of patients and conducting no investigations in 24 hours of admission in over $70 \%$ of inpatient records reviewed. Over $80 \%$ of inpatients of Iganga and Kakira hospitals had their vital signs not monitored, where as only $46.5 \%$ of inpatient of Kamuli missed their vital signs being monitored. It was also found out that $62.2 \%$ of inpatients of Iganga hospital had no access a medical officer in 24 hours of admission as compared to Kamuli (2.3\%) and Kakira hospitals (0.0\%). Kamuli hospital always adhered to the treatment guidelines compared to Kakira and Iganga hospital. Kakira hospital had $25.9 \%$ of its inpatient files with unclear prescriptions mainly due to bad hand writing, compared to $4.1 \%$ and $0.0 \%$ for Iganga and Kamuli hospitals respectively. Kakira hospital had the capacity to investigate most of the requests on the inpatients but Iganga and Kamuli did not, mainly due to logistical problems.

Frequency of Surgical Incidents; It was observed that $62 \%(\mathrm{n}=21)$ of files for patients who had surgical operations had no pre-operative laboratory investigations, while $85.7 \%$ of them had inadequate post operative notes and instructions. Kamuli does the basic pre operative investigation with some operations having adequate post operative notes and instructions.

Labour and delivery incidents; Labour and delivery incidents were not common in all hospitals but the fact that parto-graphs were not being used in all the hospitals, it is likely that mothers in labour are suffering from some harm due to poor monitoring of labour. Kamuli Hospital had a big number of babies born with low APGAR score as they reported receiving mothers with babies who were already asphyxiated.

\section{Causal pathways for medical incidents}

Medical Incidents; In Iganga hospital, poly-pharmacy of antibiotic was attributed to multiple coinfections that patients present with, where as in Kakira hospital it was attributed to limited skills of health workers, multiple patient complaints and misdiagnosis. Kamuli reported no such occurrence as 
prescriptions are based on policy guidelines. Unclear prescriptions, were attributed to poor hand writing of prescribers, heavy workload, limited skills of prescribers, prescribers being in a hurry most of the time and differences in origin of training like Kakira hospital that employs Indian trained doctors.

Surgical Incidents: It was also noted that pre operative investigations are not done due to limited logistics, staffing and limited skills. The purpose of doing routine pre operative investigation was not known given that there are no guidelines to support this. The good practice reported by Kamuli hospital was that H.B, blood grouping and cross matching is routine to all admitted patients.

On adequacy of operation notes, it was reported that poor attitude of surgeons towards writing operation notes is one of the causes of writing inadequate post operative notes. It was noted at Iganga hospital were the heavy workload does not allow writing adequate notes. At Kamuli hospital, this was not a common incident as most of their surgeons wrote adequate notes after operation.

Wrong site surgeries were not common in the study hospitals but this does not mean that they do not occur given the fact that none of the hospitals had the checklist for safe surgery.

As for identification of patients for operation, all hospitals reported limited chances of wrong identification of patients for operation as it was reported that surgeons themselves book patients for operation. However, they all accepted that they lacked a checklist to ensure $100 \%$ patient identification for operation.

Preventive Incidents; Missing some basic inpatient identification information was reported to be a common incident. Iganga hospital lacks a format and pre-designed charts to ensure that all information is recorded. Kakira and Kamuli had pre-designed charts and enabled them to fully identify their patients. Too much workload, negligence, understaffing and lack of logistics like blood pressure machines were given as the reasons for failure to observe vital signs of patients on a regular basis. Low APGAR score were being experienced simply because some mother in labour fear to be operated and so they would report late to hospital and also they would take time to accept operations. Lack of logistics would at times cause delay to carry out operations and hence it led to asphyxiated babies delivered. Kamuli hospital reported that low APGAR scores are not expected as there is close monitoring of mothers in labour for any foetal distress so as to take action in time.

Diagnostic Incidents; Due to limited skills and lack of capacity to do investigations for diagnosis, it was reported that it is possible to have a wrong diagnosis. Faulty equipment, limited staffing and poor attitude towards some tests like sputum examination were leading to delayed diagnosis. Under staffing of medical officers, limited their accessibility to patients in Iganga hospital, but it is a routine for medical officers to manage all inpatients in Kakira and Kamuli hospitals.

Investigative Incidents; It was reported that it is not common to have an inpatient to spend more than 24 hours without investigations. However, it can happen where there is limited staffing and lack of logistics to use. Failure to do basic investigations was mainly attributed to lack of basic equipment or due to mechanical problems. Kamuli hospital had a faulty X-ray machine whereas Kakira had no ultra sound machine.

\section{Conclusion}

This study, aimed at assessing patient safety culture in general hospital of South Eastern Uganda, was an observational, cross sectional and qualitative study with 144 respondents and 169 inpatient records reviewed. The study that looked at several aspects of patient safety, observed that the level of knowledge of health workers on patient safety was limited. There is therefore need for training of health workers in prevention of medical error and adherence to the principles and guidelines that promote patient safety. Manager's role in patient safety is crucial especially in enforcing and maintenance of patient safety measures, so the need for managerial leadership in patient safety. There was generally limited availability of policies and guidelines that promote patient safety in the study hospitals and hospital managers are encouraged to develop their own in addition to those developed by government in order to promote patient safety. The prevalence of patient safety incidents of $88.7 \%$ 
is high as incidents of failure to monitor vital signs of patients, conducting no or untimely investigations on patients and difficulty to access high skilled staff were found to be more prevalent. These are preventable with minimal resources required and so manager need to take action.

\section{Recommendations}

The Uganda Ministry of health needs to design training programs for the health workers on patient safety

There is need for leadership in patient safety by the managers to ensure provision and monitoring of patient safety guidelines.

Managers also need to introduce error reporting and evaluation system like introduction of patient safety committees and incident reporting tools.

\section{Acknowledgements}

The following individuals have been acknowledge for their support in the implementation and reviews of the paper; Dr. Dyogo Peter, District Health Officer Jinja and Mutiibwa Tonny health educator Buwenge General Hospital

\section{References}

[1] AHRQ (2007). Closing the Quality Gap: A Critical Analysis of Quality Improvement Strategies. Volume 7, Number 9. www.ahrq.gov. Stanford University-UCSF Evidence-based Practice Center, Stanford, CA.

[2] BATEGANYA MOSES, AMY HAGOPIAN, PAULA TAVROW, SAMUEL LUBOGA AND SCOTT BARNHART 2009. Incentives and barriers to implementing national hospital standards in Uganda. International Journal for Quality in Health Care 2009; Volume 21, Number 6: pp. 421 -426 10.

[3] CARMEN AUDERA. n.d. WHO Patient Safety Programme-Meeting the challenges Faced by Emerging Countries in the Provision of Quality Primary Health Care Cape Town. WHO.

[4] CARMEN AUDERA-LOPEZ 2011. WHO patient safety programme 3rd annual conference on safety, standards and customer services lagos 13th and 14th october 2011. WHO.

[5] DEPARTMENT OF HEALTH EXPERT GROUP 2000. "An organisation with a memory". Department of Health, United Kingdom.

[6] DONABEDIAN A. 2005. Evaluating the Quality of Medical Care. The Milbank Quarterly, Vol. 83, No. 4. Milbank Memorial Fund. Published by Blackwell Publishing

[7] EU-PSWG 2007. Recommendations on patient safety by patient safety working group. European commission health and consumer protect general. Accessed on http://ec.europa.eu/health/archive/ph_systems/docs/ev_20080617_rd01_en.pdf on 8/5/2012.

[8] IAPO (2008a), Uganda Health News: IAPO Launches Patient Safety Toolkit. Kampala, Uganda. Accessed from http://www.ugpulse.com/uganda-news/health/iapo-launches-patient-safetytoolkit/7054.aspx 24/4/2010

[9] IAPO (2008b). Addressing global safety issues. An advocacy toolkit for patients`organization

[10] INSTITUTE OF MEDICINE (IOM). 2000. "To Err Is Human: Building a Safer Health System." In L.T. Kohn, J.M. Corrigan and M.S. Donaldson, eds. Washington, DC: National Academy Press.

[11] LUWEDDE M 2011. Uganda Catholic Medical Bureau Bulletin Jan - Dec 2011. Page 13-15

[12] MOH (2009), Uganda National Health Policy II 2011-2020

[13] MOH (2011), Health Sector Quality Improvement Framework and Strategic Plan 2010/11 - 2014/15.

[14] MOH (2005), Injection safety and appropriate health care waste management. MMIS.

[15] ROSS BAKER, PETER G. NORTON, ET AL. (2004). "The Canadian Adverse Events Study: the incidence of adverse events among hospital patients in Canada". Canadian Medical Association Journal 170.

[16] WHO (2004), World Alliance for Patient Safety, Forward programme 2005. Accessed on http://www.who.int/patientsafety/en/brochure_final.pdf on 8/3/2012.

[17] WHO (2008a), Better knowledge for safe care, Global Priorities for Research in Patient Safety (first edition) The Research Priority Setting Working Group.

[18] WHO (2008b), World Alliance for Patient Safety WHO Guidelines for Safe Surgery. 
[19] WHO (2009a pp106-147), Conceptual Framework for the International Classification for Patient Safety Version 1.1 Final Technical Report.

[20] WHO (2009c). Medicines use in primary care in developing and transitional countries. Fact Book summarizing results from studies reported between 1990 and 2006.

[21] WHO (2009d). African partnership for patient safety: working for safer health care ... together. World Health Organization, 20 Avenue Appia, 1211 Geneva 27, Switzerland

[22] WHO (n.d. b). http://www.who.int/patientsafety/research/evidence_of_unsafe/en/index.html 


\title{
Relationship between Climate Change and Health of Adult Residents of Ile- Ife, Nigeria
}

\author{
Article by Ganiyu Abiodun Adedeji \\ Ph.D in Public Health, Texila American University, Guyana, South America \\ E-mail: olabode20032001@yahoo.com
}

\begin{abstract}
Background: Climate change has had a profound effect on socioeconomic, cultural, political, technological and even biological nature of man and plants in the world. This study is aimed at investigating the relationship between climate change and health of adult residents of Ile-Ife, Nigeria.

Methods: A sample survey method was used with structured questionnaire and oral interview. Random sampling technique was employed to get the sample size of 142. Informed consent of participants was obtained before commencement of the study. 142 questionnaires were duly completed and returned. Data were analyzed using frequencies, mean, standard deviation and percentages. Pearson Product Moment Correlation was employed to find the relationship between the test variables of the hypotheses.

Findings: Majority of respondents (48.6\%) had tertiary education, 20.4\% had secondary education, while $18.3 \%$ are illiterate. $42.3 \%$ got their information on climate change through radio, while only $4.9 \%$ got theirs through research institutes. 54.9\% had adequate knowledge about climate change and only $9.2 \%$ had very inadequate knowledge. 37.3\% experienced malaria and headache together due to climate change, while few (0.7\%) experienced skin rashes. Significant relationship existed between the socioeconomic characteristics of the respondents and their present health status $(r=0.348, p=0.001, \alpha=0.05)$. Significant relationship was similarly found between the socioeconomic characteristics of respondents and their perception of the effect of climate change on their health $(r=0.392, p=0.001, \alpha=0.05)$.

Conclusion: Climate change had negative impacts on the health of adult residents of Ile-Ife. Governments should ensure preservation of the ozone layer and also increase awareness of the citizens on climate change and the effects on human health.
\end{abstract}

Keywords: Climate, Climate change, Health, Relationship, Adult residents, Knowledge.

\section{Introduction}

Climate change refers to some variations in the climate system that are observable to human (anthropogenic) activities, especially those that alter the atmospheric composition of the earth and ultimately lead to global warming [10]. Global warming describes the gradual increase in the average temperature of earth's atmosphere and its oceans [2].

Climate change has had a profound effect on economic, social, cultural, political, technological and even biological nature of man and plants in the global village. Generally speaking, the physical and scientific evidence which shows that the climate of the world is changing include global rise in sea levels, drought and increasing desertification, drying up of water resources as well as increase in ambient temperature [18]. According to the World Health Organization [3], climate change affects the social and environmental determinants of health such as clean air, safe drinking water, sufficient food and secure shelter globally. Similarly, the WHO has projected that between 2030 and 2050, climate change is expected to cause approximately 250,000 additional deaths per year from malnutrition, malaria, diarrhea and heat stress.

According to [19], there are many ways through which climate change affects human health. These include: increasing temperature, rising sea levels and increasing storm frequencies, all of which have 
great implications on human health as regards injury and illness. Similarly, temperature and rainfall dynamics may increase the distribution of disease vectors such as dengue fever, malaria and incidence of diarrheal diseases. Urban floods experienced by people can make them to suffer mental disorders, spread diseases, destroy houses, assets and interrupt schooling [8].

In Africa and other developing regions of the world, climate change is a treat to economic growth, long term prosperity as well as the survival of already vulnerable populations. It has thus been projected that by 2020, between 75 and 250 million people in Africa will be exposed to increased water stress due to climate change [5].

Nigeria is one of the developing countries in the sub-tropical region where the agricultural sector, landless farmers, livestock keepers, unhealthy people and those with low level of education are exposed to the risk of climate change. Nigeria has been reported to be currently experiencing increasing incidence of diseases, declining agricultural productivity, increasing number of heat waves, unreliable or erratic weather pattern, flooding, decline rainfall in already desert-prone area in the northern region causing increasing desertification and decrease food production in the north-central region [1].

Ile-Ife is an ancient city located in Osun state, in the south-western region of Nigeria. There are farmers, traders, civil servants and transporters among others residing in this ancient city who may have different perceptions of the impacts of climate variation in this area. As a result of this, the impact of climate change on the health of these people requires careful examinations in order to find solutions to the problems that may be caused by the change in climate in this area because, productivity of the inhabitants of the area, irrespective of their means of livelihood is dependent on the state of their health.

Even though, few studies have been conducted in the past that are related to this study in Nigeria, they were conducted in other regions of the country such as the north-central [1] and south-eastern regions [7]. These regions have relatively different climate and climate changes as compared to that of the area of the present study (south-western region). This study is therefore aimed at investigating the relationship between climate change and health of adult residents of Ile-Ife, Nigeria.

\section{Research questions}

(i) What are the respondents' sources of information on climate change in the study area?

(ii) What are the common ailments/diseases associated with climate change in the study area?

(iii) How knowledgeable are the respondents regarding climate change?

\section{Research hypotheses}

Ho1: There will be no significant relationship between some selected socio-economic characteristics of the adult residents of Ile-Ife and their present health status.

Ho2: There will be no significant relationship between some selected socio-economic characteristics of adult residents of Ile-Ife and their perceived effects of climate change on their health.

\section{Methodology}

The study was conducted in Ile-Ife between May and June, 2016. Ile-Ife is an ancient city located in Osun-East senatorial district of Osun State, Nigeria lying on 7.4905 degrees north and 4.5521 degrees east. The vegetation of Ile-Ife is lowland rainforest. The climate of this study area is tropical with two prominent seasons-the raining and the dry seasons. It has an area of 111 square kilometers and a population of 167,254 according to 2006 census. The residents are predominantly Yoruba tribe.

In order to achieve the aim of the study, sample survey method was used involving obtaining information with the aid of structured questionnaire coupled with oral interview of the residents of the city. Random sampling technique was used to get the sample size of 142 from the residents of the city. Informed consent of each respondent was sought and obtained before the commencement of the study. The questionnaire was administered directly to individual respondent who was willing to 
participate in the study. Wherever necessary, appropriate interpretations were made to the respondents. The questionnaire was validated by colleagues in Obafemi Awolowo University Teaching Hospitals Complex, Ile-Ife. After few modifications, it was finalized as a data collecting tool. One hundred and sixty (160) questionnaires were distributed but, due to little difficulty in accessing some of the respondents, one hundred and forty-two (142) were duly completed and returned.

The data collected were analyzed using frequencies, mean, standard deviation and percentages. Pearson Product Moment Correlation was employed to find the relationship between the test variables of the hypotheses that were generated. Data was analyzed using SPSS software version 22.0.

Ganiyu Abiodun Adedeji

The inclusion criteria were:

1. All adult males either gainfully employed or not that were residing in Ile-Ife at the time of study.

2. All adult females either gainfully employed or not that were residing in Ile-Ife at the time of study.

\section{Exclusion criteria}

The exclusion criteria were:

1. Children and teenagers either students, apprentice or neither of the two.

2. Aged men and women who could not comprehend interview.

\section{Results}

None of the respondents was below the age of 21 years as at the time of collecting data for this study. The age range that has the lowest frequency was found to be 71 years and above with only 3 respondents representing $2.1 \%$. The age range with the highest frequency is 41 to 50 years with 46 respondents and representing $32.4 \%$. This is followed by age range 31 to 40 years old having 41 respondents and representing 28.9\%. The mean age is $41.9 \pm 11.5$ years (Table 1). Out of one-hundred and forty-two respondents in this study, a larger number (91) representing $64.1 \%$ were females while, the remaining number (51) representing $35.9 \%$ were males (Table 2 ).

Table 3 shows the respondents' marital status distribution. 30 out of the142 respondents representing $21.1 \%$ were single while, majority of them (96) representing $67.6 \%$ were married. 14 among them representing 9.9\% were divorced and only 2(1.4\%) were widowed. Regarding the educational qualification of the respondents, majority of them (69) representing $48.6 \%$ had tertiary education, this is followed by those with secondary education who were 29 in number representing $20.4 \%$, twenty-six of them representing $18.3 \%$ were illiterate and $18(12.7 \%)$ had primary education (Table 4).

Table 5 shows the major sources of information on climate change for the respondents. Majority of respondents (42.3\%) got their information through radio, 28 (19.7\%) of the respondents claimed to have gotten their information on climate change through personal experience while, only 7 of the respondents representing $4.9 \%$ of total respondents got their information on climate change through research institutes. However, 15(10.6\%), 21(14.8\%) and 11(7.7\%) of the respondents got their own information on climate change through lecture, newspaper and television respectively.

A larger number of respondents (78) representing 54.9\% claimed to have adequate knowledge about climate change. Only 13(9.2\%) claimed to have very inadequate knowledge while, 35(24.6\%) have inadequate knowledge about climate change. However, 16(11.3\%) of them have very adequate knowledge of climate change (Table 6).

Table 7revealed thedistribution of respondents on the common diseases usually experienced due to climate change. 53(37.3\%) of the respondents experienced both malaria and headache together as a result of climate change showing this to be the largest number and percentage. This was followed by those that experienced malaria only who were 43 in number representing $30.3 \%$ of the respondents. Those who had typhoid fever were 11 in number representing 7.8\%. Malaria and typhoid affected 10 respondents representing $7.0 \%$, while, $6(4.2 \%)$ of the respondents were affected by cholera and 
malaria. Cold/catarrh, tuberculosis affected 5(3.5\%) and 3(2.1\%) of the respondents respectively. However, the least number of respondents $1(0.7 \%)$ experienced skin rashes due to climate change.

Regarding the test of hypothesis ' 1 ', the correlation coefficient is 0.348 . The implication of this is that there is a positive and significant relationship between the age of the respondents and their present health status $(p=0.001, r=0.348)$. When verified, the significant value $(p=0.001)$ was lower than the critical p-value of 0.05 . In addition, there is a positive and significant relationship between the educational level of the respondents and their present health status $(p=0.001, r=0.348)$. Therefore, the null hypothesis is rejected.

On the test of hypothesis ' 2 ', the correlation coefficient is 0.392 . This implies that there is positive and significance relationship between the age of respondents and their perception of the effect of climate change on their health $(\mathrm{p}=0.001)$. This $\mathrm{p}$-value is lower than the critical p-value of 0.05 . There is also positive and significant relationship between the educational level of the respondents and their perceived effects of climate change on their health status $(\mathrm{p}=0.001, \mathrm{r}=0.392)$. This makes the null hypothesis to be rejected.

\section{Discussion}

The socio-economic variables that were analyzed are: age, gender, marital status and level of education. This study found the mean age of respondents to be $41.9 \pm 11.5$ years. Majority of them (67.6\%) were married. This results agrees with the work of [1] where they reported the mean age of respondents in their study to be 45.5 years and that majority of the respondents (53.1\%) were married. It is also consistent with the work of [13] whose work reported that over $96 \%$ of their respondents were married. This might have something in relation to the culture of the people of Ile-Ife and that of Yoruba ethnic group in general as regards the importance attached to marriage. However, the findings of this study on gender of the respondents contradicts that of [1]. This study found more female respondents $(64.1 \%)$ as compared to more male respondents $(68.4 \%)$ that was reported by them in 2013.

On the whole, majority of the respondents were found to be literate as revealed by the result of this study. This is in line with the findings of [1] where they reported $72.4 \%$ of the respondents to be literate. This finding might be attributable to the presence of first class educational institutions both within and around Ile-Ife which is the study area. There are two universities, one polytechnic and several standard tutorial centers in Ile-Ife alone. This study again found the majority of respondents having tertiary education but, this is in contrary to the work of [12] who reported majority (32\%) of respondents in his study to have had secondary education. This might again be ascribed to the presence of educational institutions in and around Ile-Ife.

Radio was found to be the major source of information on climate change to majority of the respondents. This finding contradicts the report of [12] who reported majority of respondents' source of information on climate change to be through personal experience. However, the present finding supports the work of [1] that majority (79.2\%) of respondents in their study got information on climate change through radio. The accessibility and availability of radio as a means of communication to people of the study area might be responsible for this observation.

The highest percentage (54.9\%) of respondents in this study claimed to have adequate knowledge about climate change, while $24.6 \%$ of them did not have adequate knowledge. This finding is also consistent with the report of [12] who reported similar findings where majority of the respondents (56.67\%) claimed to have adequate knowledge and 34.0\% of them did not have adequate knowledge about climate change. The relatively high percentage of respondents that had adequate knowledge about climate change can be linked to the comparatively high percentage of literacy level of majority of the respondents in this study. This is expected to have positive impacts on how to mitigate the negative effects of climate change in the study area and its environs.

Malaria, accompanied with headache is the health condition that affected the majority of respondents in the present study as revealed by the result. The health condition that had the least 
percentage affectation as a result of climate change is skin rashes. These findings are contrary to that of [1] where malaria alone was the ailment which affected majority (31.6\%) of the respondents due to climate change. They also reported tuberculosis to be the ailment which had the least percentage affectation (2.0\%) as a result of climate change. These findings are attributable to the fact that on a general note, malaria fever is rampant in Nigeria and the fact that the study area is a tropical rain forest region of the country where mosquitoes are favorably harbored. Similarly, headache is a symptom of malaria and this might be why the two goes together in majority of respondents in this present study.

The outcome of this study revealed a positive and significant relationship between the age of the respondents and their present health status, making the null hypothesis to be rejected. This finding can be attributed to individual immunity to diseases as it relates to individual age. In many cases, it is possible that individuals of lower age group may have comparatively increased immunity. Similarly, there is a positive and significant relationship between the educational level of the respondents and their present health status. This also made the null hypothesis to be rejected. This can as well be explained by the fact that the more educated a person is, the more informed the person will be on how to care for his/her health. Education is also a socio-economic attribute of humans that increases an individual's quality of life. These findings are consistent with the work of [1] who also found positive and significant relationship between the age and education of respondents and their health status.

Furthermore, this present study found a positive and significance relationship between the age and the education level of respondents and their perception of the effect of climate change on their health. The null hypothesis is also rejected in this case. This finding also corroborate the report of [1]. They similarly reported significant relationship between respondents' age and education level and their perceived effects of climate change on their health status.

\section{Conclusion}

This study assessed the socio-economic characteristics of respondents as it relates to climate change and its effects on the health of adult residents of Ile-Ife. Radio was the commonest source of information on climate change for majority of residents of Ile-Ife and many of them had adequate knowledge about climate change. Malaria, accompanied with headache affected the highest percentage of adult residents of people of Ile-Ife. Significant relationship existed between certain socio-economic characteristics of the people of Ile-Ife and their health status as well as their perception of the effect of climate change on their health. Therefore, governments at all levels should ensure programs that will prevent cutting down of trees without replacement to preserve the ozone layer. Since information is power, the government should also find means of increasing the awareness of the citizens on climate change and the possible effects on health in particular. The means of mitigating the effects of climate change on the citizens should as well be given serious attention especially, those related to health. 


\section{Figures and tables}

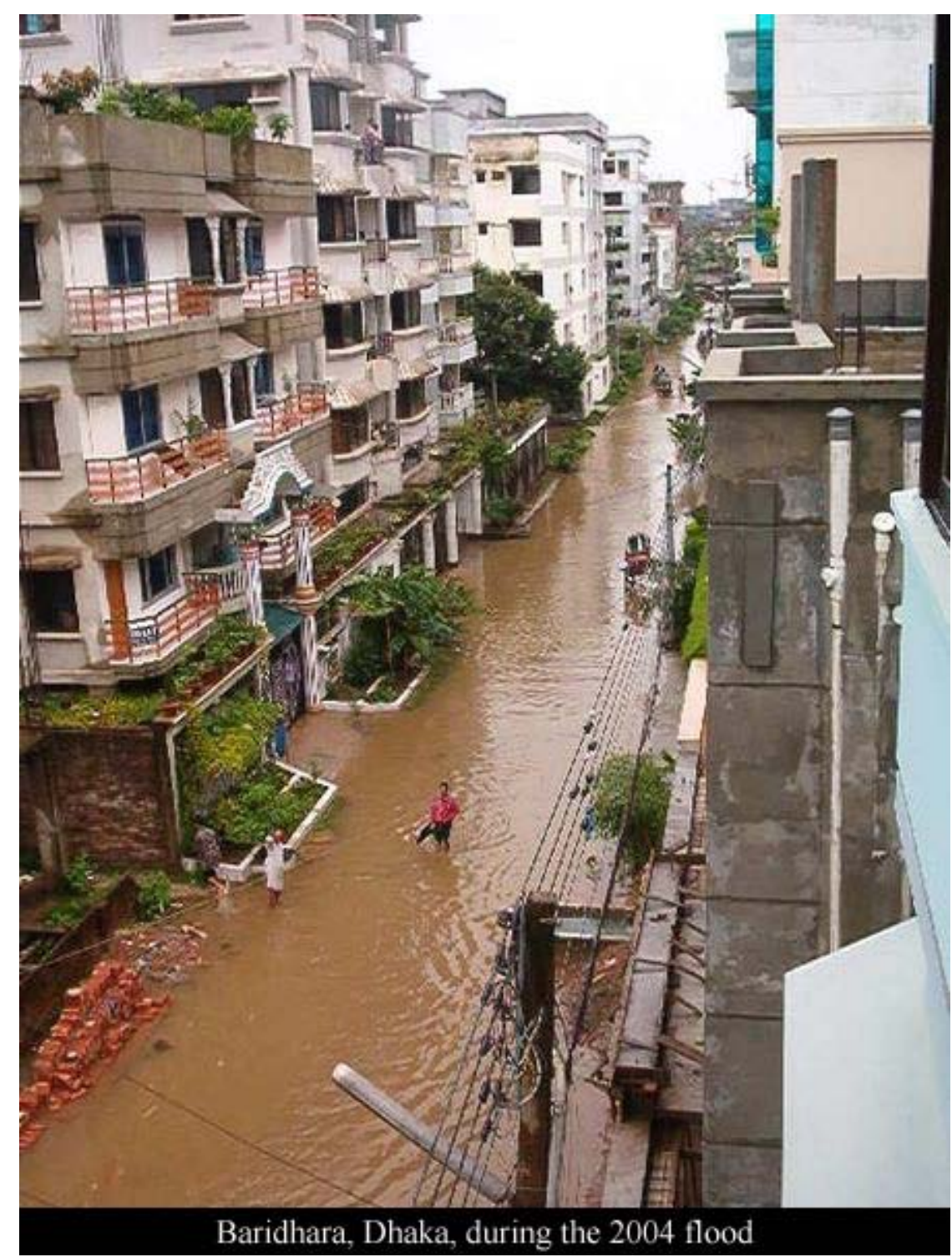

Figure 1. Flooding- A consequence of change in climate.

Table 1. Age distribution of respondents $(n=142)$.

\begin{tabular}{lll}
\hline Characteristics & Frequency (n) & Percentage (\%) \\
\hline \multicolumn{1}{c}{ Age } & & \\
\hline $21-30$ & 21 & 14.8 \\
\hline $31-40$ & 41 & 28.9 \\
\hline $41-50$ & 46 & 32.4 \\
\hline $51-60$ & 24 & 16.9 \\
\hline $61-70$ & 7 & 4.9 \\
\hline 71 and above & 3 & 2.1 \\
\hline Mean Age $=41.9$ & & \\
\hline
\end{tabular}


Table 2. Sex distribution of respondents $(n=142)$

\begin{tabular}{lll}
\hline Responses & Frequency (n) & Percentage (\%) \\
\hline Male & 51 & 35.9 \\
\hline Female & 91 & 64.1 \\
\hline
\end{tabular}

Table 3. Respondents marital status distribution $(n=142)$

\begin{tabular}{lll}
\hline Responses & Frequency (n) & Percentage (\%) \\
\hline Single & 30 & 21.1 \\
\hline Married & 96 & 67.6 \\
\hline Divorced & 14 & 9.9 \\
\hline Widowed & 2 & 1.4 \\
\hline
\end{tabular}

Table 4. Educational Qualification of respondents.

\begin{tabular}{lll}
\hline Responses & Frequency (n) & Percentage (\%) \\
\hline Illiterate & 26 & 18.3 \\
\hline Primary Education & 18 & 12.7 \\
\hline Secondary Education & 29 & 20.4 \\
\hline Tertiary Education & 69 & 48.6 \\
\hline
\end{tabular}

Table 5. Major Source of Information on Climate Change.

\begin{tabular}{lll}
\hline Source of Information & $\begin{array}{l}\text { Number of } \\
\text { Respondents (n) }\end{array}$ & $\begin{array}{l}\text { Percentage } \\
\text { (\%) }\end{array}$ \\
\hline Television & 11 & 7.7 \\
\hline Radio & 60 & 42.3 \\
\hline Lecture & 15 & 10.6 \\
\hline Newspaper & 21 & 14.8 \\
\hline Research Institute & 7 & 4.9 \\
\hline Personal Experience & 28 & 19.7 \\
\hline
\end{tabular}

Table 6: Knowledge of Respondents Regarding Climate Change.

\begin{tabular}{lll}
\hline Responses & $\begin{array}{l}\text { Number of } \\
\text { Respondents (n) }\end{array}$ & $\begin{array}{l}\text { Percentage } \\
\text { (\%) }\end{array}$ \\
\hline Very Inadequate knowledge & 13 & 9.2 \\
\hline Inadequate knowledge & 35 & 24.6 \\
\hline Very adequate knowledge & 16 & 11.3 \\
\hline Adequate knowledge & 78 & 54.9 \\
\hline
\end{tabular}

Table 7. Distribution of Respondents on the Common Diseases Usually Experienced Due to Climate Change $(n=142)$

\begin{tabular}{lll}
\hline Diseases & Frequency (n) & Percentage (\%) \\
\hline Malaria & 43 & 30.3 \\
Typhoid fever & 11 & 7.8 \\
Headache and malaria & 53 & 37.3 \\
Cholera & 3 & 2.1 \\
Headache, cholera \& & 7 & 5.0 \\
typhoid & & \\
Malaria \& typhoid & 10 & 7.0 \\
Cholera \& malaria & 6 & 4.2 \\
Tuberculosis & 3 & 2.1
\end{tabular}


Texila International Journal of Public Health

Volume 4, Issue 4, Dec 2016

\begin{tabular}{lll} 
Skin rashes & 1 & 0.7 \\
Cold \& catarrh & 5 & 3.5 \\
\hline
\end{tabular}

Hypothesis 1. The relationship between some selected socio-economic characteristics of respondents and their present health status.

\begin{tabular}{lllllll}
\hline Variable & $\mathbf{n}$ & $\mathbf{x}$ & SD & $\mathbf{R}$ & $\mathbf{P}$ & Decision \\
\hline Age & 142 & 1.19 & 0.39 & 0.348 & 0.001 & Rejected \\
Education & 142 & 1.66 & 0.52 & 0.348 & 0.001 & Rejected \\
\hline
\end{tabular}

Hypothesis 2. The relationship between some selected socio-economic characteristics of respondents and their perceived effect of climate change.

\begin{tabular}{lllllll}
\hline Variable & $\mathbf{n}$ & $\mathbf{x}$ & SD & $\mathbf{R}$ & $\mathbf{P}$ & Decision \\
\hline Age & 142 & 1.19 & 0.39 & 0.392 & 0.001 & Rejected \\
Education & 142 & 1.66 & 0.52 & 0.348 & 0.001 & Rejected \\
\hline
\end{tabular}

\section{References}

[1]. Adesiji GB, Tyabo LS, Ibrahim M, Fabiyi JO, and Oladele OA (2013). Effect of climate Change on the Health of Rural Farmers in Offa, Kwara State, Nigeria. Ethiopian Journal of Environmental studies and Management, 6(3).

[2]. Awosika LF, French GT, Nicholls RT, Ibe CE (1992). The impact of sea level rise on the coastline of Nigeria [O' Callahan J. (E.d.)] In: Global climatic change and the rising challenge of the sea. Proceedings of the IPCC workshop of Margarita Island Venezuela, 9-13. National Oceanographic and Atmospheric administration, Silver Spring, M.D., USA, pp. 690.

[3]. Canadian Institute of Actuaries (2015). Climate Change and Resource Sustainability: An Overview for Actuaries. Document 215068.

[4]. Climate change and health, Fact sheet Number 266 (2015). who.int/mediacentre/factsheets/fs266/en. Report. Summary for Policy Makers, IPCC, 2007.

[5]. Haines A, Kovats RS, Campbell-Lendrumb C, \& Corvalan, C (2006). Climate Change and Human Health: Impacts, Vulnerability and Public Health. Journal of the Royal Institute of Public Health, 120, pp. 585-596.

[6]. Idowu AA, Ayoola SO, Opele AI, Ikenweiwe NB (2011). Impact of climate change in Nigeria. Iranica Journal of Energy and Environment, 2(2): 145-152.

[7]. Odafivwotu O (2015). Public Perception of Climate Change in Yenagoa, Bayelsa State, Nigeria. Geography Journal, Article ID 208154. http://dx.doi.org/10.1155/208154.

[8]. Ojo MA and Muhammed US. (2008). Resource used efficiency in maize production among small scale farmers in Lavun Local Government Area of Niger State. International Journal of Tropical Agriculture and Food System 2(1), pp. 170-174.

[9]. Sanusi O. (2013). Climate Change: the impacts and potential benefits for the developing Nations. International Journal of Agricultural Research and Review. 1, pp. 002-012.

[10]. Tunde AM, Adeleke EA and Adeniyi EE (2013). Impact of climate variability on human health in Ilorin, Nigeria. Environment and Natural Resources Research, 3(1): pp. 488-496. 


\title{
The Power of Academic Research for Innovation in Practice and Policy: Systemic Review of Literature
}

\author{
Article by Bala Ibn Shehu Uthman \\ MRSPH, Member APHA, Nigeria \\ E-mail: balee67@yahoo.com
}

\begin{abstract}
The aim of this paper was to explore and present the impact or power of the academic research for innovation in practice and policy, that is, the academic research collaboration in the progress of policy in government and innovation in professional practices with particular emphasis on northern Nigerian region. It is a systemic review type of study design.

As a matter of fact, universities and other higher institutions like polytechnics schools, have been serving our societies for virtually a thousand years and we have no doubt in our minds that over that period of time, universities, schools of polytechnic, colleges of higher education and the world have undergone significant transformation mainly due to advancement in research that influence policy formulation and its implementation.

It is obviously clear to everyone that, the world is now more complex, more interwoven or inter-connected and changing more rapidly and that we also live in an environment that is coerced by news cycles, passing manners and uncertainty in the futures. Moreover, social structures are changing, as well as values and attitudes. There are also competition that is growing, people are increasingly mobile and the global economic becomes centre of gravity that is changing at a speed not seen before. As such, governments have to address such problems as climate change, potential pandemics of diseases and food insecurity that are global in scope and require a coordinated global response. These are achieved through research (both academic and other form of researches)

Natural and man-made disasters are becoming more common and their consequences greater. People everywhere feel under pressure. Change is inevitable and one of the important roles of universities and other higher institutions has been to make some of these changes possible through mostly academic researches that create new understanding, new technologies and the potential for action; and by providing a store of knowledge and capabilities that society as a whole has been able to draw upon.

In this paper, therefore, the author reviewed some papers written by other authors on the subject and then expressed the situation obtainable here in Nigeria, the gaps and challenges in the use of academic research in policy development and practice in the area under review. Some recommendations were also made.
\end{abstract}

Keywords: Academic Research, Innovation, Growth and Development, Policy Development.

\section{Introduction}

Academic research is a type of research that is done in an academic environment such as universities, schools of polytechnic and colleges of higher education. Generally speaking, research is a logical and systematic process of searching for knowledge or new ideas on a particular topic, events behaviors or theories.

The objective of this paper was to explore and present the impact or power of the academic research for innovation in practice and policy, that is, the academic research collaboration in the progress of policy in government and innovation in professional practices with particular emphasis on northern Nigerian region. It is a systemic review type of study design.

As a matter of fact, universities and other higher institutions like colleges of education and schools of polytechnics, have been serving our societies for virtually a thousand years and we have no doubt in our minds that over that period of time, universities, schools of polytechnic, 
colleges of higher education and the world have undergone significant transformation mainly due to advancement in research that influence policy formulation and its implementation.

In the modern world, research has become an integral part of the world's educational status and could be done in all specializations, field of line at all stages. This means that, the significance or importance of research in the modern world is so obvious that even the government of many countries or nations today invest huge sum of money on doing research and encourage conducting research in areas where research would bring about changes, growth, development, invention-innovation or renovation.

Innovation is said to be the process by which new products, processes, methods or services are created. Innovation provides added value for end users by providing better or cheaper functionality than previous options. Moreover, innovation combines changes in technology, business models, organization etc. The basic idea may be a new technical solution, a new business model or a change in organization. More often than not, however, changes in all aspects are required in order to realize the full potential.

This paper reviewed some other papers written by other authors on the subject and then expressed the situation obtainable here in Nigeria, the gaps and challenges in the use of academic research in policy development and practice in the area under review were also discussed and some recommendations were made by the writers of the papers. Some of the constraints of the academic research in Nigeria include inadequate and irregular funding, poor motivation, poor or obsolete research infrastructure, brain drain and rising workload resulting from deteriorating staff/student ratio. These constraints have also generally led to low research productivity".

Recommendations made included: The Nigerian Government should have adequate budget and release sufficient funds for research with particular emphasis on innovative or interdisciplinary research as against either surveys, impact analyses, appraisals, evaluation studies or analytical studies. The federal government should expose to a wide range significant number of technological opportunities so as to address its human development and research for innovation challenges. Technologies such as information and communication technologies, biotechnology and nanotechnology can be harnessed and applied to increase food production, fight diseases such as malaria, tuberculosis and HIV/AIDS, and increase economic competitiveness of the country. And lastly, Nigeria government should strengthen and ensure the availability of the National Science Research Technology and Innovation Fund (NSRTIF) which the country have already opted to create for the development of science and technology in the country.

\section{What is academic research?}

Generally speaking, research could be defined as an active, coherent, diligent, logical and systematic process of searching for knowledge, inquiry for new ideas or useful information on a particular topic, behaviors, events or theories.

Writing on academic research, Betsy Beacom - an eHow Contributor, wrote "Academic research which is done in an academic environment, such as a university is presented in writing using a specific format according to a style guide such as that of the American Psychological Association (APA).”

Furthermore, writing on academic research trends and futures scenarios, Stéphan Vincent wrote to say that "academic research is understood as research and development (R\&D) undertaken in the higher education sector, including universities, polytechnics, etc., and research centers that have close links with higher education institutions."

Research can, therefore, be seen as a process of finding solutions to problems after a thorough study and analysis of the situational factors.

\section{The purpose and value of academic research}

Betsy continued to write on the importance of academic research where he mentioned that

"The purpose of academic research writing is twofold: 
I. To explain the goals, methodology and results of academic research, and

II. To analyze and interpret the findings".

The main purposes of research are, therefore, to predict, describe, explain or control an intervention, theory or program. This means that, research is being conducted to foretell a phenomenon that will result or occur at time $\mathrm{Y}$ from information at an earlier time $\mathrm{X}$, to describe natural or social phenomenon, such as its activity, change over time, relationship to other phenomena, to describe or predict consequences, and know how to intervene to change those consequences or to undertake such approaches that may include experimental design and evaluation research.

In the modern world, research has become an integral part of the world's educational status and could be done in all specializations, field of line at all stages. This means that, the significance or importance of research in the modern world is so obvious that even the government of many countries or nations today invest huge sum of money on doing research and encourage conducting research in areas where research would bring about changes, growth, development, invention-innovation or renovation.

\section{The concept of research for innovation and growth}

An "innovation is the implementation of a new or significantly improved product (good or service), or process, a new marketing method, or a new organizational method in business practices, workplace organization or external relations” Oslo Manual (2005).

Research and Development was defined as "creative work undertaken on a systematic basis in order to increase the stock of knowledge, including knowledge of man, culture and society, and the use of this stock of knowledge to devise new applications”, QECD Frascati Manual (2002).

As such innovation is, therefore, the process by which new products, processes, methods or services are created. Innovation offers added value for end users by providing better and/or cheaper functionality than previous options. Moreover, innovation combines changes in technology, business models, organization etc. The basic idea may be a new technical solution, a new business model or a change in organization. More often than not, however, changes in all aspects are required in order to realize the full potential. QECD (2014)

Charlotte Brogren - Director General of VINNOVA in April 2014 wrote as a forward in a report titled 'Innovations and new technology', “The ability to create and benefit from innovation plays a central role in income, employment and quality of life. Not only do innovations contribute to prosperity, they are increasingly important in addressing the many social challenges created by our quest for prosperity". Research-based competence is said to play an increasingly important role in the development of innovations and new technology.

According to Charlotte, "We need to think of innovation not as a sudden flash of inspiration, but as a long process of searching, experimenting and learning”. Charlotte also believes that publicly funded research can contribute in many different ways and at all stages of the innovation process. For this to become a reality requires policies that allow for continuous interaction so that researchers and companies can learn from each other.

At the end, it is obvious that much of the rise in living standards is due to innovation as this has been the case since the Industrial Revolution. Today, innovative performance is a crucial factor in determining competitiveness and national progress. Moreover, innovation is important to help address global challenges, such as climate change and sustainable development.

\section{The concept of policy}

Policy is often thought of as decisions taken by those with responsibility for a given policy area - it may be in health or the environment, in education or in trade. The people who make policies are referred to as policy makers.

Policy may be made at many levels such as federal or local government, in a multinational company or local business, in a school or hospital. A specific group of decision makers who 
have high positions in an organization, and often privileged access to other top members of the same, and other, organizations are sometimes referred to as policy elites. For example, Policy elites in government may include the members of the Prime Minister's Cabinet, all of whom would be able to contact and meet the top executives of a multinational company or of an international agency, such as the World Health Organization (WHO).

Policies are made in the private and the public sector. In the private sector, a group of diverse companies under common ownership and run as a single organization may establish policies for all their companies around the world, but allow local companies to decide their own policies on conditions of service. For example, corporations such as Anglo-American and Heineken introduced anti-retroviral therapy for their HIV-positive employees in Africa in the early 2000s before many governments did so. However, private sector corporations have to ensure that their policies are made within the confines of public law, made by governments. Sometimes policy is called a program: the government's school health program may include a number of different policies: precluding children from starting school before they are fully immunized against the major vaccine-preventable childhood diseases, providing medical inspections, subsidized school meals and compulsory health education in the school curriculum.

Having known the concepts of academic research, innovation, growth and policy in government and private organization, let us now look into the relationship between these concepts. Ideally, academic research writing should have basic ingredients as organization, contents, expression and accuracy.

\section{Organization and expression of an academic research writing}

Basically, academic research writing should have a formal organizational structure. It usually begins with an abstract that summarizes the contents and helps the reader decide whether to read the entire document or not. This is then followed by the introduction which outlines the research problem, the main goal in addressing the problem and the author's stance. A literature review follows the introduction, where the author demonstrates how the research project fits into existing literature on similar topics. The methodology section then describes any surveys, laboratory experiments or other means by which data was gathered. Hence, results of the research are then presented as quantitative or qualitative information. This is then followed by a discussion section which addresses what the author learned from the research. The conclusion elaborates on the discussion and allots significance to the research findings in the context of existing research. References are mandatory so as to give credit to sources used.

\section{Content and accuracy of an academic research}

This entails using the information and findings in writing academic research. Prior to the beginning of the research project, a proposal in writing may be presented to a committee to obtain approval for the project. This proposal as earlier mentioned should include an abstract, introduction, literature review, and there should also be a description of the proposed research project and expected outcomes or results. However, after the research and writing are completed, it may be presented to a committee as part of the process of earning an advanced degree or published in a peer-reviewed academic journal as the case may be.

It is worth notice that writing an academic report or paper involves activities like thinking about a topic, reading about the topic in mind, making a case about the topic and eventually writing about the scholarly topic. In most cases, the idea is to get readers of the research work to see the topic in a new light. It should also be note that academic report differs from other types of reports one may have done (perhaps ones written for high school assignments) in that it presents both researched facts and researchers own assessment. 


\section{The systemic review of the existing literature}

Having these brief ideas about academic research writing, I would look into some of the papers written on academic research and review findings by the other authors. Four papers were reviewed by me, two indigenous that is written by the Nigerians or people working in the Nigerian's higher institutions and two other non indigenous papers, which were not written in the Nigerians context.

The Two papers that were written in the Nigerian context were titled:

1. "An Appraisal of Research in Nigeria's University Sector" (2012) written by A. K. Yusuf from Department of Basic and Applied Sciences, Hassan Usman Katsina Polytechnic, Katsina state Nigeria (Northern Nigeria), and

2. "Research and Innovation Strategies for Economic Competitiveness and Industrial Growth: Lessons for Nigeria.” (2014) written by E.H. Kwon-Ndung, L. Kwon-Ndung and J. Migap of Department of Botany, Federal University, Lafia, Department of Political Science, Nasarawa State University Keffi and Department of Economics, Federal University Lafia respectively all of Lafia. Nasarawa State (Northern Nigeria).

The other two papers not written in the Nigerian context were titled:

1. "Innovations and new technology - what is the role of research? Implications for public policy" (2014) written by L. Elg - VINNOVA

2. "Innovation and Growth-Rationale for an Innovation Strategy" (2007) by Organization for Economic Co-Operation and Development (OECD).

\section{Significance of academic research work}

Research significance is to clearly state why a research is important, what the benefits of the research would be and how the research work will contribute to knowledge in the concerned field. So the basic benefits of a research include changes in current practice, a new perspective on an old issue or other benefits to the community. The researcher may need to indicate why it is significant and how the research advances understanding of the issues under discussion.

On this issue, A.K.Yusuf (2012) (Please permit to be addressing henceforth as 'Malam Yusuf') wrote: "The role of higher education research in national development cannot be over emphasized. However, research in Nigeria's institutions of higher learning comprising the universities, polytechnics and colleges of education has yet to make a real impact on the technological advancement of the country and the socio-economic well-being of its citizenry."

More over E.H. Kwon-Ndung et al highlighted that "One of the leading unrealized opportunities in Nigerian industrial organizations is the full influence of research ideas and knowledge to transform business products and processes into long-term innovation.” They further wrote to say that "Business research and innovation contribute significantly to improvement in enterprise productivity and quality and in the integral components of business strategy and success.

In essence, research is important both in scientific and nonscientific fields. This is because in our life, new problems, events, phenomena and processes occur every day. As such, practically implementable solutions and suggestions are required for tackling new problems that arise. This signifies importance of research to our everyday life. It also implies that Scientists have to undertake research on our daily problems and find their causes, solutions, explanations and applications. Precisely, research assists us to understand nature and natural phenomena. Research is, therefore, the fountain of knowledge and provides guidelines for solving problems.

So absorbing to a considerable degree from these published literatures, there are enormous benefits of continual research and innovation on national economies, and one could proffer recommendations on how Nigeria could key into this concept to promote its economic competitiveness at the global level. 


\section{Academic research and policy development}

Reinhilde Veugelers (2014) wrote in a paper titled "The contribution of academic research to innovation and growth" that the most salient policy recommendations that stems from the analysis is that policy makers looking for ways to improve the contribution of universities to innovation based growth, should take a long-term perspective for developing an industryscience eco-system, avoiding the temptation of quick "success stories". Policy makers should be more "innovative" in their search for effective policy interventions, venturing beyond the classic spin-off and incubator programs. At the same time, they should be more serious about evaluating their new and existing instruments. To progress, policy makers should support more systematic data collection and analysis on the various pathways for universities' contribution to economic prosperity".

One clear example of a policy issue in research is the fact that research forms an integral part of public health services, it helps in giving a quality and modernized form of health services to the public. However, despite the fact that, research is meant to help in effective decision making and in making public health policies that would improve a population health, the results of many research works are usually not or underutilized by the people that are supposed to use them. This fact was clearly stated by A.K. Yusuf (2012) where he pointed out that "research in Nigeria's institutions of higher learning comprising the universities, polytechnics and colleges of education has yet to make a real impact on the technological advancement of the country and the socio-economic well-being of its citizenry."

Moreover, even in some developed countries, the government in some cases sponsored research works and may not fully utilized the results in making effective decision or policies; a very good example is that of Reinhilde Veugelers (2014) who wrote in a report titled "The contribution of academic research to innovation and growth" that "When looking at the evidence for Europe, there is a general lagging behind relative to the US, particularly on academic patenting and university spin-offs. Patenting and licensing is only two of a number of pathways for the transfer of knowledge from universities to industry, and perhaps not even the best forms. Student \& researchers' mobility from academe to industry is a critical mechanism to transfer knowledge from the university to industry, particularly when the knowledge to be transferred is hard to codify and is embodied in human capital as is the case for science-based knowledge. Although this is an area of great importance to the study of the innovation process, only recently research has started to attempt to trace researchers' intersectoral mobility". However, this project work that was carried out by Reinhilde has received funding from the European Union's Seventh Framework Programme for research, technological development and demonstration under grant agreement no. 290647.

Unfortunately, such is not the case in some developing countries, where the leaders (decision or policy makers) are only concern with what would promote their personal or political interests. In some developing countries, often an individual or donor agency may undertake a good research with marvelous results and very good recommendations that if implemented would change or improve a particular populations' health status or cause considerable economic or industrial growth, but the most painful part of it, these would only remain on paper without real implementation of the said recommendations and that means waste of resources in undertaking a research work that its results would not help in yielding anything positive. This is also supported by the paper written by E.H. Kwon-Ndung et tal (2014) that "One of the leading unrealized opportunities in Nigerian industrial organizations is the full influence of research ideas and knowledge to transform business products and processes into long-term innovation”.

\section{Changes in academic research and its application in different fields or professions}

What is changing in academic research has been disclosed by Stéphan Vincent-Lancrin (2006) where he asked the following very vital questions: "What is changing in academic research? What has changed over the past decades and what might change in the coming 
ones? Could the research mission of universities be carried out in slightly or radically different ways in the medium term? In his paper titled "What is changing in academic research? Trends and futures scenarios" he tried to answer the questions by dividing his paper into eight (8) sections as follows:

In the first section of the paper it was mentioned that research and development (R\&D) has grown significantly during the two past decades within the Organization for Economic Cooperation and Development (OECD) area, which accounted for about $80 \%$ of all R\&D expenditures in the world (OECD, 2005a). The paper further highlighted that "gross domestic expenditure on R\&D amounted on average to 2.3\% of GDP (Gross Domestic Product) in 2003, against $1.9 \%$ in 1981. In real terms (that is, controlling for inflation), R\&D expenditures have more than doubled between 1981 and 2003".

The second section of the paper pointed out that with some variations across countries, the business sector carries out and funds the bulk of R\&D in the OECD area. Giving example as in 2003, Greece, Poland, Portugal and Turkey were the only countries reporting more R\&D expenditures in the higher education than in the business sector. The prominence of the business sector has sharpened over the past decades. Between 1981 and 2003, the share of $R \& D$ performed by the business sector has risen from $65.4 \%$ to $67.7 \%$ of the total R\&D effort in the OECD area. Business expenditures on the performance of R\&D have risen from 1.26 to $1.53 \%$ of GDP that is by $141 \%$ in real terms. The business enterprise sector has also increased its financing of R\&D from 1 to $1.39 \%$ of GDP between 1981 and 2003. This increasing performance an $\mathrm{d}$ funding of $\mathrm{R} \& \mathrm{D}$ by businesses is one of the most significant trends of the past decades - explaining to some extent why OECD economies are often described as increasingly knowledge-based economies (Foray, 2004; Boyer, 2002).

So, the first section of the paper as shown above documents the growth in funding and output, while the second section shows that academic research can be characterized by its large proportion of basic research.

The remainder of the paper focused on academic research, where parallel trends were observed. It was highlighted that government funding, although the mode of allocation of public funding has changed in the past twenty years (section 3). A noteworthy trend has been the rise of the private funding of higher education and performance of basic research by the non-academic sectors (section 4). Internationalization of academic research has grown significantly (section 5), while a new attitude of civil society towards research (section 6) and new computing and networking opportunities offered by information and communication technology (ICT) are emerging as new driving forces for the future of academic research (section 7). The last section brings all these trends together by proposing four futures scenarios for discussion (section 8).

The application of research in different settings such as public health would never be over emphasized as research can lead to new contributions to the existing knowledge, and only through research is it possible to make progress in a field like public health. Research is indeed civilization and determines the economic, social and political development of a nation. The results of scientific research very often brought or force a change in the philosophical view of problems which extend far beyond the restricted domain of science itself. Research is therefore the fountain of knowledge and provides guidelines for solving problems in public health as well as in other disciplines.

\section{Constraints or problems and challenges of academic research in nigeria}

Almost every time and in our everyday life, we appreciate the use of research in supporting and providing new ideas and knowledge for example about our health and what we can do to improve it. Research provides basis for many government policies such as research on the needs and desires of the public and on the availability of revenues to meet the needs or helps a government to prepare a budget. Unfortunately there are many constraints that affect research among which were mentioned by A.K.Yusuf (2012) where he highlighted that "Constraints hampering the realization of research goals in the higher education sector include inadequate 
and irregular funding, poor motivation, poor or obsolete research infrastructure, brain drain and rising workload resulting from deteriorating staff/student ratio. These constraints have also generally led to low research productivity”.

Other challenges affecting research in Nigeria were also highlighted by E.H. Kwon-Ndung et tal (2014) where they wrote "Several factors have been cited for the poor level of research and innovation in Nigeria, such as:

I. Neglect of the education sector.

II. Lack of emphasis on science and engineering courses.

III. Most manufacturing firms were government owned and does not engage in productive R\&D to develop new products and processes that would enhance its competitiveness since they were mostly finance by government subventions:

IV. The few privately owned firms are in most cases subsidiaries of foreign multinationals and does not encourage local R \& D, they only implement production strategies and policies emanating from head-office which in most cases does not favour the development of local research development.

V. Poor funding of research institutions.

Barriers to the use of research evidence, however, are said to include: decision makers' perceptions of research evidence; the gulf between researchers and decision makers; the culture of decision making; competing influences on decision making; and practical constraints.

Suggested, but largely untested, ways of overcoming these barriers included: research targeted at the needs of decision makers; research clearly highlighting key messages; and capacity building. There was little evidence on the role of research evidence in decision making to reduce inequalities.

\section{Recommendations}

- The Nigeria government through the Ministry of Science and Technology to develop a more concise, robust and workable Science, Technology and Innovation (STI) policy which is expected to respond to the dictates of globalization, changing business environment and new/emerging technologies and thus provide for effective funding of R\&D.

- The Nigerian Government should have adequate budget and release sufficient funds for research with particular emphasis on innovative or interdisciplinary research as against either surveys, impact analyses, appraisals, evaluation studies or analytical studies.

- The federal government should expose to a wide range significant number of technological opportunities so as to address its human development and research for innovation challenges.

- Technologies such as information and communication technologies, biotechnology and nanotechnology can be harnessed and applied to increase food production, fight diseases such as malaria, tuberculosis and HIV/AIDS, and increase economic competitiveness of the country.

- Nigeria government should strengthen and ensure the availability of the National Science Research Technology and Innovation Fund (NSRTIF) which the country have already opted to create for the development of science and technology in the country.

- E.H. Kwon-Ndung et tal (2014) recommended that "for Nigeria to achieve macroeconomic development and assume its rightful position among the committee of emerging economies, it needs to reorder its priorities by committing more funds to R\&D activities to meet UNESCO standards of having at least 1\% of GDP committed to R\&D as well as faithfully implement the National R\&D Fund”. 


\section{Conclusion}

It was concluded by the study that to more effectively implement research, action is required by decision makers and researchers to address the barriers identified in the said systematic review. There is an urgent need for evidence to support the use of research evidence to inform decision making and to reduce inequalities. It should be sufficiently recognized that innovation can originate anywhere and increased education and economic growth have improved the capacity of developing countries to offer new products and services.

As right put by E.H. Kwon-Ndung et tal (2014) that "It is not a coincidence that countries such as USA or Japan are the world's top economies because their allocation of resources into creating innovation is massive. It obviously indicates that innovation is the key driving growth and prosperity. Approximately 50\% of US annual GDP growth is attributed to increases in innovation. For the past two centuries, the US has been the world-leader in developing innovative products and services. Innovation therefore is the engine for the economic growth as it makes a great contribution in economic growth and development in an economy or the world as a whole. In the words of American Entrepreneur and Apple coFounder (Steve Jobs), "Innovation clearly distinguishes between a leader and a follower". We humbly and completely concur to this".

\section{Acknowledgements}

I wish to acknowledge the support I got from my new student coordinator Ms T, Gowri of Texila American University, my project guide Dr Muhammadu Nasiru Isyaku Provost College of Education Azare Bauchi State Nigeria. I also wish to acknowledge the writers of the papers I reviewed such as A.K.Yusuf, E.H. Kwon-Ndung, L. Kwon-Ndung and J. Migap. I also acknowledge the non Nigerian writers that wrote on this field such as Stéphan VincentLancrin (OECD-CERI), Prof. Ilberto Stocchi (Rector of "Carlo Bo" University) and many others that I would not be able to mention them all here.

\section{References}

[1] A.K.Yusuf (2012), “An Appraisal of Research in Nigeria’s University Sector”. JORIND 10 (2), June, 2012. ISSN 1596 - 8308. www.transcampus.org./journals, www.ajol.info/journals/jorind

[2] E.H. Kwon-Ndung et al (2014), "Research and Innovation Strategies for Economic Competitiveness and Industrial Growth: Lessons for Nigeria”. European Journal of Business and Innovation Research Vol.2,No.6, pp.56-76, December 2014

[3] Stéphan Vincent-Lancrin (2006), "What is changing in Academic Research? Trends and Futures Scenarios". Forthcoming in the European Journal of Education, 41, 2, June 2006.

[4] Group of Eight (2013), "The Role and Importance of Research Intensive Universities in the Contemporary World”(Discussion Paper). The Group of Eight Group of Eight House Level 2, 101 Northbourne Avenue Turner ACT 2612. www.go8.edu.au

[5] Prof. Ilberto Stocchi et al (2015), "Increasing the Power of Academic Research through the Insitutional Research and Innovation Development on Macroregione Adriatico-Ioniana”. E-ISSN 22814612 ISSN 2281-3993 Academic Journal of Interdisciplinary Studies MCSER Publishing, Rome-Italy Vol 4 No 2 S2 August 2015

[6] OECD (2007), "Innovation and growth rationale for an innovation strategy". Organization for Economic Co-Operation and Development.

[7] Lennart E, - VINNOVA (2014), "Innovations and new technology - What is the role of Research? Implications for Public Policy”. VINNOVA - Swedish Governmental Agency for Innovation Systems / Verket för Innovations system ISBN 978-91-87537-16-5

[8] Betsy Beacom (2016) eHOW, "Definitions of Academic Research and Process of Writing Academic Research”. http://www.ehow.com

[9] Dr. Donald (2015), Study Modules "Research Methodology". Master Public Health, School of Public Health, Texila American University. 


\title{
Role of Counseling in the Disclosure of HIV Status to Sexual Partners among HIV Positive Women Accessing PMTCT Services in South Nigeria
}

\author{
Article by Adetumi Adetunji Subulade \\ Ph.D in Public Health, Texila American University, Nigeria \\ E-mail:drtunjisubulade@yahoo.com
}

\section{Background}

HIV infection is still associated with a lot of stigmatization and discrimination, which makes it difficult for infected individuals to disclose their status. Many studies have shown different rates of disclosure of HIV status with average of $71 \%$ in the developed world and $52 \%$ in the developing world (WHO 2004)). Different reasons were attributed to nondisclosure of HIV status which included fear of abandonment, fear of rejection and discrimination, fear of violence and fear of upsetting family members.

Counseling is integral to guiding the infected persons to disclosure and a study by Alemayehu et al (2014) in Northern Ethiopia support that counseling is important to HIV disclosure. In ANC in Nigeria, opt out counseling and testing is practiced as recommended by WHO which focused on group counseling, it is however recommended that HIV positive individuals should be privileged to have one on one counseling with counselors to avail them of the opportunity to be properly counseled on the benefits of disclosure and other HIV care (FHI, 2008).

Counseling is an intervention that gives one the opportunity to confidentially discuss his or her situation in a dialogue with the aim of helping the person to explore and work out possible solutions in a reasonable manner. Disclosure is essential to achieving good HIV care especially in PMTCT for many reasons. It motivates sexual partners to go for testing, change risky behaviors and provide support to the infected partners as showing in several studies which reported high support rate for infected persons who disclosed their status to their sexual partners. Other benefits are that it increased the opportunities for improved access to appropriate medical treatment and care and to plan HIV risk reduction with sexual partners (WHO, 2004).

Scogmar et al (2006) in the study in South Africa did not show correlation between HIV counseling and disclosure and likewise Adeyemo et al (2011) in Lagos, South west Nigeria reported low disclosure to counseling even though there was improvement in the attitude change towards disclosure after counseling. This study is therefore aimed at determining the role of counseling in the disclosure of HIV status to sexual partners among HIV positive women in PMTCT programme.

\section{Methods}

\section{Study setting}

This study was conducted in in the health care facilities that offer PMTCT services across the 18 local government areas (LGAs) of Edo state, Nigeria. Edo state is in the south region of Nigeria with 18 local governments in three senatorial districts; Edo North, Edo South and Edo Central senatorial districts. The state has an estimated population of 3, 218, 332 people, made up of 1.640,461 males and 1. 577,871 females and occupies a total land mass of 19, 308.93sq km (NPC 2006). It has 5 tertiary health facilities, 32 secondary health facilities and about 200 primary health care facilities; however PMTCT services are not offered all the health institutions. Data was collected from January to March 2016 in some of the health institutions where PMTCT are offered which included 1 tertiary health institution, 17 secondary health facilities, and 18 primary health care facilities (Edo State MOH 2010). 
Texila International Journal of Public Health

Volume 4, Issue 4, Dec 2016

\section{Study population and study design}

The study population was HIV positive women accessing PMTCT programme in the health care institutions. 904 women received PMTCT intervention in the state in a year period from August 2014 to July 2015 as reported in the DHIS. The sample size was calculated using the Kish Leslie formula for descriptive studies, with sample size $\mathrm{N}$ generated with formula $\mathrm{N}=\mathrm{pqz}^{2} / \mathrm{d}^{2}$. In the review of 25 published papers from January 1990 to December 2001 in subSaharan Africa by WHO, the least rate of HIV disclosure to sexual partners in the developing world was $16 \%$, which was used in this study as the prevalence so as to have the estimated minimum size for a good study (WHO, 2004). The sample size then with 10\% non-response rate made the final sample size to be 227 .

Cross-sectional descriptive study design was used and data was collected from the respondents with the use of structured questionnaires. The questionnaire includes demographic variables, partner characteristics, partnership, disclosure status, disclosure barriers, partner's status, partner's reaction and counseling types. The questionnaire was adapted from different literatures and local settings of the study participants were put into consideration. The questionnaires were applied in an interview session by recruited volunteers, who were well trained on the use of the tool.

\section{Data analysis}

The collated data was analyzed using SPSS version 21 software. Exploratory analysis was run to check for missing values and outliers. Descriptive analysis was run on the variables for their frequencies and test of association was assessed with crosstab to check for Chi square value and to assess the P-value for significance of associations. Several dependent variables were cross tabbed with the dependent variables. P-value less than 0.05 were considered to be statistically significant.

The study was approved by the research and ethics committee of the tertiary hospital, Irrua Specialist Teaching Hospital (ISTH) and the Edo state Hospital management board ethical committee. Formal letter of permissions were obtained from the institutions and written consent was obtained from the participants of the study. The right of the participants to withdraw from the interview or not to participate was assured throughout the questionnaire administration period.

\section{Results}

255 HIV positive women participated in the study, and most of the participants (33.7\%) are within the age range 26 to 30 years, and the highest level of education for majority (40.4\%) is secondary school. More (45\%) are self-employed, $81.2 \%$ are Christians and $93.7 \%$ are married.

Table 1. Socio-demographic characteristics of the study participants, Edo state, Nigeria

\begin{tabular}{|l|l|l|}
\hline Age of Respondents & \multicolumn{2}{|l|}{} \\
\hline Age (yrs) & Frequency & Percentage (\%) \\
\hline $16-20$ & 6 & 2.4 \\
\hline $21-25$ & 41 & 16.1 \\
\hline $26-30$ & 86 & 33.7 \\
\hline $31-35$ & 53 & 20.8 \\
\hline $36-40$ & 59 & 23.1 \\
\hline $41-45$ & 10 & 3.9 \\
\hline Level of Education & \multicolumn{2}{|l}{} \\
\hline Primary & 91 & 35.7 \\
\hline
\end{tabular}


Texila International Journal of Public Health

Volume 4, Issue 4, Dec 2016

\begin{tabular}{|l|l|l|} 
Secondary & 103 & 40.4 \\
\hline Technical & 12 & 4.7 \\
\hline Graduate & 32 & 12.5 \\
\hline Postgraduate & 17 & 6.7 \\
\hline Occupation of Respondents & \multicolumn{1}{l|}{} \\
\hline Self-employed & 115 & 45.1 \\
\hline Civil servant & 16 & 6.3 \\
\hline Private Establishment & 18 & 7.1 \\
\hline Trader & 105 & 41.2 \\
\hline No Response & 1 & 0.4 \\
\hline Religion & \multicolumn{2}{|l|}{} \\
\hline Christianity & 207 & 81.2 \\
\hline Islam & 43 & 16.9 \\
\hline Others & 5 & 2 \\
\hline Marital Status & \multicolumn{2}{|l}{} \\
\hline Married & 239 & 93.7 \\
\hline Single & 16 & 6.3 \\
\hline Total & $\mathbf{2 5 5}$ & $\mathbf{1 0 0}$ \\
\hline & &
\end{tabular}

Table 2

\begin{tabular}{|l|l|l|}
\hline \multicolumn{3}{|l|}{ Respondents' HIV status disclosure to their sexual partners } \\
\hline HIV disclosure & Frequency & Percentage (\%) \\
\hline Yes & 190 & 74.5 \\
\hline No & 65 & 25.5 \\
\hline Total & 255 & 100 \\
\hline Reasons for Non-disclosure & \multicolumn{3}{|l|}{} \\
\hline Reasons & Frequency & Percentage (\%) \\
\hline Fear of stigmatization & 12 & 4.7 \\
\hline Fear of infidelity accusation & 3 & 1.1 \\
\hline Fear abandonment/rejection & 37 & 14.5 \\
\hline Fear of physical abuse & 5 & 2 \\
\hline Multiple reasons & 4 & 1.6 \\
\hline Other reasons & 4 & 1.6 \\
\hline Status known & 190 & 74.5 \\
\hline Total & 255 & 100 \\
\hline Respondents counseled on HIV disclosure \\
\hline Response & Frequency & Percentage (\%) \\
\hline Yes & 235 & 92.2 \\
\hline No & 18 & 7.1 \\
\hline No response & 2 & 0.8 \\
\hline Total & 255 & 100 \\
\hline Types of counseling received & Frequency & Percentage (\%) \\
\hline Response & 34 & 13.3 \\
\hline Group counseling & 160 & 62.7 \\
\hline One on one & 41 & 16 \\
\hline Both & \multicolumn{2}{|l|}{} \\
\hline
\end{tabular}


Texila International Journal of Public Health

Volume 4, Issue 4, Dec 2016

\begin{tabular}{|l|l|l|}
\hline No response & 2 & 0.8 \\
\hline Not counseled & 18 & 7.2 \\
\hline Total & 255 & 100 \\
\hline \multicolumn{2}{|l|}{ Reactions of Partners to Non-disclosure } \\
\hline \multicolumn{1}{|l|}{ Reactions of partners } & Frequency & Percentage (\%) \\
\hline Supportive & 170 & 89.5 \\
\hline Indifferent & 14 & 7.3 \\
\hline Abusive & 4 & 2.1 \\
\hline Violent & 2 & 1.1 \\
\hline Total & 190 & 100 \\
\hline
\end{tabular}




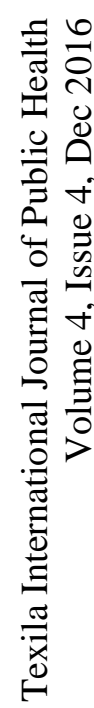

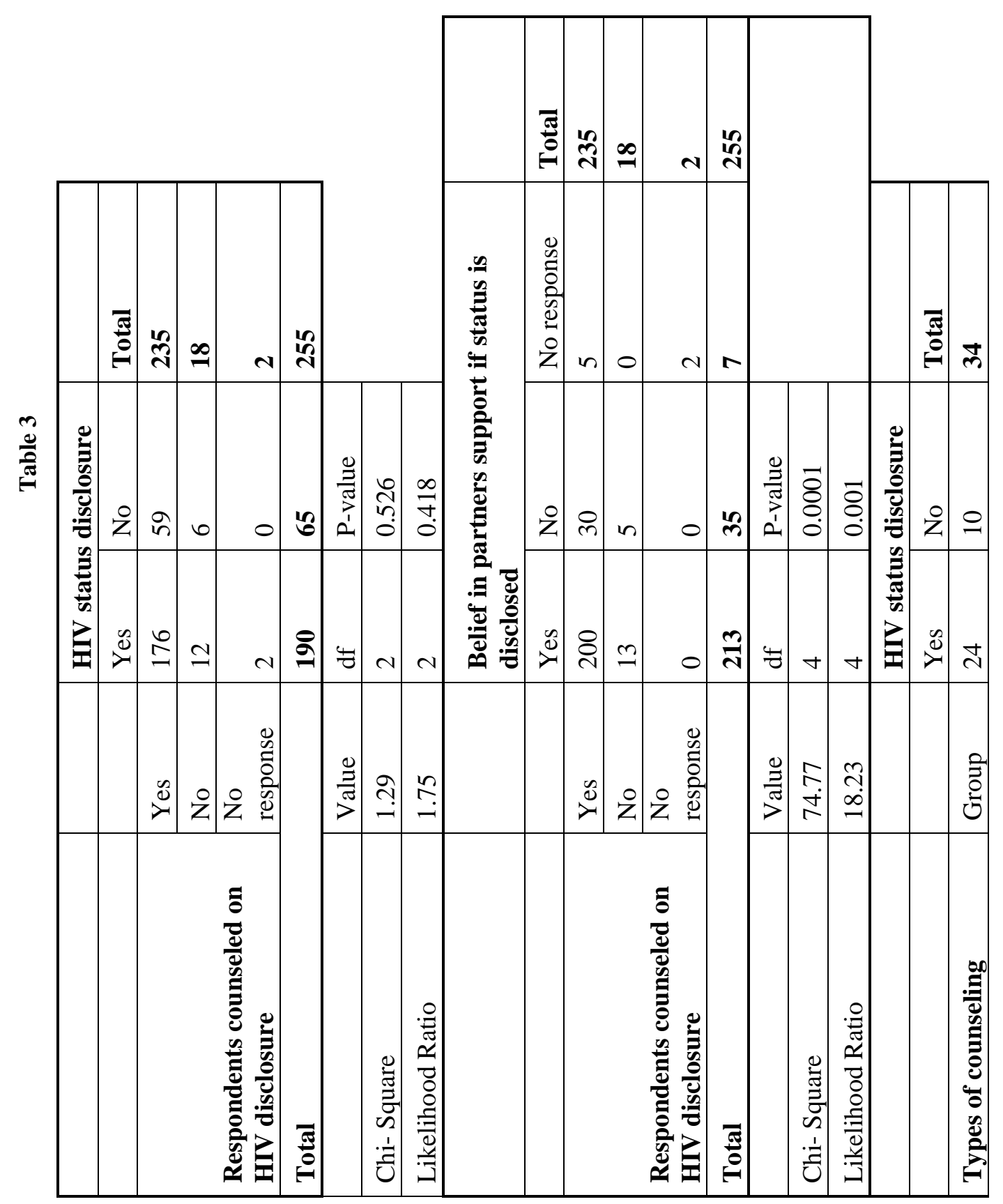




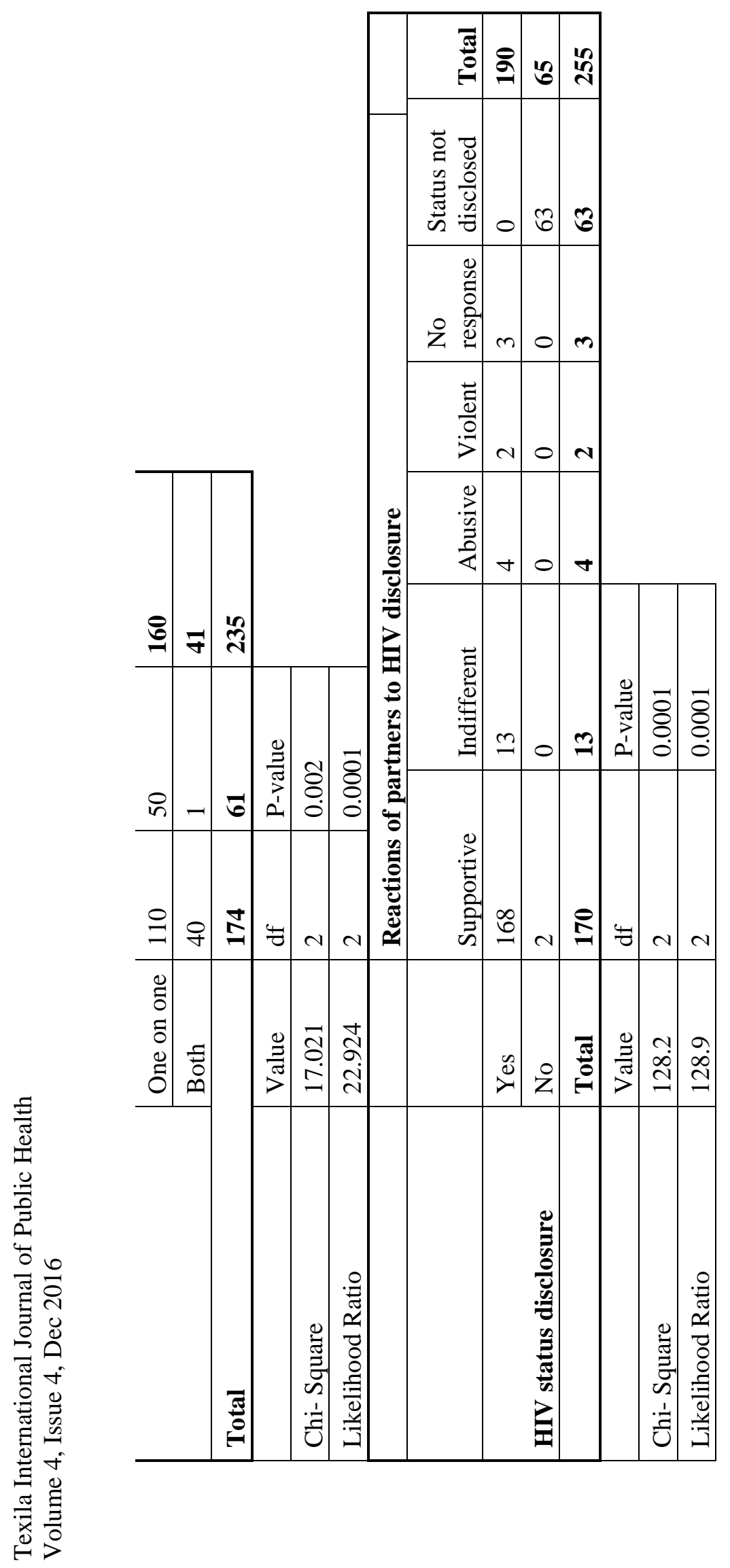


Out of the 255 study participants, 190 (74.5\%) have disclosed their disclosed their HIV status to their sexual partners. 235 (92\%) of them agreed to have been counseled at the clinic on the benefits and the need to disclose their status to their partners, and 201 (78.7\%) of the study participants had one on one sessions with the counselors. The commonest reason for not disclosing HIV status was fear of abandonment and rejection. Out of the 190 participants that disclosed the HIV status to their sexual partners, $89.5 \%$ of them enjoyed good support from their partners.

Being counseled on HIV disclosure had strong positive association with the participants' belief that their partners will support them following disclosure of status $(\mathrm{P}=0.0001)$. This was truly reflected in the strong positive association of reactions of the partners of participants and the disclosure of HIV status of the participants $(\mathrm{P}=0.0001)$.

However, the counseling of participants did not show any association with the disclosure pattern ( $\mathrm{P}>0.05)$, even though there was a positive association between HIV status disclosure and type of counseling offered to the participants $(\mathrm{P}=0.002)$.

\section{Discussion}

The study focused on determining the role of counseling in the disclosure of HIV status to sexual partners among HIV positive women in the PMTCT programme in the south Nigeria. This study assessed the pattern of counseling and its effect on HIV disclosure among these women.

The rate of HIV disclosure to sexual partners was $74.5 \%$ in this study, which was higher than the study in Northern Ethiopia with 63.8\% disclosure (Alemayehu et al, 2014). However the studies in southern Ethiopia and Uganda showed higher rate of $94.5 \%$ and $97 \%$ respectively for general disclosure to any person (Deribe et al, 2008; King et al, 2008).

In the study conducted in Northern Ethiopia, there was positive association between pretest counseling for women who knew the HIV status of their partners and disclosure of HIV status. The association could have been influenced by their knowledge of HIV status of their partners, though the type of counseling was not given whether it was one on one or group counseling.

In another study in a teaching hospital in South West Nigeria, counseling contributed to less than $50 \%$ of the impact on willingness to disclose HIV status to partners, though type of counseling was not ascertained (Adeyemo et al, 2011). Adeyemo et al however reported that counseling helps more to overcome the fear of disclosure, which supports this study, in which there is strong positive association between counseling and participants' belief that their partners would support them, though it did not show association in its direct relationship in translation to disclosure of their status. Alsoin support of this study, Sethosa et al (2005) in the study in South Africa did not show any correlation between counseling and HIV disclosure in a study that has both HIV positive men and women as study participants. All these points may be due to inadequate number of participants or the composition of participants in different studies.

Considering the above, counseling might have convinced the participants to believe that they would get support from their partners but the results did not show significant translation to the practice of actual disclosure. This was strongly supported in this study as $89.5 \%$ of participants who disclosed their HIV status got good support from their partners, and there was demonstration of positive association between the reactions of the partners to the status disclosure and HIV disclosure.

Quality of counseling which in this study was measured by the type of counseling offered through one on one or group counseling could have accounted for this kind of result. Due to the sensitive nature of HIV disclosure, one on one counseling is recommended for all PLHIV, however only 201 (78.7\%) received one on one counseling and 18 (7.2\%) participants were not counseled on HIV disclosure. This shows poor quality of counseling in the PMTCT setting. To support the effect of one on one counseling on disclosure of HIV status to partners, the study showed a strong association between the types of counseling and HIV 
Texila International Journal of Public Health

Volume 4, Issue 4, Dec 2016

status disclosure with high likelihood ratio (LR-22.9, $\mathrm{P}=0.002$ ). Not many studies were seen reporting the association between the different types of counseling and HIV disclosure.

\section{Conclusion and recommendation}

The quality of counseling offered to HIV positive women during PMTCT through one on one counseling does not only help the women to overcome the fear of being denied support by their partners, but also go a long way in making them to take necessary steps in disclosing their status. This will generate the support needed from the partners for effective PMTCT intervention. It is therefore recommended that all women in the PMTCT programme intervention should be routinely offered one on one counseling on the benefits of HIV status disclosure till they disclose. Counselors must be ready to support them in this process.

\section{References}

[1] Adeyemo, A, Adediran, A, Akinbami, A, Unigwe, O \&Akanmu, A 2011, 'Psychosocial impact of disclosure of HIV serostatus min heterosexual relationship at the Lagos University teaching hospital, Nigeria' Nigerian Medical Journal, vol. 52, no.1, pp 55-59. Available from: < http://www.ncbi.nlm.nih.gov/pmc/articles/PMC3180759/>

[2] Almayehu, M, Aregay, A, Kalayu, A \&Yebyo, H 2014, 'HIV disclosure to sexual partner and associated factors among women attending ART clinic at Mekelle hospital, Northern Ethiopia' Biomedical Central Journal of Public Health, vol. 14, pp. 746. Available from: $<$ http://www.biomedcentral.com/1471-2458/14/746>[7 August 2016]

[3] Deribe, K, Woldemichael, K, Wondafrash, M, Haile, A \& Alemayehu, A 2008, 'Disclosure experience and associated factors among HIV positive men and women clinical service users in southwest Ethiopia', Biomedical Central Journal of Public Health, vol. 8, pp.18. Available from: http://www.biomedcentral.com/1471-2458/8/81[7 August 2016]

[4] Edo State Ministry of Health 2010, Edo State Government strategic health development plan 2010-2015. Available from: www.mamaye.org.ng/.../Edo\%20SSHDP\%20revised\%2005.0.11_0.pdf. [7 August 2016]

[5] Federal Ministry of Health [FMOH] 2014, Integrated national guidelines for HIV prevention treatment and care. National AIDS/STIs Control Program, Nigeria. Available from: $<$ www.who.int/hiv/pub/guidelines/nigeria_art.pdf >. [7 August 2016]

[6] King, R, Katuntu, D, Lifshay, J, Packel, L, Batamwita, R \& Nakayiwa, S 2008, 'Processes and outcomes of HIV serostatus disclosure to sexual partners among people living with HIV in Uganda', AIDS Behavior Journal, vol. 12 no. 2, pp 232-243. [7 August 2016]

[7] Kiula, ES, Damian, DJ \&Msuya, SE 2013, 'Predictors of HIV serostatus disclosure to partners among HIV positive pregnant women in Morogoro, Tanzania', Biomedical Central Journal of Public Health, vol. 13 no. 433, pp. 1-9. Available from: < www.scirp.org/journal/PaperDownload.aspx?issueID=6099 >. [7 August 2016]

[8] Ogoina, D, Ikuale, P, Ebuenyi, I, Harry, T, Inatimi, P \& Chukwueke, O 2015, 'Types and predictors of partner reactions to HIV status disclosure among HIV infected adult Nigerians in a tertiary hospital in the Niger Delta', African Health Sciences Journal, vol. 15, no. 1, pp. 10-18. Available from: < http://www.ajol.info/index.php/ahs/article/view/114004>. [7 August 2016]

[9] Sethosa, E \& Peltzer, K 2005, Evaluation of HIV counseling and testing, self-disclosure, social support and sexual behavior change among a rural sample of HIV reactive patients in South Africa, 'PubMed Journal of Medicine, vol. 28, no. 1, pp.29-41. Available from: < http://www.ncbi.nlm.nih.gov/pubmed/15850151>[7 August 2016]

[10] Skogmar, S, Shakely, D, Lans, M, Danell, J, Andersson, R, Tsandu, N, Oden, A, Roberts, S \& Francois, V 2006, ' Effect of antiretroviral treatment and counseling on disclosure of HIV sero-status in Johannesburg, South Africa, ' PubMed Journal of Medicine, vol. 18, no. 7, pp. 725- 730. Available from: < http://www.ncbi.nlm.nih.gov/pubmed/16971281>[7 August 2016]

[11] Walcott, M, Hatcher, A, Kwena, Z \&Turan, J 2013, 'Facilitating HIV status disclosure for pregnant women and partners in rural Kenya: a qualitative study', Biomedical Central Journal of Public Health, vol. 13, no. 1115, pp. 1-13. 
Texila International Journal of Public Health

Volume 4, Issue 4, Dec 2016

[12] World Health Organization 2015, Prevention of mother to child transmission: situation and trends, Global Health Observatory data. Available from: < http://www.who.int/gho/hiv/epidemic_response/PMTCT_text/en/ >. [7 August 2016]

[13] World Health Organization 2004, Gender dimensions of HIV status disclosure to sexual partners: rates, barriers and outcomes. Department of Gender and Women Health. Available from: < http://apps.who.int/iris/bitstream/10665/42717/1/9241590734.pdf >. [7 August 2016]

[14] World Health Organization 2003, 'Preparing a research project proposal: guidelines and forms', UNDP/UNFPA/WHO/World Bank Special Program of Research, Development and Research Training in Human Reproduction. 4th Ed. Available from: < http://www.gfmer.ch/SRH-Course-2011/researchmethodology/pdf/WHO-proposal-guidelines-forms-2003.pdf > . [7 August 2016] 


\title{
Infant Feeding Challenges Encountered by HIV Positive Mothers in Korogocho Slums, Nairobi, Kenya
}

\author{
Article by Bennadette Mugita Siruri \\ M.Sc Clinical Psychology, Texila American University, Kenya \\ E-mail: bmugita@gmail.com
}

\begin{abstract}
Mother to child transmission of HIV is the major route of HIV infection in children and is responsible for nearly $90 \%$ of childhood infections. International guidelines on infant feeding for HIV- positive mothers promote exclusive replacement feeding (ERF) or exclusive breastfeeding (Laar and Govender, 2013). In spite of these guidelines, poor maternal, infant and young child nutrition (MIYCN) practices are widely documented in Korogocho, with potential detrimental effects on child growth and survival. Rates of exclusive infant feeding, both breast-feeding and formula-feeding, are suboptimal in Korogocho slums with exclusive breastfeeding for the first six months being at about two per cent. (Kimani-Murage et al., 2013). This study was thus carried out with the main objective of assessing the infant feeding challenges of HIV positive mothers in this slum which leads them to practice poor infant feeding. Purposive sampling was used to select the study site and simple random sampling was used to select a sample of 103 calculated using Fischer's method from a target population of 140. Data was collected using interviewer administered questionnaires and three focus group discussions were conducted. Quantitative data was cleaned, coded, entered and analyzed using SPSS Version 16. Qualitative data was analyzed using a three stage thematic approach through transcription of the tape recordings, summarization, thematical description and direct reporting where necessary. Quantitative data was presented in the form of tables and textual summaries. Results from this study showed poor knowledge of appropriate infant methods as only 46 (44.7\%) mothers were satisfied with the infant feeding counseling they had received from the health personnel. Poor clinic attendance by 61(59.2\%) of the mothers may have led to short and few sessions and it also affected the time of infant feeding thus the poor quality of counseling. Most of the mothers were aware of mother to child transmission (MTCT) of HIV through breastfeeding and 62(60.2\%) knew that it could be prevented through exclusive breastfeeding, 60 (58.3\%) through replacement feeding and 54 (52.4\%) through early and abrupt cessation of breastfeeding though quite a number lacked this knowledge. The concerns raised by breastfeeding mothers included; 29(56.9\%) inability to produce sufficient milk, 23 (45.1\%) infections in the baby's mouth, 19 (37.3\%) breast infections and 9(11.8\%) inability to control the feeding due to the influence of the extended family. Feelings of guilt 33(94.3\%) and cost of replacement feeding 26(74.3\%) were the major concerns among replacement feeding mothers. Though 17 (16.5\%) had ceased breastfeeding early, up to 15(88.2\%) of them lacked advice on the appropriate feeding methods after breastfeeding cessation. Mothers in this study were aware of the WHO recommendations on infant feeding and MTCT through breastfeeding and its prevention. However, they faced several challenges which include poor knowledge on appropriate infant feeding methods, inability to produce sufficient milk, high cost of replacement food and lack of knowledge on appropriate infant feeding practices after cessation of breastfeeding. More emphasis should be put on proper clinic attendance by the mothers as this will provide additional time for the health personnel to provide full information infant feeding. Provision of information on appropriate infant feeding practices after cessation of breastfeeding should be enhanced. Further investigations are required to determine the cause of insufficient milk production by the mothers.
\end{abstract}


Texila International Journal of Public Health

Volume 4, Issue 4, Dec 2016

\section{Abbreviations}

$\begin{array}{ll}\text { AFASS } & \text { Acceptable, Feasible, Affordable, Sustainable, Safe } \\ \text { AIDS } & \text { Acquired Immunodeficiency syndrome } \\ \text { ANC } & \text { Antenatal clinic } \\ \text { ARVs } & \text { Antiretroviral drugs } \\ \text { DMOH } & \text { District Medical Officer of Health } \\ \text { ERF } & \text { Exclusive replacement feeding } \\ \text { HIV } & \text { Human Immunodeficiency Virus } \\ \text { MIYCN } & \text { Maternal, infant and young child nutrition } \\ \text { MTCT } & \text { Mother to Child Transmission } \\ \text { NASCOP } & \text { National AIDS Control Programme } \\ \text { PMTCT } & \text { Prevention of Mother to Child Transmission } \\ \text { SPSS } & \text { Statistical Package for Social Sciences } \\ \text { UNAIDS } & \text { Joint United Nations Programme on HIV/AIDS } \\ \text { UNICEF } & \text { United Nations Children's Fund } \\ \text { UNFPA } & \text { United Nations Population Fund } \\ \text { VCT Voluntary Counseling and Testing } \\ \text { WHO World Health Organization }\end{array}$

\section{Definition of terms}

Acceptability: Ability of a mother to cope with the problem of not breastfeeding and resisting pressure from friends and relatives to breastfeed.

Affordability: Ability to pay for the ingredients, fuel, water and other equipment needed for replacement feeding.

Appropriate: A feeding method that is suitable or proper in the mother's circumstances

Challenges: These are any difficulties faced by the HIV positive mothers in their efforts to effect their infant feeding options.

Exclusive Breast-Feeding: A child is fed with only breast milk and no other foods or liquids by mouth (except for medicine) for the duration specified. Exclusive Replacement feeding: A child does not receive any breast milk in addition to replacement foods for the duration specified.

Feasibility: Ability of a mother who chooses replacement feeding to have adequate time, knowledge, skills and other resources to prepare the replacement food and feed her baby up to twelve times in 24 hours.

Focus group: A focus group is a small-group discussion guided by a trained leader which is used to learn more about opinions on a designated topic, and then to guide future action.

Knowledge: A familiarity, awareness or understanding of something in this context the appropriate infant feeding methods.

Mixed feeding: This is defined here as the consumption of other non breast milk products in conjunction with breastfeeding.

Safety: Replacement food should be nutritionally sound and free from germs. The water it is mixed with should be boiled, and utensils should be cleaned (preferably boiled) before each use. This means the mother must have access to a reliable supply of safe water and fuel.

Slum: A run down area of a city usually inhabited by the very poor or socially disadvantaged, characterized by urban decay, high rates of poverty, unemployment, substandard housing and poor sanitation including lack of clean water and social facilities.

Sustainability: Ability to obtain a constant supply of formula feed for the first six months of life and regular access to water without even a brief disruption. 


\section{Introduction}

\section{Background information}

The epidemic of mother to child transmission (MTCT) of Human Immunodeficiency Virus (HIV) in resource poor countries is dramatic and is responsible for nearly $90 \%$ of childhood infections. According to UNAIDS update for 2011, there were about 34 million people living with HIV worldwide (UNAIDS, 2011). Sub Saharan Africa still bears the largest share of the global HIV burden as 68\% of those living with HIV live in Sub-Saharan Africa and more women than men are HIV positive (UNAIDS, 2010). In 2010, an estimated 3,400,000 children aged less than 15 years were living with HIV in the world (WHO, 2011) and around 330,000 children were newly infected in that year alone with an estimated 230,000 dying from AIDS (UNAIDS, 2012). Without intervention to prevent mother-to-child transmission of HIV, 30-45\% of infants born to HIV positive mothers in developing countries become infected during pregnancy, delivery and breastfeeding (Muluyeet al., 2012).

Breastfeeding carries significant health benefits to infants and young children (WHO, 2007) and for several decades the promotion of exclusive breastfeeding in resource poor settings has played a critical role in improving child health by providing optimum nutrition and protection against childhood infections (Suryavanshi et al., 2003) Unfortunately, the documentation of the risk of HIV transmission through mother's milk has rendered infant feeding choice a most exigent issue and has created considerable uncertainty and fear among HIV-positive child bearing women (Leshabari et al., 2006). The HIV epidemic has challenged health systems and public health programs throughout the world. Balancing the risks of HIV transmission during breast-feeding with the risks of not breast-feeding, in settings where access to safe replacement foods, health care, and support are limited, is one of the most difficult issues facing HIV-affected families today (Piwoz and Bentley, 2005). This has resulted in a painful dilemma for millions of women in developing countries especially those in resource poor settings for whom there are no easy options (Leshabari et al., 2006).

For HIV positive women in well-resourced countries, the advice from national health agencies is to avoid breastfeeding all together because the risk of HIV transmission far outweighs the risks associated with replacement feeding. (WHO, 2003). However in Korogocho slum which is resource poor, where access to safe replacement foods, health care, and support are limited and where infectious diseases and malnutrition are the major causes of childhood death (Wikipedia, 2013), replacement feeding can be much more hazardous. Balancing the risks of HIV transmission during breast-feeding with the risks of not breastfeeding is one of the most difficult issues facing HIV-affected families in this slum. This has resulted in a painful dilemma for the HIV positive mothers there.

The national and international guidelines on HIV and infant feeding are, by definition meant to provide infant feeding recommendations in general terms. They are thus not immediately relevant or appropriate on the local level unless, as explicitly spelt out by WHO, they are adapted to the particular social and cultural context in which women make their choices of infant feeding method (Leshabari et al., 2006). This study explored HIV-positive women's infant feeding challenges encountered in trying to implement their feeding of choice in the social and cultural context of Korogocho slums in Nairobi, Kenya.

\section{Problem statement}

Infant feeding is a crucial factor in determining growth and development of a child. For infants, breastfeeding is without question the best way to be fed (WHO, 2007). However, the risk of HIV transmission from mothers to their infants during breastfeeding poses a dilemma for infant feeding in Korogocho slum. This is because Korogocho is resource poor and is experiencing an HIV/AIDS epidemic of devastating magnitude with a prevalence of $14 \%$ compared to the national $7.8 \%$ with women bearing the brunt both of poverty and HIV/AIDS (Wikipedia, 2013). Alongside poverty, unemployment, crime and other social ills, this epidemic continues to be one of the biggest problems facing HIV positive mothers in 
Texila International Journal of Public Health

Volume 4, Issue 4, Dec 2016

Korogocho slums today. Poor hygiene prevalent in the slum has resulted to the rapid spread of cholera, malaria, typhoid, dysentery, and water and air borne diseases. In spite of the WHO recommendations on infant feeding, poor maternal, infant and young child nutrition (MIYCN) practices are widely documented in Korogocho, with potential detrimental effects on child growth and survival. Both clinical trials and evaluations of PMTCT programs have found that rates of exclusive infant feeding, both breast-feeding and formula-feeding, are suboptimal here. Kimani- Murage and colleagues (2013) in their study in Korogocho on infant feeding practices reported that infant feeding practices were poor and exclusive breastfeeding for the first six months was only about two per cent. This makes the practical application of the WHO recommendations in the operational setting of Korogocho slum a difficult issue. So far no documentation has been done on the infant feeding challenges encountered by HIV positive mothers in Korogocho slums both for exclusive breastfeeding and replacement feeding. The aim of this study was to establish these challenges by HIV positive mothers in this set up which could be leading to the poor infant feeding practices. The results of this study will inform design of interventions aimed at improving infant feeding practices in urban poor settings in Nairobi, Kenya.

\section{Justification}

The current WHO recommendations are that HIV positive mothers should exclusively breast feed followed by early cessation or replacement feed if they can meet the AFASS criteria for replacement feeding. However it seems that many mothers in Korogocho are having problems in following these guidelines as poor infant feeding practices have been documented. This study aimed at finding out from the mothers the challenges that they face in acquiring knowledge on appropriate infant feeding methods, challenges of exclusive breastfeeding, early breastfeeding cessation and replacement feeding and their awareness on MTCT of HIV through breastfeeding and its prevention. Once these are known, they will assist in strengthening the information, education and communication materials used in PMTCT programs. The findings will also help in informing policies that will target the community on PMTCT through breastfeeding.

\section{Objectives}

\section{Broad objective}

To assess the infant feeding challenges encountered by HIV positive mothers in Korogocho slums, Nairobi, Kenya.

\section{Specific Objectives}

1. To determine the challenges of acquiring knowledge on the appropriate infant feeding methods in Korogocho slums, Nairobi, Kenya.

2. To determine the HIV positive mothers' awareness of MTCT of HIV through breastfeeding in Korogocho slums, Nairobi, Kenya.

3. To determine the challenges faced by HIV positive mothers who practice exclusive breastfeeding and replacement feeding in Korogocho slums, Nairobi, Kenya.

4. To identify the challenges to early and abrupt cessation of breastfeeding in Korogocho slums, Nairobi, Kenya.

\section{Research questions}

1. What are the challenges of acquiring knowledge on the appropriate infant feeding methods in Korogocho slums, Nairobi, Kenya?

2. What is the awareness of MTCT of HIV through breastfeeding among HIV positive mothers in Korogocho slums, Nairobi, Kenya?

3. What are the challenges faced by HIV positive women who practice exclusive breastfeeding and replacement feeding in Korogocho slums, Nairobi, Kenya? 
4. What are the challenges of early and abrupt cessation of breastfeeding in Korogocho slums, Nairobi, Kenya?

\section{Conceptual framework}

Based on the literature review, the following diagrammatic concepts have been identified and put in conceptual framework. They illustrate theoretical relationship between background, proximate and outcome factors. The conceptual framework identified an outcome variable infant feeding challenges which was the main focus in this study. Infant feeding challenges was the dependent variable whereas socio demographic and cultural factors were the independent variables with knowledge on appropriate feeding methods and practices being the proximate factors.

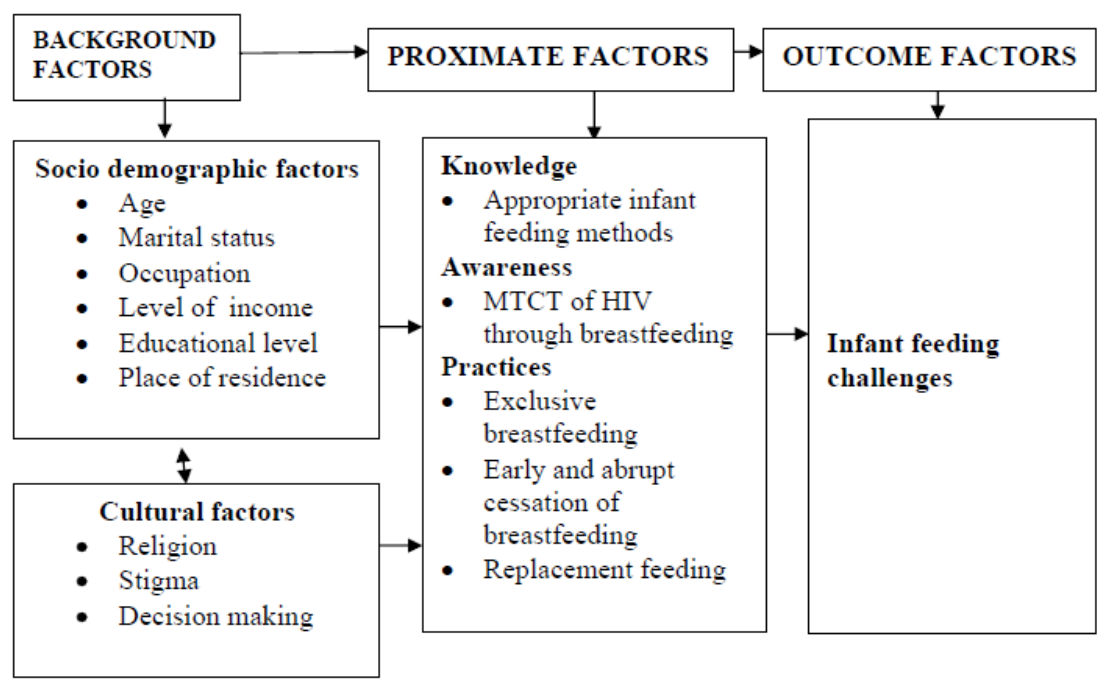

Figure 1.1 Conceptual Framework

\section{Explanation of the framework}

\section{Socio-demographic factors}

The risk of serious mortality and the disadvantages of artificial feeding are increased in poor households with inadequate sanitation, unsafe and scarce water supplies, no refrigeration, poor health services and little knowledge of hygiene. The person who provides for the family has an influence on how the respondent spends finances and so also indirectly on the feeding choice she makes. Literacy level is generally low among women and lack of education is compounded by misconceptions about HIV infections. These misconceptions lead to underestimation of interventions put in place to curb HIV spread such as appropriate infant feeding (Alcala, 2005).

\section{Knowledge on appropriate infant feeding methods}

Mothers with no counseling or poor quality counseling on feeding methods have an increased risk of transmitting HIV to their children (Chopra et al., 2005). One of the major challenges facing women in adopting and adhering to current recommendations is lack of access to good quality information.

\section{Literature review}

\section{Introduction}

The HIV epidemic has placed a strain on health systems and public health programs throughout the world. However, balancing the risks of HIV transmission during breastfeeding with the risks of not breast-feeding in settings where access to safe replacement foods, health care and support are limited is one of the most difficult issues facing HIVaffected families today (Suryavanshi et al., 2003). International guidelines on infant feeding 
for HIV-positive mothers promote Exclusive Replacement Feeding (ERF) (infant formula or animal milk) or exclusive breastfeeding (with no supplements of any kind) (Engebretsen et al., 2010). A mixed feeding pattern, where breastfeeding is combined with other milks, liquid foods or solids, has been shown to increase the risk of transmission of HIV and is strongly discouraged (Laar and Govender, 2013). Replacement feeding is only recommended if it is acceptable, feasible, affordable, sustainable and safe (AFASS). If not, exclusive breastfeeding is recommended during the first months of the baby's life" (Engebretsen et al., 2010,). To minimize HIV transmission risk, breastfeeding should be discontinued as soon as feasible, taking into account local circumstances, the individual woman's situation and the risks of replacement feeding including infections other than HIV and malnutrition (WHO, 2003a).

For HIV positive women in well-resourced countries, the advice from national health agencies is to avoid breastfeeding all together because the risk of HIV transmission far outweighs the risks associated with replacement feeding. In countries with fewer resources where replacement feeding can be much more hazardous, the recommendation for infant feeding usually depends on a mother's individual situation. This means that a mother should be advised to give replacement foods instead depending on personal circumstances (Omari et al., 2003). The AFASS of diverse alternatives to breastfeeding have been tried out including replacement feeding with modified animal milk or infant formula, wet nursing and expressed and heat treated breast milk (Rollins et al., 2004). However, the superiority of breastfeeding in reducing child morbidity and mortality is unquestionable, as it greatly reduces the risks of enteric infection and of defective nutrition, particularly in resource-poor settings (Bhandari et al., 2003). Hence, in recommending an infant feeding method to HIV-positive women, the risks implied in breastfeeding must be carefully balanced with the competing risks of not breastfeeding (Kuhn et al., 2004).

\section{Challenges of acquiring knowledge on the appropriate infant feeding methods}

In Sub-Saharan Africa, the issue of HIV transmission through breastfeeding is of public health importance particularly in countries where HIV affects significant proportion of the population and where breastfeeding is the cultural norm (UNAIDS, 2012). Studies have confirmed that about a third of HIV transmission from mother to child occurs through breastfeeding (Burr, 2011). This is as a result of inappropriate infant feeding practices. According to WHO, appropriate feeding practices play a crucial role in preventing mortality and in achieving optimal health outcomes for infants and young children during the first 6 months of life (WHO, 2012).

Infant feeding counseling based on international guidelines is considered a basis in the prevention of MTCT of HIV in Sub-Saharan Africa (Laar and Govender, 2013). According to WHO, appropriate feeding practices play a crucial role in preventing mortality and in achieving optimal health outcomes for infants and young children during the first 6 months of life (WHO, 2011). Counseling HIV positive mothers on safer infant feeding options is an important component of programs to prevent MTCT of HIV (Ketepa et al., 2011, WHO, 2003). Health services must offer women counseling, guidance and support to enable them make informed choices (Desclaux et al., 2009). Chopra and colleagues (2005) report that counseling is central to preparing mothers for making a proper informed choice about adequate feeding practices to prevent their infants from acquiring HIV infection. To help HIV-positive mothers make the best infant feeding choice, they should receive appropriate counseling that includes information about the risks and benefits of various infant feeding options based on local assessments, and guidance in selecting the most suitable option for their own situation. Counseling, information provision and support during the antenatal period is key for women to make informed choices. Postnatal follow-up is also crucial to this support, as is nutritional counseling, particularly around the period of breastfeeding cessation (WHO, 2007). According to Ehrnst and Zetterstrm (2005), the recommendations given and the way in which counseling is performed are the most important determinants of a mother's decision about how to feed her infant. Antenatal counseling needs to prepare mothers for 
common challenges during the postpartum period and especially for resisting family pressures and dealing with perceived milk insufficiency. In addition, postpartum maternal and child health services need to be structured, and health workers need to be trained to support these women after birth in maintaining their infant-feeding choice and to assist them through difficult transition periods (Dohertyet al., 2006b). Access to information and improved interpersonal communication and counseling are among many factors influencing an HIV positive mother's confidence, courage and ability to select and successfully implement the most appropriate feeding option given her own individual situation (Leshabari et al., 2007)

Lack of good quality information on infant feeding is one of the major barriers to adopting and adhering to current WHO recommendations on infant feeding and mothers with no counseling or poor quality counseling on feeding methods have an increased risk of transmitting HIV to their children (Chopra et al., 2005). Good quality pre, peri and postnatal counseling have been found to increase exclusive breastfeeding prevalence (Aidam et al., 2005).

Though studies have in different regions have documented infant feeding practices, so far no documentation has been done from Korogocho slums on challenges of acquiring knowledge on appropriate infant feeding methods hence the need for this study to establish these challenges.

\section{Awareness of HIV positive mothers on MTCT of HIV through breastfeeding}

Mother-to-child transmission (MTCT) of HIV infection remains a major public health problem and constitutes the most important cause of HIV infection in children under the age of 15 years old (UNAIDS, 2012). In 2012, 260,000 children acquired HIV infection in low and middle income countries and more than $90 \%$ of the newly HIV infected children lived in Sub-Saharan Africa, home to 92\% of pregnant women living with HIV (UNAIDS, 2013). In 2008, the adult HIV prevalence in Korogocho slums was 14\% (Wikipedia, 2013). Awareness on MTCT of HIV and knowledge of its timing usually pose a direct effect on utilization of PMTCT services (mainly HIV testing, infant feeding options and antiretroviral use (Asefa and Beyene, 2013). The objective of this study is to assess the awareness of HIV positive mothers in Korogocho slums about mother to child transmission of HIV through breastfeeding as this has not yet been documented.

\section{Challenges of exclusive breastfeeding and replacement feeding}

\section{Challenges of exclusive breastfeeding}

Breastfeeding is the norm in most cultures and is the best food for infants. It is an effective method of reducing the risk of common childhood morbidity, particularly gastrointestinal and respiratory infections, and of promoting child survival and maternal health through child spacing (WHO, 2007). The transmission of HIV through breast milk is a critical public health problem that is complicated by the fact that replacement feeding is known to lead to increased mortality risks, particularly in resource poor settings. In Africa, one third to a half of infant HIV infections are due to breastfeeding. If an HIV positive mother chooses to breastfeed, then there are several things she can do to lower the chances of her baby getting infected. The first of these is exclusive breastfeeding since studies have shown that mixed feeding substantially increases the chances of HIV transmission and death (Leroy et al., 2003; Coutsoudis et al., 2005; Iliff et al., 2005). This has indeed raised hopes that MTCT can be reduced where breastfeeding is culturally normative since breast milk provides all the fluids and nutrients that a young baby requires, so even water can and should be avoided (Suryavanshi et al., 2003). In view of these findings, it was suggested that the more strictly HIV positive mothers are able to breastfeed exclusively, the lower the risks of HIV infection and death in their infants (Iliff et al., 2005).

Though breastfeeding by HIV-positive women is a major means of HIV transmission, not breastfeeding carries significant health risks to infants and young children (UNICEF, 2012). Exclusive breastfeeding is an important component of child survival and prevention of 
mother-to-child transmission of HIV in resource-poor settings. In addition, EBF carries a 4-10 fold decreased risk of mother-to-child transmission (MTCT) of HIV compared to mixed feeding during the infant's first six months of life (Kafulafulaet al., 2013). It is a healthful behavior for HIV-exposed infants and their mothers, is helpful for birth spacing, requires minimal preparation, is not dependent upon outside materials, and breast milk does not need to be purchased. Additionally, the fact that breastfeeding is a common behavior means it is unlikely to flag the mother's HIV status (Younget al., 2011). However, current rates of EBF are well below targeted levels in both HIV-affected and unaffected populations around the world though increasing rates of EBF is one of the most powerful interventions to save child lives; the promotionof breastfeeding could prevent 13-15\% of child deaths in low-income countries (Young et al., 2011, Laar and Govender, 2013). Exclusive breastfeeding is, however rare, while early mixed feeding is common. (Becquet et al., 2005b; Coutsoudis, 2005, UNICEF, 2012). In fact, exclusive breastfeeding has been noted to be an alien concept in most African cultures, the prevailing form of breastfeeding worldwide being mixed breastfeeding. A study in Cote d'Ivoire also reported that exclusive breastfeeding was not practiced, since all women who participated in this study had given water to their children starting one day after birth (Becquet et al., 2005a). Poor breastfeeding practices are widely documented in developing countries including Kenya. For example in Kenya, only a third of children are exclusively breastfed for six months. Poor breastfeeding practices are particularly a problem in the urban slums, where most urban residents in Kenya live. According to a study by Kimani-Murage and colleagues (2013) in Korogocho only two percent of infants were exclusively breastfed for six months, hence the need for this study to determine the challenges that the mothers in Korogocho are having with exclusive breastfeeding.

\section{Challenges of exclusive replacement feeding}

Over the last several decades, the promotion of exclusive breastfeeding in resource poor settings has played a critical role in improving child health by providing optimum nutrition and protection against childhood infections (Suryavanshi et al., 2003). However, the documentation of breastfeeding as a source of HIV infection in babies born to HIV positive mothers represents a public health dilemma. The transmission of HIV through breast milk is a critical public health problem that is complicated by the fact that breastfeeding is a cultural norm and that replacement feeding is known to lead to increased mortality risks, particularly in resource poor settings (Dohertyet al, 2006a). In Africa, one third to a half of infant HIV infections are due to breastfeeding. Replacement feeding is the only $100 \%$ effective way to prevent mother-to-child transmission of HIV after birth, but the risk of infant mortality from other illnesses such as diarrhoea must be taken into account (Mnongya, 2013). As knowledge about the risk of HIV transmission through breastfeeding has reached health care workers, the general population, and individual mothers, uncertainty has developed on how best to feed infants in the context of HIV. Women who know or suspect they are HIV positive are faced with difficult and complex choices (Leshabari et al., 2006).

International guidelines on infant feeding for HIV positive mothers promote replacement feeding or exclusive breastfeeding (WHO, 2003). However, in countries where breastfeeding is the norm, formula feeding has been noted to alert a woman's family or community that she is HIV-positive, and may result in stigma or other negative repercussions (de Paoli et al., 2002). Most studies of choice of infant feeding method show that while HIV-positive women commonly make a distinct choice to exclusively breastfeed or exclusively replacement feed during pregnancy, they often end up practicing mixed feeding early in the baby's life (KonizBooher, 2004; Thairu et al., 2005).

Shapiro and colleagues in their study in Botswana where formula feeding in HIV-positive women is strongly encouraged and offered free of charge in PMTCT programmes, concluded that adherence to exclusive replacement feeding was sub-optimal and potentially over reported (Shapiro et al., 2003). A study in Zambia similarly reported that HIV positive women changed to mixed feeding very early, whether they started out with replacement 
feeding or exclusive breastfeeding (Omari et al., 2003). Similar results were reported from a study carried out in Korogocho Slum which found that mixed feeding was the norm and replacement feeding was minimally practiced among the HIV positive mothers (KimaniMurage et al., 2013). No documentation though has been done on those challenges that these mothers who opt for replacement feeding face in their day to day practice of replacement feeding, hence this study was carried out in order to help answer that.

\section{Challenges of early and abrupt cessation of breastfeeding}

The longer an HIV positive mother breastfeeds the more likely she is to infect her baby (UNICEF, 2012). For this reason, international guidelines have indicated that exclusive breastfeeding should be accompanied by early and abrupt cessation of breastfeeding. But according to a WHO consensus statement: "At six months, if replacement feeding is still not acceptable, feasible, affordable, sustainable and safe, continuation of breastfeeding with additional complementary foods is recommended, while the mother and baby continue to be regularly assessed (Thairu et al, 2005). Thus, all breastfeeding should only be discontinued as soon as it is feasible, once a nutritionally adequate and safe diet without breast milk can be provided. This should take account of the local circumstances, the individual woman's situation and the risks of replacement feeding (WHO, 2006). In order to guide health workers in assisting women to make appropriate infant feeding choices, WHO and UNICEF developed the Global Strategy for Infant and Young Child Feeding (WHO, 2003). The recommendation for women known to be HIV positive is avoidance of all breastfeeding if replacement feeding is acceptable, feasible, affordable, sustainable and safe. Otherwise exclusive breastfeeding for the first months of life is recommended, and should be discontinued as soon as it is feasible, when conditions for safe replacement feeding can be met (WHO, 2010).

Studies in Zimbabwe (Iliff et al., 2005), West Africa (Leroy et al., 2003), South Africa (Coutsoudis et al., 2001), and Tanzania (Fawzi et al., 2002) showed that more than two-thirds of all postnatal transmission occurs after the first six months of the baby's life. This provides a strong justification for supporting early breastfeeding cessation among HIV positive women. However, some studies have reported that many women have difficulty breastfeeding exclusively or weaning their children early (Coutsoudis, 2005). Although there are studies documenting successful cessation of breastfeeding, for example in the Cote d'Ivoire study (Becquet et al., 2005b), the cultural inclination toward prolonged breastfeeding patterns in sub-Saharan Africa in general makes early cessation difficult (de Paoli et al., 2001; Shapiro et al., 2003 ). Hence, several studies in diverse contexts have documented poor adherence to the recommended feeding methods (de Paoli et al., 2002; Omari et al., 2003), but there is limited evidence regarding why this is so. No documentation has been done so far concerning challenges of breastfeeding cessation among HIV positive mothers in Korogocho slums, hence the need for this study to establish the same.

\section{Methodology}

\section{Study site}

The study was carried out in Korogocho one of the largest slums in Nairobi (http://www.begakwabega.com/Korogocho-eng.html, GOK, 2009). Home to 150,000 to 200,000 people pressed into a 1.5 square kilometres, northeast of the city centre, Korogocho is an illegal settlement founded in the early eighties as a shanty town on the then outskirts of the city (GOK, 2009, http://stjohnssportssociety.weebly.com/about-us.html). Over half of the land is state property and the rest is privately owned (http://www.begakwabega.com/Korogocho-eng.html, GOK, 2009). It borders the largest dumping site in Nairobi - the Dandora dumping site - posing environmental health and security risk for the residents and surrounding settlements. With poor infrastructure, few resources, overcrowding, and proximity to the dump, health in Korogocho is poor (Wikipedia, 2013). The area has been singled out by officials because of high illegal drug and alcohol 
abuse. Like any of the other slum settlements in Nairobi, it has a large poor population with no access to minimum services, living largely in structures made out of temporary and recycled building materials - or made out of timber, mud walling, and roofing made up of substandard materials such as sacks, carton paper and polythene (http://stjohnssportssociety.weebly.com/about-us.html) There is no Proper sanitation and waste management. Water reticulation is limited and the road network is inadequate (GOK, 2009). The chief and the administration police have a permanent residence at the centre of Korogocho Village. The structures in Korogocho are very congested with an average of 5-6 persons per room and its socio-economic reality is very poor. There are no public services and the absence of the state is keenly felt. There are two city council schools with over 4,000 children and many other informal private schools which are insufficient (Wikipedia, 2013). Over $70 \%$ of the Korogocho population is less than 30 years of age and unemployment rates are high with majority of those employed working as casual workers in the formal sector industries (GOK, 2009). There are 4 health centers present in Korogocho which include Tumaini, Provide International, Vision Clinic and Kariobangi Health Centre but none operates on 24-hr basis the nearest such is Kariobangi Health Centre. There is no central sewer system and crime rates are high (http://stjohnssportssociety.weebly.com/about-us.html). With poor infrastructure, few resources, overcrowding, and proximity to the dump, health in Korogocho is poor (Wikipedia, 2013). Though the slum is supplied with water most pipes run on the surface thus risking contamination in case of leakages. Not all houses though are served by this water but some rely on water vendors or buy at some water points within the settlement (http://stjohnssportssociety.weebly.com/about-us.html). The slum is bordered to the south by Nairobi River which is heavily polluted from upstream as well as from dumping from within. There are a few communal toilets and bathrooms some of which are rundown and not functional at all and most of them are not connected to a sewer line. There are many uncovered foul drainage systems leading to mixing of clean water and foul water. Poor hygiene in the slum results to the rapid spread of typhoid, dysentery, water and air borne diseases. Sexually transmitted diseases and HIV/AIDS are also widespread. According to clinical reports from Kariobangi health centre, the leading causes of child morbidity are diarrhoeal diseases, upper and lower respiratory tract infections the commonest being pneumonia and tuberculosis (Nikolaj, 2005).

\section{Study population}

The study subjects were enrolled from a target population of 140 HIV positive postnatal mothers who had children aged between aged 6 weeks to 6 months when exclusive breastfeeding is most emphasized and enrolled in the Kariobangi Health Centre PMTCT Programme. The lower age limit of 18 years was used because they could give informed consent with the upper of 49 years being the maximum child bearing age.

\section{Inclusion criteria}

- $\quad$ Post-natal women aged 18-49 years

- Having children aged 6 weeks to 6 months

- HIV positive

- Consent to participate in the study

- Residents of Korogocho slum

- Enrolled in the Kariobangi health Centre PMTCT programme

- Mothers must be practicing exclusive breastfeeding, replacement feeding or early and abrupt cessation of breastfeeding.

\section{Exclusion criteria}

- Having children older than six months

- Unwillingness to participate in the study

- Not attending PMTCT programme 
- $\quad$ Not aged between 18 and 49 years

- HIV negative

- Not residents of Korogocho slums

- $\quad$ Practicing mixed feeding

\section{Study design}

This was a cross-sectional descriptive study design with quantitative closed-ended questions and qualitative approach with open-ended questions in primary data collection. A cross-sectional design was used because it maximized the reliability of the data collected and data was collected quickly and inexpensively compared to other research designs. In addition, the characteristics of the variables being measured could not have changed much due to the short period of data collection. Data was collected using a structured questionnaire which included basic socio-demographic indices, challenges of acquiring knowledge on appropriate infant feeding methods and challenges encountered by the exclusive breastfeeding mothers, replacement feeding mothers and those who had ceased breastfeeding early. The qualitative components of the research were FGDs which took an exploratory and descriptive approach which was useful in determining what proportion of mothers had a certain opinion. The researcher opted for this method since interaction of group members would stimulate richer responses and allow new and valuable thoughts to emerge. It also provided details that were difficult to obtain using quantitative methods. Using both methods complemented each other as qualitative methods provided in-depth information while quantitative methods provided data which answers questions (Mugenda and Mugenda, 1999)

\section{Sample size determination}

The required sample size was calculated using the Fischer at al. (1983) method for calculating sample size as quoted in Mugenda and Mugenda (1999).

Sample size $n=\left(z^{2} p q\right) / d^{2}$ where;

$\mathrm{n}=$ desired sample size

$\mathrm{z}=$ standard normal deviate at the required confidence level

$\mathrm{p}=$ is the proportion of mothers who are HIV positive. HIV prevalence among the

general population is $14 \%$ but the prevalence among women aged $18-49$ years is

undocumented. In this case, p is used as $50 \%$ to achieve the maximum sample size.

$\mathrm{q}=1-\mathrm{p}$

$\mathrm{d}=$ level of statistical significance set

Therefore at $95 \%$ confidence interval

$$
\begin{aligned}
& \mathrm{n}=\frac{\left(1.96^{2} \times 0.5 \times 0.5\right)}{0.05^{2}} \\
& =\frac{0.9604}{0.0025} \\
& \mathrm{n}=385
\end{aligned}
$$

Since the population was below 10,000 the adjusted sample size (nf) will be;

$\mathrm{nf}=\mathrm{Nn} / \mathrm{N}+\mathrm{n}$ where;

$\mathrm{nf}=$ desired sample size when population is less than 10,000

$\mathrm{n}=$ desired sample size when population is more than 10,000

$\mathrm{N}=$ estimate of the population size

Therefore at 95\% confidence interval

$$
\begin{aligned}
& =\underline{385 \times 140} \\
& =\frac{53900}{525} \\
\text { nf } & =103
\end{aligned}
$$

The sample size was calculated to be103 using the above formula. 
Texila International Journal of Public Health

Volume 4, Issue 4, Dec 2016

\section{Data collection tools}

For this study pre-tested structured questionnaires and focus group discussion guides were used for data collection. The tools were designed after an in-depth literature review and according to the objectives of the study. The questionnaire consisted of questions regarding socio-demographic profile of the mothers, challenges encountered by the HIV positive mothers in acquiring information on the appropriate infant feeding methods, challenges of exclusive breastfeeding, replacement feeding and early and abrupt cessation of breastfeeding. A focus group discussion guide was also developed to gain more insight into the mothers' infant feeding challenges. The focus group discussion guide consisted of questions that covered the same topics as the questionnaire.

\section{Recruitment and training of research assistants}

Four research assistants were trained from Kariobangi Health Centre. Training was on the aims and objectives of the study and the data collection tools. They were trained on how to conduct interviews and focus group discussions.

\section{Pre-testing of questionnaires}

This was used to refine the questionnaire design and identify errors which may only be apparent to the population concerned for example the meaning of words. The pre-test sample was similar to the trial group and took place in conditions similar to those of the actual questionnaire administration. This questionnaire was pilot tested with ten mothers who were not included in the study.

\section{Sampling techniques}

The study site was purposively selected because it is a slum whose inhabitants are poor, majority of the population are young, and it had a high HIV prevalence of HIV. Thereafter, simple random sampling was used to select the actual participants. Simple random sampling is a one stage probability sampling procedure in which members of a population are selected one at a time without a chance of being selected again until the desired sample size is obtained (Mugenda and Mugenda, 1999). Simple random sampling was considered adequate as each mother had a chance of being selected. Sampling was done by numbering all 140 target mothers using a table of random numbers. The starting point in the table was determined by randomly picking a page and dropping a finger on the page with eyes closed. The numbers were chosen up and down till all the 103 required sample size was obtained. Once a number was chosen it was not chosen again. A list of mothers was obtained from the clinic records. Mothers who attended the support group on Tuesdays and consented also participated in the FGDs.

\section{Data collection}

Focus group discussions (FGD'S) guides and structured questionnaires were used for data collection of the sampled respondents who gave consent. Four research assistants assisted in collecting the data. The interviews were conducted in Kiswahili since some respondents could not understand English. Three FGDs were conducted and the groups were chosen from the HIV positive mothers who were enrolled in the Kariobangi Health Centre PMTCT programme, registered with the support group and had infants aged between aged 6 weeks to 6 months. Each FGD consisted of 8 mothers, a note taker, a facilitator and the researcher. The focus group discussions were done on consecutive Tuesday afternoons when the mothers attended the support group. Eight mothers per group sat around a table with the researcher, a facilitator, and a note taker. The focus group discussion started with an introduction of the facilitator, the researcher, the note taker, the participants, the procedures during the discussion and an ice- breaker question to put participants at ease. The discussion topics included questions about the challenges of acquiring knowledge on appropriate infant feeding methods, and challenges faced by HIV positive mothers who practiced exclusive breastfeeding, 
exclusive replacement feeding and early cessation of breastfeeding. The facilitator translated the focus group questions to the respondents. The focus group discussions were recorded in a written format as well as on tape and the correctness of responses was checked and confirmed immediately after the discussions. Each focus group discussion lasted for approximately one and half hours. The questionnaires were filled while the mothers were in the post natal clinic and the researcher was present during the interviews. To ensure reliability, the researcher supervised all aspects of data collection and checked questionnaires for correctness and completeness immediately after completion.

\section{Data analysis and presentation}

Data analysis for the focus group discussions was conducted manually without use of a software program. Immediately after the discussion, all audio taped interviews were transcribed verbatim, and translated into English. These transcriptions and the notes from the note taker were reviewed and double-checked for consistency and accuracy by the researcher, facilitator and note taker. Transcripts of the discussions were made anonymous by using participant codes. Data analysis followed the thematic content method, which involved identifying key categories and recurrent themes concerning infant feeding challenges. Three members of the research team (the facilitator, note taker and the researcher) reviewed the transcripts several times to become familiar with the content before the process of sorting, coding, and theme identification. Themes were developed independently again based on an inductive and deductive process of issues that emerged from the interviews by combining units of meaning relevant to the open- ended questions. These independently identified themes were subsequently compared before deciding on which to report on. A final list of themes was derived and applied to the data. The main discussion topics were, challenges of acquiring knowledge on appropriate infant feeding methods, challenges of exclusive breastfeeding, replacement feeding end early and abrupt cessation of breastfeeding. The main themes that emerged were: poor knowledge of the mothers on appropriate infant feeding methods, the high cost of infant formula by replacement feeding mothers hence its unaffordability, inability of the mothers to control the feeding due to the influence of the extended family and inability to produce sufficient milk for exclusively breastfeeding mothers. The major findings of the focus group discussions were summarized in a narrative report and key statements were listed according to topics. In presenting the data, relevant verbatim quotes were reported to aid in the interpretation of the data.

Information obtained from the completed questionnaires was cleaned, coded, entered and analyzed using SPSS version 16 computer software. Quantitative data was analyzed using descriptive statistics. Statistical procedures carried out included frequency distributions, percentages, means, and standard deviation to summarize observed variables. The results were presented using tables and textual summaries.

\section{Ethical considerations}

The study proposal was approved by the School of Graduate Studies Maseno University. Permission to conduct the study in Kariobangi health Centre was sought from the District Medical Officer of Health (DMOH) Nairobi North. Informed consent was obtained individually from each of the participants before being participating in the study. This was to ensure that participation was purely on a voluntary basis. Respondents were assured of confidentiality as serial numbers and not names were used to hide their identity.

\section{Limitations of the study}

The main limitation of the study was that the population studied represented Korogocho slums in which case the study may not be generalized to all HIV mothers outside Korogocho slums. 
Texila International Journal of Public Health

Volume 4, Issue 4, Dec 2016

\section{Results}

This chapter presents the results of the data obtained from the study on infant feeding challenges encountered by HIV positive mothers in Korogocho slums.

\section{Socio-demographic and economic characteristics of the study respondents}

Table 4.1 gives the socio-demographic and economic characteristics of the study respondents. The respondents' ages ranged from 18 to 37 years, with mean age of 25.3 years and a standard deviation of 4.93. The age of the infants ranged from six weeks to six months with a mean of 3.9 months and a standard deviation of 1.5. Most of the mothers 82(79.6\%) had more than one child with 21(20.4\%), 41(39.8\%), 27(26.2\%), 7(6.9\%), 6(5.8\%) and $1(0.9 \%)$ having one, two, three, four, five and eight children respectively. The number of children ranged from one to eight, with a mean number of 2.4. Many of the mothers 70(68\%) were married while 33(32\%) were single. Majority of the mothers 84(81.6\%) either had no formal education at all $13(12.6 \%)$ or had only primary education71 $(69.0 \%)$ while $17(16.5 \%)$ had secondary education and 2(1.9\%) had tertiary education. Many respondents 52(50.5\%) were housewives, 28(27.2\%) did business and 20(19.4\%) were casual workers. Only 3(2.9\%) were in formal employment. Slightly more than half of the respondents 52(50.5\%) earned no income at all, 32(31.1\%) had a monthly income below two thousand shillings, 12(11.7\%) earned an income ranging from 2001 to 4000, 3(2.9\%) from 4001 to 6000 and 4(3.9\%) had an income ranging from 6001 to 8000 . For many respondents 53(51.5\%), husbands/ boyfriends were the main financial providers and decision makers far as use of available income was concerned followed by the mothers themselves 25(24.3\%), both husband and wife 19(18.4\%) and parents 6(5.8\%). Many 67(65.0\%) of the mothers resided in shacks, 29(28.2\%) in stone houses and 7(6.8\%) in prefabricated houses. Though a safe water supply is essential if artificial infant feeding is given to a baby only $9(8.7 \%)$ of the respondents had running water in their dwelling, 44(42.7\%) obtained water by buying, 32(31.1\%) from a tap outside their residence and $18(17.5 \%)$ used a communal tap. Only $26(25.2 \%)$ of the respondents always boiled their drinking water, whereas 36(34.9\%) added water guard and $41(39.8 \%)$ never treated their water. Many respondents 55(53.4\%) had no toilet with only 48(46.6\%) having a toilet at their place of residence. Majority $80(78 \%)$ of the respondents did not have electricity in their houses and their household waste was either dumped into a river 58(56.2\%) or disposed of in a communal waste dump 45(43.8\%).

Table 4.1 The study respondents' socio-demographic and economic characteristics

\begin{tabular}{|l|l|}
\hline Number of children & Number and percentage of respondents \\
\hline 1 & $21(20.4 \%)$ \\
\hline 2 & $41(39.8 \%)$ \\
\hline 3 & $27(26.2 \%)$ \\
\hline 4 & $7(6.9 \%)$ \\
\hline 5 & $6(5.8 \%)$ \\
\hline 8 & $1(0.9 \%)$ \\
\hline Level of education & \\
\hline None & $13(12.6 \%)$ \\
\hline Primary & $71(69.0 \%)$ \\
\hline Secondary & $17(16.5 \%)$ \\
\hline Tertiary & $2(1.9 \%)$ \\
\hline Occupation & \\
\hline Housewife & $52(50.5 \%)$ \\
\hline Business & $28(27.2 \%)$ \\
\hline Casual worker & $20(19.4 \%)$ \\
\hline Formal employment & $3(2.9 \%)$ \\
\hline Income (Kshs) & \\
\hline
\end{tabular}




\begin{tabular}{|l|l|}
\hline 0 & $52(50.5 \%)$ \\
\hline Less than 2000 & $32(31.1 \%)$ \\
\hline $2001-4000$ & $12(11.7 \%)$ \\
\hline $4001-6000$ & $3(2.9 \%)$ \\
\hline $6001-8000$ & $4(3.9 \%)$ \\
\hline Residential Houses & \\
\hline Shacks & $67(65.0 \%)$ \\
\hline Stone & $29(28.2 \%)$ \\
\hline Prefabricated & $7(6.8 \%)$ \\
\hline Sources of drinking water & \\
\hline Buys from vendor & $44(42.7 \%)$ \\
\hline Tap outside house & $32(31.1 \%)$ \\
\hline Communal tap & $18(17.5 \%)$ \\
\hline Tap in house & $9(8.7 \%)$ \\
\hline Human waste & \\
\hline Toilet absent & $55(53.4 \%)$ \\
\hline Toilet present & $48(46.6 \%)$ \\
\hline Household waste disposal & \\
\hline Dumped in river & $58(56.2 \%)$ \\
\hline Communal waste dump & $45(43.8 \%)$ \\
\hline
\end{tabular}

\subsection{Challenges of acquiring knowledge on appropriate infant feeding methods}

Table 4.2 Time of HIV test and areas of infant feeding counseling

\begin{tabular}{|l|l|}
\hline & Number and percentage of respondents \\
\hline Time of HIV test & \\
\hline During pregnancy & $90(87.4 \%)$ \\
\hline Before pregnancy & $13(12.6 \%)$ \\
\hline Area of counseling & \\
\hline Breastfeeding & $56(54.4) \%$ \\
\hline Replacement feeding & $55(53.4) \%$ \\
\hline Home hygiene & $8(7.8 \%)$ \\
\hline Early cessation of breastfeeding & $7(6.8 \%)$ \\
\hline Maternal nutrition & $2(1.9 \%)$ \\
\hline Feeding after breastfeeding cessation & $0(0 \%)$ \\
\hline Breast care & $0(0 \%)$ \\
\hline Good breastfeeding techniques & $0(0 \%)$ \\
\hline
\end{tabular}

Note: Numbers expressed are actual respondents. There were 103 respondents to all of the above factors.

Majority of the mothers 100 (97.1\%) reported having attended antenatal clinic. However, only 42(40.8\%) attended more than three times, with 16(15.5\%) attending only once, 25(24.3 \%) twice and $17(16.5 \%)$ thrice. Most $90(87.4 .1 \%)$ of the mothers reported having had their HIV test during pregnancy with only 13(12.6\%) having it before pregnancy. Table 4.2 gives the areas of income feeding counseling. Slightly more than half 56(54.4\%) of the mothers reported having been advised on breastfeeding, 55(53.4\%) on replacement feeding, 8(7.8\%) on home hygiene, 7(6.8\%) early cessation of breastfeeding and 2 (1.9\%) on maternal nutrition during breastfeeding. However, none received any counseling on feeding after breastfeeding cessation, maternal nutrition during breastfeeding or good breastfeeding techniques. Many mothers 57(55.3\%) said that they never fully understood the infant feeding counseling giving various reasons for not understanding with 40(38.8\%) saying they received the counseling immediately after obtaining their HIV positive results, 23(22.3\%) the sessions were too short, $12(11.7 \%)$ sessions were too few and $9(8.7 \%)$ the counselor was unfriendly. 


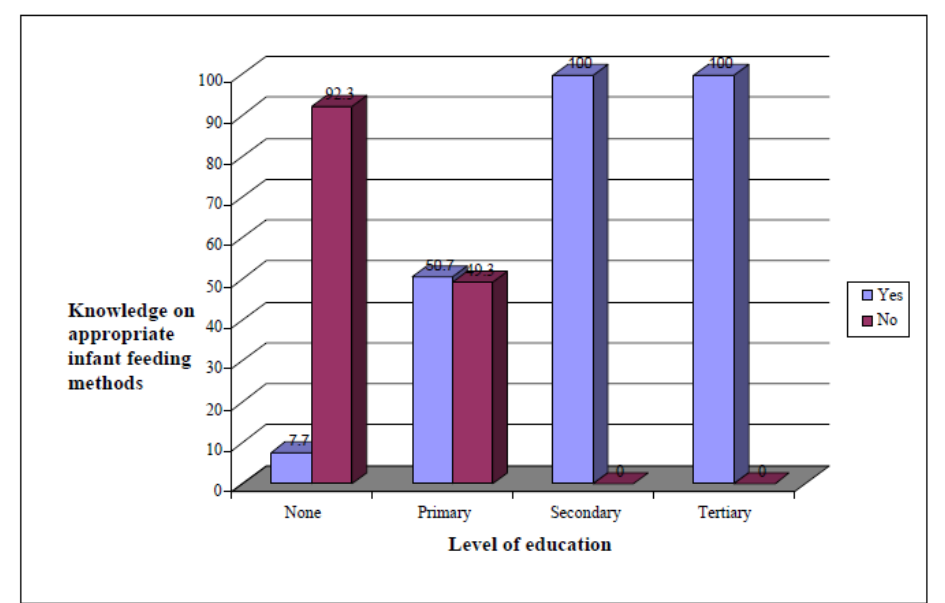

Figure 4.1 Association between respondent's level of education and knowledge on appropriate infant feeding methods

A mother's educational level seemed to have an influence on her understanding of infant feeding counseling as this understanding was higher among mothers with secondary/tertiary education as compared to those with none or only primary education (Figure 4.1).

Clinic attendance by the mothers had a direct influence on a mothers' knowledge on appropriate infant feeding methods. Mothers who attended more antenatal clinic visits had better knowledge on appropriate infant feeding methods compared to those with fewer visits (Figu4.2).

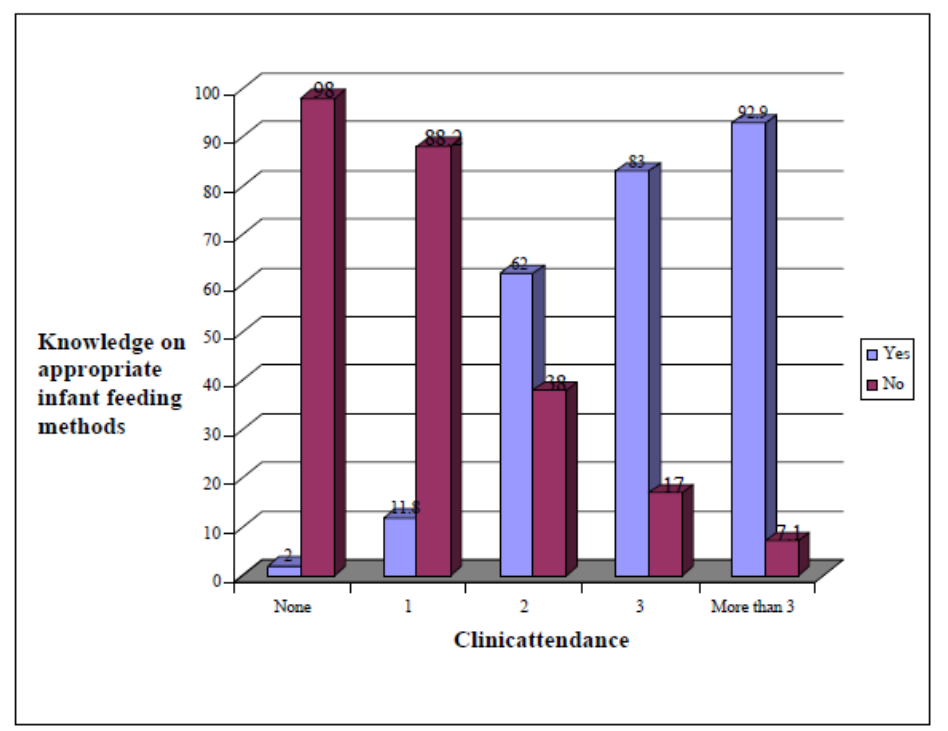

Figure 4.2 Association between mothers' number of clinic attendance and knowledge on appropriate infant feeding methods

These differences in understanding could be due to the fact that mothers with better education tended to attend clinic more times compared to those with less education. Also owing to the fact that they were better educated, they were probably at a better position to easily understand the counseling.

\section{Awareness of the mothers on MTCT of HIV through breastfeeding}

The mothers' awareness of MTCT of HIV was generally good among the study participants though some mothers had no idea at all about MTCT timing and prevention. Most mothers 80 (77.7\%) knew that HIV could be transmitted from mother to child. Knowledge of timing of MTCT was also quite high as 46 (44.7\%) knew it could be transmitted during pregnancy, 60 (58.3\%) during delivery and 63 (61.2\%) reported that HIV could be 
transmitted during breastfeeding. The mothers' knowledge on prevention of MTCT was also high as 56 (54.3\%) of the mothers knew it could be prevented through use of short course ARV drugs, 62(60.2\%) through exclusive breastfeeding, 60(58.3\%) through replacement feeding and 54(52.4\%) through early cessation of breastfeeding (Table 4.4). Though his knowledge was good, a number of mothers totally lacked knowledge on transmission during pregnancy 23(22.3\%), during delivery 26 (25.2\%) and during breastfeeding 25 (24.3\%) and also on prevention through exclusive breastfeeding13 (12.6\%), replacement feeding24 (23.3\%) and early and abrupt cessation of breastfeeding15 (14.6\%).

Table4.3 Mothers awareness on timing and prevention of MTCT (multiple responses)

\begin{tabular}{|l|c|c|c|}
\hline \multirow{2}{*}{ MTCT Timing } & \multicolumn{3}{|c|}{ Number (\%) of Respondents (N=103) } \\
\cline { 2 - 4 } & Yes & No & Don’t know \\
\hline During pregnancy & $46(44.7 \%)$ & $34(33 \%)$ & $23(22.3 \%)$ \\
\hline During delivery & $60(58.3 \%)$ & $17(16.5 \%)$ & $26(25.2 \%)$ \\
\hline During breastfeeding & $63(61.2 \%)$ & $15(14.6 \%)$ & $25(24.3 \%)$ \\
\hline MTCT prevention & & & \\
\hline Use of short course ARV drugs & $56(54.3 \%)$ & $23(22.3 \%$ & $24(23.3 \%)$ \\
\hline Exclusive breastfeeding & $62(60.2 \%)$ & $28(27.2 \%$ & $13(12.6 \%)$ \\
\hline Replacement feeding & $60(58.3 \%)$ & $19(18.4 \%$ & $24(23.3 \%)$ \\
\hline Early cessation of breastfeeding & $54(52.4 \%)$ & $34(33 \%$ & $15(14.6 \%)$ \\
\hline
\end{tabular}

A mother's education had a direct influence on her awareness on mother to child transmission of HIV through breastfeeding. The higher the mother's educational level, the better her awareness on mother to child transmission of HIV through breastfeeding. Awareness on MTCT of HIV was generally higher among the mothers with some secondary or tertiary education compared to those without any education at all or with only primary education (Figure 4.3).

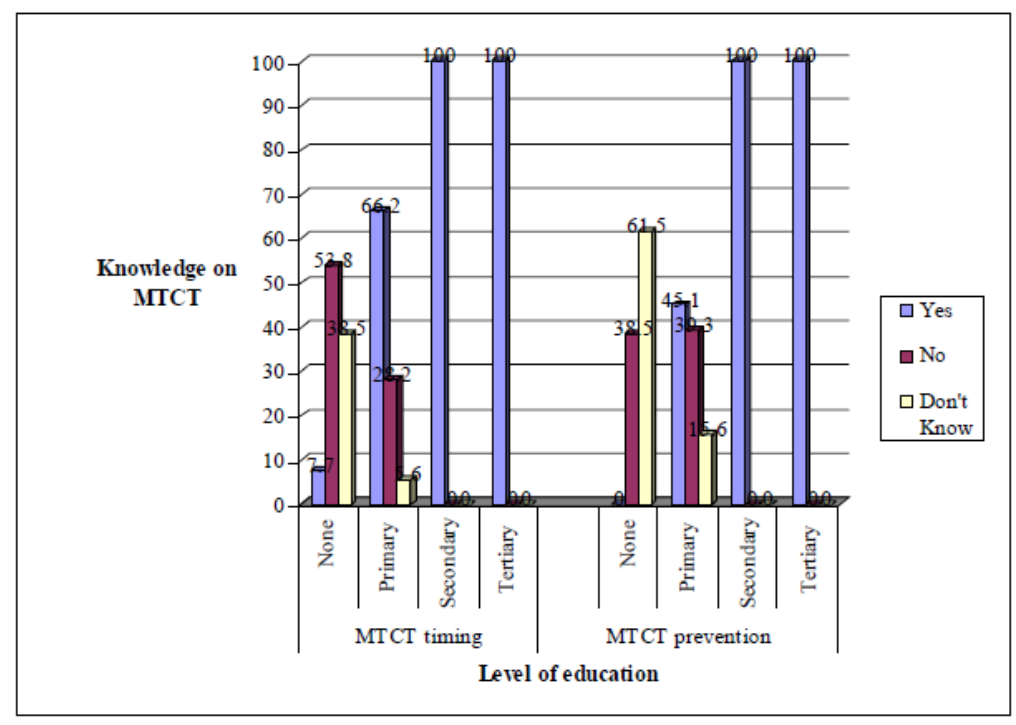

Figure 4.3 Association between respondent's level of education and knowledge on MTCT timing and prevention

Key: Yes-Mothers know that HIV can be transmitted from mother to child

No- Mothers know that HIV can't be transmitted from mother to child 
Texila International Journal of Public Health

Volume 4, Issue 4, Dec 2016

Don't know-These mothers don't know whether HIV can be transmitted from a mother to a child or not.

Antenatal clinic attendance was another major influence on a mother's awareness on mother to child transmission of HIV through breastfeeding. The higher the number of antenatal clinic visits, the better the awareness on mother to child transmission of HIV through breastfeeding (Figure 4.4).

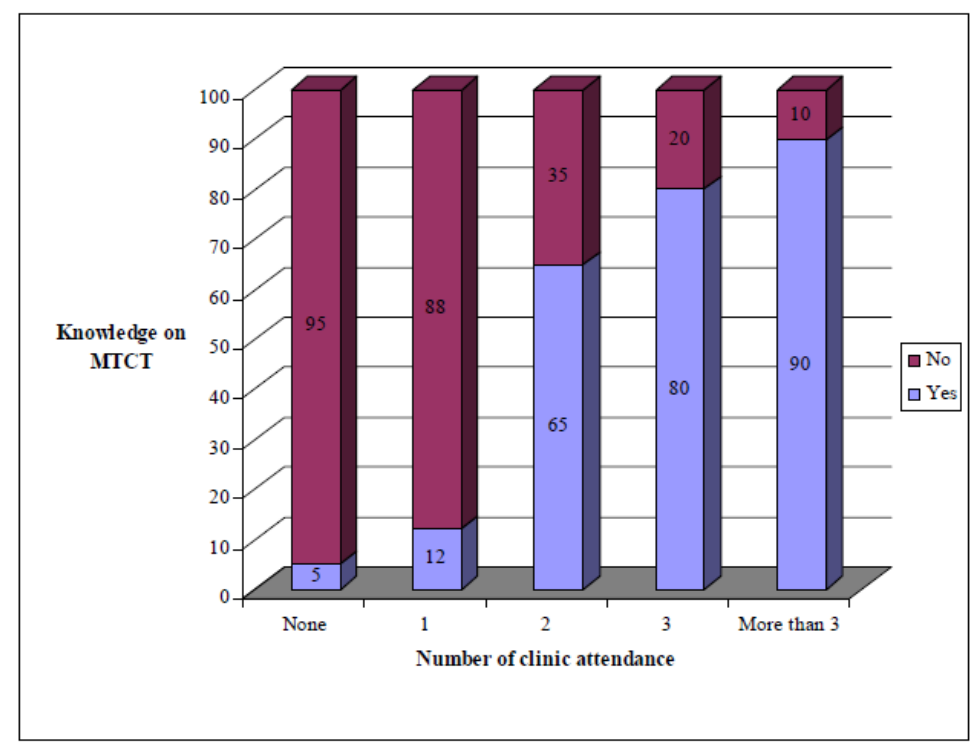

Figure 4.4 Association between mothers’ number of clinic attendance and knowledge on MTCT timing and prevention

Key

Yes -Mothers have knowledge on MTCT

No-Mothers have no knowledge on MTCT

\section{Challenges of exclusive breastfeeding and replacement feeding}

\section{Challenges of exclusive breastfeeding}

Table 4.2 gives the challenges encountered by the breastfeeding mothers. For majority of the breastfeeding mothers (29(56.9\%), failure to produce enough milk was reported as the greatest challenge.

"If you ask a mother to breastfeed exclusively, she will ask you how she will do it and yet she hasn't eaten. So even if you tell her to breastfeed, first of all that milk is not there because there is no food for to her to eat in the first place." (FGD, participant)

"Some of us don't have enough food to produce sufficient breast milk for the babies after two to three months. It is thus very hard to maintain exclusive breastfeeding of a baby at that age."(FGD, breastfeeding mothers)

Controlling the feeding was another major concern among 9(17.6\%) of the breastfeeding mothers because of the influence of other family members and some expressed fears of raising suspicion of HIV positive status $4(7.8 \%)$.

"In as much as one tries to breastfeed exclusively, there is this issue of relatives who want to give the baby other foods because they feel breast milk is not enough for the baby after the first few weeks. How can you stop them and what reason can you give them for not allowing other foods?" (FGD, breastfeeding mother).

Some mothers $6(11.8 \%)$ too expressed concerns over the difficulties in maintaining exclusive breastfeeding because they had to go to work and so could not sustain exclusive breastfeeding 
"Sometimes it quite difficult to stay at home to take care of the baby because one must go to work so as to get your daily bread. If you just stay at home, how are you going to get food? Aren't you going to die of hunger?"(FGD, participant)

"We encounter so many problems. A mother cannot sit, caring for the young baby when she has other children to take care of. The other children will suffer. She has to go out and hustle for what they will eat. In this case she will stop to breastfeed since she cannot carry the baby to work. It is not our wish. It is just the way the situation is here in Korogocho." (FGD, participant)

For other mothers, infections in the baby's mouth 23(45.1\%) and breast infections 19(37.3\%) were great challenges that made their breastfeeding experiences difficult.

Table 4.4.1 Mothers' challenges with exclusive breastfeeding

\begin{tabular}{|l|l|l|}
\hline Exclusive breastfeeding & Frequency & Percent \\
\hline Failure to produce enough milk & 29 & 56.9 \\
\hline Infections in the baby's mouth & 23 & 45.1 \\
\hline Breast infections & 19 & 37.3 \\
\hline Inability to control the feeding & 9 & 17.6 \\
\hline Had to go work & 6 & 11.8 \\
\hline $\begin{array}{l}\text { Fears of raising suspicion of HIV positive } \\
\text { status }\end{array}$ & 4 & 7.8 \\
\hline
\end{tabular}

\subsubsection{Challenges of replacement feeding}

Table 4.4.2 Mothers' challenges with replacement feeding

\begin{tabular}{|l|l|l|}
\hline Replacement feeding & Frequency & Percent \\
\hline Feelings of guilty & 33 & 94.3 \\
\hline Could not afford replacement foods & 26 & 74.3 \\
\hline $\begin{array}{l}\text { Criticism from family, friends and } \\
\text { neighbours }\end{array}$ & 19 & 54.3 \\
\hline Accusations of promiscuity & 18 & 51.4 \\
\hline $\begin{array}{l}\text { Lack of fuel for replacement food } \\
\text { preparation }\end{array}$ & 17 & 48.6 \\
\hline Problems with replacement food preparation & 12 & 34.3 \\
\hline $\begin{array}{l}\text { Lack clean water for replacement food } \\
\text { preparation }\end{array}$ & 3 & 8.6 \\
\hline
\end{tabular}

Note: Mothers gave multiple responses. 35 mothers responded to questions on replacement feeding

Table 4.4 gives the challenges encountered by replacement feeding mothers. The most commonly expressed concern by the replacement feeding mothers was feelings of guilt for not breastfeeding that was reported by 33(94.3\%) of the mothers.

"Whenever you see other mothers breastfeeding their babies, you feel so guilty for not breastfeeding yours. Actually you always keep blaming yourself for all this especially when the baby is crying." (FGD participant, replacement feeding mother).

"I hate seeing my baby crying especially now that I can't soothe him with the breast. This makes me feel like I have neglected him and yet there is nothing I can do about it. I really hate myself for the whole thing. I actually don't know what to do."(FGD participant)

"My baby is not close to me at all because even when I leave her with someone, she never cries. She is actually not attached to me and this really hurts me." (FGD participant)

"My baby cries a lot and it is not easy to soothe him without the breast. I wish I could also breastfeed him as other mothers do. But now with this problem of mine, I don't even know what to do. It really makes me feel bad."(FGD, participant)

The various reasons given for feeling guilty were that they felt; they had neglected their babies14 (40.0\%), their babies were not close enough to them 21(60.0\%), they were to blame 
Texila International Journal of Public Health

Volume 4, Issue 4, Dec 2016

for being HIV positive 13(37.4\%), their babies were not healthy enough 8(22.9\%) and their babies cried a lot 22(62.9\%).

Inability to afford replacement food26(74.3\%), lack of fuel for replacement food preparation 17(48.6\%), problems with replacement food preparation12 (34.3\%) and lack of clean water for replacement food preparation $3(8.6 \%)$ were other major challenges among these mothers.

"It is really hard for most families to afford their own meals. But it is even harder to afford replacement food for the baby leave alone buying formula or milk until the baby is six months of age?"(FGD participant, replacement feeding mother)

Due to the high cost of infant formula, most replacement feeding mothers expressed that it was simply too hard for them to buy the amount of commercial infant formula necessary to feed their infants in a safe way with replacement foods. As a result, most of them 17(48.6\%) used milk from milk vendors, 15(42.9\%) used packet milk from the shops and only 3(8.6\%) used commercial infant formula whose supply was not sustainable. None of the mothers used powdered milk.

Criticism from family, friends and neighbours19 (54.3\%) and accusations of promiscuity 18(51.4\%) was also a commonly expressed concern among these mothers. Majority 23(65.7\%) of the replacement feeding mothers lacked support as family/friends were not in favor of them replacement feeding as only $12(34.3 \%)$ of the respondents had family /friends support.

\section{Challenges of early and abrupt cessation of breastfeeding}

Table 4.5 Mothers' challenges with early and abrupt cessation of breastfeeding

\begin{tabular}{|l|l|}
\hline Early and abrupt cessation of breastfeeding & $\begin{array}{l}\text { Number (\%) of respondents } \\
\text { N=17 }\end{array}$ \\
\hline $\begin{array}{l}\text { Lacked knowledge on replacement foods to } \\
\text { give }\end{array}$ & $15(88.2 \%)$ \\
\hline Lacked replacement foods to give & $13(76.5 \%)$ \\
\hline Had breast problems & $11(64.7 \%)$ \\
\hline Criticized by/ & \\
\hline Neighbours & $9(52.9 \%)$ \\
\hline Family members & $8(47.1 \%)$ \\
\hline Friends & $3(17.6 \%)$ \\
\hline
\end{tabular}

In this study, 17 (16.5\%) mothers had ceased breastfeeding early. Almost all these mothers 15(88.2\%) reported that they had not been given any advice on feeding after breastfeeding cessation and yet more than half of them $10(58.8 \%)$ had been advised to do so by the health workers.

"These nurses just tell you to stop breastfeeding but they are never concerned about how you feed your infant after that. You are just left to struggle alone and the way everything is expensive these days." (FGD, participant)

Some of these mothers therefore lacked sufficient replacement foods, knowledge on the proper replacement foods to give, and their preparation.

"Ever since I stopped breastfeeding my baby, his health has been deteriorating. I don't know which food to give him. How I wish I could get someone to advise me on what to feed him on." (FGD participant)

Criticism was a major concern for the mothers as $8(47.1 \%)$ were criticized by their family members about their decision to cease breastfeeding early, $3(17.6 \%)$ by their friends and $9(52.9 \%)$ by their neighbours. Breast problems were experienced by $11(64.7 \%)$ of the mothers. None of the mothers however knew how to handle these +problems.

"This issue of breastfeeding cessation is not as easy as I thought. My husband and other family members keep asking me why I stopped breastfeeding the baby but I have no answer to 
give them. It is such a problem to me and I really don't know how to go about it." (FGD, participant)

\section{Discussion}

This study has shown that HIV positive mothers in Korogocho slums are faced with multiple infant feeding challenges that makes it difficult for them to effectively follow the WHO guidelines on infant feeding.

\section{Challenges of acquiring knowledge on appropriate infant feeding methods}

Counseling HIV positive mothers so that they can make informed choices on safer infant feeding options is an important component of national programmes to prevent MTCT of HIV (WHO, 2003). Mothers need to know about the feeding options in order to assist them make better decisions on how best they can feed their infants (Desclaux et al., 2009). Findings from this study show that the knowledge of the mothers on appropriate infant feeding methods was inadequate for up to 74 (71.8\%) mothers reported that they never fully understood the infant feeding counseling. The greatest challenge to acquiring this knowledge was time of infant feeding counseling. Up to 40(38.8\%) mothers reported that their poor understanding of the counseling was because they received the counseling immediately after obtaining their HIV positive results. Leshabari and colleagues (2006) in their study in Tanzania reported similar results where the involved mothers reported that they did not feel adequately informed about HIV infant feeding and that the information was often given on the same day that they received their HIV test results. They found that mothers who chose replacement feeding after being counseled expressed uncertainty about preparing the formula or cow's milk. None received written instructions to take home. Poor antenatal clinic attendance among mothers in the current study was another major barrier to the acquisition of knowledge on appropriate infant feeding methods as this made their sessions too few 12 (11.7\%) and too short 23 (22.3\%). Inadequate infant feeding knowledge was also reported by De Paoli and colleagues (2004) in their qualitative study in Moshi, Kilimanjaro region investigating counselors' infant feeding advice to HIV-positive women. This study reported that infant feeding options were not accurately explained and that informed choice of infant feeding method, as recommended in the guidelines, was seriously compromised by inadequate information. Other studies in South Africa (Chopra et al., 2005, Shah et al., 2005), Brazil (Rea et al., 2007) also reported inadequate infant feeding knowledge among HIV positive mothers. In a study in South Africa more than half of the mothers interviewed said they never got information about infant feeding at antenatal clinic. In yet another study, it was found out that women did not understand what exclusive breastfeeding meant (Bland et al., 2002).

On the contrary, a study by Laar and Govender (2013) which evaluated HIV-positive women's knowledge following infant feeding counseling showed that the women demonstrated a good understanding of HIV transmission through breastfeeding and recommended infant feeding options. Another study conducted in Zambia which assessed the knowledge and understanding of HIV-positive mothers who had received pre and post-test HIV counseling of the WHO recommended infant feeding guideline reported that 35 percent of the women surveyed, understood the risk of transmission of HIV through breastfeeding (Aika, 2003). Another study conducted in Harare, Zimbabwe demonstrated that women's knowledge of HIV and infant feeding options had improved with increased exposure to counseling. Moreover, counseled mothers were 8.4 times more likely to uptake EBF than the mothers who were not exposed to counseling (Piwoz, 2005).

\section{Mothers awareness of MTCT through breastfeeding}

Most mothers in this study knew that HIV could be transmitted from HIV positive mothers to their children during pregnancy, delivery and breastfeeding. They also knew that MTCT could be prevented through exclusive breastfeeding, replacement feeding and early and abrupt cessation of breastfeeding. However about half of the mothers were not aware of the 
Texila International Journal of Public Health

Volume 4, Issue 4, Dec 2016

association between breastfeeding and HIV transmission and ways of preventing this transmission. Similar results were reported by Asefa and Beyene, (2013) who found that only $48.4 \%, 58.6 \%$ and $40.7 \%$ of the respondents knew of the possibility of MTCT during pregnancy, delivery and breastfeeding respectively. Contrasting results were however reported by Haddis and Jerene (2006) in their study in Ethiopia where they reported good knowledge of the mothers on the risk of transmission of HIV, peri-natally and through breastfeeding.

\section{Challenges of exclusive breastfeeding and replacement feeding}

\section{Challenges of exclusive breastfeeding}

The main difficulties reported by the breast-feeding mothers were, failure to produce enough milk, infections in the baby's mouth, breast infections, inability to control the feeding, the mothers had to go to work and fears of raising suspicion on their HIV positive status. Similar results were reported in a study in Malawi (Bezner-Kerr et al., 2007) which found that a major barrier in practicing exclusive breast-feeding was the perception of insufficient milk production as women sometimes doubted the feasibility of exclusive breastfeeding and were not convinced that a baby can grow healthy until the age of six months on breast milk alone. In Tanzania, HIV-positive mothers who were not able to do exclusive breast-feeding continued mix feeding since they believed their milk was not enough to make the baby grow 'fat and shiny' as expected by kin and neighbors (Leshabari etal., 2006). Arts and colleagues (2011) in their study in Mozambique found that Health care personnel had insufficient skills to offer remedies to deal with problems such as painful or cracked nipples, inflammation or perceived insufficient production of milk. Inability to control the feeding due to the influence of the extended family was also reported by $17 \%$ of the breastfeeding mothers in this study. A study which investigated infant feeding choices and experiences of HIV-positive mothers from two Ghanaian Districts, found social pressure and local norms as factors that influenced mothers' decisions to mix feed their children (Laar and Govender, 2013). A study Malawi gave similar results which showed that that babies' fathers and grandmothers were particularly influential regarding infant feeding and mixed feeding was found to begin within the first 48 hours after birth as advised by paternal grandmothers who are perceived to be key decision makers when it comes to good parenting (Bezner-Kerr et al., 2007). In a qualitative study in South Africa which examined infant feeding decision making and practices among HIV-positive women, it was found that key characteristics of women who achieved success in exclusivity (either in their breastfeeding or formula feeding) included the ability to resist pressure from the family to introduce other fluids and to recall key messages on MTCT risks and mixed feeding (Doherty et al., 2006b). Similarly, Omari and colleagues in their study in Zambia reported that HIV-positive women changed to mixed feeding although having started out with ERF. Once again, reasons included socio-cultural and expectations of family members (partners and mothers-in-law, extended families) and community members (Omari et al., 2003).

\section{Challenges of exclusive replacement feeding}

The challenges reported by the replacement feeding mothers were feelings of guilt, inability to afford replacement foods, criticism from family, friends and neighbours, accusations of promiscuity, lack of fuel for replacement food preparation, problems with replacement food preparation, lack clean water for replacement food preparation. Most mothers found it difficult to maintain replacement feeding because of the cost involved in maintaining it. Several studies have shown cost of replacement feeding as a major barrier to replacement feeding. A study in Kilimanjaro (Tanzania) on recommended replacement infant feeding options, reported that women considered formula as unaffordable but if the formula was distributed free of charge, the majority of them (82 percent) would choose this option (Laar and Govender, 2013). In a study in Uganda, it was reported that HIV-positive mothers started breastfeeding their babies once UNICEF stopped donating free infant formula, 
suggesting issues of cost (affordability) influencing their shift (Wendo, 2003). Similarly in South Africa, HIV-positive women opted for replacement feeding when formula milk was provided free. Moreover, women of lower socio-economic status found it difficult to continue formula feeding when there was an interruption in the supply of free formula (Doherty et al., 2006 b). Similar results were reported from Kenya

(Kiarie et al., 2004) and Nigeria (Sadoh et al., 2008). Besides the cost of formula, other socio-economic considerations including access to clean water and fuel for replacement food preparation, problems with replacement food preparation, electricity, and other infrastructure necessary for the safe and hygienic preparation of formula milk were reported by the mothers in this study. In the study in Nigeria, poor access to clean water for the preparation of formula milk was an important barrier to replacement feeding (Sadohet al., 2008). In South Africa, it was found that women who possessed a kettle, flask and electricity found it easier to feed their infants with formula milk during the night (Dohertyet al., 2006 a). Still in South Africa, in the province of KwaZulu Natal, it was reported that women who intended to use replacement feeding were more likely to have access to clean water and a regular income (Bland et al., 2002).

\section{Challenges of early and abrupt cessation of breastfeeding}

The longer an HIV positive mother breastfeeds the more likely she is to infect her baby. Up to $17(16.5 \%)$ of mothers in this study had ceased breastfeeding early. Among the mothers who had ceased breastfeeding early 15(88.2\%) said their main concern was lack of advice on how to feed their infants after breastfeeding cessation and yet most of them had been advised to do so by the health workers. Some of these mothers reported lack of replacement foods, lack of knowledge on the proper replacement foods to give and their preparation was reportedly poor among these mothers. Criticism was one major concern for the mothers as some were criticized by their family, friends and neighbors. Breast problems were also reported but none of the mothers reported having any knowledge on how to handle these problems. A study in Botswana evaluating infant feeding practices by mothers at PMTCT and non-PMTCT sites also found that very few mothers had received any advice about the cessation of breastfeeding or feeding after breastfeeding cessation (Shapiro et al., 2003). Similar findings were reported from a study in South Africa that found that a mother who did not breastfeed her infant would jeopardize her reputation as a 'good mother'. People would suspect that she had a lover or that she was HIV positive (Bland et al., 2002).

\section{Conclusion and recommendations}

\section{Conclusion}

1. The main challenge encountered by HIV positive mothers in acquiring knowledge on appropriate infant feeding methods was poor clinic attendance as it affects the time, duration and the number of counseling sessions.

2. Though there was some awareness on MTCT of HIV through breastfeeding, about half of the mothers were not aware of the association between breastfeeding and HIV transmission or its prevention.

3. The challenges encountered by breastfeeding mothers were inability to produce enough milk, infections in the baby's mouth and breast infections while replacement feeding mothers experienced feelings of guilt, inability to afford replacement foods, and criticism from both relatives and friends.

4. The main challenges encountered by HIV positive mothers who had ceased breastfeeding early were lack of advice on feeding after breastfeeding cessation and criticism from both relatives and friends.

\section{Recommendations}

1. More emphasis should be put on encouraging the mothers to start antenatal clinic attendance early at the recommended time. This will provide additional time for the 
Texila International Journal of Public Health

Volume 4, Issue 4, Dec 2016

health personnel to provide full information that will help in achieving empowered decision-making on appropriate infant feeding.

2. More effort should be put to enhance the mothers' awareness on the association between breastfeeding and MTCT of HIV transmission.

3. More detailed counseling to be done to the mothers on all aspects of breastfeeding and replacement feeding as this will help them solve the common infant feeding problems.

4. Provision of information on appropriate infant feeding practices after cessation of breastfeeding should be enhanced.

5. Further investigations are required to determine the cause of insufficient milk production by the mothers.

\section{References}

[1] Aidam BA, Pérez-Escamilla R, Lartey A. (2005) Lactation counseling increases exclusive breast-feeding rates in Ghana. Journal of Nutrition. 33: 1691-1695. jn.nutrition.org/content/135/7/1691.full

[2] Aika AAO, Luo C, Kankasa C, Bhat GJ, Bunn J. (2003) Infant-feeding practices of mothers of known HIV status in Lusaka, Zambia. Health Policy and Planning; 18: 156-162.)

[3] Alcala M. (2005) State of the world population. UNFPA Publication. New York, USA

[4] Asefa A, Beyene H. (2013) Awareness and knowledge on timing of mother-to-child

transmission of HIV among antenatal care attending women in Southern Ethiopia: a cross

sectional studyJournal of Reproductive Health10: 66

[5] Background. Korogocho Slum Upgrading Programme (KSUP http://www.ksup.org

[6] Becquet R, Ekouevi DK, Viho I, Sakarovitch C, Toure H, Castetbon K. (2005b). Acceptability of exclusive breast-feeding with early cessation to prevent HIV transmission through breast milk, ANRS 1201/1202 Ditrame Plus, Abidjan, Cote d'Ivoire. Journal of Acquired Immune Deficiency Syndrome, 40 (5): 600-608.

[7] Bezner KR, Dakishoni L, Shumba L, Msachi R, Chirwa M. (2008) "We grandmothers know plenty:" breastfeeding, complemantary feeding and the multifaceted role of grandmothers in Malawi. Soc. Sci. Med.66 (5):1095-105

[8] Bhandari N, Bahl R, Mazumdar S, Martines J, Black RE, Bhan MK.(2003). Effect of community-based promotion of exclusive breastfeeding on diarrhoeal illness and growth: a cluster randomized controlled trial. Lancet, 361 (9367): 1418-1423.

[9] Bland RM, Rollins NC, Coutsoudis A, and Coovadia HM. (2002). Breastfeeding practices in an area of high HIV prevalence in rural South Africa. Acta Paediatrica, 91 (6): 704-711.

[10] Burr C K. (2011) Reducing Maternal-Infant HIV

Transmission http://hab.hrsa.gov/deliverhivaidscare/clinicalguide11/cg-402_pmtct.html

[11] Chopra M, Doherty T, Jackson D, Ashworth A. (2005) Preventing HIV transmission to children: quality of counseling of mothers in South Africa. Journal of Paediatrics94: 357-363.

[12] Chopra M, Rollins N. (2007) Infant feeding in the time of HIV: Assessment of infant feeding policy and programs in four African countries scaling up prevention of mother to child transmission programs. Global Health Sciences Literature Digest. Available at:http://hivinsite.ucsf.edu/InSite?page=jl-20-02. Accessed September 15, 2013.

[13] Coutsoudis A, Pillay K, Kuhn L, Spooner E, Tsai WY, and Coovadia HM.(2001). Method of feeding and transmission of HIV-1 from mothers to children by 15 months of age: prospective cohort study from Durban, South Africa. AIDS, 15 (3): 379-387.

[14] Coutsoudis A. (2005). Infant feeding dilemmas created by HIV: South African experiences. Journal of Nutrition, 135 (4): 956-959.

[15] Desclaux A, Alfieri C. (2009) Counseling and choosing between infant-feeding options: Overall limits and local interpretations by health care providers and women living with HIV in resource-poor countries (Burkina Faso, Cambodia, Cameroon) Journal of Social Science and Medicine.30:203-210 
[16] De Paoli MM, Manongi R, and Klepp KI. (2001). Counsellor's perspectives on Antenatal HIV testing and infant feeding dilemmas facing women with HIV in northern Tanzania. Reproductive Health Matters, 10 (20): 144-156.

[17] De Paoli MM, Manongi R, Helsing E, and Klepp KI. (2002). Exclusive Breastfeeding in the era of AIDS. Journal of Human Lactation, 17 (4): 313-320.

[18] De Paoli MM, Manongi R, Klepp KI. (2004) Are infant feeding options that are recommended for mothers with HIV acceptable, feasible, affordable, sustainable and safe? Pregnant women's perspectives. Public Health Nutrition; 7: 611-619).

[19] Doherty T, Chopra M, Nkonki L, Jackson D, Persson L. (2006a) A Longitudinal Qualitative Study of Infant-Feeding Decision Making and Practices among HIV-Positive Women in South Africa. Journal of Nutrition; 136: 2421-2426

[20] Doherty T, Chopra M, Nkonki L, Jackson D, Greiner T. (2006 b) "Effect of the HIV epidemic on infant feeding in South Africa: "when they see me coming with the tins they laugh at me”. Bulletin of World Health Organisation; 84(2):90-96

[21] Ehrnst A, Zetterstrom R. (2005) Feeding practices of HIV-1-infected mothers: The role of counselors. Acta Paediatrica, 2005; 94: 263 - 265.)

[22] Emina J, Beguy D, Zulu EM, Ezeh AC, Muindi K, Elung'ata P, Otsola JK, Ye Y. (2009)

Monitoring of health and demographic outcomes in poor urban settlements: evidence from the Nairobi Urban Health and Demographic Surveillance System. Journal Urban Health 2011, 88(2):S200-S218.

[23] Engebretsen IMS, Moland KM, Nankunda J, Karamagi CA, TylleskärT, Tumwine JK. (2010) Gendered perceptions on infant feeding in Eastern Uganda: continued need for exclusive breastfeeding support International Breastfeeding Journal, 5:13 http://www.internationalbreastfeedingjournal.com/content/5/1/13

[24] Fawzi W, Msamanga G, Spiegelman D, Renjifo B, Bang H, Kapiga S. (2002). Transmission of HIV-1 through breastfeeding among women in Dar es Salaam, Tanzania. Journal of Acquired Immune Deficiency Syndrome, 31 (3): 331-338.

[25] GOK. (2009) Korogocho Slum Upgrading Programmehttp://www.ksup.org/

[26] Haddis M, Jerene D. (2006) Awareness of antenatal care clients on mother-to-child transmission (MTCT) of HIV infection and its prevention in Arba Minc Ethiopian Journal of Health Development20(1):56-60 http://www.ajol.info/index.php/ejhd/article/view/10012

[27] Iliff, PJ, Piwoz EG, Tavengwa NV, Zunguza C, Marinda ET, Nathoo KJ. (2005). Early exclusive breast-feeding reduces the risk of postnatal HIV-1 transmission and increases HIV free survival. Journal of Acquired Immune Deficiency Syndrome, 19: 699-708.

[28] Kafulafula UK, Hutchinson MK, Gennaro S, Guttmacher S, Kumitawa A.(2013) Exclusive breastfeeding prenatal intentions among HIV-positive mothers in Blantyre, Malawi: a correlation study. BMC Pregnancy Childbirth. http://www.ncbi.nlm.nih.gov/pubmed/24195765

[29] Kiarie JN, Richardson BA, Mbori-Ngacha D, Nduati RW, John-Stewart GC. (2004) Infant feeding practices of women in a perinatal HIV-1 prevention study in Nairobi, Kenya. Journal of Acquired Immune Deficiency Syndrome, 35 (1): 75-81.

[30] Kimani-Murage EW, Kyobutungi C, Ezeh AC, Wekesah F, Wanjohi M, Muriuki P, Musoke RN, Norris SA, Griffiths P, Madise NJ. (2013) Effectiveness of personalized, home-based nutritional counseling on infant feeding practices, morbidity and nutritional outcomes among infants in Nairobi slums: study protocol for a cluster randomized controlled trial. Trials 2013, 14:445 http://www.trialsjournal.com/content/14/1/445

[31] Koniz-Booher P, Burkhalter B, deWagt A, Iliff P, Willumsen.(Eds) (2004). HIV and infant feeding. A compilation of programmatic evidence, Published for UNICEF and USAID by the Quality Assurance Project, University Research Co., LLC, Bethesda, MD.

[32] Korogocho. BEGA KWA BEGA Development project. Accessed 2009-06-02 http://www.begakwabega.com/Korogocho-eng.html

[33] Korogocho. St. John’s sports society http://stjohnssportssociety.weebly.com/about-us.html

[34] Kuhn L, Stein Z, Susser M. (2004) Preventing mother-to-child transmission in the new millennium: the challenge of breast feeding. Paediatric and Perinatal Epidemiology, 18: 10-16. 
Texila International Journal of Public Health

Volume 4, Issue 4, Dec 2016

[35] Laar AS, Govender V. (2013) Individual and Community Perspectives, Attitudes, and Practices to Mother-to-Child-Transmission and Infant Feeding among HIV Mothers in Sub-Saharan Africa: A Systematic Literature Review. International Journal of MCH and AIDS2: 152-162

[36] Leroy V, KaronJM, Alioum A, Ekpini ER, van de Perre P, Greenberg AE.(2003) Postnatal transmission of HIV-1 after a maternal short-course zidovudine peripartum regimen in West Africa. AIDS, 17(10): 1493-1501.

[37] Leshabari SC, Koniz-Booher P, Astrom AN, De Paoli MM, Moland KM. (2006) Translating global recommendations on HIV and infant feeding to the local context: the development of culturally sensitive counseling tools in the Kilimanjaro Region, Tanzania. Implementation Science. 1:22 doi: 10.1186/1748-5908-1-22. Accessed January 1, 2013.

[38] Mnongya L M. (2013) Dilemma of choice between breastfeeding and replacement feeding among HIV positive mothers in Tanzania http://www.ajol.info/index.php/dmsj/article/view/88971

[39] Muluye D, Woldeyohannes D, Gizachew M, Tiruneh M. (2012) Infant feeding practice and associated factors of HIV positive mothers attending prevention of mother to child transmission and antiretroviral therapy clinics in Gondar Town health institutions, Northwest Ethiopia. BMC Public Health. 2012 Mar 26; 12:240. doi: 10.1186/1471-2458-12-240.

[40] Mugenda O, Mugenda A. (1999). Research Methods: Qualitative and Quantitative Approaches. Act Press, NBI.

[41] Nicolaj N. (2005) Korogocho the land and the people. Monthly Review Press Book, Nairobi

[42] Omari AA, Luo C, Kankasa C, Bhat GJ, and Bunn J. (2003) Infant-feeding practices of mothers of known HIV status in Lusaka, Zambia. Health Policy and Planning. 18 (2): 156-162.

[43] Piwoz EG, Bentley ME. (2005) Women's Voices, Women's Choices: The Challenge of Nutrition and HIV/AIDS135(4):933-7. http://www.ncbi.nlm.nih.gov/pubmed/15795465

[44] Rea MF, Gomes dos Santos R, Sanchez-Moreno CC. (2007) Quality of infant feeding counseling for HIV positive mothers in Brazil: Challenges and achievements. Acta Paediatrica; 96:9499.

[45] Rollins Meda N, Becquet R, Coutsoudis A, Humphrey J, Jeffrey B. (2004) Preventing postnatal transmission of HIV-1 through breast-feeding: modifying infant feeding practices. Journal of Acquired Immune Deficiency Syndrome, 35 (2):188-195.

[46] Sadoh E, Adeniran A, Abhulimhen-Iyoha I.(2008) Infant-feeding Practices among HIV-infected Mothers in an HIV-treatment Programme. Health Population and nutrition Journal. 2008; 26: 463-467.

[47] Shah S, Rollins NC, Bland RM. (2005) Breastfeeding knowledge among health workers in rural South Africa. Journal of Tropical Paediatrics, 51 (1):33-38

[48] Shapiro RL, Lockman S, Thior I, Stocking L, Kebaabetswe P, Wester C, Peter T, Marlink R, Essex M, and HeymannJ. (2003) Low adherence to recommended infant feeding strategies among HIV-infected women: results from the pilot phase of a randomized trial to prevent mother-to-child transmission in Botswana. AIDS Educationand Prevention, 15 (3): 221-230.

[49] Suryavanshi N, Jonnalagadda S, Erande AS, Sastry J, Pisal H, Bharucha KE, Shrotri Pandurang M, Bulakh PM, Phadke MA, Robert C, Bollinger RC, and Shankar AV. (2003) Infant Feeding Practices of HIV-Positive Mothers in India Journal of Nutrition 133:1326-1331

[50] Thairu LN, Pelto GH, Rollins NC, Bland RM, and Ntchangase N. (2005) Socio-cultural influences on infant feeding decisions among HIV-infected women in rural Kwa-Zulu Natal, South Africa. Maternal and Child Nutrition, 1: 2-10.

[51] UNAIDS. (2010) UNAIDS Report on the Global AIDS Epidemic 2010. Available at: http://www.unaids.org/en/dataanalysis/Accessed September 13, 2012.)

[52] UNAIDS. (2011) AIDS at 30;Nations at the crossroads. Section 3

http://www.unaids.org/en/media/unaids/contentassets/documents/unaidspublication/2011/20110531

[53] UNAIDS. (2012). Report on the Global AIDS Epidemic. Geneva: Joint United Nations Programme on HIV/AIDS

[54] UNAIDS. (2013) Report on the Global AIDS Epidemic. Geneva: Joint United Nations Programme on HIV/AIDS.

[55] UNICEF. (2012) Nutrition HIV and Infant Feeding 
http://www.unicef.org/nutrition/index_24827.html

[56] Wendo C. (2003) HIV-positive mothers in Uganda resort to breastfeeding. The Lancet; $16 ; 362$ (9383) 542.)

[57] Wikipedia. (2013) Korogocho- Wikipedia, the free encyclopedia http://en.wikipedia.org/wiki/Korogocho

[58] WHO. (2003) UNICEF; UNFPA; UNAIDS. HIV and Infant Feeding: guidelines for Decisionmakers, Reviewed. Geneva, Switzerland World Health Organization

[59] WHO. (2006) WHO HIV and Infant Feeding Technical Consultation Held on behalf of the Interagency Task Team (IATT) on Prevention of HIV Infections in Pregnant Women, Mothers and their Infants: Geneva, Switzerland World Health Organization

[60] WHO. (2007) HIV Transmission through Breastfeeding. A Review of Available Evidence An Update from 2001 to 2007).

[61] WHO. (2011) WHO, UNAIDS and UNICEF. Towards universal access: scaling up priority HIV /AIDS interventions in the health sector. Progress report, 2011. Geneva, World Health Organization.

[62] Young SL, Mbuya NNM, Chantry JC. (2011) Current Knowledge and Future Research on Infant Feeding in the Context of HIV: Basic, Clinical, Behavioral, and Programmatic. Perspectives Advances in Nutrition.; 2: 225-243. 


\title{
Assessment of Knowledge Attitude Perception and Practice of Health Insurance Scheme among Community Pharmacies in Lagos State
}

\author{
Article by Ukamaka Gladys Okafor \\ Ph.D in Public Health, Texila American University, Nigeria \\ E-mail: chinaemelum9291@yahoo.com
}

\begin{abstract}
Introduction: In most developing countries, Nigeria in particular, there is little equity and a clear lack of universal coverage of health care. Majority of the health seeking people first visit the community pharmacies when they are ill, before visiting the hospitals, yet a large percentage of Community Pharmacies are not registered with the National Health Insurance Scheme. The objective of the study was to assess the Knowledge, Attitude, Perception and Practice of the Health Insurance Scheme among Community Pharmacists in Lagos State, with the hope that it would serve as a baseline study towards improving Community Pharmacists' involvement in the implementation of the Health Insurance Scheme.

Method: A cross-sectional descriptive study was carried out on 200 Community Pharmacists in Lagos State using a multi-staged stratified random sampling method and structured questionnaire. Analysis was done with Statistical Package for Social Sciences (SPSS) version 14.0 to obtain the frequencies, percentages and descriptive statistical results.

Result: Majority of the respondents were females (60\%), in the age range of 41years and above (47\%), without additional qualifications (70\%), and $73 \%$ with more than 16 years post qualification experience. More than $80 \%$ had poor knowledge of the major guidelines and activities in Health Insurance Scheme while $86 \%$ were neither registered nor participating. Lack of integration among health care providers, lack of prescription from hospitals, need for cumbersome data, inadequate funding and training, lack of capitation for pharmacists were seen as the major hindrances to their participation.

Conclusion: The study revealed poor knowledge, attitude, perception and practice of the Health Insurance Scheme, among Community Pharmacists. Adequate training of community pharmacists and funding of the scheme, modifying the payment system to capitation as well as improving coordination, integration and standard of operation of the Health Insurance Scheme will improve their involvement.
\end{abstract}

Keywords: Community Pharmacists, Knowledge, Attitude, Perception, Practice, Health Insurance

\section{Introduction}

\section{Health insurance system in nigeria}

In most developing countries, Nigeria in particular, there is little equity and a clear lack of universal coverage of health care. Access to healthcare is severely limited in Nigeria (Otuyemi, 2001). Inabilities of the consumers to pay for the services as well as inequitable healthcare provision have been identified among other factors that impose the limitation (Sanusi et al., 2009). Financing of Public Health services in Nigeria has been through Government subvention funded mainly from earnings from petroleum exports and user fees from patients. Decline in funding for healthcare commenced after the mid 1980's following a drastic reduction in revenue from oil exports, mounting external debts burden, structural adjustment programme and rapid population growth rate. The result as in most other developing countries was a rapid decline in the quality and effectiveness of publicly provided healthcare service. As a way out, the Government of Nigeria launched a National Health Insurance Scheme (NHIS) in June 2005 (Ononokpono, 2008). It is the opinion of Nigerian 
Government that the NHIS will solve the problem of inequity in the provision of healthcare services and help to improve accessibility to healthcare (Ibiwoye et al., 2007).

\section{Basic operations of the NHIS}

The employer and employees register with the Scheme. Thereafter, the employee enrolls him/herself with an NHIS approved Health Maintenance Organization (HMO), who will thereafter provide the employees/contributors with a list of NHIS approved Healthcare providers (public and private). The employee registers him/herself and dependent(s) with the provider of his/her choice. Contributions are earning-related and currently stand at $15 \%$ of basic salary. The employer pays $10 \%$ while the employee pays 5\% of basic salary to enjoy healthcare benefit. As at December 2015, only the employer's contribution was being implemented. The contribution made by/for an insured person entitles him/her, a spouse and 4 biological children under the age of 18 to health benefits as contained in NHIS health benefits package. Additional contributions are required for extra dependents (National Health Insurance Scheme, 2005) An enrollee reserves the right to change his/her primary healthcare provider after a minimum of 6 months, if he/she is not satisfied with the services being given. The HMO will make payment for services rendered to an enrollee to the healthcare provider an enrollee may however be asked to make a small co-payment (where applicable) at the point of service (NHIS, 2005).

\section{Stakeholders in NHIS}

- Health Maintenance Organizations

- Health Care Providers: these healthcare providers can be primary (medical doctors/prescribers), secondary (pharmacists) or tertiary.

- Financial Institutions: these include banks, insurance companies and insurance brokers.

- Government and other employees of labor.

- Enrollees/ beneficiaries.

In 2015, the Lagos State government signed the Health Management Agency Bill into law which includes the Community Based Health Insurance Scheme and the community pharmacists, among other relevant stakeholders have been invited to make submissions towards a hitch-free implementation phase. Despite the grey areas, the Association of Community Pharmacists of Nigeria in collaboration with the Health Care Provider Association of Nigeria encourages all Community Pharmacists the insurance scheme has a lot of benefits for all, including the community pharmacists (Oyebade,2016).

\section{Health care providers}

There cannot be healthcare without the healthcare providers who influence both the quality and cost of healthcare through their influences on the nature and quality of treatment required (Onuekwusi et al, 1998). The successful implementation of the Health Insurance Scheme to a large extent depends on the knowledge, attitude, perception and practice of healthcare providers. Pharmacists are certified medicine experts and are key personnels among the healthcare providers. This is because Pharmacists are custodians of medicines (drugs in form of tablet, suppositories and intravenous fluids) as well as surgical materials (plasters, bandages, sutures and other dressing materials) that are required by almost all patients for treatment or management of diseases, wound or infections after proper diagnosis.

Within the community, majority of the health seeking people first visit the community pharmacies when they are ill, before visiting the hospitals, yet a large percentage of Community Pharmacies are not registered with the National Health Insurance Scheme, despite essential drugs from NHIS accredited pharmacy providers and provision of pharmaceutical care by the Pharmacist being a major benefit package of the scheme. 
Assessment of the Scheme after four years of operation reveals less than 3\% coverage of the Nigeria population, basically employees of the federal government, armed forces, the police and other uniformed services, state governments and a handful of private sector organizations. This is due to lack of public awareness and people's acceptance of NHIS (Ibong Ukpong, 2009). The NHIS will therefore need to stimulate acceptance of the formal sector and growth of its informal sector programme; the Community-Based Social Health Insurance Programme (CBSHIP) in order to guarantee coverage for the envisaged 70 per cent of the population that belongs to the informal sector. This would optimally engage healthcare providers in private sector. The Objectives of the study therefore are:

- To assess the Knowledge, Attitude, Perception and Practice of the Health Insurance Scheme among Community Pharmacists in Lagos State.

- To serve as a baseline study towards improving Community Pharmacists' involvement in the implementation of the Health Insurance Scheme.

\section{Limitations}

- Inability of the Research Assistants to reach all the randomly selected pharmacies

- The time allocated for the study was too short to retrieve all the questionnaires, hence the high attrition rate

\section{Methods}

\section{Study area}

Lagos State, the economic nerve centre of Nigeria, is located in the southwestern geopolitical zone of the country. The State is essentially a Yoruba-speaking environment; a social-cultural melting pot attracting both Nigerians and foreigners (History of Lagos State, 2014).

Lagos State consists of three senatorial districts; Lagos Central, Lagos East and Lagos West. (History of Lagos State, 2014). According to the Pharmacists Council of Nigeria Register of Pharmacists and Pharmaceutical premises, there were 1227 pharmacists working in the private sector, 768of whom worked in community pharmacies in Lagos State in December 2014.

\section{Sampling technique}

The 768 community pharmacists constitute the sample frame from which a sample size of 257 community pharmacists was generated using Raosoft's formula for sample size determination; this sample frame is the population that run retail community pharmacies, are registered with the Pharmacists Council of Nigeria and Association of Community Pharmacists of Nigeria, and interface directly with the patients.

Multi-staged stratified random sampling method was employed in the selection of 257participants. Pre-tested semi-structured questionnaires were administered to the superintendent pharmacists or the pharmacists with the longest experience in the selected community pharmacies during the working hours. Items included in the questionnaire covered different parameters such as Ability to list the types of Insurance scheme, Objectives, Key Stakeholders, Payment System, assessment of the Knowledge, Attitude, Perception and Practice of the Health Insurance Scheme among Community Pharmacists in Lagos State.

\section{Data analysis and interpretation}

The retrieved copies of the questionnaire were entered into the Microsoft excel computer package and analyzed with Statistical Package for Social Sciences (SPSS) version 14.0 to obtain the frequencies, percentages and descriptive statistical results. 
Texila International Journal of Public Health

Volume 4, Issue 4, Dec 2016

\section{Results}

Out of the 257 total numbers of questionnaires administered, only 100 were retrieved and used for the study.

\section{Biodata}

Table 1.1

\begin{tabular}{|c|c|c|c|c|c|c|c|}
\hline \multicolumn{8}{|c|}{ Sex * Age Range Cross-Tabulation } \\
\hline & & \multicolumn{5}{|c|}{ Age Range } & \multirow[t]{2}{*}{ Total } \\
\hline & & $<26$ & $26-30$ & $31-35$ & $36-40$ & 41 and above & \\
\hline \multirow[t]{2}{*}{ Sex } & Male & 0 & 6 & 8 & 8 & 18 & 40 \\
\hline & Female & 1 & 9 & 10 & 11 & 29 & 60 \\
\hline \multicolumn{2}{|c|}{ Total } & 1 & 15 & 18 & 19 & 47 & 100 \\
\hline
\end{tabular}

Table 1.1 is a cross-tabulation of age/sex demographic information which shows that $1 \%$ of respondents of age less than 26years is a female, out of the $15 \%$ of age class $26-30,6 \%$ are male and $9 \%$ are females; $8 \%$ are males and $10 \%$ females make up $18 \%$ of the $31-35$ age range, $8 \%$ are males and $11 \%$ females make up $19 \%$ of the $36-40$ age range while $18 \%$ are males and $29 \%$ females make up $47 \%$ of the 41 years and above age range.

Table 1.2

\begin{tabular}{|l|l|l|l|l|l|}
\hline \multicolumn{6}{|l|}{ Years of Work Experience As Community Pharmacist } \\
\hline \multicolumn{1}{|c|}{} & Frequency & Percent & Valid Percent & $\begin{array}{l}\text { Cumulative } \\
\text { Percent }\end{array}$ \\
\hline \multirow{4}{*}{ Valid } & $1-5$ & 2 & 2.0 & 2.0 & 2.0 \\
\cline { 2 - 6 } & $6-10$ & 5 & 5.0 & 5.0 & 7.0 \\
\cline { 2 - 6 } & $11-15$ & 19 & 19.0 & 19.0 & 26.0 \\
\cline { 2 - 6 } & $16-20$ & 25 & 25.0 & 25.0 & 51.0 \\
\cline { 2 - 6 } & 21 and above & 49 & 49.0 & 49.0 & 100.0 \\
\cline { 2 - 6 } & Total & 100 & 100.0 & 100.0 & \\
\hline
\end{tabular}

Table 1.2 shows that work experience ranges (years) 1-5, 6-10, 11-15, 16-20 and 21 years and above have percentage frequency of 2,5,19,25 and 49 respectively.

\section{Assessment of Knowledge}

Table 1.3

\begin{tabular}{|l|l|l|l|l|l|}
\hline \multicolumn{6}{|l|}{ What Are The Health Insurance Scheme in Lagos State? } \\
\hline \multicolumn{2}{|c|}{} & Frequency & Percent & Valid Percent & $\begin{array}{l}\text { Cumulative } \\
\text { Percent }\end{array}$ \\
\hline \multirow{3}{*}{ Valid } & Ability to list & 10 & 10.0 & 10.0 & 10.0 \\
\cline { 2 - 6 } & Inability to list & 90 & 90.0 & 90.0 & 100.0 \\
\cline { 2 - 6 } & Total & 100 & 100.0 & 100.0 & \\
\hline
\end{tabular}

Table 1.3 indicates that $10 \%$ of respondents could list the Health Insurance Scheme in Lagos State while $90 \%$ of the respondents have no knowledge of the Scheme. 
Table 1.4

\begin{tabular}{|c|c|c|c|c|c|}
\hline \multicolumn{6}{|c|}{$\begin{array}{l}\text { At What Level Does The Community Pharmacist Operate in The Health Insurance } \\
\text { Scheme? }\end{array}$} \\
\hline & & Frequency & Percent & $\begin{array}{l}\text { Valid } \\
\text { Percent }\end{array}$ & $\begin{array}{l}\text { Cumulativ } \\
\text { e Percent }\end{array}$ \\
\hline \multirow[t]{4}{*}{ Valid } & Primary Health Provider & 54 & 54.0 & 54.0 & 54.0 \\
\hline & Secondary Health Provider & 6 & 6.0 & 6.0 & 60.0 \\
\hline & Tertiary Health Provider & 40 & 40.0 & 40.0 & 100.0 \\
\hline & Total & 100 & 100.0 & 100.0 & \\
\hline
\end{tabular}

Table 1.4 indicates that only 6\% of respondents have knowledge that Community Pharmacists operate as Secondary Health Provider.

Table 1.5

\begin{tabular}{|l|l|l|l|l|l|}
\hline \multicolumn{6}{|l|}{ Enrolment in The Health Insurance Scheme } \\
\hline \multicolumn{2}{|c|}{} & Frequency & Percent & Valid Percent & $\begin{array}{l}\text { Cumulativ } \\
\text { e Percent }\end{array}$ \\
\hline \multirow{4}{*}{ Valid } & Excellent & 2 & 2.0 & 2.0 & 2.0 \\
\cline { 2 - 6 } & Above average & 4 & 4.0 & 4.0 & 6.0 \\
\cline { 2 - 6 } & Average & 10 & 10.0 & 10.0 & 16.0 \\
\cline { 2 - 6 } & Below average & 4 & 4.0 & 4.0 & 20.0 \\
\cline { 2 - 6 } & Extremely poor & 80 & 80.0 & 80.0 & 100.0 \\
\cline { 2 - 6 } & Total & 100 & 100.0 & 100.0 & \\
\hline
\end{tabular}

Table 1.5 shows that $2 \%$ of respondents have excellent knowledge on enrollment of Community Pharmacists into the Health Insurance Scheme, 10\% above average while $80 \%$ have extremely poor knowledge.

Table 1.6

\begin{tabular}{|l|l|l|l|l|l|}
\hline \multicolumn{2}{|l|}{ Requirements of Accreditation of Facility } \\
\hline \multicolumn{2}{|c|}{} & Frequency & Percent & Valid Percent & $\begin{array}{l}\text { Cumulative } \\
\text { Percent }\end{array}$ \\
\hline \multirow{7}{*}{ Valid } & Excellent & 1 & 1.0 & 1.0 & 1.0 \\
\cline { 2 - 6 } & Above average & 4 & 4.0 & 4.0 & 5.0 \\
\cline { 2 - 6 } & Average & 2 & 2.0 & 2.0 & 7.0 \\
\cline { 2 - 6 } & Below average & 6 & 6.0 & 6.0 & 13.0 \\
\cline { 2 - 6 } & Extremely poor & 87 & 87.0 & 87.0 & 100.0 \\
\cline { 2 - 6 } & Total & 100 & 100.0 & 100.0 & \\
\hline
\end{tabular}

Table 1.6 indicates $1 \%$ of respondents have excellent knowledge, $4 \%$ above average, $2 \%$ average, $6 \%$ below average while $87 \%$ have extremely poor knowledge on the requirements of accreditation of facility to be registered in the Health Insurance Scheme.

Other areas where the respondents were found to have extremely poor knowledge of the scheme included objectives of the scheme (31\%); forms/types of health insurance scheme (87\%), structure (87\%); key stakeholders (87\%); payment system (72\%); steps for accreditation (82\%); and conditions for renewal of accreditation (84\%). 


\section{Assessment of Perception}

Table 1.7

\begin{tabular}{|l|l|l|l|l|l|}
\hline \multicolumn{6}{|l|}{ Is Your Facility Registered with The Health Insurance Scheme? } \\
\hline \multicolumn{2}{|c|}{} & Frequency & Percent & $\begin{array}{l}\text { Valid } \\
\text { Percent }\end{array}$ & $\begin{array}{l}\text { Cumulativ } \\
\text { e Percent }\end{array}$ \\
\hline \multirow{3}{*}{ Valid } & Yes & 14 & 14.0 & 14.0 & 14.0 \\
\cline { 2 - 6 } & No & 86 & 86.0 & 86.0 & 100.0 \\
\cline { 2 - 6 } & Total & 100 & 100.0 & 100.0 & \\
\hline
\end{tabular}

Table 1.7 indicates $14 \%$ of respondents' facilities are registered with the Health Insurance Scheme while $86 \%$ of the respondents' facilities are not registered.

Table 1.8

\section{Coordination, Integration And Standard of Operation}

\begin{tabular}{|l|l|l|l|l|l|}
\hline \multicolumn{2}{|c|}{} & Frequency & Percent & Valid Percent & $\begin{array}{l}\text { Cumulative } \\
\text { Percent }\end{array}$ \\
\hline \multirow{3}{*}{ Valid } & Strongly Agree & 84 & 84.0 & 84.0 & 84.0 \\
\cline { 2 - 6 } & Agree & 10 & 10.0 & 10.0 & 94.0 \\
\cline { 2 - 6 } & Neutral & 5 & 5.0 & 5.0 & 99.0 \\
\cline { 2 - 6 } & Strongly Disagree & 1 & 1.0 & 1.0 & 100.0 \\
\cline { 2 - 6 } & Total & 100 & 100.0 & 100.0 & \\
\hline
\end{tabular}

Table 1.8 indicates $84 \%$ strongly agree, $10 \%$ agree, $5 \%$ neutral while $1 \%$ of respondents strongly disagree on the coordination, integration and standard of operation of the Health Insurance Scheme.

Other reasons given for non-enrolment with the scheme and factors that affect the scheme include lack of integration among health care providers (90\%); lack of prescriptions from the hospitals (86\%); data integrity (96\%); cumbersome data (91\%); lack of training on data management (93\%); insufficient funds (88\%); lack of capitation (94\%) and non-payment by government hospitals (65\%).

\section{Assessment of Practice of the NHIS}

This section assessed the respondents already participating in the scheme

Table 1.9

\begin{tabular}{|l|l|l|l|l|l|}
\hline \multicolumn{6}{|c|}{ How Many Years Has Your Facility Been Providing Services? } \\
\hline \multirow{3}{*}{} & Frequency & Percent & Valid Percent & $\begin{array}{l}\text { Cumulativ } \\
\text { e Percent }\end{array}$ \\
\hline Valid & $<2$ years & 2 & 2.0 & 2.0 & 2.0 \\
\cline { 2 - 6 } & $2-5$ years & 97 & 97.0 & 97.0 & 99.0 \\
\cline { 2 - 6 } & $6-9$ years & 1 & 1.0 & 1.0 & 100.0 \\
\cline { 2 - 6 } & Total & 100 & 100.0 & 100.0 & \\
\hline
\end{tabular}

Table 1.39 shows that $2 \%$ of respondents have less than 2 years $97 \%$ have $2-5$ years experience while 1\% had 6-9 years of their facilities providing services in the Social Health Insurance Scheme. 
Table 2.0

\begin{tabular}{|c|c|c|c|c|c|}
\hline \multicolumn{6}{|c|}{$\begin{array}{l}\text { Reasons For Acceptance/Non-Acceptance of The Health Insurance Scheme } \\
\text { (Profitability) }\end{array}$} \\
\hline & & Frequency & Percent & Valid Percent & $\begin{array}{l}\text { Cumulative } \\
\text { Percent }\end{array}$ \\
\hline \multirow[t]{6}{*}{ Valid } & Strongly Agree & 2 & 2.0 & 2.0 & 2.0 \\
\hline & Agree & 40 & 40.0 & 40.0 & 42.0 \\
\hline & Neutral & 33 & 33.0 & 33.0 & 75.0 \\
\hline & \begin{tabular}{|l|} 
Disagree \\
\end{tabular} & 10 & 10.0 & 10.0 & 85.0 \\
\hline & $\begin{array}{l}\text { Strongly } \\
\text { Disagree }\end{array}$ & 15 & 15.0 & 15.0 & 100.0 \\
\hline & Total & 100 & 100.0 & 100.0 & \\
\hline
\end{tabular}

Table 2.0 shows that $2 \%$ of respondents strongly agree, $40 \%$ agree, 33\% neutral, $10 \%$ disagree while $15 \%$ strongly disagree that profitability of the Scheme are as one of the reasons for acceptance/ non-acceptance of the Health Insurance Scheme.

Table 2.1

\begin{tabular}{|l|l|l|l|l|l|}
\hline \multicolumn{6}{|l|}{ Rate of Satisfaction with The Health Insurance Scheme } \\
\hline \multicolumn{7}{|c|}{} & Frequency & Percent & Valid Percent & $\begin{array}{l}\text { Cumulativ } \\
\text { e Percent }\end{array}$ \\
\hline \multirow{7}{*}{ Valid } & Okay & 9 & 9.0 & 9.0 & 9.0 \\
\cline { 2 - 6 } & Dissatisfied & 1 & 1.0 & 1.0 & 10.0 \\
\cline { 2 - 6 } & $\begin{array}{l}\text { Very } \\
\text { dissatisfied }\end{array}$ & 90 & 90.0 & 90.0 & 100.0 \\
\cline { 2 - 6 } & Total & 100 & 100.0 & 100.0 & \\
\hline
\end{tabular}

Table 2.1 shows that $9 \%$ of respondents are okay, $1 \%$ dissatisfied while $90 \%$ were very dissatisfied about the Health Insurance Scheme.

Other reasons reported by the respondents for their low acceptance and satisfaction included payment mode not understood (80\%); payment not adequate (59\%); and number of client not sufficient (96\%).

\section{Assessment of Attitude}

Table 2.3

\begin{tabular}{|l|l|l|l|l|l|}
\hline \multicolumn{2}{|l|}{ Community Pharmacists Not Carried Along in The Scheme } \\
\hline \multicolumn{2}{|c|}{} & Frequency & Percent & Valid Percent & $\begin{array}{l}\text { Cumulative } \\
\text { Percent }\end{array}$ \\
\hline \multirow{4}{*}{ Valid } & Strongly Agree & 82 & 82.0 & 82.0 & 82.0 \\
\cline { 2 - 6 } & Agree & 17 & 17.0 & 17.0 & 99.0 \\
\cline { 2 - 6 } & Neutral & 1 & 1.0 & 1.0 & 100.0 \\
\cline { 2 - 6 } & Total & 100 & 100.0 & 100.0 & \\
\hline
\end{tabular}

Table 2.3 shows that $82 \%$ of respondents strongly agree, $17 \%$ agree while $1 \%$ is neutral that Community Pharmacists not being carried along in the Scheme are one of the factors that affect the Health Insurance Scheme. 
Table 2.5

\begin{tabular}{|c|c|c|c|c|c|}
\hline \multicolumn{6}{|c|}{$\begin{array}{l}\text { Mode of Payment Should Be Changed To Capitation To Encourage } \\
\text { Participation }\end{array}$} \\
\hline & & Frequency & Percent & Valid Percent & $\begin{array}{l}\text { Cumulative } \\
\text { Percent }\end{array}$ \\
\hline \multirow[t]{3}{*}{ Valid } & Strongly Agree & 97 & 97.0 & 97.0 & 97.0 \\
\hline & Agree & 3 & 3.0 & 3.0 & 100.0 \\
\hline & Total & 100 & 100.0 & 100.0 & \\
\hline
\end{tabular}

Table 2.5 shows that $97 \%$ of respondents strongly agree while $3 \%$ agree that the mode of payment for Community Pharmacists on the Health Insurance Scheme should be changed to capitation.

In addition $47 \%$ of the respondents strongly agree that non-challant attitude of the Community Pharmacists are one of the factors that affect the Health Insurance Scheme while 95\% strongly agree that most Community Pharmacists regret registering for the Health Insurance Scheme.

\section{Discussion}

\section{Demography}

Result of this research shows that $60 \%$ of the respondents were females while $40 \%$ were males. Over the last two decades, there has been a gender shift in the pharmacy profession as women have been graduating from schools of pharmacy at a higher rate than men for over 20 years (Stephanie et al,2006).

Also, $47 \%$ of pharmacists in community practice were in the age range of 41years and above, and this is similar to the results from a related study that found that in the American Pharmacists Association, 53\% of Community Pharmacists are in the mean age of 47 years (Schommer et al, 2007).

\section{Assessment of knowledge}

Assessment of knowledge across the parameters showed a very poor knowledge pattern of the Health Insurance Scheme among the Community Pharmacists; only 10\% of respondents could list the Health Insurance Schemes in Lagos State while only 6\% of respondents had knowledge that Community Pharmacists operate as secondary Health Provider. This shows a very poor knowledge on the Health Insurance Scheme among the respondents. A similar study conducted among members of staff of research institutes in Nigeria also revealed very low level of awareness in these institutions (Akintaro et al, 2015).

\section{Assessment of perception}

Assessment of parameters such as lack of prescriptions from the hospitals, lack of capitation, nonpayment by Government institutions and others showed negative perceptions of the Health Insurance Scheme among the Community Pharmacists. Only fourteen percent (14\%) of respondents' facilities were registered with the Health Insurance Scheme This agrees with the study on 'The Impact of National Health Insurance on Community Pharmacists in Western Region of Ghana (Adjei, 2012).

\section{Assessment of practice}

Assessments of parameters such as years of experience in providing social health insurance services, lack of understanding of payment modes, insufficient numbers of registered clients, profitability and level of satisfaction were some of the factors that lead to poor practice of the Health Insurance Scheme among the Community Pharmacists. These are in agreement with the study 'The Evolution of Taiwan's National Health Insurance Scheme' (Jason et al, 2012). 


\section{Assessment of attitude}

Factors such as non-challant attitude of the Community Pharmacists, Community Pharmacists not being carried along, non-capitation mode of payment for Community Pharmacists were the major factors that led to poor attitude among community pharmacists and which discouraged them from participating in the Health Insurance Scheme. This also agrees with the study on 'The Evolution of Taiwan's National Health Insurance Scheme' (Jason et al; 2012)

\section{Conclusion}

This study reveals that there is poor knowledge, attitude, perception and practice of the Health Insurance Scheme, among Community Pharmacists in Lagos State therefore interventions such as training, structured orientation, modifying the payment system to capitation as well as improving coordination, integration and standard of operation of the Health Insurance Scheme will improve the involvement of this set of professionals.

\section{Reference}

[1]. Adjei M.O (2012): The Impact of National Health Insurance on Community Pharmacies: A Case Study of the Western Region of Ghana. Available at http://ir.knust.edu.gh/bitstream/123456789/4338/1/Adjei\%20Moses\%20Amoah.pdf Accessed on August 25, 2016

[2]. Akintaro O.A and Adewoyin 0.0 (2015): Knowledge and Attitude towards National Health Insurance Scheme in Nigerian Research Institutes. Journal of the Open University of Tanzania Vol 20, No 1 (2015). Available on www.ajol.info Accessed on September 15, 2016

[3]. History of Lagos State (2014). Apublication of the Lagos State Government Public Service.

[4]. Ibiwoye A. and Adeleke A.A. (2007): Does National Health Insurance Promotes Access to Quality Healthcare? Evidence from Nigeria. Available at https://www.researchgate.net/publication/266850158 Accessed on August 25, 2016

[5]. Ibiwoye, A and Adeleke A.A. (2007): The Impact of Health Insurance on Healthcare Provision in Developing Countries. Ghana J. Dev. Stud., 4(21): 49 -58. [6].

[6]. Jason C and Christine Y. (2015): The Evolution of Taiwan's National Health Insurance Drug Reimbursement Scheme.

[7]. National Health Insurance Scheme (2005), Operational Guidelines, Nigerian Govt.Pub.Service.

[8]. National Health Insurance Scheme (2005): Standard Treatment Guideline and Referral Protocol for Primary Healthcare Providers, Nigerian Govt. Pub. Service.

[9]. National Health Insurance Scheme (2015): The Blue-Print Review on Community Based Social Health Insurance Scheme, Nigerian Govt. Pub Service

[10]. Onuekwusi N. and Okpala C.O. (1998): Awareness and Perception of the National Health

[11]. Insurance Scheme (NHIS) Among Nigeria Healthcare Professions. Journal of College of Medicine 3(2): 97 - 99. [13].

[12]. Ononokpono E.(2008): NHIS and the Challenges of Healthcare Delivery. http://www.dailytrust.com/content/view/4297/8.

[13]. Otuyemi, O.D. (2001): Orthodontics in Nigeria: Journey So Far and Challenges Ahead. Journal of Orthodontics 28 (1): 90 - 92. [15].

[14]. Oyebade W., (2016): Community pharmacists raise concerns over Lagos health insurance scheme http://www.dailytrust.com.ng/news/business/-nhis-should-be-well-structured-to-facilitate-healthcarereforms/141646.html\#wpMU2b9jBToiKgdi.

[15]. Owumi B., Omorogbe C., Raphael S. (2009): An evaluation of the impacts of the National Health Insurance Scheme on the Employees' Health Status at the University of Ibadan. African Journal of Social Sciences Volume 3 Number 3 (2013) 40-52. Available at http://www.sachajournals.com/user/image/ajss2013wisdom002.pdf Accessed on September 13, 2016 
Texila International Journal of Public Health

Volume 4, Issue 4, Dec 2016

[16]. PCN (2014): A list of Registered Pharmacists and Pharmaceutical Premises in Nigeria; A publication of the Pharmacists Council of Nigeria.

[17]. Raosoft (2014): Sample size calculator. Available at http://www.raosoft.com/samplesize.html. Accessed March 23, 2016.

[18]. Sanusi and Awe A. T. (2009): An Assessment of Awareness Level of National Health Insurance Scheme (NHIS) among Healthcare Consumers in Oyo State, Nigeria. The Medwell Journals 4(2) 143 - 148. [16]

[19]. Sanusi R.A and Awe, A. T. (2009): Perception of National Health Insurance Scheme (NHIS) by Healthcare consumers in Oyo State, Nigeria. Pakistan Journal of Social Sciences. 6(1): 48 - 53.

[20]. Schommer J.C, Brown L.M, Sogol E.M (2007): Career Pathway Evaluation Program 2007 Pharmacist Profile Survey. Available at https://www.ncbi.nlm.nih.gov/pmc/articles/PMC3831405/ Accessed on August 25, 2016

[21]. Stephanie F.G and Cindy D.S (2006): The Impact of Gender Shift on A Profession: Women in Pharmacy, University of Kansas, Forum on Public Policy. Available at https://pharmacy.ku.edu/ Accessed on August 14, 2016

[22]. WHO (1994): The Role of the Pharmacist in the Healthcare System, Essential Medicine and Health Products Information Portal.www.nhis.gov.ng/file/blueprint (2016). 


\title{
Periodical Screening and Health Education at Work: Producing Healthy Workforce
}

\author{
Article by Adegoke Titilayo \\ RN-MSN, Texila American University, Nigeria \\ E-mail: titilayomi4ever@yahoo.com
}

\begin{abstract}
This article investigates the benefit of workplace wellness programs, their prevalence, their impact on employee's health and medical cost, facilitators of their success in each programs (Workplace Wellness Programs Study Soeren Mattke, et.al.)

Workplace-based health and wellness programs (HWPs) may be an obvious yet under-utilized strategy for promoting positive health-related behaviors among older workers and for increasing their ability to continue to work. Given the unprecedented number of older adults who extend their labor force attachment beyond traditional retirement ages, a new vision of older adults' economic security and overall quality-of-life should take into account the intersections of aging, work, and health.
\end{abstract}

\section{Introduction}

\section{Periodic health screening}

Over the last several decades, an epidemic of "lifestyle diseases" has developed in the Nigeria; especially at work place environment. Unhealthy lifestyles, such as inactivity, poor nutrition, tobacco use, and frequent alcohol consumption, are driving up the prevalence of chronic disease, such as diabetes, heart disease, and chronic pulmonary conditions. These chronic conditions have become a major burden, as they lead to decreased quality of life, premature death and disability, and increased health care cost during work and after.

The periodic health screening is to evaluate health status, screen for risk factors and disease, and provide preventive counseling interventions in an age-appropriate manner. The goal of screening and evaluation is to prevent the onset of disease or the worsening of an existing disease. For example, measurement of blood pressure is intended to detect hypertension so as to initiate treatment and prevent subsequent morbidity (e.g., stroke or renal failure) or mortality. A further goal of the periodic health examination is to educate patients about behavioral patterns or environmental exposures that pose risks for future diseases. Examples include counseling about smoking prevention and cessation to prevent lung cancer and emphysema, seat belt use to prevent motor-vehicle injuries, or modifying sexual practices to prevent the spread of sexually transmitted disease. Workers with daily task can be exposed to health hazards that may be debilitating and life threatening. The Whole-population screening by routine periodic general health checks is an attractive concept for the general public, politicians and professionals with an interest in public health. Intuitively health checks seem to offer the opportunity for early detection of risk factors for the common causes of morbidity and mortality, or early stages of actual disease, with a subsequent prevention of diseases and disorders by early identification and treatment of risk factors is a major element of public health practice. In this article presentation explanation are broadly divided prevention interventions into those at the individual and population level at workplace. The population strategy targets whole populations irrespective of individual risk status, while the individual strategy targets those thought to be at 'high risk' of the health conditions of interest opportunity of early intervention and consequent reduction in the population disease burden. Such logic has led to widespread provision of health checks has also extended into occupational health practice, and occupational health services commonly offer and run 
such programmes on behalf of public and private employers. Such screening services are frequently promoted by occupational health services to employers on the premise of reduced disease burden in employees and subsequent reduced sickness absence.

\section{Purpose of study, methodology and result}

Purpose of study: The rationale for hypothesizing that health screenings would be effective independent of additional behavioral change programming is that employees who are aware of their health status may be motivated to make behavioral changes on their own, identify other sources of support for making behavioral changes, or seek follow-up medical care.

Method of research: Qualitative research method

Sampling methods: Are the number various age groups of FTEs (full time employees) in a food beverage organization

\section{Method}

In this research study, 250 employees from food beverage organization workplace, health promotion program, a program conducted since 2012 and using data from the 2012-2016 follow-up period. Participants were permanent employees aged between 25-35 years and above, with at least one follow up measurements annually. Baseline socio-demographic information was collected using a questionnaire while vital signs measurements and various blood testing were collected during annual /periodical health screenings on different screenings.

Results: The evidence is evaluating the effectiveness of worksite health screening demonstrates

1) Gradual decrease in various health risk and diseases attitude.

2) Enhancing positive health behavioral attitude and response that is most effective enhancing encouragement to participate in some type of health and wellness program.

3) Gradual Decrease in terminal health diseases including nil record of re-infection of co-worker, family through empowering health program/health promotion.

\section{Workplace screening}

Is an health monitoring act before, during and after work.

Is a medical assessment to detect diseases or identify people at risk/potential risk factors that may affect health of an individual while at work

\section{A workplace health program?}

- A workplace health program is a health promotion activity or organization-wide policy designed to support healthy behaviors and improve health outcomes while at work and after leaving the work (retirement).

\section{Types of screening}

- Vital signs

- Blood screening for FBC(full blood count),

- FBS/RBS(Fasting/Random blood sugar),

- Lipid profile, RVS(retroviral screening),

- HBsAg \& HCV,(Hepatitis B \& C)

- Urinalysis

- ECG

- CHEST-x-ray

- Audiometry

- Spirometry

- Visual Acuity

- Etc. 


\section{Characters of healthy workforce}

When seeing people beaming with smiles on their faces at work, in front of their duty desk, machine and position due to:

- Job satisfaction and achievement for the day;

- Low turnout to clinic for treatment but turnout to for counseling

- Low complaint about ailment,

- Seeking for medical advices (preventive treatment/curative in psychotherapy) were becoming encouraging by day,

- Productivity target met yielding to increase profit \& benefits for employer/organization

- Reduction in time loss in concentration at work, and so on;

People will believe that, there are provision of medical health services through health personnel has empowered the employee to stay healthy and however assisting the employer to make policy on both maintaining and sustaining an healthy worker.

More so, with healthy determination on lifestyle, worker can withstand pressures, bullying, adaptive and resilience to situations.

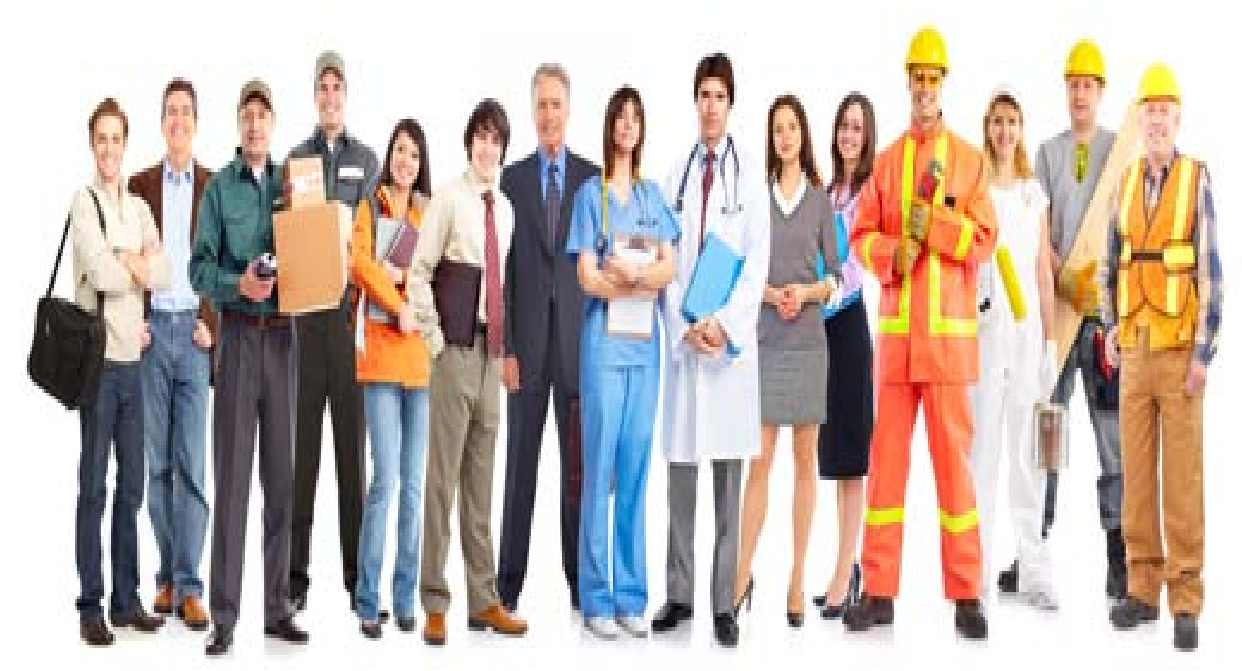

Resuming work in 2012 February has been a tough time putting the heart and behavior of people to do right in health and safety behavior for example:

- Discouraging of spitting on the floor /sneezing into the air/attitude that can be injurious to others health

- Discouraging of floor littering/poor housekeeping,

- Value the use of signage/safety rules around the workplace

- Discouraging the use of self-medication, herbal concoction, smoking around the premises and every hazardous activity that can affect health.

- Seeking prompt medical intervention when required.

- Making more emphasis on more pre-employment screening to post employment screening.

- Maintain work life balance etc.

\section{World health organization (WHO) literature review}

Through governmental legislation and regulation, employers have been made responsible for maintaining the safety of the work environment and work practices, and for the treatment, rehabilitation and compensation of workers with occupational injuries and disease. In recent decades, however, employers have begun to recognize that disabilities and absenteeism are costly even when they originate outside the workplace. Consequently, employer has begun to provide more and more 
comprehensive health promoting and protecting programs not only for employees but for their families as well.

In opening a 1987 meeting of a World Health Organization (WHO) Expert Committee on Health Promotion in the Work setting, Dr. Lu Rushan, Assistant Director-General of WHO, reiterated that WHO viewed workers' health promotion as an essential component of occupational health services (WHO 1988). (Leon J. Warshaw and Jacqueline Messite)

\section{What is a screening?}

Screening involves the utilization of a diagnostic procedure to check for the presence of a disease prior to the manifestation of clinical symptoms.

A screening is a medical assessment to detect diseases or serious health conditions. In the past, patients were treated when they became sick.

A careful history and a physical examination are important parts of the periodic health examination.

- The patient history elicits recent and current symptoms or complaints; medications being taken (and any allergies to medications); an accounting of the past medical history of the patient; the social factors that may impact on the health of the patient (e.g., marital status, household makeup, employment); a family history of illnesses affecting family members; and a review of signs and symptoms for each of the organ systems in the body.

- The physical examination consists of three modalities to gather information: inspection, auscultation, and palpation. These methods are applied in a systematic way to the major systems of the body.

- Inspection involves observation of the body part being examined. The general appearance (physical inspection), color, and any other visual characteristics are noted.

- Auscultation involves listening, often with the aid of a stethoscope.

- Palpation involves feeling both the size and texture of organs under examination. The major areas of the body to be examined are the head and neck, chest, abdomen, extremities, skin, musculoskeletal system, and nervous system.

Using the three modalities in conjunction with the patient's medical history and screening tests allows an assessment of the overall health of a patient. Now we know early detection can make health problems easier to treat and cure. Screenings improve lives, save lives, and also save money!

\section{Types of screening}

- Vital signs

- Blood screening for FBC(full blood count), FBS/RBS(Fasting/Random blood sugar), Lipid profile, RVS(retroviral screening), HBsAg \& HCV, (Hepatitis B \& C)

- Urinalysis

- ECG

- CHEST-x-ray

- Audiometry

- Spirometry

- Visual Acquity

- Mammogram

- Pap smear etc.

\section{Classes of periodical screening}

- $\quad$ Pre-employment (New intake/ Before work)

- $\quad$ Health profile (Annual Medical Screening)

- $\quad$ Food Handlers' screening(Bi-annual, 6monthly screening)

- Complete Comprehensive Health screening (Age Restricted screening 35years \&above for female and 40years and above for male). 
- $\quad$ Pre-placement screening (transfer/inter/intra departmental fit before assuming new job position)

- $\quad$ Post-employment screening (Retrenchment /After work)

\section{Health education/campaign/coaching}

\section{What is a workplace health program?}

A workplace health program is a health promotion activity or organization-wide policy designed to support healthy behaviors and improve health outcomes while at work.

\section{Workplace health promotion - What is it?}

The European Network for Workplace Health Promotion has defined workplace health promotion as the combined efforts of employers, employees and society to improve the health and well-being of people at work. This vision of workplace health promotion places particular emphasis on improving the work organization and working environment, increasing workers' participation in shaping the working environment, and encouraging personal skills and professional development.

\section{Benefits of workforce health promotion}

\begin{tabular}{|l|l|}
\hline To the organization & To the employee \\
\hline $\begin{array}{l}\text { a well-managed health and safety } \\
\text { programme }\end{array}$ & $\begin{array}{l}\text { a safe and healthy work } \\
\text { environment }\end{array}$ \\
\hline a positive and caring image & enhanced self-esteem \\
\hline improved staff morale & reduced stress \\
\hline reduced staff turnover & improved morale \\
\hline reduced absenteeism & increased job satisfaction \\
\hline increased productivity & $\begin{array}{l}\text { increased skills for health } \\
\text { protection }\end{array}$ \\
\hline reduced health care/insurance costs & improved health \\
\hline reduced risk of fines and litigation & $\begin{array}{l}\text { improved sense of well- } \\
\text { being }\end{array}$ \\
\hline
\end{tabular}

\section{What is health coaching?}

Health Coaching is a confidential partnership between the employee and a health coach with the objective of assisting the employee to achieve his or her personal wellness goals. Health coaching utilizes effective behavioral psychology principles to assist people to make lifestyle changes.

How?

Monthly health talk given to people in their various Departments /Canteen on WHO (World Health Events topics)

Weekly Health talk/ tool box/ one point lesson sent round the intranet communication network around the brewery organization.

\section{Research study 1}

In the beginning of the year especially after the Christmas/New Year Holidays, a particular screening is done to: Identity, Assess, Coordinate Health program, implement care and Evaluate and Re-evaluate care (follow up) is called the Annual Health profile screening.

Objective of the screening is:

1) To have a data base of nature of health of a workers

2) To segregate individual for care and follow up

3) To give a guide to the health personnel for health discussion topics/programs that workers and their families can benefit

4) To give a report that can enhance achieving health and safety related policies to both employer and employee. 
Texila International Journal of Public Health

Volume 4, Issue 4, Dec 2016

Table 1. Total Workforce

\begin{tabular}{|l|l|l|l|l|l|}
\hline Years & 2012 & 2013 & 2014 & 2015 & 2016 \\
\hline Male & 232 & 232 & 238 & 242 & 236 \\
\hline Female & 18 & 18 & 12 & 8 & 14 \\
\hline Total & 250 & 250 & 250 & 250 & 250 \\
\hline
\end{tabular}

Table 2. Diseases Trend

\begin{tabular}{|l|l|l|l|l|l|}
\hline Years & 2012 & 2013 & 2014 & 2015 & 2016 \\
\hline Hypertension & 32 & 26 & 22 & 18 & 16 \\
\hline Diabetes & 3 & 2 & 1 & 0 & 1 \\
\hline Hepatitis & - & - & 14 & 14 & 14 \\
\hline Tuberculosis & - & - & - & - & - \\
\hline Kidney disease & - & - & - & 1 & 1 \\
\hline Obesity & 47 & 38 & 32 & 21 & 8 \\
\hline Others & - & - & - & - & - \\
\hline
\end{tabular}

\section{Discussion}

The capacity of employee workforce that can occupy the brewery organization is at most 250, which in turn means that through retirement, sack the standby workforce used regularly were 250 .

The $\mathbf{1}^{\text {st }}$ table shows the sex distribution, while Table 2 shows the lineup of identified both communicable and non-communicable diseases along with their trend in reduction through: Education, treatment and monitoring.

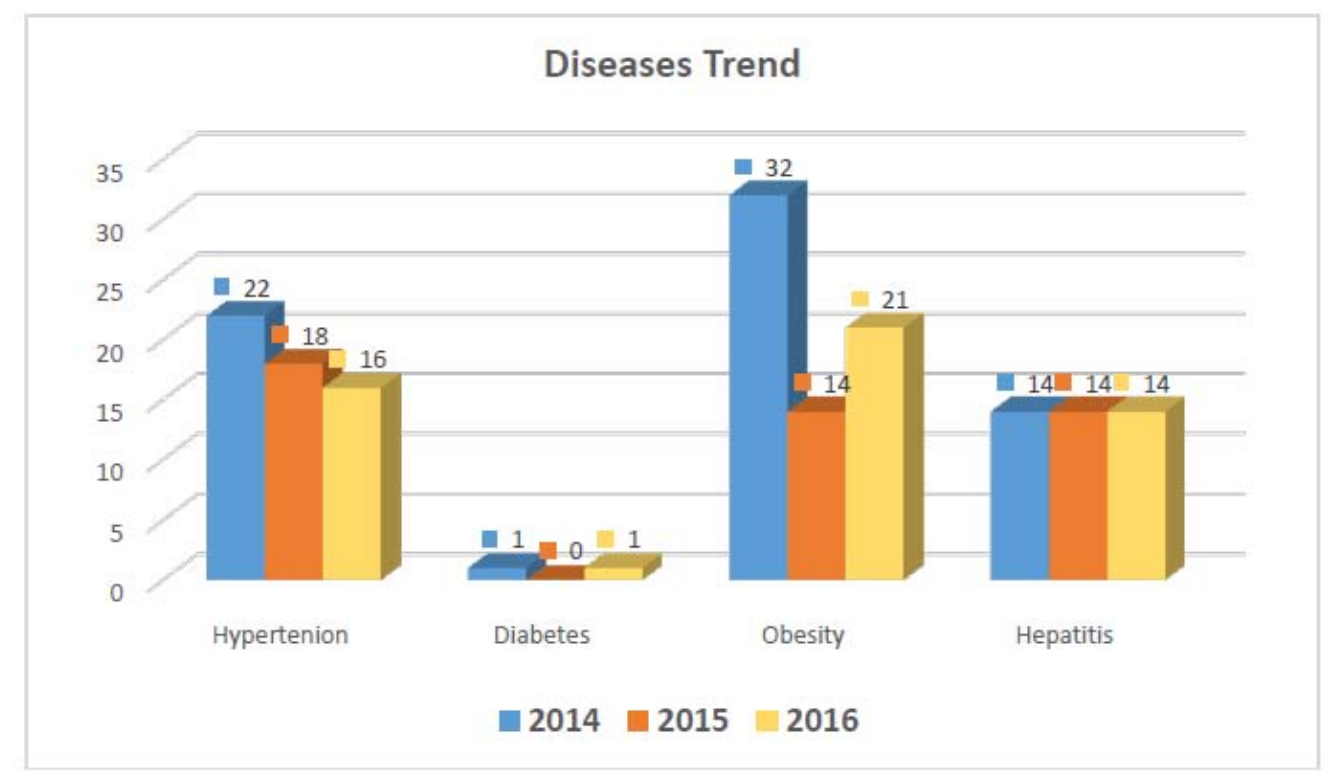

\section{Research study 2}

As Health Surveillance Nurse in food Production industry the start of food handlers' exercise took lot of challenges: encouraging participation not because of target but passion in having a healthy people in healthy environment, encouraging the affected ones in taking their medication on DOT (Direct Observation Therapy) and repeating their stool sample screening, monitoring they stay away from work till outcome of the repeat stool screening for Ascaris and SalmonellaTyphi. 
Table 3. Participation and outcome of health screening

\begin{tabular}{|l|l|l|l|l|l|}
\hline Years & 2012 & 2013 & 2014 & 2015 & 2016 \\
\hline Ascaris & 32 & 28 & 18 & 10 & 7 \\
\hline Salmonella & 17 & 13 & 5 & 3 & 1 \\
\hline Total & 49 & 41 & 23 & 13 & 8 \\
\hline
\end{tabular}

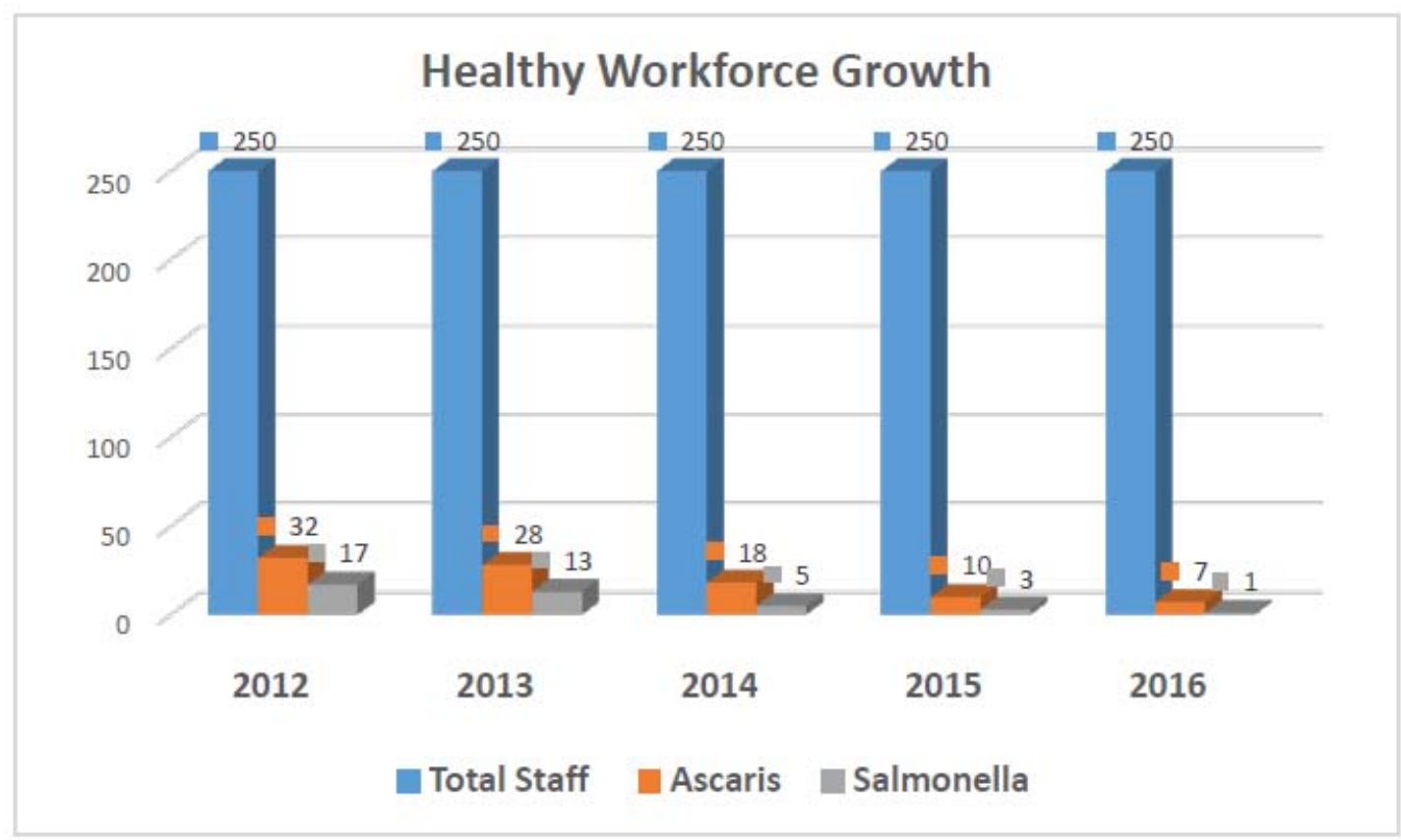

\section{Research Study 3}

\section{Treatment success through counseling from health education}

In this study, I will choose to discuss about common complaint which is STRESS in which counselling from Health Education and review discussion brought about more positive responses, compliance, and adherence to healthy lifestyle, bringing out self confidence in reducing unsafe act inself-medication use. 


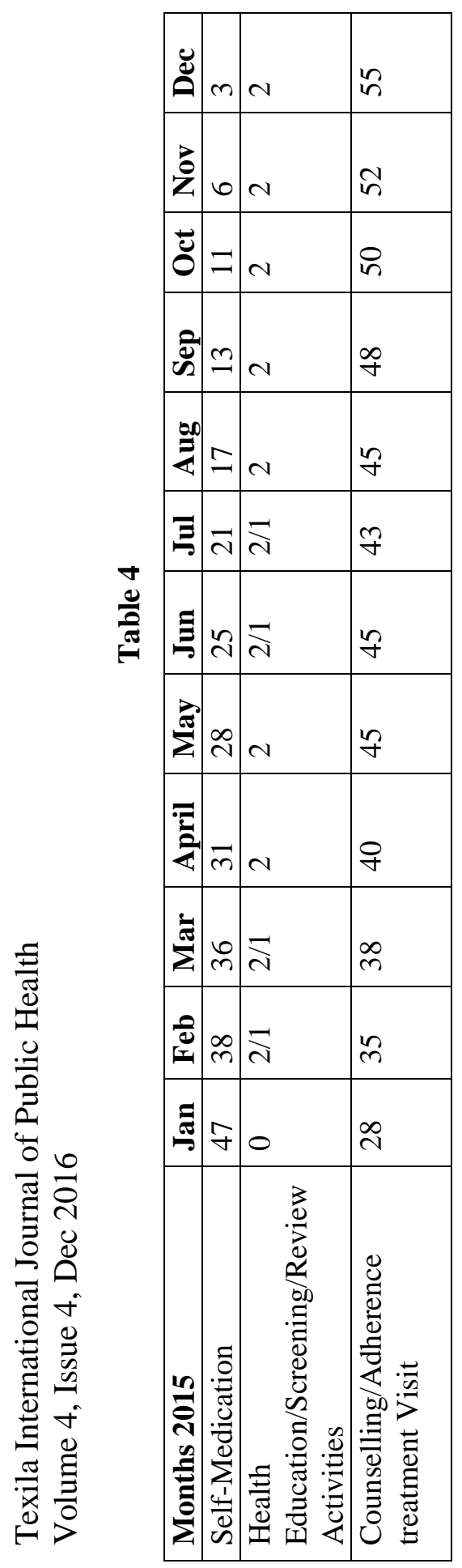




\section{Interpretation of results}

From the first row it shows, throughout the months in 2015 from Jan - Dec

The range of self-medication was reducing even when monthly Health education and health review was stable and constant creating warm atmosphere of confidence and increase relationship bonding between Medical personnel and the workforce within the organization.

\section{Effect of Health promotions / Counselling}

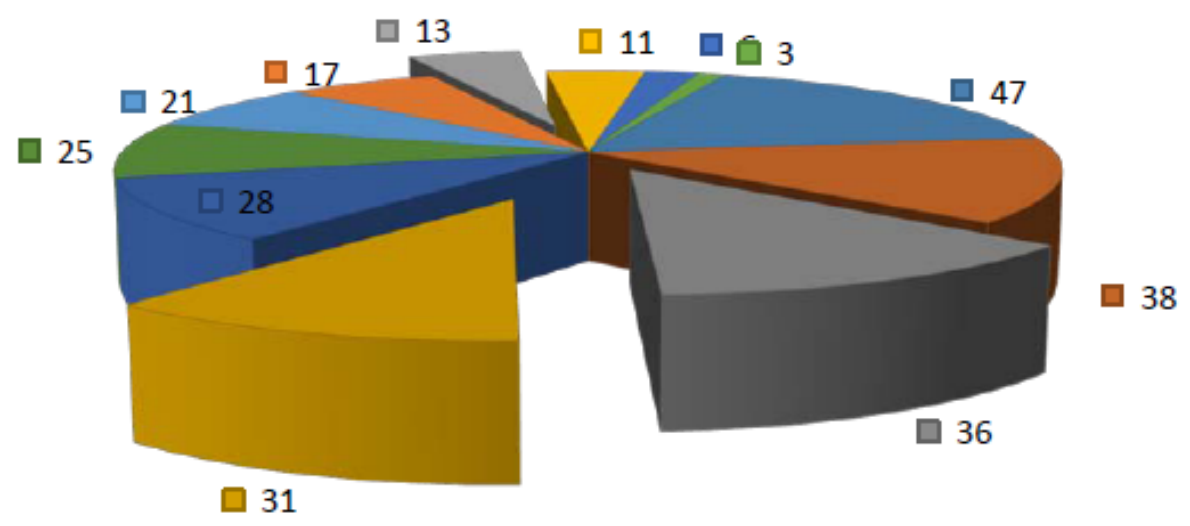

$\square$ Jan $\square$ Feb $\square$ March $\square$ April $\square$ May $\square$ June $\square$ July $\square$ Aug $\square$ Sept $\square$ Oct $\square$ Nov $\square$ Dec

\section{Conclusion}

It is clear from all of the above that the worksite health promotion programme represents an extension of the occupational safety and health programme which, when properly designed and implemented, can benefit individual employees, the workforce as a whole and the organization. In addition, it may also be a force for positive social change in the community.

Periodic health check-ups and screenings at work with health care provider are key to maximizing chance of living a longer and healthier life. Not only can they help prevent health problems before they start, but regular check-ups may also help you discover health problems early enough to increase your chances of successful treatment and recovery.

Health screenings are evaluations for employees to identify their current and potential future medical problems. The major aspect of health screening/coaching is to encourage moderate/high health risk employees to take measures to prevent the onset of worsening of a disease or illness and to adopt a healthier lifestyle.

The use of counseling as a way of responding to people in distress has grown rapidly in recent years. While it has proven popular with many people, the rapid growth of counseling has also generated some disquiet and numerous questions (Feltham 1999, 2002).

Employee Health Screenings, health promotion, health education and counseling promote overall health and wellness for employees to decrease chronic disease states, improve employee health and productivity, and reduce long-term costs.

Early detection and treatment are all beneficial to both parties: the employees and the employer! 
Texila International Journal of Public Health

Volume 4, Issue 4, Dec 2016

\section{References}

[1]. Serra C, Rodriguez MC, Delclos GL, Plana M, Gómez López LI, Benavides FG. Criteria and methods used for the assessment of fitness for work: a systematic review. Occup Environ Med 2007; 64: $304-12$ doi: 10.1136/oem.2006.029397pmid: 17095547.

[2]. Carter T. The application of the methods of evidence based practice to occupational health. Occup Med (Chic Ill) 2000; 50: 231-6.

[3]. Franco G. Evidence-based decision making in occupational health. Occup Med (Chic Ill) 2005; 55: 1-2 doi: 10.1093/occmed/kqh118.

[4]. Harris JS, Glass L, Mueller K, Genovese E. Evidence-based occupational medicine. Clin Occup Environ Med 2004; 4: 341-60 doi: 10.1016/j.coem.2004.02.002

[5]. Shepherd J. Pre-employment examinations: how useful? J Am Board Fam Pract 1992; 5: 617-21 pmid: 1462795.

[6]. Bower Peter, N Rowland, John Mellor-Clark et al. (2003) Effectiveness and cost effectiveness of counselling in primary care (Cochrane Review). The Cochrane Library, Issue 1, Oxford: Update Software.

[7]. Bower, Peter, Sarah Byford, Bonnie Sibbald et al. (2000) Randomized controlled trial of non-directive counselling, cognitive-behaviour therapy, and usual general practitioner care for patients with depression. II: Cost effectiveness BMJ 321, 1389-1392

[8]. NHS. Putting Prevention First-NHS Health Check: Vascular Risk Assessment and Management. Best Practice Guidance. www.healthcheck.nhs.uk/document.php?o=224(2 January 2013, date last accessed).

[9]. The Healthy Working Lives Award. http://www.healthatwork.org.uk/shaw/info.asp?p=142 (2 January 2013, date last accessed)

[10]. M. Bending, S. Beale and J. Hutton, An Economic Analysis of Workplace Interventions that Promote Physical Activity (York Health Economics Consortium), 2008:

[11]. http://www.citeulike.org/user/vigez/article/5010080 2 H. Vaughan-Jones and L. Barham, Healthy Work: Evidence into Action (Bupa), 2010:

[12]. http://workfoundation.com/Assets/Docs/healthy-work-evidence-into-action-report.pdf 3 World Health Organization, Preventing Chronic Disease:

[13]. A Vital Investment (2005), p. 2: http://www.who.int/chp/chronic_disease_report/en/index.html 4 Ibid., p. 18. 5

[14]. World Health Organization, Global Status Report on Non-communicable Diseases 2010 (2011), p. 1: http://www.who.int/nmh/publications/ncd_report_full_en.pdf 6 World Economic Forum/Harvard School of Public Health,

[15]. The Global Economic Burden of Non-communicable Diseases (2011): http://www.weforum.org/reports/global-economic-burden-non-communicable-diseases $\quad 7 \quad$ R.M. Honigberg and K.A. Kurth, Fulfilling the Promise of Workplace Wellness: Global Trends, Innovative Approaches and Quality Assurance Strategies No. 1-21 (URAC), 2010:

[16]. http://63.251.80.205/forms/store/ProductFormPublic/search?action=1\&Product_productNumber=IHPA\%2 oW 


\title{
Knowledge and Practice of Self-medication among Students of School of Nursing in selected schools in Osun State
}

\author{
Article by Abioye Abigail Adebisi \\ $B S N-M S N$ in Nursing, Texila American University, Nigeria \\ E-mail: sundayabioye@gmail.com
}

\begin{abstract}
Self-medication can potentially do well and also harm people. It is a common practice and internationally has been reported as being on the rise. Studies have observed self-medication as a common practice among group of health workers that included dental, midwifery and nursing students. Hence, this study assessed the knowledge and practice of self-medication among students of school of nursing in selected schools in Osun State. It was a descriptive cross-sectional survey. Samples of two hundred nursing students were included in the study using purposive sampling.

The result in this study showed that majority (91\%) of the nursing students had high level of knowledge and about two third (64.5\%) indulge in high practice of self medication respectively. More than half of them signified that presence of minor ailments and having enough knowledge about drugs were the factors that always make them to self-medicate, while more than forty percent indicated that financial constraint, previous experience, time saving, advertisement and unavailability of health care services as factors that sometimes influence self-medication. Significant relationship existed between knowledge and practice of self medication $(t=-3.116, d f=198, P<0.05)$.

Nursing students demonstrated high level of knowledge about medication and its effects. Majority indulge in self-medication practices. Those with high level of knowledge practice of self medication less. It would be safer if those who self-medicate have sufficient knowledge to prevent serious effects. It is recommended that policies be formulated to control the purchase and use drugs.
\end{abstract}

Keywords: Practices of self-medication among nursing students

\section{Introduction}

Self -medication is a common practice and internationally has been reported as being on rise and can produce a good result and be a convenient practice for patient (Verma, Mohan and Pandey, 2010). It was observed that self-medication is a common practice among group of health workers that included dental, midwifery and nursing students (Ehigiator, Azodo, Ehizele, Ezeja, and Ehigiator et al, 2013). In Nigeria, high degree of irresponsible selfmedication is practised (Olayemi, Olayinka and Musa, 2010).

Self-medication can potentially do well and also harm people. This is especially significant in those countries where prescription drugs are available over-the-counter (OTC) due to lack of enforcement of regulations (Sontakke, Bajait, Pimpalkhute, and Jaiswal, 2011). The increase in the quantities and varieties of pharmaceuticals worldwide eases the accessibility of medicine by consumers, thereby giving options for its misuse (Ehigiator, et al 2013). Recent development of the pharmaceutical companies contribute to a wide spread availability of OTC Medicine. There is also the potential for misuse and abuse of such products (Ali, Ibrahim and Palaian, 2010). Its irrational use increases the risk of adverse effects, bacterial infection, hypersensitivity, drug withdrawal symptom and of masking disease which can delay correct diagnosis (Bernal and Silva, 2010).

The common sources of self-medication are previous prescription, friends, advertisements, chemist shop and books (Joshi, Shalini and Agarwal, 2011). Self-medication is influenced by many factors such as education, family, society, law, availability of drugs and exposure to 
advertisements (Vizhi and Senapathi, 2010). Modern consumers (patients) wish to take a greater role in the maintenance of their own health and are often competent to manage (uncomplicated) chronic and recurrent illnesses (not merely short-term symptoms) after proper medical diagnosis and with only occasional professional advice. They are understandably unwilling to submit to the inconvenience of visiting a doctor for what they rightly feel they can manage for themselves, given adequate information (Vizhi and Senapathi, 2010).

Inappropriate self-medication results in wastage of resources, increased resistance of pathogens to drugs, and generally entails serious health hazards such as adverse reactions and prolonged hospitalization. Self-medication among future health care professionals can represent a serious threat to professionalism in medicine and it has potential to put at risk public trust into this profession (Lukovic, Miletic, Pekmezovic, Trajkovic, Ratkovic, et al, 2014). In Nigeria, high degree of irresponsible self-medication is practised (Olayemi, Olayinka and Musa, 2010).

The practice of self-medication among students seems to be on the increase. Dimabayao and Mohammad (2016) found the prevalence of self-medication practice among nursing students in Jazan University, Kingdom of Saudi Arabia to be $43 \%$. There has been an increasing tendency of self medication behaviour among various health sciences graduates and students including doctors, pharmacists and nurses in different regions of the world (Banerjee and Bhadury, 2012).

Some of the problems associated with self-medication such as masked diagnoses, use of excessive drug dosage, prolonged duration of use, drug interactions, polypharmacy and superinfection can occur in self-medicating individuals. A number of reasons have been adduced for the rise of self-medication among students. This study would help the researcher to picture the pattern of self-medication among nursing students, identify multiple factors associated with self-medications.

Hence the reason for this study is due to high rise of self medication in the society. The nursing students just like any other students in medical line are conversant with drugs and have basic knowledge of pharmacology. This study explored the knowledge and practise of self medication among nursing students in selected schools of nursing in Osun State.

Responsible self-medication entails using approved and available medicine in a safe and effective way as directed though without prescription (WHO, 2014). The types of drugs used are indicated for a self-recognisable condition following initial medical diagnosis, which means that users have previous knowledge of the dose, time and side effect(s) of the overdose of the drug. Responsible self-medication is possible in the developed nations because of high quality of education, accessibility to health information, safety and quality health care including government policies on health coupled with the health-seeking behaviour and sceptical expert knowledge (Talevi, 2010).

Responsible self-medication is the use of a registered or mono-graphed medicine legally available without a physician's prescription, either on an individual's own initiative or following advice of a healthcare professional. The use of prescription medicines without a prior medical prescription is not part of responsible self-medication. The safety, efficacy and quality of non-prescription medicines must be proved according to the same principles as prescription medicines (WMA, 2012).

Non-responsible self-medication is the use of drugs in the treatment of self-diagnosed ailments or symptoms of diseases without supervision or prescription by a physician (Ruiz, 2010). It is characterised by indiscriminate use of drugs for the management of ailments many of which have resulted into intoxication (Galato, Galafassi, Alano and Trauthman, 2009). Major problem of non-responsible self-medication is the lack of clinical evaluation by a medical professional which can result into wrong diagnosis and delay in appropriate treatment, drug resistance, use of expired drugs, wrong doses and prolonged duration of usage. For an individual to self-medicate appropriately, he must be able to accurately recognize symptoms, set therapeutic objectives, select appropriate medicine to be used for his 
medical condition, and determine appropriate dosage and dosage schedule taking into account his medical history, contraindication and possible side effects of the medicine. This would therefore require adequate knowledge about medicines (Auta, Shalkur, Omale and Abiodun, 2012).

The factors influencing self-medication remains issues of intense debate in academic discourse (Osemene and Lamikara, 2012). Availability of drugs in markets and poor drug regulatory practices (Fadare and Tamuno, 2011) contribute to self-medication. Many Nigerians, most times, trivialize ailments such as headache, fever, cough, throat infection, common cold and stomach ache (Emmanuel, Daniel, Achema, Afor, Onyejekwe and Gimba, 2011). Other factors like demographic factors have been found to influence self-medication. For instance, gender, age, sex and social role were discovered to have influence on selfmedication (Osemene and Lamikara, 2012). Some studies revealed higher prevalence of selfmedication among males than females (Al-Hussaini, Mustafa and Ali, 2014) while some scholars found no strong association between gender (Emmanuel, et al, 2011). On the other hand, a high level of education and professional status of mothers are showed to be risk factors for adolescent self-medication in some studies (Awosusi et al, 2015).

According to Dimabayao and Mohammad (2016), social, financial and health related factors drive the use of medications. Some factors why individuals practice self-medication include geographical difficulties in accessing health care centres and unavailability of qualified medical doctors. El-Nimr, Wahdan, Kotb and Wahdan (2015) adduced the reason for practicing self medication was that it is less expensive compared to medical care in the hospital. The fact remains that many rural communities have little or no access to modern medical care because of the uneven distribution or inadequate health facilities (Arikpo, Eja and Enyi-Idoh, 2009). This may encourage the practice of self- medication.

Several factors including poverty, cultural perception of certain diseases' entity and their perceived responses to indigenous medications have been widely reported as indicators in developing countries making the practice a necessity (Shah, Parmar, Kumkishan and Mehta, 2011). This makes it more dangerous as basic knowledge concerning the pharmacological properties of these substances/ drugs may be lacking. Improvements in people's general knowledge, level of education and socioeconomic status in many countries form a reasonable basis for successful self-medication. Several factors could affect the self medication practice and that includes sex, age, and race, educational \&economic status (Albalawi, Al-Anazi, Althamali Alzhahrani and Aloqbi, 2015).

\section{Methodology}

The study adopted a cross-sectional descriptive design. The study settings were School of Nursing, OAUTHC, Ile-Ife and School of Nursing, Wesley Guild Hospital, Ilesa, Osun-State. The target population were student nurses in the selected schools of nursing, total number of two hundred students. Purposive sampling technique was adopted in this study as only students in 200level and 300level formed the sample size.

The instrument for data collection was a self-structured questionnaire. The instrument has four sections. Section A sought the socio-demographic data. Section B assesses the knowledge of the students about self-medication. Section C determines the practices of selfmedication among students, while Section D identifies factors influencing self-medication among students. Questionnaires were administered hand to hand for four days.

The data collected was analyzed using Statistical package of social sciences (SPSS), version 20. The research questions were censored using a descriptive analysis like percentages, frequencies and tables where applicable.

In determining the level of knowledge of respondents on self-medication, each correct answer to the 11-item questions in table 2 above were scored 1 . All the questions were summed together and the highest possible score was 11 . The median score is 6 . Scores above the median score are categorized as Good knowledge about medicines and effects of self medication, while scores below had poor knowledge. In determining the level of practice of 
Texila International Journal of Public Health

Volume 4, Issue 4, Dec 2016

self medication among respondents, each correct answer in the 8-item questions in table 3 above were awarded 1 mark. All the questions were summed together and the median score was 4 and the highest possible score was 8 . Scores above the median score are said to have high level practice of self medication, while scores below had low level practice of self medication.

\section{Results}

Completely filled two hundred questionnaires were used for the analysis.

Table 1. Socio-demographic Data of the Respondents $(n=200)$

\begin{tabular}{|c|c|c|c|}
\hline Variables & & Frequency & Percent \\
\hline \multirow{3}{*}{$\begin{array}{l}\text { Age group in years: } \\
\text { Mean }=21.57, S D=3.08 \\
\text { Min }=18, \text { Max }=38, \text { Range }=20\end{array}$} & $10-19$ & 25 & 12.5 \\
\hline & $20-29$ & 167 & 83.5 \\
\hline & $30-39$ & 8 & 4.0 \\
\hline \multirow{2}{*}{ Ethnicity } & Yoruba & 191 & 95.5 \\
\hline & Igbo & 9 & 4.5 \\
\hline \multirow{2}{*}{ Gender } & Male & 26 & 13.9 \\
\hline & Female & 174 & 87.0 \\
\hline \multirow{2}{*}{ Religion } & Christianity & 137 & 68.5 \\
\hline & Islam & 63 & 31.5 \\
\hline \multirow{2}{*}{ Level of education } & 200 Level & 50 & 50.0 \\
\hline & 300 Level & 50 & 50.0 \\
\hline \multirow{6}{*}{$\begin{array}{l}\text { Position in the family (number) e.g. } \\
\text { 1,2,3: }\end{array}$} & 1 & 61 & 30.5 \\
\hline & 2 & 59 & 29.5 \\
\hline & 3 & 40 & 20.0 \\
\hline & 4 & 14 & 7.0 \\
\hline & 5 & 15 & 7.5 \\
\hline & $>5$ & 11 & 5.5 \\
\hline \multirow{5}{*}{ Number of children in the family } & 1 & 6 & 1.6 \\
\hline & 2 & 28 & 7.5 \\
\hline & 3 & 86 & 23.0 \\
\hline & 4 & 133 & 35.6 \\
\hline & $\begin{array}{l}\text { More than } 4 \\
\text { children }\end{array}$ & 121 & 32.4 \\
\hline
\end{tabular}

Table 1 above showed that the mean age and the standard deviation of the respondents were $21.57 \pm 3.08$. Majority (83.5\%) of the respondents were within ages $20-29$ years, almost all (95.5\%) were Yoruba and majority (87.0\%) were females. About two-third (68.5\%) were Christians and just half (50.0\%) of them were in the 200 level. 
Table 2. Knowledge about Medicines and effects of self-medication

\begin{tabular}{|l|l|l|l|}
\hline Knowledge Questions & $\begin{array}{l}\text { Agreed n } \\
(\mathbf{\%})\end{array}$ & $\begin{array}{l}\text { Uncertain } \\
\mathbf{n}(\mathbf{\%})\end{array}$ & $\begin{array}{l}\text { Disagree } \\
\mathbf{n}(\mathbf{\%})\end{array}$ \\
\hline $\begin{array}{l}\text { Self-medication can have harmful effects on one's } \\
\text { health }\end{array}$ & $194(97.0)$ & $4(2.0)$ & $2(1.0)$ \\
\hline Self-medication can lead to substance abuse & $192(96.0)$ & $6(3.0)$ & $2(1.0)$ \\
\hline $\begin{array}{l}\text { It is good to combine traditional medicine with } \\
\text { western medicine }\end{array}$ & $16(8.0)$ & $30(15.0)$ & $154(77.0)$ \\
\hline Antibiotics are needed for common cold & $78(39.0)$ & $29(14.5)$ & $93(46.5)$ \\
\hline $\begin{array}{l}\text { One can use the same drug for similar ailment } \\
\text { anytime }\end{array}$ & $28(14.0)$ & $23(11.5)$ & $140(74.5)$ \\
\hline $\begin{array}{l}\text { You can stop treatment as soon as the symptoms } \\
\text { had disappeared }\end{array}$ & $30(15.0)$ & $18(9.0)$ & $152(76.0)$ \\
\hline $\begin{array}{l}\text { One can take many types of antibiotics at the } \\
\text { same time during the course of a single illness }\end{array}$ & $42(21.0)$ & $19(9.5)$ & $139(69.5)$ \\
\hline $\begin{array}{l}\text { There is no big deal if one skips or forget to take } \\
\text { his antibiotic drugs }\end{array}$ & $16(8.0)$ & $25(12.5)$ & $159(79.5)$ \\
\hline $\begin{array}{l}\text { Overuse of some drugs can result in drug } \\
\text { resistance }\end{array}$ & $188(94.0)$ & $6(3.0)$ & $6(3.0)$ \\
\hline Antibiotics can be effective for viral infections & $72(36.0)$ & $28(14.0)$ & $100(50.0)$ \\
\hline $\begin{array}{l}\text { Expensive drugs are more effective and have less } \\
\text { side effects }\end{array}$ & $54(27.0)$ & $50(25.0)$ & $96(48.0)$ \\
\hline
\end{tabular}

In table 2 above, almost all (97\%) the respondents agreed that self-medication can have harmful effects on people's health, $96 \%$ also indicated that it leads to substance abuse, and $94 \%$ agreed that over use of some drugs can result in drug resistance. About three-quarter (77\%) respectively disagreed that it is good to combine traditional medicine with western medicine, $74.5 \%$ disagreed that one can use the same drug for similar ailment anytime, $76 \%$ opposed that one can stop treatment as soon as the symptoms had disappeared and $79.5 \%$ also opposed that there is no big deal if one skips or forget to take his antibiotic drugs. About twothird (69.5\%) opposed that one can take many types of antibiotics at the same time during the course of a single illness, half of them disagreed that antibiotics can be effective for viral infections. Furthermore, larger percentage (48\%) respectively opposed that expensive drugs are more effective and have less side effects, and $46.5 \%$ disagreed that antibiotics are needed for common cold.

Table 2.1. Summary of Knowledge about Medicines and effects of self-medication

\begin{tabular}{|l|c|c|c|c|}
\hline $\begin{array}{l}\text { Level of } \\
\text { Knowledge }\end{array}$ & Frequency & Percent & Median Score & Max Possible Score \\
\hline Poor Level & 18 & 9.0 & 6 & 11 \\
\hline Good Level & 182 & 91.0 & & \\
\hline Total & 200 & 100.0 & & \\
\hline
\end{tabular}

In determining the level of knowledge of respondents on self-medication, each correct answer to the 11-item questions in table 2 above were scored 1 . All the questions were summed together and the highest possible score was 11 . The median score is 6 . Scores above the median score are categorized as Good knowledge about medicines and effects of self medication, while scores below had poor knowledge. Table 2.1 showed that about almost all (91\%) of the respondents had good knowledge about medicines and effects of self medication, while $9 \%$ had poor knowledge. 


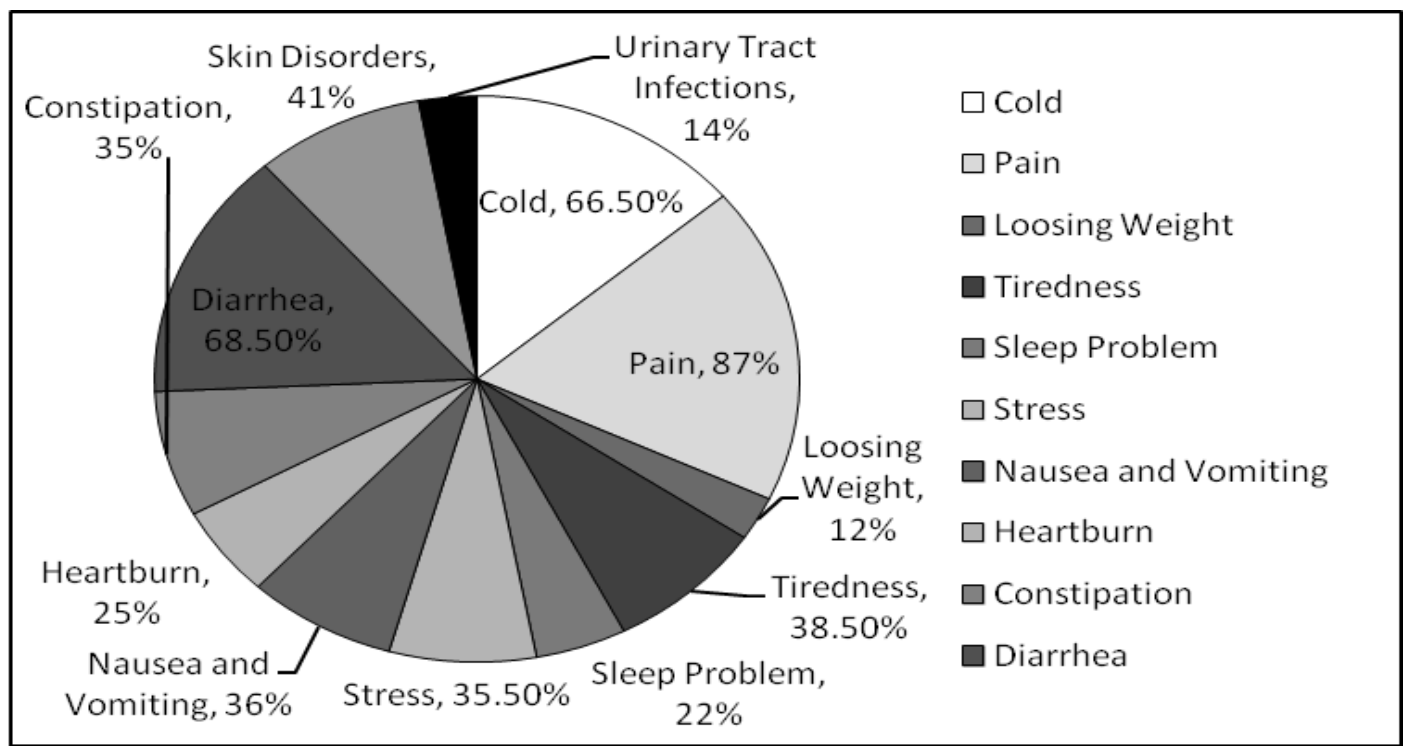

Figure 1. Factors Influencing the Use of Self-medication

The figure above showed that majority of the respondents have self-medicated for the following conditions; pain (87\%), diarrhoea (68.5\%) and cold (66.5\%).

Table 3. Practice of Self-medication

\begin{tabular}{|l|l|l|}
\hline Variables & Yes n (\%) & No n (\%) \\
\hline $\begin{array}{l}\text { Apart from treatment(s) prescribed by your practitioner, do } \\
\text { you sometimes take medicine to treat yourself? }\end{array}$ & $168(83.0)$ & $32(16.0)$ \\
\hline $\begin{array}{l}\text { Do you reuse the prescription when experienced with similar } \\
\text { symptoms? }\end{array}$ & $125(62.5)$ & $75(37.5)$ \\
\hline $\begin{array}{l}\text { Do you increase the drug dose on yourself when symptoms } \\
\text { are not relieved? }\end{array}$ & $27(13.5)$ & $173(86.5)$ \\
\hline $\begin{array}{l}\text { Do you discontinue the medicines by yourself when } \\
\text { symptoms are relieved? }\end{array}$ & $109(54.5)$ & $91(45.5)$ \\
\hline $\begin{array}{l}\text { Do you give your prescription/drugs to someone who is } \\
\text { having similar symptoms as yours before }\end{array}$ & $87(43.5)$ & $113(56.5)$ \\
\hline Do you combine herbal medicine and western medicine & $28(14.0)$ & $172(86.0)$ \\
\hline $\begin{array}{l}\text { I normally check the labels in my drug pack before using } \\
\text { them }\end{array}$ & $176(88.0)$ & $24(12.0)$ \\
\hline $\begin{array}{l}\text { I am willing to practice self-medication whenever the need } \\
\text { arises }\end{array}$ & $106(53.0)$ & $94(47.0)$ \\
\hline
\end{tabular}

Table 3 above showed the practice of self-medication among the respondents. Majority (83\%) of them indicated they sometimes take medicines not prescribed by the practitioners to treat themselves. Also, about two-third (62.5\%) signified they do reuse the prescription when they experience similar symptoms, however majority (86.5\%) do not increase the drug dose on themselves when symptoms are not relieved. A little over half (54.5\%) indicated they do discontinue the medicines by themselves when symptoms are relieved. More than half (56.5\%) of them do not give their prescription/drugs to someone who is having similar symptoms as the ones they once had. Majority $(86 \%, 88 \%)$ of them do not combine herbal with western medicine; normally check the labels in their drug packs before usage respectively. Over half (53\%) submitted that they are willing to practice self-medication whenever the need arises. 
Table 3.1. Summary of Practice of Self-medication among Respondents

\begin{tabular}{|l|l|l|l|l|}
\hline Level of Practice & Frequency & Percent & Median & Max Score \\
\hline Low Level & 71 & 35.5 & 4 & 8 \\
\hline High Level & 129 & 64.5 & & \\
\hline Total & 200 & 100.0 & & \\
\hline
\end{tabular}

In determining the level of practice of self medication among respondents, each correct answer in the 8-item questions in table 3 above were awarded 1mark. All the questions were summed together and the median score was 4 and the highest possible score was 8 . Scores above the median score are said to have high level practice of self medication, while scores below had low level practice of self medication.

Table 3.1 showed that about two-third (64.5\%) of the respondents had high level of practice of self medication, while a third had low level of knowledge about it.

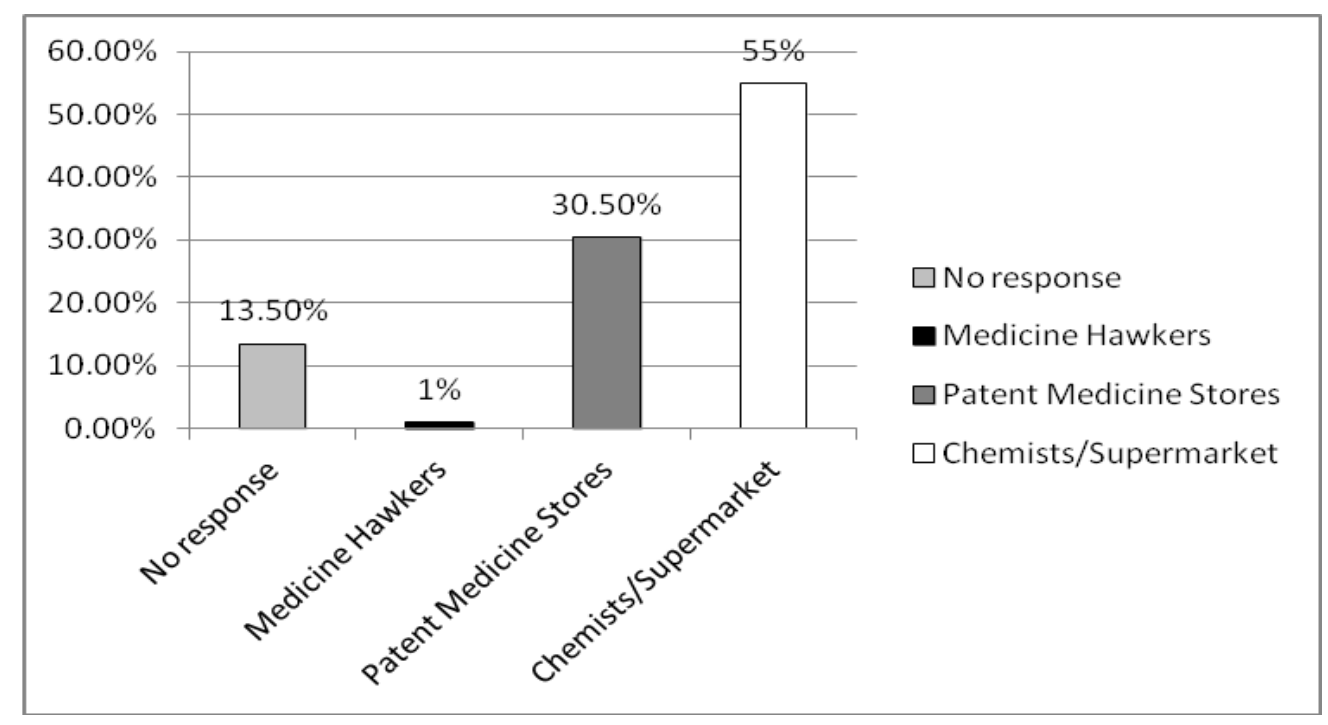

Figure 2. Preferred place to get the un-prescribed drug

The figure above showed the preferred place for respondents to get un-prescribed drugs. More than half (57.2\%) preferred chemist/ supermarket to get their non-prescribed drugs, while about a third do get it from patent medicine stores.

Table 4. Reasons/Factors Influencing Self-medication

\begin{tabular}{|l|l|l|l|}
\hline Variables & Always & Sometimes & Never \\
\hline Minor ailment & $103(51.5 \%)$ & $81(40.5 \%)$ & $16(8.0 \%)$ \\
\hline Financial constraint & $66(33.0 \%)$ & $94(47.0 \%)$ & $40(20.0 \%)$ \\
\hline Enough knowledge & $108(54.0 \%)$ & $78(39.0 \%)$ & $14(7.0 \%)$ \\
\hline Previous experience & $97(48.5 \%)$ & $93(46.5 \%)$ & $10(5.0 \%)$ \\
\hline Time saving & $75(37.5 \%)$ & $94(47.0 \%)$ & $31(15.5 \%)$ \\
\hline Health care services not available & $45(22.5 \%)$ & $93(46.5 \%)$ & $62(31.0 \%)$ \\
\hline $\begin{array}{l}\text { Lack of support from friends and } \\
\text { family }\end{array}$ & $34(17.0 \%)$ & $78(39.0 \%)$ & $88(44.0 \%)$ \\
\hline Ignorance & $79(39.5 \%)$ & $48(24.0 \%)$ & $73(36.5 \%)$ \\
\hline Advertisement & $55(27.5 \%)$ & $86(43.0 \%)$ & $59(29.5 \%)$ \\
\hline
\end{tabular}

Table 4 above depicts the reasons or factors influencing self medication among respondents. Just half (51.5\%, 54\% and 48.5\%) of the respondents signified they always see the presence of minor ailments, having enough knowledge about drugs and previous experience as a reasons for self-medication. Larger percentage (47\%, 46.5\% and $43 \%)$ of them respectively indicated that financial constraints, time saving and advertisement 
Texila International Journal of Public Health

Volume 4, Issue 4, Dec 2016

sometimes influence self-medication. More than one-third (38.8\%) indicated ignorance can always influence it.

Table 5. Relationship between the knowledge about effects of self medication and practice of self medication among respondents

\begin{tabular}{|l|l|l|l|l|l|l|l|}
\hline Variables & Knowledge & $\mathrm{N}$ & Mean & Std. Dev & $\mathrm{t}$ & df & Sig. (2-tailed) \\
\hline \multirow{2}{*}{ Practice } & High & 181 & 4.0387 & 1.67784 & -2.226 & 198 & .027 \\
\cline { 2 - 9 } & Low & 19 & 5.0000 & 2.66667 & & & \\
\hline
\end{tabular}

An independent $\mathrm{T}$ - test was conducted to examine whether there was a relationship between knowledge of respondents on effects of self-medication and the practice of self medication. The test revealed a statistically significant inverse relationship between the knowledge and practice of self medication $(\mathrm{t}=-2.226, \mathrm{df}=198, \mathrm{P}<0.05)$. Students with low level of knowledge about the effects of self medication reported high practice of self medication $(M=5.00, S D=2.67)$ than did students with high level of knowledge $(M=4.04$, $\mathrm{SD}=1.68)$.

\section{Discussion}

This study assessed the knowledge and practice of self-medication among students of school of nursing in selected schools in Osun State. Two hundred students participated in this study.

The socio-demographic distribution of the respondents revealed that their mean age and the standard deviation were $21.57 \pm 3.08$. Majority of the respondents were within age range of 20-29 years, almost all were Yoruba and majority were females. About two-third were Christians, while half of the respondents were in 200level, the other half were in 300 level.

Mehta and Sharma (2015) found in a study on the knowledge, attitude and practice of selfmedication among medical students in Chitwan Medical College, Bharatpur, Nepal that more than half of the respondent had good knowledge about self-medication regarding definition, adverse effect and different types of drug. In this study however, almost all the respondents had good knowledge about self medication. It is expected that nursing students having spent more than a year in the school should have basic knowledge on pharmacology. On the other hand, this result is at variance with Raut, Vamsi and Rao (2014) in a study evaluating the knowledge, attitude and practice of self-medication among second year BNSc nursing students, the study showed that respondents' knowledge about appropriate self-medication was poor, but knowledge of the benefits and risks of self-medication was adequate.

The result in this study showed that about two-third of the respondents had high level practice of self medication, while a third had low level practice. More than half equally signified that they are willing to practice self-medication whenever the need arises. This could be due to the fact that they are exposed to many drugs in their course of training and have basic understanding of some of these drugs. Similar findings were made by Mehta and Sharma (2015). They found the Prevalence rate of self-medication of one year period seems high i.e. $84 \%$ and $68.25 \%$ in were females. According to Klemenc-Ketiš, Hladnik and Kersni, (2011), self medication is usually considered as first choice remedy for early disease symptoms and is a part of patient's medical behaviour. More so, Ehigiator et al, (2013) observed self-medication as a common practice among group of health workers in Nigeria that included dental, midwifery and nursing students.

On the factors/ reasons for self-medication among nursing students, the study showed that about half of the respondents self-medicate always for reasons such as presence of minor ailments; and having enough knowledge about drugs as a reasons for self-medication, Also, more than forty percent indicated that financial constraint, previous experience, time saving, advertisement and unavailability of health care services are factors that sometimes influence self-medication. This result supports Raut et al (2014) in which respondents found selfmedication to be time-saving, economical, convenient and providing quick relief in common illnesses. Vizhi and Senapathi (2010) also opined that self-medication is influenced by many 
factors such as education, family, society, law, availability of drugs and exposure to advertisements, which agrees with the findings in this study.

In this study, the hypothesis was tested using independent t-test. Independent t-test showed statistically significant inverse relationship existed between the knowledge and practice of self medication among the nursing students $(\mathrm{t}=-2.226, \mathrm{df}=198, \mathrm{P}<0.05)$. Students with low level of knowledge about the effects of self medication reported high practice of self medication $(\mathrm{M}=5.00, \mathrm{SD}=2.67)$ than did students with high level of knowledge $(\mathrm{M}=4.04$, $\mathrm{SD}=1.67)$.

\section{Conclusion}

In conclusion, nursing students were found to have high level of knowledge about medication and effects of self- medication; however, majority of them still indulge in selfmedication practice. Meanwhile, their knowledge significantly influenced their selfmedication practices. Those with high level of knowledge about effects of self medication, have low level of practice of self medication. Meanwhile, it would be safe, if the people who self-medicate, have sufficient knowledge about the dosage, time of intake, side effect on over dose, because lack of information it can cause serious effects.

The following recommendations were made based on the findings in this study.

1. Although, self-medication is recommended to improve the self-care orientation, but this study found high prevalence of self-medication among nursing students with low knowledge about rational drug usage and uncontrolled availability of drugs have led to numerous healthcare issues. There is an urgent requirement to control the drugs available in the market.

2. Strict laws, control over misguiding advertisements and previous experience as this is one of the factors identified by nursing students, hence healthcare education to all is imperative.

3. The use of drugs as self-medication is mostly due to previous prescriptions, education on proper knowledge about drugs and the associated adverse effects is essential for nursing students, the communities and the healthcare providers at large.

\section{References}

[1]. Al-Hussaini M, Mustafa S, and Ali S. (2014). Self-medication among Undergraduate Medical Students in Kuwait with reference to the Role of the Pharmacist. Journal of Research Pharmacy Practice; 3 (1): 23-27.

[2]. Ali S. E., Ibrahim M. I. M., and Palaian S. (2010). Medication storage and self-medication behaviour amongst female students in Malaysia. Pharmacy Practice; 8(4): 1-7.

[3]. Arikpo G., Eja M., and Enyi-Idoh K. (2009). Self-Medication in Rural Africa. The Internet Journal of Health: 11 (1).

[4]. Auta A., Shalkur D., Omale S. and Abiodun A. H. (2012). Medicine Knowledge and SelfMedication Practice Among Students. JPRD; 4 (1): 6-11.

[5]. Awosusi and Konwea (2015). Self-medication Practice among Secondary School Students in Ekiti State, Southwest Nigeria. JAMPS, 3(2): 61-68.

[6]. Banerjee I, and Bhadury T. (2012). Self-Medication Practice among Undergraduate Medical Students in a tertiary care medical college, West Bengal. J. Postgrad. Med. 58(2):127.

[7]. Bernal B. S. R., and Silva N. N., (2010). Self-Medication in Low-Income Adults in South-Eastern Brazil. Rev SauePulica; 44(6): 1-6.

[8]. Dimabayao C. G. and Mohammad E. K. (2016). Prevalence of Self Medication Practice among Nursing Students in Jazan University, Kingdom of Saudi Arabia. IOSR-JNHS; 5 (1): 11-16

[9]. Ehigiator O., Azodo C.C., Ehizele A.O., Ezeja E.B, Ehigiator L, et al (2013). Self medication practices among dental, mid- wifery and nursing students. Eur J Gen Dentistry 2:54-57.

[10]. El-Nimr, N.A., Wahdan, I.M.H, Wahdan, A.M.H. and Kotb R.E. (2015) Self-medication with drugs and complementary and alternative medicines in Alexandria, Egypt: prevalence, patterns and determinants. East Mediterr Health J.; 21(4):256-65. 
Texila International Journal of Public Health

Volume 4, Issue 4, Dec 2016

[11]. Emmanuel A., Daniel G., Achema G., Afor B., Onyejekwe G., and Gimba SM. (2011). SelfMedication practice among undergraduate nursing students of University of Jos, Nigeria. Nigerian Journal of Pharmaceutical Sciences; 10 (2): 22-26.

[12]. Fadare J. O. and Tamuno I. (2011). Antibiotic Self-Medication among University Medical undergraduates in Northern Nigeria. J Public Health Epidemiol; 3 (5): 217-220.

[13]. Galato D, Galafassi L, Alano GM, and Trauthman SC. (2009). Responsible Self- Medication: Review of the process of Pharmaceutical Attendance. Brazilian Journal of Pharmaceutical Sciences; 45(4):625-633.

[14]. Joshi M.C., Shalini, and Agarwal S. (2011). A questionnaire based study of self-medication practices among young population. Res. J. Pharm., Biol. Chem. Sci.; 2:761-6.

[15]. Lukovic J. A., Miletic V., Pekmezovic T., Trajkovic G., Ratkovic N., et al. (2014). SelfMedication Practices and Risk Factors for Self- Medication among Medical Students in Belgrade, Serbia. PLoS ONE 9(12): e114644. doi:10.1371/ journal.pone.0114644

[16]. Olayemi O. J., Olayinka B. O., Musa A. J., (2010). Evaluation of antibiotic self-medication: Pattern amongst undergraduate students of ABU (Main Campus) Zaria. J Appl Science Res.; 2(1):3538.

[17]. Osemene K. P., Lamikara A. (2012). A study of the prevalence of self-medication practice among University Students in Southwestern Nigeria. Trop J Pharmaceutical Res. 11(4): 683-689

[18]. Shah A.P, Parmar S.A, Kumkishan A, Mehta A.A. (2011). Knowledge, Attitude and Practice (KAP) Survey Regarding the safe use of Medicines in rural area of Gujurat. Adv Trop Med Pub Health; 1(2): 66-70.

[19]. Sontakke S.D., Bajait C.S., Pimpalkhute S.A., Jaiswal K.M, Jaiswal SR. (2011). Comparative study of evaluation of self medication practices in first and third year medical students. Int J Biol Med Res.; 2(2): 561-564.

[20]. Talevi A. (2010). The New Patient and Responsible Self-Medication Practices: A Critical review. Current Drug Safety;

[21]. 5(4):342-53.

[22]. Verma RK, Mohan L \& Pandey M. (2010). Evaluation of self medication among professional student in north India: proper statutory drug control must be implemented. Asian J pharmaclinReas; 3 : 60-64.

[23]. Vizhi S. K., Senapathi R., (2010). Evaluation of the perception, attitude and practice of selfmedication among business students in 3 select Cities, South India. International Journal of Enterprise and Innovation Management Studies (IJEIMS); 1 (3): 40-4.

[24]. World Medical Association (2012). WMA Statement on Self-medication; Re-afffirmed by the $191^{\text {st }}$ WMA Council Session, Prague, Czech Republic, April, 2012. World Medical Association, Inc.

[25]. World Health Organization (2014). Essential Medicines and Health Products. Information Portal; 2014. Geneva, WHO. 


\title{
Prevalence, Knowledge and Perception of Domestic Violence among Women Attending Antenatal Care at Baraudikko Specialist Hospital, Kaduna, Nigeria
}

\author{
Article by Patricial Idoko \\ Master in Public health, Texilla American University, Nigeria \\ Email: ellabenson2015@gmail.com
}

\section{Introduction}

In early Roman Society, a woman was deemed the property of the husband and was therefore subject to his control.

The Catholic Church's endorsement of "the Rules of marriage" in the $15^{\text {th }}$ century exhorted the husband to stand as "judge of his wife. He was, to beat her with a stick upon her commission of an offense. According to the rules, beating showed a concern for the wife's soul.

In $18^{\text {th }}$ century France, if it became public that a wife had beaten the husband, he was forced to wear an outlandish costume and ride backwards around the village on a dnkey.

It was not until the 1870s that the first states in the US banned a man's right to beat his family.

Violence against women, whether pregnant or not occurs commonly around the world especially the developing world. The act cuts across all ages, cultures, ethnicity religion and educational barriers.

Domestic violence refers to any harmful behaviour directed at women or girls because of their sex it is also known as gender based violence.

The violence can take various forms, and could be physical, psychological, (emotional) sexual, economic or a combination or even neglect. It can also be in the form of threats of such acts, coercion, or arbitrary deprivation of liberty whether occurring in public or private life. A new dimension has been added now in the form of acid baths used by men especially to discipline women, girls.

The prevalence of domestic violence against women ranged between 17-37\% with considerable regional variation. Domestic violence can broadly be classified into domestic abuse, spousal abuse, child abuse, intimate partner violence (IPV), elder mistreatment.

Domestic violence or spousal Abuse in this content is a form of violence against women and when it involves pregnant women, it calls for a closer attention because of the greater danger it entails. Both the world health organization WHO and international federation of obstetricians and gynecologists (FIGO) recognize the scourge of violence against women and starting train the nineties passed various declarations on the elimination of violence against women. The factors which lead to domestic violence are a legion and range from no offence, minor to major offences.

Most countries and various religions from against domestic violence but because the cultures of the people of these countries do not frown at it, the problem has persisted it hence explains the attitude of the women to domestic violence with some even justifying it. Domestic violence may start or escalate with pregnancy.

Domestic violence is not caused by illness, gentiles, or gender, alcohol or other drugs, anger, stress victim's behaviour or relationship problems, it is a learned behaviour by batterers, and it has enormous impact on pregnant women. It is a recognized public health issue that has serious consequences on physical and mental health. Domestic violence has been associated with psychiatric illnesses, depress, anxiety, posttraumatic stress disorderattempted suicide and also important implications for the fetus as low birth weight, miscarriages, a bleeding, prematurity, abruption, or even death of either or both fetus and mother. 
Texila International Journal of Public Health

Volume 4, Issue 4, Dec 2016

There is paucity of data on domestic evidence mainly because of under reporting by the victims, but quite sequent.

\section{Background of the study area}

The study was conducted at the antenatal Clinic of the obstetrics and gynecology department of BarauDikko Specialist Hospital, Kaduna one of the twelve departments in the hospital. The department is headed by a head of department who is a consultant obstetrician and gynecologist. The department runs clinics on all five days of the week, Monday through Fridays. An average of 200 clients are seen on the obstetric clinic days while on the gynae clinic days about 100-150 clients are seen. The hospital is a 241 bedded hospital and it renders Primary secondary and tertiary health services to the citizenry, including specialist care. The hospital is a tertiary health institution strategically located in central Kaduna, the capital of Kaduna, the capital of Kaduna State North Central Nigeria. The State had a population of 6,113,503 as at March 2006. The State Capital is Industrial, Commercial and cosmopolitan. The residents are a mixed population of farmers, traders students, civil servants, retired and serving military personnel.

The main aim of the study was to determine the prevalence of domestic violence amongst pregnant women attending antenatal care at BarauDikko Specialist Hospital, Kaduna Other objectives of included finding out the response of the victims to the abuse.

- To determine the specific prevalence of domestic violence amongst the pregnant women who were respondents for the study.

- To determine which type of violence has the highest percentage of use by the perpetrators

- To propose that further study be carried out to determine the outcome of domestic violence on pregnancy

- To make recommendations on measures to curb the menace so as to reduce the morbidity or even mortality that could be associated with the horrible act.

\section{Literature review}

Ameh et al in a study on the prevalence of anthatal domestic violence amongst pregnant women at Ahmadu Bello University teaching hospital Zaria, found that of the 50 respondents who experienced-domestic violence, $36 \%$ of them were beaten up while $22 \%$ were forced to have sex. The spouse was the commonest culprit, which was similar to the Kaduna study, Thirty-Nine women of the 178 respondents felt domestic violence was excusable under certain conditions and $36 \%$ of them would keep domestic violence secret.

In another study by LA Makayoto 2013 among women seeking antenatal care at Kisumu district hospital Kenya.

In another comparative study published in the British Journal of obstetrics and gynecology, by Tonye Telema et al, the study looked at the prevalence of domestic violence in women requesting a termination of pregnancy and those attending antenatal itself. It used self administered anonymous questionnaires among 219 women in an antenatal clinic and 274 in a clinic for termination of pregnancies in the Hull and East Riding areas of the United Kingdom. The study highlight that almost half of all adult women in England and Wales have experienced domestic violence of one form, whether psychological, physical, sexual, financial or emotional. It constitutes up to $1 / 3$ of violent crimes and the direct and indirect cost of domestic violence alone in the United Kingdom is estimated to be 23 billion pound/Euro.

The results showed that among women attending clinics for termination of pregnancy, $5.8 \%$ were victims of physical abuse in the current relationship, whereas it was $0.9 \%$ amongst women attending antenatal clinics.

Women in the TOP group also suffered a higher rate of emotional abuse than those in the antenatal clinic population (9.9\% compared to 1.8\% furthermore, the study looked at reasons for requesting a termination of pregnancy. Of the 274 women requesting for a termination of pregnancy, 10 (2\%) mentioned domestic violence as a contributing factor. 
The most common reasons for requesting a TOP were financial worries and contraceptive failure.

The Authors conclude that through domestic violence was not given as a frequent reason for requesting a termination of pregnancy, women who request for an abortion are at a higher risk of domestic violence and this may be related to other life issues. They emphasize the importance of relevant training amongst healthcare professionals so that women are referred to appropriate support services in a timely and sensitive manner. They concluded by adding that the study just showed a small fraction of the true scale of the problem. Health professionals looking after pregnant women regardless of the pregnancy outcome are well placed to sensitively ask the questions which will lead to help and support.

The deputy editor of the Journal added by saying that domestic violence can be extremely damaging to a women's mental, emotional and physical health and in some cases has been linked to postnatal depression; he enjoins that more research is needed in the area to determine effective screening methods and interventions to help women suffering from any form of abuse.

It is only when this has been done, that sufficient measures can be initiated to address this growing problem that can pose a significant health risk to mother and baby.

In another study by Gyuse An et al, 2009 who wrote on the prevalence of domestic violence among antenatal women attending ECWA Evangel Hospital, Jos, over as six month period, 340 pregnant women were studied, majority of them were married and were mostly aged between 20-39 years. Domestic violence prevalence was $12.6 \%$ (43) in the current pregnancy and 63.2'6 215 previously. In conclusion the study established that in our environment women experience domestic violence during pregnancy and majority of them also have a previous history of abuse. There was a need to routinely screen for domestic violence in pregnant women so as to prevent political adverse pregnancy outcomes and to interrupt exiting abuse.

The multicentre study concluded that violence against women especially in developing countries was directly related to Low sowo economic level of the women and their intimate partner, it concluded that more effective social policies were need for this vulnerable population. The area with the lowest rates were Japan (8\%) and highest in Ethiopia 70\% and Brazil 43\%.

\section{Methodology}

\section{Study type}

We carried out a cross sectional study involving 170 pregnant women attending the antenatal clinic of BarauDikko Specialist Hospital Kaduna, over the period of 1 week in February 2016. They were served with pretested structured questionnaire.

\section{Study setting}

The study was conducted at the obstetrics and gynecology department of BarauDikko Specialist Hospital, Kaduna.

\section{Study population}

The study population was pregnant women attending the Antenatal Clinic of BDSH Kaduna.

\section{Sample size calculation}

The sample size was calculated using epic info stat cal for descriptive studies in a knan population size.

Other formulae are

Where $\mathrm{n}$ is the minimum sample size,

$\mathrm{P}$ is the prevalence of domestic violence among pregnant

Women. 
Texila International Journal of Public Health

Volume 4, Issue 4, Dec 2016

$\mathrm{Q}$ is 1-p

$\mathrm{d}$ is the sampling error

Attrition is about $10 \%$ which is added to the final figure.

\section{Sampling frame}

We used the register at the antenatal clinic and the consecutive way in which they came was used.

\section{Sampling procedure}

Proportionate Sampling

One hundred and seventy questionnaires were returned duly completed $=$ after being served with pretested structured questionnaires

\section{Data collection and analysis}

The 170 respondents were served with pretested structured questionnaires by me. The First few questions were centered on psychosocial variables including age, parity, educational level, social class and tribe. The remaining seven eqicuti explored the knowledge and perception about domestic violence among the respondents experience in the present pregnancy and even in the past was also sought. The data was analysed using epi-info version 6 statistical software.

Descriptive statistics was summarized using means, proportions and frequencies.

\section{Ethical considerations}

Written informed consent was sought from the participants. Permission to carry out this study was sought from the ethical committee of BarauDikko Specialist Hospital Kaduna.

\section{Results}

A total of 170 respondents participated in the study: The demographic characteristics of the respondents is summarized in table I, / is as follows:-

The mean age of the respondents was 26 yrs +3 yrs. Range 16-44 yrs; and most frequent age group was $26-30$ years (38\%).

$93 \%$ of the women were married. Forty five percent were of Hausa Fulani extraction while the remaining respondents were other tribes. One hundred and forty (78\%) were educated up to secondary school level.

(55\% had knowledge of domestic violence while 70, (45\%) had no knowledge of it. Concerning their view about domestic violence, (Table II, 85 (48\%) felt it was excusable under certain circumstances while 25 (14\%) felt it was always excusable.

A total of 50 respondents (28\%) had experienced domestic violence against them in the index pregnancy or in previous pregnancies (table III) 17 (34\%) were beaten up, II (22\%) were forced to have sex, 10 (20\%) had objects thrown at them 9 (18\%) were slapped and 2 (4\%) were flogged. The culprit in the 50 women who experienced domestic violence were shown in table 3 . The spouse was the commonest culprit.

On their reaction to the domestic violence they experienced, table 5, 65 (36\%) would keep it a secret, 50 (28\%) would report to their family, 28 (16\%) would report to the doctor, while others would report to in laws, polices clergy, or tell a close friend.

Table 1: View about Domestic violence amongst the Pregnant Women

\begin{tabular}{|l|l|}
\hline View & No (\%) \\
\hline No reply & 25 \\
\hline Excisable under certain circumstances & 39 \\
\hline Always excusable & 26 \\
\hline Not excusable & 80 \\
\hline Total & $170(100 \%)$ \\
\hline
\end{tabular}


Table 2: Type of Domestic violence experienced by pregnant women.

\begin{tabular}{|l|l|}
\hline Type of Domestic Violence: & No \% \\
\hline Beaten & $18(36)$ \\
\hline Forced to have sex & $11(22)$ \\
\hline Objects thrown at them & $10(20)$ \\
\hline Slapped & $9(18)$ \\
\hline Flogged & $2(4)$ \\
\hline Total & $50(100)$ \\
\hline
\end{tabular}

Table 3: The culprit responsible for the domestic violence among the 50 respondents.

\begin{tabular}{|l|l|}
\hline Reaction to Domestic Violence & No \% \\
\hline Keep it a secret & $60(35)$ \\
\hline Report to family & $50(27)$ \\
\hline Report to doctor & $28(15)$ \\
\hline Report to in-laws & $14(7)$ \\
\hline Report to clergy & $6(3.4)$ \\
\hline Report to a close friend & 52.9 \\
\hline No reply & 301.7 \\
\hline Total & $170(100 \%)$ \\
\hline
\end{tabular}

\section{Discussion}

A large percentage of the respondents about 50 of the 170 sampled had been involved in one form of abuse or the other which agrees with the local and international figure. It was appalling however to note that a huge number about 26 felt it was excusable at all; through 39 felt it could be excusable under certain circumstances.

Another distribution figure is the 50 (about 27\%) who would rather keep the abuse as a secret, and only 10 of the respondents felt they should report the issue to the police, meaning the laws of the land must be very weak or silent on issues of domestic/spousal violence even on pregnant women and depicting the low level of confidence on the systems, About 6 of the respondents could report to the clergy meaning the religious institution have a role to play in the awareness campaign.

Why the figures are more disturbing more is because domestic violence is pregnancy complication that is highly under reported hence actual statistics would be far beyond the quoted figures of between $11-70 \%$ across regions.

Most of the women felt more comfortable reporting to a family member because the family is seen as the primary unit in the society and first medium of socialization. Out study showed that about $28 \%$ of the women had experienced one form of violence or the other either in a previous or in the index pregnancy; which is a huge percentage.

The Nigerian Law and penal codes need to be more explicit on their stance on issues of gender violence; but the figures from this study is consistent with that from other African countries with similar cultures.

\section{Conclusion}

The fact that Domestic violence is a serious public health issue was highlighted and worse more in pregnancy because of its peculiar circumstance.

It was strange to find out that some women were still not aware of it or do not even know if they are in an abusive relationship.

The culture and predominant religion in the area of the study seemed to perpetuate the crime and foster it.

The major culprit was found in most cases to be the spouse and it was noticed that Low socioeconomic status and dependence on the culprits ensilaged the victim's vulnerability. 
Texila International Journal of Public Health

Volume 4, Issue 4, Dec 2016

There were weak or non-exist laws to prosecute the crime and the need to create awareness and for health care professionals to do ongoing screening to help victims of abuse curb the act to reduce consequences

\section{Recommendation}

There is a need to create awareness on the topic to let our people and especially women who are more at the receiving end know that it is a serious public health problem and should not be excusable under any circumstance, the slave trade era is over.

Screening for domestic violence can also be included in our routine antenatal screen/clinics; hence the need to train personnel in this regard.

The constitution of Nigeria upon review should make domestic violence a punishable offence so as to discourage perpetrators of the act.

Support groups could also be formed so that victims of the act will find solace/comfort with other women facing similar challenges.

Further studies are however needed to determine pregnancy outcomes in women faced with domestic violence.

\section{References}

[1] Bacchus L. Bewley S. Gillian M. Domestic violence and pregnancy, obstetrics and gynecology 2001; 3; 56-59.

[2] Catalano; R:LindRosenblat, A and R Novaco (2008) Research into the economic antecedents of violence. American Journal of Community Psychology.

[3] CDC (2006). Intimate Partner violence, Salt Sheet. Retrieved Oct. 2008 from www.cdo.gov/.

[4] Ending violence against women in population report volumes xxvii No 4 December, 1999.

[5] Gyuse AN et al, Nigerian Journal of medicine 2009 Oct-December. Prevalence of Domestic violence among antenatal women attending a Nigerian Mission Hospital

[6] Jina R, Jewkes R. Christofodes N, loots L Caring for survivors of sexual assault and Rapoe in South Africa. $1^{\text {st }}$ Edition, 2008.

[7] Little K. J. Screening for Domestic violence; identifying, assisting and empowering adult victims of abuse. Postgraduate medicine 2000 108: 1,4-9

[8] Obi S. N. and Ozinba (2007) factors associated injury with domestic violence in South East Nigeria. Journal of obstetrics and gynecology.

[9] Pierre Martin Hirsch, British Journal of gynecology deputy Editor in chief

[10] Rakel R. P. Rakel D P (eds): Rakel textbook of family medicine; $7^{\text {th }}$ edition, Souners.

[11] Saror S. F. Spousal abuse; a study in Samaru Zaria, Kaduna State, Nigeria breaking the Silence in women against violence. Proceedings of the tenth anniversary of women in Nigeria Conference 1993; 70-73.

[12] T T Wopkoma, M. Jampala, H Bexhell, R Sutbn'e S Lindar A comparative study of the prevalence of domestic violence in women requesting a termination of pregnancy and those attending the antenatal clinic BJOG 2014.

[13] Unicef (2005) violence at home (achieve) voices of youth forum. Retrieved Oct. 2008 from http.//www.unicef.org/roy/discussions/archive/index.

[14] Unicef 2001.children and women's rights in Nigeria. A wakeup call. Situations assessment and analysis. Edited by Hodege Abuja: National Population Commission and unicef.

[15] Violence against women during pregnancy systematized revision. Science Direct May-August 2014 vol.29 (2) pages 71-79. 


\title{
Ethical Challenges of International Outbreaks-A Case Study of Ebola Virus Disease
}

\author{
Article by, Okafor $\mathrm{CN}^{1}$, Nwobi $\mathrm{AE}^{2}$, Anyaehie $\mathrm{BU}^{3}$, Young $\mathrm{EE}^{4}$ \\ ${ }^{1,3}$ Department of Physiology, University of Nigeria, Enugu Campus \\ ${ }^{2}$ Department of Community Medicine, University of Nigeria, Enugu Campus \\ ${ }_{4}$ Department of Medicine, University of Nigeria, Enugu Campus \\ E-mail: ${ }^{1}$ chinyere.okafor@unn.edu.ng, ${ }^{2}$ amaebie@yahoo.com, \\ 3bond.anyaehie@unn.edu.ng, ${ }^{3}$ ekenechukwu.young@unn.edu.ng
}

\begin{abstract}
Public health measures are strictly required to prevent increase in the spread of Ebola virus disease and that includes identifying cases and quarantining persons who are suspected to have come in contact with the disease or its agent. Though quarantine restricts freedom of movement of those affected, the reasons may be justified based on the fact that health of the public needs to be protected. But though the personal rights and liberties of individuals may be expected to be lost in international outbreaks, it should not be totally taken away. There ought to be a balance between preserving individual rights and maintaining public health. Thus a legal and political framework is needed while research for therapy and vaccine are encouraged.
\end{abstract}

Keywords: Ebola virus disease, ethical challenges, international outbreaks.

\section{Introduction}

An infectious disease such as Ebola virus disease can threaten the stability of a country's or region's government, economy, and social fabric. ${ }^{1}$ Ethics is concerned with distinguishing between good and evil in the world, between right and wrong human actions, and between virtuous and non-virtuous characteristics of people. ${ }^{2}$ It can be further defined as the rules of conduct recognized in respect to particular class of human actions or a particular group, culture, etc. ${ }^{3}$ Despite the existence of ethics guidance in relation to specific diseases (e.g. pandemic flu, TB and HIV) comprehensive international/global public health ethics guidance related to epidemic outbreaks is lacking ${ }^{4}$. Ethics does not provide a prescribed set of policies; rather, ethical considerations will be shaped by the local context and cultural values. The response to any outbreak entails being prepared to limit individual rights and civil liberties in the interest of public health. International outbreaks have increased the social and economic inequalities within and between countries with its economic consequences. The recent Ebola outbreak has presented a number of ethical issues some of which are new especially due to the cultural and political atmosphere in affected countries leading to significant challenges for health care workers and public health officials trying to contain the epidemic. Some deny that Ebola is real, even going so far as to claim that there is no epidemic, with claims that the government health workers are killing patients to simulate an epidemic and receive Western funding ${ }^{5}$. Those who are ill stay away from the hospitals for fear of becoming infected with Ebola; those who have Ebola hide to avoid stigmatization ${ }^{5}$.

The last epidemic of Ebola virus disease is one of two dozen outbreaks since discovery of the virus in $1976^{5}$. It was identified along the border of Guinea and Sierra Leone March, 2014 subsequently spreading to Liberia, with a handful of cases in Nigeria associated with the arrival of an infected airline passenger ${ }^{6}$. As of October 14, 2014, a total of 8,914 probable, confirmed, and suspected cases of EVD and 4,447 deaths due to the disease, have been reported to the World Health Organization (WHO). The WHO estimated then that by December 2014, the number of new EVD cases could rise ten-fold, to 10,000 per week, and the survival rate in these West African countries was "30 percent at most"”. 
Texila International Journal of Public Health

Volume 4, Issue 4, Dec 2016

The virus is transmitted in body fluids, like blood, saliva, vomit or stool but not through the air. Caregivers of infected patients, and those who prepare them for burial, are at particular risk $^{5}$. Recent reports which states that the virus appears to be showing genetic mutations, even during the current epidemic is a source of worry. The African derived Ebola virus infections, there is an incubation period that can last from three days to three weeks ${ }^{5}$. The virus is not spread until the patient becomes symptomatic with fever, chills, headache, muscle aches, vomiting and diarrhea ${ }^{5}$. Later they develop a hemorrhagic rash, and bleeding from any mucous membranes.

Approved specific therapy for treatment is not available yet as well as vaccine for prevention. Thus intensive general medical support is very crucial for survival, with Intra Venous fluid therapy and measures for controlling bleeding. This care must be given with strict attention to barrier isolation from the contaminated fluids from the patient as well as to provide the best likelihood of survival for the infected patient ${ }^{5}$. Protective barriers for healthcare workers (gloves, gowns, masks and goggles) should be worn for identified Ebola cases $^{5}$. However, identification may be delayed because the early symptoms can resemble malaria, typhoid fever, cholera, and other illnesses which present much more commonly in the African geographic region ${ }^{5}$.

Government outbreak response activities to control the spread of Ebola has involved isolation, restriction of free movement and liberty. It is against this background that the public have raised ethical concerns and argued that outbreak response activities conflict with the constitutionally protected rights of individuals with suspected and probable Ebola cases ${ }^{8}$.

In this study, we wish to identify the ethical challenges involved in international outbreaks using Ebola virus disease as case study and proffer solutions to these ethical challenges experienced during international outbreaks.

\section{Methodology}

Information was obtained by a desk review of publications and reports on the recent Ebola virus disease outbreak and ethical challenges involved, by Center for Disease Control, World Health Organization etc. A detailed literature search was done to identify articles on the management of the recent Ebola virus disease outbreak, and to identify ethical issues experienced by health care workers and public health officials.

\section{Discussion}

The recent EVD outbreak was an international public health crisis ${ }^{9}$. The number of legal and ethical questions arising out of prevention, treatment, and public health response to EVD can be divided into social, medical, economic and psychological aspects and all are interwoven.

\section{Medical issues}

1. The use of experimental drugs in international outbreaks without consent

In this issue, the benefits and dangers involved need to be considered. As in the case of EVD, the drugs that had never been tested in human subjects were given to sick patients as there was no time to do the necessary clinical trials. So far they have only been tested in a handful of monkeys and first phase not yet completed in human beings. Thus the adverse effects were not known and the drugs could not be said to be safe or effective. For example, of the 6 people who received an experimental therapy of Z Mapp, 2 have died. This doesn't prove its efficacy or safety as long term effects cannot be assessed. On August 11, 2014, the World Health Organization convened a panel to discuss these ethical issues. Their response was widely reported: "It is ethical to offer unproven interventions with as yet unknown efficacy and adverse effects, as potential treatment or prevention”" 


\section{Who should be treated as there are always scarce resources in international outbreaks?}

The code of ethics for medical practitioners in Nigeria and other parts of the world calls on medical practitioners to first consider the well-being of their patients. But this ethical duty must be balanced with a duty not to become a source of harm to other members of the public which would likely be the case where the medical practitioner himself gets infected. Thus healthcare workers should be treated first in outbreaks so that they will not be a source of transmission of infection to the public and also be healthy enough to combat the number in the outbreaks. Also healthcare workers are most likely to enroll in trials of experimental therapies and understand the requirements of informed consent in the treatment especially in African setting with various cultural misinformation.

A lack of resources for the diagnostic and supportive services required to manage EVD is another key issue ${ }^{10}$. The absence of diagnostic kits means that the quarantine period is lengthened, as a result of which people's rights of movement are curtailed and their ability to earn is limited for periods much longer than if they had been tested during contact tracing and declared Ebola-free ${ }^{10}$. The lack of adequate protective gear as well as other healthcare items, such as gloves and single-use syringes, is also a matter of ethical concern ${ }^{10}$. The risk to which the healthcare and ancillary workers took which as well as took some lives of doctors in Nigeria who later contracted EVD while saving lives with the few protective items available are also ethical challenges that could have been avoided. Lives of health workers could have also been saved if vaccines and therapeutics to counter EVD had been available.

\section{Social and Economic aspect}

During international outbreaks as in EVD, quarantine and isolation, are often employed and this are very restrictive of personal rights especially right to liberty and freedom of movement. For example in Nigeria, many of the subjects who came in contact with an infected patient were quarantined for a very long time though they were later found to be Ebola-free and this lead to increased stigmatization from their relatives and the public. This also resulted in other contact subjects not reporting to the hospital and also not disclosing their infected relatives.

They also impact on the income earning ability of the persons under isolation e.g. during Ebola outbreak in countries like Liberia and Sierra Leone, government placed community quarantine and a three day nationwide curfew respectively and this led to limitation of movement leading to food shortages, poor access to essential services including health, social limitation and economic enhancement. The absence of a framework which ensures that the persons under quarantine do not lose any economic benefits that they may be entitled to might deter persons who suspect themselves to have been exposed to the disease agent from disclosing it.

\section{Psychological and emotional aspect}

In international outbreaks, response activities like isolation, restriction of movement affect the individuals psychologically. Using Nigeria EVD patients as example, the individuals felt neglected, isolated and abandoned with no personal contact, family or friends amidst the suffering. They became anxious, felt hopeless and helpless and with depression developing among confirmed, suspected and likely cases. During these outbreaks, medical practitioners are put under an obligation to report all cases of persons who harbor any illness or health condition that may be similar to these epidemics for isolation from the rest of the public. As a result of no emotional support individuals develop stress related disorders like ulcers, schizophrenia and posttraumatic stress disorder among the isolated cases.

The family contacts of EVD victims go through the dilemma of whether to abandon or continue to care for the victim. They live in great fear and psychological torture during the quarantine period. Relatives like spouses of EVD survivors also live in fear of possible 
Texila International Journal of Public Health

Volume 4, Issue 4, Dec 2016

continued sexual transmission of the virus after recovery and future generations yet unborn being affected.

\section{What are possible ways of combating these challenges?}

The recent control Ebola Virus Disease (EVD) in Nigeria was globally regarded as effective $^{11}$. Although there might be restrictions of individual rights, a procedural framework would help provide for any such restrictions to be minimal. This envisages that measures taken for prevention of spread of virus must also help reduce some of these ethical issues. The measures used included the following;

1. The individual must have actually been exposed to the infectious agent and thus pose an actual threat to the public as contemplated by the Nigerian Constitution.

2. The measures taken for restriction must be reasonable and effective and no discrimination must be employed.

3. The government should help provide diagnostic and supportive services and also protective wears to help the healthcare workers in management like in Nigeria were funds were generously allocated and isolation facilities built. Also infrastructures and cutting-edge technologies used for our global outbreaks were repurposed to support Ebola response $^{11}$.

4. Individuals involved should be provided with a choice, where practicable, of whether to be quarantined in a government run facility or in their own homes with rules to ensure compliance.

5. The measures taken must ensure reasonable compensation for loss of income due to the quarantined individual's inability to go to work so as not to infect others.

6. There must be adequate measures for integrating the persons who have been placed on quarantine or isolation back into the society and manage any stigmatization that may occur.

7. There is a critical need for capacity building in the ethical review of public health research and practice. Researchers, public health agencies and other stakeholders should work together to develop short courses, degree programs and other training modalities. Funding agencies should direct appropriate support to these efforts ${ }^{7}$.

8. Actions towards the invention of vaccine and drugs for treatment should be taken more seriously.

Transparency in handling public engagement with the involvement of relevant stakeholders was a cardinal pathway in the Nigerian experience. Increased public awareness about the disease and its related risks enabled people to take steps at individual, family, workplace and community level to prepare for and respond to an epidemic. Nigeria deployed all social media platforms in the fight. ${ }^{12}$. GPS systems were put to work for real-time contact tracing and daily mapping of transmission chains and contact tracing reached 100\% in Lagos and 99.8\% in Port Harcourt ${ }^{11}$. However, the use of multiple platforms by multiple groups in an uncoordinated way provided gaps in ethics.

\section{Limitations to some of these measures}

In some of the social media platforms like WhatsApp there was no censorship of what was posted and there was no punishment for wrong information by persons. This lead to lack of transparency as multiple news were being given. There is always a need to promote public compliance and mitigate fears. This led to people ingesting all kinds of alternative medications like salt water, herbs, etc.

Confidentiality which is the obligation to keep information secret unless its disclosure has been appropriately authorized by the person concerned or, in extraordinary circumstances, by the appropriate authorities was missing. 


\section{Conclusion}

This outbreak has demonstrated, like nothing before, that in today's world ${ }^{10}$ - which is characterized by interconnectedness, increasing globalization and easier means of transportation, and in which pathogens no longer respect the borders of countries - no country can remain immune to the risk of pathogens, whatever their origin, whether it is the jungles of Africa or a metropolitan city of India. Countries should, therefore, make it a priority to strengthen their health systems to manage health and disease in normal times as well as in times of emergency ${ }^{10}$. Finally, national preparedness plans for the control of epidemics are needed.

\section{Figures and tables}

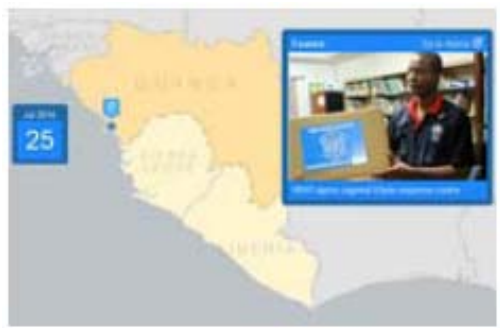

Fig 1. 2014 West Africa Ebola outbreak

Source WHO 2014

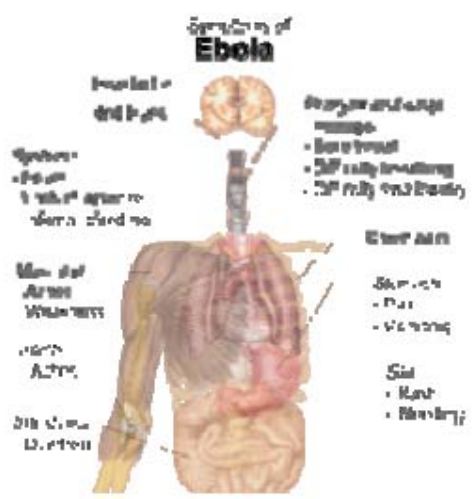

Fig 2. Signs and Symptoms of Ebola Virus Disease

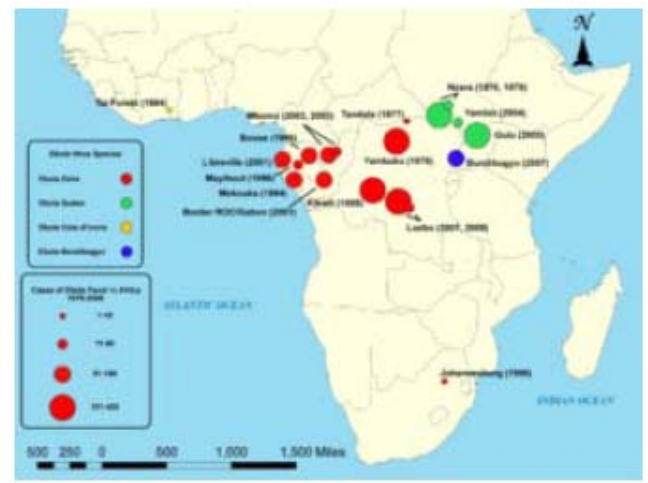

Fig 3. Cases of Ebola fever in Africa from 1979 to 2008 
Texila International Journal of Public Health

Volume 4, Issue 4, Dec 2016

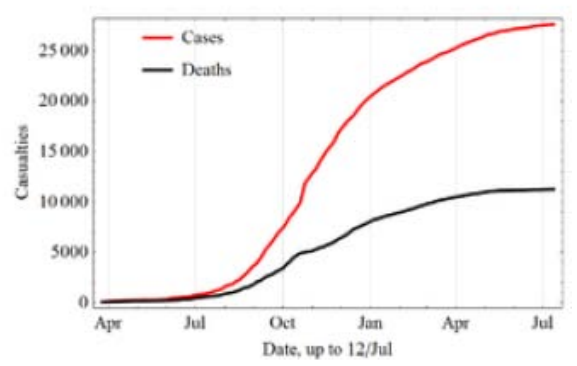

Fig 4. Increase over time in the cases and deaths during the 2013-2015 outbreak

Source Ebola Virus epidemic in West Africa

\section{References}

[1] Abha S. Ebola Virus Disease Outbreak- Incorporating Ethical Analysis into the Health System Response. Indian Journal of Medical Ethics 2014, Vol 11; 4.

http://www.who.int/csr/disease/ebola/one-year-report/nigeria/en/

[2] Center for Disease Control and Prevention: Ebola (Ebola Virus Disease): 2014 Ebola Outbreak in West Africa. Atlanta, Georgia; 2014 [http://www.cdc.gov/vhf/ebola/outbreaks/2014-westafrica/index.html].

[3] Ebola Virus Disease- Legal and Ethical considerations for Indiana. Improving Community Health through Policy Research, Center for Health Policy 2014.

[4] Global Forum on Bioethics in Research (GFBR). Meeting report: Emerging epidemic infections and experimental medical treatments. Annecy, France. 3-4 November 2015. Available from: http://www.gfbr.global/wp-content/uploads/2016/03/GFBR-2015-meeting-report-emergingepidemicinfections-and-experimental-medical-treatments.pdf (Accessed October 22 2016).

http://www.dictionary.com/browse/ethics

[5] Ibrahim W. Ethical concerns regarding Ebola control measures in Uganda, Makerere University School of Public Health 2013.

[6] Kevin G. Ebola, Epidemics and Ethics- what we have learned. Donovan philosophy, Ethics and Humanities in Medicine 2014, 9:15.

[7] Nduka UC, Igwe-Omoke A, Ogugua C. The use of social media in combating the Ebola virus in Nigeria- a review. International Journal of Medicine and Health Development.2014 19 (1/2): 97-108

[8] Osterholm MT, Moore KA, Gostin LO. Public Health in the Age of Ebola in West Africa. JAMA Intern Med. 2015; 175(1):7-8.

[9] Pan American Health Organization. Zika Ethics Consultation: Ethics Guidance on Key Issues Raised by the Outbreak. Washington, DC: PAHO, 2016. Document Number: PAHO/KBR/16-002. Available

at http://iris.paho.org/xmlui/bitstream/handle/123456789/28425/PAHOKBR16002_eng.pdf (Accessed October 22 2016).

[10] WHO (2010). Research Ethics in International Epidemic Response, Geneva 2009. 


\title{
Middle East Respiratory Syndrome Coronavirus (MERS-CoV)
}

\author{
Article by Geethamma Jolly \\ RN-MSN, Texila American University, India \\ E-mail: christy20042001@yahoo.com
}

\begin{abstract}
Middle East respiratory syndrome (MERS) is a highly lethal respiratory disease caused by a novel single-stranded, positive-sense RNA beta coronavirus (MERS-CoV). Dromedary camels, hosts for MERS-CoV, are implicated in direct or indirect transmission to human beings, although the exact mode of transmission is unknown. The virus was first isolated from a patient who died from a severe respiratory illness in June, 2012, in Jeddah, Saudi Arabia. As of May 31, 2015, 1180 laboratoryconfirmed cases (483 deaths; 40\% mortality) have been reported to WHO. MERS-CoV causes severe human infections resulting in high mortality and has demonstrated the ability to transmit between humans. So far, the observed human-to-human transmission has occurred mainly in health care settings. WHO expects that additional cases of MERS-CoV infection will be reported from the Middle East, and that cases will continue to be exported to other countries by individuals who might acquire the infection after exposure to animals or animal products (for example, following contact with dromedaries) or human source (for example, in a health care setting). Both community-acquired and hospital-acquired cases have been reported with little human-to-human transmission reported in the community. Although most cases of MERS have occurred in Saudi Arabia and the United Arab Emirates, cases have been reported in Europe, the USA, and Asia in people who travelled from the Middle East or their contacts. Clinical features of MERS range from asymptomatic or mild disease to acute respiratory distress syndrome and multiorgan failure resulting in death, especially in individuals with underlying comorbidities. No specific drug treatment exists for MERS and infection prevention and control measures are crucial to prevent spread in health-care facilities. MERS-CoV continues to be an endemic, low-level public health threat. However, the virus could mutate to have increased interhuman transmissibility, increasing its pandemic potential.
\end{abstract}

\section{Keywords}

1. Introduction

- Ecology and transmission of MERS-CoV

- Virology

- Origin

- Middle East respiratory syndrome 3-D image

- Tropism

- Transmission

- Evolution

- Natural reservoir

- Taxonomy

2. Transmission Modes

- Possible sources and modes of transmission

- Bats

- Camels

3. Clinical feature

4. Diagnosis

5. Treatment

6. Prevention 
Texila International Journal of Public Health

Volume 4, Issue 4, Dec 2016

7. Imaging findings at presentation in Saudi patients withMERC-CoV

8. Ways of protection against the MERC-CoV

9. Infection Prevention and Control Recommendations for Hospitalized Patients with MERS-CoV

- Recommendations

A. Minimize Chance for Exposures

- Before Arrival

- Upon Arrival and During the Visit

- Ensure Adherence to Standard, Contact and Airborne Precautions

A. Hand Hygiene

B. Personal Protective Equipment

C. Gloves

D. Gowns

E. Respiratory Protection

F. Eye Protection

- Using More than one Kind of Personal Protective Equipment (PPE)

- Patient Placement

- Manage Visitor Access and Movement within the Facility

- Implement Engineering Controls

- Monitor and Manage Ill and Exposed Healthcare Personnel

- Train and Educate Healthcare Personnel

- Implement Environmental Infection Control

- Establish Reporting within Hospitals and to Public Health Authorities

10. MERS-CoVStatistics

11. Comparisons

12. Summary and Recommendations

13. References

\section{Introduction}

Middle East respiratory syndrome (MERS) is a viral respiratory disease caused by a coronavirus (MERS-CoV) that was first identified in Saudi Arabia in 2012. Coronaviruses are a large family of viruses that can cause diseases ranging from the common cold to Severe Acute Respiratory Syndrome (SARS). It is caused by a virus that is different from any other virus that has been previously found in people. Symptoms of MERS include fever, cough, and shortness of breath. CDC is working with the World Health Organization and other partners to understand the public health risks from this virus

The first report of Middle East respiratory syndrome (MERS) described a patient who died from a severe respiratory illness in a hospital in Jeddah, Saudi Arabia, in June, 2012. A previously unrecognized coronavirus (MERS-CoV) isolated from this patient1 was similar to severe acute respiratory syndrome coronavirus (SARS-CoV), which caused an epidemic in 2002-03. The virus was initially designated human coronavirus-EMC, but was renamed MERS-CoV with global consensus. The genomic structure of MERS-CoV was delineated3 and dipeptidyl-peptidase (DPP4, also known as CD26) was identified as the host-cell receptor for cell entry. Reverse genetics enabled the virus's genome to be studied, and molecular diagnostic tests were quickly developed.

The high mortality rates in family-based and hospital-based outbreaks, especially in patients with comorbidities such as diabetes and renal failure, along with the respiratory droplet route of transmission, evoked global concern and intensive discussion in the media. The numbers of reported MERS cases spiked during hospital-based cluster outbreaks in the spring of 2013 and 2014; some cases are still detected throughout the year. MERS-CoV was deemed a serious public health epidemic threat, because millions of pilgrims from 184 countries converge in Saudi Arabia each year for the Hajj and Umrah pilgrimages. Fortunately, no MERS cases were associated with the 2013 and 2014 Hajj pilgrimages. 
The Middle East respiratory syndrome coronavirus (MERS-CoV), is a novel positive-sense, singlestranded RNA virus of the genus Beta coronavirus. Initially called novel coronavirus 2012 or simply novel coronavirus, it was first reported in 2012 after genome sequencing of a virus isolated from sputum samples from person who fell ill in a 2012 outbreak of a new flu.

As of July 2015, MERS-CoV cases have been reported in over 21 countries, including Saudi Arabia, Jordan, Qatar, Egypt, the United Arab Emirates, Kuwait, Turkey, Oman, Algeria, Bangladesh, Indonesia (none were confirmed), Austria, the United Kingdom, South Korea, the United States, Mainland China, Thailand, and the Philippines.

Preventing transmission of respiratory pathogens including MERS-CoV in hospitals requires the application of infection control procedures and protocols including environmental and engineering controls, administrative controls, safer work practices, and personal protective equipment (PPE). Measures that enhance early detection and prompt triage and isolation of patients who should be evaluated for MERS-CoV (Interim Guidance for Healthcare Professionals) are critical to ensuring effective implementation of infection control measures. Successful implementation of many, if not all, of these strategies is dependent on the presence of clear administrative policies and organizational leadership that promote and facilitate adherence to these recommendations among the various people within the healthcare setting, including patients, visitors, and HCP.

Between 19-22 June 2016, WHO published 3 reports on the Disease Outbreak News (DON) describing 25 cases of Middle East Respiratory Syndrome (MERS). Twenty-four of the cases were identified as having contact with a probable, single index case who was diagnosed with MERS in a hospital in Riyadh City, Riyadh Region. The 22 June 2016 DON reported that the index case had died.

Based on available information, the probable index case is a woman who presented on 10 June 2016 to the hospital with a critical health condition, not consistent with MERS symptoms. She was triaged in the emergency room of the hospital and admitted to the vascular surgery ward. Following admission the patient showed signs of respiratory illness, and MERS was suspected. The hospital diagnosed and confirmed MERS on 12 June 2016, within 48 hours of her original admission. The patient's MERS clinical symptoms were initially masked by other predominant symptoms.

Immediately following diagnosis the Ministry of Health of Saudi Arabia dispatched a rapid response team to the hospital. The team conducted active screening and contact tracing to identify health care workers, visitors, patients and household contacts who may have been exposed to MERS by the probable index patient. In addition, other public health control measures were immediately implemented in the hospital to limit further transmission.

As of 22 June 2016 twenty-four (24) contacts have tested positive for MERS including twenty (20) healthcare contacts and three (3) household contacts. In addition, one case has been diagnosed in a household contact of a hospital patient who was diagnosed with the disease after exposure to the probable index case. Twenty (20) of the twenty-four (24) have not exhibited any MERS symptoms.

According to WHO General-Director Margaret Chan "the Kingdom of Saudi Arabia has worked to improve its response to this challenging disease, especially through infection prevention and control in health care facilitates. Diagnosis is often complicated in patients affected by multiple comorbidities."

Globally since September 2012 WHO has been notified of over 1,700 laboratory-confirmed cases of infection with MERS, in 27 countries, including more than 600 related deaths.

Based on the current situation and available information, WHO encourages all Member States to continue their surveillance for acute respiratory infections and to carefully review any unusual patterns.

Infection prevention and control measures are critical to prevent the possible spread of MERS in health care facilities. It is not always possible to identify patients with MERS early because like other respiratory infections, the early symptoms of MERS are non-specific. Therefore, health care workers should always apply standard precautions consistently with all patients, regardless of their diagnosis. 
Droplet precautions should be added to the standard precautions when providing care to patients with symptoms of acute respiratory infection; contact precautions and eye protection should be added when caring for probable or confirmed cases of MERS infection; airborne precautions should be applied when performing aerosol generating procedures.

\section{Ecology and transmission of MERS-CoV}

MERS-CoV might have originally spread from bats to camels and other, as yet unidentified, intermediate hosts. The virus has circulated in camel populations in Africa and the Arabian Peninsula for at least 20 years. In 2012, MERS-CoV spread to human populations, with camels the most likely source. Several possible routes of spread from camels to humans exist. MERS-CoV is believed to be transmitted among human beings by droplet, contact, and perhaps airborne spread. MERS manifests in people in various ways, ranging from asymptomatic to fulminant infections. Patients with underlying disease such as diabetes or kidney or liver disease or who are immunocompromised develop more severe disease and have a higher mortality rate after infection. Image credits: camel birthing from Noboru Komine/Science Photo Library, camel milking from ACEI Cheung/CC BY-SA 2.0, camel owner contact from Peter Menzel/Science Photo Library, MERS virus from AMI Images/Science Photo Library.

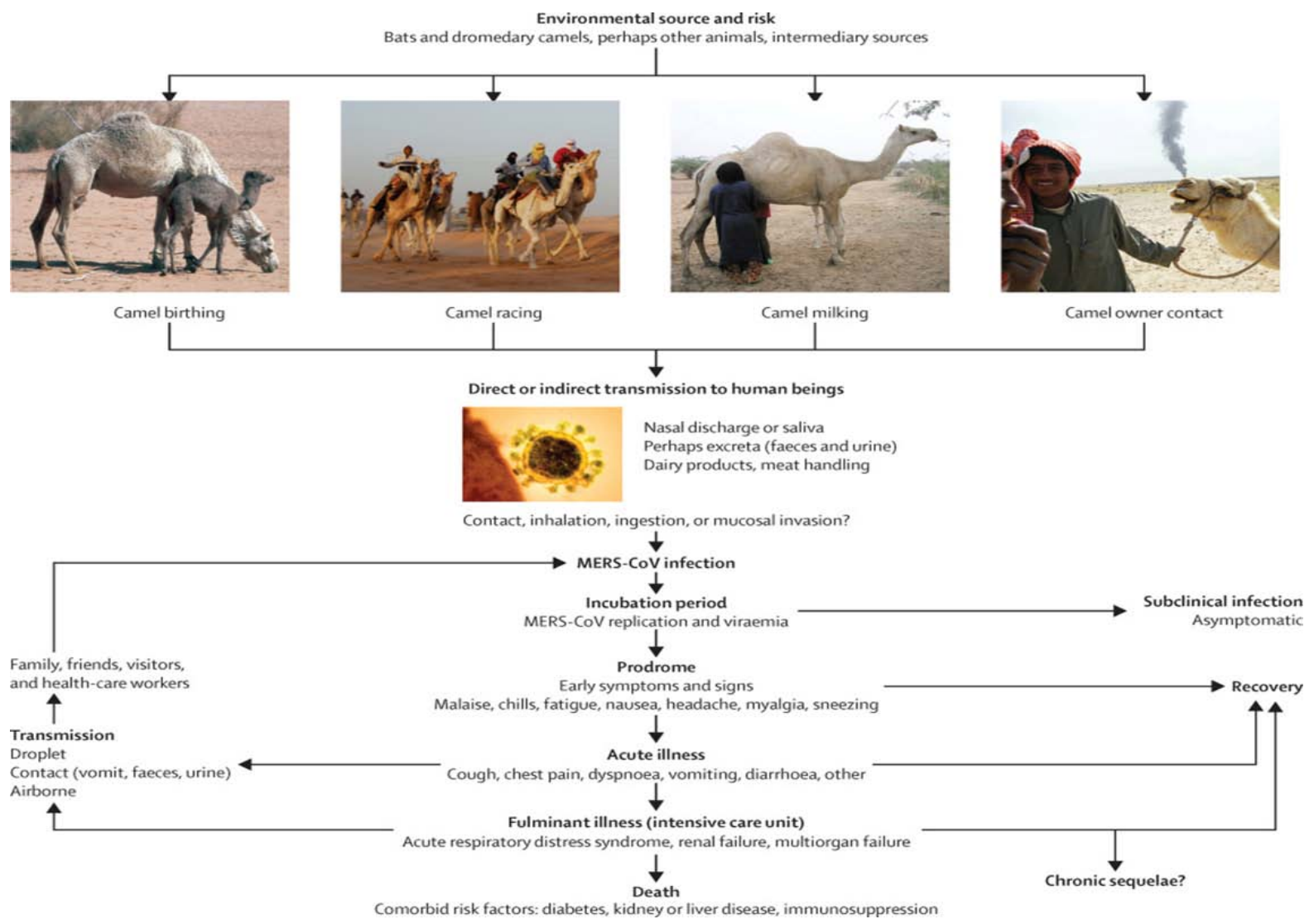

\section{Virology}

Coronaviruses are large (28-32 kb) single-stranded positive-sense RNA viruses. To enter host cells, MERS-CoV attaches to its receptor, dipeptidylpeptidase. Protease cleavage of the $\mathrm{S}$ protein is then required for virus-cell fusion and release of genomic RNA into the cytoplasm. Viral RNA transcription and replication occurs on double membrane vesicles and other membranous structures, which are derived from the endoplasmic reticulum. Transcription of the seven sub genomic mRNAs occurs via negative-strand subgenomic RNA intermediate 
The virus MERS-CoV is a new member of the beta group of coronavirus, Beta, lineage C. MERS$\mathrm{CoV}$ genomes are phylogenetically classified into two clades, clade A and $\mathrm{B}$. The earliest cases of MERS were of clade A clusters and new cases are genetically distinct (clade B).

The genomic structures of the two viruses are very similar, with proteins involved in virus replication encoded at the $5^{\prime}$ end and structural proteins encoded by genes at the $3^{\prime}$ end of the genome. Accessory proteins, which are not required for virus viability, are interspersed throughout the structural genes and might interfere with the innate immune response in infected animals. MERS-CoV has five different accessory proteins and SARS-CoVhas eight different accessory proteins, which share no sequence similarity. These differences, which presumably have different effects on induction and signaling of type 1 interferon, could explain why MERS-CoV is more sensitive to interferon than is SARS-CoV. This difference in interferon sensitivity has implications for treatment because type 1 interferon has been used to treat patients infected with SARS-CoV and MERS-CoV

MERS-CoV is distinct from SARS coronavirus and distinct from the common-cold coronavirus and known endemic human beta coronaviruses HCoV-OC43 and HCoV-HKU1. Until 23 May 2013, MERS-CoV had frequently been referred to as a SARS-like virus, or simply the novel coronavirus, and early it was referred to colloquially on message boards as the "Saudi SARS"

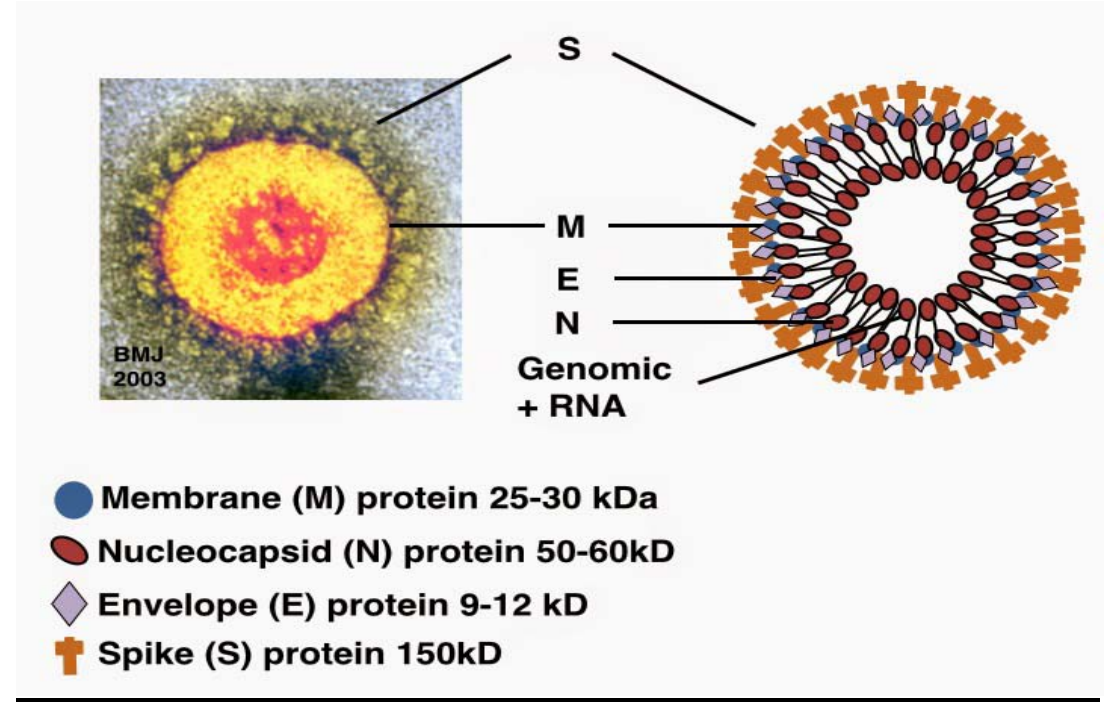

\section{Origin}

The first confirmed case was reported in Saudi Arabia 2012. Egyptian virologist Dr. Ali Mohamed Zaki isolated and identified a previously unknown coronavirus from the man's lungs. Dr. Zaki then posted his findings on 24 September 2012 on ProMED-mail. The isolated cells showed cytopathic effects (CPE), in the form of rounding and syncytia formation.

A second case was found in September 2012, a 49-year-old male living in Qatar presented with similar flu symptoms, and a sequence of the virus was nearly identical to that of the first case. In November 2012, similar cases appeared in Qatar and Saudi Arabia. Additional cases were noted, with deaths associated, and rapid research and monitoring of this novel coronavirus began.

It is not certain whether the infections are the result of a single zoonotic event with subsequent human-to-human transmission, or if the multiple geographic sites of infection represent multiple zoonotic events from a common unknown source. 


\section{Middle east respiratory syndrome 3-D image}

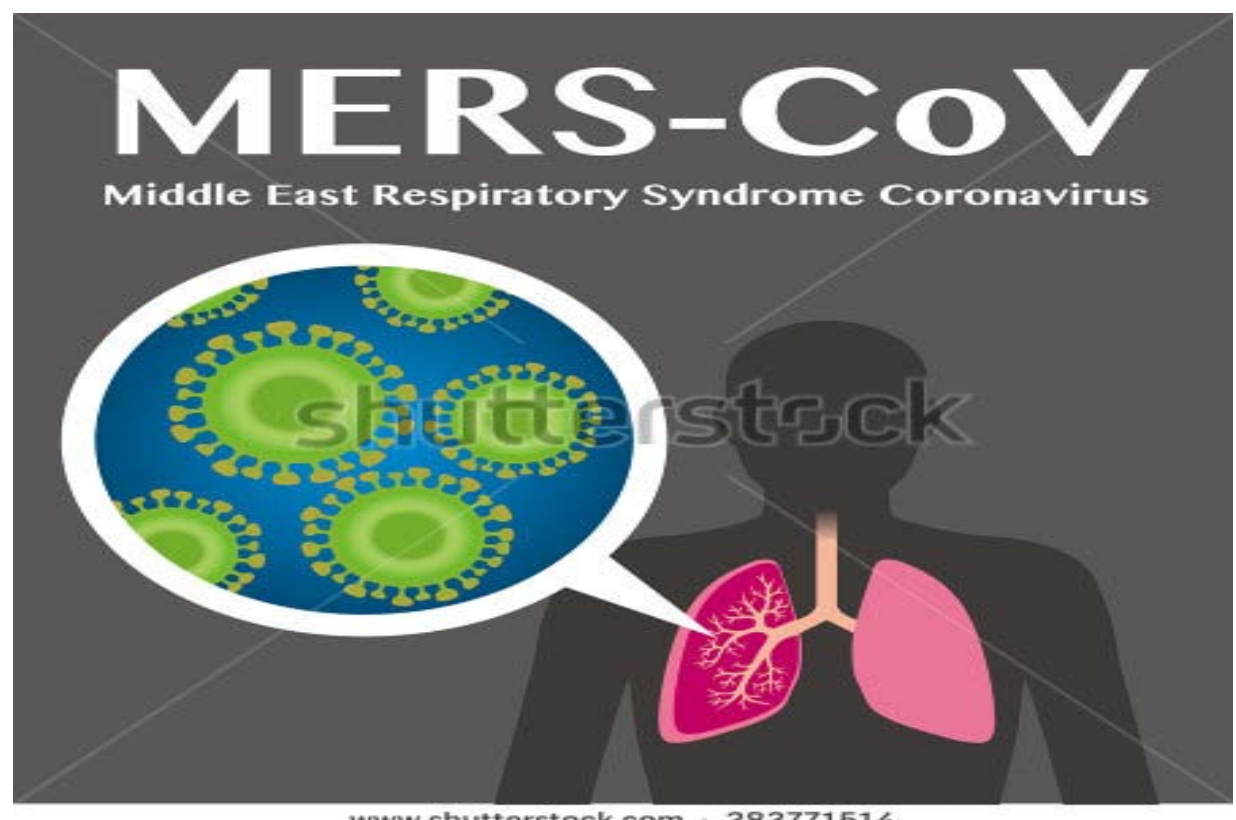

www.shutterstock.com - 283771514

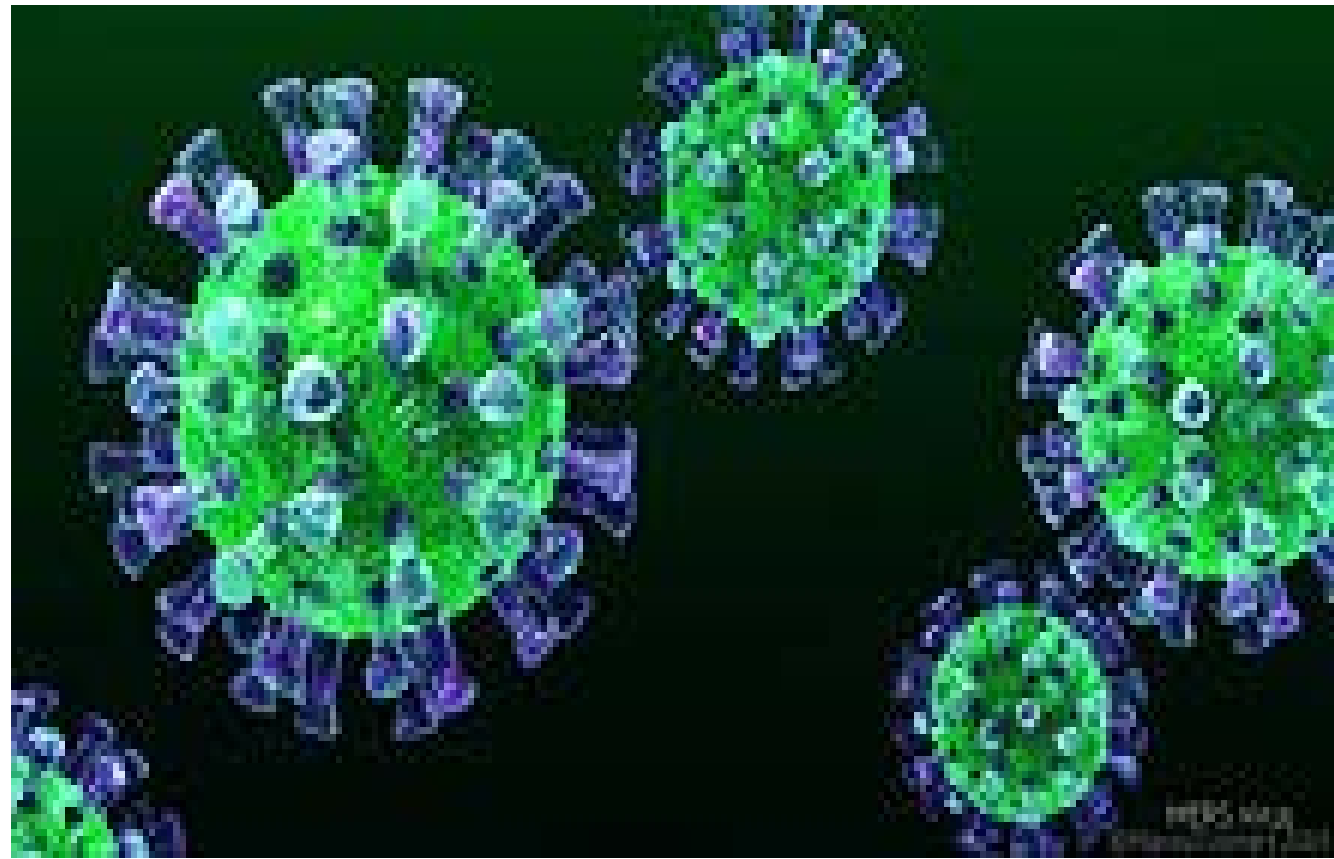

\section{Tropism}

In humans, the virus has a strong tropism for nonciliated bronchial epithelial cells, and it has been shown to effectively evade the innate immune responses and antagonize interferon (IFN) production in these cells. This tropism is unique in that most respiratory viruses target ciliated cells.

Due to the clinical similarity between MERS-CoV and SARS-CoV, it was proposed that they may use the same cellular receptor; the exopeptidase, angiotensin converting enzyme 2 (ACE2). However, it was later discovered that neutralization of ACE2 by recombinant antibodies does not prevent MERS-CoV infection. Further research identified dipeptyl peptidase 4 (DPP4; also known as CD26) as a functional cellular receptor for MERS-CoV. Unlike other known coronavirus receptors, the enzymatic activity of DPP4 is not required for infection. As would be expected, the amino acid 
sequence of DPP4 is highly conserved across species and is expressed in the human bronchial epithelium and kidneys. Bat DPP4 genes appear to have been subject to a high degree of adaptive evolution as a response to coronavirus infections, so the lineage leading to MERS-CoV may have circulated in bat populations for a long period of time before being transmitted to people.

\section{Transmission}

\section{How is Novel Coronavirus transmitted?}

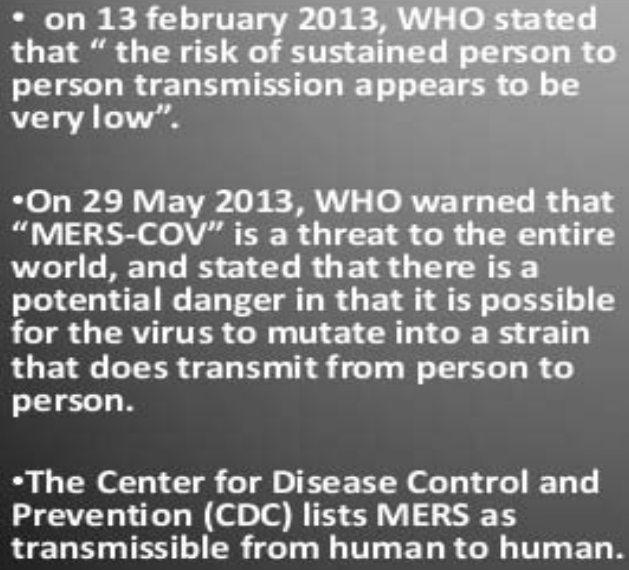

-The Center for Disease Control and Prevention (CDC) lists MERS as transmissible from human to human.

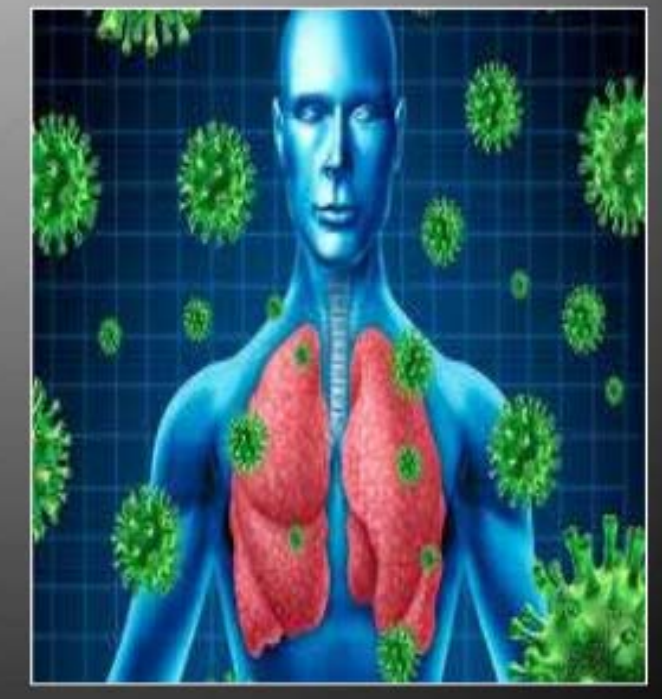

On 13 February 2013, the World Health Organization stated "the risk of sustained person-to-person transmission appears to be very low."The cells MERS-CoV infects in the lungs only account for 20\% of respiratory epithelial cells, so a large number of virions are likely needed to be inhaled to cause infection. The infection of healthcare workers (HCW) has led to concerns of human to human transmission.

Human-to-human transmission of MERS-CoV has been confirmed by epidemiological and genomic studies of cases associated with hospital and household MERS outbreaks. In a hospital-based outbreak that occurred in April and May, 2013, in Al-Hasa, an eastern province of Saudi Arabia, 23 patients receiving hemodialysis or in intensive care units were infected with a single clade of virus, with a mortality rate of $65 \%$. Spread was assumed largely to occur via large droplets and contact, although the possibility of airborne or fomite transmission was not excluded. Most infections resulted from person-to-person spread, emphasizing the importance of appropriate contact and droplet precautions to prevent transmission to other patients, health-care workers, and family members. Person-to-person spread in health-care facilities was also implicated in the 2014 MERS-CoV outbreak in Jeddah, Saudi Arabia. Patients that were initially considered primary cases were, on further investigation, found to have been exposed to MERS-CoV-infected patients, generally in health-care facilities.

MERS-CoV has spread from ill people to others through close contact, such as caring for or living with an infected person. Infected people have spread MERS-CoV to others in healthcare settings, such as hospitals. Researchers studying MERS have not seen any ongoing spreading of MERS-CoV in the community. 
MERS-CoVs isolated from single outbreaks are closely related. Genomic data are most consistent with human-to-human spread accompanied by periodic reintroduction of the virus into human populations. For MERS-CoV is generally estimated to be less than $0 \cdot 7$, substantially less than $1 \cdot 0$ associated with epidemic potential, making sustained transmission of the virus unlikely unless it mutates. By comparison, $\mathrm{R}_{\mathrm{o}}$ for SARS-CoV was more than, consistent with sustained transmission during the SARS epidemic

The Centers for Disease Control and Prevention (CDC) list MERS as transmissible from human-tohuman. MERS-CoV has been shown to spread between people who are in close contact. Transmission from infected patients to healthcare personnel has also been observed. Clusters of cases in several countries are being investigated.

On the 28th of May, the CDC revealed that the Illinois man who was originally thought to have been the first incidence of person to person spread (from the Indiana man at a business meeting), had in fact tested negative for MERS-CoV. After completing additional and more definitive tests using a neutralizing antibody assay, experts at the CDC have concluded that the Indiana patient did not spread the virus to the Illinois patient. Tests concluded that the Illinois man had not been previously infected. It is possible for silent MERS to occur, this is when the patient does not develop symptoms. Early research has shown that up to $20 \%$ of cases show no signs of active infection but have MERS-CoV antibodies in their blood.

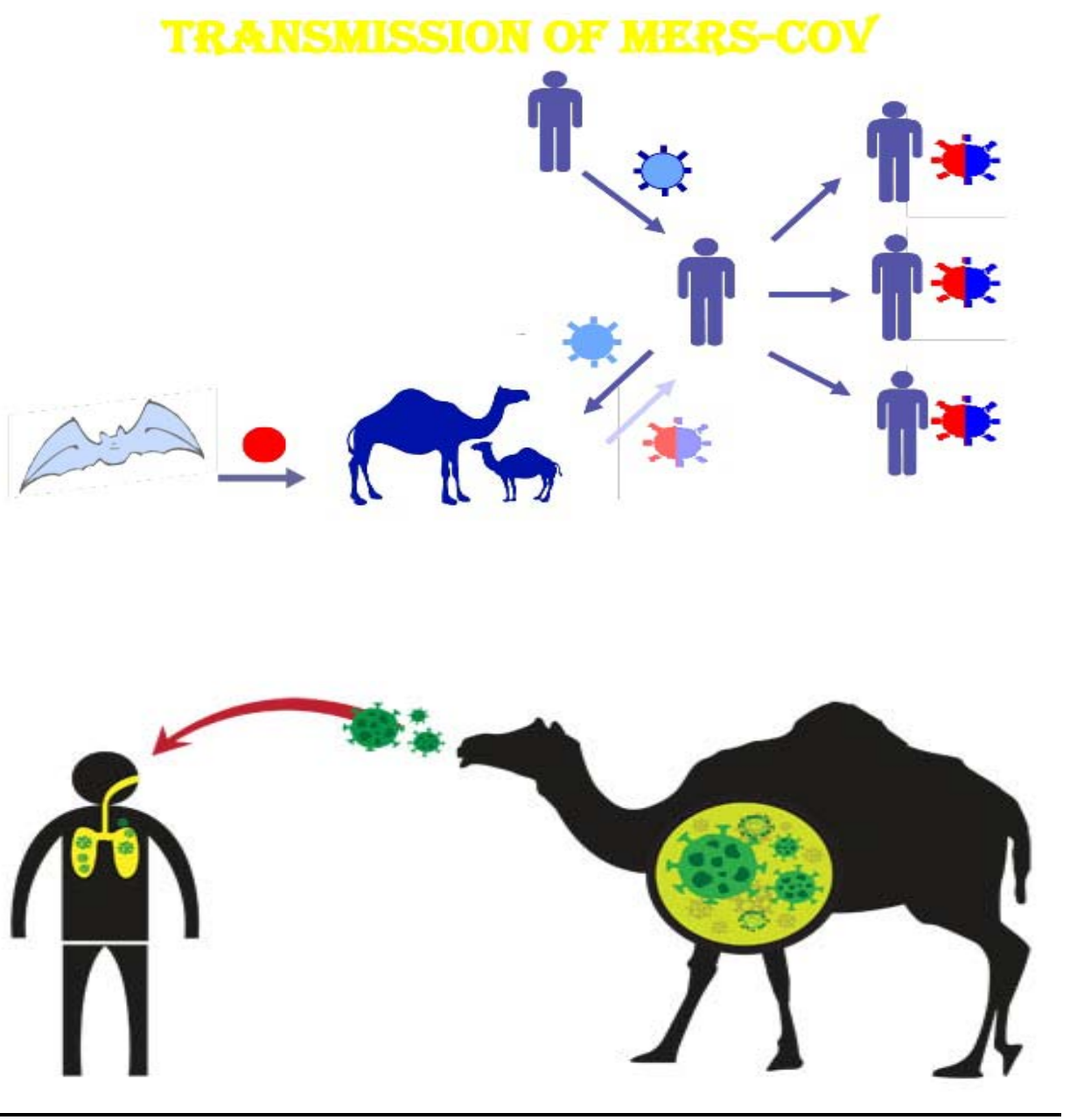




\section{Evolution}

The virus appears to have originated in bats. The virus itself has been isolated from a bat. This virus is closely related to the Tylonycteris bat coronavirus HKU4 and Pipistrellus bat coronavirus HKU5. Serological evidence shows that these viruses have infected camels for at least 20 years. The most recent common ancestor of several human strains has been dated to March 2012 (95\% confidence interval December 2011 to June 2012).

The evidence available to date suggests that the viruses have been present in bats for some time and had spread to camels by the mid-1990s. The viruses appear to have spread from camels to humans in the early 2010s. The original bat host species and the time of initial infection in this species has yet to be determined

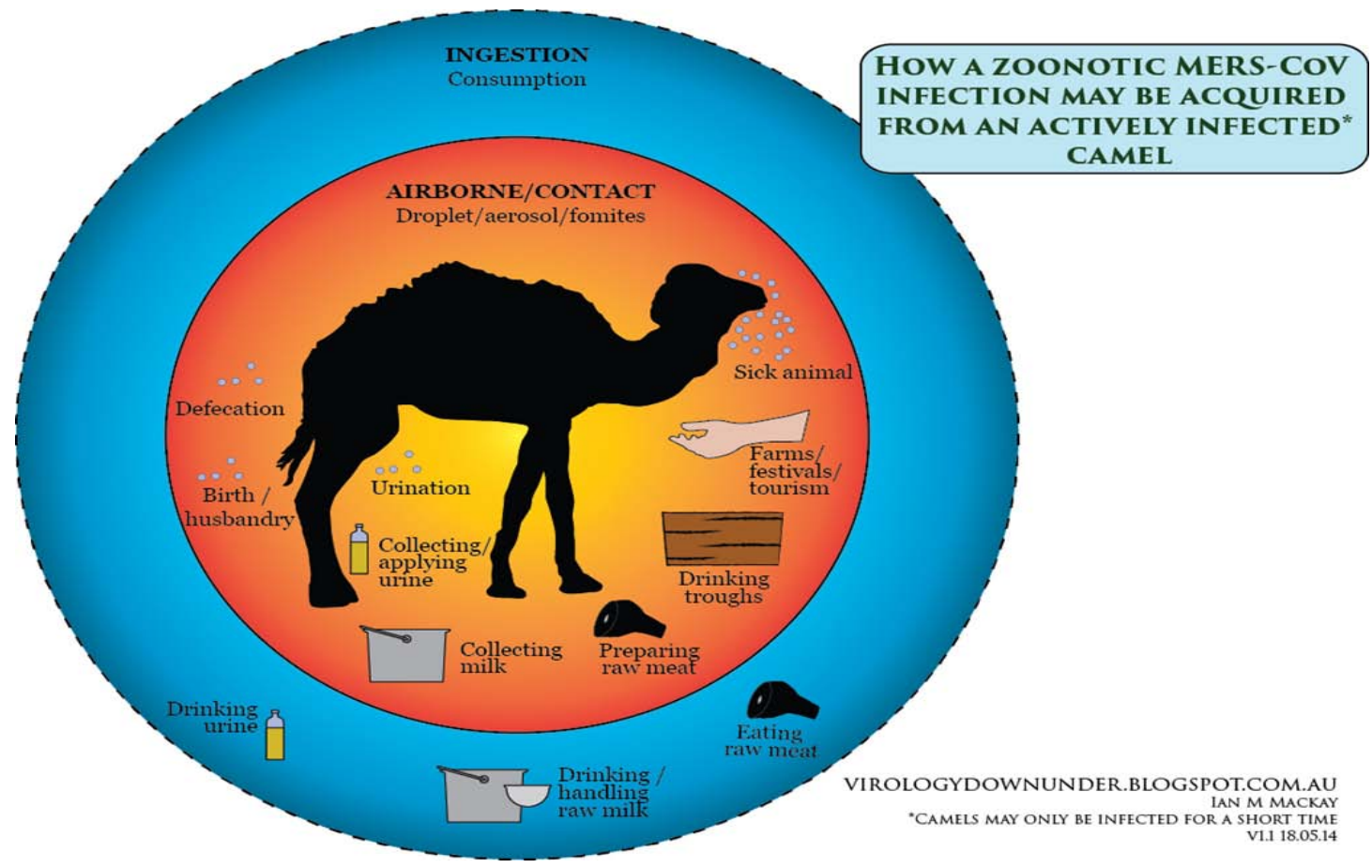

\section{Natural reservoir}

The virus is related to one found in the Egyptian tomb bat. In September 2012 Ron Fouchier speculated that the virus might have originated in bats. Work by epidemiologist Ian Lipkin of Columbia University in New York showed that the virus isolated from a bat looked to be a match to the virus found in humans. 2c beta coronaviruses were detected in Nycteris bats in Ghana and Pipistrellus bats in Europe that are phylogenetically related to the MERS-CoV virus.

The major natural reservoir where humans gets the virus infection remained unknown till on 9 August 2013, a report in the journal The Lancet Infectious Diseases showed that 50 out of 50 (100\%) blood serum from Omani camels and 15 of 105 (14\%) from Spanish camels had protein-specific antibodies against the MERS-CoV spike protein. Blood serum from European sheep, goats, cattle, and other camelids had no such antibodies.

On 5 September 2013 a seroepidemiological study published in the journal of Euro surveillance by R. A Perera et al where they investigated 1343 human and 625 animal sera indicated, the abundant presence of MERS-CoV specific antibody in 108 out of 110 Egyptian dromedary camels but not in other animals such as goats, cows or sheep in this region. These are the first and significant scientific reports that indicated the role of "dromedary camels" as a reservoir of MERS-CoV. At least one person who has fallen sick with MERS was known to have come into contact with camels or recently drank camel milk. 
Saudi Arabia and the United Arab Emirates produce and consume large amounts of camel meat. The possibility exists that African or Australian bats harbor the virus and transmit it to camels. Imported camels from these regions might have carried the virus to the Middle East.

In 2013 MERS-CoV was identified in three members of a dromedary camel herd held in a Qatar barn, which was linked to two confirmed human cases who have since recovered. The presence of MERS-CoV in the camels was confirmed by the National Institute of Public Health and Environment (RIVM) of the Ministry of Health and the Erasmus Medical Center (WHO Collaborating Center), the Netherlands. None of the camels showed any sign of disease when the samples were collected. The Qatar Supreme Council of Health advised in November 2013 that people with underlying health conditions, such as heart disease, diabetes, kidney disease, respiratory disease, the immunosuppressed, and the elderly, avoid any close animal contacts when visiting farms and markets, and to practice good hygiene, such as washing hands.

According to the 27 March 2014 MERS-CoV summary update, recent studies support that camels serve as the primary source of the MERS-CoV infecting humans, while bats may be the ultimate reservoir of the virus. Evidence includes the frequency with which the virus has been found in camels to which human cases have been exposed, seriological data which shows widespread transmission in camels, and the similarity of the camel CoV to the human $\mathrm{CoV}$.

\section{Taxonomy}

MERS-CoV is more closely related to the bat coronaviruses HKU4 and HKU5 (lineage 2C) than it is to SARS-CoV (lineage 2B) more than $90 \%$ sequence identity with their closest relationships, bat coronaviruses HKU4 and HKU5 and therefore considered to belong to the same species by the International Committee on Taxonomy of Viruses (ICTV).

Mnemonic:

Taxon identifier:

Scientific name: Middle East respiratory syndrome coronavirus

Common name: MERS-CoV

Synonym: Severe acute respiratory syndrome coronavirus

Other names:

Novel coronavirus (nCoV)

\section{MERS-CoV}

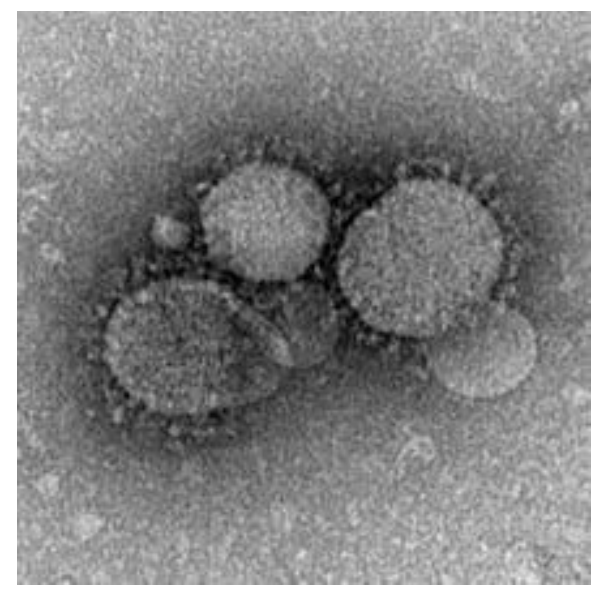

MERS-CoV particles as seen by negative stain electron microscopy. Virions contain characteristic club-like projections emanating from the viral membrane. 


\begin{tabular}{|l|l|}
\hline Virus classification \\
\hline Group: & Group IV $((+)$ ssRNA) \\
\hline Order: & Nidovirales \\
\hline Family: & Coronaviridae \\
\hline Subfamily: & Coronavirinae \\
\hline Genus: & Betacoronavirus \\
\hline Species: & MERS-CoV \\
\hline
\end{tabular}

\section{Modes of transmission}

According to the limited information available so far, there is no accurate scientific evidence identifying the way through which the virus can be transmitted from one person to another. But, it is likely to be similar to the other kinds of Coronavirus. $\mathrm{MOH}$ is making every effort, in collaboration with its partners in the international organizations, including the WHO, to learn more about ways of transmission, including through animals. The ways of human-to-human Corona transmission include the following:

1. Direct transmission through droplets produced during coughing or sneezing.

2. Indirect transmission through touching surfaces and devices contaminated with the virus, and then touching the mouth, nose or eyes.

3. Direct contact with infected patients.

4. Put on face-masks only if you are sick or visiting sick patients.

Possible sources and modes of transmission - It seems likely that dromedary camels are the primary animal host for MERS-CoV. The presence of case clusters strongly suggests that human-tohuman transmission occurs

Serologic studies have shown low prevalence of MERS-CoV antibodies in humans in Saudi Arabia. A broad antibody survey of 10,009 individuals representative of the general population of Saudi Arabia found seropositivity in 15 (0.15 percent), all but one of whom resided in five interior provinces (of 13 total provinces). In a separate survey included in the same report, 87 camel shepherds and 140 slaughterhouse workers were tested, of whom (3.1 percent) were seropositive.

Among 5235 adult pilgrims from 22 countries who visited Mecca, Saudi Arabia, for Hajj in 2013, none had a positive MERS-CoV polymerase chain reaction (PCR) from the nasopharynx; 3210 individuals were screened pre-Hajj, and 2025 were screened post-Hajj

Bats - Studies performed in Europe, Africa, and Asia, including the Middle East, have shown that coronavirus RNA sequences are found frequently in bat fecal samples and that some of these sequences are closely related to MERS-CoV sequences I n a study from Saudi Arabia, 823 fecal and rectal swab samples were collected from bats, and, using a PCR assay, many coronavirus sequences were found. Most were unrelated to MERS-CoV, but, notably, one 190 nucleotide sequence in the RNA-dependent RNA polymerase (RdRp) gene was amplified that had 100 percent identity with a MERS-CoV isolate cloned from the index patient with MERS-CoV infection; the sequence was detected from a fecal pellet of a Taphozousperforatus bat captured from a site near the home of the patient. MERS-CoV grows readily in several bat-derived cell lines.

Although bats might be a reservoir of MERS-CoV, it is unlikely that they are the immediate source for most human cases because human contact with bats is uncommon.

Camels - As noted above, it is likely that camels serve as hosts for MERS-CoV. The strongest evidence of camel-to-human transmission of MERS-CoV comes from a study in Saudi Arabia in which MERS-CoV was isolated from a man with fatal infection and from one of his camels; fullgenome sequencing demonstrated that the viruses isolated from the man and his camel were identical. The study had the following findings: 
Texila International Journal of Public Health

Volume 4, Issue 4, Dec 2016

\section{Clinical features}

The clinical manifestations of MERS-CoV infection range from asymptomatic infection to severe pneumonia with acute respiratory distress syndrome, septic shock, and multiorgan failure resulting in death.

On the basis of data related to human-to-human transmission in several clusters, the incubation period has been estimated as more than 5 days, but could be as long as 2 weeks. Median time from onset of symptoms to hospital admission is $4 \cdot 0$ days (range $0-16, n=62$ ), from onset of symptoms to admission to an intensive care unit is $5 \cdot 0(1-15, n=35)$, and from onset of symptoms to death is $11 \cdot 5$ days

Most people confirmed to have MERS-CoV infection have had severe acute respiratory illness with symptoms of:

- fever

- cough

- shortness of breath

Some people also had gastrointestinal symptoms including diarrhea and nausea/vomiting. For many people with MERS, more severe complications followed, such as pneumonia and kidney failure. About 3-4 out of every 10 people reported with MERS have died. Most of the people who died had an underlying medical condition. Some infected people had mild symptoms (such as coldlike symptoms) or no symptoms at all; they recovered.

People with pre-existing medical conditions (also called comorbidities) may be more likely to become infected with MERS-CoV, or have a severe case. Pre-existing conditions from reported cases for which we have information have included diabetes; cancer; and chronic lung, heart, and kidney disease. Individuals with weakened immune systems are also at higher risk for getting MERS or having a severe case.

Based on information we have to date, the incubation period for MERS (time between when a person is exposed to MERS-CoV and when they start to have symptoms) is usually about 5 or 6 days, but can range from 2-14 days.

MERS typically begins with fever, cough, chills, sore throat, myalgia, and arthralgia, followed by dyspnoea and rapid progression to pneumonia within the first week, often requiring ventilatory and other organ support. Although most patients with symptomatic disease present with respiratory illness, immunocompromised patients can present with fever, chills, and diarrhea and later develop pneumonia. Similar to SARS, at least a third of patients with MERS have gastrointestinal symptoms, such as vomiting and diarrhea. Risk factors for development of severe disease, in addition to an immunocompromised state, include comorbidity (eg, obesity, diabetes, cardiac disease, and lung disease). Concomitant infections and low albumin concentration are predictors of severe illness, and age older than 65 years was associated with mortality in a case series in Saudi Arabia. The few data available about viral dynamics and clinical course suggest that patients with MERS have a shorter time from illness onset to clinical presentation and to a requirement for ventilatory support than do patients with SARS and higher respiratory tract viral loads during the first week of the illness.

SARS and other severe viral illnesses, common laboratory findings of MERS include leucopenia, particularly lymphopenia. Some patients have a consumptive coagulopathy and high creatinine, lactate dehydrogenase, and liver enzyme concentrations. Co-infection with other respiratory viruses (eg, parainfluenza, rhinovirus, influenza A virus [H1N1], herpes simplex virus, influenza B virus) has been reported and nosocomial bacterial infections (including Klebsiellapneumoniae, Staphylococcus aureus, Acinetobacter species, Candida species) have occurred in patients receiving invasive mechanical ventilation.

Chest radiography and tomography findings of MERS are consistent with viral pneumonitis and acute respiratory distress syndrome, with bilateral hilar infiltration, unilateral or bilateral patchy densities or infiltrates, segmented or lobar opacities, ground-glass opacities, and small pleural 
effusions in some cases. Lower lobes are generally affected more than are upper lobes early in the course of illness with more rapid radiographic progression than in SARS.

Some patients have viral RNA in blood, urine, and stool but at much lower viral loads than in the respiratory tract.95 MERS-CoV viral loads and genome fractions in upper respiratory tract specimens (eg, nasopharyngeal swabs) are lower than in lower respiratory tract specimens, such as tracheal aspirates and bronchoalveolar lavage fluid, which probably accounts for the inefficiency of interhuman transmission. Lower respiratory tract excretion of MERS-CoV RNA can be detected after 1 month of illness in most patients, suggesting that prolonged shedding could be a source for spread in outbreaks.

\section{Signs and symptoms of Anaphylaxis}

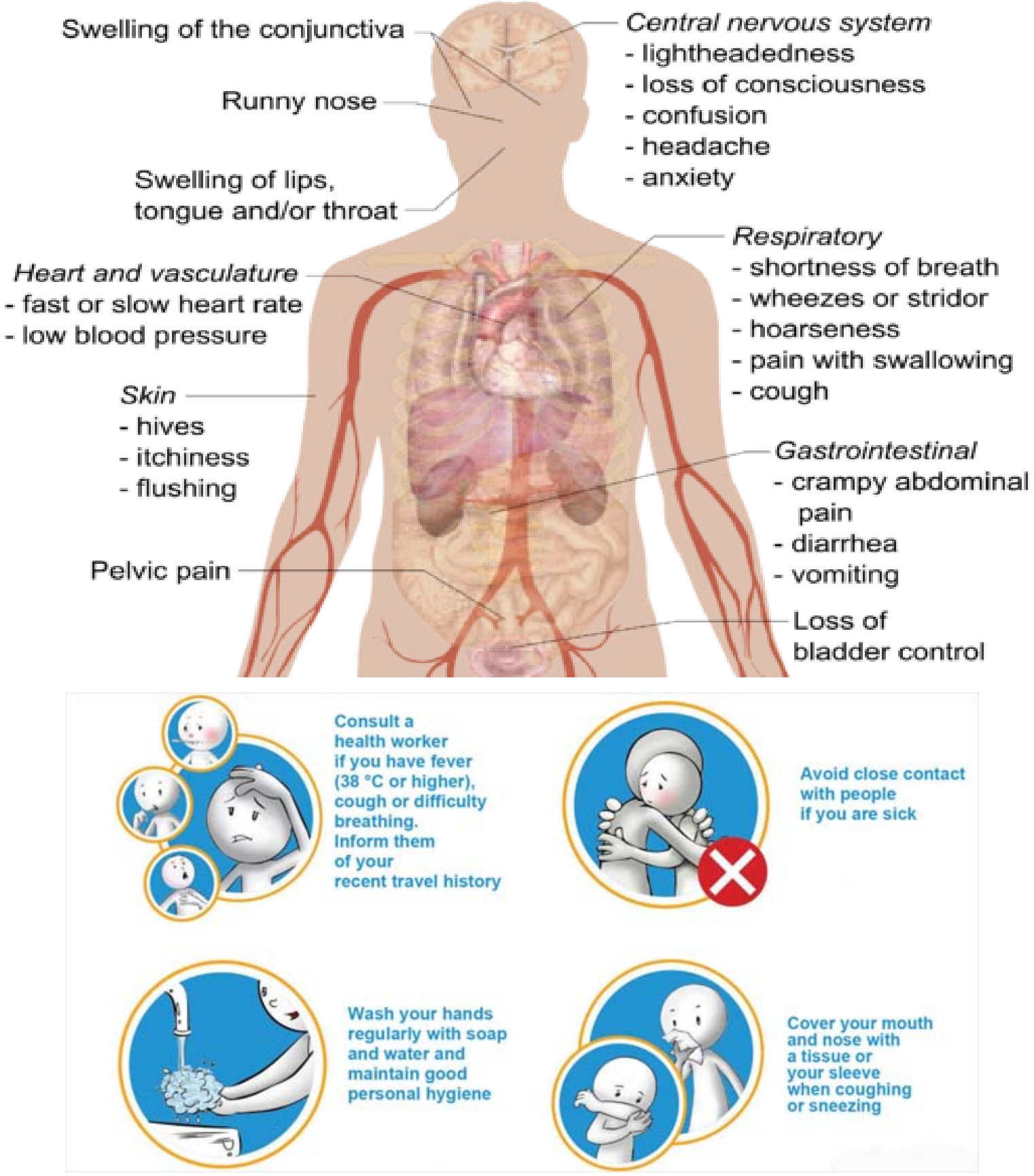


Texila International Journal of Public Health

Volume 4, Issue 4, Dec 2016

\section{Diagnosis}

Because lower respiratory tract specimens such as bronchoalveolar lavage fluid, sputum, and tracheal aspirates contain the highest viral loads, they should be collected whenever possible. MERS can be confirmed by detection of viral nucleic acid or by serology. The presence of viral nucleic acid can be confirmed either by positive real-time reverse transcription PCR on at least two specific genomic targets or by a single positive target with sequencing of a second positive PCR product. Available real-time reverse transcription PCR tests include an assay targeting RNA upstream of the E gene ( $u p E)$ and assays targeting open reading frames $1 \mathrm{~b}(O R F 1 b)$ and $1 \mathrm{a}(O R F 1 a)$. The assay for the upE target is highly sensitive and is recommended for screening; the ORF $1 a$ assay is of equal sensitivity. The ORF $1 b$ assay is less sensitive but is useful for confirmation. These assays have not shown cross-reactivity with other respiratory viruses including human coronaviruses. Two target sites on the MERS-CoV genome suitable for sequencing to aid confirmation are in the RNA-dependent RNA polymerase (RdRp; present in ORF $1 b$ ) and $N$ genes

In MERS cases confirmed by PCR, serial sampling for PCR testing from the upper and lower respiratory tracts and other body parts (eg, serum, urine, and stool) are recommended to understand viral replication kinetics and to guide infection control. Respiratory samples should be collected at least every 2-4 days to confirm viral clearance after two consecutive negative results are obtained.

For confirmation of infection by antibody detection, paired serum samples should be collected 1421 days apart with the first taken during the first week of illness. A positive screening assay (ELISA, immunofluorescence assay) should be followed by a confirmatory (neutralisation) assay. Single samples might also be valuable for identification of probable cases and should be collected at least 14 days after the onset of symptoms. Serological results should be carefully interpreted because they might be confounded by cross-reactivity against other coronaviruses

\section{Treatment}

No specific drug treatment exists for MERS and supportive treatment is the mainstay of management. Evidence-based recommendations for treatment provide the basis for decision making in clinical settings

MERS-CoV is readily inhibited by type 1 interferons (IFN- $\alpha$ and especially IFN- $\beta$ ) in cultured cells, and IFN- $\alpha 2 b$ combined with ribavirin can lessen lung injury and reduce lung titres when administered to rhesus macaques within $8 \mathrm{~h}$ of virus inoculation.

This combination was tested in severely ill patients, showing an improvement in survival at 14 days but not 28 days, possibly a result of administration in the advanced stages of disease

Several drugs inhibit MERS-CoV in cell culture, including ciclosporin and mycophenolic acid. Other compounds (chloroquine, chlorpromazine, loperamide, and lopinavir) inhibit virus replication (effective concentration50 3-8 $8 \mathrm{~mol} / \mathrm{L}$ ) in vitro, although whether these drugs will be useful in patients is unknown. MERS-CoV-specific peptide fusion inhibitors, which function similarly to the HIV drug enfuvirtide, diminish virus replication in cultured cells, providing a novel approach to MERS treatment.

\section{Prevention}

- Recommendations for prevention of MERS are available from WHO, the US Centers for Disease Control and Prevention, and the Saudi Ministry of Health. The main infection prevention and control measures are droplet precautions (wearing a surgical mask within $1 \mathrm{~m}$ of patients) and contact precautions (wearing gown and gloves on entering patients' rooms and removing them on leaving). Droplet precautions should be added to the standard precautions when providing care to all patients with signs of acute respiratory infection. Eye protection should be used when health-care workers care for probable or confirmed patients.

- Public Health England, US Centers for Disease Control and Prevention, and Saudi Ministry of Health recommendations for management of known or suspected MERS-CoV infection include 
the use of personal protective equipment such as gowns, gloves, eye protection (goggles or face shield), and respiratory protection equivalent to a fit-tested National Institute for Occupational Safety and Health-certified disposable N95 filtering face piece respirator. Patients with MERS should be placed in negative pressure rooms or in rooms in which room exhaust is filtered through high-efficiency particulate air filters. Airborne precautions with at least six air changes per hour should be applied in treatment rooms when performing aerosol-generating procedures. These recommendations are evidence-based and have proven to be effective in hospitals in affected countries.

- Camels infected with MERS-CoV can develop rhinitis or show no signs of infection and might shed virus through nasal and eye discharge and faeces. The virus can also be found in raw milk from infected camels. MERS-CoV is stable in camel breast milk for extended periods of time; thus, pasteurization or cooking is recommended to destroy the virus.

- Raw urine should not be used for medicinal purposes. Because signs of disease are non-specific, it is not possible to know whether an animal in a farm, market, race track, or slaughterhouse is excreting MERS-CoV without virological testing.

- Camel farm workers, slaughterhouse workers, market workers, veterinarians, and those handling camels at racing facilities should practice good personal hygiene, including frequent hand washing after touching animals, avoiding touching eyes, nose, or mouth with hands, and avoiding contact with sick animals. Consideration should also be given to wearing protective gowns and gloves while handling animals, especially if camels have signs of upper respiratory tract disease.

\section{Imaging findings at presentation in Saudi patients with Middle East respiratory syndrome coronavirus infection}
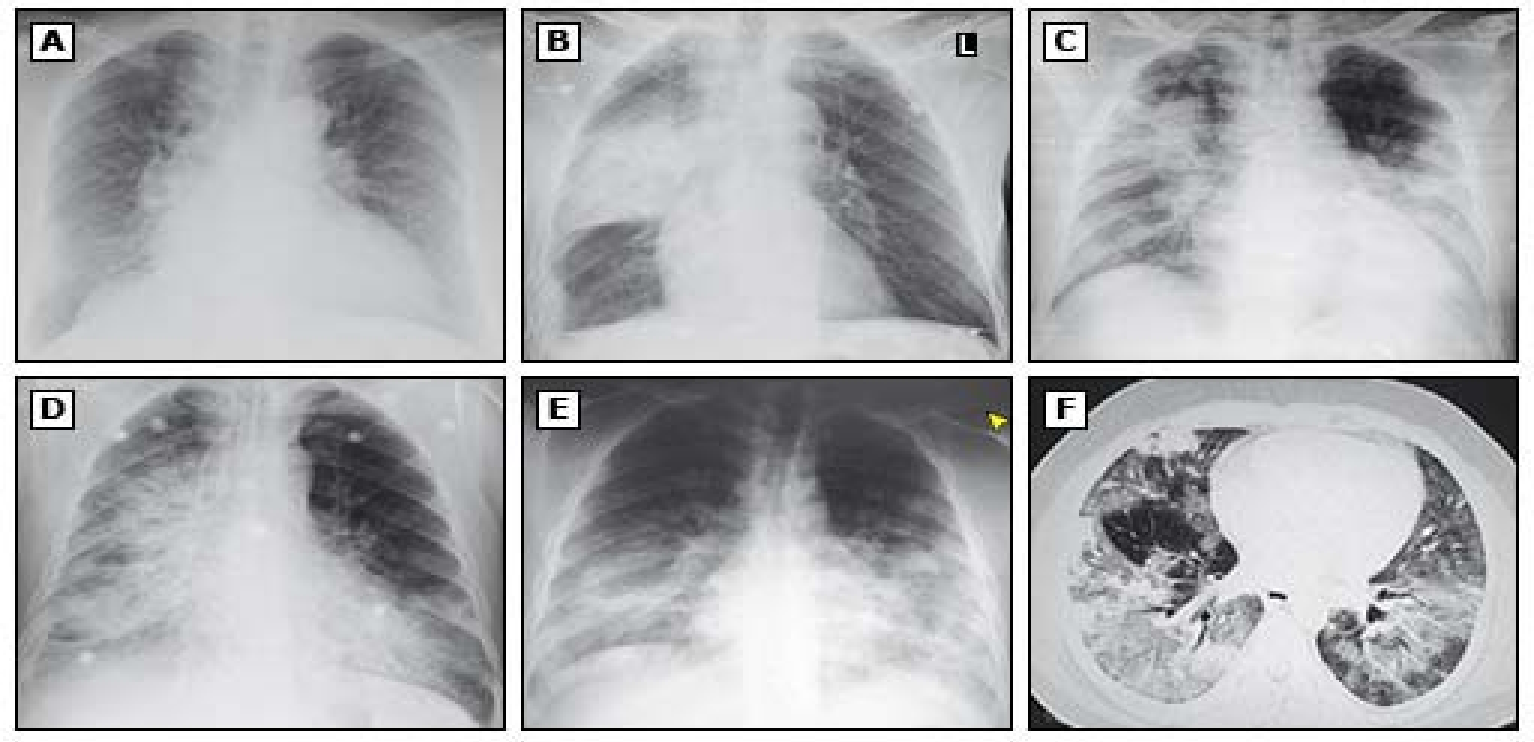

(Panel A) Chest radiograph of a 61-year-old man, showing bilateral fine reticulonodular air-space opacities, increased vascular markings, and cardiomegaly.

(Panel B) Chest radiograph of an 83-year-old man, showing right lung consolidation, right basal pleural thickening, and reticulonodular air-space opacities; rib fractures on the right are old.

(Panel C) Chest radiograph of a 56-year-old man, showing extensive bilateral extensive diffuse and focal alveolar space opacities, with opacification of the left lower lobe.

(Panel D) Chest radiograph of a 67-year-old man, showing extensive bilateral disease, with diffuse alveolar space densities, opacification, reticulonodular opacities, and bronchial wall thickening. 
(Panel E) Chest radiograph of a 49-year-old man, showing extensive bilateral mid and lower zone disease, with diffuse reticulonodular alveolar space opacities. A thoracic computed tomography scan in the same patient (Panel F) shows extensive bilateral opacities and ground-glass reticulonodular shadowing and bronchiolar wall thickening.

\section{Ways of protection against the Middle East Respiratory Syndrome-Coronavirus (MERC-CoV)}

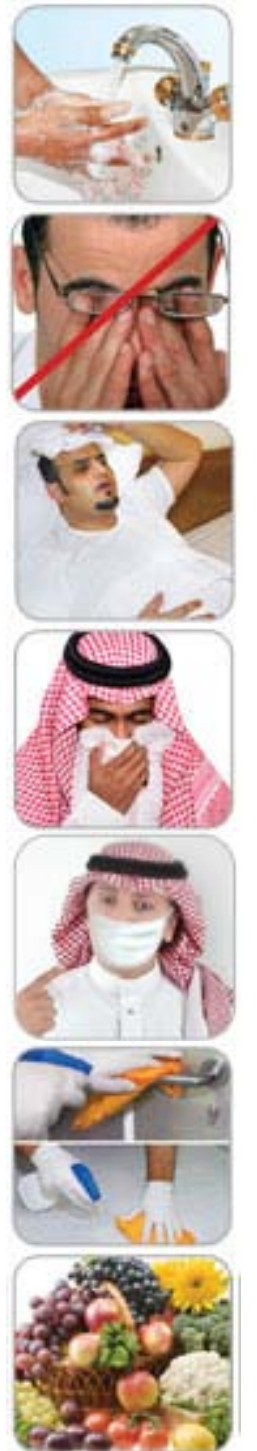

Wash your hands well and continually with water and soap, or with other disinfectants used for hand washing, especially after coughing, sneezing and using toilets. Also, don't forget to wash your hands before and after handling or preparing foods, and when dealing with patients or their personal belongings.

Try as much as possible to avoid touching the eyes, nose and mouth with your hand, because it can transmit the virus after touching surfaces contaminated with the virus.

Avoid as much as possible contacting with infected people.

Use handkerchief when coughing or sneezing and cover your mouth and nose with it, then get rid of the handkerchief in a waste basket and make sure to wash your hands. If there are no handkerchiefs, it is preferred to cough or sneeze in the top of your arm, not in the hands (palms).

Put on face-masks only if you are sick or visiting sick patients

Adhere to hygiene.

\section{Infection prevention and control recommendations for hospitalized patients with (MERS-CoV)}

Center for Disease Control (CDC) works 24/7 to protect people's health. It is the job of CDC to be concerned and move quickly whenever there is a potential public health problem. CDC continues to closely monitor the MERS situation globally. CDC is working with the World Health Organization and other partners to better understand the virus, how it spreads, the source, and risks to the public's health. We recognize the potential for MERS-CoV to spread further and cause more cases in the United States and globally. In preparation for this, we have:

- Continued to collaborate with international partners on epidemiologic and laboratory studies to better understand MERS 
- Improved the way we collect data about MERS cases

- Increased lab testing capacity in states to detect cases

- Developed guidance and tools for health departments to conduct public health investigations when MERS cases are suspected or confirmed

- Provided recommendations for healthcare infection control and other measures to prevent disease spread

- Provided guidance for flight crews, Emergency Medical Service (EMS) units at airports, and U.S. Customs and Border Protection (CPB) officers about reporting ill travelers to CDC

- Disseminated up-to-date information to the general public, international travelers, and public health partners

\section{Recommendations}

Definition of Healthcare Personnel (HCP) -HCP refers to all persons, paid and unpaid, working in healthcare settings whose activities potentially place them at risk for exposures to a patient with MERS-CoV.

\section{Minimize chance for exposures}

Ensure facility policies and practices are in place to minimize exposures to respiratory pathogens including MERS-CoV. Measures should be implemented before patient arrival, upon arrival, and throughout the duration of the affected patient's presence in the healthcare setting.

\subsection{Before arrival}

- When scheduling appointments, instruct patients and persons who accompany them to call ahead or inform HCP upon arrival if they have symptoms of any respiratory infection (e.g., cough, runny nose, fever ${ }^{1}$ ) and to take appropriate preventive actions (e.g., wear a facemask upon entry to contain cough, follow triage procedure).

\subsection{Upon arrival and during the visit}

- Take steps to ensure all persons with symptoms of a respiratory infection adhere to respiratory hygiene and cough etiquette, hand hygiene, and triage procedures throughout the duration of the visit. Consider posting visual alerts (e.g., signs, posters) at the entrance and in strategic places (e.g., waiting areas, elevators, cafeterias) to provide patients and HCP with instructions (in appropriate languages) about hand hygiene, respiratory hygiene, and cough etiquette. Instructions should include how to use facemasks (See definition of facemask in Appendix) or tissues to cover nose and mouth when coughing or sneezing, to dispose of tissues and contaminated items in waste receptacles, and how and when to perform hand hygiene.

- Provide space and encourage persons with symptoms of respiratory infections to sit as far away from others as possible. If available, facilities may wish to place these patients in a separate area while waiting for care.

- Ensure rapid triage and isolation of patients who might have MERS-CoV infection

- Identify patients at risk for having MERS-CoV infection before or immediately upon arrival to the hospital

- Implement triage procedures to detect patients at risk for having MERS-CoV infections during or before patient triage or registration (e.g., at the time of patient check-in) and ensure that all patients are asked about the presence of symptoms of a respiratory infection and history of travel to areas experiencing transmission of MERS-CoV or contact with possible MERS-CoVpatients. See the Interim Guidance for Healthcare Professionals for which patients to evaluate for MERSCoV.

- Immediately isolate those identified as at risk for having MERS-CoV infection

- Implement Respiratory Hygiene and Cough Etiquette (i.e., placing a facemask over the patient's nose and mouth) and isolate those at risk for MERS-CoV infection in an Airborne Infection 
Isolation Room (AIIR). See recommendations for "Patient Placement" below. Additional guidance for evaluating patients in U.S. for MERS-CoV infection can be found at the CDC Middle East Respiratory Syndrome (MERS) website.

- Provide supplies to perform hand hygiene to all patients upon arrival to facility (e.g., at entrances of facility, waiting rooms, at patient check-in) and throughout the entire duration of the visit to the healthcare setting.

\section{Ensure adherence to standard, contact and airborne precautions}

Standard precautions assume that every person is potentially infected or colonized with a pathogen that could be transmitted in the healthcare setting. Elements of standard precautions that apply to patients with respiratory infections, including those caused by MERS-CoV, are summarized below. Attention should be paid to training and proper donning, doffing and disposal of any personal protective equipment. who enter the room of a patient with suspected or confirmed MERS-CoV should adhere to Standard, Contact, and Airborne precautions, including the following:

\subsection{Hand hygiene}

- HCP should perform hand hygiene before and after all patient contact, contact with potentially infectious material, and before putting on and upon removal of PPE, including gloves. Hand hygiene in healthcare settings can be performed by washing with soap and water or using alcohol-based hand rubs. If hands are visibly soiled, use soap and water, not alcohol-based hand rubs.

- Healthcare facilities should ensure that facilities and supplies for performing hand hygiene are readily available to all personnel.

\subsection{Personal protective equipment}

- Employers should select appropriate PPE and provide it to workers in accordance with OSHA's PPE standards (29 CFR 1910 Subpart I). Workers must receive training on and demonstrate an understanding of when to use PPE; what PPE is necessary; how to properly don (put on), use, doff (take off) PPE; how to properly dispose of or disinfect and maintain PPE; and the limitations of PPE. Any reusable PPE must be properly cleaned, decontaminated, and maintained after and between uses.

\subsection{Gloves}

- Put on clean, non-sterile gloves upon entry into the patient room or care area. Change gloves if they become torn or heavily contaminated.

- Remove and discard gloves immediately upon leaving the patient room or care area. Please see section below on "Using More than one Kind of Personal Protective Equipment (PPE)" for recommended sequence of PPE removal.

\subsection{Gowns}

- Put on a clean disposable gown upon entry into the patient room or area. Change the gown if it becomes soiled. Remove and discard the gown immediately upon leaving the patient room or care area.

\subsection{Respiratory protection}

- Use respiratory protection (i.e., a respirator) that is at least as protective as a fit-tested NIOSHcertified disposable N95 filtering facepiece respirator upon entry to the patient room or care area. See appendix for respirator definition.

- The respirator should be the last part of the PPE ensemble to be removed. If reusable respirators are used, they must be cleaned and disinfected according to manufacturer's reprocessing 
instructions prior to re-use. If disposable respirators are used, they should be removed and discarded after leaving the patient room or care area and closing the door.

- Respirator use must be in the context of a complete respiratory protection program in accordance with Occupational Safety and Health Administration (OSHA) Respiratory Protection standard Staff should be medically cleared and fit-tested if using respirators with tight-fitting facepieces (e.g disposable N95) and trained in the proper use of respirators, safe removal and disposal, and medical contraindications to respirator use.

\subsection{Eye Protection}

- Put on eye protection (e.g., a disposable face shield) upon entry to the patient room or care area. Remove and discard eye protection immediately upon leaving the patient room or care area. Reusable eye protection (e.g., goggles) must be cleaned and disinfected according to manufacturer's reprocessing instructions prior to re-use.

\subsection{Using more than one kind of personal protective equipment (PPE)}

- Different types of PPE are used together to prevent multiple routes of transmission.

- The following sequence is a general approach to putting on this PPE combination for respiratory pathogens: first gown; then respirator; then goggles or face shield; then gloves.

- The following sequence is a general approach to removing PPE for respiratory pathogens: first gloves; then goggles or face shield; then gown; then respirator.

- Except for respirator, remove PPE at doorway or in anteroom. Remove respirator after leaving patient room and closing door.

- Careful attention should be given to prevent contamination of clothing and skin during the process of removing PPE.

- Perform hand hygiene as described above immediately before putting on and after removing all PPE.

\subsection{Patient placement}

- Place a patient who might be infected with MERS-CoV in an Airborne Infection Isolation Room (AIIR) that has been constructed and maintained in accordance with current guidelines.

- AIIRs are single patient rooms at negative pressure relative to the surrounding areas, and with a minimum of 6 air changes per hour (12 air changes per hour are recommended for new construction or renovation). Air from these rooms should be exhausted directly to the outside or be filtered through a high-efficiency particulate air (HEPA) filter before recirculation. Room doors should be kept closed except when entering or leaving the room, and entry and exit should be minimized. Facilities should monitor and document the proper negative-pressure function of these rooms.

- If an AIIR is not available, the patient should be transferred as soon as is feasible to a facility where an AIIR is available. Pending transfer, place a facemask on the patient and isolate him/her in an examination room with the door closed. The patient should not be placed in any room where room exhaust is recirculated without high-efficiency particulate air (HEPA) filtration.

- Once in an AIIR, the patient's facemask may be removed; the facemask should remain on if the patient is not in an AIIR. Limit transport and movement of the patient outside of the AIIR to medically-essential purposes. When outside of the AIIR, patients should wear a facemask to contain secretions.

- Only essential personnel should enter the AIIR. Implement staffing policies to minimize the number of HCP who enter the room.

- Facilities should consider caring for these patients with dedicated HCP to minimize risk of transmission and exposure to other patients and other HCP.

- Facilities should keep a log of all persons who care for OR enter the rooms or care area of these patients. 
- Once the patient vacates a room, unprotected individuals, including HCP, should not be allowed in that room until sufficient time has elapsed for enough air changes to remove potentially infectious particles. More information on clearance is available. In addition, the room should undergo appropriate cleaning and surface disinfection before unprotected individuals are allowed to reenter it.

\section{Manage visitor access and movement within the facility}

1. Establish procedures for monitoring, managing and training visitors.

2. All visitors should follow respiratory hygiene and cough etiquette precautions while in the common areas of the facility.

3. Restrict visitors from entering the MERS-CoV patient's room. Facilities can consider exceptions based on end-of-life situations or when a visitor is essential for the patient's emotional wellbeing and care.

4. Visitors who have been in contact with the patient before and during hospitalization are a possible source of MERS-CoV for other patients, visitors, and staff.

5. Visitors to MERS-CoV patients should be scheduled and controlled to allow for:

- Screening visitors for symptoms of acute respiratory illness before entering the hospital.

- Facilities should evaluate risk to the health of the visitor (e.g., visitor might have underlying illness putting them at higher risk for MERS-CoV) and ability to comply with precautions.

- Facilities should provide instruction, before visitors enter patients' rooms, on hand hygiene, limiting surfaces touched, and use of PPE according to current facility policy while in the patient's room.

- Facilities should maintain a record (e.g., log book) of all visitors who enter patient rooms.

- Visitors should not be present during aerosol-generating procedures.

- Visitors should be instructed to limit their movement within the facility.

- Exposed visitors (e.g., contact with symptomatic MERS-CoV patient prior to admission) should be advised to report any signs and symptoms of acute illness to their health care provider for a period of at least 14 days after the last known exposure to the sick patient.

\section{Implement engineering controls}

Consider designing and installing engineering controls to reduce or eliminate exposures by shielding HCP and other patients from infected individuals. Examples of engineering controls include physical barriers or partitions to guide patients through triage areas, curtains between patients in shared areas, closed suctioning systems for airway suctioning for intubated patients, as well as appropriate air-handling systems (with appropriate directionality, filtration, exchange rate, etc.) that are installed and properly maintained.

\section{Monitor and manage ill and exposed healthcare personnel}

1. HCP who care for patients with MERS-CoV should be monitored. They should immediately report any signs (e.g., fever ${ }^{1}$ ) or symptoms (e.g., cough, shortness of breath) of acute illness to their supervisor or a facility designated person (e.g., occupational health services) for a period of 14 days after the last known contact with a MERS CoV patient, regardless of their use of PPE.

2. HCP who develop any respiratory symptoms after an unprotected exposure (i.e., not wearing recommended PPE at the time of contact) to a patient with MERS-CoV should not report for work or should immediately stop working. These HCP should notify their supervisor, implement respiratory hygiene and cough etiquette, seek prompt medical evaluation, and comply with work exclusion until they are no longer deemed infectious to others.

3. For asymptomatic HCP who have had an unprotected exposure (i.e., not wearing recommended PPE at the time of contact) to a patient with MERS-CoV, exclude from work for 14 days to monitor for signs and symptoms of respiratory illness and fever. 
4. If necessary to ensure adequate staffing of the facility, the asymptomatic provider could be considered for continuing patient care duties after discussion with local, state, and federal public health authorities.

5. Facilities and organizations providing healthcare should:

- Implement sick leave policies for HCP, including contract staff and part-time personnel, that are non-punitive, flexible and consistent with public health guidance (e.g., policies should ensure ill HCP who may have MERS-CoV infection stay home, unless hospital admission for isolation and treatment is recommended).

- Ensure that all HCP are aware of the sick leave policies.

6. Provide employee health services that:

- Ensure that HCP have ready access, including via telephone, to medical consultation and, if needed, prompt treatment.

\section{Train and educate healthcare personnel}

1. Provide all HCP with job- or task-specific education and training on preventing transmission of infectious agents, including refresher training.

2. HCP must be medically cleared, trained, and fit tested for respiratory protection device use (e.g., N95 filtering face piece respirators), or medically cleared and trained in the use of an alternative respiratory protection device (e.g., Powered Air-Purifying Respirator, PAPR) whenever respirators are required.

3. Ensure that HCP are educated, trained, and have practiced the appropriate use of PPE prior to caring for a patient, including attention to correct use of PPE and prevention of contamination of clothing, skin, and environment during the process of removing such equipment.

\section{Implement environmental infection control}

1. Ensure that cleaning and disinfection procedures are followed consistently and correctly.

2. Standard cleaning and disinfection procedures (e.g., using cleaners and water to pre-clean surfaces prior to applying an EPA-registered disinfectant to frequently touched surfaces or objects for appropriate contact times as indicated on the product's label) are appropriate for MERS-CoV in healthcare settings, including those patient-care areas in which aerosol-generating procedures are performed. If there are no available EPA-registered products that have a label claim for MERS-CoV, products with label claims against human coronaviruses should be used according to label instructions. Management of laundry, food service utensils, and medical waste should also be performed in accordance with routine procedures.

\section{Establish reporting within hospitals and to public health authorities}

1. Implement mechanisms and policies that promptly alert key facility staff including infection control, healthcare epidemiology, hospital leadership, occupational health, clinical laboratory, and frontline staff about suspected or known MERS-CoV patients.

2. Communicate and collaborate with public health authorities.

- $\quad$ Promptly notify public health authorities of suspected or known patients with MERS-CoV.

- Facilities should designate specific persons within the healthcare facility who are responsible for communication with public health officials and dissemination of information to HCP. 


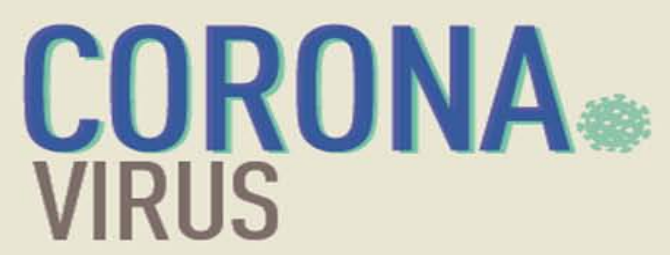

Middle East Respiratory Syndrome Coronavirus (MERS-CoV)

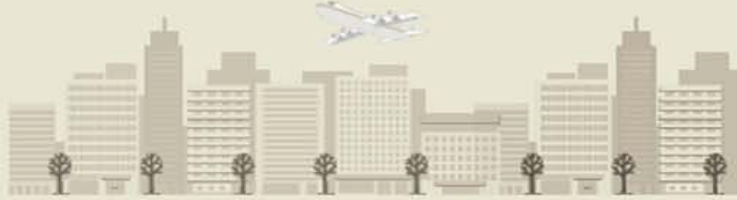

According to the recommendations of the specialists and scientists who attended the International Medical Meeting in Riyadh

Fighting Infections (of Corona and other acute respiratory infections) in Workplaces

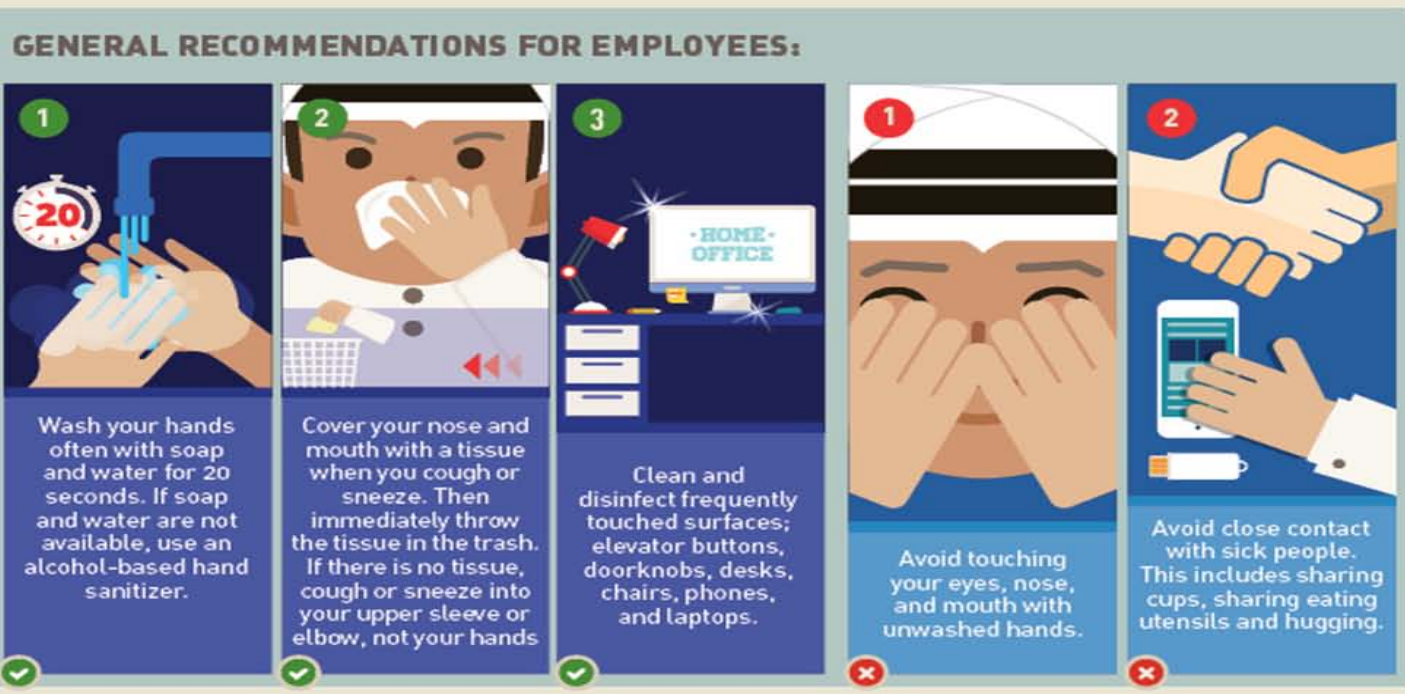

WHAT TO DO IF YOU FEEL SICK (FEVER, COUGH, SORE THROAT AND DIFFICULTY BREATHING]

If fever and respiratory symptoms (difficulty breathingl occur stay at home. Do not go back to work until free of symptoms for at least 24hrs
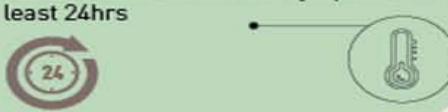

(24)

If you are diagnosed with
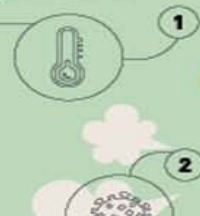

MERS CoV notify HR Do not come to work until 48 hours after you have recovered. You must test negative and be symptom free before returning to the workplace.

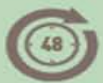

(1)

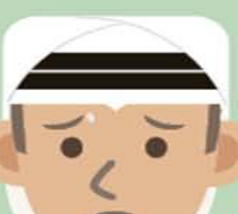

(2) Ensure all shared spaces are

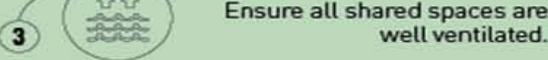

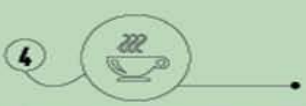

Do not share eating utensils, cups, towels, or washcloths.

5

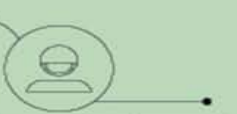

Employees should avoid contact with patients and their personal items, and use face-masks only if they are sick orvisiting sick patients

Do you have any questions ?

(8) $/ \mathrm{MOHPorta}$

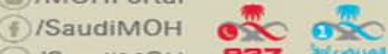

(9) ISaudiMOH $\mathbf{9 3 7}$ youm

www moh gov.sa/coronanew

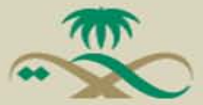

وزارة الصحة 


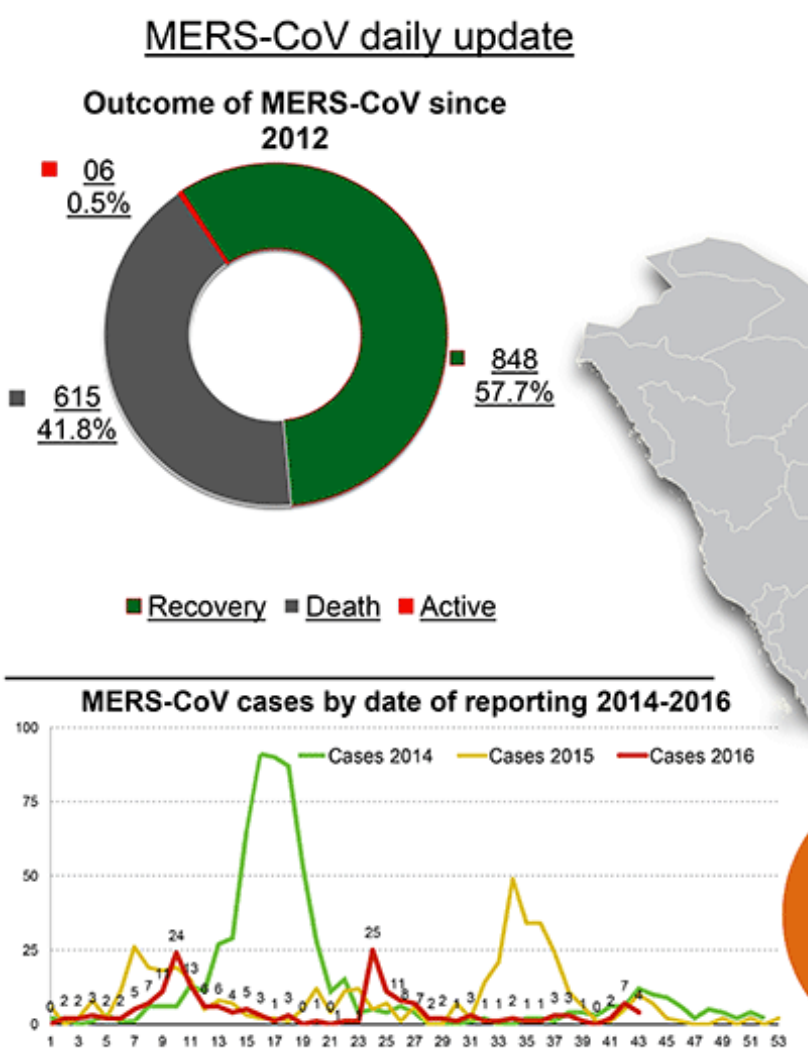

\begin{tabular}{|c|c|c|c|c|c|}
\hline & & (8) & $\mathrm{Ar}$ & $?$ & Total \\
\hline 0 & New symptomatic: & 0 & 0 & 0 & 0 \\
\hline 0 & New Asymptomatic: & 0 & 0 & 0 & 0 \\
\hline 0 & \multicolumn{4}{|l|}{ Deaths in last $24 \mathrm{~h}:$} & 0 \\
\hline 0 & \multicolumn{4}{|l|}{ Recovery in last $24 \mathrm{~h}$ : } & 0 \\
\hline
\end{tabular}

\section{Statistics}

7 Cases Under Treatment

847 Cases Recovered

The total number of confirmed MERSCOV cases is 1437+ 33 asymptomatic cases

As of 13 pm October 28,2016

* Since 2012. 615 cases passed away (May Allah have mercy upon them).

Disclaimer: The total number of cases is subject to change due to reclassification, retrospective investigation, consolidation of cases and laboratory data, and enhanced surveillance outcome.

\section{Comparisons}

Comparison of Saudi Arabia and South Korean outbreak of the Middle East respiratory syndrome coronavirus (mers-cov) infection.

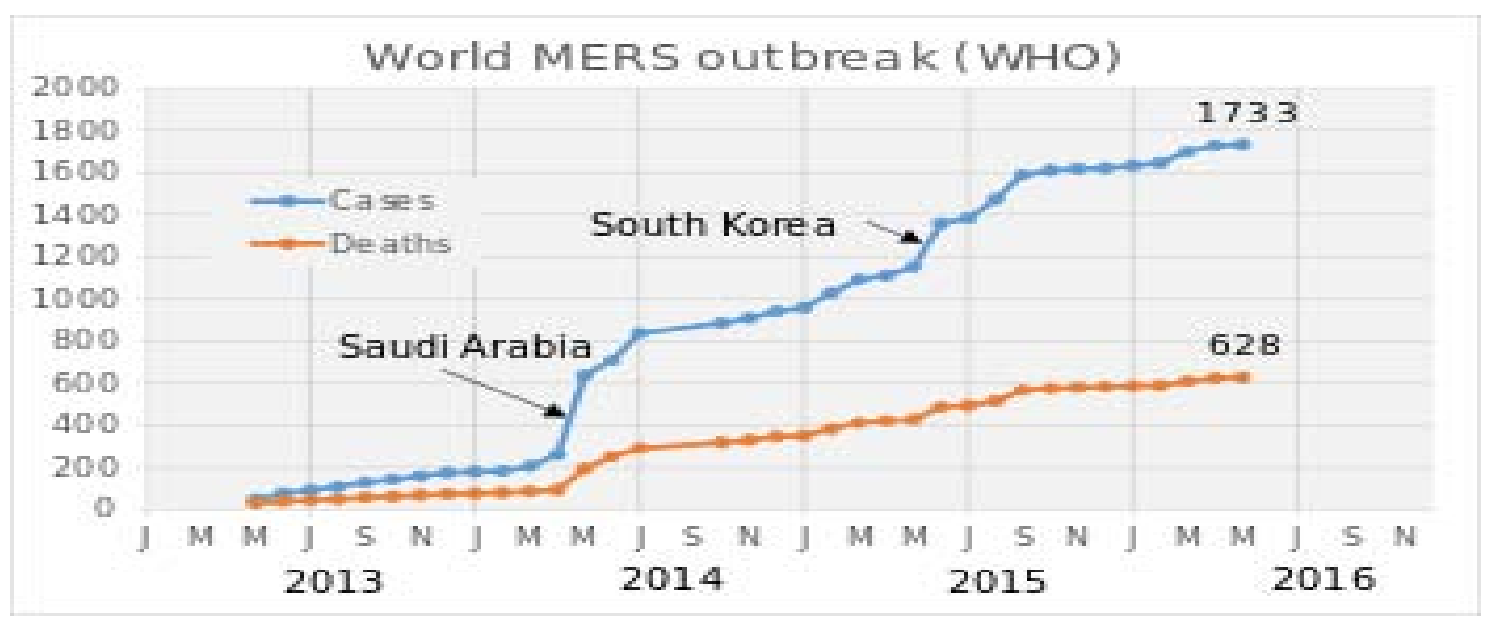


Texila International Journal of Public Health

Volume 4, Issue 4, Dec 2016

\begin{tabular}{|c|c|c|}
\hline & Saudi Arabia outbreak & South Korea outbreak \\
\hline Geographical location & Middle East Asia & Far East Asia \\
\hline City/Province & Riyadh, Jeddah & $\begin{array}{l}\text { Seoul, Daejeon, Gyeonggi } \\
\text { province }\end{array}$ \\
\hline Period & 11 Apr - 9 June, 2014 & $\begin{array}{l}\text { 4 May - Present (June 15), } \\
2015\end{array}$ \\
\hline Overall case number & 402 & 150 \\
\hline Health-care personnel (\%) & $27 \%$ & $17 \%$ \\
\hline Main transmission routes & $\begin{array}{l}\text { Health-care center } \\
\text { associated }\end{array}$ & Health-care center associated \\
\hline $\begin{array}{l}\text { Previous MERS case before } \\
\text { outbreak }\end{array}$ & Yes & No \\
\hline $\begin{array}{l}\text { Types of secondary exposure } \\
\text { who were not health-care } \\
\text { personnel }\end{array}$ & & \\
\hline $\begin{array}{l}\text { Admission to health-care } \\
\text { facility }\end{array}$ & $34 \%$ & $30 \%$ \\
\hline Emergency department & $8 \%$ & $49 \%$ \\
\hline $\begin{array}{l}\text { Visit to patient at health-care } \\
\text { facility }\end{array}$ & $17 \%$ & $29 \%$ \\
\hline $\begin{array}{l}\text { Annual outpatient } \\
\text { department visit (per } \\
\text { individual) }\end{array}$ & 4.5 & 14.6 \\
\hline $\begin{array}{l}\text { Annual number of hospital } \\
\text { admission (per } 100 \\
\text { individuals) }\end{array}$ & 10.5 & 16.1 \\
\hline
\end{tabular}

\section{Summary and recommendations}

A novel coronavirus, Middle East respiratory syndrome coronavirus (MERS-CoV) causing severe respiratory illness emerged in 2012 in Saudi Arabia. Many additional cases and clusters of MERS$\mathrm{CoV}$ infections have been detected subsequently in the Arabian Peninsula, particularly in Saudi Arabia Cases have also been reported from other regions, including North Africa, Europe, Asia, and North America. In countries outside of the Arabian Peninsula, patients developed illness after returning from the Arabian Peninsula or through close contact with infected individuals.

The number of cases in the Arabian Peninsula increased dramatically in March and April 2014 then declined sharply in ensuing months. However, cases continue to be detected. A large outbreak occurred in South Korea from May until early July 2015; the index case was an individual who had traveled to the Arabian Peninsula. Another large outbreak began in a hospital in Riyadh, Saudi Arabia, in the summer of 2015. As of mid-September 2015, it continues.

MERS-CoV is closely related to coronaviruses found in bats, suggesting that bats might be a reservoir of MERS-CoV. Camels likely serve as hosts for MERS-CoV. The presence of case clusters strongly suggests that human-to-human transmission occurs. 
Real-time reverse-transcriptase polymerase chain reaction (rRT-PCR) testing applied to respiratory secretions is the diagnostic assay of choice. Ideally, lower respiratory tract, upper respiratory tract, and serum samples should be obtained. Lower respiratory tract specimens should be a priority for collection and testing. To increase the likelihood of detecting MERS-CoV, we suggest collection of multiple specimens from different sites and at different times.

Individuals with an acute respiratory infection who have an epidemiologic link to MERS-CoV or who have had an unusual or unexpected clinical course (especially sudden deterioration despite appropriate treatment) should be tested for MERS-CoV. Certain other patients may also require evaluation for MERS-CoV infection. Specific recommendations regarding whom to test are presented above.

There is currently no treatment recommended for coronavirus infections except for supportive care as needed.

An increased level of infection control precautions is recommended when caring for patients with probable or confirmed MERS-CoV infection compared with that used for patients with communityacquired coronaviruses or other community-acquired respiratory viruses. The United States Centers for Disease Control and Prevention (CDC) recommends the use of standard, contact, and airborne precautions for the management of hospitalized patients with known or suspected MERS-CoV infection. (See 'Infection control' above.)

There is no licensed vaccine for MERS-CoV.

The World Health Organization (WHO) does not recommend either special screening for MERS$\mathrm{CoV}$ at points of entry or the application of any travel or trade restrictions. The Ministry of Health of Saudi Arabia recommended that, in 2014, older adults, those with chronic diseases, immunocompromised patients, pregnant women, and children postpone their plans to travel to Mecca, Saudi Arabia, for Hajj and/or Umrah.

\section{References}

[1]. https://en.wikipedia.org/wiki/Middle_East_respiratory_syndrome_coronavirus

[2]. http://www.moh.gov.sa/en/CCC/PressReleases/Pages/default.aspx

[3]. http://www.moh.gov.sa/en/CCC/informationcenter/pages/healthguidelines4.aspx

[4]. http://www.cdc.gov/coronavirus/mers/about/transmission.html

[5]. http://www.cdc.gov/coronavirus/mers/infection-prevention-control.html

[6]. http://www.thelancet.com/action/showFullTextImages?pii=S0140-6736\%2815\%2960454-8

[7]. http://www.cdc.gov/coronavirus/mers/faq.html

[8]. http://www.cdc.gov/coronavirus/mers/about/symptoms.html

[9]. http://www.uptodate.com/contents/image?imageKey=ID/90331\&topicKey=ID/89705\&source=outline_lin k\&search=\&utdPopup=true

[10]. odate.com/contents/image?imageKey=ID/90331\&topicKey=ID/89705\&source=outline_link\&search=\&ut dPopup=true

[11]. https://en.wikipedia.org/wiki/Middle_East_respiratory_syndrome\#Treatment 


\title{
Review of Prevention of Mother-To-Child Transmission (PMTCT) program in a Primary Healthcare Centre in Abuja, Nigeria
}

\author{
Article by Orji Ikechukwu Anthony ${ }^{1},{ }^{2}$ Okoli Ugochukwu Thompson \\ ${ }^{1}$ Disease Control Unit, Health Department, AMAC, Abuja, Nigeria \\ ${ }^{2}$ Clinical Services Department, Lighthouse Medicare Services Ltd. Abuja, Nigeria \\ E-mail: ${ }^{1}$ drtony2013@gmail.com, ${ }^{2}$ drtonyiyke@gmail.com
}

\begin{abstract}
Background: It has been shown that nearly all pediatric seropositive HIV cases were infected via their seropositive mothers, as well; almost all of these cases can be prevented through a robust PMTCT service that provides extremely effective Anti-retroviral therapy and prophylactic intervention (FMOH, 2010).

As we work towards elimination of MTCT of HIV in our country, the importance of this review of PMTCT services cannot be over emphasized.

Objectives: The objectives of the study were; to assess the prevalence of HIV among pregnant women who attended ANC at the Health center (January-December, 2015). 2. To evaluate the percentage of HIV positive pregnant women who were placed on ART in the review period. 3. To ascertain the percentage of babies born to HIV positive mothers who were given ART in the review period.

Methods: Secondary data review was employed in this descriptive cross-sectional study. It involved data extraction from ANC booking registers, PMTCT HIV screening registers, ART administration registers and case/delivery notes of HIV positive mothers, covering the review period of January-December 2015, in the study center.

Results: All the 1,418 ANC clients reviewed were screened for HIV with a sero-prevalence of $2.8 \%$. However, the percentage of seropositive clients who were placed on ART was $75 \%$, while, 25\% were lost to follow-up. Furthermore, only 33\% of the babies born to seropositive mothers received ART prophylaxis in this center.

Conclusion: An ANC sero-prevalence of $2.8 \%$ with below average ART initiation for positive pregnant women and babies born to them portends great danger towards elimination of MTCT of HIV. Therefore the study recommends urgent strengthening of PMTCT in this center and other similar centers across the country.
\end{abstract}

Keywords: PMTCT, Ante-Natal Care, HIV, Prevalence, Anti-Retroviral Therapy, Primary Health Centre

\section{Acronyms}

AIDS: Acquired Immune Deficiency Syndrome

ANC: Ante Natal Care

ART: Anti-Retroviral Therapy

ARV: Anti-Retroviral drugs

CDC: Center for Disease Control

FMOH: Federal Ministry of Health

GAC: Ghana AIDS commission

HAART: Highly Active Anti-Retroviral Therapy

HIV: Human Immunodeficiency Virus

HSS: Health Sector Strengthening

IATT: Inter-Agency Task Team

LSHTM: London School of Hygiene \& Tropical Medicine

MTCT: Mother-To-Child Transmission

NARHS: National HIV/AIDS and Reproductive Health Survey 
Texila International Journal of Public Health

Volume 4, Issue 4, Dec 2016

NACA: National Agency for Control of AIDS

PHC: Primary Healthcare Center

PLWHA: Persons Living with HIV \& AIDS

PMTCT: Prevention of Mother to Child Transmission

SDG: Sustainable Development Goals

UNICEF: United Nations Children's Fund

\section{Introduction}

Human Immunodeficiency Virus (HIV) is the virus that causes AIDS. They are of two types (HIV 1 \& HIV 2) and are of the retrovirus family (LSHTM, 2014). HIV is transmitted via direct contact with body fluids infected with HIV, like semen, blood and genital secretions; it can also be by vertical transmission from an HIV-infected mother to her child during pregnancy, delivery, or through breast milk during breastfeeding. The majority of the infection globally is caused by HIV-1 (AIDSINFO, 2016). Acquired Immune Deficiency Syndrome (AIDS) is a term which refers to the most advanced stages of the disease resulting from HIV infection. It is defined by the presence of any opportunistic infections (more than 20 of them) or HIV-related cancers $\left(\mathrm{WHO}_{1}, 2016\right)$. AIDS is a disease of the immune system resulting from HIV infection. HIV destroys the CD4 T lymphocytes (CD4 cells) of the immune system, thereby, leaving the body vulnerable to a number of life-threatening infections and cancers. To make the diagnosis of AIDS, the patient infected with HIV must have an AIDS-defining condition or have a CD4 count less than 200 cells $/ \mathrm{mm}^{3}$ (AIDSINFO, 2016)

According to the Nigeria's National PMTCT 2010 guideline, 370,000 children were newly infected with HIV in 2009 with 90\% of these cases found in sub-Saharan Africa. Note that nearly all such infections can be prevented by a PMTCT program that provides highly effective ART and ARV prophylactic interventions. This follows that an HIV free generation cannot be realized without an absolutely effective PMTCT program. Nigeria currently harbors the $2^{\text {nd }}$ highest Global HIV burden, has a general population prevalence of $3.4 \%$ by NARHS survey report, (NACA 2014) and ANC prevalence of 3.0\% (FMOH, HSS, 2014). With the above staggering statistics, the importance of a robust PMTCT program in the effort to attain zero new infection cannot be over emphasized. This underscores the need at this period for a study on this subject, to begin assessing the current prevalence of HIV infection among pregnant mothers as well as evaluating the PMTCT services for the positive pregnant mothers and babies born to them. This is in line with achieving the sustainable development goal-3 on Good health and well-being which has one of its key targets as ending the epidemics of AIDS by 2030 (SDG, 2015). Universal access to HIV/AIDS care is crucial to ending the epidemic, thus, strengthening HIV care especially PMTCT services at Primary Health Centers is a vital to achieving this feat.

This study evaluated the PMTCT services at this center with a view to finding the gaps and making recommendation for improved service delivery.

\section{Objectives}

1. To assess the prevalence of HIV among pregnant women who attended ANC at the Health center (Jan. -Dec., 2015).

2. To evaluate the percentage of HIV positive pregnant women who were placed on ART in the review period according to National guideline.

3. To ascertain the percentage of babies born to HIV positive mothers who were given ART in the review period according to National guideline.

\section{General considerations}

HIV Infection: Since 1981, when the first case of HIV/AIDS infection was recorded in USA (LSHTM, 2014), the epidemic has been on the increase globally, especially affecting sub-Saharan Africa worse than any other region of the world. According to the 2014 NARHS 
report, Nigeria with $3.4 \%$ prevalence in the general population is now the $2^{\text {nd }}$ highest HIV burdened country behind only South Africa. Furthermore, the FMOH 2014 National HIV sero-prevalence sentinel survey among pregnant women attending ANC in Nigeria revealed a $3.0 \%$ prevalence rate accentuating the need for an effective PMTCT program to halt vertical transmission of HIV to infants.

PMTCT: Prevention of Mother to Child Transmission (PMTCT) of HIV is the transmission of HIV infection from a HIV Positive mother to her baby during pregnancy, delivery and breastfeeding $\left(\mathrm{WHO}_{2}, 2016\right)$. Between $15 \%-45 \%$ of these babies will be infected without any intervention, however, with effective PMTCT, infection rate can be reduced to just above $1 \%\left(\mathrm{WHO}_{2}, 2016\right)$. PMTCT involves treatment of the positive mother with highly active anti-retroviral drugs (HAART) and giving the baby a short course of antiretroviral drugs prophylactically. Moreover, measures to prevent HIV acquisition in the pregnant woman and appropriate breastfeeding practices are also included. Evidence of the efficacy of an effective PMTCT program in eliminating the vertical transmission of HIV from an infected mother to her baby is made bare in the recent validation of Thailand by World Health Organization, in June 2016, for eliminating mother to child transmission of HIV and Syphilis $\left(\mathrm{WHO}_{3}, 2016\right)$. This is the first in South East Asia as well as the first high HIV burdened country to have achieved such a milestone, hence, proving to the rest of the world that an HIV free generation is possible globally. It only requires sound HIV prevention program especially PMTCT and political will from the Government. According to World Health Organization's report, other countries who have reported similar validation for elimination of Mother to child transmission of diseases includes: Belarus (HIV\& Syphilis), Armenia (HIV), Republic of Moldova (Syphilis), $\left(\mathrm{WHO}_{4}\right.$ 2016).

World Health Organization's guideline for the use of antiretroviral drugs for PMTCT: The World Health Organization $\left(\mathrm{WHO}_{5}\right)$ in the month of June, 2013, released the Consolidated Guidelines on the Use of Antiretroviral Drugs for Treating and Preventing HIV infection. This particular guidelines approved the initiation of Anti-Retroviral Therapy for all pregnant and breastfeeding women living with HIV. Lifelong Anti-Retroviral Therapy for this population is highly recommended, especially in generalized epidemics; irrespective of CD4 cell count (this is known as Option $\mathbf{B}+$ ) for both programmatic and operational reasons. Moreover, Countries may also choose to stop ART once risk of mother-to-child transmission has passed (i.e. at the end of breastfeeding or after delivery if no breastfeeding); unless the woman is eligible for lifelong Anti-Retroviral Therapy based on CD4 criteria (this is known as Option B). Note that in either setting, the woman continues with routine HIV care. The above 2013 guideline is still subsisting in many developing countries (due to resource limitations) even though a revised 2015 guideline has been issued by WHO which recommends option $\mathrm{B}+$ as the standard, thus, stating that ART should be initiated in all pregnant and breastfeeding women living with HIV, regardless of WHO clinical stage and at any CD4 cell count and continued lifelong $\left(\mathrm{WHO}_{5}, 2016\right)$.

Overview of HIV infection in Nigeria in relation to some African countries: According to Sagay et. al 2005, the prevalence of HIV among pregnant women was $8.2 \%$ in Jos Nigeria in 2005. In this study, it was also found that Women aged 20-29 years had more than 4-fold increased risk of HIV. Moreover, women with multiple marriages and women married to husbands who had multiple partners were also found to have increased risk of HIV infection. In Ghana, the Ghana AIDS Commission (GAC) reports that 2013 HIV prevalence among pregnant women attending Antenatal clinic is 1.9\%, which is a drop from the 2012 prevalence of $2.1 \%$ (GAC, 2013). However, this prevalence is higher than the National Prevalence of $1.3 \%$, thus, suggesting that more effort is needed to strengthen PMTCT in Ghana, if the dream of an AIDS free generation will be realized. Nevertheless, this is a far better statistics compared to Nigeria with general population prevalence of $3.4 \%$ (NARHS, NACA 2012) and ANC prevalence of 3.0\%. (FMOH, HSS, 2014), though, unlike the Ghana situation, the Prevalence of HIV infection among pregnant women is lower than the National general population prevalence. Okerentugba et. al (2015) in their study among pregnant women in a 
cottage hospital in Port Harcourt, Nigeria found a prevalence of 3.0\% same as the National prevalence according to FMOH/HSS (2014). Kiptoo et. al (2009) study in Kenya revealed an ANC prevalence of $6.7 \%$ higher than the Kenya national survey of same year which recorded 6.4\%, and 5.6\% by 2012 (Kenya AIDS response report, 2014). This is akin to the situation in Ghana where the ANC prevalence is higher than the National prevalence; therefore, more effort should be put into PMTCT to ensure transmission of HIV to children is eliminated. This is very fundamental bearing in mind that over $90 \%$ of HIV infection is via Mother to child transmission during pregnancy/delivery /breastfeeding.

Towards zero new HIV infection in Nigeria, the Place of PMTCT: To discuss the strategy of zero new infection in Nigeria, Thailand experience comes handy. According to Thailand National AIDS Committee (2015) as documented in the 2015 Thailand AIDS response progress report, Thailand is one of the countries in ASIA that subscribed to the UN General Assembly Special Session on HIV with a commitment to prevent and control the AIDS epidemic and pursue the strategy of three Zeroes: these are (i) Zero new HIV infection; (ii) Zero AIDS death; and (iii) Zero AIDS stigma and discrimination. The Country developed strategies to achieve the above, covering all aspects of HIV prevention, however, with regards to PMTCT specifically; the Thailand National strategic plan was to reduce peri-natal transmission of HIV to prevalence of less than $2.0 \%$ by 2016 as against 2014 prevalence of $2.1 \%$. The report further stated that Thailand has developed key measures and the operational plan for 2015-19 to support the policy of ending AIDS by the year 2030. The program applied the strategies of test and treat regardless of CD4 level with focus to the most affected areas and population including the PMTCT program. This has already yielded positive result as validated by World Health Organization, in June 2016 that Thailand has succeeded in eliminating Mother to child of HIV. Moreover, Thailand was one of the first countries in the Asia and Pacific region adopting the ambitious targets of providing anti-retroviral treatment to all people with HIV irrespective of CD4 count. The strategy also focused on early detection and treatment for key populations as well as improving access to services for non-Thais. This can be achieved in Nigeria by developing the right strategy to holistically tackle HIV prevention, especially paying adequate attention to PMTCT, and other forms of prevention. Making drugs available for all eligible patients for treatment, scaling up counseling and testing as well as removing all forms of discrimination and stigmatization of Persons Living with HID \& AIDS.

\section{Methods}

This is a retrospective cohort study that used the existing data for all pregnant women who attended ANC at the health center during the study review period (January -December, 2015). Data were extracted from PMTCT, ART and Antenatal registers as well as Delivery case notes of all the sero-positive clients. The study was carried out at Kagini Health Center, Gwagwa Ward, AMAC, Abuja. The site was purposively selected as it is a Primary Health Center within the ward with capacity to run a PMTCT service and has been offering the service for more than two years now. The Study Population involves a cohort of all pregnant women who attended ANC at the center from January to December, 2015. The Sample were selected using the convenient sampling method as it involved the review of all ANC records at the research site from January to December, 2015. The sample size was 1,418 pregnant women who attended ANC at the center during the review period. Data extraction strategy involves the following: 1 . The ANC booking register was reviewed, to determine the total number of pregnant women who were booked in this Health facility from January $1^{\text {st }}, 2015$ to December 31st, 2015. The booking practice is that HIV screening and counseling will be done free of charge on the first day of booking. 2. The PMTCT register was used to extract the results of the HIV screening done and the age range of the patients. 3. ART registers were reviewed to ascertain if HAART were given to the HIV positive pregnant women during the course of the ANC. 4. The case notes and the delivery files of the patients whose results were positive were reviewed to find out if ARV were given to the babies born to HIV positive 
mothers. The extracted data was analyzed by univariate analysis to make frequency tables and presented with pie, column and bar charts. Ethical approval was given by AMAC Health Department.

\section{Results}

1. The study found that 1,418 pregnant women were registered for ANC at the Kagini Health Center from January $1^{\text {st }}$ to December $31^{\text {st }}$, 2015. Moreover, $100 \%$ of these clients were counselled and screened for HIV 1 \& 2 antibody in accordance with the National guideline on PMTCT.

Age distribution of the clients were as follows: 15-24yrs (38\%), 25 - 34ys (50\%), 35yrs and above (12\%).

2. The sero-prevalence for HIV among pregnant women who attended ANC clinic at Kagini Health center in the year 2015 was 2.8\% (40/1418).

Age distribution of the positive clients were as follows: 15-24yrs (25\%), 25 - 34ys (60\%), $35 y$ rs and above (15\%).

3. The study also revealed that $75 \%$ (30/40) of the sero-positive pregnant patients received ARV therapy at this Health center. The remaining 25\% were lost to followup.

4. Furthermore, only 33.3\% (10/30) of babies born to these sero-positive mothers received ARV therapy at this Health center, $66.6 \%$ were lost to follow-up.

5. Concerning the point of HIV testing \& Counselling, $99.7 \%$ of the clients were screened at the ANC routine clinic while $0.3 \%$ were screened during labour as they were un-booked who did not attend ANC clinic.

6. Among the sero-positive clients who received ARV therapy, 30\% were initiated at a Gestational age of 14weeks -27weeks, while $70 \%$ were initiated at Gestational age of 28weeks -33weeks.

7. Additionally, $80 \%$ of the clients on ARV therapy were on triple regimen prophylaxis for PMTCT, while $20 \%$ were on lifelong ART.

\section{Discussions}

1. This center exhibited good practice with respect to testing all ANC clients for HIV $1 \& 2$ which is in line with the National PMTCT guideline. This will facilitate the diagnosis of new HIV infections as was the case in this center where 85\% (34/40) of all diagnosed cases (figure 7) and 80\% (24/30) of all cases on treatment (figure 6) were newly diagnosed cases. Detecting new infections and initiating them on ARV therapy is one sure way of ending this AIDS epidemic, therefore, this excellent practice should be encouraged and sustained.

2. The ANC sero-prevalence of $2.8 \%$ (figure 1 ) is similar to the National ANC seroprevalence of $3.0 \%$, (FMOH, HSS, 2014), which is still high, necessitating more effort to improve PMTCT services towards eliminating MTCT of HIV/AIDS in the near future. Furthermore, the age distribution of the positive clients revealed a high prevalence (50\%) for age group 25 - 34 years age group and 38\% for age group 15 24 which is similar to the findings of Sagay et. al (2009) where pregnant women aged 20-29 years had more than 4-fold increased risk of HIV infection.

3. $75 \%$ of the sero-positive pregnant patients received ARV therapy at this Health center while $25 \%$ of the clients were lost to follow-up (Figure 2). This finding is not a good practice and portends danger to the process of eliminating mother to child transmission of HIV. It was discovered that those patients who dropped out after their HIV positive status were diagnosed never received any followed-up visit/call because there was no provision made for such follow-up. There was neither any staff responsible nor any fund earmarked for the follow-up activities. This group of patients may end-up not taking the ARVs, thereby, increasing the risk of their babies getting HIV infection. This is an identified gap which as a matter of urgency must be 
addressed to strengthen the PMTCT program in this center in particular and other similar centers across the country. Further research in the area of finding reasons for drop-out may be able to proffer solutions to this challenge.

4. There is also a very poor performance indicator observed as regards the poor rate of initiation of ARV therapy and retention for the babies born to HIV positive mothers in this center. A 33.3\% rate (Figure 3) is abysmally poor against the expected 100\% initiation of ARV therapy.

This also bothers on follow-up as applied to the initiation of ARV therapy to sero-positive pregnant clients, thus, similar solution applies.

5. The high percentage of clients tested during ANC visit which is $99.7 \%$ (Figure 4) depicts high awareness of the importance of ANC clinic within the community and its environ, thus, almost all the pregnant women accessing service at this facility attended ANC clinic. Only 0.3\% (4/1418) did not attend ANC but presented in labour and delivered at the Health center. This high ANC awareness is a strength that can be leveraged upon to eliminate MTCT of HIV in this Health Center.

6. Most of the sero-positive clients were initiated on ARV therapy by 28-33 weeks (70\%), while only $30 \%$ were initiated by $14-27$ weeks (Figure 5 ) which suggest late ANC booking by most of the clients. This is an area the Health workers at this center must work on, to enhance early ANC booking, early ARV initiation which will definitely improve the prevention of transmission of HIV from the sero-positive mother to their unborn children.

7. The study revealed that all the previously diagnosed pregnant patients adhered to taking ART during the course of their pregnancy 6/40 (20\%) of the diagnosed cases and 6/30 (15\%) of those who complied with ART treatment (Figures 6 and 7). Therefore, all the patients lost to follow-up were newly diagnosed sero-positive patients. This suggest, probably poor counselling activities (post-test counselling, preinitiation counselling, adherence counselling), throwing up another area to put more effort for improved result.

\section{Conclusion}

The study revealed that the 2015 ANC sero-prevalence for HIV in Kagini health center is $2.8 \%$ which is similar to the 2015 national ANC sero-prevalence of 3.0\%. Concerning ARV therapy initiation for the 40 sero-positive pregnant women, only 30 (75\%) of them were placed on ARV therapy which fell short of $100 \%$ expected. Furthermore, out of the 30 babies born to HIV positive mothers, only 10 (33.3\%) were placed on ARV therapy which again fell short of $100 \%$ expected. These figures fell grossly short of the expected performance and portend great danger to the goal of elimination of mother to child transmission of HIV.

\section{Recommendations}

1. The PMTCT program sponsors at this facility should retrain the HIV counsellors to position them for a robust post-test, pre-initiation and adherence counselling services at Kagini Health Center. This will ensure an increased ARV initiation and retention rate.

2. Furthermore, trained treatment support specialist (TSS) should be deployed to this facility for adequate treatment support and follow-up of clients and their babies.

3. Moreover, the facility health workers should also be supported in the area of creating awareness for early ANC booking within the host community and all the catchment area communities, this will go a long way to helping in early detection as well as early ARV initiation for improved PMTCT in addition to reducing maternal mortality.

4. Lastly, supportive supervision should be provided by the PMTCT program sponsors and the Local Government Health authority to periodically monitor the PMTCT 
activities to ensure the set targets are on course; this will eliminate laxity on the part of the health workers.

\section{Further research}

This present research did not review the area of HIV testing for the infants born to HIV positive women (infants exposed to HIV)

Therefore, future research to evaluate the Percentage of infants born to HIV positive women receiving a Virological test for HIV within 2 months of birth in addition to assessing the effectiveness of the PMTCT program by evaluating the prevalence of sero-negative children after 18 months of age.

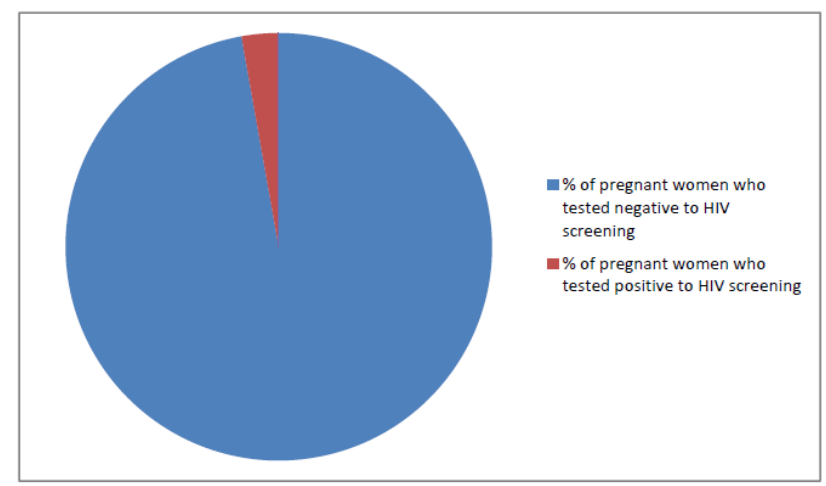

Figure 1

Pie chart representing the percentage of ANC Clients who are sero-positive and those who are seronegative to HIV screening test at Kagini Health Center in the year 2015 P= 40/1418 = 2.8\% prevalence.

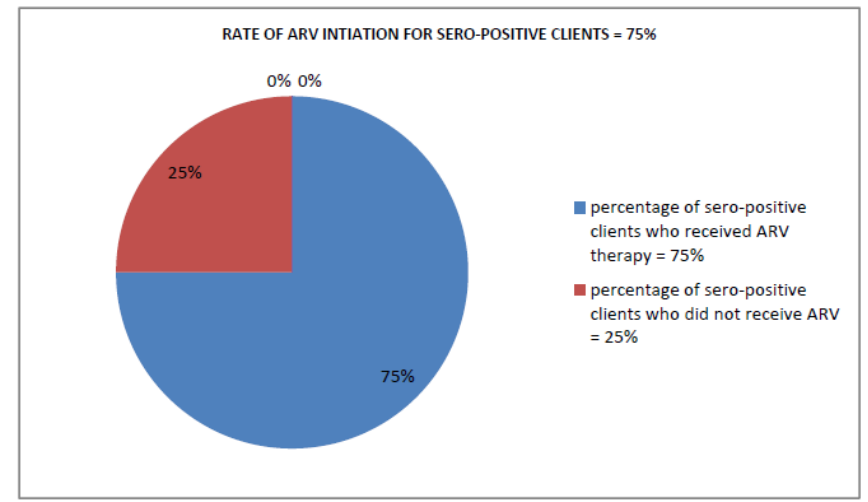

Figure 2

Pie chart representing the percentage of sero-positive pregnant clients who received ARV therapy $\mathrm{P}=$ 30/40 (75\%).

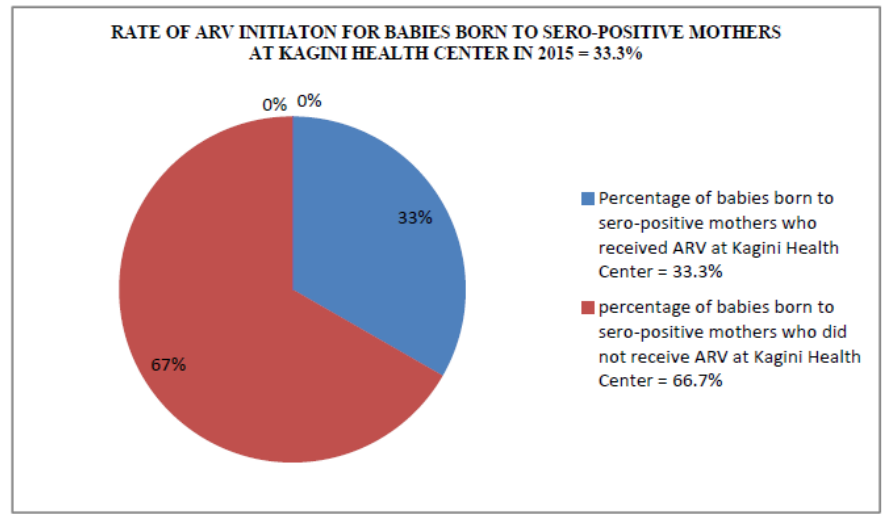

Figure 3 
Texila International Journal of Public Health

Volume 4, Issue 4, Dec 2016

Pie chart representing the percentage of Babies born to sero-positive mothers who received ARV therapy according to National guideline and those who do not at Kagini Health center in $2015 \mathrm{P}=$ $10 / 30(33.3 \%)$

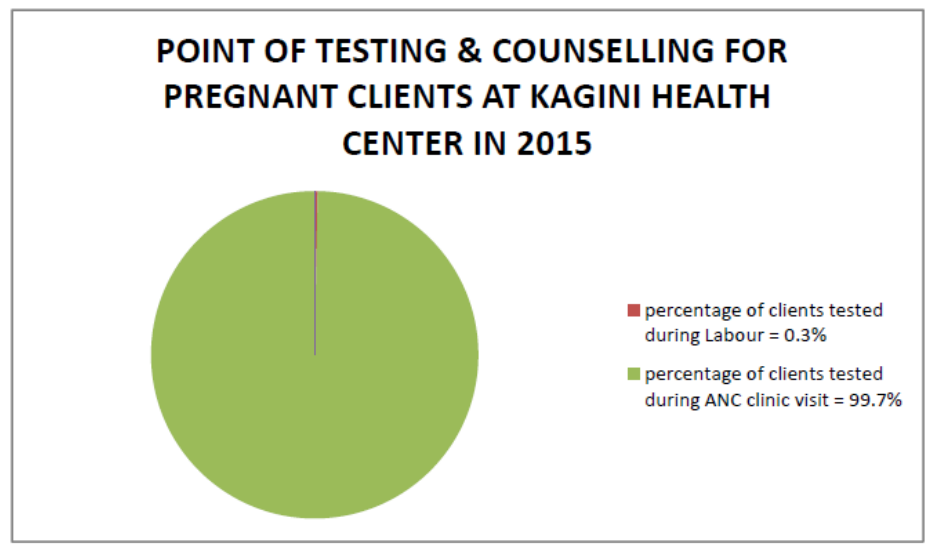

Figure 4

Pie chart representing the percentage of clients tested during ANC clinic and those whose initial presentation to the center was during Labour and thus tested while in labour at Kagini Health center in 2015. (ANC: 1414/1418 =99.7\%; Labour: 4/1418 = 0.3\%)

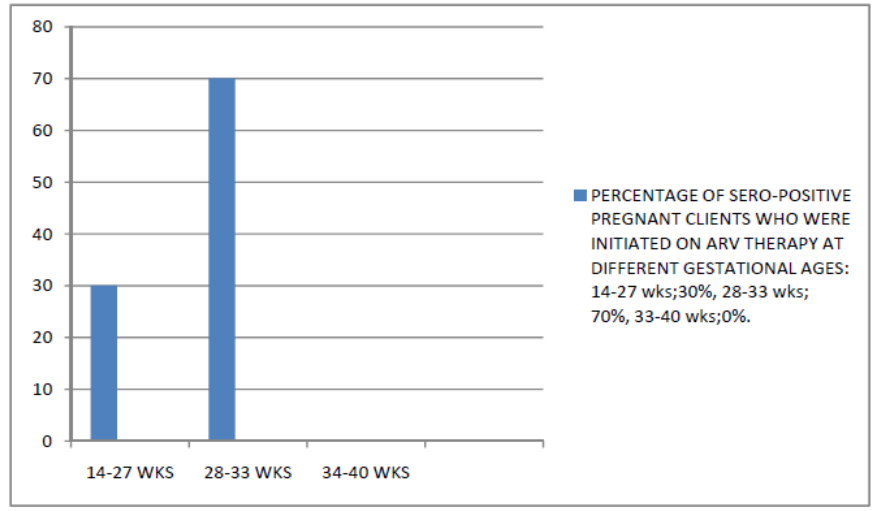

Figure 5

Bar chart showing the percentage of sero-positive pregnant clients who were initiated on ARV therapy and the gestational age at which it was initiated at Kagini Health Center in 2015 (14-27 weeks: 9/30 = 30\%; 28-33 weeks: $21 / 30=70 \%$; 34-40 weeks: 0/30 = 0\%)

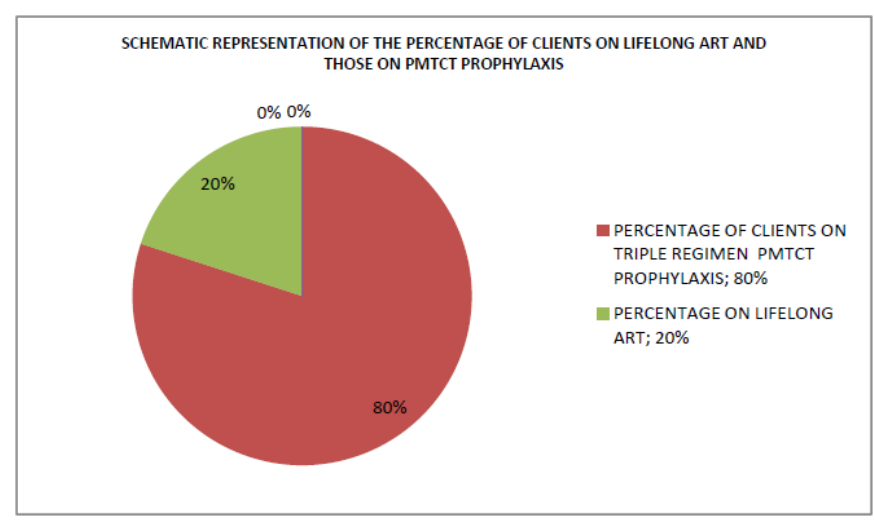

Figure 6

Pie chart showing the distribution of lifelong ART vs PMTCT triples regimen prophylaxis therapy among the sero-positive pregnant clients at Kagini Health Center in 2015. (Lifelong ART: 6/30 = 20\%; PMTCT prophylaxis: $24 / 30=80 \%$ ) 


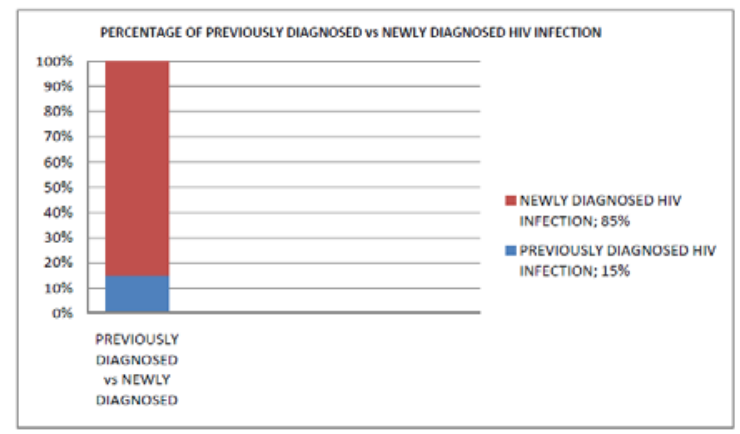

Figure 7

Column Chart showing the percentage of previously diagnosed HIV infection vs newly diagnosed HIV infection among pregnant women at Kagini Health Center in 2015. (Previously diagnosed: 6/40 = 15\%; newly diagnosed: $34 / 40=85 \%$ )

\section{References}

[1] AIDSINFO (2016). Education materials: HIV-1. Accessed from:

https://aidsinfo.nih.gov/education-materials/glossary/314/hiv-1

[2] FMOH of Nigeria, (2010). National Guideline for Prevention of Mother to Child Transmission (PMTCT) of HIV/AIDS. Pp 1

[3] FMOH, of Nigeria, HSS (2014). 2014 National HIV Sero-prevalence Sentinel Survey among Pregnant Women Attending Antenatal Clinics in Nigeria. pp 2.

[4] Ghana AIDS commission GAC (2013). Summary of the 2013 HIV sentinel survey report. Accessed from: http://ghanaids.gov.gh/gac1/aids_info.php

[5] IATT, (2015). Inter-agency Task Team on the Prevention and Treatment of HIV Infection in Pregnant Women, Mothers and Children. Monitoring \& Evaluation Framework for Antiretroviral Treatment for Pregnant and Breastfeeding Women Living with HIV and Their Infants. (IATT M\&E Option B+ Framework). CDC, WHO and UNICEF. New York. Accessed from: http://www.emtctiatt.org/wp-content/uploads/2015/05/IATT-Framework-May-2015.pdf

[6] Kenya AIDS Response Progress Report (2014). Progress towards zero. Accessed

from http://www.unaids.org/sites/default/files/country/documents/KEN_narrative_report_2014.pdf

[7] Kiptoo M., Mpoke S., Ng'ang'a Z., Mueke J., Okoth F., Songok E. (2009). Survey on prevalence and risk factors on HIV-1 among pregnant women in North-Rift, Kenya: a hospital based crosssectional study conducted between 2005 and 2006, 9: pp10. doi: 10.1186/1472-698X-9-10.

[8] National Agency for the Control of AIDS (NACA) (2014). Federal republic of Nigeria Global AIDS Response. Country Progress Report, Nigeria GARPR 2014. p.13 Accessed from: http://www.unaids.org/sites/default/files/country/documents/NGA_narrative_report_2014.pdf [9] Okerentugba P.O., Uchendu S.C., Okonko I.O. (2015). Prevalence of HIV among Pregnant Women in Rumubiakani, Port Harcourt. Nigeria. Public Health Research. 5(2): 58-

65.doi:10.5923/j.phr.20150502.03

[10] Sagay A.S., Kapiga S.H., Imade G.E., Sankale J.L., Idoko J., Kanki P. (2005). HIV Infection among pregnant women in Nigeria. International journal of Gynecology and Obstetrics, 90: (1). Pp 6167. Doi 10.1016/j.jigo.2005.30.030

[11] Thailand National AIDS Committee (NAC). (2015). Thailand AIDS response progress report, 2015. Accessed from http://www.unaids.org/sites/default/files/country/documents/THA_narrative_report_2015.pdf

[12] United Nations. (2015). Sustainable Development Goals (SDGs). Accessed from: http://www.un.org/sustainabledevelopment/sustainable-development-goals/

[13] $\mathrm{WHO}_{1}$ (2016). HIV/AIDS, online Q \& A. (updated July, 2016). Accessed from: http://www.who.int/features/qa/71/en/

[14] $\mathrm{WHO}_{2}$ (2016). HIV/AIDS, Mother-to-child transmission of HIV (updated June, 2016). Accessed from: http://www.who.int/hiv/topics/mtct/en/

[15] $\mathrm{WHO}_{3}$ (2016). Thailand is first country in Asia to eliminate mother-to-child transmission of HIV and syphilis. Accessed from: http://www.searo.who.int/mediacentre/releases/2016/1627/en/index.html 
Texila International Journal of Public Health

Volume 4, Issue 4, Dec 2016

[16] $\mathrm{WHO}_{4}$ (2016). WHO validates elimination of mother-to-child transmission of HIV and syphilis in Armenia, Belarus and the Republic of Moldova. (Updated June, 2016). Accessed from:

http:/www.euro.who.int/en/media-centre/sections/press-releases/2016/06/who-validates-eliminationof-mother-to-child-transmission-of-hiv-and-syphilis-in-armenia,-belarus-and-the-republic-of-moldova.

[17] $\mathrm{WHO}_{5}$ (2016). Consolidated guidelines on the use of antiretroviral drugs for treating and preventing HIV infection. Summary of Recommendations. Accessed from:

http://www.who.int/hiv/pub/arv/summary-recommendations.pdf 


\title{
Tuberculosis and Gender in Nigeria, Sex Differences in Diagnosis and Treatment Outcome of TB and TB HIV Infected Patients
}

\author{
Article by Ejike Kenneth Nwene \\ Ph.D in Public Health, Texila American University, Nigeria \\ E-mail: ejike.ihv@gmail.com
}

\begin{abstract}
Background: Worldwide, gender differences are reported in diagnosis and treatment outcome of TB and TB HIV patients. Religious and socio-cultural factors are responsible but largely controversial. This study assessed gender issues in diagnosis and treatment outcome of TB and TB HIV patients.

Objective: To assess gender differences in diagnosis and treatment outcome of TB and TB HIV infected patients.

Methodology: We did a cross sectional retrospective analysis of 980 TB patients treated in 6 out of 21 randomly selected local government areas of Anambra state Nigeria between 2008 and 2012. Information on age, sex, HIV status, case notification, treatment outcome was evaluated from TB treatment cards and TB registers. Treatment outcome was recorded as cured, completed treatment, failed, defaulted, died.

Results: The male female ratio among the 980 TB patients was $57.4 \%$ vs $42.6 \%$.. The study HIV prevalence is $27.7 \%$; women contributed $52.6 \%$ of this population. Women had better treatment success rate than men $(85.7 \%$ vs. $80.5 \%)$. TB treatment outcome in women compared to men were Cured (50.4\% vs 40.7\%, $p=0.063$ ), treatment completed (35.3\% vs $39.8 \%, p=0.330$ ), died (5.5\% vs5.5\%, $p=0.8812)$, defaulter (6.55 vs10.5\%, $p=0.042$ ), failure (1.6\% vs $1.5 \%, p=0.749)$.

Conclusion: We conclude more TB cases in males but females are more prone to TB HIV confection, have better treatment outcome and lower default rate.

Gender-specific strategies, including active case finding among women, increased tracking and adherence for male, are warranted to optimize TB management.
\end{abstract}

Keywords: Gender, Nigeria, Tuberculosis, HIV, Co infection, NTBLCP.

\section{Introduction}

Tuberculosis (TB) remains a major global health problem in Nigeria. TB alongside human immunodeficiency virus (HIV) ranks as the leading cause of death from infectious disease worldwide and has surpassed HIV ${ }^{(1)}$. The situation is fuelled by increasing population density, poverty, demographic changes, immigration, weak political will, poor financial control management, inadequate human resources, weak health systems, poor laboratory services, drug-resistant TB; and lately by HIV AIDS pandemic ${ }^{(2,3) .}$ All countries are affected by TB but $85 \%$ of cases occur in Africa (29\%) and Asia (56\%) ${ }^{(4)}$. Globally as at 2013, there were an estimated 9.0 million new TB cases and 1.5 million TB deaths (1.1 million among HIV-negative people and 0.4 million among HIV-positive people) ${ }^{(4)}$. The African region with approximately one quarter of the TB cases has the highest number of cases and death relative to population (280 incident cases per 100000 populations). Overall, 34\% of TB cases were estimated to be infected with HIV in African region (the highest) accounting for $78 \%$ of TB cases with HIV worldwide ${ }^{(4)}$. Nigeria is one of the 22 high burden countries that account for $80 \%$ of world TB cases. According to 2011 WHO estimate, Nigeria has estimated 320,000 cases of all forms of TB with yearly prevalence of 199 cases per 100,000 population and 210000 new cases representing an incidence rate of 133 per 100,000 population ${ }^{(5)}$. An estimated 250,000(150,000 - 350,000) TB death was recorded in Nigeria in $2013^{(4)}$. The 
Texila International Journal of Public Health

Volume 4, Issue 4, Dec 2016

current high number of TB death is unacceptable considering that TB is both preventable and treatable.

Over the years, we have had varying sex differences in different age groups and from different parts of the world for TB cases. The reasons for the sex differences are sometimes unclear ${ }^{(6)}$. Globally we have more males than females for TB case notifications and cases. In 2013, the male: female ratio in TB notification globally was 1.6, but among HBCs this ratio varied from 0.7 in Afghanistan to 2.9 in Viet Nam. ${ }^{(4)}$. Nigeria has a male: female ratio of 1.5. Variation among countries may reflect real differences in epidemiology as well as differential access to or use of health care services linked to the various TB programs. Various studies have shown that women lack of financial independence, low prioritization of women health by family members, gender specific stigma about TB are real barriers to treatment ${ }^{(7)}$. In some countries a woman with TB may be divorced if married or may find it hard to get married if unmarried while studies in Vietnam and Nepal found out that rejection, abandonment, ostracism, isolation followed TB diagnosis and leads them in some cases to traditional healers to reduce costs and stigma ${ }^{(8,9) .}$ Other causes include barriers faced by women in accessing health care, repeated visits, travel costs, delays in test reports, rigid service timings, socioeconomic and cultural adversities and reduce poor women's ability to access services ${ }^{(6)}$. Despite all these factors women are less likely to default from the treatment as compared to men ${ }^{(10)}$. Even after adjusting for confounders the male sex was a strong risk factor of unsuccessful treatment outcome ${ }^{(11)}$.

Despite these findings showing increased male involvement and poorer TB treatment outcome, men are often overlooked in discussions of gender and TB. While global TB reports and meetings on gender acknowledge the fact that the majority of TB cases and TBassociated deaths occur among men, greater focus is usually placed on women. Globally, gender in most cases is referred to as women as exemplified by the Millennium Development Goals ${ }^{[12]}$. Subsequently, emphasis on TB involving men runs contrary to global norms ${ }^{[13]}$, and strategies to assess and address men's barriers to TB care are notably absent in researches globally.

Detailed literature research showed some limited research works from South East Nigeria examining gender-related differences in TB patients notified under the NTBLCP. The present study was designed to further help these other researches find out whether gender based differences are present in the notification rates, TB HIV co infection rate and treatment outcomes of TB patients registered under the NTBLCP in Anambra state in South East Nigeria to enable effective targeting of TB control strategies.

\section{Methodology}

\section{Study design}

This is a cross sectional retrospective study done to evaluate gender effects on diagnosis and treatment outcome of TB and TB HIV co infected patients in TB DOTS facilities in Anambra State.

\section{Study population}

The study population is all the TB patients that assessed treatment in the six chosen local governments using the DOTS therapy in Anambra State between the years $2004-2008$. TB DOTS sites could be Stand Alone, Private, General, or Mission hospitals/clinics. All TB patients that got services through any health facility in the state that does not offer TB DOTS services were excluded. Anambra State is located in the South Eastern geopolitical zone of Nigeria made up of Anambra, Imo, Enugu, Abia and Ebonyi states. Anambra state has a very high density with a population of 4,182,032 individuals ${ }^{(14) .}$ and a land mass of 4844 square kilometer. Economically, Anambra state has a large urban population who occupationally are businessmen and traders. The rural areas of the state are mainly populated by farmers and petty traders. The state is made up of 21 local government areas (LGAs) all of which have existing TB DOTS facilities. The 21 LGAs are equally divided into three senatorial zones 
each having seven LGAs per senatorial zone. Presently, there are about 1000 health facilities (Private, Public, Mission) providing various levels of health care services in the state. There are 508 facilities that render Primary Health Care and 450 that render secondary health care in Anambra State. These are made up of Government hospitals including General hospital, Comprehensive health centers, health posts and primary health centers. There are also clinics, hospitals and maternities not owned by the government but by private, faith based organisations.

\section{Data collection}

Data was collected from the various LGA TB control registers in the state used for the study. Details collected include, name, age, sex, treatment unit/facility, date treatment started, treatment category, date of registration, site (pulmonary/extra pulmonary), TB smear results, $\mathrm{x}$-ray result (if applicable), HIV status and eventual treatment outcome. Some TB treatment cards were also reviewed with the LG TB registers to verify authenticity of the registers and for completeness of data collected.

Stratified sampling technique was used to conduct the study. A table of random numbers was used to select 2 LGAs each from the three senatorial zones in the state.

\section{Data analysis}

Data were analyzed with statistical package for social sciences version 15.0 (SPSS). Frequency tables, rates, ratio, proportion were used to review data. $\mathrm{P}$ value and Chi Square test were used to test statistical significance.

\section{Ethical consideration}

An official letter of request for access to official information from Anambra State Ministry of Health was written to the Commissioner of Health Anambra State; Director of Medical Services Anambra State Ministry of Health Awka and the State TBLCP Director. Patient's right to confidentiality was maintained during the study period

\section{Results}

Table 1. Socio demographic distribution of patients (Sex)

\begin{tabular}{|l|c|c|c|}
\hline \multirow{4}{*}{ Sex } & & Frequency & Percentage \\
\hline \multirow{3}{*}{} & Male & 563 & 57.4 \\
\cline { 2 - 4 } & Female & 417 & 42.6 \\
\cline { 2 - 4 } & Total & 980 & 100 \\
\hline
\end{tabular}

Table 1 show that a total of 980 TB patients registered for the study. The table also shows the distribution of patients by gender showing that, 563(57.4\%) were males and 417 (42.6\%) were females.

Table 2. TB Treatment Outcome

\begin{tabular}{|l|l|c|c|c|c|c|}
\hline $\begin{array}{l}\text { Treatment } \\
\text { Outcome }\end{array}$ & Male & Female & Total & P value & $\begin{array}{c}\text { Chi } \\
\text { Square }\end{array}$ \\
\hline & Cured & $229(40.7 \%)$ & $210(50.4 \%)$ & $439(100 \%)$ & 0.063 & 3.434 \\
\hline & $\begin{array}{l}\text { Treatment } \\
\text { completed }\end{array}$ & $224(39.8 \%)$ & $147(35.3 \%)$ & $371(100 \%)$ & 0.330 & 0.949 \\
\hline & Died & $31(5.5 \%)$ & $22(5.3 \%)$ & $53(100 \%)$ & 0.8812 & 0.022 \\
\hline & Defaulter & $59(10.5 \%)$ & $27(6.5 \%)$ & $86(100 \%)$ & 0.0442 & 4.049 \\
\hline
\end{tabular}


Texila International Journal of Public Health

Volume 4, Issue 4, Dec 2016

\begin{tabular}{|l|l|c|c|c|c|c|}
\hline & $\begin{array}{l}\text { Transfer } \\
\text { out }\end{array}$ & $12(2.1 \%)$ & $4(1.0 \%)$ & $16(100 \%)$ & 0.1586 & 1.987 \\
\hline & Failure & $8(1.5 \%)$ & $7(1.6 \%)$ & $15(100 \%)$ & 0.749 & 0.102 \\
\hline & Total & $563(100 \%)$ & $417(100 \%)$ & $980(100 \%)$ & & \\
\hline
\end{tabular}

The table also showed that the treatment success rate (cure rate plus treatment completed rate) for the females is better than that for male patients (85.7\% vs. $80.5 \%)$. Also males have higher default rate than females $(10.5 \%$ vs. $6.5 \%, \mathrm{p}=0.0442)$ showing significant association

Table 3. Prevalence of HIV Disease among TB patients

\begin{tabular}{|l|c|c|}
\hline HIV status & \multicolumn{2}{|c|}{ No of patients } \\
\hline HIV positive & 133 & $(27.7 \%)$ \\
\hline HIV negative & 348 & $(72.3 \%)$ \\
\hline Total & 481 & $(100 \%)$ \\
\hline
\end{tabular}

Table 3 showed that out of 481 TB patients that were screened for HIV, 133 (27.7\%) were HIV positive while 348 (72.3\%) were HIV negative. This puts the HIV prevalence rate of the study at $27.7 \%$.

Table 4. Socio demographic distribution of TB HIV patients (Gender)

\begin{tabular}{|l|l|c|c|c|c|}
\hline & & HIV positive & HIV negative & \multirow{2}{*}{$\mathrm{X}^{2}$} & \\
\cline { 1 - 1 } Variable & & $\mathrm{N}(\%)$ & $\mathrm{N}$-value \\
\hline & Male & $63(47.4 \%)$ & $217(62.4 \%)$ & & \\
\hline Sex & Female & $70(52.6 \%)$ & $131(37.6 \%)$ & 8.886 & 0.0029 \\
& & & & & \\
\hline & Total & $133(100 \%)$ & $348(100 \%)$ & & \\
\hline
\end{tabular}

Table 11 showed the effect of sex on HIV disease. The table showed that of the 133 HIV positive patients, $70(52.6 \%)$ were females compared to 63(47.4) who were males. There was also significant association between HIV disease and sex $(\mathrm{p}=0.0029)$

\section{Discussion}

TB programs in Nigeria aims amongst others to increase TB case notification while improving the treatment outcome.. This study reveals gender disparity in TB notification from people treated for TB in selected TB DOTS facility in the state. The study showed that out of 980 TB patients treated, 563 (57.4\%) patients were males while 417 (42.6\%) were females. This factor seen in other TB prevalence studies is of great economic importance as males are predominantly the family bread winners in Africa. Causes of increased male predominance include cultural seclusion practices, socialization patterns, and nutrition among the young females. The higher incidence of males amongst TB patients is consistent with other studies

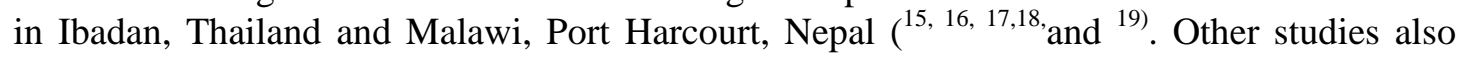
showed the effect of age in gender TB prevalence/notification as it was seen that increasing age is associated with increased male predominance in TB prevalence and notification $(22,23,24,25)$. However females have been reported to be more in number in TB treatment from other studies $\left({ }^{16,20,21}\right)$.

In low income countries like Nigeria low uptake of health care services especially by women can be attributed to differential access to health care services. Women often have fewer educational opportunities, lower income, reduced access to economic resources, poorer access to information, education and health invariably leading to lower socioeconomic status as compared with men. This means that many women are unable to locate and reach appropriate health services.[26]. In some cultural and religious settings, women are isolated 
and decisions about treatment including mobility, treatment uptake and related expenses are made by either the husband or family members ${ }^{\{27,28]}$. Furthermore, a comparison between ageand sex-specific prevalence and notification rates from 29 surveys in 14 countries suggested that the reasons for a low notification rate for TB in females was more due to epidemiological factors than a differential access of the health care. ${ }^{[27]}$ A higher proportion of women had minimal disease compared to men at the time of diagnosis, suggesting an earlier diagnosis among females. ${ }^{[29]}$

Furthermore, stigma attached to a positive TB diagnosis leads many women to forgo seeking necessary medical attention. This in some cases may lead to self medication, use of traditional and spiritual healers instead of using available DOTS centers to reduce being detected and affected stigma ${ }^{[30]}$ The male predominance for TB in the present study is consistent with data from other countries and could reflect occupational, behavioral, or immunological/biological contributions to risk ${ }^{[31,32,33]}$ Earlier studies have explained the role of cellular immunity in pathogenesis of $\mathrm{TB}^{[34]}$ Sex hormones, greater antibody production, and higher CD 4 count in women as compared with men have implication for better immune response in many earlier studies ${ }^{[35,36,37 .]}$ Other biological factors increasing male prevalence shows that men are biologically more vulnerable with more masked symptom than female (UNDP report) However females have been reported to be more in number in TB treatment from other studies ${ }^{16,20,21}$.

This study showed women having better TB treatment outcome than men. The female male cure rate is $50.4 \%$ vs $40.7 \%$ with a treatment success rate (cure plus treatment completed rates) of $85.7 . \%$ vs $80.5 \%$ ). Our study further showed that sex had a significant effect on default rate as male had a higher default rate than females ( $10.5 \%$ vs $6.5 \%$, $p$ value $=0.0442$ ). This result is supported by a study done by Daniel and Oladapo in Sagamu which showed that male sex was a factor in default and that majority of TB patient defaulted at the continuation phase of the treatment probably due to the long duration of treatment and the feeling of being well during this period. That Women are less likely to die, default, or fail on treatment has been shown in the previous studies and this finding collaborates with the present study ${ }^{[38,39,40] \text {. }}$ Further suggestions have also showed that epidemiological factors are more responsible rather than differential access to the health care for these gender differences.

Of the 481 patients tested for HIV 133were positive giving a positivity rate of $27.7 \%$. In relation to gender, $34.8 \%(70 / 201)$ of the female patients tested positive while $22.5 \%(63 / 280)$ of the male patients tested positive for HIV infection. This difference was found to be statistically significant $(p<0.05)$. This supports the fact that social inequalities, including gender and power relations, have an important impact on HIV transmission $\left({ }^{41)}\right.$. Recent reviews also suggest that women in many parts of the developing world are less likely to control how, when, and where sex takes place thereby increasing the likelihood of HIV infection ${ }^{(42) .}$ Although in their study of sex differences in the clinical presentation of urban Nigerian patients with pulmonary tuberculosis, Lawson and colleagues ${ }^{(43)}$ noted that women were more likely to be co-infected with HIV than males while Odaibo et al ${ }^{(44)}$ did not observe any significant difference in the rate of co-infection in relation to gender

\section{Conclusion}

Our study demonstrates a sex difference in the TB notification, default and TB HIV coinfection rates. This difference, traditionally attributed to poor access to health care in females, is at least partially due to biological reasons. Better treatment outcomes in females may reflect biological differences in addition to health system-related factors. Integrated research is necessary to outline the relative roles played by biological factors and gender issues in causing these differences in the notification rates and treatment outcomes of patients under the RNTCP. 
Texila International Journal of Public Health

Volume 4, Issue 4, Dec 2016

\section{Limitations}

There are some limitations with the study. The retrospective nature of the study made it impossible to evaluate the contributions of other factors that can impact on sex and treatment outcome. Also the Are was limitation on the information collected on the characteristics of patients in the program from TB treatment card and LG TB registers used by NTBLCP.

\section{References}

[1] Akinola A F, Abimbola S O, Afolabi E B. Treatment outcomes among pulmonary tuberculosis patients at treatment centers in Ibadan, Nigeria. Annals of African medicine, 2009; 8 (2): 100-104.

[2] Aggleton P, Rivers K. Gender Inequalities in Health and Diseases. Int Gender Iss 2007:28 - 32.

[3] Bello S I. Challenges of DOTS implementation strategy in the treatment of tuberculosis in a tertiary health institution, Ilorin, Nigeria. African journal of pharmacy and pharmacology, $2010 ; 4$ (4): 158- 164.

[4] Borgdorff MW, Nagelkerke NJ, Dye C, Nunn P. Gender and tuberculosis: A comparison of prevalence surveys with notification data to explore sex differences in case detection. Int J Tuberc Lung Dis. 2000;4:123-32. [PubMed]

[5] Belay T, Abebe M, Assengedegh B, Dieter R, Frank E, Ulrich S. Treatment outcome of TB patients at Gondar university teaching hospital, North West Ethiopia. BMC Public Health 2009; 9:37.

[6] Central TB Division, Directorate General of Health Services, Ministry of Health and Family Welfare, Nirman Bhawan, New Delhi. TB India 2012. RNTCP Status Report. 2012:7-17.]

[7] D. Chan-Yeung M, Noertjojo K, Chan SL, Tam CM. Sex differences in tuberculosis in Hong Kong. Int J Tuberc Lung Dis 2002;6:11-8.

[8] Diwan VK, Thorson A. Sex, gender, and tuberculosis. Lancet. 1999;353:1000-1. [PubMed]

[9] Frank-Peterside N, Onwuka A P, Okonko I O. Epidemiology of Pulmonary Tuberculosis in University of PortHarcourt Teaching Hospital: age related disparities. Science pub.net/report; 2012, 4(5).

[10] Glynn J, Sonnenberg P, Nelson G, Bester A, Shearer S, Murray J. Increasing risk of TB with increasing duration of HIV infection: results from 2000 men followed for 12 years. International journal for TB and lung disease, 2007; 11 (11):112.

[11] Gidado M, Ejembi C L. Tuberculosis case management and treatment outcome: Assessment of the effectiveness of public private mix of tuberculosis programme in Kaduna state, Nigeria. Annals of African medicine.2009; 8 (1): 25-31.

[12] G = Karim F, Islam MA, Chowdhury AM, Johansson E, Diwan VK. Gender differences in delays in diagnosis and treatment of tuberculosis. Health Policy Plan. 2007;22:329-34. [PubMed]

[13] $\mathrm{H}=$ Holmes CB, Hausler H, Nunn P. A review of sex differences in the epidemiology of tuberculosis. Int J Tuberc Lung Dis. 1998;2:96-104. [PubMed]

[14] Hawkes S, Buse K. Gender and global health: evidence, policy, and inconvenient truths. Lancet. 2013; 381:1783-1787. doi: 10.1016/S0140-6736(13)60253-6 PMID: 23683645

[15] Holmes CB, Hausler H, Nunn P. A review of sex differences in the epidemiology of tuberculosis. Int J Tuberc Lung Dis. 1998;2:96-104.]

[16] K.= Yamasaki-Nakagawa M, Ozasa K, Yamada N, Osuga K, Shimouchi A, Ishikawa N, et al. Gender difference in delays to diagnosis and health care seeking behaviour in a rural area of Nepal. Int J Tuberc Lung Dis. 2001;5:24-31. [PubMed]

[17] Karim F, Islam MA, Chowdhury AM, Johansson E, Diwan VK. Gender differences in delays in diagnosis and treatment of tuberculosis. Health Policy Plan. 2007;22:329-34. [PubMed]

[18] Khatri GR, Frieden TR. The status and prospectus of tuberculosis control in India. Int J Tuberc Lung Dis 2000;4:193-200. ]

[19] L=. Begum V, de Colombani P, Das Gupta S, Salim AH, Hussain H, Pietroni M, et al. Tuberculosis and patient gender in Bangladesh: Sex differences in diagnosis and treatment outcome. Int J Tubercu Lung Dis. 2001;5:604-10. [PubMed]

[20] Long NH, Johansson E, Diwan VK, Winkvist A. Fear and social isolation as consequences of tuberculosis in Vietnam: A gender analysis. Health Policy. 2001;58:69-81. [PubMed]

[21] Long NH, Johansson E, Diwan VK, Winkvist A. Fear and social isolation as consequences of 
tuberculosis in Vietnam: A gender analysis. Health Policy. 2001;58:69-81. [PubMed]

[22] Lawson L, Lawson JO, Olajide I, Ememyonu N, Bello CS, Olatunji OO, Davies PD, Thacher TC. Sex differences in the clinical presentation of urban Nigerian patients with pulmonary tuberculosis. West Afr J Med. 2008 Apr;27(2):82-6. [PubMed]]

[23] Lagrada L P, Uehara N, Kawahara K. Analysis of factors of treatment completion in DOTS health facilities in Metro Manilla Phillipines, a case control study. PMID,2008 ; 83(12):765 -772.

[24] Long, N.H., E. Johansson, V.K. Diwan and A. Winkvist, Fear and social isolation as consequences of tuberculosis in Vietnam: a gender analysis, Health Policy 2001, 58(1):69-81.

[25] M= Raja A. Immunology of tuberculosis. Indian J Med Res. 2004;120:213-32. [PubMed]

[26] Mark J R. Chronic cough due to tuberculosis and other infections. ACCP evidence based clinical practice, 2006; 129; 1975 -2015.

[27] Mukherjee A, Saha I, Sarkar A, Chowdhury R. Gender differences in notification rates, clinical forms and treatment outcomes of tuberculosis patients placed under RNTCP. Lung India. 2012;29:1202. [PMC free article] [PubMed]

[28] Mukherjee A, Saha I, Sarkar A, Chowdhury R. Gender differences in notification rates, clinical forms and treatment outcomes of tuberculosis patients placed under RNTCP. Lung India. 2012;29:1202. [PMC free article] [PubMed]

[29] Martinez HZ, Suazo FM, Gil JQC, Bello CG, Escalera AMA, Marquez HG, Casanova LG. Spatial epidemiology of bovine tuberculosis in Mexico. Veterinaria Italiana. 2007;43(3):629-63. [PubMed]

[30] N= Ahmed J, Chadha VK, Singh S, Venkatachalappa B, Kumar P. Utilization of RNTCP services in rural areas of Bellary District, Karnataka, by gender, age and distance from health centre. Indian J Tuberc. 2009;56:62-8. [PubMed]

[31] Nigerian Stop TB Partnership Strategic Plan 2011

[32] Nigeria National Census :2006

[33] $\mathrm{O}=$. Yang ZH, Kong Y, Wilson F, Foxman B, Fowler AH, Marrs CF, et al. Identification of risk factors for extra pulmonary tuberculosis. Clin Infect Dis. 2004;38:199-205. [PubMed]

[34] Odaibo GN, Gboun MF, Ekanem EE, Gwarzo SN, Saliu I, Egbewunmi SA, Abebe EA, Olaleye DO. HIV infection among patients with PTB in Nigeria. African Journal of Medicine and Medical Sciences. 2006;35:93-98. [PubMed]]

[35] Onifade, D.A. et al., Gender-related factors influencing tuberculosis control in shantytowns: a qualitative study, BMC Public Health 2010, 10:381, http://www.biomedcentral.com/1471-2458/10/381. [36] $\mathrm{P}=$. Martinez AN, Rhee JT, Small PM, Behr MA. Sex differences in the epidemiology of tuberculosis in San Francisco. Int J Tuberc Lung Dis. 2000;4:26-31. [PubMed

[37] Sweet H, Denison S. Gender inequalities in health and diseases. Int Gender Iss 2008: 5-32.

[38] World Health Organization, Global TB Report, Geneva;2015.

[39] WHO - Africa Region. Strategic plan for tuberculosis control for the African region: 2006 - 2010. WHO report - AFRO report 2006. Harare, Zimbabwe: World Health Organisation - Regional Office for Africa, 2006).

[40] World Health Organisation, Global TB Report, Geneva;2014.

[41] Waisbord, S., Behavioral Barriers in Tuberculosis Control: A Literature Review, The CHANGE Project/Academy for Educational Development, Washington, DC, 2005, http://pdf.usaid.gov/pdf_docs/Pnadf406.pdf.

[42] United Nations General Assembly. United Nations millennium declaration. A/RES/55/2. 2000 Sep 8 [cited 2 Aug 2016]. Available: http://www.un.org/millennium/declaration/ares552e.htm.

[43] Yamasaki-Nakagawa M, Ozasa K, Yamada N, Osuga K, Shimouchi A, Ishikawa N, et al. Gender difference in delays to diagnosis and health care seeking behaviour in a rural area of Nepal. Int $\mathrm{J}$ Tuberc Lung Dis. 2001;5:24-31. [PubMed]

[44] Zachariah R, Fitzgerald M, Massaquoi M, Acabu A, Chiloma D, Salaniponi F M L, Harries A D. Does antiretroviral treatment reduce case fatality among HIV positive patients with Tuberculosis in Malawi. International journal for TB and lung disease, 2007; 11 (8):848 -853. 


\title{
The use of Task Shifting in the Implementation of Prevention of Mother to Child Transmission of HIV (PMTCT) Services in Cameroon; the Option B+ Experience
}

\author{
Article by Nguosi Wam Joel \\ CBC Health Services, MPH Student, Texila American University, Cameroon \\ E-mail:wamjoel@yahoo.com
}

\begin{abstract}
Interventions to Prevent Mother to Child Transmission in the world have evolved over the years. Cameroon like every other country has been conforming to new recommendations from WHO based on evidence for better quality of service. Option B+ which entails provision of lifelong Antiretroviral Therapy (ART) to each pregnant and breastfeeding woman was recommended as the standard for PMTCT in 2012(1). Cameroon adopted these guidelines and set out for implementation in October 2013. The purpose of this study is to evaluate the effectiveness of task shifting from nurses to doctors in the rapid scale up of option $B+$ in Cameroon. Results show that within a period of fifteen months, a total of 520 nurses from 266 PMTCT sites in the South West region were trained on the provision of ART at MCH (maternal and child health) units. They were able to adequately provide ART to 1,754 women by December 2015 (Mvogo, 2016). These results set the pace for the scale up of Option B+ to other sites and regions across the country without putting pressure on the limited number of doctors in the country.
\end{abstract}

Keywords: Task shifting, PMTCT, Option B+, ART, MCH, HIV.

\section{Introduction}

The health system of Cameroon has over the years been facing the problem of inadequate staff in all the health professions; doctors, nurses, health technicians etc. The nurse to patient ratio is very big (16 per 10,000 patients) while the doctor to patient ratio is even worse (1 to 10,000 in urban areas and 1 to 40,000 in rural areas) (WHO, 2016). The distribution of staff amongst the existing health institutions is sometimes done with a lot of bias, influenced by political affiliations and some degree of corruption. There are some health institutions in the towns and cities that are over-crowded with staff while others in the certain rural areas barely have a few staff who are not adequately trained to take care of the health needs of the populations they serve. These health units are mostly run by just one health personnel, usually a nurse, who provides minimum services and refers to the next level when necessary.

Before now, the decision to place an HIV positive patient on Antiretroviral Therapy (ART) could only be made by a physician or a Therapeutic committee after deliberations. Cameroon has population of 23,739,000 persons (CDC, April 2016), 5\% of which are pregnant women. The prevalence HIV in the general population is $4.3 \%$ which is even higher for pregnant women $9.2 \%$. The country had achieved a coverage rate of ART of $58 \%$ which is comparatively higher than that of the neighboring countries in the sub-region.

Option $\mathrm{B}+$ is a PMTCT strategy which requires that every pregnant woman or breastfeeding mother who test positive for HIV should be placed on lifelong ART. This is different from the other PMTCT regiments that have been implemented in the country before now which had different criteria for initiation, none of which demanded immediate initiation of lifelong ART. Cameroon adopted this WHO recommendation in 2013 as the standard for PMTCT with plans of gradually rolling out the implementation nationwide by 2017 . The existing set up had just about 166 HIV-care and treatment centers in the whole country which were not well distributed across the geographical landscape of the country. Providing ART to all eligible option $\mathrm{B}^{+}$clients within the country under such a set up would practically be 
Texila International Journal of Public Health

Volume 4, Issue 4, Dec 2016

impossible or would take a very long time. The country had to decide to follow WHOs recommendation of task shifting for HIV management in resource limited settings. Task shifting is the process of delegating tasks from more specialized to less specialized health workers and has been proposed as one of several possible solutions to the dire human resource shortages facing the African health sector (WHO, 2008). There was therefore the need to empower nurses to be able to take care of this problem.

\section{Methods}

Before the start of Option B+, the approved regiment for PMTCT in Cameroon was Option A where positive pregnant women had to do a CD4 test and/or WHO clinical classification to determine which course of treatment to follow. Those who were eligible for ART (CD4 below 350 cells or WHO stage $3 \& 4$ ) were referred to the approved HIV care and treatment centers to be further evaluated and placed on ART, while those who were not eligible for ART received a single molecule ARV for the duration of the pregnancy and breastfeeding period. This was mainly to prevent mother to child transmission of HIV but had not benefits to the mother in terms of improving her health or reducing the risk of transmission of infection to her partner.

The implementation of Option $\mathrm{B}^{+}$was a new phenomenon that could not just be introduced in the current set up, considering the fact that ART was provided only at approved HIV care and treatment centers. The South west region alone has over 250 health facilities that provide maternal and child health (MCH) services spread over 18 health districts. Out of this number, just 15 were HIV care and treatment centers and covered only 11 of the 18 health districts.

The South West region was fortunate to be one amongst the two regions selected for Pilot phase of the option $\mathrm{B}+$ implementation in Cameroon. 10 health units were selected from 1 health district (Kumba) and 12 others in the other region (North west). Before selection, and initial assessment was done using a standard tool to determine their capacity to provide ART at the MCH unit. Some of the key aspects assessed include: the availability of staff, space, medication management, laboratory services etc. Three out of the 10 sites were care and treatment centers.

\section{Trainings and mentorship}

At least two nurses and nurse/midwives from the $\mathrm{MCH}$ units who previously were providing PMTCT services (Option A) were selected from each of these health facilities for training. The underwent a five days intensive training on the following areas: Generalities about HIV/AIDS, Counseling, Classes of ARVs, indications and side effects, client monitoring, opportunistic infections and data management. The trainings were led by doctors and nurses from HIV care and treatment programs. Doctors from some of these units were selected and trained on clinical supervision so that they will serve as site supervisors to the selected sites. After the nurses were trained, they we sent to spend some days at HIV care and treatment centers so that they can be familiar with the procedures and services carried out there. This was followed by implementation at the site level. Thereafter, every pregnant or breastfeeding woman who was tested positive for HIV was counseled, assessed and placed on ART to be taken for life at the MCH units in all the selected sites. Also, other positive clients who were previously on Option A and still current in care were switched to Option B+. The decision to place each client on treatment was taken by the nurses themselves, ARVs prescribed and the clients continuously monitored for any adverse effects. They received regular clinical supervision from the assigned doctors and mentorship from the regional program coordinators.

\section{Continuous quality assurance}

All the clients enrolled during this pilot phase did at least a CD4 test upon initiation as well as other work up tests like Full Blood Counts (FBC) and liver function tests. This was to set a 
baseline that would be used for assessment of the quality of treatment they are receiving and their response. Follow up CD4 tests were also done at six months' intervals upon initiation. Clients were also followed up for any side effects and adverse drug reactions. A few who developed adverse effects were transferred out to care and treatment centers for better management. Peer educators were also recruited to provide on-going psychosocial support, ensure adherence to treatment and retention in care.

\section{Results}

The pilot phase had a target to enroll 600 new clients into option $\mathrm{B}+$ in all the 22 pilot sites. This target was achieved over a period of ten months (October 2013 to July 2014). All the clients enrolled were followed up closely by the nurses with good documentation of all the interventions and close monitoring drug side effects, adverse drug reactions, adherence to medication, biological and immunological monitoring (CD4) and infant testing. The preliminary results proved to be successful and thus set the pace for scale up to others health facilities and districts in the region. The first scale up phase targeted all District hospitals and other high volume sites. In the following months, Option B+ was scaled to all the health units providing $\mathrm{MCH}$ services in the South west and North west regions, while the other regions in the country are following suit. By December 2015, a total of 520 nurses had been trained to provide ART for PMTCT from over 266 health units in the South West region of Cameroon, with over 1,754 positive women receiving ART for PMTCT that year in the region.

\section{Discussions}

The clients who were placed on treatment showed great improvement on their CD4 counts at 6 months and 12months and also recorded negative babies tested within the period of follow up. The purpose of this paper was not to show the effectiveness of these treatment regiments but rather to show that task shifting is a faster way of scaling up ART especially for PMTCT. These results are comparable to the those documented by Morris B (2009) et al, in Lusaka Zambia. Even though an in depth study has not been carried to do a comparative analysis of the client response to the treatment based on viral suppression in clients enrolled and followed up by doctors within this period, preliminary results show little difference in outcome. Further research could be carried to find out a number of issues:

- Compare the benefits of ART on the PMTCT program in this region to the previous PMTCT regiment (option A).

- Compare viral suppression rates of CD4 improvement between clients enrolled at the $\mathrm{B}+$ sites by nurses to those that were done by doctors at the care and treatment centers within the same period

\section{Conclusions}

The success of the pilot phase of option $\mathrm{B}^{+}$in the selected sites in the North West and South West regions of Cameroon which made way for the scale up to the other sites in these regions and other parts of the country shows that task shifting is an effective strategy for expansion of ART in Cameroon. Considering the fact that mother to child transmission of HIV is the leading cause of new infections in children, quick and efficient ways of reaching every positive pregnant woman with interventions that can reduce or prevent this vertical transmission are highly recommended. Task shifting thus could just be the solution needed to scale up ART for all members of the population at the different health units closer to them. In order for the Test and Treat recommendation for HIV care in the general population to be successfully implemented, task shifting has to be introduced at all levels beginning from the health units to the community.

\section{Acknowledgements}

Special thanks go to all the nurses and doctors, actors and partners who were fully involved in the scale up program. 
Texila International Journal of Public Health

Volume 4, Issue 4, Dec 2016

\section{References}

[1] CDC. (April 2016). CDC in Cameroon. Atlanta: Center for Global Health.

[2] Mary B Morris, Bushimbwa Tambatamba Chapula, Benjamin H Chi, Albert Mwango, Harmony F Chi, Joyce Mwanza, Handson Manda, Carolyn Bolton, Debra S Pankratz, Jeffrey SA Stringer and Stewart E Reid. (2009). Use of task-shifting to rapidly scale-up HIV treatment services: experiences from Lusaka Zambia. BMC Health Services Research.

[3] Mvogo. (2016). Rapport Annuel 2015. Yaounde.

[4] WHO. (2008). Train, treat, retain. Task Shifting: rational redistribution of tasks among health workforce teams; global recommendations and guidelines. Geneva, Switzerland: WHO Document Production Services.

[5] WHO. (2016, October 11). Country Cooperation Strategy. Retrieved from World Health Organization: http://www.who.int/countries/en 


\title{
Exploration into the Factors Affecting the Coverage of Household Latrines in Kagera, Tanzania
}

\author{
Article by James Barongo Bashweka \\ Ph.D in Public Health, Texila American University, Tanzania \\ E-mail: jbarongo2004@yahoo.co.uk
}

\begin{abstract}
Low coverage of household latrines in the Kagera Region of Tanzania continues to exist despite past and current interventions to improve the situation. A limited understanding of the reasons for the low coverage restricted solving of this problem. The research which aimed to explore the perceptions of community members and latrine promoters was sought to increase understanding of this problem.

Methods: Study designed was an exploratory qualitative approach that employed two qualitative research methods: focus group discussions and in-depth interviews. Focus groups discussion involved elderly community members and Ward Development Committee members who are leaders and latrine promoters. In-depth interviews involved key informants whose job descriptions includes the promotion of household latrines. Ethical approval was obtained from University of Western Cape and authorisation to conduct the study from the Kagera Regional Administrative Secretary.

Results: Content analysis revealed a thick description of respondent's perceptions in relation to factors which affect the coverage of household latrines in the Kagera Region. Interlinked factors were revealed including low community involvement and participation, poverty, cultural beliefs and taboos, gender disparity, low technical capacity of latrine promoters and poor packaging.

Conclusion: This study revealed myriad factors which affect the coverage of household latrines in Kagera Region of Tanzania. Recommendations were put forward including adoption of an integrated approach, empowerment of members, and provision of capacity building interventions for the key latrine promoters. Insights gained through this study could contribute towards improving the coverage of household latrines in the Kagera Region of Tanzania.
\end{abstract}

Keywords: Low coverage, household, latrine, sanitation, factors, promotion, perception, Muleba District, Kagera Region, Tanzania

\section{Background information}

Sanitation is an important element of health which was included as part of the Alma Ata Declaration on Primary Health Care, Health For All by the Year 2000 (WHO, 1978). This took place in the Alma Ata Declaration to plan for comprehensive Primary Health Care package advocated included basic sanitation for all people (WHO, 1978). It was anticipated that sanitation promotion would be implemented according to the Primary Health Care Principles of equity, accessibility, health promotion, prevention, intersectoral action, community involvement, decentralisation, integration and coordination of health activities (WHO, 1978). However, this did not yield the intended results until the end of the 20th century. It was claimed this due to poverty and a concentration on vertical programmes rather than an integrated Primary Health Care approach (Werner, 1995). Inappropriate stratagies such as distribution of 400 million packets of Oral Rehydration Therapy each year as part of a campaign to reduce children's deaths from diarrhoea, while over 133 million children were still dying annually in developing countries due to poor sanitation was another limitation.

Another significant global strategy that relates to sanitation was the United Nations Millennium Development Goals (MDGs) initiated in 2000 (UNDP, 2000).Within this strategy are eight development targets due to be achieved by 2015. Sanitation was incorporated within goal number seven (MDG7), which was to halve the number of people with no access to safe drinking water and 
Texila International Journal of Public Health

Volume 4, Issue 4, Dec 2016

sanitation by 2015. All 191 United Member States signed the MDGs Declaration in September 2000 (UNDP, 2000). The MDGs committed all world leaders to ensure environmental sustainability through a global partnership for development. In response to MDG7, the Government of Tanzania adopted the National Strategy for Growth and Poverty Reduction (Chaggu, 2009). Through this Government commitment, various sanitation operation targets were set to be achieved by 2010. This included the fulfilment of target 10 of MDG7 for the improvement of the health and socio-economic status and the quality of lives of people particularly children and women. In addition, Vision 2025and of the Government of Tanzania.

However, MDG7 targets on sanitation was not achieved and expected to long term challenge as it was noted by UNDP (2006) that due to current sanitation trend, Sub-Saharan African countries will only reach the Millennium Development Goal Water target in 2040 and the sanitation target in 207. The author therefore called for concerted action from all stakeholders in order to achieve MDG set targets.

Kagera region Tanzania, it was reported by Regional Secretariat and Regional Health Management Team (2012), reported that ownership of safe a household latrine was a major challenge with low coverage persistently dropping over the past four years. Statistically, in (2012) it was reported that household latrine coverage in Kagera region was 50 percent. Although this percentage rate was above the national coverage of 47 percent (MOHSW, 2009), it had decreased over the previous three years from 56.3 percent in 2008, to 52.6 percent in 2009, and 50 percent in 2010

It was further reported in the Council's Comprehensive Health Plan (2010/12) that among the top five health problems are communicable diseases including diarrhoeal diseases, worm infestation and malaria. These diseases are all related to an unsanitary environment particularly low coverage of household's latrines. This means that a high proportion of households are still practicing unsafe faecal disposal, such as open defecation on their farming plots or bushes. This type of defecation is unhygienic; it contaminates the air, the water and the general environment, leading to the spread of germs which cause diarrhoeal diseases. These diseases constituted 30 percent of all visits to the outpatient departments in the region (Region Secretariat and Region Health Management Team, 2010). The above state of affairs triggered the mind of research to conduct an explorative study in Muleba district which is one of 8 district in Kagera region as a -partial fulfillment of the requirements for the degree of Masters in Public Health at School of Public Health, University of Western

The Muleba District was chosen for this study for the following reasons: District Health Profiles from 2009 to 2011 (Council Health Management Team, 2013) estimated that, in total, only 52.4 percent of households in the Muleba District had hygienic latrines, which is far below the national target set to achieve 82 percent in rural areas and 100 percent in urban areas by 2015. The Muleba District prioritised water and basic sanitation in their council health plans and there have been several interventions to provide this to residents in this district. However, it is these interventions appeared to have had little impact on changing people's lifestyles and social behaviour towards the construction of latrines.

\section{Consequences of low coverage of latrines in the kagera region}

The consequences of low coverage of household latrines are numerous and include high morbidity and mortality levels due to diseases such as worm infestations and diarrhoea. Population Services International in Tanzania (2004) estimated that Tanzanian children suffer three to four episodes of diarrhoea per year resulting in it being a leading cause of morbidity and mortality for children under five years old. Morbidity data for all Kagera District Councils shows a high prevalence of faecal oral diseases, predominantly worms and diarrhoeal diseases, with an annual rate of 64/1000 (2012). This indicates that many people become sick due to sanitation related diseases, leading to unnecessary suffering, morbidity and mortality. In 2011, children under five years of age reporting with worm infestations and diarrhoeal diseases were 7.1 percent and 4.4 percent respectively. Outpatient cases accounted for 3.6 percent and 4.6 percent among adults and children under-five respectively. It was 
further reported that 4.9 percent of the deaths among children under five years of age were due to diarrhoeal diseases; making this the fourth highest killer of children under-five. It was also reported that 9.4 percent of adult deaths were due to diarrhoeal diseases (Region Secretariat and Region Health Management Team, 2011). The concerns went beyond the morbidity and mortality figures. The Regional Secretariat and Regional Health Management Team (2011) also claimed that the low coverage of household latrines affects community members economically. Many people become ill frequently resulting in unnecessary suffering, loss of productive time and money to cater for the treatment needed. This is due to the costs involved in taking care of those affected, such as medical care fees, drugs and laboratory tests. It also means an added workload for health institutions which are already overstretched and understaffed. This was a key rationale for the researcher to embark in this study.

\section{Key information on study area}

The Kagera Region is one of the 24 regions of the United Republic of Tanzania. It lies in the North West corner of the country, along the shores of Lake Victoria. The region covers a total area of 39,627 $\mathrm{km}^{2}$ comprising 28,388 $\mathrm{km}^{2}$ of land and $11,239 \mathrm{~km}^{2}$ of water; the largest area of water in the country.

The Kagera Region is located between $1-3^{\circ}$ south of the Equator, at a longitude of $30-32^{\circ}$ east of Greenwich. It lies at an altitude of 1100-1800 meters above sea level. The region has an equatorial type of climate with an average bi-annual rainfall of $800-1200 \mathrm{~mm}$ and a temperature range of between $9-32^{\circ} \mathrm{C}$.

Administratively, the Kagera Region deals with a total population of 2,513,188 distributed through seven districts namely, Biharamulo, Bukoba, Muleba, Ngara, Kyerwa, Missenyi, Karagwe and Bukoba municipal council. Population is composed of various tribe include Haya, Nyambo, Hangaza, Subi and Sukuma and 70 percent of the inhabitants are small-scale farmers These form the livelihood of community members. The majority of the buildings in the area are constructed using wood and mud walls, and are roofed with either grass thatch or iron sheets. (Kagera Regional Secretariat and Regional Health Management Team, 2013). These levels and the relevant bodies operating at each level are discussed below and are summarised in Figure 2.

\section{Levels 0 and 1}

Levels 0 and 1 are the levels of individual households and the community. It is at these levels that policies and guidelines for improvement need to be implemented and/or enforced. These levels represent the target groups and beneficiaries of health services, including latrine promotion interventions. This is where all health efforts are directed to improve the health status and wellbeing of people. 


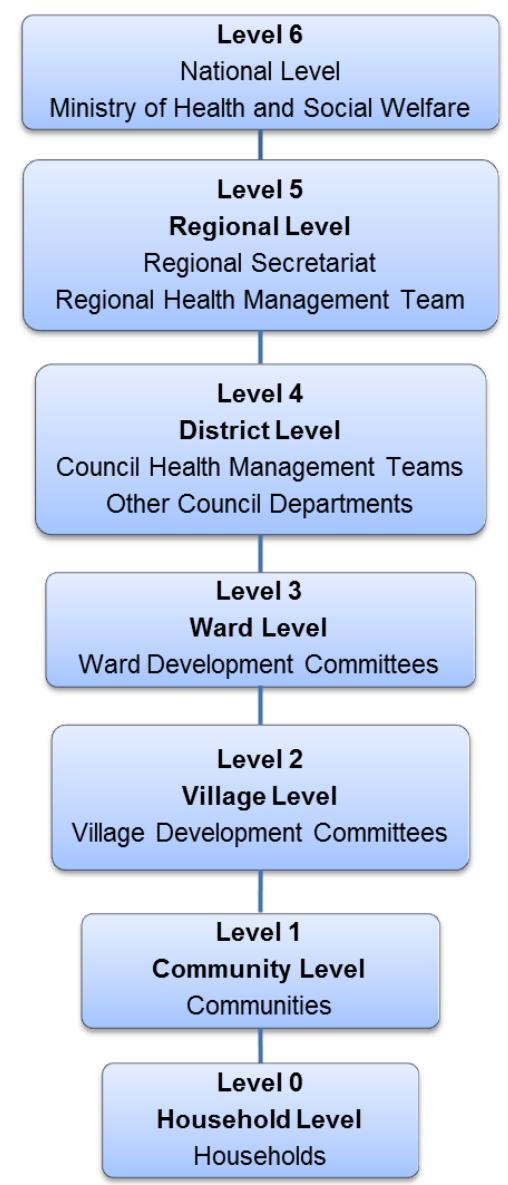

FIGURE 1. Levels involved in latrine promotion

\section{Levels 2 and 3}

The village and ward levels, under VDCs and WDCs, are close to households and the community. They are responsible for the day-to-day functions of all development issues, including latrine promotion. These levels require support from the district, level 4 , in order to be effective in supporting levels 0 and $l$ as it is the district that is responsible for policy and law enforcement.

\section{Level 4}

Level 4 is the district level where the CHMT and other council departments, such as health, education, agriculture, public works, and water and community development are found. Level 4 links Regional and Central Government with lower levels and provides technical support to wards and the village level. The CHMT, which is a top district council body, requires technical capacity and integrity in order to support levels 2 and 3. In addition, level 4 should be supported and supervised by level 5.

\section{Level 5}

The Regional Secretariat and RHMT operate at level 5, the regional level. This level is involved in policy translation and offers technical support to the district level. Level 5 also represents the Ministry of Health and Social Welfare which plays a supervisory role and provides guidelines to the CHMTs at level 4. 


\section{Level 6}

Level 6 is the Ministry of Health and Social Welfare, a top organ that works in collaboration with other bodies to develop all policies, guidelines and protocol for latrine promotion. This level also provides financial and technical assistance to the regions, level 5 (The United Republic of Tanzania Ministry of Health, 1998).

\section{Type of sanitation in kagera region}

Sanitation is one component of environmental hygiene that includes the collection and disposal of human excreta, in particular urine and faeces (UNICEF, 2008). Sanitation has two systems which are classified in two categories. The first is an onsite sanitation system, where human excreta is retained and treated on the site of defecation in a way that is hygienic and does not adversely affect the environment (WHO, 2010). The second system is an off-site sanitation system, where human excreta is removed from the defecation site by conventional sewerage and then treated and disposed of through a small bore sewer. It involves treatment and skilled operators for management, operation and maintenance and requires large quantities of water for flushing. This off-site sanitation system is not suitable in peri-urban and rural areas with water supply shortages (WHO, 2010). Onsite and off-site sanitation systems are practiced in the Kagera Region. Onsite systems are commonly used by the rural population and off-site systems are common in urban areas, for the reasons expressed above. Though there is no uniformity in the types of latrines promoted in the Kagera Region, the most common are the improved pit latrine and the ventilated improved pit latrine. Improved latrines should comprise a deep pit or trench latrine that is about $(0.76-1.22 \mathrm{~m})$ wide and 6-(1.83-3.05 m) deep. (Friend of Lake Victoria

\section{Study design}

The study type selected was that of an exploratory study aimed at understanding the respondents' perceptions of the factors contributing to the low coverage of household latrines. Two qualitative research methods were used: Focus Group Discussions (FGDs) and In-depth Interviews. This qualitative approach facilitated the collection of information that provided an understanding of the respondents' awareness and knowledge about the coverage of household latrines, based on their own experience.

\section{The aim of this study}

The research aimed to explore the perceptions of community members and latrine promoters on the reasons for the low coverage of latrines in order to increase the understanding of this issue, and look for more effective solutions. This in turn, should result in an improvement in the health status of community member in Kagera Region in general.

\section{Specific objectives}

01. To assess the perceptions of community members about the importance of latrines as a basic household structure.

02. To explore the perceptions of latrine promoters and community members regarding the role of latrine promoters in improving the coverage of household latrines in the Kagera Region.

03. To explore the views of community members and latrine promoters about the enabling and hindering factors for improved coverage of household latrines in Kagera.

04. To explore the approaches that could be used to improve household latrine coverage in the Kagera Region

\section{Sampling and study population}

The study population for the first FGD included influential, elderly people who have an informal leadership role in women or men's groups at a community level. As they come from informal 
community groups at level. They are beneficiaries and consumers of latrine promotion services. They are considered a homogenous, informal group because they share the same information, community norms and experiences, and come from the same geographical location. The sample from this population group constituted six people (one woman and five men). The selection criteria included being aged between 50 and 60 years old, living permanently in the wards and owning a house. They were purposely selected with the assistance of the Ward Executive Officer and the Ward Counsellor. Based on their experience in the community, they were considered to have sufficient information about latrine issues. These people were also knowledgeable about different factors in terms of the social, cultural and community norms in relation to defecation, faecal disposal and latrines. They were therefore considered to be information rich subjects.

The study population for the second FGD consisted members of Village Development Committees (VDCs) and Ward Development Committees (WDCs) who are latrine promoters at levels lower community level. Given their roles, they are supposed to take an active role in latrine promotion, including providing technical support and the enforcement of law, policies and guidelines to the community members and families at levels. The sample for this FGD was six members of the VDC and WDC. These were three women and three men aged between 25 to 60 years old. They were considered a homogenous sample because they have shared roles and responsibilities, and because they could be considered information rich in relation to the promotion of household latrines at ward and village levels.

The study population for the in-depth interviews comprised health and development managers from the District Council at level 4 of health services implementation (CHMT) and the Regional Secretariat and RHMT at level 5 of health services implementation (Figure 1). All have been involved in latrine promotion for more than 10 years and were selected based on their qualifications. The two respondents from district level were selected with the assistance of the District Executive Director who is in charge of all district staff. The regional level respondent was selected with the assistance of the Regional Medical Officer who is the chairperson of the RHMT. Basically the study concentrated at ward level where most of respondent were drawn and few from district and Region level as the following narrated structures.

\section{Data collection}

The researcher discussed the study with the District Executive Director and District Administrative Secretary and sought suggestions of the key informants to select for the in-depth interviews. The Ward Executive Officer was also consulted before the finalising the selection the respondents for the in-depth interviews. All the respondents were consulted to seek their willingness to participate in the research. They were all briefed on the research and an arrangement was made with them about the dates and times for individual, face-to-face interviews.

The consultation on the selection of FGD respondents took place with the Ward Executive Officer. Again appropriate times and places were arranged to conduct the discussions. The researcher was accompanied by a research assistant during both the focus groups discussions and in-depth interviews. The research assistant took notes and observed the respondents for aspects such as body language and their level of participation. In addition, the researcher used a tape recorder to record the discussion, having had this agreed to by the respondents. The recorded information was later transcribed and translated into English.

Research tools included a question guide for the FGDs and semi-structured questionnaires for the in-depth interviews. These tools were in Kiswahili which is the national and official language of Tanzania. Kiswahili was used throughout the discussion with the respondents. However, in some instances, Kihaya was used to clarify issues when it was deemed necessary by both the researcher and the respondents. This did not create any problem since the researcher and research assistant are conversant in both Kiswahili and Kihaya. 


\section{Data analysis}

As is the nature of qualitative research, data analysis was done concurrently with data collection in order to adapt the subsequent focus groups and interviews on the basis of previously captured and analysed information. The researcher employed a thick description of data from the FGDs and individual interviews and collated the information accordingly. This was followed by content analysis according to themes in relation to the factors affecting the low coverage of household latrines and possible solutions were drawn from this data. Thereafter coding and categorising of data was done to produce the meaning of respondents' responses.

\section{Ethical considerations}

The researcher obtained from the Ethical Committee at the University of Western Cape also requested permission from the Regional Administrative Secretary of the Kagera Region. Participation was voluntary and consent was sought from the individuals and groups who were interviewed. Individual responses and views were respected and all participants were assured of confidentiality and anonymity by not linking collected information to the person's name or other identification such as his/her address. In addition, the completed information was kept by the researcher in safe custody. Respondents were provided with letters in Kiswahili explaining the nature of the study, requesting their voluntary participation and assuring them about confidentiality. Consent forms were translated in Kiswahili and each participant signed it as proof of their willingness to participate, as well as their right to refuse to participate in the research or withdraw from the study at any time with no implications.

\section{Limitations}

The small sample size was a constraint due to the nature of the mini-thesis. However, the researcher adopted the principles and nature of qualitative research whereby detailed discussion and thick description provided valid and credible results. Triangulation was also applied as a means of increasing rigor which included methodological triangulation, data sources triangulation, theoretical triangulation through literature review.

\section{Relevance of the study topic}

As regards to the relevance of the topic, it was revealed and acknowledged by all FGDs and indepth interview responses that the topic was relevant. This was also supported by the literature review. In addition, responses indicated that household latrines are an important aspect in the maintenance of health and social integrity. It was further argued by most of the respondents that, though the topic is important, it had been overlooked and they therefore suggested the need for urgent attention. Given that the low coverage of household latrines is an issue of concern to both the community members and latrine promoters; this provided an opportunity for the latrine promoters to initiate a dialogue on how best to raise the level of household latrine coverage in the Kagera Region. It can also be argued that acknowledgement of this topic by the respondents can be seen as a clear indication that people are aware of this problem but, have probably lacked the opportunity to discuss it.

\section{Respondents' knowledge on sanitation problems}

The study also revealed respondents were aware about this problem, FGD respondents estimated that only one out of ten households in the vicinity owns a latrine and that even when latrines are available they are poor in terms of quality and physical appearance. This study detected several overlapping themes in relation to sanitation coverage. These themes included community involvement, economic status, culture and taboos, gender disparity, lack of motivation among the community members, knowledge on the health benefits, political factors, capacity of promoters and promotion strategies. These findings demonstrate the prevailing high level of knowledge and 
understanding of the problem among respondents; the central question however, is why latrine coverage is still a challenge despite this knowledge. The same challenge was identified by the Hesperian Foundation (2005) which found that the relationship of knowledge and the perceived benefits from latrines among community members are not always connected with the health benefits because some people are primarily interested in clean toilets, improved hygiene and privacy.

\section{Lack of community involvement}

This study revealed that apart from receiving information from health workers and leaders instructing people to construct latrines, communities are not adequately involved in latrine promotion. In addition, it was learnt that not enough support has been given at a community level to assist in latrine construction. It was further revealed that due to low community involvement, latrine promotion or education was considered to be the role of employed people and not the role of community members. Furthermore, it was found that community members are not aware of the types of latrines that exist and are also not involved in selecting which types to construct in their community. The study also found that people are told to construct latrines as a routine measure instead of enabling them to understand the appropriate type of latrines to construct. It was further found that latrine packaging, such as the promotion of VIPs, lacked the involvement of community members during their selection. A similar weakness was discussed by other researchers whereby most of interventions were noted to be of top-down approached and based on the superficial involvement of community members community. A similar weakness was discussed by Sah and Negussia (2008) that most of the sanitation promotion in Africa are of top-down and based on the superficial involvement of community members. The authors also noted that promoters emphasised coverage rather than the improvement of sanitary behaviours. There is also the tendency for promoters to only focus on hardware rather than combining it with software, which would include information, education and communication (IEC) and behaviour change communication (BCC) events (DFID, 2002). Moreover, it was emphasised by the Ministry of Foreign Affairs of the Netherlands (2012) and the African Ministry Council on Water (2011) that community led heath education in latrine promotion that involved the participation of community members improved the coverage of latrines in Mozambique and other African countries. It was further support by DFID, (2002) and the Hesperian Foundation (2005) both noting that latrine promoters should empower community members by enabling them to understand the importance of latrines including the relationship of latrines and their health and dignity.

\section{Community motivating factors}

This study revealed that community members are not motivated towards the construction of household latrines and that there is little initiative to motivate their active participation in latrine promotion activities. This was vividly noted by the elderly FGD respondents. They indicated that some of the community members who have latrines and know about their importance could not educate their fellow community members. It was further learnt that some people scorn fellow community members who try to educate them on the importance of latrines. This lack of motivation was reported to be related to culture, beliefs and taboos which are discussed in more detail below. Another reason given for the lack of motivation for latrine construction was the traditional alternatives used by the community. For example, the presence of banana plantations and bushes is seen as an advantage as they provide privacy, and this is where some people hide themselves to defecate. Moreover, community members lack technical assistance and guidance on household latrine promotion issues.

This funding is supported by most of the researchers revealed that where community motivation was done properly; it improved the coverage of latrines. For instance Sah and Negussie (2008) proposed that latrine promoters should motivate community members to understand the importance of latrines and shift them from subsidised to self-funded latrine promotion programmes. Furthermore, they recommended that latrine promoters should promote social changes that would enable 
community members to declare their villages as Open Defecation Free (ODF). WSP (2004) also argued that in latrine promotion interventions, routine measures cannot address latrine problems because they relied on outdated approaches. Arbelol (1994, as cited by Sitt, 2005) suggested that community members must participate in the initiation and organisation of their latrine promotion programmes.

\section{Economic status}

This study confirmed that their poor economic status contributed to the low coverage of household latrines. Elderly FGD respondents were of the opinion that some of the latrine construction materials require funds which most of the families in the Kagera Region cannot afford. It was further noted by the elderly FGD respondents that some people do not have decent houses and it was therefore naive to consider that people would allocate a portion of their meagre funds to latrine construction. This was also acknowledged by the in-depth interview respondents who agreed that poor economic status hinders some community members from owning latrines because they cannot afford the construction costs. The study also revealed that in some areas special technology and equipment was needed to break rocks or deal with sandy soils in order to construct latrines. The cost of this technology is too expensive for poor households. However, a few FGD respondents observed that because community members lack awareness about the implications of poor sanitation, they are not motivated to prioritise latrines. Instead, they give priority to non-essential luxuries such as alcohol and cosmetics rather than allocating funds to the construction of latrines. The issue of poverty and latrine was earmarked by other researchers that poor economic status is among the factors that contribute to poor sanitation, particularly with regards to household latrines. Mukwaya and Kusiima (1998); Munro, et al. (1991) in Uganda and Pattanayak et al. (2009) in Irissa India revealed the relationship between low economic status on the coverage of household latrines. The UNDP (2012) also highlighted that in Sub-Saharan Africa, access to sanitation was highly correlated with wealth. UNICEF and other development partners in Ethiopia (2009) suggested the consideration of economic status by motivating that affordable types of latrines are advocated during sanitation promotion

\section{Culture, beliefs and taboos}

This study revealed information which concurs with the examples taken from various literatures. The elderly FGD and WDC respondents in particular, reported that there are some cultural beliefs and taboos which account for the low coverage of household latrines. For example, the respondents indicated cultural factors, beliefs and taboos which dictate that children's faeces should not be put in adult latrines, and that some members of the family should not share latrines. This means that people have to opt for unsanitary faecal disposal, such as bush defecation, sharing of open pits with children and disposing of faeces on banana stems. According to respondents' views, these factors, to some extent, contribute to the low coverage of household latrines. However, officials at district levels argued that the cultural and traditional beliefs are outdated and that they no longer affect the ownership of latrines. This means that, despite the view of the communities, measures are unlikely to be taken by district latrine promoters to address cultural factors, and so this will remain an obstacle to latrine coverage. The finding was supported by other researchers. For instance, WaterAid and Ayele (2005) reported that in Ethiopia, cultural beliefs inhibited the uptake of household latrines because they dictated that people should prevent misfortunes by not owning latrines..

\section{The involvement of women (gender)}

This study revealed that gender inequality in latrine promotion contributes to the low coverage of household latrines in the Kagera Region. The respondents stressed that married women are not involved in latrine construction hence limiting their contribution to latrine promotion activities. This however, did not apply to all women. It was also noted that there are some female-headed households who have managed to construct latrines while some male-headed households have not. Those who argued that the low involvement of women affects the coverage of latrines noted that the construction 
of latrines in the Kagera Region is considered to be the duty of men and that some families may fail to own household latrines as the men do not consider constructing them as a priority. Involvement of women has been insisted by various authors. For instance, the WHO (2010) and Stitt (2005) noted that women are the primary caretakers of latrines and so the effects of not involving them in latrine promotion has a negative impact in improving sanitation coverage. The Hesperian Foundation (2005) added that leaving women out of sanitation planning puts them at a greater risk of health problems and other consequences that increase their burden such as caring children suffering from diarrhoeal diseases. Emphasising the involvement of women in latrine promotion, the Hesperian Foundation (2005) stressed that because women are family caretakers their involvement in the promotion of household latrines will safeguard the community. UNICEF (2010) also reported the advantages of involving women by giving an example from Koraput in India where women played an impressive role in raising the household latrine coverage to 100 percent.

\section{The role of latrine promoters}

The current study exposed many aspects where weaknesses exist. From the findings, it was evident that almost all latrine promoters are not fulfilling their roles. They were reported to be weak in terms of numbers, where one health officer is responsible for a large catchment area. In addition, they do not have the resources required to support their work, for example, transport and demonstration materials. They were also reported to lack technical capacity. Moreover, it was learnt that their approach to latrine promotion includes the use of inappropriate measures such as penalising people with no latrines for outbreaks of cholera and typhoid. Though these measures may be useful in forcing people to have latrines, they are not friendly, motivational or educational. Importantly, it was revealed by this study that there were no plans in place to improve the situation.

Furthermore, it was learnt from the FGD respondents that their leaders and health experts are not taking proper action. The elderly FGD respondents claimed that not a single meeting was organised by latrine promoters to discuss the issue of latrines. They also said that there is little attention given by district planners to educating community members on the importance of latrines and that latrine promoters at ward level get little support. The higher levels of government were also criticised. During an in-depth interview, an official from the district blamed colleagues at the district level for not giving adequate attention to latrine promotion. This indicated a relationship between low latrine coverage and inadequate involvement of latrine promoters, particularly from district level.

Another weakness described was the emphasis on addressing the outcomes of the low coverage of latrines by putting more attention on curative services without educating the community members as part of preventive measures. Respondents also reported that latrine promoters directed more effort towards public latrines than household latrines. This is a weakness that was also reported by the World Health Organisation (undated) who argued that by concentrating on societal public latrines, less attention is paid to household latrines and this leaves community members with little knowledge of the importance of household latrines. The focus and actions of latrine promoters reported above may be due to their low capacity in terms of skills and knowledge on how to address or promote latrine construction appropriately. Limited capacity of promoters in this study can be contrasted with the success in Mozambique, as reported by the Ministry of Foreign Affairs of the Netherlands (2012). The African Ministry Council on Water (2011) also reported success in African countries such as Tanzania, Uganda, Ghana and Rwanda where latrine promoters were key facilitators in the Total Sanitation Marketing project, which involved the decentralisation of policies that improved household latrine coverage. In additional, this is a weakness that was also reported by the World Health Organisation (undated) who argued that by concentrating on societal public latrines, less attention is paid to household latrines and this leaves community members with little knowledge of the importance of household latrines. The focus and actions of latrine promoters reported above may be due to their low capacity in terms of skills and knowledge on how to address or promote latrine construction appropriately. 


\section{The role and capacity of community leaders}

As regards the capacity and role of community leaders, such Ward Executive Officers, Village Executive Officers and village Government leaders the study revealed that their capacity is low and that they are not fulfilling their role in latrine promotional activities. Elderly FGD respondents stressed that community leaders including Ward Health Officers, Ward Executive Officers and Village Executive Officers are not involved in latrine promotion. The respondents further asserted that some government leaders who are supposed to enforce environmental laws that demand community members to construct household latrines, either have no latrines or have substandard ones themselves. They therefore doubted how such leaders could promote latrines while they themselves are not seen to value them. From this study, it was discovered that the low capacity among the community leaders, which includes low technical capacity and a limited understanding of their roles and responsibilities, is one of the factors which prevents them from taking an active role in latrine promotion. For instance, Ward Executive Officers and Village Executives Officers are in charge of ward and development teams whose members have different expertise. As most of these wards and village officers do not have relevant qualifications it is difficult for them to provide technical guidance or support to different sectors.

As discussed above, the lack of adequate support from district level was a major challenge. For example, it was revealed in this study that there were neither demonstration materials for latrine construction at ward levels nor transport facilities for the ward health officer who is involved in latrine promotion. Another weakness which was revealed at district level was that latrine promotional activities have been left to the health department and fall only in the environmental cluster. This means that promotional activities lack integration across different sectors. There is no multi-sectorial or intra-sectorial collaboration. This is against the principle of Primary Health Care (PHC) which stresses that PHC strategies should be cost effective, integrated programmes (WHO, 1988). Furthermore, the authors insisted that PHC should be a multi-sectorial collaboration, and requires an approach of community participation and decentralisation of the district health system through integrated and coordinated efforts. The effectiveness of integrated efforts was reported by the African Ministry Council on Water (2011) as a key factor that had led to the success stories of improved latrine coverage in African countries such as Uganda, Ghana and Rwanda.

\section{The role of political leaders}

The study revealed inadequate political will and poor commitment to latrine promotion activities. All FGDs and in-depth interview respondents were disappointed with unwillingness and inactivity of political leaders from village and ward levels in latrine promotion programmes in the Kagera Region. It was expressed by respondents that village chairpersons and councillors are inactive and do not participate as expected. At the village level, the study revealed that some leaders go for 'cheap' popularity by not enforcing environmental laws in order to win votes. It was further noted by respondents that political leaders at district and regional levels concentrate on issues which benefit them politically in preference to latrine promotion. The same was observed by Sah and Negussie (2008) who showed that between 1990 and 2000 approximately 15.7 billion USD was invested annually in the global water and sanitation sector but little of this was invested in sanitation due to lack of political will. Feachem (1980, as cited by Sitt, 2005) argued that though all countries might be encouraged to increase their annual investment in water and sanitation, the effort is negatively affected by weak political commitment. The weak political commitment applies in other contexts as well. For instance, Feachem (1980, as cited by Sitt, 2005) argued that though countries might be encouraged to increase their annual investment in water and sanitation, these efforts will be based on weak existing political commitment. The author gave an example of the Tafae Provincial Ministry of Health which failed to sustain a health programme handed over to them by the donor due to lack of political commitment. WaterAid (2005) in Ethiopia noted that due to inadequate political will, the local government did not allocate funds for latrine promotion and there was no policy framework for 
material subsidies in the household latrine construction schemes. The global implication of limited political commitment, as noted by the WHO and UNICEF (2006), is the factor for slow progress towards achieving MDG7

\section{Latrine promotion strategies}

The findings from this study in the Kagera Region showed that the strategies used by latrine promoters often achieved the opposite of what they were designed to achieve. It was revealed that the strategies used in the Muleba District contributed, to some extent, to the low coverage of household latrines because they were inconsistent and/or promoted latrines that community members could not afford. Yet the WDC and VDC members claimed that to some extent they are involved in providing education about latrines, by giving monthly health talks at the dispensary of the out patients department. This type of health education by WDCs and VDC is not adequate to raise awareness and enable the participation of community members in sanitation promotion. Furthermore, it was found that the respondents from the WDCs claim to have been facilitating the implementation of routine health education sessions on the importance of latrines and house to house inspections, yet the elderly FGD respondents claimed not to know about the type of latrine being promoted. This indicated a difference between the perceptions of latrine promoters (WDC and VDC) and the elderly members of the community. Furthermore, as their involvement appeared to be fragmented and unsystematic, it was unlikely to have a tangible impact. For example, giving one health talk a month was unlikely to contribute to the improvement of latrine status. District respondents also revealed that they had previously mobilised communities through meetings at village and institutional levels such as schools, but this was no longer done as it was donor dependent and it is not incorporated in district plans. These examples show how ineffective strategies from latrine promoters contribute to the low coverage of latrines in the Muleba District. The role of latrine promotion stratagies was also urged by other researchers: For instance, the Hesperian Foundation and UNDP (2005) suggest that some experts believe that health problems resulting from poor sanitation can be contained only if people change their behaviour in regard to hygiene. However, these ideas often fail because they do not consider the barriers which people face, such as poverty and other social and cultural factors. Another aspect is the focus on technical solutions (UNDP, 2005) such as modern toilets with flush water systems, but these may not be feasible under the prevailing conditions in the community and may create more problems than they solve

\section{Conclusions}

The exploration of the perceptions of community members and latrine promoters revealed a myriad of interrelated factors that impact on the low coverage of household latrines in the Muleba District. The respondents recognised the importance of the study topic and the importance of household latrines though they acknowledged that it was not usually given the attention required. Factors affecting the coverage of household latrines were revealed from the study respondents and from the information in the literature. The factors identified include community involvement, the capacity of community leaders and latrine promoters, economic status, gender considerations, cultural beliefs and taboos, political will and latrine promotion strategies. In addition, several suggestions were put forward by respondents about possible solutions to solve the problem of the low coverage of latrines; these also complied with the proposed measures that arose from the literature. The recommendations that follow are based on a combination of the factors and suggestions put forward by the respondents and the insights that emerged from the discussion chapter of this study. 


\section{Recommendations}

Community at community level: In order to ensure community involvement latrine promoters should put strengthening and enabling community members to be actively participation in the promotion of sanitation. This means that there should an increase in number of sensitisation sessions at community level.

At Promoters level: The Ministry of Health and Social Welfare, the Regional Health Management Team (RHMT) and the Council Health Management Team (CHMT) to develop and implement capacity building programmes for the key latrine promoters on identified above issues as follows.

In order to adress poor economic status: Latrine promotion programmes should consider the economic issues in order to find the means to support community members who are unable to construct latrines due to economic constraints. For instance, a subsidy scheme for the construction of a latrine can be introduced while building the capacity of a community member for sustainability

About Gender Considerations: It is recommended that latrine promoters should incorporate gender mainstreaming in latrine promotion and enable both women and men to take an active role in latrine promotion programmes.

Cultural Beliefs and Taboos: Promoters have to seriously consider these identified these factors and work closely with community to adress them

Concerning Political will: It is recommended that political mobilisation should be one of the components in latrine promotion

In relation to latrine Promotion Strategies: It is recommended that the strategies chosen have to be more user-friendly, practical and affordable for the majority of community members.

\section{References}

[1] Africa Minister's Council on Water, EUWI and UNDP, (2006). On Track to Meet the MDGs on Water and Sanitation: A Status, Overview of Sixteen Africa Countries.

[2] Cameron, L., (2009). Household pit latrine and child health in rural Ethiopia. Department of International Development, Young Lives, University of Oxford, United Kingdom.

[3] Chaggu, E., (2009). Sanitation Sector Status and Gap Analysis. Dar es Salaam, Tanzania.

[4] DFID, (2002). Water supply and Sanitation in DFID Programme and Project Cycle. [Online]. Available: www.lboro.ac.uk/well/resources/publications/guidance/overview.pdf'[Accessed: 12/04/2012: $6.22 \mathrm{PM]}$

[5] Diallo, M. O., Hopkins, D. R., Kane, M. S., Niandou, S., Amadou, A., Kadri, B., Amza, A., Emerson, P. M. and Zingeser, J. A. (2007). Household latrine use, maintenance and acceptability in rural Zinder. Niger International Journal of Environmental Health Research. Volume 17, Issue 6.

[6] End Water Poverty, (2010). A Programme for action: tackling the sanitation crisis. [Online]. Available: www.endwaterpoverty.org [Accessed: 8/03/2012: 6.45 PM]

[7] End Water Poverty, (2010). Sanitation and Water For All. [Online]. Available: www.endwaterpoverty.org [Accessed: 8/03/2012: 5.45 PM]

[8] Guion, L., (2006), Department of Family, Youth and Community Science, Cooperative Extension Service, IFAS, University of Florida, Gainesville, USA. [Online]. Available: http://edis.ifas.ufl.edu/FY393 [Accessed: 28/01/2012 7.30 PM].

[9] Hesperian Foundation, (2005). Sanitation and cleanness for a healthy environment [Online]. Available: http://www.hesperian.org. [Accessed: 12/01/2012 12.30 PM].

[10] Krumeich, A., Weijts, W., Reddy, P. and Meier-Weitz, A. (2001). The Benefits of Anthropological Approaches for Health Promotion Research and Practice. Health Education Research, 16(2): 121-30.

[11] McCullough, L. (2005). Women, Water and Hygiene are Key to Change in Africa. [Online]. Available: http://unicef.org/media/media_28260.html [Accessed: 29/03/2011 4.00 PM]

[12] Mukwaya, R., Kusiima, B.A. (1998). Community use of pit latrines in Mubende District, Uganda. Basic Services Fund, South Sudan. 
Texila International Journal of Public Health

Volume 4, Issue 4, Dec 2016

[13] Muleba District Council, (2011). Council Comprehensive Health Plan 2011/12. Tanzania.

[14] National Bureau of Statistics Tanzania (2010). Demographic and Health Survey. Dar es Salaam, Tanzania.

[15] Pattanayak, J. K., Yang J.C., Dickinson, K. L., Poulos, C. V., Patil, S. R., Mallick, R. K., Blitstein, J. L. and Praharaj, P. (2009). Shame or subsidy revisited: social mobilization for sanitation in Orissa, India. [Online]. Available: www.who.in/entity/bulletin/volumes/

[16] 87/8/08-057422/en/-54k [Accessed: 29/03/2011 3.00 PM].

[17] Population Service International (2004) The Prevalence of Diarrhoea In Tanzania, [Online] : http://www.psi.or.tz/our-works/safe-water.php

[18] RS and RHMT, (2011). Strategic Plan July 2010-June 2015. Regional Commission’s Office, Kagera Region, Tanzania.]

[19] Santakar, C. (2010). Achieving one hundred per cent individual household latrines coverage. [Online]. Available: www.unicef.org/india/reallives_6129.htm [Accessed: 5/06/2012 3.00 PM]

[20] Schaay N. and Sander, D., (2006). International Perspective on Primary Health Care over the past 30 years. School of Public Health, University of the Western Cape, South Africa.

[21] Stitt.T. (2005). Evaluation of rural sanitation program in Vanuatu with management recommendations. Journal of Rural and Tropical Public Health 4: 1-9 (2005)

[22] Tibaijuka. A, (2010). Gender Equity and Sanitation. Opening Statement at the UNHABITAT Gender Quality Action Assembly. Brazil.

[23] UNIAIDS, (2011). UN-Women Gender Equality and HIV/AIDS, New York. Email: genderandaids@ unwomen.org

[24] UNDP Human Development Report, (2006). Beyond scarcity, Power, poverty and global waste. [Online], Available: http://hdr.undp.org/en/media/HDR_2006_Chapter_1.pdf [Accessed: 19/12/2012 8.40 PM]

[25] UNDP, (2012). The Millennium Development Goals Report 2012. [Online]. Available: http://www.un.org/millenniumgoals/pdf/MDG\%20Report\%202012.pdf [Accessed: 14/ 12/2012 2.58 PM]

[26] UNICEF, (1998). A Manual on School Sanitation and Hygiene. Water Environment and Sanitation Guidelines, Series No 5. New York. [Online]. Available: http://www.unicef.org [Accessed: 14/ 12/2012 1.30 $\mathrm{PM}]$

[27] UNICEF and Development in partners, (2009). Technical Guidelines for the Construction and Management of Household latrines. A Manual for Field Staff and Practitioners. [Online]. Available: http://www.bsf-south-sudan.org/sites/default/files/SS+Tech+Guide--Household+Latrines.pdf

[Accessed: 12/12/2012 7.11 PM]

[28] United Republic of Tanzania, (2006). Monitoring Master Plan and Indictor information. Poverty Eradication Division, Ministry of Planning, Economy and Empowerment, Dar es Salaam, Tanzania.

[29] United Republic of Tanzania (2007). Poverty and Human development Report. Ministry of Planning, Economy and Empowerment, Mkuki nyota publisher, Dar es Salaam, Tanzania. [Online]. Available: www.povertymonitoring.go.tz [Accessed: 3/03/2012 4.15 PM]

[30] United Republic of Tanzania, (2009). Supplement to the Public Health Act 2009. Dar es Salaam, United Republic of Tanzania.

[31] United Republic of Tanzania: Ministry of Health and Social Welfare and Prime Minister's Office Regional Administration and Local Government, (2008). Functions of Regional Health Management System. Roles and Responsibilities of Regional Health Management Team, Regional referral Hospital Management Team and Regional Health Referral Board

[32] Water and Sanitation Program (WSP), (2004). Who Buys Latrines, Where and Why? Sanitation and Hygiene Field Series, Field Notes. Nairobi, Kenya.

[33] Water and Sanitation Program (WSP) Africa Region, (2008). Country Status Overview - Regional Synthesis Report Pathway to progress. Transition to Country Lead Service Delivery Pathways to Meet African's Water Supply and Sanitation Targets.

[34] Water and Sanitation Program (WSP), (2010). Country Profile Series. Dar es Salaam, Tanzania. [Online]. Available: www.wsp.org [Accessed: 6/03/2012 5.30 PM] 
[35] Water and Sanitation Program (WSP), (2011). Case study, Getting Africa to meet the Sanitation MDG. Lesson from Rwanda. [Online]. Available: http://www.wsp.org/sites/ wsp.org/files/publications/wsp-rwandasanitation-lessons.pdf [Accessed: 17/9/2012 12.44 PM]

[36] Water and Sanitation Program (WSP), (2011). Scaling up Rural Sanitation, Enabling Environment Endline Assessments. Dar es Salaam, Tanzania.

[37] Water and Sanitation Program (WSP), (2011). Financing Household on-site Sanitation for the Poor. [Online]. Available: http://sanitationupdates.wordpress.com [Accessed: 5/02/2012 3.00 PM]

[38] WaterAid and Ayele, (2005). Water is life, Sanitation is Dignity, Sanitation preference and Household latrine Designs, Briefing Note 1. WaterAid, Ethiopia.

[39] WHO and UNICEF, (2006). Meeting the MDG drinking Water and Sanitation Targets: The Urban and Rural Challenges of the decade, Geneva. Switzerland.

[40] WHO and UNICEF, (2008). Join monitoring Programme for water supply and sanitation, The UN mechanisms for accessing progress.

[41] World Bank, (2006). India Water and Sanitation, Bridging the Gaps between Infrastructure and Services. Background Paper on Urban Water Supply and Sanitation

[42] World Health Organisation, (1978). Declaration of Alma Ata, International Conference on Primary Health Care, Alma Ata, USSR: 6-12 September 1978.

[43] World Health Organisation, (1978). Primary Health Care, Report of International Conference on Primary Health Care, Alma Ata, USSR, 6-12 September 1978: 43-48.

[44] World Health Organisation, (2005). Sanitation challenge: Turning commitment into reality. [Online]. Available: www.who.int/water_sanitation_health/hygiene/envsan/sanitchallenge/en/ index7.html [Accessed: 30/3/2012 3.05 PM]

[45] World Health Organisation, (2010). Monitoring of the achievement of the health related Millennium Development Goal. Report by Secretariat. Sixty-Third World Health Assembly.

[46] World Health Organisation, (undated). The Right Fit: Are Our Institutions Up to the Job? [Online]. Available: www.who.int/entity/water sanitation/hygiene/securingsanitation3.pdf [28/3/2012: $4.30 \mathrm{PM]}$

[47] World Health Organisation, (2012). UN-Water Global Analysis and Assessment of Sanitation and Drinking Water. The Challenge of Extending and Sustaining Services. Geneva, Switzerland

[48] World Health Organisation, (2012). Health promotions, Milestones in health promotions. Statements from global conferences: The OTTAWA character for health promotion, First International Conference on Health Promotion, OTTAWA 17-21 November, 1986.

[49] Werner, D. (1995). Who Killed Primary Health Care? "How the ideal of health for all was turned into the reality of worsening health for the world's poor.” The New Internationalist, 1995. 


\title{
Knowledge of Contraceptives and Unmet Needs of Family Planning among Adolescents Aged 15-19 Years
}

\author{
Article by Bernard Temitayo Ayobami \\ Master of Public Health, Texila American University, Nigeria \\ E-mail: ayobamyjomjom@gmail.com
}

\begin{abstract}
Background: It is essential to cater to unmet needs of contraception among the adolescent group if meaningful strides are to be achieved in the uptake of contraception and prevention of unwanted pregnancies in the society.

Objective: The main objective of the study is to assess the extent of knowledge and unmet needs of family planning among adolescents aged 15-20 years.

Methodology: Secondary data from the 2013 NDHS will be used. The sample was selected using a stratified three-stage cluster design consisting of 904 clusters, 372 in urban areas and 532 in rural areas.

A representative sample of 40,680 households was selected for the survey, with a minimum target of 943 completed interviews per state. A complete listing of households and a mapping exercise were carried out for each cluster over two months. The resulting lists of households serving as the sampling frame for the selection of regular households. A fixed sample take of 45 households were selected per cluster.

Data analysis: Analyses of quantitative data will be done in SPSS version 20. Chi-square test will be used to measure the strength of associations between the various variables where a $p$ value of $=$ or $<0.05$ will be considered statistically significant.
\end{abstract}

\section{Introduction}

\section{Background information}

There has been a growing interest in patterns of contraceptive use among adolescents, due, in particular, to the social, health, and economic relevance attached to pregnancy in this age group. Thus, there is a need for reproductive health education in school and college as well as robust research to determine the contraceptive needs of adolescents. It is however unfortunate that unwanted pregnancies and unsafe terminations of pregnancy still occur in large numbers. The World Health Organization (WHO) estimates that there are approximately 20 million of unsafe abortions every year, and estimates of maternal death as a result of abortion ranged between 60,000 to 100,000 per year. Therefore, family planning programs are very important and should be readily accessible to the community. One in ten pregnancies ends in an unsafe abortion, with Asia, Africa and Latin America accounting for the highest numbers. Each year, 19 million abortions are carried out under unsanitary or medically unfit conditions resulting in some 68,000 deaths. There is a marked increase in sexual activity in the adolescent population. Adolescents need access to information about sexual and reproductive health and contraceptive choices. They must be able to make their choice to prevent unwanted pregnancies based on informed knowledge of the health concerns and side effects of such contraceptives. Very often adolescents have wrong perceptions of reproductive health matters and consider that there is little risk of pregnancy following sexual activity, and exhibit at the same time an apparent ambivalence towards contraceptive practices that result in unplanned pregnancy While most people today look forward to the increase in human freedom provided by contraception, many have mixed feelings about the other side of the coin: There may be more sexual intercourse between unmarried couples, including the very young. For this reason, official sex education classes in schools, churches, and youth organizations often shy away from the subject. Furthermore, while most educators have little difficulty explaining the 
Texila International Journal of Public Health

Volume 4, Issue 4, Dec 2016

facts of human reproduction, they are usually ill at ease describing the various contraceptive methods because they then have to discuss the details of sexual activity ${ }^{1}$.(Australia's Med J. 2011; 4(1): 43-48. Published online 2011 Jan 31. doi: 10.4066/AMJ.2011.499)

Despite high knowledge about contraceptives among adolescents its use is low. Parental attitude towards adolescent contraceptive can adversely affect contraceptive use by adolescents. Both parents and adolescents had misconceptions about contraceptive use among adolescents. For the adolescents, being sexually active, and for the parents, belief that contraceptive use has advantages for adolescent users and their own prior contraceptive use were significantly associated with agreeing that sexually active adolescents should use contraceptives. Both parents and adolescents have high knowledge about modern contraceptive use in preventing both sexually transmitted infections and pregnancy. However, misconceptions and fear of side effects is preventing parents from discussing contraception with adolescents. Parents do not have the will to also encourage adolescents to use contraceptives. There is the need to educate both parents and adolescents to dispel the misconceptions about contraceptives. Contraceptive use among adults should be encouraged as adults on contraceptives are more likely to encourage adolescent contraceptive use. (Attitude of Parents and Adolescents Towards Contraceptive Use by Adolescents in Alajo, Ayawaso Central Submetro of Accra Maya, E.T. http://hdl.handle.net/123456789/5150-)

Taking a closer look at use of contraceptives in the adolescent age group is essential for reducing the burden of unmet needs of family planning and reducing maternal and infant mortality.

\section{Problem statement}

The high rates of adolescent fertility have been a particular concern in many countries. Reducing these levels in developing countries is one of the UN's Millennium Development Goals. But even in some developed countries, high rates persist, particularly in the United States, where the teen birth rate is much higher than the rate in the majority of developed countries. The adolescent fertility rate is defined as the number of births per 1,000 women ages 15 to 19. Having children this early in life exposes adolescent women to unnecessary risks. Their chance of dying is twice as high as that of a woman who waited until her 20s to begin childbearing. In addition, early childbearing greatly reduces the likelihood of a girl advancing her education and limits her opportunities for training and employment. Globally, the trend has certainly been downward, but there are very sharp differences in levels and trends across regions. (www.prb.org/Publications/Articles/2013/adolescent-fertility.aspx)

About 16 million women 15-19 years old give birth each year, about $11 \%$ of all births worldwide. Ninety-five per cent of these births occur in low- and middle-income countries. The average adolescent birth rate in middle income countries is more than twice as high as that in high-income countries, with the rate in low-income countries being five times as high. The proportion of births that take place during adolescence is about $2 \%$ in China, $18 \%$ in Latin America and the Caribbean and more than $50 \%$ in sub-Saharan Africa. (http://www.who.int/maternal_child_adolescent/topics/maternal/adolescent_pregnancy/en/)

It should not be surprising that adolescents in sub-Saharan Africa, who have the highest rates of fertility for their age in the world, face probably the highest risks of pregnancy-related mortality, of delivery complications, and of premature births or low-birth weight babies. Teenage pregnancy in Africa also has important social and economic outcomes, the most highly publicized of which stem from lost educational opportunities when pregnancy forces young women to leave school. ${ }^{1}$ Ideally, an investigation of the consequences of adolescent childbearing and sexuality should cover a wide range of outcomes that affect not only the young mother and her child, but also other family members and society at large. it has important effects on population levels and growth, especially in populations that appear to be governed largely by natural fertility. However, there is little direct evidence on the relationship between age at first marriage and completed family size in sub-Saharan Africa. 
Most reproductive health problems experienced by adolescents are also experienced by older women. But they are exacerbated among the young, whether by physical immaturity, primiparity, or social condemnation. In societies in which marriage and childbearing are expected to begin early, the majority of pregnancies produce highly valued children. Problems, when they do arise, arise primarily from the mother's physiological immaturity: Babies suffer from low birth weights and birth traumas, and young women are not mature enough to safely carry a fetus to term or to bear a baby. These problems are often compounded by the lack of adequate medical care. Although this pattern of early marriage and childbearing has received considerably less attention than has the emerging problem of pregnancy among urban schoolgirls, the number of women potentially at risk for these problems argues convincingly for including this pattern in any discussion of the consequences of adolescent fertility. Unmarried urban schoolgirls who become pregnant attract so much attention as it tends to be identified as the major locus of troublesome adolescent fertility in Africa. Inasmuch as urban schoolgirls are very young and physically immature they face risks of childbearing similar to those of women who get married early. However, because their risks extend through their education or training, urban girls are probably slightly older, on average, than their counterparts in the early-marriage group. Yet in the case of urban schoolgirls, social condemnation makes them reluctant to seek health services; hence, they suffer additional risks from lack of prenatal care and from unsafe abortions. They may also suffer an increase in risk of sexually transmitted diseases, although the evidence on this point is thin.

(Social Dynamics of Adolescent Fertility in Sub-Saharan Africa (1993)www.nap.edu/catalog/2220/social-dynamics-of-adolescent-fertility-in-sub-saharan-africa)

Teenage pregnancy of which adolescent pregnancy is a subset, affects both developed and developing countries, it is a universal problem. It is a major public health issue irrespective of the marital status of the adolescent. Teenage fertility, establishes the pace and level of fertility over a woman's entire reproductive life span (Panday, et al., 2009, UNICEF, 2005). Bulk of adolescent pregnancy in sub- Saharan Africa occurs within marriage. (World Health Organization, 2008) These adolescents tend to have more children than those who get marry later in life. Thus, the attendant increases in prevalence of complications of teenage pregnancy in this region of the world (UNICEF, 2005). In sub-Saharan Africa 70-80\% of births to teenagers occur within marriage. Teenagers who have never been married are significantly less likely to have entered motherhood (Marcen and Bellido, 2013;www.iiste.org/Journals/index.php/JEDS/article/viewFile/10699/10904). This however does not negate the fact that they are sexually active and need to be taught how to prevent unwanted pregnancies through family planning. Teenage pregnancy in a population is a means through which linkages between fertility and socio-economic variables can be examined (Sonfield, et al, 2013;

www.iiste.org/Journals/index.php/JEDS/article/viewFile/10699/10904).

It is an early warning sign of inequality in a society (Barcena, 2013; http://www.iiste.org/Journals/index.php/JEDS/article/viewFile/10699/10904). It is more common among the poor, rural dwellers compared to the wealthy and urban dwellers. Educational level is a risk factor in teenage pregnancy - the relationship is inversely proportional (Chau-Kuang, 2013;

www.iiste.org/Journals/index.php/JEDS/article/viewFile/10699/10904). Likewise, teenage pregnancy is a major cause of dropping out of school. Teenage pregnancy and motherhood has remained a major health and social concern in Nigeria because of its association with likely higher maternal morbidity and mortality as well as child morbidity and mortality (National Population Commission and ICF Macro2009; www.iiste.org/Journals/index.php/JEDS/article/viewFile/10699/1090) 
Texila International Journal of Public Health

Volume 4, Issue 4, Dec 2016

\section{Study justification}

The study has environmental, societal and economic significance. By reducing adolescent fertility rates (AFR), better utilization and distribution of resources will be achieved thus improving on people's quality of life. Government planning will also ease with controlled fertility rates. This study is also significant to public health since by lowering fertility rates, population growth and its effects will also decline. Effects like disease due to overcrowding will be curbed. Maternal, infant and child mortality will reduce. Macronutrient deficiencies and disease especially among children due to large numbers of children, lack of financial empowerment in mothers and low educational level. The study aims at filling a gap in knowledge on contraceptive uptake among adolescents and creates baseline data viable for further research. It is hoped that the findings of the study will inform policy makers on contraceptive uptake among adolescents and will contribute to the growing need for age group transformative programs in Maternal and Child Health/Family Planning

\section{Research questions}

- $\quad$ Are adolescents aware of the available contraceptives?

- $\quad$ Are they utilizing contraceptive services?

- What are the barriers to effective utilization of contraceptives by adolescents?

\section{Objectives}

\section{Broad objective}

The broad objective of this study is to assess the utilization of contraceptives uptake among adolescents aged 15-19 years in Nigeria.

\section{Specific objectives}

- To establish whether the contraception services are available for adolescents aged 1519 years in Nigeria.

- To assess awareness of contraception among adolescents aged 15-19 years in Nigeria.

- $\quad$ To assess contraception utilization among adolescents aged 15-19 years in Nigeria.

- To establish the barriers to contraceptives' utilization among adolescents aged 15-19 years in Nigeria.

\section{Literature review}

\section{Contraception}

It is the deliberate use of artificial methods or other techniques to prevent pregnancy as a consequence of sexual intercourse. Contraception is a pillar in reducing adolescent pregnancy rates.

\section{Benefits of contraception}

The reproductive choices made by young women and men have an enormous impact on their health, schooling, employment prospects and overall transition to adulthood (www.guttmacher.org/about/journals/ipsrh/2009/patterns-and-trends-adolescents-

contraceptive-use-and-discontinuation). Effective contraception uptake helps in controlling rapid population growth. Unsustainable

Population growth rates are slowed down to match the available resources. This helps achieve environmental sustainability and economic growth both regionally and nationally. (Mundo, F. D. (2012) Primary Maternal and Neonatal Health: A Global Concern. Chicago: Springer Science \& Media Centre). Other highlighted benefits of adolescent contraception are preventing pregnancy-related health risks, reducing the need for unsafe abortion, reducing infant mortality, helping to prevent HIV/AIDS, empowering youth and enhancing education and reducing adolescent pregnancies. (who.int/mediacentre/factsheets/fs351/en/) 


\section{Provision of contraception}

Although adolescent pregnancy rates in developed countries have decreased significantly over the past decade, births to adolescents remain both an individual and public health issue. As advocates for the health and well-being of all young people, recommendation that adolescents postpone consensual sexual activity until they are fully ready for the emotional, physical, and financial consequences of sex should be made. Despite this, some young people will choose not to postpone sexual activity, and thus need help to reduce risks and negative health consequences associated with adolescent sexual behaviors, including unintended pregnancies and sexually transmitted infections. (Contraception and Adolescents; Revised. 104(5):1161PediatricsNovember 2007, VOLUME 120/ISSUE 5). Providing information to adolescents about contraception does not result in increased rates of sexual activity, earlier age of first intercourse, or a greater number of partners. If adolescents perceive obstacles to obtaining contraception and condoms, they are more likely to experience negative outcomes related to sexual activity. It is important that family planning is widely available and easily accessible through midwives and other trained health workers to anyone who is sexually active, including adolescents. Midwives are trained to provide (where authorized) locally available and culturally acceptable contraceptive methods. Other trained health workers, for example community health workers, also provide counseling and some family planning methods, for example pills and condoms. For methods such as sterilization, women and men need to be referred to a clinician.(who.int/mediacentre/factsheets/fs351/en/)

\section{Contraceptive methods}

The contraceptive methods can be classified into modern and traditional methods.

\section{Modern methods}

Modern contraceptive methods were invented so couples could act on natural impulses and desires with diminished risks of pregnancy. Modern contraceptive methods are technological advances designed to overcome biology. In this regard, modern methods must enable couples to have sexual intercourse at any mutually-desired time. Contraceptive use has increased in many parts of the world, especially in Asia and Latin America, but continues to be low in subSaharan Africa. Globally, use of modern contraception has risen slightly, from 54\% in 1990 to $57.4 \%$ in 2014. (http://who.int/mediacentre/factsheets/fs351/en/) Modern methods of contraception include female and male sterilization, oral hormonal pills, the intra-uterine device (IUD), the male condom, injectable, the implant (including Norplant), vaginal barrier methods, the female condom and emergency contraception.

\section{Traditional methods}

Withdrawal (Coitus interruptus) is aimed at preventing fertilization in that, upon ejaculation during sexual intercourse, a man draws out the penis and ejaculates outside the woman's vagina and external genitalia. It offers 96\% effectiveness in preventing pregnancy when correctly and consistently used. Many couples use it because of convenience, although, its effectiveness is somehow compromised, owing to the fact that proper timing of withdrawal is difficult. (Carroll, J. (2015) Sexuality Now: Embracing Diversity. Boston: Cengage Learning) Periodic abstinence (the rhythm or calendar method) refers to avoiding unprotected vaginal sex during the woman's most fertility days. Achieved through calendar-based methods; monitoring fertile days in the cycle of menstruation, cervical mucus and body temperature monitoring. If correctly and consistently used, they form $95-97 \%$ effectiveness in preventing pregnancy, though it requires maximum cooperation among sexual partners. (Callahan, T., Caughey, A. B. (2013) Blueprints Obstetrics and Gynecology. Baltimore: Lippincott Williams \& Wilkins.) 
Texila International Journal of Public Health

Volume 4, Issue 4, Dec 2016

\section{Contraceptive utilization among adolescents}

Among sexually active youth, contraceptive use reduces the number of unplanned pregnancies. However, before using a contraceptive, youth must first have knowledge of different methods. Understanding youth sexual behaviors and contraceptive use can help improve policies addressing reproductive health knowledge and behavior among young women. Increased knowledge can empower young women to have more control over their reproductive health and access family planning resources where needs are not being met. Improvements in sexual health behavior and knowledge among youth can lead to a decrease in the spread of STIs including HIV infection as well as fewer unplanned pregnancies, which will allow for a healthier generation of families (www.prb.org/Publications/Articles/2009/westafricayouth.aspx)

More than two-third (67\%) of the adolescents in a study carried out in Ethiopia had knowledge about reproductive health. Age, living arrangement and economic status were associated with reproductive health knowledge. However, only one-fifth (21.5\%) of the adolescents had ever used reproductive health services including family planning, sexually transmitted infections treatment and information, education and communication. Reproductive health services utilization was significantly associated with age and knowledge of reproductive health. (Amanuel Alemu Abajobir and Assefa Seme; BMC Health Services Research201414:138; DOI: 10.1186/1472-6963-14-138) recommended that an intervention for improving consistent contraceptive use among adolescents be pursued.

Further buttressing this point, a study was carried out to access the student's knowledge and use of emergency contraception which is known to be safe and effective in preventing unplanned pregnancy. The study was carried out in Ilorin, Western Nigeria, using multi-stage sampling method. Data was collected using pre-tested semi-structured self-administered questionnaire. Knowledge was scored and analyzed using SPSS version 21.0 was used for data analysis. A p-value $<0.05$ was considered statistically significant.27.8\% of the respondents had good knowledge of emergency contraception. Majority of respondents (87.2\%) had never used emergency contraception. Majority of those who had ever used emergency contraception (85.7\%) used it incorrectly, using it more than 72 hours after sexual intercourse $(\mathrm{p}=0.928)$. This shows that knowledge about Emergency contraception and prevalence of use was low. (The Pan African Medical Journal. 2016;23:74. doi:10.11604/pamj.2016.23.74.8688)

The creation of adolescent-friendly centers for reproductive health services is highly proposed if significant improvement is to be seen in contraceptive utilization among adolescents. Though a high number of adolescents know at least one contraceptive method, this knowledge does not influence them to consistently use contraceptives. Only a small percentage of the sexually active adolescents use a contraceptive method consistently. (Use of contraceptives among adolescents in Kintampo, Ghana: a cross-sectional study by Boamah EA, Asante KP, Mahama E, Manu G, Ayipah EK, Adeniji E, Owusu-Agyei S; DOIhttps://dx.doi.org/10.2147/OAJC.S56485)

\section{Barriers to contraceptive uptake among adolescents}

Race, ethnicity, age, marital status, education, income, requirements for confidential care, and fertility intentions has all been demonstrated to affect contraceptive choice (Contraception and Adolescents; Revised. 104(5):1161PediatricsNovember 2007, VOLUME 120/ISSUE 5). Parent disapproval, lack of basic information and pressure from partners were found to deter adolescents from accessing and using reproductive health services. Likewise, low parent-adolescent communication on reproductive health issues continue to be sociocultural taboos among the societies (Amanuel Alemu Abajobir and Assefa Seme;BMC Health Services Research201414:138; DOI: 10.1186/1472-6963-14-138) Adolescent-friendly centers for reproductive health services do not exist in most developing countries. This puts the adolescents off because the regular reproductive health services especially with regards to confidentiality do not encourage their visit. Regular ones are usually too judgmental and also 
stigmatizes due to lack of special training on handling of adolescents.(Use of contraceptives among adolescents in Kintampo, Ghana: a cross-sectional study by Boamah EA, Asante KP, Mahama E, Manu G, Ayipah EK, Adeniji E, Owusu-Agyei S; DOIhttps://dx.doi.org/10.2147/OAJC.S56485)

Amount of contraceptive education that providers receive appears to be insufficient and they have insufficient opportunities for continuing education on advances in contraceptive methods and changes in contraceptive protocols. Adolescents get little messages and information on the importance of contraception and the methods available. Research suggests that most adolescent girls have a strong desire to become pregnant due to internalized powerful socio-cultural values. Emotional and interpersonal barriers to the uptake of family planning services also stem from the attitudes and desires of partners and other family members regarding girls' fertility. Socio-cultural and religious norms and practices impact the use of contraception in so far as the social value they ascribe to girls versus boys and appropriate gender roles for each. Teens also face important cognitive barriers in that they lack knowledge and understanding of conception and contraception. Geographic barriers are particularly significant for rural teens and those with restricted mobility. The cost of contraception is an economic barrier for adolescents. Administrative barriers can limit the access of unmarried teens. Where teens are stigmatized for their sexuality, barriers relating to quality of care, especially the attitudes of providers are significant. (https://www.odi.org/projects/2596-barriers-contraceptive-use)

A cross-sectional study was carried out among 400 senior secondary schools students in Ojo military barracks, Lagos, Western Nigeria. Majority of them 391 (97.8\%), were in the adolescent age group (10-19 years). 67.5\% of them had correct knowledge of the use of condoms while $31.1 \%$ of the sexually active respondents have ever used any form of contraceptive with no statistically significant difference between the male and female respondents $(P=0.338)$. The most common barrier to contraceptive methods as reported by $85.1 \%$ of respondents was being too embarrassed to source for the contraceptives.(Contraceptive knowledge and practice among senior secondary schools students in military barracks in Nigeria UC Chimah, TO Lawoyin, AL Ilika, CC Nnebue)

Non-availability of wider choice of methods also reduces the ability to meet the individual needs of contraception. To examine how much contraceptive use increases as additional methods are made available to populations, data estimating contraceptive use from representative national surveys and data estimating method availability from special surveys to make comparisons for 6 modern contraceptive methods, in each of 6 years: 1982, 1989, 1994, 1999, 2004, and 2009 were used. Various method accessibility rules governing different proportions of the total population (ranging from 20\% to $80 \%$ ) that must have access to a method in order for it to qualify as "available" was used to estimate method availability. It was found that contraceptive use is greater when more methods are available to a large portion of the population, both cross-sectionally and over time. Increase in number of methods available by 1 to at least half the population gave an increase of 4-8 percentage points in total use of the 6 modern methods. A consistent pattern emerges for the relationship of contraceptive use and choice among multiple methods. Therefore, contraception use may be increased by extending the availability of current methods, by improving features of current methods, or by introducing new methods (www.ghspjournal.org/content/1/2/203.full) 


\section{Methodology}

\section{Figure}

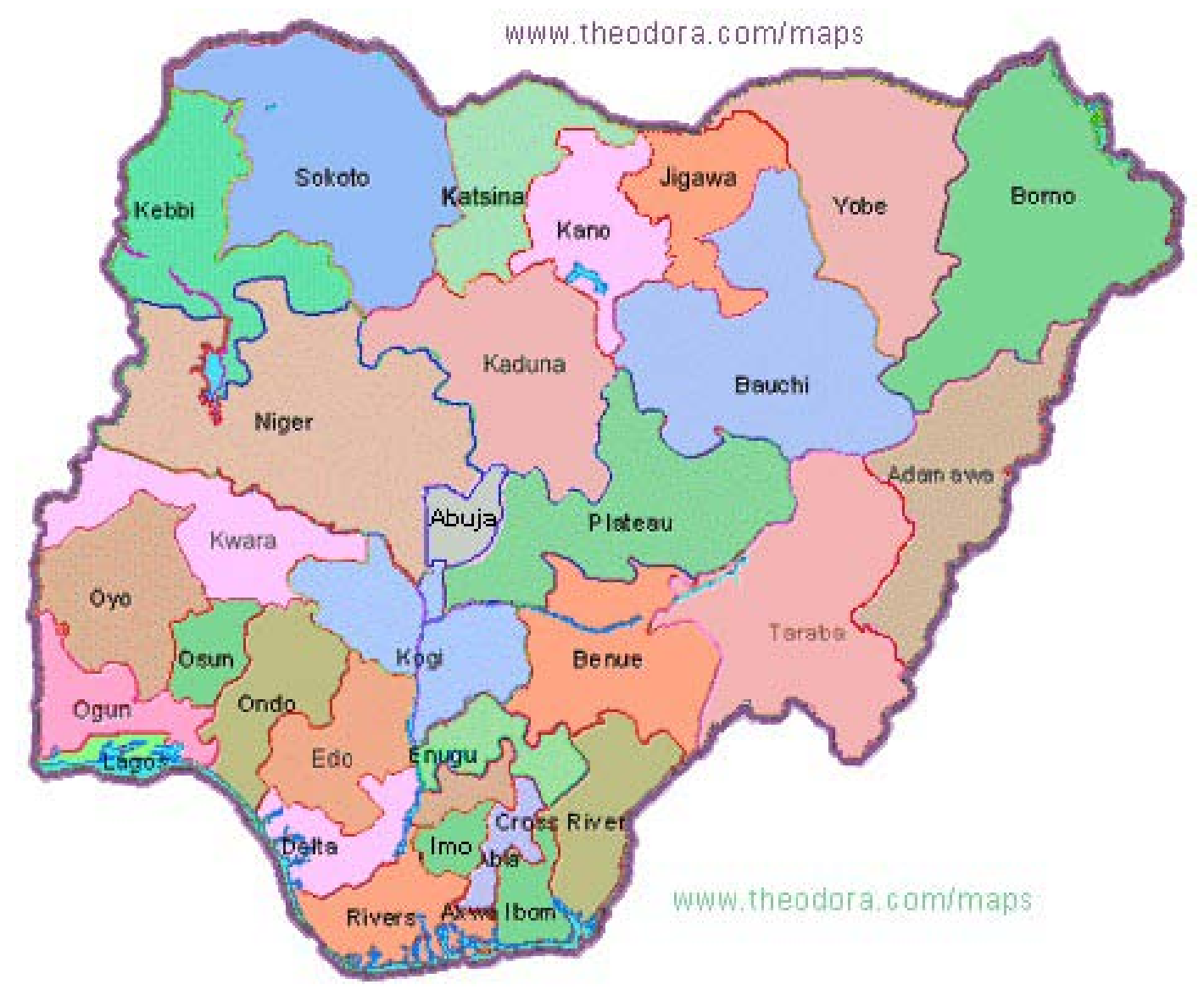

Figure 1. Nigeria lies on the west coast of Africa between latitudes $4^{\circ} 16^{\prime}$ and $13^{\circ} 53^{\prime}$ north and longitudes $2^{\circ} 40^{\prime}$ and $14^{\circ} 41^{\prime}$ east. It occupies approximately 923,768 square kilometers of land stretching from the Gulf of Guinea on the Atlantic coast in the south to the fringes of the Sahara Desert in the North. The territorial boundaries are defined by the republics of Niger and Chad in the north, the Republic of Cameroon on the east, and the Republic of Benin on the west. Nigeria is the most populous country in Africa and the 14th largest in land mass. The country's 2006 Population and Housing Census placed the country's population at $140,431,790$.

\section{Target and study population}

A nationally representative sample of 40,320 households from 904 primary sampling units (PSUs) was selected. People age 15-19 years who were usual members of the selected households or who spent the night before the survey in the selected households was eligible for individual interviews. As with previous NDHS surveys, the main objective of the 2013 NDHS was to provide reliable information on knowledge and use of family planning methods. The survey was designed to produce reliable estimates for key indicators at the national level as well as for urban and rural areas, each of the country's six geographical zones, and each of the 36 states and the Federal Capital Territory (FCT).

\section{Study design}

The cross-sectional study design will be adopted and will seek to assess the uptake of contraception among adolescents aged $15-19$ years. 


\section{Sampling}

\section{Sampling technique}

The sample for the 2013 NDHS was a stratified sample, selected independently in three stages from the sampling frame. Stratification was achieved by separating each state into urban and rural areas. In the first stage, 893 localities were selected with probability proportional to size and with independent selection in each sampling stratum. In the second stage, one EA was randomly selected from most of the selected localities with an equal probability selection. In a few larger localities, more than one EA was selected. In total, 904 EAs were selected. After the selection of the EAs and before the main survey, a household listing operation was carried out in all of the selected EAs. The household listing consisted of visiting each of the 904 selected EAs, drawing a location map and a detailed sketch map, and recording on the household listing forms all occupied residential households found in the EA with the address and the name of the head of the household. If a selected EA included less than 80 households, a neighboring EA from the selected locality was added to the cluster and listed completely. The resulting list of households served as the sampling frame for the selection of households in the third stage. In the third stage of selection, a fixed number of 45 households were selected in every urban and rural cluster through equal probability systematic sampling based on the newly updated household listing

\section{Sample size determination}

A nationally representative sample of 40,320 households from 904 primary sampling units (PSUs) was selected. 38,904 were found to be occupied at the time of the fieldwork. Of the occupied households, 38,522 were successfully interviewed, yielding a household response rate of 99 percent. All adolescents age 15-19 years who were usual members of the selected households or who spent the night before the survey in the selected households was eligible for individual interviews.

\section{Sampling procedure}

Nigeria is divided into states. In turn, each state is subdivided into local government areas (LGAs) and each LGA into smaller (secondary and tertiary) localities. Nigeria has 36 states and a Federal Capital Territory (FCT). These states are subdivided into 774 LGAs. Furthermore, the states are regrouped by geographical location to form six zones. In addition to these administrative units and geographical zones, each locality was subdivided into convenient areas called census enumeration areas (EAs). The average number of households per EA in the corresponding locality frame was assigned to each EA. The EAs in Nigeria are small in size, with an average of 211 inhabitants (equivalent to 48 households). Since these EAs were too small to be DHS clusters, the 2013 NDHS included several EAs per DHS cluster (with a preferred minimum cluster size of 80 households).

\section{Inclusion criteria}

Inclusive criteria are all the adolescents who are within the sexually active age (15 - 19 years) and who will give consent and willing to participate in the study. Adolescents below 15-19 years though sexually active will be excluded from the study.

\section{Data and data collection tools}

Both qualitative and quantitative data will be collected during the study using structured questionnaires and interview guides. The questionnaires will consist of three parts. Three questionnaires were used in the 2013 NDHS: the Household Questionnaire, the Woman's Questionnaire, and the Man's Questionnaire. The content of these questionnaires was based on model questionnaires developed by the MEASURE DHS programs. The model questionnaires were modified according to the country's requirements, in consultation with a broad spectrum of government ministries and agencies, nongovernmental organizations, and international donors, to reflect relevant issues such as family planning, The first part will 
Texila International Journal of Public Health

Volume 4, Issue 4, Dec 2016

contain demographic questions, the second part will contain the known and preferred adolescent contraceptive methods and the last will consist of questions relating to barriers to contraceptive uptake. Prior to the start of data collection, the purpose of conducting the study will be explained to the participants for them to express their willingness by granting consent.

\section{Data collection procedures}

The Household, female's, and male's Questionnaires were pretested in four locations in Makurdi (northern Nigeria), where the residents are predominantly Hausa, Yoruba, English, and Igbo speaking. The teams were divided according to languages. The supervisors and editors were drawn from among the trainees. The questionnaires were pretested in 120 households. A debriefing session was held at the end of the pretest fieldwork. Based on observations from the field and suggestions made by the pretest teams, revisions were made in the wording and translations of the questionnaires. Logistical arrangements for the survey were also discussed.

\section{Data processing and analysis}

After data collection is completed, data entry, cleaning and analysis will be done by using the Statistical Package for Social Sciences (SPSS) software, version 20 Program. In order to describe the descriptive statistic, frequencies and percentages will be computed and represented in bar graphs, pie charts and tables. Qualitative data will be analyzed in relation to the study variables. Chi-square test will be used to measure the strength of associations between the various variables where a p-value of $=$ or $<0.05$ will be considered statistically significant.

\section{Expected outcome}

The number of adolescents between the ages 15-19 years on contraceptive will be established. Levels of awareness, utilization and barriers to contraceptives' utilization among them will also be established.

\section{Results and discussion}

Table 1.0. Exposure to family planning messages among adolescents $15-19$ years

\begin{tabular}{|l|l|l|}
\hline & FEMALE (7820) & MALE (3619) \\
\hline RADIO & 24.0 & 28.9 \\
\hline TV & 12.6 & 14.6 \\
\hline NEWSPAPER/MAGAZINE & 4.0 & 4.4 \\
\hline POSTER/LEAFLET/BROCHURE & 9.0 & 10.8 \\
\hline OTHER & 3.4 & 3.3 \\
\hline NO MEDIA SOURCE & 71.2 & 65.2 \\
\hline
\end{tabular}

Table 2.0. Knowledge and use of contraceptive methods among adolescents aged 15-19 years

\begin{tabular}{|l|l|l|}
\hline & FEMALE (2251) & MALE (41) \\
\hline $\begin{array}{l}\text { HEARD OF ANY } \\
\text { METHOD }\end{array}$ & 67.0 & 86.7 \\
\hline $\begin{array}{l}\text { HEARD OF ANY } \\
\text { MODERN METHOD }\end{array}$ & 64.4 & 85.7 \\
\hline
\end{tabular}




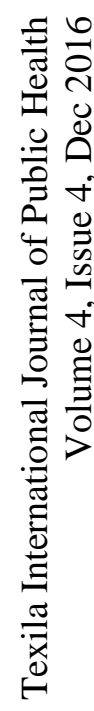

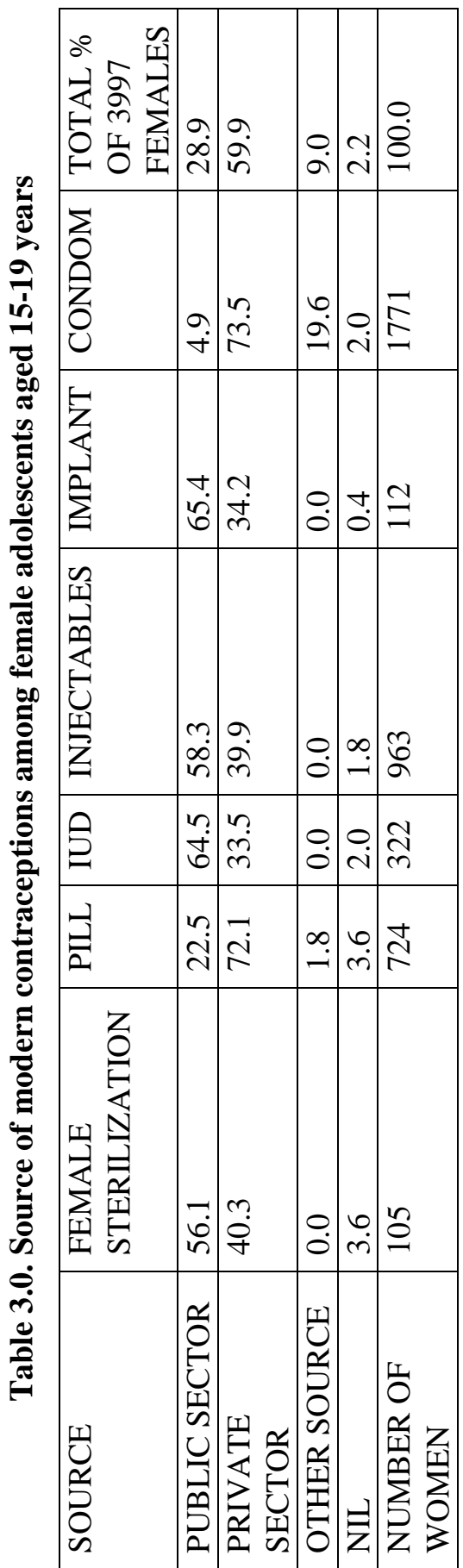


Texila International Journal of Public Health

Volume 4, Issue 4, Dec 2016

Charts representing table 3.0
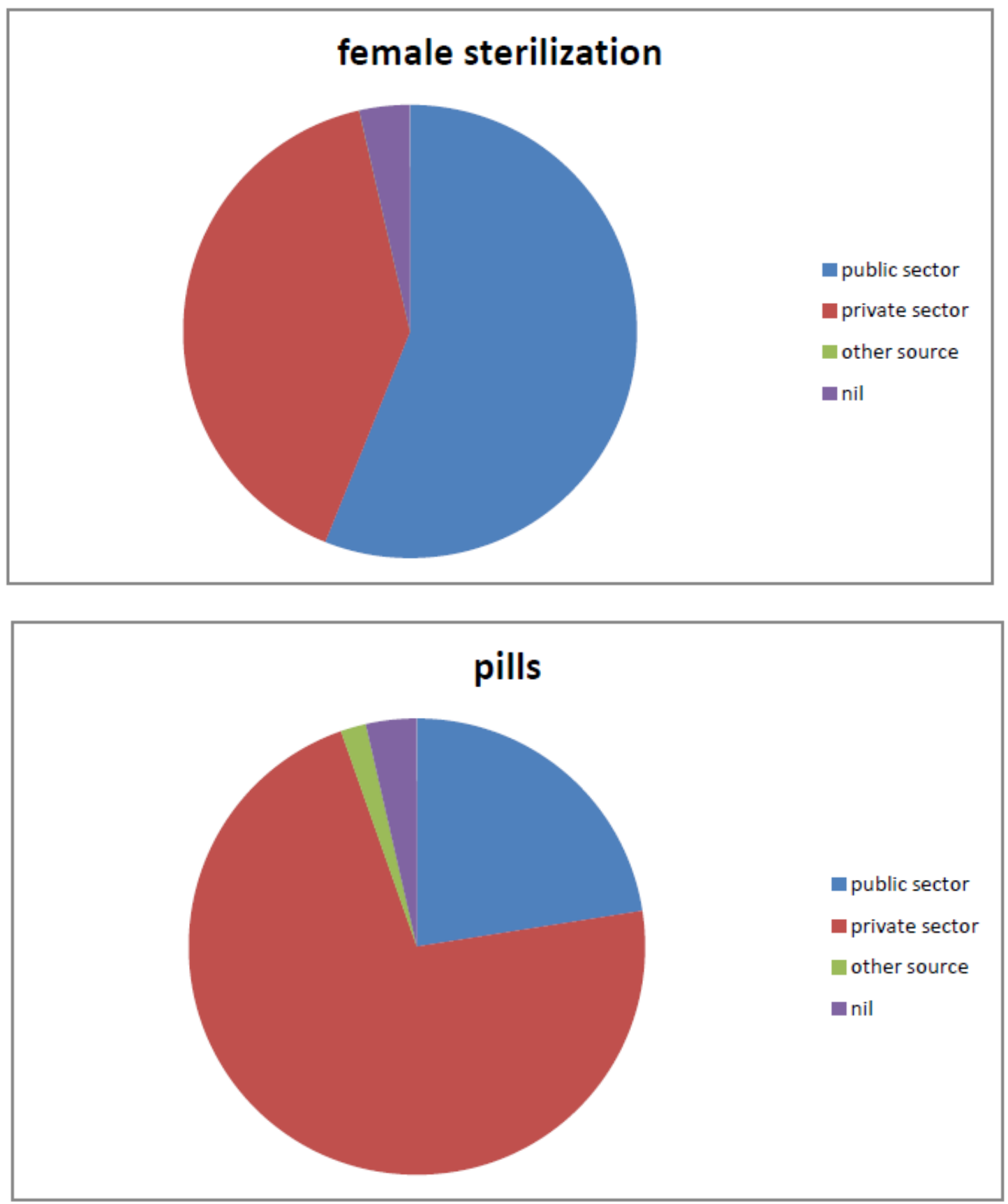


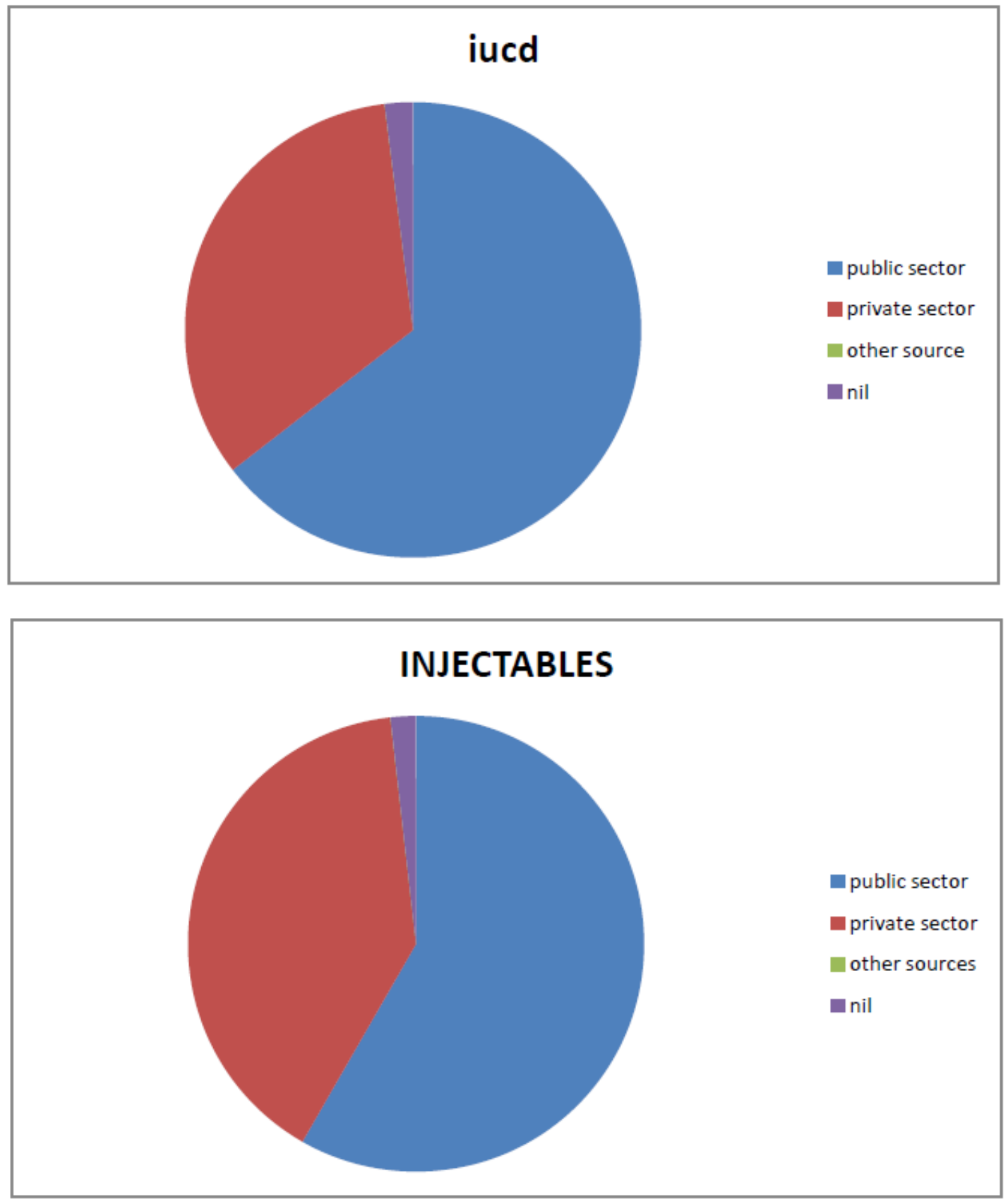



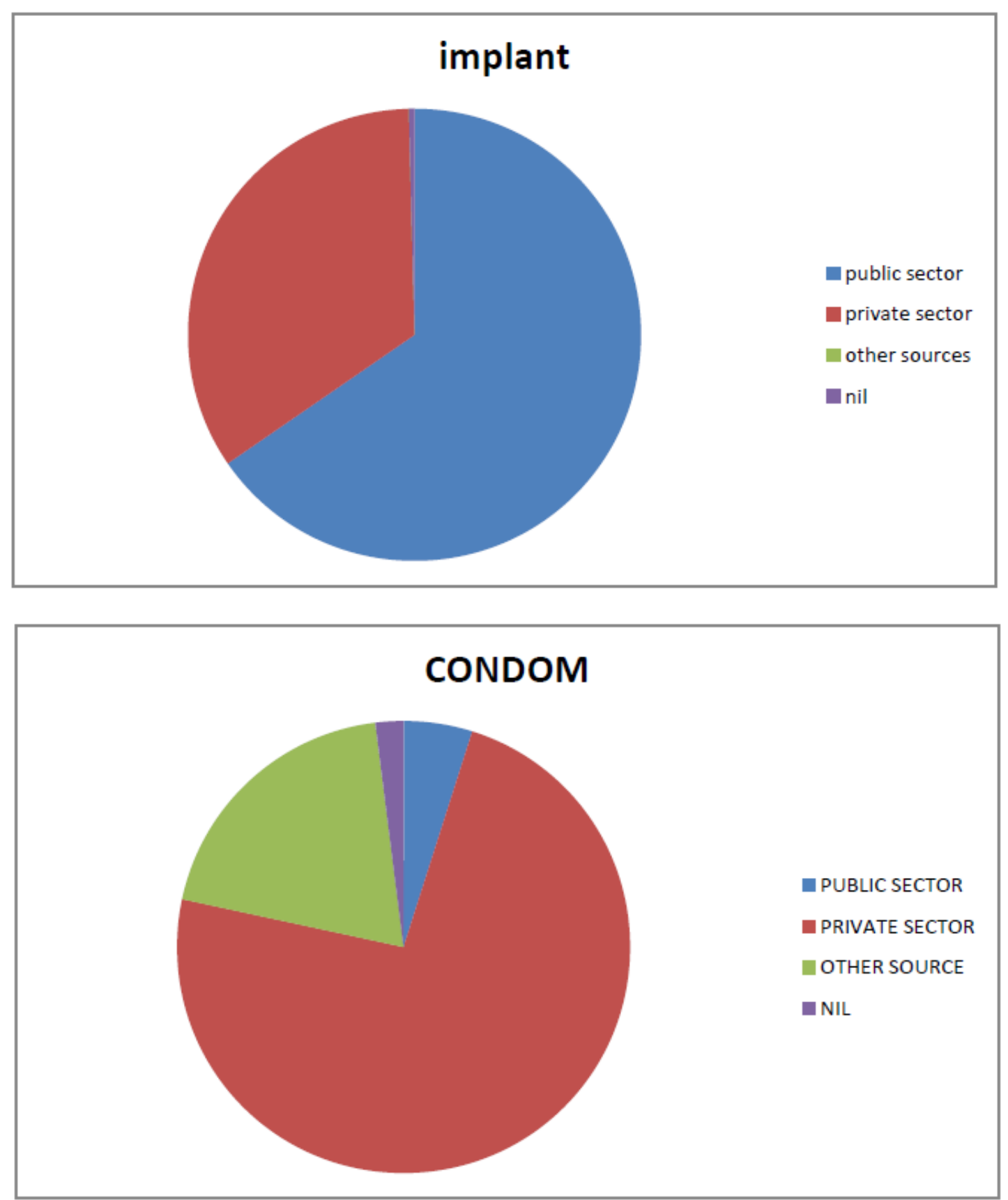

Table 4.0. Need and demand for family planning in females aged 15-19 years

\begin{tabular}{|l|l|l|l|}
\hline & FOR SPACING & FOR LIMITING & TOTAL \\
\hline MET NEED & 6.1 & 0.1 & 6.2 \\
\hline UNMET NEED & 6.2 & 0.0 & 6.2 \\
\hline TOTAL DEMAND & 12.3 & 0.1 & 12.4 \\
\hline
\end{tabular}


Texila International Journal of Public Health

Volume 4, Issue 4, Dec 2016

Table 5.0. Contact of Non-Users with Family Planning Responders Out Of 7340 Adolescents

\begin{tabular}{|l|l|l|l|}
\hline FIELD WORKER VISITED & VISITED HEALTH & & \multirow{2}{*}{ NEITHER } \\
AND DISCUSSED FP & $\begin{array}{l}\text { FACILITY IN PAST } \\
12 \text { MONTHS }\end{array}$ & & \\
& DISCUSSED FP & $\begin{array}{l}\text { DID NOT } \\
\text { DISCUSS } \\
\text { FP }\end{array}$ & \\
\cline { 2 - 4 } & $1.6 \%$ & $8.2 \%$ & $96.9 \%$ \\
\hline $2.2 \%$ & & FP & \\
\hline
\end{tabular}

Table 6.0 shows descriptive statistics for selected indicator variables in the logistic regression models Nigeria Demographic and Health survey for females only.

Table 7.0 shows effects of selected explanatory variables on the odds of an adolescent being currently pregnant (Model 1); having borne a child in the five years preceding the survey (model 2) and either of the two models (model 3).

Table 6.0

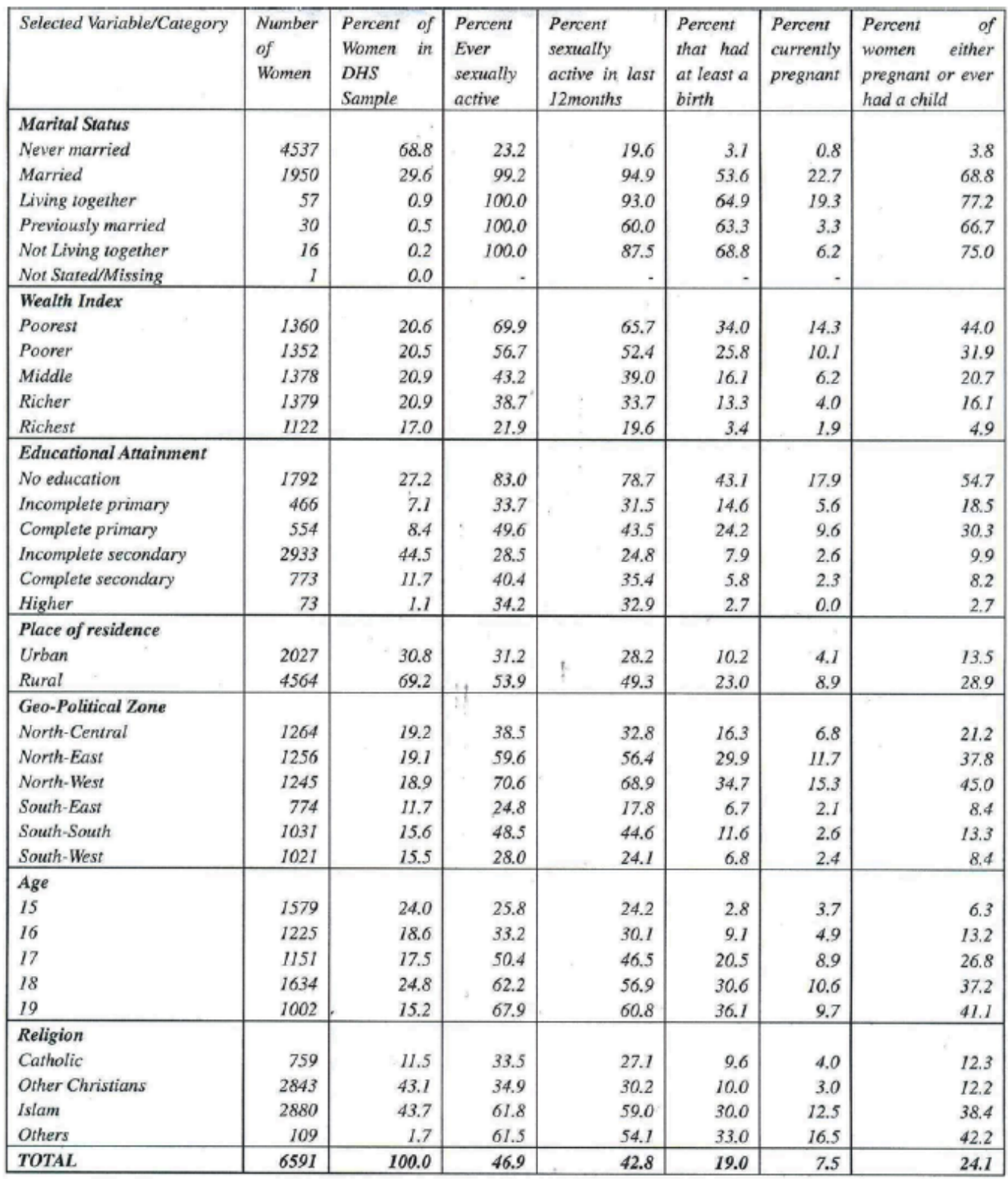


Texila International Journal of Public Health

Volume 4, Issue 4, Dec 2016

\section{Discussion}

The above tables and charts are in support of presence of met needs of contraception among adolescents. It shows there is a huge lack of knowledge of contraception, the private sector plays and still has a great role to play in bridging the gap of unmet needs of contraception and this role cannot be undermined. Most adolescents interviewed needed contraception for spacing number of children than for limiting - most adolescent pregnancies take place within the context of marriage in developing countries and is worse among people of low socioeconomic class. $30 \%$ of every adolescent is currently married in Nigeria, $19.6 \%$ of those who have never been married have been sexually active. Two thirds of those cohabiting, previously married and those not living together are currently pregnant or had borne a child. Those who are not married or previously married are less, significantly so, to be currently pregnant relative to those in marital unions. These show that adolescent marriage is still a threat to the future of our generation. Thus, investing into meeting the contraceptive needs of the adolescent population is a move in the right direction. International data over 27 years show that as each additional contraceptive method became available to most of the population, overall modern contraceptive use rose. But in 2009 only 3.5 methods, on average, were available to at least half the population in surveyed countries.

\section{Conclusion and recommendations}

Adolescents have unmet family planning needs. Enough has not been done to reduce this burden especially in rural areas and among those of low socio-economic status. Based on the complications arising from failure to meet the adolescent needs of contraceptives, it is recommended that efforts should be intensified to promote safe sexual practice and contraceptive use in this age group. Five key empowerment dimensions that need to be tackled if adolescents' contraceptive needs are to be given the strategic, multi-pronged policy attention that they merit are: socio cultural, educational, interpersonal relationships, girl child rights and empowerment with practical knowledge. Emphasis is on girls here because they bear the most brunt of problems of unsafe sex.

1. Family planning programs should strive to provide widespread access to a range of methods.

2. It is not the government's duty alone to meet the contraceptive need of the populace; there must be partnership with other stake holders.

3. Policies in support of adolescent contraception need must be encouraged and passed into law.

4. Different channels

5. Adolescent friendly centres should be open in all areas and made accessible to all so adolescents can feel free to walk into anyone at anytime and receive proper counselling.

6. Training and retraining of all family planning workers.

7. Confidentialty of the adolescents who seek to have family planning must not be breached.

8. Parents need to be educated that this transitional stage in the life of a child is very important. Thus, they must give their full support to their wards so they can turn out successful. They are the first contacts of these adolescents and they need to pass the message of sex education across well without being judgmental.

9. Education is key to making informed choices, every child must be educated.

10. Socioeconomic discrepancies should become negligible if meaningful strides are to be recorded nationwide.

\section{Acknowledgement}

I want to acknowledge the Almighty God without whom I am nothing. He gave the grace, ability and also made provision for me to be a part of this class of Master of Public health. I thank my husband for his unflinching support through the program and up till now. To my wonderful children, I say thank you for allowing me get a 
second degree. To my mother, I say you are the best. Thanks for always giving up your comfort for we, your children. To all my siblings and friends, you are appreciated. To all my teachers, thank you. To all my student coordinators, thank you for making life easy for me.

\section{References}

[1]. Australas Med J. 2011; 4(1): 43-48. Published online 2011 Jan 31. doi: 10.4066/AMJ.2011.499

[2]. Attitude of Parents and Adolescents Towards Contraceptive Use by Adolescents in Alajo, Ayawaso Central Submetro of Accra Maya, E.T. --hdl.handle.net/123456789/5150www.prb.org/Publications/Articles/2013/adolescent-fertility.aspx

www.who.int/maternal_child_adolescent/topics/maternal/adolescent_pregnancy/en/

[3]. Social Dynamics of Adolescent Fertility in Sub-Saharan Africa (1993)www.nap.edu/catalog/2220/social-dynamics-of-adolescent-fertility-in-sub-saharan-africa

[4]. Panday, et al., 2009, UNICEF, 2005

[5]. Marcen and Bellido, 2013;www.iiste.org/Journals/index.php/JEDS/article/viewFile/10699/10904

[6]. Sonfield, et al, 2013; www.iiste.org/Journals/index.php/JEDS/article/viewFile/10699/10904

[7]. Barcena, 2013; www.iiste.org/Journals/index.php/JEDS/article/viewFile/10699/10904

[8]. Chau-Kuang, 2013; www.iiste.org/Journals/index.php/JEDS/article/viewFile/10699/10904

[9]. National Population Commission and ICF

Macro2009;www.iiste.org/Journals/index.php/JEDS/article/viewFile/10699/1090

[10]. www.guttmacher.org/about/journals/ipsrh/2009/patterns-and-trends-adolescents-contraceptiveuse-and-discontinuation

[11]. Mundo, F. D. (2012) Primary Maternal and Neonatal Health: A Global Concern. Chicago: Springer Science \& Media Centre

[12]. who.int/mediacentre/factsheets/fs351/en/

[13]. Contraception and Adolescents; Revised. 104(5):1161PediatricsNovember 2007, VOLUME 120/ISSUE 5

[14]. Carroll, J. (2015) Sexuality Now: Embracing Diversity. Boston: Cengage Learning

[15]. Callahan, T., Caughey, A. B. (2013) Blueprints Obstetrics and Gynecology. Baltimore: Lippincott Williams \& Wilkins.

[16]. www.prb.org/Publications/Articles/2009/westafricayouth.aspx

[17]. Amanuel Alemu Abajobir and Assefa Seme; BMC Health Services Research201414:138; DOI: 10.1186/1472-6963-14-138

[18]. The Pan African Medical Journal. 2016;23:74. doi:10.11604/pamj.2016.23.74.8688

[19]. Use of contraceptives among adolescents in Kintampo, Ghana: a cross-sectional study by Boamah EA, Asante KP, Mahama E, Manu G, Ayipah EK, Adeniji E, Owusu-Agyei S; DOI https://dx.doi.org/10.2147/OAJC.S56485

[20]. Contraception and Adolescents; Revised. 104(5):1161PediatricsNovember 2007, VOLUME 120/ISSUE 5

[21]. Amanuel Alemu Abajobir and Assefa Seme; BMC Health Services Research201414:138; DOI: 10.1186/1472-6963-14-138

[22]. Use of contraceptives among adolescents in Kintampo, Ghana: a cross-sectional study by Boamah EA, Asante KP, Mahama E, Manu G, Ayipah EK, Adeniji E, Owusu-Agyei S; DOI https://dx.doi.org/10.2147/OAJC.S56485

[23]. www.odi.org/projects/2596-barriers-contraceptive-use

[24]. Contraceptive knowledge and practice among senior secondary schools students in military barracks in Nigeria UC Chimah, TO Lawoyin, AL Ilika, CC Nnebue

[25]. www.ghspjournal.org/content/1/2/203.full 


\title{
Risk Factors for Teenage Pregnancy and Youth Health Needs in Nkalashane, Swaziland
}

\author{
Article by Busisiwe Prudence Tsabedze \\ M.Sc Clinical Psychology, Texila American University, Swaziland \\ E-mail: busiedonsie@yahoo.com
}

\begin{abstract}
Teenage pregnancy is an enormous challenge in Swaziland. The Nkalashane clinic (Lubombo region) observed a growing number of teenage pregnancies. In 2014 alone, $49 \%$ of pregnancies were among women who had their first child before their 19th birthday. The objective of this study was to investigate risk factors of teenage pregnancy among teenage mothers (TM), teenage fathers (TF), and services needed by the at-risk youth (ARY) to prevent teenage pregnancy. Participants were identified from the clinic's registers, snowball sampling, and the 3 schools in the area. Participants completed questionnaires and focus group discussions (FGDs). Data was summarized using descriptive statistics. 43 TM, 8 TF and 73 ARY participated. TM had a family history of teenage pregnancy (42\%), had guardians with only a primary education (63\%), and had older partners (mean age difference 5.2 years). Only 44\% of TM and 38\% of TF reported using contraception at the time of first pregnancy. Reasons for not using contraception included: lack of knowledge on pregnancy (47\%) and contraception (38\%). TM reported engaging in transactional sex due to peer pressure or lack of money. In FGDs, lack of knowledge, peer pressure, difficult access to contraception, and lack of parental guidance were discussed as risk factors. The main risk factors were: lack of knowledge; peer pressure; intergenerational sex; and difficult access to contraceptives. Recommendations include: offering comprehensive sexual education to both youth and adults; strengthening the relationship between schools, communities, and clinics; training clinic staff on youth-friendly services.
\end{abstract}

\section{Introduction}

Teenage pregnancy is a global public health concern. According to the World Health Organization (WHO), 16 million women aged 15-19 give birth each year (WHO, 2014). Ninety-five per cent of these births occur in low- and middle-income countries (WHO, 2014). Although teenage pregnancies account for $11 \%$ of all births worldwide, they account for $23 \%$ of the overall burden of disease due to pregnancy and childbirth (WHO, 2014). Therefore, teenage pregnancy remains a major contributing factor to maternal and child mortality. Teenage pregnancy is also associated with many negative outcomes, including anaemia, HIV and other sexually transmitted infections, postpartum haemorrhage and mental disorders, such as depression. Teenage pregnancy is also linked to other social factors at different levels including individual, environmental, peer and culture factors that have been shown in previous studies to influence adolescent behaviour (Goucelea W. O., 2009).

Swaziland, like many lower-middle income countries, is faced with the enormous challenge of teenage pregnancy. Overall, more than one in five women reported to have had their first live birth before their eighteenth birthday (MICS, Government of Swaziland, 2010).

Many factors contribute to this phenomenon of teenage pregnancy in Swaziland. For example, the Multiple Indicator Cluster Survey (MICS; Government of Swaziland, 2010) found that $35 \%$ of women with only primary education had a live birth by the age of 18 compared with $4 \%$ of women with tertiary education. Early childbearing was also found to be associated with level of wealth in Swaziland, with teenage pregnancy being more common among women in the poorest quintile (MICS, Government of Swaziland, 2010). The young age structure of the country (approximately $60 \%$ of the population is under the age of 30 
years (DHS, Central Statistical Office, 2007)), and the HIV/AIDS epidemic has likely worsened the situation.

Data from the facility shows the following an alarming number of women young who are multi para, having had their first pregnancy when they were teenagers (26\% in 2014 Table A ; and the number of women who attended antenatal care that were less than 19 years $(18 \%$ in 2013 in 2014, resulting in 49\% of pregnancies in 2014 that were teenage pregnancies.

\begin{tabular}{|l|l|l|l|l|}
\hline $\begin{array}{l}\text { Table A: Teenage } \\
\text { pregnancies at } \\
\text { Nkalashane Clinic } \\
\text { between 20111 and 2014 }\end{array}$ & 2011 N (\%) & 2012 N(\%) & 2013 N (\%) & 2014 N (\%) \\
\hline $\begin{array}{l}\text { Totalpregnant women all } \\
\text { ages }\end{array}$ & 83 & 90 & 88 & 91 \\
\hline Pregnant women 19 years & $13(16 \%)$ & $12(13 \%)$ & $16(18 \%)$ & $21(23 \%)$ \\
\hline $\begin{array}{l}\text { Pregnant women 23 years } \\
\text { of age with 2 or more } \\
\text { pregnancies }\end{array}$ & $17(20 \%)$ & $27(20 \%)$ & $21(24 \%$ & $24(26 \%)$ \\
\hline $\begin{array}{l}\text { Total number of teenage } \\
\text { pregnancies }\end{array}$ & $30(36 \%)$ & $39(43 \%)$ & $37(42 \%$ & $45(49 \%)$ \\
\hline
\end{tabular}

The aim of the study was to explore and describe teenagers and teenage mothers' and fathers' perceptions on factors and risks contributing to teenage pregnancy among the youth in Nkalashane, Swaziland. The objectives were to determine the risk factors contributing to teenage pregnancy among the youth in Nkalashane and to gather information on how best to increase positive links between and among youth, teenage pregnancy prevention programs, and community-based clinical services.

\section{Methods}

This study was divided in three parts, a descriptive retrospective study to understand the risk factors of teenage pregnancy, a descriptive cross-sectional study to understand the services that are needed by the at-risk youth in Nkalashane to prevent teenage pregnancy and descriptive cross-sectional study to understand the challenges faced by the facility staff to prevent teenage pregnancy.

Part 1: A descriptive retrospective study to understand the risk factors of teenage pregnancy

\section{Inclusion criteria}

Teenage mothers: a woman who fell pregnant for the first time before the age of 19;

Teenage fathers: a man who impregnated a partner before the age of 19.

Sampling method: Teenage mothers were identified using clinic registers from 2013-2015 (ANC and PNC/Family Planning). Once identified, the client was called by the head nurse of Nkalashane Clinic. In addition, snowball sampling was used to reach other teenage mothers that might not have visited the facility during ANC. Teenage fathers were also sampled using snowball sampling method.

Data collection: The data collection took place in May 2015, over the course of 4 days. Teenage mothers were asked to come to the Nkalashane Clinic to participate in the study, while the teenage fathers were either interviewed at the Nkalashane Clinic or a place of convenience. Four trained peer educators obtained consent from participants, and facilitated the structured questionnaires. The questionnaires took approximately 50 minutes to complete. Participants were then asked to participate in a focus group discussion (FGD). Each FGD was conducted by two trained peer educators, and had an average of 10 participants. The duration of each FGD was approximately 45 minutes, and all FGDs were recorded using a tape recorder. FDGs were conducted in siSwati, the language of general communication in Swaziland. 
Part 2: A descriptive cross-sectional study to understand the services that are needed by the at-risk youth in Nkalashane to prevent teenage pregnancy.

Inclusion criteria: At-risk youth: someone between the ages of 12-19 years that has not yet fallen pregnant/impregnated someone. Participants had to be enrolled in one of the three targeted schools.

Sampling method: Participants were selected from three schools of the area: Nkalashane Primary School, Nkalashane High School, and Mbokojweni Secondary School. These schools were selected as a result of their proximity to the Nkalashane Clinic, and represented each school level. 26 participants (15 females and 11 males) were randomly selected from each school by the study team using class lists. Selected participants received an invitation letter and a consent form to retrieve their consent as well as their parent's consent.

Data collection: At each school, participants were divided into two groups: at-risk girls, and at-risk boys. Peer educators facilitated the questionnaires and FGDs, following the same methodology as Part 1 of the study.

Part 3: Descriptive cross-sectional study to understand the challenges faced by the facility staff to prevent teenage pregnancy.

Inclusion criteria: Nurses, orderlies, community workers and expert clients that were employed at Nkalashane Clinic at the time of the study.

Sampling method: Each staff member was asked by the study team whether they would like to be enrolled in the study.

Data collection: After retrieving their consent, each staff member answered the questionnaire. Due to small sample size, no FGD was conducted among the facility staff.

\section{Sample size}

The sample size of each group was determined using published information, taken from the Swaziland Demographic and Health Survey (Central Statistical Office, 2007), regarding the proportion of youth's knowledge regarding sexuality and safe sex. More specifically, the information used was: (1) Teenage mothers: the proportion of women aged 15-19 who were not exposed to any information source for family planning. (2) Teenage fathers: the proportion of men aged 15-19 who believe that contraception is a women's business. (3) Atrisk youth: the proportion of youth who ever had sex before 19 years old, by sex. Based on the sample size calculation and the throughput of the clinic, the study aimed at enrolling 40 teenage mothers, 25 teenage fathers, and 26 at-risk youth from each school (15 females and 11 males).

\section{Study definitions and instruments}

The questionnaires for teenage mothers/fathers and at-risk youth contained approximately 50 questions on respondent demographics (age, parents education level, family history of teenage pregnancy, etc.), emotional status (emotional support, depression, etc.), sexual behaviour and contraception (age of sexual debut, method of contraception used, etc.), safe sex knowledge (origin of information, knowledge score, methods of contraception known, etc.), healthy relations (dating older partner, peer pressure, etc.) and knowledge of services available at health facilities. At-risk youth were also asked their opinion about teenage pregnancy and its causes. The facility staff questionnaire had 15 questions which encompassed: socio-demographic characteristics, services provision (HIV testing and counselling, family planning services provision to teenagers), opinions on abortion and emergency contraception, and opinions about teenage pregnancy and youth-friendly services.

Family history of teenage pregnancy was defined as having your mother falling pregnant for the first time before the age of 19 years. Peer pressure was defined as feeling pressure from friends to do things that you do not want to. The depression score was calculated using the depression subscale of the EST-Q screening questionnaire (Aluoja et al. 1999). The Depression subscale consists of eight items encompassing cognitive and affective symptoms of depression, and each item is rated on a five-point scale ranging from 0 to 4 ( $0=$ not at all; 4 
$=$ all the time). The cut-off point for depression was a score $>11$, as previously defined by the literature (Ööpika et al. 2006, Liik, et al. 2013).

The knowledge on contraception score was calculated using 11 knowledge questions. The participants had to answer whether they think the statements were true or false and each answer was rated either 1 (correct answer) or 0 (wrong answer).

\section{Data analysis}

Questionnaires: Data entry was conducted using Microsoft Access 2007 (Microsoft Corporation, Redmond WA). The questionnaires were analysed using STATA version 12 (StataCorp, College Station TX). Categorical variables were summarized using frequency distributions, and continuous variables were summarized using descriptive statistics.

Focus groups discussions: FDGs were transcribed verbatim, and translated from siSwati into English. After three study team members read through the 11 transcripts several times, a coding schema was decided on by the study team. The coding schema followed the main themes of the study protocol: the risks factors of teenage pregnancy, the perception and knowledge of contraception and safe sex, and the recommendations for better youth-friendly services and to prevent teenage pregnancy. The FGDs were then thematically analysed using a rapid analysis method. ATLAS ti 7.5 (Scientific Software Development GmbH, Berlin) was used to support and verify themes and relationships between themes.

\section{Ethical considerations}

The study received ethical approval from the Swaziland Ministry of Health (MOH) Scientific and Ethics Committee. For each person who was contacted, the purpose of the research was explained and their voluntary participation was sought. All participants were assured that their name will not be recorded, and told that there will be no benefits or penalties for refusing or agreeing to participate in the study. Participants less than 18 years old that are pregnant or already a parent were considered as emancipated minor or mature adult, thus no written consent was required from the parents/guardians. The community and the schools involved were sensitised to the study prior to the data collection. The researchers contacted the Lomahasha Inkhundla as well as the Director of Education and Training and the Regional Education Officer from the Ministry of Education and Training (MOET) to retrieve their approval.

In terms of cultural sensitivity, the questionnaires and consent form were translated from English to siSwati by the study team, and were reviewed by the senior nurse of Nkalashane Clinic and the peer educators in order to ensure culturally sensitive wording while holding true to the questionnaire intent. The peer educators were trained to verbally administer the questionnaire in English and siSwati, two languages in which they are all fluent

\section{Results}

\section{Part 1: Descriptive retrospective study to understand the risk factors of teenage pregnancy}

\section{Quantitative findings: questionnaires among teenage mothers}

A total of 47 teenage mothers and 9 teenage fathers were enrolled in the study. However, 4 teenage mothers and 1 teenage father were excluded because they did not meet the inclusion criteria (they either had their first child after the age of 19, or did not report the age at which they had their first child). Table 1.1 presents the socio-demographic characteristics of the participants. Of the 43 teenage mothers, $42 \%$ had a family history of teenage pregnancy (i.e. their mother was $<19$ when having her first child), and the majority of teenage mothers' guardians either had no schooling, or only attended primary school. 


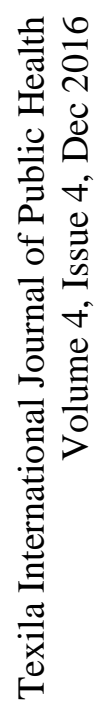

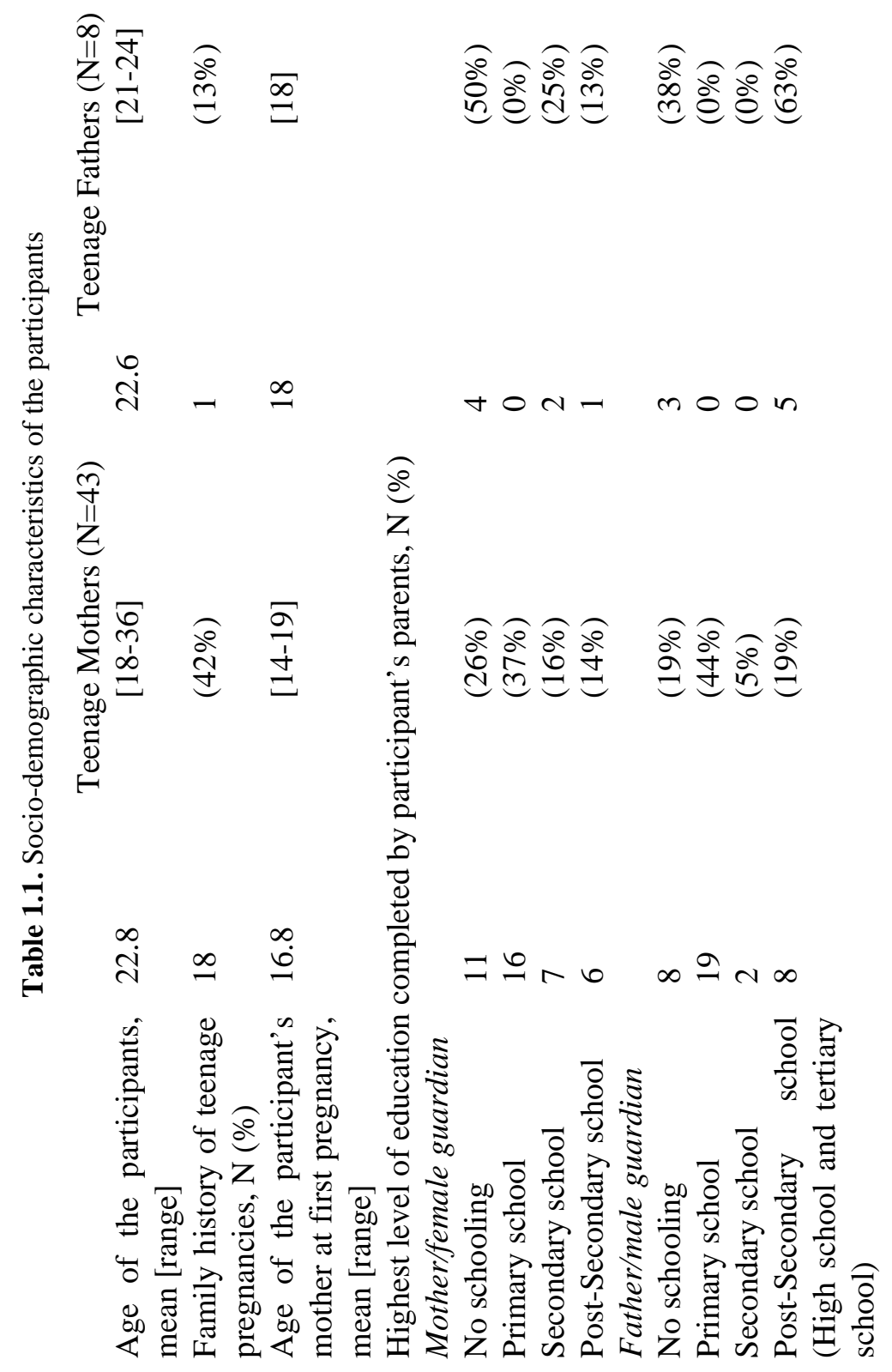


Texila International Journal of Public Health

Volume 4, Issue 4, Dec 2016

On average, the teenage mothers had their first child at the age of 17.6 years, while the teenage fathers had their first child at 18.5 years. The majority of participants were in school at the time of the first pregnancy $(63 \%$ of the teenage mothers and $88 \%$ of the teenage fathers); however, while $57 \%$ of the teenage fathers went back to school after the first pregnancy, most of the teenage mothers (81\%) dropped out of school. All the teenage mothers were dating older partners (the average age difference between the participant and the partner being 5.2 years [range $=1-14]$ ) with high levels of education ( $44 \%$ with post-secondary). 
贾
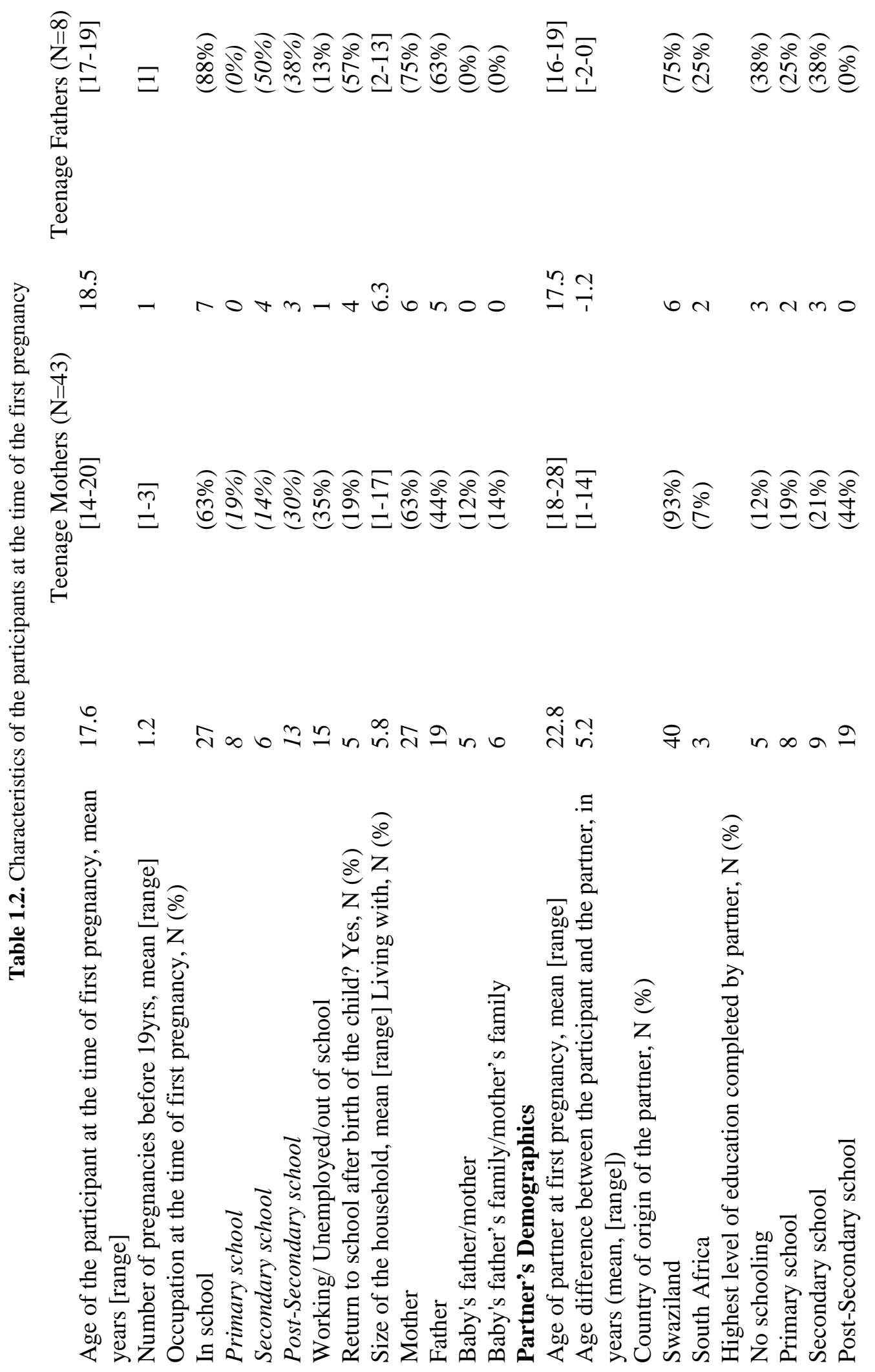
Texila International Journal of Public Health

Volume 4, Issue 4, Dec 2016

\section{Sexual behaviour and contraception use}

The average age of sexual debut was 16 years, for both teenage mothers and teenage fathers. However, $63 \%$ of the teenage fathers started having sex because they felt ready compared to only $30 \%$ of the teenage mothers. In terms of contraception use at the time of first pregnancy, only $44 \%$ of the mothers and $38 \%$ of the fathers reported using contraception, mainly condoms. According to the teenage mothers, the main reason why they got pregnant despite using contraception was because the condom broke. The table also shows the most frequently reported reasons for not using contraception; with the two most frequently reported reasons “I didn't think I could get pregnant" (58\%), "I did not know about contraception" (38\%). The teenage mothers further reported that they did not want to get pregnant (47\%) or did not know about pregnancy (35\%). On the other hand, 30\% reported that their partner wanted them to get pregnant.

Participant's knowledge about safe sex at the time of first pregnancy

$42 \%$ of the teenage mothers and $38 \%$ of the teenage fathers reported that they were not at all knowledgeable about sexuality, contraception and safe sex. The main sources of information about sexuality and contraception were health care workers (HCWs) and teachers. The participants were asked to cite all the contraception methods they knew about, and $51 \%$ of the teenage mothers and $50 \%$ of the teenage fathers were able to cite at least one correct method of contraception. On the other hand, $14 \%$ of the teenage mothers and $25 \%$ of the teenage fathers cited at least one ineffective method of contraception, mainly withdrawal. On average, the teenage mothers and fathers had high knowledge on contraception scores; however, there are still misunderstandings around safe sex. For instance, 23\% of the teenage mothers and $25 \%$ of the teenage fathers thought that "to be extra safe, it is good to use two condoms at once".

Support system, healthy behaviour and relation at the time of first pregnancy

Most teenage mothers reported strong family and friend networks at the time of first pregnancy (59\%) and did not experience peer pressure (52\%). However, teenage mothers had a high emotional state score (15.2), and 77\% were screened depressive by the EST-Q1 (i.e. emotional state score $>11$ ). None of the participants reported smoking or taking drugs at the time of the first pregnancy, however $77 \%$ of the teenage fathers and $13 \%$ of the teenage mothers reported drinking. Among teenage mothers, 64\% reported that they were dating someone 5 years older at the time of the first pregnancy, and they were also relying on the baby's father $(56 \%)$ or his family (16\%) for financial support, while most of the teenage fathers had no external source of financial support (63\%). Even though $60 \%$ of the teenage mothers reported that both they and their partner were responsible in preventing pregnancy, $71 \%$ reported that their partners had more control than them in important decisions that affected their relationship.

\section{Qualitative findings: focus group discussions among teenage mothers}

Five FGDs among teenage mothers were conducted, however due to small sample size no teenage fathers participated in a FGD.

Risks factors of teenage pregnancy

\section{Lack of knowledge on contraception and relationships}

The participants highlighted that one of the main factors related to teenage pregnancy was the lack of knowledge. Teenage mothers were lacking information on safe sex and contraception at the time of first pregnancy. For instance, even if teenage mothers were familiar with condoms, only a few had heard of injections, birth control pills, IUD, or implants. Many adolescent girls and young women entered into relationships without understanding their own rights as individuals, what may be expected of them by their partners, and how to communicate and negotiate for their own safety and protection.

"We are hiding the truth from the children. We didn't tell them that they will fall pregnant if they have sex". 
"You find that the child grows up and get a boyfriend without having proper information and then they fall pregnant."

"Some people tend to think they know more when in actual fact they don't know anything."

"In most cases the young girls don't know the meaning of being in a relationship and the only thing that will happen is that they will have sex as a definition for being in that relationship. The next thing obviously is pregnancy".

\section{Peer pressure}

The FGDs strongly highlighted that peer pressure was a risk factor of teenage pregnancy. Peers often persuaded the participants to engage in sex with older people so that they could get money, phones or other material things in exchange. Furthermore some respondents reported engaging in relationships in order to fit-in a group and not to feel as if they were missing out.

"Young people will tell each other that they have money because they are in a relationship with a certain older man and would suggest to the friend to do the same if they wanted money as well.”

\section{Lack of parental interaction}

Lack of parental guidance and support was reported as contributing to teenage pregnancy. In addition some teenage mothers reported that they were left with their grandparents who failed to advise them properly about sexuality. Being needy (financially or emotionally) or having lost your parents also seemed to have played a role in how vulnerable the teenagers were to peer pressure. It also was communicated that some parents did not execute disciplinary measures when their teenagers came home at night or with gifts.

\section{Intergenerational and transactional sex}

It emerged that teenage mothers found themselves pregnant because they often engaged in relationships with older men. Intergenerational or transactional sex was often caused by peer pressure and wanting to get money and other material things. The study pointed out that usually older men do not want to use condoms, and the teenage girls found themselves with no negotiation power. The teenage mothers further indicated that older partners had more control in the relationship and sometimes forced them to do things against their will. Teenage mothers often asserted that accepting financial or material assistance from a man meant accepting sex on his terms, which very often means sex without condoms.

"Now if it happens that you agree on something, sugar-daddies don't want to use a condom".

Poverty and orphanage were often cited as significant contributors to teenage pregnancies. Many female participants were from families that struggled to keep them in schools or provide them with all their needs. Some girls had lost both their parents and were left with no one to support them. Thus, some girls engaged in transactional sex in order to sustain their lives.

\section{Access to contraceptives}

The participants highlighted that it was difficult for teenagers to access contraceptives. Teenage mothers reported negative attitudes towards them from HCWs and shop keepers when they inquired about contraception. They also reported fear and shame when accessing condoms, since they are usually at the front desk where everyone is looking or handed over by an adult at the clinic or at shops. Furthermore, some reported being denied condoms at the shops.

\section{Perception of contraception}

Many teenagers have misconceptions and negative feelings towards modern contraception. In addition, teenage mothers reported that modern contraception (pill, IUD, injection etc.) 
may results in many adverse outcomes such as infertility, or even cancer. Others highlighted misconceptions about who can utilize contraception and when it can be used.

\section{Reflection on teenage pregnancy}

The teenage mothers stressed that teenage pregnancy resulted in many negative outcomes. For instance, many teenage mothers had to drop out of school to take care of their child. A respondent further highlighted that the first pregnancy is often followed by another, since the teenage mother is out of school and has no other future plans than to build a family.

Suggestions to prevent teenage pregnancy and provide youth-friendly services at the clinic

\section{Education on safe sex}

Most of the teenage mothers suggested educating teenagers on safe sex and contraception as a way to tackle teenage pregnancy. Teenage mothers urged the parents not to hide the truth and speak openly about these issues. They also mentioned health care workers and teachers as sources of reliable information. The teenage mothers suggested that sexual education should take place in communities, schools and clinics. Sensitizing rural health motivators (RHMs) around the issue of teenage pregnancy was also highlighted has a good way to reach the entire community.

\section{Promote abstinence}

Preservation of virginity or abstinence was promoted by most participants, but its benefits were not well understood. It seems that abstinence is associated with making a partner happy in the future, spiritual fulfilment and societal norms, values and obligations. Awarding girls who preserve their virginity could help promote abstinence and encourage others to abstain.

\section{Encourage youth-friendly clinics}

The respondents suggested that in order to prevent teenage pregnancy and provide youthfriendly services, nurses should be encouraged to interact with teenagers in a friendly manner. The teenage mothers rated the services from Nkalashane Clinic as friendly; however, this was not the case for other clinics in the area. Nurses were also urged to provide contraception services without judging the teenagers as well as respecting the patient's right to privacy by keeping the information and service confidential.

\section{Quantitative findings: questionnaires among at-risk youth}

The average age of participants was 16 years in each school. Most participants reported having a strong family and friend network, and had a low emotional state score (6.5 for the girls and 7.9 for the boys), and $17 \%$ of the girls and 19\% of the boys were screened depressive by the EST-Q1 (i.e. emotional state score $>11$ ).

In terms of the knowledge of the participant on sexuality and contraception, most of the participants reported being "somewhat knowledgeable" (76\% among girls, 69\% among boys; Table 2.1). Both at-risk girls and boys reported learning about sexuality from their parents (51\% and 38\%, respectively) or a teacher at school (54\% and $47 \%$, respectively). At-risk girls and boys further reported feeling comfortable turning to their parents (44\% and $31 \%$, respectively) or a HCW ( $46 \%$ and $28 \%$, respectively) for information about contraception and safe sex.

In terms of knowledge on safe sex and contraception, most of the high school (83\%) and secondary school (77\%) students self-reported as "somewhat knowledgeable", $42 \%$ of the primary school students self-reported as "not at all knowledgeable". The average score of the participants on sexual knowledge was 8 out of 11 . However this study highlighted that there is still confusion around safe sex and contraception. For instance, $41 \%$ of the at-risk girls and $38 \%$ of the at-risk boys thought that modern contraception (condoms, pills, etc.) can make you infertile. In addition, $27 \%$ of the at-risk girls and 38\% of the at-risk boys thought that birth control pills, injectable or IUDs can help prevent sexually transmitted infections (STIs), including HIV/AIDS. Despite having the same average age, the primary school students 
average sexuality knowledge score was lower (7.3), compared to secondary (8.6) and high school (9.5) students. The primary school students were even more confused about the safe sex and contraception issues than the secondary and high school students. For instance, $75 \%$ of the primary school students believed that drinking water after having unprotected sex prevents unwanted pregnancies, and 54\% thought that, to be extra safe, it is better to use two condoms at once.

The participants were asked to cite all the contraception methods they know, and $78 \%$ of the at-risk girls and $69 \%$ of the at-risk boys were able to cite at least one correct method of contraception, mainly condoms (97\% of the girls, $100 \%$ of the boys) and pills ( $72 \%$ of the girls, $50 \%$ of the boys). On the other hand, $39 \%$ of the at-risk girls and $28 \%$ of the at-risk boys cited at least one ineffective method of contraception. Seven respondents mentioned withdrawal, six mentioned HIV prevention methods (such as "do not share needles" or "circumcise”), four mentioned social behaviours (such as "as a girl not going out at night") and two respondents mentioned "safety period" as a method of contraception. In addition, only $50 \%$ of the primary school students were able to cite at least one correct method of contraception.

\section{Challenges faced by the facility staff to prevent teenage pregnancy}

Seven of the 9 facility staff at the Nkalashane Clinic were enrolled in the study. The two staff members that were not enrolled were the principal investigator and a nurse that was unavailable at the time of the study. As shown in Table 3.1, the majority of the facility staff is female (71\%), aged between 28-48 years and had children (86\%). Of those who were parents, many had provided information about safe sex to their children (83\%), with the average age that their children first received such information being 11.8 years [10-13].

Most of the facility staff (71\%) was comfortable providing contraceptives for adolescents. However, they were more likely to provide counselling and education to 12 year old clients compared to a 16 year old.

Some workers were not comfortable providing contraceptives to teenagers in general (29\%), and many were against providing emergency contraception (71\%), and against abortion (86\%).

\section{Discussion}

\section{Risk factors for teenage pregnancy}

\section{Socio-demographics}

Family characteristics are important in determining risk for teenage pregnancy. The majority of the parents (mothers and fathers, 63\%) of teenage mothers were either uneducated or only completed primary school. Low education levels of the parents may influence teen pregnancy considering that $19 \%$ of teenage mothers and $25 \%$ of teenage fathers received information from their parents on sexuality, contraception and safe sex. In addition, the literature highlights that teenagers whose parents are more educated are less likely to become pregnant (Kirby et al. 2007). Moreover, a large proportion of teenage mothers (42\%) had a family history of teenage pregnancy. This is not surprising as other studies found that, compared with teenagers with no family history of teenage pregnancies, teenagers whose mother had a teenage birth were significantly more likely to experience a teenage pregnancy (East et al. 2007, Kirby et al. 2007, Chagas et al. 2009).

\section{Education level}

Teenage mothers' education level was also identified as a risk factor, as $54 \%$ of teenage mothers were either in primary school $(19 \%)$, or were working/unemployed/out-of-school (35\%) at the time of their first pregnancy. Although this does not speak to their physical age, the level of education of the teenage mothers can be paralleled to their knowledge of sexual education. Indeed, even if the primary school students had on average the same age as the 
secondary and high school students, their knowledge on contraception and safe sex was much lower. In addition to low education level being a risk factor for teenage pregnancy, teenage pregnancy is also a risk factor for not completing high school. Out of the 27 teenage mothers who were in school at the time of pregnancy, only 5 (19\%) went back to school, often leading to a perpetual cycle of repeated pregnancies.

\section{Intergenerational Sex / Partner demographics (Teenage mothers only)}

In general, the partners of teenage mothers were 5.2 years older, had at least a secondary school degree (65\%), and were the main source of financial support for $72 \%$ of participants. These partner demographics make it very difficult for a teenaged girl to voice her opinion on (1) sexual debut (only 30\% of teenage mothers said they had sex for the first time because they were ready), (2) the use of contraception (26\% of teenage mothers said their partner not wanting to use condoms was a reason for not using protection; and $46 \%$ of teenage mothers indicated that they thought their partner wanted them to get pregnant, or they did not care if they fell pregnant), and (3) important decisions that affect their relationship (70\% reported they did not have control). None of the above was true for teenage fathers, which greatly speaks to gender inequality, the need to empower young women, and to have young men support the empowerment of young women.

Both quantitative and qualitative research findings from this study showed that women often assert that accepting financial or material assistance from a man means accepting sex on his terms, which very often means sex without condoms. Some of the transactional sex is perceived to be caused by extreme vulnerability like lack of food or shelter ("You go to school on an empty stomach and meet a boy who will offer to feed you in exchange for sex."). However, it is also came out from the FGDs that some engaged with older men for more social or materialistic gains such as fitting in with a group of friends or getting a phone (" $A$ boy will say she should have a relationship with him and he would give him the cellphone. The girl will oblige.").

\section{Knowledge of pregnancy and contraception}

The knowledge, or rather lack of knowledge about pregnancy and contraception clearly came across as one of the leading risk factors for teenage pregnancy. Less than 50\% of teenage mothers used contraception at the time of first pregnancy and the main reason cited for not using contraception was that they did not know that they could get pregnant (68\%) or they did not know about contraception (47\%). This is similar yet less prominent among at-risk youth who are already sexually active, with the majority ( $80 \%$ of girls, $75 \%$ of boys) indicated that they always/often use contraception, with $40 \%$ of at-risk girls reporting that they did not think they could get pregnant, yet none reported that they did not know about contraception.

Specifically related to contraception knowledge and misconceptions, a large proportion of teenage mothers and fathers reported they were "not at all knowledgeable" about contraception, sexuality, and safe sex at the time of first pregnancy (42\% among teenage mothers, 38\% among teenage father). Interestingly, the majority of at-risk youth reported being "somewhat knowledgeable", more knowledgeable than teenage parents; however, when asked about types of contraception $37 \%$ of at-risk girls and $21 \%$ of at-risk boys cited at least one ineffective method of contraception (compared to 14\% of teenage mothers and $25 \%$ of teenage fathers). This inflated perception of self-knowledge by the youth may be concerning, as at-risk youth also scored lower on the sexuality knowledge questionnaire than teenage parents, with a large proportion of at-risk youth believing that modern contraception makes you infertile, that injectable/IUDs/birth control pills can prevent STIs including HIV, and that drinking water after having unprotected sex prevents unwanted pregnancies.

Another misconception concern is the proportion of teenage mothers (12\%), teenage fathers (25\%) and at-risk youth (10\%) that listed withdrawal as an effective method of contraception. In addition, approximately $25 \%$ of teenage mothers and fathers, and $26 \%$ of 
the at-risk youth thought that "to be extra safe, it is good to use 2 condoms once". These misconceptions and misinformation are directly related to risk of pregnancy, as withdrawal is not an effective method, and using 2 condoms at once could lead to condoms breaking (25\% of teenage mothers and $13 \%$ of teenage fathers listed this as the reason for what went wrong when they used contraception at the time of first pregnancy).

Teenage parents reported having several sources of information about contraception and safe sex, which call into question the quality of information the teenagers are receiving. For example, the majority of teenage mothers and fathers indicated receiving information from HCWs at the clinic/school health, and at-risk youth indicated they were most comfortable approaching a HCW for information. However, the at-risk youth also indicated that the messages received from the clinics included: "they engage us on abstinence", "they always discourage having sexual intercourse while young...", "they warn school going kids against sexual activities and promote prevention". It is concerning that the key messages being shared to the at-risk youth are solely regarding abstinence, rather than education. Teenage parents and the majority of at-risk youth also indicated receiving information from their teachers; however, given that the Life Skills Education curriculum is not rolled-out at all schools or in pre-service training, we cannot be certain that the messages teachers are sharing are uniform and in line with the $\mathrm{MOH}$ recommendations. Teenage parents and some at-risk youth indicated internet and radio as sources of information; however, not all information that is provided via the media can be trusted as being accurate and appropriate. Finally, teenage parents indicated receiving information from parents, as did at-risk youth; so, there is a need to ensure that parents are also receiving on-going education on contraception and are counselled on how to talk to their children about sexuality and safe sex.

\section{Social connections and pressure}

Social connections are also viewed as a risk factor for teenage pregnancy. Although only $30 \%$ of the teenage mothers said they experienced peer pressure, it was clearly elucidated from the FGDs that peer pressure resulted in early sexual debut and transactional sex ("We are victims of peer pressure sometimes, a friend will tell you that if you want money you should get into unhealthy relationships"- FGD Teenage mother). Teens are more likely to have sex if their peers are older, use alcohol or drugs, or engage in other negative behaviour (Kirby et al. 2007). Similarly, they are more likely to have sex if they believe their friends have more positive attitudes toward childbearing, have permissive values about sex, or are actually having sex (Kirby et al. 2007).

Besides, numerous studies have found relationships between emotional distress or teens' use of alcohol and an increased likelihood of having sex, risky sexual behaviours, and pregnancy (Kirby et al. 2007, Saewyc et al. 2004). In this study, 74\% of teenage mothers had high emotional state scores, indicating that they were depressed at the time of first pregnancy, and $88 \%$ of teenage fathers would drink alcohol. In addition, sexual abuse was reported by both teenage mothers and at-risk youth with $26 \%$ of the teenage mothers reported being pressured into their sexual debut, and $28 \%$ of them reported being a victim of sexual violence. The majority of the sexually active at-risk youth indicated that they were pressured into their sexual debut, and $10 \%$ were victims of sexual violence. These findings relate with the literature, which report that teenage pregnancy is strongly linked to sexual abuse (Kirby et al 2007, Saewyc et al. 2004).

It was also reported in the literature (Kirby et al 2007) that teenagers who live with both parents and enjoy close relationship with them are less likely to have unprotected sex and become pregnant. However, only $56 \%$ of the teenage mothers in this study said they had a strong social network at the time of the first pregnancy. In addition

many teenage mothers and at-risk youth highlighted not receiving attention or care from their parents, due to orphanage or not living with their parents: "Some kids will feel like they are not getting any love from their parents hence when a boy comes along, she will see the boy as a potential source of love not knowing his motives" FGD Boys High school. 
Hence, the findings of the study indicated that teenagers felt unsupported in various aspects in life including socially, emotionally, economically and educationally. However, the teenagers are still expected to take precautions and be responsible ("Children [should] preserve themselves and behaves healthy" FGD Teenage mother). For instance, teenagers (especially girls) face contradictory societal pressures to preserve their virginity, while also feeling pressured to engage in sexual intercourse to satisfy a partner or to fit-in with a group of friends.

\section{Access to healthcare/contraception}

This study highlighted the perspective of the facility staff from the Nkalashane Clinic about teenage pregnancy. It was stressed that in addition to nurses, the orderlies and the community workers are providing either counselling about safe sex or access to contraceptives ("I cannot initiate [on family planning services] but if the adolescent wants [condoms], I can provide" Orderly). Even if they were not always comfortable providing contraception to teenagers (29\%), all of the facility staff stated that they will provide it if it was requested. In addition, they admitted that they do not always offer HIV testing and counselling to teenagers between the ages of 12-18 (although the 2015 Integrated HIV Management Guidelines indicate that a 12 year old can consent to testing, and with PIHTC, everyone should be offered a test when they come to the facility).

In addition, the facility staff seems to discuss or educate clients more often about contraceptive methods that are either available, in-stock or familiar with. According to the facility staff, birth control pills, condoms, and injectables are only type of contraceptives provided to the clients at Nkalashane Clinic. This can result in the nurses being less familiar with other forms of contraception, and as a result the community being less familiar with other contraception options.

\section{Limitations}

This study has some limitations. Firstly, small sample sizes, difficulties in reaching the teenage fathers, and no enrolment of at-risk out-of-school youth prevented a comprehensive analysis of the issue of teenage pregnancy in Nkalashane. Also, the low level of literacy of some of the participants might have resulted in difficulty in answering the questionnaire. Furthermore, it is possible that social desirability and limited truthfulness of respondents to sensitive questions such as sexual activity and behaviours or sexual violence resulted in under-estimation of sexual activity and behaviours or sexual violence. The instruments used for this study, such as the EST-Q to measure symptoms of depression, do not substitute for clinician determined diagnoses and thus depression rates should be interpreted with caution. Finally, even if the findings of the study can be generalised to rural areas with similar characteristics to Nkalashane, they may not be generalized to the entire young population of Swaziland.

\section{Recommendations}

This study yields evidence of teenagers' perspective on the role of the health sector and interventions that they believe are suitable to address the issue of teenage pregnancy in the Nkalashane area.

\section{MOH, MOET, Community collaboration}

Teenage mothers/fathers, at-risk youth and facility staff all stated that promoting better collaboration between schools, clinics and communities would help prevent teenage pregnancy. Strengthening education and in-service trainings on contraception for all facility staff, not only nurses, will assist with providing comprehensive and

accurate information about the effectiveness and risks associated with all contraceptive methods available to clients in Swaziland. In addition, building and strengthening the 
relationship between schools and clinics through the MOH and MOET, will encourage young people to access health services.

\section{Life skills education/Comprehensive sexuality education}

The need for comprehensive sexuality education for all (HCWs, parents, in- and out-ofschool youth) in every sphere of life was highlighted in this study. Providing age-specific educational messages and strengthening messages for the youth that is not sexually active should also be priority. Since parents were found to be one of the primary sources of information around sexuality, it is highly important to provide the right information to both parents and youth. Additionally, it is very important to roll out the life skills education in all school levels, even primary schools, since some older students are attending the schools and their knowledge scores are lower. Another recommendation is to strengthen the involvement of men in interventions and provide information to both male parents and male teenagers.

\section{Contraception}

The importance of proper use of contraception also needs to be emphasised. Condoms were the main method of contraception used by participants, and the majority of at-risk youth indicated that it is easy to access condoms. However, they also said that condoms should be placed in easily accessible areas. Participants also cited issues with effective condom use including condoms breaking (potentially because they were not using them properly). Among the at-risk youth who were sexually active but not using condoms, girls reported not having any on hand at the time (which could be improved with accessibility) or that they did not believe in them (which could be addressed with education), while boys indicated that they did not want to use them (this should also be addressed with education on the importance of using condoms to protect against not only pregnancy but STIs). In addition, the information shared around contraception commodities (side effects, dosing schedule, etc.) needs to be clarified and standardised. Indeed, misconceptions and lack of knowledge resulted in some cases in teenagers being scared away from modern contraception and turning to less effective traditional methods. It was also found that comprehensive contraception information is only provided after the first pregnancy, once the women go to their antenatal care (ANC) visits and are enrolled in family planning services. At-risk youth also reported that "Family Planning" is not the preferred term for contraception services, since the youth disassociate themselves with the thought of having families and planning. Therefore, the $\mathrm{MOH}$ may consider re-branding "Family Planning" as part of the ongoing youth friendly services initiative.

\section{Psychosocial Support}

Many teenagers were either found to be depressive or reported being survivors of sexual violence. It is crucial that youth are provided with access to culturally appropriate psychological care (Saewyc et al. 2004).

Even though peer pressure was highlighted as a risk factor for teenage pregnancy, there may be an opportunity to harness it for a positive impact because it is observed to be the best channel in reaching young people. While peers may indeed steer each other in dangerous directions, their social interaction also fuels other types of influence: support for each other, modelling of different behaviours, and trust that is more freely given (Medley et al. 2009, Odundo et al. 2013). Hence, peer pressure should be encouraged along with provision of the right information to children for them to influence each other positively. Thus, pursuing the integration of peer education into school extracurricular activities, identifying and training selected teachers as patrons of peer education clubs, developing peer education manuals, and extending peer education to out-of-school youths could be the next steps to follow in order to promote positive peer pressure (Odundo et al. 2013). 
Texila International Journal of Public Health

Volume 4, Issue 4, Dec 2016

\section{Youth Friendly Services}

Currently, it seems that young people receive and accept the healthcare services offered to them but are not advocating for an increase in the quality and diversity of services, particularly for sexual and reproductive health for youth. The following recommendations for better youth-friendly services were provided by the youth from Nkalashane:

- Open the health facilities on the weekend for youth to access services freely, because the youth are not comfortable being seen wearing school uniforms when accessing FP services during the week. The facility staff at Nkalashane also agreed that this would be useful.

- Keep condoms can in private places (like toilets) instead of waiting areas, because young people tend to be scared to pick them up from public places.

- Not having services-specific rooms, such as a "Family planning room", will help reducing stigma and discomfort brought from being seen queuing for specific services.

- Ensure code of conduct among HCWs (some participants complained about HCWs using cell phones while attending to clients and refusing to see clients), and implement a rotation of the nurses to prevent the sharing of confidential information was also suggested.

The at-risk youth indicated that they were most comfortable asking healthcare workers/school health for information on sexuality, contraception and safe sex so it is imperative that the HCWs are sharing educational and unbiased information with the youth. This aligns with the MOH's youth friendly services (YFS) approach which is currently capacitating nurses on providing services to youth. The primary goal is to encourage young people to access health services without feeling judged or ridiculed for their personal choices or health care needs. During the training, emphasis is placed on maintaining separation between the personal values of a HCW, and their ethical responsibilities as a health provider, as value judgments have been identified by adolescents as the greatest barrier to their accessing services. This will improve upon the status quo, where many facilities have only a 'youth-friendly corner' and, at most, a single staff member trained to positively interact with adolescent clients. All four regions have been reached with these trainings, with an average of 38 nurses per region to date. The head nurse at the Nkalashane Clinic attended the YFS training, which was part of the reason for embarking on this study. The Sexual and Reproductive Health Unit (SRHU) is targeting training at least $80 \%$ of nurses in each health facility, to ensure a youth-friendly environment. The findings from this study suggest all facility staff, in addition to HCWs, should be trained on YFS as the youth will ask whoever is available at the facility.

\section{Conclusion}

All Swazis of any age or status deserve to have access to friendly, appropriate, clientoriented, and affordable sexual and reproductive health services. However, these services in Swaziland apparently failed to meet the needs of adolescents. Many of the risks factors of teenage pregnancy highlighted in this study could be addressed by continued sex education to both teenagers and adults throughout the country and youth-friendly clinics

\section{References}

[1]. Aluoja A., Shlik J., Vasar V., Luuk K., Leinsalu M., (1999) Development and psychometric properties of the Emotional State Questionnaire, a self-report questionnaire for depression and anxiety. Nord J Psychiatry $\cdot$ Vol $53 \cdot$ No 6

[2]. Central Statistical Office. (2007). Swaziland Demographic and Health Survey (2006-2007). Mbabane: Central Statistical Office and Macro International Inc.

[3]. Chagas de Almeida M. C., Aquino E. M.L., (2009) The Role of Education Level in the Intergenerational Pattern of Adolescent Pregnancy in Brazil. International Perspectives on Sexual and Reproductive Health, 35(3):139-146 
[4]. Dlamini, S. (2002). The problems of teenage mothers in Southern Hhohho region of Swaziland. Pretoria: University of South Africa.

[5]. Dulitha, Nalika, Upul, Chrishantha, Alwis, Hemantha, et al. (2013). Risk factors for teenage pregnancy in Sri Lanka. Health Science Journal, (7),3.

[6]. East P. L., Reyes B.T, Horn E.J. (2007) Association Between Adolescent Pregnancy And a Family History of Teenage Births. Perspect Sex Reprod Health. 39(2): 108-115

[7]. GmbH (2015) Atlas ti 7.5. GmbH, Berlin.

[8]. Goucelea, W. O. (2009). Risk factors for Pregnancy among adolescent girls in Equador's Amazon Basin. Public Heath 26(3).

[9]. Government of Swaziland.(2010). Multiple Indicator Cluster Survey. Mbabane: Government of Swaziland.

[10]. Kirby D., Lepore G. (2007) Sexual Risk and protective factors: factors affecting teen sexual behaviour, pregnancy, childbearing and sexually transmitted disease: which are important? Which can you change? ETR Associated, The national campaign to prevent teen and unplanned pregnancy.

[11]. Liik, M., Paris, M., Vahter, L., Gross-Paju, K., Haldre, S. (2013). I-ADAM SPET imaging of serotonin transporter in patients with epilepsy and comorbid depression. BMC Neurology, 13, 204.

[12]. Medley, A., Kennedy, C., O’Reilly, K., Sweat, M. (2009). Effectiveness of Peer Education Interventions for HIV Prevention in Developing Countries: A Systematic Review and Meta-Analysis. AIDS Education and Prevention : Official Publication of the International Society for AIDS Education, 21(3), 181-206.

[13]. Microsoft Corporation (2010) Microsoft Access 2010. Microsoft Corporation.

[14]. Ministry of Health (2012) National Health Sector Strategic Plan (NHSSP) 2008- 2013 Mid-Term Review Report. Ministry of Health, Mbabane, Swaziland

[15]. Odundo, P. A, Anjuri, D. Odhiambo, T. (2013) Impact of peer education on HIV/AIDS behaviour change among secondary school youths: a static group comparison analysis of a peer education project in Rachuonyo County, Kenya. The Lancet, Volume 381, S101

[16]. Ööpika P, Aluojab A., Kaldaa R., Maaroosa H-I.(2006) Screening for depression in primary care. Family Practice; 23: 693-698.

[17]. Saewyc E. M., Magee L. L., Pettingell S. E., (2004) Teenage Pregnancy and Associated Risk Behaviors Among Sexually Abused Adolescents. Perspectives on Sexual and Reproductive Health. Volume 36, Number 3.

[18]. Sodi, E. (2009). Psychological Impact of teenage pregnancy on teenage teenagers. Limpopo, South Africa: School of Social Sciences, University of Limpopo.

[19]. StataCorp. (2011). Stata Statistical Software: Release 12. College Station, TX: StataCorp LP.

[20]. WHO.(2014, October). Maternal, newborn, child and adolescent health. Retrieved October 2014, from WHO Website: www.who.int/child_adolescent_health/en/ 


\title{
Prevalence of HIV in South Sudan
}

\author{
Article by Etiki John Firstday \\ Master of Public Health, Texila American University, Nigeria \\ E-mail: jonfirst4christ@gmail.com
}

\begin{abstract}
Human immunodeficiency virus (HIV) is the virus that causes AIDS. It attacks the body's immune system by weakening the human body's defence against disease and consequently makes one vulnerable to a number of potentially life-threatening infections and cancers. HIV is transmitted through exposure to infected blood and blood products and from infected mother to child during childbirth. This study is a cross sectional study on HIV Prevalence in South Sudan. The study reveals a prevalence rate of $2.7 \%$ for the whole country and about 14 $\%$ in some areas with the most vulnerable being between the ages of 15 to 49 . It also reveals that social factors like poverty and prevailing gender relations contribute to infection and reinfection among People Living with AIDS and their partners. This study identified that NonGovernmental Organizations (NGO) and the United Nations (UN) are key in the fight against HIV in South Sudan; as the Government of South Sudan (GOSS) is battling with basic life need such as food and shelter for the population of South Sudan. There is therefore a need for a renewed campaign against HIV/AIDS.
\end{abstract}

Keywords: HIV, AIDS, Prevalence, NGO, UN, GoSS

\section{Introduction}

HIV (human immunodeficiency virus) is a lentivirus (a subgroup of retrovirus) that causes HIV infection and acquired immune deficiency syndrome (AIDS). (Fauci, A., S., \& Lane, H.,C., 2005). AIDS is a condition in humans in which progressive failure of the body defence system thus allowing life-threatening opportunistic infections and cancers to thrive. If untreated average survival time after infection with HIV is estimated to be 9 to 12 years, determined by the HIV subtype (Wikipedia, 2015). HIV will almost always deplete the immune system, if untreated; leaving the body vulnerable to one or more life-threatening diseases that normally do not affect healthy people. This stage of HIV infection is called AIDS, or acquired immunodeficiency syndrome. The more the immune system has been damaged, the greater the risk of death from opportunistic infections (infections that take advantage of weaknesses in the immune defences). Experts agreed on the term AIDS in the early 1980 s, before the discovery of HIV, to describe the then new syndrome of profound immune suppression. Today, AIDS is understood as the latter stage along a continuum of HIV infection and disease (UNMISS.2015).

As a country battered with a long years of civil war and chequered migration history, the history of HIV in South Sudan is not well established. HIV epidemiology in South Sudan is poorly documented and also certainly in a state of rapid change (SSMJ, 2015). The Comprehensive Peace Agreement (CPA) that brought about peace after decades of war, displacement and isolation ushered in a period of normality which will have great impact on a wide spectrum of disease conditions and not least HIV/AIDS. The UNGASS report of 2008 gives the adult HIV prevalence in South Sudan as 3.1\%; with a population estimate of 10 million translating into 155,000 adults living with HIV/AIDS. This contrasts with a prevalence of $1.6 \%$ adults in North Sudan. (Sudan Medical Journal, 2009).

The UN have been active in the fight against HIV/AIDS through the MDG goal. The UN system is actively engaged in the response to AIDS. UN leadership on AIDS has been spear headed by the Joint United Nations Programme on HIV/AIDS (UNAIDS), which consists of a Secretariat and 10 cosponsoring agencies from within the system (UNAIDS, 2015). HIV is 
one of the Millennium Development Goals, and progress in responding to the epidemic will also be required to ensure achievement of other Millennium Development Goals.

The UN system monitors the epidemic to alert the world to the magnitude and nature of the situation, to detect important new trends, and to help countries determine whether their efforts are succeeding in bringing the epidemic under control. The activities have taken on particular importance following the 2001 global agreement at the UN General Assembly on the Declaration of Commitment to HIV/AIDS and the 2006 Political Declaration on HIV/AIDS, which require Member States to report periodically on progress made in the combat against the epidemic. (Munywoki, 2008). The 2008 High-level Meeting on AIDS reviewed the progress made on implementing the declarations. The UN system provides guidance in helping countries to achieve universal access to prevention, treatment, care and support for people living with or affected by HIV, a goal set in the 2006 Political Declaration. By collecting and disseminating best practices, the UN system helps to ensure that programmes and policies to achieve universal access to prevention, treatment, care and support are based on the strongest available evidence of what is effective. The UN system encourages and often sponsors cutting-edge research to improve the ability of countries and communities to mount effective efforts to curb the epidemic. In respect to HIV in the workplace, for example, the UN Cares 10 Minimum Standards provide guidance for personnel in the UN, and the ILO Code of Practice on HIV/AIDS and the World of Work provides guidance for employers throughout the world, including the UN system.

With a presence in almost all low- and middle-income countries, the UN helps countries through its joint support programmes developed by Joint UN Teams on AIDS to develop and implement effective AIDS strategies. The UN system works with governments, civil society, including people living with HIV, the private sector, faith-run organizations and external donors to strengthen national responses under a framework called the "Three Ones". The "Three Ones" are a set of principles that advise that all countries have ONE national AIDS coordinating authority, ONE agreed framework to address the epidemic, and ONE national monitoring and evaluation system. Above all, the UN system advocates an extraordinary response to the unprecedented challenge posed by AIDS.

The study therefore seeks to reveal the prevalence of HIV in South Sudan, the effect of HIV on South Sudan economy, and the role of NGO such as UN, UNAID in combating HIV in South Sudan.

\section{Methods}

A systematic literature review on HIV and its prevalence in South Sudan was done. Databases of the UN, UNAIDS and other academic websites were consulted in search for the required information. A rapid examination was conducted applying qualitative and cross sectional study. Information was equally collected through documentation, observation from IDP camps as well as rapid assessment of several IDP camps in South Sudan.

\section{Results}

The systematic search in the various database showed the prevalence of HIV in South Sudan. The various effects of HIV on the economy and its demography was equally noted accordingly.

The UNGASS report of 2008 gives the adult HIV prevalence in South Sudan as 3.1\%; with a population estimate of 10 million translating into 155,000 adults living with HIV/AIDS. This contrasts with a prevalence of $1.6 \%$ adults in North Sudan. (Sudan Medical Journal, 2009).

\section{South sudan healthcare system and HIV management}

With over 40 years of civil war with the Northern Sudan, and the global fall in oil prices, South Sudan has got one of the weakest health sector in the world today. HIV management therefore depends on foreign donor agencies (UNAIDS, 2008). This makes the health system 
to be at the mercy of foreign donors. Just about 3.6\% of South Sudan's populations are living with HIV and the GoSS has little it can do to help through its Ministry of Health due to poor health budget.

\section{the negative impact of HIV on south sudan economy}

HIV/AIDS is a health, economic and security related issue. The government of South Sudan has made a start in addressing this epidemic through the formation of the South Sudan AIDS Commission. HIV has a capacity to crippling any nation's economy if it is not well managed (. However, even when well managed it remains an economic burden to every country especially economically weak countries like South Sudan. Both those infected and affected are usually under burden of financing the delicate lives of the PLHA. (WHO Report, 2015).

Appropriate supportive statements have been made by the President of South Sudan, and the Vice President publicly undertook an HIV test. These are important beginnings of a comprehensive response to what can easily spiral into a devastating epidemic (Seeley, 2011).

\section{Effects of war and famine on HIV patients in south sudan}

A deadly surge in violence in South Sudan resulting in massive population displacement and also resulting in tens of thousands in dire need of emergency medical care. PLHA were also affected: with many abandoning their locations to places where they cannot access drugs and good foods/balanced diets. This austere condition resulted (resulting) in massive deaths due to AIDS related situations. Thus, the UNAIDS is concerned about the dire situation faced by the growing South Sudanese refugee population in IDP camps/clusters inside the country.

The UN joint programme (UNJP) remains deeply committed to meeting the humanitarian needs of the people of South Sudan, and urge the international community and other stakeholders to join in the efforts to curtail the imminent famine due to abandonment of agriculture by the people of South Sudan. War and famine usually go together resulting in difficulty in accessing balanced diet requisite for a healthy life and an immune booster for PLHA.

\section{HIV and poverty rates in south sudan}

$52 \%$ of the population live below the national consumption poverty line. Poverty is significantly lower in urban areas where only $25 \%$ of population live below poverty line compared to $56 \%$ in rural areas. Poverty index is higher in female-headed households, rated at $58 \%$, compared to $47 \%$ for men headed households. In a bid to make ends meet, prostitution and all kinds of sexual trading go on resulting in higher incidence of HIV among the poor. Also lack of education makes the indigent population unable to go to school and acquire the knowledge needed to avoid risky sexual behaviour.

Education is also a key determinant of poverty with $12 \%$ of households with a head having post-secondary education living in poverty compared to $57 \%$ of households where the head has no education. Given that poverty is a key determinant in access to health services, households headed by women and people with no education are likely to have difficulties accessing HIV services. In addition to high levels of poverty, South Sudan has a high disease burden and low levels of education, thus ranking as one of the poorest countries in the world.

\section{Anti retroviral therapy in south sudan demography}

Due to the ravaging war in South Sudan, ART access are only accessible within areas that donors consider safe with respect to security. This makes it difficult for people outside of Juba to be able to access their drugs leading to more HIV/AIDS related deaths in the states outside of the capital Juba. Achieving the vision of absolute zero new HIV infections, zero discrimination and zero AIDS-related deaths requires that everyone needing HIV treatment has access to life-saving medication and access to HIV prevention services. Antiretroviral therapy is one of the most effective tools available and it is an essential part of an efficient, 
sustainable AIDS response. Antiretroviral therapy (ART) averted 7.8 million deaths in lowand middle-income countries from the peak in 1995 until 2014 most especially in SubSaharan Africa. The many advantages of ART includes; the prevention of new HIV infections, reduction of the risk of HIV transmission by up to ninety six percent, prevention of illness, reduction of the risk of tuberculosis infections among people living with HIV by sixty five per cent. (http://www.who.int/hiv/topics/treatment/en, 2016)

\section{Internally displaced persons and HIV}

Internally displaced persons and migrant groups tend to have sexual partners often among themselves; as a result the greater risk of transmission of HIV is internal. Moreover, in other circumstances the risk of external transmission increases as in the situation of single displaced men who are employed in low status jobs and who tend to have multiple partners and commercial sex. Also IDP women have been forced to engage in commercial sex because of the poverty and economic situation. (IOM Report, 2016). These two situations are particularly true for the displaced population in all the states of South Sudan. Due to the great vulnerability of the refugees/displaced population to HIV/AIDS the absence of sufficient political will to deal with the epidemic can result in particularly higher HIV/AIDS prevalence among these groups. The economic state of the country largely affects HIV prevalence as poverty drives people to a lot of risky behaviours like prostitution etc.

\section{Healthcare system and socio-dynamics of south sudan}

South Sudan healthcare is just at the elementary stage of service provision; this is because more than half of the country population has no access to good health care. Also the social status which is determined by the economic status of the different people of the country has a great role in the kind of healthcare accessible to the individual. The healthcare system is propped by external donor agencies. (http://www.hpfsouthsudan.org/health-systemsstrengthening/, 2016)

\section{HIV and illiteracy in south sudan}

From the national levels in Africa there is a positive correlation between literacy rates and HIV infection rates. More literate countries tend to have higher rates of HIV infection. More literate African countries tend to be the most developed on the continent and they share a number of features that make them vulnerable to higher rates of HIV infection. Firstly, the most developed countries often have the largest income disparities between men and women, which is a factor associated with HIV infection rates (World Bank, 1997). Similarly, employments in the formal sector are associated with HIV infection. (Barongo, Borgdorff, Mosha, Nicoll, \& al., 1992; Serwadda et al., 1992). In South Sudan literacy rate is just about $25 \%$ which explains why the HIV prevalence is seemingly low.

\section{United nations support to south sudans combats with HIV}

The obvious situation in South Sudan is characterized by a fragile peace, lack of infrastructure and basic services, a depressed economy, and nascent government and rule of law structures with significant and urgent capacity building needs. Translating the Comprehensive Peace Agreement of 2005 into actions and programmes that will facilitate sustainable post conflict recovery, government, and delivery of services has been an immense challenge to the GoSS. Presently, the World Bank, an agency of the UN is assisting South Sudan Aids Commission (SSAC) in its technical capacity to facilitate the implementation of the MTDF for HIV/AIDS project, which was developed in consultation with representatives of GoSS, UN Agencies, Civil Society, and other key development partners. From this end the World Bank is supporting SSAC to review and update the draft HIV M\&E framework and the result framework for the MDTF-supported HIV project and the implementation plan. Goss and health workers are committed to finding ways of providing HIV prevention and treatment services to internally displaced people in the UNMISS sites. 
Humanitarian organizations and United Nations agencies, including UNMISS, UNAIDS and the Office for the Coordination of Humanitarian Affairs, provides technical and financial support to open an additional primary health-care centres, where HIV testing and counselling services are available.

These organizations also advocates the installation of a CD4 machine at the United Nations Hospital in the Malakal (Upper Nile States) camp to help health workers monitor the viral loads of PLHA.

\section{Discussion}

Based on the data reviewed, it shows that the prevalence of HIV in South Sudan is pegged at $3.1 \%$ according to the UNGASS report of 2008. In another report it stated that the prevalence rate is high and stands at $2.7 \%$ for the whole country and in some areas it is up to 14 percent with the age group most affected being individuals between the ages of 15 to 49 . This alarming rate calls for renewed action in the fight against HIV/AIDS. South Sudan might have to deal with an epidemic in ten years if HIV prevalence is not addressed adequately. (UNGASS, 2015)

Due to the poor healthcare system in South Sudan which resulted from civil war which ravaged the country, the country has very little assistance to offer to people living with HIV/AIDS. They depend heavily on foreign donors for assistance.

If HIV/AIDS is not adequately tackled, it has the tendency of crippling the economy. South Sudan being an economically weak country, HIV remains a burden to its economy. Therefore curbing the menace is very tantamount to saving the economy. Also $57 \%$ of the Sudans lives below the poverty line. Poverty is higher in households headed by females, rated at $58 \%$ compared to $47 \%$ for households headed by men. It's worthy to state that education and poverty is interrelated, therefore, households headed by educated people suffer less poverty than those who are not educated. Owing to the fact that poverty is a key determinant in access to health services, households headed by uneducated males and females are likely to have difficulty in accessing HIV services. South Sudan in correlation to the stated facts has high levels of poverty, therefore, access to HIV services may be difficult.

Observations from IDP camps revealed that internally displaced persons have sexual partners among themselves which makes transmission of HIV an internal one. However, IDP women are at greater risk of being infected with HIV due to forceful engagement in commercial sex work. These situations are particularly true for the displaced population in all the states of South Sudan. The prevalence of HIV among these group of people is very high. Also the economy of the country equally drives a lot of people to engage in risky behaviours such as prostitution.

There is a great aid from the international donors to South Sudan to help curb the menace of HIV/AIDS. Presently, the World Bank, an agency of the UN is assisting South Sudan Aids Commission (SSAC) in its technical capacity to facilitate the implementation of the MTDF for HIV/AIDS project, which was developed in consultation with representatives of GoSS, UN Agencies, Civil Society, and other key development partners. Humanitarian organizations and United Nations agencies, including UNMISS, UNAIDS and the Office for the Coordination of Humanitarian Affairs, provides technical and financial support to open an additional primary health-care centres, where HIV testing and counselling services are available.

\section{Recommendations and conclusions}

The presented findings is part of a larger research project to evaluate the prevalence of HIV in Southern Sudan. Hence, this study did not examine whether some of the concepts used in HIV (e.g., random sampling) was appropriate for use in South Sudan. This will be determined in the next phase of my study.

Nevertheless, there is high HIV prevalence in South Sudan and AIDS-related stigma in local communities. The impact of such stigma leads to non- disclosure of status by carriers. A 
Texila International Journal of Public Health

Volume 4, Issue 4, Dec 2016

broader social context such as poverty and prevailing gender relations also contribute to infection and reinfection among people living with HIV/AIDS.

It is therefore recommended that for reduction in the prevalence of HIV in South Sudan the following should be done by the Government of South Sudan (GoSS);

(i) GOSS should expand coverage, diversify approaches and intensify effort to end emergent HIV

(ii) Commit to redouble HIV-prevention efforts by taking all measures to implement comprehensive, evidence-based prevention approaches, taking into account local circumstances, ethics, cultural values, including through, but not limited to: conducting public awareness campaigns and targeted HIV education to raise public awareness about HIV; harnessing the energy of young people in helping to lead global HIV awareness (Kenny, 2009)

(iii) Reduction in risky behaviour by encouraging responsible sexual behaviour, abstinence, fidelity and consistent and correct use of condoms (Kaiser et.al, 2006).

(iv) Increasing access to essential commodities like male and female condoms and sterile injecting equipment.

(v) Ensuring that people, especially young people, have the means to exploit the potential of new modes of connection and communication. (Asego, 2008).

(vi) Significantly increasing and promoting voluntary and confidential HIV testing and counselling as well as provider-initiated HIV testing and counselling.

(vii) Increasing national testing promotion of HIV campaign and other sexually transmitted infections (Munywoki, 2008)

(viii) Giving consideration, appropriately, to implementing and expanding risk- and harmreduction programs, taking into account the WHO, UNODC, UNAIDS Technical Guide meant for Countries to Set Targets for Universal Access to HIV Prevention, Treatment and Care for Injecting Drug Users.

(ix) Encouraging male circumcision.

\section{Acknowledgement}

I acknowledge God Almighty for the strength he gave me to finish this work.

\section{References}

[1] Abebe, Y. et al. (2003). HIV prevalence in 72,000 urban and rural male army recruits, Ethiopia. AIDS, 17:1835-1840.

[2] Adlington, R., \& Burnett, A. (2014). Sexually transmitted infections as a consequence of rape. In: Peel, M. ed. Rape as a method of torture. (2014) London, Medical Foundation for the Care of Victims of Torture: AIDS, Security and Conflict Initiative (2015). HIV/AIDS, security and conflict: new realities, new responses. New York, Social Science Research Council (SSRC) and the Netherlands Institute of International Relations, AIDS, Security and Conflict Initiative (2011) Retrieved from : http://asci.researchhub.ssrc.org, accessed.

[3] AIDS, Security and Conflict Initiative [web site] (2011). New York, AIDS, Security and Conflict Initiative. Retrieved from : http://asci.researchhub.ssrc.org, accessed. Aging in Stride (2016). Retrieved from:http://aginginstride.enewsworks.com/en/12/articles/263/Seniors-and-HIVAIDS-the-StatisticsMight-Surprise-You.htm

[4] Anastario, M.P., Tavarez, M..I \& Chun H. (2010) Sexual risk behaviour among military personnel stationed at border-crossing zones in the Dominican Republic. Revista Panamericana de Salud Pública/Pan American Journal of Public Health. (2015)

[5] Asego, J. (2008). Youth in participatory education theatre against HIV/AIDS in Juba, South Sudan. XVII International AIDS Conference.

[6] Ba, O. et al. (2008). HIV/AIDS in African militaries: an ecological analysis. Medicine, Conflict and Survival.

[7] Baliunas, D. et. al. (2010). Alcohol consumption and risk of incident human immunodeficiency virus infection: a meta-analysis. International Journal of Public Health. 
[8] Barnett. T., Dutta, I. (2008). HIV and state failure: is HIV a security risk? New York, AIDS, Security and Conflict Initiative.

[9] Barnett, T., Prins, G, (2006). HIV/AIDS and security: fact, fiction and evidence; a report to UNAIDS. International Affairs.

[10] Barnett, T.\& Weston, M. (2008). Health, wealth, HIV and the economics hope. AIDS, 2(Suppl.

[11] Chirambo, K. \&Steyn, J. (2009) AIDS and local government in South Africa. Pretoria, Institute for Democracy in South Africa.

[12] Commission on Social Determinants of Health. (2008). Closing the gap in a generation: health equity through action on the social determinants of health. Final report of the Commission on Social Determinants of Health. Geneva, World Health Organization (http://www.who.int/social_determinants/resources/gkn_lee_al.pdf, accessed 17 August 2010).

[13] Cornman, D.,C. (2010). Behavioural HIV prevention interventions [slide presentation]. 2010 DPKO. (2010). Monthly summary of military and police contribution to United Nations operations. New York, United Nations. Retrieved from :http://www.un.org/en/peacekeeping/contributors/0608.shtml.

[14] Fauci, A.,S., \& Lane, H.,C.,(2005). Human immunodeficiency virus disease: AIDS and related disorders. Harrison's Principles of Internal Medicine 16th Edition. New York, McGraw-Hill Medical Publications Division http://www.unaids.org/Epi2008/doc/report_pdf.html.

[15] G8 (2008). Progress report by the G8 Africa Personal Representatives (APRs) on implementation of the Africa Action Plan. Tokyo, Group of 8 (G8) industrialized countries (http://www.mofa.go.jp/POLICY/economy/summit/2008/doc/pdf/0708_10_en.pdf, Accessed) 15 April 2011.

[16] Graeme, J.,S., Irvine, S.,S., Scott, M., \& Kelleher, A.,D., et. al. (1997). Strategies of care in managing HIV. In Managing HIV. Sydney: Australasian Medical Publishing Company Limited 1997.

[17] International Centre for Ethnic Studies (2009). A survey of HIV/AIDS awareness and risky sexual behaviour in a vulnerable population in Sri Lanka. New York, AIDS, Security and Conflict Initiative (ASCI Research Report No. 22).

[18] Iqbal, Z., Zorn, C., (2010). Violent conflict and the spread of HIV/AIDS in Africa. Journal of Politics.

[19] Karutu, C., \&McMahan (2008). Gearing up the Southern Sudanese military to prevent HIV/AIDS. [refWEAE0404] XVII International AIDS Conference.

[20] Kitahata, M.,M., Koepsell, T.,D., Deyo, R.,A., \&Maxwell, C.,L., et.al. (1996). Physicians experience with the acquired immunodeficiency syndrome as a factor in patients' survival. N Engl.J Med 1996.

[21] Kaul, I., Grunberg, I., \& Stern M, eds. (1999). Global public goods: international cooperation in the 21 st century. New York, Oxford University Press.

[22] Kenny, L. (2009). Towards universal access to integrated HIV prevention, treatment, care and support: militaries and other uniformed services [slide presentation]. 38th International Congress on Military Medicine, Geneva, UNAIDS.

[23] Kershaw, R.J. (2008). The impact of HIV/AIDS on the operational effectiveness of military forces. New York, AIDS, Security and Conflict Initiative (ASCI Research Report No. 4; http://asci.researchhub.rc.org/working-papers/Kershaw.pdf, accessed 15 April 2011).

[24] Kruijt, D. \&Balconi, J. (2008). HIV/AIDS and the Central American uniformed services. New York, AIDS, Security and Conflict Initiative. ASCI. Research Report No. 3. Retrieved from : http://asci.researchhub.ssrc.org/hiv-aids-and-the-central-american-uniformed-services/attachment, accessed.

[25] Kusasira, S. (2010). The importance and implications of knowing the HIV epidemic in the military: the Uganda Peoples' Defence Forces [slide presentation].

[26] Kaiser, R., Kedamo, T., Lane, J., Kessia, G., \& Downing, R., et.al. (2006). HIV, syphilis, herpes simplex virus 2 and behavioural surveillance among conflict-affected populations in Yei and Rumbek, Southern Sudan. AIDS.

[27] Likimani, S. (2007a). Medical and public health implications of HIV and AIDS in peacekeeping: field evaluation and analysis. Unpublished, DPKO. 
Texila International Journal of Public Health

Volume 4, Issue 4, Dec 2016

[28] Likimani, S. (2007). Some implications of HIV at peacekeeping missions [slide presentation]. DPKO Training Workshop on HIV/AIDS, Brindisi, Italy. (2007).

[29] Lowicki-Zucca, M., \& Karmin S, Dehne K-L (2009). HIV among peacekeepers and its likely impact on prevalence on host countries' HIV epidemics. International Peacekeeping.

[30] Munywoki, M. (2008). HIV and AIDS in a peacekeeping scenario: the case of Sudan. [ref XVII International AIDS Conference 2-8 August 2008.

[31] Marilynn, M. (2007). New York Times. Retrieved from: http://www.nytimes.com/2007/08/22/health/22iht-22sex.7216942.html?_r=0MilitaryHIV/AIDS

Conference, Arusha, United Republic of Tanzania (2010).

[32] McCarthy, M.,C., Khalid, I.,O., \& El Tigani (2008). A. HIV-1 infection in Juba, Southern Sudan. $\mathrm{J}$ of Med Virol 1995;46:18-20.

[33] Rawls, J. (1993). Political liberalism. New York, Columbia University Press.

[34] Sato, A. (2008). Is HIV/AIDS a threat to security in fragile states? New York, AIDS, Security and Conflict Initiative, Social Science Research Council (ASCI Research Report No. 10).

[35] Secretary-General of the United Nations. (2009). Women and peace and security: report of The Secretary-General. New York, United Nations (S/2009/465).

[36] Garrett, L. (2005). HIV and national security: where are the links? New York, Council on Foreign Relations.

[37] Seeley, J. (2011). The longitudinal impact of HIV/AIDS on agriculture and rural livelihoods in Uganda: framing paper. Swindon, Economic and Social Research Council. Conclusion and recommendations 67

[38] Seeley, J., Dercon, S. \& Barnett, T. (2010). The effects of HIV/AIDS on rural communities in East Africa: a 20-year perspective. Tropical Medicine and International Health.

[39] Sen, A. (1999). Development as freedom. New York, Alfred A. Knopf. Sexual Violence Research Initiative. (2007). Sexual violence and HIV. Pretoria, Sexual Violence Research Initiative.

[40] Barongo, Borgdorff, Mosha, \& Nicoll et.al. (1992). Employments in the formal sector associated with HIV infection.

[41] Serwadda, et. al. (1992). Employments in the formal sector associated with HIV infection.

[42] Shuper, P.A., et al. (2009). Alcohol as a correlate of unprotected sexual behaviours among people living with HIV/AIDS: review and meta-analysis. AIDS Behavior, 13:1021-1036.

[43] Sommers, M.S. et al. (2006). The effects of age and ethnicity on physical injury from rape.

[44] Sudan Tribune (2016). The menace of AIDS in South Sudan. Retrieved from: http://sudantribune.com/spip.php

?mot676.United Nations Medical Directors (2008). Position statement on HIV/AIDS. New York, United Nations Medical Directors (2008).

[45] Africa news (2016). Retrieved from: http://www.africanews.com/2016/03/03/south-sudan-s-hivprevalence-may-lead-to-an-epidemic-unaids/

[46] UNAIDS, AIDS. Epidemic update: June 2008. UNAIDS (2008). Retrieved from: http://www.unaids.org/Epi2008/doc/report_pdf.html.

[47] UNGASS HIV/AIDS in Northern Sudan. UNGASS Report January 2008.

[48] UNGASS HIV/AIDS in Northern Sudan. UNGASS Report January 2015

[49] WHO (2015). Antiretroviral therapy for HIV infection in adults and adolescents in resourcelimited settings-towards universal access.

[50] WHO Report (2016). Antiretroviral therapy. Retrieved from: http://www.who.int/hiv/topics/treatment/en/

[51] World Health Organization. (2007) WHO Case Definitions of HIV for Surveillance and Revised Clinical Staging and Immunological Classification of HIV-related disease in Adults and Children.

[52] Wegbreit, J., Bertozzi, S., DeMaria, \& Padian, N.,S. (2006). Effectiveness of HIV prevention strategies in resource-poor countries: tailoring the intervention to the context. AIDS 2006;20:12171235.

[53] Wambua, P., Kay, A., Atsbeha, T., Khamis, G. (2007). Key findings from a qualitative BCC formative assessment study in Western Equatoria state, Southern Sudan, December 2007. [refTHPE0496] XVII International AIDS Conference 2-8 August 2008. 


\title{
A New Look Care of Mother at Pregnancy \& Lactation: Socio- Cultural Practices in Neglected Population in Kapilvastu District of Nepal
}

\author{
Article by Shashi Kumar Lal Karna \\ School of Public Health, Texila American University, Nepal \\ E-mail: shashikumarlalkarna@gmail.com
}

\begin{abstract}
The study made a new look into existing practice of care of mother during pregnancy and lactation in neglected population predominantly among Muslim, indigenous and lower caste in Kapilvastu district of Nepal. Early marriage, early pregnancy and multiple pregnancies are common socio-cultural practices which is still prevalence in the community.

Women usually go to check pregnancy only for Tetanus injection. The main reason for not visiting check-up is due to family belief that it is 'not necessary'. The husband feels shyness if his wife goes to health facility to see the service providers. The additional foods during pregnancy are not compulsion by the family and women herself. Pregnant women are mostly fed with normal food as usual. Supplementary and more nutritious food during pregnancy are provided especially among economically affluent families. Social belief is that better nutrition during pregnancy will increase baby size which may cause difficulty in delivery and requires operation. Family care and support during pregnancy is low in economically backward communities. Women from poor and Dalit households have high workload during pregnancy.

Home deliveries are more common in compare to institutional deliveries 33.4\%. Delivery at health facility is not necessary', 'not customary' and 'husband or family did not allow to go health facility' as mother in law delivered her many child at home. They try all measures in home; if not succeed then only go to hospital. Women still have their babies at home because of the traditional practice of giving birth at home due to lack of money for transportation facility. Women's low autonomy to decide on maternal health issues could be one of the reasons for low institutional delivery. Unfortunately, women in Kapilvastu district were less aware on danger signs during pregnancy and delivery, and some of the lives threating signs are considered normal. Women who had made sufficient antenatal visit were more likely to deliver at health facility.

People preferred to have maternity services from local traditional practitioners called Chamaini over professional services. The Chamaini helps them in their own home together with family members; they also do massage, and bathing of women and baby. Family members, especially mother in law and relatives also support the women during delivery. The study also revealed that mal-practices in the community are high during delivery. eg, when women find difficulties in removing placenta after birth, there is practice of putting mother's hair in the mouth. People believe that this cause vomiting which results force in uterus and hence placenta is removed.

Heating the place of birth, massage with heated mustard oil to the women during postnatal period is common. Postnatal women are provided to take local made sweet soup called 'Veli' iisoup, which people believe will increase breastmilk and also accelerates uterus constriction. In Tharu culture practices providing to take chilly soup to recently delivered mothers for betterment of mother and child.

Women during postnatal period receive less care and support from the family if the newborn is female child. The care is even less if the women is repeatedly giving birth to female child.

More than50\% of the women are not aware about danger signs during pregnancy. The symptoms such as swelling, vaginal bleeding, dizziness, fever and headache were not considered as threats to the health.
\end{abstract}


Texila International Journal of Public Health

Volume 4, Issue 4, Dec 2016

In home delivery, cord cutting is done by Chamain, until and unless she arrives. The most frequently mentioned cord care by applying naval cream (36.3\%), followed by oil (19.0\%) and Kerosene (17.3\%) and ashes. Around 47\% of the new-borns bath within 24 hours of birth among Kurmi and Dalit ethnicities. In Dalitiii communities, where there is belief that newborns are contaminated with dirty blood are bathed immediately after birth.

Pre-lactating feeds are given in 45\% of the neonates; most common being sweet liquid (60.7\%). There is widespread belief that such sweet foods might be more energetic and child will be able to suck breast milk easily. Other pre-lacteal foods include animal milk and plain water. Pre-lacteal feeding are more prevalent among indigenous (54.3\%), Muslim (46.7\%) and Dalit (44.9\%).

Women herself hardly make decision to seek maternal care by themselves. Husbands and mothers-in-law were the one who have final saying in such decisions. Very low proportion of women alone had final saying in decisions related to whether to have another child (5.0\%), going for ANC visit (9.3\%) and place of delivery of the baby (8.7\%).

\section{Introduction}

Globally 7.2 million children die before their fifth birthday each year, more than $40 \%$ ( 2.9 million) of them die during their first four weeks of life and 273,500 women die due to maternal cause. Maternal death is the leading cause of death among women of reproductive age in Nepal. It is not only a health disadvantage but also a social disadvantage. Maternal Mortality Rate is 170 per 100,000 live births in Nepal (Annual report 2013). Similarly Neonatal Mortality is 33/1000 live birth. The women of reproductive age do not die from disease but during the normal, life enhancing process of pregnancy; delivery and the puerperium and most of which are avoidable. The pattern of maternal and neonatal health care utilization behaviour is furthermore problematic in Kapilvastu district.

In most of the cultures in rural Nepal, mothers are considered ritually "polluted" until Nwaraniv and are restricted to stay at home, preventing access to care during this critical period. Also, new born bathing immediately after birth and applying oil and turmeric powder to the cord stump are commonly practiced traditions and are known to increase the risk of neonatal infections. These are common practice in Kapilvastu.

\section{Objectives of the study}

The primary objective of the study is

To know the maternal and neonatal health care service utilization behaviour (antenatal, delivery, postnatal and neonatal care services).

To find out the cultural and social norms related to maternal and neonatal health care practices.

\section{Study methodology}

The study design was cross sectional, using both quantitative and qualitative methods. The quantitative part of the study was more concerned with assessing the behaviour pattern related to maternal and neonatal health care utilization, husband's supportive involvement in maternal health, while the qualitative part tried explore the underlying socio-cultural factors associated with maternal and neonatal health behaviour including service utilization.

Study methods (Data collection tools and techniques)

The study methods primarily consisted of questionnaire survey with women having children below one year of age, focus group discussion (FGD) and in-depth interview (IDI).

\section{Focus group discussion (FGDs)}

The FGDs was conducted with mothers/women's groups, decision makers (father-in-law, mother-in-law and husbands) and members of Health Facility Operation Management Committee (HFOMC). A total of 20 FGDs: 16 with members of mother's groups, 4 with mixed groups. The participants of mixed group FGDs included husbands and mother in-law 
of pregnant and recently delivered women, HFOMC members, community leader, general people, Female Community Health Volunteer (FCHV) and teacher.

\section{Semi structured in-depth interview (IDI)}

In-depth interviews were carried out with pregnant women, recently delivered women, family members, decision makers (family members, husbands, Mother In-Law, Father InLaw), selected gate keepers (Traditional birth attendants e.g. Chamain, religious leaders e.g. Moulana, Badgadh, Bhalbata, etc.), health workers from local health facility, traditional medical practitioners (e.g. Bengali doctors,) and community leaders, school teachers and other stakeholders

The qualitative tools included questions related to prevailing socio-cultural practices related to maternal \& neonatal health; service utilization practice; knowledge on danger signs related to pregnancy, delivery, postpartum and new-born

\section{Sample size for qualitative assessment}

In each of the selected Village Development Committee (VDC), 16 FGDs (one FGD per sample VDC) with mothers groups, 4 FGDs with mixed groups and 35 in-depth interviews (with pregnant women, recently delivered women, decision makers, FCHVs, health facility staffs, etc.) were conducted. Sampling for qualitative study was purposive.

\section{Result}

The study revealed that child marriage is largely prevalent in Kapilvastu district. Almost $14 \%$ of the respondents were married before the age of 12 years and around half of the women reported their age of marriage between 12 to 17 years. There is a practice of marriage at first and departure of bride to husbands' house after some time (usually in a couple of years), which is locally called Gauna. Almost 37\% of women had Gauna before the age of 18 years.

Antenatal care (ANC) refers to "care during pregnancy", and includes education, screening and treatment to promote the health and well-being of mother and foetus. Government of Nepal, in alignment with the WHO, recommends all women complete at least four ANC visit.

The proportion of women who received at least one antenatal care during the pregnancy of most recent birth was $89.5 \%$. Around $41 \%$ of the women had four or more ANC visits during their last pregnancy. However, only $36.5 \%$ of women made four ANC visits at 4 th, 6th, 8th and 9th months of pregnancy.

Half of the women who did not made ANC visit mentioned that it was not necessary to visit for ANC. They though that in case of normal pregnancy with no pregnancy related problems, it was not needed to go to health facility to see the service providers.

More than $21 \%$ of the women were not counselled on any aspects of pregnancy during ANC visit or they could not remember about counselled issues. Almost $61 \%$ of the women mentioned counselling related to nutrition and iron tablet consumption, followed by TT vaccination during pregnancy (41.5\%), safe delivery preparedness $(25.3 \%)$, danger signs during pregnancy (19.4\%), follow-up visits (13.8\%), family planning (12.5\%), breast-feeding to the baby $(9.0 \%)$ and other (3.8\%).

Around $85 \%$ of the births were protected against neonatal tetanus, while $5 \%$ of the women could not remember whether they had received TT injection or not during last pregnancy. Similarly, $72.1 \%$ took iron and folic acid tablets during pregnancy and/or delivery and $78.9 \%$ of the women were treated by ante-helminthic drug during pregnancy. Iron tablet compliance as recommended is only $11.8 \%$.

Respondents were asked to enlist the danger signs during pregnancy that may require immediate medical support. More than half of the women (53.9\%) did not know any type of danger signs during pregnancy. Women who were aware about danger signs during pregnancy more frequently mentioned haemorrhage (22.3\%), followed by swelling of face and limbs (22.0\%), severe lower abdominal pain (20.7\%), continuous vomiting (17.0\%), high 
Texila International Journal of Public Health

Volume 4, Issue 4, Dec 2016

fever (12.7\%), etc. Other dangers signs such as no weight gain, anaemia, blurred vision, convulsion, high blood pressure and difficulty in breathing were mentioned less frequently.

Women were also asked whether they experienced any danger signs during their last pregnancy. Around $43 \%$ of the women did not experienced any type of danger signs, while $23.2 \%$ mentioned swelling of face and limbs, $19.8 \%$ mentioned continuous vomiting and $16.4 \%$ each mentioned severe lower abdominal pain and haemorrhage. Other danger signs during pregnancy were experienced by relatively less proportion of women.

Women were asked whether they or their family had made any of the four birth preparedness arrangements before the delivery of the most recent birth. About $39 \%$ of the women had made no preparations at all. More than half $(55.7 \%)$ of the women reported saving money, one-fourth (28.5\%) arranged for transportation and only $13.9 \%$ had identified place and person for delivery assistance. Very few women (2.5\%) had identified a person who could donate blood if required. Some of the women also reported that they had arranged food and clothing.

The national health policy of Nepal promotes delivery at a health facility by a skilled birth attendant to ensure appropriate medical attention and hygienic conditions at delivery whereby reducing the complications and serious illness of the mother and baby. Only 33.4\% women delivered their last birth in health facility.

When asked about the reasons behind not delivering at health facility, higher proportion of the respondents reported 'delivery at health facility was not necessary' (36.2\%), followed by 'not customary' (26.3\%), 'husband or family did not allow to go health facility' (22.5\%), 'health facility was too far or there was no transportation available to the facility' (19.2\%), 'high cost related to health facility delivery' (7.5\%), 'child born before reaching facility' (6.6\%) and others.

59\% women did not know any danger signs during labour and child birth. The most commonly mentioned danger signs of labour and childbirth were prolonged labour (labour lasting more than 12 hours) (26.9\%), excessive bleeding (22.0\%), wrong positioning of baby (12.7\%), high fever (8.4\%), retained placenta (placenta not delivered within 30 minutes after delivery of baby) (7.4\%) and convulsions (5.3\%).

Regarding the key danger signs experienced during labour and child birth, more than half (52.6\%) of the women did not experienced any danger signs during their last birth. Prolonged labour, which is one of the top five major causes of maternal mortality and topmost cause of morbidity in low-income countries, was experienced by $17.3 \%$ of the women. Other complications experienced include excessive vaginal bleeding (10.5\%), convulsions (9.6\%), high fever (5.0\%), retained placenta (3.4\%) and wrong positioning of baby (2.8\%).

Women were asked whether they had received their health check-up after delivery. Around $40 \%$ of the women had received at least one PNC after delivery. One-third women (34.1\%) mentioned that they received PNC within 24 hours of delivery. The proportion of women who received PNC during 24 hours to 3 days and 3 to 7 days was $8.0 \%$ each. This shows that PNC visit after 24 hours of delivery is very low. Only 5.3\% women visited for three PNC checksup.

More than 50\% women do not know any danger signs during postnatal period. Among those who were aware of danger signs, mentioned lower abdominal pain, excessive vaginal bleeding, high fever/severe headache and foul smelly discharge from vagina respectively as a danger signs during postnatal period. Other signs mentioned by respondents were weakness (10.8\%), continuous vomiting (7.7\%), convulsions (7.1\%) and redness around nipples (5.6\%).

Regarding the danger signs experienced during postnatal period, $57.0 \%$ of the women did not experienced any danger signs. The danger signs of postnatal period commonly experienced include lower abdominal pain (19.8\%), excessive bleeding (13.3\%), high fever/severe headache $(11.8 \%)$ and extreme weakness $(10.2 \%)$. Few of the women also mentioned experiencing convulsions (7.4\%), foul discharge from vagina (6.5\%), continuous vomiting (4.3\%) and redness around nipples (4.0\%) 
Women were asked whether they have practiced different type of newborn care immediately after birth. Majority of the newborns (88.5\%) were wrapped with warm clothes immediately after birth, while around two-third of the women (67.2\%) mentioned that their newborns' eye, face and body were cleaned with clean cloth. Around half of the newborn (49.8\%) were initiated breastfeeding immediately after birth. One-fourth (25.15) of the newborns were kept skin-to-skin contact with mother (MayakoAngalo)v.

Women who delivered their youngest baby at home were asked about the umbilical cord care. More than $90 \%$ of the women mentioned that new blade was used to cut the cord, while $4.7 \%$ used old blade or other things. A non-sterile instrument was used to cut the umbilical cord in around $5 \%$ of births

Majority (83.3\%) of the mothers were using some form of application on the cord stump. The most frequently mentioned application were naval cream (36.3\%), followed by oil (19.0\%) and Kerosene (17.3\%).

Women were asked to enlist the danger signs among neonates which need immediate medical attention. Almost half of the women had no knowledge of any and listed none. Among the neonatal danger signs, difficulty in sucking breastmilk (34.1\%), fever (30.3\%), coldness/hypothermia (27.6\%), naval inflammation (19.8\%) and difficulty in breathing (15.8\%) were the most frequent signs mentioned as danger signs. Others include weakness (12.4\%), appearance of rashes (5.9\%) and low birth weight (4.0\%).

Women were also asked whether they had experienced any of the danger signs in their new-borns. Fifty-eight percent of the women did not seen any danger signs in their neonates. The most common danger signs seen by the women in their neonates were fever (23.5\%) followed by difficulty in sucking breastmilk (11.1\%), hypothermia (10.8\%), difficulty in breathing (8.0\%), naval inflammation (7.7\%) and low birth weight (7.4\%). Fewer proportion of women also noticed weakness, rashes, convulsions and yellowness of body.

Only $11.8 \%$ of the women require no permission from husbands or other senior members of the family to go to the local health facility.

The proportion of women who discussed with husbands about the number of children to have was $81.4 \%$. Similarly, $74.6 \%$ of women discussed with husbands on whether to use family planning and $70.0 \%$ discussed about women's health issues.

Qualitative findings of study

There is widespread belief that visiting health facility for ANC is required only if there health problem arises. Household work burden (unavailability of time) and no approval by senior family members were other reasons for not visiting ANC. When asked about the timing of ANC, they thought that whenever there is problem, pregnant women should go for ANC. Some women only go first time just to confirm the pregnancy.

ANC visit among Dalit and Muslim women is low as compared to other ethnicity. Women's status in Dalit and Muslim community is low and they are not supposed to go alone outside house. Women from Muslim communities are not allowed to go alone to visit health facility, which is one of the reasons for low utilization of ANC service among Muslim women. In some communities, people believe that taking iron tablet will cause abdominal discomfort such as gastritis. Some participants also revealed the community beliefs that consumption of iron tablets may cause headache and vomiting and increase the size of baby.

Regarding the feeding during pregnancy, majority of the respondent says that pregnant women are feed with normal food as usual. The Additional foods are not compulsion by the family and women herself. Supplementary and more nutritious food during pregnancy are provided especially among economically affluent families. In some cases, participants also mentioned that pregnant women should not be fed much as it will increase baby size which may cause difficulty in delivery. Fruits and green leafy vegetables are not provided to pregnant women also because of non-availability of such foods on the one hand and poor economic status of the households.

Pregnant women should not be fed much; it will increase baby size which results for difficulty in delivery. If the size of baby is large, women cannot deliver normally and require 
Texila International Journal of Public Health

Volume 4, Issue 4, Dec 2016

operation. Family care and support during pregnancy was found low in economically backward communities. Women from poor and Dalit households have high workload which does not seem decrease during pregnancy. The workload during pregnancy is almost similar to other times. We have to do all the household chores from early in the morning to late night. We do not have time for adequate rest.

Most of the participants reported that families make arrangements for extra money that may require during the time of delivery. Preparation for transportation during emergency and planning for where to deliver were not mentioned in birth preparations in most of the cases. Economically strong and educated families do birth preparedness to some extent, but not by poor households. People believe that pregnancy and having baby is a normal process and there is nothing to prepare.

Most of us do not do any birth preparedness. When any emergency arises we search for help and go to hospital. Most of the respondents in FGDs said that women usually delivery at home. Though people perceive that HF delivery is safer for mother and child, women still have their babies at home because of the traditional practice of giving birth at home as well as lack of money to cover costs related to HF delivery. It is our tradition that we have deliver a child at the place where our mothers in law used to deliver. We go to hospital, only if there is serious problem that the Chamain cannot handle.

People seek help from traditional practitioners more frequently because they placed greater value on them than on medical services especially for normal delivery. They view medical services appropriate only for very severe conditions. Financial barriers and the traditional beliefs are the major reasons for such practice.

We are very much happy to deliver at home because all the family members are available for care and support. In hospital nurses scold if a woman cries during delivery. When women find difficulties in removing placenta after birth, there is practice of keeping hair in the mouth of women. People believe that this may cause vomiting which results force in uterus and hence placenta s removed. For removing of placenta, women are asked to keep hair in their mouth. This will cause vomiting and it results force in uterus and placenta is removed.

In most of the VDCs PNC visit was very low. Women hardly go for PNC after delivery. PNC is practiced only if there is a serious health problem for the mother. One of the ANM in IDI mentioned that PNC service, including the counselling related to postnatal family planning are provided when women come for immunization of the baby. When mother and baby are healthy, there is no need to go for postnatal care to health facility. Even mother go for PNC, there is nothing to do by service provider.

Those who delivered at home were doing unsafe practice such as putting kerosene immersed cloth in vagina to stop the bleeding. The local traditional birth attendants believe that kerosene will help to reduce and stop bleeding. We put kerosene on a cloth, and the cloth is kept in the vagina that will stop the vaginal bleeding. In some VDCs dried ginger is provided to recently delivered women thinking that the ginger will stop bleeding.

Restriction of movement to delivered women outside home for some days is one of the factors which prevent PNC service utilization. The qualitative findings showed that there is a widespread concern that childbirth is a ritually polluting event. Blood coming from delivered women, the cord and placenta, as well the new-born child are considered ritually polluting. Recently delivered women are not considered to worship god for 11 days. During this period, mother and new-born are not allowed to be touched by other people; and they are not allowed to go outside home, are often kept in isolated area inside the house.

Heating the place of birth, heat and mustard oil massage to the women during postnatal period are mentioned frequently by the participants. Oil massage is provided to women even for two times a day during the initial days of delivery. Postnatal women are provided 'Veli'soup. There is widespread belief that the soup of 'Veli' will increase breastmilk and also accelerated uterus constriction. Some of the participants also mentioned providing chilly soup, though less frequently, among Tharu communities. 
In economically backward families (e.g. Dalits), women during their postnatal period are compelled to do normal household work as well as hard work too. In Brahmin/Chhetrivias well as Indigenous ethnicity, better care and support are being provided as compared to other ethnicities. The FGD participants also revealed that women during postnatal period receive less care and support from the family if the new-born is female child. The care is even less if the women is repeatedly giving birth to female child.

Mostly in home delivery, cord cutting is done by local person called as Chamain in the village. Cord cutting is not done until and unless she is there. Most of the FGD participants mentioned using new blade for cord cutting, however, there are still practice of using old blades and other household equipment (e.g. sickle) for cord cutting in remote VDCs of the district. In Dalit ethnicity, cutting the cord is considered ritually polluting event and it is done by the lowest caste women available within the Dalit.

Last time when there was a birth in my neighbour house, the families had to wait for almost 3 hours to the Chamain for cord cutting; even families do not touch the child until Chamain come for curd cutting.

Application to the cord stump continues to be a common practice among the mothers in the area. Traditionally, the most common application used in cord stump is kerosene oil. Now-adays, there is increasing practice of using Navi Malamvii. However, there are many cases in which kerosene oil are used. Their beliefs for using kerosene oil are as an antiseptic. Use of turmeric powder and mustard oil is also frequently mentioned application during FGDs.

New-borns are usually fed pre-lacteal food immediately after birth and the most common pre-lacteal food is sugar and water solution. They think that this might be more energetic and child will be able to suck breast milk easily. Animal milk and plain water are also seen to provide the new-born before initiating breastfeeding.

On the other hand there are significant numbers of participants in the FGDs who believe that it takes time to come breastmilk and breast milk will not come in majority of the women on the first day. FCHV always tell us to put the baby on the breast immediately after delivery but this does not help because the milk is not coming on the first day. My Mother-in-Law provided sugar and water solution to my baby. Most of the women in our community do same. When asked about the knowledge about the position and placement of baby while breastfeeding, women are not aware about how the baby should be placed while breastfeeding. Breast feeding is universal, but in case where breast milk is not sufficient for child only they prefer buffalo milk to feed child.

Previously, new-borns used to be bathed immediately after birth. But now-a-days, newborns bathing is generally done after 24 hours of birth. However, there also exist a number of cases where new-borns are bathed immediately after birth. In Dalit communities, where there is belief that new-borns are contaminated with dirty blood are bathed immediately after birth. One of the Chamain interviewed also supported the statement that new-born should be cleaned and bathed as soon as possible.

Both the mother and new-born, while delivery, are contaminated with dirty blood which should be cleaned. New-borns should not be kept with such dirty things for longer time. I encourage immediate bathing of both the mother and new-born.

As repeatedly mentioned, during home delivery, almost all new-borns are cleaned and wrapped with clothes, but the clothes is not necessarily the new and clean one. Immediately after birth, new-borns are cleaned and put in front of mothers or someone caries them carefully. There is practice that the families prepare for old used clothes (locally called thangna) for the use of new-borns. As a care taking practice oil massage in front of fire is provided to the new born child. Homemade mustard oil is used most frequently. Applying kajalviii (black eye polish), made up of coal to the eyes of the new-born is also found universal practice. Women mentioned protection from evil spirit as the reason for applying kajal.

Discussion was conducted to assess the level of knowledge and experience of women with regard to the danger signs during pregnancy, delivery, postnatal period and the neonates. The 
Texila International Journal of Public Health

Volume 4, Issue 4, Dec 2016

findings showed that most of the women are unaware about such type of danger signs. Few of the participants mentioned some danger signs during pregnancy such as back pain, lower abdominal pain, vaginal bleeding, swelling of face and limbs, vomiting, and dizziness. Haemorrhage, lower abdominal pain and severe headache with fever are mentioned as danger signs in all cases (pregnancy, delivery and postnatal). However, many of the women in FGDs perceived them as normal. Women mentioned that they occur when women get pregnant and that they all disappear after delivery. Some of the women mentioned lying by the fire and take rest when such symptoms arise.

I had morning sickness, dizziness, vomiting, back pain, and leg swelling; I did not do anything as these are normal during pregnancy said one the participants of FGD. Women also lacked neonatal danger signs. Among those who mentioned neonatal danger signs, difficulty in sucking breastmilk, coldness and difficulty in breathing are cited by some of the participants.

People do not consider some of the danger signs as serious issue requiring immediate medical attention. Furthermore, there is widespread belief that a women should only go to health facility if complication arises. Some participants also mentioned that it took households a long time to make a decision to seek care. Even families perceive that they need immediate medical help, there are other barriers associated in making decisions such as lack of money, difficulties in arranging transportation and others.

\section{Discussion}

The issue of maternal and neonatalcare practices in Kapilvastu district in context to 21st century is alarming situation. The national policy of safe motherhood is not complying with sustainable development goal. So, reviewing national policy must be discussed further based on ground reality for strengthening of health services in the district mainly institutional delivery and demand generation through awareness in the community to change the malpractice behavior at home level and proper planning of birth preparedness.

Similarly champion can motivate community to change in sociocultural practices especially regarding early child marriage, early pregnancy and multiple pregnancy. Now time has come to discuss on improvement of Maternal and neonatal health through multisector approach and local sociocultural accepted behavior change communication.

The political parties leader, religious leader, ward citizen forum, civil society, journalist, women groups, microcredit group, cooperative group water users group, forest users group, father in law group, father group, mother in-law group, teacher, student, clubs, NGOs, CBOs all community micro component and community representative should take lead role in social development part. It is said that without community participation, community people involvement in decision making, there is no chance to change the socio culture practices. So it is debatable for further discussion in the community to change the life of mother and children in Kapilvastu.

\section{Conclusion}

Overall, maternal and neonatal care in Kapilvastu district is quite poor. Maternal health care with regard to utilization of health services seems to deteriorate from pregnancy to delivery to the postnatal period. Higher proportion of women made at least one ANC visit, but the subsequent ANC visit is low and birth preparedness practice is low.

Most of the deliveries took place at home, attendants at delivery were mostly unskilled local birth attendants (Chamain), cord cutting practices were still unhygienic, pre-lacteal feeding exists, bathing immediately after birth continues and unhealthy beliefs and practices of breast feeding practices prevail. These all demand for the need of obvious intervention program.

Existing socio-cultural beliefs related to maternal and neonatal care negatively affected the health status of mother and new-born. Poverty and education level of the mothers and families are the hindering factors including negative cultural practices. Lack of access to basic 
maternal healthcare, poverty, illiteracy, women's low status in the society, shortage of health care professional and underutilization of currently available services are other major challenges to improving maternal health in Kapilvastu district.

For the prevailing practices, intervention should be focused towards the selective approach rather than prevailing blanket approach i.e. those factions of the society (especially Dalits and Muslims) which are devoid of relevant knowledge and practice like suppressed and unreached communities should be prioritized first.

As counselling services provided by the health workers were of poor quality and inadequate, the prevailing unhealthy practices in the area should be discussed with the health care providers and communication strategies through inter personal education during antenatal visits, home visits, community discussion and mass media should be launched. Unhealthy practices of maternal and new-born care should also be discussed with family members (husbands and mothers-in-law), relatives, Chamain and other key players in the society so that they take special action in preventing these harmful practices. There is an urgent need to educate mothers or responsible family members especially mothers in-law.

It is concluded that mothers in the study area had inadequate knowledge and carrying out some harmful practices. Behavioural change communication package designed according to the felt need of the community has favourable impact on the knowledge and safe practices of mothers for neonatal care. Improving health facilities, mother's nutrition, women's position in the society such as freedom of movement, and integrating Traditional Birth Attendants into local health services can play a vital role.

Women and family members in Kapilvastu district strongly value pregnancy, childbirth and new-born care traditions and associated cultural beliefs and they profoundly shape women's views of safety and risk during pregnancy and childbirth. To improve maternal and neonatal health status if Kapilvastu district, service providers must genuinely partner with local women inclusive of their cultural beliefs, and provide locally based primary maternity care.

Health service should make women, family members and communities feel culturally safe and culturally respected within their spiritual traditions of birth BCC package should be designed focusing on changing the adverse behaviour of women, mother-in-law, family members and Chamain. The information in the package should contained self-designed pamphlets, posters and visual cards containing simple messages in local languages (Awadhi). Culturally appropriate images should be designed based on community and subject expert feedback as well as a pilot field study. Rather than distributing such aids to women and communities, health workers, FCHVs and community mobilizers should use them while counselling and discussing with women and family members.

The BCC package should include danger signs during pregnancy, delivery postnatal and neonatal period; general pregnancy care, rest and nutrition during pregnancy and lactating period; importance of iron tablet consumption, institutional delivery and PNC; neonatal care practice (care of naval cord, initiation of early breastfeeding, proper breastfeeding practice, bathing after 24 hours, Kangaroo mother care), etc. Alternative strategies for promoting maternal and neonatal health such as home visits by service providers, interactions within women, family members and communities by using participatory BCC materials may be more effective. 
Texila International Journal of Public Health

Volume 4, Issue 4, Dec 2016

\section{Figures and table}

Education status of female vs male:

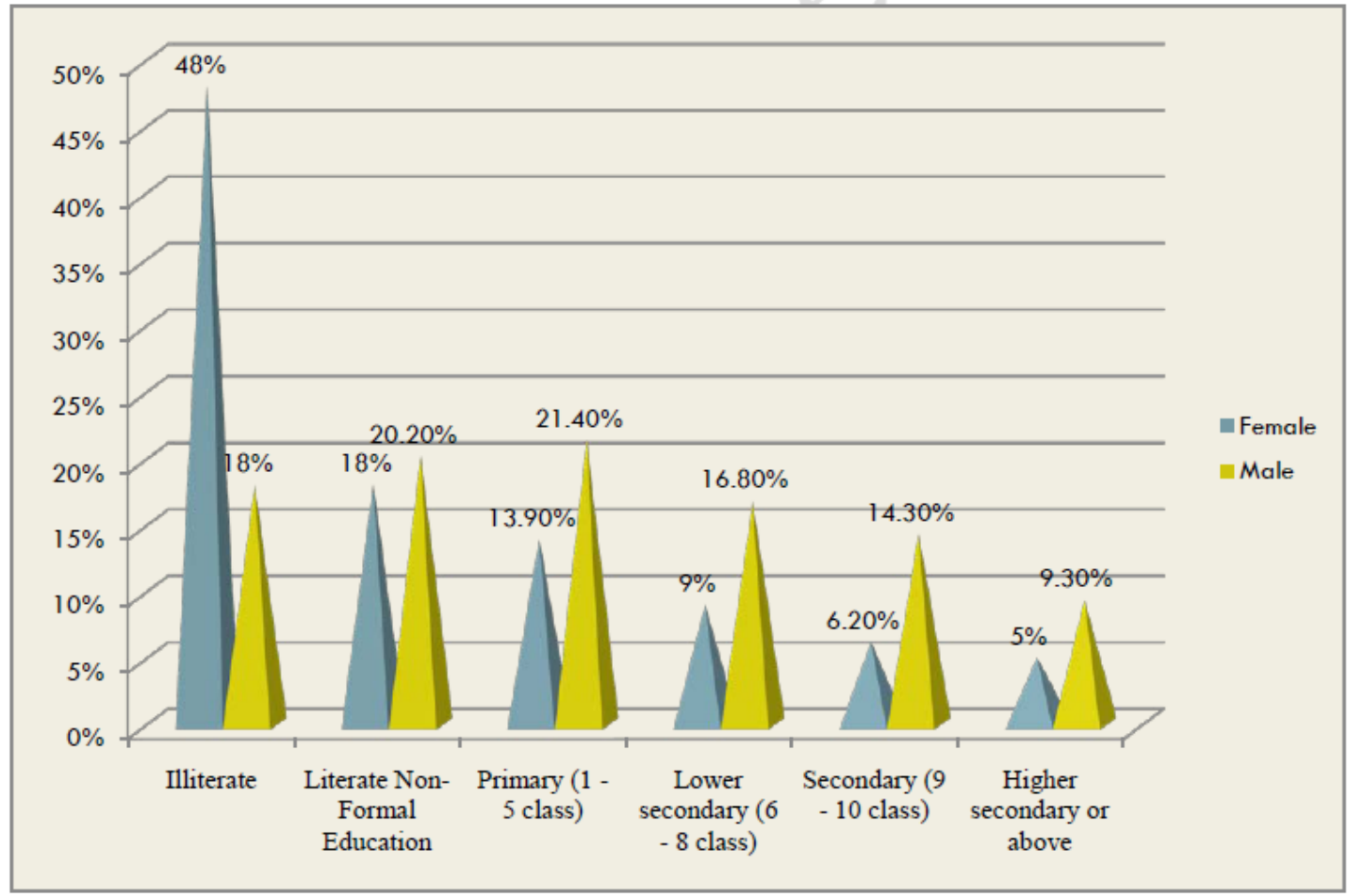

Age of marriage vs first Pregnancy:

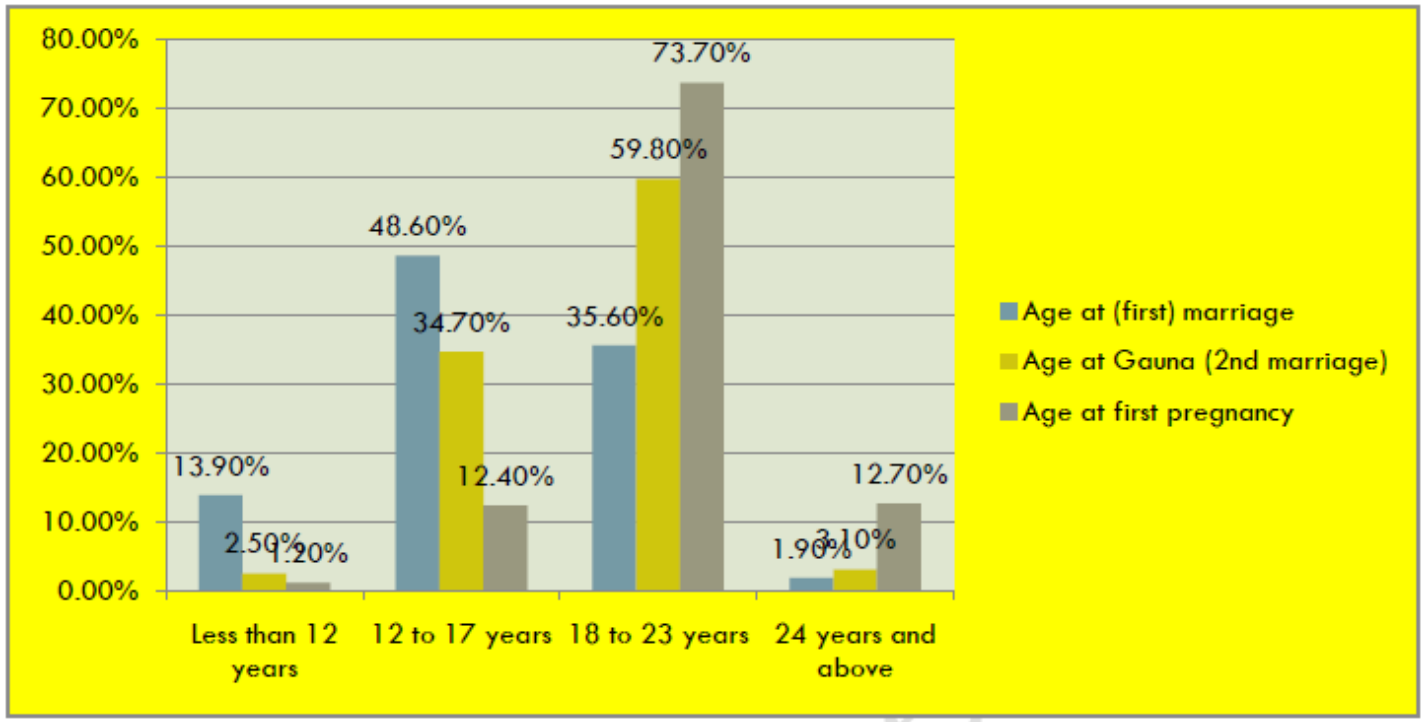


Texila International Journal of Public Health

Volume 4, Issue 4, Dec 2016
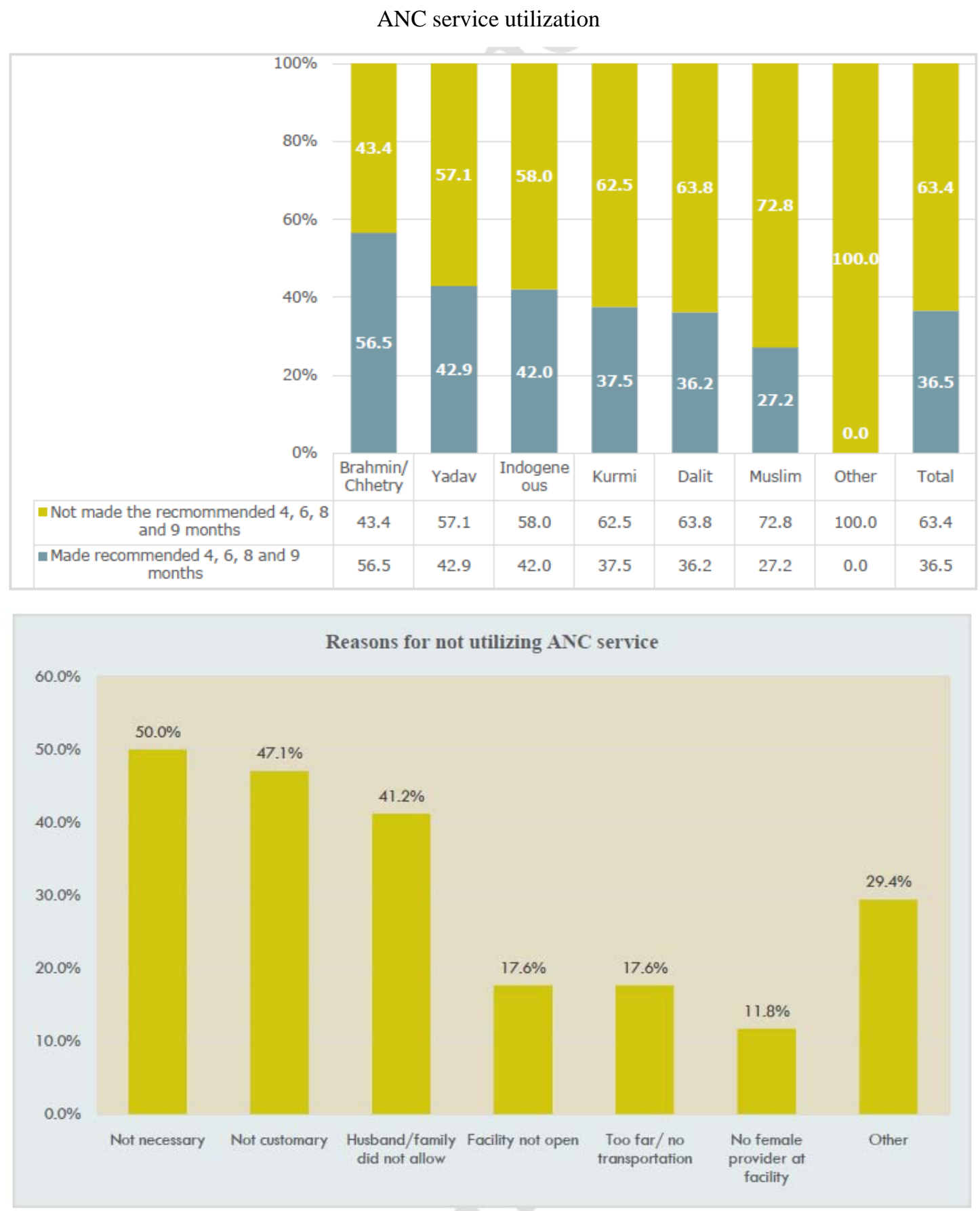
Texila International Journal of Public Health

Volume 4, Issue 4, Dec 2016
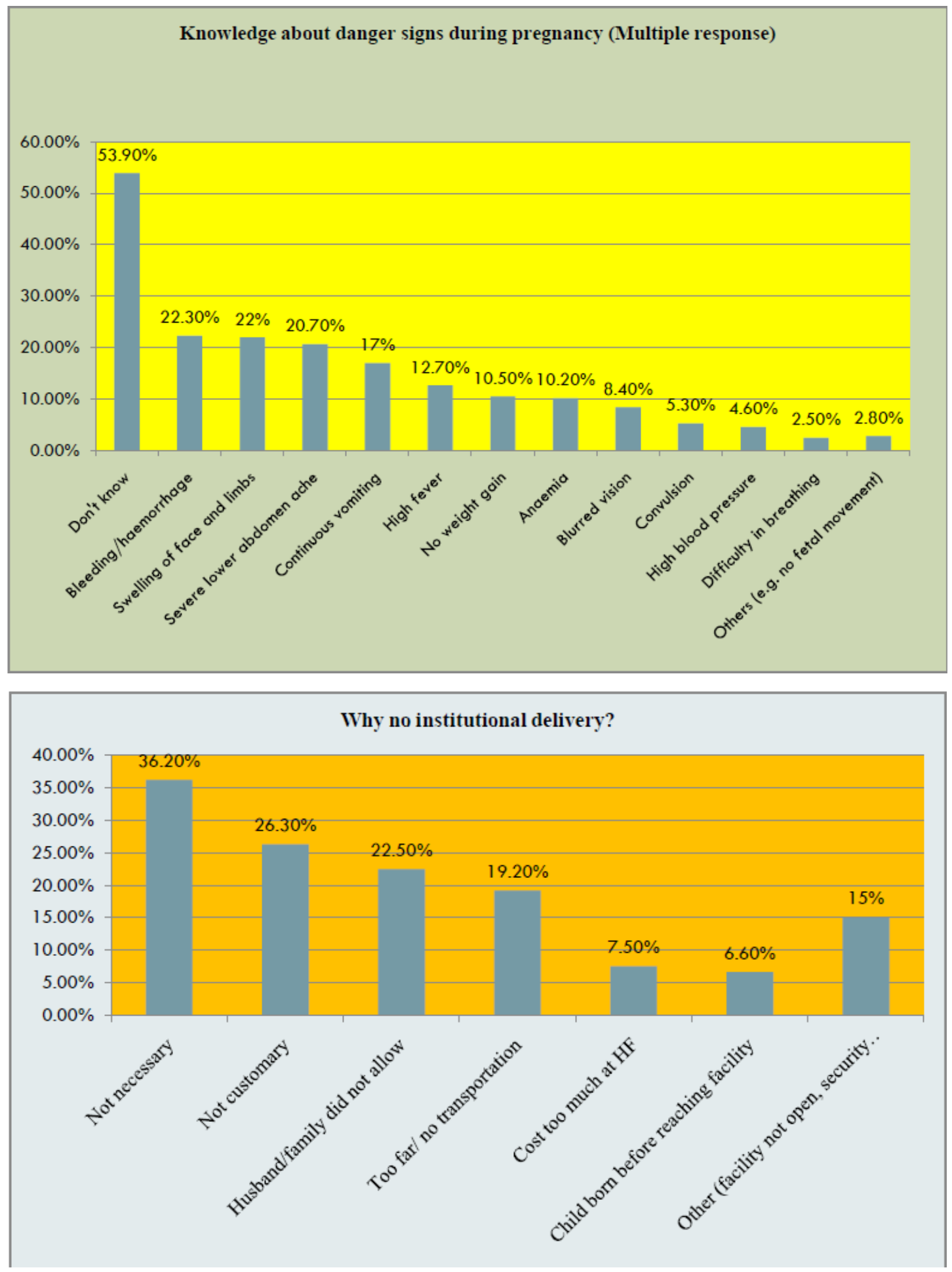
Neonatal care after birth
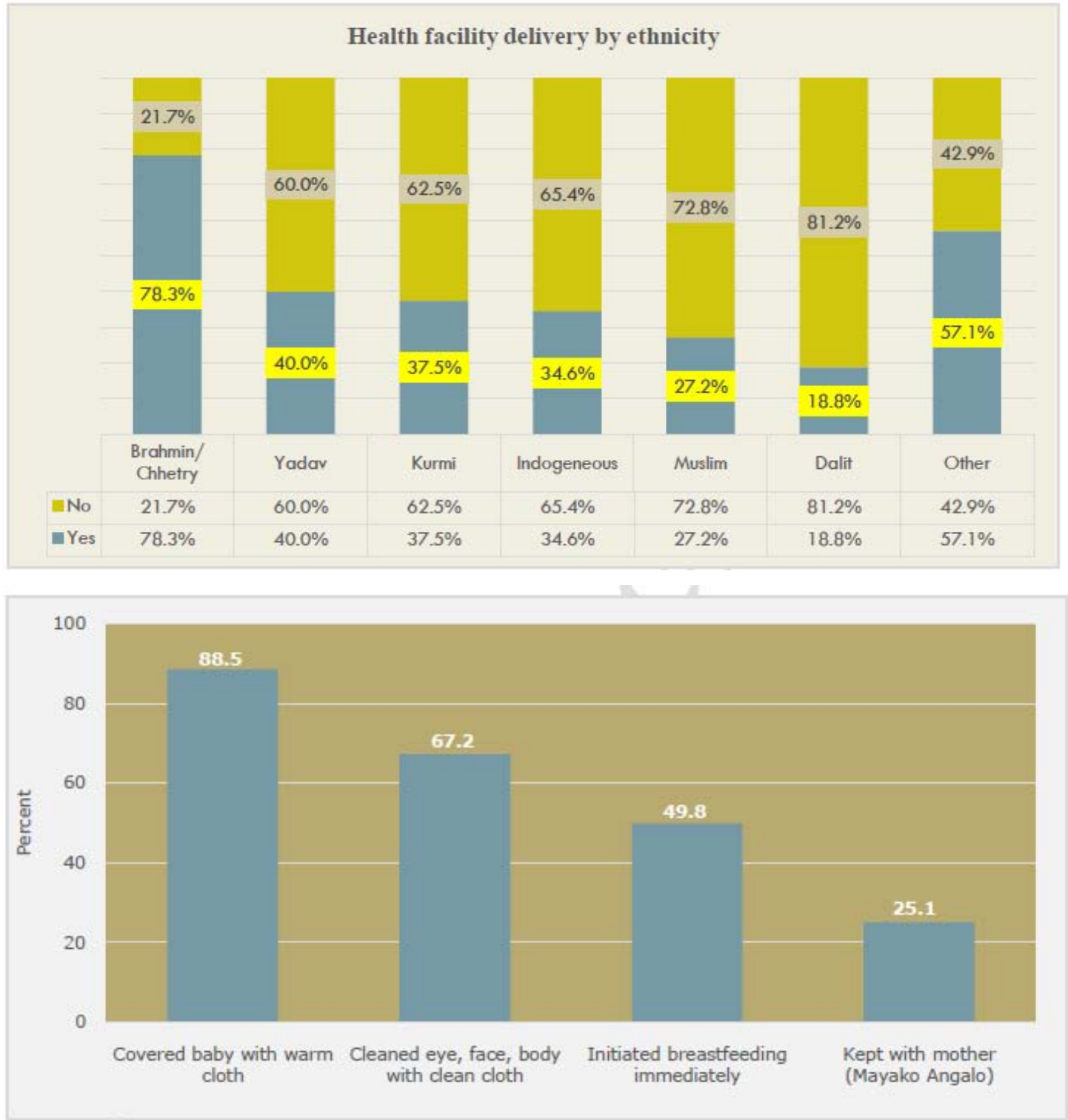

What was used to cut the cord? (Among Home delivery)

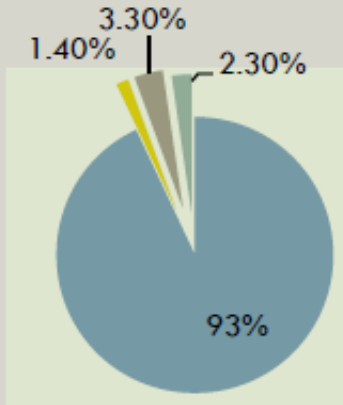

$$
\begin{aligned}
& \text { New blade } \\
& \text { Old blade } \\
& \text {-Other } \\
& \text { Don't know }
\end{aligned}
$$




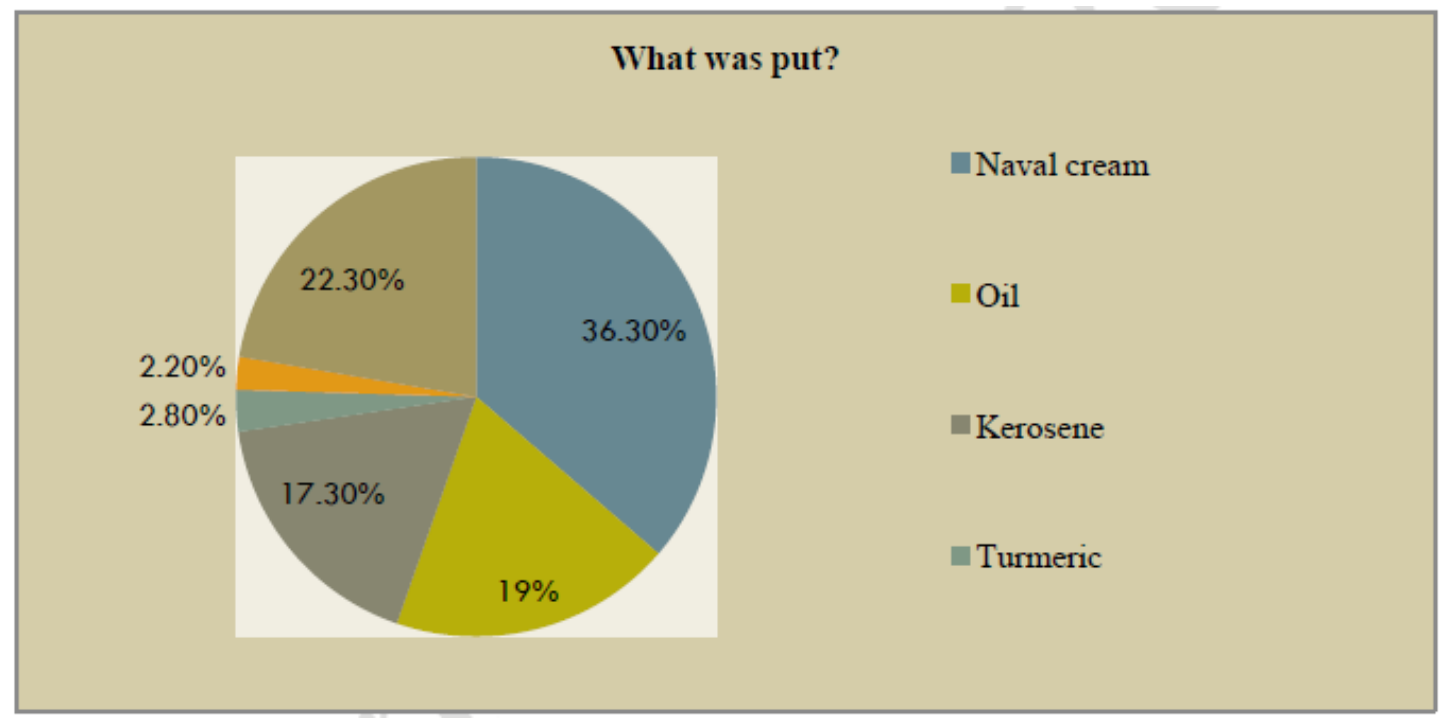

\section{Recommendations}

Based on the findings of behave mapping study, following recommendations are made.

- A very high proportion of women did not know about the obstetric and neonatal danger signs stressed the need for a plan to increase the awareness about such signs. There is an immediate need for strategic plan to increase the awareness of women about signs of obstetric complications. Health facility as well as out-reach clinics should be targeted for healtheducation on dangers signs of pregnancy, labour and after delivery to reach as many people as possible.

- Counselling women and husbands together by health worker may improve interpersonal communication among the couples. This may increase the service utilization as well as prevent harmful cultural practices.

- There is strong need to implement the community-based interventions to improve the new born care practices in community level and to reduce the high-risk new-born care practices like unsafe cord care, delayed breast feeding, early bathing, pre-lacteal feeding and discarding colostrum need through the community level health workers and volunteers.

- The study showed a strong influence of Mother In-Laws on the uptake of maternal and neonatal service utilization as well as household behaviour. Understanding their role is important if we are to design and target effective community-based health promotion interventions. Health promotion and educational interventions to improve the use of MNH should target women, husbands and family members, particularly mothers-in-law where they control access to family resources. Community mobilization and sensitization targeting women and men who provide finance for seeking care and are involved in decision making in the community is pre-requisite to improve MNH status in Kapilvastu district. Given the hierarchy of power and social position in Nepal, engaging mothers-in-law with establishing relationships of respect is one of the important steps required to change maternal health behaviour.

- While designing BCC as well as health promoting interventions, traditional views on pregnancy and motherhood as an important cultural factors influencing health seeking behaviour must not be overlooked. Allowing a family members (e.g. MILs, relatives, husbands, etc.) to accompany a woman during labour might be a possible intervention, to overcome the cultural need of family to be around and witness the delivery. It may also reduce the barrier of unfamiliar environment.

- Despite high coverage of ANC visit, very few women mentioned counselling on important aspects of MNH such as danger signs, birth preparedness, family planning, breastfeeding, newborn care, etc. Since the ANC clinic is the first contact with the women, it is necessary for the service providers to seize the opportunity and spend more 
time to give appropriate counselling, health education and discussion of plans for delivery. This will not only provide knowledge, but also build trust towards health facility.

- As the PNC behaviour significantly lags, efforts should be promoted to go for a PNC check-up within a week of birth (if the child is delivered in health facility) or immediately (if the child is delivered at home). In addition, a deliberate attempt is needed to deal with the culturally harmful practices prevailing during postnatal period.

- Recognizing the low awareness and use of family planning, there is a need to educate and motivate the couples and improve family planning services to achieve more effective and appropriate use of contraceptives. As almost all the women are breastfeeding their baby, the community's acceptance of breastfeeding presents an important opportunity in educating the population on LAM as one FP method.

- BCC intervention should specifically focus on prevailing malpractices such as keeping hair in the mouth of women to remove placenta and forcefully pressing lower abdomen during deliver; providing chilly soup of women during postnatal period; belief that providing nutritious food to pregnant women may increase fetal size which cause difficulty in delivery; applying kerosene oil in umbilical cord, prelacteal feeding; no handwashing before feeding newborn, etc.

- BCC package should be designed focusing on changing the adverse behaviour of women, mother-in-law, family members and Chamain. The information in the package should contained self-designed pamphlets, posters and visual cards containing simple messages in local languages (Awadhi). Culturally appropriate images should be designed based on community and subject expert feedback as well as a pilot field study. Rather than distributing such aids to women and communities, health workers, FCHVs and community mobilizers should use them while counselling and discussing with women and family members

\section{References}

[1]. ACHARYA, D. R., BELL, J. S., SIMKHADA, P., VAN TEIJLINGEN, E. R. \& REGMI, P. R. 2010. Research Women's autonomy in household decision-making: a demographic study in Nepal. Reproductive health, 7, 1-12.

[2]. DEPARTMENT OF HEALTH SERVICE 2014. Annual Report. Kathmandu, Nepal: Government of Nepal, Ministry of Health and Population, Department of Health Service.

[3]. GARG, P. \& GOGIA, S. 2009. Reducing neonatal mortality in developing countries: low-cost interventions are the key determinants. J Perinatol, 29, 74-75.

[4]. KABAKYENGA, J. K., ÖSTERGREN, P.-O., TURYAKIRA, E. \& PETTERSSON, K. O. 2012. Influence of birth preparedness, decision-making on location of birth and assistance by skilled birth attendants among women in south-western Uganda. PloS one, 7, e35747.

[5]. KAPHLE, S., HANCOCK, H. \& NEWMAN, L. A. 2013b. Childbirth traditions and cultural perceptions of safety in Nepal: Critical spaces to ensure the survival of mothers and newborns in remote mountain villages. Midwifery, 29, 1173-1181.

[6]. KERR, R. B., DAKISHONI, L., SHUMBA, L., MSACHI, R. \& CHIRWA, M. 2008. "We grandmothers know plenty": breastfeeding, complementary feeding and the multifaceted role of grandmothers in Malawi. Social Science \& Medicine, 66, 1095-1105.

[7]. KHAN, M. H., KHALIQUE, N., SIDDIQUI, A. R. \& AMIR, A. 2013. Impact of behavior change communication among pregnant women regarding neonatal care. The Indian Journal of Pediatrics, 80, 804-808.

[8]. MASVIE, H. 2006. The role of Tamang mothers-in-law in promoting breast feeding in Makwanpur District, Nepal. Midwifery, 22, 23-31.

[9]. MINISTRY OF HEALTH AND POPULATION-NEPAL 2007. National Medical Standard for Reproductive Health: Volume III Maternal and Neonatal Care. Kathmandu, Nepal: Family Health Division. 
Texila International Journal of Public Health

Volume 4, Issue 4, Dec 2016

[10]. MULLANY, B. C. 2006. Barriers to and attitudes towards promoting husbands' involvement in maternal health in Katmandu, Nepal. Social Science \& Medicine, 62, 2798-2809.

[11]. MULLANY, B. C., BECKER, S. \& HINDIN, M. 2007. The impact of including husbands in antenatal health education services on maternal health practices in urban Nepal: results from a randomized controlled trial. Health Education Research, 22, 166-176.

[12]. NAWAL, D. \& GOLI, S. 2013. Birth preparedness and its effect on place of delivery and postnatal check-ups in Nepal. PloS one, 8, e60957.

[13]. SIMKHADA, B., VAN TEIJLINGEN, E., PORTER, M. \& SIMKHADA, P. 2006a. Major problems and key issues in Maternal Health in Nepal. Kathmandu University Medical Journal, 4, 258263.

[14]. UNICEF 2009. The State of the World's Children 2009: Maternal and Newborn Health. Newyork, USA.

${ }^{i}$ Chamain is a traditional birth attendance who is only allowed in the community to deliver the baby, ii Local made high calorie nutritious food of sugar, ginger,grains and dry foods

iii Very poor marginalized group of people in Nepal called lower caste too.

iv the name-giving ceremony for the new born after 9 days

${ }^{\mathrm{v}}$ Like Kangaroo mother care

${ }^{\mathrm{vi}}$ Higher caste people

${ }^{\text {vii }}$ Chlorhexidine antiseptic ointment

${ }^{\text {viii }}$ Cultural believe that kajal prevent the baby from evilsprit 


\title{
A Study on Factors Contributing to Communities not Accessing Anti Retro Viral Therapy [ARVs] in some Rural Health Facilities in Eastern Province of Zambia
}

\author{
Article by James Mwale \\ Master of Public Health, Texila American University, Zambia \\ E-mail: jamesamwale2005@yahoo.co.uk
}

\begin{abstract}
The competing economical, social and political challenges makes health to remain neglected in developing countries.

Patients cannot access the ARVs without CD4 count tests, as it is a marker for immune system.

Patients have easy access for HIV (Human Immune Virus) testing than for CD4 count. It is for this reason that Pima CD4 testing machines were introduced to enable those previously unable to offer CD4 testing, to do so.

Study data shows that facilities with Pima CD4 machines have higher patients number on ARVs than those who do not have.

It is for this reason that government and cooperating partners should support procuring more Pima CD4 machine for point of care.
\end{abstract}

\section{Introduction}

The Pima CD4 test is the first true point of care solution for CD4 testing. CD stands for cluster of Differentiation and refers to certain proteins on the surface of blood cells. Cells with different function express different classes of $\mathrm{CD}$ protein. In case of CD4 T Lymphocytes, the two determining CD proteins are CD3 and CD4.The body's immune response is co-ordinated by CD4 T Lymphocytes which circulate through the blood. These cells are also known as Thelper cells or Th cells.

After a primary infection with HIV, the virus directly attack CD4 T Lymphocytes to their destruction while using them as host cells for replication. Billions of CD4 T Lymphocytes may be destroyed every day, eventually overwhelming the immune system's regenerative capacity. Following an acute HIV infection, patients may remain free of HIV related illnesses, often for years, despite on going HIV replication. During this period, the immune system is continuously weakened but remains sufficiently competent to provide immune surveillance and to prevent most infections. Eventually, the progressive loss of CD4 T Lymphocytes results in the breakdown of appropriate immune response and the outbreak of opportunistic diseases, the pathological state of AIDS.

Although the decrease in the total number of $\mathrm{T}$ Lymphocytes may not always exactly match the qualitative functions of the immune system, the total CD4 T Lymphocyte number still remains the most robust surrogate marker of immune competence.

The main objective of Pima CD4 machine is to increase accessibility for early treatment or ARVs. The machine can be used both urban and rural areas. Pima CD4 machine uses battery, solar or alternate current.

However the Pima is designed equally to suit the needs of the health care professional in the field or in the Laboratory the Pima CD4 test provides an affordable, effective and valuable tool in the management of HIV patients.

\section{Background}

Eastern Province is one of the ten provinces of Zambia situated to eastern part of Zambia. The province is surrounded by nine districts, namely: Chipata, Chadiza, Lundazi, Katete, Mambwe, Nyimba, Sinda, Petauke and Vubwi. 
Texila International Journal of Public Health

Volume 4, Issue 4, Dec 2016

The beginning of Anti retro viral therapy (ARVs) started in Chipata district which is the provincial town of the province. This meant that all the districts were to send samples for CD4 count tests to the provincial laboratories at Chipata General Hospital by then, now it is Chipata Central Hospital.

There was overload of work to do CD4 counts for the all the districts with little human resource .Results were coming after one to two months, this meant that some clients found them in critical conditions and others died. Point of care was not their. Until 2002 few CD4 machines where introduced in some districts.2013 where the introduction of Pima CD4 count machine to some health facilities in the districts to improve the turn around time of diagnosis and treatment

\section{Study problem statement}

The factors contributing communities not accessing Anti retro viral therapy services in some rural health facilities in eastern province of Zambia.

There is need to procure more Pima CD4 lymphocytes count machine as it is an effective way of monitoring the status of HIV positive patient as they commence Anti retro viral therapy.

Out of 100 health facilities sampled only 30 represented having Pima CD4 lymphocytes count this is 30\%.Also those have access to ARVs when CD4 count is done and $70 \%$ health facilities refer their clients to other institution and commencement of treatment is compromised because of long distance coverage. Here results may get one or three months before the patients receives them or may get lost on the way.

Records shows that facilities with Pima CD4 count have more clients on HIV tests as well as those taking treatment(ARVs).In comparison with health facilities having no Pima CD4 lymphocyte count machine.

Therefore there is need for the government and cooperating partners to procure more Pima CD4 lymphocytes count machines so that facilities who do not have can benefit from good turnaround time of diagnosis and treatment.

\section{Specific objective}

- Improve turn around time on diagnosis and treatment.

- Increase access on counseling and testing for human immune virus [HIV].

- Increase on openings of ART centres or treatment centres.

\section{Justification for the study}

Patients who only test for HIV have no access to ARVs until a CD4 count test is done then they have access for ARVs, therefore there is need for Pima CD4 test machines to be procured in many health facilities as it helps in monitoring treatment in rural communities as there is no advanced machines.

\section{Literature review}

The Pima CD4 test comprises of a disposable Pima CD4 test cartridge and the Pima analyser, and enables the determination of absolute counts of CD4 T Lymphocytes in whole blood without prior sample preparation.

The disposable cartridge is equipped with means to take up approminately $25 \mathrm{ul}$ of sample and contains dried reagents needed to perform the test. The test is performed in its entirely within the confinement of the cartridge and no part of the analyser has at any time contact with the sample. This minimizes the risk of Analyser contamination and eliminates sample carry over between measurements.

After insertion of the test cartridge in the analyser peristaltic movement first transports the sample into the incubation compartment where the sample interacts with the specific antibodies to immunolabel CD4 T Lymphocytes with two different fluorescent dyes emitting light at two different wavelengths. One antibody is an antibody conjugated to PE- Cy5. The 
second antibody is an anti- CD4 antibody conjugated to PE. After a defined incubation time the stained sample is automatically transferred into the separate reading compartment of the cartridge.

The Pima analyser resembles a fluorescent microscope, equipped with miniaturised optics that detects fluorescence signals, controlled by an embedded computer. CD4 T Lymphocytes carry both CD3 and CD4 surface antigens and therefore emit light at wave lengths specific for both antibody - dye conjugates. This allows the specific differentiation of CD4 T Lymphocytes from other blood cell types carrying only one of the two surface antigens. Specific requirements with regard to signal intensity, object size and many other parameters need to be met in order for an object to be counted as a CD4 T Lymphocyte. This information is encoded in the barcode of every cartridge and is used by the Pima analyser to translate the raw count into a test result of cells/ul. The result is displayed on the analyser's screen.

Results and the date/time the test was carried out are also stored in an on -board archive and are assigned to a sample ID that has been entered into analyser by the operator. An external Pima printer can be used to print a Pima test report for each test. Data can be retrieved and down loaded by the operator at any time after the test.

It has been noticed that patients who go for early diagnosis of HIV and CD4 testing have advantages of treatment in time. Early treatment help minimize opportunistic infections. Because of this, consideration of procuring and installation of Pima CD4 machines in needy areas must be a priority to the government and cooperating partners. When these services can reach rural hard to reach areas we may prolong lives to those affected.

The beauty of Pima machine, is portable and use both batteries and alternate current. The designed equally suit the needs of the health care professional in the field and non health professionals. In both developed and developing countries Pima does a recommendable work. This machine once charged it can be used for eight hours. Reagents and controls can be stored at room temperatures between 2- 30 degrees centigrade. Samples, EDTA bottles are used or finger prick method.

When it comes to errors, an error code will be shown on the Pima screen for easy maintenance .Pima has also modem and simcard for sending data to centre place for analysis.

\section{The feature of PIMA analyser}

- Has on board data archive

- Embedded software

- No external calibration

- Main A/C and battery power

- Portable and robust

- Absolute CD4 count in 20 minutes.

- Two USB ports - Pima printer and data export.

\section{Reagents- Pima CD4 cartridge}

- All reagents are sealed in the disposable cartridge

- Require only 25ul of capillary or venous whole blood

- No cold chain storage

- No manual sample handling or processing.

\section{Storage}

- Reagents and beads standard are stored at room temperature 2 - 30 degrees

- If refrigerated bring to room temperature before use.

- Keep out of direct sunlight

- Open immediately before use only

- The Pima analyser will not run on expired cartridge cassette or Pima beads standards. 
Texila International Journal of Public Health

Volume 4, Issue 4, Dec 2016

\section{PIMA beads standards}

- External standard for daily quality control

- Two ready to use cartilage - Normal , Low

- Have set amounts of fluorescent beads inside each cartridge - No further reagents are required.

- Results should be within ranges specified inside storage box

- Once opened can be used for 6 months.

- Store in storage box at room temperature out of direct sunlight.

\section{Before introduction of Pima cd4 machine in health facilities}

- Patient used to cover long distance to access CD4 count tests

- Results took one to three month's time to be out because of backlog.

- Most patients die before getting the results and treatment

- There was long turnaround time.

- Voluntary counseling and testing for HIV was low because they had no access for CD4 count test and treatment

\section{After introduction of Pima cd4 machine in health facilities}

- Reduced covering long distance

- Improved turnaround time as patients could receive result same day.

- People's health lives improved due to early diagnosis and treatment

- Improved counseling and testing

- Increase demands of services

\section{Methodology.}

This topic explains and examines how data were collected using well developed tested tools as means towards realizing study objectives. In general the topic focuses on the study design, study area, study population, sample size and sampling procedure, data collection tools, data quality control and handling, data analysis, dissemination of results.

\section{Research design}

The study used a cross-sectional design. Data collection methods included questionnaire, record review and observations. The questionnaire was developed by the researcher and was self-administered to the participants.

\section{Research site}

The study site will be Eastern province which is in the eastern part of Lusaka the capital city of Zambia and has a distance of $600 \mathrm{~km}$ from the city. And Chipata is the provincial capital for eastern province. The province has nine districts namely; Nyimba, Petauke, Katete, Chipata, Chadiza, Sinda,Lundazi, Mambwe and Vubwi with approximately a population of 1.8 million.

\section{Study population}

The province has roughly a population of 1.8million which is inclusive of farmers,business persons,workers in government and non governmental organization and non employed class. The participants in the study will be drawn from all these categories so that there is equal representation of the views.

\section{Sample size and sampling process}

The study sample size from the selection at the province was considered at following the formula and calculation as shown below:

The estimated number of patients accessing the ARVs services after HIV positive and CD4 testing is about 2000 . 
The approach used was for Systematic sampling.

- A complete list of all individuals in the study population was obtained

- Required sample size was determined

- The first individual was selected randomly from the study population list.

- After that each n(number) individual in the study population is selected e.g.

Study population $=500000$

Required sample size $=2000$

Say the first randomly selected number $=120$ from there on wards, select

$500000 / 2000=250^{\text {th }}$ number

Thus, the second number will be $=120+250=370$

The third selected number $=370+250=620$ etc.

It is simple, cheap, quick and convenient to execute if a complete list of the study population is readily available.

\section{Sampling process}

Sampling is the procedure a researcher uses together, people, places or things to study. It is process of selecting a number of individuals or objects from a population such that the selected group contains elements representative of the characteristic found in the entire group Orodho and Komba (2002,Quotd in Kombo and Tromp,2014,P,77).Therefore, this study employed a purpose sampling process/procedure to enable all patients have equal chance of being interview. Selection of the participants was from all categories of patient from health facilities. This technique was used in order to have a generalized representation of the population for the province

\section{Research instruments/ tools.}

The research instruments used in this research study were semi-structured questionnaire with both open and closed ended questions, checklist for materials required for Pima CD4 counting testing and observations. The questionnaire was designed focusing on the specific objectives of the study from which questions were developed. The observation technique was further used to have a physical check whether Pima CD4 count machine were available or not and correctly used in all targeted areas of the health facilities for this study.

\section{Data collection procedure.}

The procedure in which data was collected from the participants was through distribution of the self-administered questionnaire, analysis of the implementation of planned activities from the action plans and budgets for 2016 respectively on Pima CD4 lymphocytes count management. Furthermore, structured type of observations had to be carried out in wards and outpatient department. The reason was to observe whether all HIV positive persons have access to CD4 count as well as Antiretroviral therapy. The interviews were carried out in the months of May and August, 2016. The main questions was factors contributing to communities not accessing Antiretroviral therapy in some rural health facilities in Eastern Province of Zambia.

\section{Data management and analysis}

The raw data collected from participants at the facility had to be checked by the principle researcher each time it was collected and whatever was not convincing, effort was made to ensure correct data was got from all the respondents. This was to ensure completeness and consistence of the data in all the interview guides. The analysis of the data after compilation was through the use of the SPSS (version 20). Data cleaning was performed by running each variable to check the accuracy, inconsistency and missed values.

\section{Pre-testing of tools}

The data collection tools were the semi structured interviews (self-administered questionnaire) and checklist tested in 2 units of the health facilities in order to validate them 
Texila International Journal of Public Health

Volume 4, Issue 4, Dec 2016

prior to roll out to others. As for the observations, these were strictly the responsibility of the researcher as the units were being visited.

Installation of Pima CD4 machines in needy areas must be a priority to the government and cooperating partners. When these services can reach rural communities we may improve community lives

\section{Management of the project}

During this project of Pima CD4 machine count testing, we shall collect data to facilities were Pima CD4 count testing is done. And also collect data in health facilities where there is no Pima machine. While doing this will collect data for voluntary counseling and testing for HIV in health facility.

In this research we shall involve Laboratory scientist, Nurses, Clinical officers, Doctors, Pharmatist and nutritionalist.

\section{Financing}

\begin{tabular}{|l|l|l|l|}
\hline ITEM & QUANTITY & $\begin{array}{l}\text { UNIT PRICE. } \\
\text { USD }\end{array}$ & TOTAL. USD \\
\hline Stationary & & & \\
\hline Leaf pad & 3pieces & 5 & 15 \\
\hline Ream of papers & 2 & 5 & 10 \\
\hline Pens & 10 & 0.15 & 1.5 \\
\hline Printing material & 1000 & 0.3 & 300 \\
\hline $\begin{array}{l}\text { Travel Eastern } \\
\text { province( to and fro) }\end{array}$ & 10 trips & 200 & 2000 \\
\hline $\begin{array}{l}\text { Personnel(research } \\
\text { assistant) }\end{array}$ & $\begin{array}{l}2 \text { personnel's x10 } \\
\text { days }\end{array}$ & $100 \times 2 \times 10$ & 40,000 \\
\hline Pima Machines & 100 & 5000 & 500,000 \\
\hline Reagents Cartridges & $1000[1 \times 100]$ & 200 & 200,000 \\
\hline $\begin{array}{l}\text { Controls Beads } \\
\text { Standard }\end{array}$ & 200 & 100 & 20,000 \\
\hline & & $\begin{array}{l}\text { GRAND } \\
\text { TOTAL }\end{array}$ & $\mathbf{7 6 2 , 3 2 6 . 5 0}$ \\
\hline
\end{tabular}

\section{Time frame}

The project will start with data collection starting May to August.Then September to October,2016. Will be compilation of data and analysis. November,2016 final report writing.

\section{Ethical consideration}

Ethics is defined by Webster's dictory in Bahttachrjee(2012) as conformance to the standards of conducts of given profession or group. He further contents that ethics is the moral distinction between right and wrong and what is unethical may not necessarily be illegal.This is an important aspect in research as it protects participants from harm. To this effect, ethical clearance for the study to commence was granted by provincial Medical Officer, who is the in charge of the province as the province does not have the ethics committee which is supposed to carry out the functions. In addition consent was sought from various health facilities and individual participants before the planned tests could be used to the target group. It was imperative that respondents understood what their participantion in the study would involve. Information about the study as well as the consent forms had to be written and explained and signed consent forms were obtained from each of the respondents. 


\section{Voluntry Participation}

The respondents were informed that participation in the study was voluntary. The purpose of the study was explained to the respondents so that they could make informed decisions about whether or not to participate in the interview. They were assured that participation was purely voluntary and that even if they decided to stop at any time during data collection process, they would not be prejudiced in any way.

\section{Shared confidentiality}

The respondents were informed about shared confidentiality between the researcher and the Texila American University. They were also assured that no information given would be shared with anyone with access to the research findings unless where the respondent gave permission. They were also assured that the information given would remain confidential and they will be no detrimental consequences from the answers given.

\section{Informed consent}

This principle is concerned with offering respect and protection to research participants through assurance of confidentiality of information shared and anonymity by not revealing the identity of individuals and institutions involved (Halai, 2006).

The respondents who participated in the study were requested to sign a consent form. The consent forms clearly stated that the information given was to be treated in strict confidentiality and no names or any form of identification was to be used that would link them with information provided. The consent form stated that participation was voluntary and that the interviewees could stop the interview at any moment. All the consent forms, interview sheets, and study material were kept in a safe and secure place. The researcher will destroy these materials when his supervisors instruct him to do so.

In general ethical principles were considered in all stages of the study. The participants were free to make decisions to answer or not, any questions. Secrecy was a priority and they did not disclose their names; only a code number in the questionnaire was used.

\section{Conclusion}

Pima CD4 is the first true point of care test for CD4. The Pima CD4 test consists of the Pima analyser and the Pima CD4 test cartridge.

The Pima analyser is a portable bench- top fixed volume cytometer used for the processing and analysis of a Pima test cartridge. For in vitro diagnostic use.

Pima CD4 provides an affordable, effective and valuable tool in the management of HIV patients.

Design to perform in laboratory as well as in non- Laboratory environments, the Pima analyser can be operated on external power or by using an on board rechargeable battery. The Pima analyser require no maintenance.

Results comes out within 20 minutes and the patient can wait. Capillary and venous blood can be used. Decentralized testing possible as Pima CD4 machine are now accessable in some health facilities. These allows the immediate measurement of CD4 counts, the further monitoring of the patients and as a consequence fast access to ART.

HIV patients are treated with antiretrovial therapy[ART] to suppress viral replication. Usually a mixture of several drugs is given. The initiation of treatment is determined by the concentration of $\mathrm{T}$ helper cells and the physical condition of the patient. However, there is need to increase the number of Pima CD4 machine to fasten the accessibility of treatment and diagnosis. 
Texila International Journal of Public Health

Volume 4, Issue 4, Dec 2016

\section{References}

[1] A. Cronje. Biomedical Science Research Methodology In Medical and Health Science- Nelson Mandela Metropolitan University. South Africa.

[2] Emmel N.(2013). Sampling and choosing cases in qualitative research; A realist approach London: Sage

[3] Gtlin LN. Lyons KJ. Successful grant writing. strategies for health and human service professionals. New York. Springer Publishing co.1996

[4] Kish, L.(1965). Survey Sampling.Wiley.ISBN0-471-48900-X.

[5] Medical Research Council of Canada. Guideline on research involving human subjects. Ottawa: Ministry of supply and services

[6] Marja J. Verhoef, PHD, Robert J. Hilsden, MD MSc FRCPC Departments of medicine and community Health Sciences University of Calgary, Alberta, Canada. 2001, 2004 RJ Hilsden, MJ Verlof.

[7] NIST/SEMATECH”7.2.4.2 Sample size required”, e Hand book of statistical methods

[8]

[9] Public Health Research methodology modules by Texila American University

[10] Pima analyser manual handbook

[11] San delowski, M.(1995). Sample size in qualitative research. Research in Nursing and Health,18,179-183

[12] Woodward DK. Clifton G.C. Development of successful research grant application. AM J hosp Pharm.51:813-822, 1994

[13] Zeiger M. Essentials of writing Biomedical Research papers. New York: McGraw-Hill Inch, 1991 


\title{
Knowledge, Attitude and Practice Towards Guinea Worm among the Resident's of Juba County in Central Equatoria State
}

\author{
Article by Sebit Mustafa Sebit Ebead \\ Ph.D in Public health, Texilla American University, South Sudan \\ E-mail: sebison81@gmail.com
}

\begin{abstract}
Introduction: Dracunculiasis is one of the oldest diseases known to man. Although it is not a killer disease, it is a disease of high morbidity and complications found mostly in farming populations. Its health, social, educational and economic cost to the individual, the household and the community which is considerable and it's transmission cycle are well documented. Key intervention strategies to eradicate guinea worm are safe water supply, vector control using abate, health education and case management.

General objective: To determine the Knowledge, attitude, Practices, towards Guinea Worm Disease in Juba County.

Methodology: The study was a cross-sectional study using both quantitative and qualitative methods of data collection. The quantitative method was face to face interviews while the qualitative method included Key Informants (KIs). It was conducted in Juba county 2015 by the principal investigator (PI) and a group of trained research assistants (RAs) to establish residents' Knowledge, Attitude and Practices, towards Guinea Worm.

Result: More than a quarter of respondents or relative have ever fallen victim of Guinea worm in their life (50/138 (36\%)). A large proportion of respondent perceive drinking infected water was a cause of infection (79/138 (55.7\%)), Most of respondent obtained drinking water from River/Stream (100/232 (43\%)), most respondent said someone with Guinea worm has very much difficulty in farming (63\%), Education level was found to be strongly associated with knowledge on the cause of infection of Guinea worm. $\left(X^{2}=26.249\right.$, d.f. $\left.=6, p>0.000\right)$.

Conclusion: A large proportion of respondent perceive drinking infected water as a cause of infection Guinea worm, More than a quarter of respondent's family member fallen victim of Guinea worm, In general the knowledge attitude and practice of respondent's in Juba County in addition to other confounding factors have had an impact on the Guinea worm eradication

Recommendations: both focused and integrated health education by the health workers need to be emphasized stressing to the communities the importance of Guinea worm eradication. This can be done both at the health unit and through specific and integrated outreaches such as immunization or mass awareness to cover three messages: That Guinea worm comes from contaminated water, Villagers should prohibit a person with blisters or ulcer from entering source of drinking water and that drinking water should be filtered or boiled before drinking.
\end{abstract}

\section{Operation definitions}

Infection: It is the entry of and development or multiplication of infection agent in the body of human or animal.

Case: in epidemiology is person in population or study group identified having a particular disease.

Host: Is a person or other living animal that allow the lodgment to an infection agent under natural condition.

Endemic: Is the situation where there is normally constant number of new cases of the particular disease. 
Texila International Journal of Public Health

Volume 4, Issue 4, Dec 2016

Knowledge: Information, Understanding and skills that you gain through education or experience.

Endemic areas: Areas where a particular disease is constantly present Disease

Prevention: Stopping something bad from taking place

Household: A group of people who normally live together and share activities the can be relatives or friends.

Respondent: A person who answers questions especially in a survey.

Spouse: A husband or wife.

Schedule: A programmed or planned event to be performed

\section{Acronyms}

$\begin{array}{ll}\text { CDC } & \text { Center for Disease Control } \\ \text { CHT } & \text { County } \\ \text { Epi- Info } & \text { Epidemiology Information } \\ \text { GWEP } & \text { Guinea Worm Eradication Program } \\ \text { IDPs } & \text { Internally displaced people } \\ \text { KIs } & \text { Key Informants } \\ \text { MOH } & \text { Ministry of Health } \\ \text { PI } & \text { Principal Investigator } \\ \text { PP } & \text { Pages }\end{array}$

RA Research Assistant

SSGWEP Southern Sudan Guinea worm Eradication Program

WHO World Health Organization

\section{List if appendices}

1. Introduction letter from Kampala International University

2. Proposed work plan and budget

3. Chi-square Table

4. Questioner

5. Key Informants Guide

6. Map of Sudan 


\section{Introduction}

\section{Background}

Dracunculiasis is one of the oldest diseases known to man. Although it is not a killer disease, it is a disease of high morbidity and complications found mostly in farming populations. Its health, social, educational and economic cost to the individual, the household and the community which is considerable and it's transmission cycle are well documented. Key intervention strategies to eradicate guinea worm are safe water supply, vector control using abate, health education and case management. (Morenikeji and Adekolu, 2009)

In 1986, WHO designated dracunculiasis as the next disease scheduled to be eradicated by 1995 after smallpox (Hopkins and Ruiz-Tiben, 1991). This eradication deadline was not met and WHO then hoped to certify eradication by 2005. At the 2006 World Health Assembly (WHA) in Geneva, WHO discussed additional measures needed to stop transmission in all of the remaining endemic countries by the end of 2009 (Olajumoke, 2010).

At the beginning of the 20th century, guinea-worm disease was widespread in many countries in Africa and Asia. It is estimated that there were about 50 million cases in the 1950s. Due to concentrated efforts by the international community and the endemic countries, the number of cases of guinea-worm disease was reduced to about 96000 by 1999. Guinea-worm disease is prevalent in only 13 countries in Africa including Sudan, Nigeria, Ghana, Burkina Faso, Niger, Togo and Côte d'Ivoire. A small number of cases have also been reported in Uganda, Benin, Mali, Mauritania, Ethiopia and Chad (WHO, 2001).

There has however been tremendous progress towards the eradication of the disease. The World Health Assembly in 1986 reported that an estimated 3.5 million persons in 20 countries had the disease and approximately 120 million persons were at risk of infection in 1986. By the end of 2002, annual incidence of the disease had been reduced by more than $98 \%$. The burden of guinea worm disease today occurs in Sudan, Ghana and Nigeria. These three countries account for 93\% of all cases worldwide (Morenikeji and Adekolu, 2009).

Dracunculiasis, guinea worm disease, is an incapacitating disease affecting people in poor, remote areas of Africa, Yemen, and a few remaining areas of the Indian subcontinent where there is poor access to protected water sources. The neglect of this preventable disease and its belated recognition are analyzed within the context of changing priorities for health since the 1870s, especially the shift from the paradigm of imperial medicine to primary health Care (John, 1997)

According to Carter center (2009), reported that the disease is endemic in only six African countries: Ethiopia, Ghana, Mali, Niger, Nigeria and Sudan. WHO and its main partner, The Carter Center, are consolidating support from the international community, donors, partners and political leaders in endemic countries and communities in order to eradicate guinea worm disease

The challenge now is to interrupt and contain transmission of all cases by the end of 2009 and subsequently achieve eradication of the disease. It is crucial to implement stricter methods of reporting as the number of cases becomes fewer. WHO is now calling for uninterrupted surveillance in all endemic areas of countries at risk for a resurgence or outbreak of the disease (Carter Center, 2009).

In January-November 2007, Southern Sudan reported 6,068 cases, which is a reduction of $60 \%$ from the 15,054 cases estimated to have occurred during the same period of 2006 The cases in 2007 were reported from 2,114 villages, including 1,881 villages with indigenous cases. During the same period, Southern Sudan exported 2 cases to the northern states of Sudan, 3 cases to Ethiopia, and 4 cases to Uganda. 74\% (4675) of cases in 2007 were in persons 15 years of age and older, while 52\% (3279) of cases were in males. Forty-nine percent of cases were reportedly contained in 2006 and again in 2007, while the rate of reporting from endemic villages improved from 63\% in 2006 to $75 \%$ in 2007 (WHO, 2008). 
Texila International Journal of Public Health

Volume 4, Issue 4, Dec 2016

Sudan is the world's largest reservoir of guinea worm disease, with 70 per cent of the 35,000 cases provisionally reported in 2003. Ghana and Nigeria are the next largest endemic countries (CDC, 2003).

Sudan has now reported a provisional total of 20,581 cases (49\% contained) from 3,264 endemic villages in January-December 2006, with an average reporting rate of $59 \%$ among endemic villages. A total of 19,232 villages in South Sudan are under surveillance. UNICEF/South Sudan has completed 8 of 20, boreholes originally promised in Eastern Equatorial State's highly endemic Kapoeta County during 2006. The 8 villages concerned reported 556 of cases of dracunculiasis in 2006. None of the 13 existing boreholes scheduled for rehabilitation were rehabilitated, which could have impacted another 2,406 cases in those communities (CDC, 2007).

The number of people with guinea worm disease in the Sudan had dropped appreciably from 20,581 to 5,585 cases in 2007 (MOH southern Sudan, 2008).

According to Guinea worm eradication program status of indicators in endemic villages during 2006-2008, villages reporting indigenous cases in 2006 were 3,137 with number of cases 20, 581, while in 2007, villages reporting indigenous cases were 1,765 with number of cases 5,815 and in 2008 villages reporting indigenous cases were 947 out of 2,301 endemic villages, the reported cases is 3,618 (MOH, 2008).

About 73\% of the cases of Guinea worm reported in 2008 were from Sudan, a total of 2185 new cases from 841 villages in southern Sudan (SSGWEP, 2009).

Southern Sudan contains approximately 86 percent of all remaining cases of Guinea worm disease in the world, while Juba county report 125 cases mostly in two Payam/ sub county in 2010 (CDC, 2010).

\section{Statement of the problem}

Protracted war in south Sudan has resulted in a general collapse of formerly existing health program, the urgent of this situation has recently changed dramatically with many people returning to their villages including investors, the evidence of the phenomenal population build up and lack of water and sanitation services make Sudan to remain the greatest challenge to Guinea worm disease eradication; it reported approximately 20,300 cases in 2006, a significant but expected increase from the 5,569 reported in 2005. Southern Sudan contains approximately 86 percent of all remaining cases of Guinea worm disease in the world (CDC, 2010).

The effects of the disease are crippling. Its victims develop large ulcers, usually in the lower leg. The ulcers swell, at times to the size of a tennis ball, and burst, releasing a spaghetti-like parasitic worm ranging in length from $500-800 \mathrm{~cm}$. Victims experience a pain so excruciating that they say it feels as if their leg is on fire. Anecdotal evidence County health office shows that the problem is wide spread in two pay am, It has been long standing, affecting mainly those who are poorly educated, the low socio-economic status, and single mothers or parents.

The Southern Sudan Guinea Worm Eradication Program oversees a community-based system that supports active surveillance, monthly reporting of cases, health education, distribution of cloth and pipe filters,

In trying to solve this problem the county and partnership with NGOs, through the community own resource persons has tried to increase community mobilization for health, targeting especially the opinion leaders. This effort however has not changed the situation a lot.

A study needed to be carried out to fine out factors that have lead to occurrence of the disease, and means of prevention strategies.

\section{Research questions}

1. What are the factors responsible for the high prevalence of Guinea worm among the resident's of Juba County? 
2. What is the knowledge of the respondents, towards Guinea worm among the resident's of Juba County?

3. What are the attitudes of the respondents, towards Guinea worm?

4. What are the practices of respondents, towards Guinea worm?

\section{General objective}

To determine the Knowledge, Attitudes, Practices, towards Guinea Worm Disease in Juba County.

\section{Specific objective}

1. To determine socio-demographic profile of respondents of Juba County.

2. To assess the level of knowledge and practices towards prevention of Guinea worm among the resident's of Juba County.

3. To determine the attitudes of the respondents towards Guinea worm eradication program in Juba County.

\section{Justification}

Humans are the only known reservoirs for guinea-worm disease, so provision of poor water in remote rural areas of Juba Sub County, increase the infection of guinea-worm. About $86 \%$ of the cases of Guinea worm reported in 2009 were from Sudan. (SSGWEP.2010)

Every case of guinea worm disease posed a potential health risk to the community and should therefore be reported to the health authorities, the continuous movement of internally displaced people (IDPs), returnees and soldiers is a factor that could interrupt efforts to eliminate guinea worm in southern Sudan. In conditions of severe limitations of infrastructure services and skilled human resource in post conflict Southern Sudan, developing hygiene and sanitation framework and utilizing affordable community based communication strategies would yield positive results. This would facilitate knowledge base intervention, which includes the following:

- $\quad$ Findings of the KAP Survey will support the development of sound and evidence-based.

- Communication strategies and sector specific interventions for behavior change in endemic village.

- The study will support and serve as an instrument for planning for the line ministries of the GOSS and all sector partners for acceleration of outreach and coverage for effective and efficient interventions in the eradication guinea worm, prevention and other water borne diseases.

- The Survey findings will significantly contribute to the development of long term sustainable program intervention that would influence the guinea worm eradication program at the operational stage.

Therefore, in addition to increasing community mobilization, a study on KAP needed to be carried out to find out in order to determine whether they are among the potential factors contribute to the occurrence of the diseases in the study area.

\section{Literature review}

\section{Background}

There is evidence that Dracunclus medinensis had been identified as early as 1530 BCE. It is also believed to be referenced in the Bible in Numbers as the fiery serpents set upon the Israelites

"And they journeyed from mount Hor by the way of the Red sea, to compass the land of Edom: and the soul of the people was much discouraged because of the way. And the people spake against God, and against Moses, Wherefore have ye brought us up out of Egypt to die in the wilderness? for there is no bread, neither is there any water; and our soul loatheth this light 
Texila International Journal of Public Health

Volume 4, Issue 4, Dec 2016

bread. And the LORD sent fiery serpents among the people, and they bit the people; and much people of Israel died. Therefore the people came to Moses, and said, We have sinned, for we have spoken against the LORD, and against thee; pray unto the LORD, that he take away the serpents from us. And Moses prayed for the people. And the LORD said unto Moses, Make thee a fiery serpent, and set it upon a pole: and it shall come to pass, that every one that is bitten, when he looketh upon it, shall live. And Moses made a serpent of brass, and put it upon a pole, and it came to pass, that if a serpent had bitten any man, when he beheld the serpent of brass, he lived". Numbers 21:4-9. (Kelly and perera, 2006).

According to this passage, however, the fiery serpents kill many of the Isrealites and so do not seem to be the same as $\mathrm{D}$. medinensis which have a low mortality rate. It is also speculated to be a potential origin of the Staff of Life, also called the Rod of Asclepius, which is represented as a serpent wrapped around a staff. Because of the treatment for Guinea Worm Disease involves wrapping the parasite around a stick, it is thought to be related to this common medical image. Additionally it has been thought the image may be reference to pole described in the same passage in Exodus that the fiery serpents appear in. (Cairncross el al, 2002).

\section{Etiology of guinea worm}

The guinea worm, or Dracunclus medinesis, is a nematode transmitted through drinking water. A person drinking stagnant water containing water fleas (copepods/Cyclops) infected with mature, third-stage, guinea worm larvae. When the copepods reach the stomach, they are broken down and the larvae released. The larvae move to the free abdominanal apace. The gravid female is found in the subcutaneous tissue, especially legs, feet and knees, and rarely of other parts of the body. Where they grow for two months and then mate, after mating the male worm dies and adult female worm migrate through tissues, usually to the lower extremities of the human body. Growing and maturing as the year progresses. About a year after the hosts' ingestion of infected water, the worm releases first-stage larvae. The first-stage larvae can survive in the water without a host (copepods) for up to three days. After having been eaten by the water flea, the larvae develop within the fleas body for two weeks to a third-stage larvae, again ready to infect people, there is no animal reservoir for disease (Pedro and Boris, 1987).

\section{Life cycle of guinea worm}

The lifecycle of Dracunclus medinensis involves an intermediate host, a copepod usually of the genus Cyclops, and the definitive host, humans. Larvae in water are digested by the copepods, called water fleas, where they develop into the infective stage after 10-14 days. Water infected with water fleas are drank by humans. Once ingested, stomach acid disintegrates the water flea, exposing the larvae. The larvae will then travel through the small intestine to the body cavity. The large female and the small male will mate in a 10-14 month time period. After mating the male, who has reached approximately 1.2-2.9 cm, dies and is absorbed by the female which, afterward, reaches $60-100 \mathrm{~cm}$. Now the female contains within her thousands to millions of larvae. She will migrate through the body, usually to a lower extremity, reach the surface and die. She will begin to expel from the body. When the exposed parasite comes into contact with water, larvae detach and infect the water. Perhaps because of the parasites migration from the intestinal tract to body tissue, it is thought to be an ancestral link between parasites of the digestive tract and filarial parasites of the tissue (Susan, 1998). 


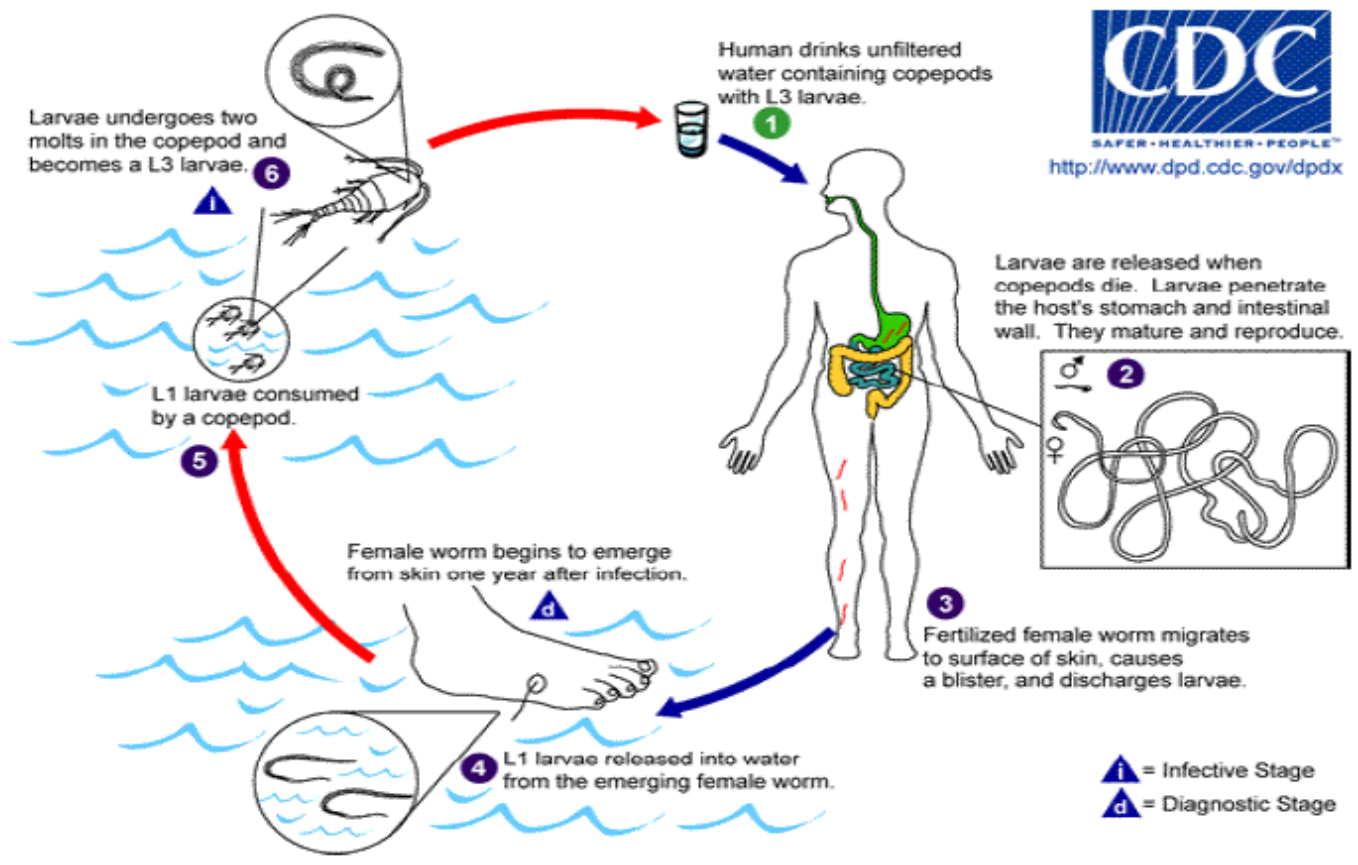

Figure 1. Life cycle of Drucunculusis (Daahir and Abdurahman, 2006)

\section{Source of infection and mode of transmission of guinea worm}

The disease is found in rural areas and is directly related to a lack of clean water in poor areas in arid regions or in parts of the tropics and subtropics with prolonging dry session. In the latter areas, maximum transmission occurs in the dry session when lagoons, ponds, and other bodies of water are at a low level and the density of infected copepods increases. In addition, the scarcity of usually forces the inhabitants to report to any sources available (Pedro and Boris, 1987).

The human host contaminates water with the larvae that escape from the emerging parasite, and in turn becomes infected by ingesting copepods, the intermediate hosts of Dracunculus medinesis, with water; the infection has a markedly seasonal character for tow reason:

1. The influence of climate on the water supply

2. The development cycle of parasite (Ralph, 1979)

In desert climates, however, transmission of the infection is more frequent in the rain session. The disease debilitates them at a time when they must be most agriculturally productive. ( $\mathrm{MOH}$, 2009).

In some areas, transmition may be greater in the dry season when people visit few pools. (Erik, 1999)

The scarcity of water usually forces the inhabitants to resort to any source available, the main sources of infection for man are shallow lagoons, ponds, well dug in dry river beds, wells that people must enter by means of access steps to obtain water. Copepods harboring the third stage larva constitute the infective element; the can only live in still water (Pedro and Boris, 1987).

In KAP study carried out in western Nigeria revealed that, majority of respondent $81.5 \%$ of those from the infected villages knew infection was from drinking infected water, while $61.2 \%$ knew in the villages at risk of infection (Morenikeji and Adekolu, 2009). 


\section{Clinical picture}

An inching and painful blister develops at the where the adult female worm emerge, thus making an ulcer. Ulcer can occur anywhere, but they are most common in body areas which are most likely to come into contact with water, feet, legs and genitals. The location of guinea worm infection was in the lower limbs (Morenikeji and Adekolu2009). The thread-likes worm can be seen in the ulcer (Erik, 1999).

\section{Treatment of guinea worm disease}

The infected parts of the body, mostly legs, were immersed in water when there is a lesion so that the worm can protrude and be wound on a stick. The sites of infection were cleaned with an antiseptic and bandaged to prevent worm from retracting and villagers from dipping the affected part in pond water (Olajumoke, 2010).

The work of Awayumi el.al (2010) on the Socio-economic burden of guinea worm disease in Ogun State: A discriminant analysis approach reveal that substantial numbers of respondents (68\%) still combine traditional methods of treating the disease with orthodox methods.( Awayumi and Sowunmi, 2019)

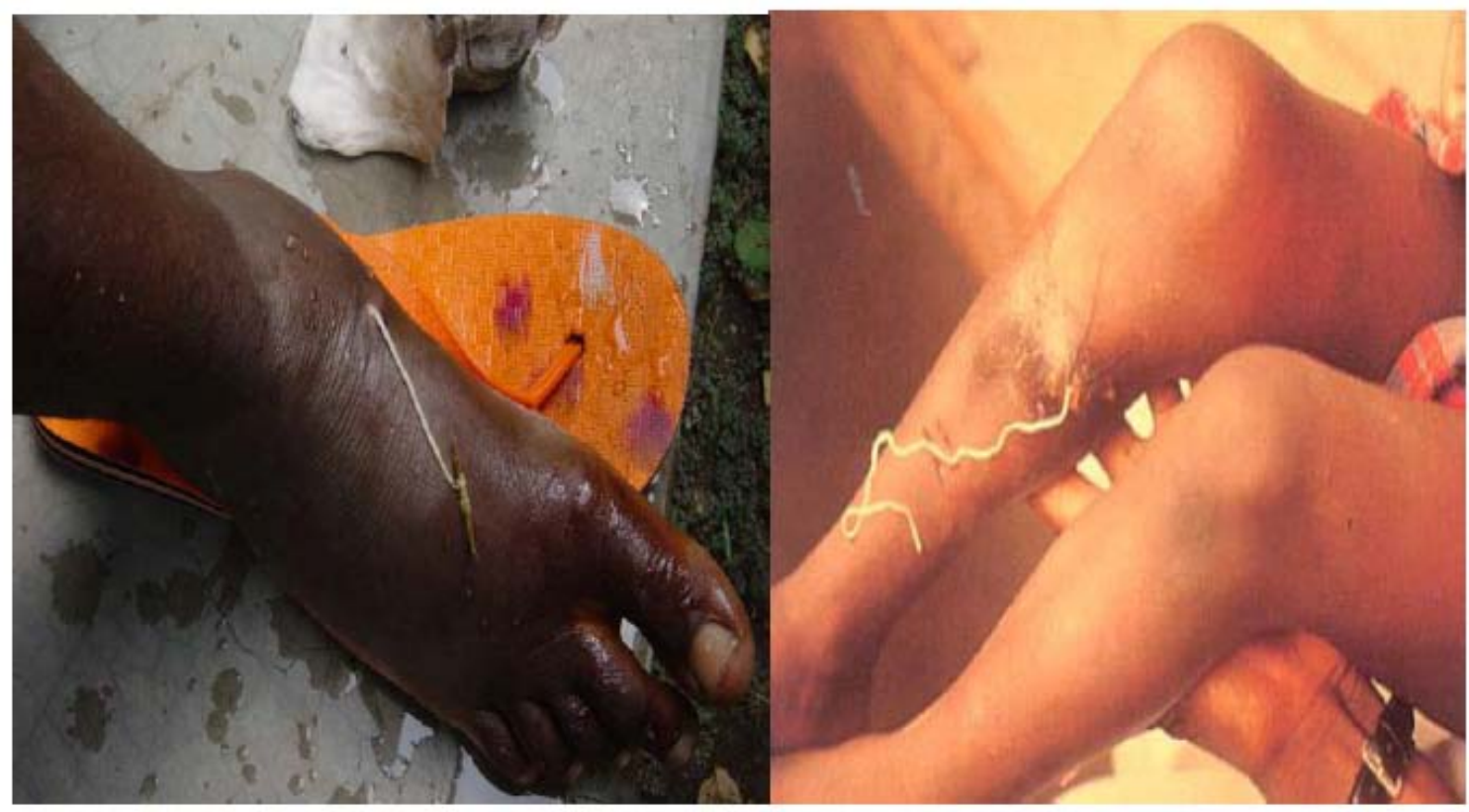

Figure 2. Worm emerge from patient leg, thus making as ulcer

\section{Economic impact of guinea worm}

Health care is consumption good as well as an investment good. As a consumption good, health care improves welfare, while as an investment commodity, health care enhances the quality of human capital by improving productivity and increasing the number of days available for productive activities. In fact, the time lost in production because of ill health indicates reduced output. This in part explains why guinea worm as a parasite that can cause ill health, has attracted a lot of studies ( Awayumi and Sowunmi, 2019)

A study carried out by Olunjde, (2008) high lighted the farmers perception on the effect of guinea worm disease on the level of their agricultural production revealed that $95.8 \%$ of them perceived that guinea worm disease had effect on the level of agricultural production, while $4.3 \%$ of them perceived that guinea worm disease had no effect on the level of their agricultural production. 
In Study in Nigeria, found that because of the disease, women were unable to care normally for themselves, their children, or their households or do other work that would add income to the family. The study of one of these two areas indicated that more than half the children who failed to appear for immunizations did so because their mothers were too ill with the disease to leave home and bring them to the clinic (David, 1990).

Morenikeji and Adekolu (2009) mentioned that $87.2 \%$ of those infected before claimed that the infection had very serious effect on their farming activities, 79.5\% said effect of infection on their economic well being for the period of infection was very high and $71.8 \%$ claimed it had very serious adverse effect on their social activities.

The period of absence from the farm may be long where both parent and children are infected by the disease. Those who are able to recover from the attack often abandon rural areas for towns and cities. revealed that large proportion of economically productive individuals of endemic villages are usually affected resulting in decreased agricultural productivity and economic hardship which often lead to rural-urban drift with its attending problems of overpopulation and increase in crime rate (Awayumi and Sowunmi, 2019).

\section{Prevention and control of guinea worm}

This is an example of a condition that can be eradicated if there is stability and community education and involvement (Erik, 1999).

Health education, which is a strong component of guinea worm disease eradication interventions, is believed to be capable of encouraging people to behave in a way that will help prevent the spread of guinea worm disease. Being able to see the link between contaminated pond water and guinea worm disease and behaving in a way to avoid drinking contaminated water offers a prospect of guinea worm disease eradication, while financial assistance from governments and non-governmental organizations towards provision of safe water sources is being awaited (Olunjde, 2008).

Involvement and participation of all community and stakeholders to eradicate Guinea worm, is the key to success. Guinea worm is eradication is about partnership, the most important of which is the partnership between the eradication program and the community (SSGWEP, 2009).

The combination of both persistent education to change behaviour patterns and implementation of measures to provide safe water has been shown to be effective in the reduction of the disease in previous studies (Olajumoke. 2009).

\section{Community base approach to eradication}

Guinea worm can only be eradicated through an intensive community effort. People at risk have the primary responsibility for taking personal and community actions that have proved effective. PCVs and other outsiders can help and promote the community's efforts, but the community must solve its own problems.

Community education is especially critical since the overall objective of the GWEP is to promote WHO's goal of eradicating Guinea worm disease by 1995. Some organizations feel that the five-year goal is unrealistic and demands too heavy a concentration of money and resources; thus some interventions have been aimed at controlling the disease instead of eliminating it. The intention is to reduce the incidence of Guinea worm to a level where public health authorities no longer consider the disease significant. To keep it within accepted limits, these efforts are focused exclusively on those areas that report a high number of cases (David, 1990).

The problem is, however, that rural peasants often move from one place to another, making the disease impossible to contain. Efforts to do so may have to continue indefinitely. in the long run, controlling the disease may be far more costly than conducting a five-year war of annihilation that involves educating the entire population to the causes and effects of Guinea worm. Even if 
Texila International Journal of Public Health

Volume 4, Issue 4, Dec 2016

the target date of 1995 is overly optimistic, waging the campaign may win the war by the year 2000. (David, 1990)

It has been high lighted by (WHO, 1998), that many cultures are reluctant to use health services because they perceive health care providers to be rude, patronizing and insensitive to the context in which they live. Interactions with the providers can be threatening and humiliating and women often feel pressure to make choices that conflict with their own health and fertility goals.

\section{Protection of water from contamination}

It has been mentioned in study carried out in central equatorial state that almost 60 percent of Juba households are using untreated water from the river or Khors as their main sources (Omar and William, 1994).

One approach to interrupting the Guinea worm cycle is to make sure that individuals suffering from emergence of worms do not come into contact with the water source itself.

Villagers can establish restrictions to make sure that no one with an open wound is allowed to draw water from the common water supply. Someone else can draw water for the person as long as the wounds continue (David, 1990).

As an additional protection, villagers can build platforms over their springs and ponds so that people can lower their buckets and draw water without setting foot in the water. Around shallow wells, they can place simple aprons and walls to prevent water from spilling against people's feet, becoming contaminated, and washing back into the well (David, 1990).

In Benin, with the assistance of UNICEF, the government is helping villagers dig infiltration galleries next to existing ponds. A sand dam allows the water to infiltrate from the pond into the gallery, which is protected to keep it free of the disease-carrying copepod or water flea (David, 1990).

\section{Filtration of contaminated water}

Filtering water to remove the disease-bearing flea is the most common method national programs in Africa are employing to deal with the Guinea worm problem. The method is easy and economical. Monofilaments of fine mesh gauze are being distributed to individuals and families so that they can filter the water in their homes. Ordinary cloth, folded over twice, is also being used for this purpose. Whenever possible, boiling the water is recommended as an added safeguard (David, 1990).

A study carried out by (Morinikeji and Adoklu, 2009) indicated that the water treatment mostly practiced by the respondents that treat water (67(88.2\%)) was filtering. 




Figure 3. A woman practicing Filtering of cloth in endemic village

\section{Chemical treatment}

Some national programs have sent government health workers to local communities to treat the water supply with the chemical temephos, also known by the brand name, Abate. The World Health Organization has endorsed the use of temephos as a safe mans of vector control. It only takes a small amount (1 mg. per litre) or 1 part per million of temephos to kill copepods; when applied in this amount, it will not harm humans, domestic animals, or fish.

The correct calculation of the volume of the water source and the amount of temephos to be added is of highest priority since any miscalculation may cause serious problems. If too much temephos is added, it can harm or kill other animals which live in or drink the water; if too little is added, it will not kill the copepods(David, 1990).

During the campaign to eradicate dracunculiasis, there has never been a single incident of human toxicity related to the use of ABATE larvicide (Temephos), including during the eradication campaign in Uganda. The ABATE larvicide's formulation for GWEPs is the $50 \%$ emulsifiable concentrate, and the standard dose used for control of copepod populations in stagnant sources of drinking water is one part per million, as recommended by the WHO Expert Committee on Insecticides.12 Assurance of safety of use of ABATE larvicide in actual or potential sources of drinking water is a function of the thorough training of ABATE larvicide application teams, adherence to the CDC Guidelines for Chemical Control of Copepod Populations in Dracunculiasis Eradication Programs, and the experience of ABATE larvicide application cadres in its use.( John et al, 2006)

It is not appropriate to use vector control in every affected village. If a village's source of drinking water is a large pond or lake, it may be too expensive to treat that much water. The suggested maximum size is 500 cubic meters of water. The chemical is added according to the amount of water the source contains. The application is easy: The chemical is mixed in a bucket with some water and sprayed or poured uniformly over the surface of the water. It will start to kill the copepods immediately. Temephos treatment should be scheduled in advance according to the peak Guinea worm season in that village or area. The community must be willing to cooperate, 
Texila International Journal of Public Health

Volume 4, Issue 4, Dec 2016

and health workers must first obtain permission from the village leaders to apply the temephos. (David, 1990)

The social impact of guinea worm disease is mainly attributable to the temporary disability suffered by the patient. Two longitudinal studies in Nigeria $(5,143)$ found that 58 to $76 \%$ of patients were unable to leave their beds for approximately a month during and after emergence of the worm. "The impact of this temporary disability is reinforced by the seasonal pattern of worm emergence; often peaking at stages of the agricultural year when the labor is maximum demanded.

Means of eradication are simple and hoped to be used as a demonstration of success for other eradication projects. Disease control efforts have universally moved from treating and preventing against individual infection to community protection, prevention, and eradication. (Kelly, 2006)

\section{The eradication initiative}

Guinea worm disease is a promising candidate for successful eradication. The cyclops is not a mobile vector like a mosquito, and the carrier state in both the cyclops and human hosts is of limited duration. Diagnosis is easy and unambiguous; cheap and effective measures are available to prevent transmission. The disease has a limited geographical distribution, and even within this area it is found only in certain communities of endemicity. Its markedly seasonal distribution in time also permits a more intensive focus on its prevention in seasonal campaigns. Lastly, as discussed above, transmission from animals to people is practically unknown (Sandy et al, 2002).

One of measures of controlling Guinea worm is that cases are advice not to enter drinking water sources while worm is emerged (Abran, 1995).

\section{Research methodology}

\section{Introduction: study setting}

\section{Study area}

The Study Area was Juba County of central equatorial state, South Sudan, which has been devastated by 22 years of civil warfare. Juba County is one of the two counties found to be endemic for guinea worm disease in central equatorial state, Juba county share boarder with the most infested county in central equatoria state which is Terkeka county. According to 2015 estimated population census, the population of the county was 372413.

The Bomas/villages under survey are Lokiyoro, lopepe, Giimara lunyalaki, and Jur tong paju yawa. These Bomas /villages are known to have a long experience of guinea worm infection they are predominantly farmers and Mundari speaking with Bari dialect. Main water sources in the Bomas /villages include rivers stream and ponds, and a borehole.

\section{Study design}

In this research, the researcher investigated the Knowledge, Attitude and Practices, towards Guinea Worm among residents of Juba Sub County in Sudan.

The study was a cross-sectional study using both quantitative and qualitative methods of data collection. The quantitative method was face to face interviews while the qualitative method included Key Informants (KIs). It was conducted in Juba county 2015 by the principal investigator (PI) and a group of trained research assistants to establish residents' Knowledge, Attitude and Practices, towards Guinea Worm.

\section{Study population}

The study population involves 138 households from Juba County. The study units were the heads of the households or their spouses at Juba County. 


\section{Inclusion and exclusion criteria}

\section{Inclusion}

Any adult in the household found to have roles to play in guinea worm disease control.

Any adult who is able to response appropriate to the questions.

\section{Exclusion}

Al heads of families in Juba Sub County who refuse to participate.

Al heads of families in Juba Sub County who participated in the study then withdraw due to any reason.

\section{Sample size determination}

Kish and Leslie (1965) formula was used to determine the number of the households that ware interviewed.

Sample size:

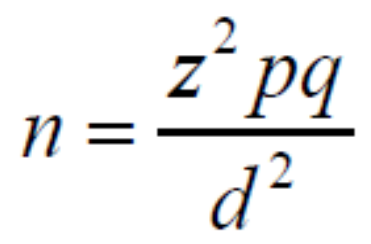

Where $n=$ sample size

$\mathrm{z}=$ scope corresponding to $5 \%$ level of significance

$\mathrm{d}=$ possible error to be tolerate $(0.05)$

$\mathrm{p}=$ expected population proportion (households) have Knowledge towards Guinea Worm in Juba county $89 \%, \mathrm{P}=(0.9)$. (WHO, 2005)

$\mathrm{q}=(1-\mathrm{p})=0.1$

Therefore, $n=[(1.96) 2(0.9 \times 0.1) /(0.05) 2=3.8416 \times 0.09 / 0.0025=0.345744 / 0.0025=138$

And for the anticipated non-response or badly filled, damaged or lost questionnaire it will be approximated to152respondents by adding $10 \%$.

\section{Sample selection procedure}

Multi stage, cluster sampling, purposive and random sampling methods were done. For key informants, purposive sampling was used while for the community respondents;

For the community a cluster sampling procedure was carried out from county to sub county level to parish (bumas) level;

Out of the fifteen sub counties (Payams) in Juba County, principal investigator selected Northern Bari sub county (Payam) and Tijor sub county (Payam) in Juba County because they are highly infested by Guinea worm and existing of the eradication program activities.

The principal investigator listed down the name of the endemic Parishes (Bumas) which make up Northern Bari sub counties (Payam) and Tijor sub county (Payam) in Juba Sub County.

The name of each endemic parish (Buma) was written in separate paper, and been folded, (to ensure that the entire parish (Buma) have the same chance of being selected.), and then principal investigator randomly pick two papers without replacement.

Lokiyoro and lopepe parishe (bumas) was randomly selected from twenty three parishes (Bumas) which make up Northern Bari sub county (Payam).

The same procedure was done to select Giimara lunyalaki, and Jur tong paju yawa required parishes (Bumas) from ten parishes (Bumas) which make up Tijor sub county (Payam). And this 
Texila International Journal of Public Health

Volume 4, Issue 4, Dec 2016

altogether gave a total of four parishes (Bumas) because each parish (Buma) was having equal chances to be selected, and the four parishes (Bumas) were representative for tow sub counties.

A total of 138 households were interviewed. In order to determine the households that was sampled or interviewed, the principal investigator obtained a list of all the households in parish (Buma) from the parish (Buma) chairpersons.

To ensure the sample of households was more representative; principal investigator calculated the proportion of sample according to each demographical area, to reduce the risk of drawing an extreme sample that is unrepresentative of the population. That was to ensure that equal and enough participants from each parish (Buma) in the sample to make valid comparisons.

To determine how many households to be sample from each parish (Buma). Principal investigator used the following calculations:

Household proportion $=$

Population of the parish (Buma) / Total population $x$ sample size

The same calculation was done to calculate the proportion of households to be interview in the four required parishes (bumas) from two sub counties.

At every required parish (buma), principal investigator identified one area of focus like a market or centred of the where the principal investigator stood and, spin a pen to get the direction of study. Cluster sampling was then done by identifying the first household in that direction for the interview and continued so with every successive fifth household until a total of eligible study units in that village had been interviewed. For the entire selected parish (buma) that make up a total of 138 respondents.

\section{Data collection process}

\section{Primary data}

\section{Quantitative data}

Semi- structured questionnaire was administered by the investigator (PI) and a group of trained research assistants (RAs) to the heads of the households.

Qualitative Data:

Included key informants interviews using KIs question guide. Which was purposively selected to include the following: Juba county health inspector, medical officer from the primary health care centers Northern Bari sub County (Payam) and Tijor sub County (Payam) in Juba County, director of Guinea worm program $\mathrm{MOH}$ central equatorial state, director of Guinea worm eradication program for Army, director of Guinea worm eradication program at carter center.

\section{Secondary data}

Include a summary of existing data. As opposed to data collected directly from respondents or "research subjects" for the express purposes of the study. These secondary data include previous research reports, Books, magazine and journal content, and government and NGO statistics.

\section{Administration procedure}

\section{Training of research assistants}

6 Research assistants fluent in English and Juba Arabic and Bari language, principal investigator selected those ones who had previous experience in data collection and trained them in data collection techniques and how to administer the questionnaire. 


\section{Pre-testing}

Prior to the interviews, the questionnaire was pre-tested in a parishes( bumas) that were not been included in the study so as to identify the difficulties, the mistakes and the misunderstanding in order to correct them.

\section{Field editing of data}

Everyday at the end of the data collection, the principal investigator checked and edit the questionnaire. The experiences and challenges of every day was shared and discussed among the research team and the next day plans was been set.

\section{Missing data}

Where there is a missing data, the research assistants were asked to go back to the field to collect.

\section{Quality control}

Quality was assured through the following:

Competent research assistants was carefully selected and trained.

For the purpose of translation the research assistants was fluent in English and juba Arabic and Bari to make sure that the respondents understand the questions.

The questionnaire was serially numbered to avoid loss and confusion. Field editing of the data was done by the principal investigator and the research assistants for correction of the errors and collection of missing data

Proper identification of key informants who are conversant with Guinea worm disease, Principle investigator select (nonrandom) group of experts who are most knowledgeable of the study issue.

\section{Ethical considerations}

Permission was sought from the from ministry of health central equatorial State through Kampala International University, northern bari payam.

Informed consent was obtained from respondents verbally

Keeping the names of the respondents out of the report ensured confidentiality

The purpose, objectives, benefits of the research outcome and participation procedures was explained to the participants.

\section{Data entry and analysis}

Data was entered EPI INFO 2002 and was analyzed using SPSS software. The information from the heads of the households or their spouses was analyzed and the results were presented as tables and graphs. The KIs interview information was analyzed manually using a master sheet and was presented as texts. Two by two tables was constructed in order to analyze associations between different variables. Chi square test was used to test the observed differences between the dependent and independent variables.

\section{Limitations to the study}

Some heads of households' were not available at their houses during the conduction of the study and this will be minimized by revisiting them and also by conducting the study during the weekends.

Some participants will give responses to impress the research team assuming that they are officials from northern bari payam. It will slightly bias the results. It will be minimized by thorough explanation of the purpose of the study. 
Texila International Journal of Public Health

Volume 4, Issue 4, Dec 2016

\section{Presentation of result, analysis and interpretation}

\section{Social demographic characteristics of respondents}

\section{Gender of the respondents}

The findings showed that majority of respondent's were males (61 \%) and few of them were females (40\%).

Table1. Gender of the Respondents

\begin{tabular}{|l|l|l|}
\hline VARIABLE GENDER & FREQUENCY $(\mathrm{N}=138)$ & PERCENTAGE (\%) \\
\hline Male & 83 & 61 \\
\hline Female & 55 & 40 \\
\hline Total & 138 & 100 \\
\hline
\end{tabular}

Age group of the Respondent $\mathrm{s}$

On age most respondent's age range 30-34 (31\%), followed by (20\%) of the respondents who were aged 35-39, (13\%) were aged 40-44 while (10\%) were above 45 years old and aged 20-24, (11\%) were aged 25-29 and few respondent's (4\%) for 15-19.

Table 2. Age group of the Respondents

\begin{tabular}{|l|l|l|}
\hline VARIABLE AGE GROUP & FREQUENCY $(\mathrm{N}=138)$ & $\begin{array}{l}\text { PERCENTAGE } \\
(\%)\end{array}$ \\
\hline $15-19$ & 6 & 4 \\
\hline $20-24$ & 14 & 10 \\
\hline $25-29$ & 15 & 11 \\
\hline $30-34$ & 43 & 31 \\
\hline $35-39$ & 28 & 20 \\
\hline $40-44$ & 18 & 13 \\
\hline $45+$ & 14 & 10 \\
\hline Total & 138 & 100 \\
\hline
\end{tabular}

Ethnicity of the respondents

Most respondent's were Mundari by tribe (65/138 (47\%)) followed by Bari (30 \%) and only Nyangwara (23\%).

Table 3. Ethnicity of the respondents

\begin{tabular}{|l|l|l|}
\hline VARIABLE & FREQUENCY $(\mathrm{N}=138)$ & PERCENTAGE $(\%)$ \\
\hline Bari & 41 & 30 \\
\hline Mundari & 65 & 47 \\
\hline Nyangwara & 32 & 23 \\
\hline Total & 138 & 100 \\
\hline
\end{tabular}

\section{Marital status of the respondents}

On marital status of the respondent's, majority are married (80\%), followed by single (15\%), while only (2\%) were widowed. However most respondent's (48 \%) were Monogamous, followed by (36\%) Polygamous and few (17\%) were single parents. 


\section{Education level of the respondents}

Slightly more than a Half of the respondent's attended primary schools (51\%), while more than a quarter of the respondent's never attended schools (39\%), and few (3\%) were Tertiary.

Table 4. Education level of the respondents

\begin{tabular}{|l|l|l|}
\hline VARIABLE & FREQUENCY $(\mathrm{N}=138)$ & PERCENTAGE $(\%)$ \\
\hline None & 44 & 39 \\
\hline Primary & 70 & 51 \\
\hline Secondary & 20 & 15 \\
\hline Tertiary & 4 & 3 \\
\hline Total & 138 & 100 \\
\hline
\end{tabular}

\section{Occupation of the respondents}

On occupation of the respondent's, it clearly depicts that a large proportion of respondent's were business persons (62/138 (45\%)), followed by (26/138(19\%)) who were peasants, Civil servant accounted for (34/138 (24.6 \%)), few respondent’s unemployed (16/138 (11.6 \%)).

Table 5. Occupation of the respondents

\begin{tabular}{|l|l|l|}
\hline VARIABLE & FREQUENCY $(\mathrm{N}=138)$ & PERCENTAGE $(\%)$ \\
\hline Peasants & 26 & 19 \\
\hline Business man/woman & 62 & 45 \\
\hline Civil servant & 34 & 25 \\
\hline Unemployed & 16 & 12 \\
\hline Total & 138 & 100 \\
\hline
\end{tabular}

\section{Knowledge of guinea worm transmit ion, cause and impact}

Knowledge of Guinea worm and member of family been fallen victim of Guinea worm.

The majority of respondents heard about Guinea worm (136/138 (99\%), while most respondents or relative have not fallen victim of Guinea worm in their life (88/138 (64\%).

Table 6. Knowledge of Guinea worm and member of family been fallen victim of Guinea worm

\begin{tabular}{|c|c|c|c|c|}
\hline VARIABLE & \multicolumn{2}{|c|}{$\begin{array}{l}\text { KNOWLEDGE OF GUINEA } \\
\text { WORM }\end{array}$} & \multicolumn{2}{|c|}{$\begin{array}{l}\text { MEMBER OF FAMILY BEEN FALLEN } \\
\text { VICTIM }\end{array}$} \\
\hline & FREQUENCY $(\mathrm{N}=138)$ & $\%$ & FREQUENCY $(\mathrm{N}=138)$ & $\%$ \\
\hline Yes & 136 & 99 & 50 & 36 \\
\hline No & 2 & 1 & 88 & 64 \\
\hline Total & 138 & $\begin{array}{l}10 \\
0\end{array}$ & 138 & 100 \\
\hline
\end{tabular}

All key informant mention that, the local name for Guinea worm was known as Firindid and Mejeke

Source of information's about Guinea worm cause, effect and prevention methods

A large proportion of respondents got information about Guinea worm from health workers (116/270 (43\%)), while more than a quarter got $t$ from relatives (116/270 (35\%)), only (3/270(1.1)) obtained information's from Radio. 
Texila International Journal of Public Health

Volume 4, Issue 4, Dec 2016

Table7. Source of information's about Guinea worm cause, effect and prevention methods.

\begin{tabular}{|l|l|l|}
\hline VARIABLE & FREQUENCY $(\mathrm{N}=270)$ & PERCENTAGE (\%) \\
\hline Relatives & 95 & 35 \\
\hline Radio & 3 & 1 \\
\hline Workshops/seminar & 25 & 9 \\
\hline Political/civil leader & 31 & 12 \\
\hline Health worker & 116 & 43 \\
\hline Total & 270 & 100 \\
\hline
\end{tabular}

Multiple responses (270)

\section{Knowledge of Guinea worm Symptoms}

Most respondents said that Pain and Swelling on lower limb was a symptom of Guinea worm (139/291 (48\%)), followed by only (32\%) who said Fever/ stream, and few said Blister on lower $\operatorname{limb}(13.7 \%)$.

Table8. Knowledge of Guinea worm Symptoms

\begin{tabular}{|l|l|l|}
\hline VARIABLE & FREQUENCY(N=291) & PERCENTAGE (\%) \\
\hline Fever/ stream & 92 & 32 \\
\hline Wound on lower limb & 20 & 7 \\
\hline Blister on lower limb & 40 & 14 \\
\hline Pain and swelling on lower limb & 139 & 48 \\
\hline Total & 291 & 100 \\
\hline
\end{tabular}

Multiple responses

\section{Knowledge on the cause of infection of Guinea worm}

A large proportion of respondent perceive drinking infected water was a cause of infection (79/138 (55.7\%)), while a quarter said eating infected food (35/138(25\%) and few mention something else (e.g. Dirtiness) (24/138 (17\%).
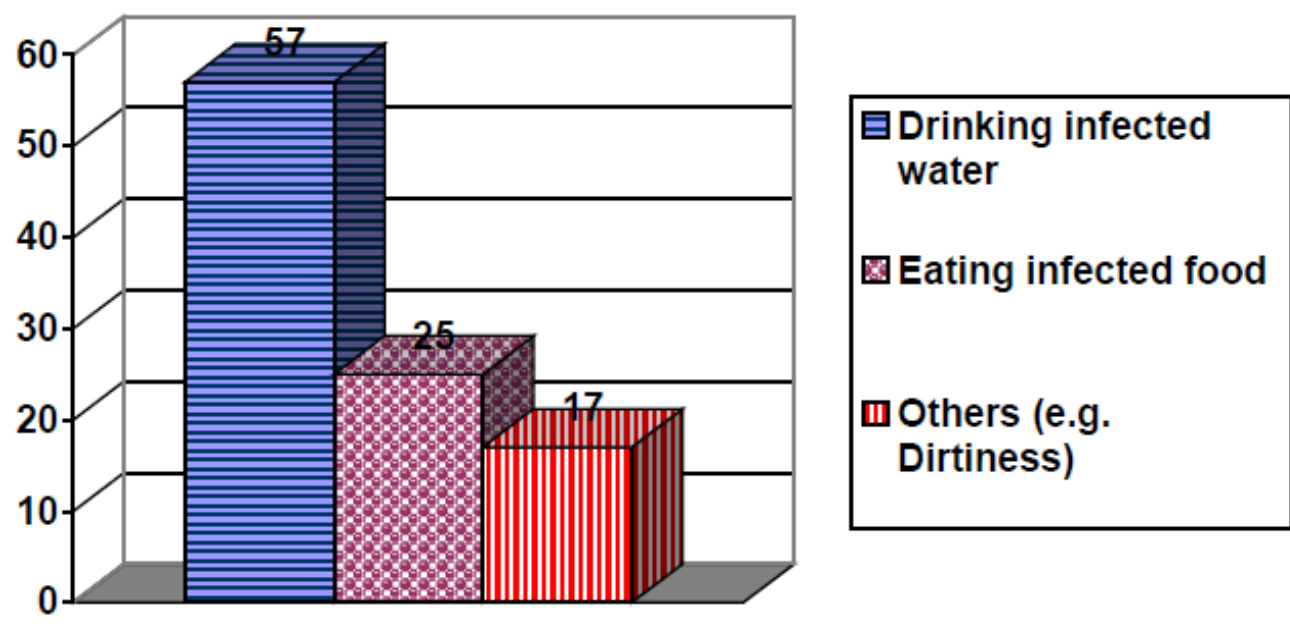

Figure 4. Knowledge on the cause of infection of Guinea worm 
Education level was found to be strongly associated with knowledge on the cause of infection of Guinea worm. (X2=26.249, d.f. $=6$, p $>0.000)$

\section{Sources of drinking water}

Most of respondent obtained drinking water from River/Stream (100/232 (43\%)), followed by more than a quarter from ponds 80/232(36\%), while only 48/232(21\%) obtain their drinking water from bore-hole.

Table9. Sources of drinking water

\begin{tabular}{|l|l|l|}
\hline VARIABLE & FREQUENCY(N=232) & PERCENTAGE (\%) \\
\hline River / Stream & 100 & 43 \\
\hline Bore-hole & 48 & 21 \\
\hline Well (un protected) & 4 & 2 \\
\hline Others (Ponds) & 80 & 36 \\
\hline Total & 232 & 100 \\
\hline
\end{tabular}

Multiple responses

\section{How community can help in preventing Guinea worm}

Many respondent said community can help in preventing Guinea worm by Educating children and other community members on how to prevent it (119/267 (45\%)). While a quarter reported that community can help in preventing Guinea worm by Communal labour to build boreholes (70/267(26.2\%)), few said they can help by Protecting sources of drinking water.

Table10. How community can help in preventing Guinea worm

\begin{tabular}{|l|l|l|}
\hline VARIABLE & $\begin{array}{l}\text { FREQUENCY(N=267 } \\
\text { ( }\end{array}$ & PERCENTAGE (\%) \\
\hline Communal labour to build boreholes & 70 & 26 \\
\hline Communal labour to clear bushes / vegetation & 36 & 14 \\
\hline $\begin{array}{l}\text { Educate children and other community } \\
\text { member's on how to prevent G.W. }\end{array}$ & 119 & 45 \\
\hline Protection of water sources & 42 & 16 \\
\hline Total & 267 & 100 \\
\hline
\end{tabular}

Multiple responses

\section{Difficulties associated with Guinea worm disease}

More than half of respondents said someone with Guinea worm has very much Difficult in walking (54\%), while few said they have a little difficulty in walking (26\%). Three quarter of respondents said someone with Guinea worm has very much difficult in running (71\%), while few said they have a little difficulty in running (16\%). Going to farm, most respondent said someone with Guinea worm has very much difficulty in farming (63\%), while only $22 \%$ said they have a little. Majority of respondent said someone with Guinea worm has very much Difficulty in earning enough to the family (76\%) and few said they don't have difficulty in earning enough to their families. 
Texila International Journal of Public Health

Volume 4, Issue 4, Dec 2016

Table11. Difficulties associated with Guinea worm disease

\begin{tabular}{|l|l|l|}
\hline VARIABLE & FREQUENCY(N=138) & PERCENTAGE (\%) \\
\hline Difficult in walking for them & 28 & 20 \\
\hline Not At All & 36 & 26 \\
\hline A Little & 74 & 54 \\
\hline Very much & 138 & 100 \\
\hline Total & 17 & 12 \\
\hline Difficult in running for them & 23 & 17 \\
\hline Not At All & 98 & 71 \\
\hline A Little & 138 & 100 \\
\hline Very much & 20 & 14 \\
\hline Total & 31 & 22 \\
\hline Difficult is it for them to go the farm & 63 \\
\hline Not At All & 87 & 100 \\
\hline A Little & 138 & 14 \\
\hline Very much & 19 & 10 \\
\hline Total & 14 & 76 \\
\hline Difficult in earning enough for the family & 100 \\
\hline Not At All & 105 & \\
\hline A Little & 138 & \\
\hline Very much &
\end{tabular}

\section{Attitude of respondents towards guinea worm}

Respondents Attitudes towards usefulness of Guinea worm eradication program

Majority of respondents perceived Guinea worm eradication program was useful (131/138 (96\%)), while only ( 6/138(4\%)) said was not Useful or useless.

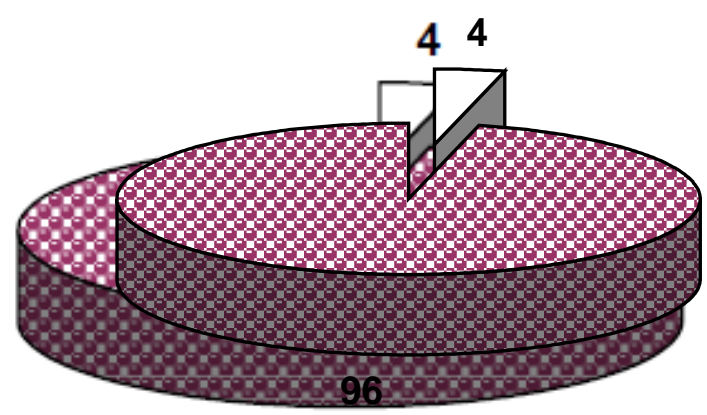

\begin{tabular}{|l|}
\hline$\square$ Useful \\
⿴囗十seless \\
Ouseless \\
\hline
\end{tabular}

96

Figure5. Respondents Attitudes towards usefulness of Guinea worm eradication program

Chi-square (X2) analysis of age, sex, Ethnicity and Education level and usefulness of Guinea worm eradication program is statistically not significant. 


\begin{tabular}{|l|l|l|l|l|}
\hline Variable & Chi-square & D.F & P-value & Remarks \\
\hline Sex & 0.061 & 1 & 0.805 & NS \\
\hline Age & 38.833 & 2 & 0.301 & NS \\
\hline Ethnicity & 0.314 & 2 & 0.855 & NS \\
\hline Education & 2.919 & 3 & 0.404 & NS \\
\hline
\end{tabular}

\section{Attitude of respondents towards health workers}

A large proportion of respondents perceived health workers as being rude (83/138 (60.6\%)), while only 43/138(31\%) perceived health workers as being friendly.

Table12. Attitude of respondents towards health workers

\begin{tabular}{|l|l|l|}
\hline Variable & Frequency(N=138) & Percentage (\%) \\
\hline Very friendly & 8 & 6 \\
\hline Friendly & 43 & 31 \\
\hline Rude & 83 & 61 \\
\hline Very rude & 3 & 2 \\
\hline Total & 138 & 100 \\
\hline
\end{tabular}

\section{Type of help needed externally to combat Guinea worm}

Most respondents said the external assistant needed to combat Guinea worm, was Technical support to educate people on prevention of Guinea worm (121/280 (43\%)), followed by more than a quarter who said provision of medication and filtrations tools $(94 / 280(34 \%))$, while only 26/280(9\%) said financial support.

Table13. Type of help needed externally to combat Guinea worm

\begin{tabular}{|l|l|l|}
\hline VARIABLE & $\begin{array}{l}\text { FREQUENC } \\
\text { Y(N=280) }\end{array}$ & PERCENTAGE (\%) \\
\hline Financial & 26 & 9 \\
\hline $\begin{array}{l}\text { Technical support to help build bore } \\
\text { holes }\end{array}$ & 10 & 4 \\
\hline $\begin{array}{l}\text { Technical support to help manage } \\
\text { cases in the community }\end{array}$ & 30 & 11 \\
\hline $\begin{array}{l}\text { Technical support to educate people } \\
\text { on prevention of Guinea worm }\end{array}$ & 121 & 43 \\
\hline $\begin{array}{l}\text { Provide medication and Filtrations } \\
\text { tools }\end{array}$ & 94 & 34 \\
\hline Total & 280 & 100 \\
\hline
\end{tabular}

Multiple responses

\section{Ever attended a seminar on guinea worm}

Few respondent reported to ever attended Seminar (25/138(19\%)), while majority 113/138 (82\%) were willing to attend seminar. 
Texila International Journal of Public Health

Volume 4, Issue 4, Dec 2016

Table14. Ever Attended a Seminar on Guinea worm

\begin{tabular}{|l|l|l|}
\hline Variable & Frequency(N=138) & Percentage (\%) \\
\hline Ever attended & 25 & 19 \\
\hline $\begin{array}{l}\text { Willingness to } \\
\text { attend }\end{array}$ & 113 & 82 \\
\hline Total & 138 & 100 \\
\hline
\end{tabular}

How community can be encouraged to participate in eradication program of Guinea worm

Many respondent said conducting meeting with community will encourage community to participate in eradication program (51/138 (37\%)), followed by mass awareness campaign (6/138 (33\%) while only 3/138 (2\%) don’t have any idea.

Table15: How community can be encouraged to participate in eradication program of Guinea worm?

\begin{tabular}{|l|l|l|}
\hline VARIABLE & FREQUENCY(N=138) & PERCENTAGE (\%) \\
\hline $\begin{array}{l}\text { Conduct meeting with community } \\
\text { members }\end{array}$ & 51 & 37 \\
\hline Community mobilization & 38 & 28 \\
\hline Mass awareness campaign & 46 & 33 \\
\hline Don't know & 3 & 2 \\
\hline Total & 138 & 100 \\
\hline
\end{tabular}

\section{Prevention and control of guinea worm}

\section{Community prevention methods}

More than a half of respondents said prohibiting patient from entering water sources was the means of prevention (80/138 (58\%), followed by people who said Filtering of water (32/138(23\%), while only 26/138(19\%) do nothing.

Table16. Community prevention methods

\begin{tabular}{|l|l|l|}
\hline VARIABLE & FREQUENCY(N=138) & PERCENTAGE (\%) \\
\hline Filtering of water & 32 & 23 \\
\hline $\begin{array}{l}\text { Prohibiting patient from } \\
\text { entering water sources }\end{array}$ & 80 & 58 \\
\hline Do Nothing & 26 & 19 \\
\hline Total & 138 & 100 \\
\hline
\end{tabular}

\section{Management of guinea worm patient}

Many respondents said they take patient to traditionalist/herbalist (137/ 237 (58\%)), while 77/237(33\%) reported taking the patient to the hospital and only $23 / 237(10 \%)$ do nothing. 
Table17. Management of Guinea worm patient

\begin{tabular}{|l|l|l|}
\hline VARIABLE & FREQUENCY(N=237) & PERCENTAGE (\%) \\
\hline $\begin{array}{l}\text { Take the person to the } \\
\text { hospital }\end{array}$ & 77 & 33 \\
\hline $\begin{array}{l}\text { Take to the } \\
\text { traditionalist/herbalist }\end{array}$ & 137 & 58 \\
\hline Do nothing & 23 & 10 \\
\hline Total & 237 & 100 \\
\hline
\end{tabular}

Multiple responses

\section{Traditional treatment of guinea worm}

Many respondents traditionally treat G.W by putting the leg on cool water in the morning and wrapping the worm on wire (84/138 (61\%), while only (54/138(39\%) Bandaging the wound and winding the worm on stick.

Table18. Traditional treatment of Guinea worm

\begin{tabular}{|l|l|l|}
\hline VARIABLE & FREQUENCY(N=138) & PERCENTAGE (\%) \\
\hline $\begin{array}{l}\text { Bandaging and winding the worm } \\
\text { on stick }\end{array}$ & 54 & 39 \\
\hline $\begin{array}{l}\text { Putting the leg on cool water in the } \\
\text { morning and warp the worm on } \\
\text { wire }\end{array}$ & 84 & 61 \\
\hline Total & 138 & 100 \\
\hline
\end{tabular}

\section{Water treatment practices at the household level}

Most respondents 62/138(45\%) said they filtered their water before drinking, 29/138(21\%) add chemical, a third of respondents 25/138(18\%) drink their water without treatment, while few 19/138(14\%) practiced sedimentation.
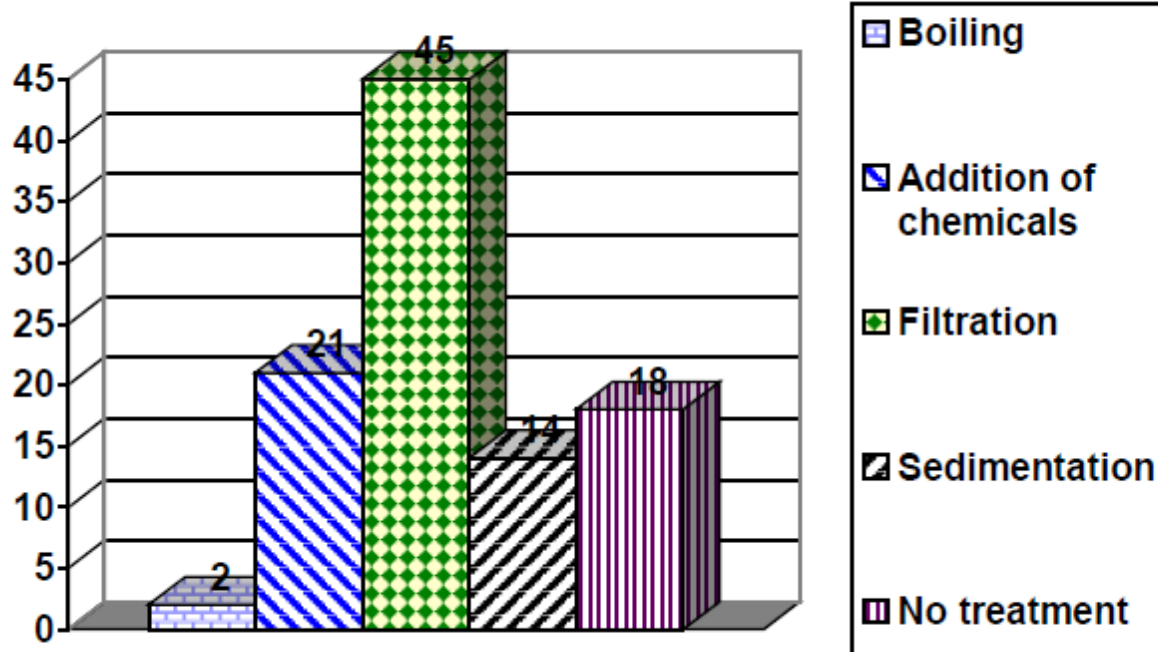

Figure 6. Water treatment practices at the household level 
Texila International Journal of Public Health

Volume 4, Issue 4, Dec 2016

All the key informants reported that some of the villagers still drink the infested water without filtering especially during their grazing or on their way to or from the farm.

2/6 KIs mentioned some villagers especially old people prefer the "natural" taste of pond water or Stream (Khur) and that borehole is salty.

Purpose of filtering cloth

Most respondent's perceive that one of the purpose of filtering cloth is to remove Cyclops m65/138(47.1\%), while only few 27/138(19.6\%) have no idea about the purpose of filtering cloth.

Table19. Purpose of filtering cloth

\begin{tabular}{|l|l|l|}
\hline VARIABLE & FREQUENCY (N=138) & PERCENTAGE (\%) \\
\hline Removing Cyclops & 65 & 47 \\
\hline Cleaning/purifying water & 46 & 33 \\
\hline Don't know & 27 & 20 \\
\hline Total & 138 & 100 \\
\hline
\end{tabular}

All the key informants reported that poor response to report cases of the disease and lack of commitment on the part of field and village volunteer workers are among the factor deteriorating the situation.

\section{Discussion, conclusion and recommendations}

\section{Discussion}

Knowledge of Guinea worm transmission, cause and impact

The study reveals that majority of the respondents have heard about Guinea worm because of the existence of a local name as revealed by the Key informants, Few respondents or relative (36\%) have fallen victim of Guinea worm, the findings is similar to what Olajumoke, (2009) reported (only $38.8 \%$ were infected before in the villages at risk of infection. $51.3 \%$ had been infected before in all the villages).

On education level, half (51\%) of the respondents attended school at least up to primary. These could have got the information about Guinea worm from the health workers during the school health programmes such as immunisation. Other respondents could have got the knowledge from the Guinea worm eradication program efforts of community mobilisation for health through the community health workers.

Some respondents could have, got the information from political and civic leaders, the media like radios and television as well as from others in the community through sharing experiences.

The occupational status of most families was reasonably fair (69\%) given the fact that the respondent's in these families were either businesspersons or civil servants, and yet social economic status is a very important factor of knowledge.

The fact that large proportions of the respondents (43\%) acquired knowledge on Guinea worm from Health workers or by sharing experiences as their most reliable medium of communication in this county, it should not be misunderstood by the general public that Health workers cold be the best means and only medium used for the dissemination of Guinea worm information however, the public should rather know that other means of media such as Radio, Posters, Workshops, Seminars can as well play a big role in disseminating information as far as mass communication is concerned.

In addition, findings revealed that, most respondents (48\%) perceived pain and swelling on the lower limb as a symptom of G.W, this finding agree with what Erik, (1999) affirm that (An 
inching and painful blister develops at the place where the adult female worm emerge, thus making an ulcer).

When respondent were asked what they perceived as the cause of infection, A large proportion (56\%) knew that infection was from drinking infected water, the finding can be compared with Morenikeji and Adekolu (2009) which revealed that majority of respondent (81.5\%) from the infected villages knew infection was from drinking infected water, On the other hand, more than a quarter of respondent (25\%) did not recognise the link between drinking contaminated water and Guinea worm, They still perceived that the infection was from eating infected food (wild animal) meat and only (17\%) reported that infection was associated with Dirtiness. This could have been explained by the fact that social and cultural factors which still influence management of Guinea worm in the county.

Education level was found to be strongly associated with knowledge on the cause of infection of Guinea worm ( $\mathrm{p}>0.000)$.

Furthermore, the finding indicated that most of respondents obtain drinking water from River/Stream (43\%), while almost two quarter (36\%) of respondent's still relied on ponds for their drinking water which are potential breeding ground for guinea worm, this finding can is comparable with Awayumi and Sowunmi, (2009) which indicated that $49 \%$ of respondents still rely on ponds for drinking water, yet in many studies, ponds have been claimed to be the ideal source of dracunculiasis transmission, also Morenikeji and Adekolu (2009) most of the respondents think that the infection is caused by contaminated pond water because cases of infection reduced when pond treatment and filtering of drinking water started. The fact that respond ant's still relied on ponds and stream could be explained by the scarcity of underground water in the area of study which led to exiguity of the bore-hole as affirmed by Key Informant's guide. That is why few (20.7\%) obtain their drinking water from bore-hole. This affirm what (Pedro el al, 1987) mentioned that the scarcity of water usually forces the inhabitants to resort to any source available, the main source of infection for man are shallow lagoons, ponds, well dug in dry river beds, wells that people must enter by means of access steps to obtain water.

Also, many respondent (44.6) said community can help in preventing Guinea worm by Educating children and other community members on how to prevent Guinea worm and this agree with what (Olunjde, 2008) mentioned (Health education, which is a strong component of guinea worm disease eradication interventions, and is believed to be capable of encouraging people to behave in a way that will help prevent the spread of guinea worm disease (Nwosu, 1989). Being able to see the link between contaminated pond water and guinea worm disease and behaving in a way to avoid drinking contaminated water offers a prospect of guinea worm disease eradication. While a quarter (26.2\%) Communal labour was able to build boreholes, few (15.7\%) said by Protection of drinking water sources.

In difficulties associated with Guinea worm disease most respondent (63\%) said someone with Guinea worm has very much difficulty in farming, the finding is similar to a study carried out by Olunjde, (2008) which highlighted that, (the farmers perception on the effect of guinea worm disease as for the level of their agricultural production revealed that $95.8 \%$ of them perceived that guinea worm disease had effect on the level of agricultural production). The finding also can be compared with Morenikeji and Adekolu (2009) who mentioned that (87.2\%) of those infected before claimed that the infection had very serious effect on their farming activities, while $(79.5 \%)$ said that the effect of infection on their economic well being for the period of infection was very high and (71.8\%) claimed it had very serious adverse effect on their social activities.

The study shows that majority of respondent (76\%) said someone with Guinea worm has very much difficulty in earning enough income for the family. this agree with a study in Nigeria, which found out that, women were unable to care normally for themselves, their children, or their households or do other additional work that would increase income to the family. The study 
Texila International Journal of Public Health

Volume 4, Issue 4, Dec 2016

indicated that more than half of the children who failed to appear for immunizations did so because their mothers were too ill with the disease to leave home and bring them to the clinic (David, 1990).

The period of absence from the farm may be long where both parent and children are infected with the disease. Those who are able to recover from the attack often abandon rural areas for towns and cities. Greenaway (2004) revealed that large proportion of economically productive individuals of endemic villages are usually affected therefore resulting in decreased agricultural productivity and economic hardship which often lead to rural-urban drift with its attending problems of overpopulation and increase in crime rate (Awayumi and Sowunmi, 2019).

Attitude: Towards the Guinea Worm Services| Health Workers and External Assistance Needed

The study shows that majority of respondents perceived the Guinea worm eradication program as being useful (96\%)). This may be explained by the fact that most respondents at least attended school hence had abetter vision of issues. Hypothesis testing shows that gender, age, ethnicity, and Education level did not significantly influence respondent's attitude towards Guinea worm eradication program.

The negative attitude towards the health workers was perceived by a large proportion of respondents (61\%) because some were genuinely unkind and rude. Respondents also reported to wait for long for the service at the health facility because of worker over load in health centre. This finding is similar to that of Yohalem, (1990) It has been high lighted by WHO, (1998), that many cultures are reluctant to use health services because they perceive health care providers to be rude.

Many respondents (43\%) perceived that the external assistance needed was technical support to educate people on prevention of Guinea worm. This overlaps with Nordberg, (1999) who reported that the most important measure in Guinea worm prevention is to educate the population. The finding also agree with David, (1990) who mention that community education is especially critical since the overall objective of the Guinea worm eradication program is to promote WHO's goal of eradicating Guinea worm disease by 1995).

Few respondent ever attended seminar on Guinea worm (19\%)), the finding can be explained by the inefficiency of the Southern Sudan Guinea worm eradication program in the county yet majority of respondent are willing to attend at anytime in future (81.8\%). Awoyemi and Sowunmi, (2009) opined that health education intervention as the only means of controlling guinea worm disease often failed due to lack of social cohesion or of uncoordinated group-action

The study also indicated that most respondent's (36\%) said that conducting meeting with community members and mass awareness campaigns will encourage community to participate in eradication. That could be explained by a large proportion of respondent's who obtained their information from health workers which could have explained to them the importance of mass community education and involvement. The findings agree with Erik, (1999) who revealed that prevention and control of Guinea Worm is an example of a condition that can be eradicated if there is stability and community education and involvement. Also similarly the Key Informants guide confirmed that community can be encourage by community sensitization. Also agree with the (SSGWEP, 2009) high lighted that the involvement and participation of all community and stakeholders to eradicate Guinea worm, is the key to success. Guinea worm eradication is about partnership, the most important of which is the partnership between the eradication program and the community.

Practice of Respondent towards Guinea worm Prevention and Treatment

The study findings indicate that more than a half of respondents (58\%) said that prohibiting patient from entering water sources is a means of Guinea worm prevention, this could be explained by the big number of respondent's who reported to obtains their information from 
health worker. Abran in 1995 exemplified that one of measures of controlling Guinea worm is that cases are advised not to enter drinking water sources while worm is emerged.

Majority respondents (59\%) said that they took patient to traditionalist/herbalist, this finding is similar to the one of Awayumi and Sowunmi, (2019) which stated that substantial numbers of respondents (68\%) combined traditional methods of treating the disease with orthodox methods while (33\%) took the person to the hospital and few (10\%) did nothing.

Additionally, because of the rural settings of the study areas, a large proportion of respondents (61\%) traditionally treat Guinea worm by putting the leg on cool water in the morning and winding the worm on wire, while few (39\%) reported bandaging the wound and wind the worm on stick, this could be explained by the fact that they learnt from the health volunteer, who have knowledge about this treatment method.

Lesthan a half of respondents (45\%) said that they filtered their water before drinking; the finding is comparable with Morinikeji and Adoklu, (2009) which shows that the water treatment mostly practiced by the respondents was filtration. The quarter of respondent's that do not treat their drinking water are still exposed or at risk of Guinea worm infection. During the key informants interview, it was affirmed that some respondent's drink water without treatment because they consider the addition of chemical to add bad smell to the water. Some were reported to drink water without treatment during grazing and from or to their fair where there is no access to safe water where by they practice sedimentation which can't remove the Cyclops. Omar and William, (1994) affirm in a study carried out in central equatorial state that almost 60 percent of Juba households are using untreated water from the river or stream (Khors) as their main sources.

The purpose of filtering cloth was clearly identified by most respondent's (47\%) who reported that removing Cyclops was the main purpose of filtering cloth, this could be explained by the fact that most respondent obtained their information from health workers, while a quarter of respondent's perceived that cleaning and purifying water as purpose of filtering cloth could still be consider knowing the purpose of filtering cloth and few (20\%) don't know the purpose of filtering cloth. This could be explained by the fact that more than a quarter of respondent's never attended school and the majority of respondent's who have never attended seminar.

This study was prompted by the need to investigate knowledge, attitude and practice towards Guinea worm based on premise that the spread of guinea worm disease is as a result of simple human behaviour related to water use and the fact that government financial resources have dwindled and provision of adequate safe water.

\section{Conclusion}

The study show that the 2009 eradication deadline to stop transmission in all remaining endemic communities by 2009 was not met due to present of new cases in most of communities.

Education level was found to be strongly associated with knowledge on the cause of infection of Guinea worm ( $\mathrm{p}>0.000)$.

More than a quarter of respondent's (36\%) family member had fallen victim of Guinea worm

A large proportion of respondent (56\%) perceived drinking infected water as a cause of Guinea worm infection.

Majority of respondent (76\%) said someone with G.W has very much difficulty in farming because an inching and painful blister develops at the place where the adult female worm emerge, thus making an ulcer

Most (43\%) of respondent's obtained drinking water from River/Stream and more than a quarter from ponds

The major sources of information to the respondent are the health workers when the respondent's go to the facilities for services or sharing experience with relatives. 
Texila International Journal of Public Health

Volume 4, Issue 4, Dec 2016

The majority (96\%) of respondents have positive attitude towards the Guinea worm eradication program, however their perception of the health workers is bad because they Health workers to be rout and unkindly.

Many respondents (58\%) preferring taking patients of Guinea worm to traditionalist/herbalist, who they think are cheaper, quicker or better.

There was statistically significant association between the education level and attitude, practise of respondent's in Juba County.

\section{Recommendations}

Both focused and integrated health education by the health workers need to be emphasized stressing to the communities the importance of Guinea worm eradication. This can be done both at Community level through resource persons such as parish (Buma) development committees as well as political, civic, and opinion leaders and the health unit and through specific and integrated outreaches such as immunization or mass awareness to cover three messages: That Guinea worm comes from contaminated water, Villagers should prohibit a person with blisters or ulcer from entering source of drinking water and that drinking water should be filtered or boiled before drinking.

The MOH should ensure that health workers change their behaviour towards the respondent's by being kind and helpful to them as away of encouraging them to participate in Guinea worm eradication program.

The MOH as well as the County administration should improve on the staffing at the health facilities so that there are enough staffs to handle the mothers immediately they come, in a bid to reduce on the waiting time.

The County Health Team Serious efforts should be made to ensure comprehensive hydro geological analysis for the suitability of sustainable boreholes which will in turn enhance uninterrupted water supply. However, where cost of sinking boreholes is unbearable field health workers should ensure that ponds are regularly treated with Abeat and water filter made available to residents of the areas that are prone to the disease.

The state authorities should strategically encourage activities that bid to uplift the education level of the respondent's. The authorities should as well gear up the governments activities in order to raise the social economic status of the people as this will also improve on the KAP of respondent's towards Guinea worm.

Support supervision and monitoring and evaluation of all health units offering health services as well as the village volunteers by the County Health Team need to be intensified.

\section{Proposed work plan and budget}

\begin{tabular}{|l|l|l|l|}
\hline No & ACTIVITY & TARGET & BUDGET(USA, Dollars) \\
\hline 1 & Communication and Transport & & 500 \\
\hline 2 & $\begin{array}{l}\text { Development of research } \\
\text { proposal }\end{array}$ & 1st September & 50 \\
\hline 3 & Literature review development & 1st October & 200 \\
\hline 4 & Development of questionnaire & 1st November & 50 \\
\hline 5 & Training of research assistant & 15th November & 50 \\
\hline 6 & Incentive for the Assistant & & 200 \\
\hline 6 & Data collection & 1st December & 200 \\
\hline 7 & Data Analysis & 15th December & 100 \\
\hline 8 & Discussion and writing of report & 15th December & 50 \\
\hline
\end{tabular}




\begin{tabular}{|l|l|l|l|}
9 & Final report & 20th December & 200 \\
\hline 10 & Total & & 1400 \\
\hline
\end{tabular}

\section{Acknowledgements}

I wish to acknowledge the following without whom the success of this research could have been impossible.

Almighty Allah, who has protected and guided me through out the period of this work, Special thanks go to Mr. Ng'ang'a Peter who supervised me in the course of this dissertation.

The Director of Southern Sudan Guinea worm eradication program for the support they offered me during this exercise.

The Director of Guinea worm eradication program central eradication state Juba Mr. Samson Sebit and other colleagues in the department for their spiritual and technical support, which were immense during this research.

The deputy director of EPI, central equatorial state Mr. Abdullah Abdurrahman.

Special thanks go to my Mother, my brother Habib, my sisters Zeinab and Haram who has put all their efforts to see that I succeed in my education till this level.

I cannot forget to thank my fellow colleques for guiding me through out my work not forgetting all the lecturers in the department of Masters of Public Health -KIU.

Last but not least my research assistants for their commitment and tireless efforts especially during the phase of data collection for this research.

May Allah reward you all abundantly.

\section{References}

[1]. Awayumi T.T and F.A. Sowunmi ( 2019), Socio-economic burden of Guinea worm in Oguni state : A discriminant analysis approach, African Journals of Agricultural Research, vol (4) pp 1138

[2]. Abran S.Benenson, (1995), control of communicable diseases manual, pp 157- 159

[3]. Centres for Disease Control Memorandum, (2007 February), Guinea Worm Wrap-up No 170. WHO Collaborating Center for Research, Training and Eradication of Dracunculiasis.

[4]. Communicable Diseases (CDS) and Water, Sanitation and Health unit (WSH), (2001), World Health Organization (WHO). 2001 (World Water Day).

[5]. Centres for Disease Control Memorandum, (2010 March), Guinea Worm Wrap-up No 170. WHO Collaborating Center for Research, Training and Eradication of Dracunculiasis.

[6]. Cairncross, Sandy; Muller, Ralph; Zagaria, Nevio (2002), Dracunculiasis (Guinea Worm Disease) and the Eradication Initiative” Clinical Microbiol Rev.; 15(2): 223-246.

[7]. Centres for Disease Control Memorandum, (2003 October), Guinea Worm Wrap-up No 136. WHO Collaborating Center for Research, Training and Eradication of Dracunculiasis.

[8]. WHO Collaborating Center for Research, (2001) Centres for Disease Control Memorandum (2001 November). Guinea Worm Wrap-up No 118, Training and Eradication of Dracunculiasis.

[9]. Carter Center, (2004), annual report, Carter Center 2004

[10]. David Yohalem, (1990), Programming Guide for Guinea Worm Eradication, Bureau for Science and Technology, U. S. Agency for Imitational Development under WASH Task No. 091.

[11]. Erik Nordberg, (1999), Communicable disease, AMREF, Kenya, PP 136-138

[12]. Southern Sudan Guinea worm eradication program, (2010), WHO Collaborating Center for Research, Training and Eradication of Dracunculiasis

[13]. John B. Rwakimari, Donald R. Hopkins and Ernesto Ruiz-Tiben, (2006), Uganda's Successful Guinea Worm Eradication Program, MOH Uganda, the American Society of Tropical Medicine and Hygiene pp 3

[14]. John M. Hunter, (1997), Geographical patterns of guinea worm infestation in Ghana, An historical contribution, Social Science \& Medicine, Volume 44, Issue 1, Pp 103-122. 
Texila International Journal of Public Health

Volume 4, Issue 4, Dec 2016

[15]. Karin E. Ekulund and Ann H. Davitsen and Taraf Hasvold, (2003), Teaching populations as means of improving general health, University of Tramso-Gana

[16]. Kelly JK and Pereira G (2006), "The problem of wate contamination with Dracunculus medinensis in southern Sudan” Journal of Rural and Tropical Public Health 5: 49-58, WHO Collaborating Center for Research, Training and Eradication of Dracunculiasis 2007.

[17]. Morenikeji Olajumoke and Adekolu Abimbola, (2009), Progress in Dracunculiasis Eradication: Ogun State, South-West Nigeria as Case Study, Journal of American Science, pp 189-193

[18]. Ministry of Health, Southern Sudan, Annual report( 2009), Ministry of Health, Southern Sudan Juba

[19]. Ministry of Health, Southern Sudan, (2008) Program Review Meeting, 2008, Ministry of Health, Southern Sudan Juba

[20]. Olunjde M.G., (2008), Farmers' Attitude to Nigerian Guinea Worm Eradication Health Education Programmes, Department of Agricultural Extension and Rural Development, University of Ibadan.

[21]. Omar S.Ertur and William J. House, (1994), Population and Human resources development in the Sudan, pp 154

[22]. Olajumoke A. Morenikeji, (2010) the Final Hurdle To Be Crossed In the Eradication of Dracunculiasis in Nigeria, Journal of American Science, 6(2).

[23]. Pedro.N.Acha and Boris Syfres, (1987), Zoonoses and communicable disease common to men and man, second addition, PAN American Organization, pp 792-797

[24]. Ralph Muller, (2005), Guinea worm disease -the final chapter, trends in Parasitology, volume 21, Issue 11, November 2005, pp 521- 524

[25]. Sandy Cairncross, Ralph Muller, and Nevio Zagaria,(2002), Dracunculiasis (Guinea Worm Disease) and the Eradication Initiative, American Society for Microbiology

[26]. Southern Sudan Guinea worm eradication program, (2009), Sudan people liberation Army Sensitization Workshop,16 October (2009), Juba

[27]. Susan Watts,(1998), Perceptions and priorities in disease eradication: Dracunculiasis eradication in Africa, Journals of Social Science \& Medicine, Volume 46, Issue 7,1 Pages 799-810

[28]. WHO, (2005), GUINEA WORM WRAP-UP, Collaborating Center for Research, Training and Eradication of Dracunculiasis,

[29]. WHO, (1998), world health day, safe mother hood journal, vol 98.1. 1, 215,21

[30]. WHO,(2008) Collaborating Center for Research, Training and Eradication of Dracunculiasis, Guinea worm wrap up( 179)Number of uncontained cases of dracunculiasis outside of Southern Sudan so far in 2008: 12 (Ghana), memorandum, February 25, 2008.

\section{Chi-square $\left(\mathrm{X}^{2}\right)$ analysis}

Chi-square $\left(\mathrm{X}^{2}\right)$ analysis of age, sex, Ethnicity and Education level and usefulness of Guinea worm eradication program is statistically not significant.

\begin{tabular}{|l|l|l|l|l|}
\hline Variable & Chi-square & D.F & P-value & Remarks \\
\hline Sex & 0.061 & 1 & 0.805 & NS \\
\hline Age & 38.833 & 2 & 0.301 & NS \\
\hline Ethnicity & 0.314 & 2 & 0.855 & NS \\
\hline Education & 2.919 & 3 & 0.404 & NS \\
\hline
\end{tabular}


Texila International Journal of Public Health

Volume 4, Issue 4, Dec 2016

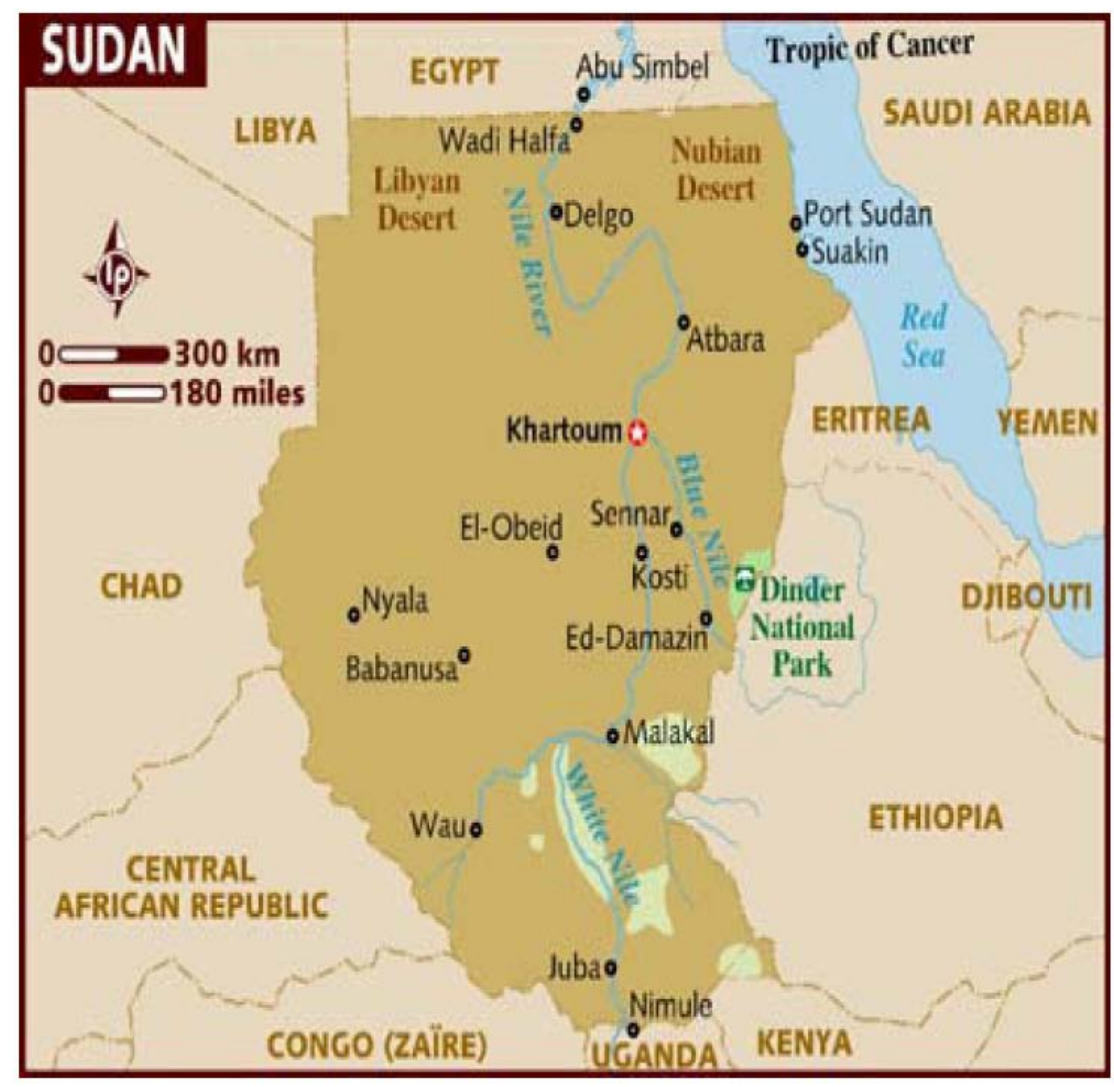




\title{
Effect of Regular Baths on the Development of Ring Worm among Primary School Children
}

\author{
Article by Ifezue Uchechi Grace \\ Ph.D in Public Health, Texila American University, Nigeria \\ E-mail:grifezue@yahoo.com
}

\begin{abstract}
Effect of regular baths on the development of ringworm of the body among primary school children was carried out using a sample size of 100 pupils from LEA primary school Pyankasa, Abuja, Federal capital Territory. This study was guided by research question and hypothesis. Inferential statistics of Chi square was used in the analysis of data collected. On the basis of the findings, conclusions were drawn and recommendations, made.
\end{abstract}

Keywords: Regular baths, Ringworm, Children.

\section{Introduction}

\section{Background of the study}

Ringworm (Tinea corporis) has been defined in Merriam Webster dictionary, (2013) as a fungal infection involving parts of the body not covered with hair. Ringworm is a fungal infection that can affect any part of the body. Ringworm is spread by direct and indirect contact with humans, animals and soil. Humans get infections through skin and scalp lesions of infected persons, contaminated clothing, bath mats, towels, floors and showers. Animals get infections through cats, dogs, mice and guniea pig. (Corporate communications unit, 2007).

Yeliz et al, (2010), also defined Ringworm (Tinea corporis), as a dermatophytic infection which is observed in all body regions except for specific locations such as hands, feet and genitalia. A human patient may be infected by another person, an animal or nature. Zoophilic strains may make the diagnosis difficult by causing inflammatory lesions in particular. (Yeliz et al, 2010).

Classically, ringworm manifests as well bordered erythematous, scaly, annular plagues widening from the centre towards the periphery and having elevated borders. Itchiness is a frequently accompanying symptom. Sometimes, vesicules and pustules are observed. Rarely, even blister formation as a secondary change of severe inflammation might be observed. The severity of inflammation changes depending on the type of fungus, the condition of patient's immunity and the degree of follicular invasion. The inflammatory response generated via zoophilic strains is more obvious than a response generated via anthropophilic strains (Sobera \& Elewski, 2008).

Atypical and common clinical appearances may occur in patients who are immune compromised. (Veraldine et al, 1999). Also atypical patterns resembling other dermatological reported illness may be observed in totally healthy individuals as noted by Bohmer et al (1998).

\section{Statement of the problem}

Ringworm is a skin infection due to a fungus. It is common especially among children. However, it may affect people of all ages. It is caused by a fungus. Ringworm can spread easily from one person to another. It can be contacted via touching someone who has the infection or contact with items contaminated by the fungus such as combs, unwashed clothing and shower or pool surfaces. The fungus that causes ringworm thrive in warm, moist areas. Ringworm is more likely when one is sweating and from minor injuries to the skin, scalp or nails. 
Texila International Journal of Public Health

Volume 4, Issue 4, Dec 2016

\section{Objectives of the study}

The broad objective of this study is to determine the effect of regular baths on the development of Ringworm of the body among primary school children.

\section{Research question}

What is the effect of regular baths on the development of Ringworm of the body among primary school children?

\section{Research hypothesis}

There is no significant relationship in the effect of regular baths on the development of Ringworm of the body among primary school children.

\section{Significance of the study}

The skin is a unique organ in that numerous signs of disease or injury are immediately observable on the skin. The skin serves as interface between the body's internal organs and the external environment. Therefore skin disorders represent the culmination of environmental forces and the internal functioning of the body. Sunlight, infectious organisms, chemicals and physical agents all play a role in the pathogenesis of skin diseases of which Ringworm is one of them. Normally, the skin flora, sebum, immune responses and other protective mechanisms defend against serious systemic infections. However, the skin frequently succumbs to attack by microorganisms whose primary clinical manifestations are in the skin.

\section{Literature review}

Review of related literature will dwell on the following topics:

Concept of fungal infection.

Concept of dermatophytosis.

The ringworm concept.

- Symptoms of ringworm infection

- Causes of ringworm infection

- Diagnosis and testing

- Prevention

- Treatment

- Prognosis

\section{Concept of fungal infection}

From, Dorlands Medical Dictionary (2013), Mycosis is defined as a fungal infection of animals, including humans. Mycoses are common and a variety of environmental and physiological conditions can contribute to the development of fungal diseases. People are at risk of fungal infections when they are taking strong antibiotics for a long period of time because antibiotics kill not only damaging bacteria, but health bacteria as well. This alters the balance of microorganism in the mouth, vagina, intestines and other places in the body and results in an overgrowth of fungus. Individuals with weakened immune systems are also at risk of developing fungal infection. This is the case of people with HIV/AIDS, people under steroid treatment and people taking chemotherapy. People with diabetes also tend to develop fungal infections. Very young and very old people also are groups at risk. (Wikipedia, 2013).

\section{Concept of dermatophytosis}

Dermatophytosis is a clinical condition caused by fungal infection of the skin in humans, pets such as cats and domesticated animals such as sheep and cattle. The term "Ringworm" commonly used to refer to such infections is a misnomer, since the condition is caused by fungi of several different species and not by parasitic worms. The fungi that cause parasitic 
infection (dermatophytes) feed on keratin, the material found on the outer layer of skin, hair and nails. These fungi thrive on skin that is warm and moist, but may also survive directly on the outside of hair shafts or in their interiors. It has been estimated that currently, up to twenty percent of the population may be infected by ringworm or one of the other dermatophytoses. (Dercoby, 2009). Dermatophytosis of the scalp, glabrous skin and nails is caused by a closely related group of fungi known as dermatophytes which have the ability to utilise keratin as a nutrient source i.e. they have a unique enzymatic capacity (keratinase). The disease process in dermatophytosis is unique for two reasons; firstly, no living tissue is invaded, the keratinised stratum corneum is simply colonised. However, the presence of the fungus and its metabolic products induces an allergic and inflammatory eczematous response in the host. The type and severity of the host response is often related to the species and strain of the dermatophyte causing the infection, secondly, the dermatophyte are the only fungi that have evolved a dependency on human or animal infection for the survival and dissemination of their species. (David Ellis,2013).

The ring worm concept.

Tinea corporis.

Tinea corporis (Also known as ringworm) is a superficial fungal infection (Dermatophytosis) of the arms and legs especially on glabrous skin; however, it may occur on any part of the body. (Bolognia et al, 2007).

\section{Symptoms}

According to Berma, (2008), symptoms of Tinea corporis may have a variety of appearances; most easily identifiable are the enlarging raised red rings with a central area of clearing. The same appearances of ringworm may also occur on the scalp (Tinea capitis), Beard (Tinea barbae) or the groin (Tinea cruris), known as jock itch or dhobi itch. Other classic features of Tineacorporis include:

o The edge of the rash appear elevated and is scaly to touch.

o Sometimes the skin surrounding the rash may be dry and flaky.

o Almost invariably, there will be hair loss in areas of infection.

\section{Causes}

Tinea corporis is caused by a fungus known as dermatophyte. These organisms normally live on the superficial skin surface, and when the opportunity is right, they can induce a rash or infection. Individuals at high risk of acquiring ringworm include those who:

- Live in crowded humid conditions.

- Sweat excessively, as sweat can produce a humid wet environment where the pathogenic fungi can thrive. This is most common in the armpits, groin creases and skin folds of the abdomen

- Participate in close contact sports like soccer, rugby or wrestling.

- Wear tight, constrictive clothing with poor aeration.

- Have a weakened immune system (e.g. those infected with HIV) or taking immunosuppressive drugs. Brannon ,(2010).

\section{Diagnosis and testing}

From Wikipedia,(2013), once a fungus is suspected, the skin will be examined and scraping, taken. These superficial scraps of skin are examined underneath the microscope which quickly reveal the presence of a fungus. If the skin scrapings are negative and a fungus is still suspected, the scrapings are sent for culture. Because the fungus grows slowly, the culture results do take several days to become positive. Other methods of diagnosis include potassium hydroxide tests $(\mathrm{KOH})$. 
Texila International Journal of Public Health

Volume 4, Issue 4, Dec 2016

\section{Prevention}

Because fungi prefer warm, moist environments, preventing ringworm involves keeping skin dry and avoiding contact with infectious material. Basic prevention measures include:

- Washing hands after handling animals, soil and plants

- Avoiding touching characteristic lesions on other people

- Wearing loose fitting clothing

- Practicing good hygiene when participating in sports involving physical contact with other people as noted in Brandon,(2010).

\section{Treatment}

Most cases are treated by application of topical antifungal creams to the skin, but in extensive or difficult to treat cases, systemic treatment with oral medication may be required. In general, ringworm responds well to topical treatment. Topical antifungals are applied to the lesion twice a day for at least two weeks, but therapy should be continued for another week to ensure the fungus is completely eradicated. The most commonly used antifungals are clotrimazole, ketoconazole, miconazole, etc. (Wikpedia,2013).

\section{Methodology}

The procedure used to determine the effect of regular baths on the development of Ring worm of the body among primary school children are presented in this chapter. It covers:

- Research design

- Description of the study area

- Population of the study

- Sample/ Sampling technique

- Instrument for data collection

- Method of data collection

- Method of data analysis

\section{Research design}

The research design adopted in this study is the descriptive survey. Descriptive survey are those studies which aim at collecting data on and describing in a systematic manner, characteristic features or facts about a given population.

\section{Description of the study area}

The study area is LEA primary school, Pyankasa, Abuja, Federal capital territory, Nigeria. The school has one headmistress, two assistant head teachers and twenty five teachers. There are four hundred and fifty pupils in the school.

\section{Population of the study}

The population of the study comprises of children, male and female from the age of 6 years to 12 years who have had cases of ring worm as well as those who have not.

\section{Sampling/sampling technique}

The sample for the study consisted of 100 children, male and female from the age of 6 years to 12 years.

\section{Instrument for data collection}

Data for the study was collected using information from teachers who handle the primary school children.

\section{Method of data collection}

Questionnaires were distributed to teachers on observation of children who have had cases of ring worm, current cases of ring worm and those who have no ring worm. Answers based 
on how regular baths affect ring worm occurrence are to be given by these teachers by means of questionnaire.

\section{Method of data analysis}

The data gathered were analysed using descriptive statistics of percentage and frequency counts as well as inferential statics of Chisquare. Level of significance was placed at 0.05. Appropriate degrees of freedom were worked out.

\section{Data presentation and analysis}

Presentation and analysis of data on the effect of regular baths on the development of ringworm of the body among primary school children. Data obtained were analysed using descriptive statistics of percentages, frequency tables as well as inferential statistics of Chisquare.

Table 1. Frequency distribution of primary school children from LEA primary school according to their gender.

\begin{tabular}{|lll|}
\hline & F\% & \\
Male & 53 & $53 \%$ \\
Female & 47 & $47 \%$ \\
\hline Total & 100 & $100 \%$ \\
\hline
\end{tabular}

Table 1 represents the frequency distribution of primary school children from LEA primary school according to their gender. Out of one hundred pupils (100) selected, 53(53\%) were male while 47(47\%) were females.

\section{Research hypothesis}

There is no significant relationship in the effect of regular baths on the development of Ringworm of the body among primary school children.

Table 2. Ringworm occurrence among primary school children from LEA primary school.

\begin{tabular}{|llll|}
\hline Ringworm & Ringworm & Total & \\
Present & Absent & & \\
Occasional baths & $64(64 \%)$ & $8(8 \%)$ & $72(72 \%)$ \\
Regular Baths & $11(11 \%)$ & $17(17 \%)$ & $28(28 \%)$ \\
\hline Total & $75(75 \%)$ & $25(25 \%)$ & $100(100 \%)$ \\
\hline
\end{tabular}

$\mathrm{X}^{2} \mathrm{Cal}=26.2 ; \mathrm{X} 20.05=3.841$.

Table 2 reveals the relationship of the effect of regular baths on Ringworm of the body occurrence among primary school children. Observation on the table shows that out of 100 children (respondents) and with regard to occasional baths, $64 \%$ of the children had ring worm while only $8 \%$ do not have ringworm. On the other hand, $11 \%$ of the children had ring worm in spite of regular baths while $17 \%$ of the children did not have ring worm.

Chi square analysis carried out on the table showed that the calculated Chisquare is greater than the tabled Chisquare, in other words we conclude that there is significant relationship in the effect of regular baths on the occurrence of ring worm of the body among children. This means that the result is significant and regular baths prevent occurrence of ring worm of the body.

\section{Discussion, summary, conclusion and recommendations}

This chapter presents discussion of results, conclusion and recommendation.

\section{Discussion of results}

The research hypothesis used in the research study was stated thus: "There is no significant relationship in the effect of regular baths on the development of ringworm of the body among 
primary school children”. Chi square analysis was carried out using the data on Table 2, and the result of the analysis showed that there is significant relationship in the effect of regular baths on the development of Ring worm of the body among primary school children. This is in agreement with (Brannon, 2010) who gave an overview of people who are at risk of acquiring ringworm.

\section{Summary}

Ring worm is an infection caused by a type of fungus called a dermatophyte. It is spread through contact with a person or animal with the infection. Ringworm infections are very common and can affect anyone. Children also are at risk of infection with ringworm.

\section{Conclusion}

Conclusion drawn in this study is that there is significant relationship in the effect of regular baths on the occurrence of Ringworm of the body among children.

\section{Recommendations}

Based on the above conclusions, the following recommendations were made.

- Practices of regular hand washing should be adopted.

- Sharing of hair brushes, hats and articles of clothing that might have come into contact with an infected area should be avoided. It is important to make children to be aware of this rule.

- Take pets to veterinarian at first sign of skin irritation.

- Ensure that sterilized instruments are used in places such as barber shop or beauty salon.

- Maintenance of regular cleaning.

\section{References}

[1]. Berman, K. (2008). TineaCorporis, All information. Multimedia Medical Encyclopedia.

[2]. Bohmer, U., Gottlober, P., Korting H.C.,(1998) Tineaenmaemimicking atopic eczema. Mycoses, PIMD.

[3]. Bolognia, J., Joseph, L., Ronald, P.,(2007). Dermatology. Mosby Elsevier. Branmon, H. (2010). Ring worm, Tineacorporis.

[4]. About.com.

[5]. David, E. (2013). Mycology. The University of Adehaide.

[6]. Dercoby, M. (2009). The truth About Ringworm. British Columbia Wrestling Association.

[7]. Dorlands Medical Dictionary (2013). Infectious diseases, epidemiology and Surveillance (2007).

Corporate communications Unit.

[8]. Meriam Webster unabridged dictionary (2013). Meriam. Webster, incorporated.

[9]. Sobera J.O., Elewski, B.E. (2008). Fungal disease in Dermatology. $2^{\text {nd }}$ ed Spain:mosby.

[10]. Veraldi, S., Gorani, A., Schmitt, E.,(1999). Tinea Corporis. Mycoses, PMID.

[11]. WebMD (2013). Understanding ringworm. Web LLC. 


\title{
The Effectiveness of Handwashing Health Education Session on Raising School Children's Knowledge and Skills of Proper Handwashing Technique. a Pre test- Post Test Design
}

\author{
Article by Marie Louise Umwangange \\ MPH, Texila American University, Rwanda \\ E-mail: umwangange2008@yahoo.fr
}

\begin{abstract}
Background: Hand washing is one of the core interventions to prevent diarrhea and pneumonia among children and is the single and only cost- effective intervention.

Objective: The main objective of this study is to evaluate the effectiveness of handwashing health education session on raising school children's knowledge and skills of proper handwashing technique.

Methods: The study design will be a quasi-experimental pre test- post test single group design. A sample of 108 school children studying in primary grade 4, and 5 at two Public schools (One urban: Gacurabwenge primary school and one rural school: Kibali primary school) in Northern Province participated in the study after a stratified systematic sampling. The study was done in October 2016 and data were analyzed in SPSS version 16.0 using paired t-test for normally distributed data and Wilcoxon rank test for data which were not normally distributed. The mean score was computed and theoretical and skills score were categorized as excellent $(80-100 \%=16-20)$, very good $(70-79 \%=14-15.9)$, good (60$69.9 \%=12-13.9)$, fair $(50-59 \%=10-11.9)$ and poor $(0-49 \%=0-9.9)$

Results: In urban school, the results of pretest theory revealed that $70.4 \%$ had excellent knowledge, $11.1 \%$ had very good knowledge. The post test theory in the same school was $70.4 \%$ for excellent knowledge, $18.5 \%$ for very good knowledge. The difference between theory pretest and posttest in urban school was statistically significant $(p=0.007)$

The results of pretest theory in rural school were different from those found in urban school with only $27.8 \%$ with excellent knowledge, $37 \%$ with very good knowledge. The post test theory for the same school was $48.1 \%, 40.7 \%$ for excellent and very good knowledge respectively. The difference between theory pretest and posttest in rural school was statistically significant $(p<0.001)$

There was a significant increase in handwashing skills from pretest to post test in both urban and rural school. In urban school the pretest revealed $22.22 \%$ of school children with excellent handwashing skills, and in post test almost all (94.4\%) school children in urban school demonstrated excellent skills of handwashing. The difference between pretest and post test skills was statistically significant $(p<0.001)$. In rural school, the same difference has been found from pretest to post test handwashing skills; in pretest, only $9.26 \%$ of school children had excellent handwashing skills and in posttest in the same school, all school children (100\%) had excellent handwashing skills and the difference between pretest and post test skills was statistically significant $(p<0.001)$.

Conclusion: Handwashing health education was effective to increase the knowledge and skills of school children regarding proper technique of handwashing in urban and rural public primary school and there is a need to teach other school children the detailed technique of handwashing with emphasis on those studying in rural area as their baseline handwashing knowledge and skills are poor compared to urban school children.
\end{abstract}

Keywords: Effectiveness, handwashing, school children, health education, knowledge, skills. 
Texila International Journal of Public Health

Volume 4, Issue 4, Dec 2016

\section{Introduction}

\section{Background}

The World Health Organization (WHO, 2016) states that diarrhea causes 760,000 deaths in children with around 1.7 billion diarrhea-related morbidity every year, globally. The Center for disease control and prevention (CDC, 2013) approximated that diarrhea kills 2,195 children every day around the World. In Rwanda, in 2011, diarrhea was the second leading cause of death in children and $80 \%$ of disease burden in Rwanda was linked to poor hygiene and sanitation (United Nations Children's Funds (UNICEF), 2011). Rwanda's aim is to reduce the prevalence of diarrhea among children from 13\% in 2010 to 9\% by 2018 through efforts in promotion of handwashing practices with special focus in school-going children (Rwanda Ministry of Health, 2014)

Hand washing is one of the core interventions to prevent diarrhea and pneumonia among children and is the single and only cost- effective intervention (CDC, 2013; Maternal and Child Survival Program (MCSP), 2015). Hand hygiene is a fundamental way to prevent infection as in most feco-oral infections, hands are an important vector. If handwashing is done effectively, it becomes an important measure to limit the spread of microbes (CDC, 2009; Nair, Hanumantappa, Gurushantswamy, Siraj, \& Raghunath, 2014; WHO, 2015). Encouraging handwashing habits among children is comparable to the anti-diarrheal vaccine and can prevent diarrhea-related illness and deaths (UNICEF, 2012)

One study in India revealed that many children do not always use soap when they are washing hands and almost half (47.3\%) never used soap (Ray, Amarchand, Srikanth, \& Majumdar, 2011). When hands are washed with soap, children's diarrhea death would be decreased by 47\% (UNICEF, 2011). Education about proper hand hygiene reduces the occurrence of diarrhea in children by half. Proper handwashing before eating and after using the bathroom/toilet can reduce exposure to germs and improve children's development and welfare (CDC, 2013).

In 2012, the UNICEF reported that in Rwanda, only two per cent of the population practice handwashing in urban and rural areas (UNICEF, 2012)

In Rwanda, the Rwanda village concept project (RVCP) conducted handwashing education sessions in primary schools in Southern province and helped children to learn how to wash hands and maintaining their body healthy (Global Giving, 2013).

\section{The problem statement}

The presence of Escherichia coli (E. coli) on hands after hand washing in school children when they came from the toilet (Saboori, Greene, Moe, Freeman, Caruso, Akoko, \& Rheingans, 2013) can be resulted from improper hand washing and there is a need to teach school children the detailed technique of handwashing.

In Rural Kenya, Patel, Harris, Juliao, Nygren, Were, Kola, ... Quick, 2012) trained teachers on handwashing in order to transmit the information to students. In Rwanda, little is known about the effectiveness of handwashing education program in school children; thus in this study, the training was given to school children themselves allowing them to directly observe the proper handwashing technique and be able to do a return demonstration.

\section{The significance of the study}

The curriculum and health education sessions focused on raising children's awareness and knowledge of the importance of handwashing and proper handwashing, but few studies focused on the skills and practice of proper handwashing technique. Many studies used the simple handwashing technique with wet the hands, put on the soap, rub the hands together, rinse and dry (Harrison, 2012; Mahmud, Spigt, Bezabih, Pavon, Dinant \& Velasco, 2015). The purpose of this study is to evaluate the effectiveness of theoretical and practical health education session on knowledge and practice of the proper handwashing technique of school children; thus after this study, the children should know how to wash their hands and practice 
the proper handwashing technique which will contribute to the reduction of feco-oral transmissible infections.

\section{Research question}

Is one hand washing health education session effective to raise the knowledge and practice of proper handwashing technique of school children in Rwanda?

\section{Objectives}

\section{General objective}

The main objective of this study is to evaluate the effectiveness of the proper handwashing technique on raising knowledge and skills of school children in the effective handwashing technique.

\section{Specific objectives}

The specific objectives of this study are:

To identify handwashing knowledge and skills of school children before the intervention i.e. 30 minute theoretical health education session and skills demonstration of proper handwashing technique.

To identify handwashing knowledge and skills of school children after the intervention i.e. 30 minute theoretical health education session and skills demonstration of proper handwashing technique.

To determine if there is a difference between the pretest and posttest scores of children after receiving theoretical health education session and practical health education session and compare the knowledge and skills of proper handwashing technique of school children in urban and rural Public school.

\section{Methods}

\section{Study area}

The study area was composed of two public schools (one urban: Gacurabwenge primary school, and another one located in rural area: Kibali primary school) located in Byumba sector, Gicumbi district of the Northern Province in Rwanda.

\section{Study design}

The design of this study was a quantitative quasi-experimental pretest-posttest design. The pretest-posttest study design is appropriate to evaluate the effectiveness of an intervention by comparing the baseline results before the intervention (pretest) with the results after the intervention (post test). It shows that the outcomes resulted from the intervention and not the previous knowledge of the participants. There was no control group.

\section{Study population}

The target population was the primary school children studying in grade 4 and 5 attending two public schools (one urban school and one rural school) in Byumba sector of Northern Province, Rwanda.

\section{Sample size and sampling}

The sample will be composed of 108 primary school children. A hundred and eight pairs are sufficient in pretest-posttest study which uses paired t-test in analysis with $\alpha$ of 0.05 , power (1- $\beta$ ) of 0.9 , estimated paired mean difference to be detected: 0.5 and expected standard deviation of 1.5 (http://biomath.info/power/prt.htm). The sample was obtained using a stratified systematic sampling with two strata: grade 4 and grade 5 . Twenty seven children were included in each stratum in each school using a systematic sampling where number 1,3 , $5,7,9,11,13,15,17,19,21,23,25,27,29,31,33,35,37,39,41,43,45,47,49,51,53$ on each classroom students list with signed consent forms and assent forms was included in the 
Texila International Journal of Public Health

Volume 4, Issue 4, Dec 2016

sample. If one or another child do not want to participate or was not available, then a child with a following odd number on the list was included and participated in the study.

\section{Inclusion and exclusion criteria}

Primary school children studying in grade four and five who are at least nine years old were included in the study; the children in these grades have the capabilities to follow the WHO steps of handwashing. Excluded were students in grade one, two, three, six, seven, eight, nine and above. Children whose age is less than nine years were also excluded from the study.

\section{Data collection tools and procedures}

The WHO detailed steps of handwashing composed of 10 steps (from step 0 to step 9) were used to test children's prior skills of handwashing technique and also were used after the intervention to evaluate the outcome of health education session.

Data were collected in two public primary schools (one urban school: Gacurabwenge and one rural school: Kibali). Data were collected in two separate days, one day for urban school, and one day for rural school. It was started by data collection of previous knowledge and skills of handwashing of children (pretest): 20 closed-ended questions with yes or no answers were used as a pre-test and post test where each correct answer values a score of one and the wrong answer values a score of zero. The pretest practical part was consisting of the observation of how children wash their hands, and the allocation of a score of two for each correct step of handwashing using WHO detailed steps of handwashing and score of zero for incorrect or missed step. The same questions and observation were used in posttest. The maximum total score was 20 in theoretical questions and 20 in practical part. The score for Knowledge and skills was ranged as Excellent: 80 -100\%, Very Good: 70- 79\%, Good: 6069\%, Fair: 50-59\% and Poor: 0 - 49\%.

Intervention: A health education session was consisting of theoretical part and insisted on the importance of handwashing and the consequences of not washing hands properly, the important moments of handwashing, materials used to ensure proper handwashing and the parts of the hands to focus on during handwashing and lastly the duration of the entire technique of handwashing. The theoretical education took 30 minutes which is effective in delivering handwashing instructions (Celik \& Pancoe, 2012).

The WHO steps of handwashing (from step 0 to step 9) was used to teach the skills of handwashing and was the one to assess the learned skills after health education with 2 marks for each step. The following are the steps of handwashing according to WHO (2008):

- wet hands with water,

- apply enough soap to cover all hand surfaces,

- rub hands palm to palm,

- right palm over left dorsum with interlaced fingers and vice versa,

- palm to palm with fingers interlaced,

- backs of fingers to opposing palms with fingers interlocked,

- rotational rubbing of left thumb clasped in right palm and vice versa,

- rotational rubbing, backwards and forwards with clasped fingers of right hand in left palm and vice versa,

- rinse hands with water then,

- dry the hands with proper towel.

All materials were in Kinyarwanda, the vernacular language for Rwandans. The author and two assistants who are both registered midwives collected data. The assistants were trained to the same standard in handwashing as the author, and familiar with the pretest and post test data collection. 


\section{Data analysis}

The pretest and post test scores for each child were entered in the computer and children's scores were analyzed using paired t-test (for normally distributed data) and Wilcoxon rank test (for data which are not normally distributed). SPSS software version16.0 will help in data analysis. The mean score was computed and theoretical and skills score were categorized as excellent $(80-100 \%=16-20)$, very good $(70-79 \%=14-15.9)$, good $(60-69.9 \%=12-13.9)$, fair $(50-59 \%=10-11.9)$ and poor $(0-49 \%=0-9.9)$. The $\mathrm{p}$ value of 0.05 will be considered as statistically significant.

\section{Timeframe}

Data collection was done in October, 2016 in two different days (one day for urban school, and one day for rural school) from 10: 00 A.M to 12: 30 PM.

\section{Ethical consideration}

The study was approved by the Institutional Review Board (No 257/CMHS IRB/2016) of the College of Medicine and Health Sciences, University of Rwanda before data collection and the consent form and the assent forms were signed by the parents and children respectfully who voluntarily participated in the study. The school authority i.e. Head teacher in charge of school directorate also gave the written permission to conduct the study

\section{Limitations of the study}

The study was conducted in two primary schools in one sector of Northern Province of Rwanda, so its effectiveness could not be generalized in children from other communities or to children aged less than 9 years.

\section{Results}

Descriptive Statistics

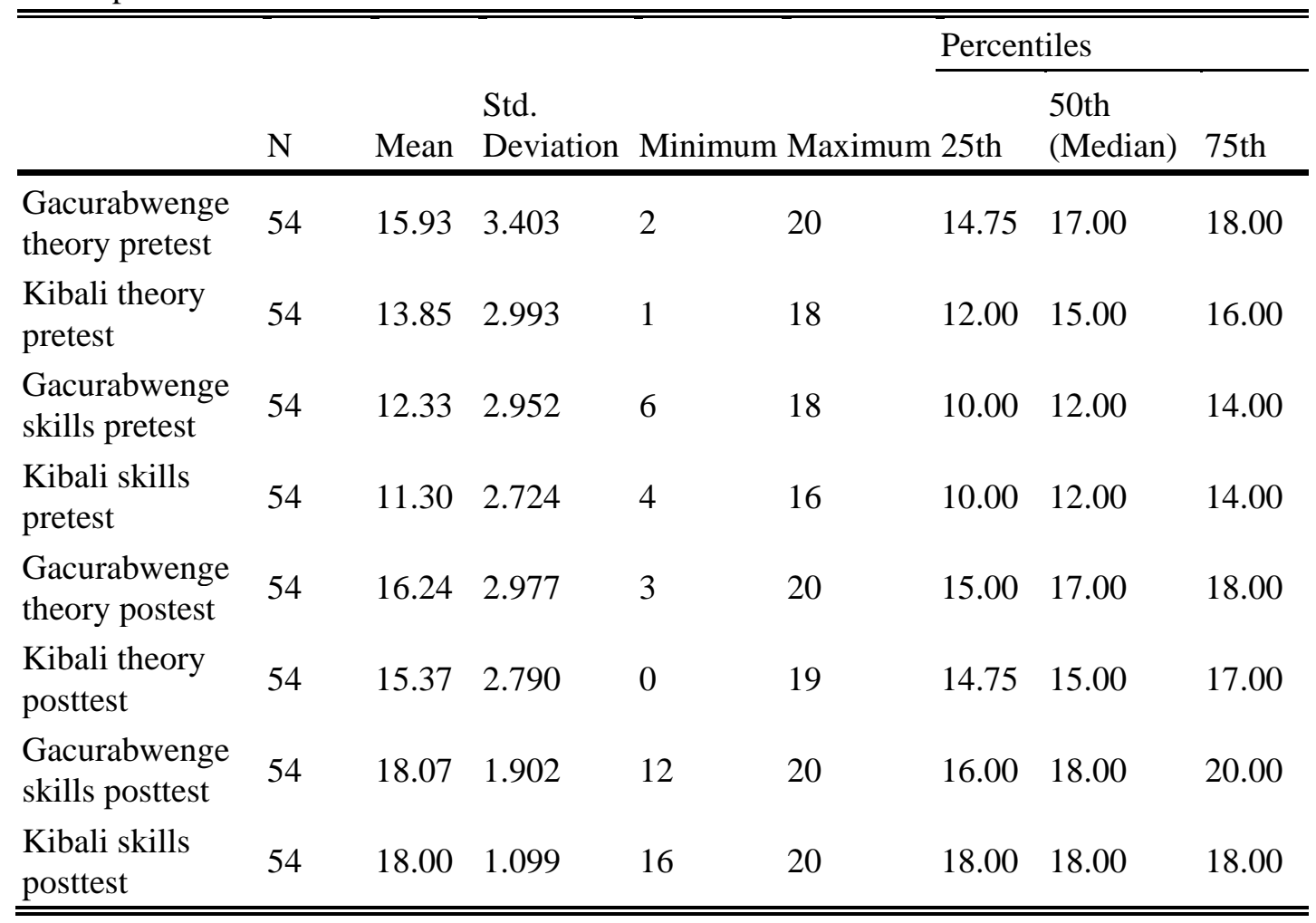

The median score during the theoretical pretest was 17 (IQR: 14.75-18) in urban school; while in rural school the median score was 15 (IQR: 12-16). The post test median score in 
Texila International Journal of Public Health

Volume 4, Issue 4, Dec 2016

urban school remain 17 (IQR: 15-18); whereas in rural school, the median score of theoretical knowledge after the intervention was 15 (14.75-17) over 20 maximum score.

There is a significant increase in mean score of hand washing skills after demonstration from $12.33 \pm 2.95$ to $18.07 \pm 1.90$ in urban school and from $11.30 \pm 2.72$ to $18.00 \pm 1.09$ in rural school.

\section{Knowledge of handwashing in urban school after intervention}

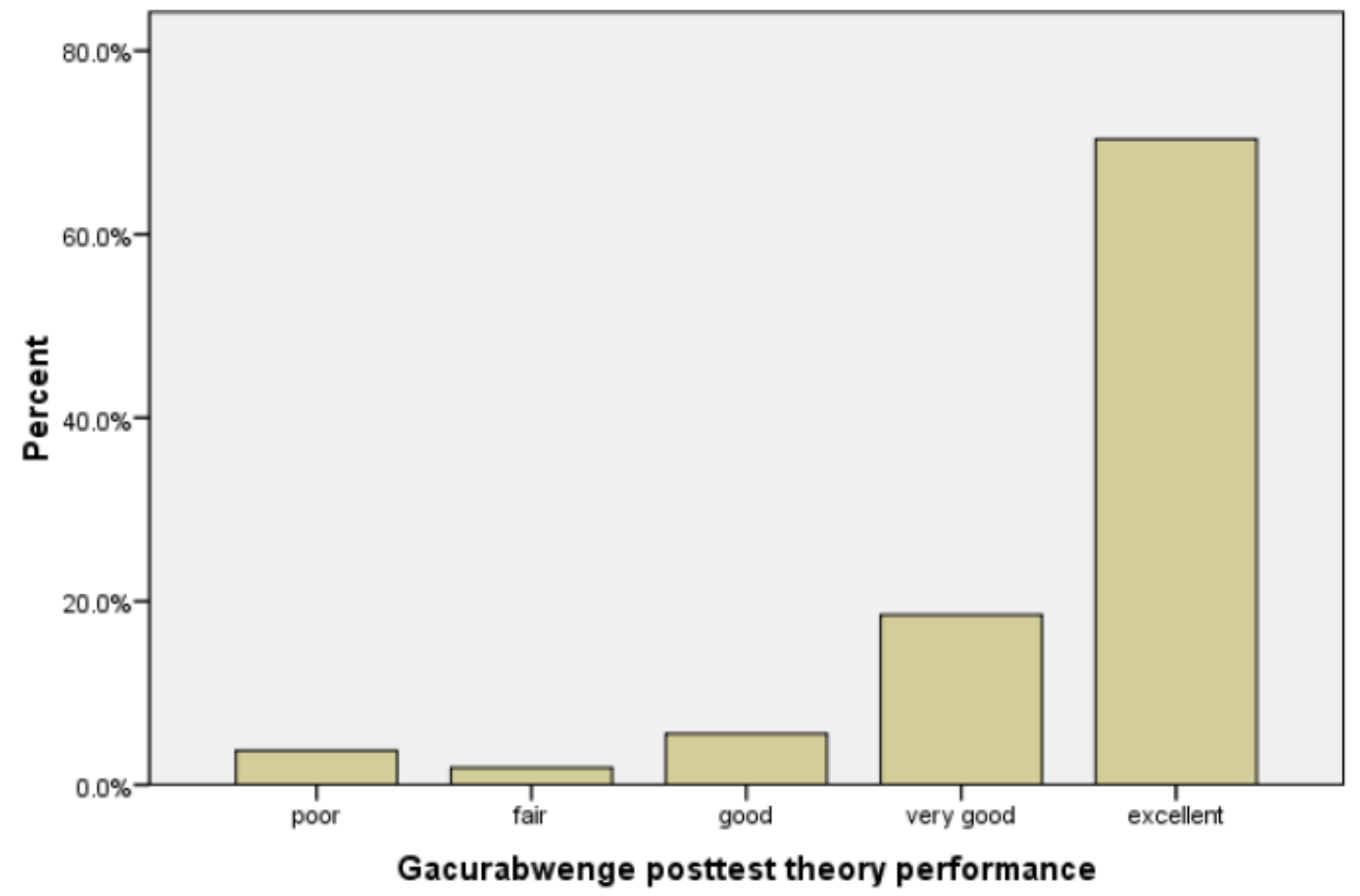

This graph shows the baseline theoretical knowledge of school children studying in one urban school towards hand washing: $70.4 \%$ had excellent knowledge, $11.1 \%$ had very good knowledge, 9.3\% had good knowledge, 3.7\% had fair knowledge and 5.6\% with poor knowledge. 


\section{Knowledge of handwashing in urban school after intervention}

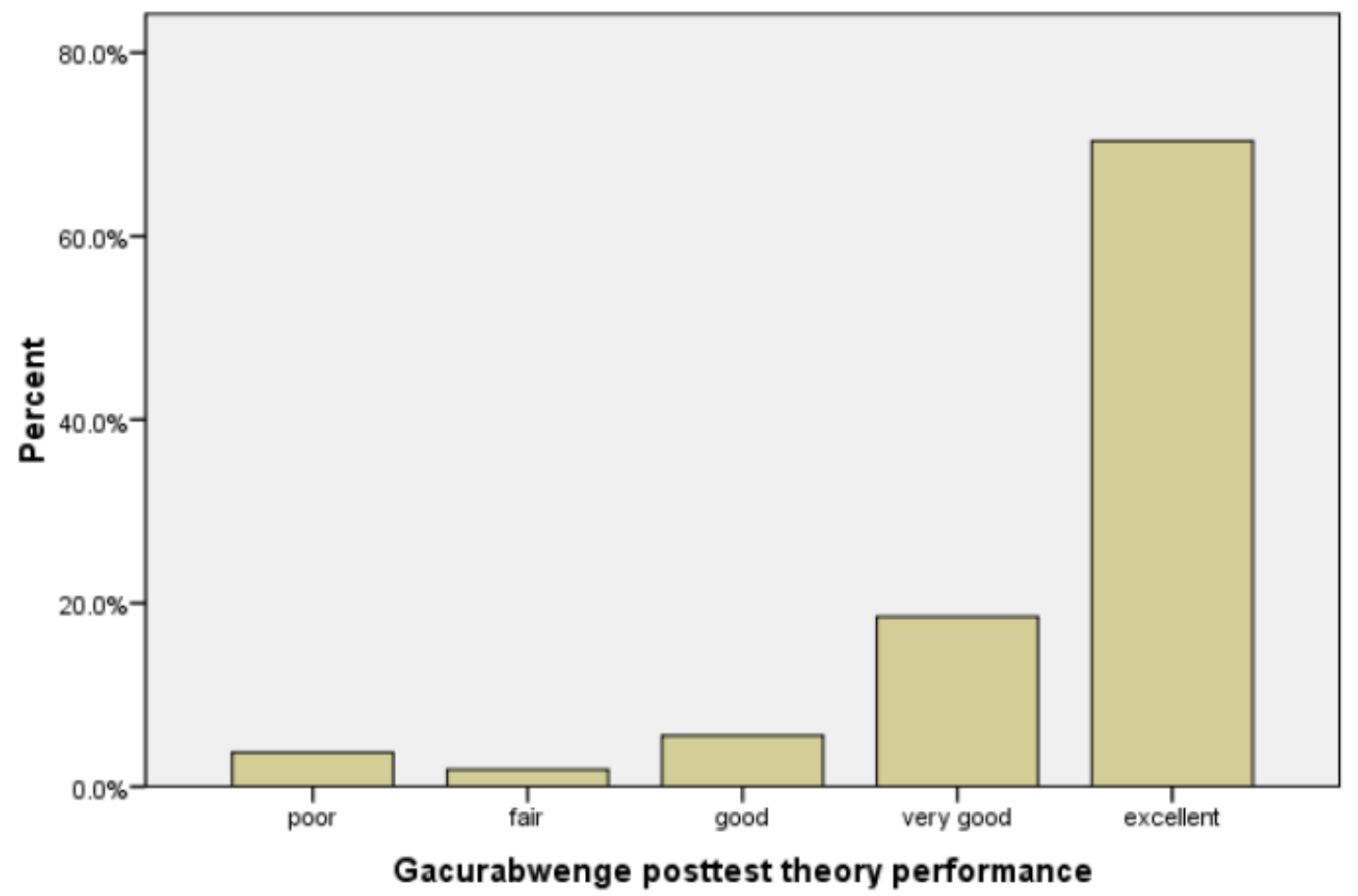

This graph shows the theoretical knowledge of school children studying in one urban school towards hand washing after receiving 30 minutes health education on handwashing: $70.4 \%$ had excellent knowledge, $18.5 \%$ had very good knowledge, $5.6 \%$ had good knowledge, $1.9 \%$ had fair knowledge and $3.7 \%$ with poor knowledge. 
Texila International Journal of Public Health

Volume 4, Issue 4, Dec 2016

Knowledge of hand washing in rural school before intervention

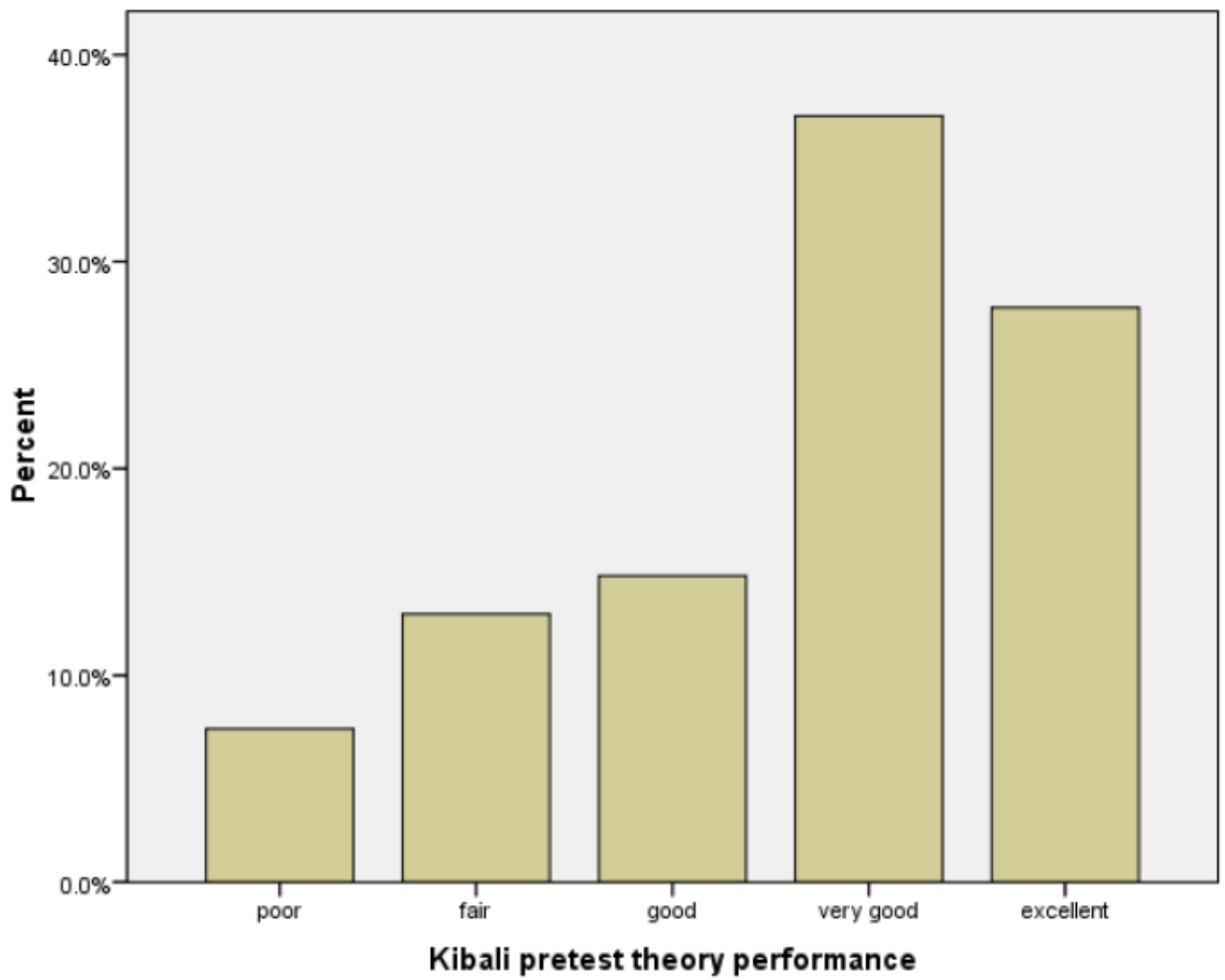

This bar chart shows the knowledge of school children in rural school before 30 minutes theoretical health education on hand washing: $27.8 \%$ of school children had excellent knowledge before intervention (at baseline), 37.0\% had very good knowledge before intervention, $14.8 \%$ had good knowledge. $13.0 \%$ and $7.4 \%$ had fair and poor knowledge respectively. 
Knowledge of hand washing in rural school after intervention

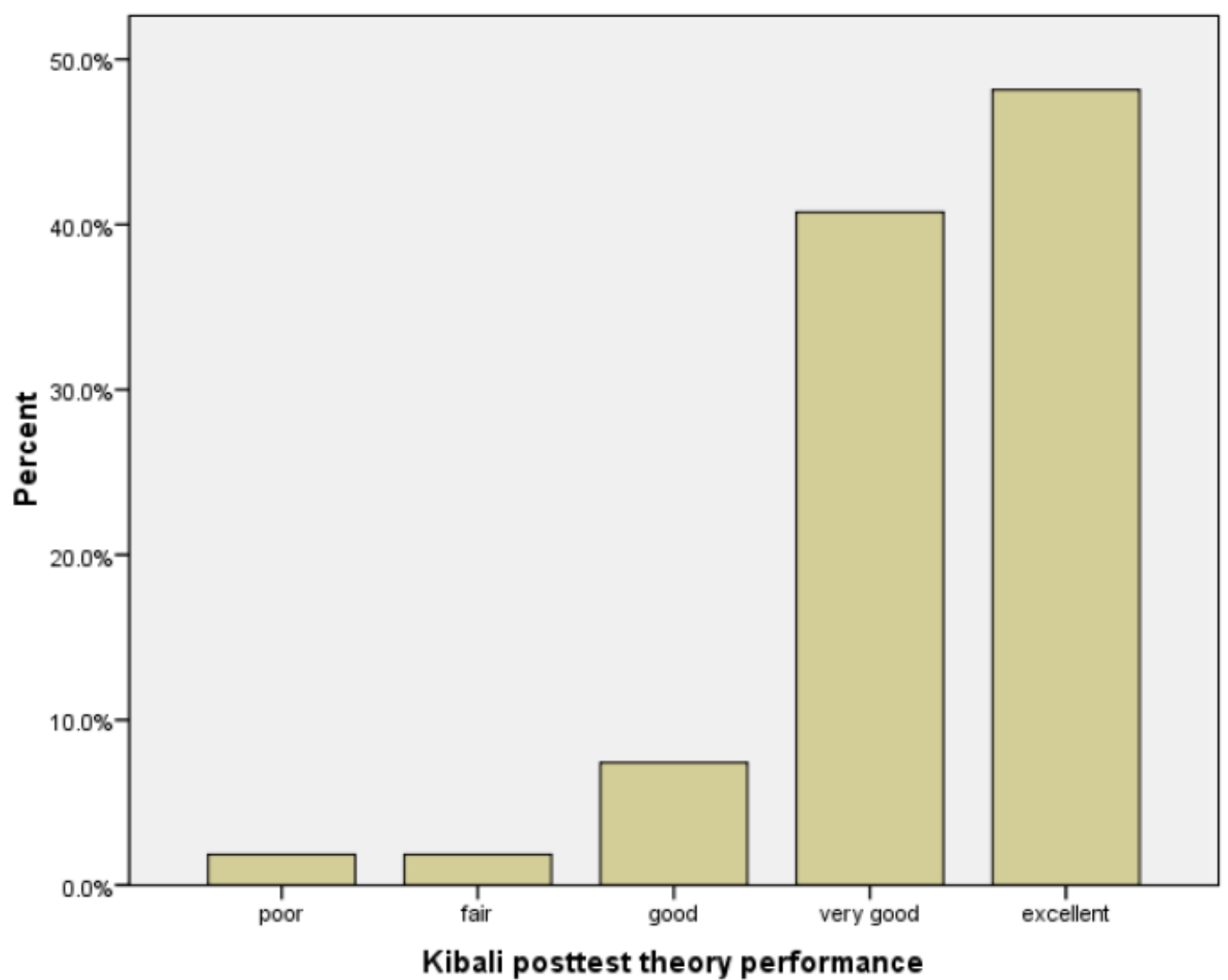

This bar chart shows the knowledge of school children in rural school after 30 minutes theoretical health education on hand washing: $48.1 \%$ of school children had excellent knowledge after intervention, $40.7 \%$ had very good knowledge after intervention, $7.4 \%$ had good knowledge, while $1.9 \%$ had fair knowledge and 1.9\% had poor knowledge. 
Texila International Journal of Public Health

Volume 4, Issue 4, Dec 2016

Hand washing skills of school children before demonstration in urban school

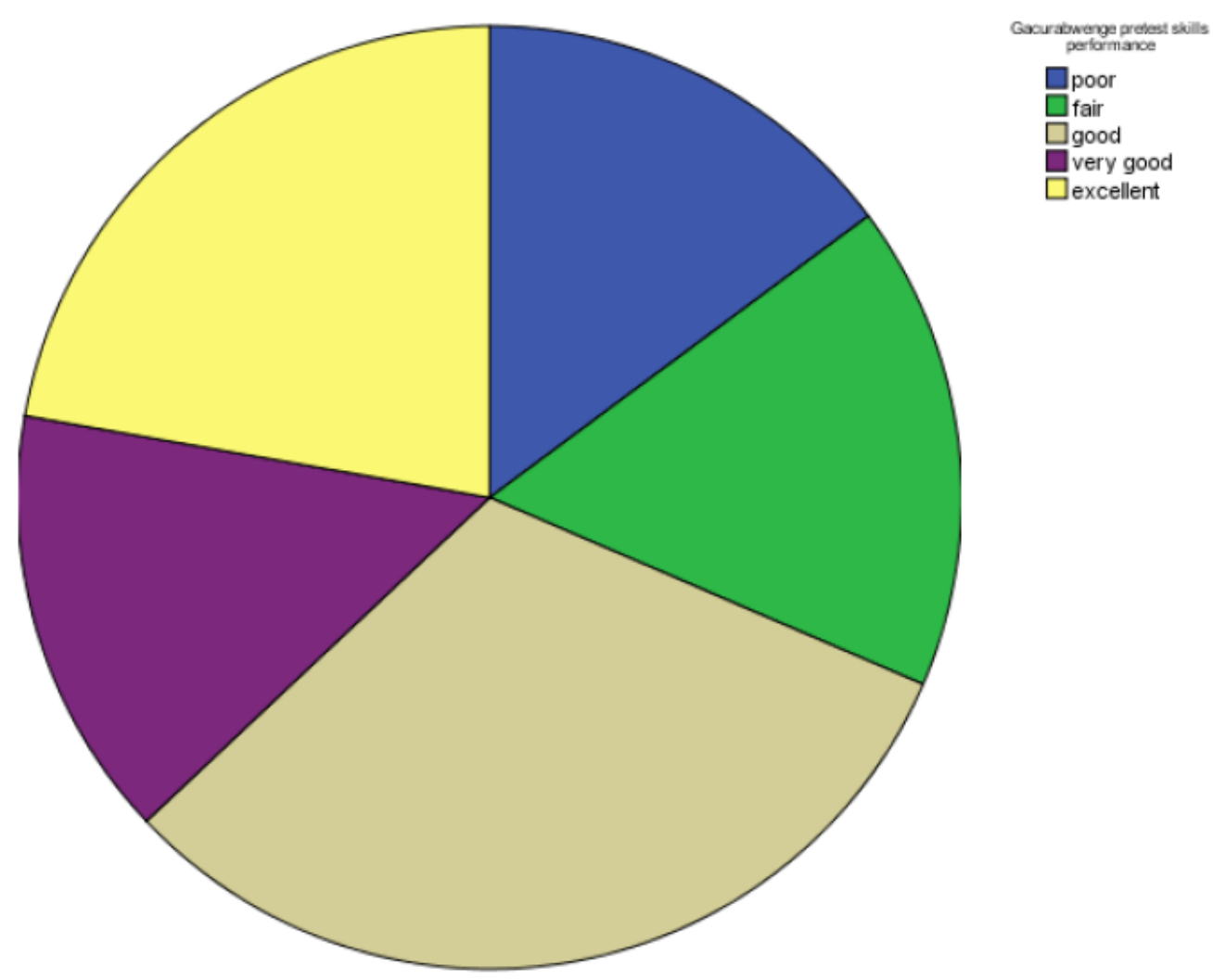

Before demonstration of proper technique of hand washing, 22.22\% of school children in urban school had excellent handwashing skills, $14.81 \%$ had very good handwashing skills, $31.48 \%$ had good handwashing skills, $16.67 \%$ had fair handwashing skills and $14.81 \%$ had poor handwashing skills. 


\section{Hand washing skills of school children after demonstration in urban school}

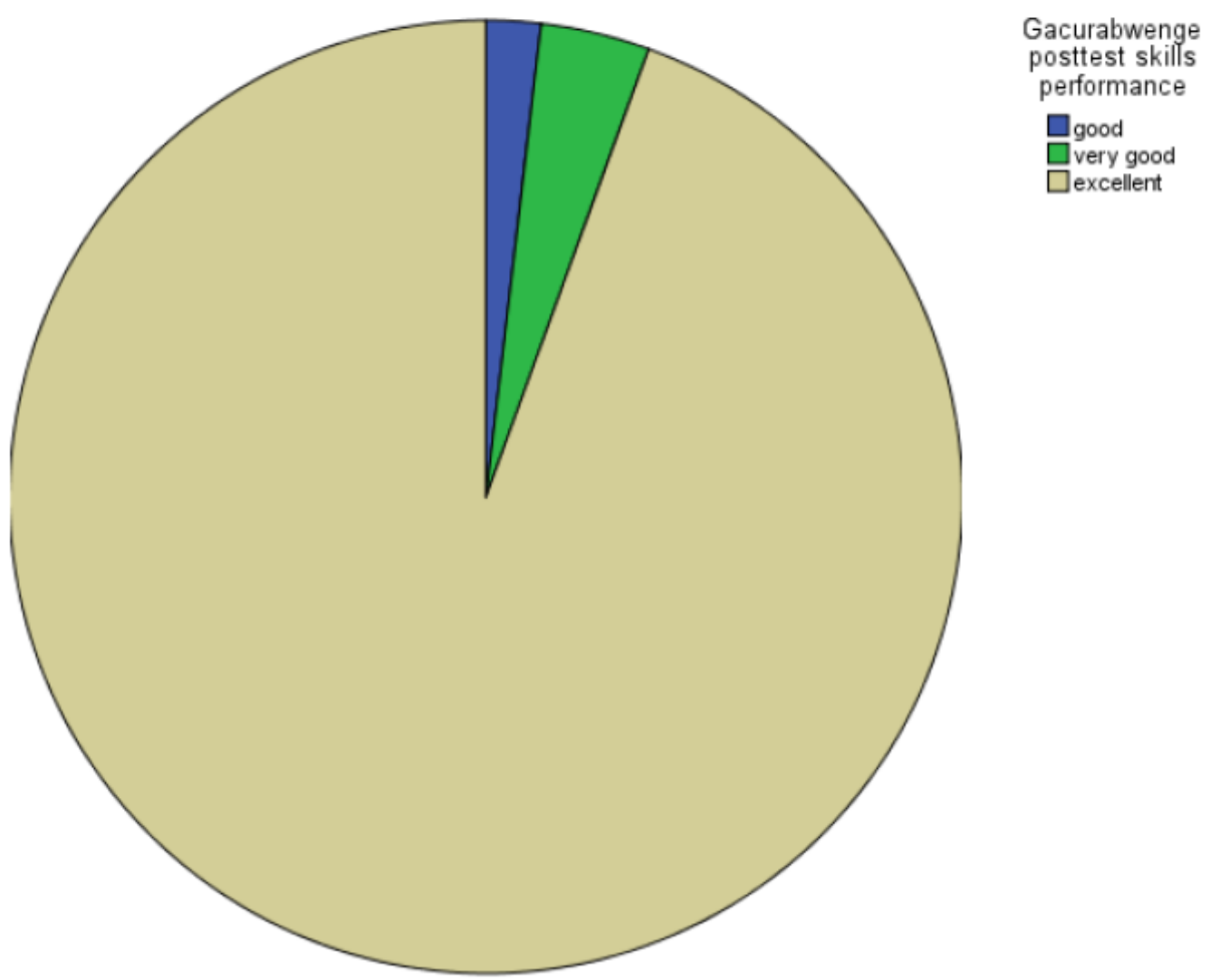

A high percentage of school children in urban school demonstrated the correct technique of handwashing after demonstration of the technique: $94.4 \%$ had excellent handwashing skills, $3.70 \%$ had very good handwashing skills, $1.86 \%$ had good handwashing skills after demonstration. No one demonstrated fair and poor handwashing skills after demonstration of the proper technique of handwashing. 
Texila International Journal of Public Health

Volume 4, Issue 4, Dec 2016

\section{Hand washing skills of school children before demonstration in rural school}

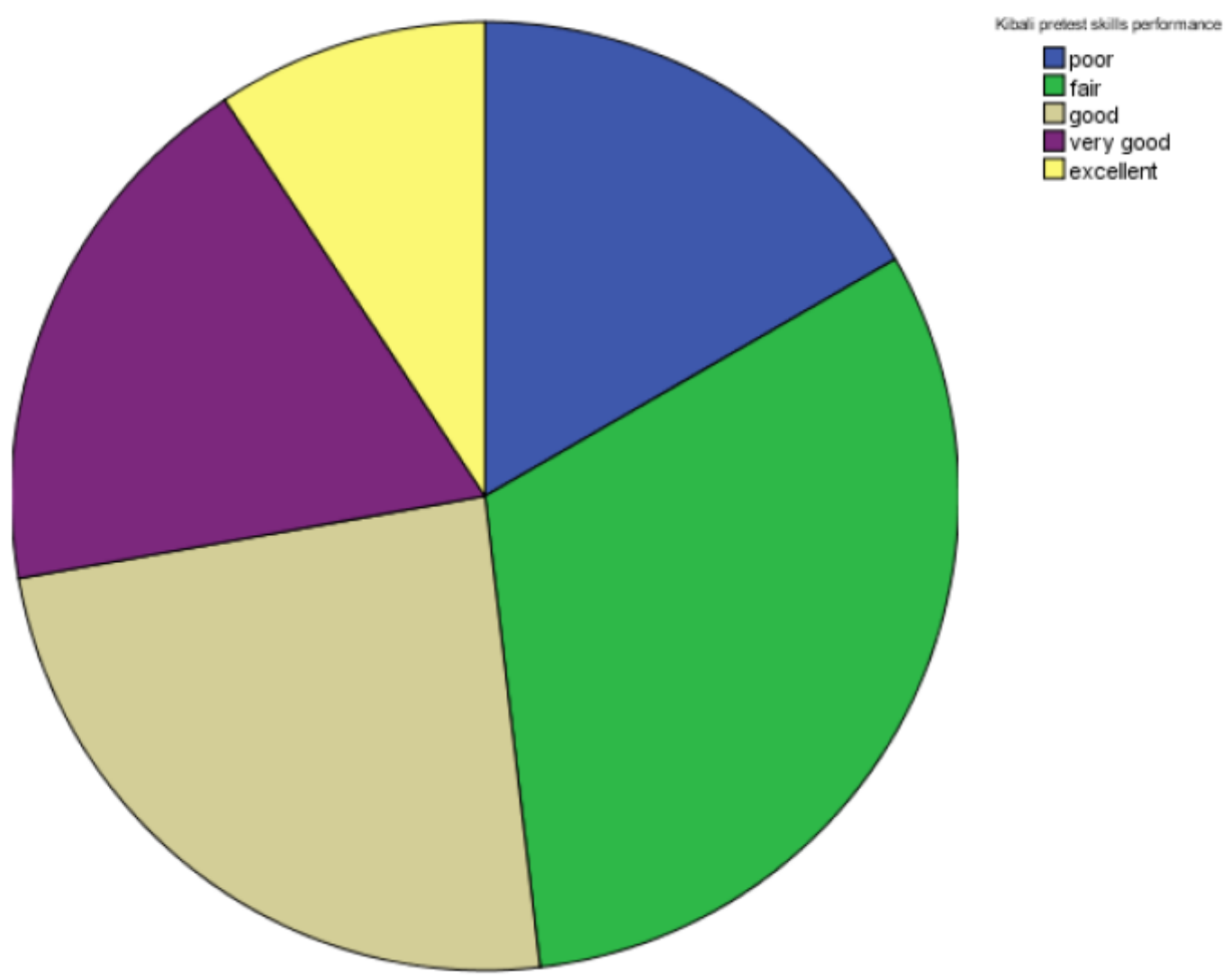

Before demonstration of proper technique of hand washing in rural school, $9.26 \%$ of school children had excellent handwashing skills, $18.52 \%$ had very good handwashing skills, $24.07 \%$ had good handwashing skills, $31.48 \%$ had fair handwashing skills and $16.67 \%$ had poor handwashing skills. 


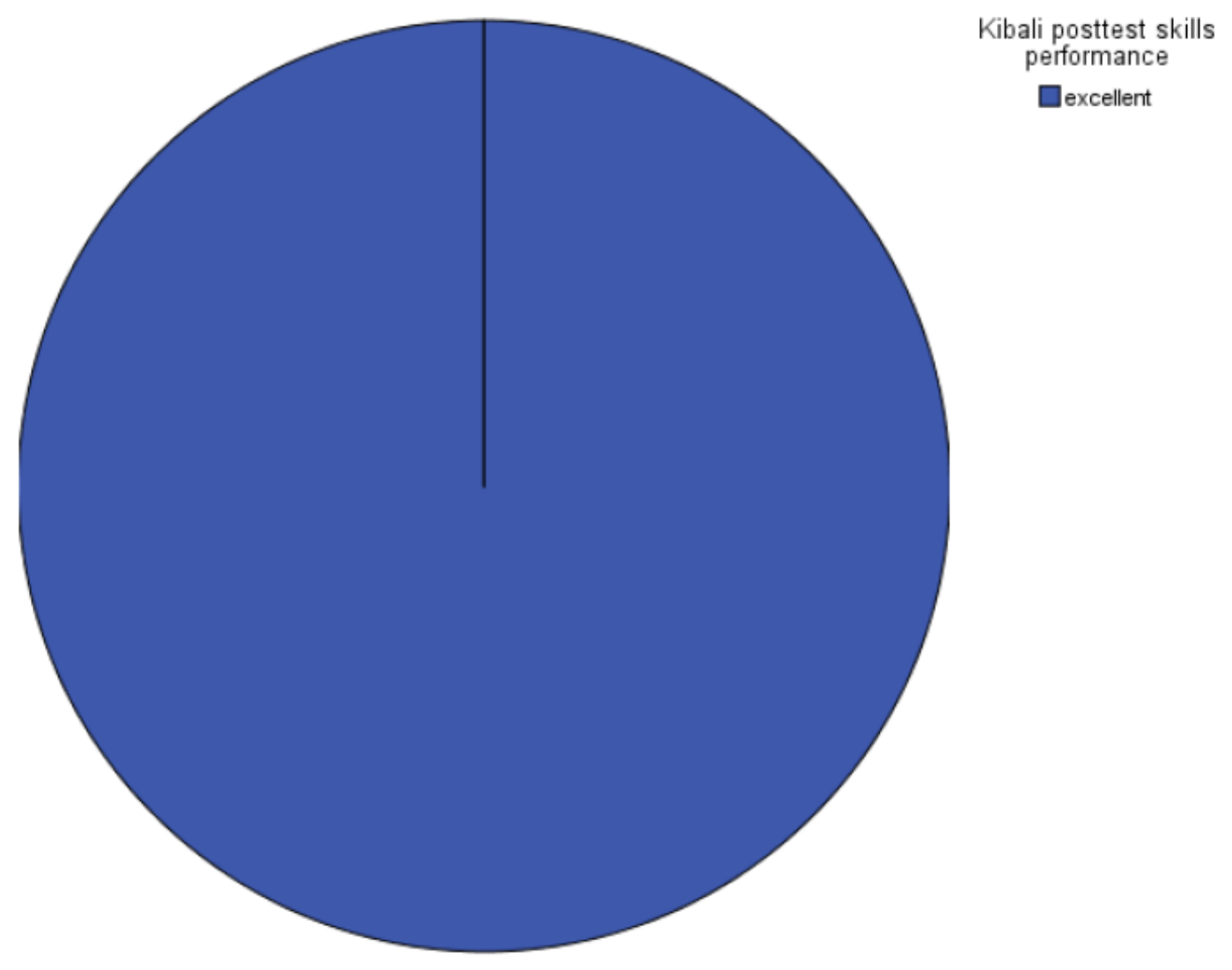

All (100\%) school children in rural school had excellent handwashing skills after demonstration and had significantly improved their handwashing technique compared with their skills before demonstration where only $9.26 \%$ had excellent knowledge.

Difference between theory pretest and posttest in urban and rural school

\begin{tabular}{lll}
\multicolumn{3}{c}{ Test Statistics $^{\mathbf{b}}$} \\
\hline \hline & $\begin{array}{l}\text { Gacurabwenge theory } \\
\text { postest - Gacurabwenge }\end{array}$ & $\begin{array}{l}\text { Kibali theory posttest - } \\
\text { theory pretest }\end{array}$ \\
& Kibali theory pretest \\
\hline $\mathrm{Z}$ & $-2.719^{\mathrm{a}}$ & $-4.545^{\mathrm{a}}$ \\
Asymp. Sig. (2-tailed) & .007 & .000 \\
\hline \hline
\end{tabular}

a. Based on negative ranks.

b. Wilcoxon Signed Ranks Test

There is a statistically significant difference between pretest theoretical score and posttest score in both urban school $(\mathrm{p}=0.007)$ and rural school $(\mathrm{p}<0.001)$, and the post test scores are higher than the pretest scores. 
Texila International Journal of Public Health

Volume 4, Issue 4, Dec 2016

Difference between handwashing skills pretest and post test in urban and rural school

Paired Samples Test

\begin{tabular}{|c|c|c|c|c|c|c|c|c|}
\hline & & \multicolumn{5}{|c|}{ Paired Differences } & \multirow[b]{3}{*}{ df } & \multirow{3}{*}{$\begin{array}{l}\text { Sig. (2- } \\
\text { tailed) }\end{array}$} \\
\hline & & \multirow[b]{2}{*}{ Mean } & \multirow{2}{*}{$\begin{array}{l}\text { Std. } \\
\text { Deviation }\end{array}$} & \multirow{2}{*}{$\begin{array}{l}\text { Std. } \\
\text { Error } \\
\text { Mean }\end{array}$} & \multicolumn{2}{|c|}{$\begin{array}{l}\text { 95\% Confidence } \\
\text { Interval of the } \\
\text { Difference }\end{array}$} & & \\
\hline & & & & & Lower & Upper & & \\
\hline $\begin{array}{l}\text { Pair } \\
1\end{array}$ & $\begin{array}{l}\text { Gacurabwenge } \\
\text { skills pretest - } \\
\text { Gacurabwenge } \\
\text { skills posttest }\end{array}$ & $\begin{array}{l}- \\
5.741\end{array}$ & 2.748 & .374 & -6.491 & -4.991 & $\overline{-}^{-}{ }^{53}$ & .000 \\
\hline $\begin{array}{l}\text { Pair } \\
2\end{array}$ & $\begin{array}{l}\text { Kibali skills } \\
\text { pretest - Kibali } \\
\text { skills posttest }\end{array}$ & $\begin{array}{l}- \\
6.704\end{array}$ & 2.668 & .363 & -7.432 & -5.975 & 18.46453 & .000 \\
\hline
\end{tabular}

There is a statistically significant difference between pretest skills score and posttest score in both urban school $(\mathrm{p}<0.001)$ and rural school $(\mathrm{p}<0.001)$, and the post test scores are higher than the pretest scores.

Comparison of pretest/posttest knowledge and skills in urban and rural school

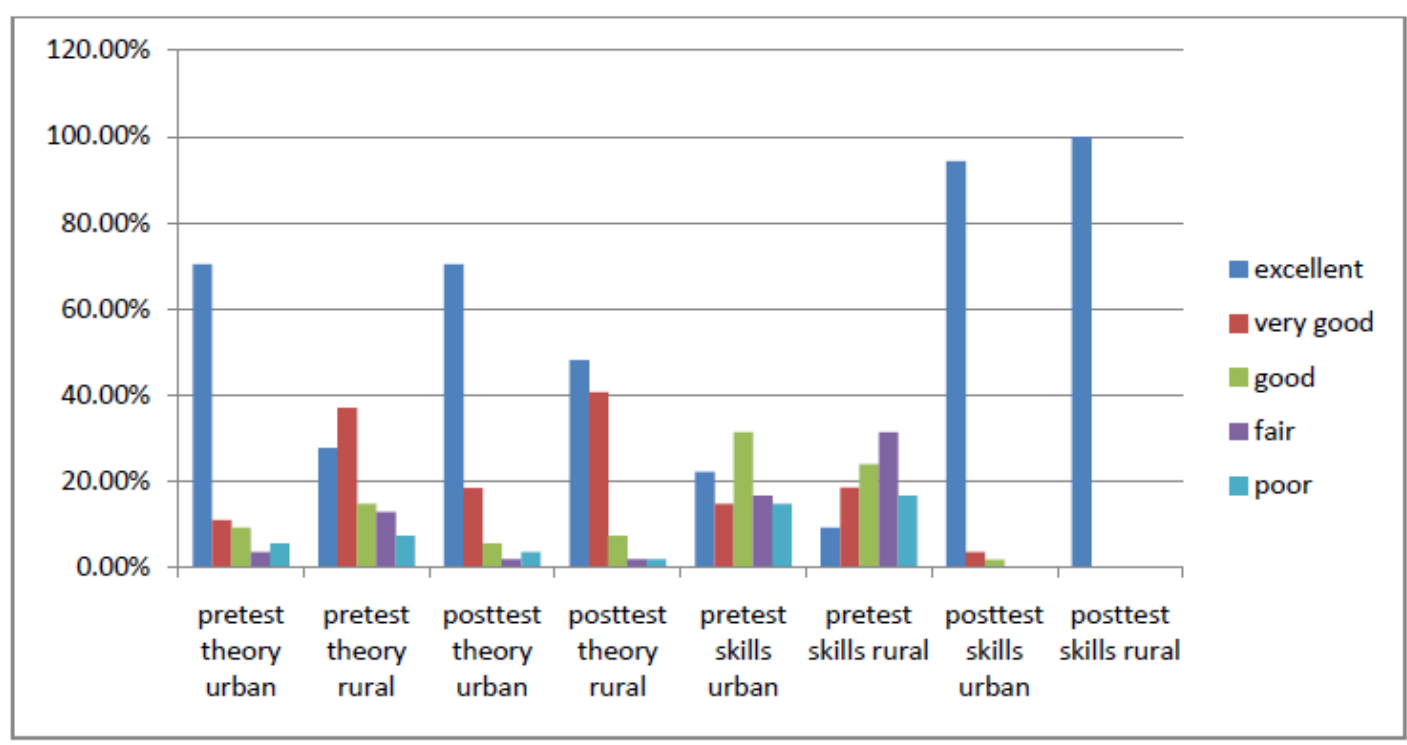

This graph shows that $70.4 \%$ versus $27.8 \%$ excellent handwashing knowledge in urban and rural school during theory pretest, $70.4 \%$ versus $48.1 \%$ excellent handwashing knowledge in urban and rural school during theory post test. The same for handwashing skills the excellent pretest score was $24 \%$ in urban and $9.6 \%$ in rural school. This shows the difference in handwashing knowledge and skills in school children in urban and rural school. The excellent post test handwashing skills in both urban school and rural school were quite similar with high percentage in rural school (94.4\% in urban and $100 \%$ in rural school).

\section{Discussion}

This study found that in urban school, during pretest theory $70.4 \%$ had excellent knowledge, $11.1 \%$ had very good knowledge, 9.3\% had good knowledge, 3.7\% had fair knowledge and $5.6 \%$ with poor knowledge. The post test theory in the same school was $70.4 \%, 18.5 \%, 5.6 \%, 1.9 \%$ and $3.7 \%$ for excellent knowledge, very good, good, fair and poor 
knowledge respectively. The difference between theory pretest and posttest in urban school was statistically significant $(\mathrm{p}=0.007)$

The results of pretest theory in rural school were different from those found in urban school with only $27.8 \%$ with excellent knowledge, $37 \%$ with very good knowledge, $14.8 \%$ with good knowledge, $13 \%$ with fair knowledge and $7.4 \%$ with poor knowledge. The post test theory for the same school was $48.1 \%, 40.7 \%, 7.4 \%, 1.9 \%$ and $1.9 \%$ for excellent, very good, good, fair and poor knowledge respectively. The difference between theory pretest and posttest in rural school was statistically significant $(\mathrm{p}<0.001)$

There was a significant increase in handwashing skills from pretest to post test in both urban and rural school. In urban school the pretest revealed 22.22\% of school children with excellent handwashing skills, $14.81 \%$ with very good handwashing skills, $31.48 \%$ with good handwashing skills, $16.67 \%$ with fair handwashing skills and $14.81 \%$ with poor handwashing skills. In post test in the same school, after demonstration of proper technique of handwashing, almost all (94.4\%) school children in urban school demonstrated excellent skills of handwashing. The difference between pretest and post test skills was statistically significant $(p<0.001)$. In rural school, the same difference has been found from pretest to post test handwashing skills; in pretest, 9.26\% of school children had excellent handwashing skills, $18.52 \%, 24.07 \%$, 31.48\% and $16.67 \%$ had very good handwashing skills, good handwashing skills, fair handwashing skills and poor handwashing skills respectively, in posttest in the same school, all school children (100\%) had excellent handwashing skills and the difference between pretest and post test skills was statistically significant $(\mathrm{p}<0.001)$. This improvement in handwashing has been also found in one study done in India (Rubanprem Kumar, Aruna, \& Sasikala, 2014)

School children in urban public school had baseline knowledge in handwashing theory; more than two third (70.4\%) of school children at Gacurabwenge primary school had excellent knowledge before theoretical health education and the same percentage had excellent knowledge in posttest (after health education), whereas only $27.8 \%$ of school children in rural public school had excellent knowledge before health education. This is possibly due to lack of sources of information like media (radio, television...) and other means of communication in rural communities.

The percentage of school children who had excellent theory score has been similar in pretest and post test in urban school and has been increased from pretest to post test in rural school (20\% increase) and there was a tremendous increase in excellent skills score from pretest to post test in both urban (72\% increase) and rural school (90.7\% increase), this is similar to the findings in Georgia, USA showing the ability of handwashing education on raising the knowledge of school children towards handwashing technique (Harrison, 2012). These findings showed that school children can follow the 10 steps of handwashing of the World health organization and be able to emphasize on critical areas of the hands where microbes may be hidden namely between fingers, in fingernails, therefore school children should be demonstrated how to wash their hands in details in order to eliminate the microbes, not just a routine of putting water and soap. The steps that are usually used by healthcare personnel (WHO, 2008) due to its effectiveness in eliminating germs on their hands can also be followed by a 9 years old child and be adopted as a better way of washing hands. This is confirmed by the post test skills performance in rural school where all the school children (100\%) had excellent score (80-100\%) after handwashing technique demonstration following a baseline of only $9.3 \%$ of excellent handwashing skills score.

\section{Conclusion and recommendations}

Handwashing health education was effective to increase the knowledge and skills of school children regarding proper technique of handwashing in urban and rural public primary school and there is a need to teach other school children the detailed technique of handwashing with emphasis on those studying in rural area as their baseline handwashing knowledge and skills need more improvement compared to urban school children. 
Texila International Journal of Public Health

Volume 4, Issue 4, Dec 2016

\section{References}

[1]. Abraham, C. (2015). Ideas for Exploring Handwashing. Good Health Is In Your Hands! Retrieved April 25, 2016, from http://www.cdc.gov/handwashing/training-education.html

[2]. Assefa, M., \& Kumie, A. (2014). Assessment of factors influencing hygiene behaviour among school children in Mereb-Leke District, Northern Ethiopia: a cross-sectional study. BMC Public Health, 14, 1000. doi:10.1186/1471-2458-14-1000

[3]. Biran, A., Schmidt, W., Varadharajan, K. S., Rajaraman, D., Kumar, R., Gopalan, B., ... Curtis, V. (2014). Eff ect of a behaviour-change intervention on handwashing with soap in India (SuperAmma): a cluster-randomised trial. The Lancet Global Health, 2(3), e145-e154. doi:10.1016/S2214109X(13)70160-8

[4]. CDC. (2013). Improving child development. Retrieved from http://www.cdc.gov/healthywater/global/index.html

[5]. CDC. (2013). Global water, Sanitation and hygiene. Global diarrhea burden. retrieved from http://www.cdc.gov/healthywater/global/diarrhea-burden.html. $\quad$ Retrieved from http://www.cd.gov/healthywater/global/diarrhea-burden.html

[6]. Celik, L. a., \& Pancoe, D. L. (2012). Healthy School Environment: Effectiveness of Hand Washing Instruction in an Elementary School Setting. NASN School Nurse, 27, 194-196. doi:10.1177/1942602X12444451

[7]. Center for disease control and prevention (CDC). (2009). Vessel sanitation program. General information on hand hygiene. Retrieved from www.cdc.gov

[8]. Global Giving. (2013). strengthen hand washing to 800 children in Rwanda. Retrieved from https://www.globalgiving.org/projects/clean-hands-to-save-lives/reports/?pageNo=1

[9]. Harrison, J. A. (2012). Teaching Children to Wash Their Hands - Wash Your Paws, Georgia! Handwashing Education Initiative. Food protection trends, 32(3), 116-123.

[10]. Ilechukwu, G., Ilechukwu, C., Ozumba, A., Ojinnaka, N., Ibe, B., \& Onwasigwe, C. (2010). Some behavioural risk factors for intestinal helminthiasis in nursery and primary school children in Enugu, south eastern Nigeria. Niger $J$ Clin Pract., 13(3), 288-293. Retrieved from http://hinarilogin.research4life.org/uniquesigwww.ncbi.nlm.nih.gov/uniquesig0/pubmed/20857787

[11]. Johansen, A., Denbæk, A. M., Bonnesen, C. T., \& Due, P. (2015). The Hi Five study : design of a school-based randomized trial to reduce infections and improve hygiene and well-being among 6 - 15 year olds in Denmark. BMC Public health, 15, 207. doi:10.1186/s12889-015-1556-1

[12]. Lee, R. L. T., Leung, C., Tong, W. K., Chen, H., \& Lee, P. H. (2015). Comparative efficacy of a simplified handwashing program for improvement in hand hygiene and reduction of school absenteeism among children with intellectual disability. American Journal of Infection Control, 43, 907-912. doi:10.1016/j.ajic.2015.03.023

[13]. Maternal and Child Survival Program. (2015). Water, Sanitation and Hygiene (WASH). Retrieved from http://www.mcsprogram.org/our-work/water-sanitation-and-hygiene-wash/

[14]. Nair, S. S., Hanumantappa, R., Gurushantswamy, S., Siraj, M. A., \& Raghunath, P. (2014). Knowledge, Attitude, and Practice of Hand Hygiene among Medical and Nursing Students at a Tertiary Health Care Centre in Raichur, India. ISRN Preventive Medicine, 2014. doi:doi.org/10.1155/2014/608927

[15]. Patel, M. K., Harris, J. R., Juliao, P., Nygren, B., Were, V., Kola, S., ... Quick, R. (2012). Impact of a Hygiene Curriculum and the Installation of Simple Handwashing and Drinking Water Stations in Rural Kenyan Primary Schools on Student Health and Hygiene Practices. American Journal of Tropical Medicine and Hygiene, 87(4), 594-601. doi:10.4269/ajtmh.2012.11-0494

[16]. Ray, S. K., Amarchand, R., Srikanth, J., \& Majumdar, K. K. (2011). A Study on Prevalence of Bacteria in the Hands of Children and Their Perception on Hand Washing in Two Schools of Bangalore and Kolkata. Indian Journal of Public Health, 55(4). doi:10.4103/0019-557X.92408

[17]. Rubanprem Kumar, S., Aruna, S., \& Sasikala, M. (2014). Effectiveness of hand hygiene teaching on knowledge and compliance of hand washing among the students at a selected school in Mugalivakkam village, Kancheepuram Districtln. Journal of Nursing and Health Science (IOSRJNHS), 3(4), 56-60. Retrieved from http://www.iosrjournals.org/iosr-jnhs/papers/vol3-issue4/Version2/H03425660.pdf 
[18]. Rwanda Ministry of Health. (2014). Rwanda launches Hygiene Campaign in Schools. Retrieved April 02, 2016, from

http://moh.gov.rw/index.php?id=34\&L=-

1\%27\&tx_ttnews\%5Btt_news\%5D=550\&cHash=681f30cedc22611c435f30a67f576e85

[24]. Saboori, S., Greene, L. E., Moe, C. L., Freeman, M. C., Caruso, B. a., Akoko, D., \& Rheingans, R. D. (2013). Impact of regular soap provision to primary schools on hand washing and E. coli hand contamination among pupils in nyanza province, Kenya: A cluster-randomized trial. American Journal of Tropical Medicine and Hygiene, 89, 698-708. doi:10.4269/ajtmh.12-0387

[25]. Tandukar, S., Ansari, S., Adhikari, N., Shrestha, A., Gautam, J., Sharma, B., ... Sherchand, J. B. (2013). Intestinal parasitosis in school children of Lalitpur district of Nepal. BMC Research Notes, 6(1), 1. doi:10.1186/1756-0500-6-449Harrison, J. A. (2012). Teaching Children to Wash Their Hands Wash Your Paws, Georgia ! Handwashing Education Initiative, 32(3), 116-123.

[26]. Rubanprem Kumar, S., Aruna, S., \& Sasikala, M. (2014). Effectiveness of hand hygiene teaching on knowledge and compliance of hand washing among the students at a selected school in Mugalivakkam village, Kancheepuram Districtln. Journal of Nursing and Health Science (IOSRJNHS), 3(4), 56-60. Retrieved from http://www.iosrjournals.org/iosr-jnhs/papers/vol3-issue4/Version2/H03425660.pdf

[27]. Umwangange, L. M. (2016). Knowledge and attitude of hand washing among school children and education on hand washing technique. Rural East Rwanda. South American Journal of Public Health, 4(special issue), 1-8. http://doi.org/10.21522/TIJPH.2013.04.02.Art019

[28]. Xuan, L. T. T., \& Hoat, L. N. (2013). Handwashing among schoolchildren in an ethnically diverse population in northern rural Vietnam. Global Health Action, 6, 1-8. http://doi.org/10.3402/gha.v6i0.18869

[29]. UNICEF. (2012). Simple handwashing crucial to halting diarrhoeal and water-borne diseases, UN stresses. Retrieved from http://www.un.org/apps/news/story.asp?NewsID=43289\#.VtwnnH195dg

[30]. Vivas, Alyssa; Gelaye, Bizu; Aboset, Nigusu; Kumie, Abera; Berhane, Yemane,; Williams, M. A. (2011). Knowledge, Attitudes, and Practices (KAP) of Hygiene among School Children in Angolela, Ethiopia. Journal of Preventive Medicine and Hygiene, 51(2), 73-79.

[31]. WHO (2015). Clean care is safer care. Retrieved from http://www.who.int/gpsc/clean_hands_protection/en/

[32]. WHO (2008). WHO guidelines on hand hygiene in health care. Retrieved from www.who.int/gpsc/5may/.../who_guidelines-handhygiene

[33]. http://biomath.info/power/prt.htm 


\title{
Clinical and Radiographical Evaluation of the Healing of Large Periapical Lesions using Triple Antibiotic Paste, Photo Activated Disinfection and Calcium Hydroxide When used as Root Canal Disinfectant
}

\author{
Article by Dexton Antony Johns \\ Ph.D in Clinical Research, Texila American University, India \\ E-mail:dextonjohns@gmail.com
}

\section{Introduction}

Elimination of microorganisms from the root canal system is one of the objectives of the root canal treatment and has a substantial effect on the treatment outcome. Accepted treatment procedures to eliminate the infection include a combination of chemo-mechanical debridement, application of an inter appointment dressing containing an antimicrobial agent and finally sealing of the root canal. Unfortunately, micro organisms may remain after conventional canal preparation, either within the dentinal tubules or bound within the apical dentin plug. Therefore for complete eradication of infection, the pulpal remnants as well as smear layer should be removed from the root canals.

Some investigators recommend the use of calcium hydroxide as an intracanal dressing in a multiple-visit approach. The environment within the system, however, is such that delivering the medicament and maintaining a high $\mathrm{pH}$ homogeneously is a challenge. For these and other reasons, certain microbial species in a limited group of cases do survive and can be responsible for persistent infections $(1,2)$. Thus, the search for a better alternative has led to the discoveries of newer antimicrobial agents.

The Cariology Research Unit of the Niigata University has developed the concept of 'Lesion sterilization and tissue repair LSTR' therapy $(3,4)$ that employs the use of a combination of antibacterial drugs for disinfection of oral infectious lesions, including dentinal, pulpal, and periradicular lesions. Repair of damaged tissues can be expected if lesions are disinfected (5). Metronidazole was the first choice because it has a wide bactericidal spectrum against anaerobes (6), which were common in oral sites. However, some bacteria in lesions were resistant to metronidazole and, thus, two other antibacterial drugs, e.g., ciprofloxacin and minocycline, should be mixed with metronidazole (7) in an effort to eliminate all the bacteria. Finally, extensive in vitro and in situ studies have been conducted showing the mixed drugs to be effective against oral bacteria $(5,8,9)$. The disadvantage of this mixture is the discoloration caused by minocycline present in it (10).

In recent years novel antimicrobial approaches to disinfect root canals have been proposed that include Photo Activated Disinfection [PAD]. PAD uses a combination of photosensitising dye, such as Tolonium chloride solution [TC] [synonym Toluidine Blue O], and light of a specific wavelength. This combination using light at 633G2 nm has been shown to kill high numbers of bacteria in planktonic suspension, probably by disruption of the bacterial membrane by short range free radicals or reactive oxygen species. TC is unchanged by the process, which ceases when irradiation stops (11).

The present study was designed to evaluate clinically and radiographically the healing of periapical lesions using triple antibiotic paste, PAD and calcium hydroxide when used as root canal disinfectant.

\section{Material and methods}

The study is conducted as a prospective clinical trial to compare and evaluate clinical and radiographic healing following nonsurgical treatment of periapical lesions when PDT, triple antibiotic paste and calcium hydroxide were used as root canal disinfectant. Sixty patients [20 for PDT, 20 for triple antibiotic paste, 20 for calcium hydroxide] with periapical lesions in the 
Texila International Journal of Public Health

Volume 4, Issue 4, Dec 2016

maxillary anterior region were selected from the outpatient section of the Department of Conservative Dentistry \& Endodontics, Govt. Dental College, Kozhikode to participate in this study. The study started in the year 2010 after the approval of the ethical committee of Govt. Medical College, Calicut. Patients were randomly allocated into 3 groups by a random allocation software. One blinded nurse enrolled all participants and assigned them to intervention. The data was statistically analyzed by a statistician who was unaware of the allocated group.

\section{Inclusion criteria}

Patients between 15-30years of age who had periapical lesions in the maxillary anterior region. - Exclusion criteria - All patients who respond positive to allergic patch test [triple antibiotic paste] and drugs. - Teeth with previous endodontic therapy performed. - Patients with a history of any systemic diseases. • Pregnant and lactating women. • Tooth associated with vertical root fracture and coronal perforation. $•$ Tooth affected with calcific degeneration. - Presence of external or internal root resorption. - Blunderbuss apex. - Clinical parameters Clinical details about the treated tooth included: [i] tenderness to pressure and percussion of the tooth, [ii] tenderness to palpation of adjacent soft tissues, [iii] presence of an associated sinus tract or swelling in the adjacent soft tissues, [iv] periodontal probing profile around the tooth, and [v] the type and presence of an adequate coronal restoration and 'seal'. Radiographic parameters - Radiographs Periapical radiographs were taken by a radiologist using the long-cone paralleling technique [Asahi x-ray unit GX-60N; Asahi Roentgen International, Kyoto, Japan]. Kodak DF-57 films [Eastman Kodak, Rochester, NY], which were automatically developed and fixed [Level 360; Flat Co, Kobe, Japan], were used in this study. • Radiographic examination Viewing conditions were standardized using a slide viewer [Flash-pak projector; Slidex Co, Tokyo, Japan]with magnification [6.6X]. The periapical status was assessed by using the periapical index [PAI]. Each tooth was assigned to 1 of the PAI scores by using visual references (12) for the 5 categories within the scale (Fig. 1, Table 1). After scoring the teeth, the results were compared to a gold standard atlas, and Cohen kappa value was [0.81]. According to Landis and Koch [1977] (13), Kappa scores greater than 0.8 indicate "good agreement".

- Periapical Index $\bullet$ Favorable healed: 3, 4, 5 at IPO [initial pre operative] --> 1-2 at Follow up or 1-2 at IPO -->1-2 at Follow up. healing: 3, 4, 5 at IPO improves but isn't --> 1-2 at Follow up. - Unfavorable not healed/healing 5-3 at IPO stays --> 5-3 at Follow up. or 1-2 at IPO --> 3, 4, 5 at Follow up. - Determination of outcome Treatment success was assessed using two outcome measures. For this part of the study, successful treatment based on strict criteria was defined as absence of pain, clinical evidence of inflammation or swelling and conventional radiographic measures of complete healing/ presence of a normal periodontal ligament space. Successful treatment based on loose criteria was defined as absence of pain, clinical evidence of inflammation or swelling and conventional radiographic measures of complete healing/presence of a normal periodontal ligament space or incomplete healing [if there was reduction in size of the lesion without return to normal periodontal ligament space width]. If a tooth had been extracted because of endodontic problems [persistent pain, swelling, sinus or periapical radiolucent lesion], the treatment was considered failed. General Steps All the cases were treated by one operator using a standardized technique. The access to the pulp chamber was gained and rubber dam was placed. The working length was using electronic apex locator Root ZX [J.Morita MFG. Corporation, Kyoto, Japan] and by files in radiograph. In most cases drainage was performed daily on two to four subsequent appointments until discharge through the canal ceased. The access cavities were sealed with zinc oxide eugenol cement [Dental Products of India, Mumbai, India] after drainage. Intracanal medication and photodynamic therapy was not applied to the canal until active drainage ceased. The root canals were finally instrumented by a conventional step-back technique using K-type files, and copious irrigation with $1 \%$ sodium hypochlorite [Nova Dental Products Pvt. Ltd, Mumbai, India], 17\%EDTA [B. N. Laboratories, Mangalore, India] 
and $0.2 \%$ chlorhexidine [Vishal Dentocare Pvt. Ltd., Ahmedabad, India] under rubber dam isolation. • Group 1 Calcium hydroxide paste [Multical, pulpdent, USA] was used • Group 2 Tri antibiotic paste [adapted from Hoshino et al.] containing Ciprofloxacin [Cifran500mg, Ranbaxy Laboratories Ltd., India], Metronidazole [metrogyl 400mg,J.B.Chemicals and Pharmaceuticals Ltd., India] and Minocycline [Minoz100mg,Ranbaxy Laboratories Ltd.,India] mixed with Macrogol Ointment and Propylene Glycol was used. • Group 3 Tolonium chloride $0.01 \% \mathrm{w} / \mathrm{v}$ in aqueous solution was the photosensitizer and $300 \mu \mathrm{m}$ diameter fiber coupled diode laser [MMOptics, São Carlos, SP, Brazil] was used. The root canals were obturated with AH plus sealer [Dentsply, DeTrey, Konstanz, Germany] and gutta-percha [Dentsply-Maillefer, Ballaigues, Switzerland] using a cold lateral condensation technique. Following root canal obturation, the teeth were permanently restored with composite resin in all the groups.

Post operative maintenance Analgesics and antibiotics were prescribed. Both clinically and radiographically post endodontic evaluation was done at 3 month, 6 months, 12months, and 18 months.

\section{Statistical analysis}

The statistical analysis was performed using a commercially available software [SPSSs 11, SPSS Inc., Chicago, IL, USA]. The study was designed for testing superiority of the disinfection modalities in the root canal. The primary outcome variable was measured using PAI index and clinical parameters. The X2test was used to compare the data from baseline to those at 3, 6, 12 and 18months for each treatment group and to analyze the statistical significance between the three groups. The significant level was set at $\mathrm{p}<0.05$.Kruskal-Wallis Test was done to to compare the efficacy of each intervension.

\section{Results}

A total of 60 patients fulfilled the inclusion criteria and were included in the study. The patients were selected with a preoperative score of 4 or 5 . There were no significant differences for the PAI Scores between the three groups at the start of the experiment (Table 2). At three month follow up there was no significant change in thePAI score. The radiographic changes for group 1 (Fig. 1) group 2 (Fig. 1) group 3 (Fig. 1). Significant changes in the $\mathrm{p}$ value [0.029] occurred at 6 months with $80 \%$ of PAD group having a PAI score of 3 . However only $30 \%$ and $45 \%$ of Calcium hydroxide group and triple antibiotic group respectively moved to PAI score of 3. At 12 month one patient in PAD group had dropped out from the study. The remaining 19 patients had lowered their PAI score to 3 from their initial PAI scores of 4 and 5.The PAI score in triple antibiotic paste changed to 3 in 95 $\%$ of patients, after 12 months. At 18 months follow up $15 \%$ of cases failed in calcium hydroxide group, $5 \%$ in triple antibiotic paste and no failure cases were seen in PAD group. Success criteria were divided into strict and loose, while the former had statistically significant $\mathrm{p}$ value the latter did not. (Fig. 2,3). Kruskal-Wallis Test showed an increased mean value for PDT and a significant change in p value. (Table 3) Bonferroni post hoc test was done to compare if there is any significant change between groups. Only significant change was found between calcium hydroxide and photo activated disinfection.

\section{Discussion}

Calcium hydroxide is widely used as an intracanal medicament to eliminate microbes in infected root canals (14). Since its introduction by Hermann in 1920, calcium hydroxide has been widely used in endodontics. It is a strong alkaline substance, which has a $\mathrm{pH}$ of approximately 12.5. In an aqueous solution, calcium hydroxide dissociates into calcium and hydroxyl ions. Souza et al., suggested that the action of calcium hydroxide beyond the apex may be four-fold: [a] anti-inflammatory activity, [b] neutralization of acid products, [c] activation of the alkaline phosphatase, and [d] antibacterial action (15). By these mechanisms the bacteria in inaccessible areas of the root canal system are killed enabling in the periapical 
Texila International Journal of Public Health

Volume 4, Issue 4, Dec 2016

healing. However, there was no increase in antimicrobial effect of calcium hydroxide when left for longer periods in the root canal because the hydroxyl ions do not pass through patent dentinal tubules to alkalize the medium surrounding the teeth (16). The high alkaline $\mathrm{pH}$ cannot be maintained within the dentinal tubules because of the buffering effect of dentin (17). A success rate of 80.8 (18) and 73.8\% (19) has been reported with calcium hydroxide, when used for endodontic treatment of teeth with periapical lesions. In our study after an eighteen month follow up $85 \%$ success was noted. Clinical evaluation did not prove to show any difference among the three groups, in contrast radiographically there was a change. Loose criteria of success [which includes incomplete success and complete success as successful outcome] showed no difference in success among the groups. Evaluating the success by means of strict criteria the percentile of success is reduced to $35 \%$ in calcium hydroxide group. However it is the most common, economical and readily available intracanal medicament. Research with topical antibiotics has shown that a combination of metronidazole, ciprofloxacin, and minocycline is effective in vitro at killing common endodontic pathogens from necrotic/infected root canals (9). This antibiotic combination is also an effective disinfectant in vivo (20). However, caution should be taken when giving local or systemic drugs. Although the volumes of the drugs applied in this therapy were small, and there were no reports of side-effects, care should be taken if patients are sensitive to chemicals or antibiotics. Minocycline binds to calcium ions via chelation to form an insoluble complex which can cause discoloration of tooth (21). The disadvantage of tooth discoloration induced by minocycline. can be overcome by Cefaclor and fosfomycin (10). This paste cannot be used in patients who respond positively to an allergic patch test to any of the components. The preparation of the drug combination is not time consuming. It is able to address a diverse amount of root canal flora with little chance of resistance. There was a marked reduction in the PAI score from 3 months to 18 months, with $60 \%$ of cases having a PAI score of 2.Clinical criteria also suggests an equal success percentile when comparing triple antibiotic paste and photo activated disinfection. According to strict criteria 13 were successful among the 20 cases in this study; this was much higher than the calcium hydroxide group. Successful killing of S. mutans and E. faecalis by PAD using either methylene blue or tolonium chloride dyes has been reported, with kills of between $97-99.9 \%$ for planktonic bacterial loads of up to 10 million organisms. using an exposure time of I20 seconds (22). Also when used in the root canal environment, more consistent killing is seen with tolonium chloride than with methylene blue (22). A key property of photosensitisers to be used with the root canal environment is that they should absorb laser light in the middle red portion of the visible spectrum, since these wavelengths of light give the greatest penetration of dentine and can also penetrate any blood that may be present (23). Middle red wavelengths will also exert direct effects on Gram-negative anaerobes. The work of Lee (22) demonstrated that the killing effect obtained is greater when the laser light is delivered using a flexible endodontic diffuser which reaches to within $4 \mathrm{~mm}$ of the apex and gives even irradiation of the root canal system, rather than a bare optical glass fibre. These results obtained in our study undoubtedly indicate the use of an optical fiber to improve the irradiation in root canals. The fiber probably distributes homogeneously the light inside the root canal guaranteeing a better photoreaction; also, the technique of irradiation using helicoid movements may have contributed to the results. PAD is a treatment that can be delivered as an addition to conventional endodontic therapy and produces a remarkable additional reduction in bacterial burden. Moreover it appears that a second PAD treatment is even more effective than the first PAD. The reason for this observation is probably that the recolonization of microorganisms occurs in a less complex biofilm compared with the initial infection that is probably in a fully developed biofilm. Furthermore, as in the second treatment, the number of viable microorganisms was smaller than in the first treatment; the reactive oxygen species formed during PAD had a bigger chance of producing an irreparable oxidative stress because of the ratio between reactive oxygen species and microorganisms (24). We have employed tolonium chloride as the photosensitizer and a diode laser coupled with an optical fiber as a light source. The use of 
a chelating agent after instrumentation, in our case EDTA instead of citric acid used by Bonsor (25), acts as a cleaner and disrupter of the biofilm expanding the access of the tolonium chloride to the canal system. Our results concluded a $100 \%$ success using loose criteria and by clinical valuation. Interestingly there were no failure cases. After 18 months $80 \%$ of cases in the PAD group had a PAI score of 2 . Whatever means was used for success [clinical and radiographic) PAD proved to be the best among the groups. However, there are several limitations that may be associated with the intra-canal use of laser that cannot be overlooked (26).The emission of laser energy from the tip of the optical fiber or the laser guide is directed vertically along the root canal wall and not necessarily laterally to the root canal walls (27). Thus, it is impossible to obtain uniform coverage of the canal surface using the laser $(26,27)$. It has been recommended in root canal treatment as an alternative or a supplement to currently used disinfection methods (28). The number of failure cases were less in PAD group because less chances of development of resistant species (29) as compared to other groups Triple antibiotic paste is a cheaper alternative to photo dynamic therapy. Our study shows there is no difference in the clinical outcome in all the three groups however radiographically there is a statistically significant difference in the strict criteria. This indicates the need for radiographic method for identifying success rather than clinical means. The study concluded that the PAD group was most effective root canal disinfectant and aided in the healing of periapical lesions.

\section{References}

[1] Bonsor S J, Nichol R, Reid TM, Pearson GJ. Microbiological evaluation of photo-activated disinfection in endodontics (an in vivo study). Br Dent J. 2006;25:337-41.

[2] Caliskan MK, Sen BH. Endodontic treatment of teeth with apical periodontitis using calcium hydroxide: A long-term study. Endod Dent Traumatol. 1996;12:215-21.

[3] Caliskan MK.. Prognosis of large cyst-like periapical lesions following nonsurgical root canal treatment: A clinical review. Int Endod J. 2004;37:408-16.

[4] de Souza V, Holland R, Nery MJ, de Mello W, Bernabé PF, Otoboni Filho JA. Root canal treatment of pulpless teeth with Hexocalex. Histological study in dog. Rev Fac Odontol Aracatuba. 1978;7:19- 24. e236 J ClinExp Dent. 2014;6(3):e230-6. Intra canal disinfection

[5] Garcez AS, Nunez SC, Hamblim MR, Suzuki H, Ribeiro M Photodynamic therapy associated with conventional endodontic treatment in patients with antibiotic-resistant microflora: a preliminary report. Journal of Endodontics. 2010;36:1463-6.

[6] Garcez AS, Nuñez SC, Hamblin MR, Ribeiro MS. Antimicrobial Effects of Photodynamic Therapy on Patients with Necrotic Pulps and Periapical Lesion. J endod. 2008;34:138-42.

[7] Goodis HE, Stabholz A. Pulpal effects of thermal and mechanical irritants. In: Hargreaves K M, Goodis H E.Seltzer and Bender's dental pulp. Carol Stream I L: Quintessence Publishing 2002.

[8] Hoshino E, Takushige T. LSTR 3Mix-MP method-better and efficient clinical procedures of lesion sterilization and tissue repair (LSTR) therapy. Dent Rev. 1998;666:57-106.

[9] Hoshino E, Kurihara-Ando N, Sato I, Uematsu H, Sato M, Kota K, Iwaku M. In vitro antibacterial susceptibility of bacteria taken from infected root dentine to a mixture of ciprofloxacin, metronidazole and minocycline. Int Endod J. 1996;29:125-30.

[10] Haapasalo HK, Siren E, Waltimo TMT, Ørstavik D, Haapasalo MP. Inactivation of local root canal medicaments by dentin: an in vitro study. Int Endod J. 2000;33:126-32.

[11] Ingham HR, Selkon J, Hale JH. The antibacterial activity of metronidazole. J Antimicrob Chemother. 1975;1:355-61.

[12] Kim JH, Kim Y, Shin SJ, Park JW, Jung IY. Tooth discoloration of immature permanent incisor associated with triple antibiotic therapy: A case report. J Endod. 2010;36:1086-91.

[13] Landis JR, Koch GG. The meastuernent of observer agreement for categorical data. Biometrics. 1977;33:159-74.

[14] Lee MT, Bird PS, Walsh LJ. Photo-activated disinfection of the root canal: a new role for lasers in endodontics. AustEndod J. 2004;30:93-8. 
Texila International Journal of Public Health

Volume 4, Issue 4, Dec 2016

[15] Molander A, Reit C, Dahlén G. The antimicrobial effect of calcium hydroxide in root canals pretreated with 5\% iodine potassium iodide. Endod Dent Traumatol. 1999;15:205-9.

[16] Ozan U, Er K. Endodontic treatment of a large cyst-like periradicular lesion using a combination of antibiotic drugs: a case report. J Endod. 2005;31:898-900.

[17] Ørstavik D, Kerekas K, Eriksen HM. The periapical index: a scoring system for radiographic assessment of apical periodontitis. Endod Dent Traumatol. 1986;2:20-34.

[18] Orstavik D, Haapasalo M. Disinfection by Endodontic irrigants and Dressing Of Experimentally Infected Dentinal Tubules Endodontic journal of Traumatology. 1990;6:142-9. Vijayaraghavan R, Mathian V M, Sundaran AM, Karunakaran R, Vinodh S. Triple antibiotic paste in root canal therapy J. Pharm Bioallied Sci. 2012;4:S230-3.

[19] Odor TM, Watson TF, Pitt Ford TR, McDonald F. Pattern of transmission of laser light in teeth. IntEndod J. 1996;29:228-34.

[20] Rios A, He J, Glickman GN, Spears R, Schneiderman ED, Honeyman AL Evaluation of photodynamic therapy using a light-emitting diode lamp against Enterococcus faecalis in extracted human teeth. Journal of Endodontics. 2011;37:856-9

[21] Sundqvist G, Fidger D, Sjogren U, Persson S. Microbiological Analysis Of Teeth with Failed Endodontic Treatment And The outcome Of Conservative Retreatment. Oral Surg Oral Med Oral Pathol. 1998;85:86-93.

[22] Sato T, Hoshino E, Uematsu H, Noda T. In vitro antimicrobial susceptibility to combinations of drugs of bacteria from carious and endodontic lesions of human deciduous teeth. Oral MicrobiolImmunol. 1993;8:172-6.

[23] Sato I, Ando-Kurihara N, Kota K, Iwaku M, Hoshino E. Sterilization of infected rootcanal dentine by topical application of a mixture of ciprofloxacin, metronidazole and minocycline in situ. IntEndod J. 1996;29:118-24.

[24] Stuart KG, Miller CH, Brown CE Jr, Newton CW. The comparative antimicrobial effect of calcium hydroxide. Oral Surg Oral Med Oral Pathol. 1991;72:101-04.

[25] Stabholz A, ZeltserR, Sela M, et al. The use of lasers in dentistry:principles of operation and clinical application. CompendContinEduc Dent. 2003;24:811-24.

[26] Takushige T, Cruz EV, Asgor Moral A, Hoshino E. Endodontic treatment of primary teeth using a combination of antibacterial drugs. IntEndod J. 2004;37:132-8.

[27] Tanase S, Tsuchiya H, Yao J, Ohmoto S, Takagi N, Yoshida S. Reversed-phase ion pair chromatographic analysis of tetracycline antibiotics: application to discolored teeth. J Chromatogr B Biomed Sci Appl. 1998;706:279-85.

[28] Williams JA, Pearson GJ, Colles MJ. Antibacterial action of photoactivated disinfection \{PAD\} used on endodontic bacteria in planktonic suspension and in artificial and human root canals. Journal of Dentistry. 2006;34:363-71.

\section{Calcium hydroxide}

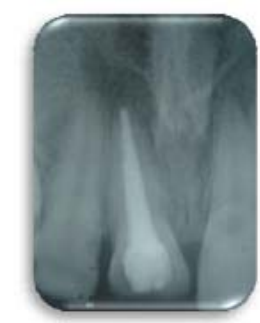

Obturation

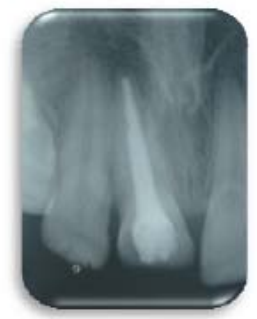

6 months

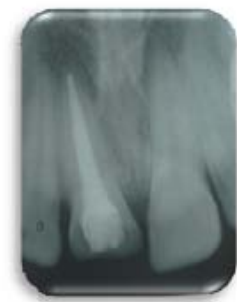

18 months

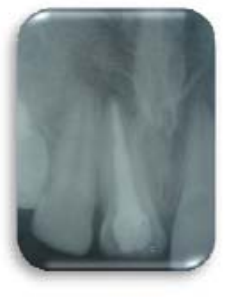

12 months 
Triple antibiotic paste

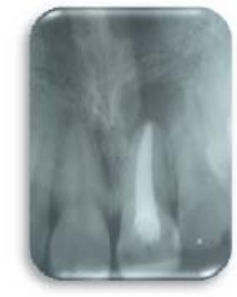

Obturation

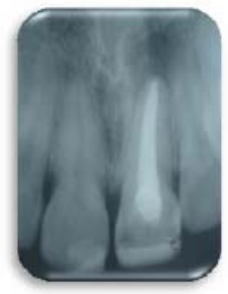

6 months

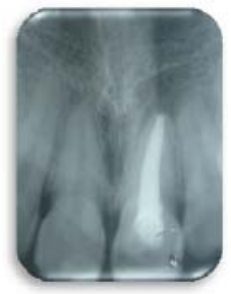

18 months

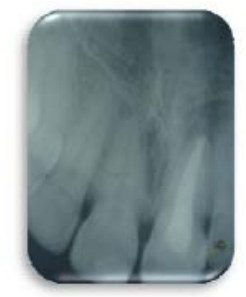

12 months

Photo activated disinfection
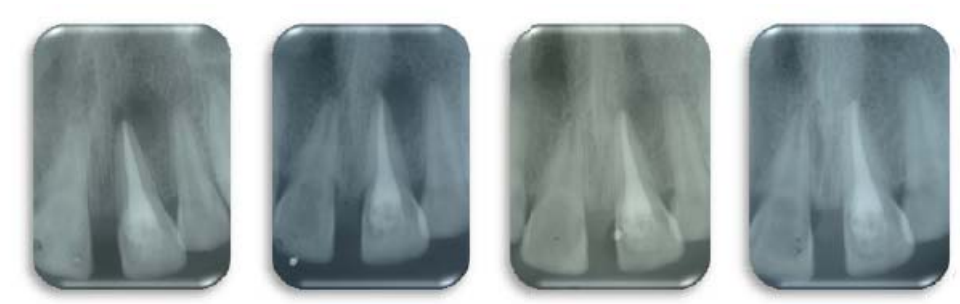

Obturation

6 months

12 months

18 months

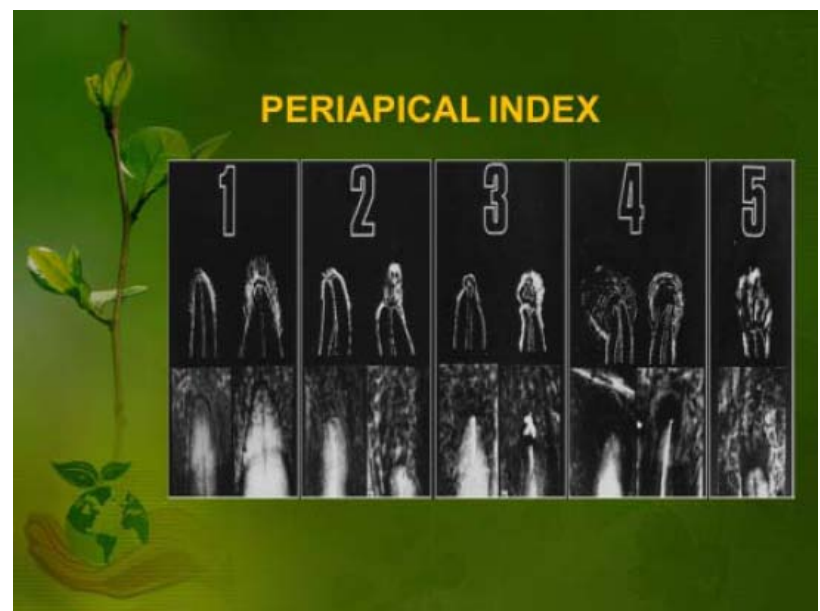




\title{
Prevalence, Knowledge and Perception of Domestic Violence among Women Attending Antenatal Care at Barau Dikko Specialist Hospital, Kaduna
}

\author{
Article by Patricia Elameyi Idoko \\ Master in Public Health, Texila American University, Nigeria \\ E-mail: ellabenson2015@gmail.com
}

\section{Introduction}

In early Roman Society, a woman was deemed the property of the husband and was therefore subject to his control.

The Catholic Church's endorsement of "the Rules of marriage" in the $15^{\text {th }}$ century exhorted the husband to stand as "judge of his wife. He was, to beat her with a stick upon her commission of an offense. According to the rules, beating showed a concern for the wife's soul.

In $18^{\text {th }}$ century France, if it became public that a wife had beaten the husband, he was forced to wear an outlandish costume and ride backwards around the village on a donkey.

It was not until the 1870s that the first states in the US banned a man's right to beat his family.

Violence against women, whether pregnant or not occurs commonly around the world especially the developing world. The act cuts across all ages, cultures, ethnicity religion and educational barriers.

Domestic violence refers to any harmful behaviour directed at women or girls because of their sex. it is also known as gender based violence.

The violence can take various forms, and could be physical, psychological, (emotional) sexual, economic or a combination or even neglect. It can also be in the form of threats of such acts, coercion, or arbitrary deprivation of liberty whether occurring in public or private life. A new dimension has been added now in the form of acid baths used by men especially to discipline women, girls.

The prevalence of domestic violence against women ranged between 17-37\% with considerable regional variation. Domestic violence can broadly be classified into domestic abuse, spousal abuse, child abuse, intimate partner violence (IPV), elder mistreatment.

Domestic violence or spousal Abuse in this content is a form of violence against women and when it involves pregnant women, it calls for a closer attention because of the greater danger it entails. Both the world health organization WHO and international federation of obstetricians and gynecologists (FIGO) recognize the scourge of violence against women and starting from the nineties passed various declarations on the elimination of violence against women. The factors which lead to domestic violence are a legion and range from no offence, minor to major offences.

Most countries and various religions frown against domestic violence but because the cultures of the people of these countries do not frown at it, the problem has persisted. it hence explains the attitude of the women to domestic violence with some even justifying it. Domestic violence may start or escalate with pregnancy.

Domestic violence is not caused by illness, genetics, or gender, alcohol or other drugs, anger, stress victim's behaviour or relationship problems, it is a learned behaviour by batterers, and it has enormous impact on pregnant women. It is a recognized public health issue that has serious consequences on physical and mental health. Domestic violence has been associated with psychiatric illnesses, depression, anxiety, posttraumatic stress disorder attempted suicide and also important implications for the fetus as low birth weight, miscarriages, bleeding, prematurity, abruption, or even death of either or both fetus and mother. 
Texila International Journal of Public Health

Volume 4, Issue 4, Dec 2016

There is paucity of data on domestic evidence mainly because of under reporting by the victims, but quite frequent.

\section{Background of the study area}

The study was conducted at the antenatal Clinic of the obstetrics and gynecology department of Barau Dikko Specialist Hospital, Kaduna one of the twelve departments in the hospital. The department is headed by a head of department who is a consultant obstetrician and gynecologist. The department runs clinics on all five days of the week, Monday through Fridays. An average of 200 clients are seen on the obstetric clinic days while on the gynae clinic days about 100-150 clients are seen. The hospital is a 241 bedded hospital and it renders Primary secondary and tertiary health services to the citizenry, including specialist care. The hospital is a tertiary health institution strategically located in central Kaduna, the capital of Kaduna State North Central Nigeria. The State had a population of 6,113,503 as at March 2006. The State Capital is Industrial, Commercial and cosmopolitan. The residents are a mixed population of farmers, traders students, civil servants, retired and serving military personnel. The predominant language spoken is hausa.

The main aim of the study was to determine the prevalence of domestic violence amongst pregnant women attending antenatal care at Barau Dikko Specialist Hospital, Kaduna Other objectives of included finding out the response of the victims to the abuse.

- To determine the specific prevalence of domestic violence amongst the pregnant women who were respondents for the study.

- To determine which type of violence has the highest percentage of use by the perpetrators

- To propose that further study be carried out to determine the outcome of domestic violence on pregnancy

- To make recommendations on measures to curb the menace so as to reduce the morbidity or even mortality that could be associated with the horrible act.

\section{Literature review}

Ameh et al in a study on the prevalence of domestic violence amongst pregnant women at Ahmadu Bello University teaching hospital Zaria, found that of the 50 respondents who experienced-domestic violence, $36 \%$ of them were beaten up while $22 \%$ were forced to have sex. The spouse was the commonest culprit, which was similar to the Kaduna study, ThirtyNine women of the 178 respondents felt domestic violence was excusable under certain conditions and $36 \%$ of them would keep domestic violence secret.

In another study by LA Makayoto 2013 among women seeking antenatal care at Kisumu district hospital Kenya.

In another comparative study published in the British Journal of obstetrics and gynecology, by Tonye Telema et al, the study looked at the prevalence of domestic violence in women requesting a termination of pregnancy and those attending antenatal itself. It used self administered anonymous questionnaires among 219 women in an antenatal clinic and 274 in a clinic for termination of pregnancies in the Hull and East Riding areas of the United Kingdom. The study highlight that almost half of all adult women in England and Wales have experienced domestic violence of one form, whether psychological, physical, sexual, financial or emotional. It constitutes up to $1 / 3$ of violent crimes and the direct and indirect cost of domestic violence alone in the United Kingdom is estimated to be 23 billion pound.

The results showed that among women attending clinics for termination of pregnancy, $5.8 \%$ were victims of physical abuse in the current relationship, whereas it was $0.9 \%$ amongst women attending antenatal clinics.

Women in the TOP group also suffered a higher rate of emotional abuse than those in the antenatal clinic population (9.9\% compared to 1.8\% furthermore, the study looked at reasons for requesting a termination of pregnancy. Of the 274 women requesting for a termination of pregnancy, 10 (2\%) mentioned domestic violence as a contributing factor. 
The most common reasons for requesting a TOP were financial worries and contraceptive failure.

The Authors conclude that though domestic violence was not given as a frequent reason for requesting a termination of pregnancy, women who request for an abortion are at a higher risk of domestic violence and this may be related to other life issues. They emphasize the importance of relevant training amongst healthcare professionals so that women are referred to appropriate support services in a timely and sensitive manner. They concluded by adding that the study just showed a small fraction of the true scale of the problem. Health professionals looking after pregnant women regardless of the pregnancy outcome are well placed to sensitively ask the questions which will lead to help and support.

The deputy editor of the Journal added by saying that domestic violence can be extremely damaging to a women's mental, emotional and physical health and in some cases has been linked to postnatal depression; he enjoins that more research is needed in the area to determine effective screening methods and interventions to help women suffering from any form of abuse.

It is only when this has been done, that sufficient measures can be initiated to address this growing problem that can pose a significant health risk to mother and baby.

In another study by Gyuse An et al, 2009 who wrote on the prevalence of domestic violence among antenatal women attending ECWA Evangel Hospital, Jos, over as six month period, 340 pregnant women were studied, majority of them were married and were mostly aged between 20-39 years. Domestic violence prevalence was $12.6 \%$ (43) in the current pregnancy and 63.2'6 215 previously. In conclusion the study established that in our environment women experience domestic violence during pregnancy and majority of them also have a previous history of abuse. There was a need to routinely screen for domestic violence in pregnant women so as to prevent possible adverse pregnancy outcomes and to interrupt exiting abuse.

The multicentre study concluded that violence against women especially in developing countries was directly related to Low socio economic level of the women and their intimate partner, it concluded that more effective social policies were needed for this vulnerable population. The area with the lowest rates were Japan (8\%) and highest in Ethiopia 70\% and Brazil 43\%.

\section{Methodology}

\section{Study type}

We carried out a cross sectional study involving 170 pregnant women attending the antenatal clinic of Barau Dikko Specialist Hospital Kaduna, over the period of 1 week in February 2016. They were served with pretested structured questionnaire.

\section{Study setting}

The study was conducted at the obstetrics and gynecology department of Barau Dikko Specialist Hospital, Kaduna.

\section{Study population}

The study population were pregnant women attending the Antenatal Clinic of BDSH Kaduna.

\section{Sample size calculation}

The sample size was calculated using epic info stat cal for descriptive studies in a known population size.

Other formulae are

Where $\mathrm{n}$ is the minimum sample size,

$\mathrm{P}$ is the prevalence of domestic violence among pregnant

Women. 
Texila International Journal of Public Health

Volume 4, Issue 4, Dec 2016

$\mathrm{Q}$ is 1-p

$\mathrm{d}$ is the sampling error

Attrition is about $10 \%$ which is added to the final figure.

\section{Sampling frame}

We used the register at the antenatal clinic and the consecutive way in which they came was used.

\section{Sampling procedure}

Proportionate Sampling

One hundred and seventy questionnaires were returned duly completed $=$ after being served with pretested structured questionnaires

\section{Data collection and analysis}

The 170 respondents were served with pretested structured questionnaires by me. The First few questions were centered on psychosocial variables including age, parity, educational level, social class and tribe. The remaining seven questions explored the knowledge and perception about domestic violence among the respondents experience in the present pregnancy and even in the past was also sought. The data was analysed using epic-info version 6 statistical software.

Descriptive statistics was summarized using means, proportions and frequencies.

\section{Ethical considerations}

Written informed consent was sought from the participants. Permission to carry out this study was sought from the ethical committee of Barau Dikko Specialist Hospital Kaduna.

\section{Results}

A total of 170 respondents participated in the study: The demographic characteristics of the respondents is summarized as follows:-

The mean age of the respondents was 26 yrs +. Range 16-44 yrs; and most frequent age group was 26-30 years (38\%).

$93 \%$ of the women were married. Forty five percent were of Hausa Fulani extraction while the remaining respondents were other tribes. One hundred and forty (78\%) were educated up to secondary school level.

(55\% had knowledge of domestic violence while 70, (45\%) had no knowledge of it. Concerning their view about domestic violence, (Table 1, 39 felt it was excusable under certain circumstances while 26 (14\%) felt it was always excusable.

A total of 50 respondents (28\%) had experienced domestic violence against them in the index pregnancy or in previous pregnancies (table II] 18 (34\%) were beaten up, II (22\%) were forced to have sex, 10 (20\%) had objects thrown at them 9 (18\%) were slapped and 2 (4\%) were flogged. The culprit in the 50 women who experienced domestic violence were shown in table 3. The spouse was the commonest culprit.

On their reaction to the domestic violence they experienced, table 4; 60 (36\%) would keep it a secret, 50 (28\%) would report to their family, 28 (16\%) would report to the doctor, while others would report to in laws, polices clergy, or tell a close friend. 
Table I. View about Domestic violence amongst the Pregnant Women

\begin{tabular}{ll} 
View & No (\%) \\
\hline No reply & 25 \\
Excisable under certain circumstances & 39 \\
Always excusable & 26 \\
Not excusable & 80 \\
Total & $170(100 \%)$
\end{tabular}

Table : Type of Domestic violence experienced by pregnant women.

\begin{tabular}{ll} 
Type of Domestic Violence: & No \% \\
\hline Beaten & $18(36)$ \\
Forced to have sex & $11(22)$ \\
Objects thrown at them & $10(20)$ \\
Slapped & $9(18)$ \\
Flogged & $2(4)$ \\
Total & $50(100)$
\end{tabular}

Table 3. The culprit responsible for the domestic violence among the 50 respondents.

\begin{tabular}{ll} 
Reaction to Domestic Violence & No \% \\
\hline Keep it a secret & 60 \\
Report to family & 50 \\
Report to doctor & 28 \\
Report to in-laws & 14 \\
Report to clergy & 6 \\
Report to a close friend & 5 \\
No reply & 7 \\
Total & $170(100 \%)$
\end{tabular}

\section{Discussion}

A large percentage of the respondents about 50 of the 170 sampled had been involved in one form of abuse or the other which agrees with the local and international figure. It was appalling however to note that a huge number about 26 felt it was excusable at all; through 39 felt it could be excusable under certain circumstances.

Another disturbing figure is the 60 (about 27\%) who would rather keep the abuse as a secret, and only 10 of the respondents felt they should report the issue to the police, meaning the laws of the land must be very weak or silent on issues of domestic/spousal violence even on pregnant women and depicting the low level of confidence on the systems, About 6 of the respondents could report to the clergy meaning the religious institution have a role to play in the awareness campaign.

Why the figures are more disturbing more is because domestic violence is a pregnancy complication that is highly under reported hence actual statistics would be far beyond the quoted figures of between $11-70 \%$ across regions.

Most of the women felt more comfortable reporting to a family member because the family is seen as the primary unit in the society and first medium of socialization. Our study showed that about $28 \%$ of the women had experienced one form of violence or the other either in a previous or in the index pregnancy; which is a huge percentage.

The Nigerian Law and penal codes need to be more explicit on their stance on issues of gender violence; but the figures from this study is consistent with that from other African countries with similar cultures.

\section{Conclusion}

The fact that Domestic violence is a serious public health issue was highlighted and worse more in pregnancy because of it's peculiar circumstance. 
Texila International Journal of Public Health

Volume 4, Issue 4, Dec 2016

It was strange to find out that some women were still not aware of it or do not even know if they are in an abusive relationship.

The culture and predominant religion in the area of the study seemed to perpetuate the crime and foster it.

The major culprit was found in most cases to be the spouse and it was noticed that Low socioeconomic status and dependence on the culprits increased the victim's vulnerability.

There were weak or non exist laws to prosecute the crime and the need to create awareness and for health care professionals to do ongoing screening to help victims of abuse curb the act to reduce consequences

\section{Recommendation}

There is a need to create awareness on the topic to let our people and especially women who are more at the receiving end know that it is a serious public health problem and should not be excusable under any circumstance, the slave trade era is over.

Screening for domestic violence can also be included in our routine antenatal screen/clinics; hence the need to train personnel in this regard.

The constitution of Nigeria upon review should make domestic violence a punishable offence so as to discourage perpetrators of the act.

Support groups could also be formed so that victims of the act will find solace/comfort with other women facing similar challenges.

Further studies are however needed to determine pregnancy outcomes in women faced with domestic violence.

\section{References}

[1] Bacchus L. Bewley S. Gillian M. Domestic violence and pregnancy, obstetrics and gynecology 2001; 3; 56-59.

[2] Catalano; R:Lind Rosenblat, A and R Novaco (2008) Research into the economic antecedents of violence. American Journal of Community Psychology.

[3] CDC (2006). Intimate Partner violence, fact Sheet. Retrieved Oct. 2008 from www.cdo.gov/injury.

[4] Ending violence against women in population report. volumes xxvii No 4 December, 1999.

[5] Gyuse AN et al, Nigerian Journal of medicine 2009 Oct-December. Prevalence of Domestic violence among antenatal women attending a Nigerian Mission Hospital

[6] Jina R, Jewkes R. Christofides N, loots L Caring for survivors of sexual assault and Rape in South Africa. $1^{\text {st }}$ Edition, 2008.

[7] Little K. J. Screening for Domestic violence; identifying, assisting and empowering adult victims of abuse. Postgraduate medicine 2000 108: 1,4-9

[8] Obi S. N. and Ozumba (2007) factors associated with domestic violence in South East Nigeria. Journal of obstetrics and gynecology.

[9] Pierre Martin Hirsch, British Journal of gynecology deputy Editor in chief

[10] Rakel R. P. Rakel D P (eds): Rakel textbook of family medicine; $7^{\text {th }}$ edition, Sounders.

[11] Saror S. F. Spousal abuse; a study in Samaru Zaria, Kaduna State, Nigeria breaking the Silence in women against violence. Proceedings of the tenth anniversary of women in Nigeria Conference 1993; 70-73.

[12] TT Wokoma, M. Jampala, H Bexhell, S Lindow A comparative study of the prevalence of domestic violence in women requesting a termination of pregnancy and those attending the antenatal clinic BJOG 2014.

[13] Unicef (2005) violence at home (achieve) voices of youth forum. Retrieved Oct. 2008 from www.unicef.org/roy/discussions/archive/index

[14] Unicef 2001 Children and women's rights in Nigeria. A wakeup call. Situations assessment and analysis. Edited by Hodege Abuja: National Population Commission and unicef.

[15] Violence against women during pregnancy systematized revision. Science Direct May-August 2014 vol.29 (2) pages 71-79. 


\title{
Pre-Menstrual Training, Menstrual Hygiene Practices, Attitudes and Disorders among Nigerian Adolescents
}

\author{
Article by Afusat Adesina \\ Ph.D in Public Health, Texila American University, Nigeria \\ E-mail: afusatgain@gmail.com
}

\begin{abstract}
Objectives: Menstruation is a normal physiological process that begins during adolescence and may be associated with various symptoms occurring before or during the menstrual flow. Normal menstruation depends on a highly coordinated interaction between the hypothalamus, pituitary glands, ovaries and endometrium, with all events usually occurring in a cycle time frame often between 21 to 35 days. This study is therefore carried out to determine the influence of pre-menarcheal training on menstrual hygiene practices, the various menstrual disorders among the girls, as well as, the influence of educational status on menstrual hygiene practices, with a view to making necessary recommendations that would help improve such practices.

Methods: This cross sectional study was carried out in Lagos Nigeria. The target population was adolescent girls in this city. A multi-stage sampling technique was used to select the respondent. All data were statistically analysed, using statistical package for the social sciences (SPSS) and statistical test of significance was performed with Chi-Square test. Results: A total of 526 consenting respondents participated in the study with a mean age $\pm S D$ of $14.09 \pm 2.21$ years. Most of the respondents had their menarche (first menstruation) around 12 to 13 years of age, with the mean age \pm SD being $12.51 \pm 1.44$ years. 184 (35.0\%) experienced dysmenorrhoea (painful menstruation) during their last menstrual period and menorrhagia by 34 (6.5\%) of the respondent. Also, 142 (27.0\%) of the respondents have had a cycle $<21$ days or $>35$ days within their last three menstrual cycles.

Conclusion: Pre-menstrual training is common among these adolescent girls as it is evident in their menstrual hygiene practices. However, dysmenorrhoea and menorrhagia are common problems among adolescent girls thus health education \& health promotion are the best ways to deal with menstrual hygiene \& disorder issues effectively.
\end{abstract}

Keywords: Training, menstrual, hygiene, adolescent, Nigeria.

\section{Introduction}

Adolescence can be described as the transition period from childhood to adult use during which pubertal development and sexual maturation happen. In girls, it marks a special period signifying the transition from girlhood to womanhood. This period of transition is marked with the onset of menarche, which signifies a crucial landmark in girls' lifetime. During pubertal development, physical, hormonal, cognitive, psychological, among other changes occur simultaneously in such individual, with variations from person to person, due to several factors including genetic, environmental, nutritional, among other factors. Menstruation, a very crucial event in the reproductive life of women, is a normal physiological process that begins during adolescence and may be associated with various symptoms occurring before or during the menstrual flow [1]. Normal menstruation depends on a highly coordinated interaction between the hypothalamus, pituitary glands, ovaries and endometrium, with all events usually occurring in a cycle time frame often between 21 to 35 days. Menarche, which is the first menstruation period of life is a milestone that signifies maturation of reproductive potential and physiological growth and this normally happens at the age of 11 to 15 years most often and menopause, which is the end of woman's reproductive phase, most commonly occurring between the age of 45 to 55 years [2]. Although the physiology of menstruation and 
genital tract generally are taught in schools across Nigeria, the practical management of menstruation has often been seen as not appropriate for public discussion [3]. Menstrual disorders such as delayed menarche, dysmenorrhoea, pre-menstrual symptoms, among others, generally cause some apprehension among adolescents including their family members thus further justifying the reason to know the pattern of menstrual cycle, the training, practices and variations [4, 5].

A Nigerian research on the impact of pre-menarcheal training on menstrual practices andhygiene showed that the mean age was $14.9 y e a r s$ and $55.2 \%$ of the girls received premenarcheal training, with mothers (74.7\%) being the most common source of information [6]. In Eastern Sudan, some researchers reported that only $73 \%$ of the girls interviewed experienced menarche as at the time of the interview, with the mean age of 13.07 years, which was 0.9 years younger in the urban girls. The majority of the girls (76.4\%) experienced delayed menarche while $68.5 \%$ had regular period with cycle length ranging between 21 to 35 days. They also reported $83.1 \%$ dysmenorrhoea and 59.8\% pre-menstrual symptoms [7]. A 2012 research outcome in India revealed that abnormal cycle length was common and affected $30.48 \%$ of the girls, with $56.15 \%$ dysmenorrhoea experience and $56.16 \%$ premenstrual syndrome reported. The mean ages for menarche were 13.51 and 13.67 years for urban and rural areas respectively [8]. In 2016, the authors of the cross-sectional study on menstrual disorders revealed that dysmenorrhoea was the most common menstrual disorder with $48.82 \%$, followed by abnormal cycle length (19.96\%) and menorrhagia (11.80\%) among girls whose average was 13.12 years [9]. Moreover, in Ethiopia, the authors of a study on menstrual pattern in the Northwest reported that, a normal cycle of 21 to 35 days was observed in $70.3 \%$ of the girls, mean duration of flow was 4 days with a range of 2 to 7 days, irregular cycles observed in $42.8 \%$ of the girls, $39.7 \%$ got information about menarche from their mothers, $26.6 \%$ from friends and $21.8 \%$ through teachers while the mean age was 16.9 years, the mean age at menarche was 15.8 years [10]. In Northern Nigeria, a 25.6\% premenstrual symptoms and $69.0 \%$ regular menstruation were reported among secondary school girls with mean age of 15.35 years while the mean menarche age was 12.53 years [11]. Authors of the Lebanese research on pattern of menstrual disorders reported $54.0 \%$ premenstrual syndrome, $43.8 \%$ irregular duration of menstruation and $38.1 \%$ dysmenorrhoea [12]. This study is therefore carried out to determine the influence of pre-menarcheal training on menstrual hygiene practices, the various menstrual disorders among the girls, as well as, the influence of educational status on menstrual hygiene practices, with a view to making necessary recommendations that would help improve such practices.

\section{Research hypothesis}

1) Educational status has no significant influence on menstrual hygiene practices

2) Relationship with mothers have no significant effect on pre-menarcheal training

3) Educational attainment of mother have no significant effect on pre-menarcheal training

\section{Materials and methods}

This cross sectional study was carried out in Lagos Nigeria. The target population was adolescent girls in this city. A semi-structured questionnaire was administered consecutively on 526 respondents. Demographic and socio-economic information obtained were included. A multi-stage sampling technique was used to select the respondents from metropolis. In stage 1 from a sampling frame of the entire number of local government areas in Lagos State, one-third number of LGAs was selected using simple random sampling method. In stage 2, a list of towns in each of the selected LGA's was randomly made. In stage 3, houses in the towns were randomly selected. The final stage involved in the selection of consenting adolescent girls. The questionnaires were then administered on the respondents. 


\section{Sample size}

Sample size calculation was done using 95\% confidence interval, 0.05 precision and prevalence rate. Using prevalence of menstrual abnormalities of $45.6 \%$ in school girls by Adinma \& Adinma, 2008 [1]. With the use of Leslie Fischer's formula for population $>10,000$, the formula for sample size calculation is: $n=Z^{2} P Q / d^{2}[13]$.

$\mathrm{n}=\mathrm{Z}^{2} \mathrm{PQ} / \mathrm{d}^{2}$

Where:

$\mathrm{n}=$ minimum sample size, $\mathrm{d}=$ degree of precision (taken as 0.05 ),

$\mathrm{Z}=$ standard normal deviation at $95 \%$ confidence interval which is 1.96 ,

$\mathrm{P}=$ proportion of the target population (estimated at $22.2 \%$ which is $45.6 / 100=0.456$ ),

$\mathrm{Q}=$ alternate proportion (1-P) which is $1-0.456=0.544$

$\mathrm{n}=(1.96)^{\underline{2}}(0.456)(0.544)=382$ $(0.05)^{2}$ 19

Also, adding a 5\% non-response rate, the minimum sample size (n) will be 5/100 X $382=$

Thus, it will be $19+382=401=n$

Statistical Analysis

Data was statistically analysed using Statistical Package for the Social Sciences (SPSS) for windows version 20.0 software (SPSS Inc., Chicago, IL, USA). All data were expressed as Mean \pm Standard Deviation (SD). Frequency counts were generated for all variables and statistical test of significance was performed with Chi-Square test. Significance was fixed P $<0.05$ and highly significance is $\mathrm{P}<0.01$.

\section{Results}

Socio-Demographic Data

A total of 526 consenting respondents participated in the study. The mean age \pm SD is14.09 \pm 2.21 years. Most of the respondents Christians, 316 (60.1\%) and are mainly in senior secondary school, 268 (51.0\%) followed by junior secondary school, 206 (39.2\%). The girls are mainly from a nuclear family background, 380 (72.2\%). The mothers' level of education were mainly diploma and first degree, 194 (36.9\%) followed by secondary school certificate holders, 74 (14.1\%).

Three hundred and thirty eight, which is equivalent to $64.3 \%$, of the respondents had premenstrual training, that is, information about menstrual cycle before first cycle, as they were told about and made to expect the first bleeding, with this done by mother, as reported by 258 respondents (49.1\%). Three hundred and thirty $(62.7 \%)$ of them were told how to collect menstrual blood, mainly informed that they should collect the blood into sanitary pads and $390(74.1 \%)$ were told how to dispose off the materials used to collect the menstrual period, with toilet/pit latrine, dust bin and burning listed as ways of disposal. Meanwhile, 432 (82.1\%) of the respondents currently use sanitary pad as the menstrual absorbent/material to collect their menstrual period. The primary source of information for menstruation is mainly through the mother, 322 (61.2\%). Menorrhagia, which is an abnormally heavy or prolonged bleeding, that is, the use of four or more fully soaked pads a day or bleeding more than 8 days, was said to have been experienced by $34(6.5 \%)$ of the respondent during the last menstrual period. Also, 142 (27.0\%) of the respondents have had a cycle $<21$ days or $>35$ days within their last three menstrual cycles.

In table 2, most of the respondents are reported to have had their menarche (first menstruation) around 12 to 13 years of age, with the mean age \pm SD being $12.51 \pm 1.44$ years. Most of them reported the first menstruation experience to be frightening, 170 (32.3\%). With last menstrual blood flow duration being reported mostly as 4 and 5 days, the mean \pm SD of blood flow duration is $4.40 \pm 1.14$ days. Regarding the amount of the last menstrual blood flow, most of the respondents reportedly used 2 pads per day. One hundred and eighty four (35.0\%) experienced dysmenorrhoea (painful menstruation) during their last menstrual period, with 124 (23.6) reportedly using drugs during the course of the pain chiefly pain 
Texila International Journal of Public Health

Volume 4, Issue 4, Dec 2016

killers or analgesics such as acetaminophen and non-steroidal anti-inflammatory drugs (NSAIDs) and prescribed by their mothers in most of the cases.

\section{Discussion}

This research outcome has shown that most of the respondents are in the range of 11 to 16 years, with the mean age \pm SD being $14.09 \pm 2.21$ years. This is very similar to other research outcomes which showed their mean age to be in this range $[6,9,10,11]$. Three hundred and thirty eight, which is equivalent to $64.3 \%$, of the respondents had pre-menstrual training, that is, information about menstrual cycle before first cycle, as they were told about and made to expect the first bleeding, with this done by mother. This is comparable to the outcome of another research which reported that $55.2 \%$ of the respondents received pre-menarcheal training and perhaps mainly through their mothers [6]. In this study, pre-menarcheal training was found to be significantly associated with the educational attainment of the respondents' mothers, thus influencing the probable information passed on to the girls. 432 (82.1\%) of the respondents currently use sanitary pad as the menstrual absorbent/material to collect their menstrual period. This is not strange owing the fact the pads are readily available and affordable, perhaps most girls believe the pads help prevent genital infections. However, with most of the information on pre-menstrual training and training obtained from the mother and not elsewhere especially places health workers or hospital or even in the school through teachers show that organized health information and education is highly required for adolescents as they complement family life education learned from home, thus in the process will serve to correct the wrongly passed information and enhance correct peer health education propagation.

One hundred and eighty four (35.0\%) experienced dysmenorrhoea (painful menstruation) during their last menstrual period. This is not in agreement with other studies that have shown far higher proportions, as 83.1\% dysmenorrhoea was reported in Eastern Sudan [7], 56.15\% dysmenorrhoea in India [8] but similar to other studies including the $38.1 \%$ dysmenorrhoea reported in Lebanon [12] and 48.82\% respondents in India. The painful menstruation was reportedly said to have hampered certain part of the respondent's social life or even schooling activities, especially with menstrual symptoms mainly including backache, headache, fatigue and mood swing complicating the issue, as the menstrual symptoms form part of regular women cycle largely because dysmenorrhoea begins around the time menstruation begins, with the pain often around the pelvis or lower abdomen. Furthermore, $142(27.0 \%)$ of the respondents have had a cycle $<21$ days or $>35$ days within their last three menstrual cycles. The outcome is in agreement with the Eastern Sudan and Ethiopian studies which showed $68.5 \%$ and $70.3 \%$ respondents respectively had regular period with cycle length ranging between 21 to 35 days [7, 10]. This can be considered a regular event especially as ovulation is said to occur in the first two years after menarche [14]. Pre-menstrual symptoms are found to be very common among these adolescents with mood changes, breast tenderness, generalized fatigue, among others, which is in agreement with other studies; $59.8 \%$ premenstrual symptoms in Sudan [7], 56.16\% pre-menstrual syndrome in India [8] and 25.6\% pre-menstrual symptoms in Northern Nigeria [11].

Most of the respondents had their menarche (first menstruation) around 12 to 13 years of age, with the mean age \pm SD being $12.51 \pm 1.44$ years. This is in contrast to the Sudanese research outcome which reported $76.4 \%$ delayed menarche [7], as well as the mean age at menarche reported as 15.8 years in Ethiopia [10], but similar to the outcome of the study in Northern Nigeria where the mean menarche age of 12.53 years was reported [11] and in India, where the mean ages for menarche were 13.51 and 13.67 years for urban and rural areas respectively [8]. This shows that generally girls experience menarche at different ages, the timing of which is influenced by the female biology coupled with environmental factors especially nutrition as well as genetics.

The acceptance of the first hypothesis on educational status on menstrual hygiene practices shows that education doesn't necessarily determine the menstrual hygiene practices. Also, the 
acceptance of the second hypothesis on the relation with mothers on pre-menarcheal training shows that the training is not dependent on the closeness of the adolescent girl with the mother. Meanwhile, the rejection of the third hypothesis on educational attainment of mother having no significant effect on pre-menarcheal training shows that the education of the mothers determine the possible information that would be stepped down to the young girls as this is evident in the fact that most of the mothers have got diploma and first degree qualifications.

\section{Conclusion}

Pre-menstrual training is common among these adolescent girls as it is evident in their menstrual hygiene practices. However, dysmenorrhoea and menorrhagia are common problems among adolescent girls thus health education \& health promotion that include sexual and reproductive health are the best ways to deal with menstrual hygiene \& disorder issues effectively. It is therefore advised that these be included in the high school curriculum and implemented by teachers in order to enhance the teachings at home by the mothers of these young girls.

\section{References}

[1]. Adinma ED \& Adinma JI. Perceptions and practices on menstruation amongst Nigerian secondary school girls. Afr J Repro Health. 2008; 12: 74 - 83.

[2]. Adam HPJ. Menstruation in young girls: A clinical prospective. Obst Gynecol. 2002; 99 (4): 655 662 .

[3]. Aniebue UU, Aniebue PN \& Nwankwo TO. The impact of pre-menarcheal training on menstrual practices and hygiene of Nigerian school girls. Pan Afr Med J. 2009; 2 (9): 1- 9.

[4]. Abdel Aziem AA, Duria AR, Mona M \& Ishag A. Age at menarche and menstrual cycle pattern among school girls in Kassala in Eastern Sudan. J Pub Health \& Epid. 2011; 3 (3): 111 - 114.

[5]. Adam HPJ. Menstruation in young girls. A clinical perspective. Obst. Gynecol. 2002; 99 (4): 655 662.

[6]. Daniel WW, Cross CL. Biostatistics: A foundation for analysis on health sciences, $10^{\text {th }}$ edn. New York, NY: Wiley, 2013.

[7]. Dutta DC. Textbook of gynaecology. $6^{\text {th }}$. Ed. New Delhi: Jaypee; 2015. p.82.

[8]. Diaz A, Laufer MR \& Breach L. Menstruation in girls and adolescents: Using the menstrual cycle as a vital sign. Paediatrics. 2006; 118 (5): 2245 - 2250.

[9]. Dambhare DG, Wagh SV \& Dudhe JY. Age at menarche and menstrual cycle pattern among school adolescent girls in Central India. Glob J Health Sci. 2012; 4 (1): 105 - 111.

[10]. Desalegn TZ, Berihum M \& Abay M. Age at menarche and the menstrual pattern of secondary school adolescents in Northwest Ethiopia. BMC Women Health. 2009; 9 (29): 1 - 8.

[11]. Kharde A, Reddy R, Phulambrikar R \& Jadhav J. A cross-sectional study on menstrual age and menstrual disorders. Int J Health Sci \& Res. 2016; 6(6): 19 - 23.

[12]. Karout N, Hawai SM \& Altuwaijri S. Prevalence and pattern of menstrual disorders among Lebanese Nursing students. East Mediterr Health J. 2012; 18 (4): 346 - 352.

[13]. Marianne E, McPherson ME \& Korfine L. Menstruation across time: menarche, menstrual attitudes, experiences and behaviours. Women's Health Issues. 2004; 14: 193 - 200.

[14]. Sulaymen HU, Ameh N, Adebiyi G et al. Age at menarche and prevalence of menstrual abnormalities among adolescents in Zaria, Northern Nigeria. Annals Nig Med. 2013; 7(2): 66 - 70. 
Texila International Journal of Public Health

Volume 4, Issue 4, Dec 2016

Table 1. Socio-demographic data of respondents

\begin{tabular}{|l|c|}
\hline VARIABLES & Frequency (\%) \\
\hline Age Group (years) & $26(4.9)$ \\
\hline 10 years & $56(10.7)$ \\
11 years & $54(10.3)$ \\
12 years & $70(13.3)$ \\
13 years & $88(16.7)$ \\
14 years & $78(14.8)$ \\
15 years & $88(16.7)$ \\
16 years & $30(5.7)$ \\
17 years & $26(4.9)$ \\
18 years & $10(1.9)$ \\
19 years \\
\hline Type of family & $380(72.2)$ \\
\hline Nuclear Family & $112(21.3)$ \\
Extended Family & $34(6.5)$ \\
No Response & $316(60.1)$ \\
\hline Religion & $210(39.9)$ \\
\hline Christianity \\
Islam \\
\hline Level of education \\
\hline Junior Secondary School \\
Senior Secondary School & $206(39.2)$ \\
Ordinary Level (O'Level) Degree & $268(51.0)$ \\
Undergraduate & $44(8.3)$ \\
\hline Position in family & $8(1.5)$ \\
\hline First Daughter \\
Middle Daughter \\
Last Daughter & $292(55.5)$ \\
Only Daughter & $132(25.1)$ \\
No Response & $72(13.7)$ \\
\hline Relationship with mother & $28(5.3)$ \\
\hline Very Close & $2(5.3)$ \\
Close & $416(79.1)$ \\
Ordinary Not Close & $86(16.3)$ \\
No Response & $10(1.9)$ \\
\hline
\end{tabular}

Table 2. Pre-menstrual training and menstrual hygiene practices

\begin{tabular}{|l|c|}
\hline VARIABLES & Frequency (\%) \\
\hline Current menstrual period absorbent/material disposal \\
\hline Water Closet & $116(22.1)$ \\
Dustbin & $100(19.0)$ \\
Burning & $84(16.0)$ \\
Pit Latrine & $50(9.5)$ \\
Washing (Cloth) & $32(6.1)$ \\
Farmland/Farm Location & $16(3.0)$ \\
Anywhere & $8(1.5)$ \\
No Response & $120(22.8)$ \\
\hline Age at menarche (first menstruation) in years \\
\hline 9 years & $12(2.3)$ \\
10 years & $36(6.8)$ \\
\hline
\end{tabular}




\begin{tabular}{|c|c|}
\hline $\begin{array}{l}11 \text { years } \\
12 \text { years } \\
13 \text { years } \\
14 \text { years } \\
15 \text { years } \\
\text { No Response }\end{array}$ & $\begin{array}{c}64(12.2) \\
132(25.1) \\
120(22.8) \\
96(18.3) \\
38(7.2) \\
28(5.3)\end{array}$ \\
\hline \multicolumn{2}{|c|}{ Experience at first menstruation } \\
\hline $\begin{array}{l}\text { Confusing } \\
\text { Frightening } \\
\text { Expectant } \\
\text { No Response }\end{array}$ & $\begin{array}{c}128(24.3) \\
170(32.3) \\
88(16.7) \\
140(26.6) \\
\end{array}$ \\
\hline \multicolumn{2}{|c|}{ Attitude towards subsequent menses } \\
\hline $\begin{array}{l}\text { Undesirable } \\
\text { Unprepared } \\
\text { Satisfactory } \\
\text { No Response }\end{array}$ & $\begin{array}{c}70(13.3) \\
176(33.5) \\
130(24.7) \\
150(28.5) \\
\end{array}$ \\
\hline \multicolumn{2}{|c|}{ Duration of last menstrual blood flow (in days) } \\
\hline $\begin{array}{l}3 \text { days } \\
4 \text { days } \\
5 \text { days } \\
6 \text { days } \\
7 \text { days } \\
\text { No Response } \\
\end{array}$ & $\begin{array}{c}130(24.7) \\
164(31.2) \\
176(33.5) \\
38(7.2) \\
34(6.5) \\
20(3.8) \\
\end{array}$ \\
\hline \multicolumn{2}{|c|}{ Amount of last menstrual blood flow } \\
\hline $\begin{array}{l}1 \mathrm{pad} / \text { day } \\
2 \mathrm{pads} / \mathrm{day} \\
3 \mathrm{pads} / \mathrm{day} \\
4 \mathrm{pads} / \mathrm{day} \\
5 \mathrm{pads} / \mathrm{day} \\
\text { No Response }\end{array}$ & $\begin{array}{c}50(9.5) \\
194(36.9) \\
178(33.8) \\
26(4.9) \\
12(2.3) \\
66(12.5) \\
\end{array}$ \\
\hline \multicolumn{2}{|c|}{ Dysmenorrhoea (painful menstruation) experience } \\
\hline $\begin{array}{l}\text { Mild } \\
\text { Moderate } \\
\text { Severe }\end{array}$ & $\begin{array}{c}60(11.4) \\
82(15.6) \\
32(6.1)\end{array}$ \\
\hline \multicolumn{2}{|c|}{ Pre-menstrual symptoms } \\
\hline $\begin{array}{l}\text { Depression } \\
\text { Pimples } \\
\text { Generalized Fatigue } \\
\text { Breast Tenderness/Pain } \\
\text { Mood Changes } \\
\end{array}$ & $\begin{array}{c}24(4.6) \\
82(15.6) \\
12(2.3) \\
64(12.2) \\
108(20.5) \\
\end{array}$ \\
\hline \multicolumn{2}{|l|}{ Menstrual symptoms } \\
\hline $\begin{array}{l}\text { Fatigue } \\
\text { Irritation } \\
\text { Nausea } \\
\text { Headache } \\
\text { Backache } \\
\text { Dizziness } \\
\text { Diarrhoea } \\
\text { Mood Swing/Change }\end{array}$ & $\begin{array}{c}58(11.0) \\
38(7.2) \\
24(4.6) \\
52(9.9) \\
62(11.8) \\
12(2.3) \\
12(2.3) \\
48(9.1) \\
\end{array}$ \\
\hline
\end{tabular}


Texila International Journal of Public Health

Volume 4, Issue 4, Dec 2016

Table 3. Chi square result showing factors influencing pre-menstrual training and menstrual hygiene

\begin{tabular}{lllll} 
VARIABLES & $\boldsymbol{\chi}^{\mathbf{2}}$ & df & Critical value & Decision \\
\hline $\begin{array}{l}\text { Educational status on menstrual hygiene } \\
\text { practices }\end{array}$ & 16.158 & 12 & 21.03 & Accepted \\
$\begin{array}{l}\text { Relationship with mothers on pre- } \\
\text { menarcheal training }\end{array}$ & 12.210 & 8 & 15.51 & Accepted \\
$\begin{array}{l}\text { Educational attainment of mother on pre- } \\
\text { 25.408 }\end{array}$ & 14 & 23.69 & Rejected
\end{tabular}
menarcheal training

1) Educational status has no significant influence on menstrual hygiene practices

2) Relationship with mothers have no significant effect on pre-menarcheal training

3) Educational attainment of mother have no significant effect on pre-menarcheal training

The null hypothesis is rejected when the test statistic is greater than the tabled value or critical value. 


\title{
The Three Delay Model as Framework to Assess the Burden of Maternal Deaths in the Urban District of Kitwe, Zambia
}

\author{
Article by Elvis Chipili \\ Ph.D in Public Health, Texila American University, Zambia \\ E-mail: Mpunduchipili@Gmail.Com
}

\begin{abstract}
In Zambia, it is estimated that in excess of 398 women every year die from pregnancy related complications out of every 100,000 live births. The lifetime risk of a woman dying from a pregnancy related complication is 1: 20. The largest contributor to this high number of maternal deaths from the national level perspective has long been considered to be the delay in deciding to seek maternal and obstetrical care at both household and community levels with very little attempts to explore on extent to which the third delay factors have contributed to the high numbers of maternal deaths that have continued to occur un averted in facilities serving s referral centres. This study therefore provided an assessment framework based on the Three Delay Model to explore and assess how the third delay was impacting on the current burden of maternal mortality in an urban setting of Kitwe District of Zambia.

Method: The study was prospective cross-sectional descriptive study involving case file review of maternal deaths that occurred in the delivery facilities of Kitwe District (Hospital and Clinics). The Study Population included all women that had died from pregnancy related complications in the delivery centres of an urban district (Kitwe) of Zambia in 2014 and 2015. The study investigated 30 maternal deaths (25 reviewed cases and 5 unreviewed cases). Data was collected using an adapted 2004 WHO tool: Beyond the Numbers: Reviewing maternal deaths and complications to make pregnancy safer and the Country's Ministry of Health document: 'Beyond the Numbers; Maternal Death Review Forms.

Results: The study revealed majority (56\%) came from the low density areas within the age range of 25-29 years (50\%). Majority (44\%) were referred from health centres within the vicinity hospital, 22\% accessed the facilities using their own means of transport. Referral response was poor with 50\% of the deceased being evacuated after 3 hours following decision to transfer them from the attending local clinic. Most mothers (55\%) came into the facility in a fully conscious state with normal vital signs. Haemorrhage following delivery $(\mathrm{PPH})$ was the leading cause involving $44 \%$ of the diseased, followed by hypertensive disorders including eclamptic fits. Sepsis following incomplete abortion led to $22 \%$ of deaths with deaths occurring on average of 8hrs following admission to the facility. All attendant staff was skilled birth attendants.

Conclusion: The three Delay Model provides such a frame work to explore and identify different barriers women face in accessing quality, timely and effective maternal health care services needed to prevent such deaths. Using this framework, this study has revealed that the burden of maternal deaths occurring in Kitwe District is mainly due to the factors related to the third delay causes of maternal deaths.
\end{abstract}

\section{Introduction}

There are many interlinking factors which can prevent women and girls from access high quality maternal and family planning care. Recognizing the different barriers women face in achieving the timely and effective medical care needed to prevent deaths occurring in pregnancy and childbirth should be on top of the agenda for health care systems promoting Safe Motherhood Practices. The three Delay Model provides such a frame work to explore and identify different barriers women face in accessing quality, timely and effective maternal health care services needed to prevent such deaths. The model identifies three groups of factors which may stop women and girls accessing the levels of maternal health care which 
Texila International Journal of Public Health

Volume 4, Issue 4, Dec 2016

they need: delay in making decision to seek care, delay in reaching the care and delay in receiving appropriate and adequate health care $(\mathrm{MoH}, 2010)$. This study will therefore provide an assessment framework based on the Three Delay Model to identify which of these factors are impacting on the current burden of maternal mortality in an urban setting of Kitwe District.

In Zambia, a significant and big burden of women's ill health in the childbearing group is due to pregnancy and child birth related complications. These women are in the productive age group of 15 to 49 years. It is estimated that 398 women every year die from pregnancy related complications out of every 100,000 live births. The lifetime risk of a woman dying from a pregnancy related complication is 1: 20. This means that a pregnant woman in Zambia has a twenty times chance of developing and dying from pregnancy related complication $(\mathrm{MoH}, 2010)$. Over fifty percent of these maternal deaths are attributed to direct causes of postpartum haemorrhage, sepsis, obstructed labour, abortion, and eclampsia. It has been long noted that majority of these women who die from pregnancy related complications die either at home or on their way to the hospital. The largest contributor to this high number of maternal deaths from the national level perspective was considered to be the delay in deciding to seek maternal and obstetrical care at both household and community levels. Whereas some studies have been done to ascertain the impact of the first and second delay on maternal deaths, the search for the third delay studies yielded no results. This is one of the topics that has been under researched $(\mathrm{MoH}, 2010)$.

Kitwe district is located in the Copperbelt Province of Zambia and covers a total of 737 square kilometres. The district has 32 operational health facilities of which 12 are delivery centres (BEmONC) and One Central Hospital providing CEmONC services. The other two hospitals (Wusakile mine and Sinozam) are privately owned. Population profiles are presented in the table below:

Figure 1. Population number and Key indicators:

\begin{tabular}{|l|l|l|}
\hline \multirow{2}{*}{ category } & 2014 \\
\cline { 2 - 3 } & Number & \% of total population \\
\hline Children $0-11$ months & 16,893 & 2.7 \\
\hline$<5$ year & 101,632 & 16.2 \\
\hline $5-14$ years & 168,755 & 27.0 \\
\hline Women 15 - 49 years & 178,208 & 28.5 \\
\hline All Adults 15 years + & 355,278 & 56.8 \\
\hline Total male (All ages) & 311,341 & 49.8 \\
\hline Total female ( all ages) & 324,324 & 50.2 \\
\hline Total Population / 1 & 625,665 & 100 \\
\hline Population growth rate & & 3.0 \\
\hline
\end{tabular}

Source: SCO, 2010 Census population and Housing, Zambia Population and demographic Projection 2011 - 2035

Whereas previous studies have shown that the first and second delays have been implicated in the burden of maternal deaths in the country and in particular the rural setting where communities stay a distant from the health facilities offering delivery services, and accessibility to health care services are a challenge, no research in Zambia has attempted to discover the extent to which the third delay factors have contributed to the high numbers of maternal deaths that have continued to occur un averted in facilities within the vicinities of the communities. For instance the number of maternal deaths in Kitwe district have shown an upward trend in the past three years with 2015 recording the highest number. Most of these cases occur at Kitwe Central Hospital, the districts only Government owned health facility.

The figure figures below provides a picture of the delivery care in Kitwe. 
Figure 2. Availability of emergency maternal obstetrical Care

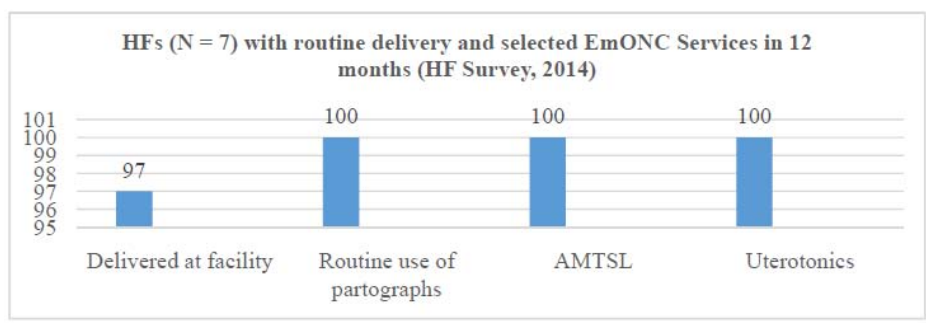

Figure 3. selected determinants

\begin{tabular}{|l|l|}
\hline Selected Determinants & Kitwe District \\
\hline Supply side (HF survey, 2014) & $70 \%(\mathrm{~N}=10)$ \\
\hline HFs with $\geq 1$ AMTSL trained HCWs & $29 \%(\mathrm{~N}=7)$ \\
\hline HFs with Magnesium Sulphate & $100 \%(\mathrm{~N}=7)$ \\
\hline HFs with Oxytocin & $0 \%(\mathrm{~N}=7)$ \\
\hline HFs with mothers' waiting shelters & $86 \%$ \\
\hline Demand Side (HH survey-LQAS, 2014) & $11 \%$ \\
\hline Mothers who live within 1hr walking distance from HF & $17 \%$ \\
\hline Mothers birth related complications during delivery & $84 \%$ \\
\hline Satisfied with delivery service & \\
\hline Perception on birth preparedness &
\end{tabular}

Household Survey - Lot Quality Assurance Sampling, 2014 


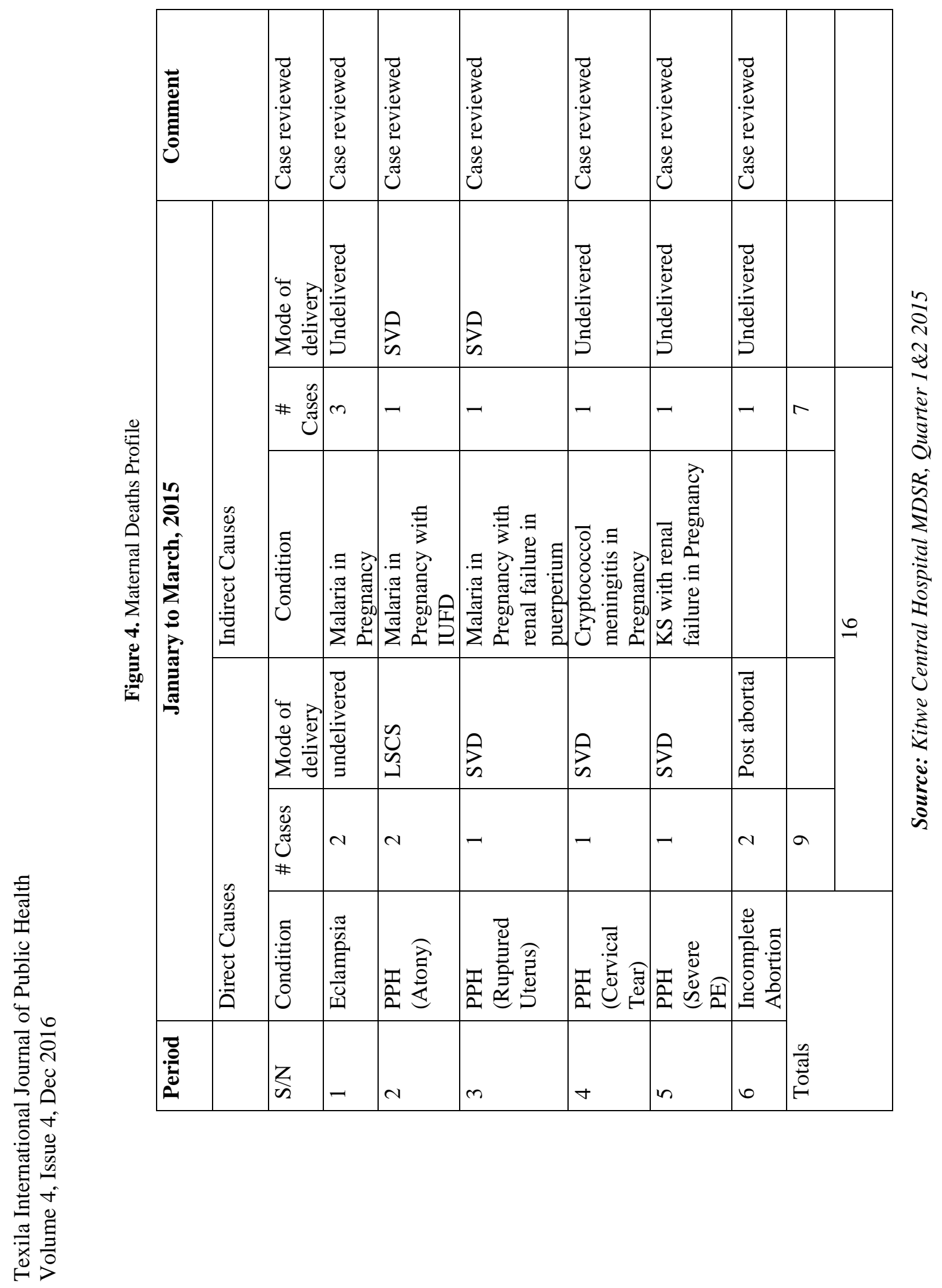




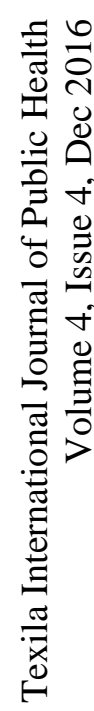

\begin{tabular}{|c|c|c|c|c|c|c|c|c|c|c|}
\hline Uة & & 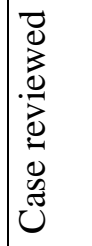 & 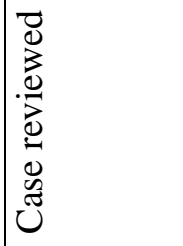 & 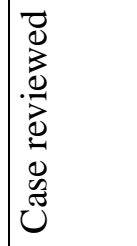 & 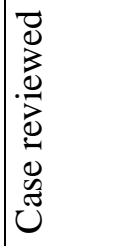 & 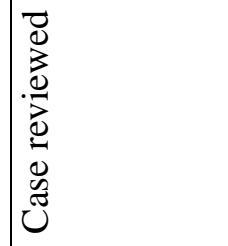 & 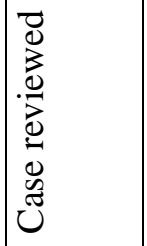 & 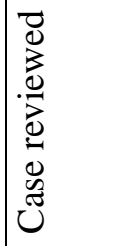 & & \\
\hline \multirow{6}{*}{ 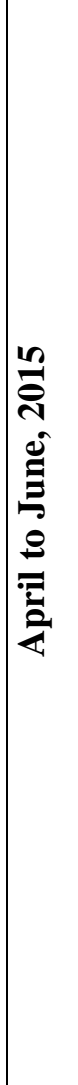 } & \multirow[b]{3}{*}{ 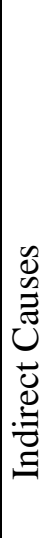 } & 过 & 忿 & is & & & & & & \\
\hline & & \# & - & -1 & $\neg$ & & & & $m$ & \\
\hline & & 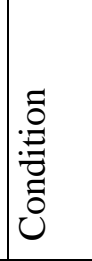 & 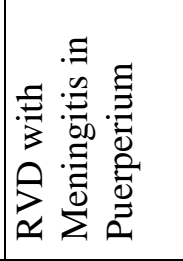 & 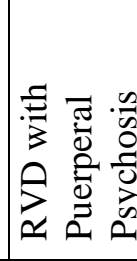 & 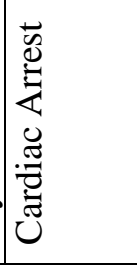 & & & & & $\sigma$ \\
\hline & \multirow{3}{*}{ 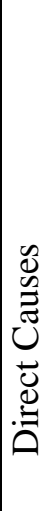 } & 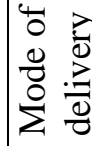 & $\int_{0}^{2}$ & 矛 & 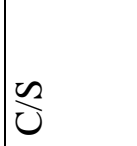 & $\frac{n}{0}$ & 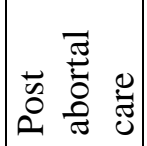 & $\frac{s}{0}$ & & \\
\hline & & 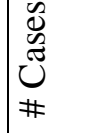 & $\neg$ & -1 & - & $\neg$ & - & -1 & 6 & \\
\hline & & 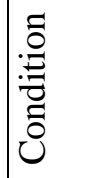 & $\begin{array}{l} \\
+ \\
+\end{array}$ & 詹 & 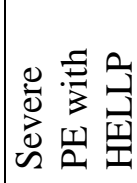 & 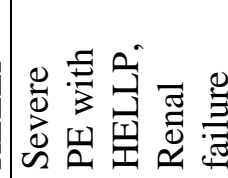 & 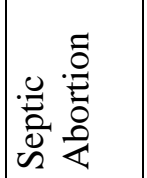 & 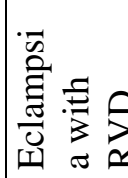 & \multirow[b]{2}{*}{ 쥼 } & \\
\hline 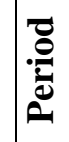 & & $\frac{z}{\omega}$ & -1 & $N$ & $m$ & $\nabla$ & L & 0 & & \\
\hline
\end{tabular}




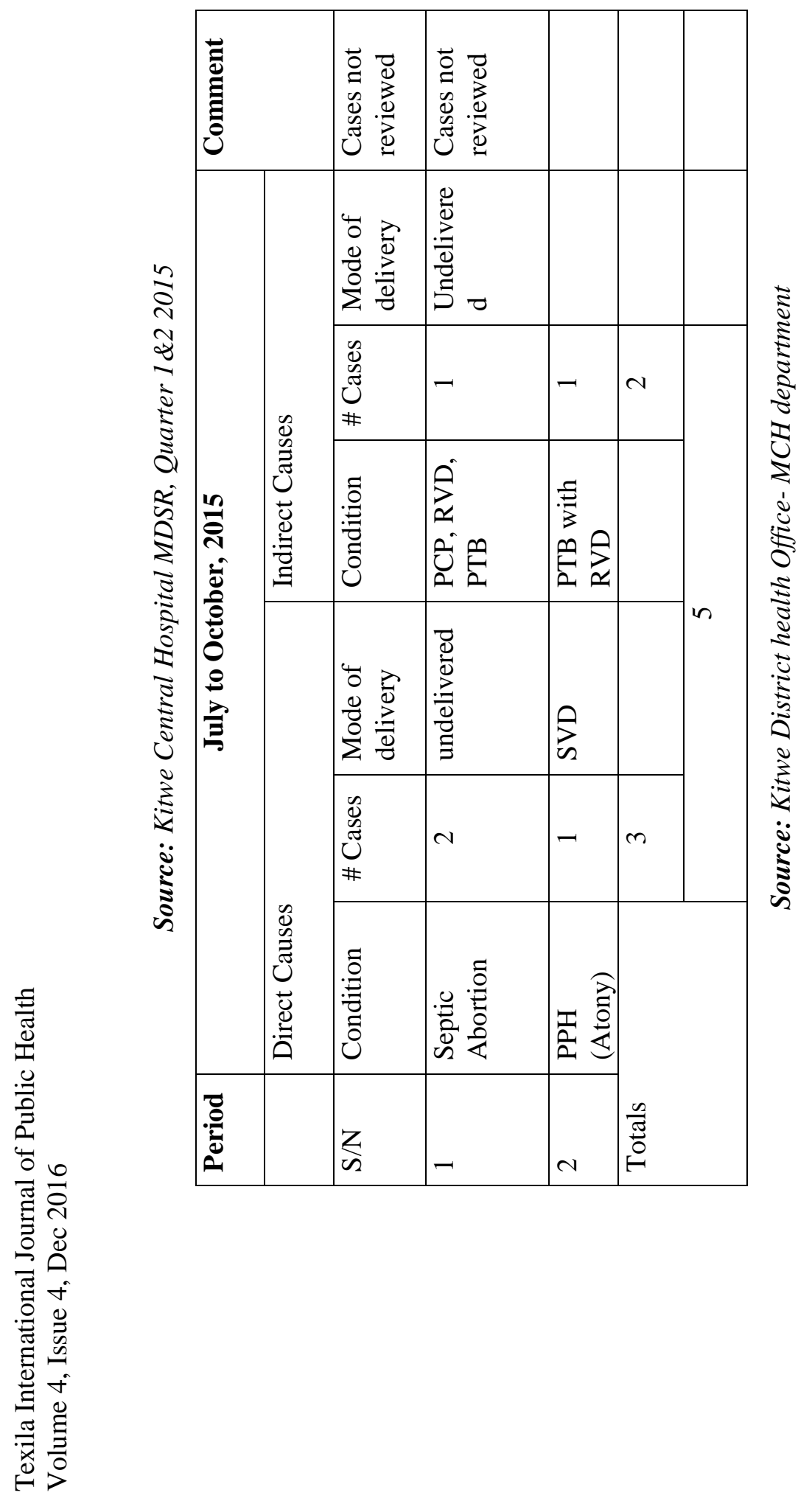


It was scope of this study to apply the Three Delay Model to identify which of the three delays is significantly impacting on the current burden of maternal mortality in an urban setting of Kitwe District.

\section{Objectives}

\section{Main objective}

The main objective of the study was to determine and describe the type of delay commonly contributing to the burden of maternal deaths in Kitwe District.

\section{Specific objectives}

1. To determine the types of delay that commonly contributed to maternal deaths of pregnant women referred and admitted to Kitwe district delivery facilities.

2. To describe the characteristics of women (demographic and pregnancy related) that died from pregnancy complications amongst women admitted to Kitwe district delivery facilities

3. To assess the timing and adequacy of treatment offered to victims of maternal deaths in the admitting delivery facilities of Kitwe District

4. To determine the inpatient duration of stay of maternal death victims

5. To determine the category of staff (Skilled or unskilled) that provided delivery care services to victims of maternal deaths.

\section{Study design}

\section{Methodology}

The study was prospective cross-sectional descriptive study involving case file review of maternal deaths that occurred in the delivery facilities of Kitwe District (Hospital and Clinics). The deaths occurred and were reported by the facilities they occurred from to the District Health Office and reviewed by District Maternal Death Surveillance and Response (MDSR) Committee for all the four quarters in 2014 and three quarters in 2015.

\section{Research setting}

There are twelve health centers in Kitwe, in addition to Kitwe Central Hospital, that provide delivery care services. All of these delivery centres have trained midwives that provide twenty four hour labour and delivery services. However, all the twelve delivery centers refer patients with pregnancy problems (antenatal, intrapartum or puerperal) to Kitwe Central Hospital which has 24 hour anaesthetic cover for the operating theatres and on-site blood transfusion availability throughout the year.

\section{Study Population}

Included all women that had died from pregnancy related complications in the delivery centres of Kitwe and that met the definition of maternal death including cases referred to Kitwe central Hospital from surrounding districts.

\section{Sampling technique}

Owing to the small number of cases, all cases were considered and included in the study.

\section{Sample Size}

Consisted all maternal cases recorded in the three quarters in 2015 and one month in the fourth quarter of the same year. Each quarter being 3 months period. The study sample therefore consisted only of maternal deaths related to direct causes of maternal deaths of 25 reviewed cases and 5 unreviewed cases. 
Texila International Journal of Public Health

Volume 4, Issue 4, Dec 2016

\section{Research instruments}

The study employed the use of an adapted data collection tool which was used for the abstraction of details (See appendix). The data collection tool was based on the WHO document: Beyond the Numbers: Reviewing maternal deaths and complications to make pregnancy safer (2004). In the Ministry of Health document: 'Beyond the Numbers; Maternal Death Review Forms; Community Data Collection Instruments' was also used (MOH 2005).

\section{Data analysis}

Data was tabulated as simple frequency distributions using appropriate class divisions when more than 2 variables were involved (e.g. age 15-19, 20-24 years etc). Although this was a descriptive study, for illustrative purposes only, comparisons were made of variables (e.g. age, gravidity/parity, blood pressure, days in hospital).

\section{Study Results}

Figure 5 Patients’ demographic characteristics

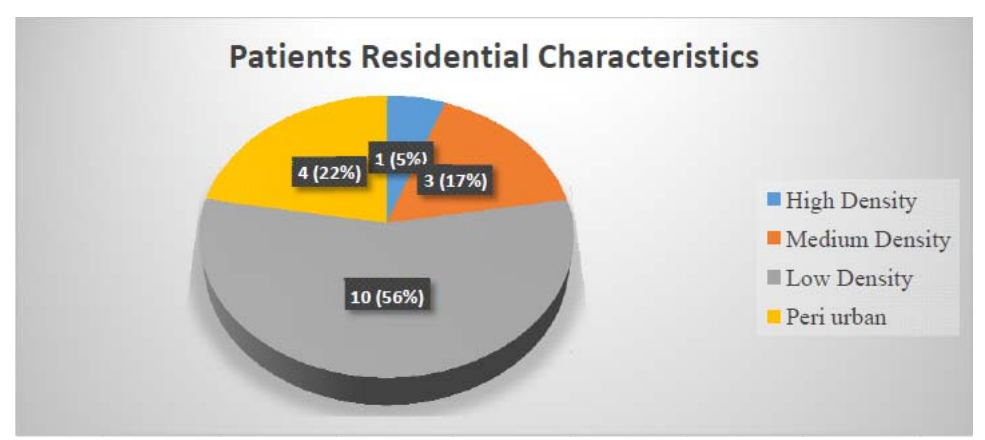

Majority of the deceased clients came from the low density areas (56\%) and $17 \%$ came from the Medium density areas. Only 5\% came from the high density areas with 22\% recorded from the peri urban population.

Figure 6: Age distribution

\begin{tabular}{|l|l|l|l|l|}
\hline S / N & Age range & Frequency & Total & Percentage \\
\hline 1 & $15-19$ years & I & 1 & 6 \\
\hline 2 & $20-24$ years & IIII & 4 & 22 \\
\hline 3 & $25-29$ years & IIIII IIIII & 9 & 50 \\
\hline 4 & $30-34$ years & IIIII II & 4 & 22 \\
\hline 5 & 35 and above & & & \\
\hline
\end{tabular}

Majority of the deceased mothers were from the rage range of 25-29 years (9), closely followed by $20-24$ years range. In the third category were the mothers from the $30-34$ years. Only one case (6\%) was recorded from the age range 15 - 19yrs and no death was recorded in the age arrange 35 - 45yrs old. 
Figure 7. Referral status to health facility

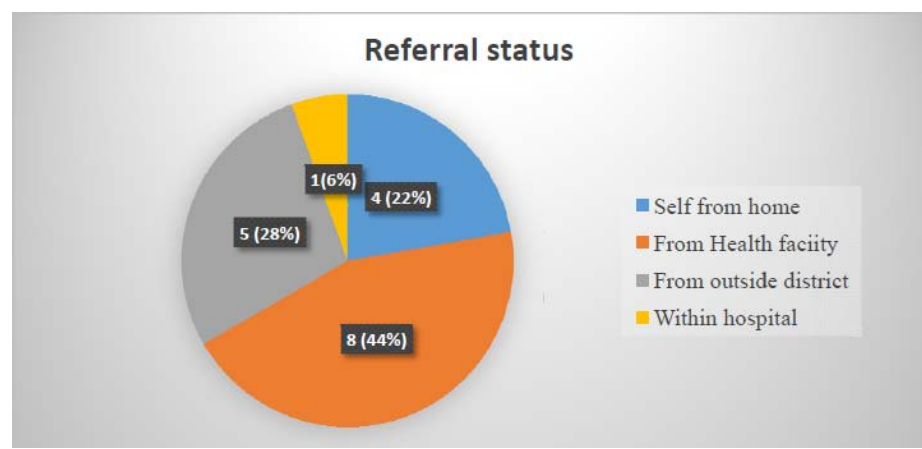

Eight (44\%) out of 18 deceased mothers were referred from the local health facilities to the Central hospital for further management using the institutional ambulances. Five (28\%) were referred from the institutions outside Kitwe district by ambulances from their respectful referring institutions, Four (22\%) accessed the facilities using their own means of transport whilst only 1 client (6\%) was already in the hospital admission wards when the death occurred.

Figure 8. Referral response:

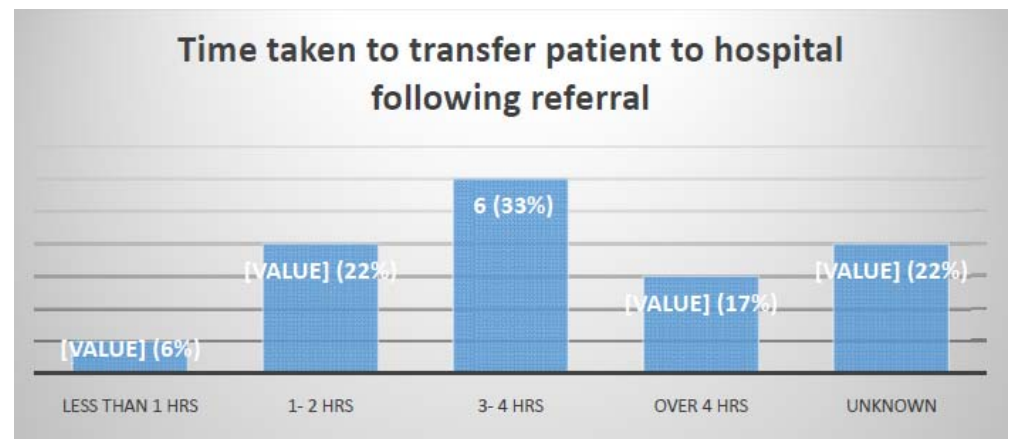

Majority of mothers (over 50\%) were only evacuated to the hospital for further attention by specialists after 3 hours following decision to transfer them from the attending local clinic. $22 \%$ were referred within $1-2$ hours following decision to evacuate them whilst another $22 \%$ of mothers times of referral were not indicated on the case sheets.

Figure 9. Condition of mothers on admission

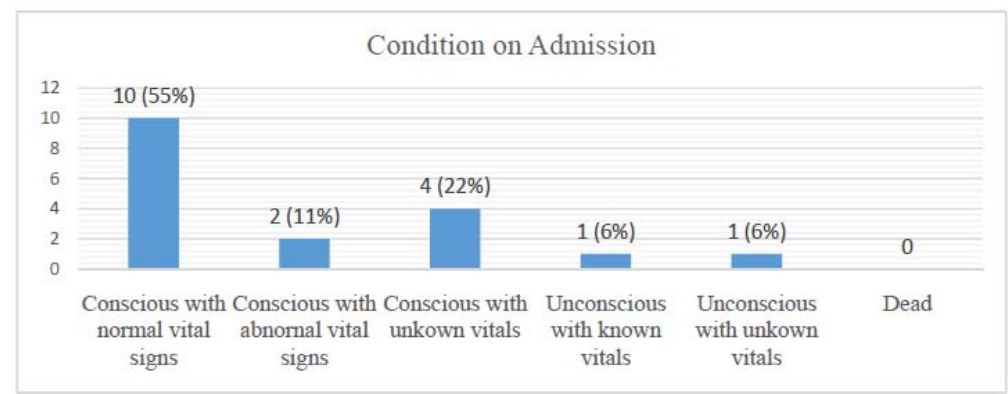

Majority of clients (55\%) came into the facility in a fully conscious state with normal vital signs recorded at admission. Only two cases $(11 \%)$ had a record of being conscious with abnormal vital signs (BP and temperature) and no one was brought into the facility already dead. 
Texila International Journal of Public Health

Volume 4, Issue 4, Dec 2016

Figure 10. Diagnosis

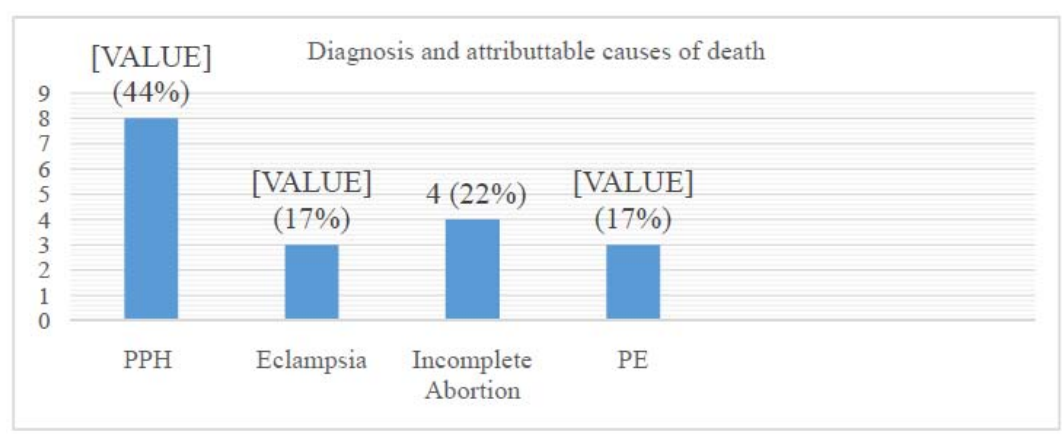

Haemorrhage following delivery (PPH) was the leading cause at $44 \%$, followed by hypertensive disorders including eclamptic fits causing 34 deaths whilst sepsis following incomplete abortion led to $22 \%$ of deaths.

Figure 11. Length of stay in facility

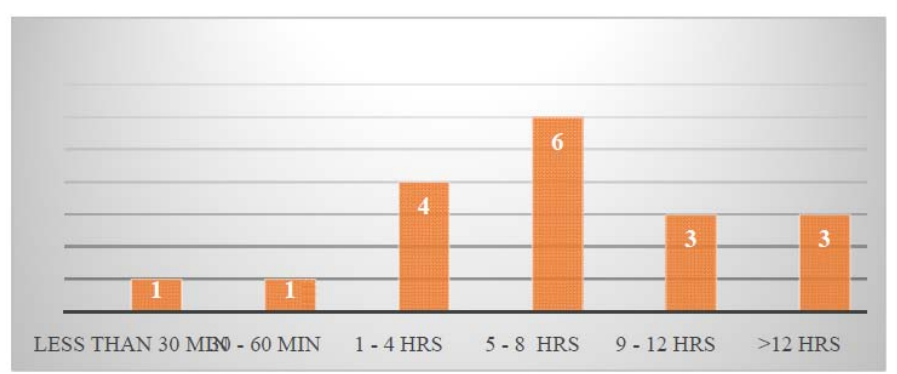

Nine of the mother died between 5 to 12 hours following admission, 3 died after more than 12 hours of hospital stay whilst 4 mothers died within the $1-4$ hours after admission. Only two mothers died less than an hour from admission.

Figure 12. Category of birth attendant

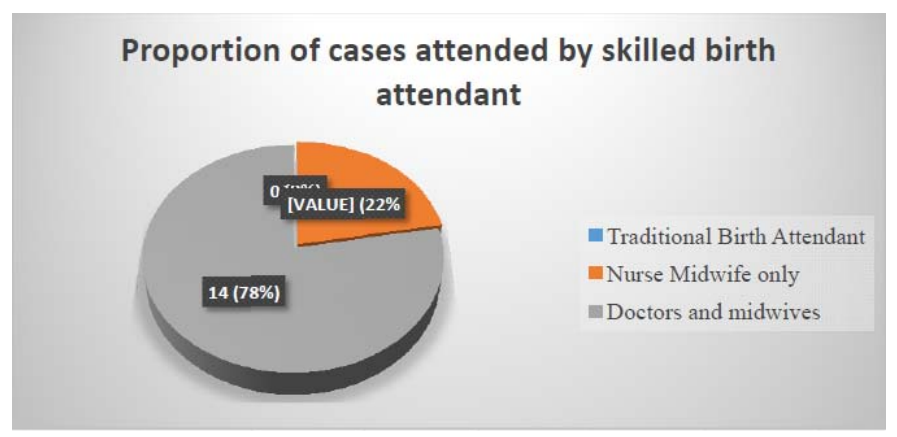

All the cases were attended to by skilled birth attendants (midwives and Doctors). No case was attended to by traditional birth attendants. All the 18 cases were attended to by midwives; $22 \%$ by midwives only, and the rest of the cases $(78 \%)$ were on admission attended to by midwives before referring them to Doctors for surgical interventions.

\section{Discussion}

The study established that all the burden of maternal deaths occurring and being recorded at Kitwe Central Hospital could be classified as those belonging to the third delay of maternal. Under this model, the patient or the mother has managed to reach the health care in time but for some reasons she fails to receive appropriate treatment (care). Failure to receive appropriate care could be due to service inadequate (shortage of staff, inadequate equipment and supplies, absence of service), could also be due delays by poor staff attitude, incompetence, oversight and simply negligence. This finding is in contrast with the some studies conducted in the country that have suggested that most of maternal deaths occur either 
at home or on the way to hospital due to poor health seeking behaviour and distance to health facility (MoH, 2010). In terms of distance to health facility, Kitwe is an urban mining town and most of the residential areas are within an hour's walk to the nearest health facility $(\mathrm{MoH}$, 2014). Most patients therefore easily reach the health facilities by walking or by privately owned cars (minibuses / Taxis). Once at the facility (delivery centre) pregnancy related complications are referred to hospital (Kitwe Central Hospital).

In this study, majority of the women that suffered maternal death were aged between 25 29 years and came from low density areas of the township. All the mothers were referred from facilities within Kitwe (72\%) and from heath institutions in districts outside Kitwe district (28\%). Further study could be needed to determine if at all there are differences in the way clients are attended to in relations to their social economic statuses at Kitwe Central Hospital. The main mode of transport to the hospital on referral was the ambulance service (72\%) whilst $28 \%$ used privately owned transport. However, there was a considerable lapse of time from the time referral decision was made to the time the ambulance service was provided. Majority were only evacuated after 3 hrs. following referral. This is another delay within the facilities and clients despite being in the facility they can be moved quickly enough to access appropriate treatment. This is an indication of poor referral system. Review of the deceased case records indicated that majority of clients (55\%) presented to the attending facilities whilst walking and in fully conscious state with normal vital signs recorded at admission. A smaller number (11\%) had a record of being conscious with abnormal vital signs (BP and temperature) and none was admitted in an unconscious state or dead. However, most complications were noted upon delivery (PPH) or during the period of labour within the facilities. Complications were noted during the process of labour monitoring or upon admission in those that presented with incomplete abortions by attending midwives. Attending midwives were mandated to refer a patients once noted with complication to Central Hospital. However, this study revealed that most mothers (50\%) due to inadequate ambulance service could only be evacuated to hospital after 3 hours following decision to refer them. In $22 \%$ of those referred, no referral time was indicated on their transfer letters and case sheets. This is a kind of service inadequate. The mothers despite reaching the health care early could not be moved in quick time to reach the next appropriate care. In this way patients were subjected to longer stay at the primary health care facility.

The study also established that upon reaching the central hospital, clients were received and attended to by midwives and doctors. Most reached the Central hospital in conscious and stable conditions and stayed for considerable length of time before meeting their fate. A striking feature was that most mothers $(67 \%)$ met their fate after staying for considerable number of hours (5 - 12hrs) in the referral centre (hospital) whilst in the hands and care of the skilled birth attendants (midwives and Doctors). Most deaths were due to haemorrhage (PPH) following delivery (44\%) and sepsis following unsafe abortions (22\%). Only two mothers died less than an hour from admission. This is also a matter demanding inquiry considering that fact that both haemorrhage and septic abortion are conditions that are treatable and deaths from such can be avoidable if appropriately handled. It would be of interest to undertake another study to assess the readiness of the Central Hospital to handle emergency obstetrical care cases in terms of skills of staff and service adequacy (equipment, drugs and supplies)

\section{Conclusion}

The three Delay Model provides such a frame work to explore and identify different barriers women face in accessing quality, timely and effective maternal health care services needed to prevent such deaths. The model identifies three groups of factors which may stop women and girls accessing the levels of maternal health care which they need: delay in making decision to seek care, delay in reaching the care and delay in receiving appropriate and adequate health care. Using this framework, this study has revealed that the burden of maternal deaths occurring in Kitwe District is mainly due to the factors related to the third delay causes of maternal deaths. 
Texila International Journal of Public Health

Volume 4, Issue 4, Dec 2016

\section{References}

[1] Central Statistics Office (2010) Zambia Demographic and health Survey. Lusaka. Government Printers

[2] Kitwe Central Hospital (2015) Health information management system; Maternal death and surveillance Report. Kitwe Central Hospital.

[3] Ministry of Health (2010) Campaign for Accelerated Reduction of Maternal Mortality in Africa. Lusaka. Ministry of Health

[4] Ministry of Health (2014) LOT quality Assurance Sampling; facility and household Baseline Study. Lusaka. Ministry of Health.

[5] World Health Organization (2004). Beyond the numbers: Reviewing Maternal Deaths and Complications to make pregnancy safer. Geneva. World Health Organization. 


\title{
Economic Burden of Low Back Pain among Quarry Workers Attending Outpatient Physiotherapy Clinic at a Tertiary Health Institution in Ondo State, Nigeria
}

\author{
Article by Ebenezer Obi Daniel \\ Ph.D. in Public Health, Texila American University, Nigeria \\ E-mail: dannypressy@texilaconnect.com
}

\begin{abstract}
Problem: The economic burden of health care in developing countries (like Nigeria) especially among the low social class and those involved in risky environment and occupations is worrisome and increase the out-of-pocket expenses of such individuals and expose them to poverty. A limited amount of data exists on the burden of low back pain (LBP) especially in developing countries.

Objective: This study was carried out to determine the economic burden of LBP of quarry workers who attend out-patient physiotherapy clinic of a tertiary health institution in Owo, Ondo State.

Methods: This study was carried out at Federal Medical Centre Owo in Ondo State, Nigeria. A descriptive cross sectional survey of forty quarry workers with LBP (28 males, 12 females) receiving physiotherapy at Federal Medical Centre, Owo, was carried out with purposive sampling method (non-probability sampling). Data on the economic burden of LBP and socio-demographic information of participants were collected using a self-developed questionnaire, reviewed by research experts. Data was analyzed using descriptive statistics of proportions, mean and standard deviations.

Outcome: It was discovered in this study that, the cost of Physiotherapy represents the highest cost (63\%) among the direct costs, followed by the cost expended on Physician visit (23.56\%) while the cost of diagnostic tests represents the least (3\%). Among the indirect costs, the expenditure on paid help, 34000 naira (45.7\%) is the highest, while that of meals outside home, 9738.46 naira (13.0\%) is the lowest. On the overall, this study reveals that the direct cost of low back pain among quarry workers (60.6\%) forms the bulk of expenses of the management of low back pain by quarry workers. It is recommended that, policy formulation on alleviating the economic burden of ailments associated with risky jobs should be considered in developing countries, the research work should be carried out using larger population, inclusion of other risky occupations in future researches and that other possible factors that can be responsible for the low back pain of such workers should be taken into consideration in future studies.
\end{abstract}

\section{Introduction}

Low back pain (LBP) is the most common musculoskeletal problem that brings patients to the hospital. It is usually accompanied by painful limitation of movement, often influenced by physical activities and postures and may also be associated with referred pain (Omokhodion and Sanya 2003). In the United States, LBP has reached epidemic proportions and represents a significant threat to the public health of its citizens.(Kovacs et al 1997). The recurrence of the condition is common. (Deyo 1996)

The lifetime prevalence is over $70 \%$ in industrialized countries, with peak prevalence between ages 35 and 55. In Nigeria, the prevalence of LBP among hospital workers was reported to be $46 \%$, with the highest prevalence (69\%) recorded amongst nursing staff, followed by secretaries/administrative staff (55\%) and cleaners/aids (47\%). Heavy physical work (45\%), poor posture (20\%) and prolonged standing or sitting (20\%) were the most frequent activities associated with LBP amongst these workers (Van Tulder et al 2006)

Some studies have found the prevalence of LBP to be stable over several years. In Germany, the prevalence of LBP was found to be stable over a decade. The high number of patients with recurrent 
pain makes it difficult to distinguish between prevalence of acute and chronic LBP. (Van Tulder 2006, Huppe et al 2007, Ihleback \&Eriksen 2007)

Justification of the study: Low back pain is a common work-related ailment among quarry workers. Many studies have been carried out to unravel the prevalence and predisposing factor of LBP, but there is a dearth of documented studies toward the economic burden of LBP, especially among the quarry workers whose work is almost always associated with LBP. This is the motivation towards this study.

\section{Statement of the problem}

In the developing nations like Nigeria, the popular payment system for health care deliveries on the part of the patients is out-of-pocket system. Only few citizens, predominantly the occupants of the formal sector are enrolled under Social Health Insurance (SHI) mostly in developing nations. Almost all of the quarry workers are not eligible to enjoy the benefits of SHI neither do they have the financial capacities to register under Private Health Insurance (PHI). This implies that, any health care facility enjoyed by this category of people will be personally paid for, through out-of-pocket payment system, which has the potential to add to the financial burden of quarry workers, most of who are paid meager wages/salaries. This can have gross negative effect on their wellbeing and welfare, and increase their level of poverty.

\section{Research questions}

The following research questions were answered by this study;

1. What is the direct cost of managing the Low Back Pain among quarry workers attending outpatient Physiotherapy clinic at Federal Medical Centre, Owo.

2. What is the indirect cost of managing the Low Back Pain among quarry workers attending outpatient Physiotherapy clinic at Federal Medical Centre, Owo.

3. What is the comparison between the direct and indirect cost of managing LBP among quarry workers attending out-patient Physiotherapy clinic at Federal Medical Centre, Owo.

\section{Significance of the study}

This study will serve as a search light into the burdens faced by the people involved in the hard labor jobs with respect to the treatment of the associated ailment. It will serve as a yardstick towards the proffering of possible interventions into how to assist the developing countries in reducing the economic burden of direct and indirect cost of managing occupational diseases and injuries.

\section{Limitations of the study}

1. The researcher is a known person to most of the quarry workers who attends the Physiotherapy outpatient clinic (as the researcher is also a Physiotherapist), and this may lead to response bias

2. The study did not include other possible factors that may be responsible for the LBP of the participants of this study.

In order to reduce the effect of the (1) above, one research assistant was incorporated for the purpose of data collection through questionnaire.

\section{Literature review}

\section{Introduction}

Low Back Pain (LBP) represents the leading musculoskeletal cause of disability and is the most frequently reported condition for which people receives outpatient physiotherapy (Jette et al, 1994). LBP has been referred to as a 20 century enigma which continues to cause disability and distress in a large proportion of the adult population (Waddel, 1998). LBP may not be a life threatening condition but it constitutes a major health problem in the world (Deyo and Phillips, 1996). It is usually 
accompanied by the painful limitation of movement, often influenced by physical activities and posture, and may be associated with referred pain (Kovac et al, 2006).

Low back pain is neither a disease nor a diagnostic entity of any sort, it is usually defined as pain localized below the margin of the last ribs (costal margin) and above the inferior gluteal lines, with or without lower limb pain (Van Middelkoop et al,2010) It is one of the most common cause of musculoskeletal disorder related to work status and condition (Frank et al,1996) It occurs in similar proportions in all cultures, interferes with quality of life and work performance, and is the most common reason for medical consultations (Ehrlich,2003). It remains the leading cause of disability in persons younger than 45 years old [Lu,2003). More than one-quarter of the working population is affected by LBP each year, (Lee et al,2001) with a lifetime prevalence of 60-80\% (Hartvigsen et al,2000) and a large percentage of LBP claims for long durations -more than 90 workdays lost (Murphy and Volinn,1999) At some point in life, between 15\% and 20\% of adults have this syndrome (Ehrlich,2003;Frank et al,1996) in which most cases (90\%) are nonspecific and occur in all age groups (Ehrlich,2003).

Low back pain is a complex condition with several factors contributing to its occurrence. Most knowledge on risk factors of LBP stems from cross sectional studies which cannot evaluate the temporal sequence between a risk factor and the occurrence of pain (Riihimäki,1991). Three different groups of potential risk factors have been identified in LBP :(a) individual factors such as body weight and age, (b) biomechanical factors such as heavy physical load, lifting, twisted postures, and vibration, and (c) psychosocial factors such as job control and job satisfaction (Keriri,2013).

Work related LBP which is a form of Mechanical - or nonspecific - LBP is the most commonly reported by the population (Daniele et al, 2012). The human body has a center of gravity, which keeps the balance between muscles and bones to maintain the integrity of structures and protect them against injury in any position - standing, sitting or laying down. In nonspecific LBP, imbalance typically occurs between the functional load - which is the effort required for work and activities of daily living, and ability - which is the potential for performing these activities (Daniele et al, 2012). Nonspecific LBP is characterized by the absence of structural change in which there is no disc space reduction, nerve root compression, bone or joint injuries, marked scoliosis or lordosis that may lead to back pain. Despite the lack of structural change in nonspecific LBP, it can limit daily activities and cause temporary or permanent inability to work, being one of the main causes of absence at work in the Western world (Krismer and Tulder, 2007).

The incidence of nonspecific LBP is higher in workers subjected to heavy physical exertion, such as weight lifting, repetitive movements, and frequent static postures ( Andrade et al,2005; Dagensis et al,2008). Lower back pain is a neuro-musculoskeletal disorder of the lumbar region caused by inflammation and/ or mechanical strain. It can originate from vertebral zygopophyseal joints, disc, muscles, ligaments and neural tissue due to trauma or repetitive strain, leading to degenerative changes of the lumbar spine (Maitland, 1986). Work-related low back pain, is any back pain originating in the context of work and considered clinically to have been probably caused, at least in part, or exacerbated by the claimant's job

(Ajeet,2013). Occupations involving heavy physical work are found to be a significant statistical risk factor in the development of lower back pain (Hartvigsenet al., 2001). Heavy physical work activities can lead to mechanical straining of the lumbar structures if done in an improper ergonomic manner. Mechanical straining of the lumbar structures causes inflammation, and this leads to lower back pain via the activation of the unmyelinated C nociceptors (Johnson, 1997).

Low back pain originating from physical work activities, is significant especially in situations where there is daily lifting of more than ten kilograms (Palmer et al., 2003); excessive hours spent on repetitive actions, (Guo, 2002) and extreme lumbar flexion when doing heavy lifting activities, (Hoogendoornet al., 2000). These actions lead to accumulation of neuromuscular damage and inflammation of the lumbar spinal structures (Williams et al., 2000; Zedkaet al., 1999). 
Texila International Journal of Public Health

Volume 4, Issue 4, Dec 2016

Mining work such as quarrying task is often characterized by very difficult and challenging conditions involving manual material handling, heavy lifting, repetitive movements and tasks, forceful manual-exertion and exposure to whole body or segmental vibration (as a result of work tool handling) that are known to predispose people to work related musculoskeletal disorders (Steiner et al, 1999; Scharf et al, 2001).

Low Back Pain (LBP) being the most common musculoskeletal problem in the work place (Omokhodion and Sanya, 2003), is a major cause of work- related disability (Cunningham et al, 2008), which is associated with major costs in terms of health resource usage, worker disability and absenteeism (Maniadaki and Gray, 2000). LBP has been established as one of the most common reasons for sick leave in the western world (Reiso et al,2003). Furthermore $70-85 \%$ of adults in the general population is believed to experience at least one episode of low back pain at some time during their lives ( Andersson, 1999).

A study by, Lotters and Burdorf (2006) indicated that working class employees in an industry are prone to high incidence of short and long-term sick leave absence due to the high-risk of developing lower back pain. Devereaux (2004) indicated that lower back pain is the second leading cause of absence from work in the United States of America, and accounted for $25 \%$ of all work days lost. The lifetime prevalence for occupation related lower back pain, with each incident lasting for two to more weeks, is $13.8 \%$ in China and $60 \%$ to $90 \%$ in the Unites States of America (Devereaux, 2004). In South Africa, the annual occurrence of occupation related lower back pain has been found to be between $55.7 \%$ and $63.9 \%$, among the employees of two South African steel manufacturing companies (Van Vuurenet al., 2003). Work related low back pain is also prevalent in Nigeria with Aliu and Saidu (2006) reporting 64\% a prevalence rate for

work- related low back pain among stone quarry workers in northern Nigeria while Egwuonwu et al,(2013) reported 78.9\% prevalence rate of work-related low back pain among drivers, mechanics, blasters, crushers and drillers working in a quarry industry in a South Eastern Nigeria.

A global survey indicated that occupation related lower back pain causes a loss of 818,000 disability-adjusted life years annually (Punnettet al., 2005). According to the American College of Occupational and Environmental Medicine (2003), 73\% of the employees with lower back pain, which originated at work, were still absent from work a month after the original onset of the lower back pain symptoms. Absenteeism from work due to occupational induced lower back pain is an expensive health issue, (Murphy et al., 1999; Borenstein, 2000), due to the high compensational medical expenses and disability claims (Fransenet al., 2002; Van Tulder et al, 2000)). Thus, a study by Fransen et al., (2002) indicated that $23.9 \%$ of claimants were still receiving compensational payments for lower back pain three months after their initial assessment.

\section{Epidemiology}

Low back pain (LBP) is neither a disease nor a diagnostic entity of any sort (Ehrlich, 2003). It is a common problem which affects the majority of adults at least once in a life time. It is irksome, of global concern, as common as headache affecting all age groups and races (May, 2001; Hazard, et al, 1996). It is a prevalent musculoskeletal condition, and a common cause of disability especially in its chronic/recurrent state. The majority of LBP episodes resolve spontaneously while a significant minority becomes recurrent and a small percentage remain persistent (Dunn and Croft, 2004).

Reviews of the literature describing LBP point prevalence in the developed world have produced variable estimates of prevalence rates (Loney and straford,1999). In the studies deemed by Looney and Stratford to be methodologically superior, the LBP point prevalence was estimated to be $6.8 \%$ in North America, 12\% in Sweden, 13.7\% in Denmark, 14\% in the United Kingdom, 28.4\% in Canada, and 33\% in Belgium (Loney and straford,1999). Walker et al (2004), estimated the point prevalence of LBP at $25.5 \%$, six-month period prevalence at $64.6 \%$ and lifetime prevalence at $79.2 \%$. The retrospective one-year first incidence of LBP in the sample was $8.0 \%$. These data suggest that LBP is 
common in the Australian population, with four out of five adults experiencing LBP in their life and approximately one in 12 experiencing a new episode of LBP over a 12-month period.

It is estimated that episodes of low back pain, that are frequent or persistent have been reported in $15 \%$ of the United State of America population, with a lifetime prevalence of $65 \%$ to $80 \%$, it is also stated that $28 \%$ of the United State of America industrial population will experience disabling low back pain at some time and $8 \%$ of the entire working population will be disabled in any given year, contributing to $40 \%$ of all lost work days (Lawrence et al, 1998).

In South Africa the annual occurrence of occupational related lower back pain has been found to be between $55.7 \%$ and $63.9 \%$, among the employees of two South African steel manufacturing companies (Van Vuuren et al., 2003). Work related low back pain is also prevalent in Nigeria with Aliu and Saidu (2006) reporting 64\% a prevalence rate for work related low back pain among stone quarry workers in northern Nigeria while Egwuonwu et al,(2013) reported 78.9\% a prevalence rate of work related low back pain among drivers, mechanics, blasters, crushers and drillers working in a quarry industry in a South Eastern Nigeria.

\section{The consequences of work-related lower back pain}

Work-related lower back pain among blue-collar workers leads to many consequences, which affect the employee as well as the employer (Hochanadel et al., 1993, Elders and Burdorf, 2004). These consequences involve loss of productive life years, high medical claims, sick leave, and unemployment (Morken et al., 2003, Punnett et al., 2005, Lotter and Burdorf, 2006.). Morken et al. (2003) and Lotters and Burdorf (2006) looked at the prevalence and prognostic factors of sickness absence among industrial workers. They found that blue-collar workers have a high risk for both short- and long-term sickness absences due to musculoskeletal disorders, which included lower back pain (Lotters and Burdorf, 2006 and Morken et al 2003). Gluck and Oleinick's (1998) survey indicated that the claim rate for lower back pain peaks in men in the 24 to 34 year range. The highest rates are in manual labor occupations. These claim rates give one an insight into the manual workers' need to compensate for lost income due to sick leave, unemployment and/ or disability (Gluck and Oleinick, 1998)

Sick leave and unemployment are indicated in a survey of interviews and literature reviews by Pransky et al. (2002), who found that $60 \%$ of people who suffer with lower back pain lose one week of work per year. Only half of these employees return to their pre-injury job a year after injury and $20 \%$ are unemployed due to their injury (Pransky et al., 2002). Using a logistical regression model the American College of Occupational and Environmental medicine predicted that $73 \%$ of employees, with occupational lower back pain, were unable to resume their work one month after initial assessment. To prevent back pain and its added cost, risk factors need to be identified and subsequently addressed to prevent the high cost, sick leave and unemployment. These risk factors also give one insight into which medical intervention is necessary for the effective management of workrelated lower back pain at minimal medical cost (Harvigsen et al., 2001 Devereaux, 2004

\section{Predisposing factors for development of work-related low back pain}

\section{a. Heavy physical work}

Heavy physical work, heavy lifting, twisting and vibration are significant work-related risk factors (Devereaux, 2004). A cross-sectional and five year prospective study conducted by Harvigsen et al. (2001) indicated that blue-collar workers that are subjected to physical workload, over a five-year period, are prone to lower back pain. A relative lower proportion of workers who do sedentary work, experienced lower back pain, in contrast to a significant proportion of workers who do heavy physical work (Harvigsen et al., 2001). Thus, a sedentary job has a statistically significant protective or neutral effect in relation to lower back pain. In contrast, a heavy physical job constitutes a statistically significant risk factor (Harvigsen et al., 2001). 
Texila International Journal of Public Health

Volume 4, Issue 4, Dec 2016

\section{b. Repetitive activities}

Workers who spend time on both repeated strenuous physical activities and repeated bending, twisting or reaching on a typical job have higher prevalence of lower back pain than those who do not $(\mathrm{p}<0.05)$ (Guo, 2002). There is a significant $(\mathrm{p}<0.05)$ risk to develop lower back pain when the employee is exposed to twisting, bending, sitting, kneeling, squatting, caring load and handling bulky material (van Vuuren et al., 2005). Hoogendoornet al. (2000) states that workers who lift a load of at least 25kg repetitively, (more than 15 times per working day), fall at risk of developing lower back pain.

\section{c. Vibration and lifting}

Palmer et al. (2003) investigated whole body vibration and occupational lifting as potential risk factors for lower back pain. Significant associations were found at work between daily lifting of weights greater than $10 \mathrm{~kg}$ (Palmer et al., 2003). There is, however, little relevance to the exposure and amount of vibration, during driving of industrial vehicles. Fransen et al. (2002)'s study, in which borderline significance, $(\mathrm{p}<0.05$, OR: 1,6$)$ was found for vibration during driving, confirms the above finding. Job requirement of lifting for three-quarters of the day or more, has been found to be a significant, independent determinant for chronicity of lower back pain, $\mathrm{p}<0.05$. (Fransen et al., 2002). In addition, carrying a load, handling bulky material, kneeling and squatting when doing any lifting activity. Among South African industrial workers, are significant risk factors for lower back pain (van Vuuren et al., 2005). Lifting thus seems to be a major risk factor for the development of lower back pain.

\section{Economic burden of low back pain}

The economic burden of a disease is the sum of all costs associated with that condition which would not otherwise be incurred if that disease did not exist. (Dagenais $S$ et al 2008)

However, given the many categories of costs that must be considered (direct, indirect and intangible), it could be challenging to fully estimate the economic burden of an illness as data is often not available. Intangible costs are rarely included when estimating the economic burden of any illness because of the general societal uneasiness about placing a monetary value on these aspects of a disease. LBP is a costly condition to the society in terms of work absenteeism, health care utilization, and disability benefits. Previous estimates of the total annual cost of LBP in the United States have ranged from \$20-\$50billion. According to Katz (2006), the direct and indirect costs of low back pain, are estimated at $\$ 60$ billion annually in the United States.

A closer evaluation of the economic burden of LBP reveals that it is the commonest reason for activity limitations in individuals under the age of 45 , the second most common complaint heard in physician's offices,(Lively 2002), the third leading cause for surgery, and the fifth most common cause for hospitalization (Deyo 1996). Hemmila found that about one-third of the direct costs (health care utilization) of LBP were spent on complementary therapies and that sick leaves accounted for $55 \%$ of the total cost. (Krishnaney et al 2007, Hemmilä 2002). LBP is the most expensive benign condition in industrialized countries and it is the number one cause of disability that affects people less than 45 years. For those older than 45 years, it is the third leading cause of disability. It results in significant restrictions on activities of daily living and participation, such as inability to work (Gatchel et al 1995). Furthermore, the economic and societal impact of LBP appears to be huge. Individuals with LBP incur millions of dollars in medical expenditure each year in the United States (Katz 2006)

This economic burden is of particular concern in developing countries where there are already limitations in health care delivery and funds are directed towards epidemics such as human immunodeficiency virus/Acquired Immune Deficiency syndrome.(Walker et al 2004 


\section{Methodology}

\section{Study area}

Federal Medical Centre, Owo is located in the Owo Local Government Area of Ondo State in Nigeria. The hospital provides health care services at the primary, secondary and tertiary levels to the people within its catchment areas which are Ondo, Kogi, Edo, Ekiti and Osun States and its surrounding States. It also receives patients from all states of the Federation because it is situated a stone's throw from the highway that links Abuja to Lagos. It is also an approved training centre by both the West African Postgraduate College and National Postgraduate College to train Resident Doctors in some specialist area of Medicine. It is a 250 bed tertiary health centre with average monthly attendance, by all groups, at the outpatient department put at 5,200 and the bed occupancy not less than $80 \%$ at every point in time.

\section{Study population}

The target population in this study was the quarry workers who have developed a clinically confirmed mechanical low back pain. They are people who are known active workers of any of the surrounding quarries in the Owo community. Both male and female quarry workers with LBP, and are attending Physiotherapy outpatient clinic at Federal Medical Centre, Owo, participated in the study.

\section{Sampling procedure}

The sampling procedure employed in the study is a purposive (non-probability) sampling method. The orthopedic clinic days, during which LBP cases are also treated, are Wednesdays and Fridays. Quarry workers who are LBP patients attending Physiotherapy outpatient clinic are recruited as they come to clinic for a period of four weeks (eight clinic days). The total number of patients recruited during this period was forty (40).

\section{Study design and method of data collection}

This is a cross sectional descriptive survey study. Data on the economic burden of LBP and sociodemographic information of participants were collected using a self-developed questionnaire. The questionnaire used was reviewed by the research experts, and their inputs were incorporated in the final questionnaire used in the collection of data.

\section{Data analysis}

Data analysis was done using the Statistical package for Social Science (SPSS) version 17. Data was analyzed using descriptive statistics of proportions, percentages mean and standard deviations.

\section{Inclusion criteria}

The inclusion criteria for this study include

1. Male and female quarry workers

2. Quarry workers with mechanical low back pain, and are attending Physiotherapy outpatient clinic at Federal Medical Centre Owo.

\section{Exclusion criteria}

The exclusion criteria were

1. All other patients with LBP, attending Physiotherapy outpatient clinic but are not quarry workers.

2. Quarry workers with LBP, managing other ailments apart from LBP at out-patient Physiotherapy clinic. 


\section{Ethical considerations}

\section{Consent}

An approval to conduct the study was obtained from Health Research Ethics Committee of Federal Medical Centre, Owo. Participants in the study were informed in writing about the study. They were also guaranteed the confidentiality of whatever information given by them in the study tool. A statement of informed consent was clearly written on the questionnaire, which was signed by the respondent before filling the questionnaire.

\section{Beneficence}

Findings will be communicated to the host management and state ministry of health. Advocacy efforts will be instituted at the policy formulation and stakeholders' level.

\section{Non-Malficence to the participants}

No harm of any kind was done to participants as a result of this study

\section{Presentation of results}

A total of forty quarry workers with Low Back Pain receiving physiotherapy at the Federal Medical Centre, Owo, Ondo State, Nigeria, participated in this cross-sectional study. The majority $(70 \%)$ of the participants were male. The age group of participants ranged from 20 to 50 years. A large percentage (62.5\%) of the participants were between twenty and thirty years old (table 1). Respondents with primary education accounted for the highest $(40 \%)$ number of respondents. The majority (75\%) of the participants were married.

Table 1. Socio-Demographic Characteristics of Participants

\begin{tabular}{|l|l|l|}
\hline CHARACTERISTICS & $\begin{array}{l}\text { NUMBER } \\
(\mathrm{N})\end{array}$ & PERCENTAGE (\%) \\
\hline SEX & 28 & 70 \\
\hline Male & 12 & 30 \\
\hline Female & 25 & 62.5 \\
\hline AGE GROUP (YEARS) & \multicolumn{2}{|l|}{} \\
\hline $20-30$ & 10 & 25 \\
\hline $31-40$ & 5 & 12.5 \\
\hline $41-50$ & 30 & 75 \\
\hline MARITAL STATUS & 7 & 17.5 \\
\hline Married & 2 & 5 \\
\hline Single & 1 & 2.5 \\
\hline Widowed & 2 & 5 \\
\hline Co-habiting & 8 & 20 \\
\hline LEVEL OF EDUCATION & 14 & 35 \\
\hline University & 16 & 40 \\
\hline Post-Secondary & \multicolumn{1}{|l}{} \\
\hline Secondary &
\end{tabular}

From the table 1 above, 28 (70\%) of the participants were male, majority, 25 (62.5\%) were between ages 20-30. Thirty (75\%) were married while 16 (40\%) had primary education. 
Table 2. Direct cost of care of low back pain of quarry workers

\begin{tabular}{|c|c|c|c|}
\hline VARIABLES & MEAN (Naira) & $\begin{array}{l}\text { Standard } \\
\text { Deviation-SD } \\
\text { (Naira) }\end{array}$ & PERCENTAGE (\%) \\
\hline \multicolumn{4}{|l|}{ Physician visit } \\
\hline Male (M) & 29169.6 & 13254.25 & \\
\hline Female (F) & 23408 & 13057.05 & \\
\hline & & & 23.56 \\
\hline \multicolumn{4}{|l|}{ Physiotherapy } \\
\hline M & 75426 & 68875.2 & \\
\hline F & 86344 & 62650.55 & \\
\hline \multirow{2}{*}{\multicolumn{4}{|c|}{ Diagnostic tests }} \\
\hline & & & \\
\hline$M$ & 3782 & 1521.85 & \\
\hline $\mathrm{F}$ & 2893.33 & 787.6 & \\
\hline \multirow{2}{*}{\multicolumn{4}{|c|}{ Topical creams }} \\
\hline & & & \\
\hline $\mathrm{M}$ & 7488 & 2661.5 & \\
\hline $\mathrm{F}$ & 7160 & 2627.62 & \\
\hline \multirow{2}{*}{\multicolumn{3}{|c|}{ Supportive devices }} & 6.4 \\
\hline & & & \\
\hline $\mathrm{M}$ & 3500 & 0 & \\
\hline \multirow[t]{2}{*}{$F$} & 3750 & 353.55 & \\
\hline & & & 3.12 \\
\hline \multicolumn{4}{|l|}{ Medication } \\
\hline $\mathrm{M}$ & 0 & 0 & \\
\hline $\mathrm{F}$ & 2796.33 & 903.7 & \\
\hline & 0.92 \\
\hline TOTAL & 114661.25 & 74230.53 & 100 \\
\hline
\end{tabular}

From the table 2 above, among the direct cost, the cost of Physiotherapy represents the highest cost (63\%), followed by the cost expended on Physician visit (23.56\%) while the cost of diagnostic tests represents the lowest (3\%).

Table 3. Indirect cost of low back pain of quarry workers

\begin{tabular}{|l|l|l|l|}
\hline VARIABLES & MEAN (Naira) & SD (Naira) & $\begin{array}{l}\text { PERCENTAG } \\
\text { E }(\%)\end{array}$ \\
\hline TRANSPORTATION & 17772 & 13526.12 & 23.9 \\
\hline $\begin{array}{l}\text { ACCOMPANYING } \\
\text { PERSON }\end{array}$ & 12938.18 & 9331.78 & 17.4 \\
\hline MEALS OUTSIDE HOME & 9738.46 & 4850.69 & 13.0 \\
\hline PAID HELP & 34000 & 19287.3 & 45.7 \\
\hline TOTAL & 74448.64 & 46995.89 & 100 \\
\hline
\end{tabular}

In the table 3 above, among the indirect cost, the expenditure on paid help, 34000 naira (45.7\%) is the highest, while that of meals 9738.46 (13.0\%) outside home is the lowest. 
Texila International Journal of Public Health

Volume 4, Issue 4, Dec 2016

Table 4. Economic cost of low back pain among quarry workers

\begin{tabular}{|l|l|l|l|}
\hline ECONOMIC COST & MEAN & SD & PERCENTAGE (\%) \\
\hline DIRECT & 114661.25 & 74230.53 & 60.6 \\
\hline INDIRECT & 74448.64 & 16837.13 & 39.4 \\
\hline TOTAL & 189109.89 & 91067.66 & 100 \\
\hline
\end{tabular}

Table 4 above, shows the cost distribution of LBP (direct cost, and indirect cost) of quarry workers. It reveals that the direct cost of low back pain among quarry workers $(60.6 \%)$ forms the bulk of expenses of the management of low back pain by quarry workers.

\section{Discussion recommendation and conclusion}

\section{Discussion}

The economic burden of a disease is the summary of all costs associated with that condition. This means that the burden of a disease cannot be obtained if that condition does not occur in the first place. The categories of costs incurred on any condition include direct cost, indirect cost and intangible cost. However, in this study, the direct and indirect costs of care were summed up as the economic burden. This study revealed a huge average annual economic cost of care relative to the earning capacity of an average Nigerian. Due to the dearth of documented data on economic burden of low back pain in Nigeria, comparison is only possible with other parts of the world. The findings of Katz 2006, and William etal 2009, that indirect costs contribute $85 \%$ of the total costs of LBP does not support the findings of this study. In this study, indirect cost contributed $39.4 \%$. This may be as a result of the fact that the majority of the participants bore all the expenses of the direct and indirect costs unlike what obtains in developed countries where healthcare is borne mainly by the government and insurance companies. No single participant of this study was covered by any health insurance institution.

The ratio of direct costs to indirect costs of care obtained from this study (3:2) is analogous to the previous studies' findings of Finnish (Dagenais S et al, 2008, Shekelle PG et al, 1998 and Katz 2006) reported in 2002, in which almost one third of the direct back pain costs in health care utilization was spent on complementary therapies and sick leaves which accounted for $55 \%$ of the total costs. According to this study, Physiotherapy visit (63\%) was responsible for most of the direct cost incurred on low back pain by the quarry workers, followed by the physician visit (23.56\%). This finding is similar to the findings in Lafuma et al (1998) where physical therapy contributed the most (41.6\%) of the direct cost of care followed by physicians' fees (23.9\%).

Indirect costs include lost earnings and productivity of both patients and the family members who take care of them. Some diseases like cancer and hemorrhagic strokemay result in premature death. In this case, the indirect cost (according to human capital approach) is the loss in potential future earnings. In this study, indirect cost of care included the cost of transportation to keep appointments, cost of transportation of the accompanied person, cost of meals outside the house, and the cost of paid help. The estimate of indirect cost obtained from this study could be limited by the fact that only a minority of the participants (quarry workers with LBP) expended cost on meals for accompanied persons, paid help and had meals outside the house. A closer evaluation of the economic burden of LBP reveals that it is the most common reason for activity limitation in individuals under the age of 45(Lively, 2002). LBP is the most expensive benign condition in industrialized countries and it is the number one cause of disability that affects people less than 45 years and for those older than 45 years, it is the third leading cause of disability. It results in significant restriction on activities of daily living and on participation, such as inability to work (Gatchel 1995). 


\section{Recommendations}

Following the findings of this study, the following recommendations were given

1. Policy formulation on how to alleviate the economic burden of occupational ailments associated with risky jobs should be considered in Nigeria and possibly, in other developing countries.

2. It is pertinent for other interested researchers to carry out more studies in order to explore the economic implications of LBP on a larger population.

3. The tentacle of research in this direction should be extended to other risky occupations, apart from quarrying, that can be associated with Low Back Pain.

4. The other possible factors that can be responsible for the Low Back Pain of the workers should be taken into consideration in the sub-sequent researches.

\section{Conclusion}

This study has revealed a considerable direct and indirect costs incurred by quarry workers with Low Back Pain in a tertiary health institution in Nigeria. The direct cost outweighs that of the indirect cost, and among the direct costs, the Physiotherapy visit was ranked the highest, while paid help ranked the highest among the indirect costs. The findings in this study confirm the popularity of outof-pocket expenses on health care in developing countries like Nigeria. The continuation of this trend will continually subject the citizens of the developing nations to poverty associated with the direct and indirect cost of assessing the health care for various ailments. This ugly situation then calls for attention from all and sundry, if the actualization of Universal Health Coverage (UHC) will be a thing of reality in low income countries. The proper integration of Social Health Insurance (SHI) and Community Based Health Insurance (CBHI) into all categories of the citizens of low income countries will go a long way to help in achieving this much desired goal of UHC, and there will be relief of economic burden associated with health care, especially for this category of workers involved in environmentally/occupationally risky jobs.

\section{References}

[1]. Ajeet Jaiswal (2013): Low Back Pain and Work-Related Risk Factors among Drivers of Pondicherry. International Journal of Scientific Footprints ; 1(2): 7-16

[2]. Aliu and Saidu;(2006): Occupational hazards and safety measures among stone quarry workers in northern Nigeria shows Nigeria Medical Practitioner vol 50(2);pp42-47

[3]. American college of occupational and environmental medicine. Sessions 2301 (2003): Current research in occupational and environmental medicine.771-77

[4]. Andersson GB (1999): Epidemiological features of chronic low-back pain. Lancet 1999;354:581-5

[5]. Andrade SC, Araújo AG, Vilar MJ (2005): Escola de Coluna: revisãohistórica e suaaplicaçãonalombalgiacrônica. Rev Bras Reumatol,45(4):224-248.

[6]. Araoye M O (2003): Subject selection and sample size determination: Research methodology with statistics for health and social sciences. $1^{\text {st }}$ ed. Nathadexpublishers. ilorin, Nigeria. pp;115-129

[7]. Borenstein D (2000): Epidemiology, etiology, diagnostic evaluation, and treatment of low back pain. Current opinion in orthopedics, 11(3): 225-231

[8]. Cunningham C., Doody C. and Blake C. (2008): Managing low back pain: knowledge and attitude of hospital manager. Journal of Occupational Medicine 258:282-288

[9]. Dagenais S (2008): A systematic review of low back pain cost of illness studies in the United States and internationally Spine; 8:8-20.

[10]. Daniele TatianeLizier, Marcelo Vaz Perez, RiokoKimikoSakat (2012) Exercises for Treatment of Nonspecific Low Back Pain RevistaBrasileira de Anestesiologia Vol. 62, No 6, November-December

[11]. Danneels LA, Vanderstraeten GG, Cambier DC, Witvrouw EE, Cuyper HJD (2000) Computed tomography of trunk muscles in chronic low back patients and healthy control subjects. Eur Spine J;9:266-72.

[12]. Devereaux M W. (2004) Low back pain. Primary care, Clinics in office practice. 31(1) 65-70 
Texila International Journal of Public Health

Volume 4, Issue 4, Dec 2016

[13]. Deyo RA (1996) Low back pain. A primary care challenge. Spine; 21(24): 2826-2832.

[14]. Deyo RA, Battie M, Beurskens AJ, Bombardier C, Croft P, Koes B, Malmivaara A, Roland M, VonKorff M, Waddell G. (1998): Outcome measures for low back pain research. A proposal for standardized use. Spine ;23:2003-13.

[15]. Deyo RA, Rainville J, Kent DL (1992) What can the history and physical examination tell us about low back pain? Jama ;268(6):760-765.

[16]. Deyo, R. and Phillips W. (1996): Low back pain: A primary care challenge. Spine 21:2826-32.

[17]. Egwuonwu V.A, Abidemi T B, Aiyejunsunle C B, Ezeukwu O A, Auwal A, C Okoye C E.(2013) A CrossSectional Survey Of Work Related Musculoskeletal Disorders Prevalence And Associated Risk Factors Among Quarry Workers In A South Eastern Nigerian Community. The Internet Journal of Epidemiology, Volume 11 Number 2.

[18]. Ehrlich GE. (2003): Low back pain. Bulletin of the World Health Organization, 81 (9): 671-676.

[19]. Ferreiro F, Moore T, Fredericson M. (2008): Core stability exercise principles. Curr. Sports Med. Rep., Vol. 7, No. 1, pp. 39Y44.

[20]. Frank JW, Kerr MS, Brooker AS (1996) Disability resulting from occupational low back pain. Spine ; 21:2909-17.

[21]. Fransen M, Woodward M, Norton R, Coggan C, Dawe M, Sheridan N. (2002) Risk factors associated with the transition from acute to chronic occupational back pain. Spine, 27(1): 92-98

[22]. Gatchel RJ, Plantin PB, Mayer TG. (1995): The dominant role of psychosocial risk factors in the development of chronic low back pain disability. Spine; 20: 2702-2709.

[23]. Hartvigsen J, Leboeuf YC, Lings S, Corder EH. (2000) Is sitting-while-at-work associated with low back pain? A systematic critical literature review. Scand J Public Health; 28(3):230-239.

[24]. Hartvigsen, J, Bakketeig, L, Leboeuf-Yde, C, Engberg, Lauritzen, T. (2001) The association between physical workload and low back pain clouded by "Healthy

[25]. Hazard, R.G. (1996): Chronic low back pain and disability. The efficacy of functional restoration. Bulletin of Hospital Joint Disease, 55, 213-6.

[26]. Hoogendoorn, W, Bongers, P, De Vet, H, Douwes, M, Koes, B, Miedema M. (2000): Flexion and rotation of the trunk and lifting at work are risk factors for low back pain: results of a prospective cohort study. Spine, 25(23): 3087-3092

[27]. Huppe A, Muller K, Raspe H (2007): Is the occurrence of back pain in Germany decreasing? European Journal of the Public Health; 17(3): 318-322.

[28]. Ihleback C, Eriksen. (2003): Are the myths of low back pain alive in general Norwegian Population? Scand J Public Health; 31: 395-398.

[29]. Jette, A.M., Smith K., Haley S. and Davis K.D. (1994) Physical therapy episode of care for patients with low back pain. Physical Therapy 74; 101- 115.

[30]. Johnson M I. (1997) The Physiology of sensory dimensions of clinical pain. hysiotherapy83 (10): 526-536

[31]. Katz JN. (2006): Lumbar disc disorders and low-back pain: socioeconomic factors and consequences. Journal of Rheumatic Diseases; 88(2): 21-40. 11.

[32]. Kovac F.M., Muriel A., Medina J.M., Abraira V., Sanchez M.D.C., Jauregi J.O. and the Spanish Back Pain Research Network. (2006). Psychometric characteristics of the Spanish version of the FAB questionnaire. Spine 31: 104-110.

[33]. Kovacs FM, Abria V, Povo F, Heinbaun DG (1997). Local and Remote Sustained Trigger Therapy for exacerbation of Chronic Back Pain. Spine; 22(7) 788-797.

[34]. Krismer M, van Tulder M. (2007) Strategies for prevention and management of musculoskeletal conditions. Low back pain (non-specific). Best Pract Res ClinRheumatol, 2007;21:77-91.

[35]. Lafuma A, Fagnani F, Vautravers P. (1998): Management and cost of care for low back pain in primary care settings in France. Pharmaco Economic;14(3): 313-22.

[36]. Lawrence RC, Helmick CG, Arnett FC. (1998) Estimates of the prevalence of arthritis and selected musculoskeletal disorders in the United States. Arthritis \& Rheumatism 41:778-799. 
[37]. Lee P, Helewa A, Goldsmith CH, Smythe HA, Stitt LW. (2001): Low back pain: prevalence and risk factors in an industrial setting. J Rheumatol ; 28(2):346-351

[38]. Lively MW (2002): Sports medicine approach to low back pain. Spine; 95(6): 642-648.

[39]. Loney P, Stratford P, (1999): The prevalence of low back pain in adults: A methodological review of the literature. Physical Therapy 79(4):384-396.

[40]. Lotters F, Burdorf A. (2006): Prognostic factors for duration of sickness absence due to musculoskeletal disorders. Clinical Journal of Pain, February 22 (2): 212-221

[41]. Lu JLP. (2003): Risk factors for low back pain among Filipino manufacturing workers and their anthropometric measurements. ApplOccup Environ Hyg, 18(3):170-176.

[42]. Maitland G D. (1986) Vertebral Manipulation, fifth edition, Butterworths\& Co publishers, 119-128

[43]. Maniadakis, N. and A. Gray. (2000): The economic burden of back pain in the UK. Pain 84:95-103.

[44]. May, S.J. (2001): Patient satisfaction with management of back pain (Part 1). Physiotherapy, Hochanadel

C D, Conrad D E. 1993. Evolution of an on-site industrial physical therapy program, JOM 35(10), October: 1011-1016

[45]. Murphy, P, Volinn, E. (1999): Is occupational low back pain on the rise? Spine, 24(7): 691-697

[46]. Omokhodion FO, Sanya AO (2003) Risk factors for low back pain in office workers. Journal of Occupational Medicine; 53:287-289.

[47]. Omokhodion FO, Umar US, Ogunnowo BE (2000): Low Back Pain in a Nigerian University Journal of Occupational Medicine; 53: 287-289.

[48]. Omokhodion, F.O. and Sanya A.O. (2003): Risk factors for low back pain in the office workers. Journal of Occupational Medicine 53: 287-289.

[49]. Palmer K T, Griffin M J, Syddall H E, Pannett B, Cooper C and Coggon D. (2000): The relative importance of whole body vibration and occupational lifting as risk factors for low-back pain. Occupational and Environmental Medicine, 60: 715-721

[50]. Riihimäki H. (1991): Low-back pain, its origin and risk indicators. Scand J Work Environ Health ; 17:8190.

[51]. Scharf T, Vaught C, Kidd P, Steiner L, Kowalski K, Wiehagen W, Rethi L, Cole H: (2001): Toward a typology of dynamic and hazardous work environments. Human and Ecological Risk Assessment;7(7): 18271841.

[52]. Shekelle PG, Coulter I, Hurwitz EL, Genovese B, Adams AH, Mior SA, Brook RH. (1998): Congruence between decisions to initiate chiropractic spinal manipulation for low back pain and appropriateness criteria in North America. Ann Intern Med.; 129: 9-17.

[53]. Van Middelkoop M, Rubinstein SM, Verhagen AP et al. (2010) Exercise therapy for chronic nonspecific low-back pain. Best Pract Res ClinRheumatol; 24(2):193-204

[54]. Van Tulder, Becker A (2006). European guidelines for the management of acute nonspecific low back pain in primary care. European Spine Journal ; 15(2): S169-S191.

[55]. van Tulder, M.W.; Becker, A.; Bekkering, T.; Breen, A.; Teresa, M.; del Real, G.; Hutchinson, A.; Koes B.; Laerum, E.; Malmivaara, A. (2009): European guidelines for the management of acute nonspecific low back pain in primary care on behalf of the cost B13 Working Group on Guidelines for the Management of Acute Low BackPain in Primary Care.

[56]. Van Vuuren B J, Becker P J, van Heerden H J, Zinzen E, Meeusen R. (2005): Lower back problems and occupational risk factors in a South African steel industry. American Journal of Internal Medicine, May 47 (5): 451-457

[57]. Van Vuuren B, van Heerden J, Bekker P, Zinzin E, Meeusen R. (2003): Lower back problems among workers at two industrial sites in South Africa. Medicine \& Science in Sports and Exercise 35(5) Supplement 1, May, S334

[58]. Waddell G. (1998) The Back Pain Revolution. Edinburgh: Churchill Livingstone.

[59]. Walker BF, Muller R, Grant WD (2004): Low back pain in Australian adults. Prevalence and associated disability. Journal of Manipulative \& Physiological Therapeutics 27(4):238-244. 
Texila International Journal of Public Health

Volume 4, Issue 4, Dec 2016

[60]. William JH, Money JK, Kristina SB. (2009): Implications for physical activity in the population with low back pain. American Journal of Lifestyle and Medicine 2009; 3(1): 63-70.

[61]. Williams M, Solomonow M, Zhou B, Baratta R V, Harris M. (2000): Multifidis spasm elicited by prolonged lumbar flexion. Spine, 25(22), 15 November, 2916-2924

[62]. Worker" effect: Population-base cross-sectional and 5-year prospective questionnaire study. Spine, 26 (16): 1788-1792

[63]. Zedka M, Prochazka A, Knight B, Gillard D, Gauthier M. (1999): Voluntary and reflex control of human back muscles induced pain. The Journal of Physiology, 20(2), 591-604 


\title{
The Prevalence, Risk Factors and Treatment Methods for Tungiasis among Residents of Musokoto Sub-Location, in Kenya
}

\author{
Article by Ngetich Albert ${ }^{1}$, Kirorei Kiprotich ${ }^{2}$ \\ Ph.D. in Public Health, Texila American University, Kenya \\ E-mail: ngetichalbert@yahoo.com
}

\begin{abstract}
Tungiasis is a parasitic skin disease caused by sand flea Tunga penetrans. In Kenya, little data has been published regarding tungiasis. In Nambale health centre, tungiasis accounted for $4 \%$ of total morbidities. Therefore this study sought to assess the prevalence of, risk factors and treatment methods for tungiasis among residents of Musokoto, in Kenya. Purposive sampling method was used. Logistic regression was used to determine the risks factors associated with tungiasis. A total 1557 participant from 333 randomly selected households took part in the study. Of the 1557 participants, a total of 441(28.3\%) at least had jiggers at one point in their life. Out of the 441, 287(65\%) were confirmed to have jiggers on examination whereas $9(2 \%)$ did not have jigger by the time of the study. Toes on the extreme sites were more infested however the distribution of infestation was moral less the same for the all toes. Above $50 \%$ of those infested were aged 10 years and below. Logistical regression analysis revealed that place of sleeping $(P<0.001, O R=1.319, C I=1.180-1.474)$ significantly influenced jiggers infestation. The type of floor of the house $(P=0.036, O R=$ 3.608, CI $=1.089$ - 11.955) was also found to significantly influence jiggers infestation. Source of water was more likely to influence jigger infestation $(P=0.001, O R=2.050, C I=$ 1.334 - 3.150). The results are essential for community, local Public Health Officers, national and international public health agencies for interventions aimed at controlling jigger's infestation.
\end{abstract}

Keywords: Tunga penetran, Tungiasis, Ectoparasitosis and Fecundation.

\section{Introduction}

Tungiasis is a parasitic skin disease caused by female sand flea Tunga penetran, which burrows into the skin usually, on the feet (Collins et al., 2009). It is also a neglected public health problem in endemic areas in Latin America, the Caribbean and Africa, and causes considerable morbidity in the affected communities. Ugbomoiko et al., 2007 stated that, despite its notoriety tungiasis is not regarded a serious health problem of which this is a misconception.

This flea lives in the soil or sand and feeds intermittently on hosts such as humans, domestic animals such as cattle, sheep, pigs, chickens, dogs, mice and wild animals. The preferred habitats of Tunga penetrans are warm, dry environments with sandy soil and dust (Sanusi et al., 1989; Winter et al., 2009). They enter human hosts through penetration in the skin. The ectoparasitosis is associated with poverty and occurs in many resource-poor communities in the Caribbean, South America and Africa and these communities prevalence may be as high as $50 \%$ in the general population. (Feldmeier et al., 2004).

Tunga penetrans is known to cause significant debilitation in areas of deprived resources and infrastructure. The jigger flea is the smallest known flea, measuring less than $1 \mathrm{~mm}$ in length (Feldmeier et al., 2004). After entering its host (both humans and domesticated animals), the gravid female flea undergoes substantial growth, growing to around 2000 times its size (640 um) in six days.

The sand flea became known to the Spaniards not long after Christopher Columbus had landed at the American continent in 1492 and was probably inadvertently introduced into Angola in the $17^{\text {th }}$ till $19^{\text {th }}$ century by ship, subsequently spreading all over Africa, Pakistan 
Texila International Journal of Public Health

Volume 4, Issue 4, Dec 2016

and West India along the trade routes and by expeditions (Heemskerk et al., 2005). Although endemic in tropical America, Africa and West India, knowledge of this infection is rare in Europe and Northern America. The sand flea originally occurred only on the American continent and the Caribbean Islands, but spread in the late $19^{\text {th }}$ century throughout subSaharan Africa and to Madagascar (Hoeppli, 1963); (Heukelbach, 2004)). Two recent studies from Nigeria and Cameroon indicate that still today tungiasis is a major public health problem in West Africa (Njeumi et al., 2002). A study conducted in Northwest Cameroon by Collin et al., 2009) showed that out of 1,151 individuals that were examined, 610 individuals (53\%) were infested with Tunga penetrans with the prevalence highest in children, diminishing in adults and then increasing again in the elderly.

Ahadi Kenya Trust, an organization that works in Kenya to eradicate the jigger flea, estimates that the jigger flea may infect over 2.6 million Kenyans. Many people have been suffering from jigger infestation in silence. No comprehensive survey has been carried out, making it difficult to give actual number of those affected (Ahadi Trust, 2010).

Studies done in Muranga and Uasin Gishu by Njau et al., (2012) and Choge et al., (2006) respectively showed that prevalence in those districts among children 5-14 years was 67\% and $21 \%$ respectively. Further interventional studies carried out in neighboring Emuhaya constituency revealed that 39\% of Ematsuli primary school had tungiasis. Majority of the children walked barefooted to school increasing the risk of infestation (BDSP, 2010). Prevalence in the hospital was reported to be $4 \%$ of the total morbidities. However, the prevalence of tungiasis is uncertain in the entire Musokoto community and other adjacent locations. Therefore the study sought to establish the prevalence of Tungiasis in the location.

Despite its notoriety, the jigger flea is not regarded as a serious threat to health (Ugbomoiko et al., 2007). Unfortunately this is a common misconception. Tungiasis results in significant morbidity, manifesting itself in a number of symptoms such as severe local inflammation, auto-amputation of digits, deformation and loss of nails, formation of fissures and ulcers, gangrene and walking difficulties. Secondary infection also poses considerable risk; many lacking immunisation are vulnerable to tetanus (Clostridium tetani), often proving fatal. Complaints of insomnia are also common due to the intolerable itchiness of the infestation (Muehlen et al., 2006).

Muenhlen et al., (2006) states that the common factors that are seen to aggravate tungiasis include poor housing conditions, lack of water, poor hygiene and wearing open shoes. He further revealed that viable prevention and intervention methods for combating the disease include paving of public areas and house floors and the use of closed shoes when feet touch contaminated soil. While shoes could serve well in reducing invasion of the Tunga penetrans, the problem here lies in affordability. Given that where tungiasis prevails the population is poor, shoes may not be seen as a priority. A probable intervention could be regular inspection of feet and immediate extraction of embedded fleas with subsequent disinfection of the lesion to protect against infections (Wachira, 2012).

In the past few years, the public health importance of tungiasis in resource-poor populations has been highlighted from different countries, including Brazil, Argentina, Haiti and Nigeria (Joseph et al., 2006). Pilger et al. (2008) argues that tungiasis is much more prevalent in communities who usually wear flip - flop (slippers) and often sleep on dirty floors. The challenges with the term dirty floor that Pilger and colleagues, (2008) did not clarify the meaning of dirty floors. However, risk factors for infestation have only been addressed in a single study from Brazil (Muehlen et al., 2006) nevertheless sustainable intervention measures have never been assessed systematically. In Kenya, a study done in Muranga by Njau et al., (2012) concluded that the risk factors for tungiasis in the area were walking barefoot, keeping domesticated animals especially pigs and dogs and living in mad build houses. No risk factor studies have been conducted in the neighboring location of Musokoto.

Ahadi Trust (2010) outlines the treatment of tungiasis through washing of affected areas with soap and water, dry the cleaned areas, soaking the affected areas with potassium 
permanganate or disinfect with savlon solution for 15 minutes, then application of petroleum jelly to the affected area. A clinical trial study by Heukelbach, (2002) shows that ivermectin 200mg tablets are effective in treatment of tungiasis for a period of two weeks. However, due to the zoonotic aspect of Tungiasis, control of affected communities is much more complicated and challenging than in other ectoparasites associated with poverty, such as scabies and pediculosis, which do not have animal hosts (Heukelbach et al., 2004). Domesticated animals such as dogs, cats, pigs and goats should be treated with available onanimal insecticides, including collars, shampoos and sprays. In addition, environmental insecticides could be used during the early and late stages of the flea to break the life cycle. With the challenge of having virtually non-existent epidemiologic data on tungiasis, control measures can only be planned when the weight of the disease, underlying forces behind the spread and risk factors are better understood (Ugbomoiko, 2007).

At Musokoto most residents have built temporary structures for housing with roofs made of either tin/metal and/or thatched. Floors and walls are smeared with mad or clay, which could be associated with tungiasis infestation. Treatment of tungiasis at Nambale health center is an ongoing process and accounts for $4 \%$ of the total morbidities. The majority of the cases are children and the elderly. The prevalence of tungiasis cases in the outpatient department of Nambale health center serving Musokoto residents is known but the prevalence in the entire community is not yet established. Lack of knowledge on the overall prevalence of tungiasis in Musokoto could deter the government and other stakeholders to put in place interventions that could help in controlling and prevent further cases of tungiasis. Treatment methods and products used by the residents of Musokoto sub-location is still not known. Knowing the treatment methods used by residents of musokoto is critical in as so much that this would highlight whether or not the residents are using effective methods that eventually would put under control tungiasis infestation. Lack of knowledge on the risk factors associated with tungiasis impedes advice measures that could be given to residents of musokoto to enable community led interventions in controlling tungiasis by taking care of such risk factors. Hence this study aims at identifying prevalence of tungiasis infestation, risk factors associated with tungiasis and modes of treatment used by Musokoto residents to treat tungiasis cases.

Epidermal parasitic skin diseases (EPSD) occur worldwide and have been known since ancient times. Despite the considerable burden caused by EPSD, this category of parasitic diseases has been widely neglected by the scientific community and health-care providers (WHO, 2010). Tungiasis has many clinical features of a neglected tropical disease and thus can be considered as a paradigm: it is endemic in poor communities and rural areas, it is associated with stigma, and there are no products in the commercial markets targeting the treatment of the disease (Heukelbach et al., 2001; Molyneux et al., 2005). Despite the fact that the prevalence of tungiasis in Musokoto is $4 \%$ according to the hospital data (BDSP, 2010), the actual prevalence of tungiasis in the entire community of musokoto is not known and so it is important that a study of this nature was carried out to establish the actual prevalence of tungiasis in the entire population.

Tungiasis is a manageable parasitic infestation and the use of proper treatment methods should put tungiasis under control. Nevertheless, the treatment methods used by residents of Musokoto to control tungiasis are uncertain and so it was imperative that an investigation of this nature carried out to establish the treatment methods used by these residents. Sustainability of treatment outcomes depends on several factors including but not limited to household risk factors that could favor persistent tungiasis infestation of Musokoto residents. Knowing of such risk factors would assist in devising appropriate interventions to control tungiasis. It was thus necessary to investigate the risk factors associated with tungiasis infestation among residents of Musokoto sub location. 
Texila International Journal of Public Health

Volume 4, Issue 4, Dec 2016

\section{Methodology}

\section{Study site}

Musokoto sub-location is a region in western Kenya $30 \mathrm{~km}$ to the Busia border between Kenya and Uganda. Its coordinates are $0^{\circ} 26^{\prime} \mathrm{N} 34^{\circ} 9^{\prime} \mathrm{E}$. It borders three sub-locations namely Bukhayo central, Kwilare and Bukhayo East. (BDSP, 2010). The Musokoto sub-location and its villages are governed by assistant chief and village elders respectively. Majority of the population has lived in the area since birth except for migrants working in various organizations/institutions in the little town of Nambale.

The community can be regarded as a typical rural settlement. Majority of the residents live in temporary houses of thatched houses with mud smeared walls and floor. Different weather patterns of dry seasons and rainy seasons occur i.e. January - March dry season and April august are rainy seasons. Economically they depend on agriculture for a living as major source of income through cattle keeping, fishing and farming (majorly maize and beans). Domestic animals (pigs, goats, sheep and dogs) roam around in the villages. There is poor infrastructure of road networks as roads in the division are not tarmac (BDSP, 2010).

The community lacks appropriate urban services like electricity, pipe-borne water and a public sewage system. Open wells, boreholes and the nearby rivers serve as the source of water. It is served by only one major health facility other being dispensaries in other sublocations. The majority of the people walk barefooted, defecates in the surrounding bush and scatter domestic waste in the vicinity of their homes as observed (BDSP, 2010). Its position is as shown in appendix G: study site map.

\section{Study population}

The total population of Musokoto sub-location is 3,335 persons and with 667 households. It is composed of eight villages namely Kaludeka, katomei, logiri, Walatsi, Makutano, Otiri, Musoma and Ongaroi. The Public health officers in the area estimated that the sub-location had frequent cases of tungiasis as reported from the school going children. Nambale division, where Musokoto location is based has poverty levels stand at 64.5 percent hence a high risk factor for tungiasis (BDSP, 2010).

\section{Study design}

A cross sectional study design using mixed data collection method i.e. semi-structured questionnaire for quantitative data and key informant interviews for qualitative data was adopted. Cross sectional design involves observation of all of a population, or a representative subset, at one specific point in time (Groove, 2003).

\section{Sample size determination}

To get the representative sample for the household's population a sample size estimation formula of Yamane was use (Yamane, 1967).

\section{Sampling procedure}

Purposive sampling method was used to select Musokoto sub-location based on the previous reports of tungiasis prevalence from the health center. This is because most treated cases of tungiasis at Nambale health center originated from Musokoto sub-location. The 8 villages in the sub location were used in the study and 333 households were sampled using proportionate systematically random sampling at a sampling interval of 2 .

\section{Data collection}

Before the onset of the study information meetings was held with the community administrative leaders such as chiefs, sub-chief and the village elders at their respective territories. Selection and recruitment of a nurse and 8 community health workers (from respective village) was done. The nurse recruited aided in supervision and collection of data. Community health workers were given codes and identification cards. Training and a pilot 
study was carried out in two of the villages in Kwilare sub-location in the division and 20 households picked at random for piloting. Details shown in table 3.2 below. Validity and reliability was accepted at a reliability co-efficient of 0.70 .

\section{Data collection tools}

Quantitative data collection methods were adopted for the study. During the study, randomly sampled households were visited and members examined for the presence of embedded sand fleas. The pre-tested questionnaire was then applied in English.

\section{Measurement of variables}

The information collected consisted of five categories: (1) socio-demographic factors (such as sex, age, education); (2) housing and associated factors (such as type of construction of the house, type of floor inside house, sanitary conditions, presence of electricity, waste disposal); (3) ownership and presence of domestic animals; (4) clinical and personal effects brought about by Tunga penetrans infestation (5) knowledge, attitudes and practices related to tungiasis (such as knowledge on transmission, regular use of footwear, common resting place, preventive measures, treatment). Children of 6 years and above to provide information directly, while in the other cases information will be obtained from the guardians after their consent. Legal guardians/parents will sign their consents forms. A household was revisited when a family member was absent.

Clinical examination performed by inspecting carefully the legs, feet, hands and arms. To guarantee privacy, other topographical regions of the body not examined. This approach is considered acceptable, as in endemic communities more than $99 \%$ of tungiasis lesions occur on legs, feet, hands and arms (Heukelbach et al., 2002).

During clinical examinations the following findings was considered diagnostic for tungiasis: an itching red-brownish spot with a diameter of 1-3 mm, a circular lesion presenting as a white patch with a diameter of 1-4 mm with a central black dot, black crust surrounded by necrotic tissue, as well as partially or totally removed fleas leaving a characteristic sore in the skin (Eisele et al., 2003). Localization and number of lesions recorded. As defined by Muehlen et al., 2006 the presence of less than 5 lesions considered as mild, of 6-30 as moderate and of more than 30 lesions as heavy infestation. All clinical examinations and interviews was done by a single person, to eliminate inter-observer bias. If a household member is found positive of tungiasis, Servin Dudu dust applied in the living area.

\section{Statistical analysis}

Data was entered using Epi Info software (version 6.04; Centers for Disease Control and Prevention, Atlanta, USA) and checked for entry errors by rechecking all data entries with the original data forms. Then, data was transferred to IBM Statistical package software (version 17.0) for analysis.

Prevalence was determined as percentage of infested individual out of total household population examined for tungiasis. Logistic regression was used to establish the risk factors that affected the jiggers infestation. Bivariate analysis was also carried out to calculate how different combined variables could affect the risks factors.

\section{Ethical considerations}

Permission to perform the study was obtained from Maseno University Graduate studies (SGS) and authorization sought from Maseno university ethics committee. Participation was voluntary after counseling using a participants counseling form and consent by participants was on the basis of participation. Potential risks and benefits were explained in the form.

Confidentiality of the participants assured prior to filling of the questionnaires and all data collected was not shared and stored by only the investigator in his private computer. The 
Texila International Journal of Public Health

Volume 4, Issue 4, Dec 2016

participants explained to about the purpose of the study, its duration and benefits of the research stud and they were given an opportunity to ask questions where need arises.

\section{Results}

\section{Socio-demographic and economic profile of the household members}

\section{Socio-demographic characteristics of the study participants}

A total of 1557 participants randomly selected from 333 households took part in the study. Out of this study participants 768(49.3\%) were males whereas females were 789 (50.7\%). Almost half, 777(49.87\%) were aged 15 years and below, 652(41.87\%) were aged between 16-50 years old and only $128(8.2 \%)$ were more than 50 years old. About two thirds, 927(59.5\%) of the study participants were single; 247(15.9\%) were married with 144(9.2\%) and 239(15.4\%) being separated/divorced and widowed respectively. The details are contained in table 4.1 below.

Table 4.1. Socio-demographic characteristics of the study participants

\begin{tabular}{|c|c|c|}
\hline Variable & & Frequency n(\%) \\
\hline \multicolumn{3}{|l|}{ Gender } \\
\hline Male & & $768(49.3)$ \\
\hline Female & & $789(50.7)$ \\
\hline \multicolumn{3}{|c|}{ Age distribution (years) } \\
\hline $1-5$ & & 300(19.3) \\
\hline $6-10$ & & 285(18.3) \\
\hline $11-15$ & 192(12.3) & \\
\hline $16-20$ & 175(11.2) & \\
\hline $21-25$ & $124(8.0)$ & \\
\hline $26-30$ & $132(8.5)$ & \\
\hline $31-35$ & $75(4.8)$ & \\
\hline $36-40$ & $76(4.9)$ & \\
\hline $45-50$ & $70(4.5)$ & \\
\hline$>50$ & & $128(8.2)$ \\
\hline \multicolumn{3}{|l|}{ Marital status } \\
\hline Single & & $927(59.5)$ \\
\hline Married & & 247(15.9) \\
\hline Separated/divorced & & $144(9.2)$ \\
\hline Widow & & 239(15.4) \\
\hline
\end{tabular}

\section{Socio-economic characteristics of the study participants}

The socio-economic parameters of the study participant that were investigated included level of education, main occupation and religion. Majority of the participants, 1369(87.9\%) had at least completed primary level of education 65(4.2\%) did not complete their primary education, 47(3.0\%) completed their secondary education with 27(1.7\%) not completing secondary education, only $10(0.6 \%)$ had at least tertiary/university education and lastly 40(2.6\%) were illiterate. Approximately a third, 477(30.6\%) of the study participants were students, 300(19.3\%) were considered as under-aged and so were not in any employment, 278(17.9\%) worked as house helps, 223(14.3\%) were farmers, 126(8.1\%) were housewives yet $121(7.8 \%)$, and $7(0.4 \%)$ were traders and civil servants respectively. A paltry 25(1.6\%) were not employed. On religion the study established that 1552(99.7\%) were Christians and only $5(0.5 \%)$ were of the Muslim faith. Table 4.2 is on socio-economic characteristics of the study participants. 
Texila International Journal of Public Health Volume 4, Issue 4, Dec 2016

Table 4.2. Socio-economic characteristics of the study participants

\begin{tabular}{lll}
\hline Variable & & Frequency $\mathbf{n ( \% )}$ \\
\hline $\begin{array}{l}\text { Level of education } \\
\quad \text { Illiterate }\end{array}$ & & $40(2.6)$ \\
$\quad$ Primary complete & $1369(87.9)$ & \\
$\quad$ Primary incomplete & & $65(4.2)$ \\
$\quad$ Secondary complete & & $47(3.0)$ \\
Secondary incomplete & & 26(1.7) \\
Technical/university & & $10(0.6)$ \\
Main occupation & & \\
Under-age & $300(19.3)$ & \\
Farmer & $223(14.3)$ & \\
Trader/town & $121(7.8)$ & \\
House help & $278(17.9)$ & \\
House wife & $126(8.1)$ & \\
Civil servant & $7(0.4)$ & \\
Students & $477(30.6)$ & \\
No work & $25(1.6)$ & \\
Religion & & \\
Christian & $1552(99.7)$ & \\
Muslim & $5(0.3)$ & \\
\hline N = 1557. & & \\
& &
\end{tabular}

\section{Prevalence of tungiasis among residents of Musokoto sub-location.}

Of the 1557 that participated in the study a total of $441(28.3 \%)$ said they at least had jiggers at one point in their life whereas 116(71.7\%) said they never had jiggers. Of the 441 who said they had jiggers, 287(65\%) of them had jiggers on examination whereas $9(2 \%)$ did not have jiggers found on them while $145(33 \%)$ refused to be examined by the nurse. See figure 4.1 .

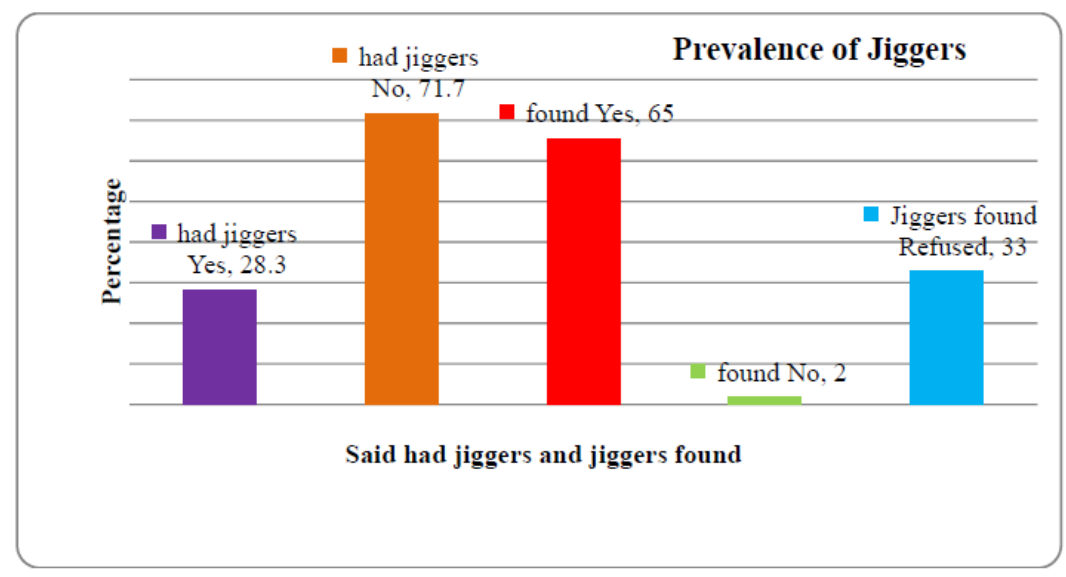

Figure 4.1. Percentage of participants who said they had jiggers and Jiggers were found on screening.

Prevalence of Tungiasis, socio-demographic and economic characteristics of the study participants

The jiggers infestation was significantly influenced by the household size $(\mathrm{P}=0.002$, $\mathrm{OR}=1.424$, $\mathrm{CI}=1.137-1.784)$, occupation $(\mathrm{P}<0.001$, $\mathrm{OR}=1.129$, $\mathrm{CI}=1.085-1.175)$ and education $(\mathrm{P}=0.025, \mathrm{OR}=1.187, \mathrm{CI}=1.021-1.379)$ of the participants. See table 4.3. 
Texila International Journal of Public Health

Volume 4, Issue 4, Dec 2016

Table 4.3. Association between jiggers infestation and socio-demographic and economic factors.

\begin{tabular}{|l|l|l|l|l|l|}
\hline Variable & Df & \multicolumn{1}{c|}{ Sig } & \multicolumn{1}{c|}{ OR } & \multicolumn{2}{c|}{ 95\% C.I } \\
\hline & & & & Lower & Upper \\
\hline Household size & 1 & 0.002 & 1.424 & 1.137 & 1.784 \\
\hline Gender & 1 & 0.738 & 0.963 & 0.772 & 1.201 \\
\hline Age & 1 & $<0.001$ & 0.888 & 0.852 & 0.926 \\
\hline Marital status & 1 & $<0.001$ & 0.749 & 0.672 & 0.837 \\
\hline Occupation & 1 & $<0.001$ & 1.129 & 1.085 & 1.175 \\
\hline Education & 1 & 0.025 & 1.187 & 1.021 & 1.379 \\
\hline
\end{tabular}

\section{Site infested and severity of the infestation}

On assessment on severity of tungiasis it emerged that toes on the extreme sites were more infested even though the distribution of infestation was more or less the same for all the toes. Severity reveals that the first toes were less severely infested as opposed to the fourth and fifth toes in regardless of site of infestation.

Table 4.4. Severity of infestations of the toes

\begin{tabular}{|l|l|l|l|l|}
\hline & \multicolumn{3}{|c|}{$\begin{array}{c}\text { Frequency n(\%) of severity of } \\
\text { infestation of toes }\end{array}$} & \\
\hline Toe infested & \multicolumn{1}{|c|}{ Mild } & Moderate & \multicolumn{1}{|c|}{ Severe } & Total infested n(\%) \\
\hline $1^{\text {st }}$ Left toe & $91(46.2)$ & $74(37.6)$ & $32(16.2)$ & $197(12.80)$ \\
\hline $1^{\text {st }}$ Right toe & $48(52.2)$ & $44(47.8)$ & $0(0.0)$ & $92(5.97)$ \\
\hline $2^{\text {nd }}$ Left toe & $37(20.56)$ & $33(18.33)$ & $110(61.11)$ & $180(11.69)$ \\
\hline $2^{\text {nd }}$ Right toe & $31(20.7)$ & $30(20.0)$ & $89(59.3)$ & $150(9.74)$ \\
\hline $3^{\text {rd }}$ left toe & $20(21.7)$ & $32(34.8)$ & $40(43.5)$ & $92(5.98)$ \\
\hline $3^{\text {rd }}$ Right toe & $23(19.5)$ & $31(26.3)$ & $64(54.2)$ & $118(7.67)$ \\
\hline $4^{\text {th }}$ Left toe & $56(32.2)$ & $21(12.1)$ & $97(55.7)$ & $174(11.30)$ \\
\hline $4^{\text {th }}$ Right toe & $29(18.7)$ & $19(12.3)$ & $107(69.0)$ & $155(10.08)$ \\
\hline $5^{\text {th }}$ Left toe & $83(45.9)$ & $42(23.2)$ & $56(30.9)$ & $181(11.77)$ \\
\hline $5^{\text {th }}$ Right toe & $88(44.0)$ & $49(24.5)$ & $63(31.5)$ & $200(13.00)$ \\
\hline Totals & 506 & 378 & 658 & $1539(100)$ \\
\hline
\end{tabular}

Table 4.5. Pathology of infestations of the toes

\begin{tabular}{|l|l|l|l|l|l|l|}
\hline & \multicolumn{5}{|c|}{ Pathology } \\
\hline & $\begin{array}{c}\text { hypertrop } \\
\text { hic nail } \\
\text { rim }\end{array}$ & Fissure & Ulcer & $\begin{array}{c}\text { deformati } \\
\text { on of nails }\end{array}$ & $\begin{array}{c}\text { loss of } \\
\text { nail }\end{array}$ & $\begin{array}{c}\text { deformati } \\
\text { on of toe }\end{array}$ \\
\hline $\begin{array}{l}1^{\text {st }} \text { Left } \\
\text { toe }\end{array}$ & $7(3.6)$ & $25(12.7)$ & $16(8.1)$ & $33(16.8)$ & $93(47.2)$ & $28(14.2)$ \\
\hline $\begin{array}{l}1^{\text {st }} \text { Right } \\
\text { toe }\end{array}$ & $52(56.5)$ & $27(29.3)$ & $13(14.1)$ & $0(0.0)$ & $0(0.0)$ & $0(0.0)$ \\
\hline $\begin{array}{l}2^{\text {nd }} \text { Left } \\
\text { toe }\end{array}$ & $29(18.6)$ & $22(14.1)$ & $42(26.9)$ & $24(15.4)$ & $21(13.5)$ & $18(11.5)$ \\
\hline $\begin{array}{l}2^{\text {nd }} \text { Right } \\
\text { toe }\end{array}$ & $57(38.0)$ & $33(22.0)$ & $24(16.0)$ & $23(15.3)$ & $10(6.7)$ & $3(2.0)$ \\
\hline
\end{tabular}


Texila International Journal of Public Health Volume 4, Issue 4, Dec 2016

\begin{tabular}{|l|l|l|l|l|l|l|}
\hline $\begin{array}{l}3^{\text {rd }} \text { left } \\
\text { toe }\end{array}$ & $5(5.4)$ & $15(16.3)$ & $22(23.9)$ & $35(38.0)$ & $13(14.1)$ & $2(2.2)$ \\
\hline $\begin{array}{l}3^{\text {rd }} \text { Right } \\
\text { toe }\end{array}$ & $23(19.5)$ & $\begin{array}{l}41.0(34 . \\
7)\end{array}$ & $25(21.2)$ & $15(12.7)$ & $7(5.9)$ & $7(5.9)$ \\
\hline $\begin{array}{l}4^{\text {th }} \text { Left } \\
\text { toe }\end{array}$ & $15(8.6)$ & $13(7.5)$ & $18(10.3)$ & $39(22.4)$ & $45(25.9)$ & $44(25.3)$ \\
\hline $\begin{array}{l}4^{\text {th }} \text { Right } \\
\text { toe }\end{array}$ & $13(8.4)$ & $69(44.5)$ & $23(14.8)$ & $6(3.9)$ & $22(14.2)$ & $22(14.2)$ \\
\hline $\begin{array}{l}5^{\text {th }} \text { Left } \\
\text { toe }\end{array}$ & $36(19.9)$ & $30(16.6)$ & $33(18.2)$ & $57(31.5)$ & $25(13.8)$ & $0(0.0)$ \\
\hline $\begin{array}{l}5^{\text {th }} \text { Right } \\
\text { toe }\end{array}$ & $16(8.0)$ & $46(23.0)$ & $27(13.5)$ & $35(17.5)$ & $63(31.5)$ & $13(6.5)$ \\
\hline $\begin{array}{l}\text { Total } \\
\text { Patholog } \\
\text { y }\end{array}$ & $253(16.59)$ & $\begin{array}{l}323(21.1 \\
8)\end{array}$ & $\begin{array}{l}243(15.9 \\
3)\end{array}$ & $270(17.70)$ & $\begin{array}{l}299(19 . \\
60)\end{array}$ & $137(8.98)$ \\
\hline
\end{tabular}

Note: total pathological cases were 1525

Table 4.6. Severity and pathology of infestations of other body sites

\begin{tabular}{|l|l|l|l|l|l|}
\hline $\begin{array}{c}\text { Site of } \\
\text { infestation }\end{array}$ & \multicolumn{1}{|c|}{ Mild } & Moderate & \multicolumn{1}{|c|}{ Sever } & $\begin{array}{c}\text { Desquamation } \\
\text { of skin }\end{array}$ & $\begin{array}{c}\text { Ulcer of } \\
\text { the skin }\end{array}$ \\
\hline Sole & $14(24.56)$ & $27(47.36)$ & $16(28.08)$ & $41(71.92)$ & $16(28.08)$ \\
\hline Lateral rim & $11(20.37)$ & $10(18.52)$ & $33(61.11)$ & $17(31.49)$ & $37(68.51)$ \\
\hline Heel & $6(54.55)$ & $1(9.1)$ & $4(36.35)$ & $6(54.55)$ & $5(45.45)$ \\
\hline Right arm & $3(30)$ & $3(30)$ & $4(60)$ & $6(60)$ & $4(40)$ \\
\hline Left arm & $3(23.07)$ & $4(30.77)$ & $6(46.16)$ & $5(38.5)$ & $8(61.5)$ \\
\hline
\end{tabular}

\subsubsection{The age group of Musokoto residents mostly infested by tunga penetrans}

The study revealed that $52.5 \%$ of those with tungiasis were aged below 10 years. The remaining victims were aged above 10 years of age. Table 4.7 shows the details on the prevalence of tunga penetrans with age.

Table 4.7. Prevalence of tunga penetrans with age

\begin{tabular}{ll}
\hline Age range & Frequency $\mathbf{n ( \% )}$ \\
\hline $1-5$ & $86(19.5)$ \\
$6-10$ & $135(33.0)$ \\
$11-15$ & $64(14.5)$ \\
$16-20$ & $34(7.7)$ \\
$21-25$ & $20(4.5)$ \\
$26-30$ & $14(3.2)$ \\
$31-35$ & $14(3.2)$ \\
$36-40$ & $11(2.5)$ \\
$45-50$ & $17(3.9)$ \\
$>50$ & $35(8.0)$ \\
\hline
\end{tabular}

Establish the risk factors associated with tungiasis in Musokoto sub-location.

\section{Individual risk factors}

The individual risks factors that were investigated in this study were on where one sleeps, what is put on feet while inside the room, where time is spent, and participant's opinion on source of jiggers. A total 440 household heads/guardians responded to these questions. The study findings revealed that 389(88.4\%) slept on traditional made beds, 46(10.5\%) used 
Texila International Journal of Public Health

Volume 4, Issue 4, Dec 2016

mattresses on modern beds, 3(0.7\%) used mattresses laid on the floor whereas 2(0.5\%) used mats laid on the floor. Out of the 440 household head/guardians 394(89.5\%) mentioned that they put on slippers while inside the rooms whereas $46(10.5 \%)$ said they walk barefooted while inside the room. Majority of the household heads/guardians 388(88.2\%) said members of their families spent most of their times resting within their yards. Another 115(26.13\%) said they spent most their time inside the house. When asked about the sources of jiggers a sizeable number of the household/guardians, 364(82.7\%) did not have an idea where jiggers come from. About 43(9.8\%) were of the opinion that jiggers from sand, 19(4.3\%) and 14(3.2\%) said that jiggers come from pigs and dogs respectively. Other sources of jiggers that were also mention included dirt 22(5\%), dust $11(2.5 \%)$ whereas $3(0.68 \%)$ and $2(0.45 \%)$ respectively argued that jiggers were as a consequence of drought and climate change. When the association between jiggers infestation was computed using logistical regression analysis it emerged that where one sleeps i.e. mattress/bed, mattresses/floor, mat/floor and traditional beds was more likely to significantly influence jiggers infestation $(\mathrm{P}<0.001$; OR=1.319; $\mathrm{CI}=$ $1.180-1.474)$. Other individual risk factors such as what one put on feet while inside or outside the house and where time is spent were significantly less likely to influence jiggers infestation (what is put on inside the house $-\mathrm{P}<0.001$, $\mathrm{OR}=0.134$, $\mathrm{CI}=0.106-0.171$; what is put on feet outside the house $-\mathrm{P}<0.001$, $\mathrm{OR}=0.107$, $\mathrm{CI}=0.08-0.144$ and where time is spent $-\mathrm{P}<0.001$, OR $=0.159, \mathrm{CI}=0.129-0.197$. See table 4.9.

Table 4.8. Individual risk factors and tungiasis in Musokoto.

\begin{tabular}{lll}
\hline Variable & Frequency n(\%) & P-Value \\
\hline Where one sleeps & & \\
Matress/bed & $46(10.5)$ & $<0.001$ \\
Matress/floor & $3(0.7)$ & \\
Mat/floor & $2(0.5)$ & \\
Traditional bed & $389(88.4)$ & \\
What is put on feet inside a room & \\
Slippers & $394(89.5)$ & $<0.001$ \\
Barefoot & $46(10.5)$ & \\
Resting place & & \\
Veranda & $7(1.6)$ & $<0.001$ \\
Yard & $388(88.2)$ & \\
Backyard & $45(10.2)$ & \\
Where else time is spent & \\
House & $115(26.13)$ & $\mathbf{0 . 0 1 5}$ \\
Under a tree & $30(6.81)$ & \\
Source of jiggers & & \\
Pig & $19(4.3)$ & $<0.001$ \\
Sand & $43(9.8)$ & \\
Dog & $14(3.2)$ & \\
Don't know & $364(82.7)$ & \\
Other sources of jiggers & \\
Dirt & $22(5)$ & \\
Dust & $11(2.5)$ & \\
Drought & $3(0.68)$ & \\
Climate change & $2(0.45)$ & \\
Don't know & $402(91.37)$ & \\
\hline
\end{tabular}


Table 4.9. Association between jiggers infestation and individual risk factors

\begin{tabular}{|l|l|l|l|l|l|}
\hline Variable & df & $\mathbf{P =}$ value & OR & \multicolumn{2}{|l|}{$\mathbf{9 5 . 0 \%}$ C.I. } \\
\hline & & & & Lower & Upper \\
\hline Where one sleeps & 1 & $<0.001$ & 1.319 & 1.180 & 1.474 \\
\hline $\begin{array}{l}\text { What is put on feet inside the } \\
\text { house }\end{array}$ & 1 & $<0.001$ & 0.134 & 0.106 & 0.171 \\
\hline $\begin{array}{l}\text { What is put on feet outside } \\
\text { the house }\end{array}$ & 1 & $<0.001$ & 0.107 & 0.080 & 0.144 \\
\hline Where time is spent resting & 1 & $<0.001$ & 0.159 & 0.129 & 0.197 \\
\hline
\end{tabular}

\section{Accommodation risk factors associated with tungiasis}

The study revealed that all the households $440(100 \%)$ were mud walled structures with only $3(0.7 \%)$ of concrete/cement house floor and $437(99.3 \%)$ of the households were of sand/mud floor. However 417(94.8\%) of the houses had zinc/iron roofing whereas only 23(5.2\%) being grass thatched. The other aspects of accommodation that were also investigated in relation to jiggers infestation were type of street and type of lighting system used by a household. It emerged that 423(96.1\%) of the households were situated along sand/murram roads or paths whereas $17(3.9 \%)$ of the households were in areas where the street was of clay type of soil. When asked about the lighting system 439(99.8\%), which is almost $100 \%$ of the participants said they used kerosene or lamp to light their houses. Table 4.10.

Table 4.10. Family and individual risk factors and tungiasis in Musokoto.

\begin{tabular}{lll}
\hline Variable & Frequency $\mathbf{n}(\%)$ & P-Value \\
\hline House structure & & \\
$\quad$ Concrete & $0(0)$ & $\mathbf{0 . 0 0 3}$ \\
$\quad$ Mud & $440(100)$ & \\
House floor & & \\
$\quad \begin{array}{l}\text { Concrete/cement } \\
\quad \text { Sand/mud }\end{array}$ & $3(0.7)$ & $\mathbf{0 . 0 2 4}$ \\
House roof & $437(99.3)$ & \\
$\quad$ Zink/iron & $417(94.8)$ & 0.065 \\
$\quad$ Grass thatched & $23(5.2)$ & \\
Type of street & & \\
$\quad$ Sand/murram & $423(96.1)$ & 0.766 \\
$\quad$ Clay & $17(3.9)$ & \\
House light & & \\
$\quad$ Electricity & $0(0)$ & 0.393 \\
$\quad$ Kerosene/lamp & $439(99.8)$ & \\
$\quad$ Solar & $1(0.2)$ & \\
\hline
\end{tabular}

Logistical regression analysis was performed to establish the association between jigger's infestations and accommodation risk factors highlighted above. The analysis revealed house floor types was significantly associated with tungiasis and that house hold floor types was three times more likely to influence jigger's infestation. $(\mathrm{P}=0.036, \mathrm{OR}=3.608, \mathrm{CI}=1.089-$ 11.955). The type of street or soil type was less likely to influence jiggers infestation ( $\mathrm{P}=$ 0.789 , $\mathrm{OR}=1.802, \mathrm{CI}=0.607-1.930$ ). See details in table 4.11 . 
Texila International Journal of Public Health

Volume 4, Issue 4, Dec 2016

Table 4.11. Association between jigger's infestation and family and individual risk factors

\begin{tabular}{|l|l|l|l|l|l|}
\hline Variable & df & P= value & OR & \multicolumn{2}{|l|}{$\mathbf{9 5 . 0 \%}$ C.I. } \\
\hline & & & & Lower & Upper \\
\hline House floor type & 1 & 0.036 & 3.608 & 1.089 & 11.955 \\
\hline House roof & 1 & 0.054 & 0.629 & 0.393 & 1.009 \\
\hline Street & 1 & 0.789 & 1.082 & 0.607 & 1.930 \\
\hline House light & 1 & 0.927 & 0.937 & 0.235 & 3.745 \\
\hline
\end{tabular}

\section{Water and sanitation risk factors}

Water and sanitation risk factors associated with tungiasis infestation were also investigated. The water risk factors looked at the sources of water whereas the sanitation risk factors that were investigated included where waste sources are put; and treatment given to the waste products as well as the site of the waste bin. Approximately 413(93.9\%) of the household sourced there water from the river whereas 27(6.1\%) sourced their water from the wells. Other water sources were boreholes $1(0.2 \%)$ and spring $20(4.5 \%)$. On sanitation 396(90.0\%) disposed-off their waste in the household garden and 26(5.9\%) disposed in the yard and 18(4.1\%) disposed-off their waste in the compost pit. When asked whether they burned their waste or not, only 18(4.1\%) answered in the affirmative whereas 422(95.9\%) did not burn their waste. All the $440(100 \%)$ of the household did not have a waste bin within the house compound.

Logistical regression analysis (table 4.12) confirmed that source of water, household waste disposal and treatment significantly influenced jiggers infestation $(\mathrm{P}=0.001, \mathrm{OR}=2.050$, CI $=1.334-3.150$ ) for source of water implying that source of water was more likely to influence jiggers infestation compared to waste disposal site $(\mathrm{P}<0.001$, OR $=0.564$, $\mathrm{CI}=$ $0.409-0.776)$ and waste treatment e.g. burning $(\mathrm{P}=0.002$, $\mathrm{OR}=0.449, \mathrm{CI}=0.268-0.751)$. See details in table 4.13

Table 4.12. Water and sanitation risk factors associated with tungiasis in Musokoto.

\begin{tabular}{|c|c|c|}
\hline Variable & Frequency n(\%) & P-Value \\
\hline \multicolumn{3}{|c|}{ Source of water supply } \\
\hline Well & $27(6.1)$ & 0.001 \\
\hline River & 413(93.9) & \\
\hline \multicolumn{3}{|c|}{ Other water sources } \\
\hline Borehole & $1(0.2)$ & $<0.001$ \\
\hline Spring & $20(4.5)$ & \\
\hline \multicolumn{3}{|c|}{ Waste product (place to put) } \\
\hline Yard & 26(5.9) & 0.001 \\
\hline Garden & 396(90.0) & \\
\hline Compost pit & $18(4.1)$ & \\
\hline \multicolumn{3}{|c|}{ Burn the waste? } \\
\hline Yes & $18(4.1)$ & 0.002 \\
\hline No & 422(95.9) & \\
\hline \multicolumn{3}{|c|}{ Waste bin in the home? } \\
\hline Yes & $0(0)$ & 0.001 \\
\hline No & $440(100)$ & \\
\hline
\end{tabular}


Table 4.13. Association between jigger's infestation and water and sanitation risk factors

\begin{tabular}{|l|l|l|l|l|l|}
\hline Variable & df & P= value & OR & \multicolumn{2}{|l|}{$95.0 \%$ C.I. } \\
\hline & & & & Lower & Upper \\
\hline Source of water & 1 & 0.001 & 2.050 & 1.334 & 3.150 \\
\hline Where is household waste put & 1 & $<0.001$ & 0.564 & 0.409 & 0.776 \\
\hline Burn the waste & 1 & 0.002 & 0.449 & 0.268 & 0.751 \\
\hline
\end{tabular}

\section{Type of domesticated animal and risk factors associated with tungiasis.}

Of the 440 households only 19(4.3\%) of the households domesticated dogs and 421(5.7\%) did not have dogs. A total of $9(42.90 \%)$ had at least one dog whereas $1(4.80 \%)$ had four and five dogs each. When asked about domestication of cats only 15(3.4\%) confirmed that they domesticated cats of this $14(45 \%)$ had at least one cat and only 1(5\%) had up to four cats. Pigs were domesticated by $12(3.4 \%)$ of the households. Of the twelve households that domesticated pigs $7(58.33 \%)$ had a pigsty whereas $5(41.67 \%)$ practiced free range pig keeping. The participants also mentioned domestication of other animals e.g. goats $2(0.5 \%)$, chicken 18(4.1\%) and cows 27(6.1\%). See table 4.14 .

Logistical regression analysis revealed that having a dog or cat and numbers of such dogs or cats significantly influenced jiggers infestation and the number of dogs present was more likely to significantly influence $(\mathrm{P}=0.001$, $\mathrm{OR}=1.179$, $\mathrm{CI}=1.070-1.299)$ jiggers infestation compared to the number of cats $(\mathrm{P}=0.006$, $\mathrm{OR}=1.145, \mathrm{CI}=1.040-1.261)$. Having other animals was more likely to significantly influence $(\mathrm{P}<0.001, \mathrm{OR}=1.517, \mathrm{CI}=$ $1.234-1.864)$ jiggers infestation. The presence of rats in the house was less likely to influence $(\mathrm{P}<0.001, \mathrm{OR}=0.477, \mathrm{CI}=0.334-0.680)$. See table 4.15 .

Table 4.14. Risk factors of type of animal domesticated and tungiasis in Musokoto

\begin{tabular}{|c|c|c|}
\hline Variable & Frequency n(\%) & P-Value \\
\hline \multicolumn{3}{|c|}{ Domesticate a dog? } \\
\hline Yes & $19(4.3)$ & \multirow[t]{2}{*}{0.001} \\
\hline No & $421(95.7)$ & \\
\hline \multicolumn{3}{|c|}{ How many dogs? } \\
\hline 1 & $9(42.90)$ & \multirow[t]{6}{*}{0.013} \\
\hline 2 & $6(28.60)$ & \\
\hline 3 & $4(19.00)$ & \\
\hline 4 & $1(4.80)$ & \\
\hline 5 & $1(4.80)$ & \\
\hline 6 & $0(0)$ & \\
\hline \multicolumn{3}{|c|}{ Do you have a cat? } \\
\hline Yes & $15(3.4)$ & \multirow[t]{2}{*}{0.005} \\
\hline No & $(96.6)$ & \\
\hline \multicolumn{3}{|c|}{ How many cats? } \\
\hline 1 & $14(45)$ & \multirow[t]{4}{*}{0.037} \\
\hline 2 & $1(30)$ & \\
\hline 3 & $4(20)$ & \\
\hline 4 & $1(5)$ & \\
\hline \multicolumn{3}{|c|}{ Domesticate a pig? } \\
\hline Yes & $12(3.4)$ & \multirow[t]{2}{*}{0.360} \\
\hline No & $428(97.3)$ & \\
\hline \multicolumn{3}{|c|}{ If YES how do they live? } \\
\hline Pigsty & $7(58.33)$ & \multirow[t]{2}{*}{0.271} \\
\hline Free & $5(41.67)$ & \\
\hline
\end{tabular}


Texila International Journal of Public Health

Volume 4, Issue 4, Dec 2016

Table 4.14. Risk factors of type of animal domesticated and tungiasis in Musokoto

\begin{tabular}{ccc}
\hline Variable & Frequency n(\%) & P-Value \\
\hline \multicolumn{3}{c}{ Other animals domesticate? } \\
Yes & 47(10.7) & $<0.001$ \\
No & 393(89.3) & \\
What type of animals? & $<0.001$ \\
Goat & 2(0.5) & \\
Cow & 27(6.1) & \\
Chicken & 18(4.1) \\
N/A & 393(89.3) & \\
\hline
\end{tabular}

Table 4.13. Association between jigger's infestation and Risk factors of type of animal domesticated.

\begin{tabular}{|l|l|l|l|l|l|}
\hline Variable & df & P= value & OR & \multicolumn{2}{|l|}{$95.0 \%$ C.I. } \\
\hline & & & & Lower & Upper \\
\hline Have a dog & 1 & 0.001 & 0.422 & 0.256 & 0.696 \\
\hline No. of dogs & 1 & 0.001 & 1.179 & 1.070 & 1.299 \\
\hline Have a cat & 1 & 0.006 & 0.541 & 0.257 & 0.792 \\
\hline No. of cats & 1 & 0.006 & 1.145 & 1.040 & 1.261 \\
\hline Have a pig & 1 & 0.282 & 0.700 & 0.366 & 1.341 \\
\hline No. of pigs & 1 & 0.160 & 1.090 & 0.967 & 1.228 \\
\hline Where the animals live & 1 & 0.538 & 1.140 & 0.750 & 1.733 \\
\hline Have other animals & 1 & $<0.001$ & 1.517 & 1.234 & 1.864 \\
\hline Rats present in the house? & 1 & $<0.001$ & 0.477 & 0.334 & 0.680 \\
\hline
\end{tabular}

To establish the modes of treatment used by the residents to manage the disease.

When participants were asked if they removed jiggers, 440(100\%) said they do using needles 247(56.1\%) and sticks/thorns 193(43.9\%). To treat the jiggers, kerosene 402(91.4\%) was mostly used while $38(8.6 \%)$ used no products in the market. No participant used savlon antiseptic. Other products mentioned to be used include hydrogen peroxide $1(0.22 \%)$, cattle dip 2(0.45\%), Omo 5(1.13\%), magadi (sodium bicarbonate) 3(0.68\%) and warm water 2(0.45\%). See table 4.14 .

Table 4.14. Modes of treatment used by the residents of Nambale to manage tungiasis.

\begin{tabular}{|c|c|c|}
\hline Variable & Frequency n(\%) & P-Value \\
\hline \multicolumn{3}{|c|}{ What do you do in case of a jigger infestation? } \\
\hline Remove the jigger & $440(100)$ & $<0.001$ \\
\hline \multicolumn{3}{|c|}{ How do you remove the jiggers? } \\
\hline Needle & 247(56.1) & $<0.001$ \\
\hline Stick/thorn & 193(43.9) & \\
\hline \multicolumn{3}{|c|}{ Products used in treating jigger wounds } \\
\hline No product used & $38(8.6)$ & $<0.001$ \\
\hline Kerosene & 402(91.4) & \\
\hline Savlon & $0(0)$ & \\
\hline \multicolumn{3}{|c|}{ Other products used in treating jigger wounds } \\
\hline Hydrogen peroxide & $1(0.22)$ & 0.216 \\
\hline Cattle dip & $2(0.45)$ & \\
\hline Magadi & $5(1.13)$ & \\
\hline Omo & $3(0.68)$ & \\
\hline Warm water & $2(0.45)$ & \\
\hline
\end{tabular}




\section{Discussion}

The study findings are discussed objective wise while cross - reference with similar studies done elsewhere. The first specific objective was to establish the prevalence of tungiasis among residents of Musokoto sub-location. The study findings point that out of the study participants (1557), only a third said they had had jiggers at one time in their lives and on clinical examination of those who answered in the affirmative sixty five percent were found to be slightly higher compared to a similar study done by Ade-Serrano and Ejezie (1981) in a rural Lagos State, Nigeria. In the Lagos study the prevalence of tungiasis was forty percent. In another study done in two towns of South - West Trinidad revealed a tungiasis prevalence of thirty one and forty percent, respectively for the two towns i.e. Icacos and Fullarton (Chadee et al., 1991a, 1991b). In another study Ade-Serrano and Ejezie (1982) found a prevalence of 42 percent in a Southern town of Nigeria.

The prevalence of jiggers in males and females was almost equal implying that gender did not significantly influence the prevalence of jiggers $(p=0.743)$. Looked at by age it emerged that age of an individual significantly influenced the prevalence of jiggers. This finding corroborates that of Heukelbach (unpublished observation) that equally revealed that jiggers was more prevalent in children than in adults. Looking at prevalence by specific age groups, the observation in the current study is similar to that of Heukelbach et al. (unpublished observation).

Arene (1984) and Chadee (1994) argues that decline in tungiasis by increase in an individual's age could be a function of keratinization. Nevertheless, this could be due to a number of socio-economic and personal factors such as evidenced in the current study. Previous studies have linked tungiasis infestation to families of poor socio-economic status. The study participants in the current study were living in the rural areas of Musokoto and were of very poor socio-economic status (table 4.2). Additionally, Heukelbach, (2005) and Litvoc et al., (1991) equally linked poor socio-economic status to high prevalence of tungiasis. The other aspect of prevalence that was investigated was body sites infested and severity of the infestation. The current study has demonstrated that jiggers can infest any part of the body i.e. toes, sole, lateral rim of sole; heel and arms. Jiggers infestation presented in the form of fissures; hyperthropic nail rim; ulcerations; nail and toe deformation and loss of nails. Others included desquamation and ulceration of the skin. Feldmeier et al., 2003; Feldmeier and Heukelbach, 2009 in separate reports on epidermal parasitic skin diseases sheds light on pathology and severity of tungiasis on finger nails and heels, toes confirming similar jiggers manifestation by tungiasis as was observed in the current study.

Ferran et al. (2009) also realized that a nodular lesion on the sole of a patient who had visited Venezuella contained Tunga penetrans flea. Nordlund, (2009) was also able to diagnose tungiasis from the hands, skin, toes, nails and sole of his patients. Also according to Nordlund (2009) the cases presented in the form of fissures, abscesses, suppurations. The lesions, according to Nordlund (2009) can progress into osteomyelitis or gangrenes and nails can be lost in most cases.

The second specific objective of the study explored the risk factors associated with tungiasis.

Pilger et al. (2008) argues that tungiasis is much more prevalent in communities who usually wear flip - flop (slippers) and often sleep on dirty floors. The challenges with the term dirty floor that Pilger and colleagues, (2008) did not clarify the meaning of dirty floors. But assuming that' dirty floors' is synonymous to mud floors then the findings of the current study is in agreement with the views of Pilger and his colleagues (2008). Mazigo et al., (2010) while conducting a tungiasis prevalence survey in a rural village in Ruseas ward of Tanzania describes the housing condition of the infested as one with mud walls made of tree poles and a dusty dirty floor littered with garbage. This clearly confirms that tungiasis is associated with dirty living environments. In this view, therefore it is critical that residents of Musokoto improve on their housing conditions especially materials used in flooring. Unregulated disposal of household waste can lead to animals such as rodents residing within 
Texila International Journal of Public Health

Volume 4, Issue 4, Dec 2016

the homestead and this can lead to difficulty in controlling the jigger flea, which can reside and feed even on rats (Witts et al., 2004). Cleanliness and tidiness of the household and its environments is very important not only in controlling Tunga penetrans but also other household bugs (Curtis et al., 2003). In this study, it is in agreement with Witts and colleagues above information since Musokoto residents with unregulated disposal of waste associated with tungiasis infestation on table 4.12.

Reportedly, Pampiglione et al. (2003; 2009) revealed that sand flea (Tunga spp.) infestations in humans and domestic animals were positively correlated i.e. domestication of animals was linked to Tunga penetrans infestation in humans. The animals that Pampiglione linked to Tunga penetrans infestation in humans were dogs and pigs. The domestic animals previously associated with Tunga penetrans (Pampiglione et al., 2003; 2009) and were also mentioned in the current study included goats, cats, pigs, bovines and chickens. Other studies (Ribeiro et al., 2007; Heukelbach, 2004; Linardi and Guimaraes, 2000; Fioravanti et al., 2003; Pampiglione et al. 2003; 2009) have also reported and linked domestic animals as hosts to Tunga penetrans flea, which the causative agent of tungiasis.

The third specific objective investigated treatment modes used by residents of Musokoto to treat tungiasis. In many cases tungiasis is a self-limiting infestation upon removal of the Tunga penetrans ball. However, due to the resulting skin rupture, infections may result, especially in cases of poor personal hygiene and environmental sanitation. It is therefore imperative that tungiasis is treated. In the current study, the study participants indicated use of various modes of treatment including physical removal of the jigger. Products mentioned to be used to treat jigger infestation/infections after removal of the jigger ball are kerosene, savlon, hydrogen peroxide, cattle dip, sodium bicarbonate (soda ash), omo and use of warm water.

Nordlund (2009) recommends that jiggers should be removed surgically under sterile conditions. Heukelbach (2006) has advised that there are no effective oral or topical drugs that can be used in the treatment of tungiasis. Nevertheless, in a study using a plant-based repellant - Zanzarin, a lotion made from coconut oil; jojoba oil and aloe vera, applied twice daily reduced newly imbedded fleas by $92 \%$ and the number of skin lesions by $87 \%$. The limitation of the current study was that it did not capture the success through follow up of the modes of treatment used by Musokoto residents infested with jiggers on their reduction of imbedded jigger fleas and also in the reduction of skin lesions. Worth noting is the high prevalence of tungiasis among the study participants, which in itself is a pointer that the modes of treatments used by the study participants are not effective and so a more effective anti-tunga ointment such as Zanzarin could be recommended for topical use by Musokoto residents. This recommendation is supported by the documented success of Zanzarin by the previous studies (Feldmeier et al., 2006; Schwalferberg et al., 2004). In the Tanzania study Mazigo et al. (2010) advised the caretakers of the jiggers infested individuals to clean the wounds of the victims using Dettol and also to take the infested persons for tetanus vaccination. In the current study it was not known whether persons infested with jiggers were actually vaccinated against tetanus. Lack of tetanus vaccination of those infested with jiggers may be a health threat to such persons, especially young children who play with soil and so may be exposed to infections by Clostridium tetanii.

\section{Conclusion}

\section{Prevalence}

There was a high prevalence of tungiasis in the division and most of the cases were found in children of schooling age. This is attributed to barefoot walking to school and domesticating animals in the homestead.

\section{Risks factors}

As evident from the study, where one sleeps and spends time while at home determines human infestation of jiggers. If persons spend most time resting outside the house and sleeps 
on the floor they will get infested with jiggers. Mud floor types and sand streets is also the habitat for jiggers. Pigs, dogs and cats also harbor jiggers and the more they are in the compound and living with humans, the more the chances of getting tungiasis among the family members. People fetching water from long distances i.e. rivers have higher chances of infestation.

\section{Modes of treatment}

Most residents used crude methods for surgical removal of the jigger and also used none recommended products for its treatment. These products could cause infection and other complications such as tetanus and gangrene among others.

\section{Recommendations}

1. More emphasis/strategies to be put in the control and management of tungiasis at musokoto Location because of the high prevalence in the area.

2. Health education regarding tungiasis to be provided to the community on its management, stigma, and control. School children to wear shoes while they go to school to avoid infestation.

3. Regular domesticated animals spraying with insecticides will help reduce the fleas in the animals hence reduced egg larvae.

4. It emerged that victims of jiggers infestations do not receive tetanus vaccination, it is herby recommended that the government should consider vaccinating residents of jigger endemic areas with tetanus vaccines.

\section{References}

[1]. Ade-serano A, Olomolehin G, and Adewenwi G. (1982): Treatment of human tungiasis with niridazole: a double blind placebo controlled trial. Annals of Tropical Medicine and Parasitology, 76, 89-92.

[2]. Ahadi Trust. (2010). The jigger menace in Kenya: Jigger magazine, 2(1). retrieved 26 June 2012, www.ahadi-trust.org.

[3]. Arene Fo. (1984) The prevalence of sand flea (Tunga penetrans) among primary and post-primary school pupils in Choba area of the Niger Delta. Public Health; 98: 282 - 283.

[4]. BDSP. (2010): Implementation of the national population policy for sustainable development. Ministry of planning and national development. Nairobi: HSK consulting LTD.

[5]. Choge J, Wanjala P, Koech J, Kirui S, and Ayaya S. (2006): Tunga penetrans, pediculus capitis and sacorpte scabei among children $<15$ yrs in Kamgut location, Uasin Gishu district, Kenya. Journal of Agriculture Moi university, 5: 38-44.

[6]. Collin G, McLeod T, Konfor N, Lamnyan C, and Ngarka L. (2009): Tungiasis. A neglected health problem in rural Cameroon. International Journal of Collaborative Research on Internal Medicine and Public Health, 1(A): 2-10.

[7]. Feldmeier H, Eisele M, Van Marck, Mehlhorn H, Ribeiro R, and Heukelbach Jorg. (2004): Investigation on the biology, epidemiology, pathology and control of Tunga penetrans in Brazil: Clinical and Histopathology. Parasitology Research, 94: 275 e82.

[8]. Feldmeier H, Heukelbach J, Eisele M, Souza A, \& Barbosa L. (2002): Bacterial superinfection in human tungiasis. Journal of Tropical Medicine and International Health, 7: 559-64.

[9]. Groove S, \& Burns Nancy. (2003): Understanding Nursing Research: Building evidence based practice (4th ed.). St Louis Missouri: Saunders Elsevier.

[10]. Heemskerk J, Van Empel, \& Jakimowicz J. (2005): Tunga penetrans: A case report and review of literature. Acta Chirulgica Belgica, 105: 548-550.

[11]. Heukelbach J. (2004). The animal reservoir of Tunga penetrans in severely affected communities of North east Brazil. Medical Veterinary Entomology, 18(5); 329-33.

[12]. Heukelbach J, Franck S, and Feldmeier H. (2004): Therapy of tungiasis: a double randomized control trial with oral ivermectin. Memorias Do Instituto Oswaldo Cruz, 99; 873-6. 
Texila International Journal of Public Health

Volume 4, Issue 4, Dec 2016

[13]. Heukelbach J, Wilcke T, Eisele M, \& Feldmeier H. (2002): Ectopic localization of tungiasis. Journal of Tropical Medicine and Hygiene, 67; 214-216.

[14]. Heukelbach J, Wilcke T, Harms G, and Feldmeier H. (2005): Seasonal variation of tungiasis in an endemic community. American Journal of Tropical Medicine and Hygiene, 72; 145-149.

[15]. Heukelbach, J., Costa, A., Wilcke, T., Mencke, N., and Feldmeier, H. (2004). The animal resorvour of Tunga Penetrans in severely affected communities of Nothern Brazil. Medical and Vetenary Entomology, 18; 329 - 335.

[16]. Hoeppli R. (1963): Early references to the occurence of Tunga penetrans on Tropical Africa. Acta Tropica, 20; 143-52.

[17]. Joseph J, Bazile J, Mutter J, Shin S, Ruddle A, Ivers L, and Lyon E. (2006): Tungiasis in rural Haiti: a community based response. Transaction of Royal Society of Tropical Medicine and Hygiene, 100; 970-974.

[18]. Linardi, J., and Guimaraes, L. (2000). Sifona Pterosdo Brazil. Museu Zoologico Universidade Sao Paolo, 48 - 53.

[19]. Litvoc, J., Leite, R., and Katz, G. (1991). Apsectos epidemiolo Agicos do te Atano no estado de Sao Paulo Brazil. Revista Do Instituto de Medicina Tropical De Sao Paulo, 477 - 484.

[20]. Mazigo H, Behamana E, and Zinga M. (2010): Tungiasis infestation in Tanzania: A case report. Journal of Infection in Developed Countries, 4(3); 187-189.

[21]. Molyneux D, Hotez P, and Fenwick A. (2005): Rapid-impact interventions: How policy of intergrated control for Africa's neglected tropical diseases could benefit the poor. Public Library of Science, Medicine, 2; 298 e87.

[22]. Muehlen M, Feldmeier H, Wilcke T, and Heukelbach J. (2006): Identifying risk factors for tungiasis and heavy infestation in a resource-poor community in Northeast Brazil. Transaction of Royal Society of Tropical Medicine and Hygiene, 100; 371-380.

[23]. Nordlund, J.J. 2009. Cutaneous ectoparasites. Dermatologic Therapy; 22: 503-517

[24]. Njau N, Wanzala P, Marion M, Liana A, \& Heukelbach J. (2012): Tungiasis in rural Kenya, an emerging infectious disease. Retrovirology, 9; 1-37.

[25]. Njeumi F, Nsangou C, Ndjend A, Koga G, Ostanello F, and Pampiglione S. (2002): Tunga penetrans in Cameroun. Revue de Medecine Veterinaire, 153: 176-180.

[26]. Pampiglione S, Fioravanti M, Gustinelli A, and Onore G. (2009): Sand flea (Tunga spp.) infections in humans and domestic animals: state of art. Medical Veterinary Entomology, 2:172.

[27]. Pampiglione, S., Fioravanti, M., Gustinelli, G., Onore, B., Mantovani, A., and Luchetti, C. (2009). Sand flea (Tunga ssp) infections in humans and domestic animals: State of art. Medicine and Vetinary entomology, 23: 172 - 186.

[28]. Pampiglione, S., Tretini, M., Fioravanti, M., Onore, G., and Rivasi, F. (2003). Additional description of a new species of Tunga from Ecuador. Annal tropical Medicine of Parasitology, 10: 9 15.

[29]. Pilger, D., Schwalfenberg, S., and Heukelback, J. (2008). Investigations on the biology, epidemiology, pathology, and control of Tunga penetrans in Brazil: Importance of animal reservoirs for human infestation. Journal of parasitology, 102: 875 - 880.

[30]. Ribiero, J., Coehlo, S., and Ruas, J. (2007). Infestac de Tunga penetrans siphonaptera: Tungidae em cascos de vacas leteiras Holandez-Zebu. Arquivos Brazileiros De Medicina Veterinaria e Zootenicia, 59: 520 - 522.

[31]. Sanusi I, Brown E, Shepard T, \& Grafton W. (1989): Tungiasis: Report of one case and review of the 14 reported cases in the United States. Journal of the American Academy of Dermatology, 20(2): 941-4.

[32]. Schwalfenberg S, Witt LH, Kehr JD, Feldmeier H, Heukelbach J. 2004. Prevention of tungiasis using a biological repellent: a small case series. Ann Trop Med Parasitol; 98(1): 89-94.

[33]. Ugbomoiko U. (2007): Tungiasis: High prevalence, parasite load, and morbidity in a rural community in Lagos State, Nigeria. International Journal of Dermatology, 46: 475-481.

[34]. Ugbomoiko U, Ariza L, Ofoezie I, and Heukelbach J. (2007): Risk factors for Tungiasis in Nigeria: Identification of targets for effective intervention. Public Library of Science, Neglected Tropical Diseases, 1(3): e87. 
[35]. Wachira Ann. (2012): Tungiasis: Infestation of the jigger flea in resource poor communities in Africa. Africa Public Health, 1: 2.

[36]. WHO. (2010): Epidermal parasitic skin diseases: A neglected category of poverty associated plagues. Journal of the World Health Organization, 87: 152-159.

[37]. Winter B, Oliveira F, Wilcke T, Heukelbach Jorg, and Feldmeier H. (2009): Tungiasis-related knowledge and treatment practices in two endemic communities in Northeast Brazil. Journal of Infection in Developed Countries, 3(6): 458-66.

[38]. Yamane T. (1967): Statistics: An introductory Analysis (2nd ed.). New York: Harper and Row. 


\title{
Plasmodium Falciparum and Schistosoma Heamatobium Infections in Pregnant Women Attending Antenatal Clinic in Sekondi-Takoradi Metropolis Western Region Ghana
}

\author{
Article by Verner. N. Orish ${ }^{1}$, Danny flint Yeboah ${ }^{2}$, Ekene Nwaefuna ${ }^{3}$ Richmond \\ Afoakwah $^{4}$ \\ ${ }^{1}$ Department of Microbiology, School of Medicine, University of Health and Allied \\ Sciences, Ho, Volta Region, Ghana \\ ${ }^{2,}{ }^{4}$ Department of Biomedical and Forensic Sciences, School of Biological Sciences \\ University of Cape Coast \\ ${ }^{3}$ Ghana Atomic Energy Commission Accra, Biotechnology and Nuclear Agricultural \\ Research \\ E-mail: orishv@yahoo.com
}

\begin{abstract}
Plasmodium falciparum and Schistosoma hematobium infections are very common parasitic infections that affect pregnant women in the tropics. In this study we evaluated the prevalence and contribution to anemia of Plasmodium falciparum and Schistosoma heamatobium among pregnant women attending antenatal clinic in Sekondi Takoradi Metropolis.

This is across sectional study involving pregnant women attending antenatal clinic in Effia nkwanta regional hospital, Esikado hospital, Takoradi hospital and Jemima Crentsil hospital. Plasmodium falciparum detection and hemoglobin estimation were done from blood samples collected. Urine microscopy was done using the wet mount technique to detect the presence or absence of Schistosoma heamatobium

A total of 872 pregnant women were sampled, 23.4\% (204/872)were infected with plasmodium falciparum infection, 3.3\% (29/872) were infected with Schistosoma heamatobium infection and 34.2\% (298/872) were anemic. Plasmodium falciparum infection had a significant association with anemia 32.2\% $(96 / 298)(P<0.001)$, Schistosoma heamatobium infection had no significant association with anemia, 4.4\% $(6 / 298)(p=0.3)$

Plasmodium falciparum infection was higher and contributes more to anemia in pregnant women than Schistosoma heamatobium infection in this study. However it is very important to screen pregnant women for other parasitic diseases with lower prevalence than malaria to evaluate their burden and contribution to morbidity in pregnancy.
\end{abstract}

\section{Introduction}

Parasitic diseases constitute a significant portion of global infectious disease burden. Occurring worldwide but found mainly in tropical areas of the world and in sub-Sahara Africa where environmental and socio economic factors allow both vectors and pathogens to thrive facilitating spread of disease in the human population [1, 2].

$P$. falciparum is the deadliest of the Plasmodium species that cause severe forms of the disease in malaria endemic west Africa [3, 4]. In this region the risk of infection is higher for children and pregnant woman because of issues of rudimentary and altered immunity respectively [5, 6]. Pregnant women are particularly susceptible to infection during their first and second pregnancy on account of gravidity dependent immunity [7, 8]. Close to 10,000 pregnant women die from $P$. falciparum from over 25 million malaria infections yearly in sub-Sahara Africa $[9,10]$. These infections carry grave consequences for both mother and child.

Schistosma heamtobium (SH) is a trematode that infects millions of people in Sub Sahara Africa[11, 12]. It causes urinaryschistosomiasis characterized frequently by hematuria and less frequently with dysuria [13]. Infection is gotten when infective cercaria penetrate the skin 
Texila International Journal of Public Health

Volume 4, Issue 4, Dec 2016

of persons who come in contact with fresh water bodies like rivers, lakes and dams[14]. In many places in urban and rural settings in sub-Sahara Africa people use these water bodies as means of recreation like swimming, as a means of livelihood as in fishing and for domestic use as in washing of house old materials [15]. Children of school going age, women and men use these water bodies as a way of life.

In Ghana, pregnant women are exposed to both infections of P.falciparum and SH. Malaria in pregnancy is a serious public health issue constituting 28.1\% of all OPD attendance. 13.1\% of all admission and 9.1 of all maternal deaths [16]. SH in pregnant women on the other hand does not enjoy a robust statistical data like that of malaria, however some studies showed $4.5 \%$ prevalence in two districts in Ghana $[17,18]$. The burden and prevalence of these infections varies in different regions and districts in Ghana. It is very important that more work be done in various regions and districts in Ghana to evaluate the burden of these two parasites in pregnant women. The objectives of this study was (1) to evaluate the prevalence of plasmodium falciparum and SH in pregnant women attending antenatal clinic (2) to evaluate the contribution of plasmodium falciparum and $\mathrm{SH}$ to anemia in pregnant women attending ANC in Sekondi Takoradi metropolis.

\section{Methodology}

\section{Study site}

This study was carried out in the Sekondi-Takoradi metropolis, Ghana. Sekondi-Takoradi, comprising the twin cities of Sekondiand Takoradi, is the administrative capital of the western region of Ghana with a land area of $385 \mathrm{~km} 2$. It is Ghana's fourth largest city and an industrial and commercial Centre with a population of about 335,000. The metropolis is an urban Centre surrounded by towns and villages. Temperatures are high with an average of 22 ${ }^{\circ} \mathrm{C}$. It has a mean annual rainfall of $2.350 \mathrm{~mm}$, which is experienced heavily in May and June with the minor rains occurring between September and October.

\section{Study population and design}

Pregnant women attending their antenatal care (ANC) visits were strategically sampled from four hospitals in the metropolis with the intention of recruiting pregnant women from sub-urban and rural communities of the city. These hospitals included Effia- Nkwanta Regional Hospital, Essikado Hospital, Takoradi Hospital and Jemima Crentsil Hospital. This cross-sectional study was carried out from the month of January to the month of October, 2010. Each facility was visited once every week on their routine antenatal days. Pregnant women, cross-checked with ultra-sound or with clinical evidence of pregnancy, were included in the study while pregnant women with significant bleeding were excluded from the study.

\section{Questionnaire administration}

Each consenting pregnant woman was asked of her demographic characteristics, education and occupational history, past and present obstetrics history. History of fever and any other illness during the pregnancy were asked.

\section{Sample collection}

About $5 \mathrm{ml}$ of venous blood were collected from the pregnant women by a trained laboratory technician from the median cubitalvein. Blood samples were collected into an EDTA bottle and temporarily stored in an ice chest and were transported to a designated reference laboratory for same day analysis and storage. About $10 \mathrm{ml}$ of urine was collected from the pregnant women in a clean container

\section{Malaria diagnosis}

Laboratory diagnosis of malaria was performed using fast RAPID response antibody kit (Premier Medical Corporation Ltd). The brand of the RAPID response kit was specific for the detection of P.falciparum antigens. The presence of two lines in the text kit well indicated 
positive for $P$. falciparum malaria. The RAPID response kit contained a membrane strip precoated with monoclonal antibody specific for histidinerich protein 2 antigen of $P$. falciparum. For proper confirmation of malaria parasites, thick and thin smear with Geimsa staining were performed and examined microscopically using 100 power fields under oil immersion. Malaria parasites were counted against 200 leukocytes, read independently by two competent microscopists and where they had discordances, a third microscopist reassessed the slide. Malaria diagnosis was defined on the identification of any asexual blood stages of $P$. falciparum species in the thick and thin smears while a slide was pronounced negative when 100 high power fields have been examined using x100 oil immersion objective lens.

\section{Urinary schistosomiasis diagnosis}

$\mathrm{SH}$ detection was done using microscopy of urine sediments. About $10 \mathrm{ml}$ of urine was collected from the pregnant women during their antenatal visits at the hospital or clinic premises. Urine samples were centrifuged and sediments examined under the microscope and eggs of SH counted directly. This was done by two microscopists and discordant results were resolved by a third microscopist.

\section{Haemoglobin estimation}

Haemoglobin estimation was performed using cyanmet hemoglobin method [19] Anaemia was defined based on WHO criteria haemoglobin levels of $<11 \mathrm{~g} / \mathrm{dL}[20]$.

\section{Ethical clearance}

Ethical clearance for the study was gotten from the Ghana Health Service Ethics Review Committee. Written informed consents were received from the recruited pregnant women.

\section{Data analysis}

Data and statistical analyses were performed using IBM SPSS Statistics version 17.0 (SPSS Inc., IL USA). Frequency distributions were done for all the characteristics of the pregnant women in the study (age, marital status, occupation, education, malaria and HIV status, anaemia, gravidity). These characteristics of the pregnant women were further analyzed using either Pearson $\chi^{2}$ tests or Exact $\chi^{2}$ test and ANOVA for the comparison of mean.95\% confidence interval (CI) were used to measure the strength of the association and $\mathrm{P}$ $<0.05$ was considered statistically significant.

\section{Result}

A total of eight hundred and seventy-two pregnant women were sampled for this study. Table 1 shows the characteristics of these pregnant women. 298 (34.2\%) of the women were anaemic, 204 (23.4\%) had Plasmodium falciparum infection while 29 (3.3\%) had Schistosoma heamatobium infection. Majority of the women were married (93.1\%), attended secondary school (61.4\%) and were between the ages of 20-30s (60.6\%).

Table 2stratifies the pregnant women based on their malaria status. There was no significant association $(\mathrm{p}=0.349)$ between the level of education and Plasmodium infection. There was also no significant association $(\mathrm{p}=0.9)$ between $\mathrm{SH}$ and Plasmodium falciparum infection. However age was significantly associated $(\mathrm{P}=0.02)$ with Plasmodium falciparum infection as the prevalence of Plasmodium infection was higher among pregnant women between the ages 13-19. Anemia also had a significant association $(\mathrm{p}<0.001)$ with Plasmodiumfalciparum infection.

Table 3 stratifies the pregnant women based on their SH infection status. There were no significant association seen between education and maternal anemia and age of the pregnant women with $\mathrm{SH}$ infection.

Table 4 stratifies the pregnant women based on their hemoglobin level. There was an association between anemia and Plasmodium falciparum infection as there was a significant difference $(\mathrm{p}<0.001)$ between Plasmodium prevalence among pregnant women with anemia 
Texila International Journal of Public Health

Volume 4, Issue 4, Dec 2016

and pregnant women without anemia. There was no association noted between with $\mathrm{SH}$ and the hemoglobin levels of the pregnant women.

\section{Discussion}

Plasmodium falciparum and SH infections are common parasitic infection in sub-Sahara Africa. In this study we looked at their prevalence and their burden in contributing to anemia in pregnant women attending ANC in Sekondi-Takoradi metropolis.

In this study the prevalence of $P$. falciparum infection was very much higher than that of $\mathrm{SH}$. Though both infections have same spatial distribution in endemic areas, $\mathrm{SH}$ have a more focal distribution and complex transmission cycle[21]. While P.falciparum requires female Anopheles mosquito as a vector for transmission to humans in the comfort of their homes, $\mathrm{SH}$ on the hand requires human-cercaria contact in a susceptible fresh water habitat. SekondiTakoradi is predominantly a coastal city with mainly salty sea water. However very few suburbs surrounding the metropolis have rivers that are potential source of SH infection. The paucity of appropriate fresh water bodies in the metropolis might explain the low prevalence of 3.3\% compared to two other studies done in Bawku in the northern region and damaged district in Accra Ghana that both had a prevalence of 4.5\% [17, 18].

P.falciparum infection was found to be associated with the age of the pregnant women as the prevalence was significantly higher in teenage pregnancy. This finding is in agreement with a study done in the northern part of Ghana 22]. Teenagers are basically still developing their immunity and hence with pregnancy there is a further depression of their immune system compared to their adult counterpart [23].

$P$. falciparum infection contributed more to anaemia than $\mathrm{SH}$ infection in this study. However, it is a well-established fact $\mathrm{SH}$ causes anemia and negative birth outcomes in pregnant women $[17,24,25]$. The insignificant contribution to anemia in this study might be due to the low prevalence of SH in this study. Despite the higher prevalence of $P$. falciparum in this study, it has been known to cause anemia in infected individuals especially in pregnant women and children [4, 26, 27].

\section{Conclusion}

While the prevalence of $P$. falciparum infection in pregnancy remains high in SekondiTakoradi just like all other parts of Ghana, that of SH infection is quite low, possibly due to the paucity of suitable fresh water habitats. Due to its low prevalence, $\mathrm{SH}$ infection contributes insignificantly to anaemia in pregnant women in the metropolis. Malaria, on the other hand, is still a big issue for pregnant women in Sekondi-Takoradi and other endemic areas, contributing greatly to anaemia. Notwithstanding, screening for other parasitic diseases to evaluate their burden and their contribution to morbidity in pregnant women is still very important

Table 1. General characteristics of pregnant women

\begin{tabular}{lrcc}
\hline Characteristics & & $\begin{array}{r}\text { Frequency } \\
(\mathbf{n = ~ 8 7 2 )}\end{array}$ & $\begin{array}{c}\text { Percentage } \\
(\mathbf{\%})\end{array}$ \\
\hline Age (Years) & $15-19$ & 107 & \\
& $20-29$ & 529 & 60.4 \\
& $30-29$ & 221 & 25.4 \\
& $40-49$ & 15 & 1.8 \\
Marital Status & Married & 812 & 93.1 \\
& Single & 60 & 6.9 \\
Education & & & \\
& None & 171 & 19.6 \\
& Primary & 128 & 14.7
\end{tabular}


Texila International Journal of Public Health Volume 4, Issue 4, Dec 2016

\begin{tabular}{lrcc} 
& Secondary & 535 & 61.4 \\
Occupation & Tertiary & 38 & 4.4 \\
& & & \\
& Seamstress/Hairdresser & 238 & 27.3 \\
& Trader & 367 & 42.1 \\
Farmer & 132 & 15.1 \\
Malaria Status & Food vendor & 135 & 15.6 \\
& & & \\
Haemoglobin & Positive & 204 & 23.4 \\
& Negative & 668 & 76.6 \\
S hematobium & & & \\
& Anaemia & 298 & 34.2 \\
& Normal & 574 & 65.8 \\
& & & \\
& Present & 29 & 3.3 \\
\hline
\end{tabular}

Table 2. Characteristics of pregnant women stratified by malaria status

\begin{tabular}{|c|c|c|c|c|}
\hline Characteristics & & $\mathrm{P}$ - value & $\begin{array}{l}\text { Malaria } \\
\text { Positive (\%) }\end{array}$ & $\begin{array}{l}\text { Malaria Negative } \\
\text { (\%) }\end{array}$ \\
\hline \multirow[t]{5}{*}{ Education } & & 0.349 & & \\
\hline & None & & 45 (26.3) & $126(73.7)$ \\
\hline & Primary & & 33 (25.9) & $95(74.2)$ \\
\hline & Secondary & & 115 (21.4) & $420(78.5)$ \\
\hline & Tertiary & & $6(15.8)$ & $32(84.2)$ \\
\hline \multirow[t]{3}{*}{ Age of woman } & & 0.02 & & \\
\hline & $<19$ years $(107)$ & & 37 (34.6) & $70(65.4)$ \\
\hline & $>20$ years $(765)$ & & $162(21.2)$ & 597 (78.0) \\
\hline \multirow[t]{3}{*}{ Maternal anaemia } & & $<0.001$ & & \\
\hline & $<11 \mathrm{~g} / \mathrm{dl}$ & & $96(32.2)$ & 202 (67.8) \\
\hline & $>11 \mathrm{~g} / \mathrm{dl}$ & & $108(18.8)$ & $465(81.0)$ \\
\hline \multirow[t]{3}{*}{ S. hematobium } & & 0.9 & & \\
\hline & Present & & $6(20.6)$ & 23 (79.3) \\
\hline & Absent & & $198(23.5)$ & $645(76.5)$ \\
\hline
\end{tabular}

Table 3. Characteristics of pregnant women stratified by S.H status

\begin{tabular}{lllll}
\hline Characteristics & & P - value & S.H. Present (\%) & S.H absent (\%) \\
\hline Education & & 0.57 & & \\
& None & & $4(2.3)$ & $167(97.7)$ \\
& Primary & & $5(3.9)$ & $123(96.1)$ \\
& Secondary & & $20(3.7)$ & $515(96.3)$ \\
& Tertiary & & $0(0)$ & $38(100)$ \\
Age of woman & & 0.13 & & \\
& $<19$ years (107) & & $6(5.6)$ & $101(94.39)$ \\
Maternal anaemia & $>20$ years (765) & & $23(3.0)$ & $742(97.0)$ \\
& $<11$ g/dl & 0.2 & $13(4.4)$ & $285(95.6)$ \\
& $>11$ g/dl & & $16(2.8)$ & $558(97.2)$ \\
\hline
\end{tabular}


Texila International Journal of Public Health

Volume 4, Issue 4, Dec 2016

Table 4: Baseline characteristics of the pregnant women stratified by haemoglobin level

\begin{tabular}{lccc}
\hline Characteristics & $\begin{array}{l}\text { Hemoglobin }(<11 \mathrm{~g} / \mathrm{dL}) \\
(\mathrm{n}=298)\end{array}$ & $\begin{array}{l}\text { Haemoglobin }(>11 \mathrm{~g} / \mathrm{dL}) \\
(\mathrm{n}=574)\end{array}$ & P value \\
\hline Education & $57(19.9)$ & $109(19.7)$ & \\
$\quad$ None & $43(15)$ & $77(13.9)$ & 0.11 \\
Primary & $182(63.4)$ & $338(61.1)$ & \\
Secondary & $5(1.7)$ & $29(5.2)$ & \\
$\quad \begin{array}{l}\text { Tertiary } \\
\text { Occupation }\end{array}$ & & $286(94.7)$ & \\
$\quad$ Farmer/trader & $149(96.8)$ & $9(3)$ & 0.27 \\
Civil service & $1(0.6)$ & $7(2.3)$ & \\
$\quad \begin{array}{l}\text { Teacher } \\
\text { Malaria }\end{array}$ & $4(2.6)$ & & \\
infection & & $107(18.7)$ & \\
$\quad$ Negative & $204(68)$ & $16(2.8)$ & 0.3 \\
Positive & $96(32)$ & $558(97.2)$ & \\
S hematobium & & & \\
Present & $13(4.4)$ & & \\
Absent & $285(95.6)$ & & \\
\hline
\end{tabular}

\section{List of abbreviations}

SH: Schistosomaheamtobium

EDTA: Ethylenediaminetetraacetic acid

ANC: antenatal care

OPD: outpatient department

\section{Declaration}

\section{Competing interest}

Authors declare that they have no competing interest

\section{Authors' contributions}

ORISH Verner conceived, planned, executed the study and drafted the manuscript as well as analysis of data; Richmond Afoakwah, helped in drafting the manuscript; Ekene Nwaefuna and Danny flint Yeboah edited/reviewed and revised the manuscript. All authors have read and approved the final manuscript.

\section{References}

[1]. Artavanis-Tsakonas, K., Tongren, J. E., \& Riley, E. M. (2003). The war between the malaria parasite and the immune system: immunity, immunoregulation and immunopathology. Clinical \& Experimental Immunology, 133(2), 145-152.

[2]. Adegnika, A. A., Ramharter, M., Agnandji, S. T., AtebaNgoa, U., Issifou, S., Yazdanbahksh, M., \& Kremsner, P. G. (2010). Epidemiology of parasitic co-infections during pregnancy in Lambaréné, Gabon. Tropical Medicine \& International Health, 15(10), 1204-1209.

[3]. Brooker, S. (2007). Spatial epidemiology of human schistosomiasis in Africa: risk models, transmission dynamics and control. Transactions of the Royal Society of Tropical Medicine and Hygiene, 101(1), 1-8.

[4]. Beeson, J. G., Brown, G. V., Molyneux, M. E., Mhango, C., Dzinjalamala, F., \& Rogerson, S. J. (1999). Plasmodium falciparum isolates from infected pregnant women and children are associated with distinct adhesive and antigenic properties. Journal of infectious diseases, 180(2), 464-472.

[5]. Bhaskaram, P., Balakrishna, N., Radhakrishna, K. V., \& Krishnaswamy, K. (2003). Validation of hemoglobin estimation using Hemocue. The Indian Journal of Pediatrics, 70(1), 25-28. 
[6]. Clerk, C.A., Bruce, J., Greenwood, B. \& Chandramohan, D. 2009. The epidemiology of malaria among pregnant women attending antenatal clinics in an area with intense and highly seasonal malaria transmission in northern Ghana. Trop Med Int Health. 14(6):688-95.

[7]. Chitsulo, L., Engels, D., Montresor, A., \& Savioli, L. (2000). The global status of schistosomiasis and its control. Actatropica, 77(1), 41-51.

[8]. DeMaeyer, E. M., Hallberg, L., Gurney, J. M., Sood, S. K., Dallman, P., Srikantia, S. G., \& World Health Organization. (1989). Preventing and controlling iron deficiency anaemia through primary health care: a guide for health administrators and programme managers.

[9]. DATE, E. A. N. (2014). I hereby declare that this submission is my own work towards the MPhil and that to the best of my knowledge, it contains no material previously published by another person nor material which has been accepted for the award of any other degree of the university, except where due acknowledgement has been made in the text (Doctoral dissertation, KWAME NKRUMAH UNIVERSITY OF SCIENCE AND TECHNOLOGY, KUMASI).

[10]. Friedman, J. F., Mital, P., Kanzaria, H. K., Olds, G. R., \& Kurtis, J. D. (2007). Schistosomiasis and pregnancy. Trends in parasitology, 23(4), 159-164.

[11]. Froeschke, G., Harf, R., Sommer, S., \& Matthee, S. (2010). Effects of precipitation on parasite burden along a natural climatic gradient in southern Africa-implications for possible shifts in infestation patterns due to global changes. Oikos, 119(6), 1029-1039.

[12]. Gething, P. W., Patil, A. P., Smith, D. L., Guerra, C. A., Elyazar, I. R., Johnston, G. L., ... \& Hay, S. I. (2011). A new world malaria map: Plasmodium falciparum endemicity in 2010. Malaria journal, 10(1), 1.

[13]. Guyatt, H. L., \& Snow, R. W. (2001). The epidemiology and burden of Plasmodium falciparumrelated anemia among pregnant women in sub-Saharan Africa. The American journal of tropical medicine and hygiene, 64(1 suppl), 36-44.

[14]. Greenwood, B., Marsh, K., \& Snow, R. (1991). Why do some African children develop severe malaria?. Parasitology today, 7(10), 277-281.

[15]. Guyatt, H. L. \& Snow, R. W. (2004). Impact of malaria during pregnancy on low birth weight in sub-Saharan Africa. Clin Microbiol Rev. 17(4), 760-9. Review.

[16]. Gray, D. J., Ross, A. G., Li, Y. S., \& McManus, D. P. (2011). Diagnosis and management of schistosomiasis. BMJ, 342(may16_2), d2651-d2651.

[17]. Ghana health service, (2005). Malaria in Pregnancy Training manual for Health professionals.

[18]. Hotez, P. J., \& Kamath, A. (2009). Neglected tropical diseases in sub-saharan Africa: review of their prevalence, distribution, and disease burden. PLoSNegl Trop Dis, 3(8), e412.

[19]. Orish, V. N., Onyeabor, O. S., Boampong, J. N., Aforakwah, R., Nwaefuna, E., \& Iriemenam, N. C. (2012). Adolescent pregnancy and the risk of Plasmodium falciparum malaria and anaemia-A pilot study from Sekondi-Takoradi metropolis, Ghana. Actatropica, 123(3), 244-248.

[20]. Pullan, R., \& Brooker, S. (2008). The health impact of polyparasitism in humans: are we underestimating the burden of parasitic diseases?. Parasitology, 135(07), 783-794.

[21]. Stevens, G. A., Finucane, M. M., De-Regil, L. M., Paciorek, C. J., Flaxman, S. R., Branca, F., ... \& Nutrition Impact Model Study Group. (2013). Global, regional, and national trends in haemoglobin concentration and prevalence of total and severe anaemia in children and pregnant and non-pregnant women for 1995-2011: a systematic analysis of population-representative data. The Lancet Global Health, 1(1), e16-e25.

[22]. Siegrist, D., \& Siegrist-Obimpeh, P. (1992). Schistosomahaematobium infection in pregnancy. Actatropica, 50(4), 317-321.

[23]. Tatem, A. J., Smith, D. L., Gething, P. W., Kabaria, C. W., Snow, R. W., \& Hay, S. I. (2010). Ranking of elimination feasibility between malaria-endemic countries. The Lancet, 376(9752), 15791591.

[24]. Takougang, I., Meli, J., Fotso, S., Angwafo 3rd, F., Kamajeu, R., \& Ndumbe, P. M. (2003). Hematuria and dysuria in the self-diagnosis of urinary schistosomiasis among school-children in Northern Cameroon. African journal of health sciences, 11(3-4), 121-127. 
Texila International Journal of Public Health

Volume 4, Issue 4, Dec 2016

[25]. Uneke, C. J. (2007). Impact of Placental Plasmodium falciparum Malaria on Pregnancy and Perinatal Outcome in Sub-Saharan AfricaI: Introduction to Placental Malaria Yale. J Biol Med. 80(2), 39-50.

[26]. WHO. (2003). The africa malaria report. Geneva (WHO/CDS/MAL/2003.1093).

[27]. Wilkins, H. A., Goll, P. H., Marshall, T. D. C., \& Moore, P. J. (1984). Dynamics of Schistosomahaematobium infection in a Gambian community. I. The pattern of human infection in the study area. Transactions of the Royal Society of Tropical Medicine and Hygiene, 78(2), 216-221. 


\title{
Determining the Relationship between Home Environment and Academic Performance. a case of Clinical Medical Rehabilitation Students of Obafemi Awolowo University
}

\author{
Article by Ilesanmi Oluwafemi Temitayo \\ Ph.D. in Public Health, Texila American University, Nigeria \\ E-mail: aboundinggrace08@yahoo.com
}

\begin{abstract}
The environment a child finds himself goes a long way in determining his learning ability and ultimately his academic performance in school. Home environment has been recognized as having a relationship with the academic achievement of students. The present research study was designed to assess the various home environment variables which are predictive of academic performance of clinical Medical Rehabilitation students in Obafemi Awolowo University $(O A U)$. The variables under consideration were the academic performance (grade point average) as a dependent variable and the parents' level of income, level of education, residential area, marital status, family structure, and students' accommodation type, average number of meals taken per day, study hour, and gender were independent variables. The data were collected from 102 clinical students who were purposively sampled from the department of Medical Rehabilitation using structured questionnaire. Data were collated and analyzed using descriptive and inferential statistics of Pearson Chi-square and multiple regression analyses. The result showed that there was statistical significant association between academic performance and father's level of income, the number of study hours per day and the average number of meals taken per day. In conclusion, this study reveals that father's level of income, number of study hours per day and average number of meals taken per day as home environment variables considered is predictive of academic performance of Clinical Medical Rehabilitation Students of OAU.
\end{abstract}

Keywords: Home environment, academic performance, clinical students

\section{Introduction}

The environment a child finds himself goes a long way in determining his learning ability and ultimately his academic performance in school (Ayodele, 2006). Home environment has been recognized as having a relationship with the academic achievement of students (Ajila and Olutola, 2007; Ichado, 1998; Nzewuawah, 1995). Studies have found that the physical environments among other factors are all variables that affect students' achievement (Molnar, et al, 2000). The factors/variables that affect student performance may be termed as student factors, family factors, school factors and peer factors (Crosnoe, Johnson and Elder, 2004; Eamon, 2005). Generally these factors include age, gender, geographical belongingness, ethnicity, Parents marital status, socio economic status (SES), Parents' education level, Parents' profession, language, income and religious affliation. Researches have shown that school environment factors, student role performances, peer factors have been shown to affect test scores (Eamon, 2005; Crosnoe et al 2004; Santor et al, 2000). Research has found that socioeconomic status (SES), parental involvement and family size are particularly important family factors (Major banks, 1996). The most important predictor of achievement in school associated with the family is socioeconomic status of parents (Munsincer, 1999; Dubey, 1972). Socio economic status can be defined as a person's overall social position to which attainments in both the social and economic domain contributes. Socioeconomic background refers to parents' educational attainment, occupation, level of income and social class placement (Jeynes, 2002; McMillan \& Western, 2002). Parental education and family socioeconomic status level have positive correlations with the student's quality of 
achievement (Jeynes, 2002; Mitchell \& Collom, 2001; Ma \& Klinger, 2000; Caldas \& Bankston, 1997; Parelius \& Parelius, 1987). While there is disagreement over how best to measure SES, most studies indicate that children from low SES families do not perform as well as they potentially could at school compared to children from high SES families (Graetz, 1995). Various studies have tried to find out the relationship between these home environment variables and the academic performance of University students in Nigeria and other parts of the world. However, there have been limited studies on which home environment variable best predict the academic performance of University students using grade point average (GPA) in Nigeria. This study is a survey which sought to determine the relationship between home environment variables and academic performance of clinical Medical Rehabilitation students in the College of Health Sciences of Obafemi Awolowo University, Ile Ife, Osun State.

\section{Significance of study}

The study will help to reveal components of home environment responsible for students' academic performance in a university in Nigeria. It will also compare the relationships of the variables of home environment as they affect the academic performance of students in university and help to determine how the variables best predicts their contribution to good academic performance. This is particularly useful for policy makers, health administrators and clinical educators in the educational planning and implementation as it offers empirical support for them. Furthermore, students would also benefit from the study through suggestions offered on the interactions of the variables to improving academic performance. The study will lay a solid foundation which subsequent researchers in similar studies may build upon.

\section{Statement of problem}

Many studies have examined the factors affecting the academic performance of graduate students which included socioeconomic status of parents, family structure amongst others. Home environment variables have been shown to contribute to the academic performance of students. Presently I am not aware of any study in Nigeria which sought to determine the relationship between home environment variables and academic performance especially among university students. This study therefore attempts to investigate parents' socioeconomic status, gender, average number of meals taken per day, hours of study, accommodation type which is home environment variables as contributory factors to students' academic performance among Clinical Medical Rehabilitation students of Obafemi Awolowo University.

\section{Research questions}

The major research questions for this study include the following:

a. What home environment variables are predictive of academic performance (using GPA) among Clinical Medical Rehabilitation Students in OAU?

b. How good are family environment variables at predicting grade point average among Clinical Medical Rehabilitation Students in OAU?

\section{Research objectives}

1. To assess the various home environment variables which are predictive of academic performance using grade point average of Clinical Medical Rehabilitation Students in OAU.

2. To determine which home environment variable best predicts academic performances using grade point average of Clinical Medical Rehabilitation Students in OAU.

\section{Hypotheses}

1. Parent's level of income would not have a significant association with the academic performance of clinical medical rehabilitation students. 
2. Parent's level of qualification would not have a significant association with the academic performance of clinical medical rehabilitation students.

3. Family structure would not have a significant association with the academic performance of clinical medical rehabilitation students.

4. Gender would not have a significant association with the academic performance of clinical medical rehabilitation students.

5. The average number of meals taken per day would not have a significant association with the academic performance of clinical medical rehabilitation students.

6. Type of accommodation of students would not have a significant association with the academic performance of clinical medical rehabilitation students.

7. Parents' residential area would not have a significant association with the academic performance of clinical medical rehabilitation students.

8. Number of hours of study would not have a significant association with the academic performance of clinical medical rehabilitation students.

9. Parents' marital status would not have a significant association with the academic performance of clinical medical rehabilitation students.

\section{Literature review}

Educational performance of school has also been found to vary according to the student's sex (Horne, 2000). Reviews of the evidence suggest that boys suffer an educational disadvantage relative to girls, especially in terms of performance in literacy (Buckingham, 2000b, 1999 Chambers and Schreiber, 2004). Still other researches have found little to no difference in achievement between the sexes (Chamber and Schreiber, 2004; Eitle, 2005).

Nutrition is closely linked to overall physical health and is a correlate of academic performance (Hoffman, et al, 2010). Socioeconomic status is significantly correlated with both academic performance and obesity (Baxter et al, 2011). Gender, ethnicity, and father's occupation are significant contributors to student achievement (McCoy, 2005; Peng and Hall, 1995). Krashen (2005) concluded that students whose parents are educated score higher on standardized tests than those who parents were not educated. The academic performance of students heavily depends up on the parental involvement in their academic activities to attain the higher level of quality in academic success (Bernard, 2004; Shumox and Lomax, 2001; Henderson, 1988). Family structure has also been noted to contribute to academic performance of students. Children from families of single parent (sole parent are likely to have lower educational performance (Rich, 2000). Students from non-metropolitan area are more likely to have lower educational outcomes in terms of academic performance and retention rates than students from metropolitan area (HREOC, 2000; Cheers, 1990). Lower educational attainment has also been found to be associated with children living in public housing compared to those in private housing (Sparkes, 1999). A number of studies have found that a child's home environment account for a substantial portion of the effects of family income on cognitive outcomes in young children (Duncan and Brooks-Gunn, 1997). Studies have also shown that school effort in an indicator of academic performance (Ceballo et al, 2004; Carbonaro, 2005). School effort has been defined as the amount of time and energy that student expend in meeting the formal academic requirements established by their teacher and/or school. High student effort leads to greater educational values, which in turn indirectly affects student performance. This has been linked to higher student grade point average (GPA) (Carbonaro, 2005). GPA refers to a ccumulative grade point average a student earns for all university courses. Research proves that university or even high school GPA predicts a student's academic performance (Mckenzie and Schweitzer, 2010).

Shoukat et al, 2013 considered gender, age, teaching, faculty, students schooling, residential area of students, medium of instructions in schools, tuition trend, daily study hour and accommodation as hostelries or day scholar as factors which affect the students academic gain and learning performance. Kanyongo et al, 2006 in their study considered possession of such things lie piped water, electricity, refrigerator and television which collectively taken to 
be a measure of socioeconomic status. SES, together with several other factors were used as measures of the students' home environment in their study. Ajila and Olutola (2000) investigated Parents' socioeconomic status on University students' academic performance. The study revealed that family income, occupations, house type, level of Parents' education and dwelling area exert a significant influence on academic achievement. Kingdom (1996) reported that home factors have significant correlation with students' academic achievement. He argued that student's age and number of hours of home study per week affect academic achievement. He also identified family economic status as being significantly related to academic achievement. Chadwick et al, 1976 conducted a study on Indian education in the city and found that family instability is significantly related to GPA for females and not for males.

Academic success is an excellent indicator for the overall well being of youth and a primary predictor and determinant of adult health outcomes (Strabstein and Piazza, 2008). Variation in the social economic background remains one of the major sources of educational inequality. Policy makers and researchers have sought to find out which factor(s) really contribute to the academic performance of higher institution students so as to know how to direct policies that will meditate these factors and hence proffer an influence which will yield a good outcome for then as a good academic performance has a positive correlation to their future achievement.

\section{Methods}

\section{Study area and population}

This study was carried out in the department of medical rehabilitation, faculty of Basic Medical Sciences, College of Health Sciences of ObafemiAwolowo University, Ile-Ife, Osun State, Nigeria. Clinical students (Clinical 1 and 2) of the department of medical rehabilitation (comprising of Physiotherapy and Occupational therapy) were the study population.

\section{Research design}

The research design employed for the study is ex-post facto using a survey design and a multiple regression design. Asika (1991) stated that ex-post facto research is a systematic empirical study in which the researcher does not in any way control and manipulate the independent variables because the situation for the study already exists or has already taken place. The author further opined that the researcher could not manipulate the independent variables because they cannot be manipulated. However, the researcher can indeed create or contrive a situation that will generate the requisite data for analysis. In this study, the home environment factors are located from factors studied in the education literature.

\section{Data collection}

Information was collected from respondents by means of a pre-tested 20- item, purpose designed, self- administered anonymous questionnaire containing open and closed ended questions. The questionnaire was divided into four major sections for ease of administration. The instruments are structured questionnaire aimed at eliciting the respondents' view about the relationship between home environment variables and their academic performance.

Section one of the questionnaire contained 6 items which sought for information on demographic data such as gender, age, religion, course option, course level and ethnic group.

Section two of the questionnaire contained 4 items which required the respondents to supply information on their present cumulative grade point average, type of residential accommodation they use, the number of personal study hour(s) per day and the average number of meals taken per day. Section three of the questionnaire contained 5 items which required the respondents to supply information on their Parents' level of income per month, Parents' educational attainment, family structure, Parents' residential area and Parents' marital status. Section four of the questionnaire contained 5 items which are close and open ended questions which sought to find out students response on factors may affect their academic 
performance which include interest in the course of study, peer influences, perception of the course of study and parents' support.

\section{Sample Size determination}

The minimum sample size was calculated using Yamane (1967) using the equation

$$
\mathrm{n}=\frac{\mathrm{N}}{1+\mathrm{N}(\mathrm{e})^{2}}
$$

where $\mathrm{n}$ is the sample size, $\mathrm{N}$ is the population size which is 121 clinical medical rehabilitation students and e is the level of precision at $\pm 5 \%$ (A 95\% confidence level and $\mathrm{P}=0.5$ are assumed for the equation). Therefore $\mathrm{n}=93$. To give allowance for an anticipated non-response rate of $10 \%$ ( 9 respondents), the sample size was increased by 9 to make 102 respondents. A total of 121 questionnaires were then taken to the students to be distributed for the study. 102 (response rate of 84\%) were returned and used for the analysis. Each respondent was provided with an assurance of confidentiality of information he or she provides in the questionnaire.

\section{Sampling method}

A purposive sampling method was used to select clinical students from the department of Medical rehabilitation comprising both Physiotherapy and Occupational therapy. They are students who are in their 400 and 500 levels and had spent sufficient time in the course to accumulate a substantive grade point average which will be of relevance to present study and this could now be generalized to larger population of students in future studies.

\section{Data analysis}

The data gathered through the completed questionnaires were collated, analyzed and presented using both descriptive and inferential statistics. Inferential statistics used was multiple regression analysis and Pearson Chi-square analysis. In this study a linear model of clinical student performance was designed. The students cumulative grade point average (CGPA), which constitutes the dependent variable was got from the questionnaire where it was imputed as high performance ( $>60 \%$ ) and low performance (between 50 and $59 \%$ ) and father's income, mother's income, father's education, mother's education, family structure, average number of meals taken per day, student accommodation type, parents' residential area, study hour, gender and parents marital status as independent variables. All clinical medical rehabilitation students in OAU the sample consist of $(\mathrm{n}=102)$. Close ended questions were used in part one to three while part 4 constituted both closed and open ended questions to elicit response of respondents on questions which have been established in other literatures as contribution to students academic performance. Data from questionnaire was complied, sorted, edited, classified and coded into the coding sheet of SPSS 13.0 (version) and Microsoft Excel 2007.

\section{Results}

\section{Demographic characteristics of the study population}

The profile of 102 respondents interviewed with the questionnaire is shown in Table 1 . The clinical students who participated in the survey had more males than females $(62.7 \%$ males and $37.3 \%$ females). The sex distribution is shown in figure 1 . The mean age was 22.9 years with most of respondents (75\%) in the 20-24years age bracket. These were followed by those aged 25-29years (23.4\%). Majority of the students who participated in the study were in clinical 1(51.6\%), Physiotherapy option (87.5\%), Christians (79.7\%) and mostly Yoruba tribes $(93.8 \%)$.

\section{Association between student academic performance and home environment}




\section{variables}

Research question 1 was answered using tables $2-13$ to know which home environment variables are predictive of academic performance using GPA among clinical medical rehabilitation students in OAU.

Table 2-13 are Chi-square analyses which show associations between student academic performance and father's income, mother's income, father's education, mother's education, family structure, gender, average number of meals taken per day, student type of accommodation, parents residence, study hours, parents marital status (parents together), Parents marital status (parents together).

Table 2, Table 8 and Table 11 showed there were statistical significant association between academic performance and father's income, average number of meals taken per day and study hours per day..

Table 3,4,5,6,7,9,10, 12, and 13 showed there was no statistical significant association between student academic performance and mother's income father's education, mother's education, family structure, gender, student type of accommodation, parent's residence, marital status (parents divorced), marital status (parents together).

\section{Predicting relationship between student academic performance and home environment variables}

Research question 2 was answered using table 14. It is a regression statistics for independent and dependent variables. In the summary, academic performance using CGPA was used as dependent variable and the father's income, mother's income, father's education, mother's education family structure, number of meals taken per day, student accommodation type, parent's residential area, study hour, gender and parent's marital status (parent divorced, parents together) as independent variables. The result showed that $\mathrm{R}^{2}=12.6 \%$. This shows that $12.6 \%$ variations in academic performance are due to the independent variables considered. The coefficients of fathers' income, mothers' income, mothers' education, family structure, average number of meal taken per day, study hour, parents' residence, gender, parents divorced and parents together show that a unit increase in academic performance by 0.37 , $0.05,0.17,0.18,0.66,0.37,0.44,0.09,0.54,0.53$ respectively, holding other factors as constant. The coefficients are insignificant at $5 \%$ level of significance. Also, the coefficients of fathers' education and student accommodation type show that a unit increases in these variables cause of decrease in academic performance by -0.25 and -0.11 , holding other factors as constant. The coefficients are also insignificant at $5 \%$ level of significance.

\section{Discussion}

This study was conducted to carry out a survey to determine the relationship between home environment variables and academic performance of clinical medical rehabilitation students of ObafemiAwolowo University in Ile-Ife, Osun State, Nigeria. Studies on home environment variables and academic performance have been of special interest because of the significant impact it has on the health and well being of the students. The sex distribution in this study had more male respondents than female respondents. This result is similar to a study carried out in 2013 which also reported male respondents higher in number than female respondents (Ali Shoukat et al, 2013). The result also showed higher Christians respondents and Yoruba respondents than any other religious and tribes respectively. This result can be explained by the fact that the sampled University is predominantly a Christian institution situated in Yoruba land. By that it means that the study environment will usually reflect the characteristics of the study population.

Father's level of income, average number of meals taken per day and the number of hours of study had a significant association with the academic performance of the students. This result corroborated the studies by Abdu-raheem, 2015; Lacour and Tissington, $2011 \mathrm{l} \mathrm{Ali,}$ Shoukat et al, 2013 which showed a significant relationship between father's level of income and academic performance. However, the study by Hijazi and Naqvi, 2006 corroborated the 
result that parent level of income has a significant relationship with academic performance with deference to mother's level of income which the result of this study did not show.

Credence to this result Pollit (1984), observed that good nutrition is an endogenous factor that affects learning ability and skill before and after the child is in school. Also, Acham et al, 2012 found a significant association between consumption of breakfast and a midday meal with academic achievement of students in Uganda. Also in credence to this result, Ali et al (2013) found that study hours significantly affect the academic performance of students of Islamia University, Pakistan. Also, Hijazi et al (2006) found that the number of hours spent in study after colleges on daily basis significantly affect academic performance of students of Punjab University of Pakistan. These home environment variables of father's level of income, average number of meals taken per day and number of hours of study by the students significantly predict academic performance in this study. Other home environment variables considered such as parents' level of education, family structure, parents' residential area, and parents' marital status did not significantly predict association between them and academic performance in this study. This may not mean that these home environment variables would not predict a significant association with academic performance in other climes and settings as some studies have showed a significant association (Shoukat Ali et al, 2013; Adeyemi and Adeyemi, 2014; Abdu-raheem, 2015, Hijazi and Naqvi, 2006; Asikhia, 2010).

Overall, the contribution of home environment factors considered in this study was about 13 percent of the variance in academic performance. This means that home environment factors account for a little bit greater than tenth of the variance in the academic performance. This shows that there are other variables which are not considered in this study which account for the other measure of variance in academic performance.

\section{Conclusion}

The outcome of this study reveals that father's level of income, average number of meals taken per day and the number of hours of study as home environment variables considered which are predictive of academic performance of clinical medical rehabilitation students of ObafemiAwolowo University, Ile-Ife.

\section{Recommendations}

Based on the findings in this study, the following are therefore recommended:

1. Because this study is only for the clinical medical rehabilitation students of ObafemiAwolowo University, Ile-Ife, it will be advisable that the study should be conducted at a wide level of the whole University or to other Universities so that the results may be externally valid.

2. Policies that will improve the level of employment opportunities for the parents should be encouraged by government as these will affect the level of income of parents and guardians which will otherwise affect the academic performance of students.

3. Public health campaigns should be facilitated to families to enlighten them about the significance of improving the nutrition status of their children which is a key factor in improving health and academic performance of their children.

4. Conducive environment for reading should be made available for the students by the authorities as good number of hours will be required to assimilate the volume of academic materials required for their learning. 
Table 1. Demographic characteristics of respondents by Gender Variables

\begin{tabular}{|c|c|c|c|c|c|c|}
\hline & $\begin{array}{l}\text { Males } \\
\mathrm{N}\end{array}$ & $\begin{array}{l}(64 ; 62.7 \%) \\
(\%)\end{array}$ & $\begin{array}{l}\text { Females } \\
\mathrm{N}\end{array}$ & $\begin{array}{l}(38,37.3 \%) \\
\%\end{array}$ & $\begin{array}{l}\text { Total } \\
\mathrm{N}\end{array}$ & $\begin{array}{l}(102 ; 100 \%) \\
\%\end{array}$ \\
\hline $\begin{array}{l}\text { Age } \\
20-24 \\
25-29 \\
\geq 30 \\
\end{array}$ & $\begin{array}{l}48 \\
15 \\
1 \\
\end{array}$ & $\begin{array}{l}(750) \\
(23.4) \\
(1.6) \\
\end{array}$ & $\begin{array}{l}35 \\
3 \\
- \\
\end{array}$ & $\begin{array}{l}(92.1) \\
(7.9) \\
- \\
\end{array}$ & $\begin{array}{l}83 \\
18 \\
1 \\
\end{array}$ & $\begin{array}{l}(81.4) \\
(17.6) \\
(1.0)\end{array}$ \\
\hline $\begin{array}{l}\text { Course level } \\
\text { Clinical I } \\
\text { Clinical } 2 \\
\end{array}$ & $\begin{array}{l}33 \\
31 \\
\end{array}$ & $\begin{array}{l}(51.6) \\
(48.4)\end{array}$ & $\begin{array}{l}21 \\
17\end{array}$ & $\begin{array}{l}(55.3) \\
(44.7)\end{array}$ & $\begin{array}{l}54 \\
48 \\
\end{array}$ & $\begin{array}{l}(52.9) \\
(47.1)\end{array}$ \\
\hline $\begin{array}{l}\text { Course option } \\
\text { Physiotherapy } \\
\text { Occupation } \\
\text { Therapy }\end{array}$ & $\begin{array}{l}56 \\
8\end{array}$ & $\begin{array}{l}(87.5) \\
(12.5)\end{array}$ & $\begin{array}{l}28 \\
10\end{array}$ & $\begin{array}{l}(73.7) \\
(26.3)\end{array}$ & $\begin{array}{l}84 \\
18\end{array}$ & $\begin{array}{l}(82.4) \\
(17.6)\end{array}$ \\
\hline $\begin{array}{l}\text { Ethnic group } \\
\text { Yoruba } \\
\text { Igbo } \\
\text { Hausa } \\
\text { Others }\end{array}$ & $\begin{array}{l}60 \\
2 \\
- \\
2 \\
\end{array}$ & $\begin{array}{l}(93.8) \\
(3.1) \\
- \\
(3.1) \\
\end{array}$ & $\begin{array}{l}33 \\
3 \\
- \\
2 \\
\end{array}$ & $\begin{array}{l}(86.8) \\
(77.9) \\
- \\
(5.3) \\
\end{array}$ & $\begin{array}{l}93 \\
5 \\
- \\
4 \\
\end{array}$ & $\begin{array}{l}(91.2) \\
(4.9) \\
- \\
(3.9) \\
\end{array}$ \\
\hline $\begin{array}{l}\text { Religion } \\
\text { Christianity } \\
\text { Islam }\end{array}$ & $\begin{array}{l}51 \\
13 \\
\end{array}$ & $\begin{array}{l}(79.7) \\
(20.3)\end{array}$ & $\begin{array}{l}32 \\
6 \\
\end{array}$ & $\begin{array}{l}(84.2) \\
(15.8)\end{array}$ & $\begin{array}{l}83 \\
19 \\
\end{array}$ & $\begin{array}{l}(81.4) \\
(18.6)\end{array}$ \\
\hline
\end{tabular}

Table 2. Student academic performance and father's income

Father's Income

\begin{tabular}{|l|l|l|l|l|l|l|l|l|}
\hline Performance & 10-20T & 20-50T & $\mathbf{5 0 - 1 0 0 T}$ & $\begin{array}{l}\mathbf{1 0 0 -} \\
\mathbf{2 0 0 T}\end{array}$ & $\mathbf{> 2 0 0 T}$ & $\begin{array}{l}\text { Pearson } \\
\mathbf{X}^{\mathbf{2}}\end{array}$ & Df & Sig \\
\hline $\begin{array}{l}\text { Low } \\
\text { performance }\end{array}$ & 13 & 13 & 9 & 15 & 12 & 9.776 & 4 & 0.044 \\
\cline { 1 - 5 } $\begin{array}{l}\text { High } \\
\text { performance }\end{array}$ & 3 & 4 & 8 & 8 & 17 & & \\
\hline
\end{tabular}

where $\mathrm{T}$ - Thousand naira

Table 3. Student academic performance and mother's income

Mother's Income

\begin{tabular}{|c|c|c|c|c|c|c|c|c|}
\hline Performance & $10-20 T$ & $\begin{array}{l}\text { 26- } \\
50 T\end{array}$ & $50-100 T$ & $\begin{array}{l}\text { 100- } \\
200 T\end{array}$ & $>200 \mathrm{~T}$ & $\begin{array}{l}\text { Pearson } \\
X^{2}\end{array}$ & Df & Sig \\
\hline $\begin{array}{l}\text { Low } \\
\text { performance }\end{array}$ & 16 & 12 & 12 & 16 & 6 & \multirow[t]{2}{*}{4.824} & \multirow[t]{2}{*}{4} & \multirow[t]{2}{*}{0.306} \\
\hline $\begin{array}{l}\text { High } \\
\text { performance }\end{array}$ & 4 & 7 & 9 & 16 & 4 & & & \\
\hline
\end{tabular}

where $\mathrm{T}$ - Thousand naira

Table 4. Student academic performance and father's education

Father's Education Level

\begin{tabular}{|l|l|l|l|l|l|l|l|}
\hline Performance & $\leq$ Sec & Dipl & B.Sc & $\geq$ M.Sc & $\begin{array}{l}\text { Pearson } \\
\mathbf{X}^{\mathbf{2}}\end{array}$ & Df & Sig \\
\hline Low performance & 10 & 8 & 24 & 20 & 0.597 & 3 & 0.897 \\
\hline High performance & 5 & 4 & 16 & 15 & & & \\
\hline
\end{tabular}

Sec- secondary school, Dipl- diploma, B.Sc- Bachelor, M.Sc- Master

Table 5. Student academic performance and mother's education 


\begin{tabular}{|l|l|l|l|l|l|l|l|}
\hline \multicolumn{10}{|c|}{ Mother's Education Level } \\
\cline { 1 - 6 } Performance & $\leq$ Sec & Dipl & B.Sc & $\geq$ M.Sc & $\begin{array}{l}\text { Pearson } \\
\mathbf{X}^{\mathbf{2}}\end{array}$ & Df & Sig \\
\hline Low performance & 14 & 21 & 20 & 7 & 2.024 & 3 & 0.567 \\
\hline High performance & 7 & 10 & 18 & 5 & & & \\
\hline
\end{tabular}

Sec- secondary school, Dipl- diploma, B.Sc- Bachelor, M.Sc- Master

Table 6. Student academic performance and family structure

Family Structure Sponsor

\begin{tabular}{|l|l|l|l|l|l|}
\hline Performance & One Parent & Two Parents & $\begin{array}{l}\text { Pearson } \\
\mathbf{X}^{\mathbf{2}}\end{array}$ & Df & Sig \\
\hline Low performance & 19 & 43 & 0.810 & 1 & 0.368 \\
\hline High performance & 9 & 31 & & & \\
\hline
\end{tabular}

Table 7. Student academic performance and gender

\begin{tabular}{|l|l|l|l|l|l|}
\hline Performance & Male & Female & $\begin{array}{l}\text { Pearson } \\
\mathbf{X}^{\mathbf{2}}\end{array}$ & Df & Sig \\
\hline Low performance & 39 & 23 & 0.046 & 1 & 0.830 \\
\hline High performance & 25 & 15 & & & \\
\hline
\end{tabular}

Table 8. Student academic performance and average number of meals taken per day

\begin{tabular}{|l|l|l|l|l|l|l|}
\hline Performance & $\mathbf{1}$ meal & $\mathbf{2}$ meals & $\mathbf{3}$ meals & $\begin{array}{l}\text { Pearson } \\
\mathbf{X}^{\mathbf{2}}\end{array}$ & Df & Sig \\
\hline Low performance & 7 & 43 & 12 & 5.689 & 2 & 0.049 \\
\hline High performance & 0 & 28 & 12 & & & \\
\hline
\end{tabular}

Table 9. Student academic performance and performance and student type of accommodation

Accommodation Type

\begin{tabular}{|l|l|l|l|l|l|}
\hline Performance & Hostel & $\begin{array}{l}\text { Private } \\
\text { accommodation }\end{array}$ & $\begin{array}{l}\text { Pearson } \\
\mathbf{X}^{2}\end{array}$ & df & Sig \\
\hline Low performance & 38 & 24 & 0.015 & 1 & 0.902 \\
\hline High performance & 25 & 15 & & \\
\hline
\end{tabular}

Table 10. Student academic performance and parents’ residence.

Parents Residence

\begin{tabular}{|l|l|l|l|l|l|}
\hline Performance & Rural & Urban & $\begin{array}{l}\text { Pearson } \\
\mathbf{X}^{\mathbf{2}}\end{array}$ & df & Sig \\
\cline { 1 - 4 } Low performance & 14 & 48 & 2.648 & 1 & 0.104 \\
\cline { 1 - 3 } High performance & 4 & 36 & & & \\
\hline
\end{tabular}

Table 11. Student academic performance and study hours per day

Study hours

\begin{tabular}{|l|l|l|l|l|l|l|}
\hline Performance & $<\mathbf{2 h r s}$ & $\mathbf{2 - 5 h \mathbf { h }}$ & $\mathbf{>}$ hhrs & $\begin{array}{l}\text { Pearson } \\
\mathbf{X}^{\mathbf{2}}\end{array}$ & $\mathbf{d f}$ & $\mathbf{S i g}$ \\
\hline Low performance & 7 & 43 & 12 & 5.689 & 2 & 0.049 \\
\hline High performance & 0 & 28 & 12 & & & \\
\hline
\end{tabular}

Table 12 Student academic performance and parents marital status (parents divorced) 
Parents Divorced

\begin{tabular}{|l|l|l|l|l|l|}
\hline Performance & Yes & No & $\begin{array}{l}\text { Pearson } \\
\mathbf{X}^{\mathbf{2}}\end{array}$ & Df & Sig \\
\hline Low performance & 4 & 58 & 0.093 & 1 & 0.761 \\
\cline { 1 - 3 } High performance & 2 & 38 & & & \\
\hline
\end{tabular}

Table 13. Student academic performance and parents marital status (parents together)

Parent's together

\begin{tabular}{|l|l|l|l|l|l|}
\hline Performance & Yes & No & $\begin{array}{l}\text { Pearson } \\
\mathbf{X}^{2}\end{array}$ & Df & Sig \\
\cline { 1 - 4 } Low performance & 54 & 8 & 0.004 & 1 & 0.925 \\
\cline { 1 - 3 } High performance & 35 & 5 & & & \\
\hline
\end{tabular}

Table 14. Regression statistics for independent and dependent variables

\begin{tabular}{|l|l|l|l|l|}
\hline & & Coefficient & Standard Error & Significant (P-value) \\
\hline Performance & FINCOM & 0.372 & 0.228 & 0.103 \\
\hline & MICOME & 0.051 & 0.249 & 0.837 \\
\hline & FEDUC & -0.250 & 0.284 & 0.380 \\
\hline & MEDUC & 0.177 & 0.318 & 0.578 \\
\hline & FSTRUC & 0.184 & 0.561 & 0.743 \\
\hline & MEAL & 0.659 & 0.485 & 0.174 \\
\hline & STUDYHR & 0.373 & 0.426 & 0.381 \\
\hline & STUACCOM & -0.114 & 0.484 & 0.814 \\
\hline & PRESIDENCE & 0.442 & 0.723 & 0.541 \\
\hline & GENDER & 0.088 & 0.473 & 0.853 \\
\hline & PRROVRCED & 0.541 & 1.249 & 0.665 \\
\hline & PTOGETHER & 0.531 & 0.877 & 0.545 \\
\hline & CONSTANT & -6.347 & $3 / 539$ & 0.073 \\
\hline
\end{tabular}

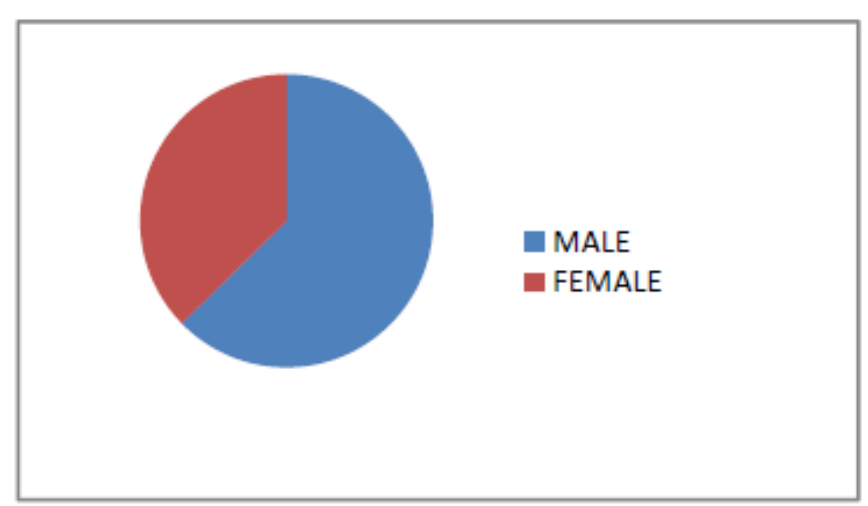

Figure 1. Gender distribution of respondents

\section{References}

[1]. Abdul-raheem B. O (2015). Parents' Socio-economic status as predictor of secondary school students` Academic performance in Ekiti State, Nigeria. Journal of Education and practice. Vol 6. No.1, 2015. ISSN 2222-1735.

[2]. Adeyemi A.M and Adeyemi S.B (2014). Personal factors as predictors of Students' academic achievement in Colleges of Education in South Western Nigeria. Education Research and Reviews. Vol (4). Pp 97-109. 
[3]. Ajila, C and Olutola, A. (2000). Impact of parent's socioeconomic status on University Student's academic performance: Ife Journal of Educational Studies 7(1), 31-39

[4]. Asika, N (1991). Research methodology in the behavioural sciences. Lagos. Longman Nigeria Plc. [5]. Asikhia, O.A (2010). Students and teacher`s perception of the causes of poor academic performance in Ogun State Secondary Schools, Nigeria. Implication for counseling for National Development. European Journal of Social Sciences. 13 (2): 229-249.

[6]. Ayodele S.O. (2006). Educational Opportunities for Nigeria learner, how to we fore thus far? A paper presented at the workshop organized by Network for Gender Sensitive Educational Management in Africa and the British Consul in Nigeria.

[7]. Barnard, W. M. (2004). Parent involvement in elementary school and educational attainment. Children and Youth Services Review, 26, 39-62.

[8]. Baxter, S.D., Royer J.A., Hardin, J.W, Guinn, G.H, and Devlin, C.M. (2011). The relationship of school absenteeism with body mass index, academic achievement and socioeconomic status among fourth-grade children. Journal of School Health, 81, 417-423.

[9]. Bratti, M. and Staffolani S (2002). Student Time Allocation and Educational Production Functions. University of Ancona Department of Economics working Paper No. 170

[10]. Buckingham, J (1999). The puzzle of boys' educational decline: a review of the evidence. Issue analysis, No. 9, Centre for Independents studies, Sydney.

[11]. Buckingham, J. (2000b). Boy troubles: understanding rising suicide, rising crime and educational failure, CIS policy monograph 46, Centre for Independent studies, Sydney.

[12]. Caldas, S.J., \&Bankston C.L. (1997). The effects of school population socioeconomic status on individual student academic achievement. Journal of Educational Research, 90; 267-277.

[13]. Chadwick, Bahr and Stauss (1976). India education in the city: Correlates of academic performance. J. Educa. Res. 70(2): 11-12

[14]. Chambers, E.A. \& Schreiber, J.B. (2004). Girls' academic achievement: Varying associations of extracurricular activities. Gender and Education, 16(3), 327-346

[15]. Cheers, B. (1990). Rural disadvantage in Australia. Australian Social Work, 43(1), 5-13.

[16]. Considine, G. and G. Zappala (2002). Factors influencing the educational performance of students from disadvantaged backgrounds, in T.Eardley and B. Bradbury, Eds,Competing Visions: Refereed proceedings of the National Social Policy Conference 2001, SPRC Report 1/52, social policy Research Centre, University of New South Wales, Sydney 91-107.

[17]. Council of Chief State School Officers. Policy Statement on School Health; 2004

[18]. Crosnoe, R., Johnson, M.K., Elder, G.H (2004). School size and the interpersonal side of education: An examination of race/ethnicity and organizational context. Social Science Quarterly, 88(5), 1259-1274

[19]. Duncan, G.J., and Brooks-Gunn, J. (Eds.) (1997). Consequences of Growing up poor. New York: Rusell Sage Foundation.

[20]. Dunkle MC, Nash MA. Beyond the Health Room. Washington DC: Council of Chief State School Officers, Resource Centre on Educational Equity; 1991

[21]. Durden, G.C. and Ellis, L.V (1995). The effect of attendance on student learning in principles of Economics, American Economic Review 85, 343-346

[22]. Escarce, J.J. (2003). Socioeconomic status and the fates of adolescent. Retrieved on September 27, 2007 from http://www.pubmedcentral.nih/gov article render.fcgi?artid

[23]. Fraser, E. (1985) School and home. London: University of London Press

[24]. Graet Z, B. (1995). Socio-economic status and school Education. DEET/ACER Canberra.

[25]. Hedwig, A., Kikefunda, J., Malda, M., Oldewage- Theron, W. H and Egal Abdukadir, A (2012).

Breakfast, midday meals and academic achievement in rural primary schools in Uganda: implications for education and school health policy. Food and Nutrition Research 2012: 56: 10: 3402/frn.v56 to. 11217.

[26]. Health, S.B (1990). The wider society and education. Boston Allyn and Bacon Inc.

[27]. Henderson, A.T. (1988). Good news: An ecologically balanced approach to academic improvement. Educational Horizons, 66(2), 60-67. 
[28]. Hijazi S. T., RazaNaqvi, S. M. M (2006). Factors affecting Students' Performance. A case of private colleges. Bangladesh e- journal of Sociology. Volume 3 Number l. January 2006.

[29]. Hoffman, J.A., Franko D.L. Thompson, D.R, Stallins, V.A. and Power T.J (2010). Longitudinal behavioral effects of a school-based fruit and vegetable promotion program. Journal of Pediatric Psychology, 35, 61-71. DOI: (0.1093/jpepsy/jop041)

[30]. Horne, R. (2000). The performance of males and females in school and tertiary education, Australian Quarterly, 72 (5/6) 21-26.

[31]. Human Rights and Equal Opportunities Commission (2000). Emerging Themes: National Inquiry into Rural and Remote Education, HREOC, Sydney.

[32]. Ichado, S.M. (1998). Impact of Broken Home on Academic Performance of Secondary School Students in English Language. Journal of Research in Counselling Psychology 4(1) 84-87

[33]. Jeynes, W.H. (2002). Examining the effects of parental absence on the academic achievement of adolescents. The challenge of controlling for family income. Journal of Family and EconomicIssues, 23(2), 56-65

[34]. Kanyongo, G.Y, Certo J and Launcelot, B.I (2006). Using regression analysis to establish the relationship between home environment and reading achievement: A case of Zimbabwe. International Education Journal, 7(5), 632-641. ISSN 1443-1475 @2006 Shannon Research Press.

[35]. Kingdom (1996). The quality and Efficiency of Public and Private Schools. A case study of Urban India. Oxford Ball. Econ. Statist. 58 (1): 55- 80.

[36]. Krashen S. (2005). The hardwork hypothesis: Is doing your homework enough to overcome the effects of poverty? Multicultural Education, 12( ), 16-19.

[37]. Lacour, M, and Tissington L.D. (2011). The effects of poverty on academic achievement. Journal of Educational Research and Review. 6 (7): 522-527.

[38]. Ma, X., \& Klinger, D.A. (2000). Hierarchical linear modeling of student and school effects on academic achievement. Canadian Journal of Education, 25(1), 41-55.

[39]. Majoribanks, Kevin. (1996). Family learning environments and students' outcomes: a Review Journal of Comparative Family Studies 27(2), 373-394

[40]. McCoy, L.P. (2005). Effect of demographic and personal variables on achievement in eight grade algebra. Journal of Educational Research, 98(3), 131-135

[41]. Mckenzie K, Schweitzer R (2010). Who succeeds at University? Factors predicting academic performance in first year Australian University students. Higher Education Research and Development. 20 (1): 21-33.

[42]. Mitchell, D.E, \& Collom, E. (2001). The determinant of student achievement at the academy for Academic Excellence. CA; school Education. University of California

[43]. Munsincer, H (1999). Fundamentals of Child Development. New York: Harcourt Brace Jovanrich Inc.

[44]. National School Boards Association. Beliefs and Policies of the National School Boards Association. Alexandria, VA: National School Boards Association; 2009

[45]. Nzewuawah, P.N. (1995). The effects of single-parenthood on the Academic performance of Students. Unpublished M.Ed Project University of Lagos

[46]. Parelius, R. J. \&Parelius, A. N (1987). Sociology of education. USA: Prentice Hall International

[47]. Peng, S. S, \& Hall, S.T. (1995). Understanding racial-ethnic differences in secondary school science and mathematics achievement (NCES No 95710). Washington DC: U.S. Department of Education

[48]. Pollit, Ernesto. 1984. Nutrition and Academic Achievement. Paris, France: UNESCO.

[49]. Rich, A. (2000). Beyond the classroom: How parents influence their children's Education, CIS Policy, monograph 48, Centre for Independent studies, Sydney.

[50]. Roberts, G.A (2007). The effect of extracurricular activity participation in the relationship between parent involvement and academic performance in a sample of third grade children Retrieved from https://www.lib.utexas.edu/etd/d/2007/robertsg 1118/Robertsg11186.pdf

[51]. Shoukat, A., Haider, Z., Khan, H., Ahmed, A (2013). Factors contributing to the Students Academic Performance. A case study of Islamia University Sub-campus. American Journal of Educational Research. 1(8):283-289, doi: 10. 12691/education 1-8-3. 
[52]. Scale, E.C., and Rochikepartain, E.C (2003) Boosting students Achievement. New Research on the power of Development Assets. Search Institute Insights Evidence 1(1), 1-10

[53]. Shonkoff, J.P. and D.A. Philips, eds, (2000), from Neurons to Neighborhoods: The Science of Early Childhood Development, National Academy Press, Washington DC.

[54]. Shumox, L. \& Lomax R(2001). Parental efficacy: predictor of parenting behaviour and adolescent outcomes. Parenting, 2(2). 127-150

[55]. Sparkes, J. (1999), Schools, Education and Social Exclusion, London School of Economics, London

[56]. Srebstein J, Piazza T. Public Health Safety and educational risks associated with bullying behaviors in American adolescents. International Journal of Adolescent Medicine and Health 2008; 20(2): 223-233. 


\title{
Perceived Determinants of Distribution of Counterfeit Drugs in Community Pharmacies, Calabar Municipality Local Government Area, Cross River State, Nigeria
}

\author{
Article by Agada Peter Okpe ${ }^{1,}$ Okareh Oladapo Okareh ${ }^{2}$, Ugobo Emmanuel Eteng ${ }^{3}$ \\ ${ }^{1}$ Senior Pharmacy Specialist, Howard University PACE Center (HU PACE), Strengthening \\ Integrated Delivery of HIV/AIDS Services (SIDHAS) project, Cross River State Office, \\ Calabar, Cross River State, Nigeria \\ E-mail: pagada09@gmail.com \\ ${ }^{2}$ Senoir Lecturer, Dept. of EHS, Faculty of Public Health, College of Medicine, University of \\ Ibadan, Nigeria \\ E-mail:dapsy2001@yahoo.co.uk \\ ${ }^{3}$ Howard University PACE Center (HU PACE), Strengthening Integrated Delivery of \\ HIV/AIDS Services (SIDHAS) project, Cross River State Office, Calabar, Cross River State, \\ Nigeria \\ E-mail: emmanuelugobo@ymail.com
}

\begin{abstract}
Background: The proliferation of counterfeit drugs is of public health concern and worthy of discourse.

Aim: The aim of the study is to assess the perceived factors affecting the distribution of counterfeit drugs in community pharmacies in Calabar municipality.

Methodology: This study is a cross sectional descriptive study that employed the use of closed ended pretested questionnaire for the collection of data. Data was analyzed using the SPSS 20.0.

Results: Findings show that 23(74.2\%) of the respondents were males while 8(25.8\%) were females. Majority of the respondents 28(90.8\%) were community pharmacist, 2(6.5\%) nurses and 1(3.2\%) pharmacy technician. Findings show that about $58 \%$ of purchase of drugs is been determined by the medical/pharmacist representative while $42 \%$ of drugs purchased is been determine by the distributor. Majority of the respondents 19(61.3\%) buy their drugs from medical /pharmacist representative. Respondents were able to detect counterfeit drugs through: customers report (19\%), close scrutiny (32\%), regulatory officials (13\%) and news/company alerts (36\%). Poverty 10(32\%), greed $6(19 \%)$, heavy taxes/VAT on drugs 5(16\%), government policies towards health care delivery $5(16 \%)$, and poor implementation of relevant laws by government agencies 5(16\%) were factors identified as responsible for proliferation of counterfeit drugs.

Conclusion: Poverty is a significant factor responsible for the proliferation of counterfeit drugs. The most common means used by community pharmacists to identify counterfeit drugs are scrutiny and news/alerts. There is need to create more awareness, and seek collaboration with community stakeholders in the fight against counterfeit drugs.
\end{abstract}

Keywords: Counterfeit drugs, community pharmacists, drug distribution

\section{Introduction}

World Health Organization (2010) defined counterfeit drugs as drugs that have been deliberately or not well labeled with respect to identity and or source which makes it difficult to track the manufacturer of such drugs (1). The counterfeited drugs could include incorrect ingredients, misstated amount of the active ingredients, or lack quality control in the manufacturing of the drug. According to NAFDAC Akunyili (2006) in its definition of counterfeit drugs included preparations without active ingredients, preparations that are toxic, expired drugs that are relabeled, drugs issued without 
complete manufacturing information and drugs that are not registered with the National Agency for Food and Drug Administration and Control (NAFDAC) (2).Looking at the above definition, it can be deducted that counterfeit drugs are drugs that are adulterated, inappropriate, and illegal and poses a threat to human health.

The availability of counterfeit drugs in the market presents a serious public health problem, particularly in developing countries such as Nigeria, and may have a significant impact on the national disease and economic burden. It occurs in developing and developed countries (3). Current estimate suggests that $10 \%$ of prescription drugs sold worldwide are counterfeits, fake or contaminated, and in parts of Africa and Asia, the figures exceed $50 \%$ (4).

Counterfeit medicines are widespread and represent a threat to public health which can lead to healthcare failures such as resistance to antibiotics and the spread of disease within a community, as well as loss of life. Research has also shown that poor-quality medicines can reach the market through deliberate fraudulent practices by those that want to get rich overnight. There is low awareness of the problem of counterfeit medicine; a problem that could lead to public-health crisis (5).

Measuring the magnitude of the phenomenon of counterfeit drugs turns out to be extremely complicated, particularly due to various reasons that have to do with the disposable means to detect the trafficking routes, the number and the identity of those involved in the production and distribution processes, and the difficulty in systematizing and coordinating the information from the various stakeholders in charge of keeping, collecting and analyzing data (5).

Available statistics have tried to propose figures on the exact percentage of counterfeit medicines within the worldwide pharmaceutical market. Their estimations reflect both the magnitude and the volatility of the problem. The percentages of counterfeit medicines in different national pharmaceutical markets vary from as 1 percent to as high as 50 percent. In general, higher percentages refer to less developed countries and economies in transition, whereas, lower percentages refer to the developed countries. Therefore, it is essential to take into account geographical, economic, legal and social criteria in order to interpret these percentages (4).

Research has shown that counterfeit medicines is less spread in more developed countries due to a combination of enhanced legislation, stronger institutions and a more efficient regulatory control. According to the WHO, developed countries such USA, Australia, Canada, Japan, New Zealand and those within the European Union (EU) have a very low proportion of counterfeit medicines no more than one per cent of market value (1).

However, the fact that a considerable amount of counterfeit drug cases are declared on an annual basis by developed countries proves that this problem still affects both developed and developing countries. Case studies can illuminate what statistics cannot.

Nevertheless, the situation is more dramatic in less developed countries due to fragile economies, widespread poverty, lack of regulation, difficulties in controlling the system, as well as the difficulties in furthering and enforcing strong legislative measures. WHO estimate shows that counterfeit medicines would represent approximately ten percent of the entire amount of medicines worldwide (1). Pfizer estimates that counterfeit Viagra alone causes a loss of 2 billion USD in sales (ref). According to the centre for medicine in the public interest, based in the United States of America, counterfeit drug sales generated 75 billion USD globally in 2010 (6). The situation seems to be even worse in some African countries.

\section{Methodology}

The research was carried out in Calabar municipality, Cross river state, Nigeria. The study is a community based descriptive study design that assess the determinants of counterfeit medicines. The design was selected for this study because it provided numeric descriptions of the population and described events as they are, as they were or as they will be (7). The target population was owners of community pharmacies in Calabar municipality. The respondents were the community pharmacists or individuals running these community pharmacies. Questionnaire was used for collecting data in this 
study. The primary data was obtained from the questionnaires. The questionnaires contained closeended questions with structured questions. Questionnaires were used because it saves time and confidentiality of information is assured. Pilot study was conducted to test validity and reliability of research instruments, using randomly selected areas outside the study area with similar characteristics.

The data collected was entered in excel environment and exported to SPSS version 22.0 for analysis and was presented in form of frequency tables, statistical tables, charts, and bar graphs (8). Qualitative analysis involved coding and organizing collected data into numerical variables and concepts that address the research questions (9).

Before the commencement of the research, permission was granted from Cross River State Health research ethics committee to carry out the research in the state. During field work, information sheets about the study in Calabar municipality were given out to the respondents, explaining why the research was carried out, by whom, and what it would involve. In community pharmacy outlet, verbal consent from participant was sought before starting the interview and was thanked at the end of the interview. Participants were allowed to withdraw from interview at any time he or she wanted.

Confidentiality of all study participants was assured. Everybody was informed that no names or direct identification made to the questionnaire, except numerical identification number was used for follow up. Before interview, study respondents were requested to participate voluntarily. Respondents were also told of the benefits they will derive from participating in the study

\section{Results}

\section{Socio-demographic characteristics}

Findings show that 23(74.2\%) of the respondents were males while $8(25.8 \%)$ were females. The distribution of marital status shows that majority of the respondents $19(61.3 \%)$ were single while $12(38.7 \%)$ were married. About $97 \%$ of the respondents were Christians with professional distribution of $28(90.8 \%)$ trained community pharmacist, 2(6.5\%) nurses and $1(3.2 \%)$ trained pharmacy technician (table 1.0).

Majority of the respondents were within the age group of $36-40$ years, followed by 26-30 years 7(23\%); 31-35years ;6(19\%), 41-45years, 5(16\%); 46-50years, 3(9.7\%) and 20-25 years 2(7\%);

\section{Determinants and sources of drugs}

Findings show that about $58 \%$ of purchase of drugs is been determined by the medical/pharmacist representative while $42 \%$ of drugs purchased is been determine by the distributor. Majority of the respondents 19(61.3\%) buy their drugs from medical /pharmacist representative, 9(29\%) buy their drugs from the wholesalers, while 2(6.5\%) buy their drugs from open market. Respondents identified patents medicine vendor drug distribution outlets (32.3\%), road side hawkers (35.5\%), approved pharmaceutical shops(16.1\%), and unapproved pharmaceutical shops(9.7\%) as sources of cheap drugs (table 2.0).

\section{Detection of counterfeit drugs and determinants of counterfeit drugs}

Respondents were able to detect counterfeit drugs through: customers report (19\%), close scrutiny (32\%), regulatory officials (13\%) and news/company alerts (36\%) (Table 3.0). Factors responsible for the proliferation of counterfeit drugs includes:poverty 10(32\%), greed 6(19\%), heavy taxes/VAT on drugs 5(16\%), government policies towards health care delivery 5(16\%), and poor implementation of relevant laws by government agencies 5(16\%) (Fig 1.0)

\section{Measures to reduce counterfeit drugs at the community level}

Respondents suggested the following measures to reduce the proliferation of counterfeit drugs at community level: creating awareness on counterfeit drugs (35\%), developing curriculum on how to identify counterfeit drugs by consumers (16\%), seeking collaboration with community stakeholders in the fight against counterfeit drugs (19\%), important information to be readily available to health care 
Texila International Journal of Public Health

Volume 4, Issue 4, Dec 2016

professionals on identification of counterfeit drugs (16\%) and engaging health care professionals in drug counterfeit surveillance (13\%) (table 4.0).

Table 1. Socio-demographic characteristics

\begin{tabular}{|l|l|l|}
\hline Variable & Frequency & Percent \\
\hline Sex & 23 & 74.2 \\
\hline Male & 8 & 25.8 \\
\hline Female & 31 & 100.0 \\
\hline Total & 19 & 61.3 \\
\hline Marital status & 12 & 38.7 \\
\hline Single & 31 & 100.0 \\
\hline Married & \multicolumn{2}{|l|}{} \\
\hline Total & 30 & 96.8 \\
\hline Religion & 1 & 3.2 \\
\hline Christian & 31 & 100.0 \\
\hline Others & 28 & 90.3 \\
\hline Total & 2 & 6.5 \\
\hline Professional qualification & 1 & 3.2 \\
\hline Trained pharmacist & \multicolumn{2}{|l|}{} \\
\hline Nurse & 31 & 100.0 \\
\hline $\begin{array}{l}\text { Trained pharmacist } \\
\text { technician }\end{array}$ & \multicolumn{1}{|l|}{} \\
\hline Total & 2 & 6.5 \\
\hline \multicolumn{2}{|l|}{} \\
\hline Age distribution of respondents & 22.6 \\
\hline 20-25Yrs & 7 & 19.4 \\
\hline 26-30Yrs & 6 & 25.8 \\
\hline 31-35Yrs & 8 & 16.1 \\
\hline 36-40Yrs & 5 & 9.7 \\
\hline 41-45Yrs & 3 & 100.0 \\
\hline 46-50Yrs & 31 & \\
\hline Total & \multicolumn{2}{|l|}{} \\
\hline
\end{tabular}

Table 2. Determinants and sources of drugs

\begin{tabular}{|c|c|c|c|}
\hline Variable & Frequency & Percent & p-value \\
\hline \multicolumn{4}{|l|}{ Determinants of source of drugs } \\
\hline Distributor & 13 & 41.9 & \multirow[t]{3}{*}{0.369} \\
\hline $\begin{array}{l}\text { Medical/pharmacist } \\
\text { representative }\end{array}$ & 18 & 58.1 & \\
\hline Total & 31 & 100.0 & \\
\hline \multicolumn{4}{|l|}{ Sources of drugs } \\
\hline $\begin{array}{l}\text { Medical/pharmacist } \\
\text { representative }\end{array}$ & 19 & 61.3 & \multirow[t]{5}{*}{0.001} \\
\hline Wholesalers & 9 & 29.0 & \\
\hline open market & 2 & 6.5 & \\
\hline Non response & 1 & 3.2 & \\
\hline Total & 31 & 100.0 & \\
\hline \multicolumn{4}{|c|}{ Where cheap drugs can be bought } \\
\hline Patent medicine vendor drug & 10 & 32.3 & 0.104 \\
\hline
\end{tabular}




\begin{tabular}{|l|l|l|l|}
\hline distribution outlets & & \\
\hline Road side hawkers & 11 & 35.5 & \\
\cline { 1 - 3 } Approved pharmaceutical shops & 5 & 16.1 \\
\cline { 1 - 2 } $\begin{array}{l}\text { Unapproved pharmaceutical } \\
\text { shops }\end{array}$ & 3 & 9.7 & \\
\hline Total & 29 & 93.5 & \\
\hline
\end{tabular}

Table 3.:Detection of counterfeit drugs in community pharmacies

\begin{tabular}{|l|l|l|l|}
\hline \multicolumn{3}{|l|}{ How counterfeit drugs is being detected } & \multirow{2}{*}{ p-value } \\
\hline By customers report & 6 & 19.4 & \multirow{2}{*}{0.238} \\
\cline { 1 - 2 } Close scrutiny & 10 & 32.3 & \\
\cline { 1 - 2 } Regulatory officials & 4 & 12.9 & \\
\hline News/company alerts & 11 & 35.5 & \\
\cline { 1 - 2 } Total & 31 & 100.0 & \\
\hline & & & \\
\hline
\end{tabular}

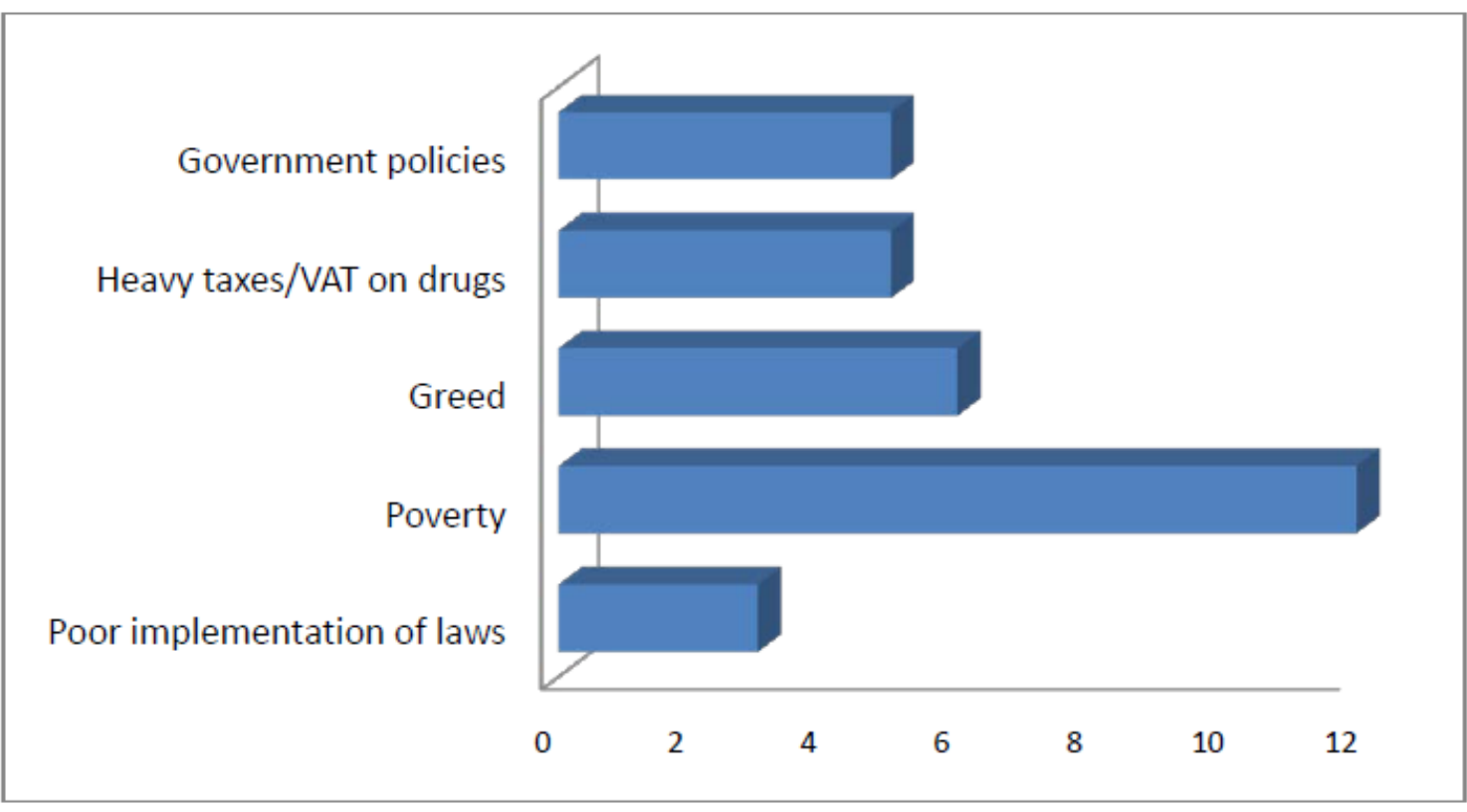

Fig 1.0. Factors responsible for increased growth of counterfeit drugs

Table 4.0. Suggested measures to reduce counterfeit drugs at the community level

\begin{tabular}{|l|l|l|l|}
\hline Variable & Frequency & Percent & P-value \\
\hline Create awareness on counterfeit drugs & 11 & 35.5 & 0.635 \\
\cline { 1 - 2 } $\begin{array}{l}\text { Develop curriculum on how to identify counterfeit } \\
\text { drugs by consumers }\end{array}$ & 5 & 16.1 & \\
\cline { 1 - 2 } $\begin{array}{l}\text { Seek collaboration with community stakeholders in } \\
\text { the fight against counterfeit drugs }\end{array}$ & 6 & 19.4 & \\
\cline { 1 - 2 } $\begin{array}{l}\text { Make important information readily available to } \\
\text { health care professionals on identification of } \\
\text { counterfeit drugs }\end{array}$ & 5 & 16.1 & \\
\cline { 1 - 2 } $\begin{array}{l}\text { Engage health care professionals in drug } \\
\text { counterfeit surveillance }\end{array}$ & 4 & 12.9 & \\
\cline { 1 - 2 } Total & 31 & 100.0 & \\
\hline
\end{tabular}


Texila International Journal of Public Health

Volume 4, Issue 4, Dec 2016

\section{Discussion}

Counterfeit pharmaceuticals remain one of the world's fastest growing industries. Recent trends suggest an increase in counterfeit drug sale to over $\$ 70$ billion in 2010, an increase of over $90 \%$ from 2005. A report by Pfizer, a global pharmaceutical firm, on counterfeit drugs states that profits from counterfeiting today surpasses gains made from heroin and cocaine (10).

Findings from this study shows that majority of the respondents (61\%) source their drugs from medical /pharmacist representative, 29\% source their drugs from the wholesalers, and only $6.5 \%$ source their drugs from open market, which is similar to findings from a study carried out by Odiliet.al, (2006) (11). The study revealed that majority of the respondents claimed they sourced their drug products personally from wholesalers. For respondents that buy their drugs from the wholesalers, there is much concern about where the wholesalers get their drugs. There is available evidence that major pharmaceutical distributors and even medical representatives dump their products in unlicensed open markets in order to meet sales targets and make quick turnover(2)

Respondents were able to detect counterfeit drugs through: customers report (19\%), close scrutiny (32\%), regulatory officials (13\%) and news/company alerts (36\%). This finding is very encouraging as it suggests that the respondents are aware of the occurrence of counterfeit drugs and are encouraged to check for drug security measures in order to identify such counterfeit drugs. However, it is important to note that fake and counterfeit drug detection, using only visual inspection is not full proof and so is unreliable except when the suspected drug is from unsophisticated forgers.

Factors such as weak legal framework, consumers' attitude towards counterfeit medicines and higher prices charged on imported drugs encourage the proliferation of counterfeit drugs (6).

In developed countries, minimal or no tariffs are charged on pharmaceutical products $(2,13)$. This is markedly different in less developed nations where high taxes and tariffs are usually charged on genuine medicines, thereby resulting in eventual escalation in drug prices, diminution in incentive to adequate supply of drugs and resulting in scarcity of the drugs that may be exploited by the counterfeiters (12).

According to Olusegun (2013) (10), greed, ignorance and corruption are other factors contributing to the prevalence of fake drugs in Nigeria. Corruption and greed is seen from the drug regulating authorities and the drug importers and manufacturers. The effectiveness of regulatory bodies is negatively affected by the high level of official manipulations and corruption in the Nigerian healthcare system. It is common knowledge that the law enforcement agencies are paid off to look the other way, while the business of fake drugs flourishes. Corruption and conflict of interest are the driving forces behind poor drug regulation, which directly encourages drug counterfeiting (14).

\section{Conclusions/recommendations}

Poverty is a significant factor responsible for the proliferation of counterfeit drugs. The most common means used by community pharmacists to identify counterfeit drugs are scrutiny and news/alerts. Community pharmacists and other allied health professionals should well trained on how to identify counterfeit drugs.

There is need to create more awareness on counterfeit drugs, and seek collaboration with community stakeholders in the fight against counterfeit drugs.

It is also important to implement regulatory measures which should be complemented by efforts to minimize drug diversion and strengthen communication between manufacturers, providers, and regulatory authorities (15).

\section{Limitations of the study}

This study had the following limitations which should be addressed in future research. One of its limitations is that of history as respondents may not recall all the information in the past due to loss of memory. This study is limited by the inability of respondents to identify counterfeit drugs by chemical 
method. Other professionals, other than community pharmacist were involved in this study which makes it difficult to generalized the study to community pharmacist.

\section{References}

[1]. World Health Organization (2012). Substandard and counterfeit medicines. Fact sheet No. 275, 2012. Available at http://www.who.int/mediacentre/factsheets/2012/ss275/en/ (last accessed 6 ,march 2016).

[2]. Akunyili DN (2006). Strategies employed in combating drug counterfeiting in Nigeria. A paper presented at the WHO Workshop in collaboration with Italian Medicines Agency and The International Federation of Pharmaceutical Manufacturers and Associations, Held in Rome, Italy $15^{\text {th }}-18^{\text {th }}$ Feb. 2006

[3]. Lewis, K. (2009). The fake and the fatal: the consequences of counterfeits. The Park Place Economist, XVII, 47-58.

[4]. Newton PN, Lee SJ, Goodman C, Fernández FM, Yeung S, Phanouvong S, Kaur H, Amin A, Whitty C, Kokwao G, Lindegardh N, Lukulay P, White L, Day N, Green M, White N (2009) Guidelines for field surveys of the quality of medicines: a proposal. PLoS Med 6

[5]. Charles Clift (2010). Combating counterfeit, falsified and substandard medicines: defining the way forward? centre on global health security, ghbp 2010/01

[6]. Opiyo, J.K. (2006). Responses of pharmaceutical firms to the challenges of illegal imports. Nairobi: Nairobi University.MBA Thesis.

[7]. Oso ,W.Y \&Onen, D. (2009). Writing Research Proposal and Report. Nairobi: Sitima

[8]. Chambers, R. L., \& Skinner, C. J. (Eds.). (2003). Analysis of survey data. John Wiley \& Sons.

[9]. Mugenda, O. M. \&Mugenda, A. G., (2003), Research Methods; Quantitative and Qualitative Approaches, Acts Press, Nairobi, Kenya

[10]. Olusegun Akinyandenu (2013). Counterfeit drugs in Nigeria: A threat to public health. African Journal of Pharmacy and Pharmacology 7(36), pp. 2571-2576, academicjournals.org/AJPP

[11]. Odili, Valentine U., Osemwenkha Sylvia, Eke Esther U. and Okeri Henry A (2006). Identification of Counterfeit Drugs by Community Pharmacists in Lagos State. Tropical Journal of Pharmaceutical Research, 5(1), pp. 545-550

[12]. Morris, J., \& Stevens, P. (2006). Counterfeit medicines in less developed countries. London: International Policy Network, May, 3, 6.

[13]. Harris, J., Stevens, P., \& Morris, J. (2009). Keeping it real: Combating the spread of fake drugs in poor countries. International Policy Network

[14]. Akiny, O. (2013). Counterfeit drugs in Nigeria: A threat to public health. African Journal of Pharmacy and Pharmacology, 7(36), 2571-2576.

[15]. Fadlallah, R., El-Jardali, F., Annan, F., Azzam, H., \&Akl, E. A. (2016). Strategies and Systems-Level Interventions to Combat or Prevent Drug Counterfeiting: A Systematic Review of Evidence Beyond Effectiveness. Pharmaceutical Medicine, 30(5), 263-276. 


\title{
Knowledge and Practices of Personal Hygiene among Senior Secondary School Students of Ambassadors College, Ile- Ife, Nigeria
}

\author{
Article by Ilesanmi Oluwafemi Temitayo \\ Ph.D. in Public Health, Texila American University, Nigeria \\ E-mail: aboundinggrace08@yahoo.com
}

\begin{abstract}
Background: Personal hygiene deficiency diseases have been found to be a serious public health problem and people often affected are school children. These have been attributed to inadequate knowledge of personal hygiene and its practices.

Methods: This study is a cross- sectional study to investigate personal hygiene knowledge and practices of senior secondary school, Ile -Ife, Osun State, Nigeria. A pre-tested 25- item, purpose designed, self- administered questionnaires were used to collect information on knowledge and practices of the respondents on personal hygiene. Data were collated and analyzed based on descriptive study design.

Results: The result showed that the senior secondary school students who participated in the study were almost evenly distributed by gender (50.7\% males and $49.3 \%$ females). Most of the respondents (50\%) were in the 12-14 year age bracket. The result also showed that majority of the respondents (98.2\%) had good knowledge of personal hygiene, could accurately identify the components and some of the harmful consequences of not engaging in sufficient personal hygiene practices. The result also showed that majority of the respondents had good hygienic practices including taking bath (99.6\%), brushing teeth (98.2\%) and washing hands (65.9\%).

Conclusion: Senior secondary school students of Ambassadors College, Ile- Ife have good personal hygiene knowledge and good personal hygiene practices.
\end{abstract}

Keywords: Personal hygiene, knowledge, practices

\section{Introduction}

Personal hygiene is an important global public health issue since long. Hygiene refers to practices associated with ensuring good health and cleanliness. Personal hygiene is the practice of maintaining cleanliness of ones own body. Good hygienic care as well as practices in terms of personal hygiene contributes to a large extent on factors relating to healthful living and prevention of hazards from diseases. These health risk factors are directly related to some important daily activities implicated with worthy operational actions and obligatory responsibilities, such as washing hands before meals and after defeacation with soap, brushing teeth at least twice a day specially after breakfast and after meals, taking bath with soap regularly, keeping nails short and taking regular exercise (Ali et al, 2013).

It is estimated that unsafe water, and lack of sanitation and hygiene every year claim lives of more than 1.5 million under five children from diarrhea (Mukherjee et al, 2014). Poor hygiene behaviour is a major problem in developing countries (Van Wijk et al, 2003). Hygiene and sanitation related diseases are a huge burden in developing countries; causing many people to fall ill even to die (UNICEF, 1998). A large fraction of the world's illness and death is attributable to communicable diseases. Sixty- two percent and 31\% of all deaths in Africa and Southeast Asia respectively are caused by infectious disease. This trend is especially notable in developing countries where acute respiratory and intestinal infections are the primary causes of morbidity and mortality among young children. Inadequate sanitary conditions and poor hygiene practices play major roles in the increased burden of communicable disease within these developing countries. The morbidities arising due to 
poor personal hygiene practices are more evident in the slum areas because of high population density, spread of respiratory infection, inadequate water supply, lack of sanitary facility, diarrhea and warm infestation, inadequate nutrition leading to anemia, malnutrition and vitamin deficiency (Raghava, 2005). Education must be provided to increase the level of knowledge. Schools are acknowledged as important places for developing health promotion and influencing health-related behaviours (Haaple et al, 2004; Moon et al, 1999; Sidebottom, 1995), including hygiene-related behaviours. Once habits are established in adolescence, they tend to be long-lasting and difficult to alter in adulthood (Wills et al, 2005). Thus, children educated in an effective way whilst at school may become adults who observe good hygiene practices. Knowledge influences people health. Through basic education and public knowledge individuals become aware of the meaning of self-protection and personal hygiene (Badran, 1995). Knowledge, attitude and practice of personal hygiene of school children have been found to increase significantly after education (Mukherjee et al, 2014; Biswas et al, 1990). In Nigeria, dental caries constitutes one of the major oral health problems with its prevalence being particularly high among young children and adolescents and the occurrence closely related to oral hygiene and socio economic class (Akpata, 2004). Adegbembo and El-Nadeef (1995) reported caries experience as high as 30 and 43\% among Nigerians aged 12 and 15 years, respectively.

There are many studies about the knowledge and practices of personal hygiene which were done on different groups (Tan et al, 2013; Miko et al, 2012; Suchitra et al, 2007). There are limited research findings to determine knowledge and practices of personal hygiene among secondary school students in Nigeria. However, this study is, therefore, directed to investigate the knowledge and practice of personal hygiene of senior secondary school students of Ambassadors College, Ile Ife, Nigeria as a case sample.

\section{Significance of study}

There is need to assess the personal hygiene knowledge and practices of this target group because they are more likely to engage in practices that may be inimical to their health than other groups and thus make them susceptible to hygiene deficiency illnesses. Furthermore, assessing their basic knowledge is essential for developing an effective personal hygiene education programs. In addition, the findings from this study can also provide basic and useful information for policy formulation and strategic interventions on personal hygiene among school students. The outcome of this study will serve as a guide for further research in this area.

\section{Statement of problem}

Several studies have shown that poor personal hygiene contribute to cross transmission of microorganisms, gum infections, increased rate of infectious illnesses, incidence of food borne outbreaks and reproductive tract infections. These have been attributed to inadequate knowledge of personal hygiene and its practices. Personal hygiene deficiency diseases have been found to continue to be a serious public health problem in developing countries like Nigeria and people often affected are school children. Moreover, to the best of my knowledge, limited studies focused on young students have been found in the literature and there is no formal study conducted concerning personal hygiene knowledge of secondary school students in Ile- Ife, Nigeria. Therefore, this study is aimed at assessing personal hygiene knowledge and practices of these senior secondary school students.

\section{Research questions}

The major research questions for this study include the followings:

1. Do senior secondary school students of Ambassadors College in Ile-Ife know about personal hygiene?

2. Do senior secondary school students of Ambassadors College in Ile-Ife engage in personal hygiene practices? 


\section{Research objectives}

1. To assess the knowledge of the senior secondary school students of Ambassadors College, IleIfe on personal hygiene.

2. To assess the practices of the senior secondary school students of Ambassadors College, Ile- Ife on personal hygiene.

\section{Literature review}

Personal hygiene is a concept that is commonly used in medical and public health practices. It involves maintaining the cleanliness of our body and clothes. It is personal. It is defined as a condition promoting sanitary practices to self. The knowledge and practice of personal hygiene are vital in all our everyday activities. The public health purposes of personal hygiene include the prevention of faeco-orally transmitted diseases, aesthetic values and social impact (Bastos, 2010). The components of personal hygiene include body hygiene (skin care), oral hygiene (oral care), hand washing (hand care), face hygiene, fingernail and toe nail hygiene (nail care), ear hygiene, hair hygiene, foot hygiene, arm pit and bottom hygiene, clothes hygiene and menstrual hygiene. Several studies show that personal hygiene practices include: seeing a doctor, seeing a dentist, regularly washing (bathing or showering) of the body, regular hand washing, brushing and flossing of teeth, basic manicure and pedicure, feminine hygiene and healthy eating (Ali et al, 2013; Bastos, 2010). Body hygiene pertains to hygiene practices performed by an individual to care for ones bodily health and well being. It is achieved by using personal hygiene products including: soap, hair shampoo, hair conditioner, cotton swabs, deodorant, chapstick, cream, lotion, facial tissue, hair clippers, nail clippers, nail files, skin cleansers, razors, shaving cream, skin cream and toilet paper (Bastos, 2010). All these products are used to improve health and well being. Oral hygiene refers to the care of the mouth and the teeth. It is achieved by going to the dentist, brushing the teeth and flossing the teeth. Diseases or conditions associated with poor oral hygiene include tooth decay, gum infection and bad breath (OU, 2016). The hand is important in adolescents especially secondary school students because when not properly taken care of, can serve as a medium of transfer of harmful microorganisms not just to the individuals, but also from one individual to another. A number of infectious diseases can spread from one person to another by contaminated hands, particularly gastro intestinal infections and hepatitis. Hand hygiene is recognized as the leading measure to prevent cross-transmission of microorganisms (Boyce et al, 2002; Pittet et al, 2000). A proper hand hygiene can help prevent the spread of these organisms. Some forms of gastro-enteritis can cause serious complications, especially for young children, the elderly or those with a weakened immune system. A causal link between hand hygiene and rates of infectious illness has been established in the literature (Aiello et al, 2002). A recent meta-analysis of 30 hand hygiene studies found that improvements in hand washing reduced the incidence of upper respiratory tract infections by $21 \%$ and gastrointestinal illnesses by 31\% (Aiello et al, 2008). Hand hygiene significantly reduces illness-related absences in elementary school students by $26 \%$ (Nandrup- Bus, 2009). Deficiencies in hand hygiene have been associated with outbreaks of viral gastroenteritis (Moe et al, 2001), upper respiratory tract infections (White et al, 2005; White et al, 2003) and group B streptococcal colonization (Bliss et al, 2002) among college students. Although mortality and morbidity associated with viral respiratory and gastrointestinal illnesses among college students are relatively low, these infections contribute to absenteeism that may, in turn, affect academic productivity and performance (ACHA, 2011). It was reported that poor hand hygiene contributed to 42\% of food- borne outbreaks in the United States in the period of 1975- 1998 (Aycicek et al, 2004). Critical times for hand washing include after using the toilet, after cleaning a child, and before handling food (Nandrup- Bus, 2009; Scott et al, 2007). Menstrual hygiene deals with the special health care needs and requirements of women during monthly menstruation or menstrual cycle. These areas of special concern include choice of the best protection of feminine hygiene products; how often and when to change the feminine hygiene products; bathing care of the vulva and vagina as well as the supposed benefits of vagina douching at the end of each menstrual period (John Hopkins, 2008). 
Provisions for good menstrual hygiene include home- made remedies like pieces of cotton cloth which are either placed on a woman's undergarment or on a home- made belt that wraps around the waist. These cloths can be washed, dried and used again. Available commercial products for women's hygiene during menstruation include pads, tampons and cups (Paul, 2007). The practice of good menstrual hygiene reduces the incidence of reproductive tract infection (RTI). Thus, the consequences of RTIs are severe and may result in significant negative impact to a woman's health including chronic pelvic pain, dysmenorrhea (painful periods) and in severe cases infertility. Reproductive tract infections, which have become a silent epidemic that devastates women's lives is closely related to poor menstrual hygiene (Dasguptal et al, 2008; Ten, 2007). Menstrual hygiene and management will directly contribute to millennium development goal (MDG) - 2 on universal educations, MDG- 3 on gender equality and women empowerment (Ten, 2007). Poor knowledge and practice of, and attitudes to personal hygiene has negative consequences for a child's long term overall development (Scott et al, 2007).

Knowledge is defined as the capacity to acquire, retain and use information. It is also a mixture of comprehension, experience, discernment and skill (Dong, 2015). It is a complicated construction characterized by the structure and the content of the information stored in the memory (Dong, 2015). Practice is regarded as the application of rules and knowledge that leads to action (Dong, 2015).

\section{Methods}

\section{Research design, study area and population}

A descriptive cross sectional study was conducted on personal hygiene knowledge and practices of senior secondary school students of Ambassadors College, Ile- Ife, Osun State, Nigeria. The study was carried out in Ambassadors College, a well-known and reputable private secondary school in IleIfe town. Ile-Ife is an ancient city of Yoruba land situated in Osun State which is located in the SouthWestern part of Nigeria. The study population consisted of the secondary school students' boys and girls in the senior secondary school one, two and three (SSS1, SSS2, and SSS3) of the College.

\section{Data collection}

Information was collected from respondents by means of a pre-tested 25- item, purpose designed, self- administered anonymous questionnaire containing open and closed ended questions.

The questionnaire was divided into three major sections for ease of administration. Section A containing 5 items focused on demographic characteristics of respondents. Section B containing 11 items focused on questions on knowledge of the respondents about personal hygiene while section $\mathrm{C}$ containing 9 items focused on questions on practice of the respondents about personal hygiene.

\section{Sample size determination}

The minimum sample size was calculated using the Leslie and Kish formula for descriptive studies $\mathbf{N}=\mathbf{P}(\mathbf{1}-\mathbf{P}) \mathbf{Z}^{2} / \mathbf{D}^{2}$ where $\mathrm{N}$ is the minimum sample size needed; $\mathrm{D}$ is the level of error that can be tolerated ( 0.05 chance of error) and $\mathrm{P}$, the estimated proportion of personal hygiene knowledge among college students from a previous study (Bastos, 2010) was $80 \%$ i.e. $p=0.80$. Z is the standard variation corresponding to confidence level. At confidence level of 95\%, $\mathrm{Z}=1.96$.

Therefore, $\mathrm{N}=0.80(1-0.80) 1.96^{2} / 0.05^{2} \mathbf{N}=\mathbf{2 4 5 . 8 6}$. To give allowance for an anticipated nonresponse rate of $10 \%$ ( 25 respondents), the sample size was increased by 25 to make 271 respondents. A total of 280 questionnaires were then taken to the school to be distributed for the study.

\section{Sampling method}

A simple random sampling method was used to select students from senior classes (SSS1, SSS 2 and SSS 3) of a private secondary school in Ile-Ife with age ranges from $12-20$ years to participate in the study. Of the 280 questionnaires distributed, 276 (response rate of 99\%) were returned and used for the analysis. Each respondent was provided with an assurance of confidentiality of information he 
or she provides in the questionnaire.

\section{Data analysis}

The completed questionnaires were collated, analyzed and presented using descriptive statistics of simple percentages, frequency distribution, means and ranges where applicable.

\section{Results}

\section{Demographic characteristics of the study population}

A total number of 276 senior secondary school students of Ambassadors college participated in the study in which $50.7 \%$ of them were males and $49.3 \%$ were female. Majority of the respondents (50\%) were between the ages of 12 and 14 years. The result also showed that the percentage distribution of the students in their various classes were very close as we have $36.6 \%$ in SS1, 38.6\% in SS2 and $25.4 \%$ in SS3. Largest percentages of them were Christians (95.3\%) as shown by the result. The result also showed that largest percentages of them were Yoruba (93.5\%) as shown in table 1.

Table 1. Demographic Characteristics of the study population

\begin{tabular}{|l|l|l|}
\hline $\begin{array}{l}\text { Socio-demographic } \\
\text { characteristics }\end{array}$ & Frequency & Percentage \\
\hline Age & 138 & \\
12-14 years & 133 & 50.0 \\
15- 17 years & 5 & 48.2 \\
18-20 years & $\mathbf{2 7 6}$ & 1.8 \\
Total & & $\mathbf{1 0 0 . 0}$ \\
\hline Sex & 140 & \\
Male & 136 & 50.7 \\
Female & $\mathbf{2 7 6}$ & 49.3 \\
Total & & $\mathbf{1 0 0 . 0}$ \\
\hline Class & 101 & \\
SSS 1 & 105 & 36.6 \\
SSS 2 & 70 & 38.6 \\
SSS 3 & $\mathbf{2 7 6}$ & 25.4 \\
Total & & $\mathbf{1 0 0 . 0}$ \\
\hline Religion & 263 & \\
Christianity & 13 & 95.3 \\
Islam & 0 & 4.7 \\
Traditional & $\mathbf{2 7 6}$ & 0.0 \\
Total & & $\mathbf{1 0 0 . 0}$ \\
\hline Ethnic group & 258 & 93.5 \\
Yoruba & 9 & 3.3 \\
Ibo & 0 & 0.0 \\
Hausa & 7 & 2.5 \\
Others & 2 & 0.7 \\
Non response & $\mathbf{2 7 6}$ & $\mathbf{1 0 0 . 0}$ \\
Total & & \\
\hline
\end{tabular}

\section{Personal hygiene knowledge levels of the respondents}

The result showed in table 2 below that 270 (97.8\%) of the respondents had heard of the term 'personal hygiene'. School constituted the largest source of information about personal hygiene accounting for $46 \%$ of responses. Parents accounted for $43.5 \%$ followed by books $17.4 \%$. Friends, Churches and Mosques constituted the least accounting for 12.7\% and 13\% respectively. More than 
95\% of respondents responded true to personal hygiene as practices performed by individual to care for ones bodily health and well being through cleanliness. All the respondents responded true to personal hygiene includes cleanliness of the body and clothes. $99 \%$ of respondents responded true to personal hygiene includes regular brushing and flossing of teeth. $98 \%$ of respondents responded true to personal hygiene includes regular and proper hand washing. $88 \%$ of respondents agreed that personal hygiene includes balanced rest and exercise. About $80 \%$ and $77 \%$ responded true to seeing a doctor and dentist respectively as part of personal hygiene. The percentage of knowledge of respondents about personal hygiene products is $98.7 \%$. The percentage of knowledge of respondents about disease or condition which could be caused or worsened by poor personal hygiene is $63.2 \%$.

Table 2. Distribution of personal hygiene knowledge of respondents

\begin{tabular}{|l|l|l|}
\hline Variable & Frequency & Percentage \\
\hline Have you ever heard about the & & \\
term “personal hygiene”? & & \\
YES & 270 & 97.8 \\
NO & 6 & 2.2 \\
Total & $\mathbf{2 7 6}$ & $\mathbf{1 0 0 . 0}$ \\
\hline Where did you find out about & & \\
it? & & \\
School & 127 & 46.0 \\
Media & 46 & 16.7 \\
Books & 48 & 17.4 \\
Church/ Mosque & 36 & 13.0 \\
Friends & 35 & 12.7 \\
Parents & 120 & 43.5 \\
\hline Personal hygiene includes & & \\
practices performed by & & \\
individual to care for ones & & \\
bodily health and well being & & \\
through cleanliness? & & \\
TRUE & 271 & 98.2 \\
FALSE & 0 & 0.0 \\
NON RESPONSE & 5 & 1.8 \\
Total & $\mathbf{2 7 6}$ & $\mathbf{1 0 0 . 0}$ \\
\hline Personal hygiene includes & & \\
cleanliness of the body and & & \\
clothes? & & \\
TRUE & 276 & 100.0 \\
FALSE & & \\
Total & & \\
\hline Personal hygiene includes & & \\
regular brushing and flossing of & & $\mathbf{1 0 0 . 0}$ \\
teeth? & & \\
TRUE & 274 & \\
FALSE & 1 & \\
NON RESPONSE & 1 & \\
Total & $\mathbf{2 7 6}$ & \\
\hline Personal hygiene includes & & \\
regular and proper hand & & \\
washing? & & \\
& & \\
\hline
\end{tabular}




\begin{tabular}{|l|l|l|} 
TRUE & 270 & 97.8 \\
FALSE & 6 & 2.2 \\
Total & $\mathbf{2 7 6}$ & $\mathbf{1 0 0 . 0}$ \\
\hline Personal hygiene includes & & \\
balanced diet, rest and exercise? & & \\
TRUE & 244 & 88.4 \\
FALSE & 30 & 10.9 \\
NON RESPONSE & 2 & 0.7 \\
Total & $\mathbf{2 7 6}$ & $\mathbf{1 0 0 . 0}$ \\
\hline Personal hygiene includes & & \\
seeing a Doctor? & & \\
TRUE & 220 & 79.7 \\
FALSE & 53 & 19.2 \\
NON RESPONSE & 3 & 1.1 \\
Total & $\mathbf{2 7 6}$ & $\mathbf{1 0 0 . 0}$ \\
\hline Personal hygiene includes & & \\
seeing a Dentist? & & \\
TRUE & 213 & 77.2 \\
FALSE & 60 & 22.7 \\
NON RESPONSE & 3 & 1.1 \\
Total & $\mathbf{2 7 6}$ & $\mathbf{1 0 0 . 0}$ \\
\hline
\end{tabular}

\section{Personal hygiene practices level of the respondents}

The result showed in table 3 below that $99.6 \%$ of the respondents said they took a bath every day. $91.3 \%$ took a bath 1- 2 times daily whilst $6.9 \%$ had their baths 3- 4 times daily. $98.2 \%$ of respondents brushed their teeth daily. $93.8 \%$ brushed their teeth 1- 2 times daily while $4 \%$ brushed their teeth more than 2 times in a day. $46.4 \%$ of the respondents said they cut their nails weekly followed by 33\% which reported they cut their nails monthly. $65.9 \%$ of the respondents said they wash their hair daily followed by $14.1 \%$ which wash their hair monthly being females. About $47 \%$ and $46 \%$ responded they often see their doctor and dentist respectively in a year in the absence of illness. $91 \%$ of the respondents responded yes to eating balanced diet, exercise and rest well. The percentage of the practice of respondents about when do you wash your hands is $69.1 \%$. The percentage of the practice of respondents about the use of hygiene promoting products is $57.6 \%$.

Table 3. Distribution of personal hygiene practice level of respondents

\begin{tabular}{|l|l|l|}
\hline Variable & Frequency & Percentage \\
\hline $\begin{array}{l}\text { Do you take a bath } \\
\text { everyday? }\end{array}$ & & \\
YES & 275 & 99.6 \\
NO & 1 & 0.4 \\
Total & $\mathbf{2 7 6}$ & $\mathbf{1 0 0 . 0}$ \\
\hline How many times in a day? & & \\
1-2 TIMES & 252 & 91.3 \\
3- 4 TIMES & 19 & 6.9 \\
NON RESPONSE & 5 & 1.8 \\
Total & $\mathbf{2 7 6}$ & $\mathbf{1 0 0 . 0}$ \\
\hline $\begin{array}{l}\text { Do you brush your teeth } \\
\text { everyday? }\end{array}$ & & \\
YES & 271 & 98.2 \\
\hline
\end{tabular}




\begin{tabular}{|c|c|c|}
\hline $\begin{array}{l}\text { NO } \\
\text { NON RESPONSE } \\
\text { Total }\end{array}$ & $\begin{array}{l}3 \\
2 \\
276 \\
\end{array}$ & \begin{tabular}{|l|}
1.1 \\
0.7 \\
$\mathbf{1 0 0 . 0}$ \\
\end{tabular} \\
\hline $\begin{array}{l}\text { How many times in a day? } \\
\text { 1-2 TIMES } \\
\text { 3- } 4 \text { TIMES } \\
\text { NON RESPONSE } \\
\text { Total } \\
\end{array}$ & $\begin{array}{l}259 \\
11 \\
6 \\
\mathbf{2 7 6} \\
\end{array}$ & \begin{tabular}{|l|}
93.8 \\
4.0 \\
2.2 \\
$\mathbf{1 0 0 . 0}$
\end{tabular} \\
\hline $\begin{array}{l}\text { How often do you cut your } \\
\text { nails? } \\
\text { DAILY } \\
\text { WEEKLY } \\
\text { MONTHLY } \\
\text { RARELY } \\
\text { NON RESPONSE } \\
\text { Total }\end{array}$ & $\begin{array}{l}13 \\
128 \\
91 \\
10 \\
34 \\
276\end{array}$ & \begin{tabular}{|l|}
4.7 \\
46.4 \\
33.0 \\
3.6 \\
12.3 \\
$\mathbf{1 0 0 . 0}$
\end{tabular} \\
\hline $\begin{array}{l}\text { How often do you wash } \\
\text { your hair? } \\
\text { DAILY } \\
\text { WEEKLY } \\
\text { MONTHLY } \\
\text { ONCE IN } 3 \text { MONTHS } \\
\text { NON RESPONSE } \\
\text { Total }\end{array}$ & $\begin{array}{l}182 \\
29 \\
39 \\
9 \\
17 \\
276\end{array}$ & \begin{tabular}{|l|}
65.9 \\
10.5 \\
14.1 \\
3.3 \\
6.2 \\
$\mathbf{1 0 0 . 0}$ \\
\end{tabular} \\
\hline $\begin{array}{l}\text { How often do you see your } \\
\text { Doctor in a year in the } \\
\text { absence of illness? } \\
\text { REGULARLY } \\
\text { NEVER } \\
\text { NON RESPONSE } \\
\text { Total }\end{array}$ & $\begin{array}{l}131 \\
110 \\
35 \\
\mathbf{2 7 6} \\
\end{array}$ & \begin{tabular}{|l|}
47.4 \\
39.9 \\
12.7 \\
$\mathbf{1 0 0 . 0}$ \\
\end{tabular} \\
\hline $\begin{array}{l}\text { How often do you see your } \\
\text { Dentist in a year in the } \\
\text { absence of illness? } \\
\text { REGULARLY } \\
\text { NEVER } \\
\text { NON RESPONSE } \\
\text { Total }\end{array}$ & $\begin{array}{l}128 \\
104 \\
44 \\
276 \\
\end{array}$ & \begin{tabular}{|l|}
46.4 \\
37.7 \\
15.9 \\
$\mathbf{1 0 0 . 0}$ \\
\end{tabular} \\
\hline $\begin{array}{l}\text { Do you eat balanced diet, } \\
\text { exercise and rest? } \\
\text { YES } \\
\text { NO } \\
\text { NON RESPONSE } \\
\text { Total }\end{array}$ & $\begin{array}{l}251 \\
23 \\
2 \\
\mathbf{2 7 6} \\
\end{array}$ & \begin{tabular}{|l|}
91.0 \\
8.3 \\
0.7 \\
$\mathbf{1 0 0 . 0}$
\end{tabular} \\
\hline
\end{tabular}

\section{Discussion}

This study was conducted to assess the personal hygiene knowledge and practices of the senior secondary school students of Ambassadors College, Ile- Ife, Osun State, Nigeria. A total of 276 senior secondary school students were involved in this study. The largest percentage of the participants 
comes from the 12- 14 (50\%) years age group followed by the 15- 17 years age group which constituted $48.2 \%$ of the total respondents. Only $1.8 \%$ of the students were aged $18-20$ years. This is not surprising as most primary schools turn out most of their students from primary 5 when they age an average of about 10 years. There was an almost equal sex distribution with 140 (50.7\%) male respondents and 136 (49.3\%) female respondents. This is not unexpected also as the school is a coeducational school. The result also showed higher Christian respondents and Yoruba respondents than any other religions and tribes respectively. This result can be explained by the fact that the sampled private school is primarily a Christian college school located in Yoruba land. This invariably shows that the study environment will usually reflect the characteristics of the study population.

\section{Knowledge of respondents on personal hygiene}

Majority of the respondents (97.8\%) have heard about the term personal hygiene. This can be explained by the fact that the subject is taught in ancillary topics especially in primary school and junior secondary school in subjects like social studies and home economics. This further strengthened by the fact that majority of the respondents found out about it from school followed by parents with church, mosque and friends as the least source of information by the respondents. This result is supported by a similar study by Bastos (2010) and it shows that the concept of personal hygiene is not taken too seriously outside the confines of the academic environment. Majority of the respondents (98.2\%) agreed that personal hygiene includes all practices performed by an individual to care for ones bodily health and well being through cleanliness. The result obtained in this study is supported by a similar study of Bastos (2010) which showed that all the respondents agreed true to the definition of personal hygiene. In another similar study by Kumar et al, 2015, about $85.5 \%$ of the respondents knew correctly the meaning of personal hygiene. All the respondents agreed that personal hygiene includes cleanliness of the body and clothes. Almost all the participants (99.2\%) viewed regular brushing and flossing of teeth as part of personal hygiene. Majority of the respondents (97.8\%) viewed regular and proper hand washing as part of personal hygiene. Also, most of the respondents (88.4\%) responded true to personal hygiene including balanced diet, rest and exercise. This shows a good degree of knowledge among participants. This can be explained that most of these issues are covered in part of their curriculum at some point in time or other during the course of study. However, the level of knowledge dropped to about $79.7 \%$ and $77.2 \%$ when asked if personal hygiene involved seeing a doctor and a dentist respectively. The not too impressive degree of knowledge shown by the respondents on the issue of visiting a doctor or dentist as part of personal hygiene can be explained by the fact that hospitals and clinics are viewed as places to be visited by the sick and hence most individuals would not visit one except there is a pressing issue.

\section{Practices of respondents on personal hygiene}

Almost all the respondents (99.6\%) claimed to have their baths everyday with $6.9 \%$ of the total respondents having their bath 3- 4 times a day. In a similar study by Ali et al, 2013, 85.17\% were accustomed to taking their bath regularly. A similar result was obtained about oral hygiene with $98.2 \%$ brushing their teeth every day and 93.8\% of the respondents reported brushing their teeth 1- 2 times in a day. Approximately 69 percent of the study sample brushed their teeth at least twice daily in a study by Al- Wahadni et al, 2006. Those reporting tooth brushing with frequency of twice or more/day mounted toonly $24.5 \%$ ofthetotalstudents, significantly more among the caries free students (44.4\%versus $15.5 \%$ withcaries, $\mathrm{P}=0.001$ ) in a study by Amin et al, 2008. In another study by Talinova, 2008, $90 \%$ of the grammar school students replied they cleaned their teeth twice a day. This can be attributed to the fact that most of the respondents are teenagers and are likely to carry out these activities as they foster peer acceptance upon which outward appearance is based and which is also highly valued at this stage of their lives. Also, $46.4 \%$ of the respondents reported they cut their nails weekly. This result was supported by another study by Ghose et al, 2012 although slightly higher where $74.2 \%$ of the students were found trimming their nail once a week. Also in this study $65.9 \%$ of the respondents reported washing their hairs daily. The practice of the respondents about washing of 
hands is $69.1 \%$. This should be taken with a pinch of salt because as earlier stated most of the respondents agreed that hand washing is a part of proper personal hygiene, their attitude towards it was not commensurate to the degree of knowledge demonstrated hence the likelihood that this rate of hand washing is done only ceremoniously without paying heed to its real importance thereby making it ineffective. The percentage of the respondents who practiced seeing their doctors and their dentists regularly in the absence of illness were $47.4 \%$ and $46.4 \%$ respectively. The findings of this study was supported by a study by Ogundele et al, 2008 who reported that only few of the adolescents go for dental check up at least once a year. This result was in contrast to a study by Talinova, 2008 where 80 $\%$ of the grammar school students undergo regular dental examination at least twice per year. Also, $91 \%$ of the respondents practiced eating balanced diet, take exercise and rest. This was in contrast to a study by Ali et al, 2013 which reported that $91.53 \%$ of the respondents were not inclined to take exercise regularly.

\section{Limitation of the study}

This study is not without some limitations. One, the study is based on self- reported information and thus is subject to self- report bias. To correct this, effort was made to reduce the impact of this bias by making the questionnaire a guided self- administered process. Two, the students used for this study were drawn mainly from a private high school in Ile-Ife and therefore the outcome of the study cannot be generalized as they are not true representatives of all the secondary school students in IleIfe. Three, the number of respondents got from senior secondary school 3 (SSS3) were not up to those respondents in Senior Secondary School 1 and 2 because they were writing their final exams at the time of collecting the data and they were not readily available to fill the questionnaire.

\section{Conclusion}

The outcome of this study reveals that majority of the senior secondary school students considered in this study have good level of personal hygiene knowledge and a good number of them have high level of personal hygiene practices.

\section{Recommendation}

In view of the above conclusion, the followings are therefore recommended:

1. Attention should be given to the monitoring and evaluating personal hygiene practices among Ambassadors College students.

2. There is need for continuous educational programs to improve the personal hygiene practices of these students.

3. Personal hygiene knowledge and practices of these private college students can be compared with those in the public or rural secondary schools.

4. Personal hygiene knowledge and practices of students from other Colleges for the entire Ile- Ife town in a larger way can also be conducted.

\section{References}

[1]. Adegbembo, A.O., El- Nadeef, M.A.I (1995). National survey of periodontal status and treatment need among Nigerians. Int. Dent. J., 45: 197-203.

[2]. Aiello, A. E., Larson, E. L (2002). What is the evidence for a causal link between hygiene and infection? Lancet Infect Dis. 2: 103- 110.

[3]. Aiello, A. E., Larson, E. L (2002). Causal inference: the case of hygiene and health. Am J Infect Control. 60: 503- 510.

[4]. Aiello, A. E., Coulborn, R. M, Perez, E, Larson, E. L (2008). Effect of hand hygiene on infectious disease risk in the community setting: a meta- analysis. Am J Public Health.98: 1372- 81.

[5]. Ali, M.Y., Rahman, M.M., Siddiqui, M. H (2013). Exploring degree of awareness about healthcare and hygienic practices in Secondary School Students residing in semi- urban areas of Bangladesh. CBMJ. Vol 2, No 1.Pp 55- 62. 
[6]. Akpata, E.S. (2004). Oral health in Nigeria. Int. Dent. J., 53: 361-365.

[7]. Amin, T.T., Al- Abad, B.M (2008). Oral hygiene practices, dental knowledge, dietary habits and their relation to caries among male primary school children in Al Hassa, Saudi Arabia. International Journal of Dental Hygiene. 6(4): 361- 70. Doi: 10.1111/ j.1601- 5037. 2008. 00310.

[8]. Al- Wahadni, A.M., Al- Omri, M.K., Saeed, K.N (2006). Oral health attitudes, Knowledge, and Behaviour among School children in North Jordan. Journal of Dental Education. Vol. 70 No 2.Pp 179- 187.

[9]. American College Health Association (2011). American College Health Association- National College Health Assessment II: Reference Group Executive Summary fall 2010. American College Health Association; Lithicum.

[10]. AshrafulHayet, S. M., Hafizul Islam, M. D., Awal, M. A (2015).Knowledge of Oral Hygiene and Oral Health Status among the Secondary School Students. International Journal of Dental Medicine. 1(2): 17- 21. Doi: 10.11648/ j.ijdm.2015.0101.12.

[11]. Aycicek, H., Aydofan, H., Kucukkaraaslan, A., baysallar, M., Baousstaoflu, A. C (2004). Assessment of the bacterial contamination on hands of hospital food handlers. Food Control. 15 (4): 253- 259.

[12]. Badran, I.G (1995). Knowledge, attitude and practice: The three pillars of wisdom and excellence: A place in the medical profession. East. Mediter. Health J., 1: 8-16.

[13]. Bastos, T. S (2010). Personal hygiene, Knowledge, Attitude and Practice of Secondary School Students in Ikeja. https://www.scibd.com/doc/36903339.

[14]. Biswas, A.B., Roy, A.K., Das, K.K., San, A.K., Biswas, R (1990). A study of the impact of health education imparted to school children on their knowledge, attitude and practice in regard to personal hygiene. Ind J Pub Hlth. 34(2). 87- 92.

[15]. Bliss, S. J., Manning, S. D., Tallman, P., Baker, C. J., Paerlman, M. D., Marrs, C. F., et al (2002). Group B Streptococcus colonization in male and nonpregnant female university students: a cross sectional prevalence study.Clin Infect Dis. 34: 184- 90.

[16]. Boyce, J.M., Pittet, D (2002). "Guideline for hand hygiene in health-care settings. Recommendations of the healthcare infection control practices advisory committee and the HICPAC/SHEA/APIC/IDSA hand hygiene task force,” Morbidity and Mortality Weekly Report, vol. 23, no. 12, pp. S3-S40.

[17]. Carneiro, L., Kabulwa, M., Makyao, M., Mrosso, G., Choum, R (2011). Oral health knowledge and practices of secondary school students, Tanga, Tanzania.Int J Dent. Doi: 10.1155/ 2011/ 806258.

[18]. Dasgupta A, Sarkar M (2008). Menstrual hygiene: How hygienic is the adolescent girl? Indian J Community Med. 33(2):77-80.

[19]. Dong, T.T.M (2015).The knowledge, attitude, and practice of consumers towards food safety issues: A review of Taiwan. International Journal of Research Studies in Management 2015 October, Volume 4 Number 2, 13-22.

[20]. Ghose, J.K., Rahman, M.M, Hassan, J., Khan, M.S.R., Alam, A.A (2012). Microbes and Health. Vol 1 No 1.PP 34- 37.

[21]. Haaple, I., Probart, C (2004). Food safety knowledge, perceptions and behavior among middle school students. JNutr Educ Behaviour. 36: 71-6. Hygiene and environmental health module. A series on personal hygiene. The Open University. February, 2016.

[22]. John Hopkins, B (2008). The INFO project. Key facts about the menstrual cycle. School of Public Health, centre for communication program. http://www.Infoforhealth.Org/inforeports/menstruation.Pdf Comm. Med.33: 77- 80.

[23]. Kadi, A.A., Salati, S.A (2012). Hand hygiene practices among medical students. Interdiscip Perspect Infect Dis. Doi: 10. 1155/ 2012/ 679129.

[24]. Kumar, K.S., Akoijam, B.S (2015). Knowledge of personal hygiene and water borne diseases and practice of personal hygiene among students of central Agriculture University, Manipur, India. Int J Community Med Public Health. 2(4): 592- 595. Doi: 10. 18203/ 2394- 6040.ijcmph 20151053.

[25]. Miko, B.A., Cohen, B., Conway, L., Gilman, A., Seward, S.L., Larson, E (2012). Determinants of personal and household hygiene among college students in New York City, 2011.Am J Infect Control. 40(10). 940- 945. Doi: 10.1016/ j. Ajic. 2011.12.015. 
Texila International Journal of Public Health

Volume 4, Issue 4, Dec 2016

[26]. Moe, C. L, Christmas, W. A, Echols, L. J, Miller, S. E (2001). Outbreaks of acute gastroenteritis associated with Norwalk- like virus in campus setting. J Am Coll Health. 50: 57- 66.

[27]. Moon, A.M., Mullee, M.A., Thompson, R.L., Speller, V., Roderick, P (1999). Health-related research and evaluation in schools.Health Education. 1: 27-34. Nandrup-Bus, I (2009). Mandatory hand washing in elementary schools reduces absenteeism due to infectious illness among pupils: a pilot intervention study. Am J Infect Control. 37: 820-826. 10.1016/j.ajic.2009.06.012.

[28]. Ogundele, B.O., Ogunsile, S.E (2008). Dental health knowledge, attitude and practice on the occurrence of Dental caries among Adolescents in a Local Government Area (LGA) of Oyo State, Nigeria. Asian Journal of Epidemiology, 1: 64-71. Doi: 10.3923/ aje. 2008.64.71.

[29]. Paul D (2007). A report of an ICMR funded research project: Knowledge and practices of Adolescent girls regarding reproductive health with special emphasis on Hygiene during menstruation. New Delhi. National Institute of Public Cooperation and Child Development (NIPCCD).

[30]. Pittet, D., Hugonnet, S., Harbarth, S et al.(2000). "Effectiveness of a hospital-wide programme to improve compliance with hand hygiene,” The Lancet, vol. 356, no. 9238, pp. 1307-1312.

[31]. Raghava, P.K (2005). School Health. Ind. Jour. Of Com. Med. 30(4).

[32]. Scott, B. R. T., Curtis, V., Garbrah-Aidoo, N (2007). Health in our hands, but not in our heads: understanding hygiene motivation in Ghana. Health Policy Plan. 22 (4): 225-233. 10.1093/heapol/czm016.

[33]. Sidebottom, D (1995). School health education: do too many cooks spoil the broth? Health Education. 6: $17-23$.

[34]. Suchitra, J.B., Devi, L.N (2007). Impact of education on knowledge, attitude and practices among various categories of health care workers on nosocomial infections. Indian Journal of Medical Microbiology. Volume 25.Issue 3.Pp 181- 187.

[35]. Talianova, M (2008). Attitude to and knowledge of oral hygiene of secondary school students. School and Health.21(3).Pp 199-209.

[36]. Tan, S.L., Cheng, P.L., Soon, H.K., Ghazali, H., Mahyudin, N.A (2013). A qualitative study on personal hygiene among food handlers at selected primary schools in Klang valley area, Selangor, Malaysia. International Food Research Journal. 20 (1): 71- 76.

[37]. Taylor, J.H., Brown, K.L., Toivenen, J., Holah, J.T (2000). A microbiological evaluation of warm hair driers with respect to hand hygiene and the washroom environment. Journal of Applied Microbiology. 89(6): 910- 919.

[38]. Ten VA (2007). Menstrual Hygiene: A Neglected Condition for the Achievement of Several Millennium Development Goals. Europe External policy Advisors.

[39]. UNICEF (1998). A manual on school sanitation and hygiene. Towards Better Programming Water, Environment and Sanitation Technical Guidelines. New York: UNICEF.

[40]. Van Wijk C., Tineke M (2003). Motivating Better Hygiene Behaviour. Importance for Public Heath Mechanisms of Change. Edited by: Steven E. The Hague, Netherlands: IRC International Water and Sanitation Centre.

[41]. White, C., Kolble, R., Carlson, R., Lipson, N (2005). The impact of a health campaign on hand hygiene and upper respiratory illness among college students living in residence halls. J Am Coll Health. 53: 175- 81.

[42]. White, C., Kolble, R., Carlson, R., Lipson, N., Dolan, M., Ali, Y et al (2003). The effect of hand hygiene on illness rates among students in university residence halls. Am J Infect Control. 31: 364- 70.

[43]. Wills, W., Backett-Milburn, K., Gregory, S., Lawton, J (2005). The influence of the secondary school setting on the food practices of young teenagers from disadvantaged backgrounds. Health Educ Res. 20: 458-65.

[44]. WHO: Water, sanitation and hygiene links to health; Facts and figures. 2004, Geneva: WHO. 


\title{
Prevalent Leadership Styles and their Compatibility to the New Ways of Working in General Hospitals in Nigeria
}

\author{
Article by Maclawrence Kolapo Famuyiwa \\ Chest Clinic, Apapa General Hospital, Apapa, Lagos, Nigeria \\ E-mail: maclawrencefamuyiwa@yahoo.com
}

\begin{abstract}
Context: Hospital patients desire more flexibility in health care delivery, hence developing new ways of working (NWW), and making the leadership styles in these hospitals to be compatible will ensure this.

Design: Prevailing leadership style and its compatibility to New Ways of Working were assessed by self-administered and pretested questionnaire. Descriptive statistics to elucidate on the demography of the respondents were done, mean score and standard deviation values were used to examine the variables. Spearman's rho correlation was used to identify the association in the responses.

Setting/Participants: A stratified sampling method was used to select samples for this study, and these samples were surveyed for their views on the prevalent leadership styles and how this prevailing leadership style can accommodate NWW.

Outcome measures: Some features of both task-oriented and person-centered leadership styles were identified. Then the respondents' agreement to the existence of these features of each leadership style and how NWW could be accommodated was examined.

Results: 100 questionnaires were distributed, 81 (81\%) of the questionnaires were returned. The mean score of the two leadership styles were $2.11 \pm 1.11$ and $2.16 \pm 1.11$ respectively with $a$ significant correlation ( $r=0.871, p<0.001)$. The compatibility of prevalent leadership style to 'New Ways of Working' was $4.29 \pm 1.74$.

Conclusion: Both task-oriented and person-centered leadership are present, and little adjustment are necessary for NWW to be accommodated. NWW will allow patients to overcome the encumbrances of busy schedules robbing them off an access to quality health care.
\end{abstract}

Keywords: Compatibility, Leadership styles, New Ways of Working, General Hospitals.

\section{Introduction}

Over the years, a change in patients' behavior has been noticed in the way they wish to be attended to in hospitals, especially the public hospitals in Nigeria, where hitherto, they had suffered a great inconsideration in the way they receive care from various hospital staff and are given clinical appointments not taken cognizance of the peculiarity of the type of work they do or the traffic quagmire the metropolitan lifestyles imposes on their easy movement. The new trend being proposed now, through NWW, is for them to be able to determine how and when they wish to be attended to by these hospital staff, so it behooves on these staff to be able to adequately respond to this by developing a new way of working (NWW).

The main clog in this is that these patients ability to determine when and how they would receive care from the health providers in these General Hospitals, apart from the hospital staff themselves, is the leadership and the styles of leadership in these hospitals, it is thus the mandate of this study to establish the prevalent leadership style in these hospitals and how this type of leadership can be able to accommodate NWW, or if possible find out an alternative style of leadership that will be most apropos for NWW. 
Also it is a known fact that medical practitioners in General Hospitals have devised a particular way in which they are expected to carry out their functions in the hospitals, they have clinic days in which they meet their patients, and patients' absenteeism is greatly abhorred and resented. Consulting rooms are traditionally the meeting place, and rarely do they extend consultation to outside these rooms to accommodate patients that fail to meet up appointments. Even the governments, who are their employers, also frown at the idea of health providers, under their employment, to offer professional services outside the confines of consulting rooms in the General Hospitals, this is not hiding the fact that many of these health care providers when given this flexibility have not turned around in the past to end up converting General Hospital patients to theirs in order to augment their income with money realized from privately treating these patients.

There is therefore a serious need for further research and capacity enhancement in these General Hospitals in order for a new way of working to be developed so as to meet the increasing health needs and more say of the patients in how they receive health care, which has to be at their own convenience and at the most appropriate place and time, which will be made feasible with the use of latest technological developments. This also has to put into consideration the flexibility in the way the health workers are expected to carry out their work, and also for the leadership styles in these hospitals to be receptive to all these changes that the implementation of NWW may exhume, yet still able to offer a good management guide to ensure that not only are patients satisfied but also the staff, as well as the realization of providing the best health care to these patients.

'The New Ways of Working' (NWW) being proposed to make the patients to be incharge of how they receive hospital services, has various definitions (Baane, Houtkamp \& Knotter, 2010; Volberda, Jansen, Tempelaar \& Heij, 2010)' For example, Bijl (2009) defined it as a vision whereby recent developments in information technology act as a catalyst for a better design and management of knowledge work. This involves the reconstruction of the physical work place, the organizational structure and culture, the management style as well as a better design and management of knowledge worker and his manager. This definition has been established to encompass all other definitions as it includes the four most important focus areas (people, organization, work environment and technology).

NWW is thus important to ensure that patients especially those attending out-patient clinics and seeking specialist consultations in General Hospitals can be in the confines of their offices and homes as well as other places and still be able to receive quality healthcare from their doctors and other hospital staff making use of latest technologies most notably social media such as Facebook, Twitter, Skype, Whatsapp, Oovoo, Join me etc, and this will also ensure that these health workers will also be able to flexibly attend to the health needs of their patients from anywhere without compulsorily needing to be physically present within the hospital premises except when they need to attend to emergency cases. NWW involves an employee successfully juxtaposing his work with the working environment, and the flexibility of the work ambience to suit various sorts of activities (Bijl, 2007;,Bijl, 2009; Egmond van (2010), which often resulting in offices of these employees being mere meeting points for staff and should be designed in such a way that staff gladly physically meet each other there to work together (Bijl, 2009).

The emphasis NWW places on the result demands a different organization of the work place, the organizational structure and the style of leadership. Additionally, the current technology offers the opportunity to work without the restriction of time or location (Bijl, 2009). The New Ways of Working explores the separation of the constraints of time and place from staff flexibility and the usage of innovative technological developments, resulting in the rendering of a satisfying service to the patient. It is also believed that NWW will offer staff the opportunity to combine work and home life better, enabling them to work with more flexibility, as well as further their personal development (Houtkamp \& Knotter, 2010). To effectively achieve NWW it then means that staff will now also be expecting different opportunities than they have ever had, which means a change in the leadership style is inevitable in order for NWW to be accommodated. 
Leadership on the other hand, has been defined as a process of influencing others for the purpose of performing a shared task (Fiedler, 1967). Different authors have identified different types of leadership styles, Lewin, Lippit and White identified three major types of leadership styles they termed authoritarian, democratic and laissez-faire, and since then other leadership styles have been defined (Lewin, Lippit \& White, 1939).

Fiedler (1964) recognized two styles of leadership, he called task-oriented, and relation-oriented or person-centered. Fiedler (1966) described the task-oriented leader as the one that pays more attention on the job, and takes a special interest on the specific tasks assigned to each employee to reach goal accomplishment. This leadership style pays very little attention to the team needs, and so may not be motivational style of leadership to adopt, and so it requires a very close supervision and control before the expected results could be achieved, this style of leadership was called the deal maker (Rowley \& Roevens, 2000).A task-oriented leader dictates to the followers what has to be done, the best way to do it and with the leader partaking in the performance of the work (Klutymans, 2010; Taberno, Chambel, Curral \&Arana, 2009).It is thus concerned with the degree to which the leader takes the initiative for activities within the group.

Person-centered leadership, on the other hand, refers to the level to which the manager pay attention to the well-being of his staff. This type of leaders exhibits great appreciation for properly carried out tasks, and treats the followers as equals by emphasizing the difference in work satisfaction and enhancing the sense of self-worth amongst staff. A people-oriented leader supports, trains and develops his personnel, so as to ensure effectiveness and efficiency, and he does so by increasing job satisfaction and genuine interest to do a good job (Firdler, 1966).

A person-centered leadership, staff support, the realization of connections with staff and collaboration have been suggested to be the essential ingredients of NWW (Bijl, 2007; Bijl, 2009),but some other authors have rather suggested results-oriented leadership which corresponds to taskoriented leadership instead of a person-centered leadership to be that to be included as part of the essential ingredients of NWW De Leede \& Kraijenrink, 2014). This will be explored in further details in this study, with the aim of establishing the prevailing leadership style between task-oriented and relation-oriented leadership styles presently being used within the General Hospital set ups in Nigeria. 'New Ways of Working' should, however, offer staff the freedom to show and establish important competences such as responsibility, flexibility and entrepreneurship (Bijl, 2009).

This study will also explore how these style of leadership as described by Fiedler ${ }^{6}$ will affect the introduction of new ways of working which this study tends to investigates among hospital staffs in a General Hospital in Nigeria. The study becomes necessary to ensure that the desire of patients presently attending out-patients clinics in General Hospitals in Nigeria to have flexibility in the way they receive care from hospital staff, not only within the confines of the hospitals but also outside of them, finally becomes a fruition.

\section{Methodology}

\section{Description of study area}

The study was conducted in a General Hospital situated in Apapa, Lagos, Nigeria. The location of the hospital is the home of two most important ship ports in Nigeria which handle approximately $60 \%$ of ship cargo traffic in Nigeria, it is home to many Nigerians and quite a number of Lebanese, Indians, and Chinese nationals. The hospital, where the study was conducted, serves the residents of Apapa, and also those of Ijora, Orile, Ajegunle, Amukoko etc that are immediate its suburbs. The hospital is multi-specialty, with departments of Obstetrics and Gynaecology, Paediatrics, Medicine, Surgery, Community Medicine, Dentistry and also facilities for nursing, physiotherapy, pharmacy, laboratory, medical social work.

The respondents used for this study consists of management and non-management staff of this Hospital, where NWW is not being presently practiced. A preliminary study done showed that about 357 staff are listed in the nominal roll of the hospital, 25 of them belong to the management staff who 
constituted the Hospital Management Committee, the Head of Departments and Head of Sub units, while the rest can be categorized as the non-management staff.

\section{Sampling technique/ sampling size}

The sample size used in this study was calculated using Taro Yamane formula as follows:

$$
\begin{aligned}
& \mathrm{n}=\frac{N}{1+\mathrm{N}}(\mathrm{e})^{2} \\
& \text { Where: } \\
& \mathrm{n}=\text { Sample Size } \\
& \mathrm{N}=\text { Elements of population in this study is } 357 \\
& \mathrm{e}=\text { Error of sampling, in this study is } 10 \text { percent or } 0.10 \text { proportion. }
\end{aligned}
$$

Therefore, substitution in the formula:

$$
\begin{aligned}
\mathrm{n} & =\underline{357} \\
& =\mathbf{1 + 3 5 7 ( 0 . 1 0 ) ^ { 2 }} \\
& =\mathbf{7 8 . 1 2}
\end{aligned}
$$

Furthermore, owing to the diverse professional status of the respondents involved in this study, a stratified sampling method was adopted for this study by drawing separate random samples from amongst the different professional cadres found in this General Hospital: Doctors, Dentists, Pharmacists, Physiotherapists, Administrators, Accountants, Medical Records Officers, Nurses and Other Staff. This method was also adopted to draw random samples between the management and non-management staff.

\section{Data collection method}

This study used questionnaire for data collection since this is particularly appropriate for deductive research providing an easily accessible and controllable way for collecting and explaining data. I sought for expressions of interest from all surveyed respondents using an introductory letter explaining the aim of the study and the anonymity of the answers, polite reminders were personally given by me three days to and repeated again a day to the deadline for the collection of the questionnaire. It has been stated that re-notification and follow-ups increase the response rate (Cooper, 2003).The list of concepts also accompanied the questions for clarification purpose.

I designed the study instrument after a rigorous literature review (Memish, et al, 2014; WHO, 2013; Gautret, Benkouiten, Salaheddine, Belhouchat, Drali \& Parola, 2013; Al-Tawfik \& Memish, 2014). After an initial draft of the questionnaire was designed, it was validated in 2 steps. Firstly, the study instrument was discussed with the senior academics versed in research work to give their expert opinion with respect to its simplicity, relativity and importance. Secondly, a pilot study was conducted by the selection of a small sample of health care professionals $(n=9)$ who gave their opinions on making the questionnaire simpler and shorter. Participants from all professions working within the hospital studied were selected for the pilot study. Amendments from the participants were considered and used in modifying the questionnaire, while ensuring its consistency with the published literaturere view (Memish, et al, 2014; WHO, 2013; Gautret, Benkouiten, Salaheddine, Belhouchat, Drali \& Parola, 2013; Al-Tawfik \& Memish, 2014). After a thorough discussion, I finalized the questionnaire and subsequently distributed to the participants for their response. The data of the pilot study was not used for the final analysis.

The first section of the questionnaire consists of the questions on demographic information: Gender, Age, Education level, Specialty/Department, and job functions. The rest of the sections contains questions on the prevailing leadership style and the compatibility of present leadership style to the introduction of 'New Ways of Working'. Responses were evaluated through 7 point Likert scale of agreement, A score of 1 was given to strongly agree, 2 to agree, 3 to somewhat agree, 4 to 
neither agree nor disagree, 5 to somewhat disagree, 6 to disagree and 7 to strongly disagree. A mean score of $<5$ was considered as agreement while score of $\geq 5$ was taken as disagreement.

Furthermore, a snapshot approach or cross-sectional study design was employed as the study was conducted at a specific moment in time. As such, there was no time available to conduct a longitudinal study. It was also desirable to know the state of affairs at this specific moment in order to be able to take action in the short term. The primary source of data collection for this study was through the use of validated questionnaire and data was collected in May, 2016.

\section{Reliability and validity of data collection instrument \\ Reliability}

Reliability "refers to the degree to which observes scores are free from errors of measurement" (Dooley, 2009). Reliability is measured by the consistency of the scores". Cronbach's alpha (Cronbach, 1951), was used to determine the homogeneity of the data collected. The internal reliability of the leadership style questionnaire was determined.

The contents of the questionnaire that was finally used, have reliability coefficient calculated using SPSS v.20 and the value of Cronbach's alpha (Cronbach, 1951) was 0.81, Cronbach's Alpha values higher than 0.7 is considered reliable (Nunnally, 1978).

\section{Validity}

Validated questionnaire was used in this study in order to increase reliability. A validated questionnaire incorporates validity which reflect whether the research is actually measuring what it is supposed to measure, this is the extent to which the collection of data, the techniques used and the analysis ensured inter-dependent findings (Saunders, Lewis. Thornhill, Booijl \& Verckens, 2011).

\section{Data analysis method}

The data generated from this study was analysed using SPSS version 20. Mean and standard deviation were employed for the univariate analysis. Bivariate relationships between 7-item Likert scales were analysed using Spearman's correlation coefficient $r$ for correlation, because the measurement scale is ranked (Bryman \& Bell, 2011).

\section{Results}

\section{See Table 1}

Table 1 shows that $69.1 \%$ of the respondents were female while $30.9 \%$ were male. This indicates that both male and female sexes are represented.

\section{See Table 2}

Table 2 reveals that $80.4 \%$ of the respondents were between 26 and 50 years age range, out of which $60.3 \%$ are within the age group 41 and 50 years. Those below 25 years and those above 56 years of age were $1.2 \%$ respectively of the respondents. Overall, the data shows that all working age groups are represented.

\section{See Table 3}

Table 3 indicates that $65.5 \%$ of the respondents have more than a bachelor degree, with $20.8 \%$ of these group of respondents even having a post-graduate degree, 9.9\% had OND/NCE, $21.0 \%$ had a School of Nursing certificate, and only $2.5 \%$ had a Secondary School certificate, this is a confirmation that the respondents are well educated to understand the questions and provide reliable answers.

\section{See Table 4}

Table 4 shows that the core staff of the hospital, supposedly including the Nurses, Doctors, Dentists, Pharmacists, Physiotherapists and Laboratory workers constituted $76.6 \%$ of the respondents, 
Texila International Journal of Public Health

Volume 4, Issue 4, Dec 2016

an indication that all the core hospital staff needed for the purpose of this research are well represented.

\section{See Table 5}

The non-managerial staff among the respondents as revealed in Table 5 constituted $74.1 \%$ of the respondents while $25.9 \%$ were managerial staff which include Head of Departments, Head of subunits and members of Hospital Management Committee, a confirmation of a good representation of all cadres of staff in the sample.

\section{See Table 6}

Table 6 shows the respondents agreed most with the statement that their leaders have a strong orientation towards employees under them getting the job done and at the scheduled time. This statement on the average has a mean of 1.64 and the standard deviation of 0.97 which is an indication that the study instrument is a good measure of this variable. The average mean of the table is 2.11 which indicates an agreement by the respondents that task-oriented leadership is prevalent and the average standard deviation of 1.11 indicates that the instrument is a good measure of the variable.

\section{See Table 7}

Table 7 shows that the respondents on the average agreed most with the statement that their bosses encourage harmonious relationships between employees, with a mean of 1.74 and a standard deviation of 0.66 . On the average, the mean of the opinion of the respondents that relation-oriented leadership style is more prevalent is 2.16, an indication of an agreement. The standard deviation of 1.10 is also not too large indicating that the instrument is a good measure of the variable.

Furthermore, the Spearman's Correlation test $(r=0.871, \mathrm{p}<0.001)$ revealed a positive relationship between task-oriented leadership style and relation-oriented or person-centered leadership style, and a cumulative look at both Tables 6 and 7 showed that on the average both Task-Oriented and RelationOriented Leadership styles are agreed, by the respondents, to be existing in the General Hospital studied by the respondents, going by their means of $2.11(\mathrm{SD}=1.11)$ and $2.15(\mathrm{SD}=1.10)$ respectively, but with task-oriented leadership style being the more prevalent going by the mean values of Tables 6 and 7, respectively.

\section{See Table 8}

Table 8: The statement stating that their bosses allows flexibility in the way they carry out their duties attracted the highest level of agreement, with a mean of 3.31 and a standard deviation of 1.67. Also, on the average, the mean of Table 8 is 4.29 which is $<5$ and hence in the region of agreement to the statement as set out in the research methodology for this study, this thus indicates that there is an agreement, though marginal, by the respondents that the present leadership style is compatible with 'New ways of Working'.

\section{Discussion}

The findings of this study indicate that though both task-oriented and relation-oriented leadership styles are prevalent, task-oriented leadership is still dominant. This finding is similar to the outcome of a study conducted to know the leadership style of hospital pharmacy directors, where it was found out that a mixture of highly relationship-oriented and highly task-oriented were prevalent among hospital pharmacy directors (Parrett, Hurd, Northcraft, McGhan \& Bootman, 1985).It has also been opined that a task-oriented leadership will have to be prevalent in an organisation for the "New Ways of Working" to be successfully introduced and implemented in any organization (De Leede \& Kraijenbrink, 2014),though some other authors have asserted that a task-oriented leadership style does not contribute to the implementation of NWW in a financial organization studied in Holland (Stoffers, Kurstjens \& Schrijver, 2015).Bijl, (2001, 2009)however, suggested that it is rather a person-centered leadership style environment that is needed for the successful introduction of "New Ways of 
Working” in any organization, these conflicting recommendations by researchers are not surprising, but what matters is for clinicians to have leadership expertise in all settings to implement change based upon good clinical decision making built around a patient-centered approach to care (Cooper, 2006).

This study also reveals that though the responses of the respondents were on the average, a depiction of neutrality to the variable, that the leadership style prevailing presently in General Hospitals in Nigeria is compatible with the 'New Ways of Working', but the responses were still taken as a marginal agreement to the variable as it was set out in the research methodology for this study. This finding is in tune with the works of some other authors (Bijl, 2007, 2009; De Leede \& Kraijenbrink, 2014), who all established that "New Ways of Working" does not need a mixture of relation-oriented and task-oriented leadership styles that was revealed to be prevailing in this study, but probably either a sole presence of task-oriented or person-centered leadership style, also this their responses may be regarded as precautionary since the 'new Ways of Working is still alien to them and it is after its introduction that they can actually be bold in their assertion of whether the leadership style that is currently in place in their work place would be adequate or not, this can be construed to mean that the attainment of a good leadership in any situation can only be more of a journey than a destination and this could only be recognized in practice (Donnelly, 2003), hence, the best leadership style for the implementation of the 'New Ways of Working' would only evolve as an adaptation process.

\section{Conclusion}

It can be concluded from this study that with the prevalence of both task-oriented and personcentered leadership in General Hospitals in Nigeria, the introduction and implementation of 'New Ways of Working' can still be accommodated, with very little adjustment to the leadership style. However, it is in the interest of all staff of these hospitals to accommodate a new way of working, which apart from giving them flexibility to carry out their work and ultimately achieving the best balance between their work and private lives, also enables patients they serve to derive more satisfaction in the way they are served by these hospital staff.

\section{Tables}

Table 1. Gender of the Respondents

\begin{tabular}{|l|l|l|}
\hline Gender & $\begin{array}{l}\text { Number of } \\
\text { Respondents }\end{array}$ & Percentage \\
\hline Male & 25 & 30.9 \\
\hline Female & 56 & 69.1 \\
\hline Total & $\mathbf{8 1}$ & $\mathbf{1 0 0}$ \\
\hline
\end{tabular}

Table 2. Age range of the Respondents

\begin{tabular}{|l|l|l|}
\hline Age Range & $\begin{array}{l}\text { Number of } \\
\text { Respondents }\end{array}$ & Percentage \\
\hline 25 \& Below & 1 & 1.2 \\
\hline $26-30$ & 11 & 13.6 \\
\hline $31-35$ & 9 & 11.1 \\
\hline $36-40$ & 16 & 19.8 \\
\hline $41-45$ & 19 & 23.5 \\
\hline $46-50$ & 19 & 23.5 \\
\hline $51-55$ & 5 & 6.2 \\
\hline 56 \& Above & 1 & 1.2 \\
\hline
\end{tabular}




\begin{tabular}{|l|l|l|}
\hline Total & 81 & 100.0 \\
\hline
\end{tabular}

Table 3. Education level of the Respondents

\begin{tabular}{|l|l|l|}
\hline Education Level & $\begin{array}{l}\text { Number of } \\
\text { Respondents }\end{array}$ & Percentage \\
\hline Secondary School & 2 & 2.5 \\
\hline OND/NCE & 8 & 9.9 \\
\hline $\begin{array}{l}\text { School of Nursing } \\
\text { Certificate }\end{array}$ & 17 & 21.0 \\
\hline Bachelors/HND & 42 & 51.9 \\
\hline Post Graduate Degree & 11 & 13.6 \\
\hline Others & 1 & 1.2 \\
\hline Total & $\mathbf{8 1}$ & $\mathbf{1 0 0}$ \\
\hline
\end{tabular}

Table 4. Socio-Demographic Characteristics of the Respondents

\begin{tabular}{|l|l|l|}
\hline Specialty/Department & $\begin{array}{l}\text { Number of } \\
\text { Respondents }\end{array}$ & Percentage \\
\hline Nursing & 29 & 35.8 \\
\hline Medical & 11 & 13.6 \\
\hline Dental & 3 & 3.7 \\
\hline Pharmacy & 11 & 13.6 \\
\hline Physiotherapy & 2 & 2.5 \\
\hline $\begin{array}{l}\text { Health Information } \\
\text { Management }\end{array}$ & 5 & 6.2 \\
\hline Laboratory & 6 & 7.4 \\
\hline Account & 6 & 7.4 \\
\hline Administration & 5 & 6.2 \\
\hline Medical Social Worker & 3 & 3.7 \\
\hline Total & $\mathbf{8 1}$ & $\mathbf{1 0 0}$ \\
\hline
\end{tabular}

Table 5. Job function of the Respondents

\begin{tabular}{|l|l|l|}
\hline Job Function & & \\
\hline Managerial & 21 & 25.9 \\
\hline Non-Managerial & 60 & 74.1 \\
\hline Total & $\mathbf{8 1}$ & $\mathbf{1 0 0}$ \\
\hline
\end{tabular}


责

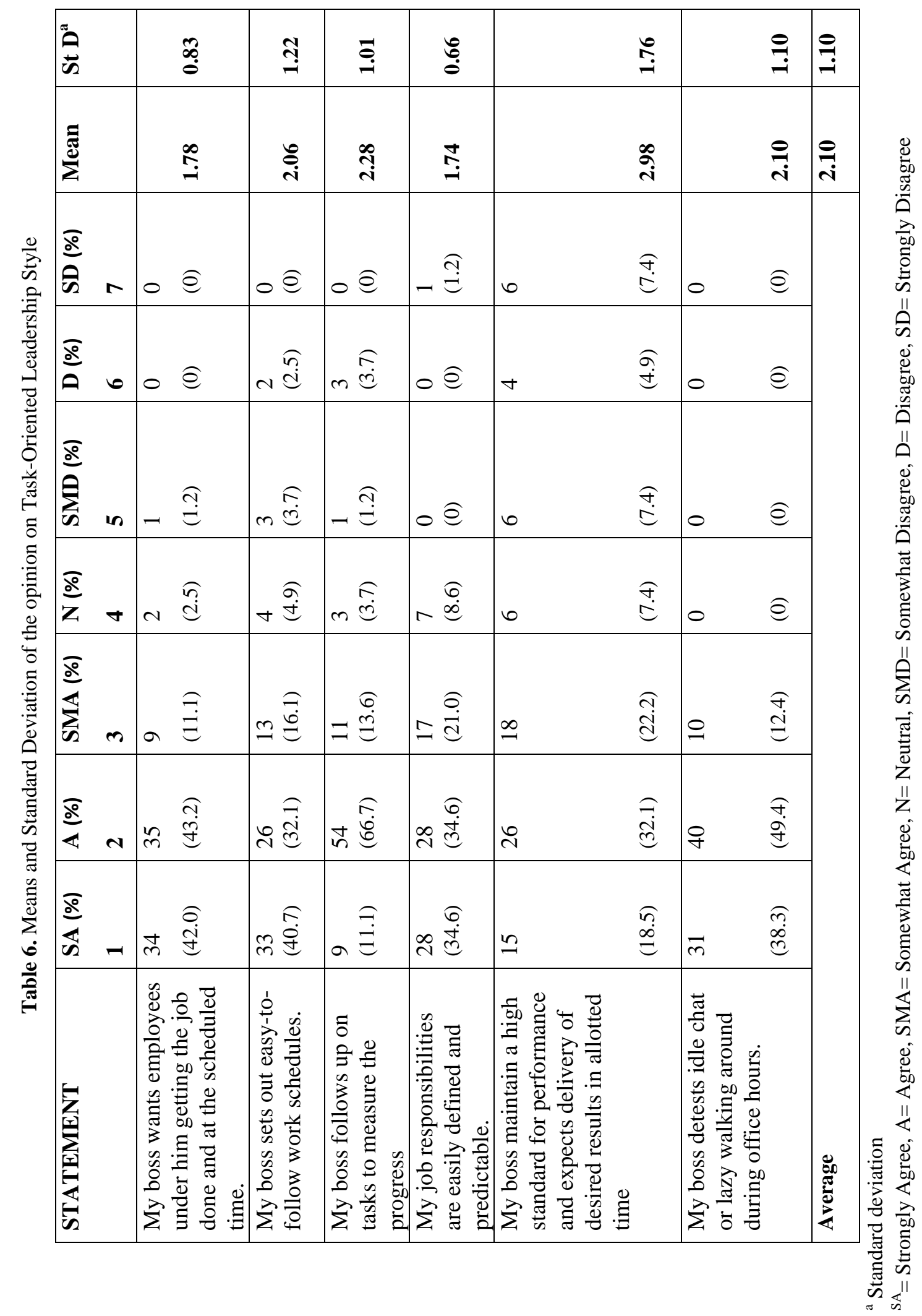




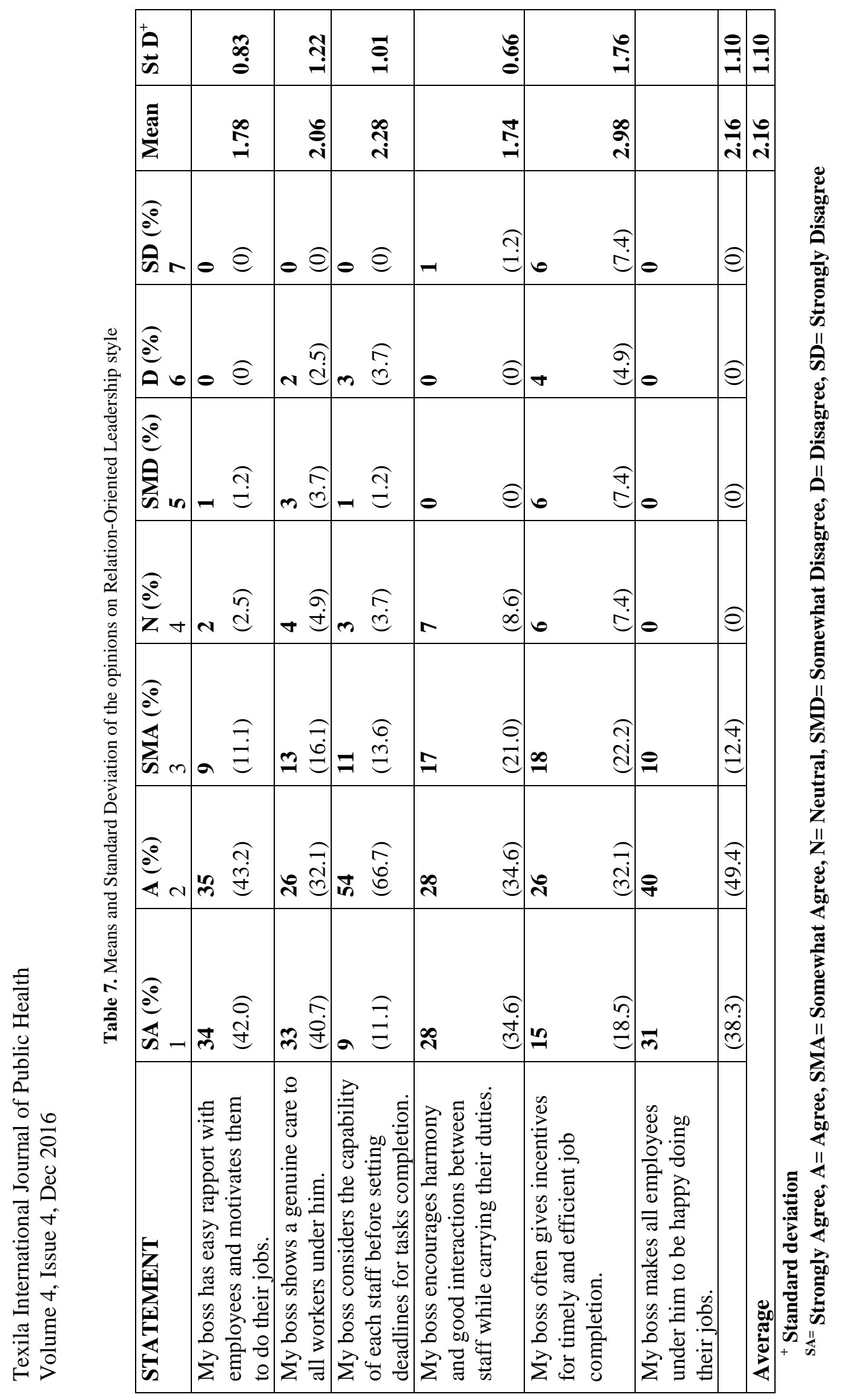


吾

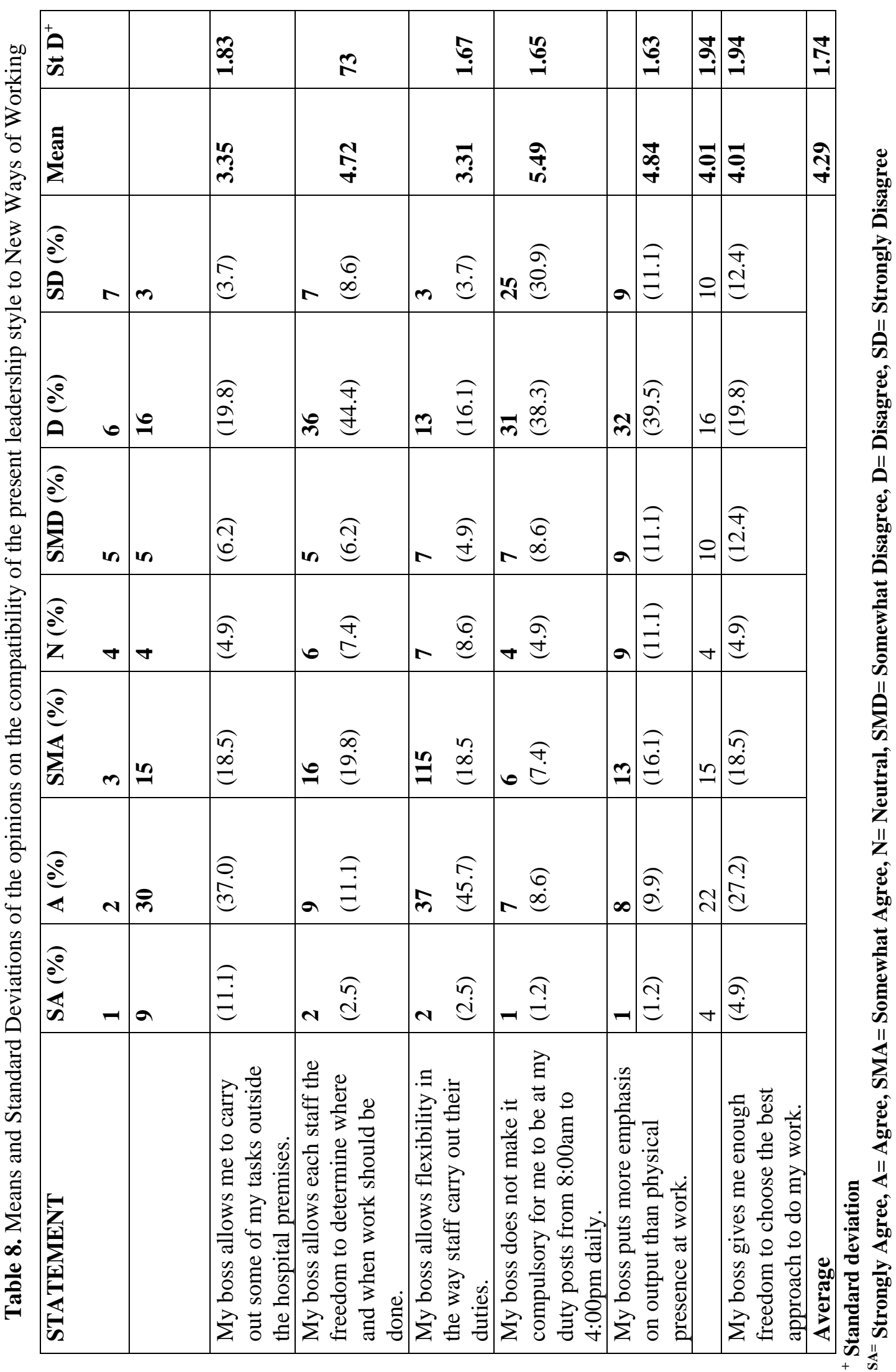


Texila International Journal of Public Health

Volume 4, Issue 4, Dec 2016

\section{References}

[1]. Al-Tawfiq, J.A., Memish, Z.A. (2014). What are our pharmacotherapeutic options for MERS-CoV?Expert Rev. Clin Pharmacol. 2014; 7: 235-238. 10.1586/17512433.2014.890515.

[2]. Baane, R.H., Houtkamp, P., \&Knotter, M. (2010).Het nieuwe werken ontrafeld [New ways of working figured out]. Assen: Koninklijke Van Gorcum; 2010.

[3]. Bijl, D. (2007).Het nieuwe werken: Op weg naar een productieve kenniseconomie [New Ways of working: heading for a productive knowledge economy]. Den Haag: Sdu Publishers bv.2007. Dutch.

[4]. Bijl, D. (2009).Aan de slag met het nieuwe werken [Let's get to the new ways of working]. Zeewolde: Par CC. 2009. Dutch.

[5]. Bryman A. \&Bell, E. (2011). Business Research Methods (3rd edition). New York: Oxford University Press Inc.; 2011.

[6]. Cooper S.J., (2003). An evaluation of the leading an Empowered Organisation Programme. Nursing Standard; 2003: 17(24): 33-9.

[7]. Cronbach, L.J. (1951). Coefficient alpha and the internal structure of tests. Psychometrika. 1951; 16:297334.

[8]. De Leede, J \& Kraijenbrink, J. (2014).The Mediating Role of Trust and Social Cohesion in the Effects of New Ways of Working: A Dutch Case Study. Human Resource Management, Social Innovation and Technology (Advanced Series in Management, Volume 14). England. Emerald Group Publishing Limited, 2014; 14, 3-20.

[9]. Donnelly, G.F. (2003). Why Leadership is important to nursing. In Austin S, Brewer M, Donnelly G, Fitzpatrick MA, Harberson G, Hunt PS, Morris M, editors. Five Steps to Successful Nursing Management. Springhouse, PA: Lippincott, Williams and Wilkins; 2003.

[10]. Dooley, D. (2009). Social research methods. 4th ed. Harlow: Pearson Education Limited; 2009.

[11]. Egmond van, H. (2010).Het nieuwe werken: Van visie naar praktijk [New ways of working: From vision to practice]. Alphen aan den Rijn: Kluwer. 2010. Dutch.

[12]. Fiedle, F.E. (1964). A contingency model of leadership effectiveness. In L. Berkowity (Ed.), Advances in experimental social psychology. New York: Academic Press; 1964: Vol. 1, pp150-190

[13]. Fiedler, F. E. (1966). Personality and situational determinants of leadership effectiveness. In D. Cartwright and A. Zander (Eds.), Group dynamics. 3rd ed. New York: Harper \& Bow; 1966: 302-380.

[14]. Fiedler, F.E. (1967).A theory of leadership effectiveness. McGraw-Hill: Harper and Row Publishers Inc.; 1967.

[15]. Fox, R., Crask, M.\&Kim, J. (1988). Mail survey response rate a meta-analysis of selected techniques for inducing response. Public Opinion Quarterly; 1988: 52(4), 467-491.

[16]. Gautret, P., Benkouiten, S., Salaheddine, I., Belhouchat, K., Drali, T. \&Parola, P. (2013). Hajj pilgrims knowledge about Middle East respiratory syndrome coronavirus, August to September 2013. Euro Surveill. 2013; 18: 20604

[17]. Kluytmans, F. (2005).Leerboek personeels management [Learning book human resource management]. Groningen: Wolters-Noordhoff. 2005. Dutch.

[18]. Lewin, K., Lippit, R, \& White, R.K. (1939). Patterns of aggressive behavior in experimentally created social climates. Journal of Social Psychology, 1939;10, 271-301.

[19]. Memish, Z.A., Al-Tawfiq, J.A., Makhdoom, H.Q. Al-Rabeeah, A.A., Assiri, A., Al-Hakeem, R.F., AlRabaiah, F.A., Alhajjar, S., Flemban, H., Balkhy, H., Barry, M., Alhaassan, S., Alsubaie, S. \& Zumla, A. (2014). Screening for Middle East respiratory syndrome coronavirus infection in hospital patients and their healthcare worker and family contacts: a prospective descriptive study. Clin Microbiol Infect. 2014; 20: 469474. 10.1111/1469-0691.12562.

[20]. Nunnally, J. (1978).Psychometric theory 2nd ed. New York: McGraw-Hill; 1978.

[21]. Parrett, EE.., Hurd, PO.., Northcraft, G., McGhan, W.F.\&Bootman, J.L. (1985). Leadership styles of hospital pharmacy directors. American Journal of Hospital Pharmacy. 1985; 42: 69-73.

[22]. Rowley, R. \& Roevens, J. (1999).Organize with Chaos, Management Books 2000 Ltd. 1999. ISBN 9781852525613. 
[23]. Saunders, M., Lewis, P., Thornhill, A., Booij, M. \& Verckens, J. P. (2011).Methoden en technieken van onderzoek [Methods and techniques of research]. Amsterdam: Pearson Education Benelux; 2011. Dutch.

[24]. Stoffers, J., Kurstjens, J., \& Schrijver I. (2015). Leadership and New Ways of Working: A Case Study in a Financial Service Organisation. International Journal of Business and Economics Research; 2015: Vol. 4, No. 3: 157-162. doi: 10.11648/j.ijber.20150403.18

[25]. Taberno, C., Chambel, M.J., Curral, L. \&Arana, J.M., (2009). The role of task-oriented versus relationship-oriented leadership on normative contract and group performance. Social behavior and personality; 2009: 37(10): 1391-1404. doi: 10.2224/sbp.2009.37.10.1391.

[26]. Volberda, H., Jansen, J., Tempelaar, M. \& Heij, K. (2010). Monitoren van sociale innovatie: Slimmer werken, dynamisch managen en flexible organiseren [Monitoring social innovation: working smarter, dynamic management and organising flexible]. Magazine for HRM, 2010;1, 85-110. Dutch.

[27]. WHO (2013). MERS-CoV Research Group. State of knowledge and data gaps of Middle East Respiratory Syndrome coronavirus (MERS-CoV) in humans. PLoS Curr. 2013; 5: 


\title{
Prevalence of Hepatitis-B infection among Pregnant Women in a Primary Healthcare Centre in Abuja, Nigeria
}

\author{
Article by Orji Ikechukwu Anthony ${ }^{1}$, Okoli Ugochukwu Thompson ${ }^{2}$ \\ ${ }^{1}$ Disease Control Unit, Health Department, AMAC, Abuja, Nigeria \\ ${ }^{2}$ Clinical Services Department, Lighthouse Medicare Services Ltd. Abuja, Nigeria \\ E-mail:drtony2013@gmail.com,drtonyiyke@gmail.com
}

\begin{abstract}
Background: Hepatitis B is adjudged to be one of the most infectious diseases in the world and a major public health problem with about $5 \%$ of the world population as asymptomatic carriers translating to 350 million people harboring hepatitis B virus (HBV) globally. Chronic infection with HBV occurs in up to $90 \%$ of infants infected at birth, 30\% for children aged one year to five years, and 6\% from six years and above. Thus, prevention of perinatal infection is an important strategy to reducing the prevalence of chronic hepatitis B infection in Nigeria being an endemic country. Emphasis therefore is placed on the screening of all pregnant women for HBsAg during the antenatal visit so as to detect positive women whose new borne will need prophylaxis to reduce the risk of contracting the infection.

Objectives: 1. to determine the percentage of pregnant women who were screened for Hepatitis B at PHC Karu, Abuja in 2013.2. To determine the sero-prevalence of Hepatitis B among pregnant women screened at PHC Karu, Abuja, in 2013.3. To determine whether the policy of prophylaxis against peri-natal infection for neonates of sero-positive mothers were strictly followed at this PHC during the review period.

Methods: This is a retrospective cross-sectional study which used secondary data extracted from antenatal registers, laboratory registers, HBsAg-positive patients' antenatal and delivery case notes for the period under review - Jan.-Dec. 2013.

Results: All the 856 pregnant women who registered for ANC in this PHC were offered HBsAg screening, 99.3\% (850) complied with the screening, and 8.5\% (72) sero-prevalence recorded. All the positive cases were referred to secondary health facility for HBIG prophylaxis; however no follow-up was done to ascertain the outcome.

Conclusion: The high endemic rate of $\mathrm{HBV}$ infection, (8.5\% prevalence) requires more effort at preventing the vertical transmission. 100\% screening rate for all ANC clients is highly encouraged as well as 100\% follow up rate for exposed infants' HBIG prophylaxis.
\end{abstract}

Keywords: Prevalence, asymptomatic, HBV infection, pregnant women, Primary Healthcare Centre, HBsAg screening.

\section{Acronyms}

$\begin{array}{lll}\text { ANC } & : & \text { Ante Natal Care } \\ \text { AMAC } & : & \text { Abuja Municipal Area Council } \\ \text { CDC } & : & \text { Centers for Disease Control and Prevention } \\ \text { DNA } & : & \text { Deoxyribonucleic Acid } \\ \text { HBcAg } & : & \text { Hepatitis B core antigen } \\ \text { HBIG } & : & \text { Hepatitis B Immunoglobulin } \\ \text { HBsAg } & : & \text { Hepatitis B surface antigen } \\ \text { HBV } & : & \text { Hepatitis B Virus } \\ \text { PHC } & : & \text { Primary Healthcare Center } \\ \text { USPSTF } & : & \text { U.S. Preventive Services Task Force } \\ \text { WHO } & : & \text { World Health Organization }\end{array}$


Texila International Journal of Public Health

Volume 4, Issue 4, Dec 2016

\section{Background}

Hepatitis B surface antigen (HBsAg) formerly called Australian antigen because it was first described in the serum of an Australian aborigine in 1963 and in 1968, the Australian antigen was discovered to be related to type B hepatitis (Emechebeet., al 2009). According to the work by Emechebe et.al, they reported that David S. Dane, a $20^{\text {th }}$ century English Virologist found virus-like particles in the serum of patients suffering from type B hepatitis in 1973 and these particles were designated as the hepatitis B virus (HBV) also called Dane particles. Hepatitis B is adjudged to be one of the most infectious diseases in the world and a major public health problem with about $5 \%$ of the world population as asymptomatic carriers translating to 350 million people harboring hepatitis B virus (HBV) globally (Aminuet., al 2013). The WHO report on HBV stated that, a global mapping can categorize the world into three as regards the prevalence of chronic Hepatitis B infection. These are high $(>8 \%$ prevalence), intermediate ( $2-8 \%$ prevalence), and low ( $<2 \%$ prevalence), thus by this classification, Nigeria is a high endemic area. Furthermore, Aminuet., al (2013) indicated that Chronic HBV infection is a major risk factor for deaths from cirrhosis and liver cancer and the infection has reached hyper-endemic levels in Nigeria with the sero-prevalence of hepatitis B virus surface antigen (HBsAg) estimated to range from $10 \%$ to $40 \%$.

Lin K. \& Vickery J. (2009) stated that in 2004, the U.S. Preventive Services Task Force (USPSTF) recommended that exposure to Hepatitis B virus infection should be screened for every pregnant woman when they attend their first ante-natal clinic. To do this screening, HBsAg strip test should be used. This recommendation was based on screening on evidence that this screening when followed-up with preventive vaccination of neonates born to HBsAgpositive mothers will substantially reduce the risk for chronic HBV infection among these children. Thus in order to reduce mother to child transmission of Hepatitis B, the passiveactive immunization strategy with Hepatitis B immune globulin and Hepatitis B vaccine at birth for the neonates born to Hepatitis B positive women is widely recommended. This recommendation is found in the Australian National Antenatal care guidelines, UK's National collaborative center for women's and children's health and the U.S preventive services task force.

In Nigeria, this guideline is adopted, emphasizing the screening of all pregnant women for Hepatitis B surface antigen during the antenatal visit so as to detect positive women whose new borne will need prophylaxis because they are at higher risk of contracting the infection from vertical transmission. How is the Primary Healthcare Centre (PHC) carrying out this role of screening the pregnant women during antenatal visits? What percentage of the clients test positive to Hepatitis B surface antigen? What was done for the new borne of positive mothers? These questions were what prompted this study.

Objectives of the study: 1 . to determine the percentage of pregnant women who were screened for Hepatitis B at PHC Karu, Abuja, from January-December 2013.2. To determine the sero-prevalence of Hepatitis B among pregnant women screened at PHC Karu, Abuja, from January-December 2013.3. To determine whether the policy of prophylaxis against perinatal infection for neonates of sero-positive mothers were strictly followed at this PHC during the review period.

\section{Literature review / general considerations}

Hepatitis B Infection: Formerly known as 'serum' hepatitis, hepatitis B infection is an acute systemic viral infection with major pathology in the liver, caused by hepatitis B virus (HBV) and transmitted usually through the parenteral route (Park, 2007). According to WHO (2014), Hepatitis B virus is a double stranded DNA virus from the hepadnaviridae family. It measures about $42 \mathrm{~nm}$ and has a nucleocapsid core, the 'HBcAg' measuring about $27 \mathrm{~nm}$. These are surrounded by outer envelope made of lipoprotein. This outer coat contains the Hepatitis B surface antigen (HBsAg).Viral hepatitis B infection represents a serious worldwide public health problem, a disease often under diagnosed in the tropics since hepatitis B infection represents only one of the several pathologic conditions which may 
result in liver damage (Azubike \& Nganginieme, 1999).Park (2007) gave a succinct picture of the characteristics \& possible sequelae of hepatitis B infection as he explained that the disease is characterized by a tendency to long incubation ranging from 6 weeks to 6 months and a protracted illness with a variety of outcomes. Usually acute self-limiting infection (80-95\%), which may be subclinical or asymptomatic in some cases with about 5-15\% failing to resolve, thus leading to persistent carrier state. He further stated that persistent chronic hepatitis may lead to progressive liver disease including chronic active hepatitis and hepatocellular carcinoma.

Epidemiology: Hepatitis B infection is a globally endemic disease occurring more in the tropical and developing countries. More than 2 billion people worldwide have been infected at one point in their life with about 350million chronic carriers (Park, 2007). The carrier state is defined as the presence of HBsAg for more than 6 months (Lucas \& Gilles, 2003). The disease prevalence has been grouped into; 1 . low endemic ( $<2 \%$ prevalence), 2 . intermediate endemic, (2-8\% prevalence), 3. high endemic ( $>8 \%$ prevalence). The prevalence varies from region to region and countries with high standard of personal and environmental hygiene tend to have low prevalence of the disease for example, $0.1 \%$ prevalence is recorded in some European countries while up to $15 \%$ prevalence were found in some tropical countries (Lucas and Gilles, 2003).Different authors have recorded varying prevalence rates from studies done in Nigeria ranging from; 37-46\% (Azubike \& Nganginieme, 1999), 9-39\% (Emechebe et.al, 2009), $10-40 \%$ (Aminu et.al. 2013). Thus, it is an obvious fact that prevalence rate in Nigeria is above $8 \%$, making it one of high endemic countries of the world. For infants infection, those infected at birth has been shown to be more prone to developing chronic infection as stated by Emechebe et.al., (2009), Chronic infection with HBV occurs in up to $90 \%$ of infants infected at birth while children aged one year to five years, there infection leads to about on $30 \%$ chronicity and the figure drops further in children aged six years and above with only about 6\% developing chronic infection. Therefore, prevention of perinatal infection is an important strategy to reducing the prevalence of chronic hepatitis B infection in Nigeria. Transmission; Hepatitis B transmission is blood borne, transmitted by inoculation as stated by Lucas and Gilles (2003). Transmission may occur by ; transfusion of blood or blood products, accidental inoculation e.g. shared use of unsterilized hypodermic needles drug addicts, mass immunization, tattooing, ritual scarification, other modes are through insect bites, vertical transmission from carrier mother during perinatal period, sexual intercourse (heterosexual \& homosexual), serous exudates of skin ulcers (direct contact inoculation), \& injury -associated sports (Lucas \& Gilles, 2003). The high risk groups are health workers, haemophiliacs, haemodialysis patients, sexually promiscuous, homosexuals, and Intra Venous drug users (Longmore et.al. 2001). Babies born to Hepatitis B carrier women are also at high risk of infection (Collier et.al. 2003). Though, vertical transmission from infected mother is high risk route of infection, available studies has shown a rather low transmission rate of 2.8\% by Abdulsalam et, al., (1986). However, considering high fertility rate of Nigeria, this will be translated to a very high number of children. Incubation Period; Longmore et.al,(2001) stated that the incubation period is 30days to 180days. However, Park (2007) related the median incubation period to be lower than 100 days (range 45 to 180 days). He explained that lower doses of the virus tend to result in longer incubation period. Clinical picture; Prodromal symptoms include fever, malaise, anorexia, nausea, arthralgia. Jaundice with or without hepatomegaly, splenomegaly, adenopathy and urticaria, (Longmore et.al, 2001). The picture can be complicated by carrier state and chronic liver disease which may follow infection. Chronic liver disease may be severe, may progress to primary liver cancer (Park, 2007). For diagnosis, there are three distinct antigen-antibody systems that relate to HBV infection and a variety of circulating makers that are useful in diagnosis.

Treatment: The treatment is supportive; alcohol should be avoided as well as other hepatotoxic drugs. Chronic HBV may respond to interferon alpha or other antiviral drugs like lamivudine, famciclovir, (Longmore et.al, 2001). 
Texila International Journal of Public Health

Volume 4, Issue 4, Dec 2016

Prevention and Containment: Prevention has been a major aim in managing viral hepatitis B. Three broad strategies are: health education, screening and vaccination. 1. Health education; Enlightenment of the general public on the various modes of transmission and preventive measures will go a long way towards preventing the spread especially in resource limited setting (Emechebe et.al. 2009). 2. Screening; Screening of all pregnant women is now recommended (Collier et.al, 2003). The aim is to detect positive client for adequate prophylaxis for their new borne. Also sexual partners of any positive client should also be screened and vaccinated. Screening is also recommended for all donors of blood before bleeding and screening of all blood and blood products before transfusion. Hepatitis B Vaccine; There is active vaccination done with older plasma derived vaccine and the newer Recombinant DNA vaccine. It is given at day 0,1 month \& 6month intervals. There is also passive vaccination with Hepatitis B immunoglobulin (HBIG), in addition, there is a combination of the two vaccines, active -passive immunization. It's recommended to vaccinate all children within the first year of life and this has been incorporated into the immunization schedule (Lucas\& Gilles, 2003). Infants of known carriers should be given passive -active immunization, HBIG within 12hours of birth and Hepatitis B vaccine within 7days of birth (Collier et.al, 2003).Health workers and other members of at risk group should be vaccinated (Lucas \& Gilles, 2003).

\section{Methods}

This is a retrospective cross-sectional study which used secondary data extracted from antenatal registers, laboratory registers, HBsAg-positive patients' antenatal and delivery case notes for the period under review - Jan.-Dec. 2013 at the health center. The study area is primary Health Center, Karu, (AMAC),in Abuja, Nigeria. The site was selected by purposive sampling. This technique was used in order to select a Primary Health Center with high volume of ANC client's turnover to get a sizable number of participants, enough, to validate the study as well as one with functional laboratory and qualified personnel running the HBsAg laboratory tests. Primary Health Center, Karu fulfilled these criteria and thus was selected. The Study Population involved all pregnant women who attended ANC at the health center from January to December, 2013. The total Population Sampling method was used in order to actualize the objective of measuring the prevalence of chronic HBV infection among the pregnant women attending ANC at the Centre. While the 2013 ANC register was the sampling frame, the sample size was all the 856 pregnant women who attended ANC at the center during the review period. The strategy for data extraction consists of the following: Firstly, the antenatal booking (first visit) register was reviewed, to ascertain the number of patients that were booked from $1^{\text {st }}$ January 2013 to $31^{\text {st }}$ December 2013. Note that the policy of this PHC is that all the pregnant women were referred to the laboratory section for routine ANC test which includes HBsAg screening on their first visit. The result will be evaluated on their second visit. Secondly, the ANC register was used to compare with the Laboratory register for recording routine ANC results in order to check if all the women actually did the test or otherwise. Thirdly, the Laboratory register was used to check the number of women whose HBsAg test results were negative and those that were positive. Fourthly, the case notes of the patients whose results were positive were reviewed to find out the plan/ line of management for prophylaxis against HBV infection as documented in the case notes. Exploratory method of data analysis was employed in the study, using simple arithmetic and easy- to-draw charts to summarize data. The results were reported in the form percentages and presented using pie bar and column charts.

\section{Ethical Clearance}

Ethical approval was given by the ethical committee of the Health Department, Abuja Municipal Area Council (AMAC), Federal Capital Territory, Nigeria. The confidentiality of patient's information was maintained through the research process. 


\section{Results}

1. Demographics of the sample population revealed the distribution of the age of respondents as $31 \%$ from age group of 25-29 (highest), 29\% for 20-24 years, $20 \%$ for $30-34$ years, $15 \%$ for $14-19 y e a r s$ and $5 \%$ for 35-43years (table 1). While the occupational distribution as shown in table 2, revealed the highest group to be Public servants at $45 \%$, Traders (22\%), House Wives (18\%) and Farmers (15\%).

2. 856 pregnant women registered for ANC in this Primary health center and al the clients (100\%) were referred to the laboratory unit for routine ANC test including HBsAg test (Figure 1).

3. 850 (99.3\%) of these pregnant women did the test and continued ANC in this PHC, six of them $(0.7 \%)$ dropped out and did not do the test (Figure 2).

4. $778(91.5 \%)$ of these 850 were negative for HBsAg while $72(8.5 \%)$ tested positive (Figure 3).

5. All the $72(100 \%)$ positive patients were referred to a secondary health facility (Figure 4), for continuation of ANC and delivery in view of lack of facility for HBIG (Passive immunization of the new borne).

6. Two of the women still came in labour to the PHC and delivered successfully. The record showed that they received Hepatitis B vaccine (active immunization) and referred to the secondary health facility for further care in view of HBIG for the new borne (passive immunization).

7. The case notes of all these referred women did not show evidence of any follow-up whatsoever to the referral secondary health facility and no feedback were given them.

\section{Discussions}

The study revealed that about 99\% of the clients were screened for HBsAg test in this center in the review year. This is a very good achievement, however $100 \%$ screening is desirable as recommended by CDC (2016) to prevent perinatal HBV transmission by identifying HBV-infected pregnant women and providing hepatitis B immune globulin and hepatitis B vaccine to their infants within 12 hours of birth. It is nevertheless, noted from the study that the roughly $1 \%$ of the clients (figure 2) who declined the test was due to lack of funds, therefore, the Nigerian Government needs to assist the poor clients who cannot afford this test to achieve $100 \%$ screening of the pregnant women for HBsAg. This is very pertinent because according to WHO (2016), hepatitis B is most commonly spread via mother to child at birth in highly endemic areas, furthermore, $80-90 \%$ of these infants infected during the first year of life develop chronic infections, thus, there is a great need to prevent this infection in these vulnerable group.

Moreover, a sero-prevalence of approximately 9\% (Figure 3) was found in this study, revealing that Karu environ is highly endemic for chronic hepatitis B infection especially among pregnant women. This is similar to the study by Zampino et.al (2015) who reported that Nigeria is among some African countries where HBV infection is hyper-endemic (greater than $8 \%$ of HBsAg chronic carriers in the general population). Therefore, robust preventive strategy need to be put in place in this center to protect the exposed neonates, as well as, public awareness campaign for the general public for screening and vaccination of seronegative clients especially as it concerns the high risk groups in accordance with World Health Organization's screening recommendation (WHO, 2015).

The study also found that all the pregnant women positive for HBsAg screening were referred to a secondary health facility (Figure 4), in accordance with the treatment guideline, since this PHC do not have capacity for administration of hepatitis B immune globulin to the exposed new born babies. According to Shiraki (2000) and CDC (2016), it is necessary to treat the infants of HBsAg positive mothers with hepatitis B immune globulin at birth, followed by HBV vaccination. These referrals were commendable good practice, but, on the other hand, no follow-up was made to ascertain whether the referred clients reported to the health facility and if they were given the required service. This is a gap in the service 
Texila International Journal of Public Health

Volume 4, Issue 4, Dec 2016

provision line identified from the study which must be urgently addressed by the facility Managers.

\section{Diagrams}

\section{Table 1. Age}

The age distribution of the ANC clients at the center in 2013 is between 14 and 43 as $\mathrm{g}$ given in table 1 . The results show the distribution of the age of respondents as $31 \%$ from age group of $25-29$ (highest), $29 \%$ for $20-24$ years, $20 \%$ for $30-34$ years, $15 \%$ for $14-19 y e a r s$ and $5 \%$ for 35-43years.

\begin{tabular}{|l|l|l|}
\hline AGE & FREQUENCY & PERCENT (\%) \\
\hline 14-19 YEARS & 129 & 15 \\
\hline 20-24 YEARS & 246 & 29 \\
\hline 25-29 YEARS & 266 & 31 \\
\hline 30-34 YEARS & 172 & 20 \\
\hline 35- 43 YEARS & 43 & 5 \\
\hline TOTAL & 856 & 100 \\
\hline
\end{tabular}

\section{Table 2. Occupation}

The occupation distribution of the ANC clients at the center in 2013 are as follows: Public Servants (45\%), Traders (22\%), House Wives (18\%) and Farmers (15\%).

\begin{tabular}{|l|l|l|}
\hline OCCUPATION & FREQUENCY & PERCENT (\%) \\
\hline HOUSE WIFE & 154 & 18 \\
\hline $\begin{array}{l}\text { PUBLIC } \\
\text { SERVANT }\end{array}$ & 385 & 45 \\
\hline FARMER & 128 & 15 \\
\hline TRADER & 189 & 22 \\
\hline TOTAL & 856 & 100 \\
\hline
\end{tabular}

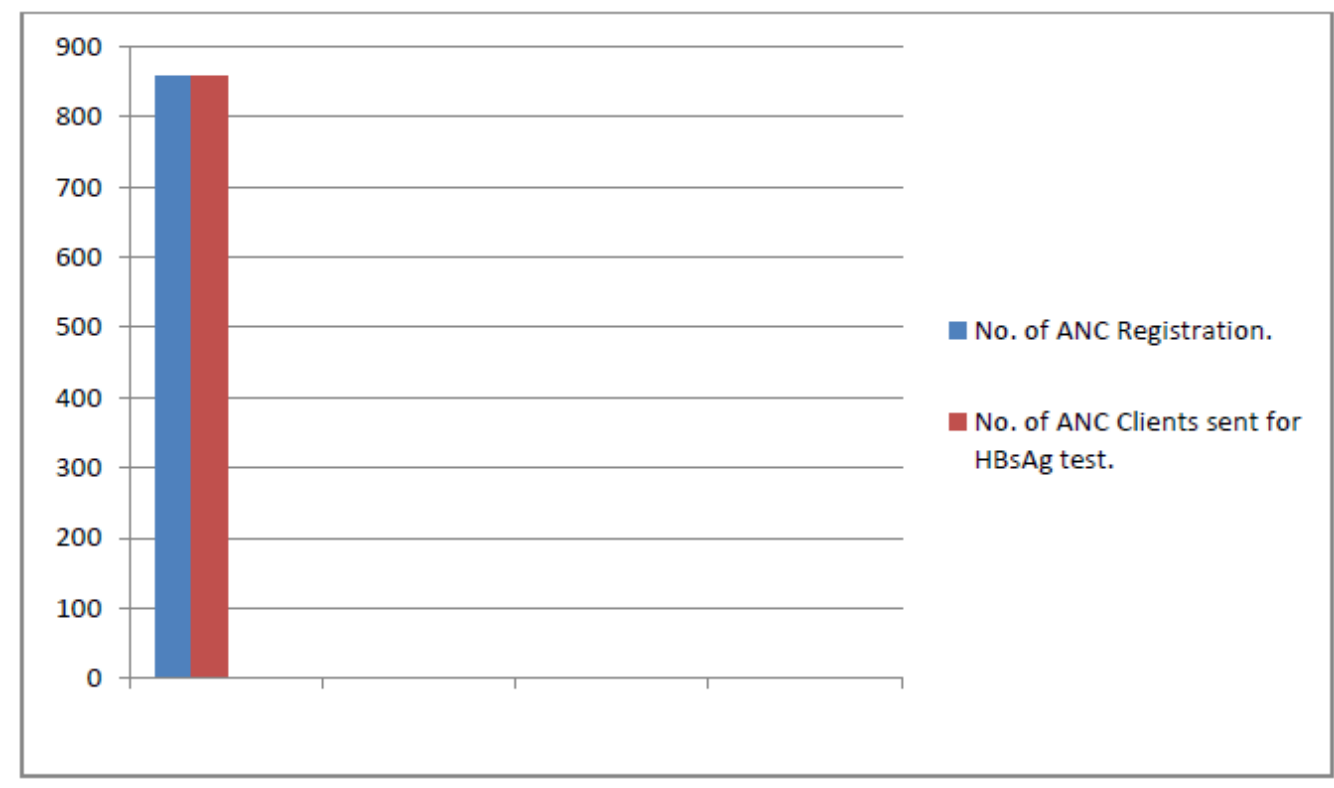

Figure 1.

Bar chart representing the number of ANC visit and number of ANC clients sent for HBsAg screening test at PHC Karu in 2013 (JAN.-DEC.). P1 $=856 / 856=100 \%$, P2= $856 / 856=100 \%$. 


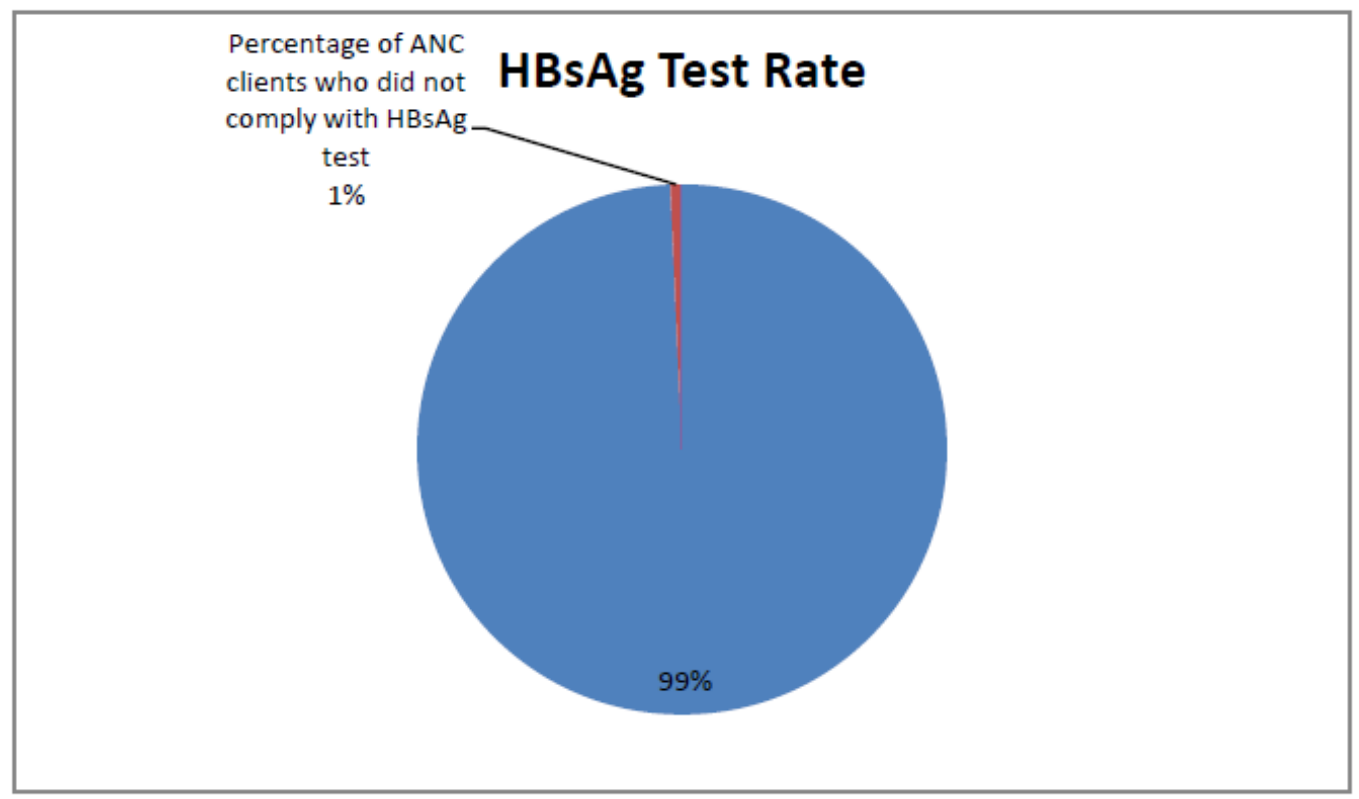

Figure 2.

Pie chart representing the percentage of ANC clients who did not do the HBsAg screening test offered them at PHC Karu, in 2013 (JAN.-DEC.). P= 6/856=0.7\% 1\%. About 99\% complied with thee test.

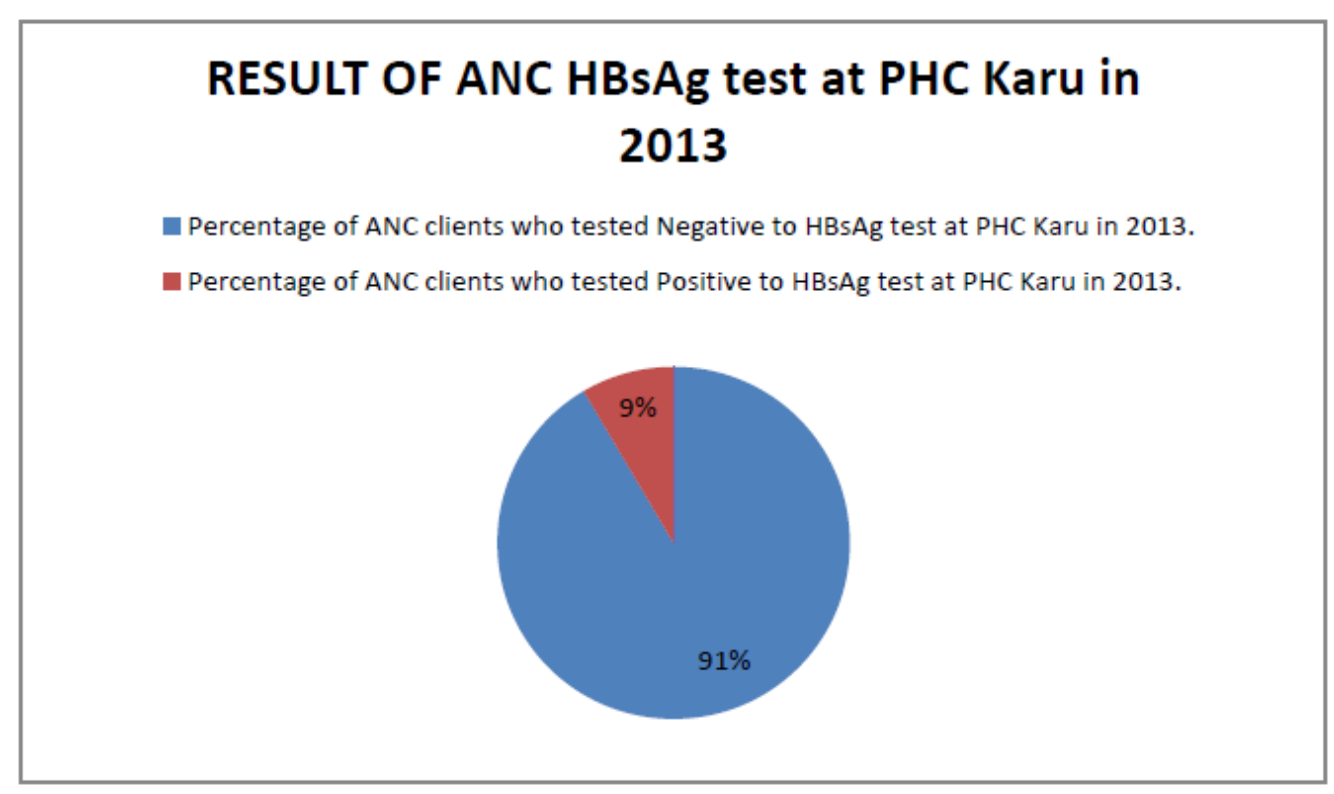

Figure 3

Pie chart representing the percentage of ANC Clients who tested negative and those who tested positive to HBsAg screening test at PHC Karu in 2013. $\mathrm{P}=72 / 850=8.5 \% \sim 9 \%$ (seropositive), $\mathrm{P}=778 / 850=91.5 \%$ (seronegative) 
Texila International Journal of Public Health

Volume 4, Issue 4, Dec 2016

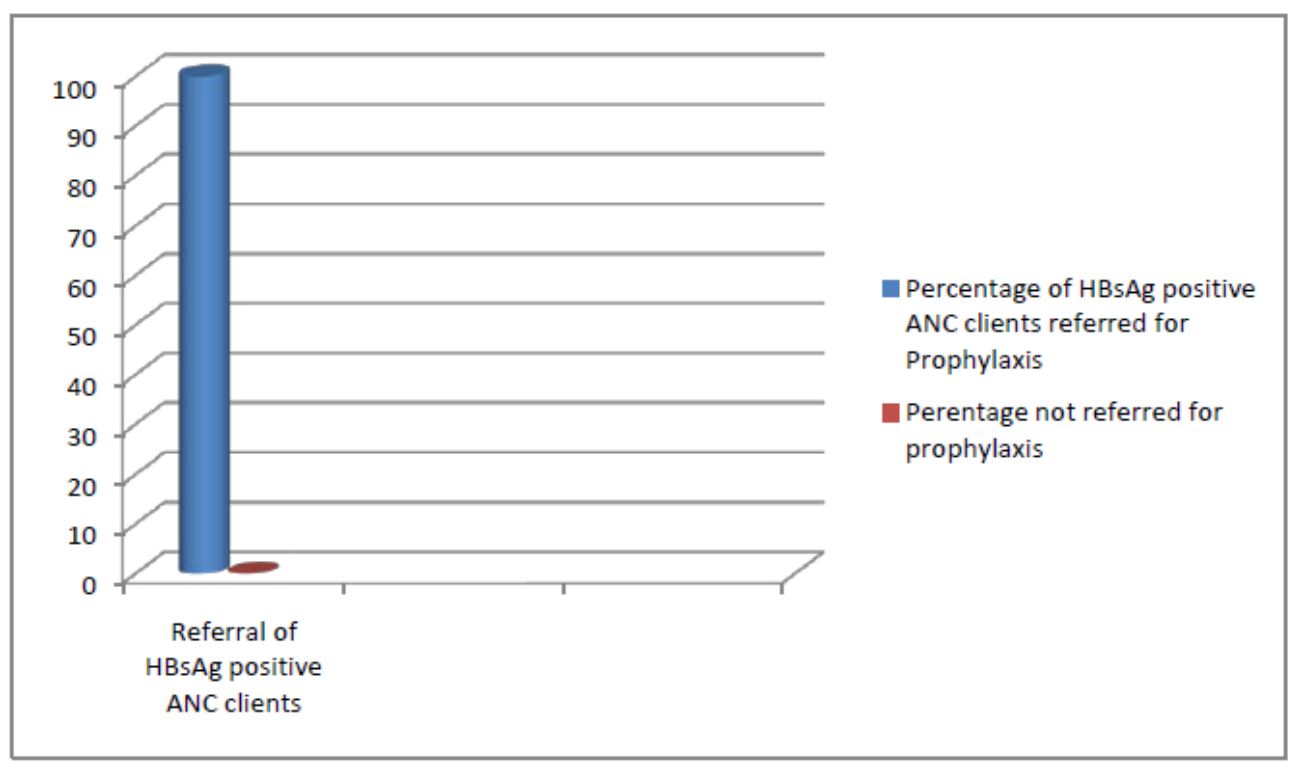

Figure 4

Column chart representing the percentage of ANC HBsAg-positive clients referred to a secondary health facility for prophylaxis for their new borne. $\mathrm{P}=72 / 72=100 \%$.

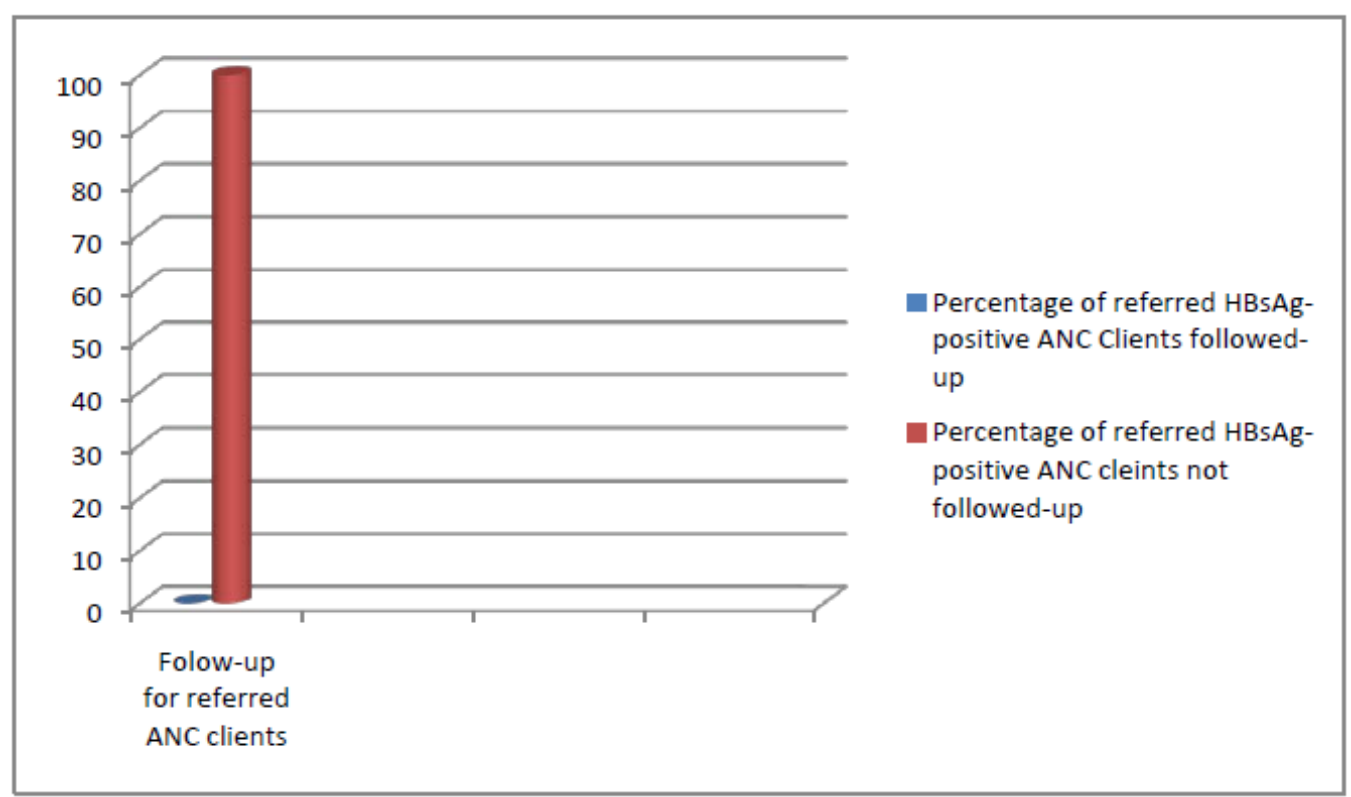

Figure 5

Column chart representing the percentage of Referred HBsAg-positive ANC clients that were followed-up after referral to a secondary health facility. $\mathrm{P}=0 / 72=0 \%$

\section{Conclusion}

The high endemic rate of $\mathrm{HBV}$ infection, (8.5\% prevalence) requires more effort at preventing the vertical transmission of HBV from seropositive clients to their newborns. The screening rate for ANC clients for HBsAg of 99.3\% s extremely commendable, nevertheless, $100 \%$ screening rate for all ANC clients is ideal, therefore, highly encouraged and zero follow-up for exposed infants with regards to HBIG prophylaxis is very poor and unacceptable practice. This goes to say that referral of all seropositive clients to a secondary health facility for prophylaxis for their newborns is a very good practice but should be followup to ensure that the services were rendered. 


\section{Recommendations}

In view of the findings from this study, the following are hereby recommended:

1. That the capacity of the PHC Karu be improved to Comprehensive PHC status such that more services like HBIG prophylaxis, caesarean section surgery etc., will be offered there.

2. That the traditional two-way referral system be institutionalized in the PHC such that follow-up of all referred cases is carried out for better service delivery to the patients.

3. That the HBsAg screening for pregnant women be made free of charge by the government to allow for all of them to access the service.

4. Further research at the secondary health facilities where these patients were referred to, in order to ascertain whether the prophylaxis guideline was strictly followed in managing these patients is strongly recommended.

\section{Limitations of the study}

The study was based on review of secondary data; therefore, any inadequacy/improper documentation of data could have introduced bias into the study.

\section{Acknowledgement}

My special thanks go to the officer in charge of PHC Karu, the nurses and midwives at the ANC section and the laboratory staff for their assistance and cooperation during this study.

\section{References}

[1]. Abdulsalami N., Tekena O. H., Sergei O. V, Germano M. R., Bernard B. A., Vitaly A. A. (1986) Prevalence of hepatitis B infection markers in representative areas of Nigeria. Intrn J Epiderm 1986; 15:274.

[2]. Aminu M.,Okachi E.E.,Abubarka S.M.,Yahaya A. Prevalence of hepatitis B virus surface antigen among asymptomatic students in a Nigerian University. Ann Afr Med [serial online] 2013 [cited 2014 Apr 4]; 12:55-6. Available from:

http://.annalsafrmed.org/text.asp?2013/12/55/108257.

[3]. Azubike J.C.,N kanginieme K.E.O. (1999). Paeditrics and child heath in a tropical region. Owerri Nigeria, African educational services.pp: 132.

[4]. CDC (2016). Viral hepatitis-hepatitis b, perinatal transmission, updated October, 2016. Accessed from: https://www.cdc.gov/hepatitis/hbv/perinatalxmtn.htm

[5]. Collier J., Longmore M., Scally P. (2003). Oxford handbook of clinical specialties, $6^{\text {th }}$ Ed. New Delhi, Oxford university press. Pp: 100,158.

[6]. Emechebe G O, Emodi I J, Ikefuna A N, Ilechukwu G C, Igwe W C, Ejiofor O S, Ilechukwu C A. Hepatitis B virus infection in Nigeria - A review. Niger Med J [serial online] 2009 [cited 2014 Apr 4];50:18-22. Available from: http://www.nigeriamedj.com/text.asp?2009/50/1/18/71932

[7]. Lin K, Vickery J. Screening for Hepatitis B Virus Infection in Pregnant Women: Evidence for the U.S. Preventive Services Task Force Reaffirmation Recommendation Statement. AHRQ Publication No. 09-05134-EF-3, June 2009.

http://www.uspreventiveservicestaskforce.org/uspstf09/hepb/hepbpgart

[8]. Lucas A.O.,Gilles H.M. (2003) Short textbook of public health medicine for the tropics, $4^{\text {th }}$ ed. London, Hodder Arnold. Pp:57-58

[9]. Park K. (2007) Park's textbook of preventive and social medicine, $19^{\text {th }}$ Ed. Jabalpur India, Bhanot publishers Pp:175-179

[10]. Longmore M.,Wilkinson I.,Torok E. (2001). Oxford handbook of clinical medicine, $5^{\text {th }}$ Ed. New York, Oxford university press. Pp:578-579

[11]. Shiraki K. (2000). Perinatal transmission of hepatitis B virus and its prevention. Journal of Gastroenterology/Hepatology, Suppl:E11-5.Accessed :

https://www.ncbi.nlm.nih.gov/pubmed/10921375

[12]. World Health Organization (2014). Global alert response: Hepatitis B. Available from http://www.who.int/csr/disease/hepatitis/whocdscsrlyo20022/en/index2.html, accessed on 04/04/2014. 
Texila International Journal of Public Health

Volume 4, Issue 4, Dec 2016

[13]. World Health Organization (2015). Guidelines for the Prevention, Care and Treatment of Persons with chronic Hepatitis B infection. p46. Accessed from:

http://apps.who.int/iris/bitstream/10665/154590/1/9789241549059_eng.pdf?ua=1\&ua=1

[14]. World Health Organization (2016). Hepatitis Fact sheet, updated July 2016. Accessed from: http://www.who.int/mediacentre/factsheets/fs204/en/

[15]. Zampino R., Boemio A., Sagnelli C., Alessio L., Adinolfi L.E., Sagnelli E., and Coppola N. (2015). Hepatitis B virus burden in developing countries. World Journal of Gastroenterology, 21(42):

11941-11953. Accessed from: https://www.ncbi.nlm.nih.gov/pmc/articles/PMC4641116 


\title{
Retrospective Study of Fatal Dengue Hemorrhagic Fever in Lahore City
}

\author{
Article by Samra Ashraf \\ Master in Nursing Texila American University, Pakistan \\ E-mail: Samrashrf@yahoo.com
}

\section{List of Abbreviations}

DHF Dengue Hemorrhagic Fever

AST Aspartate Aminotransferase

ALT Alanine Aminotransferase

WHO World Health Organization

LFT's Liver Functioning Tests

RFT's Renal Functioning Tests

\section{Introduction}

Dengue fever is one of the most common mosquito-borne viral diseases of human beings. It has become a major reason for public health concern internationally over the recent years because of disease morbidity and mortality. Globally around 2.5 billion people are living in areas where dengue viruses can be transmitted. Spread of mosquito vectors \& viruses in geographical distribution are two main reasons of rise in incidence and prevalence of dengue fever \& appearance of dengue hemorrhagic cases. Urban areas of the tropics have been identified to be highly endemic. According to estimates made by WHO around 50-100 million infections of dengue are prevalent every year globally. (Deen et al. 2006) In Pakistan first dengue outbreak was reported in Karachi in 1994 as environmental conditions are conducive to Aedes mosquito breeding. Economic and security related migration introduced virus to Lahore as well. According to Punjab Health Department 590339 suspected cases were reported in Lahore \& 21685 confirmed by serology. It has been observed that 5-10\% of these cases develop DHF.(Mahmood et al. 2013)

Dengue is mainly transmitted by mosquito vector i.e. Aedesaegypti and can also be transmitted by A. albopictus to a lesser extent. Virus that causes dengue has four different types that are closely related to each other. Infected female mosquitoes transmit this virus to human beings through bite. An infected mosquito can transmit this virus to humans for the rest of its life. Symptoms of dengue range from very mild fever to very high fever including intense headache, retro-orbital pain, muscular and joint pain, and rashes. There is no vaccine or any specific medicine to treat dengue. Patients having dengue fever are advised to take rest and drink ample fluids. They are advised to use paracetamol in order to reduce high grade fever or visit the physician if fever persists. Recovery from infection by one provides lifelong immunity against that serotype but confers only partial and transient protection against subsequent infection by the other three. There have been enough proofs showing that subsequent infection increases the risk of severity of disease which can result in DHF (WHO).

Leaking of plasma, fluid accumulation, respiratory distress, and intense bleeding and organ impairment makes severe dengue a fatal complication. Warning signs includes decrease in temperature (below $38^{\circ} \mathrm{C} / 100^{\circ} \mathrm{F}$ ), severe abdominal pain, rapid breathing, bleeding gums, malaise, and restlessness, continuous vomiting and hematemesis. These can occur three to seven days after first symptom recognition. In order to prevent complications and minimize the risk of death adequate and timely health care is required in next 1-2 critical days.(Halstead 1980)

In 1950s when dengue epidemics occurred in the Philippines and Thailand then Dengue hemorrhagic fever was first identified. Till 1970 nine countries had encountered epidemic 
Texila International Journal of Public Health

Volume 4, Issue 4, Dec 2016

DHF and this number has increased more than four times and keeps on rising. Today rising number of DHF cases are causing increased dengue outbreaks in the Americas, and in Asia, where all four dengue viruses are endemic. DHF has turn out to be a prominent reason of hospitalization and demise among kids in several states. In Asia, widespread DHF has enhanced geologically from Southeast Asian regions to west China. Various regional states of the South and Central Pacific have encountered significant or slight DHF outbreaks. In previous twenty years deterrence and management has come to be more immediate with the escalating geographical spread of dengue and dengue hemorrhagic fever and higher ailment occurrence (Gubler 2002).

In the absence of bleeding or organ manifestation, DHF is medically challenging to diagnose, and the numerous etiologic agents can barely be distinguished by clinical tests. The specified diagnosis of DHF depends mainly on laboratory testing.(Drosten et al., 2002)

\section{Review of literature}

\section{Dengue hemorrhagic fever}

(Gubler, 2002) DHF largely an illness of kids below fifteen years of age, but can occur among elderly as well. It is recognized by abrupt beginning of fever, which generally continues for two to seven days, and a wide range of nonspecific signs and symptoms. Throughout the critical period of disease, it is challenging to differentiate DHF from dengue fever and other illnesses found in tropical regions. The differential diagnosis through the severe stage of illness should include influenza, typhoid, rubella, malaria, measles other viral hemorrhagic fevers, and number of other ailments that can be found in the acute phase as a broad-spectrum virus-related disorder. There is no pathognomonic sign or symptom for DHF during the acute stage; contrarily when fever disappears, typical appearances of plasma seepage starts, causing exact clinical diagnosis feasible among several patients.

\section{History}

(Guzman et al. 1999) Dengue hemorrhagic fever in adults in outbreak pattern was noticed for the very first time through the Cuban DHF epidemic of 1981. Records of DHF in people elderly than 15 years have steadily elevated, primarily in the American area. Throughout the 1997 Cuban DHF outbreak, 205 DHF cases were noticed, all with serologic or virologic evidence. Of these, 12 affected individuals deceased. The 12 lethal cases were categorized as DHF in accordance to the Guidelines for the Prevention and Control of Dengue and Dengue Hemorrhagic Fever in the American Area.

\section{Geographical distribution}

(Pinheiro et al,. 1997) Around two-thirds of the world's inhabitants reside in places swarmed with dengue vectors, primarily Aedesaegypti. All of the four dengue viruses are distributed, often concurrently, in most of these regions. It is approximated that around 80 million individuals turn out to be attacked yearly despite the fact that significant underreporting causes the alert of much lesser statistics. Presently dengue is endemic in all major regions other than Europe and outbreak dengue hemorrhagic fever (DHF) develops in Asia. The occurrence of DHF is much greater in the Asian countries than in other areas.

\section{Dengue in pakistan}

(Khan et al. 2013) Dengue fever appeared to be a significant wellbeing issue in Southeast Asia particularly Pakistan \& until any particular vaccination or any antiviral substance turn out to be accessible, healthcare provider need to be dependent to quick recognition for hazard variables affiliated to producing Dengue fever complications; simply identical to alert characteristics described via WHO and those recognized by research. Study tries to determine medical and biological variables like bleeding signs, disturbed LFT's, occurrence of protein and blood in the urine as probable forecasters of serious Dengue Fever. This can help in developing an aggressive strategy for dealing with such patients. Research revealed that 
extent of Dengue Fever as a risk for producing DSS can be forecasted by occurrence of excessive IgG levels, considerable P-value of 0.001; bleeding signs, p-value $<0.0001$; and elevated serum AST \& ALT, p-value of 0.01 \&0.004 accordingly. Although hazard for producing dengue hemorrhagic fever in patient with dengue fever can be forecasted through bleeding existence, URBC \& URP and elevated ALT in serum (Khan et al. 2013).

\section{Dengue hemorrhagic fever surveillance}

(Chairulfatah et al. 2001) In Indonesia, it is rule to inform about cases of dengue hemorrhagic fever (DHF) during $24 \mathrm{~h}$ to the local health authority. The objective of this study was to assess the competence, precision and communication delay of this information processes. In four main hospitals of the city of Bandung, medical archives of hospitalized DHF cases admitted between April 1994 and March 1995 were revised. This list of DHF cases was matched with the list of informed cases to the Bandung Municipality Health Office. Throughout the research duration, 569 dengue hemorrhagic cases and 81 dengue shock syndrome (DSS) cases were detected. Only 199 (31\%) of the 650 hospitalized cases with assumed DSS/DHF were informed to the Bandung Municipality Health Office. The proportion of fatal cases was considerably lower in all hospitalised cases i.e.1.7\% than among informed cases i.e. 2.5\%. In only 443 of the 583 hospitalised cases (76\%) in whom a dengue serological investigation was implemented, had this test positive. Of the 199 reported DHF/DSS cases151 (76\%) had a positive haemagglutination inhibition test. This study shows that the surveillance system for DHF/DSS in Bandung should be strengthened. DHF/DSS cases should be reported on the basis of a diagnosis made during hospitalisation preferably after a serological confirmation is obtained. (Chairulfatah et al. 2001)

\section{Outbreak in lahore}

(Humayoun et al. 2008) In a study conducted in Lahore in 2008 Out of the total of 110 dengue infected patients, 70 were male and 40 were female. The most common symptoms include fever (100\%), myalgia (68.2\%), headache (55.5\%), nausea (39.1\%), skin rash (53.6\%), mucocutaneous hemorrhagic manifestations (58.2\%), and ocular pain (20\%). Classic dengue fever (DF) was seen in $41.8 \%$ of the patients, $56.4 \%$ had dengue hemorrhagic fever (DHF), and only $1.8 \%$ developed dengue shock syndrome (DSS). Thrombocytopenia, leukopenia, and abnormal aspartate aminotransferase (AST)/alanine aminotransferase (ALT) were more frequently encountered in DHF and DSS as compared to DF. Ten patients had DEN4, five had DEN2, and two had DEN3 serotypes. The high frequency of DHF during the 2008 outbreak and the presence of three different dengue serotypes, emphasize the need to prevent and control dengue infection. Health authorities should consider strengthening surveillance for dengue infection, given the potential for future outbreaks with increased severity. It is also suggested that primary care physicians should be educated regarding recognition of DHF and to identify patients at high risk of developing DHF and DSS. (Humayoun et al.) In a study conducted in Lahore 2011about DHF outbreak found that there was 359 probable DF and 281 confirmed DF cases. The development of DHF, neurological manifestations and overall mortality was more frequent in confirmed DF group. Comparison between DHF/DSS and DF cases revealed a significant difference in vomiting $(\mathrm{p}=0.04)$, purpuric rash $(p<0.001)$, systolic blood pressure $(p=0.002)$, serum ALT $(p<0.001)$, hospital stay ( $\mathrm{p}<0.001)$, neurological involvement $(\mathrm{p}<0.001)$ and coagulopathy $(\mathrm{p}<0.001)$ between the two groups. Among 159 DHF patients, 108 (67.9\%) had bleeding from gums and oral cavity, 73 (45.9\%) had haemetemesis and 82 (51.5\%) malaena, 41 (25.8\%) had epistaxis, 12 (7.5\%) developed intracranial bleeding, 18 (11\%) had hematuria, 12 (7.5\%) had fresh bleeding per rectum and 37 (23\%) developed haemoptysis. Overall mortality was 3\%, but mortality in DHF/DSS cases was $6 \%$ and $41.6 \%$ for DSS cases. Logistic regression analysis showed that abdominal pain, purpuric rash, ascites, thrombocytopenia, coagulopathy and raised ALT had a statistically significant predictability for developing DHF. (Ahmed et al.) 
Texila International Journal of Public Health

Volume 4, Issue 4, Dec 2016

\section{Diagnosis}

(Halstead, 2007) Diagnosis of dengue falls into two stages: stage I, fever and viraemia accompanied by NS1 antigens in blood; and stage II, the early post-febrile period lasting a few weeks when IgM and IgG antibodies are in excess. During primary infection, viraemia more or less coincides with fever (figure 3). However, during a secondary infection, the duration of viraemia can be 2 or 3 days, whereas presence of NS1 antigens in blood lasts somewhat longer. The diagnostic importance of the two stages of dengue infection should be understood by the doctor. An inexpensive, rapid, sensitive, and specific test is needed to diagnose dengue during the febrile stage. One such test is marketed by Bio-Rad and uses a dengue group-specific NS1 monoclonal antibody in an ELISA format to detect dengue NS1 antigen in blood. This test confirmed $85 \%$ of PCR-positive serum samples.

\section{Policy making for prevention}

(DeRoeck et al,. 2003) A survey of policymakers and other influential professionals in four Southeast Asian countries (Cambodia, Indonesia, Philippines and Vietnam) was conducted to determine policymakers' views on the public health importance of dengue fever and dengue hemorrhagic fever (DHF), the need for a vaccine and the determinants influencing its potential introduction. The survey, which involved face-to-face interviews with policymakers, health programme managers, researchers, opinion leaders and other key informants, revealed an almost uniformly high level of concern about dengue fever/DHF and a high perceived need for a dengue vaccine. Several characteristics of the disease contribute to this high sense of priority, including its geographic spread, occurrence in outbreaks, the recurrent risk of infection each dengue season, its severity and the difficulty in diagnosis and management, its urban predominance, its burden on hospitals, and its economic toll on governments and families. Research felt to be key to future decision-making regarding dengue vaccine introduction include: disease surveillance studies, in-country vaccine trials or pilot projects, and studies on the economic burden of dengue and the cost-effectiveness of dengue vaccines. The results suggest favorable conditions for public and private sector markets for dengue vaccines and the need for creative financing strategies to ensure their accessibility to poor children in dengue-endemic countries.(DeRoeck et al. 2003)

(Gonzalez et al. 2005) A dengue 3 epidemic occurred in Havana City from June 2001 to March 2002. 12,889 cases were reported, with 81 DHF cases. From this, 76serologically confirmed cases were studied descriptively. Results showed Bronchial asthma and white race were important risk factors for the severe form of the disease. Fever (100\%), headache (92.1\%), myalgia (76.3\%), arthralgia (73.7\%) and retro-orbital pain (57.7\%) were the most frequent general symptoms. Vomiting and abdominal pain were observed in $59.2 \%$ and $48.6 \%$ of cases, respectively. The most common bleeding site was the vagina (64\%), followed by the skin (55.2\%). Eighteen patients (23.6\%) had shock syndrome. Laboratory findings included thrombocytopenia (100\%), hemoconcentration (93.4\%), an increase in liver enzymes (82.8\%), and leukopenia (71\%). Ultrasound detected thickening of the gallbladder wall in $35.1 \%$, pleural effusion in $20.3 \%$, and splenomegaly in $12.9 \%$ of cases. These findings contribute to a better understanding of the clinical aspects of DHF in adult patients due to the dengue 3 virus. (Gonzalez et al. 2005). In Lahore during 2006 epidemic this report on the Lab based surveillance of a public hospital where most of the patients from Lahore city or its suburbs. This study confirmed the presence of epidemic of DHF in Pakistan and suggests that there are be more than one serotypes present in Lahore. Visitors to Pakistan should be warned about the possibility of dengue infection and encouraged to use mosquito repellents. Clinicians in Pakistan should consider dengue in their differential diagnosis of patients presenting with fever or hemorrhage of unknown cause. This could lead to improved clinical and virologic surveillance for dengue. (Shahzad et al. 2007)

(Gibbons et al,. 2002) In study about incidence in Lahore among the 341 acute cases, 166 (48.7\%) were confirmed by IgM dengue specific kit. IgG was used on 200 suspected reinfected patients. Among them 79 (39.5\%) were positive, 3 (1.5\%) in gray zone and 118 
(59\%) were negative. Male to female ratio was 1.25:1. Most patients presented typical sign and symptoms of fever, headache, myalgia, anorexia, malaise, and skin rash and retro orbital pain in 98, 81, 75, 63, 47 and 41\% respectively in descending order. Among 245 confirmed dengue fever patients 43 (17.6\%) were considered dengue hemorrhagic fever cases on the basis of lab and clinical findings. More prevalence has been observed in old age (37.8\%) as compared to children (7.1\%) in age group 1-15 years. Continuous surveillance and education of the clinician is essential for the recognition of the risk factors of dengue hemorrhagic fever for early diagnosis and management. (Mahmood et al. 2009)

\section{Risk factors for dengue hemorrhagic fever}

(Pang et al. 2012) A study explored demographic and co morbidity risk factors for DHF in adult dengue epidemics in Singapore in year 2006 (predominantly serotype 1) and in year 2007-2008 (predominantly serotype 2). Retrospective case-control study was conducted with 149 DHF and 326 dengue fever (DF Adult dengue patients in Singapore who were 30-49 years, Chinese, female, had diabetes or diabetes with hypertension were at greater risk of developing DHF during epidemic of predominantly serotype 2 . These risk factors can be used to guide triaging of patients who require closer clinical monitoring and early hospitalization in Singapore, when confirmed in more studies. (Pang et al.)

In an age- and sex-matched case control study, total of 132 cases of dengue hemorrhagic fever/dengue shock syndrome and 249 randomly selected controls were recruited from two major teaching hospitals of Lahore, Pakistan. A semi structured questionnaire was used to collect data through interview and by reviewing clinical records. Odds of developing dengue hemorrhagic fever (DHF) and dengue shock syndrome (DSS) among diabetics are higher than in controls, but this association was not found statistically significant (OR. 1.26; 95\% CI. 0.78-2.03; $P=0.34)$. Similarly, no association was observed in individuals suffering from hypertension (OR. 0.93; 95\% CI. 0.57-1.49; $P=0.76$ ). Odds of developing DHF and DSS were higher for bronchial asthma (adjusted OR. 1.34) and pulmonary tuberculosis (adjusted OR. 1.41); however $P$ values were insignificant. Presence of diabetes mellitus, hypertension, ischemic heart disease and bronchial asthma among patients contracted dengue fever will not increase the risk of dengue hemorrhagic fever and dengue shock syndrome. (Mahmood et al. 2013) Although the liver is not a major target organ, pathologic findings including centrilobular necrosis, fatty change, Kupffer cell hyperplasia, acidophilic bodies, and monocyte infiltration of the portal tracts have been reported in patients with and/or dengue shocksyndrome (DSS) (Bhamarapravati et al, 1967; Burke, 1968). With such involvement, it would be expected that liver function tests would be abnormal. Liver involvement in dengue infection has been reported to be mild and manifest by raised liver enzymes. Of late there have been reports of fulminant hepatitis with high mortality in-patients with dengue infection (George, 1987; Suvatte et al, 1990). Innis et al (1990) reviewed the clinical course and liver histopathology of 19 fatal cases of dengue infection. In this study acute liver failure had been identified as a cause of death in DHF by dengue virus types 1 to 3 . The mode of liver injury whether a direct effect of the virus replication or a consequence of host response to infection could not be inferred.(Wahid et al. 2000)

Most DHF cases occur after sequential heterotypic DV infections (secondary infection), and circulating DV levels early in illness correlate with increasing dengue disease severity. The DV nonstructural protein NS1 is a $46-50-\mathrm{kDa}$ glycoprotein expressed in infected mammalian cells in both membrane-associated (mNS1) and secreted (sNS1) forms and is not a component of the dengue virion. Circulating sNS1 has been detected in acute-phase serum samples of patients with DV infections. The goals of this study were to determine whether plasma levels of sNS1 correlate with viremialevels, whether they are higher in DHF than in DF, and whether sNS1 levels early in illness could identify patients at risk of developing DHF. Immune complex formation with sNS1 and sNS1 binding to endothelial cells have been proposed as potential factors in DHF pathogenesis. Whether high circulating levels of 
Texila International Journal of Public Health

Volume 4, Issue 4, Dec 2016

antibody-bound or free sNS1 protein following peak viremia play a direct role in the pathogenesis of DHF is unknown and will require further investigation (Libraty et al. 2002).

\section{Treatment}

(Gibbons et al,. 2002) No specific therapeutic agents exist for dengue; steroids, antivirals, orcarbazochrome (which decreases capillary permeability) have no proven role. In patients without shock, oral hydration should be started early. Paracetamol (aspirin and other non-steroidalanti- inflammatory drugs should be avoided owing to the increased risk for Reye's syndrome and haemorrhage) can be used for fever and analgesia. Assessment of the patient's condition includes packed cell volume, platelet count, liver function tests, prothrombin time, partial thromboplastin time, electrolytes, and blood gas analysis. The patient's clinical condition should be monitored until at least 24 hours after defervesence because of the risk of shock

\section{Statement of problem}

- To identify the potential risk factors for Dengue Hemorrhagic Fever.

- Descriptive epidemiology of deaths with Dengue Hemorrhagic Fever.

- Spatial distribution of Dengue Hemorrhagic Fever in catchment areas of Shalamar.

\section{Materials and methods}

\subsection{Study design:}

A retrospective study of DHF was conducted in ICU and medical units of tertiary care hospital Lahore city from April 2016 to October 2016 to collect data from 2009 to 2016 about cases of DHF.

\section{Study area}

This study was conducted at Intensive care Unit (ICU) in one of the tertiary care hospitals of Lahore city. This tertiary care hospital contains 350 beds and lies between $30^{\circ} 34^{\prime}-30^{\circ} 31^{\prime}$ $\mathrm{N}$ and $74^{\circ} 22^{\prime}-74^{\circ} 47 \mathrm{E}$. The study area (ICU) is located in the hospital adjacent to ObsGynae ward (Labour room and Gynea operation theatre) and General operation theatre (GOT). Comprises of 9 beds; 3 beds (Bed-1 to Bed-3) allocated for patients with surgical or gynecological problems and 6 beds (Bed-4 to Bed-9) allocated for patients with medical problems. This intensive care unit was only admitting the patients requiring close monitoring or aggressive interventions referred from other wards or emergency room of the hospital. It was estimated that on average each 1 patient was referred to be admitted in ICU from other wards or emergency room. Control data was collected from different medical units of hospital.

\section{Sample size}

All cases of DHF deaths from 2009 to 2013 were included in the study, who were admitted in ICU after referral from different units with the diagnosis of DHF. A case was matched with a control on the ratio of 1:1. Controls were selected from confirmed cases of DF who survived.

\section{Selection of case}

A case was selected as case if he/she was confirmed dead by the hospital authorities and whose death was notified to health authorities due to DHF.

\section{Selection of controls}

A control was selected randomly from patients confirmed for DF who was cured and survived. 


\section{Inclusion criteria}

ELISA (Enzyme linked immuno-absorbent assay) confirmed Dengue fever patients admitted to Shalamar Hospital Lahore and willing to participate were included.

\section{Exclusion criteria}

Patients who were not confirmed by ELISA, complicated cases, or some other diseases with clinical signs similar to DF and those who refuse to participate were excluded from the study.

\section{Data collection procedure}

Data about cases was collected from the hospital records and close family member of the dead patient and from control on a structured questionnaire developed by the investigator. Questionnaires was completed in a face-to face interview \& telephonic interview with the family member of cases (dead patients) and controls (treated patients) and data about age, gender, demographic information, diabetes status, Hypertension, Asthma, allergies treated with corticosteroids, smoking, TB, paralysis and other relevant factors was collected. Purpose of the study was explained to all the attendants/relatives of the patients and verbal consent was taken prior to investigation.

\section{Statistical design}

To manage the data, a database was created in Microsoft Office excel 2010. The data analysis was done using SPSS v.16 software. Univariable analysis was conducted to find out the association between potential risk factors and the occurrence of deaths. Chi-square test was used to determine the relationship between gender, age group, Diabetes, Hypertension, TB Asthma, Allergies, Smoking, and Paralysis and outcome of interest (death among DHF patients). Factors found significant $(\mathrm{p}<0.25)$ were included in the Multivariable analysis. A pvalue less than 0.05 , was considered statistically significant in multivariable analysis (Hosmer et al. 2004).

\section{Results}

A total of 53 patients admitted to Intensive Care Unit from 2009-2013 were followed during the study period. These patients/ attendants were asked about the presence of comorbidities like Diabetes, Hypertension, Asthma, Allergies and occurrence of bleeding phenomena was recorded in the structured questionnaire attached (Annexure I). After the collection of data, each patient was matched with the inclusion and exclusion criteria. On matching 46 patients out of 53 met the inclusion criteria and included in the study and rest of the 7 patients were excluded from the study. And 46 controls were selected from medical units with the diagnosis of Dengue fever.

Table 4.1 Number of total patients included in study meeting inclusion criteria

\begin{tabular}{|l|l|l|}
\hline Status & Number & Percentage \\
\hline $\begin{array}{l}\text { Patients who met the } \\
\text { inclusion criteria }\end{array}$ & 46 & $86 \%$ \\
\hline $\begin{array}{l}\text { Patients who did not meet the } \\
\text { inclusion criteria }\end{array}$ & 7 & $14 \%$ \\
\hline $\begin{array}{l}\text { Total Number of Patients } \\
\text { followed }\end{array}$ & 53 & $100 \%$ \\
\hline
\end{tabular}


Texila International Journal of Public Health

Volume 4, Issue 4, Dec 2016

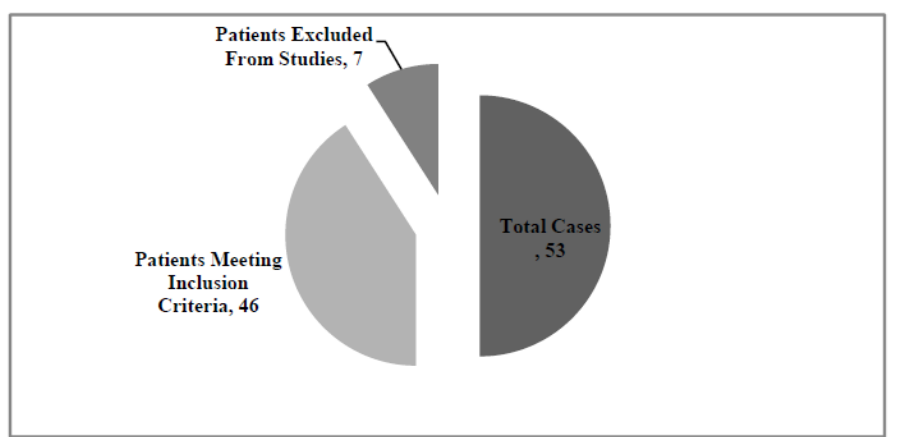

Fig. 4.1 Number of total patients included in study meeting inclusion criteria

Out of 53 patients who were selected during the study period $86 \%$ met the inclusion criteria i.e. they were confirmed cases of DHF. Rest of the $14 \%$ were excluded as they had very complicated condition or refused to participate in study.

Following table and figure shows the frequency distribution and bar charts of the patient's ages admitted to ICU and medical units with dengue and DHF. As it is visible in Table 4.2 that more patients are in younger age group.

Table 4.2 Age distribution according to groups

\begin{tabular}{|l|l|l|l|l|}
\hline \multicolumn{1}{|c|}{ Age } & Frequency & Percent & $\begin{array}{c}\text { Valid } \\
\text { Percent }\end{array}$ & $\begin{array}{c}\text { Cumulative } \\
\text { Percent }\end{array}$ \\
\hline $0-20$ & 7 & 7.6 & 7.6 & 7.6 \\
\hline $21-40$ & 40 & 43.5 & 43.5 & 51.1 \\
\hline $41-60$ & 31 & 33.7 & 33.7 & 84.8 \\
\hline $61-80$ & 11 & 12.0 & 12.0 & 96.7 \\
\hline $81-100$ & 3 & 3.3 & 3.3 & 100.0 \\
\hline Total & 92 & 100.0 & 100.0 & \\
\hline
\end{tabular}

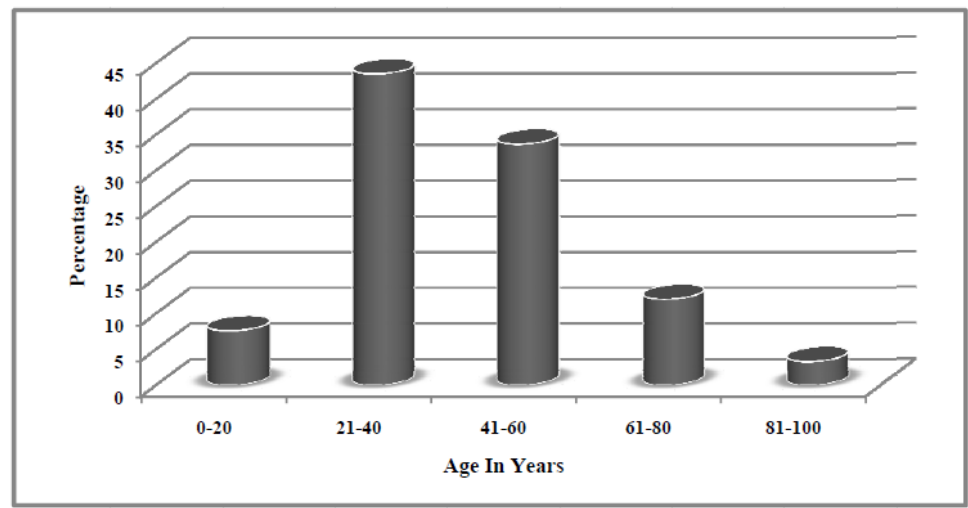

Figure 4.2 Frequency Distribution of cases and controls according to age groups

Figure. 4.3, represents the frequncy distribution of cases and controls according to gender. It shows that percentage of male patients is higher as compared to females. 


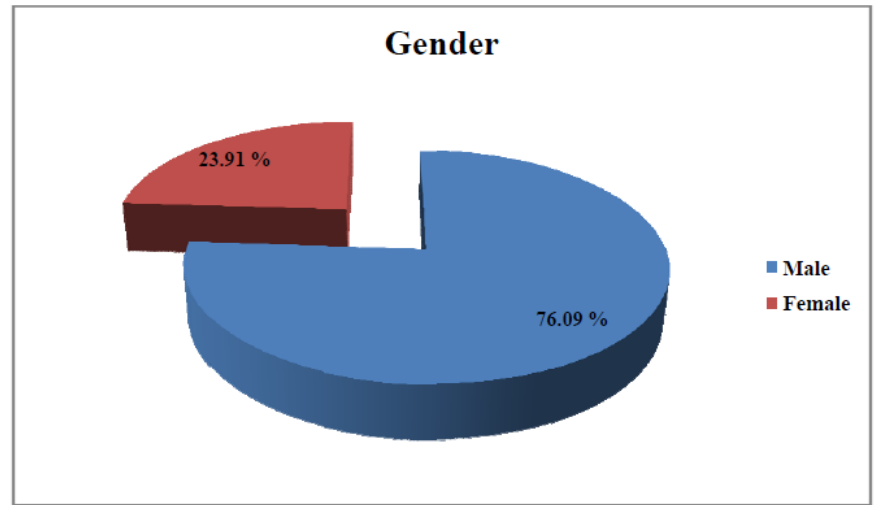

Figure 4.3. Gender based distribution of all patients

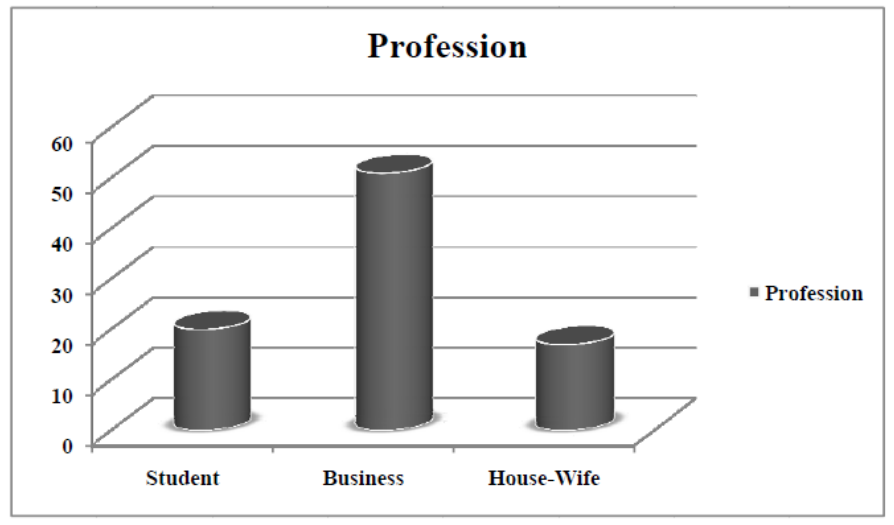

Figure 4.4. Profession wise distribution of all patients

Figure 4.4 shows the body temperature distribution of the cases and controls and it is shown that more patients are in the temperature range of 100-102 F.

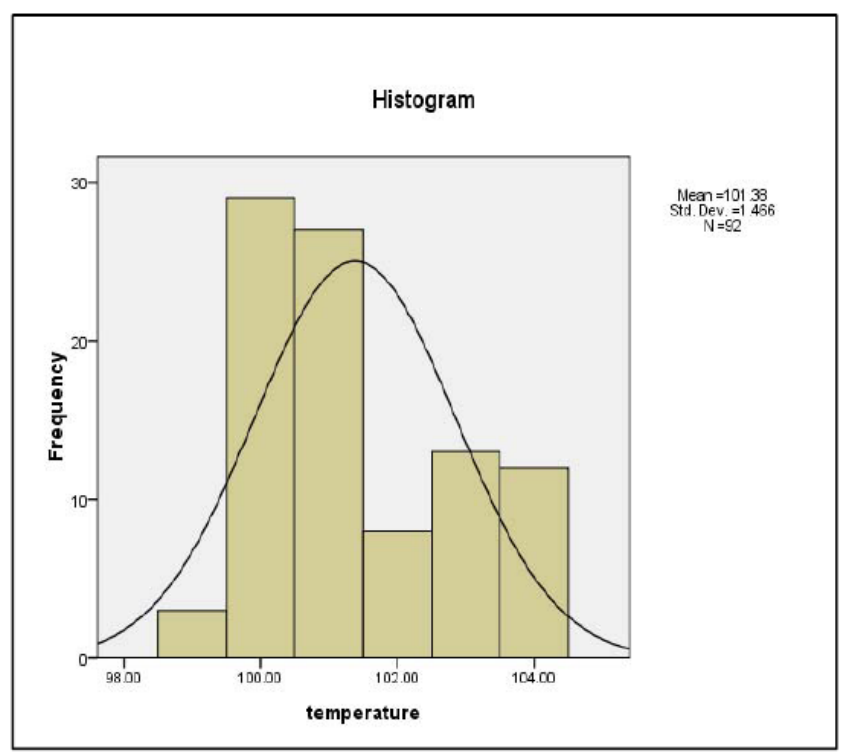

Figure 4.5 Body Temperature (in Fahrenheit) frequency chart

Table 4.3 shows the chi square association of diabetes mellitus among cases and controls. P-value $<0.01$ is considered highly significant for this association. 
Texila International Journal of Public Health

Volume 4, Issue 4, Dec 2016

Table 4.3 Chi square test of diabetes and outcome of interest

\begin{tabular}{|l|l|l|l|l|l|}
\hline & Value & Df & $\begin{array}{l}\text { Asymp. Sig. } \\
\text { (2-sided) }\end{array}$ & $\begin{array}{l}\text { Exact Sig. } \\
\text { (2-sided) }\end{array}$ & $\begin{array}{l}\text { Exact Sig. } \\
\text { (1-sided) }\end{array}$ \\
\hline Pearson Chi-Square & $21.204^{\mathrm{a}}$ & 1 & .001 & & \\
Continuity Correction $^{\mathrm{b}}$ & 19.320 & 1 & .000 & & \\
Likelihood Ratio & 22.138 & 1 & .000 & .000 & .000 \\
Fisher's Exact Test & & & & & \\
$\mathbf{N}$ of Valid Cases & 92 & & & & \\
\hline
\end{tabular}

a. 0 cells $(.0 \%)$ have expected count less than 5 . The minimum expected count is 21.00 .

b. Computed only for a $2 \times 2$ table

Number of patients having diabetes mellitus varied from group to group as illustrated in following figure.

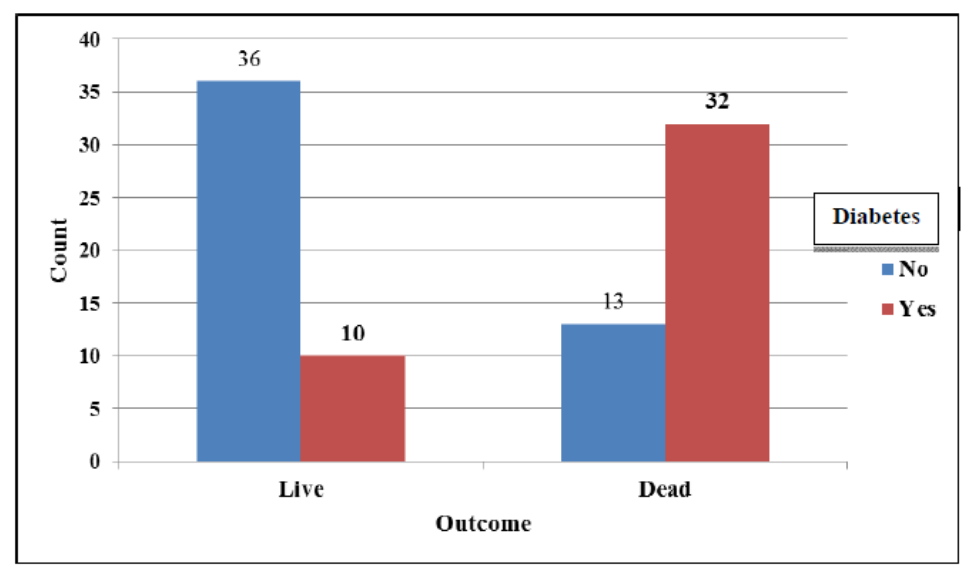

Fig 4.6 Distribution of Diabetes Melitus in different groups

Table 4.4 shows the chi square association of Hypertension among cases and controls. $\mathrm{P}$-value $<0.02$ is considered highly significant for this association.

Table 4.4 chi square test of Hypertension with outcome of interest

\begin{tabular}{|l|l|l|l|l|l|}
\hline & Value & Df & $\begin{array}{l}\text { Asymp. Sig. } \\
\text { (2-sided) }\end{array}$ & $\begin{array}{l}\text { Exact Sig. } \\
\text { (2-sided) }\end{array}$ & $\begin{array}{l}\text { Exact Sig. } \\
\text { (1-sided) }\end{array}$ \\
\hline $\begin{array}{l}\text { Pearson Chi-Square } \\
\text { Continuity Correction }\end{array}$ & $9.787^{\mathrm{a}}$ & 1 & .002 & & \\
Likelihood Ratio & 8.526 & 1 & .004 & & \\
$\begin{array}{l}\text { Fisher's Exact Test } \\
\text { N of Valid Cases }\end{array}$ & 9.969 & 1 & .002 & .003 & .002 \\
\hline
\end{tabular}

a. 0 cells $(.0 \%)$ have expected count less than 5 . The minimum expected count is 22.50 .

b. Computed only for a $2 \times 2$ table 
Number of patients having hypertension varied from group to group as illustrated in following figure.

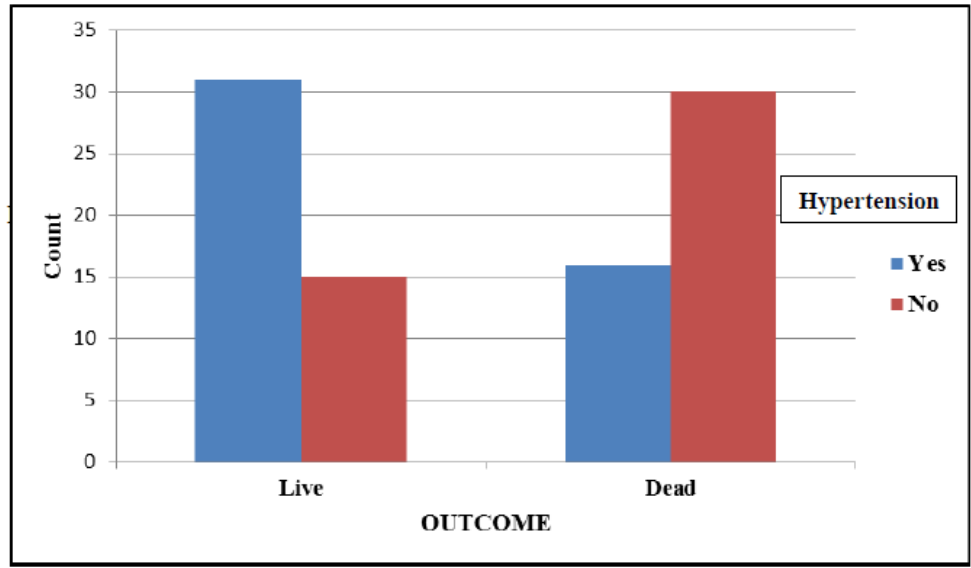

Fig 4.7 Frequency distribution of Hypertension

Table 4.5 cross tabulation of age groups according to cases and controls

\begin{tabular}{|c|c|c|c|c|c|c|c|c|}
\hline & \multicolumn{5}{|c|}{ Age in years } & \multirow{2}{*}{ Total } \\
\hline & & & $0-20$ & |21-40 & $41-60$ & $61-80$ & |81-100 & \\
\hline \multirow{4}{*}{ 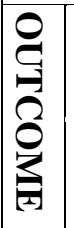 } & 胥: & Count & 3 & 24 & 14 & 4 & 1 & 46 \\
\hline & D & \% within OUTCOME & $6.5 \%$ & $52.2 \%$ & $30.4 \%$ & $8.7 \%$ & $2.2 \%$ & $100.0 \%$ \\
\hline & $\underset{D}{\nabla}$ & Count & 4 & 16 & 17 & 7 & 2 & 46 \\
\hline & 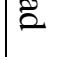 & $\%$ within OUTCOME & $8.7 \%$ & $34.8 \%$ & $37.0 \%$ & $15.2 \%$ & $4.3 \%$ & $100.0 \%$ \\
\hline \multirow{2}{*}{\multicolumn{2}{|c|}{ Total }} & Count & & & & & 3 & \\
\hline & & $\%$ within OUTCOME & $7.6 \%$ & $43.5 \%$ & $33.7 \%$ & $12.0 \%$ & $3.3 \%$ & $100.0 \%$ \\
\hline
\end{tabular}

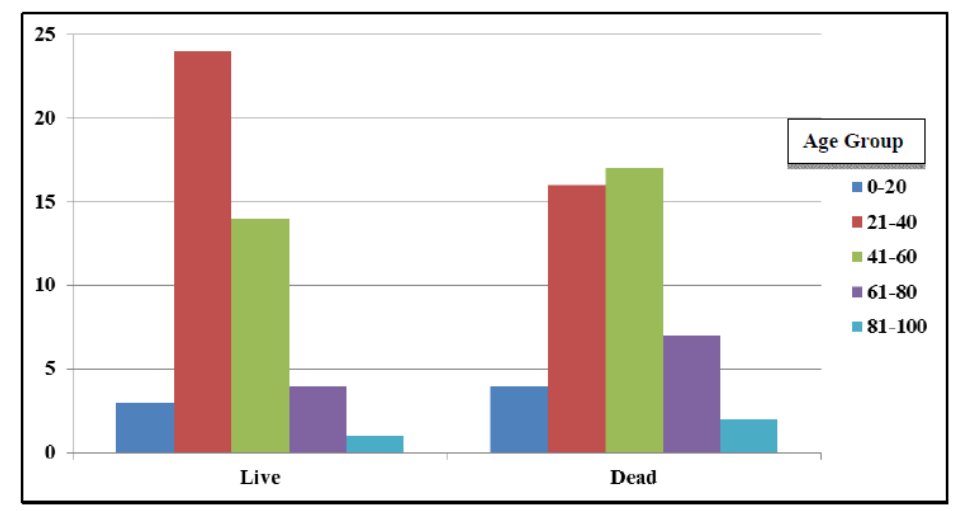

Fig 4.8 Distribution of age among cases and control 
Texila International Journal of Public Health

Volume 4, Issue 4, Dec 2016

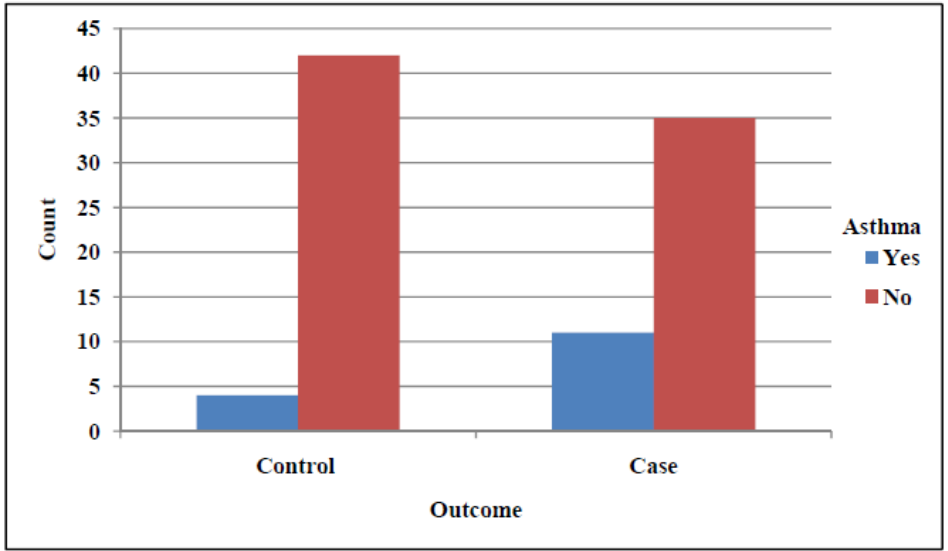

Fig 4.9 Frequency Distribution of Asthma among cases and control

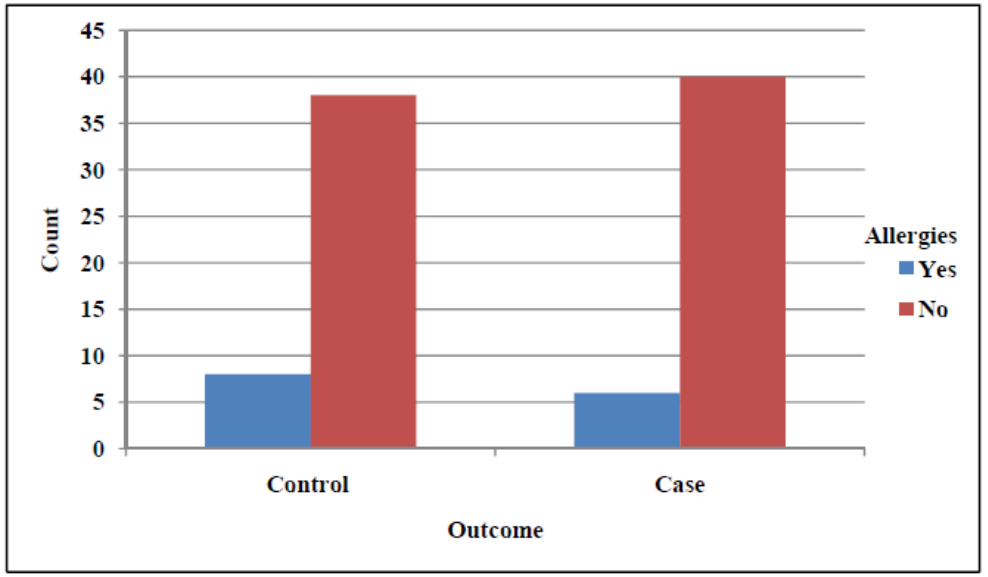

Fig 4.10 Frequency Distribution of Allergies among cases and control

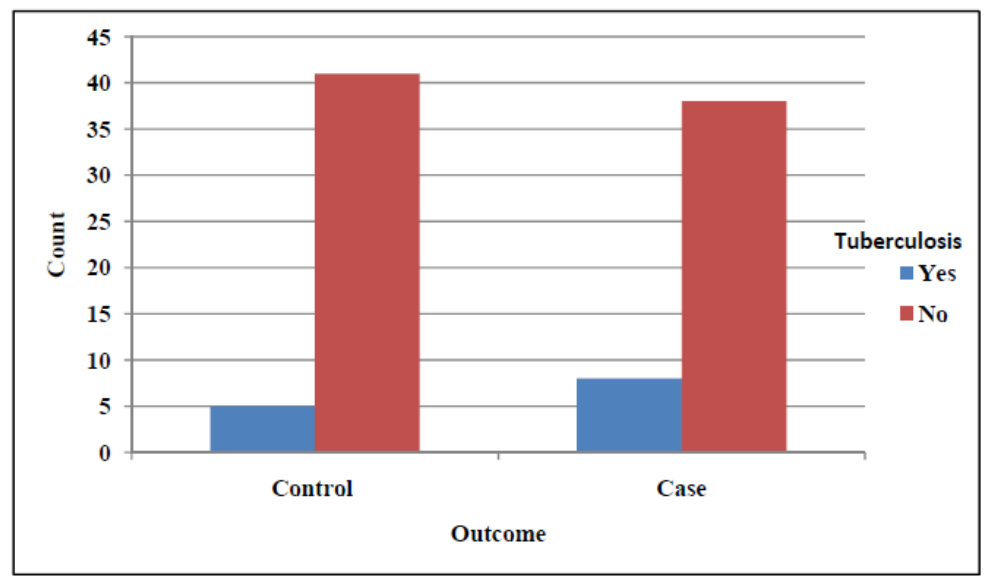

Fig 4.11 Frequency Distribution of Tuberculosis among cases and control 
Texila International Journal of Public Health

Volume 4, Issue 4, Dec 2016

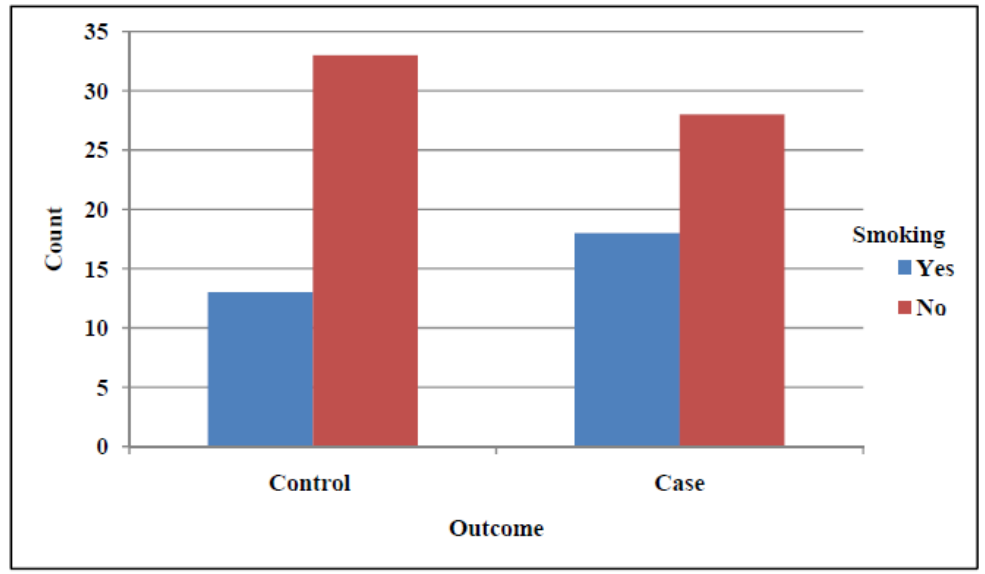

Fig 4.12 Frequency Distribution of Smoking among cases and control

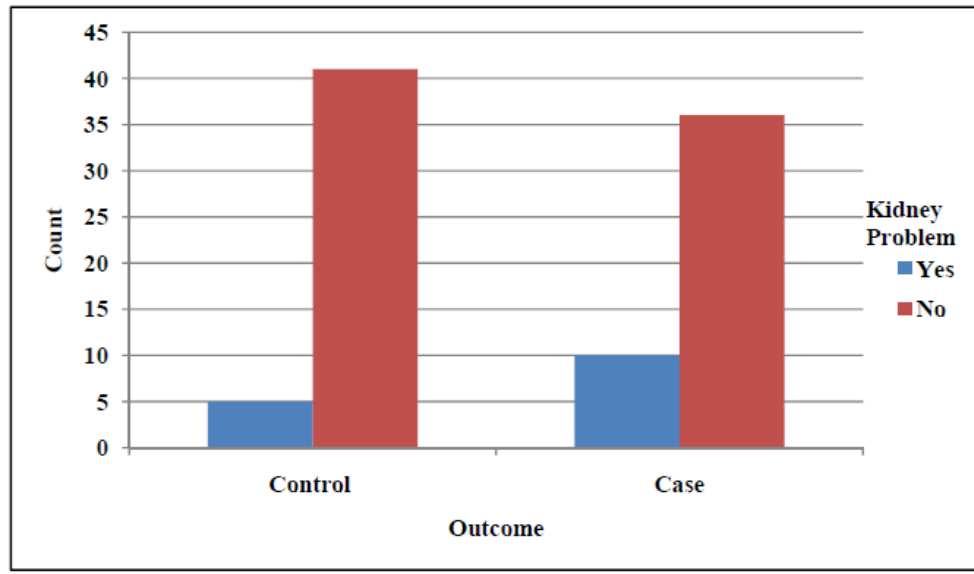

Fig 4.13 Frequency Distribution of Kidney Problems among cases and control

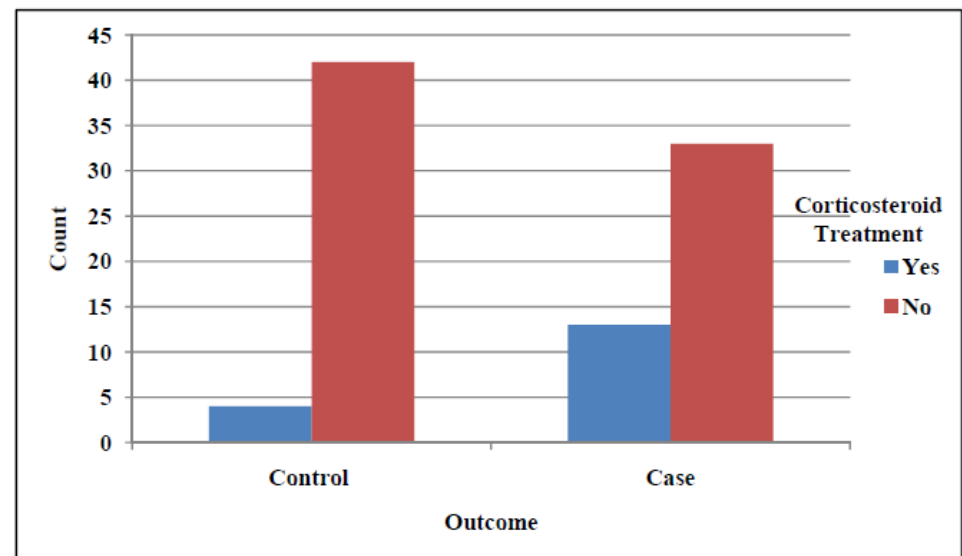

Fig 4.14 Frequency Distribution of Corticosteroid Treatment among cases and control 
Texila International Journal of Public Health

Volume 4, Issue 4, Dec 2016

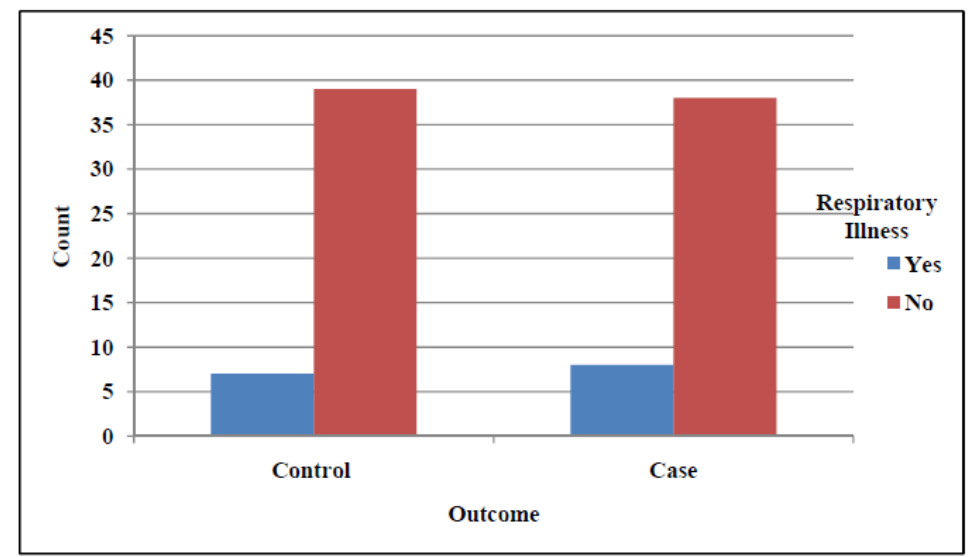

Fig 4.15 Frequency Distribution of Respiratory Illness among cases and control

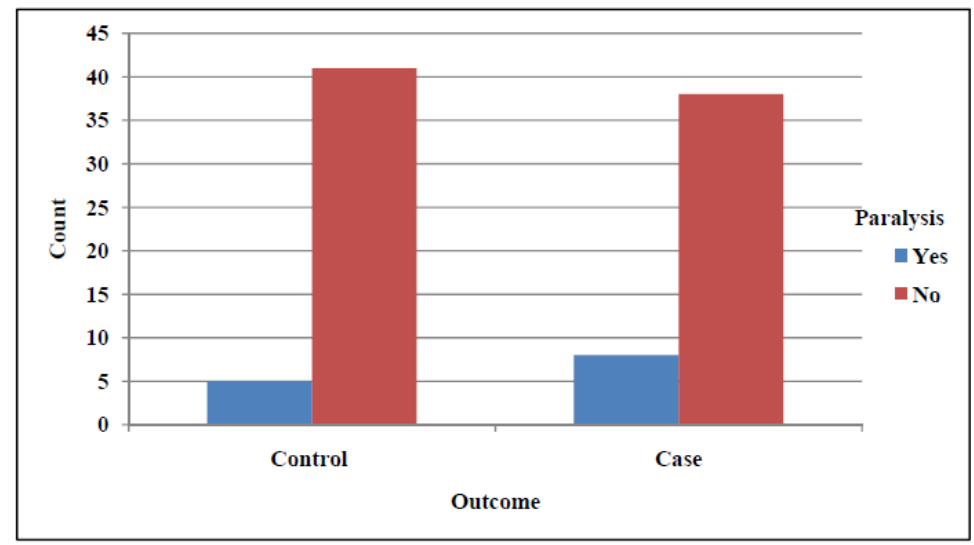

Fig 4.16 Frequency Distribution of Paralysis among cases and control

\section{Univariable analysis}

Table 4.6 Results of univariable analysis of the possible risk factors and indicators of DHF. Linear regression model was used to study the associations between the risk factors variables and DHF.

\begin{tabular}{|c|c|c|c|c|c|c|}
\hline Variable & $\begin{array}{l}\text { Level of } \\
\text { response }\end{array}$ & Case & Control & OR Ratio & $95 \%$ CI & P-value \\
\hline \multirow[t]{2}{*}{ Gender } & Female & 8 & 13 & \multirow{2}{*}{2.2} & \multirow{2}{*}{$\begin{array}{l}0.7644- \\
6.332 \\
\end{array}$} & \multirow{2}{*}{0.144} \\
\hline & Male & 38 & 32 & & & \\
\hline \multirow[t]{2}{*}{ Diabetes } & Yes & 32 & 10 & \multirow{2}{*}{4.667} & \multirow{2}{*}{$1.932-11.27$} & \multirow{2}{*}{0.000617} \\
\hline & No & 14 & 36 & & & \\
\hline \multirow{2}{*}{ Hypertension } & Yes & 31 & 14 & \multirow{2}{*}{9.5} & \multirow{2}{*}{$2.213-40.78$} & \multirow{2}{*}{0.00246} \\
\hline & No & 15 & 32 & & & \\
\hline \multirow[t]{2}{*}{ Asthma } & Yes & 11 & 4 & \multirow{2}{*}{2.75} & \multirow{2}{*}{$\begin{array}{l}0.8757- \\
8.636\end{array}$} & \multirow{2}{*}{0.0832} \\
\hline & No & 35 & 42 & & & \\
\hline \multirow[t]{2}{*}{ Allergies } & Yes & 6 & 8 & \multirow{2}{*}{0.75} & \multirow{2}{*}{$\begin{array}{l}0.2602- \\
2.162\end{array}$} & \multirow{2}{*}{0.594} \\
\hline & No & 40 & 38 & & & \\
\hline \multirow[t]{2}{*}{ Tuberculosis } & Yes & 8 & 5 & \multirow{2}{*}{1.6} & \multirow{2}{*}{$\begin{array}{l}0.5234- \\
4.891\end{array}$} & \multirow{2}{*}{0.14} \\
\hline & No & 38 & 41 & & & \\
\hline \multirow[t]{2}{*}{ Smoking } & Yes & 18 & 13 & \multirow{2}{*}{1.5} & \multirow{2}{*}{$\begin{array}{l}0.6739- \\
3.339\end{array}$} & \multirow{2}{*}{0.321} \\
\hline & No & 28 & 33 & & & \\
\hline \multirow{2}{*}{$\begin{array}{l}\text { Kidney } \\
\text { Problem }\end{array}$} & Yes & 10 & 5 & \multirow{2}{*}{2.25} & \multirow{2}{*}{$\begin{array}{l}0.6929- \\
7.306\end{array}$} & \multirow{2}{*}{0.177} \\
\hline & No & 36 & 41 & & & \\
\hline
\end{tabular}




\begin{tabular}{|c|c|c|c|c|c|c|}
\hline \multirow{2}{*}{$\begin{array}{l}\text { Corticosteroid } \\
\text { Treatment }\end{array}$} & Yes & 13 & 4 & \multirow{2}{*}{3.25} & \multirow{2}{*}{$1.09-9.967$} & \multirow{2}{*}{0.0393} \\
\hline & No & 33 & 42 & & & \\
\hline \multirow{2}{*}{$\begin{array}{l}\text { Allergies } \\
\text { Treatment }\end{array}$} & Yes & 10 & 2 & \multirow{2}{*}{5} & \multirow{2}{*}{$1.096-22.82$} & \multirow{2}{*}{0.0377} \\
\hline & No & 36 & 44 & & & \\
\hline \multirow{2}{*}{$\begin{array}{l}\text { Respiratory } \\
\text { Illness }\end{array}$} & Yes & 8 & 7 & \multirow{2}{*}{1.167} & $0.3921-$ & \multirow{2}{*}{0.782} \\
\hline & No & 38 & 39 & & 3.471 & \\
\hline \multirow[t]{2}{*}{ Paralysis } & Yes & 8 & 5 & \multirow{2}{*}{1.6} & $0.5234-$ & \multirow{2}{*}{0.41} \\
\hline & $\mathrm{No}$ & 38 & 41 & & 4.891 & \\
\hline
\end{tabular}

Multivariable Analysis

Table 4.7 the results of multivariable analysis of the possible risk factors and indicators of DHF.

\begin{tabular}{|c|c|c|c|c|c|c|}
\hline Variable & $\begin{array}{l}\text { Level of } \\
\text { response }\end{array}$ & Case & Control & OR Ratio & $95 \% \mathrm{CI}$ & P-value \\
\hline \multirow[t]{2}{*}{ Diabetes } & Yes & 32 & 10 & \multirow[t]{2}{*}{3.924} & \multirow[t]{2}{*}{$1.326-11.61$} & \multirow[t]{2}{*}{0.0135} \\
\hline & No & 14 & 36 & & & \\
\hline \multirow[t]{2}{*}{ Hypertension } & Yes & 31 & 14 & \multirow[t]{2}{*}{5.902} & \multirow[t]{2}{*}{$1.183-29.44$} & \multirow[t]{2}{*}{0.0304} \\
\hline & No & 15 & 32 & & & \\
\hline \multirow{2}{*}{$\begin{array}{l}\text { Corticosteroid } \\
\text { Treatment }\end{array}$} & Yes & 13 & 4 & \multirow[t]{2}{*}{5.647} & \multirow[t]{2}{*}{$1.298-24.57$} & \multirow[t]{2}{*}{0.0210} \\
\hline & No & 33 & 42 & & & \\
\hline
\end{tabular}

Fig 4.16 Spatial Distribution of cases and control

\section{Discussion}

Dengue is a major neglected tropical disease in the tropical and subtropical regions of the world. It is predominantly found in urban and semi-urban areas, and results in a wide spectrum of clinical manifestations, from asymptomatic infection, undifferentiated fever, dengue fever (DF) to severe infection known as dengue hemorrhagic fever (DHF) and dengue shock syndrome (DSS). It is estimated about 50 million infections occur annually, with 500,000 DHF cases and 22,000 deaths.(Pang et al. 2012)

Increases in human population, uncontrolled urbanization, and international travel can explain much of the spread and persistence of dengue in the twentieth and early twentyfirst centuries. It has been estimated that the minimum population size required to sustain dengue transmission is $10,000-1,000,000$. An estimated 3.5 billion people, or half the world's population, are at risk for DENV infection in tropical and subtropical countries (Jennifer et al. 2008).

This present study (cross sectional) conducted in intensive care unit (ICU) and Medical units at Shalamar Hospital Lahore, for a period of 4 months (January 2014 to April 2014). All patients admitting to ICU with diagnosis of DHF were taken as sample size for cases as it was only 9 bedded unit. This ICU in Shalamar is only for patients referred from other wards of the hospital and according to an estimate 1 patient admits to ICU/per day. Total 53 patients admitting in ICU were followed out of which 46 patients met the inclusion criteria and 7 patients were excluded from the study as they had very complicated condition. 


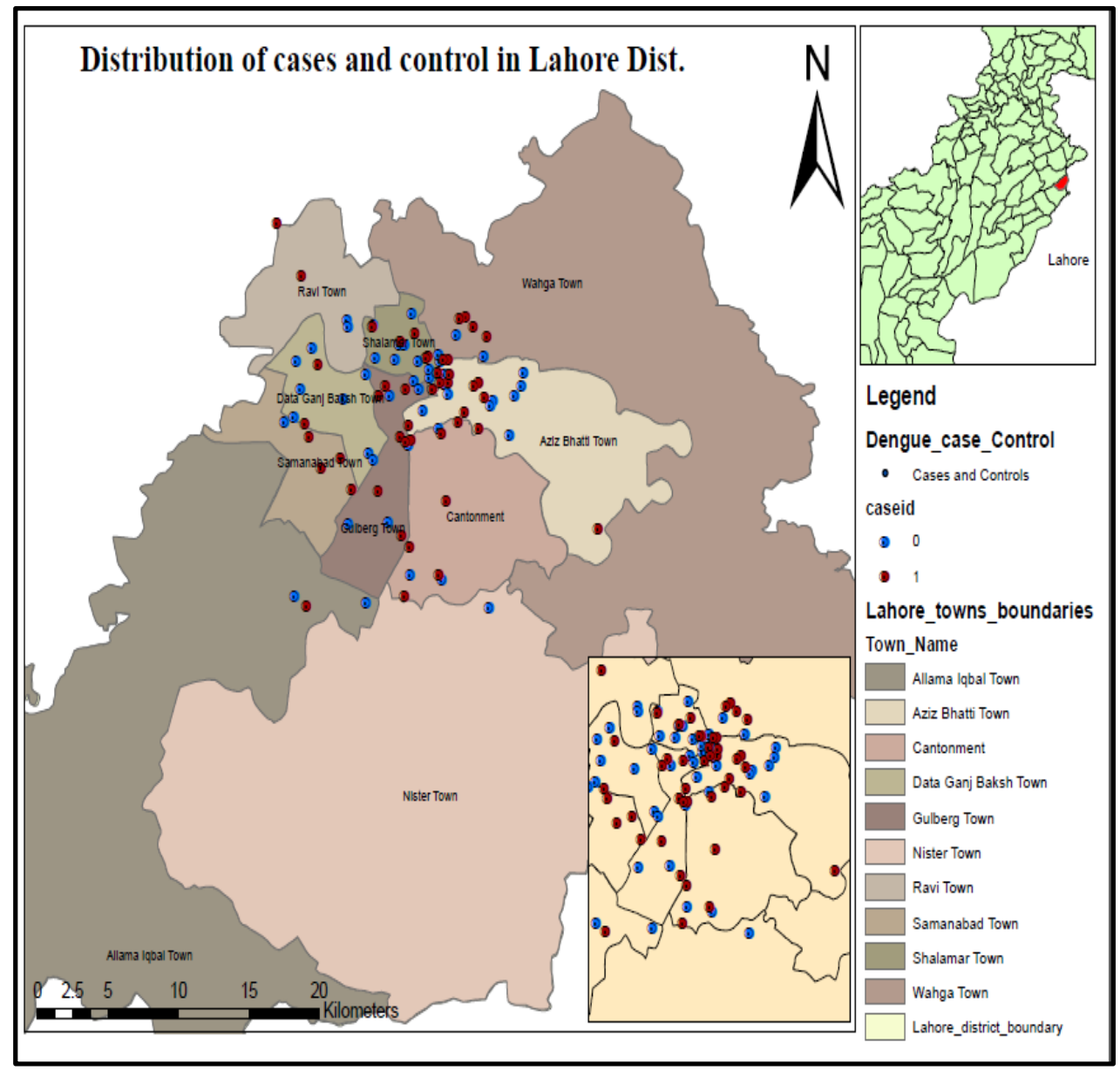

\section{Climate}

The term climate change refers to multiyear, large-scale changes in climate patterns, including fluctuations in both rainfall and temperature; global warming refers to an increase in the average global temperature related to the greenhouse effect. Lahore, the second biggest city of Pakistan lies between $31^{\circ} 15^{\prime}-31^{\circ} 45^{\prime} \mathrm{N}$ and $74^{\circ} 01^{\prime}-74^{\circ} 39^{\prime} \mathrm{E}$, covers a total land area of $1772 \mathrm{~km}^{2}$. The Climate of Lahore is a hot semi-arid and enjoy four weathers, during summer months of May to July, temperature climbs to $48^{\circ} \mathrm{C}$, follow by monsoon with heavy rainfall and winter months of December in which temperature drops to $0^{\circ} \mathrm{C}$. A $2{ }^{\circ} \mathrm{C}$ increase in temperature would simultaneously lengthen the lifespan of the mosquito and shorten the extrinsic incubation period of DENV, resulting in more infected mosquitoes for a longer period of time. (Fernandez et al. 2004) In this sense the climate of Lahore and surroundings is ideal for growth and propagation of dengue fever.

\section{Gender}

In this questionnaire based case control study, the proportion of male and female, was $76.09 \%$ and $23.91 \%$ respectively. Which clearly indicated that male patients were majorly victimized by dengue, outdoor activities of male gender may be a reason for it.

\section{Profession}

Amongst the 92 respondents, 20(21.4\%) belonged to group of students, 51 (55.4\%) patients were in business group of occupation and 17 (18.47\%) belonged to house wife group. These figures indicate that life style has no significant effect on occurrence of dengue. Precautionary measures are mandatory for everyone. 


\section{Age}

One of the important factors which may affect the occurrence of DHF is age. Results of this study indicate that $40 \%$ of cases were less than 30 years age. Most epidemiologic studies also find that children and adolescents under age 20 are at increased risk for DHF/DSS, independent of other risk factors, which may be related to increased capillary fragility and decreased tolerance for insult to microvascular integrity in this age group. (Jennifer et al. 2008).

DHF/DSS is characterized by rapid onset of capillary leakage accompanied by thrombocytopenia, altered homeostasis, and damage to the liver indicated by increases in aspartate aminotransferase and alanine aminotransferase (Halstead, 2007).

Results shown that bleeding signs and symptoms like Hematemesis, blood in stool, bleeding gums and positive urinalysis to be significantly associated with DSH cases where as petechiae and purpura (OR $0.06 \& 0.10$ respectively) are shown to be non-significant. Like previous research revealed that extent of Dengue Fever as a risk for producing DHF can be forecasted by occurrence of bleeding signs, p-value $<0.0001$; and elevated serum AST \& ALT, p-value of $0.01 \& 0.004$ accordingly.(Khan et al. 2004)

Since pathophysiology of this disease still poorly understood and there is no exact mechanism to predict or identify which would develop DHF and DSS there for evidence can be collected by screening patients at early stage for monitoring and intervention. This study was started on this hypothesis that certain comorbidities might increase the risk of developing DHF. Patients of DHF were compared with those who had only dengue fever for presence of comorbidities. In univariable analysis (Table 4.6) results of this study shown that risk factors like Diabetes (p-value0.000617) and OR 4.667, Hypertension (p-value 0.00246) OR 9.5, Asthma (p-value 0.0832) OR 2.75 and previous treatment for allergies (p-value 0.0377 ) to be significantly associated with the development of DHF whereas age, gender, smoking to be non-significant. And these results are consistent to a case control study which was done to test the hypothesis that the subjects suffering from diabetes mellitus, cardiovascular diseases, bronchial asthma, tuberculosis, and chronic liver disease have higher odds of developing dengue hemorrhagic fever and dengue shock syndrome if they contract dengue virus infection. Age difference was not found to be statistically significant.(Mahmood et al. 2013)

In multivariable analysis (Table 4.7) Diabetes (95\% CI- 1.326-11.61) with OR 3.924, Hypertension (95\% CI 1.183-29.44) with OR 5.902, Corticosteroid treatment (95\% CI 1.29824.57) with OR 5.647 are found to be significantly associated with development of DHF.

Diabetes is a metabolic disorder that reduces the use of glucose by organism and changes the anatomical and physiological integrity of endothelium due to permanent inflammatory condition, which is caused by activation of T-lymphocytes. This process leads to release of pro-inflammatory cytokines such as gamma interferon \& TNF $\alpha$. These cytokines are known to have fundamental role in one of the main phenomena responsible for clinical manifestation of DHF, the third space shift, which is a consequence of endothelial dysfunction and results in hypotension, shock and hemoconcentration. Likewise Hypertension also has detrimental effects on endothelial functions which may help trigger the phenomena of fluid shift resulting from increased vascular permeability that characterizes DHF.

The immune system in allergic individuals may be persistently activated with signs of inflammation in tissues and capillaries. If use of steroid for treatment of allergies is considered especially for severe allergies, then it can be concluded that severe allergy is more likely to lead to inflammation and liberation of pro-inflammatory cytokines in tissues, particularly endothelium.

Use of corticosteroid itself can increase risk of DHF as it increases capillary fragility such in treatments of allergies, asthma etc. Limitation of my study is very small study to assess such factors. (Figueiredo et al. 2010)

Results of this study should be interpreted considering its smaller size, retrospective nature as results are dependent upon quality of data available and collected. There can be selection bias as all patients were hospitalized and health care seeking behavior may be the cause. 
Texila International Journal of Public Health

Volume 4, Issue 4, Dec 2016

During dengue epidemics most patients are seen in outdoor setting and are sent to home because all cannot be hospitalized in spite of risk of developing DHF. These identified risk factors can be used to categories patients for efficient use of resources in monitoring and prevention of DHF.

\section{Summary}

About two-thirds of the world's population lives in areas infested with dengue vectors, mainly Aedesaegypti. All four dengue viruses are circulating, sometimes simultaneously, in most of these areas. It is estimated that up to 80 million persons become infected annually, although marked underreporting results in the notification of much smaller number of cases. Currently dengue is endemic in all continents except Europe and epidemic DHF occurs in Asia and in the Americas. The incidence of DHF is greater by far in Asia than in the Americas.(Drosten et al. 2002)

Risk of Fatal Dengue hemorrhagic Fever is increased with co morbidities like Diabetes A retrospective study conducted about potential risk factors associated with fatal DHF. Descriptive data about the enrolled patients was collected from the Shalamar hospital on a structured questionnaire. Descriptive epidemiology about fatal DHF was described in terms of place, person and time.

The data analysis was done using SPSS v.16 software. Chi-square test was used to determine the relationship between gender, age group, Diabetes, Hypertension, TB Asthma, Allergies, Smoking and Paralysis and outcome of interest. P-value of $<0.05$ is considered statistically significant (Hosmer et al. 2000)

The study identified potential risk factors associated with Fatal Dengue Fever like age to be significantly associated with DHF cases whereas Diabetes and Hypertension were not found to be significantly associated. Limitation of the study is its smaller size and confirmation requires larger scale studies. These finding could be utilized by the health authorities to guide triaging of patients who require closer monitoring and early hospitalization when confirmed in more studies in Lahore.

\section{References}

[1]. Ahmed S, Mohammad W, Hamid F, Akhter A, Afzal RK, Mahmood A.2011. The 2011 dengue haemorrhagic Fever outbreak in lahore-an account of clinical parameters and pattern of haemorrhagic complications. J Coll Physicians Surg Pak. 23 (7): 463-467.

[2]. Chairulfatah A, Setiabudi D, Agoes R, van Sprundel M, Colebunders R. 2001. Hospital based clinical surveillance for dengue haemorrhagic fever in Bandung, Indonesia 1994-1995. Acta tropica. 80 (2): 111-115.

[3]. Deen JL, Harris E, Wills B, Balmaseda A, Hammond SN, Rocha C, Dung NM, Hung NT, Hien TT, Farrar JJ. 2006. The WHO dengue classification and case definitions: time for a reassessment. The Lancet. 368 (9530): 170-173.

[4]. DeRoeck D, Deen J, Clemens JD. 2003. Policymakers' views on dengue fever/dengue haemorrhagic fever and the need for dengue vaccines in four southeast Asian countries. Vaccine. 22 (1): 121-129.

[5]. Drosten C, Göttig S, Schilling S, Asper M, Panning M, Schmitz H, Günther S. 2002. Rapid detection and quantification of RNA of Ebola and Marburg viruses, Lassa virus, Crimean-Congo hemorrhagic fever virus, Rift Valley fever virus, dengue virus, and yellow fever virus by real-time reverse transcription-PCR. J. clin microbiol. 40 (7): 2323-2330.

[6]. Fernandez-Mestre MT, Gendzekhadze K, Rivas-Vetencourt P, Layrisse Z. 2004. TNF-alpha-308 Aallele, a possible severity risk factor of hemorrhagic manifestation in dengue fever patients. Tissue Antigens. 64:469-72

[7]. Figueiredo MAA, Rodrigues LC, Barreto ML, Lima JWO, Costa MC, Morato V, Blanton R, Vasconcelos PF, Nunes MR, Teixeira MG. 2010. Allergies and diabetes as risk factors for dengue hemorrhagic fever: results of a case control study. PLoS neglected tropical diseases. 4 (6): e699. 
[8]. Gibbons RV, Vaughn DW. 2002. Dengue: an escalating problem. BMJ: British Medical Journal. 324 (7353): 1563.

[9]. Gonzalez D, Castro OE, Kouri G, Perez J, Martinez E, Vazquez S, Rosario D, Cancio R, Guzman MG. 2005. Classical dengue hemorrhagic fever resulting from two dengue infections spaced 20 years or more apart: Havana, Dengue 3 epidemic, 2001-2002. Int J Infect Dis. 9 (5): 280-285.

[10]. Gubler DJ 2002. Epidemic dengue/dengue hemorrhagic fever as a public health, social and economic problem in the 21st century. Trends Microbiol. 10 (2): 100-103.

[11]. Guzman MG, Alvarez M, Rodriguez R, Rosario D, Vazquez S, Valdes L, Cabrera MV, Kouri G. 1999. Fatal Dengue Hemorrhagic Fever in Cuba, 1997. IJID. 3 (3): 130-135.

[12]. Halstead S 1980. Dengue haemorrhagic fever—a public health problem and a field for research. Bulletin of the World Health Organization. 58 (1): 1.

[13]. Halstead SB 2007. Dengue. The Lancet. 370 (9599): 1644-1652.

[14]. Humayoun MA, Waseem T, Jawa AA, Hashmi MS, Akram J.2008. Multiple dengue serotypes and high frequency of dengue hemorrhagic fever at two tertiary care hospitals in Lahore during the 2008 dengue virus outbreak in Punjab, Pakistan. Int J Infect Dis. 14 e54-e59.

[15]. Jennifer L. Kyle, Eva Harris. 2008. Global Spread and Persistence of Dengue. Annu. Rev. Microbiol.62:71-92

[16]. Khan MIH, Anwar E, Agha A, Hassanien NSM, Ullah E, Syed IA, Raja A. 2013. Factors Predicting Severe Dengue in Patients with Dengue Fever. Mediterr J Hematol Infect Dis. 5 (1).

[17]. Libraty DH, Young PR, Pickering D, Endy TP, Kalayanarooj S, Green S, Vaughn DW, Nisalak A, Ennis FA, Rothman AL. 2002. High circulating levels of the dengue virus nonstructural protein NS1 early in dengue illness correlate with the development of dengue hemorrhagic fever. J. Infect. Dis. 186 (8): 1165-1168.

[18]. Mahmood K, Jameel T, Aslam HF, Tahir M. 2009. Incidence of dengue haemorrhagic fever in local population of Lahore, Pakistan. Biomedica. 25 93-96.

[19]. Mahmood S, Hafeez S, Nabeel H, Zahra U, Nazeer H. Does Comorbidity Increase the Risk of Dengue Hemorrhagic Fever and Dengue Shock Syndrome? ISRN Tropic Med. 2013.

[20]. Pang J, Salim A, Lee VJ, Hibberd ML, Chia KS, Leo YS, Lye DC. 2012. Diabetes with Hypertension as Risk Factors for Adult Dengue Hemorrhagic Fever in a Predominantly Dengue Serotype 2 Epidemic: A Case Control Study. PLoS Negl Trop Dis. 6 (5): e1641.

[21]. Pinheiro FP, Corber SJ. 1997. Global situation of dengue and dengue haemorrhagic fever, and its emergence in the Americas. World Health Stat Q. 50 161-169.

[22]. Shahzad MK, Ijaz T, Ijaz S, Younus M. 2007. Lab Based surveillance of Dengue Hemorrhagic Fever during 2006 Epidemic in Lahore. Int J Agro Vet Med Sci. 1 (0): 13-16.

[23]. Wahid S, Sanusi S, Zawawi MM, Ali RA. 2000. A comparison of the pattern of liver involvement in dengue hemorrhagic fever with classic dengue fever. 


\title{
An Assessment of the Psychosocial Effects of Almajiri system on Child's Development in Gwange Ward Maiduguri, Borno State, Nigeria
}

\author{
Article by Emmanuel O. Chukwu ${ }^{1}$, Habu Haruna ${ }^{2}$ and Terna M. Fiase ${ }^{3}$ \\ ${ }^{1,3}$ School of Nursing Mkar, Gboko, ${ }^{2}$ Department of Nursing Science, College of \\ Medical Sciences, University of Maiduguri, Nigeria \\ E-mail: emmanwaguy42@yahoo.com
}

\begin{abstract}
Children are known to be the source of joy in every family especially when the parents can afford their basic needs. Children in the northern part of Nigeria are prone to deprivation through almajiri system of education mainly due to respect for misunderstood religious concept and culture among other causes. This study of psycho-social effects of almajiri system on child's development was conducted in Gwange ward, Maiduguri, is aimed at identifying the psychological effects of almajiri system on child's development as well as the social effects of almajiri system on child's development. A descriptive design was used for the study. Data was obtained from respondents (almajiris) using structured questionnaire. The data was presented and analysed using descriptive statistics. Hypotheses were formulated and tested using Chi-square. The findings of this study revealed that the almajiris are affected both psychologically and socially due to lack of adequate care, loneliness, feeling of anger, lack of proper feeding and security, exposure to dangers and negligence by the society. Based on these findings, community health workers, psychologists, sociologists and government should be in the fore front of taking care of the almajiri system. Recommendations were made to families, communities, government and Non Governmental Organisation's on ways of improving the system and incorporating it with western education.
\end{abstract}

Keywords: psychosocial, effects, almajiri, development

\section{Introduction}

The Almajiri system is a traditional system of education associated with Islamic education practiced in some parts of Africa and Asian countries (especially the Muslim dominated countries). The word "Almajiri” emanated from an Arabic word "Al-muhajjirun" meaning "emigrants" describing someone who leaves his home in search of knowledge in Islamic religion (Kabiru, 2012). The almajiri system of education as practiced today in northern Nigeria is seriously abused as evidenced by the conditions under which the system is operating. Today, the word Almajiri has acquired a completely new meaning; it is mostly referred to as beggars roaming the street in our towns and cities. They are seen swarming the streets of northern Nigeria like locusts begging for alms in order to sustain themselves and their mallams (Obioha, 2009; Thinkquest, 2010). The almajiri who is thought to be a pious pupil in search of knowledge became rather a social problem in the society. They practically, depend on people for their food and other life needs (Ibrahim, 2008). In the course of begging on the streets, they are exposed to various forms of hazards and situations. Begging for food took most of his time instead of learning, Yahaya (2004). This is in contrast with Federal Government of Nigeria (2004) proclamation which state that 'every Nigerian child shall has a right to equal educational opportunities irrespective of any real or imagined disabilities'.

Several factors can be associated with the poor organizational structures of the Almajiri system of education. These factors may include but not limited to: high striking poverty line in the families to take care of their children's basic needs, (Bello, 2006). Nura,(2010) reported that Almajiri's sleep on worn out mats and sometimes up 30 Almajiris sleep in a room that is not well ventilated, making them vulnerable to all forms of airborne infections and other 
Texila International Journal of Public Health

Volume 4, Issue 4, Dec 2016

diseases while some sleep in uncompleted buildings or by the roadside. Shagari. F (2009) equally opined that the Almajiri system was originally designed to give children Qur'anic knowledge but the structure has been changed as the Almajiri child is seen only as a begging street child. Some Mallams do not even allow their children to mingle with the Almajiris to the extent that they allow their own children to attend formal school. The Almajiris are exploited by their mallams, which include going to farm, fetching water for his domestic use, collecting fire wood and sometimes bringing back the proceed from begging, this affects psychological and physical development of a child (Kano State Government, 2012).

Begging is one of the most disturbing social ills of our time and Parents are becoming so insensitive to the welfare of their children that they dispatch them to unknown places to take care of themselves without making any arrangement for their feeding, medical care, shelter and other necessities of life (Dukku, 2009). Sadly, the economic hardship is taking its toll on the almajiri's as they hardly get left over, and so, they resorted to doing menial jobs like nail cutting, cap weaving cobbling to feed, Yaro Boys etc. The begging and menial jobs proceeds are used to sustain themselves and their teachers (Malams).

Kopoka. A. (2000) pointed out that children involved in begging run enormous risks, often darting between cars in heavy traffic begging for alms with a high risk of accidents. Most of these children are seen roaming the streets hopelessly and helplessly begging for alms to survive and because of the harsh realities they find themselves in end up becoming juvenile delinquents and subsequently adult criminals. Child beggars suffer severe psycho-social consequences of being exposed to constant abuse and aggression from the general public. They spend greater part of their formative years like forgotten refugees in their own country struggling, hustling and suffering, (Hassan \& Moses 2010).

Attitude of the society towards the almajiris is a complete paradox; some treat them with contempt and exploit them while others give them alms and food out of sympathy or after using them to run errands. They are left to scavenge for food remnants. Social psychologists noted that when a child is exposed to labor at a teenage age and deprived basic needs or no benefit and entertainment, such child normally develop the habit of loneliness and this may lead to schizophrenia. In an effort to capture the plight of the almajiris Abdullahi (2011) lamented that the almajiris endure utter deprivation, and their appearances leave much to be desired. With their unkempt hair, dirty faces, blistered lips, tainted teeth, crusty skin, stinking bags and bare feet; they are distinctive. Armed with plastic bowls, decorated with shabby attires, and congregated into small groups, they accost members of the public with alluring songs and soliciting alms. Almajiris are vulnerable to being used as political thugs by benefactors who take advantage of their lack of formal education. They are considered as great security risks as many of them have become miscreants who actively participate in ethnic, religious and political violence and terrorism (Christian, 2010). Therefore, children's rights such as right to education, health, entertainment, association, interaction, shelter and nutrition must be protected, preserved and maintained. Once these essential needs are provided, there is no doubt that they can perform wonderfully in their undertaking as leaders of tomorrow. It is unfortunate that at the age of four, a child is taken somewhere else to fend for self in terms of feeding, accommodation, clothing and medicament. The vulnerability of these almajiris made them handy for criminal activities including terrorism as they were already antagonistic to western culture and opposed to society which has failed to treat them well, (Peace, 2012).

\section{Statement of the problem}

The number of Almajiri's seen roaming the streets of Maiduguri is increasing by day and this has become a subject of concern to the researchers and other well meaning Nigerians. According to Kano State Ministry of Education Statistics as cited by Abdulrafiu (2009); Borno is reputed as a center of Islamic learning having 389,048 Almajiri's with 4,468 Tsangayas (Almajiri schools) with indigenes: 266,160 while from other states 118,280. Non Nigerians 4,608 and yet the figure is not conclusive as the Almajiri census is still ongoing. 
The system is growing in a geometrical progression turning it into modern slavery and worst of all affecting the child's development in all forms.

The Almajiri's are seen swarming the streets of Borno and other states in the country especially Northern states like locusts. They are mostly seen with bowls in their hands in a sorry looking state, usually very dirty and in tattered clothes. They sleep on worn out mats in a room where about 25 of them live with no proper ventilation making them vulnerable to all forms of air borne infections and other diseases associated with the harsh Maiduguri weather. Most of these children because of the harsh realities they find themselves in end up becoming criminals and burden to the society instead of social and spiritual assets.

Therefore, this research is aimed at assessing the psychosocial effects of Almajiri system of education on child's development with view to finding useful information that will guide policymakers in decision making regarding Almajiri system of education.

\section{Objectives of the Study}

The specific objectives of the study are:

1. To identify the psychological effects of Almajiri system on child's development.

2. To explore the social effects of Almajiri system on child's development.

\section{Hypothesis}

1. There is no significant difference between the number of children in the family the Almajiri's child comes from and the care of the Almajiri child.

2. There is no significant difference between separation of child from parents and how the Almajiri child feels.

3. There is no significant difference between the environment the Almajiris live in and their security needs.

\section{Method}

\section{Study design}

A descriptive survey design was used for this study because it deals with accurate and factual description and the summary of the actual situation.

\section{Study setting}

The research work was conducted in Gwange wards 1 and 2 of Maiduguri. Gwange was created in 1975 by Baba Gwange, later developed into Gwange 1, 2, 3 wards. These wards are headed by the district head called Alhaji Zanna Mai Jir. Gwange 1 is further divided into 5 units and each is headed by a Bulama. Generally, the predominant inhabitants are traders, truck drivers, bricklayers and embroider. The custom and tradition of the residents are highly influenced by Islam. The population is multiethnic. Gwange ward as the area of study is one of the area where Almajiri System of Education is highly practiced.

\section{Study population and sampling technique}

Convenient sampling method was used to select 150 almajiris used for this study; 6 schools were picked out of 46 schools found in Gwange I while 9 schools were picked out of the 52 schools found in Gwange II using simple random sampling technique. Ten (10) almajiris from each of the 15 schools chosen from Gwange I and II made up the selected 150 almajiris as earlier mentioned.

\section{Instrumentation}

A structured questionnaire was formulated by the researchers which was translated into Hausa language. The instrument validated by expert where content validity index was computed and the result obtained was 0.81 which indicated the instrument validity. Ten copies of the questionnaire were pre-tested at Mairi Kuwait, Jere LGA, Borno State using test retest method to ensure consistency and reliability of the instrument. Reliability coefficient of 
Texila International Journal of Public Health

Volume 4, Issue 4, Dec 2016

0.75 was obtained which made it right for the study. The questionnaire included three sections. Section A was for demographic data of almajiris, section B was about the psychological effects of almajiri system and section $C$ was about the social effects of almajiri system.

\section{Procedure for data collection}

The researchers obtained an ethical approval from the District Head of Gwange.150 respondents were selected over the period one month. Informed consent was obtained from the respondents. The questionnaire was translated into Hausa language to the respondents for data collection. The researchers trained additional three people who assisted in data collection (by using the checklist; asking them and filling the appropriate options).

\section{Method of data analysis}

Data was analyzed after collection by the researchers using descriptive and inferential statistics (simple frequencies, percentages and chi-squares was used for testing the relationship at 0.05 level of significance). All data were presented in tab

\section{Findings}

Table (1). socio demographic data

\begin{tabular}{|l|l|l|}
\hline Age & Frequency & Percentage (\%) \\
\hline $5-9$ & 37 & 24.67 \\
\hline $10-14$ & 62 & 41.33 \\
\hline 15 and above & 51 & 34 \\
\hline Total & 150 & 100 \\
\hline State of origin of almajiris & & \\
\hline Borno & 62 & 41.33 \\
\hline $\begin{array}{l}\text { Other Northern States in } \\
\text { Nigeria }\end{array}$ & 64 & 42.67 \\
\hline Not from Nigeria & 24 & 16 \\
\hline Total & $\mathbf{1 5 0}$ & $\mathbf{1 0 0}$ \\
\hline $\begin{array}{l}\text { Number in the family of } \\
\text { almajiris }\end{array}$ & & \\
\hline$<5$ & 21 & 14 \\
\hline $5-10$ & 65 & 43.33 \\
\hline$>10$ & 38 & 25.33 \\
\hline 15 and above & 26 & 17.33 \\
\hline Total & $\mathbf{1 5 0}$ & $\mathbf{1 0 0}$ \\
\hline $\begin{array}{l}\text { Type of family the Almajiri } \\
\text { child comes from }\end{array}$ & & \\
\hline Monogamy & 53 & 35.33 \\
\hline Polygamy & 97 & 64.67 \\
\hline Total & $\mathbf{1 5 0}$ & $\mathbf{1 0 0}$ \\
\hline Tribe of almajiri & 63 & 31.33 \\
\hline Kanuri & & 42 \\
\hline Hausa/Fulani & \\
\hline & & \\
\hline
\end{tabular}




\begin{tabular}{|l|l|l|}
\hline Babur & 11 & 7.33 \\
\hline Shuwa Arab & 12 & 8 \\
\hline Others & 17 & 11.33 \\
\hline Total & $\mathbf{1 5 0}$ & $\mathbf{1 0 0}$ \\
\hline
\end{tabular}

Table I shows that respondents from age 10 - 14 years were the majority with 62 (41.33\%) followed by 15 and above years with 51(34\%) and lastly $5-9$ with $57(24.67 \%)$.

The table equally also shows that $64(42.67 \%)$ of the respondents were from other Northern States in Nigeria, 62(41.33) were from Borno and 24(16\%) were non-Nigerians.

On the respondents' numbers in their family, 5 - 10 were 65(43.33\%), >10 38(25.33\%) while 15 and above 26 (17.33\%). 97(64.67\%) of the respondent were from polygamous family and 53(35.33\%) were from monogamous family.

Ethnicity distribution shows that Hausa/Fulani has the highest frequency among the Almariris with 63(42\%) followed by Kanuri with47 (31.33).

Table (2). Do the almajiri receive adequate care?

\begin{tabular}{|l|l|l|}
\hline Variables & Frequency & Percentage (\%) \\
\hline Yes & 43 & 28.67 \\
\hline No & 107 & 71.33 \\
\hline Total & 150 & 100 \\
\hline
\end{tabular}

Table 2 shows that $43(28.67 \%)$ receive adequate care while $107(71.33 \%)$ do not receive adequate care.

Tables (3). Psychological effects of Almajiri system

\begin{tabular}{|c|c|c|c|c|c|c|}
\hline \multirow{3}{*}{$\begin{array}{l}\text { Questions } \\
\text { Questions } \\
\end{array}$} & \multicolumn{4}{|l|}{ Variables } & \multirow{2}{*}{\multicolumn{2}{|c|}{ Total }} \\
\hline & \multicolumn{2}{|l|}{ Yes } & \multicolumn{2}{|l|}{ No } & & \\
\hline & Frequency & $\%$ & Frequency & $\%$ & Frequency & $\%$ \\
\hline $\begin{array}{l}\text { Do you stay with your } \\
\text { parents? }\end{array}$ & 41 & 27.33 & 109 & 72.67 & 150 & 100 \\
\hline $\begin{array}{l}\text { If no, are you disturbed } \\
\text { as a result of separation } \\
\text { from your parents? }\end{array}$ & 99 & 66 & 51 & 34 & 150 & 100 \\
\hline $\begin{array}{l}\text { Are you bullied or } \\
\text { maltreated by your } \\
\text { malams or seniors? }\end{array}$ & 89 & 59.3 & 61 & 40.67 & 150 & 100 \\
\hline $\begin{array}{l}\text { Do you feel lonely and } \\
\text { angry as a result of the } \\
\text { system? }\end{array}$ & 110 & 73.33 & 40 & 26.67 & 150 & 100 \\
\hline
\end{tabular}

Table 3 shows that the respondents that stay with their parents are 41(27.33\%) and 109(72.67\%) do not. Those that are disturbed as a result of separation from their parents are 99(66\%) while 51(34\%) are not. On bullying or maltreatment by their Malams 86(59.3\%) acknowledged while 61(40.67\%) said no. Those that feel lonely and angry as a result of the system are $110(73.33 \%)$ while those are not $40(26.67 \%)$.

Table (4). How does the Almajiri Child feels about the system

\begin{tabular}{|l|l|l|}
\hline Variables & Frequency & Percentage (\%) \\
\hline Happy & 40 & 26.67 \\
\hline Sad & 110 & 73.33 \\
\hline Total & 150 & 100 \\
\hline
\end{tabular}


Texila International Journal of Public Health

Volume 4, Issue 4, Dec 2016

Table 4 shows that 40 (26.67\%) of the respondents are happy about the system while $110(73.33 \%)$ are sad.

Table (5). Places where Almajiris live and sleep at night (Social effects).

\begin{tabular}{|l|l|l|}
\hline Variables & Frequency & Percentage (\%) \\
\hline In a building & 80 & 53.33 \\
\hline In an open environment & 62 & 41.33 \\
\hline On the street/by the roadside & 8 & 5.33 \\
\hline Total & 150 & 100 \\
\hline
\end{tabular}

Table 5 Shows that those who live and sleep in a building have the highest score of 80(53.33\%) followed by those who sleep in an open environment 62(41.33\%) and lastly those who sleep on the street/by the road side are 8(5.33\%).

\begin{tabular}{|c|c|c|c|c|c|c|}
\hline \multirow{3}{*}{$\begin{array}{l}\text { Questions } \\
\text { Questions }\end{array}$} & \multicolumn{4}{|l|}{ Variables } & \multirow{2}{*}{\multicolumn{2}{|c|}{ Total }} \\
\hline & \multicolumn{2}{|l|}{ Yes } & \multicolumn{2}{|l|}{ No } & & \\
\hline & Frequency & $\%$ & Frequency & $\%$ & Frequency & $\%$ \\
\hline $\begin{array}{l}\text { Do you normally have } \\
\text { regular meals? }\end{array}$ & 59 & 39.33 & 91 & 60.67 & 150 & 100 \\
\hline $\begin{array}{l}\text { Do you think you are } \\
\text { safe and secured where } \\
\text { you live or stay? }\end{array}$ & 47 & 31.33 & 103 & 68.67 & 150 & 100 \\
\hline $\begin{array}{l}\text { Would you like to go for } \\
\text { western education? }\end{array}$ & 95 & 63.33 & 55 & 36.67 & 150 & 100 \\
\hline $\begin{array}{l}\text { Do you feel neglected } \\
\text { by the society? }\end{array}$ & 103 & 68.67 & 47 & 31.33 & 150 & 100 \\
\hline
\end{tabular}

Table (6). Social effects

Table 6 shows the respondents that have regular meals as 59(39.33\%) while those that do not have are with highest frequency of 91(60.67\%). Those that think they are safe and secured where they live or stay are $47(31.33 \%)$ while those that think they are not safe and secured 103(68.67\%). 95(63.33\%) of the respondents would like to go for western education while 55(36.67\%) would not. Those that feel they are neglected by the society are 103(68.67\%) while those that feel they are not are 47(31.33\%).

\section{Testing of hypothesis}

Research hypothesis were tested using chi square $\left(\mathrm{x}^{2}\right)$ at 0.05 level of significance are as follows:

1. There is no significant difference between the number of children in the family the Almajiri child comes from and the care of the Almajiri child receives

Hypothesis table (1): There is no significant difference between the number of children in the family the Almajiri child comes from and the care of the Almajiri child.

\begin{tabular}{|l|l|l|l|l|l|}
\hline & \multicolumn{6}{|l|}{ Number of Almajiris in their family } \\
\hline Care they receive & $<\mathbf{5}$ & $\mathbf{5 - 1 0}$ & $\mathbf{1 0}$ & $\mathbf{1 5}$ and above & Total \\
\hline Adequate care & $21(14.98)$ & $58(46.37)$ & $28(27.11)$ & $0(18.55)$ & 107 \\
\hline No adequate care & $0(6.0)$ & $7(18.63)$ & $10(10.90)$ & $26(7.45)$ & 43 \\
\hline Total & 21 & 65 & 38 & 26 & 150 \\
\hline
\end{tabular}

$\left(\mathrm{x}^{2} \mathrm{c}(83.46)>\mathrm{x}^{2} \mathrm{~T}\right.$ (7.815), $\mathrm{df}=3, \mathrm{p}=0.050$..

The calculated $x^{2}$ is 83.46 while the tabulated value of $\left.x^{2} 7.815\right)$, $d f=3, p=0.050$.

Since the calculated of value $x^{2}$ is greater than tabulated value of $x^{2}$, the null hypothesis is rejected. By rejecting the null hypothesis, we therefore, conclude that there is a significant 
relationship between the number of children in the family the Almajiri child comes from and the care Almajiri child receives.

Hypothesis table (2): There is no significant difference between separation of child from parents and how the Almajiri child feels.

\begin{tabular}{|l|l|l|l|}
\hline & \multicolumn{3}{|l|}{ Separation of almajiri child from parents } \\
\hline $\begin{array}{l}\text { How the almajiri } \\
\text { child feels }\end{array}$ & With parents & Without parents & Total \\
\hline Happy & $15(10.93)$ & $25(29.1)$ & 40 \\
\hline Sad & $26(30.06)$ & $84(80)$ & 110 \\
\hline Total & 41 & 109 & 150 \\
\hline
\end{tabular}

$\left(\mathrm{x}^{2} \mathrm{c}(2.85)<\mathrm{x}^{2} \mathrm{~T}(3.842), \mathrm{df}=1, \mathrm{p}=0.050\right.$.

The calculated $x^{2}$ is 2.85 while the tabulated value of $x^{2} 3.842$, $d f=1, p=0.050$.

Since the calculated of value $x^{2}$ of less than tabulated value of $x^{2}$, the null hypothesis is accepted. By accepting the null hypothesis, we therefore, conclude that there is no significant relationship between separations of child from parents and how the Almajiri child feels.

\section{Discussion of findings}

\section{Psychological effects of almajiri system on child's development}

The findings of this study showed that 41(27\%) Almajiris stay with their parents while 109 (73\%) do not. 99(66\%) of Almajiris were disturbed while 51 (34\%) feel okay. This finding is in accordance with Dukku (2009) who reported that parents are becoming insensitive to the welfare of their children that they dispatch them to unknown places to take care of themselves. Also Encyclopedia Britannica (2005) opined that the Almajiris are isolated from their parents, taken to places mostly far away from their parents as such when they see other children in the company of their parents they always feel depressed and rejected. This implies that when a child is deprived of intimate parental care, such a child can potentially be disturbed, depressed and may feel rejected by his parents and the society at large.

The result of the study equally showed that the Almajiris who are bullied or maltreated by their Malams or seniors were 89 (59\%) whiles those who are not $61(41 \%)$. This is in accordance with Tafida (2008) who reported that Malamsare unable to cater for the Almajiris needs send them to do menial jobs and begging. This implies that the mallams and the seniors Almajiris take advantage to ask them to beg and where failure to deliver on such assignment could be problematic for the Almajiris in question.

On the loneliness and angry feelings by the Almajiris, the result showed that 110(73\%) Almajiris feel lonely and angry while $40(27 \%)$ do not. This is again, in agreement with social psychologists thought which noted that when a child is exposed to labour at a teenage and deprived of little or no benefit and entertainment, such child have high risk of developing the habit of loneliness or introvert behaviours in future.

\section{Social effects of Almajiri system on child's development}

On the social effects, the results showed that, 80(53\%) of Almajiris live and sleep in a habitable building, 62(41\%) live in an open environment, 8(5\%) stay on the streets/by the roadside. This finding corresponds with Nura (2010) who reported that the Almajiris sleep on worn-out mats, with about 30 of them sleep in a room without good ventilation while some of them sleep in uncompleted buildings or even by the roadsides. This situation signifies disconnect between the intention (knowledge) and reality on the ground. Therefore, for the intention to be fully achieved, the anomalies associated with the system must be addressed.

The result also Showed that 59(39\%) of the respondents have normal regular meals while 91(61\%) do not. This is in line with Nura (2010) who opined that the economic hardship in the country is taking its roll on the Almajiris as they hardly get leftovers rather they had resorted to doing menial jobs to feed. 
Texila International Journal of Public Health

Volume 4, Issue 4, Dec 2016

On the question of whether the Almajiri feel neglected by the society, 103(69\%) feel neglected while $47(31 \%)$ do not feel neglected. This finding is in concordance with Tafida (2008) who reported the Almajiris are regarded as outcasts, public nuisance and social miscreants by the society. This is supported by UNICEF (2001) that child beggars suffer severe psychosocial consequences for being exposed to constant abuse and aggression from the general public.

\section{Conclusion}

Majority of the respondents are affected psychologically and socially as a result of the Almajiri System. This is due to lack of adequate care, feeling of anger and loneliness, lack of proper feeding, exposure to dangers, lack of proper security and being neglected by the society. Many of the Almajiris would want to go for western education if given the opportunity.

\section{Recommendation}

Recommendations and suggestion were proffered on the ways of improving the Almajiri system. Since it is both a matter of religion and culture which existed for decades uprooting it is certainly not the best option but improving it.

- Community health workers should involve the community through mobilization and health education on the effects of poorly organized Almajiri system education on child's development.

- Mass sensitization campaign to enlighten the society on the dangers of the abuse of system.

- Government and other stakeholders should identify the areas where the almajiri system is still prevalent and co-ordinate the activities of the malams inline with modern Qur'anic learning (Islamiyya) which will broaden the knowledge of the students on Qur'anic education.

- Government should explore all the possibilities of co-opting and integrating the identified Almajiri education centers into compulsory universal basic education (UBE) scheme while retaining the religious content.

- Community health workers should educate their client/patient on the importance of child spacing.

- National and State Assemblies should enact laws that will provide for proper structuring and positioning of the almajiri system.

- Poverty alleviation and mass literacy skills should be pursued vigorously with to improving the standard of the almajiri system.

- Government should collaborate with nongovernmental organizations in the mobilization and integration of the Almajiri system with the western education system.

\section{References}

[1]. Abdulrafiu, L, (2009). Almajiri-Breeding Future Terrorists. Tell, magazine. Available at www.citizensfornigeria.com/index.php/action/item/617-almajiri. Accessed on 20/06/2015.

[2]. Abdullahi, M. (2011) The Almajiris : Nigeria Child Beggars 2011. Available at www.thealmajiris-nigerias-child-beggar Accessed on 20/07/2015.

[3]. Bello, A. (2006) the almajiri syndrome: religion, culture or menace. Expert from paper presented, Kano Nigeria

[4]. Christian, Pure foy (2010). Nigeria's Almajiri Children: Learning a Life of Poverty and Violence. Education Data for Decision Making. Abuja.

[5]. Dukku, A.(2009): Almajiri- 10million kids begs in the north. Available at www.nairaland.com Accessed on 15/08/2015.

[6]. Federal Government of Nigeria (2004). National Policy on Education. Lagos: NERDC Press 
[7]. Hassan, I\& Moses, A.(2010). From to Madarassa: The transformation of Almajiri. Gbooza Mobile. Available at www.gbooza.com/m/discussion. Accessed on 23/08/2015.

[8]. Ibrahim, S. (2008). Menace of street begging in Kano State. Available at http://www.nationaldalies.org Accssed on 14 ${ }^{\text {th }}$ June, 2014.

[9]. Kabiru I. (2012). The north and almajiri phenomenon. Available at www.gamji.com/article8000/NEWS8282.htm

[10]. Kano State Government (2012) Report of Committee on Almajiris.

[11]. Kopoka, A. (2000). The problem of street children in Africa (A paper presented at the international Conference on Street Children and Street Children's Health in East Africa, Held in Darees-sala, Tanzania.

[12]. Nura. M.(2010) Almajiri- breeding of future terrorists. Available at www.nairaland.com. Accessed on 10 August, 2015.

[13]. Obioha, E. (2009) Becoming a Street Child in Poverty Ridden Society: A Descriptive Case of Kaduna Metropolis, Nigeria. Journal of Social Sciences, 19, 41 -49.2009

[14]. Peace, U. (2012). The Need to Remodel Almajiri System in Nigeria. Available at http://desertherald.com/?p=1434. Accessed on 12/12/2014.

[15]. Tafida U.A. (2008). lead debate on the almajiri bill for establishment of the national commission for the eradication of child destitute. Blogspot.com

[16]. Think Quest (2010). Child Abuse in Nigeria. Available at http://library.thinkquest.org/06aug/00168/history.html. Accessed on 12/12/1014

[17]. Yahaya Suleiman (2004). The Amajirai and the Rights of the Child to Education Towards Sustainable Development: Education for Sustainable Development in Nigeria, A book of Readings Vol. 1. Minna : Niger State College of Education. 


\title{
Innovative Policies on Air Pollution Control in China - A Case Study of the Relationship between Environmental Changes and Health Conditions in China
}

\author{
Article by Zubairu Aishat Gimbiya \\ Master of Public Health, Texila American University, China \\ E-mail:dadisgal2008@yahoo.com
}

\begin{abstract}
China has seen the fastest rate of growth and development in recent times. Despite this reality, there has been a disconnect between the development of the economy and the welfare of the citizenry, and while we saw policies in place aimed at driving economic growth and development, a comprehensive policy aimed at protecting environmental health was either non-existent or poorly implemented.

The importance of the environment cannot be overemphasized especially with respect to China and the many changes it has encountered over the past couple of decades.

China has seen a great deal of development happen rapidly, numerous policy changes over a short period of time and most importantly, a direct impact on the health and welfare of the citizens.

This study aims to look at the policies driving innovation and development, the extent of implementation of said policies as well as the effect on the everyday Chinese and what measures are in place to curtail the negative effect of such changes and the extent of implementation of said measures.

We strive to establish an imbalance in the rate of development across all sectors of the economy leading to a negative effect, especially on health and welfare as well as life expectancy, quality of life and death toll.
\end{abstract}

Keywords: Air pollution; Innovative policies; China; Health.

In this part, state the purpose of the study. The following should be stated clearly:

- Problem to be solved?

- Any existing solutions for the problems?

- Which is the Best one?

- Limitations?

- Achievements?

Air pollution is the introduction of particulates, biological molecules, or other harmful materials into earth's atmosphere, causing diseases, allergies, death to humans, damage to other living organisms such as animals and food crops. It is typically separated into two categories: Outdoor air pollution and indoor air pollution.

Outdoor air pollution involves exposures that take place outside of the built environment. Examples include: fine particles produced by the burning of fossil fuels (i.e. the coal and petroleum used in traffic and energy production); noxious gases (sulfur dioxide, nitrogen oxides, carbon monoxide, chemical vapors etc.); ground - level ozone (a reactive form of oxygen and a primary component of urban smog); tobacco smoke.

Indoor air pollution refers to the pollutants found in indoors. The main cause of indoor air pollution is inefficient fuel combustion from rudimentary technologies used for coking, heating and lighting. There are also natural indoor air pollutants, like radon, and chemical pollutants from building materials and cleaning products that also impact the health.

An air pollutant is a substance in the air that can have adverse effects on humans and the ecosystem. These substances can be solid particles, liquid droplets, or gases. A pollutant can be of natural origin or man-made. Pollutants are classified as primary or secondary. 
Primary pollutants are usually produced from a process, such as ash from a volcanic eruption. Other examples include carbon monoxide gas from motor vehicle exhaust, or sulfur dioxide released from factories.

Secondary pollutants are not emitted directly. Rather, they form in the air when primary pollutants react or interact. Ground level ozone is a prominent example of a secondary pollutant. Some pollutants may be both primary and secondary: they are both emitted directly and formed from other primary pollutants.

The various activities that release these pollutants into the atmosphere can be divided into two major categories.

They could be from smoke stacks of power plants, manufacturing factories, waste incinerators, as well as furnaces and other types of fuel-burning devices. Other sources result from motor vehicles, marine vessels and aircrafts, fumes from paint, hair spray, aerosol sprays and other solvents.

Examples are carbon monoxide gas from motor vehicle exhaust, sulfur dioxide from factories; nitrogen oxides from electric discharges, volatile organic compounds; ammonia $\mathrm{NH}_{3}$, odors from garbage, sewage and industrial processes; radioactive pollutants; and chlorofluorocarbons.

An understanding of the link between energy consumption ad technologies, air pollution and related environmental impacts is necessary to evaluate the different air pollution control options lacking in China's current policy decision making.

\section{Relationship between environmental changes and health conditions in china}

With a booming economy and ever-increasing demand for energy, China has built new coal-fired power plants at an astonishing rate. Today, coal provides over $60 \%$ of China's electricity and the lion's share of its air pollutants, from soot to sulphur dioxide.

While cars and trucks also contribute to air pollution in cities, it will be impossible to improve air quality in China without moving away from coal.

Coal burning is the biggest contributor of air pollution in Beijing and surrounding area, according to a University of Leeds study sponsored by Greenpeace East Asia. Previous studies have linked outdoor air pollution to premature deaths and child asthma in the industryintensive region which arguably has the worst air quality in China.

China simply cannot afford to allow air pollution to continue taking such a heavy toll. The country's rapid growth in coal consumption has been brought on by extensive industrial expansion, which in turn, has increased pressure on the environment and public health conditions. In order to turn around the deteriorating air conditions, China must fundamentally change its development model, starting with a significant reduction in coal consumption.

After over 30 years of sustained rapid development since the reform and opening up, China has achieved a stunning and eye-catching economic growth, enabling it to become the world's largest developing country with a huge population, with output of the staple industrial and agricultural products ranking top worldwide. China's international status is also rising by the day. From the "Clay-footed Giant" and "Sleeping Lion in the East" in the $18^{\text {th }}$ Century to the "Soaring Dragon" in the $21^{\text {st }}$ Century, China has traveled a long road of economic development.

Nowadays, environmental problem has become one of the most severe problems confronted by human beings, which cannot be avoided wherever you are. Protect the earth as well as our sharing living space has been the consensus of the whole human society. Since the $20^{\text {th }}$ century, human beings have created unprecedented material civilization by virtue of the advance of science and technology and the largely increase of social productive forces. But at the same time, resources, environment pollution, ecological damage and other problem are becoming increasingly outstanding, which are threatening the survival and development of human beings. People have realized that, we must change the consciousness of "challenging the nature" and the traditional development mode "pollution first and treating later," and try 
to seek a sustainable development road in which people, economy, society, environment and resource coordinate with each other.

Owing to its large population and relatively low standard of economic development, China has to face the problems of how to protect its environment and ecology throughout the development process. China has a vast expense of territory and complex natural conditions such as climate and topography. At present, China is in the stage of accelerated industrialization and urbanization, a period in which the conflict between economic growth and environmental protection is quite salient. From 1980s, a series of ecological deterioration phenomena, such as water and soil erosion, grassland degradation, desertification, disappearance of biological diversity and so on, appears due to the growth of population, over exploitation and use, techno, environment pollution and ecological deterioration are serious in some ranges of China: the emissions of major pollutants surpass the environmental carrying capacity; pollutions such as water, land, and soil are severe, solid waste, vehicle exhaust, and persistent organic pollutants are increasing.

Through a series of important strategic measures, China strengthens environmental protection and construction, curbs the deterioration of the environment and protects the earth together with governments and people from other countries. In present global context, the environment and development problems in any country and region will become problems for all human beings. Solving the environmental problems in china not only conforms to the development goals of china, but also greatly embodies the common benefits of all human beings.

Air pollution poses the biggest threat to the environment in China. After nearly 40 years of development, China better understands these problems. Energy-saving and emissionreduction was one of the important targets of "the $11^{\text {th }}$ Five Year Plan," and reductions of energy consumption and total emissions of major pollutants have become the major binding index.

China's “ $11^{\text {th }}$ Five Year Plan,” points out, until 2010, the two binding indexes of pollution emission reduction, i.e. chemical oxygen demand (COD) and sulfur dioxide $\left(\mathrm{SO}_{2}\right)$ emission, will be reduced by $10 \%$ compared with 2005 , that is to say, the national COD will be reduced from 14.142 million tons in 2005 to 12.728 million tons, and $\mathrm{SO}_{2}$ emission will be decreased from 25.494 million tons to 22.944 million tons.

Through the implementation of desulphurization in electric power plant and the construction of urban sewage disposal plant, the total emission of $\mathrm{SO}_{2}$ and $\mathrm{COD}$ in China were both reduced for the first time in 2007. These two indexes still kept a good reduction trend in 2008, in which, $\mathrm{SO}_{2}$ emission was 23.212 million tons, reduced by $5.95 \%$ compared with 2007 and $8.95 \%$ with 2005. This also means that the air quality in first tier cities is better in general and is improved compared with 2007. However, it cannot be denied that pollution in some cities in China is still a very serious problem and the acid rain pollution is quite severe.

With efforts to tackle the air pollution problems in China, on March 5, 2014, China's Premier Li Keqiang pledged that the country would take stronger measures over the coming year to reduce the control air, water and soil pollution, speaking in his annual address at the opening of the National People's Congress NPC meetings in Beijing. Li said that China would "declare war" on pollution and would raise energy efficiency, reduce vehicle emissions and prevent and monitor airborne dust. He also said that around 50,000 smaller coals - fired furnaces would be shut down and that China would increase the use of de-nitrification and desulfurization technology in larger coal-fired power plants. China will continue the policy goal of having China IV diesel provided nationwide, and removing around 6 million older vehicles from the roadways, by the end of the year, Li said March 5.

A separate report released by the National Development and Reform Commission NDRC before Li's speech outlined goals for reducing energy intensity per unit of gross domestic product GDP by 3.9 percent, and reducing carbon intensity per unit of GDP by 4 percent by the end of the year, compared with the year before. 
Outlining goals for key pollutants targeted for reduction in the " $12^{\text {th }}$ Five - Year Plan" (2011 - 2015), the NDRC said the aim is to reduce sulfur dioxide emissions by 2 percent and nitrogen oxide emissions by 5 percent, compared with the year before. Both discharge levels of chemical oxygen and ammonia nitrogen have 2 percent reduction targets.

State - run China Daily newspaper on February 28, 2014 quoted that the officials from the Beijing Environmental Protection Bureau added more severe punishments to the revisions of the capital's own air pollution action plan, which officially took effect on March 1.

\section{China's national action plan on air pollution}

In the eleventh five year plan for economic development in china, the government put forward a master plan with the environment as one of its major issues. This master plan was designed to among other things, guarantee public health; promote ecological civilization construction; combine governmental control and market regulation, overall promotion and key area demonstration, cross-area cooperation and local management, as well as quantitative reduction and qualitative improvement.

In order to do so, the government sought to reduce dependence on fossil fuel as a source of energy; Increase the supply of clean energy; Improve Legislation System and Regulations, and Implement Strict Supervision and Management According to Laws. The policy was also designed to improve the innovative capacity of the country as well as accelerate technological transformation in a constantly changing world.

Strengthen comprehensive control and decreasing pollutant emissions

Optimizing industrial structure and promoting industrial restructuring and upgrading

Accelerating technological transformation in enterprises, and improving innovation capacity

Accelerating energy structure adjustment and increasing supply of clean energy

Conducting entrance control for energy saving and environmental protection concerns, and optimizing industrial layout

1. Strengthen comprehensive control and decreasing pollutant emissions: To remedy small coal - fired boilers, promoting construction of centralized heating, "coal to gas" and "coal to electricity" projects; to accelerate construction projects of desulfurization, de-nitrification and dust control; to promote pollution control facilities for coal - fired power plants.

a. Deepening non-point source pollution control: to conduct comprehensive control over urban dust; to carry out oil and smog pollution control on restaurants.

b. Strengthening mobile source pollution control: to strengthen urban transportation management; to improve fuel quality, to accelerate elimination of yellow-labeled and older vehicles; to improve environmental management of motor vehicles; to accelerate upgrading of low-speed vehicles; to promote new energy vehicles.

2. Optimizing Industrial Structure and Promoting Industrial Restructuring and Upgrading

a. Conducting strict control over production capability increase in "two-intensive" industries (energy-intensive and pollution-intensive).

b. Accelerating elimination of backward production: to follow the guidance of

" Guiding catalog for elimination of backward technologies, devices and products in some industrial sectors (2010)" and "Guiding catalog for adjusting industrial structure (2011) (revised)"; to conduct comprehensive investigation over scattered small-scale industrial enterprises of backward devices and poor devices for environmental protection.

c. Reducing excessive production capacity: to increase enforcing and punishing intensity concerning environmental protection and energy consumption; to formulate fiscal, land and financial policies to promote exit of "two-intensive" enterprises; incremental production project in production-excessive industries will not be approved. 
d. Suspending illegal projects under construction in industries of extremely excessive production capacity. Here, local government should strengthen organizational leadership and supervision to play its role.

3. Accelerating Technological Transformation in Enterprises, and Improving Innovation Capacity

a. Strengthening technological research and promotion: to strengthen support for science and compounds control, diesel (vehicle) emissions purification, environmental monitoring, new energy vehicles, smart grid, etc. and their promotion; to increase international communication and cooperation on advanced technologies and management experiences.

b. Promoting cleaner production comprehensively: to conduct cleaner production audits in key industries, including iron and steel, cement, chemical, petrochemical, non-ferrous metal smelting and so on; to promote product innovation of nonorganic solvent-based paints and pesticides; to develop new varieties of slowrelease fertilizers.

c. Promoting circular economy: to encourage development of industry clusters and conduct circular improvement over the clusters; to promote synergistic waste disposal of industrial furnaces and blast furnace among cement and iron and steel industries; to promote re-production of electromechanical products.

e. Fostering energy saving and environmental protection industries: to transfer political requirements to curb air pollution into market demands for the development of energy saving and environmental protection industries; to encourage foreign investment in these industries.

4. Accelerating Energy Structure Adjustment, and Increasing Supply of Clean Energy

a. Controlling total amount of coal consumption: to formulate mid and long term targets for national coal consumption, and implement target-based and responsibility specific management; new construction projects in Jingjinji Area, Yangtze River Delta and Pearl River Delta should be prohibited to construct affiliated coal-fired power plants.

b. Accelerating replacement to clean energy: to increase supply of natural gas, synthetic natural gas (SNG) and coal bed methane; to formulate SNG development plan, so as to promote the industrialization and scaling up of SNG, with the premise of meeting environmental requirements and water demands; to develop hydropower, geothermal power, wind power, solar power, biomass and nuclear power with the premise of guaranteeing safety issue; to accelerate replacement rate of natural gas facilities in Jingjinji Area, Yangtze River Delta and Pearl River Delta.

c. Promoting cleaner utilization of coal: to increase proportion of coal washing; to prohibit import of low quality coal of high-ash, high-sulfur content; to constrain import of sulfur petroleum coke; to expand banning area of pollution-intensive fuel combustion in urban area, and spread to rural area gradually.

d. Increasing efficiency of energy utilization: to strictly implement energy saving evaluation and audit system; to promote development of green building, by implementing green building standards first in public building and public housing invested by government; to promote heat metering reform; to accelerate construction and improvement of heat pipe network.

Limited use of cars - using the odd number/even number system. (limitation - people just buy two cars increasing the number of cars in use and by extension increasing the amount of emissions)

Publicity campaigns; putting out alerts on days when pollution is severe. Shutting down schools and public places to limit outdoor activities

Cutting down industrial activity by imposing maximum emission limits on companies cutting down fossil emissions. 
Texila International Journal of Public Health

Volume 4, Issue 4, Dec 2016

\section{Chinese anti-pollution law}

\section{Limitations}

One year after the Chinese government enacted the new "Measures on Environmental Information Disclosure" laws, an investigation by Greenpeace China has found that 18 Chinese and multinational firms are failing to comply with the regulations.

The law, which went into effect in May 2008, requires companies to publish their pollution information within 30 days of being reported as breaking pollution standards by local environmental bureaus. One year later, many top corporations had violated the terms of the law.

The multinational firms on the list are: Shell, Samsung Electronics, Nestle, LG, Kraft, Motorola, Denso and Bridgestone. Another 10 Chinese firms were found to be evading the regulation's requirements.

Greenpeace undertook the investigation to compare the regulations required in China -and companies' failure to abide by them -- with the regulations those same companies adhere to in other countries.

China's "Measures on Environmental Information Disclosure" law is seen as a step toward developing regulations similar to the Toxics Release Inventory in the United States, which has been credited as one of the most effective and low-cost tools for reducing industrial pollution in the U.S.

"Evidence shows that a strong information disclosure system helped reduce pollution in the United States by 61 percent in 20 years," said Tianjie Ma, Senior Campaigner for Greenpeace China. "The public has a right to know about what these corporations are discharging in the rivers and lakes around their communities and what risks they face."

This investigation shows how, just as China has become central to many firms' supply chains, it is also quickly becoming ground zero for environmental issues. With the country recently overtaking the United States as the world's biggest emitter of greenhouse gases, the need for swift progress on environmental issues of all types has moved to center stage.

\section{References}

[1]. China’s Environment by Liu Junhui \& Wang Jia

[2]. China’s Economy by Wu Li, Sui Fumin \& Zheng Lei

[3]. http://www.chinadaily.com.cn/m/drc/2015-08/18/content_21637145.htm

[4]. https://en.wikipedia.org/wiki/Air_pollution

[5]. http://www.who.int/phe/health_topics/outdoorair/databases/background_information/en/index1.ht $\mathrm{ml}$

[6]. http://www.greenpeace.org/eastasia/campaigns/air-pollution/problems/

[7]. http://www.bna.com/china-outlines-environmental-n17179882762/ 


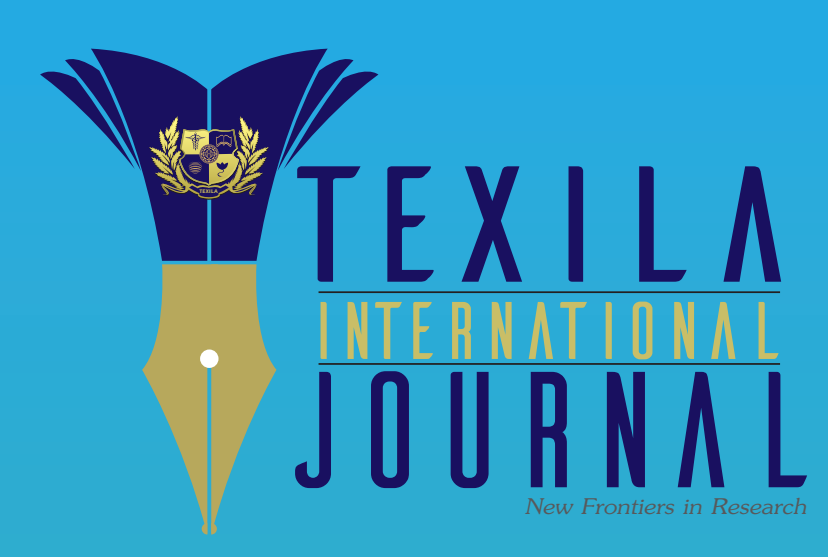

\section{Texila American University,}

Providence, Georgetown,

Guyana, South America.

Telephone: (+592) 2318118 / (+592) 2318111

E-mail: ejournal.assist@tau.edu.org

Skype: texila.aco32

Whatsapp: +918056580933 